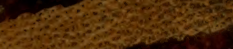

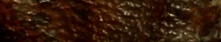
his.

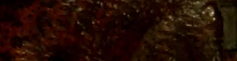

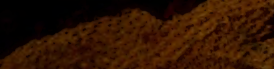
if공

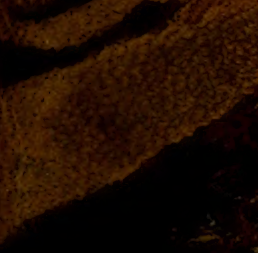

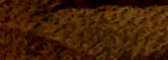

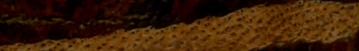
tis:
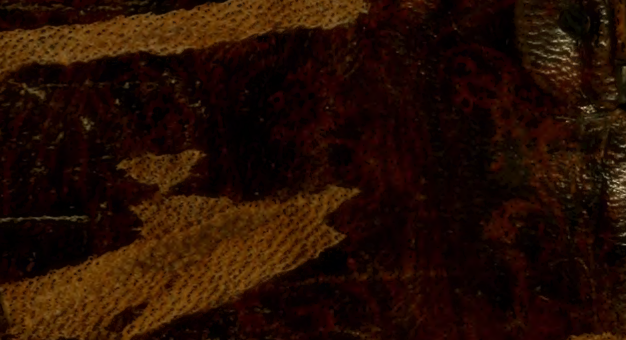

$2 \frac{x-1}{20}$
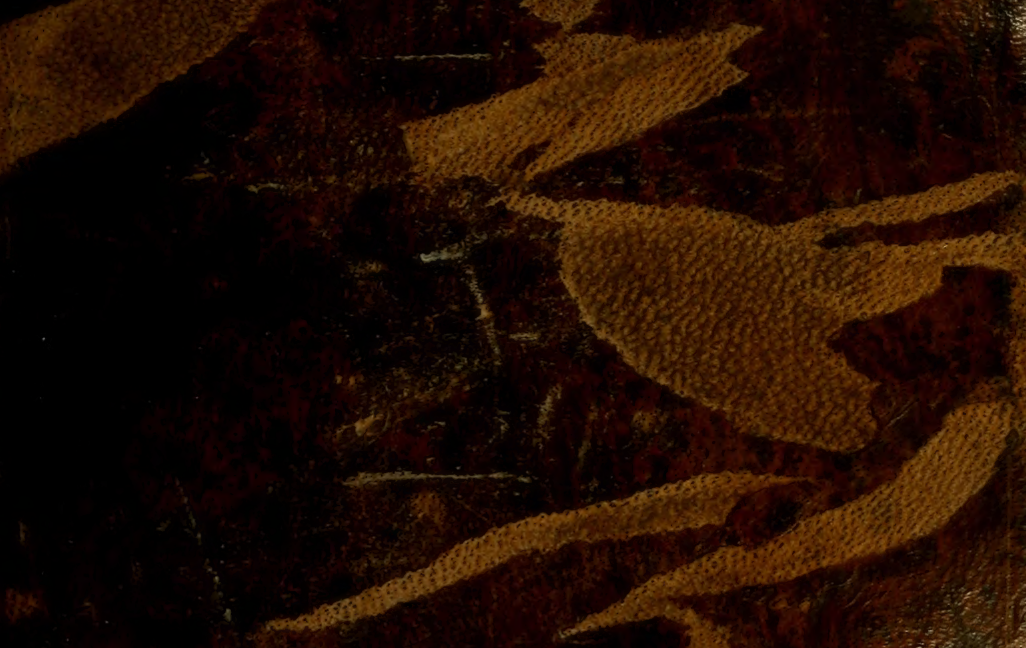

gers?
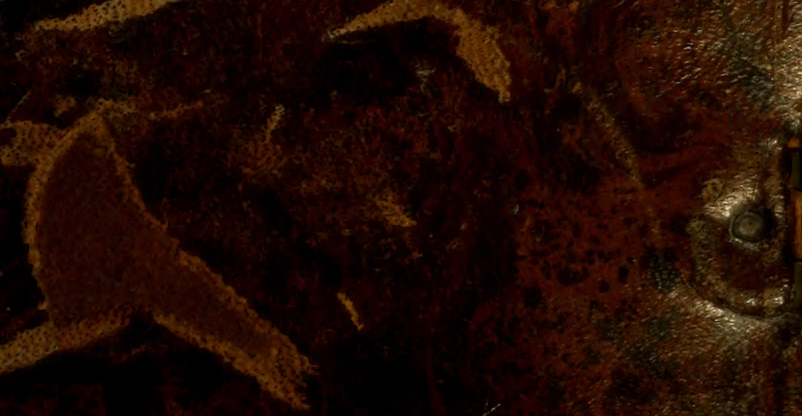


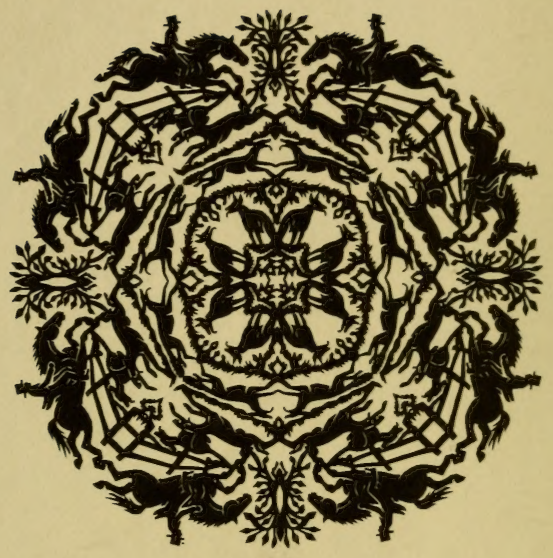

JOHN A.SEAVERNS 
Cy ,

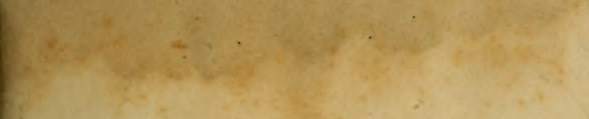

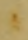

$$
\begin{aligned}
& x^{2} x^{2} \\
& 2+4 x+2
\end{aligned}
$$

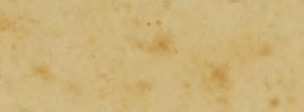

$$
\begin{aligned}
& \text { - }
\end{aligned}
$$

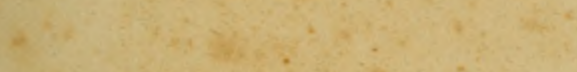

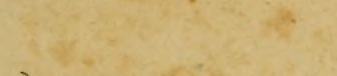

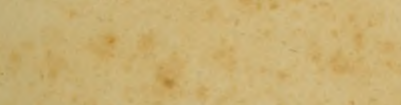

$$
\begin{aligned}
& \text { In. } \\
& +x+243 \\
& \text { iss } \\
& 2 \times-e^{2} \\
& 20:-y^{2}=0
\end{aligned}
$$

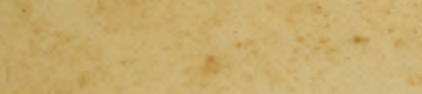

$$
\begin{aligned}
& \text { toris } \\
& -3 \sin ^{2} x x^{2}
\end{aligned}
$$

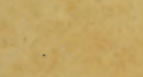

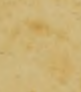

$$
\begin{aligned}
& \text { (4) }
\end{aligned}
$$

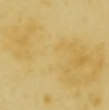

$$
\begin{aligned}
& \text { is } \\
& 5
\end{aligned}
$$

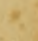

$$
\begin{aligned}
& (x-3)
\end{aligned}
$$
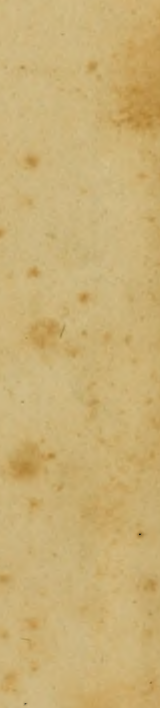

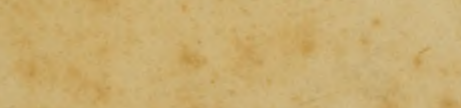

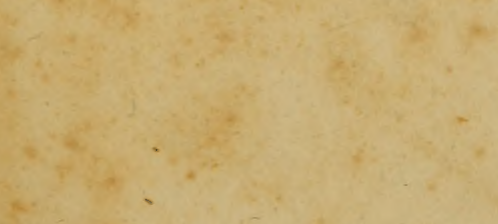

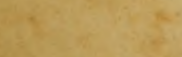

$$
\begin{aligned}
& (2+2+2+20
\end{aligned}
$$

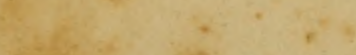





\section{Steorge Simon abinters woblerfabenex}

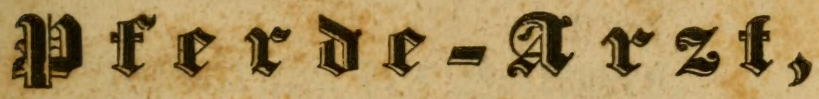
welder grünolid lebrt

noie man die Complexion ber $\mathfrak{P f e r d e , ~ i f r e ~ \Re a t u r ~}$ unt Allter erfennen, alle innerlichen und äufierlichen Frantheiten heilen,

fo wie aud

wie man biefétben yor bevorf́tehenben Hebeln verwahren fönne, nebft einigen, bödjft feltenen,

\section{fit $\mathfrak{r} \mathfrak{j} \mathfrak{u} \mathfrak{g} \mathfrak{e} F$ Foblen} vielfad) bemábrt gefunbenen

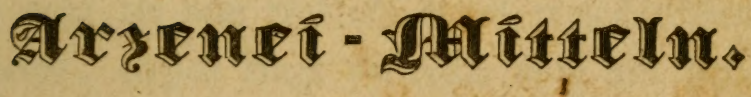

Durd)gefehen, verbefaert, mit neuen $3 u$ fáçen und erleidjternten Rupfern verfében von

\section{Jatentinertebter.}

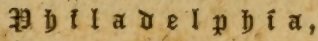
Şerausgegeben von $\Re$ e $u$ ben G utb. 


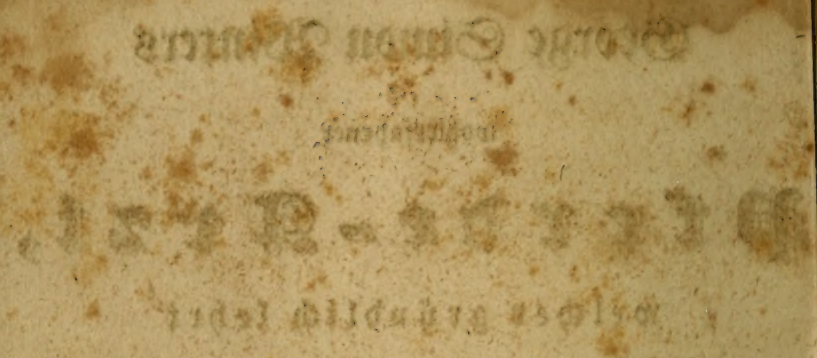

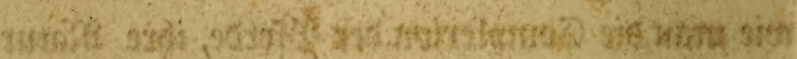

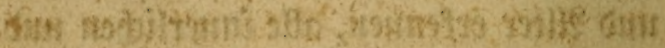

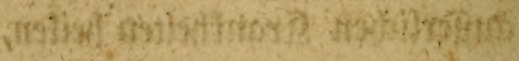

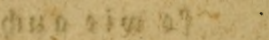

23ove

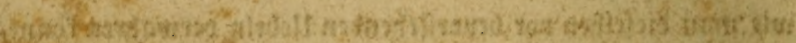

EMrrarad according to the Act of Congress, in the year 1839 , by J. \& S. MILLER, in the Clerk's Office of the District Court of the Eastern District of Pennsylvania. 


\section{Anmerftut Des 2 erlegers.}

Einer ber roidtigften uno unentbehrlidgften

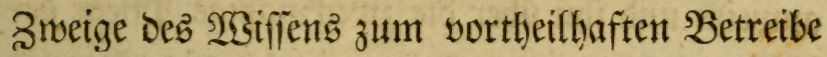
Der sanowirthjhaft, ift unftreitig-eine möglichft genaue Senntniß Der Eigenjobaften uno znedfmä= fitgen Behanolung Der Şaußthiere. Unter Diefen giebt 2ufmerffamfeit des seanowirthes in einem jo ho=

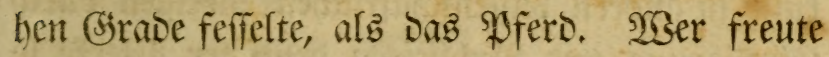
fith nicht bei Dem 2 (nblidie biefez majeftätifchen Thteres; mefien 2 (uge verweilte nid)t mit $\mathfrak{B e r}=$ gnügen auf oem graziöb einherfhreitenden Pferbe, Uno bieß finto nicht bie einzigen Puntte, bie wir zum sobe des Pferbez herworkeben fönnten;

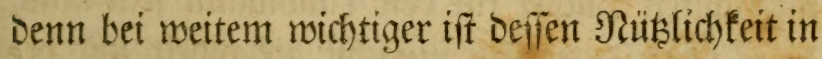
Den mannich fachen Befdäftigungen, zu benen $\mathrm{e}^{\mathrm{B}}$ gebrautht werien fann.

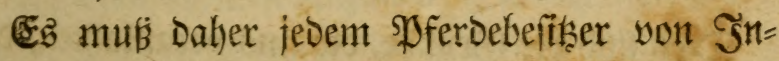
tereffe fein, fith bie Mittel zu verichaffen, Durch 


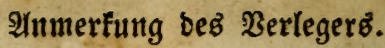

weldbe er fich die nöthigen Sienntniffe zur gehöris gen Pflege Derfelben erwerben fann. Ein Buch), Daz Diejen Siegenitand in einer verftändidgen Sprache abhandelt, Dem sanbmann über bie ver. fdjebenen an Den \$ferben eridheinenden Sympto= me uno Srantheitšzufälle genügende Ertflärung extheilt, enolidh ifm die brauchbaren Seilmittel anmeifst und ifn über die zmedémäßsige Pflege Der \$ferbe belehrt, war baher ein längft erfanntez und namentlich unter Den Deutichen sunbleuten

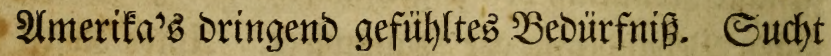
man Dem Mangel an guten, gemeinnübigen $\mathfrak{B u ̈ =}$ doern unter bem Deutidben amerifanifben Publi= lum in andern wiffenfthaftlidben 3meigen ourds Einfülyrung uno Publiciren Deuticher SEerfe to nadb uno nach abzukelfen, fo wurbe Dody unfers

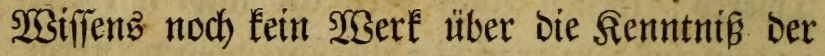
Shterarzneifunft unternommen, obnohl ein fol= d)eb Sjanobuds unftreitig etnes oer nothigften uno nühlidbften Büdber für oen sanomann fein mus, da eb feine Sntereffen zunächfit abhandelt uno bee förbern hilft.

Dies find die Sründe, die นnืิ veranlaß̂ten, die Seraubigabe einez $\mathfrak{Z}$ ertę zu unternehmen, defien 
গüß̨̧ Den Sanomann, fotjon längft uno fo vielfeitig aner= knnnt wuroe, dẩ wir es für liberflüsig balten, hier weitere rechtfertigente Benveggrünoe anzu= führen. STBohl mag es MBerfe geben, bie tiefer in

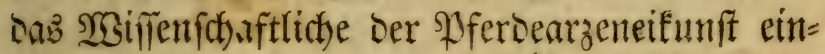
sringen uno mit mefyr gelelyrter \$ebanterie ge= idstieben fino; indefien möd)te nicht leidst eines verbanten fein, Daš Dem sanomanne mehr prafti=

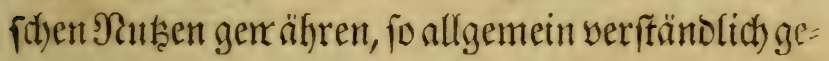
id)rieben utto baher, fo vorjüglich zll empfehlen! jein süfte, als ne $r$ P f e r $b e=\mathfrak{A} \mathfrak{r} z t$. Mandhe Etellen, bi:für Den gewöhnlichen sefer unoentlid) fosienen, wurben erläutert; 3weifel, Die feither Durd) Er: falfrumg erflärt, berichtigt; unb viele anbere zeit=

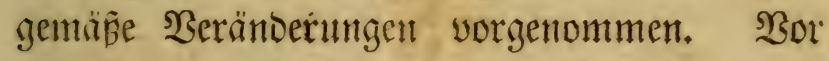
allem?that man bei bent burbfehen befondere 2 uf = merffamfeit auf oaz Ientifidunadyen Der Recepte werwentet. B̧eraltete incsicinifche Benennungen Die etwa felbft mandhen Irpotilefern unbefannt fein mödhten, nurben meggelnfien uno dafür die jeţt gangbaren Namen binzugeictst, fo Dấ man zuner: fidftlich) hofft, es werbe fich in siejem Putnfte nid)t bie geringfte Edywierigftif in ien $\mathfrak{B} e g$ ftellen. 
6

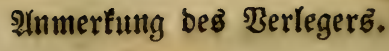

Man bezweifelt Daher nidyt, Daß̂ Die Sherauşgabe

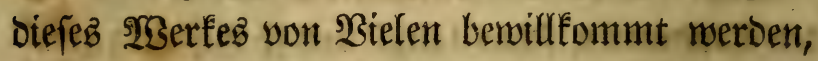
uno unter Den beutichen sanoleuten in Amerifa

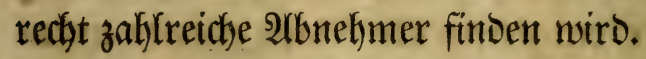

$$
\text { Der Sूeraug geber. }
$$

Ighitabetphia, 1840. 


\section{$\mathfrak{B} \mathfrak{O} \mathfrak{r} \in \mathfrak{E}$.}

Die tägliche (Erfahrung lehrt, baß bie \$oferbe man: d)erlei SranÉbeiten, Mängeln uno (Siebrechlich)eiten an (Gemütb, Sinnen uno Särper unterworfen find; uni. es iff ein bemerfenswerther Utmftand, bas foldhe ungünftige 3ufälle weit eher bie fdoỏnen und foftbaren

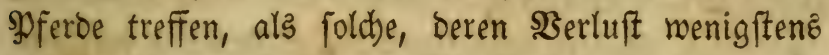
nid)t fo fdhmerzlich wäre. Die Notbmendigkeit madjt rs unz baber zur \$oflint, alle Sorgfalt barauf zu ver= wenden, biefe fchäblichen Ltebel, fo weit es in menja)li= d)en Sräften ftebt, abzumebren uno allen möglichen Flleiß aufzubieten, ein Mittel ausfindig zu mad)en, roourd) bie zufälligen Srankfyeiten geboben und allen=

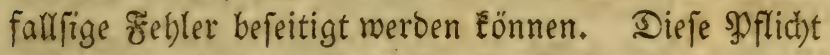
erifheint um fo bringender, wenn man bedenft, wie me= nig Plerbe man beutzutage antrifft, bie gänzlich von Srankbeiten, Mängeln, an (Semütb), Sinnen uno Reib befreit mären.

\$o nun neben andern Utrachen auch bie augen=

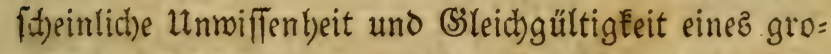
Een Theiles berjenigen, weld)e fid) Die 2fušübung Der

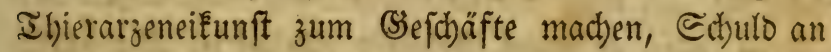
Dem 2rbnebmen bes 2Cnjebenz aud bes beffern uno ge= willentaftere Ibeilez der Ighierärzte ift, möge man

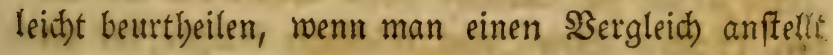


über Den Stanopunft ber İhierarzeneitunft in ätterex und neuerer 3eit. Sdbon in früben seiten fino zabl= reidbe Suackfalber bem Fortichreiten biefer $23 i f$ Tent jd)aft

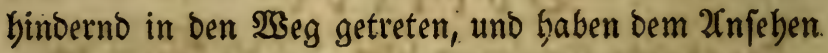
gebilbeter Thbierärzte in ben 2 ugen bez \$oublifums ge: fchabet. Ein alter Sdriftfteller ruft baber mit Ent= rüftung aus: ,\$b auch bie 2rebeit, fo bie Efelärzte verrichten; noch fo gering und verädytlich erifbeint, fo

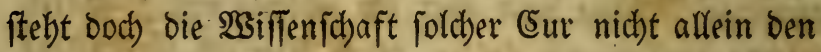
ehrbarften, fondern auch ben bereojamften und verftän= Digften \&euten zu.

Wenn nun bie (sur bes ( 5 jelz fd)on als ein ad)tbarez (Sefchäft bingeffellt wiro, um wie viel mebr ift es bie

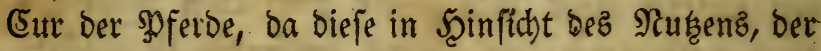
Schönbeit uno 3reckémäpigkeit jene bei weitem über = treffen. S3alenus meloet von ben shufinern, dap. fie aus bem (seruch bes pferbes Sürch, beffen innerliche gute ocer böfe (Semüthsftimmung uno Nerbauungs: werkzeuge wafkrnebmen fönnen.

(Ez baben fich folon fo viele treffliche und in ber menichlichen (sejellychaft boch geftellte Männer ber Bebandlung ber \$oferde uno Bearbeitung ber zu biefem (Se) wobl barüber keine SBerichiedenbeit der Meinungen ob= malten follte, ob biejes (sejchäft ad)tbar fei ober nicht. Nag es auch noch hin uno wieber engherzige \&eute geben, welche bie 2lubüber biejer Runft mit ben $\mathfrak{N a =}$ men soferbe=, şieb)=, ober (Ejelărzte belegen, ber ber= 
ftänoigere İheil bes Shublifums befinirt biefe Beimör: ter in feinem jobimpflichen Sinne.

SSenn es fich die 2lten fobon forgfältig angelegen fein liesen, ibre gemachten Erfahrungen zu veröfifent=

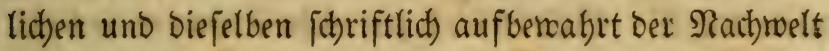
fu überliefern, um wie viel mebr follten wir heutzutage Darauf bebacht fein, bie Erkenntnip̃ biejer Sumft zu er= weitern, ba unz zu biefem Befufe weit mebr Şilfzmit= tel zu (Sebote fteben, als jenen Männern, bie meiftens ibre Refultate ourd) müb james (Experimentiren judben musten, fo wie auch ibrem löblicten Seippiele baburch

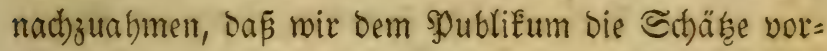
legen, bie wir bei unferm Forichen aufgefunden baben. Daburd) würoen auch bie Seicïhter Diefer loblichen Runft weniger (Selegenbeit zu SEerläumoung finden, reil fie mit ifren lügenbaften \&äfterungen ourd Die augenfitheinlichen Proben felbft zu Echanben gemadts wütben. Diejenigen Dagegen, weld)e fith mit Erfolg biefer $\mathfrak{B i f f e n f t h a f t ~ b e f l e i p i g e n , ~ w u ̈ t b e n ~ v o n ~ a l l e n ~ v e r = ~}$ nünftigen Menfchen gefdäht uno geadhtet werben.-

Da in unjern Iagen gar manche Rrankbeiten unter Den Sुferden vorgetommen, worüber bie 2fltein theils Eeine Beobachtungen anferlten, beren genaue und rid)= tige (Erkenntnis ifnen robl aud) nicht leicht möglid) gervefen räre, fo follten wir um fo fleifiger uno enfif ger nachforfiten, um barüber inz reine zu kommen.

(5) ift baher zu bebautern, bas man mabrnefimen

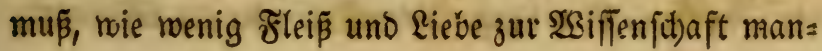


d)e Befolger biefer Sunft an ben Iag legen. Dods Darf man fich baburd) nicht gänzlich entmutbigen laf fen. Erblicft man ja boch auch nod) unter ber Spreu bin uno mieder ein Şeizentorn; eben fo geht ez mit biefer Sunft. (Sibt es auch) gar viele Stümper, fo feblts eE Dod) auch nicht an einzelnen Nännern, welche mit einem Fleiß̧e biefe $\mathfrak{S i f f e n j h a f t ~ e r f o r j d e n , ~ w i e ~ e s ~ D e r e n ~}$ Nüklidbeit veroient.

Utser nicht allein in Der şraxis, fonbern audb in ber

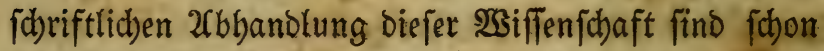
febr viele Sמfujcher aufgetreten. $\$ D b$ nun gleid) bie Männer bon Fach es leicht entbecken, menn ein Stief= kins fid) bie 2 (utorichaft angemajt, fo baben boch in manchen Fällen ibre Schriften bazu gebient, Dem Spub= lifum eine ?art Wiberwille gegen bie \$pferbearzeneibü= d)er beizubringen, indem fo nach und nach bie Meinung bei Bielen (Fingang zu finden fohien, als fei bicfer (S) genftano nod) nie grünolich bebandelt morden.

SBor einigen Sabrbunderten gebörten bauptjächlich. Die Sd)miede zu Den beften Rennern Der Spferdearzonei= Eunft, nicht etroa meil fie ein spfero befblagen und einen Rüftwagen macben fonnten, fonbern weil man unter

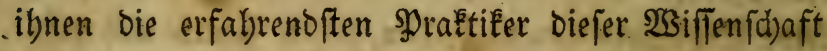
antraf. 2Uls einen $\mathfrak{B e l e g}$ biefür Eönnte man bie That: fache anfühven, baß̄ Saifer 2levander einen eigenbän= Digen Srief an feinen Scufichmied fabrieb uno biefem die soflege feiner Syferbe bor 2Cllen anvertraute und brin= geno anempfabl; Denn 2Clexander war sin 2Ronard, 
Der Den Gohen $\mathfrak{B}$ erth) Der $\mathfrak{P}$ ferte zu würoigen verftand uno es an Der nötbigen Sorgfalt für Deren (Sejuno: beitzerbaltung nicht feblen ließ̄. Man möd)te wobl frigen, welithe grünolidse Erfahrung über bie şferbe= Sur man beutzutage bei ben ๔amieden antrifft, obrobl viele von ifnen glauben, Daf́ fie bie einzigen \&eute mä= ren, bie ein \$ूferd zu curiten verftänden. Es ift aller= Dings zu wünfhen, Daßs oies allenthalben ber zall fein möchte, uno wenn bie Schmiede nut fortfahren müroen, fich Diefer Sunft mefor zu befleiffgen, fo müpten fid aud

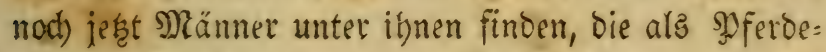
ärzte rübmlid) genannt zu werben veroienten. Sie be= fifzen bierzu mand)es gute Mittel, bei deren $\mathfrak{B e n u t h u n g ~}$ wefentliche Dienffe gelciftet roerden tönnen. Bor aflerit follten fie ilyre 2fufmerffamleit auf folgende Ponfte richten: 1) auf bie eigentliche (Erfenntnip̃ ber Srant= beiten ; 2) aus welchen Utrfachen biefelben entipringen; 3) woraus fie unfeglbar zu eriennen; 4) wie fie zu verbüten und 5) wie fie zu brilen fino. Trenn biefel= ben, fo wie aud bie SPferdebefifyer überbaupt bie Unter= weipungen, die id) innen in biefem werke vorlege, gebörig ftudicen und in 2fnwenoung bringen, fo merben

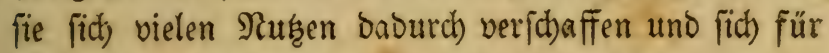
bie gebabte פäbe reidhlich belobnt finden.

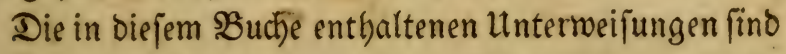
meiftens Das Rejultat gemachter Erfahrungen; wobl=

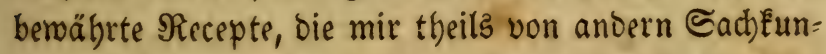
bigen Männern mitgetbeilt wurben, babe id) ebenfallz 
benust, fo wie mandbe alte Sorjahriften verglichen, bie in geoiegenen Scilfzbüd)ern enthalten fino. Die Mie= berbolung ber alten guten Regeln Eann eben fo wenig als bie (sröfnung neuer (Erfindungen fchäblich fein. 


\section{Rothmendige Erinnerungen,}

welche in biefer

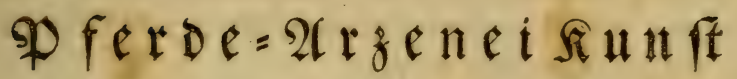 noohl in $2(d)$ z zu nel)men finto.}

\section{I}

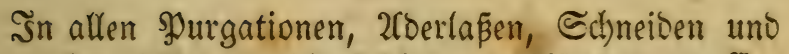

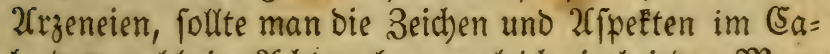
lender mohl in $2(d) t$ nehmen, gleid)mie bei ben Men: folsen.

\section{II.}

SBEenn mann einem SNferde einen Eingü gibt odet fonft 2 rzeneien in Den $\mathfrak{L}_{e i b}$ bringt, follte foldbes afles nüchtern gejobeben, uno man zum nenigften das sp fero orei ober vier Stunden balauf faften la ken, auch wofern ez Sranfheit halber fortfommen Eann, eine halbe Stunde barauf reiten oder fübren, Damit fక eine $\mathfrak{B}$ emegung babe.

\section{III.}

WBenn man bei einem Sמferbe eine Galbe, Slitäten ober einen 2(nftrich gebraud)en will, weld)e ourch bie Scaut wohl ins Fleifd) uno (Seäber operiren follen, fo follte man bem Şferbe an bem ichabbaften Sot bie Scaare mit einer Scheere fein fauber binweg fobeeren. 
IV.

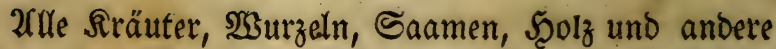
Sceilmittel müßen in Der gehörigen 3eit gefammelt uno nach Den in Den Rräuterbüchern gemachten 2(nmeifun= gen behandelt merben.

\section{V.}

Das Frließ̄waß̄er, welches man brautht, follte vor ber Sonnen 2fufgang vom Strom binweg, uno nid)t gegen Den Strom gefthöpft merden.

\section{VI.}

$\mathfrak{Z}_{\mathfrak{n}}$ Éeinem $\mathfrak{I} a g$ follte man zugleich purgiren und aberlap̃en.

\section{VII.}

2Ctrez reuer zu Den 2(rzeneien zu Eochen ober diffilli= ren follte mit einem Eryftall gegen bie Sonne mittelft eines ๔chwamms angezündet werben.

\section{VIII.}

2crle spulver, welche in bie 2Cugen geblafen werben, múffen fo fein fein, als ber fleinefíe Staub.

\section{IX:}

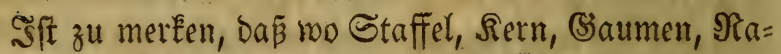
chenffect)en ftebet, immer einz und baffelbe meint.

\section{$\mathrm{X}$.}

Sr allen Recepten, wo Eingüffe, Ratwerge, Salben, - Spflafter uno Ernffiren vorfommen, objchon nibht alle= mal babei ftebet, foll man basjenige, was zu fd)meiben ober zu pülvern ift, auf Das aller fubtilefte madjen, ebe man es mit andern feucbten singrebienzien ver: 
mijcht, auzgenommen biejenigen Spulber, welche man mit Fleiß̄ gröblicht ftöß̣t, Damit die Soferde biefelle nid)t verblajen cönnen.

\section{XI.}

2alle SInftire müffen laulidht applicirt werden, nicht ju falt uno nid)t zu warm, uno else man bab sinftir anwenoet, follte man mit einer mit §d)reinenifd)mals Doer Baumöl gef(t)mierten Scand, Dem Spferbe in ben Sointern grzifen, uno Den Mift beraus räumen.

\section{XII.}

SEei ałen Ëingüflen ift zu beobachten, bas man bem soferde nid)ts in die \&uftröhren giefle, meil fomft das \$fert jäbling erfiticen mökte, und wenn fold)es etra gefd)eben wäle, fo follte man nid)tz nad)giesen, fondern bas sffero alshald Darauf umfübren, und itmmit einem andern Trane zu Şülfe fommen, als nemlid) mit matm

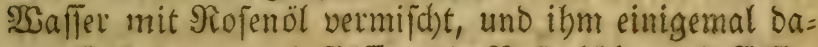

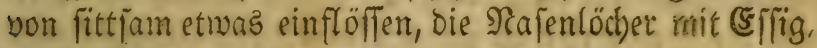
worin Soley gefotten worden, beftreichen.

\section{XIII.}

2alles Sauterifiren ift beffer mit Eupfermen alb eifer: nen S̃nftrumenten.

\section{XIV.}

SBei allen (singüffen, Gdhneiben, Sauterifiren ober fonftigen (suren, too es gefälutich, und oer Fetothfall vonnöthen ift, foute man bas spfero mit Binben uno anoern Silfzmitteln wohl verwahren. 


\section{Nothmenbige Erinnerunger.}

\section{XV.}

In ber Seelfucht keine 2rber zu laffen, meil poldtes Göchff fchäblich ift, ja gemeiniglid) balo ber Iob barauf folgt.

\section{XVI.}

SBeim Sd)neiben, Brennen und 2rberlaffen follte man bie 3eichen uno 2fipeften des Scimmels im Ealender wohl beobadten, und fein I bier an einem (Slied, wann Der Rono in feinem Beichen ift, arzeneien, biez gilt aud) beim Eauterifiren, 2foertaffen, Schneiben und \$urgiren.

\section{XVII.}

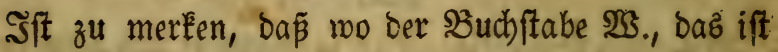

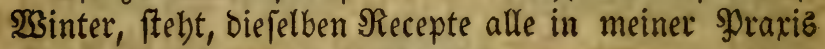
oft bewährt befunden morben feien.

\section{XVIII.}

Die (Erfabrung lebrt aber auch) öfters, Daß̧ bie mei= feen von biefen guten Compofitionen und fchönen $\Re R e=$ cepten nid)ts als vergebliche 5eoffnung geben, entweber weil bie Epezereien alt uno verfälfcht fino und Die Siraft verloren baben, oder weil viele bie 2frt Der 3ubereitung nicht miffen, uno bas Mittel unorbentlid) uno zur $\mathfrak{U}_{\mathfrak{n}}=$ zeit angewendet wiro, welches von jehr großer $23 i d$ tig= Eeit ift, baher man zu einem erfahrnen und treuen 2(po= thefer feine Buflucht nebmen follte. 


\section{Der exfe Theil}

beg

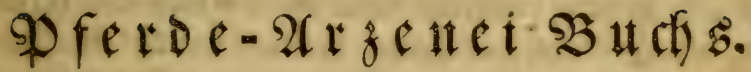

\section{Daz 1. Capitel.}

SBon Dent Ltriprung aller Sranffeiten Der $\$$ Pferde.

(S)leid)wie Das \&eben und $\mathfrak{B}$ elen eines jeben lebendi=

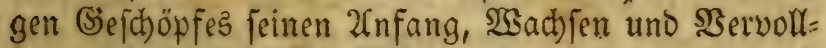
fommunng aus orei \$ुrinzipien bat; eben fo baben aud alle Srankbeiten Der spferde ibren Uriprung aus Denfel: ben, wenn nemlicb eine Itnoronung in ibnen, fonobl inner = als äufferlich vorgehet, woraus bann bie un= fel)lbarliche Serftörung Derfelben entipringet, uno bat= auf ferner, wo nicht bie Seilung an Denfelben bald ge=

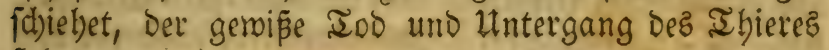
folget.

Sind Daber bie brei syringipien (auf recht beutjd) zu fagen) die Drei 2anfänge eines jeden (sejhöpfes nichts anders, alb biejenigen brei Scauptifücke, toorin eines

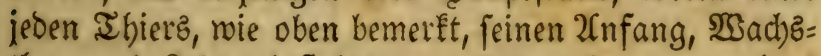
thum uno \&eben keftehet, Denn wenn Deren nur einez zu menigoser überflüffig in De!n I Ihier fich befindet, fo gibts eine Utnoronung, worauf bann fowobl innerli= d)e, als äuserlicbe SranÉbeiten entffeben. 
Diefe brei গুorinzipien aber merben mit Namen alfo genannt : Sal bas Salz, Sulphur Der Sdywefel, Mer= curius ber flüchtige und ooch feud)te (Seift. Das Salz, als bie Erroe, begreift allez srrobifche und \&eibliche, ber Sdinefel, als bas Feuer, alles Șişige und Fette, ber

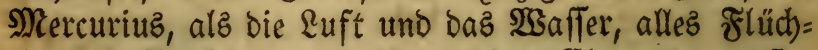
tige uno Feud)te; woraus bann bie 4 (Elementen entfte:

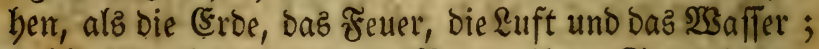
welche beibe lestere in Dem Mercur ihren Stano haben. Die Eroe ift falt uno trocken, Das Feuter beís uno tro=

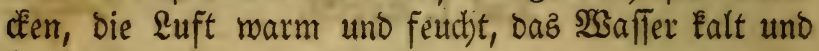
feucht:

2(uz biefen 4 Eslementen entftehen nun bie 4 com=

- plexionen, Sanguiz, \$2blegma, Eholera, Melandyolie. Sanguiz kommt von ber \&uft, \$oblegma vom $23 a f l e r$, Eholera ober sBiliz yom Freuer, umo Melancholie von Der Ěrbe. Itno je mehr ein I hier von einer unter bie: fen bejariebenen Eomplexionen bei fich bat, je mebr ar: tet es berje(ben nach) ; aljo entipringet audb, menn ein Uteberflü ober Mangel an einer unter biefen Complexi= onen gefunden miro, eine folche Aranfleit Daraus, bie

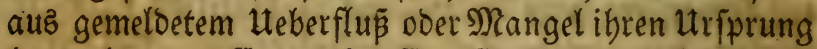
bat, als zum Exxempel: (Ein Eholerer, entffebet von übermäfifiger ŞSige uno Irockenbeit, ober alfzuvieler melandbolifcher Sä̈lte uno Irockengeit. 
SPFerbe=2lrzenei Bud\%.

\section{Das 2te Sapitel.}

\section{$\mathfrak{B}$ on Dem Sanguinifden uno Der blutreiden Somplexion.}

Dat Şlut ift ein bifiger und feuchter Scumor (eine warme Feud)tigkeit) uno wiro von ben 2Cergten in ein natürliches uno nid)t natürliches $\mathfrak{B l u t}$ getbeilet. Das natürlidbe Blut ift ein bişiger und feuthter Scumor, in Der Subftanz mittelmäffig, an ber Farbe rotb, an Dem

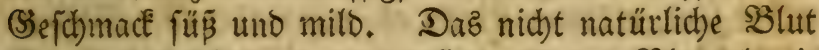
ift biefez, weld)ez von Dem erfifgemeldeten Slut abmei= d)et, jeooch feine gemiß̉e (sinfd)räntungen uno Maas bat, uno menn es biejelbe überidyreitet, nid)t mehr für Blut, fondern für einen andern Scumor zu balten ift,

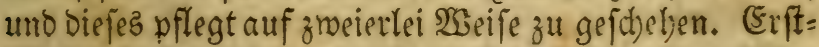
(id) Dutch SEeränberung eigener Subftanz, obne andere Bermifdung; nachber nid)t regen feiner, fonoern an= Derer Urfacter. Die erfte Seranderung geidiebet mie= Derum auf zroeierlei $\mathfrak{S S}_{\text {Sei }}$ e, nemlid), wann entweder bie Gubftanz dicker oder bünner ift als fie fein follte, oder aber weil es angebrannt wirt; weld)es bünn ift, wito in bie gelbe (sall vernandelt, welibes aber biek ift, wirb in bie fabrarge (3all berändert. Sum andern nicht ourd) (iid) uno feine Subftanz, fondern negen eimes an= Dern wiro das SBlut nid)t natürlich, wenn nemlici) ein anderer Scumor bamit vermifhet roirb, weld)es auf vie= lerlei $\mathfrak{W}_{\text {eije wiederfahren }}$ (ann, nad) allerband $\mathfrak{S}_{\mathrm{et}}=$ mifchung Dev (şalle, melandtolifdhen uno plylegmatifhen Materien, ourch meldye es von bem natürlichen silute unterichieben mirb.

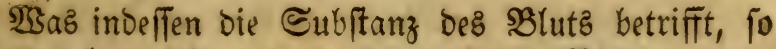
wiro nad) berfelben bas wibernatürlid)e Blut von bems 
natürlichen unterichiebon, uno erfennet, erffticit), mantr bas SBlut oider uno trüber ift, alsbann miro bie idhwarze Sall bamit vermifht, hingegen ift es zarter, fo ift die gelbe Salf bamit vermi (je)t ; zmeitens nimmt es unter= ichieoliche Farben an fich, Denn wegen bez phlegmati.

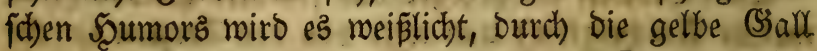

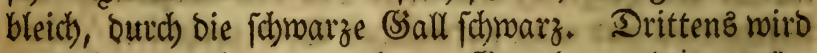
ez auth-unterichieden ourch ben (Şevutch von beim natür= lichen şlut, benn wenn faule Friufifigkeiten bamit ver=

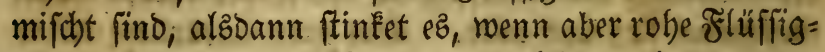
Eeiten barunter vermifdtet merben, alzbann hat es gar

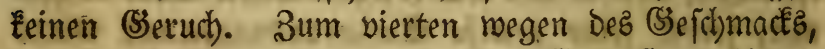
Denn burd) SBermifchung Der gelben (Sall ift es bitter, burd) bie fchroarze (Siall fauer, burd) bas \$oblegma ge= ichmadtos.

Ěz find alfo biejenigen soferbe, welche janguinifcher Natur fino, bie (Eoelften unter allen, fröblich, mutbig, herzhaftig, venerifd, gelebrig, uno nicht bophaft ooer unbeftänoig, haben ein jubtiles uno marmes (Seblüt, roourd) bie (Sieifter vom Sherzen in alle (Slieber augge= theilt werbert; Esinez fchönen Sopfz, großer braunen

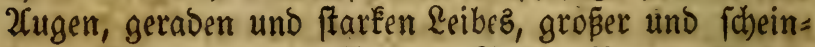
bater SBlutabern, von Farben, Fuths, Sraun, 2tpfel= graue, $\Re$ othichimmel, $B$ laujchimmel, SBraun uno $\Re$ Roth = ichecten, find gut zur (Seneration und Foblen=3ucht, $D a=$ von gute und gefunde \$ferde, befonder' aber mebe Sengfte als Stuth= 


\section{Das 3 te Sapitel.}

\section{Bon Dem Phlegma unD Der phlegmatijoln Eomplexion.}

Det phlegmatifit)e weip̃e Scumor folgt auf Das Blut, weld)er nad) Dem slut in Der sproportion Der reichfte iff ; Diefer wirb auch in einen natürlichen uno nicht na= türlichen getbeilet. Der natürliche zmar ift fälter uno feuchter, und nach oer Eubfanj sin rober Samor, an Der Farbe meifflid)t fdeineno, an bem (Sierud) und (S)e= fümad füflid)t. Diefer Soumor, madjoemer wohl ge= Eocht, twito er in SBlut uerroandelt, ex bat feint!l eigen= th)ifmliden Sit in Dem $\Omega_{e}$ ib, gleidivie bie fdimarze tund gelbe Gall, fondern wird mit Dem Slut burd) Den \&eib ausgetbeilt, bamit er zu gelegener Beit in Slut mutirt werben fann. Differ Seumor ift aud) auf grveierlei Weife in bem Reibe nothmendig und aut) nülf̧lid). (5rft: (ith) ift ex nothwendig, Damit bei Nangel bes SIlutz, meld)es Das eigenthumliche Nutriment ift, moourd) Die (S)lieber von diefem Scumor ernährt werben. Sum an= Dern ift Diefer Scumor notgmendig, Damit er mit Dem Slut vermifichet rerde, uno mit bemfelben biejenige (Slieber, welche einer phlegmatifhen Iemperatur find, als bas Sirn, belfe erhalten und ernäbren; ïberdies ift êt nüşlich, weil er bie (silieber befeudtet, alfo, bas fie nid)t Durd) Die ftarke Rinftrengungen uno Berwegun= gen ausgetrocknet werben.

Der natürlicbe phlegmatifude Scumor aber ift berje= nige, welcher anoere Sualitäten als bie natürlichen an= nimmt, jeood) aud) peine (Simjhränfungen uno Maas bat, welibe, menn er fie überfdreitet, nid)t mebr ein phlegmatifher Scumor zu nennen ift. Diefes aber ges 


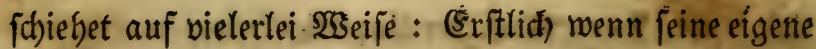
Subfítanz obne Bernifichung ancerer Dinge veränbert miro, weldjez auf vielerlei 2 Seife gefchieht, bann mo b̈fters biejer Scumor nach Der Meinung Der Menfchen ganz gleid) zu fein ficheint, aber bodh ganz ungleid) uno unterfichiedlid) ift, bejonderz in bem Maagen und in Den (Seoärmen; Diejer, weldher in bem Magen liegt, Eann Durch (Erbrechen aużgenorfen werden; Derjenige Scumor aber, welcher fit) in Den (Şeoärmen fammelt, aud) bis= weilen in ben 2roern ber alten Thiere fid vermelyret,

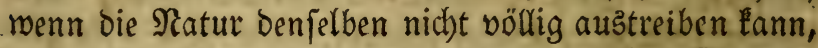
uno bods bon dem Seerzen und den innerlichen (Sliebern getrieben miro, feget er fidh bernach, in bie Beine und an= Dere $\mathfrak{U}$ ntertheile bes Reibes, mešmegen bann bie Sdhin= beine uno räüe ber alten I Ihiere ofterz auflaufen uno geffumellen, welthes gemeiniglich ben bicken uno feiften miederfäbrt, uno benen, bie faft lauter feuthte Epeifen

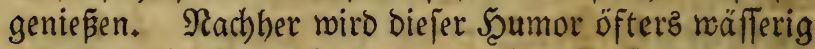

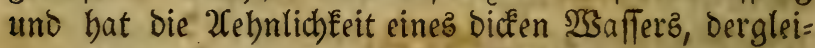
chen in ben Speidjel, weldhe bie Speifen nicht wohl ver= Dauen, uno welche übermäpig trinken, gefehen wiro.2SBiederum wirb Diefer Şumor dick und weiß, nann nem=

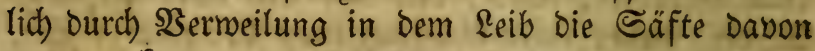

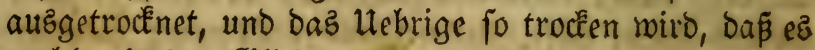
nachber in ben Ssliebern Gängen bleibt, baher baz sूo= Dagra, ber Stein uno andere ßrankheiten entipringen. 2(uß̄erbem wirb nod) ein anderer bičer Scumor gefunden, melcher an ber Farbe uno (Sewid)t einem geidsmelzten

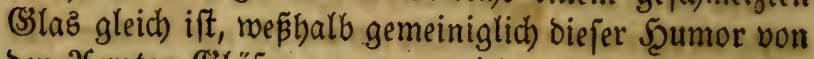
ben 2 ferzten (Slälern genaunt wiro.

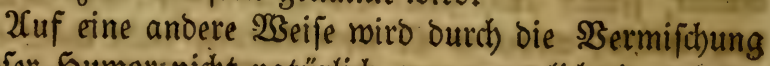
biejer Scumor nidit natürlid), wenn nemlid) ein anderer 


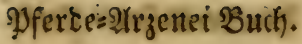

äufferlidjer S్ Sumor binzu fommt, alz SBlut, gelbe oder fdwarze (3all. SSEnn mit biefem Şumor bas Slut vermifd)t iff, alzbann ift er jüp, uno macht folläferig: wenn robe Scumors Damit vermifht werden, alsbann mird er geidjmadeloz uno wäflerig, weld)er bernach we= gen fdrwadber Serbautung in Den \&eibern Den 2(ppetit zum Effen benimmt, unto aud) gar fohläferig mad)t. 2Sofern aber bie getbe Sall Dazu fommt, alzoann miro oas Sphlegma fauer uno leicht, nie aud) beipend uno tro= céen, weld)es aus bem Speid)el reicht in 2 dht geriommen rwerben fantr.

Diefer Scumor ift in Denjenigen gar bäufig, meldhe farke SGSeine trinfen, unmäpig leben, uno viel gefalzene Epeije geniesen, baber gefäbrlid)e (Satbarte fommen; wemin aber Diejer Saumor lange 3eit in Dem Diagen bleibt, alsbann erwectet er bismeilen einen febr gropenen Durft, wenn er aber lang bin und wieber burd) bie Därme läuft, alsbann verurfad)t er bie rotbe $\Re u b r$.

SEenn bie fitwarze (Sall Damit vermengt mirb, als= bann wirb das şblegma fauer, und wird vielmehr in

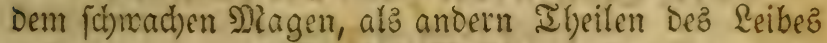
gefunden, Denn bie idnarze (3)efl Durdi) ifre Ratur an= geben, zu Dem Sd)lunb bes Magenz fteiget, Damit fie die Epeijen verbauen belfe, unb ben Şunger wie aud) Den natülidjen 2rppetit erwecke, baber biefe, wenn fie fith bimunter feset, mit Dem phlegmatifden Sumor ber= mifcht wito, uno benjelben fauer machet, welches aus Dem fauten 2(uffteigen bes Nagenz leidttlid) abgenom= men werden Eann. SBisweilen wirb das Sुblegma aud) von Den Speifen in Dem Magen fauer gemadt, obne Bermiffung irgend pines andern Scumors.

Daber find diejenigen $\$$ ferde, weldbe ifre Complexion 
allein aus ber phlegmatifochen Feuthtigkeeit haben von Natur ungeidhidet, ungelebrig, faul, fchroach ano kraft= los, weil bas şblegma bas̈ allerkältefte uno meifte in Dem \&eibe ift faift, fchläferig, bickëopfig, fpectbälfig, flein von 2roern uno Serven, fetten, weisen uno mäffe= rigen 2utugen, flüffitigen Sct)enkéeln, großen bicken uno bängenden Shren, pinen langen unberweglid)en Schweif, von Farben, Rotbjobimmel mit vielen meiß̈en Şaaren

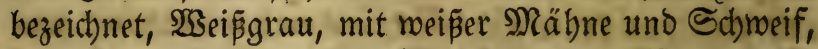
baben Darneben in allen Mixturen zum öftern meipe Mäbne uno Edhweif, nicht venerifd, audh) zur (Senera= tion nidjt tüd)tig, weil Das Sperma gar zu Ealt uno flüfig bei innen ift, uno obfchon \$ferbe bavon fallen, jeooch nichts gutes barauz werden miro, biefe \$perbe geben viel Mift und Waffer von fich.

\section{Das 4te Capitel.}

Bon ber Sholera ober (Sall, uno der choleri= fichen Eomplextion.

Die CEbolexa ift bie gelbe (Saall, ein bişiger uno tro: d'ener Şumor, weldber aus jubtilem bişigem Şeblüte berrügrt ; biefer wiro autd) in einen natürlicben uno un= natürlichen Scumor eingetheilt. Der natürliche Scu= mor ift marm uno trodên, Defien Subftanz Dünn uno fubtil, bie Farbe gelb uno röthlid), cinez bittern (Se= fojmad'?. Diefe gelbe (3)all, menn fie in ber \&eber er= jeugt wirb, alsbann wird fie alfobalo in zwei ITheile ausgetbeilt. Der eine Thyeil verfügt fich in bie (S)al= len=Blajen, ber andere Theil riro mit Dem Blut zu ben 
2rbern gebrad)t, uno biefes mirb aus Nothmendigkeit uno zur Şülfe erforbert; aus నotbroendigḱeit zmar,

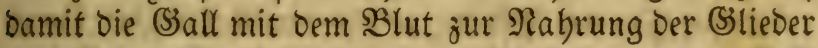
vermifcht metbe, in welchem ein I Iheil Der gelben (Sall

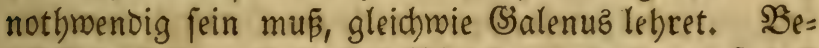
bülflid) ift fie, weil fie bas slut fubtil macht, auf Daß ez Defto beffer in bie engen @trapen, die (S)lieder zu näb)= ren, einoringe.

Die natürliche (3all miro für Diejenige gebalten, wel= d)e von oer erftgemeldeten (Sall abweidht, jeood) ibre ge= wiffe (sinfd)ränkungen bat, meld)e, fo fie biefelben über= id)reitet, nicht mehr für bie (Sall, fondern für einen an: Dern Scumor gebalten wirb. Daj aber fie ibre Ein=

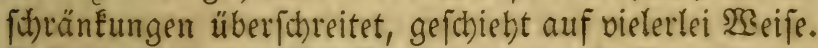

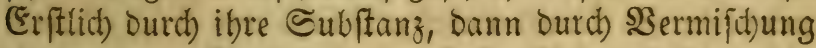
eines anoern Scumors, troourd) fie nid)t natürtld) wiro.

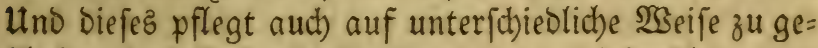

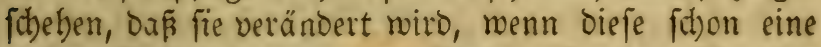
andere (Sall oder eine andere Natur ift, mit weldjer Der phlegmatifhe Scumor vermifht wiro, ein anderer, mit meld)em Die fdhmarze (Gall vermifat wirb. Die gelbe (Sall, welthe burd) ibre cigene ভubftanz nidist natürlid) wirb, ift aud) zroeierlei : Denn eine andere Patur ift bie, weld,e in ber \&eber entffelget, öfters burdh große Scike, alfmo das Subtile abgefondert, uno das Didfe in bie fd)marze (Sall verändert wirb. (Fine andere, weldhe in Dem Magen aus den unverdauten corrumpirten Epeifen ober in ben 2roern aus andern Scumoren berfommt.Diefe ift mieber zmeierlei, bie eine ift ber Farbe nad) Dem \&aud) gleich, Die andere roftig, welche von ber erffen berfommit, wenn fie bie reud)tigfeit verlieret, ift fehs 


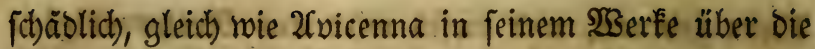
Tbierarzeneifunịt bewiefen bat.

-. Daber fino die \$ferde, meldbe von cholerifder (Som: plexion fino, einer bigigen und trockenen গatur, Hleiner bisigen \&eber, Eleinen und trodkenen Sूerzenz, weil bie Sholera, bas ift, bie Silge in innen Die SDberband be= bält, und bie andern Freuchtigkeiten an ber Nenge über= trift, und foldbes um fo viel mebr, menn fie in bisigen Rändern gefallen find, (obwobl unter und in Denfelben Die vier (complexionen ibren Stand haben.) SBon Den Scaaren find fie furz uno fubtil, an oer Farbe Sdjwei $\beta=$ Fuchs, Єchwarzbraun, Rapp, Soldofarb, Ssoldbraun, Fald), Sibroarzfocten, baben in allen Mixturen fdhroarze (Extremitäten, beldhe von ber verbrannten (5hole= ra beifommen, Eraufe fchmarze Nähne und Edweif, fub= tile, grope und aufgelaufene fibeinbare SBlutadern, ftar= Een, geidhwinden und emfigen 2ithem, zornig, herzhaft, gropmüthig, und hifigen (Seifts, reich), fchnell, jeooch) von nicht gar zu groper Stärke, wenn man fie tränfet,

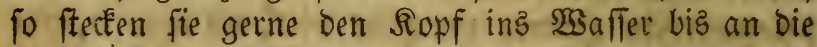
Scälfte, baken Fleine, fdomale, länglid)te uno Dürre söpfe, an benen man faft alle 2roetn uno Nerven, wie aud) an allen (Sliebern uno Gchenteln jehen fann, wel= d)e bie Nenge ber lebhaftin (Sieifter zu erfennen geben, Eurze, fpizige und eng beifammen gewadjfene SDyren; warmes Shirn, großße feuriae, fonellberwegende, trockene uno fold)e 2(ugen, weldhe wobl auffen bor Dem Ropf lie= gen, groß̧e weite. Näuler uno Najelöd)er, bie innmen= big bobl find, eine weite Bruft, beiß̧en Magen, einen (d)önen, geraben, aufgeid)offenen uno wobl proportio= nirten \&eib, zarte, rabne, uno faubele bon allen flüften uno (Sallen befreite Schenfel, beben ben ভchneif gerne 
in bie Scöbe, wenn fie geführt ober geritten melden, uns braufen oft mit dem Naul, find gefräfifg und geben wenig, Dazu trockenen Naift von fich, befonoers in bific gen Ränbern, alloa fie von trodkenen Epeifen unterbal= ten werien, befommen gar gerne, wegen alfiz groper Scise und Irockenbeit, s) Rängel an ben 2ugen, ift ib= nen aud) Der Durft fobalich, weşbalb fie fid) fehr leid)t übertrinfen, find baarechtig und Senarifó), aber präfti: cen nid)t fo viel als bie fanguinifden, fid) aud im $\mathfrak{B} e=$ ft)älen, fowobl mit Den Gtutben, als Scengften barnath zu richten.

\section{Das 5te Eapitel.}

\section{Bon Der Melandyolie uno Der melandiolifoben}

\section{Somplerion.}

Die Meland)olie wiro genannt bie fibnarge (S3all, iff ein falter uno trockener Saumor, Diefe fdrwarze (Sall witb auch in bie natürliche uno unnatürlidye eingetbeilt. Die natüllictse iff gleich an bie Sefen und fdhlimme Uteberflüfigfeit Des ऊieblüts, das ift, Die fdwnarze Ball ift ein bickes SBlut, an ber Frarbe fohwars, uno an Dem Sefdumade bitter und fauer, gleidyoie zum öftern bie= jenige, weldse fid erbrechen, erfabren. Diefe, nachoem fie in ber \&eber gebildet, wird !alsbald in zwei Theile eingetheilt, Der eine Theil mit Dem Slut gebet in bie 2loern, ber andre Theil mirb zu ber $\mathfrak{M i l}_{3}$ getragen, wel= (het Ibeil mit bem SBlut in bie 2coern fliest, ift nid)t allein bem slut behullflid), fondern aud) nothwendig. Nothwendig Deproegen, Damit die fdwarze (S)all mit Dem 


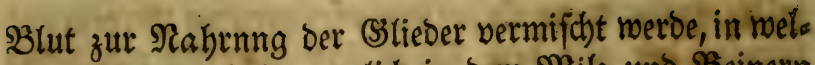
d)en (šliebern, als nemlid) in bem Milz uno seinern notbroendig etraas von ber fatwarzen (Sall zur redten Iemperatur erforoert mirb. Nërslich ift fie, weil bas jubtile und bünne $B$ lut baburde ein wenig bicé miro,

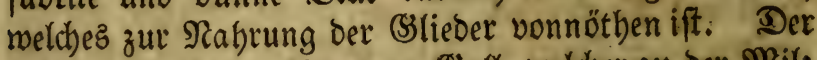
andere Iheil ber fdimarzen (Sall, melcher zu Der Mrilz gezogen wiro, ift gleidjfallz notbmenoig uno behülflich. Rotbmendig ift diefer Theil, meil baburd) ber Milz Nabrung gegeben miro. Neülich ift er, weil er bie Feuct)=

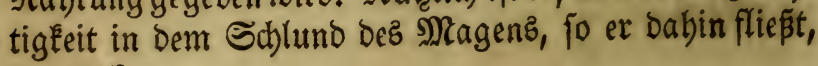
austrocknet.

Die nid)t natürlidbe fdnwarze (sall ift, meld)e von bee natürlidben abweicht, jeood) ibre gemiffe (sinjid)ränfun= gen uno Maaß bat, weldbe fo fie biejelbe überfdhreitet, nicht mebr für biefen Scumor, fondern für einen andern

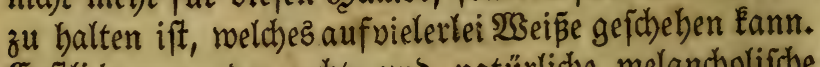
(srfflid), wenn ber rechte und natürliche melandyolijche Scumor gebraten uno angebrannt wird, uno in feiner cigenen Effenz verfault, ift cin faurer Scumor, unlieb= lid), gleid) einem shech, meld)es, fo es auf bie (5roe ge= goß̈en wirb, autb bie Mäuje und Mtuden nidbt ver= fucben, wann er mie Esfitig fichäumet. Diefer Scumor entffebet, wenn bie natürliche (Sall in Dem Reib verblei= bet, two nicht ausgetrieben, fondern barin verfifift uno faul miro.

Die zmeite (Seftalt ber nicht natürlidben fobmarzen (s)alf rübrt aus andern verbrannten Spumoren, als nem= lid) aus ber febr verbrannten gelben (sall ber, Denn

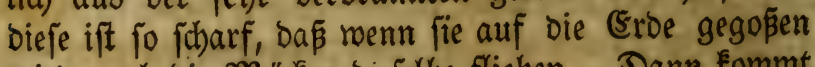
miro, aud bie Mücken biejelbe flieben. Dann Eommt auch foldber Scumor aus bem jefre bişigen (S) blüt und 
verbrannten phlegmatijhen Materie ber, weldher nach 3eugniß bez 20vicennes nicht fo fcharf ift, als berjenige, relcher aus der verbrannten gelben (Sall berfommt, welches auch (Salenus befräftigte. \&ef̧terer verfichert nämlich, Daß̧ Derienige Şumor, weldher aub ber ber= brannten gelben (Salle berfommt, Der alleridhärffite fei.

Die britte Sseftalt ber nicht natürlichen fdyarzen (5)alle nimmt ifren 2 rnfang uno Uriprung von einer fteinigten Sorrection, wenn nemlich für bie (S)efhnul= ften Nedicamente gebraucht rerben, weldhe febr ziehen und zertheilen, alsbann wiro allez, mas barin bünn und jubtil ift, zertbeilt, und bas übrige Dicfe ganz bart, wie ein Stein, unb ausgetrodfnet, relches hernad) in ei= nen melandjolifchen Şumor bermandelt miro.

Die vierte (Seftalt Der nid)t natürlichen Meland)olie Doer fondarzen (Sall entffeht, wann ein anderer Scumor mit Der nidyt natüriduen Relandjolie vermifdet mild, welches, menn es gefdieht, alsoann fie millo uno füs wirb, fo aber bie fdwarze uno gelbe (S)alle Durcheinander vermifht wird, alsbann wiro biefer Scumor entroeder bitter oder fauer.

Dataus geht herbor, bap dieje Sुferbe, melche ihre ra= bicem aus oer Meland)olie allein baben, falt uno tro=

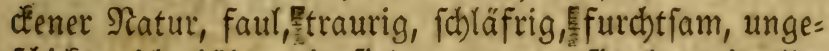
fdicfe, nicht jähzornig fino, wenn man fie aber mit aller Semalt zum 3orn bewegt, werden fie gerne Desperat uno enolid) gar (5holerer, ungelehrig, altgefdaffen, gro $\beta=$ Eöpfig, mit groß̉en reiten bängenden Shren, ober gar über alle Napen eng zufummen gewad)fenen langen Shren, fleinen Dunfelblauen oder fonnarzen 2lugen,

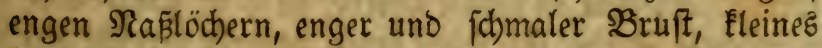
barten uno bünren 2thems, mager uno boch fare uno 
grop nom Reibe, rauber Scaar, von Farbe, Schwarz=

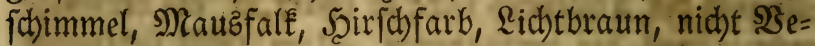
nerifd, bepiwegen zur (Seneration ganz untüchtig, find gefräffitg uno geben boch nicht viel Natift von fich.

\section{Das 6te Sapitel.}

\section{Bon allen biefen Complexionen.}

2us allen diejen Somplexionen mun Eann man eines

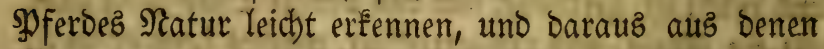
Mixturen jein Urtbeil über biejes oder jenes Spfero fál= len, und feinen Schlü Darüber machen. Sum (Exem: pel, ein şfero ift bon Satur d)olerifder Complexion,

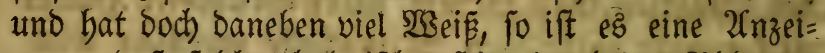
gung, baj folche cholerifche Shife ourch baz spblegma temperirt fei ; Sift ein soferd folnarz oder Dunfelbrau= ner Farbe, und an bem äufferften Ende, als dem Naul, Schultern und Sïgen etwas lidbtbräunlid), fo ifts eime

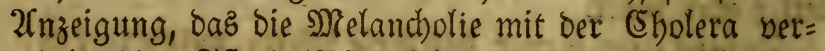
mijht fei. Sit ein spfero forwarzgraut mit weiffen $5 x=$ tremitäten, und viel $\mathfrak{B} e i \beta_{\beta}$ gezeichnet an Füpen und an ber Stirn, fo zeigt es an, daz foldhes spfero feinen $\mathfrak{t r}=$

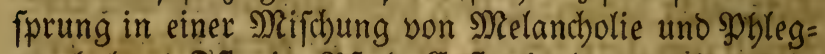
ma babe. Sit ein sूfero Eaftanienbraun mit menig

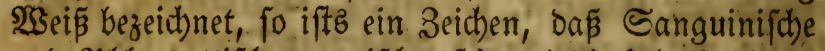
und Shblegmatifche vermijchet jei, uno die Sberband an Demielben habe; Denn je mefr uno größere Beichen einer jeden Gomplexion an einem spferde, fie fei in ganzer oder bermijhtef zarbe, fich feben lapen, je mehr berricht bie= 
felbe in bem SPferb, beß̃en Seidben zum gröp̈ten und meiften Daran gefpührt wiro. Uno wiro biermit, waz von Den Somplexionen Der झुferde ju fdreiben, geendigt.

\section{Das 7te Eapitel.}

\section{Bon Dem 2llter Der Yferbe, und wie Daffelbe zu erfennen.}

Shas das 2lter ber Spferbe betrifft, fo erreichen fie zwar verfdiedene 2flter, allein nadboem bismeilen bie Randes=22 rt ober $\mathfrak{W a r t e}$ Derfelben iff, erftreckt fid) auth ibs 2lter; Denn man ließst in geidhichtlichen 2 serzeid)= nipen von Spferden, weldhe nicht allein zu grofern 2flter fommen, fondern aud) Darneben jederzeit ibre Etärke und Serzhaftigfeit bebalten, namentlid) wiro ermäbnt,

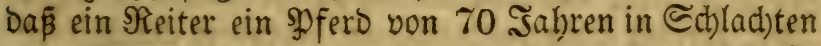
uno Sd)armüzeln geritten, uno feine Scerrendienfte rübmlic, Darauf verfeben babe. Des 2llexanoer Nag= niz Bucephalus batte 30 Sabre mitgemacht, als pr in

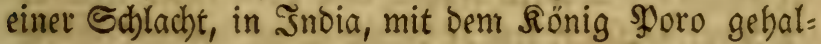
ten, mit einem $\mathfrak{P f e i l}$ erichopen worden. Earl ber 8te Sönig in Franfreich, hat in einer Sulacht, weldhe er mit ben Şerzogen von Mantua uno Ferrara gefämpft, ein einäugiges fowwarzes $\mathfrak{P}$ fero von 24 Sabren geritten, wie aud) nod) eins von $\mathbf{3 0}$ Jahren in eben gemeloeter Sd)lad)t. (5laudins Sorte, ein berübmter $\Re$ itter von Spaoua, hat ein SDfero 20 Sabre in feinem Dienfte ge= babt, bernaib einem Sobriften, Samillo Eolonna genannt, verkauft, weldbes Spfero biejem (Samillo wie aud) feinem Sobn \$ompejo in Dem Sirieg-bor hoben ๔ena, unb in 
ber Sd)ladt, als Strozzi gejdlagen nurbe, febi nobl geoient, uno bernach noth lang gelebt bat.

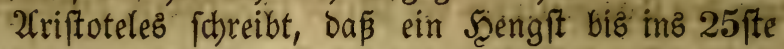
Sabr, eine Stuth aber bis ins 40fte Sabr ibr 20lter

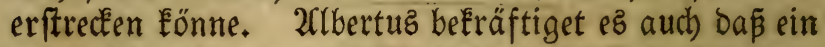
\$fero fein alter biz auf 30, 40 unt 50 Jabr bringe.

Eine alte Sarbarifhe Stuth, nachoem fie ein Saval= lier lange im ßrieg getirautcht, uno ibr manchmal Das Eeben fauer gemadht, bat biefer Stuth, nadjoem fie un=

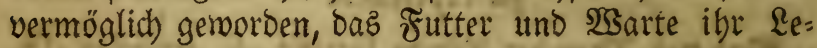
benlang zu reichen veroronet, uno foldhes einige 3eit fortgefergt; als er aber einsmals im siauld) auf (Finra= then feiner guten Freunde einer (um ibre 2(nimofität auch im Goben ifter zu probiren) überrebet nutbe, bieje Stuth in einen mit einer Mauer umgebenen Mola cin = zupperren und einen Qöwen zu ibr zu la pen, bat er fol= ches geicheben, uno ben \&öwen zu ihe binein fpringen lapen, welcher bann mit böllig aufgetbanem Nad)en auf bie Stuth binzugeiprungen, gegen meldben aber bie Stuth im erften 2(ngriff fith fo ritterlid) gewebrt, uno mit einem ber vorbern Füßen, Dem \&ömen alfo Einz an ben Ropf verjeģte, baje er bavon ganz betäubt nurbe

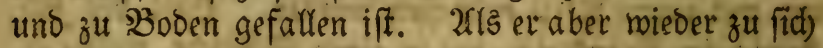
getommen, hat er bie Stuth noch einmal angefallen, bie fich aber wieber tapfer gewehrt, biz endlich Der \&öwe ber Stuth Den einen Sug vom Qeibe gerißen, und biefelbe alio vollenos getöbet hatte; ber Röme aber in ber nad)= folgenden Racht von Den yon ber Stuthe empfangerren Sthlägen audh geftorben fei.

Sd) wilf aber aud yon bem 2llter ber soferbe bar= thun, mas bei meinet Zeit geicheben, uno id jelbften

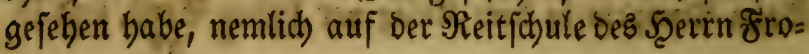


beni, zu Sceibelberg unterfatiedide syferte, im Sahr 1655 uno 1656, als id Damals auf feiner Reitfdute geritten, zu 25 biz 30 sabren gejeben, weld)e ifgre \&ec= tionen alle nod) gut uno wobl gemadt haben, wie dann aljo fein genanntes Meberlein (war ein Barb yon ganz ichwarzer Farbe und ein (Eapreolift) Damals itson 20 Jabre alt, uno bennodb bei allen Hebungen aetragen, uno nichts defto meniger einer ber beften Epringer ge= wejen; Der Facius gieng beim Rennen recht bart, uno wobl barneben bielt et genauten Iact, welibes ein gherd von 24 sabren war. Der alfo genannte grope Nor= Dan, von Farbe ein Blaujhimmel, Der in Sallotaden

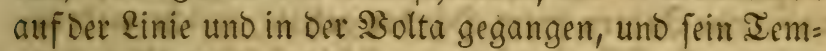
po fo juft uno bart babei, als ein Mferdes machen Eann, gemadtt, war fichon bamals ein \$ferd von einigen zwan= zig Jahren. Sm Sabr 1668 babe ich inn noch ange= troffen, Da er nod) feine Edjulen gut uno juft um ben झुileum gemadht, nidht weniger fein Iraffi meldyes ein Eifenfithimmel mar, oen er von einem franzöfifiten Sf: fizier, weld)er Iraffí gebeišen, befommen, uno daneben mofl und in ber \$affada gegangen; war bamals zu obenbejchriebener Beit breipig sabre alt, anberer feiner soferbe zu gejd)meigen.

Daß̧ aber Şertm Frobenius \$ferbe foalt genorben, uno boch ein uno ben andern $\mathfrak{B S e}_{\text {eg }}$ fo geoauert, ift bie Itrache, weil Şert Frobenius bas Sprid)mort gar moht in 2(d)t genommen: Das nemlich bas 2ug Des Serrn Das \$pfero fett uno gut madht; Denn er hat feine \$oferde gar wohl mit ber 23 arte uno Futter in 2(d)t genom= men, uno felbft täglid feine Ställe unterfucht uno gefe= ben, wie feine \$ferbe gewartet werben. Im Shochfüriftl.

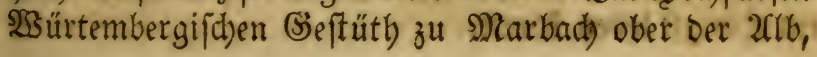


Mferbe:2Arzenei Bud).

uno im Slofter SIffenbaufen, allmo ich mich in 9 viertel Sabr, bis nach Sr. Şodhfürftl. Durchl. Scerzogs (5 ber= barts Scochfeel. (Sebächtniß Iod, melcher ein fold)er Serr war, und Damals ein foldbes (Seftüth gebabt, Deßs= gleichen spferdezudbt menig Serren in (suropa baben werben, auch Durch Deßen SEerftano und Sronung afles angeordnet murbe; benn er bat alles felbft münolid) be= fohlen, roas biefem oder jenem Scengit für Stutben, was biefer ober jener Stutbe für ein Scengft ober Ef fel zu geben, oder an welchen Sort bieję oder jenes froblen auf bie $\mathfrak{B}$ aide biflute gethan weroen, aufgebalten uno Stutbenmeifter gewejen, babe id) viele Stutben zu 20 - uno mebr Sabren unter Şänden gebabt, melche mebren= theils nach Sffenbaujen zum (5.elgeftüth getban mor: ben, und etliche Sabr nod) fhöne Maulefel gebracht ba: ben. Die Urjache aber ift Die SBergmaide, morin fel=

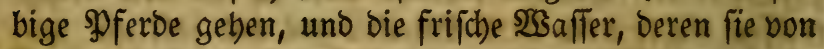
Sugend auf gemohnt find; Denn alle spferbe, melche in bergigten und rauben Siten gefallen, auch bor bem 6 . Sabr nicht gar zu febr angeftrengt morben, eine viel größere Stärfe und 2flter befommen, alz andere aus moraftigen (segenden, abjonderlic) bie Frieplänoifchen Spferbe, weldbe, fo fie auper ibrem sande in bergigte Derter, allno Eurze uno raube $\mathfrak{B}$ aide, auch harte $\mathfrak{B a}$ a = fer find, gethan merben, gar felten gut thun, uno un= ter zrölfen ber balbe Theil faum bavon fommt, und in

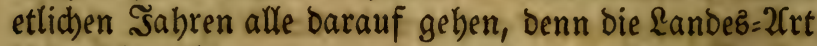
läpt fich nitbt zmingen, niel weniger bie \&uft, $\mathfrak{S}_{\text {affer }}$

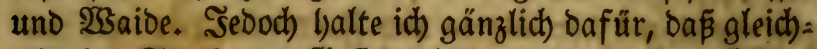
wie eine Stuth zum (Seftüth länger alb ein Sengft fön= ne gebraudbt werben, aljo aud) eine Stuth länger ala ein Scengft leben tönne. 


\section{গJerbe=2(rzenei Butd).}

Das alter eines গুferves zu erfennen, fiehet man fol= ches bauptfäd)lidj uno am allergemiffeften an Den 3äh)= nen; Denn ein soferb hat 40 Bäbne, welche folgender= masen unterfofieden jind: 3 u oberft im Maul 6 , unten

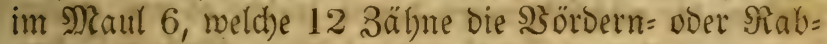
zäbne genamt werben, aus meldhen 12 3ähnen neben benen 4 Scacken, aud j̧unoszähne genannt, Das 2ltter eines soferdes erfannt wirb ; bernad) find bie Stoct: zäbne, 12 unten und 12 oben, mit welliten das Sauen gefchiebt, Denn fo bald ein foblen geboren wirb, to hat ę alle feine Salme, auper den 4 Szacten=3ähnen.W3ann num ein Fohlen in Das vierte Sabr gebt, bismei= len gefchiebet es auch vor bem (Ende Des britten Salnes, aber gat felten, to fangen bie S5acten= ober STundszäh= ne an zu rachfen, an weldsen man bas 2utter eines \$yferdes gar nobl erfennen fann. Denn je jünger ein spero ift, je fouarfer, Eürzer uno bünner fie find, je äl= ter aber Das sDfero ift, je volfemmener, größet uno runver diefelbe werden, Deß̈wegen in diefem Fall fid) vor Dem Setrug wohl vorzufehen, Denn man kann fie dün

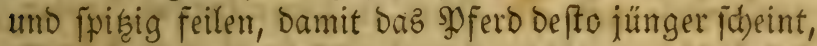
allein man barf biefelbe nur inmendig begreifen, fino fie glatt uno eben, fo find fie gefeilt worben, benn bie von शatur junge Saacfenzälne fino inmendig nid)t glatt fondern Gaben (S)ruben ober eine Şöhle, woran man bie= fen Unterichied mohl merfen Eann; mandhe follagen ith= nen foldhe Scackenzäbne gar aus, Damit man baz 2rlter nid)t erkennen folle.

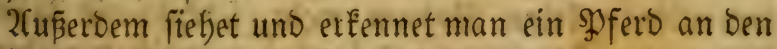
vörberften 12 3ähnen oben uno unten, benn wenn dą britte Sabr berbei nabet, (jeood) fangen einige \$ferte langfamer an zu zabnen, als bie andern, befonders bie 
Wallfadyen) fo fallen, man nennt es auch fohieben bre: chen, Dem spfero bie mittelften 4 vorbern 3ähne, als 2 oben uno 2 unten aus. $\mathfrak{B s e n n}$ das vierte Sabr herbei nabet, fo fohiebet ober brid)t es mieberum 2 unten uno 2 oben, bie näd)ften neben benen, welche es vor einem Sabr geidboben. Im berannabenden fünften sabre ichiebet es bie äuferften vier, als 2 oben uno 2 unten. 2̧ann es nun ausgebrochen (gefchoben) bat, alsoann ifts bei feinem rechten (Serwächs, uno fängt bann an in

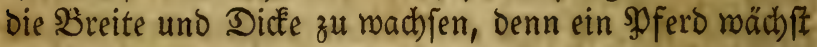
in bie Scöbe bia inz fünfte, in bie SBreite bis ins fechffe Sabr, uno bann ift es in leiner rechten Dyerfection in Dem (Ssemädb3. Die gefdjobene Bähne fino nicht jo meí̃ gleich) wie bie, welche es aus Mutterleib mit fich gebracht, fondern Sconigfarb, mit eingetieften (Siübchen und fdhwarzen Iupfen barin, weldhe Iupfen man Bob = nen ober Den Rern nennt, Denn wenn die Bäbne oben ganz glatt und weís find, fo ift bas \$ferd alt und hat bie Bohnen aubgefreflen. SDbmoblein Scengft fich eher ausfrifst als eine Stuth ober $\mathfrak{B a}$ allach.

(S) feine SBrüd)e gethan, eben fo uno in gleichen Sahren verlieret es die Sohnen an Denfelben 3ähnen, Die es der Soromung nach geidoben bat; Dann erftlich fript es bie. Bobnen aus an ben 4 vorberften 3ähnen, 5, 6, 7, 8, im fiebenden; (Denn im 6ten ฐahr ftebet es ftifle, 9 , $10,11,12$ im achten, und $13,14,15,16$ im neunten sabr. Nad) Dem neunten Sabr bat eza an ben yorbern Unnterzäbnen Éeine Bobnen mebr, fondern bie 3äbne fino glatt, volltommen, uno fangen an weis zu werben, Deşgleichen audb) bie Şadfen: 3äbne nunmebr vollfommen

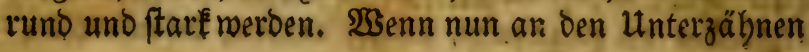




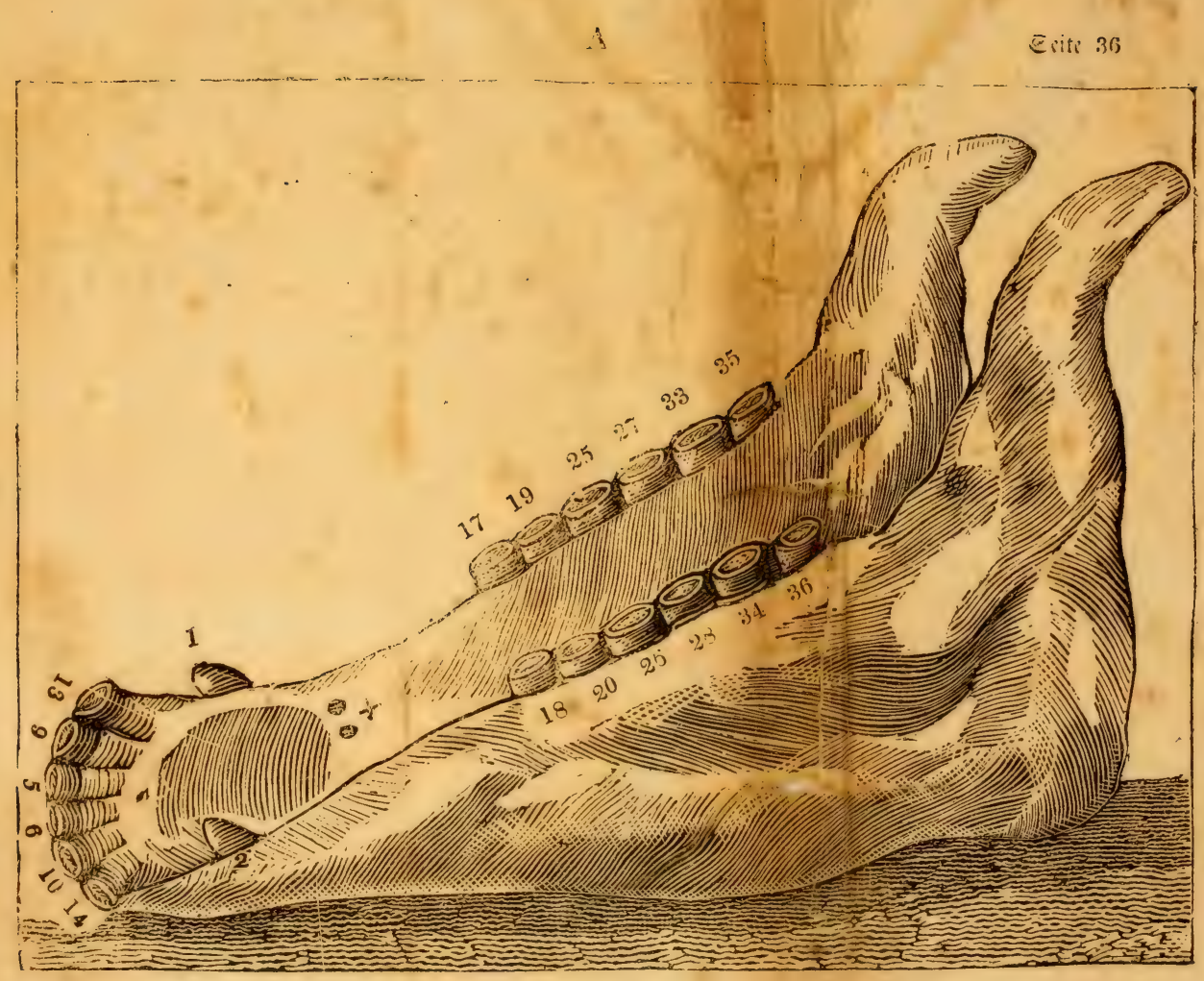




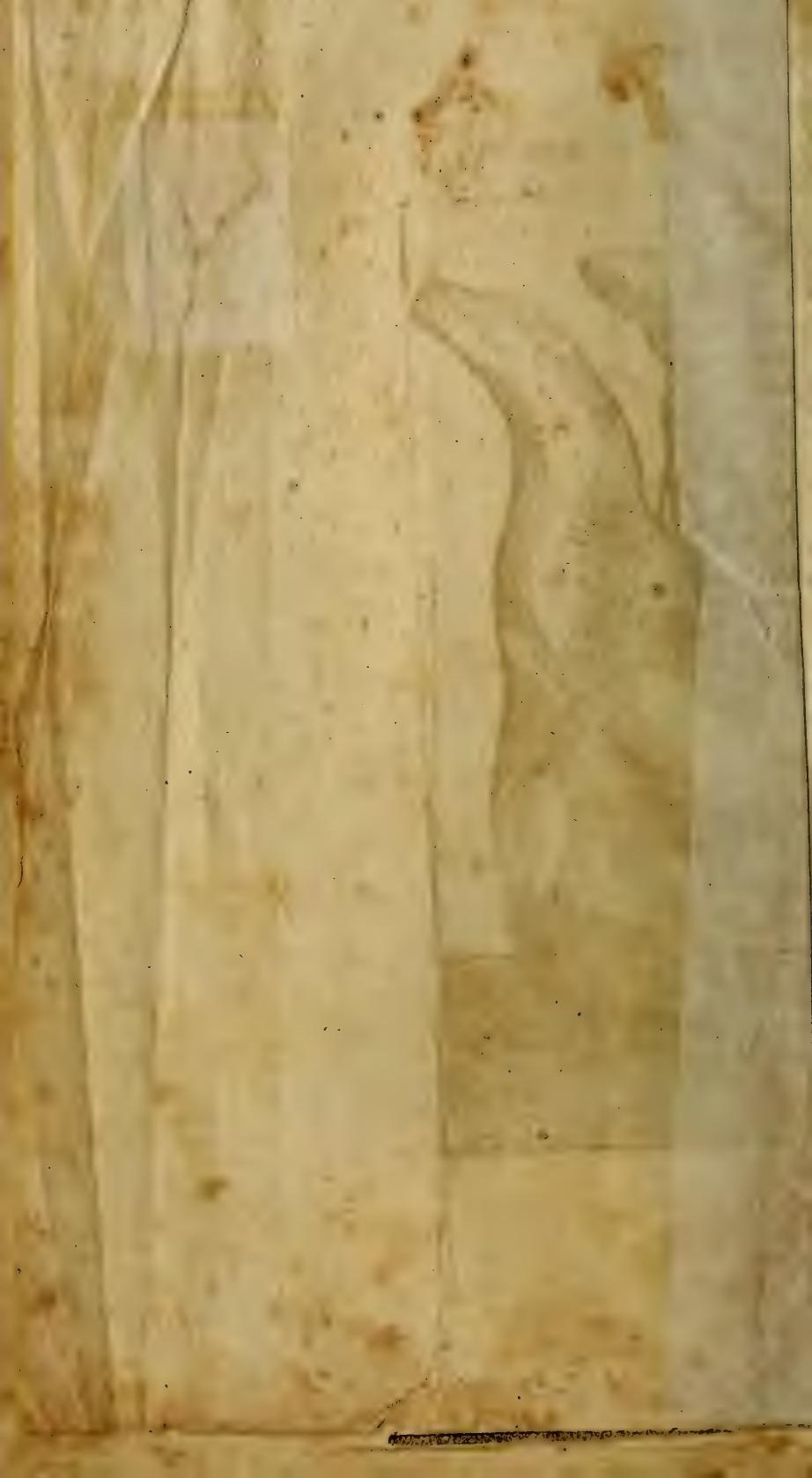




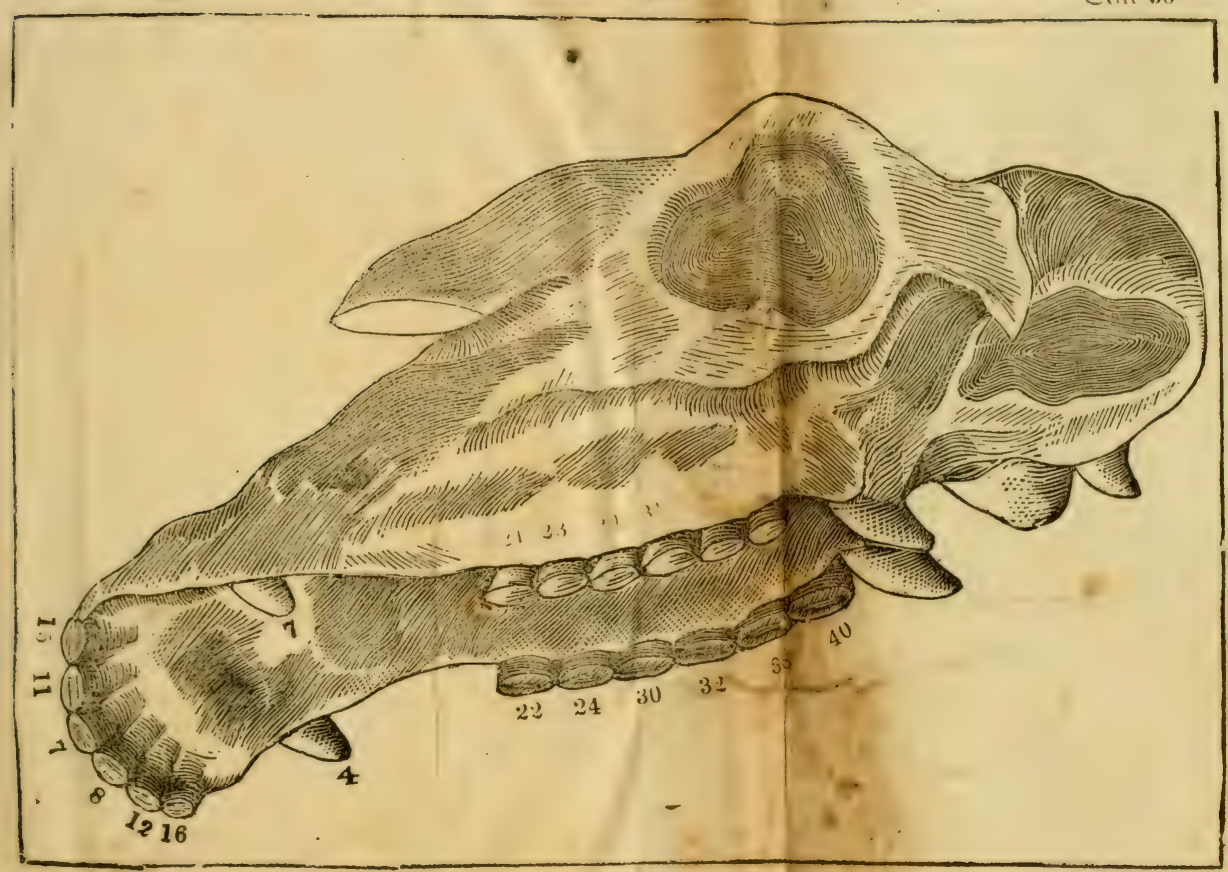




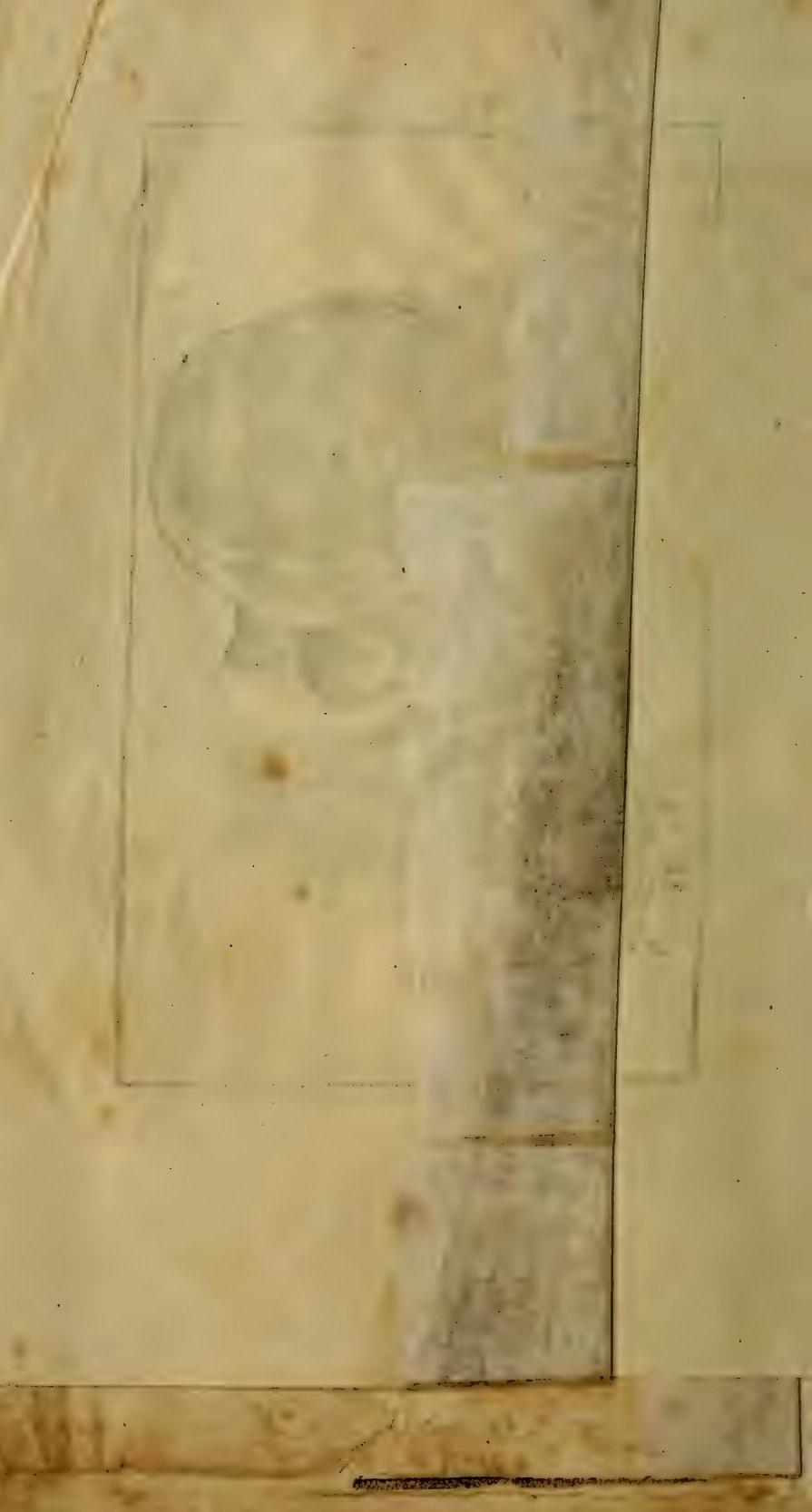


von bem barten Futter Der fohmarze Setn ober Bohnen reggegangen, und unten Eeine Rennung mehr, fo fängt es alsbann an Den obern an, uno gebt ungefähr um Das eilfte uno zmölfte ber fd)warze Rern an Den erft= gejchobenen Sberzăbnen, গ20. 7 und 8 binmeg, nach fol= d)er Rafirung ber Bohnen erbebt fich bie (Ebene Der Sälne allgentad) über fidd), bis in bas breizehnte Jabs, Da fid) aud) zugleid) Die lange $25 a r z e n$ an ben Echenfeln gemreiniglid) mit verlieren. $\quad \mathfrak{M}$ daz vierzehnte uno fünfzebnte Sabr verlievt fid) Der אern in obern nadjfol= genden 3ähnen, No. 11, 12. Dieje merben aud) ebe= ner, länger weiß̄er uno älter, bie Scactenzähne werden Dabei bider und ftumpfer.

Utm bas fechzehnte und fiebenzehnte Sahtr verliert fid') aud) Der Rern ber obern (Esctzäbne, aud) No. 15, 16. Die Sämme fino länger, ganz eingefreffen und einge= Eerbt, Der (Saaumen niro mager uno bürr, Denn in mit= telmäfitgen sabren ift er erbaben uno fleifadigt.

Um das 18 uno 20 biz 30 Sabr, werben alle Bäbne oben und unten je länger je weišer, Deşgleichen je älter je länger, bas 3ahnfleiffh weicht ganz zurück uno mito locfer, bie Scadfen werben aud) lang, biff uno rund, wie ein Finger, bie obern Bäbne reichen vor bie vorbern

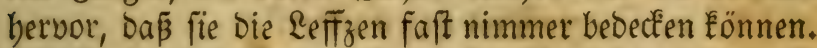
Esz ift aber Dabei zu merfen uno aud) nicht zu vergef= Fen, Daß̄ bie Fohlen, wann fie ifre andere Sähne ichies ben, źugleid) aud) bie Stoofzäbne ichieben, als nemlich)

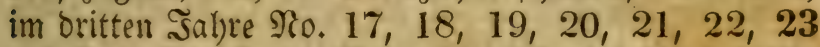
und 24. Sm vierten sabre গo. $25,26,27,28,29$,

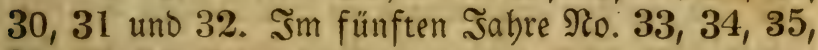
$36,37,38,39$ und 40.

WSann man nun an einem \$ुferbe Daz 2flter an ben 


\section{8}

Mferbe:2Trzenei ßudd.

Bähnen erfennen - will, fo mus man bemielben nach den Bobnen feben, wie oben gemeldet, objichon auch bie $S_{e}=$ trüger in biefem Stück febr follau uno abgerichtet find,

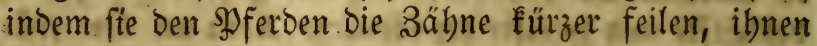
mit einem Meifel die 3äbne mieder bobl joblagen, Man= Deféern oder Schnefel in bie (Sirübchen hinein legen, uno ein glühendes Esifen barauf balten, fo befommen Die 3ähne wieder fithwarze Sohnen ober Rern; menn man aber mit einem fddarfen Syfriemen ober fpisigen Eifen barin gräbt, fo fann man es auch mieber heraus thun, welches aber an jungen \$Pferden nicht gejheben Eann; überdiez fann man einem SPferde die Sähne nimmermebr fo gleid) formiren; als fie ihm von Statur gewachjen. Die Stuthen befommen auch bisweilen bie Shackenzähne nur theilmeife, bejonders diejenigen, mel=

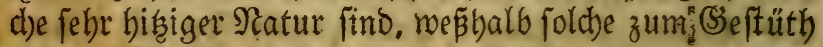
uno ber (Seneration nicht to tauglid) fino als bie andern, Da fie weniz Foblen bringen, aud zum öftern unfrucbt: bar, im Ulebrigen aber für bie aller arbeitfamfte und Dauerbaftefte $\mathfrak{s}$ ferbe zu balten fino.

\section{Daz 8te Capitel.}

\section{Bon Den 5aupt frranfleiten.}

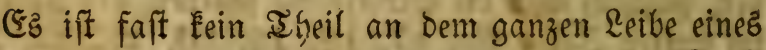

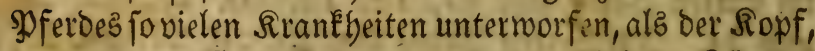
Denn bie meiften Störungen an Den übrigen Sörtper= theilen üben einen foldhen (Einflus auf ben Sopf́, Da

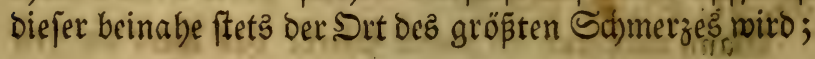


gubem ift Det Sopf für fid) felber Durch feine empfino: fameten నetven, gat vielen eigenthümlidben Rrankbeis ten ausgeferst.

(5) fino aber ber Saupt=Schmerzen viererlei, als nemlid) geidieht Der erffe Saauptidnerz in Den Sirn= fellen, uno wiro in breierlei Sorten unterichieden, nem= (id): Sephalalgia, Sephaläa, Scemicrania. Die an= Dere pflegt die Subftanz und 2 Sejen Des Seirns felbft anzugreifen und zu verlefen, als ba find die Unfinnig= Eeit, Nania, bie meland)olifhe Iobigkeit, Das Sirnmü=

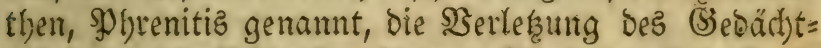
nip̈es uno die Sdhlaftrankgeit. Die britte 2frt ift $38=$ wohnt bie Spacia uno die Scöblen bes Scirns anzufül= len, Den Sinn und Bemegung zut verbindern, als da fins bie fallends Sudtt oder Epileplie, Der Sdbwindel, SEer= tigo genannt, ber Sd)lag, 2poplexie, die \&älmung,

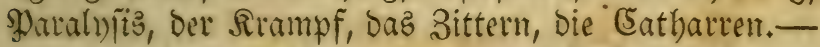
Die vierte 2 rt verlegt die austwendigen Theile bes Şaupts, als ba find Şrarausfallen, laufig und grïn= Diges Sarupt, gefdylagen oder vermundet merden, von weldien lef̧tern auswendigen SEerlef̧ungen in Dem Drit= ten Theil biejes Saudb gebandelt merben foll.

\section{Das 9te Capitel.}

\section{Bon Den Sauptidnutuzen, weldye in ben} Sirnfellen fich sefinden.

Diefe Sauptidymerzen rerben, wie obenbefdrieben, in brei Slasen abgetbeilt : Der erfte beifst Sephalalgia, meld)er nemlid) nicht lang wäbret, Der andere (Sephalär, 
der langwäkreno uno fix ift, ber oritte Semicrania, bez auf einer Seite dez Scauptz, ez jei auf Der rect)ten ober linken Seite, fich aufbält. Wsir mollen fie aber alle unter Dem গamen Des Scauptidtmerzenz begreifen.

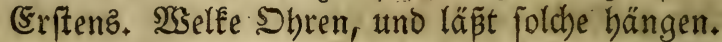

3weitenz. Laufen bem \$ferde bie 2lugen auf, ge: fotwellen babei, und Eann übel fehen, und bat foldte faft allezeit zut.

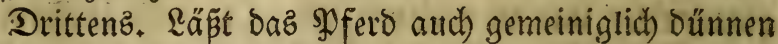
Schaum, (Beifer und Utnflath aus Dem Maul fallen.

Biertens. Das Maul und Der Ropf ift bismeilen bisig nno trodéen, uno bat keine vollemmene Sinne.

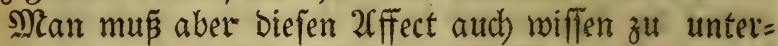

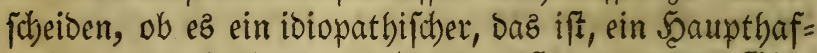
tenoer, ober ein inmpathifcher, daz ift, von andern (Slie= Dern communiçirter Edbmerz fei, weld)er Unter fdjed ba= rimmen zu merken, Daß̃ ber Soiopathifche allezeit im Shaupt bleibt, Der Sympatbifhe aber bält 2(6wech)slung, thut zut gewiser Beit mehr ober weniger webe. Sol= cher ift entweber vom ganzen 2 eib, wenn nemlich ber Eeib in Fiebern in eine Fermentation gefereft niro, ober aber von einem leibenden \$stied allein, aus dem Nagen,

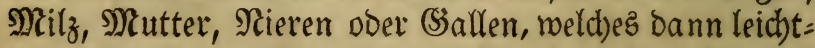
(id) abzunobmen iff, meil zugleid) aud) an bem Sort bez leibenden SSliedes $\mathfrak{B}$ eichmerung empfunden miro. STn= nerliche Utrachen fino icharfes bifíges (3eblüt, Deffen Dämpfe ftets in Das Scaupt; als nach) einem (Samin ge= trieben werden, da fie bann die Sirnfelle reisen oder fpannen, überflüfítgez Seblüt, Deß̄en Ueberflū ftetz nach Dem Ropf fteiget, mie bie fpringenden sutellen nach) Den Bergen, uno gar bäufig nimmt foldhes übri=

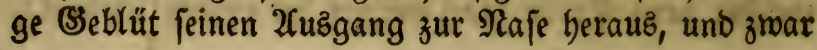


mit fonberlidber (5rleid)terung Des Şauptz. 2reuperli= d)e llrfadjen fino: Ealtes Irinken, Rälte, Scike, wenn fid) Die (Salle in Dem Nagen generiret, bisciges frutter, grope Reifen im hikigen Sommer ober Ealten $\mathfrak{B i n t e r . ~}$

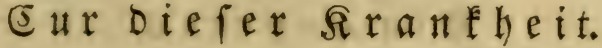

S3or allen Dingen follte man dem פferbe Den $\mathfrak{L}$ eib offen balten, und ibm bie 2roern bei ben Echläfen off= nen, aber nicht viel Blut beraus lasen, uno ibm nad)= folgenten ltmid)lag um bas Scaupt binden :

(Semablene Epreuer, Fodbe fie im Sommer mit (5)

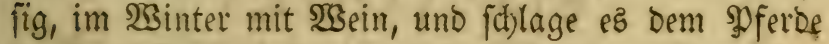
um Den Sopf, und roiederbole foldbes zum öftern, Da= rauf gib ibm nachfolgende spurgation :
Rhapontic 3 \&oth,
Tamarinden 4 Ioth,
İnis 1 Suintlein,
Eerbenichromm 1 \&oth,
SBeinftein 1 \&oth,

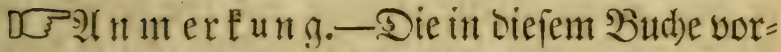

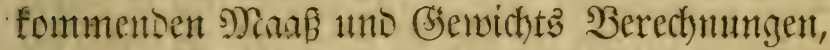

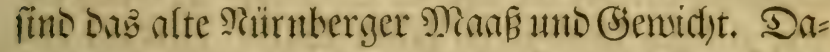
mit Sebermann leidht auffinien fönne, wie viel jede einjelne Singale in hiefigem Rereintigten Strnten Senvidhte ausmadyt, hat man am Schlube siefes Butthes cine ausfithrlidye Tnbelle angefithrt, in Der jeber einzulne Manâ uno Semid)totheil mit bem alten Nairnberger (Sienvid)t neben Dem ?tmerifant= fdyen erieheif uno vergliden werben fann. 
alles untereinanoer gepulvert, uno in $1 \frac{1}{2}$. Raaß $\mathfrak{B}$ af: fer gelegt, uno über Nacht Darinnen liegen laFen, bes andern Morgens bis auf ungefebr ein Maás einfieben laß̄en, und bem spferbe laulidbt auf einmal eingegonen.

Ein a n bereb.

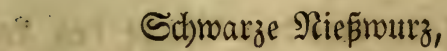

Salpeter, von einem fo viel als yom anbern,

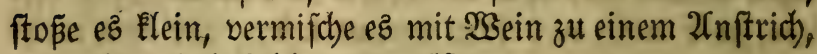
uno wieberbole folctes zum öftern.

(E) $\mathrm{in}$ anderez.

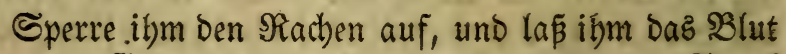
auz bem (Saaumen, bernach) giepe ihm folgenden Irunk ein :

(3eftōenen (Eppidjaamen $\frac{1}{4}$ Mfund,

Die Brübe worin ?auct) gejotten, 2 Maaß́, Baumöl,

Wein, jebes $\frac{1}{4}$ gh fund,

alles unter einanber gemifht, einmal lapen auffieben, in zwei gleiche. Iheile getheilet, und dem פूferbe zmei Tage nacheimander laulicht eingegoßen, reite ez Darauf allgemadb bin uno ber uno la $\tilde{\beta}^{\text {es }}$ barnad) ein menig tu= ben, alsoann küble es im falten $\mathfrak{S}$ affer, gleid)wie bie= jenigen, weldhe fich zu fehr nach Erbifing überfreffen

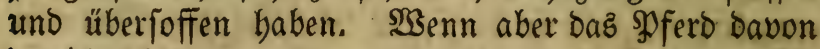
burdbbrüchig geworben, uno bünnen $\mathfrak{U n}_{n}$ flath von fid) pferchet, fo wirb ez von biefer RranEbeit erledigt,

(Ez pfleget fich auch bismeilen in bie scauptwebeta=

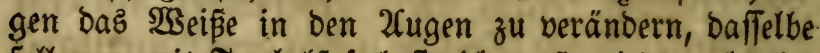
foll man mit Fenchelfaft beftreiden, fo wiros auch mie. ber gut. 
fape alles zu sুulver, mit einem balben Maaß untereinander gemifht, gefeiht, uno foldbes. hernach bem sofero laulicht in beibe sajelöcher gegopen.

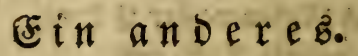

EIfig $\frac{1}{4}$ Maa $\tilde{\beta}$,

Baumöl $\frac{1}{4}$ Mfund,

Salpeter 2 Ioth,

untereinander gemifat, und bem \$f feroe banon oft in Die Shren getröpfelt.

E $\mathfrak{i n}$ anderez.

Sfterlucia 2 Roth,

$\mathfrak{B e i n} \frac{1}{4} \mathfrak{M a a} \tilde{\beta}$

Foche und mifache alles untereinander, und giepse bem Sुfero laulicht ein.

(E) $\mathfrak{i} \mathfrak{n} \mathfrak{a} \mathfrak{n} \mathfrak{e} \mathfrak{e} \mathfrak{e} \mathfrak{b}$.
Salpeter $1 \frac{1}{2}$ \&ot
Salz 1 loth,
WBein $\frac{x}{4}$ Maaß̄,

milche alles untereinander, uno láp bem sojero laulicht in ben Sdhlund giepen, "wno no $\mathfrak{U n}_{n}$ fath vorbanden,

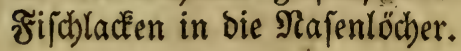

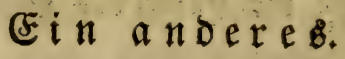

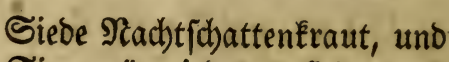
Sinngrün, jedę 3 Scänoeboll,

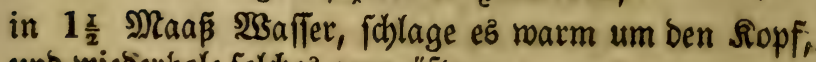
uno wieberbole folches zum öftern. 


\section{(E) $\mathfrak{i} \mathfrak{a}$ กDe $\mathfrak{e} \mathfrak{e}$.}

Nimm Den Saft von Röbleraut $\frac{3}{4}$ Raấ,

(serftenmebl $\frac{1}{2}$ ⿰马 funo,

Şonig $\frac{1}{2}$ Maā̄,

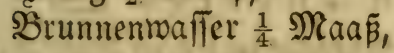

alles untereinander gemijdt, und bem $\$$

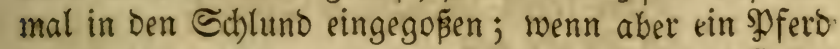
gar zu lange bavon purgiten follte, fann man es ftillen mit Nachfolgendem :

Scübnerfberben (pin Rraut, in Ratein 2 na $=$ galliz genannt) Diefes Saftez 8 (oth,

Serftenmebl 4 \&oth,

madbe Sildbelchen Datau uno gib ifm oft baven ein, bazu mit Futter geröftete ฉinjen ober (Sierfte mit guter: Sleien vermifdot.

Eine $\mathfrak{A} \mathfrak{o p f} \mathfrak{f} \mathfrak{l} \mathfrak{b} e_{\text {. }}$

Bibergail 2 \&oth,

Eorbeeren 4 Iotb,

$\rightarrow$

Salpeter,

\$ect),

WBeirauch bes folect)teften, jebes 4 Ioth,

2flt Baumöl,

Butter, jedes 12 Roth,

alles untereinander zerftopen, und ein wenig Salarn von einem jungen Snaben Datunter gemijcht, und falbe ber Sopf Damit.

Eine andere Salbe.

Bleimei位 12 Ioth,

Srunnenwa

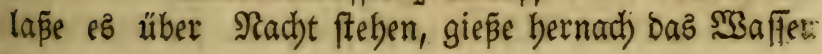




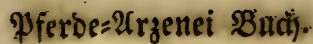

von bem Bleimei $\beta$, thue bernadh zu Demielben SBleimeiß, Sconig, Baumöl, jebes : Loth, fto zu einer Salbe, uno beftreiche Den నopf Damit.

E

(sän ferid) einez jeden Neonats gefammelt,

3 șände volf,

Eine balbe Shanowoll Salz,

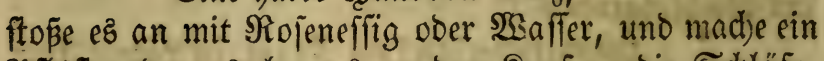
Syflafter Darauz, lege es um den Siopf an bie Schläfe, uno alle 3 ooer $\mathbf{4}$ Stunden mieberbole foldtes, gib ibm auch) nachfolgenden (Eingu隹 :

Suittenblütbe $\frac{1}{2}$ Scand voll,

Salbeiblütbe 1 Loth,

Subenfirfcten 2 \&oth,

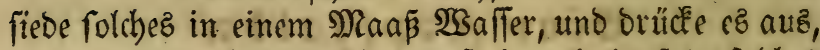

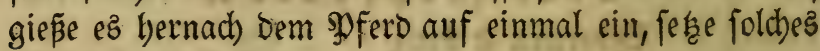
etliche Tage fort.

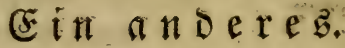

Teufilsored 2 Ioth,

Şonigwaffer,

Saft von Serfte, jeobs I Suart, Rofenoôl 20 \&oth,

anter einanber gemifdt, und bem goferb auf einmal ein=gegoßien.

(Ez bekommt bismeilen auch ein spferd in biejer Srankbeit einen 3ufall, Daß̃ nemlich bemjelben nicht al= Yein ber Ropf, fondern ber ganze $\mathfrak{E}$ eib hisig miro, ba = von ez Dann Das Futter abjalägt, fchleebeugt, uno fängt langfam uno erbeblid) an zu feufzen, Dem fork man grü= 


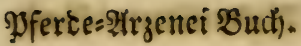

nes Sraut oder Salatblätter mit Effig befprengt oft in bas Naul fchieben, um bie Şif̧e Damit auछ̧zuzieben uno zu lofichen, aud) ibm nadbolgenden (5ingus geben :

\section{Iragant 3 $\mathfrak{L}$ oth, \\ Saffian $\frac{1}{2}$ loth,}

\$ineentörnet 1 SF vor im $\mathfrak{2 a}$ fer geweidt worben,

Diefes alles untereinander geftopen und gemifd)t, uns in 3 I beile getheilet; Davon

Rimm 1. Ibeil,

Bein ein Suart,

Sorfęelfrautwa ITer 1 S.uart,

alles untereinander gemifht, und Dem SDfero auf eirt= mal eingegoêen; wenn aber ein Fieber bazu jd)lüge, meld)es gemeiniglid) gefchiebet, bejonders wenn es aus groper Senötbigung berfommt, alsoann brauche nach= folgenden Eingur:

\section{Iragant 3 soth), . 2ronmurzel 2 :oth, \\ 2inoorn, \\ Shineentörner, jedes 4 Roth, \\ 9) Topp 1 Scanowoll,}

alles untereinander zerftopen und vermifd)t, in zmei glei= de I Seile getbeilt, won biefem

Rimm 1. Ibeil,.

Siegenmild) $\frac{1}{2}$ Maaß̃ ,

Saumöl $\frac{1}{4}$ Sf funo,

Wein $\frac{1}{2}$ Maa $\tilde{\beta}$,

alles untereinander gemijht, uno bem Sूferbe auf ein: mal eingegeben. 


\section{Ein anderes, in zufallenien fiebern.}

Den ausgepreşten ভaft von gefod)ter (Seer= fte $\frac{1}{2}, \mathfrak{M a a \beta}$,

Bocfen Un njoblitt $\frac{1}{4}$ Pf fund,

Schaaffleifd mit (Soriander uno Dillen mobl

gefoct, in einem Mörjel zerftopen, uno bie Brübe bason gepreßst, biefer SBrübe 1 Maa $\tilde{\beta}$,

mijithe mit Dem ßorigen, theils in zwei gleiche Theile, uno gieße ez bem \$f fero auf zmeimal ein ; bernach mus man Dem Mferb Daz Maul mit Effig uno ভalz aus=

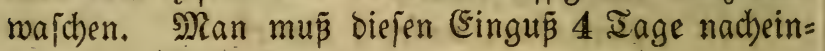
ander fortiegen.

(E) $\mathfrak{n}$ anderes.

Deterteinfaamen 1 Loth,

Bibenell,

SBärnurgel, jedes $1 \frac{1}{2}$ Loth

(Sartbeil,

Eameelftroh, jeoes 1 goth,

dieś allez untereinander geftoß̄en uno gepülvert, uno mit einem Maaß şonigwaffer auf einmal eingegop̉en.

\section{Die ßerrflegung.}

1. Der Stall foll kühl uno nicht gar bell, audd mit einer faubern Streu verfelyen fein.

2. Das Futter follte wenig fein, unter welchem viel geröftete Berfite oder Rinfen fein forr.

3. Das פूfero mit einer Decke mohl zugedectit.

4. Der Iranf nidbt gar zu fult ober zu warm fein, unter weldhen Irank Salpeter follte gemifcht werden.

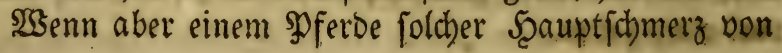


balbe ober viertel Stunde barin ftecken lapen, alsoann wieber herauz zieben, fo miro das \$f ferb huften, fdmup = fen, uno bie böje Freuchtigkeiten von fich rerfen.

Şenn aber burch baz Rinnen biejer gefalzenen Feud)= tigkeiten, bie গajelöcher inwendig wuno merben follten, fo follte man Lorbeeröl und ungejalzene Butter, eines fo viel als bas andere, untereinander mifach, und bem Spferb bie Nafelöcher inmendig bamit einreiben, uno aud) bes andern నags folgenden (singuß geben :

$$
\begin{aligned}
& \text { - Wuein } \frac{1}{4} \text { Maá̃, } \\
& \text { Baumöl ․ 암 }
\end{aligned}
$$

Dieŝ alles wobl untereinander gemifdht und bem Spferd auf einmal in bie :ajelöcher gegoßen,

\section{E in a n Dereb $\mathfrak{W}$.}

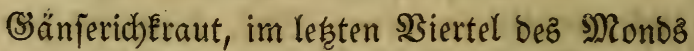
gefanmelt, gilt gleid), in weldem Monat es ift, einige Şánde voll,

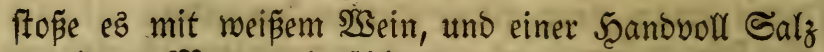

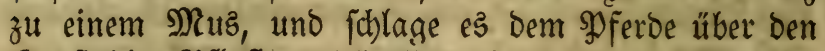

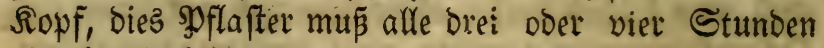
reperirt werben.

So foll ihm aud alle Tag folgender (singü gege= ben werben :

St. Sobannis= Sraut 2 Seände voll, Sraupimünz 1 Şano volf, Peterlein= Saamen 3 Roth, ŞPin 1 Maaßa,

fiebe es wohl untereinander, orücke es aus uno giepe es bem Sffero auf einmal ein. 


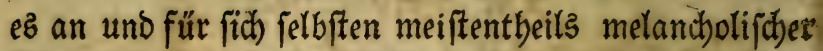
Natur ift, und foldbe Melandbolie bey ibm gar úber= bano nimmt. Drittenz, wenn ez yon Natur Melan= doolifch ift, uno einem unerfabrnen Bereuter ober suben unter bie Şand Eommt, (Da in foltbem Sুaß ein Sube, und ein folcber tyrannifcher Solot einer fo gut als Der andere, ja ber Sube um einen (Srab nod) befler als jener ift) benn ber Sube tractirt Daz sofero icharf, um Der Utrfache willen, baj er folches furdytfam uno hurtig mache, und ez Defto leid)ter verḱaufen Eönne. Der tyrannifche Sereuter aber, auz lauter Unmiffenheit, Einbildoung und Eigenfinnigkeit ein jolches armes I hier fo barbarifo) uno graujam tractiret, um ben Sopf berum folläget, uno ez über fein Sermögen barzu nöthigen mill, (wie idh bergleid)en Befellen viel Eenne, ja foldhe, um ibrer böd)ften Sgnoranz willen, uno

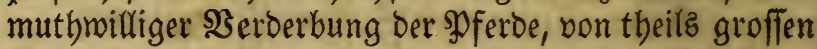
Scerren mit groffer und mebr als boppelter SBefolloung

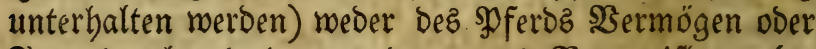
sugend achtend, Daraus bann aus Serzweiflung (ex Defperatione) ein folches \$fert in biefes Ulebel und

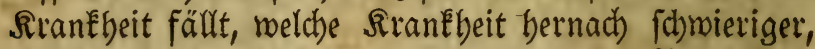
alz bie erfte, fo erblich genannt wiro, um Der Smpreffion millen, zu curiren iff, und Dann batz auf Der Reit= Sd)ul aubgelernet, uno gebet bernad) zum $\Re$ Reit=Sdhmiot

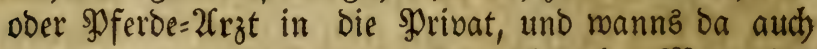
ausgelernet, fo miro fein voriger idhwacher Mercurius in ihm fo flüchtig, Daß er Daz ganze \&and auz, in Den

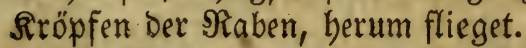

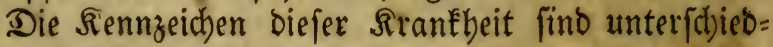
lid): Etlidben

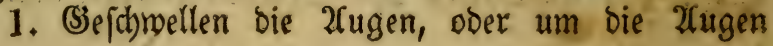




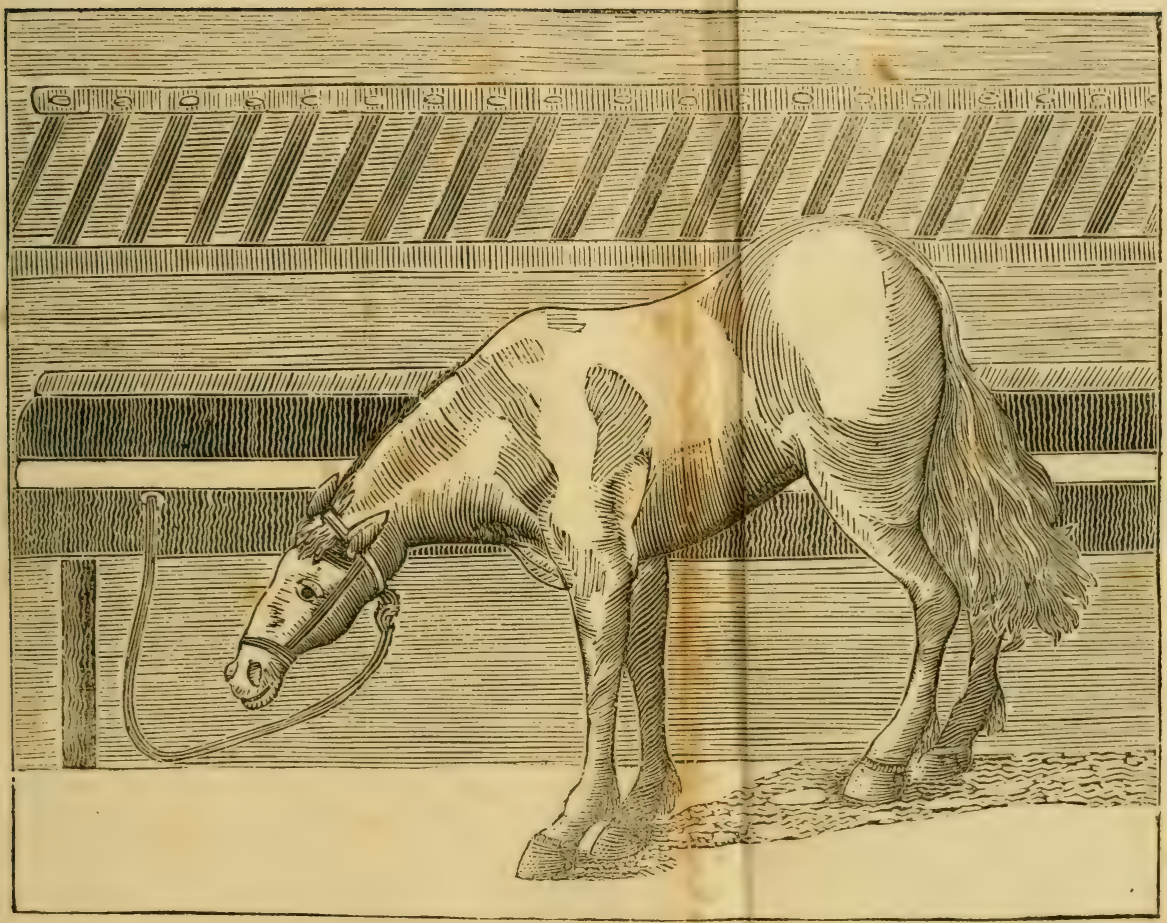




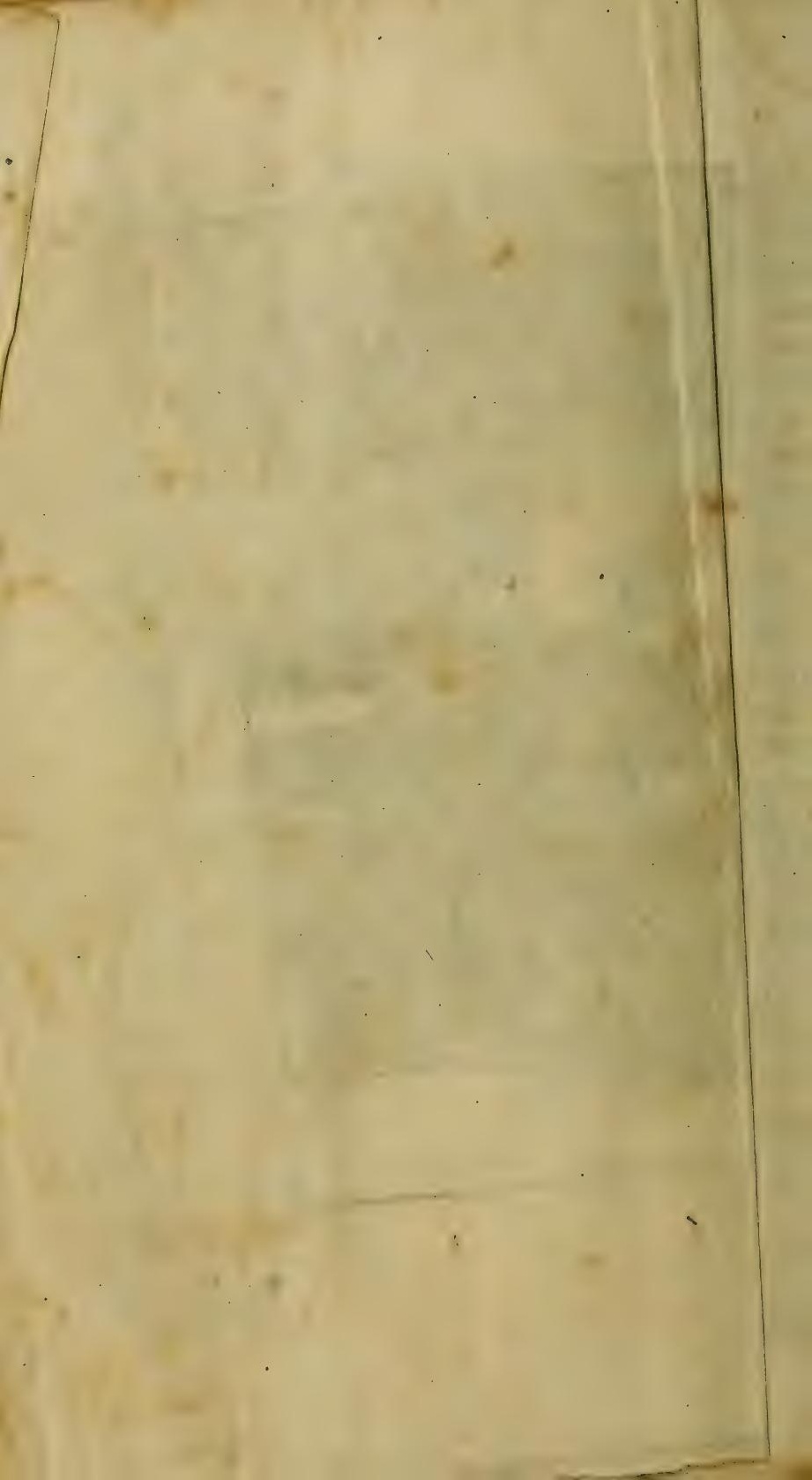




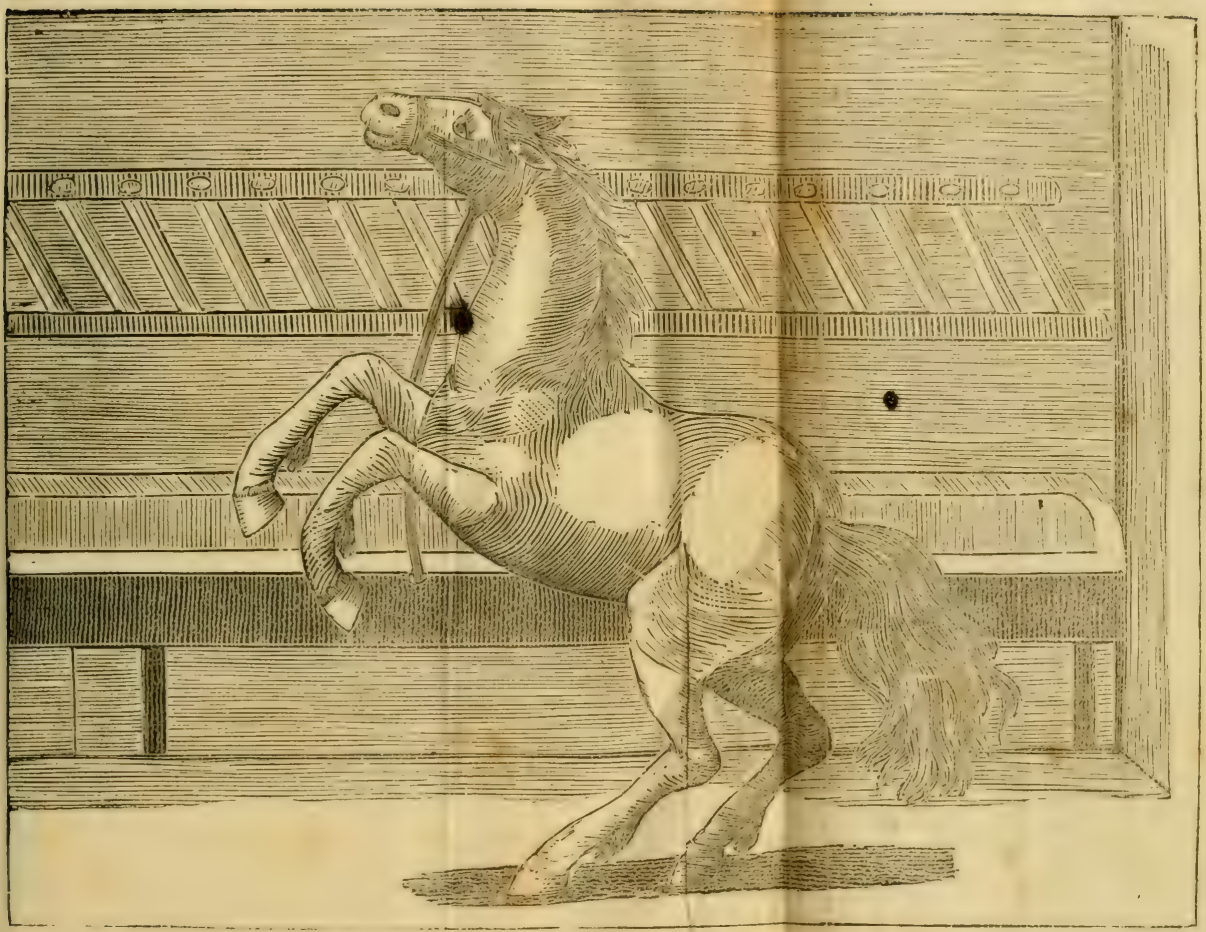


Eritt 52

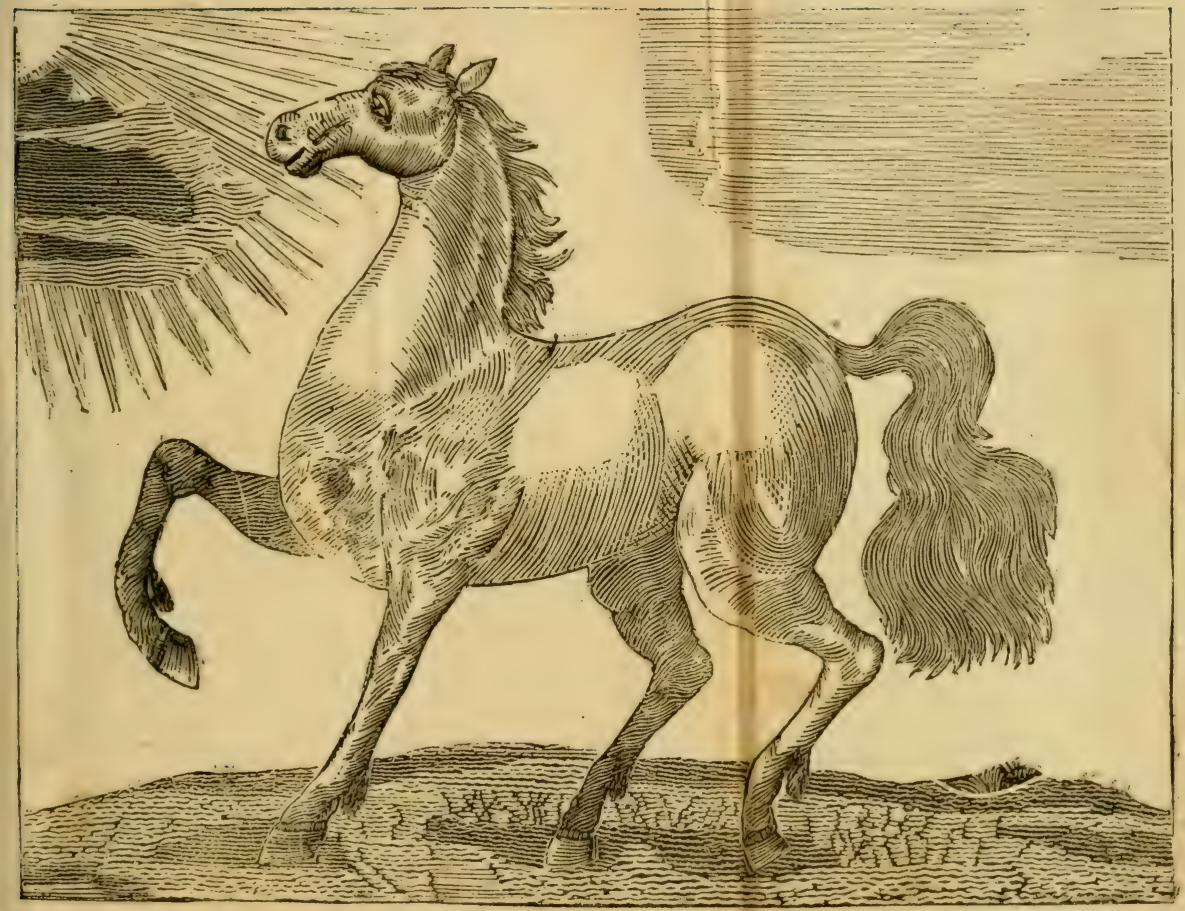


$\because$.

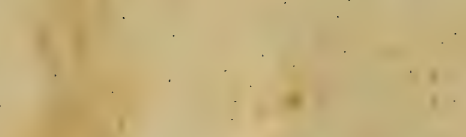

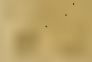

.
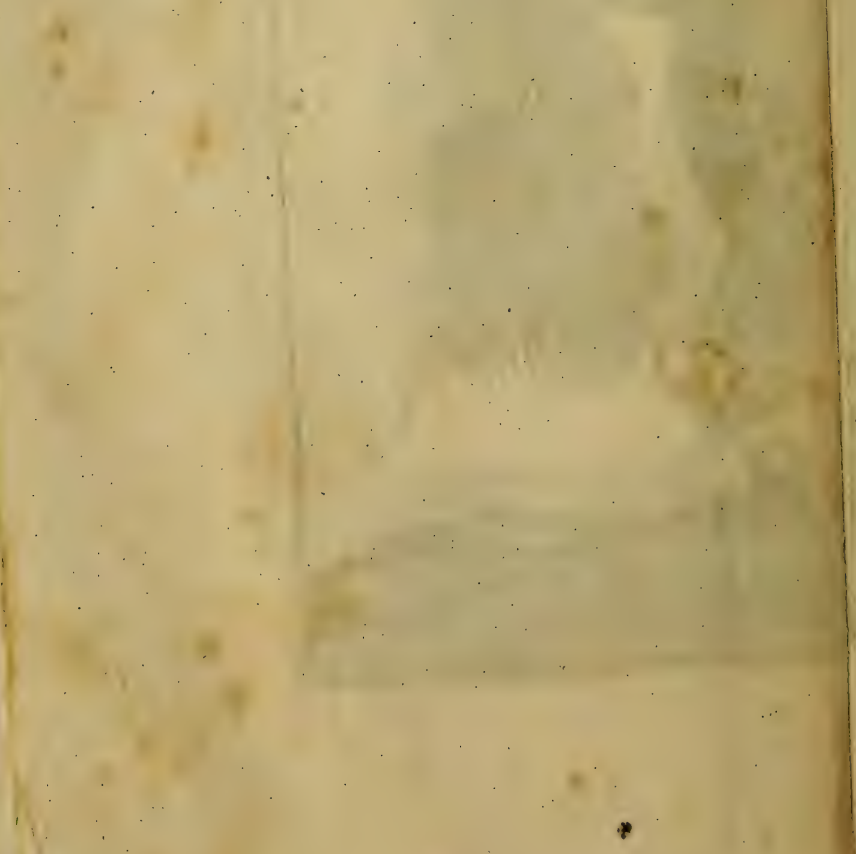

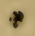


reitet, taumeln fie im Sreiz berum, uno fallen bis; weilen gar nieber bejonders im Suni, Suli und 2uguft, vorzüglich roann fie vorber befitälet haben. Sab babe felbit joldhes an etlichen spferden erfabren. Siebe Fig. श.. 3.

\section{(5) $\mathrm{r}$.}

Fürs erfte muß man Den \&eib offen balten, bernach

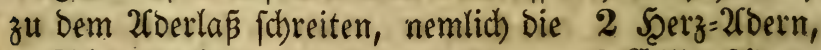

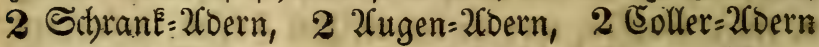
hinter Den Sbren, uno bie 2 Sdlaf=2roern, alzoann Den Sopf pogleid) mit vernilichtem Baum= Sel uno

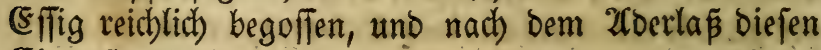
Eingü geben :

Safft von grünem Soriander oder zertbeil= tem $\mathfrak{Q}$ auch 6 \&oth,

(S)amanderlein,

Ěrogall Der Feilfarben, jebea 3 \&oth, alles untereinander geftoflen und vermifint, babon bem SPferd täglid) 3 Ioth in einem warmen $\mathfrak{B}$ affer in ben Scals gegonfen, uno folchem nachfolgenden umidylag um Den Ropf gethan:

\section{Sreparirte Rreide $\frac{1}{2}$ Sुfund,}

Sdien = oder $\Omega$ üb $=$ Mift 1 Sofund,

(Selöfd)ten Salc) $\frac{x}{4}$ Sp fund,

bies alles mit (s.jig untereinanber gemifcht, und vorber klein zerftopen, ein wenig auf Soblen marm netben laffen, und Dem \$ुfero, fo marm es Daffelbe leiden Eann, um ben אopf gejhlagen, nachbem vorber bie Saare am Ropf weggefdoren. 


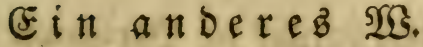

Extract von Riezmurz $\frac{1}{2}$ Loth,

Salapwourzel $\frac{1}{2}$ Loth,

Sfammonie 1 Suintlein,

Saffran 1 Suintlein,

Saft vom 2 segoorn 2 Ioth,

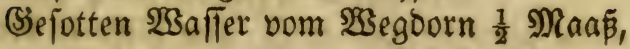

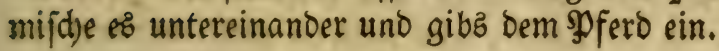

\section{(E) $\mathfrak{i} \mathfrak{a} \mathfrak{n}$ bereb $\mathfrak{E}$.}

Baummurzel,

Sichoriennurzel

Fendbetwurzel, jeoes ein Loth,

Melifinen,

Betonien,

Sirichzunge,

Soermeng,

(Eroraudi),

Maṕlieben,

Soppen, jeoes $1 \frac{1}{4}$ Loth,

Salbei 1 Ioth,

Eitronen= Schaalen 2 Roth,

Eapperen=:Rinden 3 Roth,

Senesblätter, Espithymi, jedes 1 \&oth,

2Cnis, Fenchel, jebes $\frac{1}{2}$ Roth,

Singber 1 Ioth,

diejes alles untereinander zerichnitten und zerftopen, in

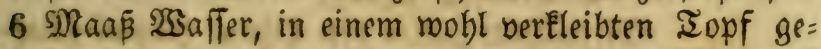

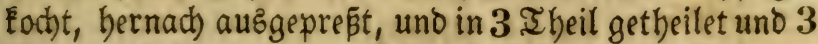
Tage nacheinander bem spero laulid)t in ben Shals ge=

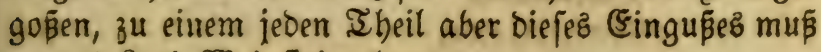
man 1 Loth গSseinftein thun. 
Folget Darauf bie \$urgation

Extract von jojwarzet פiebnutzel 1 lotbr Maftix 1 Scrup. Simmet 1 ๔ctup.

SBenel Saft 4 Roth.

(Sefottenes 2(niz=2Baffer $\frac{1}{4}$ MRaaß,

mifche alles untereinander, uno gieße ez dem \$ूferd auf einmal in ben Scals; man kann ez zwel ober orei mal brauchen.

\section{E $\mathfrak{i} \mathfrak{a}$ กberebे}

Eapee einem Ejel hinter ben Solren betoe 2roern fohla= gen, an bem Sort mo man ben \$oferben ben raeifel hin= weeg fut thun pflegt, fange foldhes in einem neuen ver= glafirten Şafen auf, neşe eine neue ungebraud)te \&ein= wand Darin, laßje ez eintrockenen, bernad) idjneibe von Diejer Eeinmant 3 Fingerbreit und eine' Fingerz lang

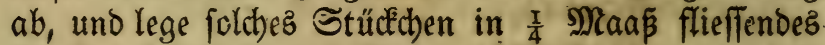

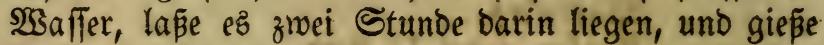

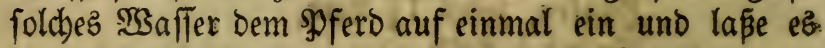
Darauf nobl fonmiken, folches fetze brei Iage fort.

\section{(E) in anderez $\mathfrak{E}$.}

Saft von St. Sobannib= Sraut und $\$$ Blumer 4 ⿰ু

Son Scühnericherben, mit sourpurfarben. SBlumen, 2 \$fund,

(E) fen $1 \frac{1}{2}$ spfuno,

Schjenzung,

Rothe Rofen,

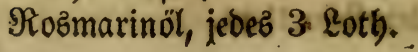


Safran $1 \frac{1}{2}$ Suintlein,

Raffienrinoe 3 \&oth,

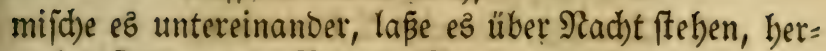
nad) diffillite es in Balneo Maria, Das Difteflirte mie= Der über frifube Materiam gegonen, uno zum andern= mal biffillirt; hernad) vermifd)e 2 spfund foldbes Di: ftillirtes mit 2 Loth ber Ėifenz; St. Sobanniztraut fo mit Branntwein extrabiret worden, Morgenz uno

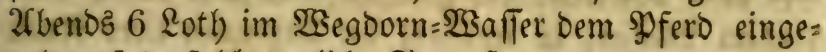
geben, fere foldyes etlidye Iage fort.

\section{Ein anderes}

Sitrum 2(ntimonium $\frac{1}{2}$ Suintlein,

Saffran $\frac{1}{2}$ Suintlein,

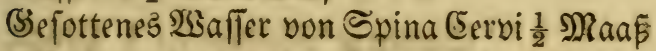

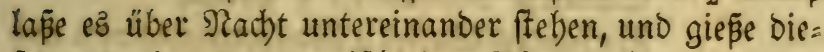

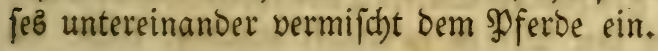

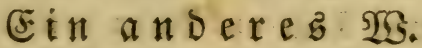

Shepar 2fntimonium 2 Suintlein,

Saffran $\frac{1}{2}$ Suintlein,

St. Sobannisfraut=Waffer $\frac{1}{2}$ Maaß,

Dies alles untereinanoer gemifot, und bem spferb auf einmal eingegoßen ; follte es ben erften $\mathfrak{I} a g$ nid)t pur= giren, fo tann man es noch zivei Iage nacheinandet

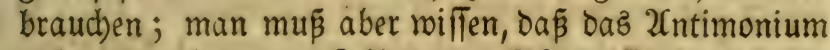
nicht allemal in Den \&eibern Der sूferbe fichtbarlid) Die gemün[d)ten 2Cusleerungen zuwege bringt.

\section{Eี $\mathfrak{n}$ andereb $\mathfrak{W}$.}

Senesblätter 4 Loth,

Rbabarbara 1 Rotb,

St)marze Nieshourzel 2 Ioth, 
Ryrobalanorum \$mnium, Iurpeti, jebes $1 \frac{1}{2}$ Suintlein, Irochif. 2(thandel 2 Suintlein, Scammoneam 3 Suintlein, Saffran, Mapłtix, jebes $\frac{1}{2}$ Suintlein, Simmet 2 suintlein,

bies alles untereinanoer gemifdt, uno in 3 Maap flief=

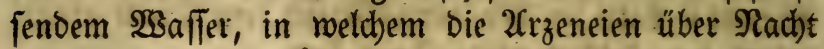
geftanden, wobl gefotten, und bie sBübe in 2 Theile getbeilet, und auf zmeimal, zmei Iage nacheinander eingegopen.

\section{Ein andereb $\mathfrak{Y G}$.}

\section{Sdbwarze Niezmurzel $\frac{x}{4}$ \$ूfund,}

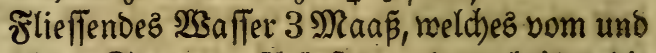
nicht gegen ben Strom geichöpft worben, beize bie Niezburzel zmei Tage und Sadht Darin, hernach fiebe ez miteinander in einem neuen Şafen, und thue ben Schaum fleisig babon, meil er febr giftig ift, bernach) feibe es ab und thue zu biejer Srübe nachfolgende ge: jottene Brühen : Brübe von Epina (Servi (Boot's=

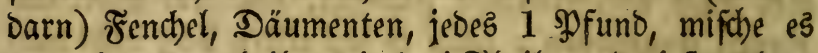
untereinander, theile es in orei Theile, uno giepe es dem פoferb auf breimal in brei Iagen nacheinander ein ; in

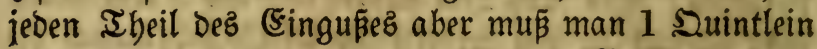
Bimmet, uno $\frac{1}{2}$ Suintlein gepülverten Maffix tbun.

Man Eann Dem \$pfero audb nad)folgenden küblen $\mathfrak{u}$ míblag um ben నopf in einem Iuch binden :

Seeblumen,

Rottich) Eraut,

Magfaamenbäupter, jebes 4 Şanowolt. 
Pferde:2(rgenei Budh).

wobl untereinanber mit Geeblumen= $\mathbb{B}$ a uno überichlagen.

\section{Ein a noereb.}

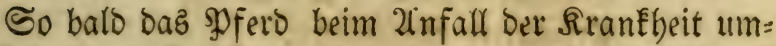
fället, (bann fie pflegen bizmeilen, wann fie täubifa) uno Dumm fino, gat umjufallen) fo lape ibm gefdhmino stli: che Sperionen auf Den Leib fallen, uno auf Der rechten Seite bie Siecht = uno $\mathfrak{B u g}=2$ (Dern mit einem Snftrument entzroei reipen.

(5)

Salapnurzel,

Iniz,

Fend)el, jedes 2 suintlein,

Senesblätter 2 Ioth,

গুäparirte ichnarze Niesnmurzel 1 Loth, .

(Sereinigter $\mathfrak{B}$ einftein 1 \&oth,

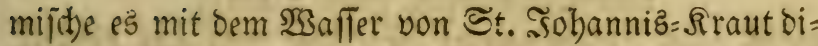

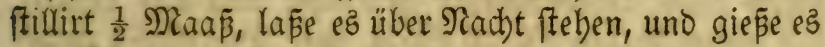
Dem SDferd auf cinmal ein.

\section{Ein andereb.}

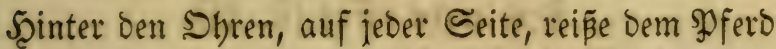
eine 2loer entzmei, Darnad) fdneibe ihm hinten vom Sdbranz ein Stückden eines (Sliedes ab, nimm her: nad) einen blauen wollenen Faden, ziehe ifm Denfelben mit einer Eupfernen ober filbernen Nabel gmerch ourd)

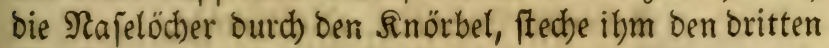
Staffel, und reipe ifm bie 2loern unter ber 3unge ent= zroei, laße es robl bluten, uno gebe ifm täglid) 4 Loth 2ajoran unter Dem Futter fu freflen. 


\section{(E) $\mathfrak{i} \mathfrak{n} \mathfrak{a} \mathfrak{D} \in \mathfrak{x} \in \mathfrak{B} \mathfrak{Y}$.}

Weinftein $1 \frac{1}{2} \cdot \mathfrak{R}_{0} \mathrm{th}$,

Irrebs=2fugen 1 Loth,

(Summi Suttae 3 Suintlein,

\$räparirt Scirfahborn,

Eitronenfibalen,

Simmet, jebez 1 suintlein.

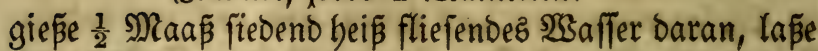

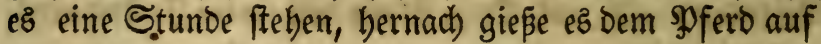
einmal in ben Scals.

\section{Ein andereb.}

Lape Dem $\mathfrak{p}$ fero mitten auf ber 3unge eine 2lder,

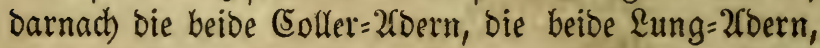

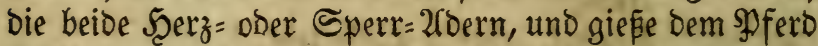
3 Morgen nacheinander nachfolgenden Trank ein :

(Siebranntes Scirfohyorn 2 \&oth,

Maienblümlein=:SBaffer,

Ravendel= $\mathfrak{Z}$ a fifer, jedez 2 Lotb,

bieję alles untereinanoer gemifhet uno auf einmal, mit einem balben Maa $\mathfrak{B}$ Sein ooer Bier=Effirg einge= gopen.

Sin હfyffier für Diefe franllyeit, wenn ber seib nicht offen ift. $\mathfrak{1}$.

scterlein,

Fenchel,

Spargen, jebes 3 Loth,

Steinwurzel $4 \mathfrak{L o t h}$,

(Eroreidb), Steinflee, Shirfd)zunge,

Epntbymi, jeoes $1 \frac{1}{2}$ Loth

Eamillen, Sorragen, Ddhjenzungen, jebes

1 goth, 
Fenchelfaamen, 2fnisfaamen, jebes 2 Souint= lein.

alles zufammen in 3 Maaß Brühe von gefod)tem Scam=

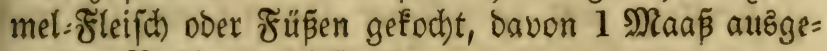
prester Brühe, zu diefer thue

Dillöl $6 \mathfrak{Q}$ oth,

Rożmarinöl 3 Ioth),

Eonfect. Scamed).

Diacatholicon, jeoes 2 Loth,

Extract von f́twarzer Riesmutzel 2 Su.

Salz 1 , Sanowoll,

biez alles untereinander gemifd)t, uno Dem \$ुfero raarm gegeben.

(E) $\mathfrak{n}$ a $\mathfrak{n}$ Dereg $\mathfrak{E}$.

(Erbrauch,

Inmeeio,

SDdjenzungen,

Sortetid), jebes 1 Scanduoll,

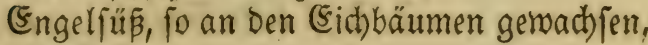
2 Lotb,

Senezblätter, 3 Ioth,

Fencheliaamen,

TSiefeneümmel, jedes 1 goth,

fitebe alles zufammen mit 2 Maá fliejendem $\mathfrak{G a f f e r}$ biz zum halben ITheil, hernad) prefle bie SBühe Davon, uno thue Daran Rlabatbara Ecammoneum, jebes 1 Roth, giepe es dem झुfero auf einmal ein.

\section{E $i \mathfrak{n}$ a $\mathfrak{n}$ Dere $\mathfrak{E}$.}

Frif Lavendel=2Saffer in bie \$bren geichüttet.

Die $\mathfrak{B}$ erpflegung.

1. Der Stall foll nidyt bell pondern finfter, ftill un 


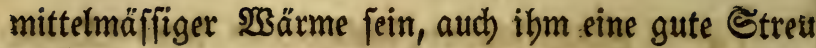
madken.

2. Daz Futter follte menig uno gebrochen fein, als WSeizentleien uno gebrodbener Scaber; audh foll man itm grünen (Eppich ober Sheu borlegen.

3. Daz Trinken follte, wenn möglich, won einem flieffenden $\mathfrak{B a} a$ fer, und darinnen $\mathfrak{B}$ egoorn, St. Soban= niskraut, (Sauddbeil mit ben rothen SBlumen, Däumen: ten, Majoran, Betonien, Maplieben=BRlumen, Braun= murzel, jedes gleid) viel gefotten werden, Darunter unter ein Ed)aff $\mathfrak{S}$ affer allezeit 1 Ioth 2 seinftein follte ber= mijat fein.

4. $\mathfrak{B}$ ofern e\& in"ber Mania jebr tobet, follte man es

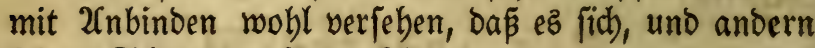
Eeinen Schaben zufügen Eönne.

\section{Dab Ilte Eapitel.}

\section{Bon Der Sirnmüthigfeit, Unfinnnigécit Dollen} Soller, in Satein \$hrenitis genannt.

Diefe Srankbeit ift an fich) felber ein Morbuz \$era= cutuz, nemlid) eine (Entzünoung bez Scirns uno feiner Frelle, mit fteter ûnfinnigkeit uno hişigem Fieber, mel= dhes entffebet von einer übernatürlichen 2(usfchüttung Der (Balle, mit ihrer @ebärfe baz (Seblüt im ganzen Eeib in eine Sboleram erregend ; welchez aleich jam als

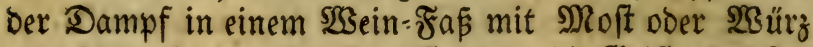
angefüllet, in ben Ropf aufifteigend, Die Seifter bes \&e= bens beftig betrübet und Dermaffen etreget, Dep̄roegen 


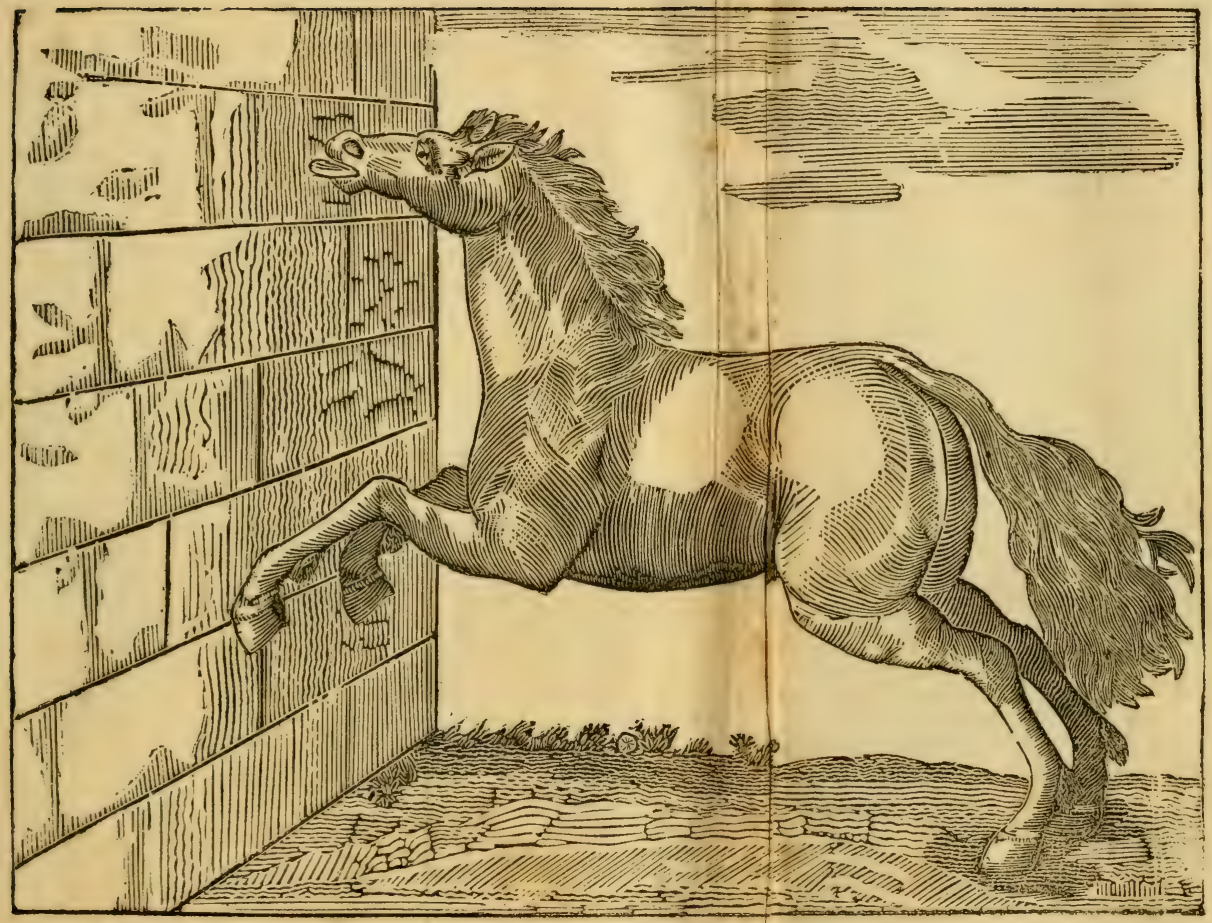




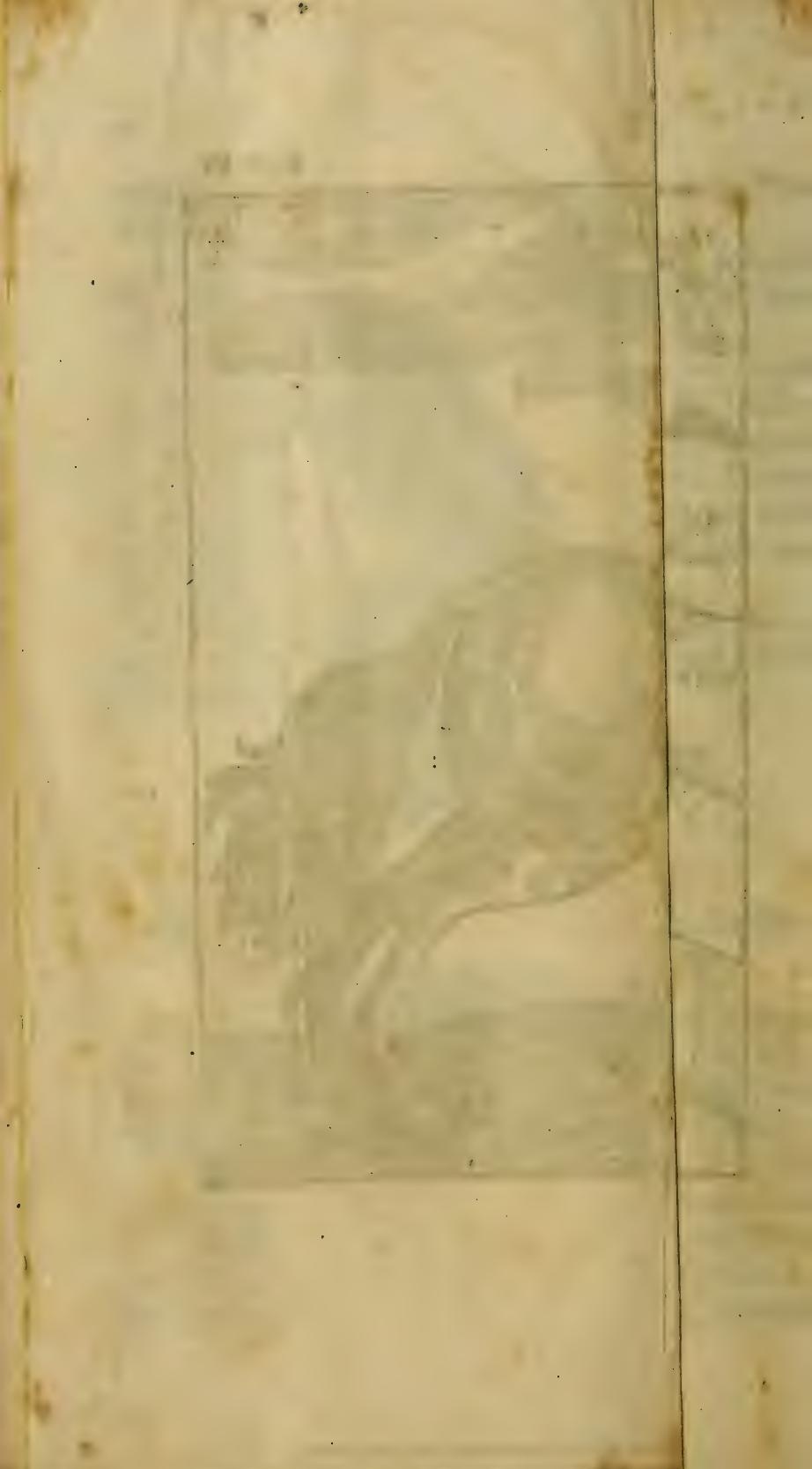




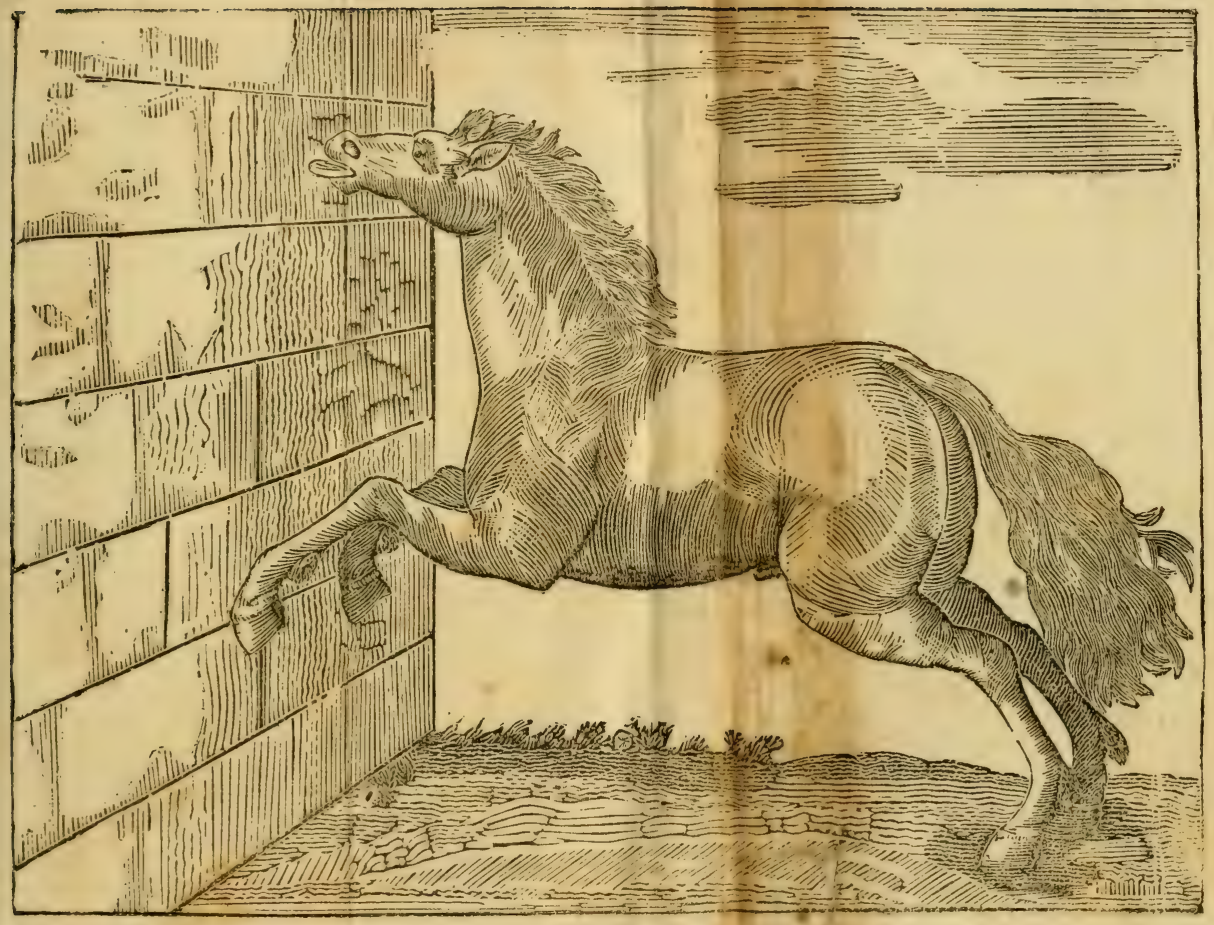




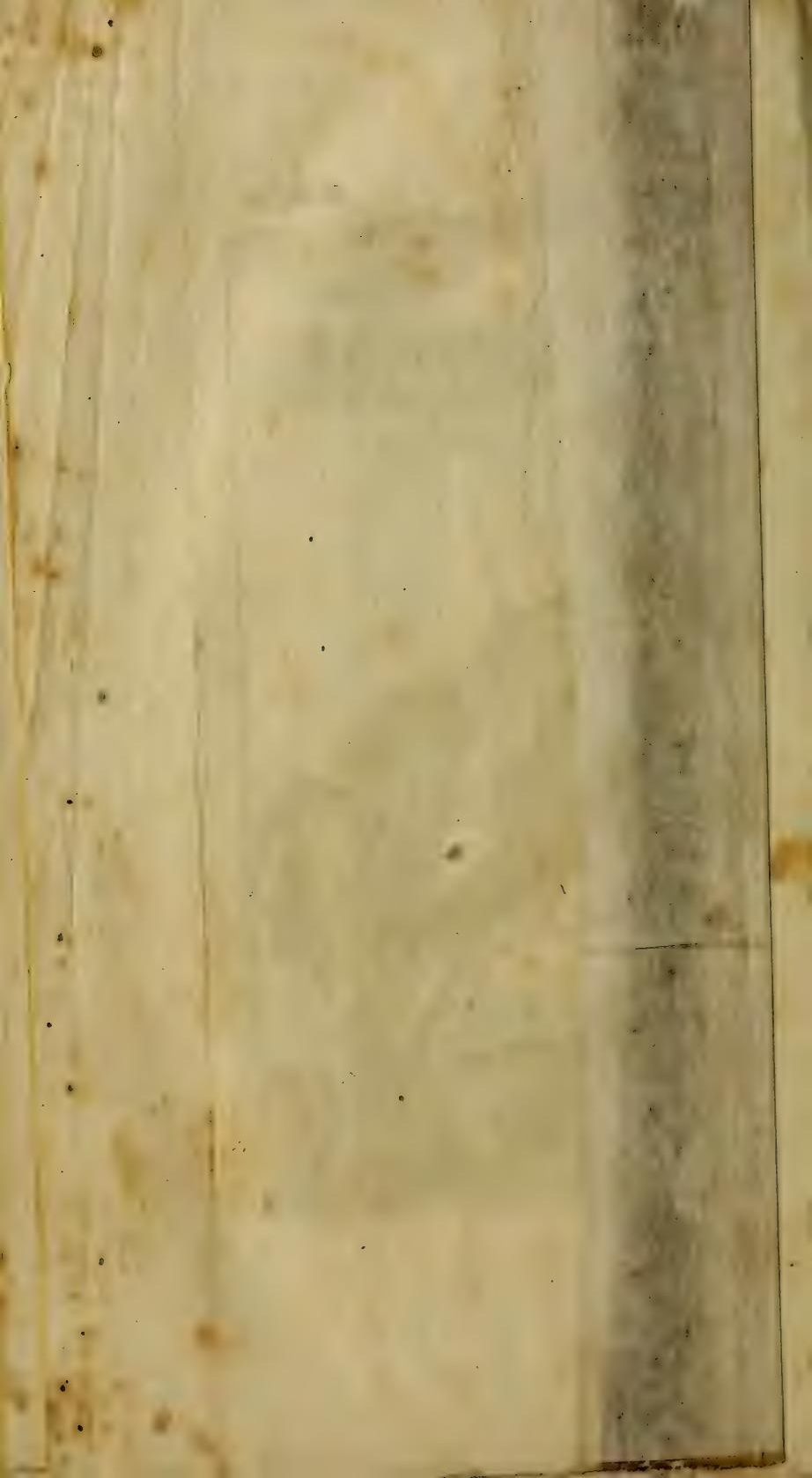


Mania fich verändert bat, ober auch, burch allzu fbarfe Iractirung ber ohne baz von Natur ber bifigen sুofer =

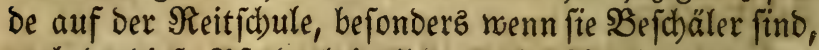
aud ba biefe soferbe bei allzu groper 2Trbeit meder bei Iage nod) Nachts ifre Rube, und keinen Colaf ha= ben. (5ben fo auch vom Befcálen, wenn folche \$f ferbe vor einem Sabr bejuält baben uno hernach das andere Sabr bavon abgehalten meroen; wie auch Deşgleichen bie Stutben ex nimia SBenere, menn fie nicht kefchält werben, biefen 2fffect befommen. Ueberdiez befonmen

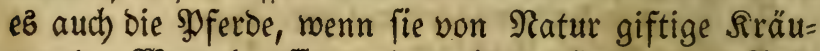
ter ober $\mathfrak{B u r}$ eln effen, wie autb ben Scopfen und Irä= bern. 2alle Sollerer ermeifen fich gemeiniglich im Som= mer Sriente Sanicula, mandbmal aud im Seerbft uno Frübling, felten aber im $\mathfrak{W}$ inter.

\section{Sie 3eidben Diefer unäcbten \$hrentitis find:}

1. Sfit Der 2 them llein und oft, weil wegen Snflam= mation bas 3nerchfell fich nicht febr berwegen fann, uno Despregen Defto Eleinere uno öftere $2 u f t$ flöpfung ge= idbiebet.

2. Şft bie Stimme leiz und beifer, weil bas Șnftu= ment Der Refpiration berhindert wird.

3. Die Unfinnigkeit und das Ioben ift bismeilen ftärker ober fchmäd)er, nachoem ez mit Dem 2(ffect fdylimmer ober beffer miro, und ift nidyt anbalteno mie Die Sorige; Doch ift fie in Der Snflammation Des 3nerchfells auth beharrlich, uno ift bei biejer allezeit (s)efdroulft und 2fuflaufen in Der Seite mit Dabei.

Die ächte Sphrenitis ift ganz töbtlid) uno unlseilbar, bie unächte şhrenitiz aber wiro bizmeilen mieber curirt, wienobl mit groper Nühe, wenn nemlich die Natur uno 
Sräfte nod) ftark, uno nid)t beftige Sufälle babei find,

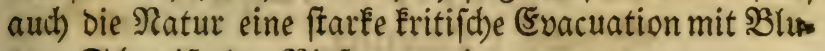
ten, Sd)reiß̄ oder Nieß̄en vornimmt.

\section{Die Eur Diefer Sranflfeit.}

F̛ürs allererffe muß man bas গুJerd mit Binden gut verwabren, bamit es fich und andern Eeinen Sdbaben thun möge, und ben $\mathfrak{e}$ eib wohl offen halten, forobl mit (5lyftiten, alz den 1 trin fortzutreiken, uno die 2roerlape wie im vorigen Sapitel von ber Coller=2CDer angegeben tworden, vorzunebmen ; jeood) foll man in biefer Srank = beit Eaum balb fo viel silut heraus laßen, uno nad) fol= genoen Eingǘ geben.

şfeffer= Sörner, an ber 3ahl 20,

Snei (5ier,

Shonig 2 \&oth,

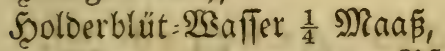

alles untereinander gemifotht und bem $\mathfrak{P}$ fero auf einmal eingegeben.

Ein anteres, nenn viel Feuchtigfeet vorhanden.

Euphorbium 1 Suintlein,

Taujenogüldonfraut 1 Roth,

Meirauth 1 Suintlein,

Dies ftope und mifthe alles untereinander, uno vermifacte

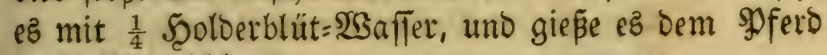
in bie Najelödher.

(E) in anderez $\mathfrak{B G}$.

Separ 2rntimonum 2 Suintlein,

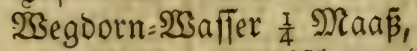

bieb alles untereinander gemijht, und bem gofero auf einmal eingegósen. 
Pferbe=2lrzenei Buth.

\section{E in anderer E $\mathfrak{i n g} \mathfrak{A}$.}

SBeiraud 1 suintlein,

Der $\mathfrak{3 u r z e l ~}$ Panaciz 2 Lotb,

Steinbred) 6 Ioth,

Şonig 4 Ioth,

Steinbrech-:Saffer $\frac{1}{2}$ Maā.

alles untereinander gemifcht und bem \$ूfero auf einmal eingegeben.

Ei $\mathfrak{n} \mathfrak{a} \mathfrak{D} \in \mathfrak{r} \in \mathfrak{b}$.

(S) örrte graue (5jelznürmex $\frac{1}{2}$ Suintlein, Beinrauten 1 Scanbooll,

Butter $\frac{1}{4}$ Sf funo,

fiebe e's untereinander und tröpfele bem Sूfero bawon täglich in bie șbren.

E in anderes

Brenne bas spferd mit einem glübenden (sifen auf bie Stirn, bart unter Dem Schopf, wie aud) auf beiden Seiten bes Schlafz, fo nimmt bie Scite bie Sdyraach= beit bes Ropfes mit binneg, uno bringt das Shirnfell zur (sejundbeit; audh gieb ihm nachfolgenoen (singus.

Brenne einen Raben mit fammt Den Febern und (sin= gemeiben, in einem wobl'merwabrten Scafen zu Sुulber:

Son biefem Syulver nimm 2 sotb,

Pulver von verbrannten Irebien 1 Ioth,

श. $\mathfrak{B}$. Die Jrebje müfTen in einem vermachten $\mathfrak{S a} a=$ fen verbrannt werben und zmat zu Der 3eit, wo bie Sonne in bas 3eichen dez $\mathbb{R}$ ömen tritt.

St. Sobannižkraut 1 Ioth,

Enzian, Scorzonera, $\mathfrak{W}_{\text {eirauch, }}$ Rosmmarin, Ierra Sigillata, jedę $\frac{1}{2}$ Ioth 
mifde es untereinander mit einem $\mathfrak{M a a} \tilde{\beta}$ fließendem TSaffer, morih 9 lebendige Rreb fezerftopen morden find, uno ichütte es bem \$ferb auf einmal ein. Seçe bies

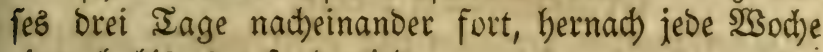
einmal, bis ę gejuno miro.

\section{E i $\mathfrak{a}$ n Dereb.}

Saftrite folche \$ু ferde alzbald, wenn ez Scengfte find, uno nachoem fie wieber gebörig bergeftellt find thut man am beften, wenn mant fie zu verEaufen fucht; Denn

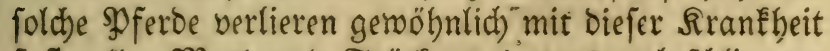
faft allen Mutb) uno Stärfe, uno, was noch fhlimmer iff, ez pflegt gerne jebez Sabr um biefelbe Beit ber Iaub Eollerer bei ibnen fid) einzuftellen.

(5) $\mathfrak{i t}$ a noeres.

Calbei 3 Ioth,

Bibenell 2 Rotb),

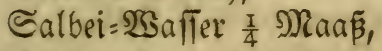

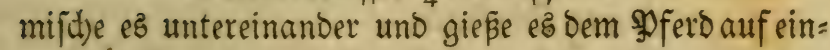
mal ein.

E $\mathfrak{i} \mathfrak{a} \mathfrak{n} \mathfrak{D} \in \mathfrak{x} \in \mathfrak{E}$.

Soerba Sharis, in Deutich) Einbeer,

von biejer bürten Seere nimm täglidh 3 Suintlein,

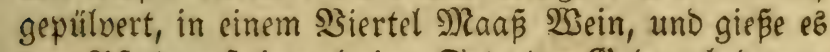
Dem झुfero auf eimmal ein. Sege den (Sebrautch Dayon eine Beitlang fort.

Ein Elyftier zu biejem (sebrechen $\mathfrak{I B}$.

(Eibifch=:23urzel 6 Loth,

\$appeln,

\&attich,

Singelfraut, jebes 4 Şänderoll, 
Dürre Mohnéppfe 4 Ioth,

(Sejdälte Serfte 8 \&oth,

Eetifienfdiramm 1 Lotb,

alles zeridonitten, zerftopen und untereinander gemiifdst, auch in genugiámem marmen $23 a f f e r$ gefod)t.

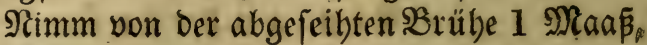

Frifche ausgezogene (Saffia, 6 Ioth,

Soloquint 1 Suintlein,

Shonig 6 Ioth,

Eierootter 7 ,

Sodbjalz 4 \&oth,

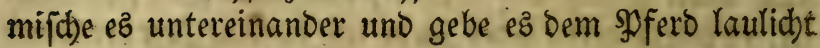
Durd ein Inftrument.

E $\mathfrak{i} \mathfrak{a} \mathfrak{a} \mathfrak{D} \in \mathfrak{r} \in \mathfrak{B}$.

Sollunder: $S_{a} \mathfrak{l}_{z} 2$ Loth,

Ënzian,

Scorzonera, jebes $\frac{1}{2}$ Ioth),

Ierra Sigilluta,

St. Sobannis=-Sraut, jebez 1 goth,

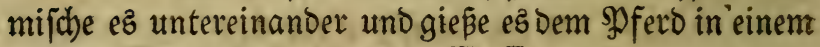
balben Maaß Scollunderblüt= $\mathfrak{B a f f e r}$ cin.

E $\mathfrak{i} \mathfrak{a} \mathfrak{n} \mathfrak{D} \in \mathfrak{R} \mathfrak{e}$.

Enzian,

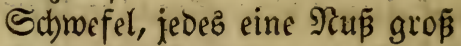

Baumöl fo miel barunter gemijd)t, Daß̃ ez

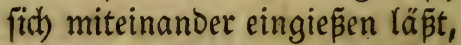

jold)es giepe ihm Dann auf einmal in bie Rajelöcher uno lape ez fich bavon macker braujen.

Ein andereb.

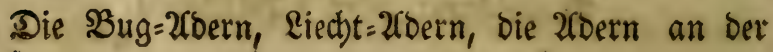


auf beiben Seiten, und Spor:2Coern fo viel bes \$fferbes Siäfte erlauben mögen, Blut herauz laffen, bamit bie verborbene Flüffigkeiten von bem Scaupt unternärtz ge= zogen werben. Nach dem 2Coerlaßen foll man bem Spfero bie Echenkel oft mit roarmem SWafler majchen, uno den ganzen $\mathfrak{L}$ eib mit Sel uno Salz nobl reiben, hernach bes andern Iages folgende $\mathfrak{R}$ axirung eingeben :

Willoe (Surkenfaft 2 Ioth,

Sdhmertelmurzel 1 Ioth,

Roblerautjaft 8 \&oth,

Scolderblüt $=\mathfrak{B} a$ affer $\frac{1}{4}$ Maa $\tilde{\beta}$,

untereinander gemifat und auf einmal eingegeben in ei= nem Eingur, gebrauche ę brei זage.

Ein anoereb.

Serichnittene grüne $\mathscr{S}$ urzel von nilben. Su: cumern ein biartel \$funo,

Saurzeln von Sdweinsbrod 6 Ioth,

Flieflendes $\mathfrak{B a}$ flè orei Maaß̃,

fiede es zum balben Theil ein und prefle es aus : ber: nach)

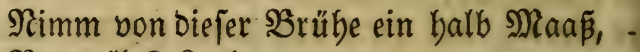
Baumöl 8 Roth,

mijche es untereinander und giepe ez dem SDfert auf einmal ein, gebraudb?, eร zmei ober brei Tage nadbem es beftig purgiret.

Ein a noereb.

Şeiß̄e Nieşnurzel 2 Suintlein,

Sconig 4 \&oth,

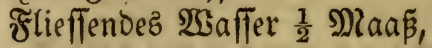

mifche alles untereinander und gieß̧e es ocm গুferd auf cinmal ein, und braucbe folgende (5lyftier: 


\section{Pferbe=2(rgenei Buth.}

- Rattich, (Serfite, Spappeln, Bingelfraut, Sebelfraut, Seeblumen, Sfterlucev,

Salz, jeoes 1 Sanonoll,

fiede afles in flieflendem $\mathfrak{B}$ affer, bernach orüfe bie Srübe aus uno gebe ifm bavon eine Maẩ auf einmal laulicht ein.

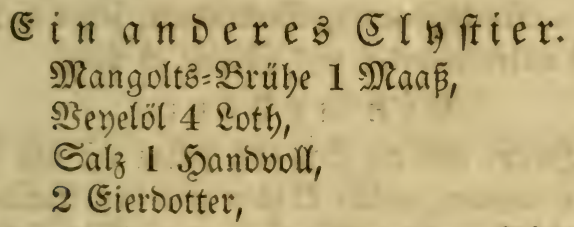

mifche es untercinander und gebe es bem গুJero warm.

(5) in a n Dereb.

Nimim Nangolt,

Bingelêraut,

Sappeln,

Rattich,

Senelfraut,

(Serfte, jedes 1 Şanovoll,

fiebe es in flieffendem $\mathfrak{B a f l e r}$ und nimm von Der $\mathfrak{B r u ̈ h e}$

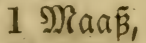

Bebelöl brei Loth,

2uzgezogene (Saffia's Soth,

Salz 1 Şanbooll,

alles untereinander vermifht und laulid)t eing?geben.

Nan foll inm aud daz Scaupt mit nadfolgendem purgiren :

Beifuß = $\mathscr{B}$ urzel 1 Suintlein, in bie Naje geblajen uno bas Scaupt mit nact)folgen= Dem gerwajchen: 


\section{Rojen $=$ Del, 4 Roth, \\ Rofen= 23 affer 12 Ioth, \\ Effíg $\frac{1}{2}$ Raa}

untereinander gemifcht und bas Scaupt oft damit gewa= ichen.

Ein andereb.

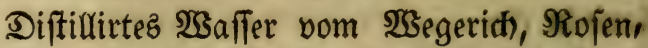
Sachtjchatten, Seeblumen, jedes 6 Roth, miface es untereinander uno fallage es über.

E in andereb.

Das Scaupt uno die Sdjenfel follen oft nit Bäbern gewajchen werden, weldhe Eüblen uno ben Sdhlaf brin= gen : als ba fino warm $\mathbb{2}_{3}$ affer, worin Magfaamen gefotten morden, aber berjelbe madbt nicht allein ichlafen, fonbern vertilgt aud) bas Fieber bez Scauptez uno löfot Die Şise aub.

(E) in a ndere.

Sevlen,

Weiper Mag[aamen,

Sdjöleraut,

(S)erfte,

Eattichjaamen,

2ultaunnurzel, jedes 1 Scanowoll,

lape es fo lang fteden bis das Waffer roth wiro ; alz=

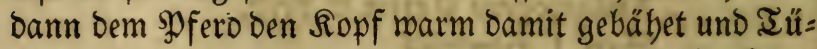
dher barin eingenezet und alfo warm um ben Sopf ge= fhlagen : renn man es einigemal gebraudt, fo follte

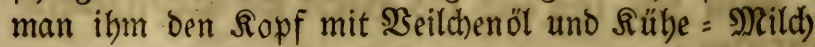
untereinander vermifat, fdomieren.

$$
\begin{aligned}
& \text { Eine andere Salbe. } \\
& \text { Beil=\$el, }
\end{aligned}
$$




\section{Rofen= Del}

Seeblumen=:Del,

Dill=:Del, jeoes 2 Loth,

Saffran $\frac{1}{2}$ Loth,

bies alles untereinander vermifht uno den ganzen Sopf Damit gefalbet.

(sine andere Bäluung für Den Sopf.

Seild)en, Rilienmulzel, (5amillen, (Eppid),

Rauten, Münz,

Eteinflee, jebes 1 Scanovodr,

dies alles untereinanoer gemifdet und in $\mathfrak{B a}$ affer gefot= ten, und Den Ropf Damit gebälset.

(5i ne andere Eur.

Redige dem Syferd oben bei Dem אopf, am 21nfang des Scaljes bie Scaut zu beiden Geiten, thue eine Rieb= ftöfelmurzel himein uno vernäbe fie, fo wirbs alabalo Eiter zieben, Die $\mathfrak{B}$ urzel berauz fallen uno Dem \$ूfero Der Soller vergehen.

\section{(E) $\mathfrak{i} \mathfrak{a} \mathfrak{n} D$ ere $\mathfrak{E}$.}

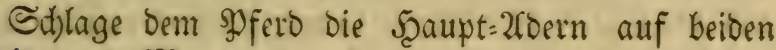
Ceiten alle Monat eimmal.

\section{(E) i in a d o e e b.}

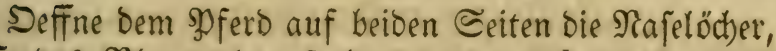
lás bas SBlut geben fo lange es mill, barnad) nimm Saffran und $\mathfrak{B}$ seirautch und lege es auf eime (S) hut und räuchere es Damit ; bernad) nimm einen lebendigen 2 (al, jerflopfe inn mit einent ๔d)legel mohl, alsbann nimm eine gute Scanovoll $\mathfrak{E}_{a}$ l, SBaumol fo viel als nöthig iff, laß̧e ben 2fal ganz barin zerficben, ftope ez hernach

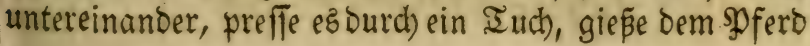




\section{4}

Pferbe:2(rzenei Burn.

täglid) ein menig bavon in bie Shiren, becte bem \$y fers

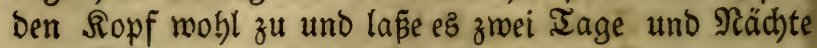
ohne EffTen uno Irinken ftehen.

\section{(E) in a d e re b.}

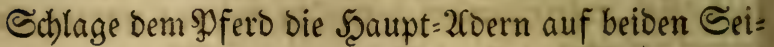
ten, brenne Daffelbe unter bem હd)opf einen Finger lang, mit einem fpişigen (Eifen, zroifd)en Şaut uno Fleifd,

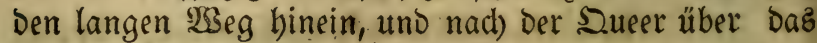
Şirn unter bem Sihopf einen Strid); nimm alşann einen (3̧änfekeil, fd)miere benfelben mit Loröl, flecke inn Dem Sferb in bas gebrannte $\mathfrak{L}_{\text {odh }}$ jeoen Iag einmal; bernad)

Rimm Eolophonium 2 Loth,

(5)ummi 2 (ntmoniacum 2 Lotb),

Sctwarz Dect),

Șarz, jebes 1 \&oth,

Seirautd),

Maftix,

Dractenblut, jebes 1 soth,

lape allez untereinanter gehen, mache ein $\$$ flafter bar: aus uno lege es dem \$p ferve fo warm als es baffelbe lei= Den Eann lïber Das SSirn.

$$
\text { E in andereb. }
$$

(Seftó̄enen weí̄en Senft 1 Roth

vermifche ben mit $\mathscr{B S a f f e r}$ und gieß̋e Demfelben einen \&öf

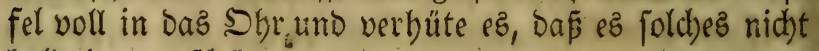
balo beraus foütte.

$$
\text { sin anderes. }
$$

Die SBrübe von wiloen Sürbifien gefotten, Sollumberwurzel gefotten, jeoes $\frac{1}{4}$ MRaaß, Ealpeter 2 gotb, 


\section{Perbe:Prgenté Bud).}

mijhe es untereinander und ichütte eह bem SPferd auf einmal ein.

\section{(F) in anoereb.}

Siede fitmarze Niesmurzel in Effig uno reibe bamit Den Sopf und ganzen Reib.

\section{(E) $\mathfrak{a} \mathfrak{n} \mathfrak{D} \in \mathfrak{r} \in \mathfrak{B}^{\circ}$}

(Srünen Eppid) Elein zerftop̄en 2 Şände voll, Sonig 8 \&otb,

ธatoomömlein 2 ?oth,

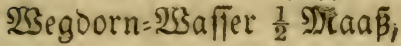

mild)e es untereinander und fhütte es dem Sूferd ein.

(4) $\mathrm{i} \mathfrak{a}$ a $\mathrm{D}$ ereb.

Eppichfaamen,

Maceoonifche Speterfilienjaamen,

Salatiaamen,

Nagiaamen,

Sicanaro,

(Seoörte's uno gepülvertes Majoranfraut, jebes 1 ¿öffelvoll,

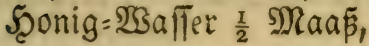

mifche eह untereinander und fhütte es bem SDferd auf einmal ein; gebrauche es $\mathbf{5}$ Iage nacheinander.

\section{(5) in andereb.}

Bebecte ben liopf mit einem rauben Sdhaafsfell, mil= des vorber mit Baumöl gefithmietet morben.

\section{(E) in anoereb.}

Menichenfoth mit $\mathfrak{B}$ ein vermifht und bem Syferbe eingegopen. 


\section{E in andereb.}

Enzian, Rorbeer,

Bibenell, jedes 1 Loth,

Dfter(ucey,

Murrben, jedes 2 Suintlein,

bieŝ alles untereinander gemif̧bt uno gepülvert uno mit eirem balben Maá Sconigwaffer eingegeben.

E) $\mathfrak{i}$ andereb.

(3ebranntez \$ুulver von Siränchen,

Enzian, jeoes 2 Loth,

Myrrben, $\mathfrak{B}$ eirauth, jedes 1 Ioth,

Bergmünze 3 \&otb,

Ierra Sigillata,

bies alles untereinander gemi jott uno gepülvert, in einem $\frac{1}{2}$ Maaß $\mathfrak{B S e g o o r n}=$ ober Scotoerblüt=2Baffer eingegoßenen.

E $i \mathfrak{n}$ Cryfter.

Die Srühe von blauem Senlen=-Sraut $\frac{1}{2}$

Maá̃,

Rojen=Şonig 6 Roth,

Salz 1 Szanowoll,

alles untereinunder zu einem Elyftier gefotten uno warm gebrautbt.

E $\mathfrak{i} \mathfrak{n} \mathfrak{n} \mathfrak{D} \in \mathfrak{R} \in \mathfrak{B} \mathfrak{I G}$.

Uloes Scepatica 2 goth,

Scammonium 2 Suintlein,

Ifarum, Salap, jebes 1 Loth),

Iurbith 2 Suintlein,

Igaricum, ๔enezblätter, jebes 1 Ioth,

פräper. fchmarze SRieznourzel,

Simmet, jebes 2 Suintlein,

Rbapontic 1 Ioth, 
man unteroepen mit ihnen umgeben, wie man mill.WBenn fife aber für fich felbfit nicht freffen mollen, mus man ibnen foldhes in einem (singü beibringen.

Wsenn fie alfo foblafen uno man fie gerne mieder er= wecken mollte, fo nimm ein Suintlein weípe গiesmur= zel, 2 Suintlein Sibergail, vermifabe es mit bem aller= ichärfiten (sffig, thue es innen in bie Najelödber uno wajche ifnen ben Sopf uno bas (Sejchröt mit Ealtem জaûter.

\section{Ein anderes.}

SDpium, calcinir eb auf einem Biegelftein ; nimm hernadh biefen Spium, $\mathfrak{B}$ einftein, jebes 2 Ioth,

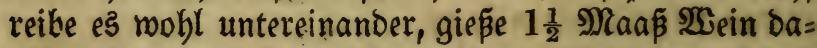

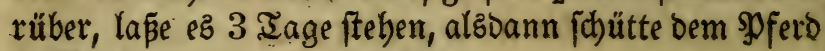
$\frac{1}{4} \mathfrak{M a a \beta}$ bavon auf einmal ein.

Die $\mathfrak{B u t b}$ ober $\mathfrak{U n}$ finnigkeit aber, welche von bem

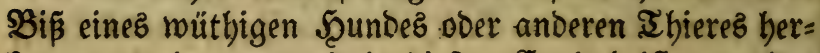
fommt, curitt man wie in biefem Eapitel ift gemelbet worben, ober man hilft innen auf folgende $W_{\text {Seife : }}$

W3ajdbe ben gebißzenen Sort mit Der gefottenen \$rü= be von (S)rinomurzel gut ab und brenne ez roobl mit einem glühenden (Eifen, Damit es \&uft erbält uno bie Ruffen hinweg Eommen uno madhe ein \$yflafter aus (S)rinowurzel uno lege es über; giepe ibm aud) zum offern folgenden Irane ein :

\$oulver von gebrannten Rrändben,

(Sebrannte Rrebz, Scorzonera,

Enzian, jebes 2 \&otb, Srebzaugen 1 Eoth, alles untereinander gepülvert unø gemifoht, in einem $\frac{1}{2}$

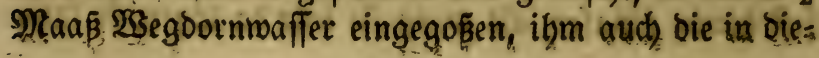


fem Eapitel bejdriebene (Elyftier geben uno täglid) (En= zian unter das Futter mijchen.

\section{Sin anderes für Den $\mathfrak{B}$ iß von wüthigen und giftigen Shieren $\mathfrak{2 B}$.}

Rauten, Salbei, wilde Maßjliebenblätter uno Blumen, jedes 3 Scänce voll,

Die $\mathfrak{B u r z e l}$ von Scundsoorn, "

Scorzonera, jedes 2 Loth,

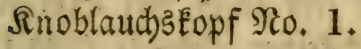

bafe die's alles ganz Elein untereinander, hernach ftope es robl und thue eine Eleine Şandvoll Salz barunter, von biefem mache einen 2fufichlag und lege es \$pflafter: weis liber; man mup aber die $\mathfrak{B}$ unden vorber mit ei= nem eifernen Snftrument robl fchaben und reinigen, uno mit laulichtem $\mathfrak{W B}_{\text {ein, }} \mathfrak{B}_{3}$ affer und ein wenig Salz vermijht, wobl auswajchen uno bäben und bie $\mathfrak{B S}_{\text {unden }}$ alle Tage mit biejem 2 uffid)lag verbinden, aber nidht mebr austrajhen uno mit foldem 2(uffidlag 9 Tage fortfabren, bernach gieb ibnen jeoen Iag früb nüd)= tein nachfolgenden (singur :

Son Diefem obenbefdriebenen ifuffalag 6 soth,

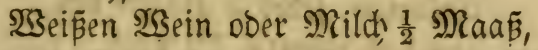

mifide es unter einander und fidütte ez bem Spferd auf einmal ein, gebrauche es neun Iage.

$\mathfrak{B S e n n}$ die $\mathfrak{W}$ unde am neunten Tage nid)t zu ift, fo (d)miere îe mit (Eieröl, weldhes per befcenfum gemadit iff. Mit Diefem Stücfe babe idh, mit (Sottes Scilfe, eine Stuthe in Dem $\mathfrak{S}$ ürtembergifdsen (Seftüt) auf Der ath, weld)e von einer id)warz= uno röthlichen, Eurzen Sd)lange an einem vorbern $\mathfrak{F} u \tilde{\beta}$, nabe beim fäp̄el, 


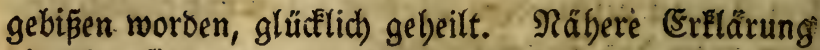
bierüber findet man im britten $\$$ buch in bem 14 ten $\mathbb{E}_{\mathfrak{a}}=$ pitel über ben $\mathfrak{B} i \tilde{\beta}$ giftiger İhiere.

\section{Die $\mathfrak{B}$ er p flegung.}

1. Der Stall foll nidbt Dunkel, aud nidbt zu bell fein, baß aud) weder Sonne noch Mono binein ficheinen Eann, jeood) lüftig, tübl uno trocken.

2. Dem $\mathfrak{3}$ ferbe follte man allezeit eine gute Streue machen und wenn es jehr tobet, mit Binden nohl verwabren, bamit es fich feinen Sdjaden thun fönne.

3. Soll man ibm in 4 ober 5 Iagen fein Futter

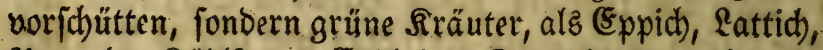

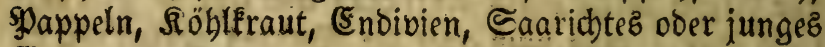

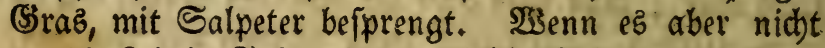
um bie Beit im sabr wäre, wo loldhe Siräuter zu befom= men fino, joll man ibm $\mathfrak{B s e i z e n f l e i e n ~ m i t ~ S c o n i g m a f f e r ~}$ befprengt zu freêen geben, jeooch) Eärglid) uno nicht zu viel auf einmal.

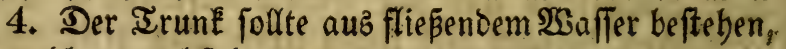
in weldjem nachfolgendes gefotten worben:

Map̧lieben 4 Scänoe voll,

Sauerampferkraut,

Endivien, jedes 3 Şänte voll. Şollunberwurzel 12 goth,

Rbapontic 6 \&oth,

2 Segoorn mit fammt den Rinden und

Wurzeln 8 Qoth,

Şypericon (St. Şobannią.) 2 Scändebofr. Ealpeter 8 Roth,

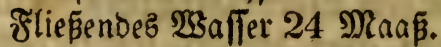

5. W̧enn der Reib nidbt offen ift, fo muß ę zum öf= tern clyftirt werben. 


\section{gyferte=:2rzenei Buch.}

6. 2uf jeden Eingū brei oder vier Stunden faften lapen.

\section{Das 12 te Eapitel.}

\section{פon Dem Edtuminel Der Pferbe, was man aud) Den Mord nennet.}

Der Cdymindel ift eine gefäbrliche Srantbeit uno menn er fich oft einftellt, gewounnlich ein $\mathfrak{B}$ orbote ber

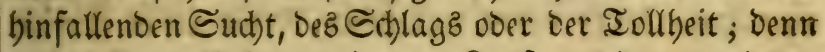
er hat feinen Urjprung in Dem Sopf, aus den unordent= lid)en Berwegungen, weldbe bie bläftigen Seifter in bem= felben Srte des (Sebirns erregen, meld)e (Spifter wiederum von ber Untechtmäjigkeit des (Şehirns inwen= oig in Dem Ropf erwadjen uno von ben falten zeben Feudtigfeiten ifren urfprung baben, ober werben aus Dem Magen, $\mathfrak{L} e$ ber ober andern nieorigen Srten bes Reibes binauf in ben Ropf verfichicfet. Sa es werden folche bläftigen (Sieifter auch bann erregt uno fo ber Schwindel verurfacht, wenn die Spferbe erbif̧t werden, Doer einen böfen (Seftane im Stalle doer anderşwo ba= ben uno benjelben burd) Die গajelöd)er in Den Siopf hir: auf zieben, oder fdnell uno lang in einem Sreizlauf berum gegrwungen merden, ober gar zu lang müpig fte= ben uno dabei zu viel freffen uno wenig verbauen.$25 e n n$ burd) irgend eine der genannten Urjachen bitaige uno fdharfe Feud)tigkeiten im Magen entffehen, fo fan= gen biefelben fogleich an fid zu vermelyen; es ift $b a=$ ber bringend nothnendig, Das man fich fidnell nach Sçilfe umfiebt. 


\section{Die Zeichen biefer Rrantleit fint:}

1. Das Spferd Eann nidht recht in bie Sonne feben uno wenn man es Dagegen reitet oder fübret, fo tau= melt $e \xi$, gebt in bie Scöbe uno fällt binter fich. Siebe Figur 3 bei bem IaubEoller.

2. Rauft aud) bismeilen immer auf eine Seite, bis es niederfällt und liegt alz menn es todt märe; menn es eine SSeile gelegen, fo fteht es auf uno foüttelt fich, als wenn ibm nidhtz gefehlt hätte.

3. Befommen e's gerne biejenigen Spferbe, melche man Şajentöpfe nennt uno foldhe, welche großße B̉ajen baben.

\section{Eur Diefer Sranflecit.}

Sor allen Dingen foll man ben $\mathfrak{L} e i b$ offen Galten.

Saamen bon langen 3miebeln,

2lloez, jedes 2 soth,

Weiper $\mathfrak{O f e f f e r} 6$ Loth,

Şonig= $23 a$ fler $\frac{1}{4}$ Maa $\tilde{\beta}$,

mifche alles untereinander uno gieß̧e es bem Spferb auf einmal ein; gieb ifm auf ben 2 Cbend nadfolgende (5ly)= ftier :

Pappeln,

Mangolt,

Bingelfraut, jebes 1 Şanowoll,

Brübe von gefottenen Rleien $1 \frac{1}{2}$ פaaß́,

fiede es mobl untereinander, alsbann thue bazu

Siera picra 2 \&oth,

\&erchenichnamm $\frac{1}{2}$ \&oth,

Salz 2 Ioth,

mifche alles untereinander uno gebrauche es.

Rape ifm bes andern Iage bie Sopfader uno eine 
gen uno groß̋ welches theils faule, fduläfrige ano turannifche Sereiter in Sommerzzeiten wobl beobachten follten, bas fie ifre SNferbe fein Morgens früb um 4 ubr in Der Süble an= fangen zu reiten, uno nicht erft den 2 nfang um 8 ober 9 ubr machen und um 1 oder 2 ubr Nachmittags en = Den, mie ids ez an unterichieblichen Srten nur allzu oft gejeben habe, denen ez hodhnöthig wäre, Dẩ man fie alle Morgen mit einem guten eidhenen oder hagebornen Mrorgenfegen aufroedte, bamit fie ibren Scerren ifre Sूferbe nidht fo mutbroillig zu @ibanben brädten, bie

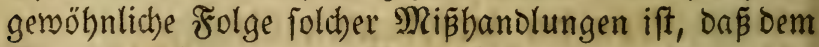

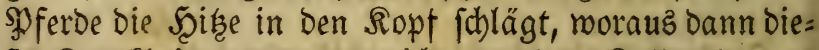
fe Srankbeitzart, wenn nicht gar ber foller, barauz entftebt.

Die Spferbs, meld)e von ber fallenten Sucht ergrif= fen werden, find indesen faft obne 2fusnabme von me= lancholifuler ober phlegmatifder Eomplexion; bie von melandholifcher Complexion befommen fie im abnehmen= Den, bie von phlegmatifder hingegen im zunehmenden Rono.

Die $\mathfrak{u}$ rjachen find eine allzu feuchte uno falte con = fiftenz Des (3ebirns, ooer allzu viel gefammelte phleg= matifche und melancholifche Feud)tigfeit, woourch bie Scöhlen und Durd)gänge des. (Sebirns plöklich gefpert uno bie hin uno lyergebenden animalifchen Spiritus des ganzen \&eibz aufgebalten werben, oder einige ichäbliche - im (Sebirn verborgene Sualitäten, ober ein im Ssebirn entftehendes 2(poftem; bismeilen auch wenn etwas an ben Scirn = Fellen corrumpirt roirb, oder menn bas. (Se $=$

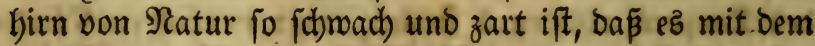
$a b=$ und zunebmenden sicht biffluirt und confluitt; odet 
Dent fidäolicbe berbe uno rälle Dämpfe aus bem $\mathfrak{N a}=$ Ben uno andern Rörpertbeilen mitgetheilt werben.

2euperliche Utrjachen find giftiger 3orn und beftige

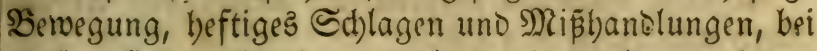
groper Şife, mie oben erwabnt, mie aud) angeborne erblitise Dispofition, (weld)es im (Sieftut nobl zu beo= bad)ten iff) beftiges গngen ber \$Nagenmürmer, bei ben Stutben abjonoerlid) oder von faulen giftigen Däm= pfen ber Särmutter.

Den jungen SDferden unter Dem fünften Sahr ift ez meiftenz töotlid), fonft aber eine langwierige Srantheit Der alten SPferde, weldje nid)t leid)t fo vollfommen zu cu=

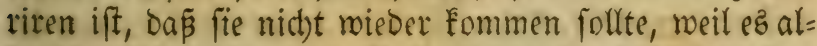
lemal von Der fdyarzen (S3alle oder meland)olifhem Scu= mor participirt. Daber find folde Spferde gemeinig= (id) melandbolifder (Somplexion und fteben traurig im Stalle. SEenn der Siranflyeitzanfall oft fommt, fo bleibt bas Spferd eimmal Davon auf Dem Jlá, ba von Der beftigen (Semalt der Sufälle daz (3)ebirn fo febr zerrüttet uno auper feiner Dispofition gebracht wirb, Daß̃ alsbann eine Berrei Das Spferd gleid) auf oer હtelle todt ift.

Die (Erfenntnis und Beichen Diefes (Siebrechens roer: den folgenderweije wahrgenommen :

1. Das Sמferd fält unverfehens auf die (5roe, bis= weilen mit einem lauten gevräll, da es bann burd) ben beftigen Fall einen gemaltigen Siblag auf Den Soben thut.

2. Der ganze \&eib wiro Srampflaft gezogen uno aufgetrieben, bie 2fugen glofen hervor, ez fnirfchet mit Den 3ähnen utno beiset biejelben zujammen, Der 2athem gebet mübjam uno mürgeno. 
3. Sdlägt ben నopf hin uno her uno ftrampft mit

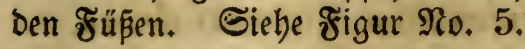

4. $\mathfrak{e a ̈ p t}$ bisweilen während ber Dauer des 2 nfalla Siotb uno Scatm von fict).

5. Şegen Enoigung Deß Sturmz fließ̄et ihm Şeifev und Schaum zum Nuno herauz, ba Dann balo bernach Daz spferd roieder aufifehet und yon ben gejdhehenen

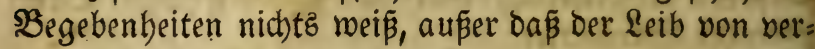
gangener Iortur febr matt ift.

6. Fallen etlidye \$ferbe bahin, als wenn fie toot rären uno rübren fidh gar nicht, uno wenn ber Şaro= xyfimus vorüber, bolen fie einen langen 2 (them und fte: ben audb wieder auf, lasen aber babei auch einen ftar: Een Sseifer aus bem Maul fallen, und bas beipen bie

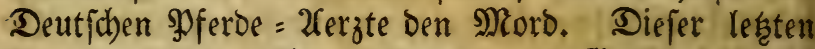
2(rt babe id) 2 träd)tige Stutben, mit (Sottce Scilfe, in einem Sabr glüctlich curirt, wie aud bon ber erften 2rert unterichiedlidbe, welche nie mieber babon befallen

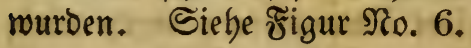

\section{(5) $\mathfrak{r}$ biefer $\mathfrak{A} \mathfrak{r} \mathfrak{a}$ flfeit.}

Fürs alleterfte foll man bem $\mathfrak{p}$ fero den \&eib offen

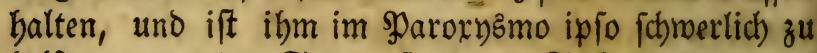
Gelfen, wegen bes Strampfenz uno Sd)lagens mit Den Schenketn. Riegt aber baz $\$$ ferb als ob es todt wäre mit ben Sdbenfeln uno rübret fich nicht, fo follte man ibm geidhwind ben britten Staffel ftechen uno bie 2roern unter ber 3unge öffnen, auch oas SBlut ihm in ben

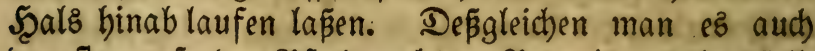

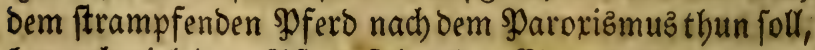
bernad) gieb bem \$fero folgenden (singü : 


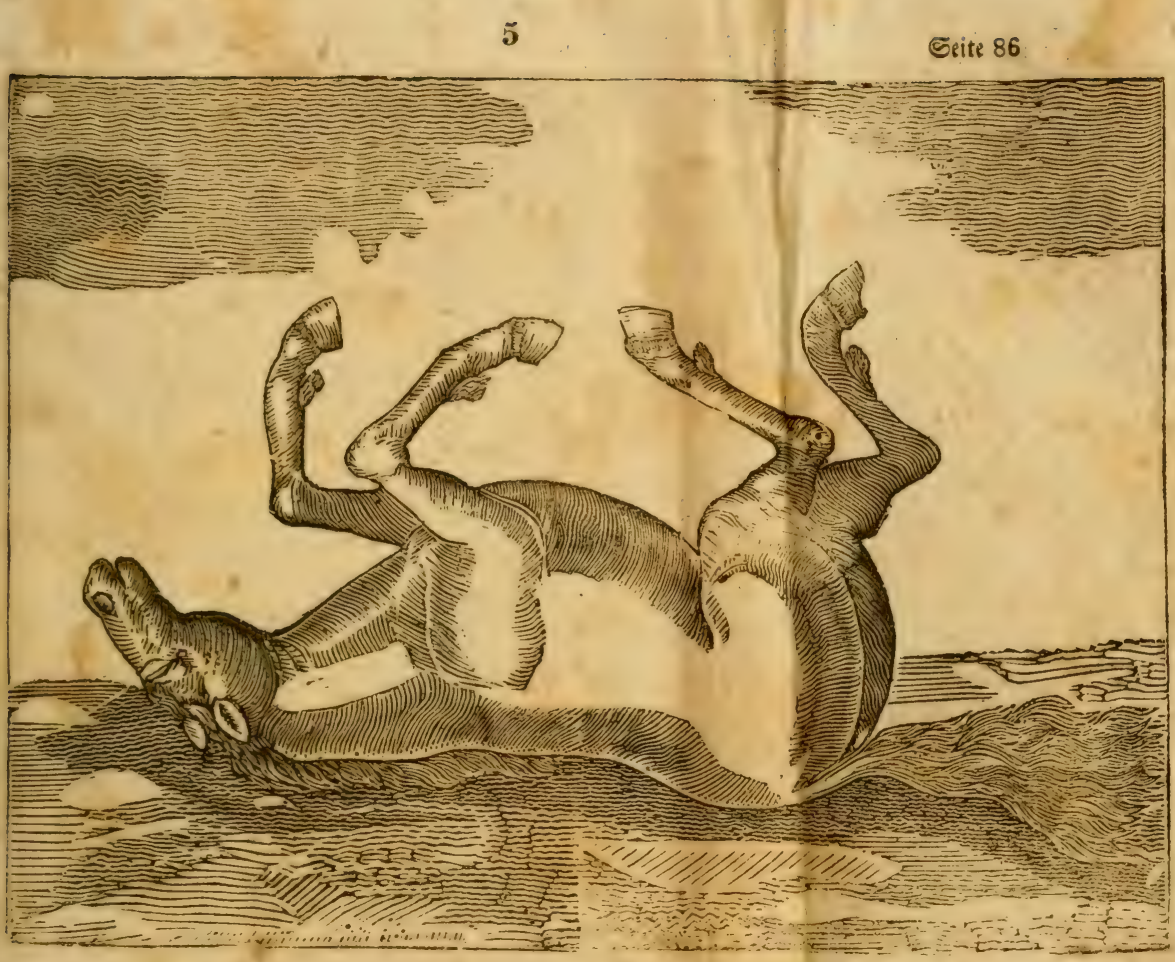




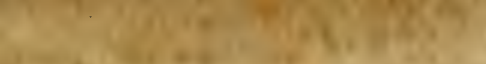
$7+4,5.10$

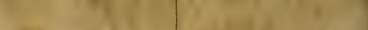

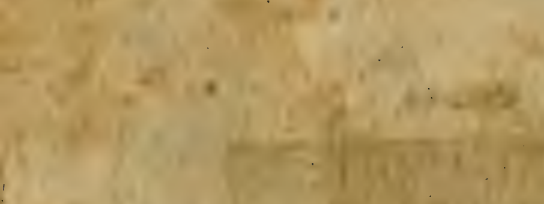

8.

and

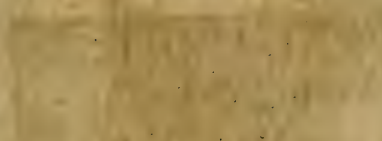
$4=8$ $y=x$ $\cdot$

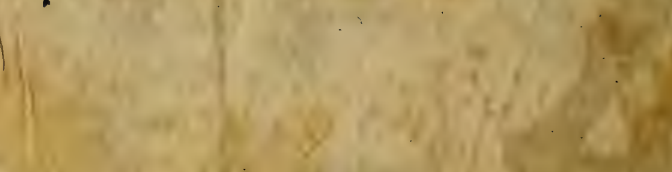
x.70, $6, y^{2}$ W $620 \times$

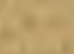

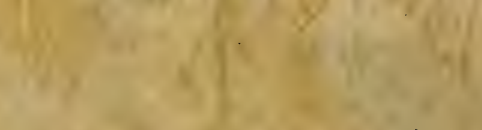
$\left(x^{2}+5\right)=2 x+3$

,

$\sqrt{2}$

$+$

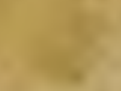
is: .

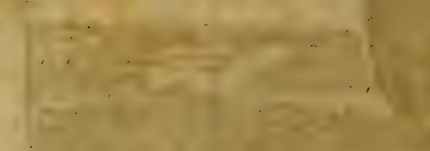

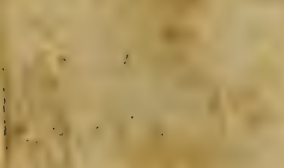
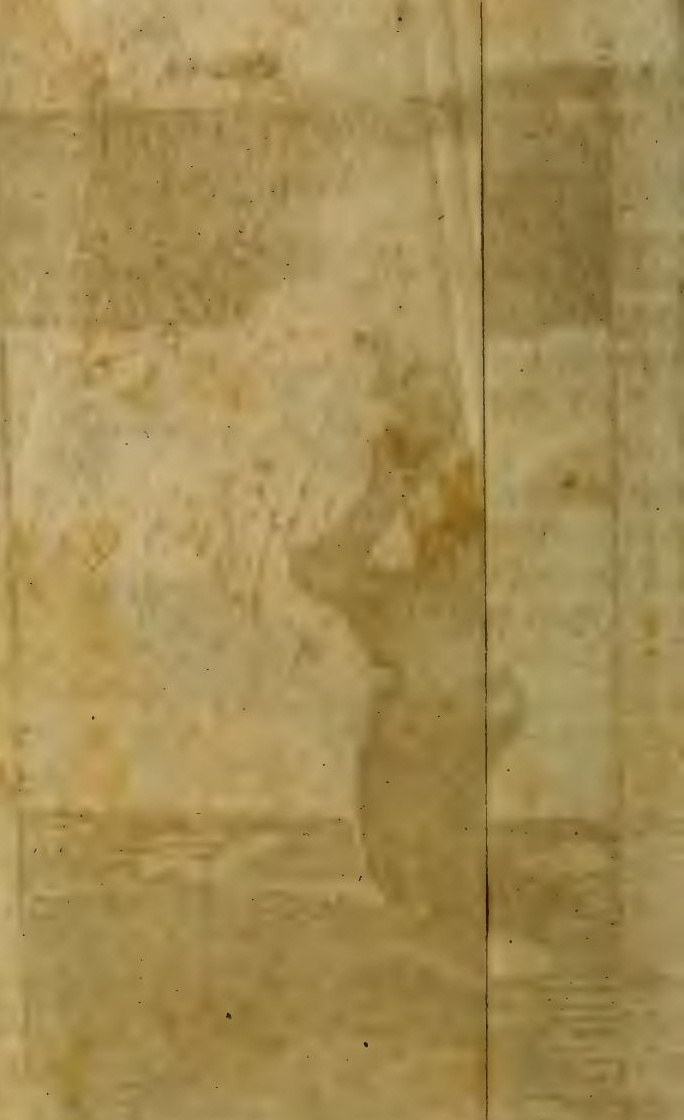

1

i. $7 x=0$

8

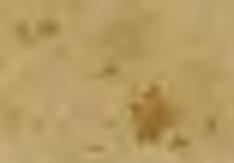

$-m+2-4$

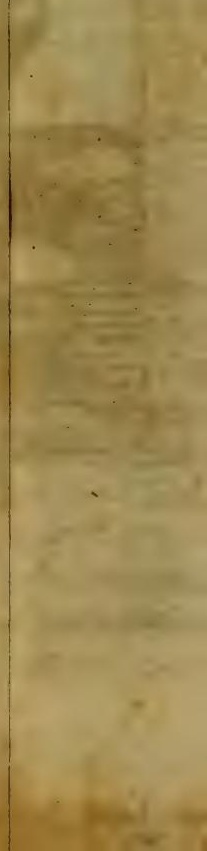



$x^{2}+7-2-+1$

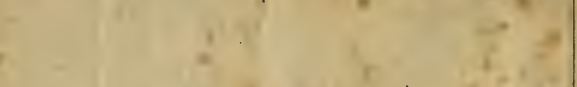

$2+2+2+2$

$+7+\mathrm{NO}^{-1}+2$

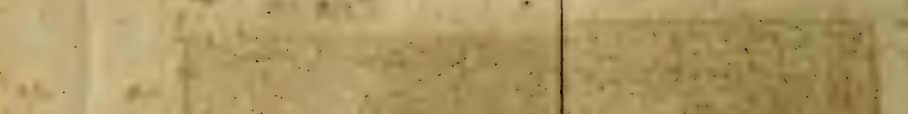

$\ln _{-1} \ln ^{2}$

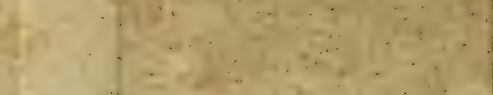

$x=2+2 x+2$

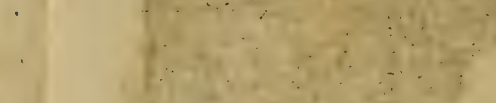

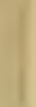

1

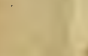

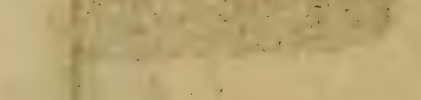

5

.

s..

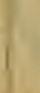

$\operatorname{lit}_{1}$

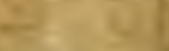

간.

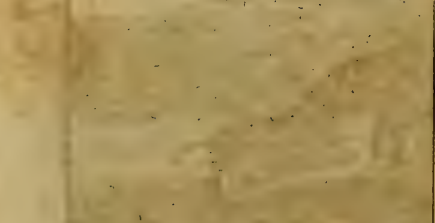

$+2$
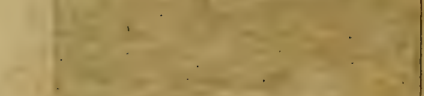

$\begin{array}{lcl}\ddots & \ddots & \\ \vdots & \vdots & \end{array}$

I

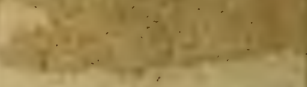

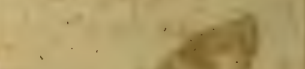

$+$

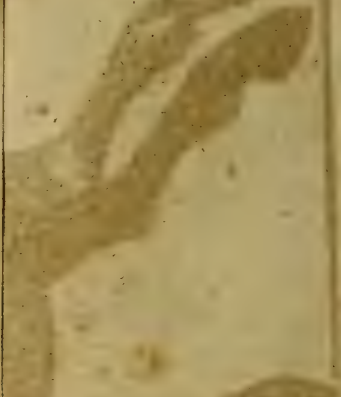

(2) 
gूöonienmurzel, Baalorianmurzel,

Florentinifche Benelmurzel,

2fngelica, jebes 4 loth,

Betcnien=:Blätter uno Şipfel,

Rotbe (Sauchbeil, Mielipenen,

Eijentraut, jeoes 4 5̧ändebolr,

Ifnişaamen,

Fendheliaamen, jeoes 3 Roth,

BBiloer ভaftranfaamen, હenezblätter,

Engelfǘs, jedez 4 Roth,

Eerd)enichwamm,

Szermodact I. jedes 2 Loth,

Ravendel mit Rraut und $\mathfrak{B l u ̈ t ,}$

Salbei mit Rraut und Blüt, jeoes 2 Şăn= Devoll,

diez alles untereinander gemifát, mit 8 Maan $\mathfrak{B a}$ affer

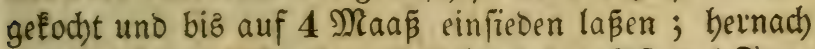
auagepreșt, in 4 I beile getheilet und Dem \$ofero 4 Iage nad)rinander fein laulid)t eingegosen und einen balben Tag Darauf faften la $a \tilde{e}$.

Cin andereb für eine Ctuthe $\mathfrak{W}$.

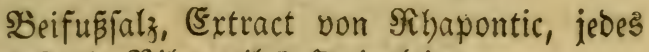

1 Loth, SBibergeil 1 Suintlein,

(Sialappä 1 Roth, Majoran $\frac{1}{2}$ Suintlein, mifiche es untereinander und fouttte es bem $\mathfrak{p}$ fero in

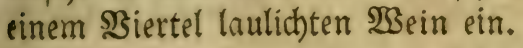

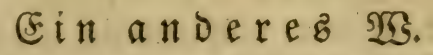

(Extract von Niestwurzel $\frac{1}{2}$ Loth,

Sepottene Brühe von blauen Beildben un Æraut 1 Maaß, 
mifche es untereinanoer und fchütte ę dem SDferd lau= licht ein.

(5) $\mathfrak{n}$ a nderes $\mathfrak{Y S}$.

(S)ummi (s)uttä 1 Suintlein,

Uloę $\frac{1}{2}$ \&oth,

Scammonium $1 \frac{1}{2}$ Suintlein,

SBeinftein 2 $\mathfrak{o t b}$,

in einer balben Maaß warmen $\mathfrak{W}$ affers vermifdst uns Dem Sferd eingegeben.

\section{(E) in andereb $\mathfrak{Y G}$.}

Ssieb inm von nachfolgenoem Syulver täglich 3 Inth ;u frefien, als den 2 Cbeno vor bem Neuenlicht, Den 2Cbeno

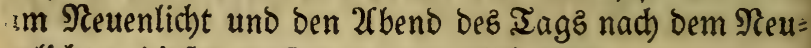
inlidbt; Diefes mus man monatlid) thun :

Sinober vom 2(ntimonium, welcher $3 \mathrm{mal}$ per fe rectificirt worden, 2 Suintlein,

Spöonienturzel,

SSilder Balorian,

2Angelic,

(Salgan, jedes $1 \frac{1}{2}$ Ioth),

Sräuter uno (sipipfel von rotbem (šautchbeil, Betonien, Salbei,

Eifentraut, jedes 2 Şändeboll,

sichenmiftel 6 \&oth,

St. SobannißEtraut uno Blumen 1 Şanov,

Senesblätter 2 Scändeboll,

Rinoenblüt 1 Şanovoll,

Fenchel 2 \&oth,

Someranzenichalen,

Rapontic jedes 2 \&oth, 
biez alles untereinander vermijht und bem SPferb auf einmal in bie Najelöcher gegoßen.

Man foll aud zu 2rnfang biejer Sirantbeit bem Spfero beide Sporl = uno Schrank=2loern fo mie auf Dem Sthmanz 2roerlaffen und wobl bluten lasen, Damit es bie Feudtigkeiten vom Sopf binmeg ziebe ; Rach vier בagen purgiere mit folgendem:

Shiera picra 2 Roth,

Eoloquinten= Mark,

Stechasfraut, jedes 1 Ioth.

Bibergeil 2 Suintlein,

Eetchenichroamm 1 Ioth,

Baumöl I $\frac{1}{4}$ Pfuno,

Sconigwaाter $\frac{1}{2}$ Maaßa,

biez alles untereinander gemifht und bem झुferb einges gop̈en.

\section{Eine andere Purgierung.}

Senezblätter 3 \&oth,

fiebe eine Brübe Davon; hernach nimm bie Srübe uno thue Darein

Scammonium 3 Suintlein,

Eercheniformamm,

B3ilde Eucumerwurzel,

Spoponac,

Ssemeine şanac. jebes 1 Loth,

Sconig 2 \$f fund,

alles untereinander gemifdbt uno bei einem Soblenfeuer fittjam untereinanber fieben laäen; bernach bem şferb täglich 2 groß̄e \&óffelooll Dabon, nebft 2 Ioth Baumöl in $\frac{1}{2} \mathfrak{M a a} \tilde{\beta}$ marmen $\mathfrak{B a f f e r}$ mif́chen und eingießßen, und fold)ez fo lang fortferen, bie man glaubt, ba genugjam purgitt [ei. 


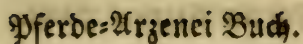

Man Eann ifm aud) am britten Tage ein leid)tes (elyftier maden.

Samillen, זill,

Taujenogüldentraut, jeoes 1 Şandvoll,

Sonig 6 \&otb,

श्Rark von (Soloquinten 1 Ioth,

alles untereinander gemijut, gefotten, abgejeibt und zи einem Elnftier gebraud)t.

Fin anderes SIyftier.

Die Şrübe von einem Şammelzkopf, fo viel zu nachfolgenoar Rifhung nöthig iff,

Salz 2 Roth, Saumöl 1 Ioth,

Sonig 3 rotb,

5ुiera picra 2 \&oth,

Iaufenogüldentraut 2 5̧andevoll,

Ierchenichroamm 1 \&oth,

bies alles untereinander gefotten uno zu einem Slyftiex gebraudt.

Rach Diefer (5lyftier lape dem spfero aud) Den fiopf purgiren :

Siberaeil, Sertram, jedes 1 Suintlein, pülopere es untereinander und blafe es dem $\mathfrak{g}$ ferbe in die গaje.

Eine andere $\mathfrak{S o p f}=$ und Şirn=\$urgirung.

Soloquinten= Mark 1 Roth, vom riloen (Sucumernjaft 3 \&oth,

mijhe es untereinander, Dann ausgepreft uno dem 2 fert in bie Naje gejprïzt, fo wiro es niepen.

Eine antere fopf Purgirung.

Majoranmaffer $\mathbf{2}$ Ioth,

3einrautenfaft 1 Iotb, 
untereinander gemifdt uno bem spferbe in bie शafelö= der gegópen.

\section{Ein a noereb.}

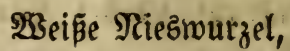

Beifußrnurzel, jeoes 2 goth,

Son Dem Rraut Laferpitium 1 Loth,

mifabe ef untereinander zu şulver und blaje es Dem spferd ein.

Man bindet ifm auch auf bas Munoftũce ein Sace = lein, melches gefüllt ift mit Bertram, Sciera, Maftix. Şfeffer, jedez $\frac{1}{2}$ loth, uno läft es barauf fäuen.

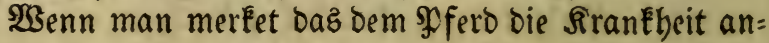
fommen will, uno es möglid) zu thun ift, fo foll man demjelben gefdhwind einen Tupf mit einem glübenden Eifen mitten auf Det Etirn, einen andern oben binter Dem Senick und einen gerabe auf ben Ropf geben.

\section{Der $\mathfrak{i} \mathfrak{a} \mathfrak{n}$ foll fein.}

Sd)lüffelblumen= Sraut,

Enzian, jedę 3 Șändevoll,

Lorbeer, Runo SIterlucen,

Bertram, jedee I Scandooll,

Sconig 1 Pfund,

allez untereinanber mit einer genugfamen Menge $\mathfrak{B a}=$ fer bermijht, uno bas פुfero bavon trinken lapen.

Ein andereb.

Die Şarnblajen von cinem wilden Edrwein, mit allem bem was barin iff, in einem Bact: ofen geoürtt und zu Soulver gemadht 1 \&oth,

$\therefore$ Şonig 3 \&oth.

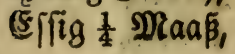


Ein anderez.

Rannżtreu 3 Roth,

Sconigmaffer $\frac{1}{4}$ SDFund,

untereinanbee gemifatt und bem Pुferd eingegeben.

(5in a noereb.

Şirichborn, Epagyr. präparirt, 1 Ioth,

शRenftruum virginis vel mulieriz. $\frac{1}{2}$ suintl.

Sauerampfermafter $\frac{x}{4}$ Maaß̧,

untereinander gemijcht und auf einmal eingegeben.

E i $\mathfrak{n}$ no ere .

Nimm von Den Wrarzen, weldje baz Spfero an ben Füpen bat $\frac{1}{2}$ Loth,

gepülvert und in einem \$peint marmen 5 ffig oder $\mathfrak{S}$ ein

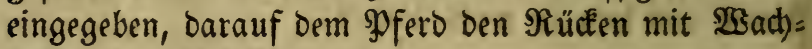
bolderöl mobl geidsmiert.

Ein anderes.

. Weipe fpanifde Seife gefduabt 1 Roth.

Sübe= Milib 1 Maá̃

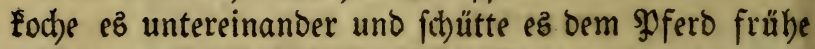
nücbtern auf einmal ein, etliche $\mathfrak{W}$ ochen nacheinander.

E i $\mathfrak{n}$ n o e reb.

Sobalo baz Pfero mieberum vom Fall aufgeffanden, fann man ibm Şunosigalle in (5fïg zu trinken geben, fo befommt es foldbe Sranfleit nicht mehr.

Die Rerpflegung.

1. Der Stall foll bunfel, warm, aber nidbt tämp= fig fein, uno bas spfero eine gute Streu unter fid) baben.

2. Daz Futter foll gebrodben, als . Şaber, SSiden, $23 a i z e n$ und nid)t falter ther feuchter Natur fein. 
zu befdoweren, fondern nur bie Şand= Sur recommandi= ren roollen. Man giebt ibm einen Tupf mit einem glü= benden (Eifen binten auf Das (Senick, einen andern born auf bie Stirn unter ben Sdbopf uno den britten auf ben Sdmoanz. Uno bizfez jei aljo von biejer unbeilfamen strankbeit genug.

\section{Daz 15te Eapitel.}

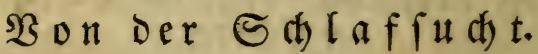

Die $\Xi$ blaffud)t ift nid)t allein eine beftige, fondern auch eine töotlid)e Srantbeit, menn man Derfelben nicht bei Seiten vorfommt.

Dieje Irantbeit entftebet vom erfälteten \$blegma, welches fidh in Dem (Sebirn fammelt. Denn im Fall Die Freuchtigkeit obne Schärfe ift, fo giebt eह im (Sebirn nur eine Ealte Befdwerung und Snclination zum $\subseteq$ d)laf, nimmt allez (Şeorachtni $\tilde{\beta}$ bin, mie gleid)falls audb bie Berwigung fammt Den Sinnen, verberbt bie \$ुbantafie uno miro, menn fie ohne Fieber ift, ber tiefe Sdlaf ge= nannt. Sit aber Schärfe babei, fo giebtz einen wund= beifenoen Flū, morauf Dann ein (Sejchmür ober Fieber folgt, meldbes Fieber aber, megen ber Ealten phlegmati= iden Materie mit groperer Şike uno (sntzünoung nicht heftig wütben Eann, fondern giebt vielmebr ebenmäpig eine ftetige Sd)läfrigkeit.

3u Beiten entffteben im (Sebirn auch) Iubercula, mel: d)e Daffelbe enolid) Hlemmen uno alfo eine (Srabation uno anbaltende Schläfrigfeit verurfadben. 


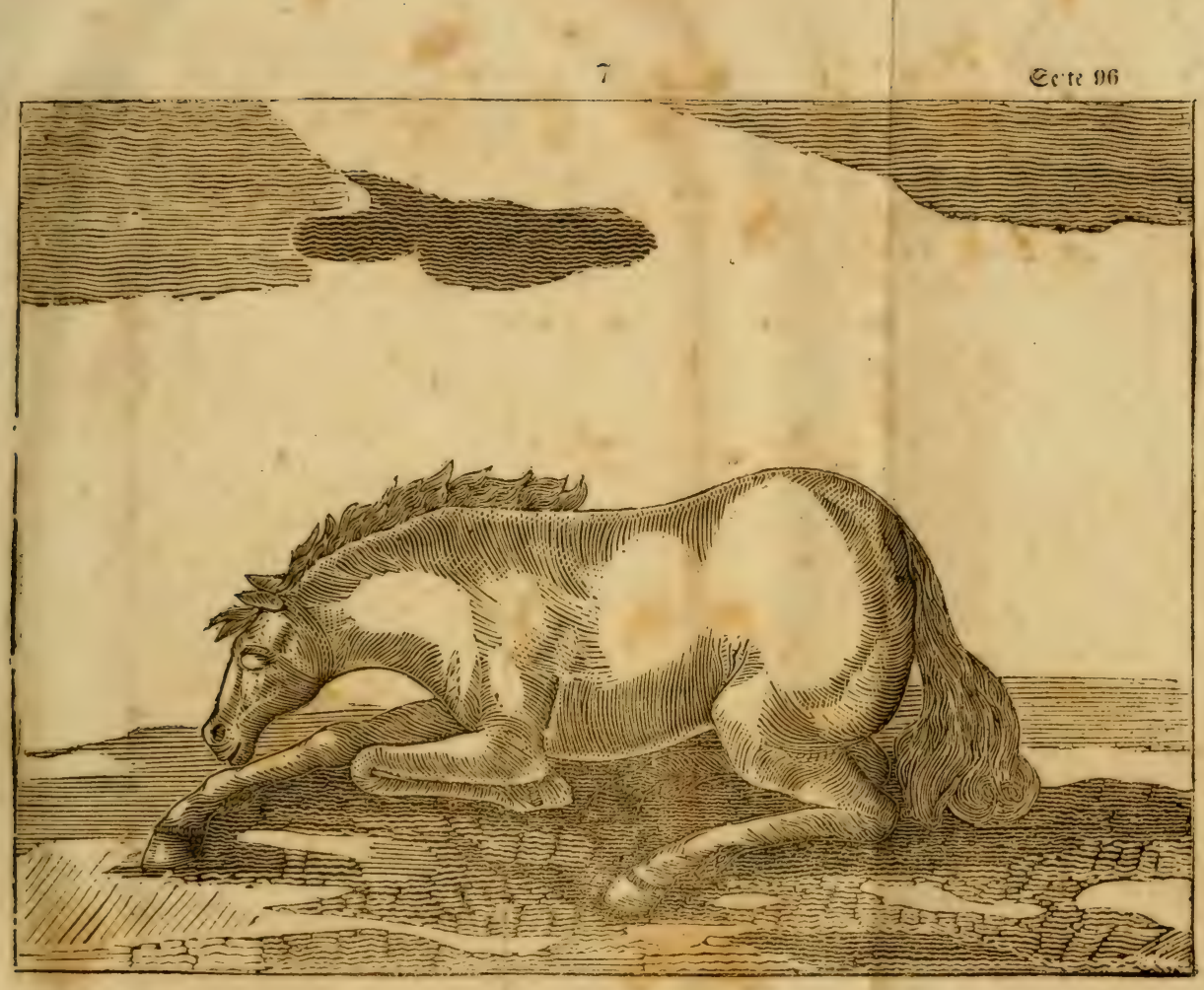




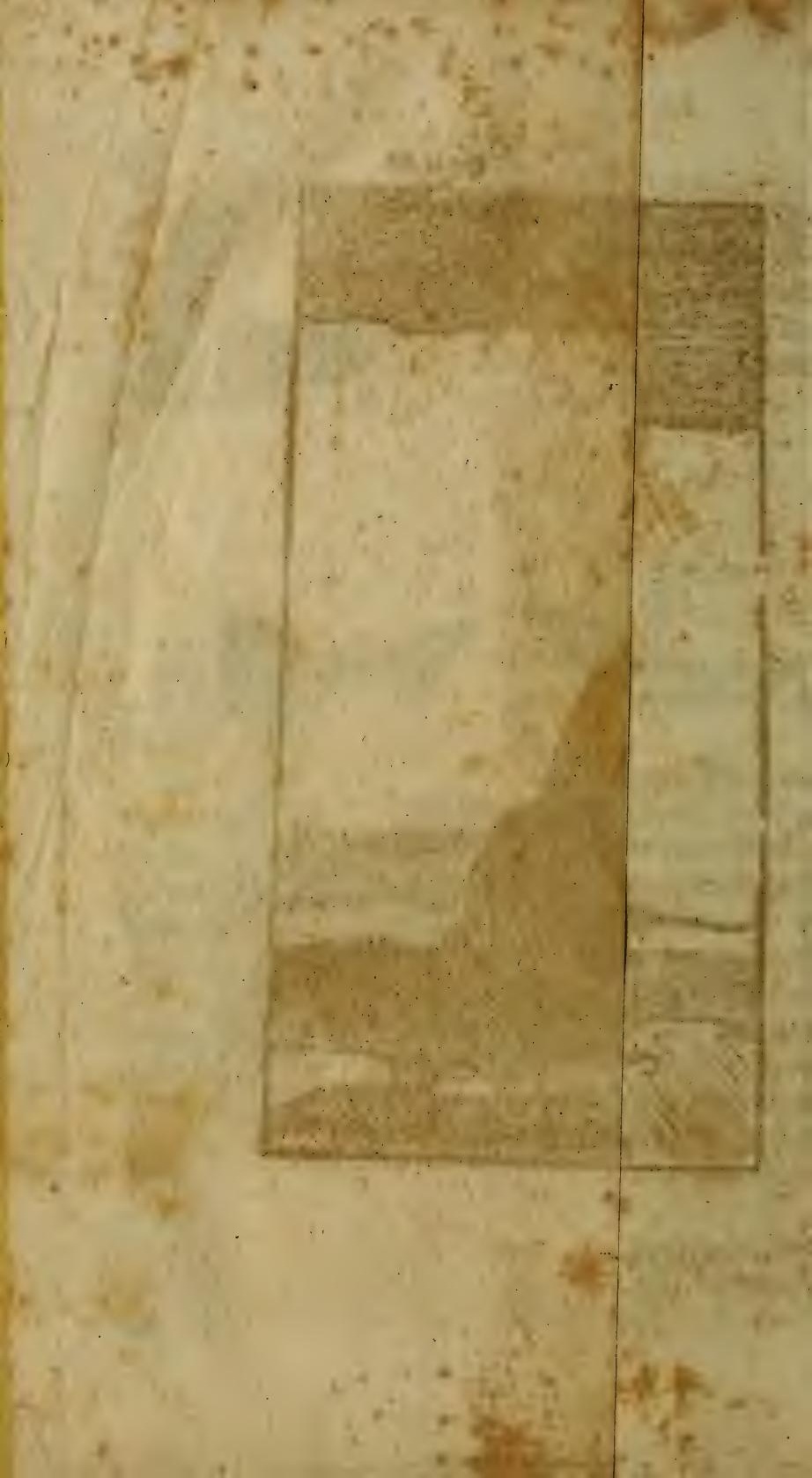




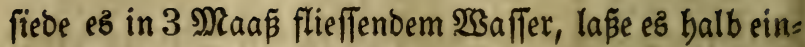

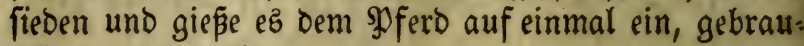
d)e ę mebrere Tage.

Man mus in allen fälllen barauf feben, wie man mit Errwärmung und 3ertbeilung Der Ealten Naterie des (Sebirns befchäftiget fei, uno zu 2 2 bfübrung ter Nate= rie vom Sebirn foll man nachjolgendes styftier ge= brauchen $2 \mathfrak{B}$.

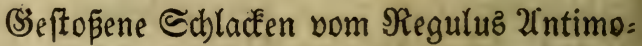
nium 2 Loth, farke Lauche 2 Maa $\tilde{\beta}_{\text {, }}$ lapee es untereinander fieben, biz bie Lauche roth wirb; bernach

Nimm von biefer Lauche 6 \&öffelvoll,

Baumöl 3 Loth

Siera picra 2 loth,

\&erchenficroamm 1 \&oth,

SaujengüloenEraut 1 Scanovoll,

Salz 2 \&oth,

Brübe von einem Sđaafżopf 2 Maá⿱㇒冋,

alles untereinanoer gemifcht biz auf eine $\mathfrak{N a a \beta}$ einge= fotten und alsoann angemendet.

Man muß aber baz Saaumöl uno bie 6 löffelooll rauche erft zuleşt in bie übergebliebene SBrübe gieß̄en, und nicht fieden; man foll auch überbies Dem glfero Den SSil bel auf ber @tirn mit obenbeichriebener Sauche mobl uno oft nefen, fo wirft bas (Slyftier befto beper : Scernach) brauche nachfolgendes Niespulver 23.

Nieşwurzel, Bertram,

Majoran, jeoes 2 loth,

Sthmarzen Soriander,

Euphorbium, jedes 1 Ioth,

alles untereinander vermifcht und geffopen und bem 


\section{Pferbe=:2rgenei Bud).}

spfert bavon einen @erupel auf einmal in beibe Najes löder eingeblajer.

Ein anberes গitȩ̂pulver.

Nimm Turbeth. Mineralis 1 Loth

Sü̈bolz 3 Ioth),

untereinander gemifd)t uno am britten $\mathfrak{I} a g e$ ber (Trank= beit einen ganzen oder andertbalb ๔crupel in bie $\Re a=$ felöd)er geblajen: nach meiterm Serlauf von brei $\mathfrak{a} a=$ gen fann man e's wieder gebraudben.

Der ganze Sberk̂nf, bas Sienid uno um bie Schläfe follte man es mit nadfolgendem Del fdumieren $\mathfrak{B}$.

Biegel 4 loth, Regenwürmer $=$ Del,

$\mathfrak{B a d}$ holder= Del, jebes 2 Loth,

Bibergeil,

Sohonnisklumen=:Del, fedes 1 Roth,

alles untereinanier gemifd)t.

$$
\text { E in Einguß } \mathfrak{B} \text {. }
$$

Scammonium $\frac{1}{2}$ Ioth,

Bibergeil 1 Loth),

Sconigmaffer $\frac{1}{2}$ Maa $\tilde{\beta}_{\text {, }}$

alles untereinander gemifd)t und bem Sfferd eingegoßer.

Man foll ifm aud), wenn es fid zur Befferung fohi= det, etlid)e Morgen nadjeinander folgenden હingu级 einjchütten :

গimm Bibergeil 1 Suintlein,

Meerzmiefeljaft 1 Loth,

Sconignaffer $\frac{1}{4}$ Naa $\tilde{\beta}_{\text {, }}$

untereinander gemifd)t und eingegofien.

Und weil Diefe Franḱfeit gern nieder formmt, foll

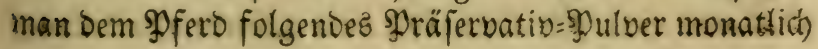


3 Iage vor bem Reuenlid)t biz zum erften \$siertel $\frac{1}{2}$ Soth eingeben.

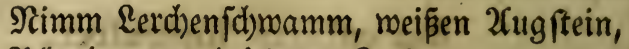

গুöoniennurzel, jeoes 2 Sotb,

WBeinftein 6 soth,

alles untereinander gepülvert uno gemifdt, uno in einem $\frac{1}{4}$ Maá⿱ $\mathfrak{B}$ Sein eingegópen.

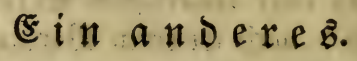

Rimm rothen Bucten oder Beifuß 8 Eoth,

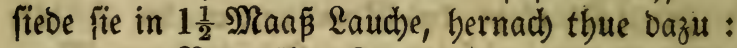

Baumöl 6 Loth, mifche es untereinanoer und fhütte igm eine balbe Maẫ auf einmal babon ein, biefez mieberbole bez Iaģ viermal.

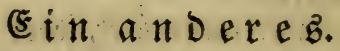

Sparkaldjichaum 6 Roth,

Rbapontic,

Spicanaro,

Eapernmurzel, jebes 4 Loth,

zerftope und mifche es untereinander uno gieb ilym von Dem sूulver 3 Löffelvoll in anderthalb Maáp laulichtem TSaffer autf einmal ein.

Ein anderes.

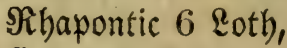

Salmuz,

Saperwurzel, jebes 10 \&otb,

alles untereinander gemifot und zerftopen, Davon einem

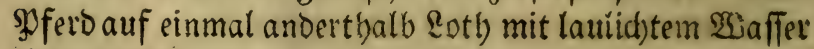
eingegeben.

Reibe ibm bie Sithenfel aud) auß̃erbem mit Effig, 
aber, wenn bich bie Sräften zu jahroach beoünten und es auch) 2(tterżhalber anderz nicht fein fann, bie aber auf ber Raje ober auf bem Sdhneif, um bie Materie allein yon Dem Sopf binneg zu zieben uno nicht bornemlich

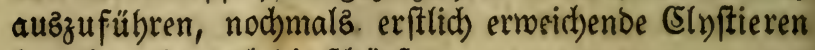
brauchen, hermach bie foürfern.

\section{E $i \mathfrak{n}$ C $\mathfrak{y}$ fit ier.}

Taujenogüldenfraut, Bergmünz, YY Fopp,

Stöbaskraut,

Beimeino, jebes 1 Scanovolr,

Serchenfinwamm, Salz, Soloquint,

Stickinurzel, jeoes 2 suintlein,

Engelfür, řenthel,

^ümmel, jeoes $1 \frac{1}{2}$ Ioth,

tape alles in $\mathfrak{2}$ aller bis auf bie Scälfte einfieben, thue bernach, menns ourd)gefeigt ift, zu ber SBübe

Şiera picra 4 \&oth,

(Eoloquint. Mark,

Scammonium jedez 1 suintlein,

Salz 1 loth,

Rercbenfibnamm 1 Suintlein,

madbe 3 cinftiere daraus und gebrauche es.

(ङ) $\mathfrak{i} \mathfrak{i}$ \& $\mathfrak{i} \mathfrak{g} \mathfrak{u} \hat{\beta}$.

Soley, Salmuz, Spicanardi,

Sappernwurzel, jedes 1 Ioth,

fiede ez in 1 Maaß $\mathfrak{B a}$ alfer bis zum balben I beil, feibe es ourd), theile ez in 2 gleidbe Theile uno giepe es bem \$fero auf einmal 1 I beil ein.

\section{Die $\mathfrak{B}$ expflegung.}

Der Stall joll bell, trodken uno lüftig lein.

Das Futter foll fein : 
fid) biejelben zu ibrem $\mathfrak{x}$ nfang uno uriprung zuziefien uno, biz man ifnen burd gebübrliche sittel wieberum zu Soulfe Eommt, aljo bleiben.

Derfelbe nimmt bizneilen alle Sslieber bez ganzen Sörpers zugleid) und miteinander ein, ober bismeilen biefes oder jenes allein. Derjenige weldher ben ganzen Sörper einnimmt, binbet uno bält bie (s)lieber bermar =

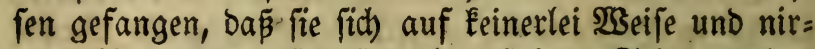
geno hin, meder auf biefe noch auf jene Seite menden Eönnen, uno wiro gemeiniglich) Siehtbier (Tetanus) ge= nannt, weil fich bie Mäufe uno Nerben ohne Unterla einzieben.

Es ift aber Der Srampf breierlei 2 rtt, nämlich. Der welcher bie (S)lieder vormärtz ziehet, Der andere ziehet bie (s)lieder zurück und bann ber britte und lefete neber Gin noch baber, fondern ben Şals mit fammt bem \&eib

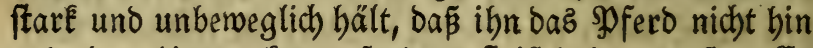

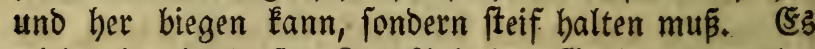
wiro aber in Diejer Sranflyeit das SSebirn, bismeilen ber 2 nnfang oder Sbertheil bes Mark̂̉ in (Srät, oder fonften biefe oder jene Spann=2Coern uno Mäufe ange= fochten. Der Srampf, ben man daz Siehe, daz న hier beißet, ift eime von ben alfergefdnoindeften Iodgefäbr= lichften Rrantheiten, fommt baupt fächlich aus zweierlei Utracten, nemlid) von ber alfzugropen 2fusleerung uno von ber übermäßigen Erfüllung. 2Uuz ber Evacuation uno Iuzleerung zwar bann wenn bas spferd etwa eine meite Reije gethan, ober eine Beitlang ununterbrochen Gart uno forrer gearbeitet, grope unleibentliche Şize ber Sonne auggeftanden ober lang gefaftet hat, benn foldhes allez verzebret, trodfnet uno macht baß fid bes $=$ balb bie Nerben uno Näu[e zurüct zieben uno främpfig 
welche Die finnlidbe Seifter pllegen Dabin zu manoern, eingenommen uno verffopft merben uno der \&eib, fammt feinen (S)ieoern erfarrt, ftrack uno ausigedegnt bleiben, oder wenu die soferbe aud) für fith felbft einer böfen Somplexion fino, bergleid)en in foldben I hieren gemei= niglid) phlegmatifity uno bläftig zu fein pflegt. Denn

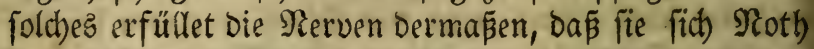
balber in die 3 reite ausbreiten uno Kürzer merden mü $\tilde{e}$ en.

Die Beichen, moran diefe Irankheit erfannt wiro, find vielerlei.

Sommt Die Sranlbeit aus Erffülung her fo ift bas \$fero vorber fett, bick uno mobléleibig gemefen, uno mit ber Irankbeit iäblingen, fammt einem そreber überfallen morben.

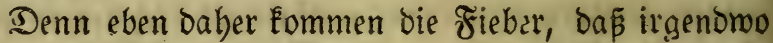

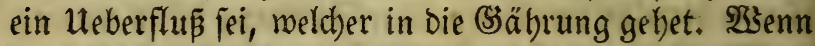
nun nach Dem Srampf und 3ufammenziebung Der Nete=

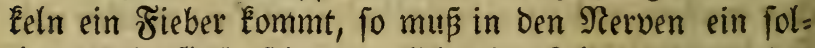
(b)er Ueberflup fein, nemlid) ein Ealter fpannender Sdbleim, meldber burch $\mathfrak{B}$ ärme vertrieben mertoen mus. Da nun ein jebez Fieber eine Șike madtt, die Şike aber zur Serzebrung folches Ealten Urberflupes gut ift fo folget Daß in foldhem Fall ein Fieber behülflich iff.

Dic aber woldhe Durd) eine unntäßige 2(uzleerung ba: zu fommen, fino gemeiniglich mager uno baben anbal= teno hatt uno jober arbeiten, auch offters gropen Şun= ger babei leiben münen. Subem fommt auch Diefe Irantheit, wenn fie ourch 2(uzleerung berurfacht worben, fein allgemad) mit ber 3eit uno nid)t fo jäblingen, weil nach fold)er Srantheit, weld)e eigentlich ein Fieber iff, zuerft ber Srampf Eommt. Denn bie Şif̧e Dec. 
Maul=(Sefperr uno ift fo man 24 Etunden martet, un= Geilbar ; Eommt autb oft von Serzauberung ber. Sie= be Figut शo 8.

WGenn er natürlicherneife von Ueberfüllung uno Eal= ten zäben Feubtigkeiten hertommt, fo hat Das spfero inzmijchen Die Jäferwürmer in Magen Dabei und es ift vemnach bobe 3eit, foldhe zu töbten, Denn Das syfero

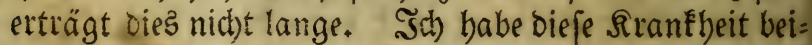
Derfeitz, (SStt lob! oft uno glüdlich curirt, fonobl an ben Säfermürmer, alz am ß̉erzaubern; wie mir bann,

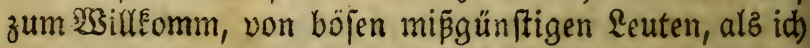
Den erften Tag auf oie Scodt= Fürfflichen $\mathfrak{i s u ̈ r t e m b e r g . ~}$ Stuterei gezogen, 8 Shferde auf einmal baz शaul=(Se= fperv befommen, weldben id) aker mit (Sottez Scilfe, bald wieder gebolfen babe. WBann folche spferbe ge= hen, halten fie ibre Echenkel ftrack, zieben Die Füße binten nach. Siebe Figur No. 9, uno wenn fie bar= nieber fallen, Eönnen fie fid felbft nicht mieder aufbel= fen, fonoern firen auf Den lintern Füren, wie bie

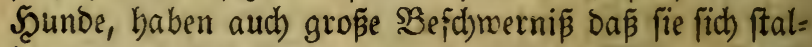
len mögen, miften aber oft wioer ifren $23 i t l e n$. Dann

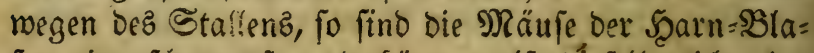
fen eingeforumpft uno önnen alfo biefelbe niobt ein = zieljen : Dagegen bie andern, welche zum 2lfter bienen, iglaxirt ober nuchgelasen; uno auserdem ift aud bie austreibende Sraft an uno für fió) felbft in foldben Sु) feroen (d)wa(t) uno unvermoglich.

Senn aber ber Rrampf allein Den vorbern $\mathfrak{L}$ beil bes Leibez, als ben Sals uno bie şruft und vorbere Ed)en= Eel, cingenommen, ba bält bas İbier feinen Scals ftract uno unberweglid), uno fann bie vordern Echenfel nicht: biegen; bie Blut-2rortn auf ben vorbern BBügen uns. 


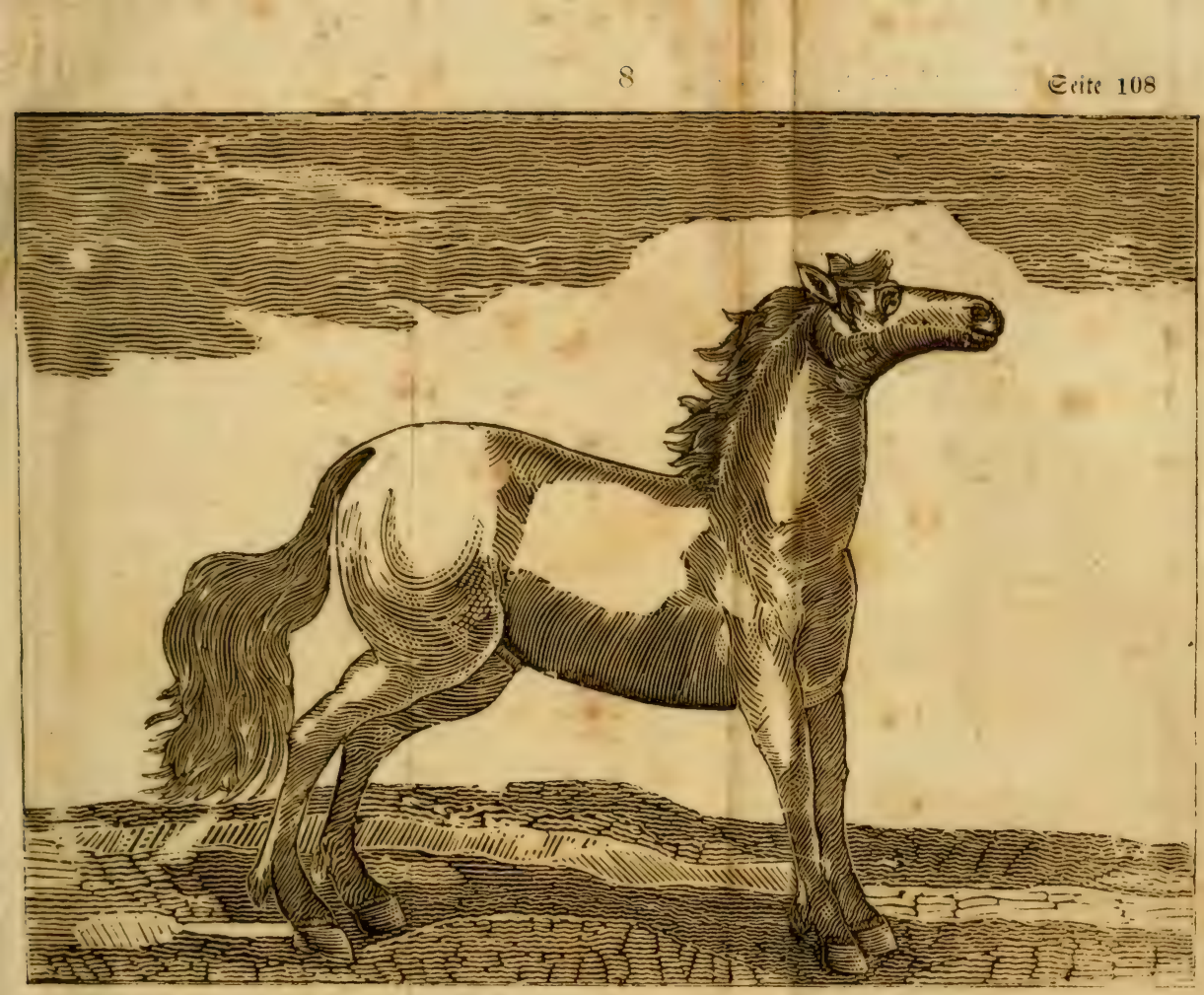


$$
\therefore
$$

$\therefore$

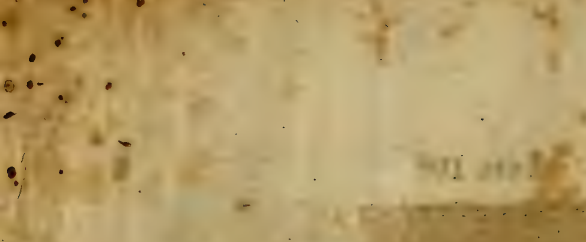

?.

$f=4$

4.

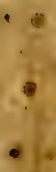

t

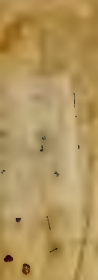

. $1=$

.

i.

$\because \quad:$
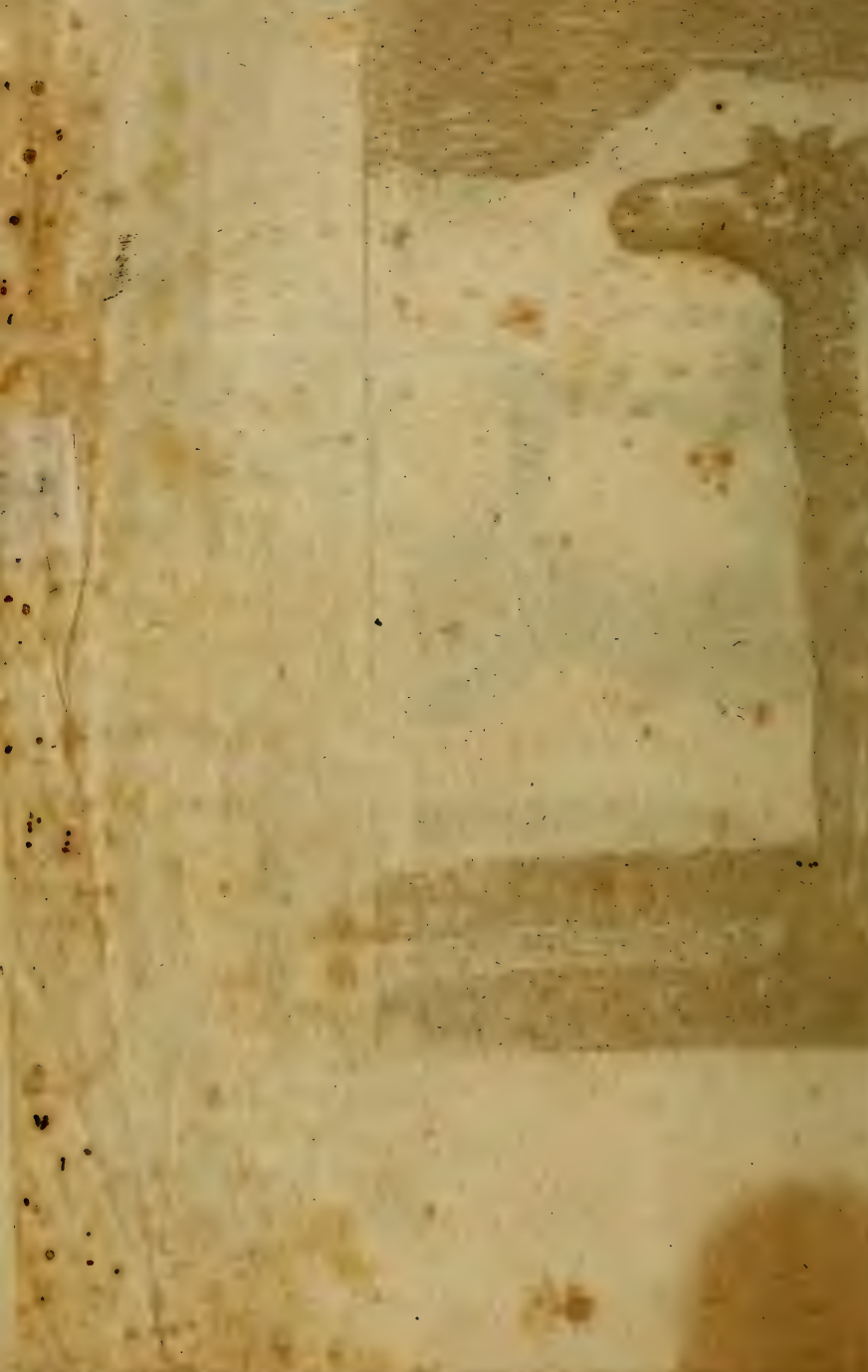

$+$
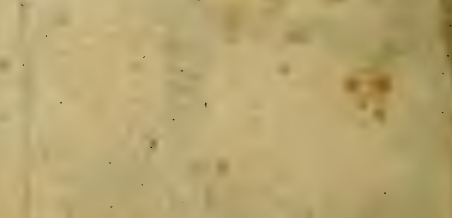

$+\quad-$

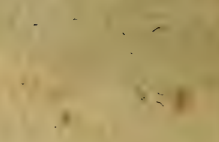




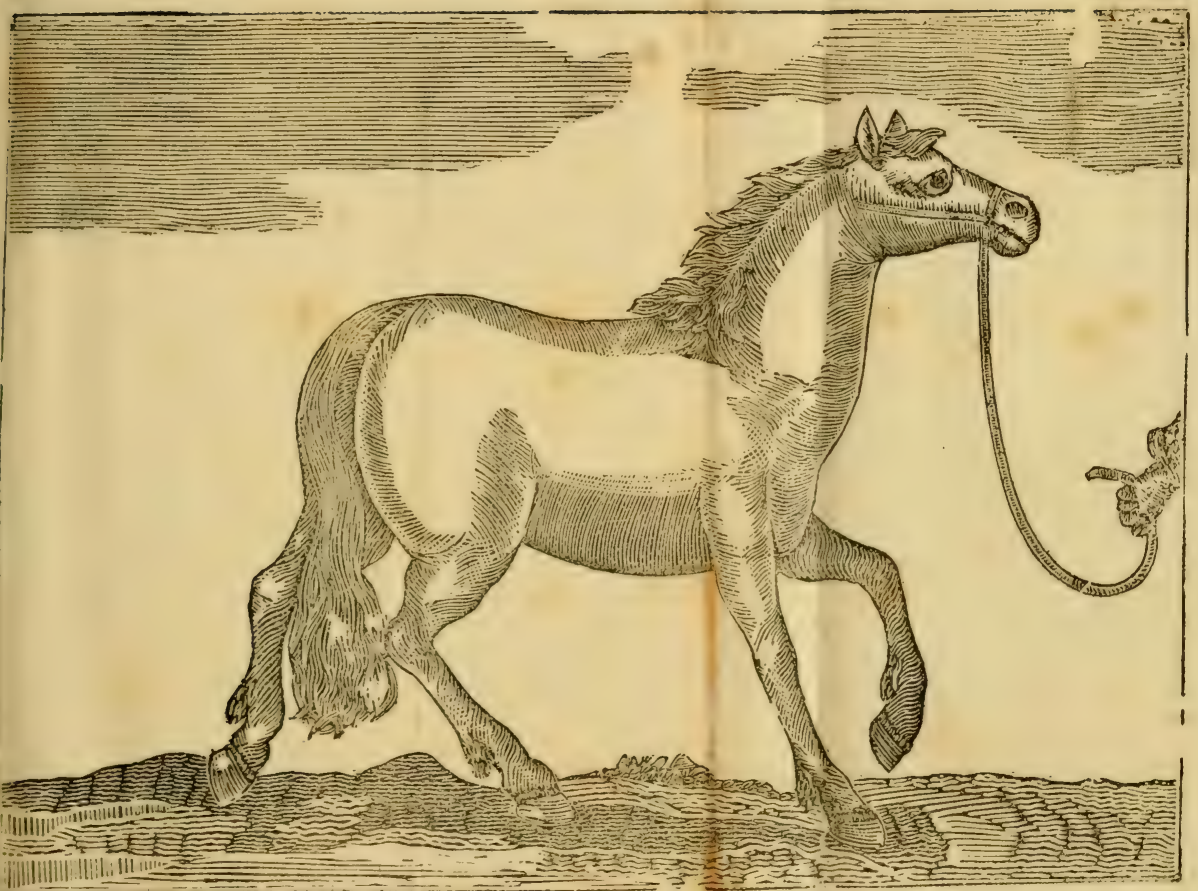




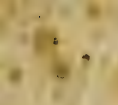

1

.

1

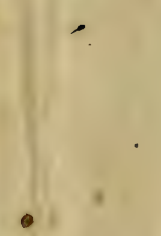

항
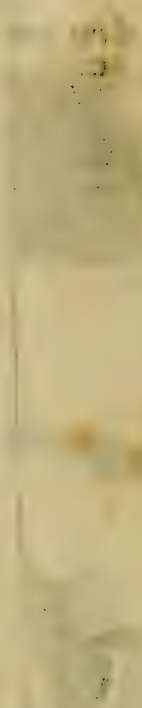

?

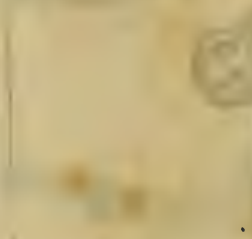

(1)
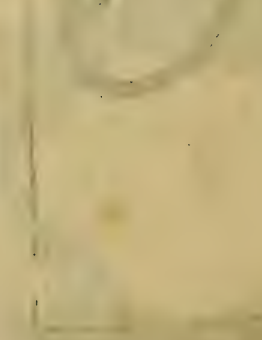

6

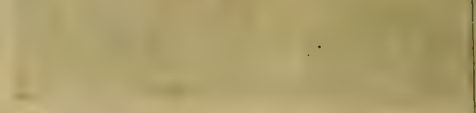




\section{Baumöl 8 \&oth,}

Şonigwafter 1 Maá,

ङalz 4 Ioth,

mifabe es untereinander uno gebraudbe eร..

Ein andereb.

Singeleraut,

MauerEraut,

RöblErautblätter, jeoes 1 Şanowol,

Şaffer 1 Maá̄,

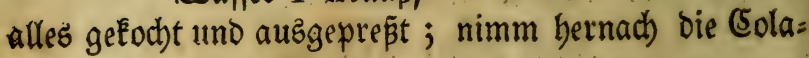
tur und thue barzu

\section{Eajifia 3 Ioth, \\ Seil=:Del, \\ Rauten $=\mathfrak{S}$ el, jeoes 4 Loth, \\ ๔alz 3 Loth,}

untereinander gemifht uno warm gebraudst.

Nadjoem Der Reib alfo gereinigt, to mus man ibm bie Feuchtigkeiten von bem ropf binmeg leiten. BSieb ihm Dafür in ben Muno cin bidés Reiffig vom Fei= genbaum, $\mathfrak{W a d h}$ holder= ober Rorbeerbaum, 25 seiben ober eine Sdjenjenne, mit Sconig bejd)miert, uno lapee es ba: ran făuen Den ganzen Tag, (außgenommen wenn es effen ober trinfen forl) bamit fie bie Bähne nicht aufein= ander fesenen, Denn wenn foldhes einmal geidjelyen, foifts aus mit bem \$fero. Man Eann Dem \$sfert audi) Ber=

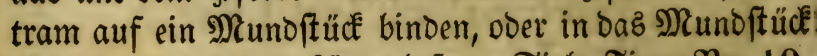

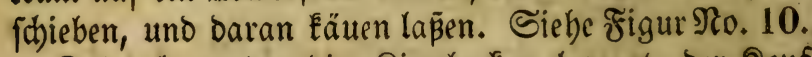

Daburd) werben bie Rinnbacken bemegt, Der నopf geteinigt und Die Şerftopfung dez Siebbeinz uno ber Rajelöcher eroffinet : oder man gieß̧e $\mathfrak{B}$ ein auf einen

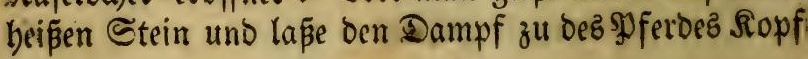




\section{. Corallen: פRos 2 Suintlein,} Wermutbroaffer $\frac{1}{4}$ Maā̄,

lape es über গacht zujammen fteben und fothütte es bem SPfero morgens frübe ein.

\section{(F) a noereb.}

Shlangen = Solver $\frac{1}{2}$ Roth,

Menftrum Sirginis bel muliers cin flect: dben,

Saftran 1 Sountlein,

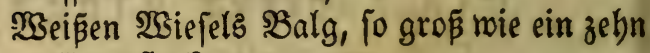
Eenteffüue,

Bibergeil $\frac{1}{2}$ loth,

Sein $\frac{3}{4}$ Maaß̃,

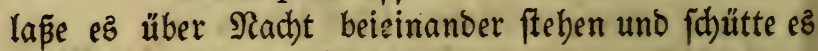
Dem Şferd auf einmal ein.

$$
\text { (5) } i \mathfrak{n} \text { - } \mathfrak{n} \text { deres. }
$$

Schlangen = Spulver $\frac{1}{2}$ loth,

Separ 2fntimonium 1 Suintlein,

Scorzonera 1 loth,

Menftrum Rulierz ein Fleçlein,

Saffran 1 Suintlein,

Wein $\frac{1}{2}$ Raaß̃,

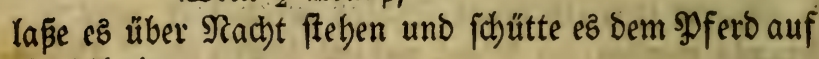
einmal ein.

Ein anderer Einguf.

Nimm Sorbeer 2 loth,

खुeipen SPfeffer 1 loth,

Şeinrautben 2 Scänbevoll,

alles untereinanber geftopen, mit 8 loth Baumöl in $\frac{1}{4}$ Maaß $\mathfrak{B}$ ein vermijđt und auf einmal eingegeben. 


\section{gfferbe=:Argenei Budh.}

Ein anderer Eingut.

Nimm $\mathfrak{W}$ Beintautben= Saamen 4 loth),

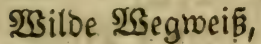

Seterfitien=Saamen, jedes 2 loth

fiümmel,

Enzian,

Salpeter,

Bibergeil,

Spopanac, jedes 1 loth,

alles untereinander geftopen, bavon bem spferbe täglid) 2 Löffelwoll in einen warmen $\mathfrak{B e i n}$ oder (Serftenmaf: fer eingegeben und gleich barauf 8 loth Saumöl, ba= mit ez ibm nid)t roieder auffteige.

Ein a noerer E ing $\mathfrak{b}$.

Nimm Bibergeil,

গ⿴囗i

soeterfitien= Saamen, jeder 1 loth,

Sonig 2 \&öffelvoll,

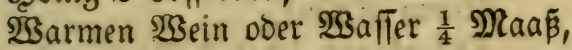

vermifat untereinander und oem spfero eingegoßen.

Man follte aud) ein jolches Pfero mit ermärmenoen Salben rohl reiben.

\section{Eine Salbe.}

Nimm Sibergeil,

Baumöl, jedes 3 loth,

Regennürmeröl 4 lotb,

Beinrautböl,

Eoröl, jedez 3 loth,

Unguenti Ugrippä $\frac{1}{4}$ SPfuno,

untereinander gemifht uno angerwendet. 
Eine andere Salbe.

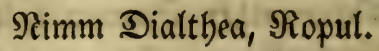

$\mathfrak{U n}$ guent. agrip. jebez $\frac{1}{4}$ ⿰ু丨 fund,

Eoröl, Terpentinöl,

Sobannizöl, jebes 6 loth,

Euphorbium 3 lotb,

mijche alles untereinanoer.

sin anoereb für Den Srampf an einem B́lieb.

Shanffraut, Stengel uno $\mathfrak{B u r z e l , ~ b a c f e ~ u n o ~}$ fiebe es in $\mathfrak{B a f f e r}$, binde es ihm warm auf bas . Stlied

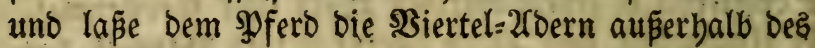
Riegelz johlagen.

\section{(E) i a ก}

SRache Baumöl mobl warm, tauche einen wollenen Eappen binein und binde es dem $\$$ fero mobl warm über

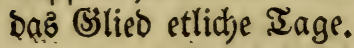

\section{[C: $\mathfrak{i}$ andere .}

Rimm Salbei,

Dillenéraut, jebez 3 Şändeboll,

Rotben Röbl 6 Şänbevoll,

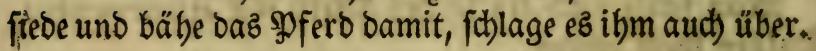

(sine andere Salbe.

Rimm $\mathfrak{t}$ nguent. agrippä. Martiaton.

Salbe von Sbifd, jebez $\frac{1}{4}$ S.fund,

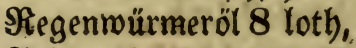

Fichtenöl 12 loth,

\&oröl 6 lotb),

Eoftenöl,

Sävenbaumöl, jebea 4 lotb)

alles untereinanoer gemiļwit. 
Ein anderes.

গimm $\mathfrak{W a d b} \frac{1}{2}$ Şfuno,

(Salbanum $\frac{1}{4}$ SPfund,

Ierpentin $\frac{1}{2}$ Pfund,

Bibergeil 8 loth,

Sciridumark 8 loth,

פfeffer 4 lotb,

Baumöl $1 \frac{1}{2}$ ş funo,

mad)e es untereinander über bem Feuer zu einer Salbe.

(F) i a n $\mathfrak{n}$ eres.

Timm Ierpentin 16 loth,

Spopanac 4 loth,

\&orber 12 loth,

Fiditenöl $\frac{1}{4}$ Ş funo,

mifche alles untereinander, fiede ez in $2 \mathbb{S a}$ fiter zu einer Salbe und jamiere daz গুferb am ganzen Reik bamit.

Eine anoere Salbe.

গimm Bibergeil,

Spopanac, Rorbeer,

Dürre Echmertelnurzel, jedes 8 lotb,

2fmmontacum, Salbanum,

Ieufelabredé,

(Sarpobalfamum, jedes 6 loth),

Euphorbium 4 lotb,

Spick $=$ Sel,

Sffeffer, jebes 2 loth,

Fud)sichmalz 2 loth,

Lorberiol,

Eamillenöl, jeoes 1 Ş)fino,

2ltes Baumöl 4 sुfuno, 
untereinander gemijht und eine Salbe baraut ge: madts.

Eine andere Salbe.

Rimm Sbif $=$ Salbe,

Salbe von 2rragonia,

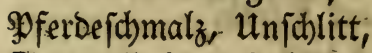

Storaxöl, jeoes 3 loth,

mifche es untereinander zu einer Salbe.

Ein a noeres.

গimm Fuchsöl 2 loth,

Euphorbium=:el,

פfeffer: Del, jedez 1 loth,

Tirpentin=sel 2 loth,

WBax-Sil 1 loth;

Scolder $=$ Del;

Eoften=\$el, jebes 2 loth),

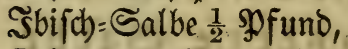

Sdyweinen= Sdymal $\frac{1}{4}$ SPfund,

mifobe alles untereinander zu einer Salbe; und menw: man baz \$ferb Damit gefthmiert bat, foll man alsbald folgendes soulver barauf frreuten :

Pulver żum 2uffitreuen.

Rimm פgolen 6 loth,

Senfiaamen,

Lorbeer, jeoes 4 loth,

Euphorbium 2 lotb),

untereinanoer gemifcht und ein \$oulver baraus gemadit. Wenen num ein \$fferd aljo gefd)miert morden iff, muś man es mit Tübjern wohl zubecten und an einen warmen Sort ftellen, Damit es fdhwif̧t, alsbann ben 
nach ber Runft zu einer Salbe.

Senn ber Srampf aber auf ein (Sefdhrür exfolget, fo mús man ermeidbende, ermärmende und jertbeilende Sacben auflegen.

Rommt er aber vom Fallen, Schlagen, Stopen oder verwunden, rovon ifm bie Spann=2roern ffarrigt ge $=$ morven, fo muß man ben Sdbmerz ftillen uno ber গler=

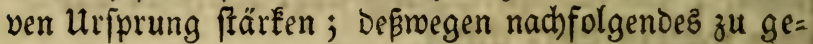
brauchen : Spurgire erfftich bas \$pfero bernach

গimm Dillöl, Eamillenöl, jebes 6 loth,

Rein = Sel ein SBiertel spfuno,

fhmiere bas spferd nobl an Dem ichadhaften Sort ba: mit barauf lege ibm narme Sădfden über, in melchen gefottene (Serfte, Samillen, Bockshorn und \&einnalfer gefotten worden ift.

WBenn aber ber Srampf auf einen giftigen Stid) ober $\mathfrak{B} i \tilde{\beta}$ erfolget, fo foll man ibm Darauf legen $\Theta_{c a}=$ biofen, mit (Fierbotter gebraten, fo wie aud) Item, Enzian, Salbei, Lorbeer, Diptam, İberiac.

Şat aber bas Spfero viel Bläften in ben Єdbenteln, fo iff biefes bie befte uno nächfte Eur, Daß̧ man ibm bie Damit bebafte (Sslieder mit Den Shänden und rarmen Iulchern mohl reibe, ober bäbe ibm bie Sdbentel oft mit nachfolgenoem:

$$
\begin{aligned}
& \text { Nimm Bacbmünz, (Samillen, } \\
& \text { Eorbeer= Blätter, } \\
& \text { Rauten, Galbei, }
\end{aligned}
$$

fiede es roobl untereinander und bäbe ifm die Sd)enfet bamit.

Wुenn Der אrampf aus ber unmäffigen 2(usleerung 
berfommt, fo ift es gemeiniglich töotlid), jebod) nimmt man bann befeudstende Mittel vor bie Scand: 2013 man ftellet bas \$fferb in Commers = 3eiten in einen ftillen, feud)ten und etwaŝ füblen Sort, Dagegen im Minteran cinen mittelmäß̈igen, uno läpt ę fid) fein allgemad) be= wegen; giebt ifm afle Tage 1 ober 2 SInftiete, Mlor= gens frübe nüct)tern.

Nimm Srübe von Scammelšfopf fo viel bier:

zu genug ift,

Beil $=$ Del 6 loth,

Den Sdleim vom Flöbefraut, 8 lotb,

Salz 2 Loth,

vermijche es zu einem SInftier.

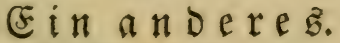

Nimm $\frac{1}{2}$ Maaß marme Milch,

8 (sierdotter,

Seil-Sol 6 loth,

Salz, 2 loth,

untereinander gemifd)t.

Den $\mathfrak{e i b}$ foll man ifm täglid) mit Milch uno $\mathfrak{B e i l =}$ Sel wohl fidmieten, oder ein Sुflafter von \&einjaamen, Boctzhorn uno Sbijhnurzel in $\mathfrak{B a}$ aller gejotten, mit (Serfte uno SBeil=Sel vermifdt, überid)lagen auf ben

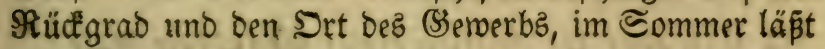
man fie aud idmieren, wie obengemeloet ; uno um ben Leib inmendig zu befeuchten, fdütte ibm alle Morgen

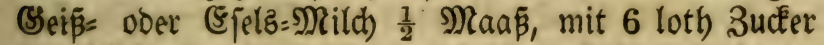

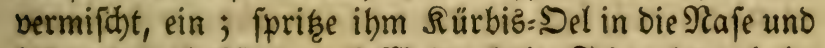
lase ez aut) käuen auf 23 eidenbolz, Feigenbaumbolz ooer eine Sdhjenfenne, mit Sconig beftridhen. 
Seine Speife fei frifches (sraz, Şeu, Scaber, Spelz,

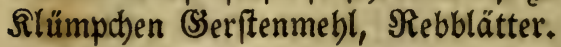

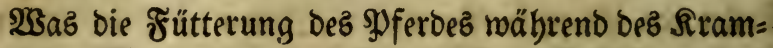
pfes betrifft, weldber aus übermäffitger Erfüllung ber= Fommt, fo follen ibre Speifen einer marmen Somplexion fein, alz eingemeid)te ober gebrochene rotbe Sichern, Erven, zmeigebadken Brod, SSerfte, Lorbeer, gefottene

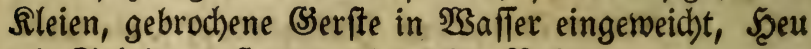
mit Salniter beftreuet, aber keine Bobnen.

Der Irane foll laulidyt fein, sin $\mathfrak{B a}$ affer, worin Şer= ftenmehl, Şonig, నichern uno şfeffer gefotten morben.

So foll man auch ibm, um bie Sinnóadéen'zu bewe= gen oft zu freflen geben.

\section{Daz 17te Eapitel.}

\section{$\mathfrak{B} \cup \mathfrak{n}$ De m Feifel.}

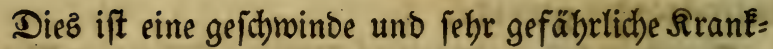
beit, fommt gemeiniglich mit ber Darmgicht, bismeilen audb ofne. Darmgidbt an, uno no beren innerbalb 12 Stunden nicht $\Re$ Rath geidjaft mirb, ift biefelbe tötlich Doer jelgr former zu curiren.

Eg fino aber die 3eichen Diefer Srantheit diefe:

Das গুferb fällt ganz matt und fraftlos bahin, legt Den Ropf auf bie Errbe, ftredt alle Siere von fich, fre: het wieder auf, legt fich bann mieber nieber und blähet fidh, als wenn es bie 23 ürmer bisen ober fonft (S) rimmen im \&eib bätte; die \$̧ren uno bas (sefdyröt fino falt 


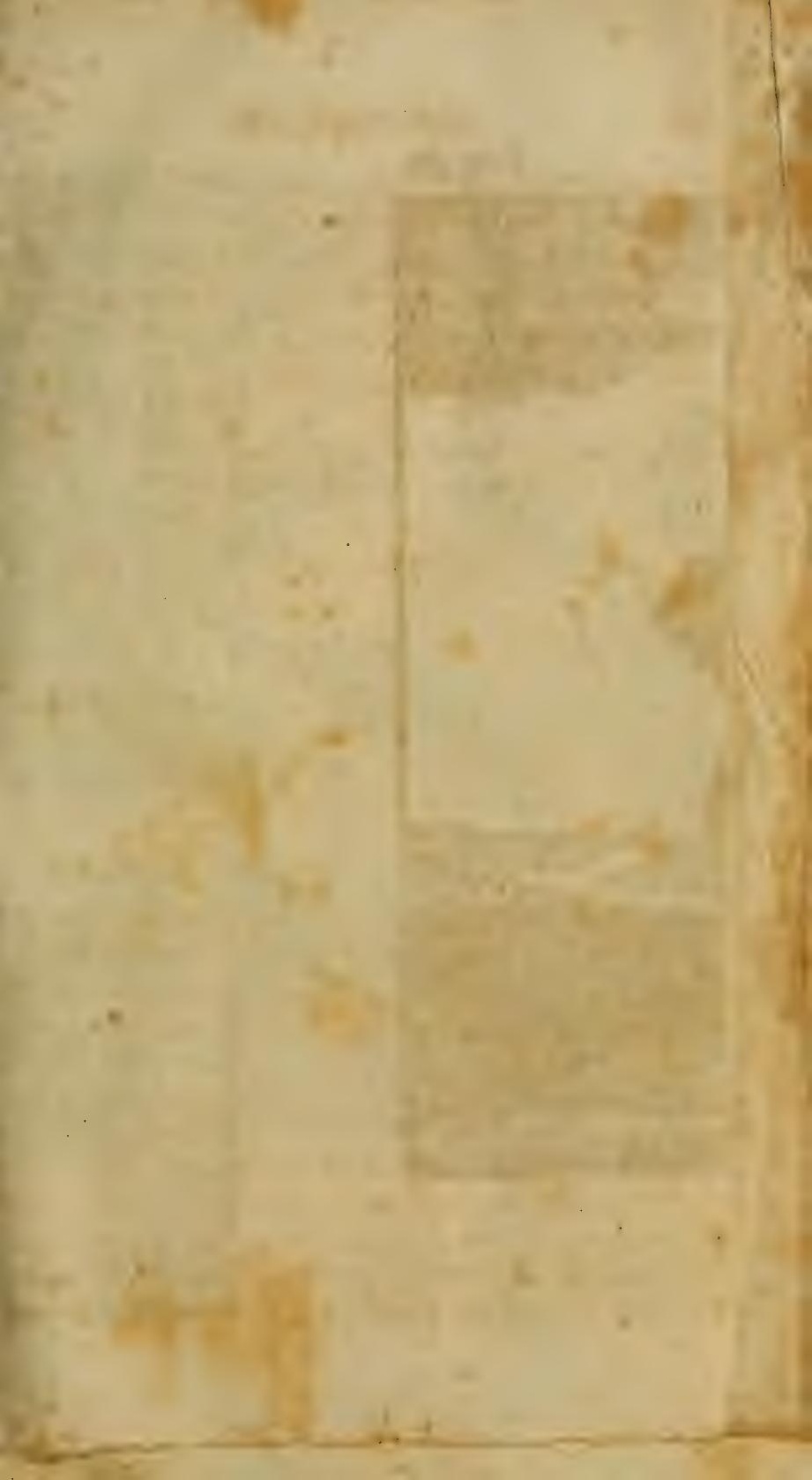




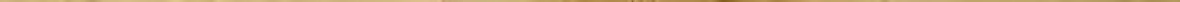




\section{Pferbe=2(rzentei Butâ).}

\section{Ein anderes.}

Rann Eann ifm folgenden (singur, wetth es nad) Der Deffnung nitht nad)lapen follte, geben :

Mnrrben 1 Suintlein,

Iragaranth' '2 Suintlein,

Saffran $\frac{1}{2}$ Suintlein,

Beiraudh, Ieufelzored", jeotछ 1 Suintlein. Sconig 6 Röfrelvoll;

Şolderblütbraffer 4 loth,

W̧ein eine halbe Maá̃,

alles untereinander geftopen und gemijat.

(E) anderez

Separ 2intimonium 3 suintlein,

Bein oder Erorauchmafter $\frac{1}{4}$ Maaß̄,

mijhe es untereinander und foütte es auf einmal ein.

E $\mathfrak{i}$ a $\mathfrak{n}$ Dereb $\mathfrak{X}$.

Mithribat 1 loth,

Iberiac 2 suintlein,

Saftran 1 Suinltein,

Branntwein 8 lotb,

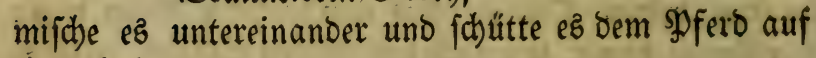
einmal pin.

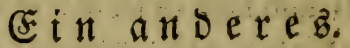

Deffne ifm bie Srofpel=21Der in ber Siufe, auf bei= ben Seiten, bie mittlere 3ung=2roer, bie Sd)lemmader an ber Spife ber 3unge, ober bie 2coer auf ber 3unge, und reibe ihm bie 3unge nohl mit geftopenem Snob= lauch in Efitig geweicht.

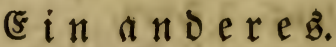

Shütte ifm Salitwafier und Sceringslack ins Sobr, und ein $\frac{1}{4}$ Maaß in ben Radben: 


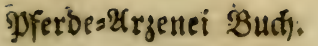

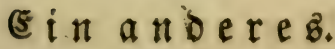

Eabiebe inm (3)undelreben mit ๔alz vermijat in bie Najelöd)er:

E in a ndereb.

Binde inm গ্Sermuth auf bas (sebiß̄.

\section{(5in anderez.}

Sd) jenzungennurzel,

(S)ute Seinridynurzel, jebes $\frac{1}{2}$ loth;

(S)undelreben 1 loth,

Salz $\frac{1}{2}$ Scanovoll,

fdiebe es ilym in ben Rachen.

(5in a noereb $\mathfrak{H}$.

Mithrioat 2 suintlein,

Sibergeil 1 Suintlein,

Saffran $\frac{1}{2}$ Suintlein,

Ein Stücthen Siefet=Balg, fo grop als ein 10 Eentifüuck, Menjodentoth 10 loth,

SBilde Rürbismurzel 1 loth,

\section{Wein 1 Maāi,}

intereinanoer gemijdt und auf einmal eingegeben.

(5in andereb.

şrepe ben ๔aft von frifhen (s)undelreben, thue ibn dem şferd in bie গajelödher, halte biejelbe ein menig zu to miro bas Sুferb anfangen zu braußen, uno ber Fei= fel vergeben.

Ein an

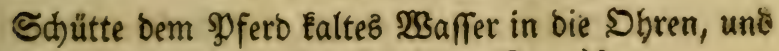
fiteche ihm ben britten Staffel (ober Sern.)' 


\section{Ein anderes.}

Nebme ein fpisig (Eichen = Spolz, ftect)e ifm sureer burdh bie Najenfrufpel, ffed)e ihm ben britten Staffel,

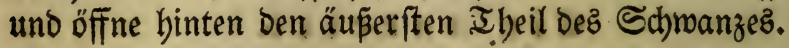

(E)

(Srabe Meerrettig im zrübling oder Sherbft, pül= vere benfelben, und wenn ein Pfero den Feifel befommt, fo fohultte ibm 1 loth, mit $\mathfrak{B}_{\text {Bein }}=\mathbb{E}$ fifig ein.

\section{Ein andereb.}

(Sieb ifm, wenn bu nidtets anders baben Eannft, ein menig Sconig zu verfchlingen.

E in a noereb $\mathfrak{T S}$.

Farrenmarzel, weldbe im 2 equinoctio obne Eijen gegraben worden, Sundelreben, jedes 1 loth, Ieufelsoreck 2 Suintlein, Snoblauch 3 Sében, ŞGeiraud) 1 Suintlein, Ein $\frac{I}{2}$ Maás. Effig,

untereinander zerftopen und Dem $\$$ ferd eingego Dem man zu norber bie Syrren, Saumen, 3unge uno Sd)wanz mit einer Fliethen geöffinet bat.

\section{Ein a noereb.}

Saft von Sunbelreben $\frac{1}{4}$ Maá,

Menichenfoth 1 5̧anduoll,

Bibergeil $\frac{1}{2}$ loth,

Saffran $\frac{1}{2}$ Suintlein,

Menftruum Mrulieris, ein Flectiden fo groß wie cin balber Thaler, 
PFerbes2(rgenei Budf).

Saffran $\frac{1}{2}$ Suintlein,

Ieufelsorect $\frac{1}{2}$ loth,

Wein $\frac{1}{4}$ Maa $\tilde{\beta}$,

untereinander vermifothet und eingegeben.

Man follte audd ben Freifel in allem, wie bie Darm= (Gid)t curiren.

Ein andereb.

Damit bem झुferb bie Freifel nidbt anftoße, fo gieb ibm bes Sabres etlichemal geftopenen Schwefel unter bas శ̌utter.

D i e $\mathfrak{B} \mathfrak{e} \mathfrak{r} \mathfrak{p}$ fle $\mathfrak{g} \mathfrak{u} \mathfrak{n} \mathfrak{g}$.

1. Der Stall foll warm uno trodéen fein.

2. Soll man bem $\$$ Pferb eine gute Streu madjen.

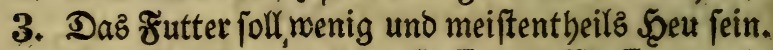

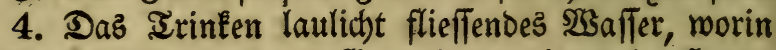

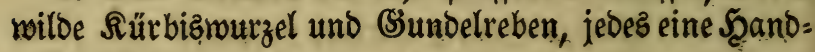
voll, gejotten worben.

\section{Daz 18te Capitel.}

\section{$\mathfrak{B} \circ \mathfrak{n}$ D e $\mathfrak{A} \mathfrak{A} \mathfrak{g} \in \mathfrak{n}$.}

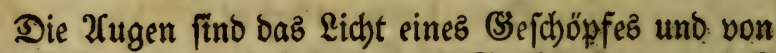
Der (Seftalt runo, befteheno in 3 Feuchtigkeiten uno 7

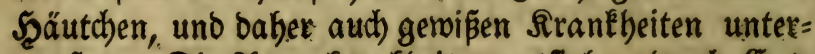
worfen. Die 2ugenfrankbeiten entfteben burd) Ent=

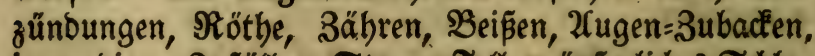
inmendigen Bufällen, Staren=Feillen, äuperliches Sdbla: gen, Zrallen, Stopen, Sted)en, $u_{*}$. . $w_{8}$ 
Die imerliden urfad)en find, flüffige uno feudte Somplexion, Ueberlaoung mit Sseblüt, gallichte Sdärfe Dez (seblüts.

(eurierlide Utrad)en fino Raud), Staub, Sel, grope

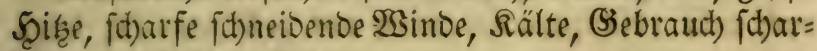
fer aufriedsenter Speifen.

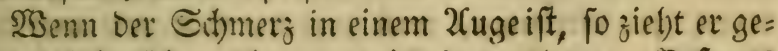
meiniglich fith auth getne in Das andere. Sefteres 2Bieberfommen Der 2lugenfd)merzen pflegt enolid) Fle= dfen ober gar Blinobeit mit fit) zu bringen.

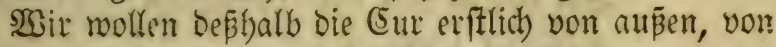
Den Gtaren-Fellen anfangen, Deren giebt es oreicrlei, Det meipe, graue uno fdrwarze, weldher lef̧tere unbeil= bar ift.

(5s entifebet aber Der Star entweder von einer jutbti=. len, aud) bisweilen einer biď́en uno zäben Ealten Freuch= tigkeit, weld)e von bem (Siehirn burd) bie (Sefid)t3nerven zu Den 2ugen leerab fteiget, oder menn bas İbier auf Den Ropf oder bie 2fugen geichlagen oder geftrosen wiro, Doer Darauf fällt, entweder in Dem 2rugapfel ober zwi= fhen Den Şäutti)en Rbagoide uno bem tranbenformi= gen, uno bann der (5ryftallinen Feuchtigkeit; wemn el zu feiner Sollfommenbeit gelangt, fo gleicht or einem fubtilen Spinnengenebe uno benimmt Dem 2fuge fein. (Siefid)t.

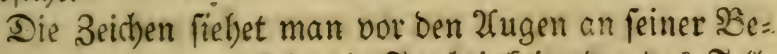
wegung, wenn nemlith bie Feuchtigkeit ober Das Fell, Dab fich in Dem 2(ugapfel zwifchen Dem Şäutchen $\Re$ ha= goide uno Der (5ruftallinen Foudbtigkeit feben. läp̄t, weïlid)t, nad) Dem Şimmel=Blauen neigt, 2tichenfarbe oder gelb ift, fonft befl uno flar uno ourd)fdeineno, uno menn man es mit ben. Şänden angreift balo ba kalo: 
Doxtbin meidhet; wo foldbe Seichen fino, ba ift nodj et:= maz zu boffen mofern bie bajelbit geftandene Feuchtig= Eeit nidgt gar bick, idbrouligt unb hart ift.

Biejen Staren nun, wenn er nod) neu und fubtil, nod) nicht zujammen geronmen uno geftanden iff, bazu auch ben $\mathfrak{2}$ pfel mut ein wenig trüb uno nicht ganz neiß macht, zu vertreiben, mus man bie (sur, mie aud) bie Szerpflegung, als auch Speife und Irank auf, folgende 23 eife wobl in 2(d)t nehmen.

Bor allem Den seib clyftieren.

Lein $=$ Del $\frac{1}{2}$ SPfund,

Sonig 4 lotb,

Soloquinten= Mark,

\&erchenfdinamm, jebes 1 \&oth,

Scammonium 1 Suintlein,

Extract. Capcarinde 4 \&oth,

Salz 1 Şandooll,

Flieffendez $\mathfrak{B a f f e r , ~ f o ~ v i e l ~ a l s ~ n o ̈ t h i g ~ i f f , ~}$

fiebe es untereinander, alsbann nebme von ber abgefeif)=. ten Srübe 1 Raaß̃ uno gebrauble es warm.

$\mathfrak{U}$ m bie Freudtigkeiten aber zum 2 tubfübren gejdickt zu madben, gebe ibm zebn Iage nacheinander nichtz an: bets zu freffen alz $\mathfrak{B}$ seizentleien, mit Bockzhornfaamen, Eerchenichwamm uno Sconig vermifht, ober gieb ifym etlid)e Sage nacheinander folgenden Eingué ;

\&orbeer, Enzian,

Runde SIfterlucey,

Qerdbenid)roainm,

Iutbith, jedes 1 Ioth,

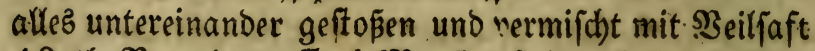
4 Loth, Betonienmafler $\frac{1}{2}$ Maaß auf einmal eingegonen. 
Ei a a nereb.

Bengelwurzel 3 Ioth,

Sappelnutzel,

Saumól jebes 8 Ioth,

3ucter,

$\Re$ ojen=šonig, jeoes $\frac{1}{4} \mathfrak{N}$ fund,

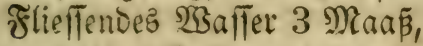

Die 2rzeneien wohl zerftopen, miteinanoer gejotten, in 2

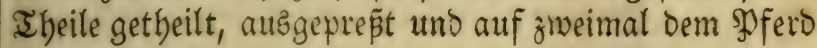
eingegopen.

(E) in anderez

Salapnurzel 1 Loth,

Scammonium $\frac{1}{2}$ Loth,

(S) ummi guttä, Fenchel,

2fniz, jeoes 1 S.uintlein,

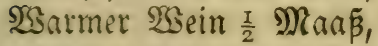

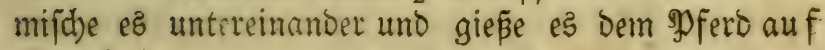
einmal ein.

(E) in a N Dereb.

Bo ofishornfaamen 6 Loth,

Ierpetin, Baumöl,

Şonig, jeoes 2 Loth,

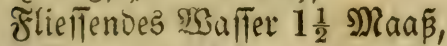

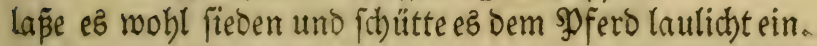

E in a noeres.

Ulten Spect 4 פfumo,

Scammonium,

(5oloquinten= Mark,

झुulvis bierä picr.

Serdjenfidrwamm jebes $1 \frac{1}{2}$ Loth,

alles mohl untereinander geftopen. 
Ierpentin, Sconig, jebes 3 Loth,

Fencheliaft 8 \&otb,

(Serftenmebl 1 ş fund,

alfez untereinander żu einem Ieig vermifchet, uno $\Omega$ Iü= cheldben fo gros als ein Şühnerei Daraus gemacht, als über ben andern Tag einem \$FerD 2 derjelben eingeben, 3 Stunbe bernach herum geheftet fitehen läen und auf Das (Şebiê folgenbez in ein Säutlein gebunden :

Bertram,

Sdjöltraut, Rlapperrofen, jebes $\frac{1}{2}$ \&oth, Shonig 2 \&oth,

viel beser aber ift, wenn man foldhes in ein Mundftüet

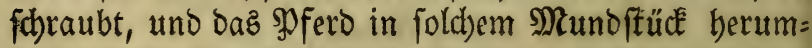
beftet, Denn man Eann foldye 2arzeneien beraus uno bin= ein thun, und burch bie runbe \&ödher empfindet bas sूfero Den (sffect uno arbeitet ftetz nit bem Maul uno ber 3unge. Sithe Figur $\mathfrak{R}_{0}, 10$.

2Uüerbalb ben 2lugen aber foll man foldhe Mittel gebraudhen, weldhe zeitigen und zertheilen uno bie Feuch = tigkeiten abtreiben, aber mit ben ichwädbern anfangen, weldbe nidbt fo gewaltig angreifen:

Sconig, altę Baumöl, Fendheliaft, jebez 1 Iotb,

untereinander gemifht, zu einer Salbe gemad)t uno in die 2fugen geftrichen.

\section{E in a noeres. \\ Fendbeliaft 12 gotb, \\ Sconig 4 loth,}

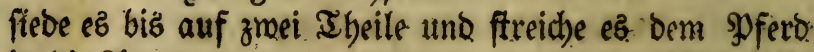
in bie Xugen. 


\section{Ein $\mathfrak{a}$ a}

Ealcinirte Sdjnectenbäujer ober Mrujchet 2 Loth,

(Salif̧enftein 2 suintlein, Sngwer 1 suintlein,

alles untereinander ganz zart gepülvert uno bem গুferb etwas bavon täglit) in bie 2 (ugen geblajen, uno bann Slettentourzel im Futter zu freffen geben.

(E) $\mathfrak{n}$ ก

Sngmer 1 Ioth,

Maibutter,

Sconig, jeocz po viel als nöthig ift,

mad)e eime Salbe barauz uno ftreiche es in bie 2 fugen.

(E) $\mathfrak{i} \mathfrak{a} \mathfrak{n} \mathfrak{D} \mathfrak{e} \in \mathfrak{B}$.

(Ealcinirt \$ittriol, biß er roth) geworben ein Eotb,

SBeinrauten geoörtrt, $\frac{1}{2} \mathfrak{L}$ oth,

untereinander jubtil gepülpert und in bie Xugen ge= blajen.

\section{Ein andereb.}

Ssundelrebenfaft,

Eauche non Sdjölkrautajche, jeoes gleidjoiel, mifche ę untereinander uno ftreiche es in bie 2 (ugen.

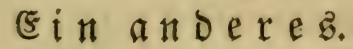

Sd)ölfrautjaft 10 Ioth,

Sconig 6 Ioth,

untereinander gemijht, über einem Roblfeuer zu einer Șalbe gejotten uno in bie 2fugen gethan, 
Ein andereb.

Bobre ben Rern aus frifchem 2 fpenbolz, und fülle Den Sit mit $\mathrm{Sal}_{3}$, (sid)lage unten und oben einen SBlock bavor und vertrenne das 2 fpenbolz, fo mirft ou bas Salz ganz grau calcinitt finden, biez blaje dem spfero in bie 2fugen.

Ein andereb.

Die (Salle von einem Rebhubn odar Şahnen, trö= pfele bem

Ein and $\mathfrak{i} \mathfrak{r} \mathfrak{e}$.

Bermifche borbejchriebene Salle mit bem @aft von Rauten, Frend)el, Sconig, 2fugentroft, Shölfraut uno Eifentraut, eines fo viel als bas andere uno mache es zu einer Salbe.

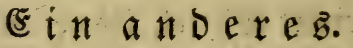

Rothe Rmeifen, fammt den Biern, thue fte nobl vermad)t in ein (Slaz, und thue bas (Slaz in einen Teig

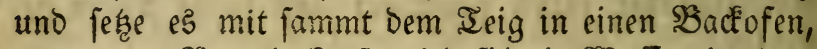
menn man $\mathfrak{B}$ roo backt, fo wiro fid) ein $\mathfrak{W}$ affer in bem (Slaz erzeugen, diez tröpfele Dem \$ferd in Die 2rugen.

E $i \mathfrak{n} \mathfrak{a} \mathfrak{n} \in \mathfrak{e} \in \mathfrak{b}$.

2utggepresten Saft von fdwwarzen 2Smeifen 2 Ibeile,

Sranntwein 1 I beil,

milche es untereinander und ftreidhe es in bie 2rugen.

Ei in a n Dereb.

Nebme von einem frifden (5i Den Dotter zufammt

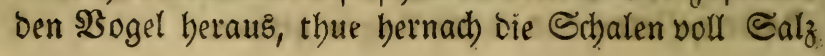


134.

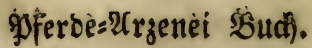

\section{E $\mathfrak{i} \mathfrak{n} \mathfrak{a} \mathfrak{n} D$ er $\mathfrak{e}$.}

Calcinirte \$̧ sulver von Shajenbeinlein, entweder allein ober mit bellglänzendem Salz vermifcht, und blaje es

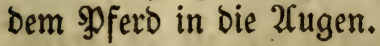

\section{E $\mathfrak{i} \mathfrak{n} \mathfrak{a} \mathfrak{n} \mathfrak{D} \in \mathfrak{r} \in \mathfrak{s}$.}

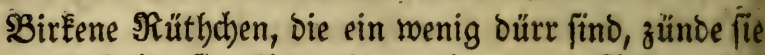
an und balte fie über einen zinnernen Teller ober Sd)üffel, aber aufredbt, bas ber Srand am Sinn anfte= be, fo giebt es ein Sel, mit bempelben fdymiere bas rell.

(sieridaten,

Sdynedfenbäualein, jebes 8 Ioth, calcinirs thue bazu meißen Scübnermift, 2 \&oth, Sngmer 1 Loth,

milche es untereinanoer zu einem zarten \$ुulver.

(E) $\mathfrak{i} \mathfrak{a} \mathfrak{n} b \mathfrak{e} \mathfrak{e} \mathfrak{B}$ IIG.

Schollerautjaft 4 Ioth,

Sal 2rrmoniacum 1 Duintlein,

Daz $23 a f f e r$ von gebrannten eslftern (5̧e:

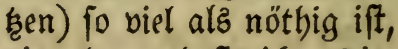

mifche es untereinander und frteid)e ez in bie 2 (ugen.

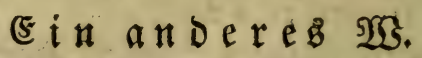

Das \$ुulver von calcinitten §räben,

Ealcinirten $\mathfrak{B a d b t e l n}$,

Ealcinirten Elfftern, jebes 2 Ioth,

Meiftermurzel, 2 \&oth.

mifate ez untereinander zu einem zarten \$ुulver und blaje es bem গুpert in bie 2ugen.

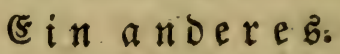

(Sropée Rlettenmurzel, ober jobmarze Rieprnurzet

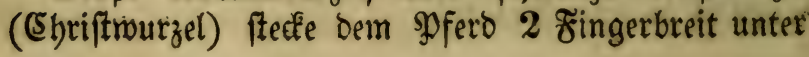


mifche es untereinander uno blafe oem \$fferb bavon in bie 2tugen.

(5 in a n Deres.

Das $\mathfrak{W a}$ afler vck Rettig diffillirt, Fenchel, Meifternurzel,

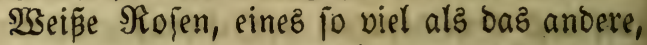
mijche es untercinander und ftreiche es Dem গुferd in bie Uugen.

Mit Diefen Stüden fann man ben @tarn, wenn ex nod) neu und von auff́teigenden Dämpfen entiprungen ift, gar mobl vertreiben.

Sun wollen wir zu ber Sur bes andern Staarz, welcher eingewurzelt und alt geworben iff, fchreiten, mo nemlich Der 2ugapfel ganz geflecf́t uno die roäflerigte Feuchtigkeit gleidham erfroren ift. Soldhe spferbe foll man 2 nfangs roobl uno oft purgiren, nad)ber bie slut= 2 doern an ben 2Cugen uno binter ben Shren öfnen.SBSenn nun Der Staar zeitig uno bu benfelben ftechen willft, fo la Nacht nichts zu freffen geben, den folgenden Norgen aber lä̈ Daz \$ूferb werfen, entmeder auf linde Streu ober trodfenen Mift, Damit es im Fallen feinen Gdha= ben befommen möge, wohl binden, damit ez fid) felbft uno andern Eeinen Schaben tlun fönne, auch Dem $\mathfrak{g}$ fer ben Scals uno Sopf fo zu red)t legen, bamit man ifm olne alle Şinderniß̄e zu Den 2Cugen fommen fönne.-

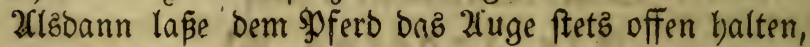

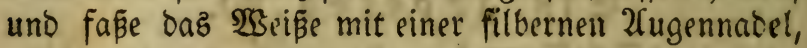
welde nicht fehr fpisig ift uno gieb nohl acht daß bu nid)t ftatt bes hornförmigen SDäutleinz, tas Trauben= jormige antreffeft, uno oas 21 ug alfo veriegeft, zmei 
গferbe=:2trzenei $\mathfrak{B u d}$.

Aruipel genannt, bedienen, weldbes aber befto bejer iff, wenn ę. in ber Stunde, wo ber Neumono eintritt, ge=

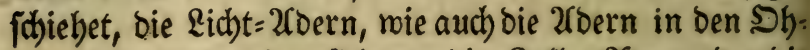
ren und binter Den Sheen, bie Soller=210er, ober bie 2roer 6 Fingerbreit unter ben 2(ugen, mit : Genoen (sijen brennen. Nach biefem Eann man nach)= folgende Salbe braudben.

\section{IS.}

2fichenjd)malz 1 loth,

Şadtêlifhmalz 2 Suintlein.

Sel von ber 2falruppen=Reber 1 Suintlein.

Sdbölf́rautialz 2 Scrupel,

Rojenfalz 1 Ecrupel,

Fendelifalz 2 Ecrupel,

bies alles mifhe untereinander und jobmiere bas refl Morgens und 2Cbends Damit.

\section{ほin $\mathfrak{a} \mathfrak{n} D \in \mathfrak{E} \in \mathfrak{B} \mathfrak{W}$.}

Xgtftein 1 lotb,

Rotbe Eorallen $\frac{1}{2}$ loth,

sperlenmutter, 2Cloez,

Ealcinirte Edbmalben,

Bleimeí,

Eierfhalen, jebez 1 Quintlein,

Salmiac 2 Scrupel,

allez zufammen gepülbert uno gemifht, uno bem $\$$ foero Norgenz uno Xbends eingeblajen.

(E) $\mathfrak{i} \mathfrak{n} \mathfrak{a} \mathfrak{n} \mathfrak{B} \in \mathfrak{r} \mathfrak{e} \mathfrak{B} \mathfrak{W}$.

\$ुerlenmutter 2 \$uintlein,

Iutia präparirt, Bleimei $\beta_{\text {, }}$

श्रichtz, jebeb $\frac{1}{2}$ Squintlein 


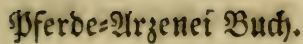

Ungerifden $\mathfrak{B i t r i o l} 1 \frac{1}{2}$ Suintlein,

Buctêt 2 Suintlein,

diez allez untereinander gemijott uno gepülvert, MRor= gens und 2lbenos tem \$ुfero in Das 2luge geblajen.

\section{(E)}

Sngmer, Scajetwurzel,

Bimfenftein, jebes $\frac{1}{2}$ loth,

(Saliz̧enftein 1 souintlein,

Ratten=Mebl, fo in Rorn=2(edern mad) jen,

1 loth.

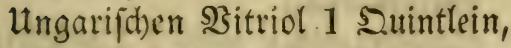

alles untereinander gepülvert, uno Morgens uno 2Cbenoz Dem $\$$ fero eingeblafen.

Ein anderes $\mathfrak{T S}$.

Reigerjomalz 1 Suintlein,

(säñefchmalz,

Şa enfdhmalz,

2(ji)enfchmaly, jebes 2 Suintlein, Shajen= Sall, Del von Watruppen=Leber, Ealz von Fenchel, jeoes 1 Suintlein,

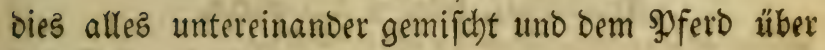
bą Fell geftrichen.

(Ein anderes গIS.

Falken= $\Re_{0}$ th,

(Sänie= Rotb, jebes $\frac{1}{2}$ lotb,

Selben Senft faft,

Weinrautenfaft, jeoes $\frac{1}{4}$ Suintlein,

Sd)ollerautjaft 1 Suintlein,

miphe e's untereinanber zu einer Salbe. 


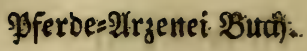

(5in andereb.

(eierjaten 1 loth,

Ealcinirte Sdymalben,

Wegmartenwurzel,

Tugentroft,

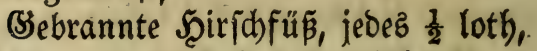

untereinander zu einem Spulver vermijatt.

(F) $\mathfrak{i} \mathfrak{a} \mathfrak{n} \mathfrak{D} \in \mathfrak{r} \mathfrak{e} \mathfrak{B}$.

Rornratten $=$ Mebl,

(sibifchjaamen, jebes 2 loth,

Wegruartjalz,

Sdböl'krautialz, jeose 1 suintlein,

Dies aflez untereisander gemijat uno mit Şonig zu. Salz gemadht.

Ein $\mathfrak{a} \mathfrak{n}$ bereb $\mathfrak{B}$.

Roth Schnecten=SDel,

Xalruppen=\$lel, jedes 1 suintlein,

Xfiden fammalz,

Waachtelichmalz, jebes 2 suintlein,

Sdbölkrautjalz,

Nisegwart $a a_{z}$,

Fendbelfalz, jebez. $\frac{1}{2}$ suintlein,

mijche es untereimander zu einer Salbe.

$\mathfrak{A} \mathfrak{u} \mathfrak{g} \mathfrak{n}=\mathfrak{W} \mathfrak{a}$ f f e $\mathfrak{r}$ : $B$.

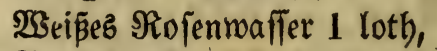

Fend)elnaffer $\frac{1}{2}$ loth

W̉eí̄ez Rilienmaffer 1 lotb,

Schwarzez Rirfdbenblüthwaffer 1 loth,

Fendbelfalz 2 Scrupel,

Ungarifchen Sitriol 1 Suintlein,

alles untereinander gemifch)t. 


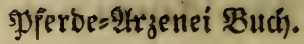

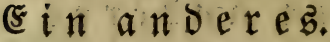

Mefle bem Pferd 2 3lwerchfinger unter ben 2 ugen berab, Dajelbft findeft ou eine 2Coer, fithneide fie entzroi

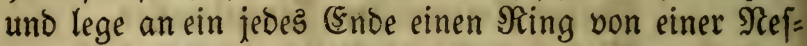
jelnurzel, laßje mobl bluten, ftelle es in einen finftern Stall sno thue die Sring mieder meg.

\section{Ein a n D e r e b.}

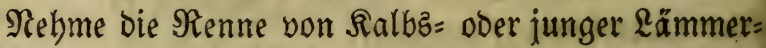
Nägen, wenn ein $\mathfrak{P}$ ferb im rechten 2 uge daz Fell hat,

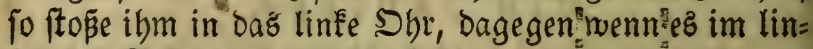
ken bas Fell bat, inz rechte $\$$ Dhr.

Ein andereb.

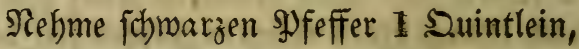

Wुeiß̄en $\mathfrak{P}$ feffer $\frac{1}{2}$ Suintlein,

Salpeter 2 loth, Sconig,

Saumöl, jedes gleid viel und fo viel bis es genug zu einer Salbe ift

mifche es untereinander.

Ein andereb.

Slia Sepiä, 1 loth, gebrannt Salz,

2ugftein $\frac{1}{2}$ loth

Saffran $\frac{1}{2}$ Suintlein,

(Salifenftein 1 suintlein,

Sonig,

Baumöl, fo viel zu einer Salbe genug ift,

bermifche es unterienander.

(5) in and

Fuchs: (salle $\frac{1}{4}$ Suintlein,

5̧onig 2 lothr. 
Ifferbe:2(rzenei Bud).

Diftillit Nelken Sel 1 @crupel,

SPfeffer $\frac{1}{2}$ Suintlein, mijhe alles untereinanoer zu einer Salbe.

E in a n bereb.

Ungarifd $\mathfrak{B i t r i o l} 1$ loth,

Sonig 4 \&öffel voll,

fodje eह über einem getinben Feuer gu einer Salbe.

Ein a ndereb शुg.

Rabenfchmalz 2 loth,

2ugftein 2 Suintlein,

mifche es untereinander.

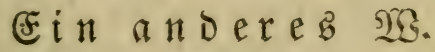

Scajelnurzel, Wheip̄nurzel,

arottenblumennurzel,

Birnbăumenmiftel, jeoes 2 loth,

mifde es untereinander zu einem Syulver, uno blaje es Dem Shferd in bie 2 ugen.

E in a n o e re?.

2uripigment, Iutia, S̃ngroer, SDfeffer,

Ungarifo Sitriol, jeoce $\frac{1}{2}$ loth,

Rofentonig, fo viel bierzu nöthig ift,

mijche es untereinander zu einer Salbe.

(5in andereb.

sebme die Beer von Spheu,

Sdyrofel, jedes gleid) viel,

brenne diefes zujammen auf einem Tigel, zerftope es hernach und blaje es bem spfero in bie 2fugen.

(sin a noereb.

Sal Armoniac. Murrben, jedez 1 Suintl. 
Storax calam. 1 Suintlein, Beiper $\mathfrak{x}$ feffer, 2 Suintlein,

Feberweif, Salpeter, jebes 2 suintlein, 2lloes Succotrin 3 S.uintlein, NSeiraud, Utngarifdyen S3itriol, jedez 1 souintleim, Sconig, to viel nöthig if zu einer Salbe, untereinander gemifot.

Wenn junge F̌bblen Mängel an Den Zutgen baben, ift es gemeiniglid) von Tatur und fenmer zut beilen, ben= noch iftes fứt folde febr bienlich, menn ber Miono neu ift, Den britten Tag hernoch Den Staffel im Saaumen geftodyen. Farmer Die SSurzil und Das Sraut SBalori= an, Daz an Dem Solnanniz= Tag früh gegraben, auf beiben Seiten an ben Soblaf gebunden, auth in bie $\mathbb{R}$ äf)= ne und ๔chopf = Scaar gebängt, audi) in Das IrinEmaffer gelegt, und bayon faufen lapen.

Daz 19 te Eapitel.

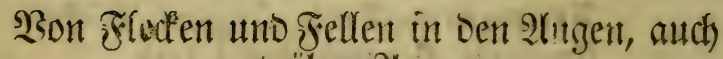
triben 9 tugen.

Diefe fommen entweber burd) einen Schlag ober Stof̂, ober fonften ourch phlegmatifune Feuchtigkeiten in bas Scornförnige Scäutlein, und ift je einer tiefer oder bünner als oer anbere; wenn folche beide fubtil und bünn find, find fie noch wobl zu curiten.

Iutia präparitt 1 lotb),

(Eorallen $\frac{1}{2}$ lotb),

Sucferer 1 lotts,

Eampfer 1 suintlein, 
Sarcocolla $\frac{1}{2}$ Suintlein, Ebermuzeljaft, Rautenmaffer, S(b) albenfirutmafter, Fenchelmafter, SSeipez Siofenmanter, jedes 4 loth, untereinander gemijht uno luber bas 2úng gefollagen.

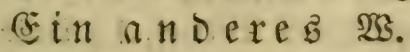

Die Şurzel von Sुfaffemröhrd)en oder Şabidhtsêtraut um Sartbolomäi gegraben, wenn die @onne nod) in Der Sungfrau ift, uno angelyängt, vertreibt alle 2fugen= Flecten.

\section{(C) in a noerez}

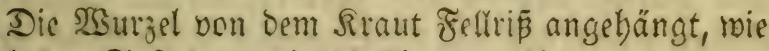
aud) ben ङaft bavon in bie 2lugen gethan.

\section{Ein andereb.}

Salcinitte Edwalben- Nefter 1 loth,

(Salbanum 1 Suintlein,

5ृonig 3 loth,

untereinander zu einer Salbe vermifdt.

Ein a ndereb.

Nerrben, 1 loth,

Saffran 2 Suintlein,

Şonig 4 loth,

untereinander zu einer Salbe bermifacht.

\section{(5in anderebs.}

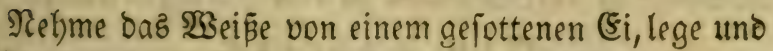
fülle ęs aus mit 3ucfercanoi, binde es mohl wieder zu= jummen, febe es in einem (S)laz ooer vergläperten (Ge $=$ foritr an einen feudten Sit, fo tropft eine Feuchtig= feit heraus, alsoann prêle das übrige vollends beraus,

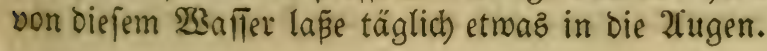




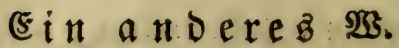

Summadb 1 loth,

2lloes Succotrina 2 sountlein,

Rinden von füpen (Sranat=2Cepfeln, 1 Sau.

\$erlen 2 Ecrupel,

$\mathfrak{u n g a r i f c h e n ~} \mathfrak{S i t r i o d ,} 1 \frac{1}{4}$ Suintlein,

allez untereinander zu einem jubtilen Şulver gemadb)t uno in bie 2fugen geblajen.

Ei $\mathfrak{n} a \mathfrak{n}$ ber $\mathfrak{e}$ b.

Rebme rotbe Sdinnecten, ftreue Salz barauf in ei= nem Scafen, Daßj fie fich fäubern, hernad) nehme bie

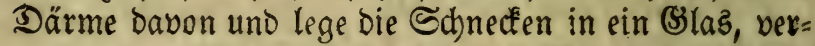
mache es wohl und hänge es an bie Sonne, fo miro ein Sel Darauz, biez ftreiche dem \$fero in bie 2ugen.

(E) $\mathfrak{i} \mathfrak{a} \mathfrak{n} \mathcal{D} \mathfrak{e} \mathfrak{e} b$.

2lloes Succotrinä 1 Suintlein,

Fendbeliaft 2 loth,

Drei Esiertlar,

vermifthe es untereinander zu einer Salbe.

E $\mathfrak{i} \mathfrak{n} \mathfrak{n} \mathfrak{D} \in \mathfrak{r} \in \mathfrak{b}$.

Ealcinit Şirfdborn 1 lotb,

Rothe Corallem,

Iutia, jebez 2 Suintlein,

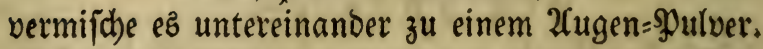

Ei $\mathfrak{n}$ andereb.

2lloeb Succotrinä 1 loth,

(Selbe Merobalani 2 Suintlein,

Ridits 2 loth,

untereinander vermifd)t uno in bie 2(ugen gethan. 


\section{Pferbe=2(rgenti Bud).}

\section{(5in, a noeres.}

Sundelrebeujaft 4 lotb,

Iutia, präparirt,

Xloes Succorrin. jedes 2 loth

Eampfer 1 loth,

Fenchelwaffer,

SBeinrautenwafier,

Ro/entoafler, jedes 2 loth,

alles untereinanber vermijd)t.

Ein andereb.

Sconig 3 loth, Salz 2 loth,

Römijhen SBitriol 2 suintlein,

Rojenwaller 8 lotb,

mifict) eŝ untereinanoer.

(E) i a n Dere $\mathfrak{B}$.

Den Saft von Sdjöléraut uno ber Sisurzel Rautenfaft,

Fendellfaft, eines fo viel als bab andere uno thue es in bie 2rugen.

\section{Ein andereb.}

Waja)e bas 2(uge vorber mit (5undelrebenjaft uno blaje ibm von nachfolgendem spulver binein :

Salcinirt Sirichborn, (5ierfichalen,

Meeripinnenfdalen,

Sheinftein, jeoes gleichviel,

alles untereinanoer gepülvert uno gemifhtht.

\section{(5 in andereb.}

Ealcinire bie todten jun Jen Şühner bie in ben Sd)u= len ftecten bleiben, mit fammt ben (d)alin, bavon neb)= me 4 loth; (Salcinirte weipe $\Xi$ dhneden mit fammt ben 
Scăuछcthen 4 loth, Sconig fo viel bierzu nöthig ift ; zu einer Salbe gemadht uno in bie 2fugen geftrichen.

Für trübe Flecten in Den Xugen, nebme Scajenionmalz 3 loth,

sngmer 1 loth,

madbe es zu einer Salbe und rumiere es in bie 21ugen.

Ei $\mathfrak{a} \mathfrak{n d e r} \mathfrak{e b .}$

Waffer baz 24 Stunden über ungelöbtem Ralk geftanden $\frac{1}{4}$ Maẫ,

Salmiak 2 loth,

rüfre es in einem meffingnen Möriel wobl untereinan= ber, fo wirb es blau; Dies ift für alle Flecken ber $2 \mathfrak{u t}=$ gen, trübe 2 ugen, uno das 2 ugenrinnen.

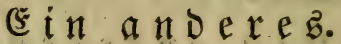

Streiche bem Shferb eine Mifchung von Rauten= uno

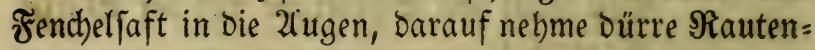
föpfe, pulberiftre diefelben uno blafe fié ibm in bie 2Cugen.

E in andereb.

Römifhen Sitriol 1 loth,

Salmiake,

Sampfer, jeoes 1 suintlin,

Weiper SSein 12 loth,

Dies alles robl in ein (Slas vermad)t und in bie Sonne 14 Iag gebängt, ober auf einen warmen sfen geftellt,

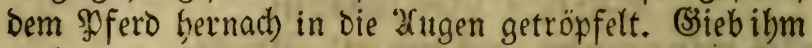

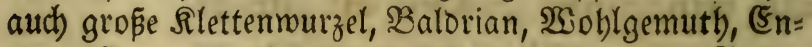
zian, $\mathfrak{W}$ ermuth), eines fo viel als baz andere im Futter zu freffen.

E in a ndereb: Sorenneffelnfalz 1 lotb, 


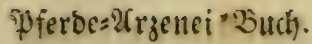

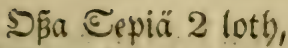

Sd)nedtenidalen,

(5alcinirte 26ad)tel, jeoes 1 lutb),

mifd)e es untereimanoer zu cinem ?tugenpulver.

Ein andereb.

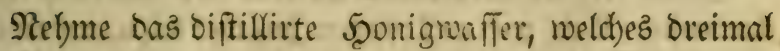
beruber gezogen worden, uno tbue ç in bie 2rugen.

Eiti anderes.

Bom Etofi oter Salng in oie 2ugen.

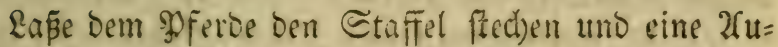
genaber auf oer Seite öfrnen, auf welt)er fit) ber Sda= ben befindet; man lege ibm bernad) bes Iagz einige mal folgenden Umid)lug üter baz 2ruge :

Rojenvaffer, (5ierflar,

mijche beibes unterimander, netge leinene Rappen barin, uno jollage es oft über.

E in a II Derez.

Beip̄e Rilienmurzel, Sd)öleraut,

Fendiel, jedes 1 loth,

Rofenwaffer 8 loti),

laß̃e es miteinander in einem roobl vermadyten (s)las robl fieden.

Ein a th

Salcinirtes Sुulver von Deeripinnenichalen, Schnečentyäurer, jeoes 2 lotb,

Murrben 1 lotb,

Şonig,

Rofen= Sel, jedes 4 loth,

madje es zu einer Ealbe. 
Ein andereb.

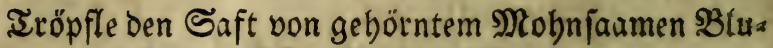
men uno Rraut, in båz fohabbafte 2 ug.

\section{Ein andereb.}

Stope frijhes Sdbölfraut fammt Der $\mathfrak{B u r z e l}$, thue ein menig Salz und geftopenen SIngmer bazu, vermifche es mit (sffig und fallage es oft über bas 2ruge.

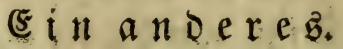

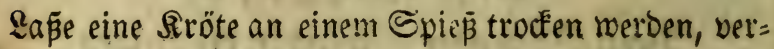
brenne biejelbe in einem neuen glapirten Scafen, Damit es (iid) zu einem ganz feinen şulver ftopen la pe, uno blaje es bem Pferbe in bie 2 ugen. Dies Nittel ift

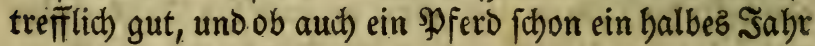
ein Fell gehabt bätte.

\section{Das 20fte Capitel.}

\section{Fon Dem Nagel Der Ylugett.}

Der Nagel iff zroeiertei an Den 2ugen, einer ift nid)tร anderz, alz ein hartez Fell, Daz über ben ganzen 2 u ug= apfel leçlich gehet, ber andere Sagel aker if natürlid) in allen spferdes 2ugen, ood) nicht in einen spfero jo großs, als in Dem andern; ber erfte Nagel ift nid)t zu curiren, als wie alle andere 2lugenfelle; ber andere aber mus auf nachfolgende $\mathfrak{B e i f e}$ gefdhnitten werben :

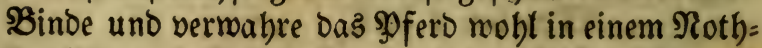
ftall, alboann faffe Den গagel mit Dem linfen Daum und Biebefinger feft, uno fteche mit einer Nabel, in we doer ein langer Faben gebunden, Daburd), [a tann man 
ibn fein beraus zieben uno binten ablöjen; alboann

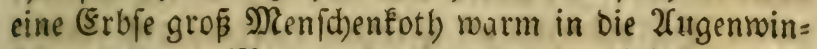
Eel gelapen. Man mus aber bit bem 2ublöen rookl ad)t baben, baj man nicht zu viel Scaut binneg idhnei= be, fonft befommt Das SPfird Flarraugen.

\section{Das 21fte Sapitel.}

32on ben hibigen, fdywärenten uno triefenoen 2ugen, nte audh 'Jlattern in Denfelben

\section{Doer andern Edriben.}

Diefer Nangel iff entweder ein Flup̃ vom Scaupt, von Scikge oder Fälte, oder fommt vom Fallen, Edla: gen, Stoßen oder Sermunden.

\section{Sie Beidsen find fenmbar.}

1. Rotbe bişige 2rugen.

2. 2ufgelaufene SBlut:2Coern.

3. Iriefen ber 21ugen.

4. Eiter in Den $\mathcal{L}$ ugen ober $\mathfrak{A}$ ugenwinkeln.

5. Blattern in Den 2lugen.

Laßje ifm monatlich die Srufpel=24Dern, wenn Der Slono neu ift (angenommen im $\mathfrak{M i o d e r})$ und alle $\mathfrak{B i e r}=$

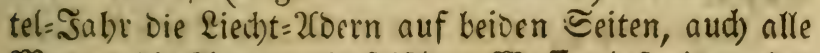
Morgen bie ?ugen mit frifhem $\mathfrak{B a f l e r}$ befprif̧en, bes

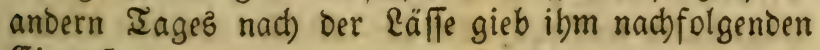
(ङingu防 :

Eerdenifhnamm,

2lloes (Epathicam, jetes 2 loth,

Scammonium $\frac{1}{4}$ lotb), 


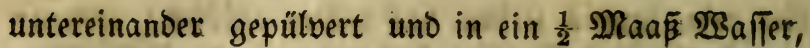
worin Shollundermurzel gîfotten worben, auf einmal eingegopen.

Ein anderer Einguß $\mathfrak{B}$.

Senesblätter 2 lotb,

Rercbenichroamm $1 \frac{1}{2}$ lotb.

Scammoniuni,

Sngreer, jedes $\frac{1}{2}$ lotb,

2nis 1 loth,

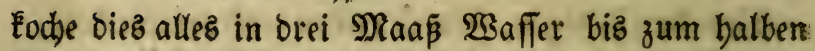
I beil, hernach theile es in 2 Theile uno foutte es bem Sofero laulicht in 2 Iage nacheinander ein. Seernadb. thue dem \$ुferd täglid) nadfolgenden Saft in die 2(ugen.

BS.

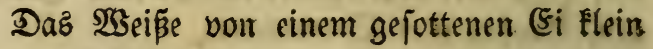
zeridunitten,

Sacbarum Saturni, (Bleizuderer) $\frac{1}{2}$ Scrup. Sampfer 2 (Sran,

S3eip̌en Sitricl 7 (Sran.

Sconig 1 loth,

thue es alles in ein (S)las mit cinem meiten $\mathfrak{R u n o l n d ) , ~}$ rübre es mobl untereinander, lape ez 3 Stunden ftehen, preß̧e den Saft bavon uno tröpfle etmaz bavon in bie Rugen.

Steche bem $\$$ ferb die 2roern in bem $\$$ br mit einem

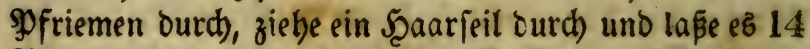
Tage barin und thue ifm bas $\mathfrak{B} a f f e r$ von Den blauen 23 gevarten in bie 2 ugen.

Betonienwaffer,

Rautennaffer, eines jo viel als das andere, und iprige es bem spferd in bie 2fugen. 


\section{Ein a nereb.}

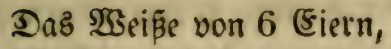

Maftix,

Seiraud), jebes 1 suintlein,

mifa)e es untereinander uno fd)lage eŝ über oas 2 (uge.

E in a \#Dereb. গIS.

Rojenwa fier 4 lotb,

2laun 1 lotb,

it)lage es roobl untereinander zu einem Sdbaum uns lage es Dem şferd über das 2fuge.

\section{(5in andereb.}

Şonig 4 loth,

F̌endhellaft,

গautenjaft, jebes 2 loth,

mifibe es untereinander zu einer Salbe.

\section{E in a noereb.}

Sithlage das Walfer von Şollunderijbmämmen, mit (Fierflar vermifd)t, über bie 2fugen.

E in anderes.

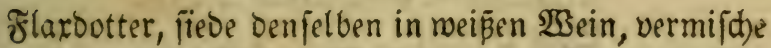

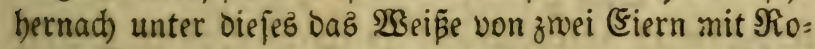
ientaffer wobl angeflcpft uno fidlage es bem Sffero über Das 2ruge.

\section{Ein andere $\mathfrak{E}$ :}

Flores bom Bink (werben gemadt, wie man bie Flores 2(ntimonium madbet) $1 \mathbf{S u .}$ Bleizudeter 12 SSran. Rojenmaller 4 lotb, allez zujammen in ein (S)las getban, 24 Stunden fteben 
laß̄en, oft mit einem Şölzchen umgerübrt, uno beş gez etliche Iropfen in foldhe hisige 2ugen getban.

Ein andereb.

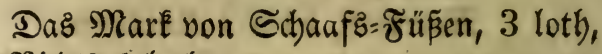

Nichta 1 loth,

mifche es untereinander zu einer 2 ugenfalbe.

E in andereb গ্G.

Syurgiere biefe Pferbe mit ber Spect= Sur, und brau= d)e ihm 8 Tage barnad, folgendes (Styftier :

Singelfraut,

Sappeln, Mangolt,

Blau SeilenEraut, jebes 1 Şandooll,

Flieffendes $\mathfrak{3 a f f e r ~} 3$ Maā̄,

fiebe es zum halben I beil, hernath nimm von ber ab= gejeibten $\mathfrak{B r u ̈ b e}$ ein Maaß̄,

Saaumöl,

Sconig, jedes $\frac{1}{2}$ Sf fund,

Eierbotter 12 ,

Şierä picrä,

Senediç̃ä an. jebes $1 \frac{1}{2}$ loth,

Extract von (5a)̈iarinde 3 loth,

Salz 2 loth,

vermifit)e es untereinander zu pinem E!nftier, uno ge= braucbe es laulicht.

(5i $\mathfrak{n} \mathfrak{a} \mathfrak{n} \mathfrak{D} \mathfrak{e} \in \mathfrak{B}$.

Rotben Soluz 2 loth

(sierflar, to viel alz nötbig iff, mifche es untereinander zu einer Salbe.

E $i \mathfrak{n}$ andereb $\mathfrak{B}$.

Şaus?nurzelfaft 3 loth,

gidats 1 loth, 


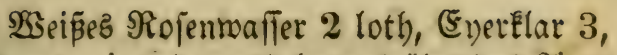
mijitte allez untereinander uno lege es üher vas 2 uge.

Ein a noereb IR.

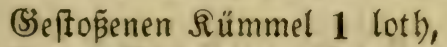

(S)rüre $\mathfrak{S e i n r a u t e n b l a ̈ t t e r ~ u n d ~ S n o ̈ p f ~} 3$ lotb

Eiertlar 2,

Rofenwaffer, fo viel zu: Mixtur nöthig iff, mifd)e es untereinander uno lege es luber das 2ruge.

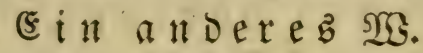

Separ antimonium,

Eafrran, jeoes $\frac{1}{2}$ Suintlein,

2fgaric 1 loth,

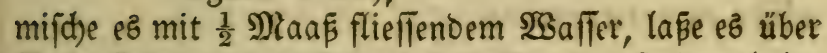
Racht fteben uno idu ütte es Dem Doferi auf eimmal ein.

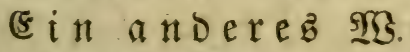

(Eierf́lar von 3 (Eiern, ood) Den Bogel her: auz getban,

Sampfer 1 Suintlein,

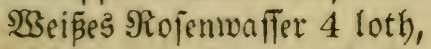

mifd)e es untereinanoer zu einer Nixtur uno beftreid)e Daz 2uge damit.

\section{(E) $\mathrm{in}$ andereb.}

Bäbe fie oft mit (Sierflar uno narmer Meild, oder mit ber warmen Brübe von Steinflee und Bockghorn= faamen.

Sind bie 2ugen eiterich unb unrein, fo wajde fie oft mit reikem Rojenmalfer, worin Sampfer aufgelöst ift, aus. Dies thut man auch mit Sconig uno 3ucfermaffer.

E i $\mathfrak{n}$ a $\mathrm{D}$ ere s.

Radbe eine Mixtur von 3uctercandi uno Rojentaffer. 
Ei $\mathfrak{n}$ a $\mathfrak{d}$ ere . WSegerid) faft, (Eierklar,

mifobe bies untereinanber und ftreiche es dem Spfero in Die 2 ugen.

Einandereb.

Rofenöl 4 loth, Esieroottern 2,

Saffran 1 suintlein,

mache es zu einer Salbe.

Ein andereb.

Norrben 2 suintlein,

2loe 1 Suintlein, Siojenöl 2 loth,

Mnrtenwaffer, fo viel nöthig ift,

mirche es untereinander.

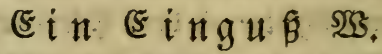

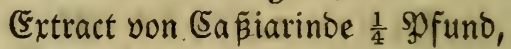

Mann 4 loth, 2lloes (Saball. 2 loth,

2fgaric 3 loth, Sconig 1 গু funo,

vermifuce es mit gefottener $\mathfrak{B r u ̈ b e ~ v o n ~ T a m a r i n o e n ~} \frac{1}{2}$ IRaá.

E i n a noere.

3äume das झुfeto auf uno thue in oaz boble \$)? und: ftüct Stapbifagria, Bertrammutzel, Dfeffer uno Salz.

Ein a n D ere b.

Rotb́en Roluz 1 Rotb,

Drachenblut 2 Suintlein,

(3) ull =2Cepfel,

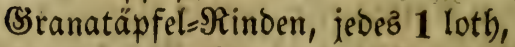

2loes $\frac{1}{2}$ loth, 23 seiraud) 1 Suintlein,

Bobnenmebl 2 loth,

(Eierflar, fo viel bierzu nötbig iff, 
Itntereinander zu einem Pflafter gemifd)t und überid)la= gen.

\section{Ein a n d e re.}

Iröpfle inm $23 e i b e r=$ Mil(d) bincin.

\section{Ein andere}

Siede Fönum gräcum (Boofibornjaamen) in (Ster: ftenwaller, fd)lage es Dem SPfert über bas 2fuge und majit)e oder bäbe es oft mit foldjem 2 saller.

\section{(5) $\mathfrak{n}$ a no}

Rofenwafter, Fend)elwafler,

2ugentroftwafler,

Rautenmafler, jeoes 2 loth),

(3)undelrebenjaft 4 loth,

2lloe, Iutia, jedes 1 loth),

mifa)e es untereinander und thue es in bie 2 ugen.

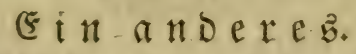

SBleineí̃ 2 loth), Iutia 1 loth),

Eiertlar 3,

Rofenül 2 lotb),

Rofenwafter 3 loth,

milide es untereinander und freiche es über.

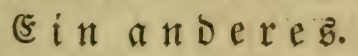

Sauterifire auf jeber Seite der Stim 3 Etrich, ift gut für alle 2utgenflüße.

(5) $\mathfrak{n}$ a $\mathfrak{n} \in \mathfrak{r e b}$.

Sief 2clbum, 1 loth),

Spium 20lexanor. 1 Suintlein,

Nichtz 1 loth,

Slutftein, arabijher (Summi, jebez 1 Su. 


\section{2lloes 2 suintlein, Iragacanth 1 Suintlein,}

allez untereinander geftopen zu einem şulver, zu ben 2lugen zu gebrauchen.

\section{Ein anderes.}

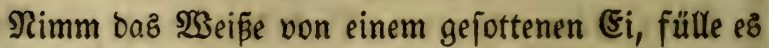
mit nachfolgenden 2 rzeneien, binbe es feft zu, bänge es in ein robl vermadhtes (S)las uno laße es in rarmem WBaffer fieden, fo wirft bu ein $\mathfrak{W a f f e r}$ im (S)las befom= men, diefes fittrire, fo baft bu ein Eöftlidbes $\mathfrak{W a f f e r ~ z u ~}$ Augenmunden.

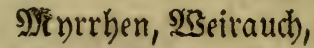

2loeb, Sarcocoll.

Saffran, jeoes 1 Scrupel,

2rabifuber (S)ummi 2 Scrupel,

Ķeipen Mohnjaamen,

Nibil 2lexanorin.

Bleimeip̄, jebez 1 Scrupel,

miface es untereinander in bas gefottene 2 seiße vom \&i, wie oben ffebet. Wenn bie 2tugen von Şif̧e ganz rei überlaufen, bient folgendes S్faffer : (Summi, Saftran, mit Rofenwaffer etwaz biclich gemad)t, und bie 2(ugen mit einer Feder beftrichen.

$\mathfrak{B}$ enn ein 2 fug bermunoet iff.

⿰豸勺צ.

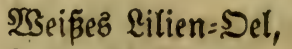

Rofen=SDel,

Sonigmaffer, jeoes fo viel als nötbig iff,

(5in renig Srünipan,

mijche es untereinanoer zu einer Salbe und lege es auf. 


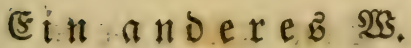

Sd)lage ober fomiere ihm das Bleimeis: Sel oder in Ërmangelung Deß̄en, Die Şleimeişalbe über.

$33 e n n$ aber die 2fugenlieder muno find, fo mus man fie beften, uno folglid) Eübleno Mixturmafler gebrauchen.

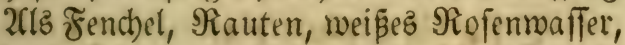
untereinander gemifdt, lineingefprifet uno ein Şfla= fter Seratum Sarbarum über bas 2fuge fdhlagen.

$\mathfrak{W}$, nn bie $\mathfrak{B}$ unde zubeilen will, foll man nad)folgen: be Salbe fleipisig brauchen :

(Saud)beilfaft, Fend)elfaft, Eppid) jaft, SSeintautenjaft, 2fugentroft jaft, jedez 6 loth, Şonig 8 loth, SRindsgalle 2 loth,

fiede es untercinander zu ciner Salbe.

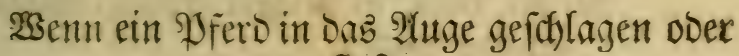
geftofien.

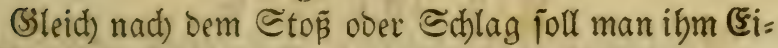
erflar mit Rojenwaffer vermifd)t überidhlagen, ober Sdjwalbenfrautiaft.

(F) $\mathfrak{i} \mathfrak{a}$ ndereb.

Sucter 3 loth, rothe Corallen,

Sict)ts, jeors $1 \frac{1}{2}$ loth, Sconig 2 loth,

Rofenmafier, Fenchelwajler,

Sd)walbenf́rautwafler, jedez 6 loth, mifde es untereinanoer uno fothiete daz 2(uge bamit.

Nimm Rlabafterfalbe mit Nofenöl vermifat uno id)lage es über bas 2 Uuge, fdhmiere es auch bamit

Ksenn vas 2luge vom Siblag oder Stoṕ voll 3äh= ren überläuft.

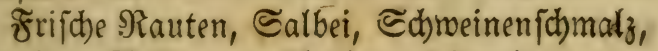
mache es zu einer Salbe und fdnmiere es bamit. 


\section{Yfferbe=2lrzenei $\mathfrak{B u d}$.}

\section{(अ) in anderes.}

W̉enn ein $\$$ ferb in Das 2 uge geftopen Doer gef hlagen $\Re$ Rjen=Sel 1 loth, 2labafterfalbe 3 loth,

miche es untereinander.

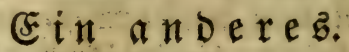

WSeiraud) 1 loth,

Eierklar, fo viel hierzu nothig ift,

milche es untereinanoer.

\section{(5: in andereba.}

Sprite ifm von nachfolgendem in bas 2ruge, ober wajdje bas 2luge bamit :

Saft von Siundelreben,

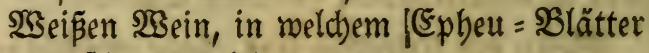
gefotten worben.

\section{Ein andereb.}

Meeripinnenichalen calcinirt, 3uckercandi, jedes gleid) viel, ftope es zu einem Soulver und blaje bavon in baz Xuge.

(E) in andereb. Sarcocolla, 2loes Succotriniä, Summach, jebes gleich viel, löje es auf in WEein und das 2luge Damit gewajchen.

Blattern und Siefdyüre in Den 2lugen.

Diefe find in Dem Sornförmigen Scäutlein, wie aud) bismeilen in bem weisen Scäutlein, feben anfangs (c)rwarz, hernach graulicht, Eommen von groper Nenge

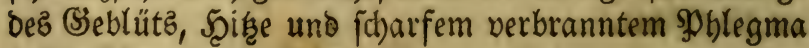
$\rightarrow$ ber.

Diefem foll man im 21nfang aljo begegnen, lape ifm 
cine Scats=2CDer uno ben britten Staffel ftechen ; Sמur= giere bas $\mathfrak{D}$ ferd uno braudbe if)m etlid)emal ein (Slnftier.

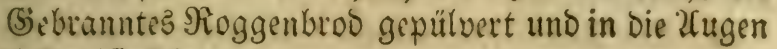
geblajen iff febr gut.
(5) $i \mathfrak{n}$ ก
Succum Incium,
Saftran, jedez 1 Scrupel,
Salcocolla,
WSeirauth, jeces 2 Ecrupel,

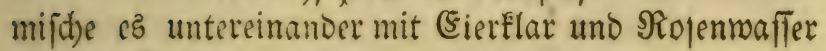
ou einer Salbe.

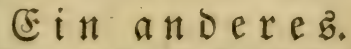

Murrben, Seiraud, jebes 2 ๔crupel,

Safiran 1 Scrupel,

mijibe es untereinander uno blaje es bem SPfero in bie atugen.

(E) in a noeres.

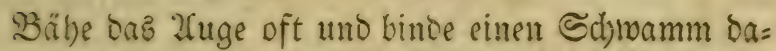

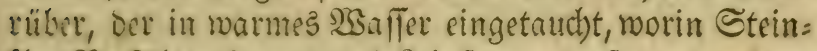
Elee, Bodfshornjaamen und Reinjaamen gejotten worden.

SBenn bieje befdriebene Gadben nidht belfen mollen, muв̈ man biejenigen Mittel braudben, weldhe man zu Den @taren: Fellen gebraucht, ober bie Bläzchen mit ei= ner filbernen ?adel öfrnen.

\section{Die Berpflegung.}

1. Soll ber Etall nicht zu marm, aud) nicht zu Ealt, trodén, nidht feudbt oder bämpfigt und fo eingeridhtet

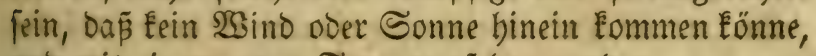
uno mit einer guten Gtreu berfeben werden.

2. Das, Futter foll gebrodjen fein, rie audjein linbes

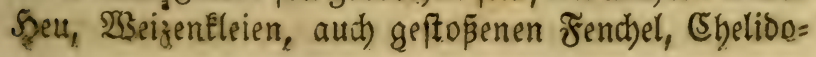




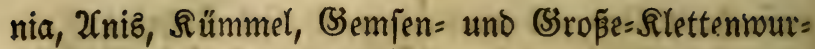
zel, unter baz Futter mijchen.

3. Der Irant foll laulid)t fein, worin Fendhel (Sro=

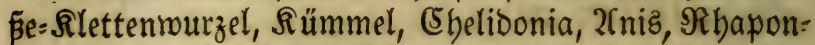
ticum, Senezblätter, geftopenen Mcinftein, (S)undelre= ben, Rauten, 2Cugentroft, Şemfentourzel und Balbrian gejotten worben.

Das 22fte Eapitel.

Эon Den Shren=Sranfleiten, uno erftlich von Der Taublyeit.

Die \$Jferbe baben aud ibre Srantheiten an bem (Siebör, gleichwie bie Menfchen ; Eommen aljo bie Rranebeiten, uno varnemlich Die Taubbeit, von überflüffiger Ealten, zäben Feuchtigkeit von Dem Şirn, noourch Der Uubgang verftopft miro, ober ber bohle inmendige I beil

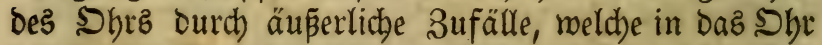
binein fommen, biejenigen \$ferbe aber, welchen bas (sebör veroorben ift, hören folde Dinge, Dergleichen bie anbern (10 um biefelben find) nicht bören, machen $b a=$ her ben Scals offters jäbling frumm, heben die Söpfe in bie Scöhe, fpizen bie Shren feben bald über balo vor fich uno geben Damit zu werfteben, Daß̧ fie auf Dasjenige, waz fie nicht hören, fonft fleiß̄ig 2(d)tung geben.

Sa, es ift aud) biefes eine Scaupt Ur Uadbe, daß fie ficheu fino, mitten in ibrem (s)ang ftille fteben uno auf Eeinerlei $\mathfrak{S B e i f e}$ fort wollen, ober auch mieberum zurück bröllen, oder auf eine Seite ipringen, alz märe etwas. 
zugegen, Dafür fie fidh zu fürdten; Doer fie biegen bie Ropfe Dem Sit zu, von woljer fie vermeinen, Daß dar (Setös berfomme, fteben ganz liber ifnen felbft verffar= ret, voller Gdurecken uno Furd)t, uno (d) naufen beftig, als bie, weldje etwas (Erid)redtiches uno ungemöhnli= d)es bören.

Sold)e Sुferte foll man an einen mittelmäßigen Sort ftellen, gebrodbenes Futter geben, wie aud) Sileien uno gef(t) ittenes Stroh Darunter mifchen, etlidhe Norgen nacheinander, ebe ou zur völligen (Sur fdureiteft, hernad) gieb ihm 2 Tage nad)folgenden (singuß :

SDiera picra 1 loth), \&erd)enfdymamm 2 loth, Soloquintenmark 1 loth,

Sdbreinejd)malz, ober zerfopenen Spect, 1 Pfund,

Baumöl 2 şfund,

untereinander gemifdst und laulid)t auf einmal gebraudst Sernad) tröpfele ifm nad)folgenoes in bie Shren : \{alb: $5 \mathrm{el}$, weldbes von feinem ซett gemad)t ift, 1 suintlein, Sorol, Epicföl, jebes $1 \frac{1}{2}$ suintlein, Bibergeil 1 suintlein,

biefes alles untereinander gemifdst und in bie Shren ge= tröpfelt, 6 ober 8 Tropfen auf einmal, ober nége Baummolle barin, made einen 3apfen baraus und fte= ce es in Das Dhr.

Benn man nun foldhes des Norgenz gethan hat,

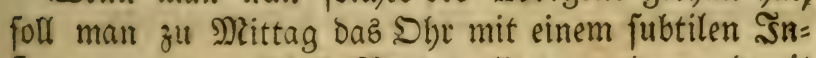
frument, um welbes Saaumwolle gerounden und mit Sconigmafler genef̧t iff, fleis̄ig aus]äubern uno barauf bie Srübe, in welcher Gtabwurzel, Iorbeer, Fichten= laub uno Bibergeil gefotten roorben, hinein giesen. 
Ein anderez Del zum Eintröpfeln.

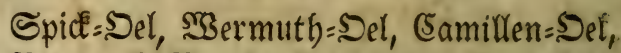
Bibergeil, Rinozgalle, jecez 1 suintlein,

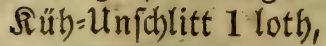

afles untereinander gemijotst.

Eี $\mathfrak{i} \mathfrak{a} \mathfrak{n} D \in \mathfrak{r} \in \mathfrak{B}$.

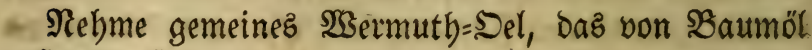
gejotten ift.

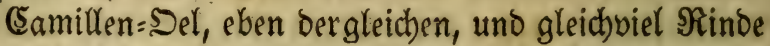
von Eichenbolz, barin gejotten und eingetröpfelt.

\section{Ei i a noeres.}

Sfterlucey 1 loth, Şonig 2 loth,

mady Bapfen bavon und ftecte es in bie SDhren,

E $i \mathfrak{n}$ and $\mathrm{n}$ ere $\mathrm{B}$.

Iröpfele ibm Rettiglaft in bie SDhren.

है $\mathrm{inandereb.}$

Mäusöbrleinjaft, (3)undelrebenjaft,

Rettig, iebez gleidubiel,

untereinander gemif̧)t und in bie ŞGren getröpfelt.

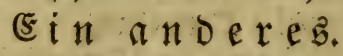

Brannterwein, welcher zmeimal über bie rothen $2($ mei= fen gezogen worden, in bie Shren getröpfelt.

(E) in andereb.

WSegridhjaft, $\mathfrak{S}$ ermuthjaft, Eamillenjaft, untereinander genijobt und in bie Sorren gethan.

(5) in andereb.

Der Saft von Nettigkraut ober Wsurzel,

Eamillenjaft, jebes 1 lotb,

milche e's untereinanoer uno tröpfele es in bas $59 \mathrm{br}$. 


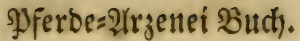

\section{(5) $\mathfrak{i}$ andereb.}

Den ausgenresten Saft von rotben 2 meifen, uno trópfele es in Das 5 hr.

$2 \mathfrak{B}$ az Die SBerpflegung betrifft, fo foll bicfelbe genaut bejorgt weroen wie im näd) ften (Sapitel über Die Shren= (d)merzen angegeben werben wirb.

\section{Daz 23fte Eapitel.}

Bon Den Shren=Gdymerzen, meldyer von einem (S)ef(t)wïr herrulbrt.

Diefer fommt bei den \$ुferden von hişigen Däm= tfen bes (selbims, fo wie aud) vom Sulagen, Stopen, Fallen, Gtechen oder menn ifnen fonften etwas fpicí ges oder ftad)lidtes in Das s Dhe fommt, Da hernach in =

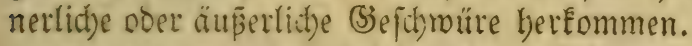

Die Seichen diejes (sebrechens, roenn es innerlid) ent= ftehet, find biefe :

1. Seängen foldse sूferde die Söpfe auf die Errbe, und lapen das f(d)merzhafte Shr hängen oder biegen es

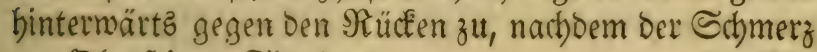
am Shr jeinen Sis bat.

2. Unterfteben bisweilen foldbe mit Den Füpen zu Eraken.

3. Sind ifmen die Sbren gejdmollen und bisig an= zugreifen.

4. Räuft audb bismeilen Feud)tigkeit uno unrath aus ben Sflen. Diejenigen aber, meld)e auz einer hi= • sigen Raterie entiptungen, werben, (wenn man ifnen 
an bie SDrenwurzeln füblet) ganz higig befunden, be: ren Uriad)e eine übermäßige Freuchtigfeit ift, bie madbt Dem \$pferb daz Scaupt ganz fdrwer, alfo baj ez bajel:

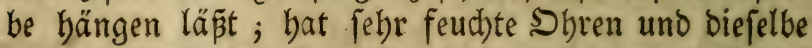

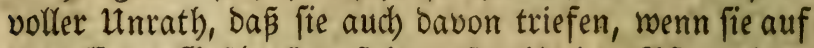
ein offenes (Sefdw ür erfolgen, fo gibt bas SুPfero einen üblen (Seftant von fich).

Diejen Sferden foll man eine 2coer auf bem Sopf offnen, ein Elyftier geben und Dann barauf purgiren.

\section{$\mathfrak{B S}$.}

Sierä picrä,

Senedicftä, jedes 1 loth,

Lerdenfinamm 1 loth,

Iurbith. Scammonium, jebes $\frac{1}{2}$ loth,

(3ummi (Suttä, 1 Suintlein,

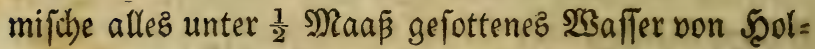

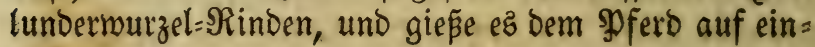
mal ein.

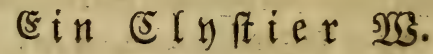

Sুappelnêraut, Bingelkraut,

Slau Seilentraut,

Mangolt, jeoes 1 Scanovoll,

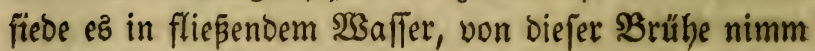
1 Maấ :

(Extract von Cafiarinde 2 lotb),

Şierä picrä, 1 loth,

2 sierbatter,

Baumöl $\frac{1}{4}$ Ş fund,

Salz 1 loth,

- mijche es untereinander und gebrauche es marm.

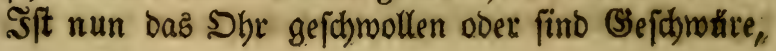


fowobl äuserlid) alz innerlid), vorfanden, fo mus man jertbeilende Gadben braudben und bie fre zeitigen :

Staubmebl,

(Se)fópenen \&einfaamen, jebes 6 loth), Bocfshornfaamen 4 loth.

diefe Dinge fubtil untereinander gepülvert uno mit jer: lapenem Sd)reinenfit)malz vermifht, lege ez über bie (Sefdiwulft, es wiro diefelbe balo zertbeilen uno zeitig madjen.

\section{(E) in a}

Den Gaft von Iefdelfraut, und tröpfele ifn warm in bie Shren.

\section{E in andereb Mु.}

Si)leim von Suitten=Sern, \&einjaanten,

Bocḱabornfaamen, jeoes 2 loth,

Soubneridimalz,

Entenfd)malz,

mijiche es untereinander und folag es auf bas $5 \mathfrak{h r}$, in= mentig uno ausmenoig.

(e: in anderez $\mathfrak{X}$.

23eiraud) 2 lotb,

(3) ummi Elemi 1 loth.

Drachenblut, 2 Suintlein,

Sूedf 2 loth,

Ierpentin 1 loty,

mijd)e es untereinander zu einem Syflafter uno lege es über, es mirb es bald zeitigen und aufzieben.

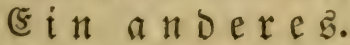

Sodfzhornfaamen,

Reinjaamen, jedes 3 loth,

(Sirinomurzel in Effig gefotten, hernach allez 
untereinander geftopen, mit @dhweinejchmalz vermifd)t uno über bas 5 hr gefdlagen.

\section{Ei in and e reb.}

SSenn das (Sefdhwüt nid)t zeitigen mill.

(Sauterifice es mit einem Eifen, fo muto es fdhon flief: fen, beile es hernach zu, mie andere offene Sdjäben.

\section{(5) $\mathfrak{n}$ a $\mathfrak{n}$ deres 2 S马.}

SBdellium,

Storax liquio. jebes 2 Suintlein,

(S)

Scirfchen= Uunjchlitt, 4 loth,

Şeiß̧ę \&einöl, fo viel hierzu nöthig ift,

untereinander gemijdt uno übergefiblazen.

BSenn es aber nidht auforectsen mollte und bod) fichon zeitig wäre, muß̃ man ę mit einem S̃nftrument öffnen, uno daz Sel mit $\mathfrak{W}$ ein, Sel und Salz untereinander gemifht reinigen, bernaci) diefe Salbe gebrauchen.

\section{W3.}

Spoponac 2 loth, Mutrken,

grseirauch, jedes 1 loth,

(Serftenmebl 2 loth, Sonig, fo viel nöthig ift,

alles untereinanoer bei einem Soblfeuer zu einer Salbe zerlaß̄en.

23enn aber bas Solv von fid felbft aufbrid)t und an= fängt zu fliepen, follte man fold)es auch mobl reinigen mit Baumwolle, oie vorber in Sel uno $\mathfrak{W}$ sein getaudst morben, auswifd)en, oder gar mit einem SDgrlöffel, uno nad)folgendes binein fprifen :

Mäusöbrlein, Sbijh,

Bocķ̧̇ornfaamen, alles geftoßen, 


\section{Wferbes?(rzenei Butí).}

Leinfaamen, jedes 2 loth,

Rinoşgalle,

Mild), jeoes 4 loth,

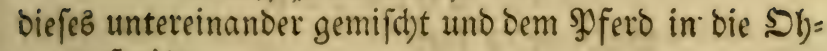
ren gefprifet.

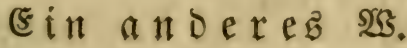

Sollte man ifm aud) folgenien ๔d)nupftabad in bie Rajelöd)er blajen, Denn er reiniget Das Şaupt febr.

Iaback 1 Sf funo,

B̉eip̃en Şundsotect 6 loth),

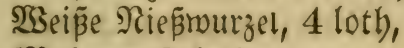

Rajotan 3 loth,

Rangen SDfeffer 1 lotb,

Supborbium 2 suintlein,

bies alles robl untereinander gepülvert uno dem $\$$ fero bavon in bie Rafelöder geblafen.

\section{(5in a nderes.}

(5) ranatäpfel Rinden, fiebe biejelbe in Menfdhenbarn und fprife es ifm in bie shren.

(5in andereb.

Iröpfele Rindzgalle mit Mild) vermifcht binein.

(5in a $n \mathfrak{D} \in \mathfrak{r} \in \mathfrak{b}$.

Senfamin= Del, füßes Mandel=Sel, untereinander gemifat und binein getban,

(5) in a noreb.

Sconig 6 loth, (sfifg 12 loth, mifhe es untereinander und Iröpfele es binein.

(5in andereb. Rofenwafler, Effig, jedes 4 loth, 


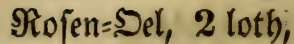

untereinar ber gemijcht und binein getban.

(Ein andereb.

\section{Salpeter, 1 loth,}

sifig 6 loth,

lape cs folviren, taudbe einen Schromm hinein uno fte: dee ez in Das SDhr, lape Denfelben über Nacht Darin fte= deen.

Ein andereb.

Rautenjaft 2 lotb,

Saft von Selbaumlaub, 1 loth,

Sranatäpfelrinden 2 suintlein,

Effing 4 loth,

alles untereinander gemifd)t und linein gefprif̧t.

E in a nd $\mathfrak{i} \mathfrak{e} \mathfrak{b}$.

Mnrrben, Seiraud, jedes 2 Suintlein,

Spium, Bibergeil, jebes 1 Suintlein,

löpe es in 6 soth \&ffig uno 12 \&oth Sconig über einem soblfeuter auf und tröpfele bavon in bie Shren.

E $\mathfrak{i} \mathfrak{i} \mathfrak{a} \mathfrak{d} \in \mathfrak{r} \in \mathfrak{b}$.

Den Scarn von einem jungen Snaben oft in bie Shren gefprift und die Shien bamit gejäukert.

E $\mathrm{i} \mathfrak{n}$ a noereb.

Nebme Nannzharn, Fifdylacken, jedez $\frac{1}{4}$ Naaß̄, mi= iche es untereinanber und rajd) bie Shren bamit auz.

Ein andereb.

Betonienfaft oder Srübe,

(Stinonurzel, gleidyviel,

triefe es in bie Şgren. 


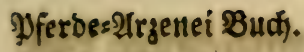

\section{(5) in anderes.}

Sandaraca pulverif. 1 unze,

madje ein Sconigjapfen bataus, uno ftecte e? in bie $5 \mathfrak{S h}=$ ren.

$\mathfrak{B}$ enn aber $\mathfrak{S}$ ürmer in Den Shren wadjen, fo fülle

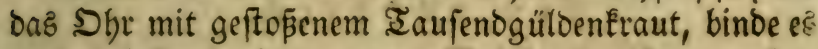
ơ unt lap̃e es einen ganzen Tag barin, albbann thue e? heraus und fprife nad)folgende Sadjen bimein :

Bilbe Eucumernfaft,

SPfirfingsfaft, jebes 2 loth,

Saumól 1 loth, untereinander gemijht.

SBenn bie $\mathfrak{B}$ ürme toot find, fo mus man fie mit ei= nem Snftrumont beraus thun, fo nun bas (ङefd)wür ganz gereinigt, foll man es wieber zubeilen mit nadfol= genden Gachen :

SGeiraud) 1 loth), Sarcocolla $\frac{1}{2}$ loth, Şonig 3 loth, $\mathfrak{S}$ sein 12 loth,

afles untercinander gemifat und baz shr bamit ge= idbmiert.

(E) in a n Dereb.

Sd)neide die Etelle no es meid) ift, mit einem MRef fer freugweife auf uno reibe (S) rünpan binein, fo wer: Den bie 23ärme getobtet, welde man hernach heraus nebmen uno ben Gdjaben mit guter Salben mieber zu= beilen poll.

\section{E in a n beres:}

Iroppfele etlichemal in bie Beulen; ba Die $\mathscr{S}$ ürme in= nen fino, nadboem fie vorker geöfnet, Baljamum, Sul= phutatum Ierpentinöl binein:

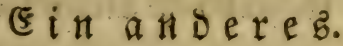

aloe 1 loth, 
Sandaracd 1 Suintlein, Mntrben 2 Suintiein, Sconig 4 lotb, 'TSEein $\frac{1}{4}$ Maa

lape alles untereinander uno idhmiere die Sobren bamit.

\section{E in anderes. 2fllaun 2 lotb,}

löfe benfelben in sfifig auf und wafhe bie shren bamit.

Ein anderes.

Siebe rothen Seifuß, $\mathfrak{B r i d e n}$ und $\mathfrak{E u l f r a u t}$ in

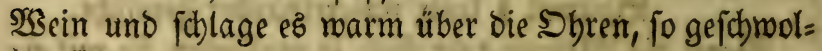
len find.

(E) $\mathfrak{n}$ and $\mathrm{ereb}$.

Rebme शū̄öl, Sconig, einez fo viel als bas andere und fdomiere es in bie Shren.

(E) $\mathfrak{i} \mathfrak{a} \mathfrak{n} D$ ere

WSeidenblätter $\frac{1}{4}$ פfund,

GSeftopienen Schmefel 2 loth,

Effíg $\frac{1}{2}$ Maá̄, Baumól $\frac{1}{2}$ Pfuno,

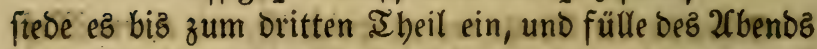

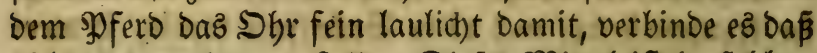
nichts bavon betauz falle. Diejes Mittel ift in folchen.

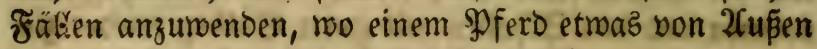
in baz Şhr gef́ommen oder gefallen ift.

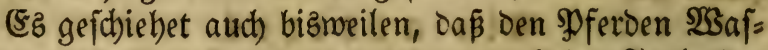

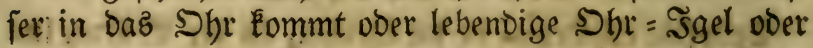
anoere bergleidjen İbierchen binein friechen; ebenfo er=

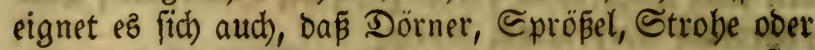
andere ftechende Segenftänoe binein fallen ocer gefto= jen werben.

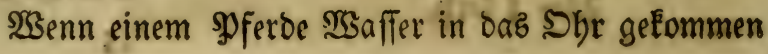




\section{Wferbe:2(rzenei But).}

ift, fo nehme man ein Bäuldhen von 230 olle, tauche baf= felbe in Baumöl uno Salpeter uno wajd)e Damit bas Shr fo gut als möglid aus; hernads Eann man Saaum= Sel mit Salpeter vermifdt ins Dbr tröpfeln.

Bsenn lebenbige Iabierdyen binein fommen, fo foll man ein fubtiles Snftrument mit SSoll umbidelt und mit Scarz bejdmiert in bas Sobr ftecten, uno fold)ez wohl bin uno her wenben, Damit es basjenige İ bier, weldjes bineingefommen, bertibren mag, uno alfo wie= Der herausgezogen merbe. Soer tröpfele ๔aft von Co= loquinten uno Eapern Iropfenweis binein, ober fonft eines andern warmen Sels fo viel, Dás bas She voll unto das Iffierchen burch Daselbe über fich gehoben wer= De uno gleichfam beraus idjwimme, ober, indem bas sूfero ben Ropf uno Solen foüttelt, wie fie denn in biefen fällen geroöhntich zu thun pflegen, herauz fomme.

SBenn aber fonften etraa binsin gefallen ober gefto. pen roorben, folle folches mit einem Sobrloffel ober Erum= men Scäctchen heraus gezcgen werten. Şenn man ç aber bamit nid)t geminnen fann, fo foll man oft war= mes 23 affer in oas Shr fprif̧en, fo treibt es basjenige, fo bineingefommen, aud) berauz.

\section{Die $\mathfrak{B} e r p f l e g u \mathfrak{n g}$.}

1. Der Stall foll mittelmäß̈ig marm fein, obne allen SBsino uno Sonnenifbein.

2. Das Futter foll gebrochen fein, lindes Şeu.

3. Der Trank foll nict) zu falt fein morin Süpholz,

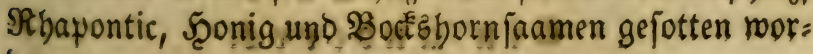
Den. 


\section{Pferbe:2ragenei Budf.}

\section{Das 24fte Capitel.}

\section{Bon be m Nafengefd) wü r.}

Die Şauptflüpe fino Feudbtigkeiten, von meldben, menn bas Scaupt boll iff, diefelbe in die andere (slieber berab fließ̧en uno mancherlei gefälyrliche Sranḱbeiten,

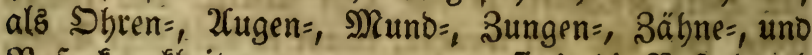
Najenfrantbpiten erregen; menn fie in bie Naje berab fallen, alsoann erregen fie Najengeidhwüre, bas belle Safentropfen oder einen ftarken $\Re$ iog.

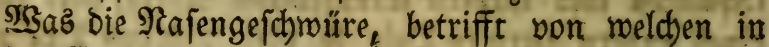
biefem Eapitel abjonderlid foll gemeldet merben, fo ent= fpringen biefelben bon ben-fisarfen berabfallenden

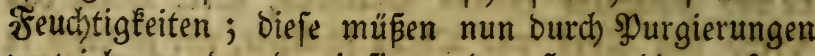
wertricben werden, bamit fie von Dem Scaupt hinmeg kommen, foldhes auch wieder geffärft werbe, bamit ez bes Utnratbs nick)t mebe auf = uno annebme uno zu der Saje verichicke, zu weld)er (Sur dann eben biefe MRittel follen gebraucht merben, welche im Eapitel ron Dem Siopfwebe uno flüken fino befhrieben worden, wie aud bie 2lder= lāese; überoies follte man ben ichabhaften Srt mit 23sein, weldher mit Şonig vermifcht ift, roobl bäben uno wajchen, ober mit (Effig, weldher mit Sconig vermifcht ift, bernach fann man es aud) mit folgenber Mixtur roafchen :

Efitig $\frac{1}{2} \mathfrak{R a a}_{\beta_{1}} \mathrm{Salz}_{3}, 3$ loth âlaun 2 lotb,

untereinander gemiffot und gefotten, und roobl mit ges rafchen ober in bie Najelöd)er gefpriąt.

Ein andere

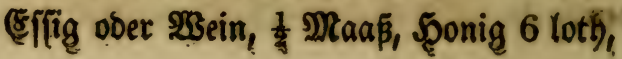




\section{Pferbe-2lrzenci Bud).}

Egyptijde Salbe 2 loth,

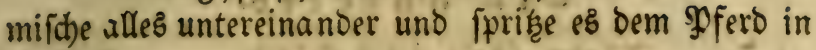
bie Raje.

\section{Sin andereb.}

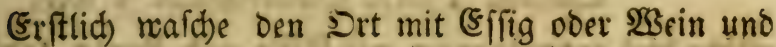
Soonig mit einander vermifdt fleipig aus, Darnad blafe ein roenig von nad)folgentem syulver in bie Rafe:

SBeipe Niesprourzel 2 loth,

Düre (Sartenfräßé 4 loth,

mirdbe es untereinander.

Ein anderes.

Mnrrben 2 lotb), 2fllaun 3 lotb),

(Salläpfel, 2 lotb,

Sebranntes supfererz 1 loth,

mijhe es untereinander, mad)e eह zu einem গु)ulver uno blaie Dem SPferd bavon auf einmal ein flein menig in Die Naje.

E $i \mathfrak{n} \mathfrak{a} \mathfrak{n} \in \mathfrak{T} \in \mathfrak{B}$.

Drachenblut 2 lotb,

2ulaun, $\frac{1}{2}$ Sf fund, Jerpentin 8 loth,

Difitel 3 loth, Eifig fo viel als nöthig ift, mijd)e es untereinander und mache ez zu einer Salbe, in biefelbe taud)e eine şurzel ober aus Fladbs gemad)=

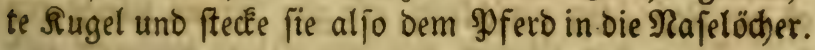

(5in andereb. ungelöichten Salf 8 loth, xiche, Sconig, jedes 4 loth,

23zin, Efiig, jeoes fo viel als nöthig iff,

milche es untereinander, mache eine Salbe baraus unt,

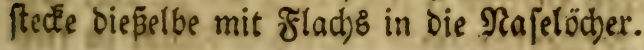




\section{Ein a noereb.}

\section{2rilaun, Salz, jedez 2 loth, \\ S.ebrannteb SBlei, 3 lotb; \\ Salmiac 1 loth, Sleimeipjalbe 4 loth,}

mijhe dies untereinanoer mit Effig uno Sconig, fo vier als nötbig iff, madbe eine meiche Salbe baraus und ge: brauche fie mie bie vorige. $\mathfrak{S e n n}$ aber bie Scbärfe

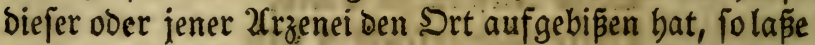
ifnen etlidbe Mal warme నübemild in bie Najelöder binein fprifen uno bes Sulvers von $\mathfrak{B S e i r a u c h}$ binein blajen.

\section{Das. 25fte Capitel.}

Bon Dem übermäbigen Fleifh ober SSefdinulfet in ber Nafe, Polypus genannt.

Diejer Mlanget ift ein weiches Fleifd, melches unna=

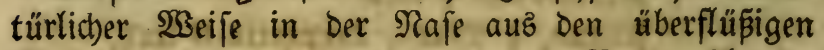
Feuchtigkeiten ent jpringt, ooer auf ein Najengefdroür, welcyes nidbt aus dem funbament gebeilt worben, folgt; befommt viel $\mathfrak{B s u r z e l ~ u n o ~ n i m m t ~ b i s m e i l e n ~ a l f o ~ z u , ~ b a ~}$ ę die Najelöcher verichliejt, oft gar herauz bängt uno Dem Ihier Den (Seruch und Den 2 them benimmt und verk̂ürzt, gibt einen roiderlichen (Sieftank von fid), macht bas \$ffero melandjolifd) uno nager, Daß́ ę medet jonaufen noch niešen fann, läß̈t eiterichen Unflath auz

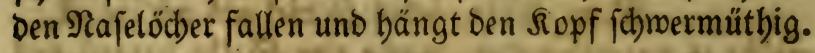

(sieb foldhen spferden 8 Iage lang vir ber Sur täg=

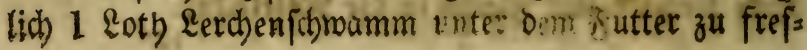




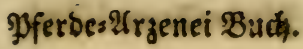

fen, bernad) menn bex Eerdbenfanamm 8 Tage lang gebraudst worben, follte man nadfolgende şurgation gebraudjen :

\section{3.}

Rerchenichmamm, 1 loth,

Scierä picrä 2 loth), (Summigutä 2 Suintl.

Scammonium 1 Suintlein,

Salapwurzel 1 loth,

Iurbith, $\frac{1}{2}$ Suintlein,

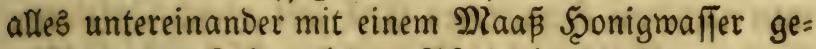
mijcht und auf einmal bem Soferb eingegoßen.

Dieje \$ुurgation muß Dem Sুfero alle vierzebn Iage gegeben merden, bis ber Sdhaden gebeilt ift, mie aud alle $\mathfrak{W}$ odbe ein SIyftier und alle zreei Tage vor ber Şurgation aud) ein (SInftier.

Racboem nun bie Şurgation bas erfte Mal geidbe= ben, foll man ben Sdbaden mit einem beisen (5ifen Sau: terrijiten, oder folibe Arzeneien brauchen, bie äzenen, uno Das Fleifh verzebren, als :

Majoranjaft, (5ordenbenedictenfaft, jedez 2 loth, (Ealmuspulver,

Roth Sorianderpulver, jedes ein Suintlein, untereinander gemijht uno in bie গaje gefprif̧t.

\section{Fin andereb.}

Rebme ben Saft von Eleiner Sd)langennurzel brei Soth, gepülverten @aamen von Drachennurzel, die

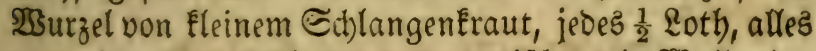
untereinander gepülvert und gemifdt, mit $\mathfrak{S o l l e ~ o b e r ~}$ Flads in bie গaje geftoptt.

(5in a no exe.

Sandaraca 2 lotb, 


\section{\$ulver bon @d)langenflautjaamest ein lotb,} vermifche es untereinander uno ftecfe es mit 280 offe in bie Nafe.

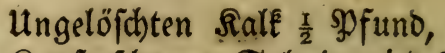

Rupferid)aum, Salmiac, jeoes 2 loth,

fiebe biefe Sceilmittel nohl in einem fließenden $23 a f f e r$ und fprifie bavon in bie গlafe.

WBenn man ben Sdjaden aber beraubichneibet uno

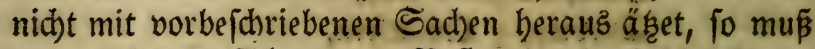
man nad) Dem Sdynitt Den Reft mit obenbeidgriebenen Sachen vollenos beraus äken ooer nachfolgenoe Sachen gebraucben.

Rebme rothes నupferwaffer, ftreue es barauf ober vermilche es mit Efifig uno beftreiche ben \$rt Damit.

\section{(E) $\mathfrak{n}$ a noeres.}

Nebme den Saft von Dem Sraut \&ajerpitio, bermi= The es mit Sconig und fichmiere ben \$rt bamit, oder Supfergrün darauf geftreut.

(E) in a n bereb.

Nehme ungetöichten Ralf mit (sfifig vermi cht, ober römif t)en Sitriol, ober bas \$ुulver von dem Echlan= genEraut, ober bie grüne Salbe von §upfer uno Şonig untereinander temperitet barauf getban.

Die 2rrzeneien aber, welche bas žlleifh Durchnagen, verzebren uno ganz binmeg äten, fino oer Saft von Majotan.

Die ßerpflegung anbelangent.

1. Der Stall foll mittelmäßig warm uno nidbt feud)t uno windig ooer gar zu falt fein.

2. Dab Futter fod rein yon allem Staub und ba= 


\section{פूferbe:-2.rzenei Bud).}

runter Betonien, rotber Bolus oder gemeiner Booluz ver= mija)t fein.

3. Der Irane foll laulicht fein, morin Bocţ̧orn= faamen, Betonien und Sceionifd)munofraut gefotten rorden.

\section{Das 26ite Sapitel.}

\section{Bon Dem übermä̈igen Rafenbluten.}

Diefes Hebel fommt von Dem überflüpigen Sscblüt, Doer wenn irgendeine sBlutader gefprungen ober zerrifen worden, ober wenn es in ober auf bie Naje geftopen, geid)lagen oder verlefet worden, oder wenn es in groper Şike wider die ?latur gejagt worden, denn Durch fold)e übermäß̈ige Bernegungen des \&eibez miro ibm daz Scaupt um fo viel erbiket, Die (Seifter mit fammt Dem (seblüt entzündet, bie SBlutadern überfüllet uno alfo das (Se= blüt beides Durd die Unmäpigkeit Der Serwegung gleid)= fam entbrannt uno (Sholerifh) gemad)t, Daßj es in Den roern nicht bleiben Eann, fondern Diefelbe eröffnet uno Durch bie Najelöd)er heraus rinnet.

Diejen şferden follte man um den Sopf leinene $\mathfrak{I}$ ü= (ber, reldhe in (5ifig gemeid)t, umidhlagen, bie Sd)en= fel uno (Siejaröt oft mit (sfifg uno frifhem Sirunnen= maller beftreichen uno reiben, eine 2coet auf Dem Sopf Doer an Dem Şals gegen die ๔eiten hin, ba bas̉ Blut zum Rajeloch beraus läuft, öfinen laßen, uno Slyftier brauchen, bie Scaar bon Der Stirn binneg fbeeren unb folgendes spflaiter überlegen :

\section{Dradbenblut 2 suintlein,}


Rotben Bolus 2 lotb,

Bsiloe Sranatenblüthe,

2cacia, jeoes 1 loth, Esiertlar 6

Rofenwaffer, Rattichwaffer,

Nad)tidhattenwaffer,

Marienciftetmaffer,

WSegeritimarfer, jebes 2 loth,

mijche es untereina:ber uno follage es über.

Ein andereb.

Brunnenterefieñaft,

(5iertlar, Bobnenöl,

mijche ez untereinander zu einem şflafter.

(E) i a $\mathfrak{n}$ Der $\mathrm{eb}$.

Iragacanth 4 loth,

Rotben Bolus 8 loth,

Drachenblut 3 loth:

ŞSeiraud), Maftix, jebes 1 loth,

2Bilde (Branatäpfelblït 2 lotb,

(Serftenmebl 12 loth,

EierÉlar 12,

Effig, fo viel nöthig iff,

mifhe es zu einem \$flafter und follage es über.

Ein ander $\mathfrak{e}$.

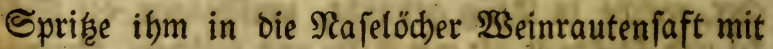
Effitg bermifht, ooer 2 Loth Rauten mit (Effig angeftoßen.

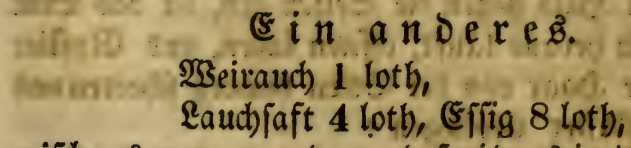

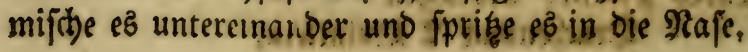




\section{goferbe=singenei $B$ Bud).}

\section{(5in an Dereb.}

2(ttic) jaft, (S)rün Sorianderfaft,

2fllraunjaft, eintes fo viel als bes andern,

Effig 10 viel nöthig ift, mifde es untereinarider uno fprife es in die Rafe.

(5 in andereb.

Blafe ifm bas \$ুJulver vom gebrannten \$apier uno Bolle in bie Naje.

(5) in a ndereb.

Blafe ifm calcinirtes Şirfdyorn in bie গafe.

(E) $\mathfrak{n} \mathfrak{a} \mathfrak{n} \operatorname{ereg}$ গু.

Uloes Epatica 2 loth,

SBeiraut), Drathenblut, jedes 1 loth,

Rothen Bolus 3 loth,

Slein zerjat)nittene Sajenbaar $\frac{1}{2}$ loth,

mifche es untereinander und blaje es bem Sू)ferd in oie Naje.

Ein a n Dereb $\mathfrak{X}$.

Şeoörten भूferdemifí,

Efelsmift,

Săuorect, jedes 2 loth,

Rauten 1 lotb), mijhe es untereinander uno blaje es bem Sfferd in die Naje.

E $\mathrm{i} \mathfrak{n}$ andereb $\mathfrak{B}$.

(Sampfer 1 loth,

Wilbe (Sranatenblüthe 2 loth,

Rotbe Sorallen 1 loth,

SBlutifein 3 lotb,

(5alläpel 2 loth, 


\section{Murrben, rothe Rofen, jebes 1 loth,}

mifde es. untereinander und blaje ez bem gofero in bie Naje.

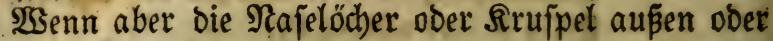
inmenbig verwundet iff, foll man in= ober ausmendig Den Sdbramm, welchen man bovift nennet, mit $25 s e i=$ rauth vermifd)t binein fohieben ober barauf thun, ober

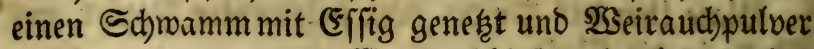
beffreuet, binein in bie 23 unde fahieben oder legen, ober ein Inftrument mit $\mathfrak{B}$ eiraud), Spinnenweb, Eierflar und Sel beftreichen, binein thun, benn biefe alle baben Die Rraft bas Blut zu ftillen uno bie verlestęe Srufpel zu beilen.

\section{Die $\mathfrak{B e r p f l e g u n g . ~}$}

1. Der Stafl foll an einem ftiflen Drt, mittelmäpigig warm und von aller feuchten \&uft oder $\mathfrak{B}_{\text {Sinde }}$ befreit fein.

2. Das Futter follte gebrod)en uno mit rotbem $\mathfrak{B}_{0}=$ luz vermifácht meroen.

3. Daz Irinken laulidjt uno etwas fchönes Mefl barunter vermengt fein.

\section{Dab 27fte Eapitel.}

\section{Bon Den Flüpen, melct) von Dem Gethirn} herab fallen.

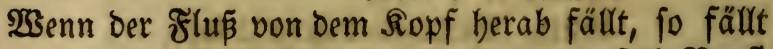

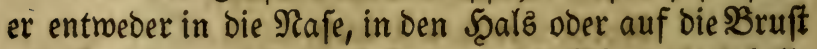
uno Rungen ; alsoann befommen die গুFerbe baz belle oder Elare Majentropfen, einen trodenen Şuften, Reel= 


\section{Pferbes:2(rzenei buts.}

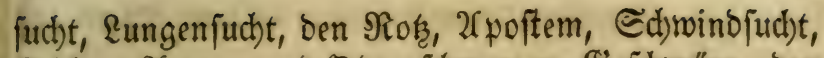
Reid)en, 2(ugen = uno Sorenfd)merzen, Siefdymüre, ben $\mathfrak{3}$ urm, Fifteln, Flopgallen, Uberbein, Şliebermebe und bergleidhen.

Diefe sूferde ziehen Die Srseichen ein und aus, bie Rafelöb)er bismeilen meb: ooer beftiger als gewöhnlid) ein, benegen bie $23 e i d$ en oder Seiten bei Dem 2thmen gemaltig, alz mie die bämpfigte $\$$ ferbe.

Solde Flüfe entitehen entweber aus ber $\mathfrak{L}$ eber, wenn bie (Salle verffopft ift, oder von groper erlittener Säl= te, ober auch wenn cin SPfero gar zu fehr erficht wor= ben ift und gleich Darauf in ein Ealtes $\mathbb{Z}$ baffer gerittem, oder an einen Ealten Sit geffellt morben, ober von allzu groper Erbifung im Sommer; biefelben merben ba= ber eingetbeilt in Ealte uno hipige Flüpe.

\section{Daz 2Sfte Eapitel.}

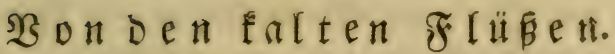

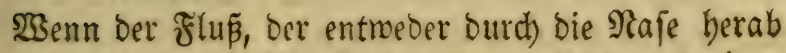
rinnet, ober in oie Siruft ober \&unge fällt, aus einer Ealten Feudtigkeit entftanden, fo fließst ber Fluß bick und zäbe, bie Najelöchet find oft verftopft, baz Maul ift mit weipem $\Xi$ baum gefüllt, und Der Ropf und bie 2lugen bleiben in biejem Fralle von Scike befreit. 2Cls ein wirkfames Mittel kann man folgenden (Singū ge= ben :

\$̧onig $\frac{1}{2}$ Maaßs,

Seritenmafter $\frac{1}{2}$ Mlaẫ,

Süpholz 4 loth), 
Eoche bies untereinander uno fchütte es bem $\$$ Dferd auf einmal ein.

Ein anoeres.

Intimonium Diaphoreticum, $1 \frac{1}{2}$ ober 3

Suintlein,

Separ 2 Untimonium 1 Suintlein,

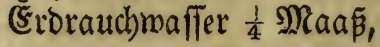

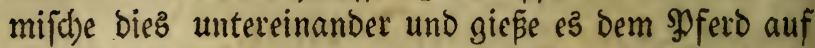
einmal ein, becke ez warm zu uno lape mobl batauf rei=

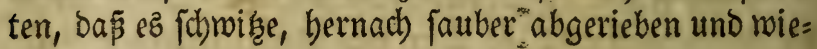
ber zugebedt.

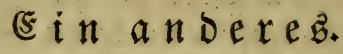

SBinde ifm ein Sädkden auf bas (šebiß̄ nachfolgen= de Şegenfänoe, als Sertram, ভäbenbaum, Süßjbolz, cines fo viel alz das andere, uno befte es im Stano berum, laß̄e täglich 2 Stunden baran Eăuen, fo miro fich) ber Flü rejolviren.

\section{E $\mathfrak{i n} \mathfrak{a} \mathfrak{n} \in \mathfrak{r} e \mathfrak{b}$.}

Rape bem soferd ben Staffel ftechen, die 2rbern auf ber 3unge uno bem Scalz ficlagen; bes andern Tages nad)folgenden Irank einfdütten :

unjer Frauenbaar,

Stöbazkraut, jeoes eine Şanovoll,

Rofinen, Sebaften, jebes 2 loth,

Datteln, Feigen, jedez 12,

lā̄e in einem $\mathfrak{B a}$ afler alles wohl fieben, hernach ausge=

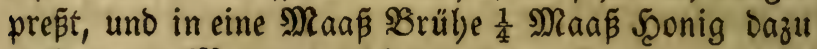
getban und Norgenz nüchtern eingegoßen.

\section{ङ in a $\mathfrak{n}$ Dere}

Senf 3 lcth, Spfeffer 2 suintlein, 
Brübe von gejottenen Rauten uno Seifuß cin $\frac{1}{4}$ Maá̃,

W3eī̄en 23 cin $\frac{1}{4}$ Raลấ,

lape ez ein wenig untereinander fieden und fdutte bem $\mathfrak{\text { pferd }}$ warm ein.

Ein andereb.

Diptam, Ěbeben, Epinacaroi,

Sümmel, Ingmer, jedes 1 loth,

Eierootter 20,

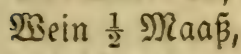

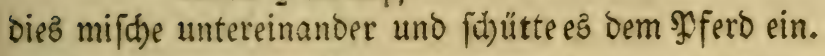

Sin Daunf uno Rauch gegen Diefes (Sebrecten.

Rosmarin eine Scanovoll,

Camillen, Mop, Scolder, Dillen, Steinflee, W3aflermünze, ein jedes 3 Şändevoll,

lap̧e es im 2 affer fieben und Den Dampf Dem Sुferd in die Naje geben.

E i n a to erer $D a m p f$.

Maftix, Sescirauch, jeoes 1 Suintlein,

Rorbeer 1 lot: , Solen 3 Şänoevoll,

Rümmel, Rosmarin, jeoes 1 loth,

mijhe es untereinander, auf $\mathfrak{S} 0$ blen gelegt uno bem פpferd den Dampf in die Nafe geben lafen.

(s in a n dere $\mathfrak{b}$.

Rebme $\mathfrak{B}$ olle oder eine lange (Sänsfeder, tauche fie in Scolder, Dill uno SBeinrauten= Del uno fobiebe fie in dic গRaje.

Fin a noereb. Jkijhalbe 4 lotb, 
186 Pferbes:argenei $\mathfrak{B u t f \%}$

Eor = Sעel 6 loth, Sertram 2 loth,

mijche es untereinander uno fchmiere bas Şaupt bamit.

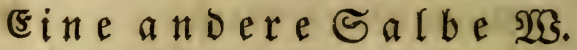

Murrben 3 lotb, Spid 2 loth,

Sibergeil, 1 Suintlein,

Rojen = Sel 6 loth, Rorbeer $=$ SDel 10 loth,

althee 12 loth, Sopulion 6 loth.

mifche es untereinander zu einer Saupt falbe.

(E) $\mathfrak{i} \mathfrak{a} \mathfrak{n} \mathfrak{D}$ ere $\mathfrak{b}$.

Runde Şobltourzel 4 loth,

WSein 26 loth,

mijche es untereinander und fprife ez Dem spferd in die sqaje.

\section{Das 29fte Capitel.}

Von Den Flüfen, weldye aub Der Sikse entitanden fino.

Denjenigen Flüpen, welthe von groß̧er Scize berfom =

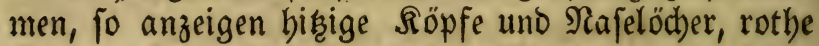
2lugen um biefelbe bobe erbabene Blutabern, mie gleid)= falls aud) um bas \$iaul berum, foll manauf folgende Weije entgegenmirken, nämlich bor allem 1 ooer 3 Iage nad)jolgenden (singữ frübe eingieß̄en :

(Serftenbrübe,

Magโaamenbrübe, jedes $\frac{1}{2}$ Maaß́,

Eerchenfchramm 1 loth,

Turbith $\frac{1}{2}$ loth,

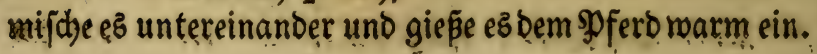


188

Ifferbe:2(rgenei $\mathfrak{i t u d ) . ~}$

E i $\mathfrak{i}$ a $\mathfrak{n}$ Dereb.

Fif

Weip̧en $\mathfrak{G e i n} \frac{1}{4}$ Maaß̃,

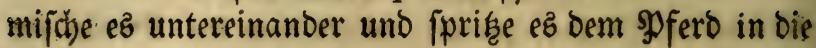
গaje.

(E) Wsilde Cucumernfaft 1 lotb, Berlaßjenen $B$ utter 8 lotb,

mijche es untereinander und giepe ez Dem spferd in bie graje.

Ein andereb.

Madbe ifm einen $\Re$ auth von Sd)wefel, won $230 b l g e=$ muth voer von einem $\mathfrak{L}$ umpen von leinenem Iuth.

\section{(F) in a ndereb.}

Nebme eine lange Feder, tauche fie in Rorbeer= Sel uno Sutter, ftecke es dem Spfero in bie Naje, oder neb= me folche freber, ftreiche fie mit ficharzer Seife, ftreue bernach Euphorbium barauf und ftecte es bem Spfero in bie Raje.

- E $i \mathfrak{n} a \mathfrak{n} \boldsymbol{D} \mathfrak{e} \mathfrak{e b}$.

Solonurzer 4 loth,

Sorbeer 2 loth, \&aubanum 1 loth,

Şachs, fo viel nöthig ift,

macbe ez zu einem Sुflafter uno lege ez über den Siopf.

Ein andereb.

Sdhwefel 1 loth,

(Sampfer 2 suintlein, (sffig $\frac{1}{4}$ Maán,

vermifche es untereinander, giepe es bernach auf einen

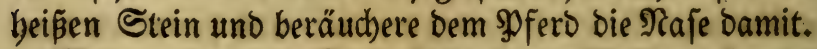
B̧enn aber ber $\mathscr{f} \mathfrak{l u} \beta \tilde{\beta}$ nidjt fort will, jo mús man 
vorbeugen, baß̄ er nid)t auf die SBruft ober \&unge berab

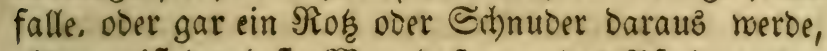

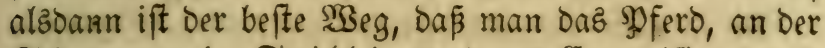
Stitn born ein Strithlein 2 oder 3 Sauterifire, Damit ę 2)aterie gäbe, Dar Fluß fith refolvire uno Dort bin ziebe: ober man ziebe ibm unter Den Sinnbacken zmi= idhen Scaut und Fleif(b), aud) in Der Seite ein Scaarjeil, fo miro ber Flup fit) audb Dorthin zieben und austinnen.

\section{Die ßerpflegung während diefer beiben flüpen foll fein:}

1. Sin nidht gar zu bisiger ober Ealter Stall, fein trocfen und temperilt.

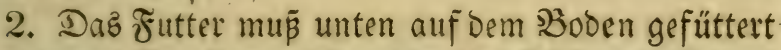
werden mit Speifen, welde nid)t über fid in bas Scaupt Dämpfen, alz Sleien, Roggen, (Sierfte, SBohnen, alles vorlber gefotten, oder gebrad)ene (Sierften mit Bodf'shorn: faamen ober Süßjolz vermijd)t.

3. Der Iranf foll laulid)t fein, worin Sodf3born= faamen, Gerfte und Sconig gefotten worben.

\section{Daz 30fte Sapitel.}

\section{Bon Dem Rok ober Githmber.}

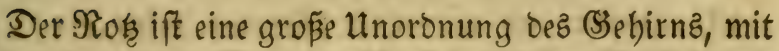
und neben einer Materie, für fiit) felbfit gefäbrlich uno übel zu vertreiben und von Ratur aljo befuhaffen, bas er auth andere Ibiere anftecken fann. Diefer ift nun

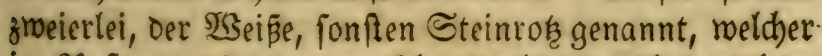
im 2 nfang und menn er nicht beraltet, mohl zucuriren. 
ift, ber andere aber, geblid)t uno mit Blut vermifobt fammt einem üblen (Seftant, ift nidjt mebr zu beilen.

23ir wollen bep̧balb bier zuerft über ben Steinrog abbandeln und unterfuchen, auz weld)en Utrfachen fein Entfeken berleitet uno wie Derjelbe etwa geheilt mer= Den Eönne.

\section{Die Sennzeichen beider Rokse find:}

1. $\mathfrak{Z S e n n}$ baz \$fero warm geritten worben uno man ithm die CSurgel zuhält, fo thut ez, als wenn ez erfticken wollte.

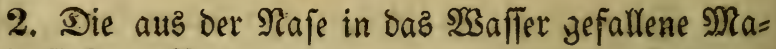
terie finkt zu $\mathfrak{B o d e n}$.

3. Die Materie fliepet ohne alfez aufhören.

4. Sf: bie Materie mei $\tilde{\beta}_{\text {und }}$ ohne einigen böfen (Se= rud), fo ifte ce ber Steinrós.

5. Sift Die Materie gelk, rötglidht ober mit $\mathfrak{B l u t}$ vermifht, to iff es unbeilbar.

6. Iapsen folche \$ferde bizmeilen faule Feuthtiglei= ten zu Dem Maul herauz fallen.

7. Sieben bas $\mathfrak{2}$ affer, welches fie eben geioffen ha= ben, mit einer großjen Menge Utnflath mieber von fich),

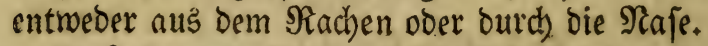

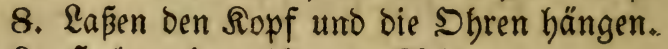

9. Scaben einen ichmeren 20them.

10. Schlagen baz Futter ab, mie auth bas Irintên.

11. Souften und zieben bie 20 seiden beftig ein.

12. Șaben Ealte Rafelöcter.

13. श्Serben mager unt faul.

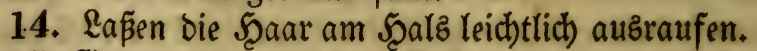

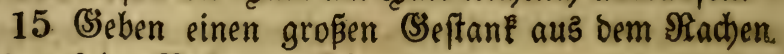
uno aus ber Raje bon fid.). 
Diefer entftebet aus drei verjchiedenen $\mathfrak{u r}$ jachen; erft = lid) von Dem Sishirn, für Daz andere von einer langen verbaltenen Seeljucht, orittens fann es ein \$pferd von Dem 2 nnftecten befommen.

Der von Dem Siehirn entipringt aus einem $U_{e}$ eber= flus ber Fent)tigkeit in oem (3) birn, weldber eine Fäul= nis verurjad)t, uno siejer iff aut) weis uno eine Ealte Raterie, wenn aber bie gelbe mit foldber Feudhtigkeit fith vermifit)t, wiro es nod) ärger und iff nidht mebr zu curiten.

Son Der Reelfud)t aber Fommt er aud bismeilen ber, menn fie veraltet und in einen ganz Ealten Scauptfluß fich verändert hat.

Einem foldhen SPferd laß̄e eine Scalzaber fpringen, bod) nicht zu viel, bes andern Iags barauf

Srebme Minrenen 1 suinttein,

Şoblmutzel, Enzian, jebes 2 Suintlein,

Rorbeer, Elfenbein, jedes 1 loth,

Salap, Soldanella, jedes $\frac{1}{2}$ lotb).

2rgric 1 loth,

Sconig 6 loth, SKein $\frac{7}{2}$ Maấ,

mifde es untereinander uno gieb ez Dem 2 ferb 4 Iage nad)einander allemal Dreje Dofits frübe ein.

E in a noerer e $i n g u f$.

Fend)el 2 loth, @üsholz. 4 loth).

Brandtlattig, 3 Scändevoll,

Sconig 12 lotb,

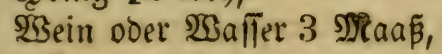

lape es robl fieben und gieße es dem গু) ferb laulid)t auf zrweimal ein.

Sernad) purgiere das SDferd mit folgenoem : 


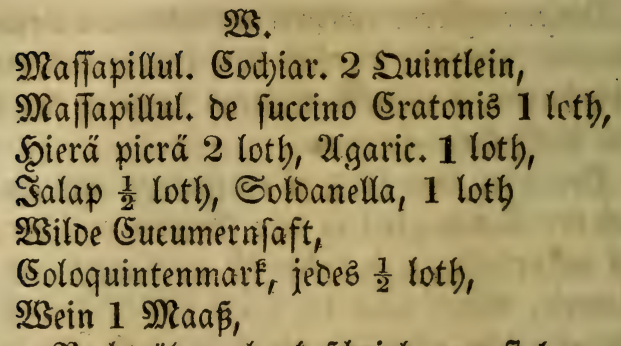

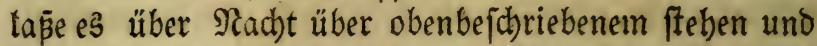
Den andern $\mathfrak{T} a g$ allez wobl umgerühtt und auf einmal Dem \$ferd eingegopen.

Eine andere $\mathfrak{P u r g a t i o n} \mathfrak{2}$.

פillbe Sucumernfaft, Soldanella, Iurbith,

2fgaric, jebes $\frac{1}{2}$ loth,

Salap I loth, 2 Sein $\frac{1}{4}$ Mañ

mifche es untereinander uno foüutte ez dem \$pferb auf cinmal ein.

E in a n Dereb.

- Shepar 2(ntimonium 1 lotb,

Saf̈ran $\frac{1}{2}$ Suintlein, $2 B$ ein $\frac{1}{2}$ Maaß̃,

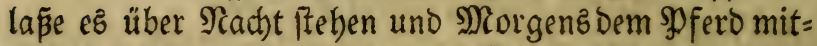

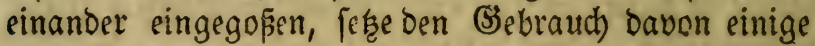
Iage fort.

\section{(5) i a a dereb.}

(Es ift aud) Der (5oloquintenfaft mit $\mathfrak{B e i n}$ vermifcht bierzu bienlid), Denn ef reinigyet daz (seśjirn, zertl)silt bie \$ollegma und andere zäbe Feuchtigkeeiten und zieht bieferbe auz der Tiefe ber (s)lieber heraub.

\section{(E) in andere}

Şaarftrang 2 loth),

Fenchel 1 lotb, 
Salap 2 Suintlein, Iurbith 1 Suintlein, Bein $1 \frac{1}{2}$ Maá⿱㇒㠯,

Eoche es miteinander und fohütte ę einem ftarken gropen \$ferb auf einmal ein.

E $\mathfrak{i} \mathfrak{n} \mathfrak{n} \mathfrak{b} \in \mathfrak{r} \in \mathfrak{B} \mathfrak{M}$.

Scammonium 1 loth,

Salap, Rbapontic, 2fgaric, jebes $\frac{1}{2}$ loth,

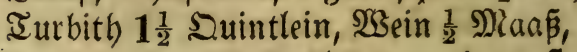

mifche bies untereinanoer uno fchütte ę einem ftarken \$ffero auf einmal ein.

E in a $\mathfrak{n}$ bereb.

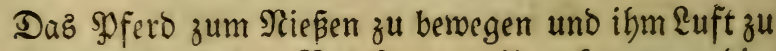
machen, wie aud) Den $\Re$ of fortzutreiben, Eann man bie= jenigen Sachen brauchen, meldhe in bem Capitel bon ben F̌tǚnen fino befchrieben worden.

\section{Die $\mathfrak{B e r p f f e g u n g . ~}$}

Dieje \$fferde follte man ftreng yon andern \$ferben abjonoern und allein in einen mittelmäßig warmen Sort ftellen, ba fie einen ganzen ๔tall boil uno nod) mebr anffecten Fönnen, uno meil foldser 2 fffect an fich felbft eine Ealte Materie ift, melde fich in Der Scirnichale ver= fammelt, alfo foll man folden \$ferden ermärmende und zertheilende Speifen uno Setränfe geben.

Das Futter foll gebrod)ene Ridjern, Şeizen, Sleien uno Berfte fein.

Der täglide Irané foll fein :

Iaufenogüloenfraut 3 Şändevol,

Inoblaud),

Sngmer, jebez 6 loth,

Srefienfaamen 4 lotb,

(salmus 8 lotb, 


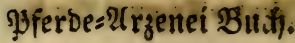

3ungen, roobur(i) Dann bie meatus oder (sెänge, butw్ meldbe die finnlichen (s)eiffer ifren Sugang zu ber Sun= ge baben, gebemmt und ibnen alfo die Sraft ber (5m: pfindlichleit uno Benegung allerbings benommen wer= Den.

Die erfte Scülfe ift, daß̃ man bas (S) hirn purgire, bie 3ungen unteroeß̄en abmechblungsmeife mit nadffol= gendem oft majd)e und reibe :

Bertram 1 lotb,

Rojen 2 loth,

Sngmer 1 loth,

mifibe es untereinander und fiede es mobl in sffitg und waiche bie 3unge oft bamit, bernad,

Nebme Sfeffer 2 loth,

Bibergeil $\frac{1}{2}$ suintlein,

mijche es untereinander uno reibe bie 3unge oft bamit.

Ein andereb.

Rinosigalle 10 loth,

Bibergeil 1 loth,

fope es wobl untereinander und fâmiere bie 3unge ba= mit.

E i $\mathfrak{n}$ a $\mathfrak{n}$ ere

Bertram 1 loth,

Senf, פ̧feffer, jeoes 3 Suintlein,

Salmiac 1 Suintlein,

mifche es untereinander uno reibe bie 3unge Damit.

Ein andereb.

Iaujenogültenfraut 6 loth,

M̧ein 1 Maaß́,

fiebe es wohl und wajke bie 3unge oft bamit. 


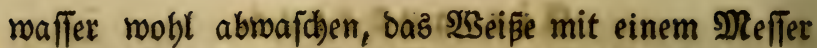
mebl abjhaben uno barauf folgende Salbe fdhmieren :

Saft bon Sliven 1 loth;

Rojenbonig 4 loth,

milche es untereinanoer.

E i a n

Saft bon Sliben 3 loth,

Efifg 12 loth, Salz 2 loth,

mifche es wobl untereinander, nachoem bie 3unge wohl abgeidtabt uno gewaichen ift, fo reibe es mit nachfol= genoer Mixtur :

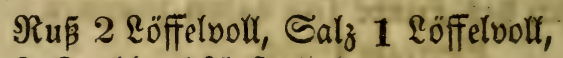

3 ßnoblaucheöpfe,

ftop̃e biez nobl untereinander, yor allem aber foll man Dem \$pfero eine Blutreinigung geben :

Shepar 2fntimonium 1 Suintlein,

Scorzonerawafier 16 loth,

mifhe es untereinander zu einem (singü, ift dis sunge fegr aufgelaufen, fo joll man bem spfero auf beiden Seiten bes Scaupts eine 2(Der offnen, mie auch unter

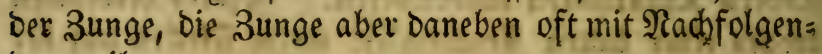
Dem reiben :

\section{Sfeffer 2 loth,}

Bertram, Ingmer, jebes 1 loth.

untereinander gemifobt.

\section{e in andereb.}

SDoer man nimmt Salz uno Efifig uno reibt bie 3un= ge jo lang, biz fich Die (Sejd)wulft zertbcilt, benn biefe beibe Stücke haben die Siraft beibes :zu-zertheilen uno bie vetfammelte Raterie aúgzutroctenem. 


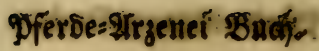

\section{9: E in a n Dereb.}

Sdbmiere es oft mit Rofengonig.

Ein anderes.

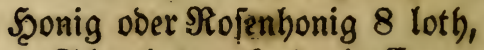

(Sejalzenen Schmeinşmark, oder in (Ermangeling def= fen Sthroeinefdymal; 10 Loth, mifche es untereinander zu einer Salbe.

(E) in and $\mathfrak{x} \in \mathbf{B}$.

Ungelöidhten Salk, weldber breimal gena $=$ fithen worben,

Salz, jeoes 6 loth, S5onig $\frac{1}{2}$ Mtaaß,

fiebe es untereinander zu einer Salbe.

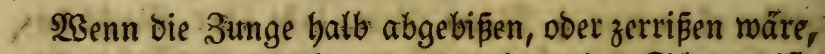
mus man mohl überlegen, wie und no ber Sdjaden iff, Denn wenn ber Sdjaben vornen an Der Z3unge märe, und gar viel von ber 3unge berunter bienge und nicht mebr zu beften, biefetbe folle man vollends abjhneiben uno oft mit nachfolgender Ealbe ichmieren:

Rojenbonig $\frac{1}{4}$ פूfuno,

sommeranzenichaalen,

(Sranatäpfelichaalen,

Sdbmarzmurzet, jeope 2 loth;

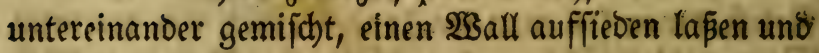
bie 3unge Damit gefdhmiert.

Desgleid)en fo man bie surnge heften wollte, foulte man bieje Salbe brauchen, uno nachfolgendes täglich im Futter zu frefien geben :

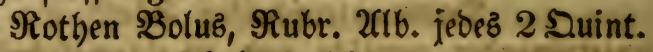
IEeufelzored $\frac{1}{2}$ Suintlein, mifche es untereinander und gebe es auf einmal in zits 


\section{Pferbe:2શrzenei Bud).}

ter zu freffen. (5z joll aber Daz Futter gebrod)en fein, bis Dab spferd geheilt ift.

Ein a noereb.

פgfeffer 1 loth,

(Sebrannten 2flaun 2 lcth),

Sconig 6 loth,

mifbe es untereinander zu einer Salbe und beftreiche bie 3unge bamit.

Ein a noere

2Sajche bie 3unge oft mit 2Ctlaunwalfer.

$$
\text { E } i \mathfrak{n} \text { a no } \mathfrak{e} \mathfrak{x} \mathfrak{e} \text {. }
$$

Sdjönes Mehl 6 loth,

5̧onig, fo viel z̆ einer Salbe genug iff,

thue barunter $\Xi_{a l z} 6$ loth, und mifho es untereinan= Der.

(5z haben audd) etlide \$ferde Eleine $\mathfrak{W a r z e n ~ a u f ~ D e m ~}$ Eanal bart unter ber 3unge figen, SBib. \&it. 2f. mit $†$ bezeid)net, meldbe man Dorrmarzen zu nennen pfleget, biefelbe foll man in abnet)menden Mond mit einer Sd)eere abzmidén, Dann fie babon nidht zumehmen fön= nen, und Den Sort mit Effitig uno Salz roohl reiben.

\section{Die \$erpflegung foll fein:}

1. Esin mittelmäpigiger warmer Stall.

2. Das Futter follte gebrodben fein, worunter $\mathfrak{B e r}_{\mathrm{e}}$ denifhramm uno rothe Sidjern vermengt find.

3. Der Irank foll laulidjt fein, in meldjes fobö= nes Mebl uno Sconigmaffer gethan morben, wie auds etraas Salpeter. 


\section{Pferde:2rrgenei : Buth.}

\section{Dab 33fte Capitel.}

\section{Bon Den Bähnen uno Deren Sebrechen.}

Der Bafnjichmerzen und (Şebredben fino vielerlei, un= ter welchen bie bekeannteften bierber gefégt werden.

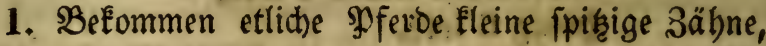

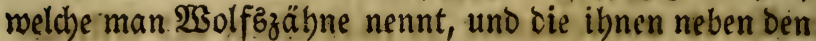

- andern Bäbnen berwadbjen, weldje nicht allein Dem \$fero

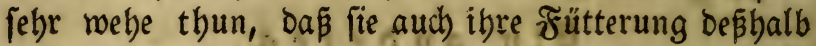
nid)t recht geniésen können, fondern es nebmen foldhe פoferbe am \&eib nidjt rectit zu, fo lange foldhe 3äbne da fino.

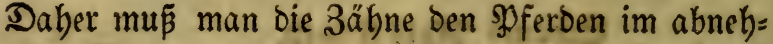
menden Mond, im Beidhen bes Fijch ober Ņaffermannz mit einem [harfen Meisel ausjichlagen ober mit einer 3ange austreisen, aber wohl 2rdhtung geben, Das man ez mit ber $\mathfrak{2}$ urzel berauzbringe.

2. (Ez merben aud) ben झूferben fonobl bie Shacten= als Etodzäbne mit zunebnendem 2Ulter, jedoch einem früher als an bem andern, indem ez auth ben Folken zu

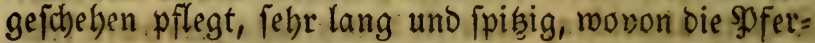
De fiti in bie SBacten hauen uno fich nicht ted)t füttern Eönnen, weldde man ibnen mit einem langen (Eifan $a b=$ follagen uno eben madben mús.

3. Befommen bie : Soferde aud) ben Sahnfdumerzen von ben Flüpen, welthe von bem Scaupt herab fallen, wovon bas 3abnfleifich roth gefdimollen, hisigig uno ent= zünoet wiro, Das spfero läp̈t Daneben viel Schaum auz Dem Maul fallen. Um biez $\mathfrak{H}_{e}$ bel zu beben, foll man Den britten Staffel ftechen, Die 2roern unter bes 3unge lap̧en und bas MRaul mie audd bie äähne felbiften täglich 


\section{Pferbe:2(rzenei Bud).}

mit Sifig uno Salz untereinander vermifdt roobl $a b=$ reiben uno bernach falgendes auf Das 3abnfleifd) fdomie= ren :

Siepülverten Bertram 2 loth,

Campfer 1 Suintlein, Şonig 1 loth. mifche es untereinander zu einer Salbe.

E $i \mathfrak{n}$ a $\mathfrak{d e r e b}$.

(5)ranatäpfelidbelfen pulverifirt 2 loth,

Sconig, fo viel als nötbig ift,

mifche es untereinander zu einer હalbe.

(5) i a

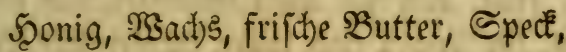

Saumöl, Scarz eines fo viel als bas andere, zerlape es über einem gelinden Feuer zu einer Salbe.

\section{(sin $\mathfrak{a} \mathfrak{n} \mathfrak{D} \in \mathfrak{r} e \mathfrak{b}$.}

Siebe SGeidenlaub in Sconigmaffer, waiche bem \$P fero bas 3ahnflleifd) Damit und ftreue ifm bas Sgulver von গुgeibenblättern auf bas 3abnfleifh.

4. Befommen bie SPferbe aud 3abnidumerzen, von Den fdarfen Munoftücken, weldhe ibnen nitht allein bie Eaben, (Biller) mund machen uno zerreisen, fonoern aud) bas Bein gar von einander fdneiden, reldhes it) = nen fehr rebe thut, und febr langfam beilet.

Dicien foll man ben Gd)aben oft mit (sffig, motin ๔alz, 2(llaun, beionifd)es $\mathfrak{B Z u n b f k a u t ~ g e f o t t e n ~ m o r b e n , ~}$ auşwajd)en, und ben Schaden mit Sconig, mit Şulup: von Sfterlucen vermifd)t fidmieren.

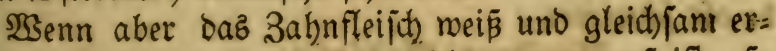
ftorben wäre uno bie Sitge nid)t ga: zu groß̧ ift, fo fommt fie aus faltem sphlegma ber. In biefem. falle 
follte man, um eine balbige Şeilung zu bemirken täg= lid) Das Babnfleifd) unb Rinnbacten mit warmem (Effig, in weld)em Bertram uno $\mathfrak{B}$ oblgemut gefotten wurbe,

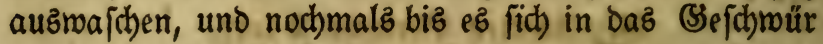
vertheile, oaz 3abnfleich mit folgender Mixtur oft rei= ben und idmieren :

$$
\begin{aligned}
& \text { Bertram, Senftmabl, jebes } 3 \text { loth, } \\
& \text { Sconig, fo viel genug ift, }
\end{aligned}
$$

untereinanber zu einer Salbe vermifcht.

5. Befommen bie \$pferbe auch Den 3abnformerzen, wenn fie Sähne fobieben, Da ez bizmeilen fehr hart an=

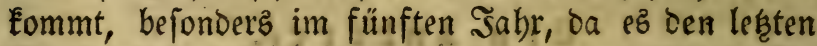
Bruch thut, Daś fie aud) biemeilen gar nidts frefien Eönnen, bie 2 fugen find ignen bunfel, das Maul hişig, und lauft ifnen viel (Seifer aus bem Mautl.

Für biefe झूferbe aber ift anders nichts zu gebrau= doen, als Das man ibnen das Maul oft mit obenbejdhrie=

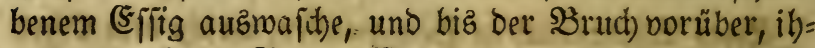
nen gebrodbenez Futter, 2 Beizeneleien mit Sconignaffer vermifobt, zu frefiten gebe, und baneben mit laulichtem SSafter, in weldbem idbönes Mebl uno ein menig Sconig vermi ç̧t ift, tränf́e.

6. Beformmen Die \$ferbe aud) 2(poftem und (se= fonmüre, in und auf bem Babufleifh. Soldhe foll man wenn fie zeitig find, mit einer Flieten oder fonft einem fibarfen und fpigigen Inftrument offnen, bie Materie

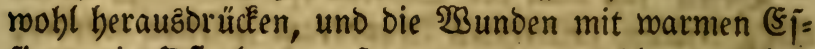
fig worin Sifterlucen gefotten worden, roblauzmajchen und wenn ez trocken gemorben, mit nadbfolgender Sal= be oft fdomieren :

Bepuilverte Balläpfel, Sranatäpfelichelfen, jeoes 2 lotb, 
währeno es nad) Dem Zutter greift, fich felbft in biefer Scaut fängt ; Der હdymerz miro Dann fo beftig, Daß

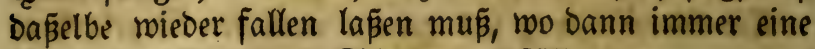
bebeutenoe \$uantität @d)aum mitfällt.

In biefem Falle Eann man Das \$pero brennen uno mit Sconig uno (șfifig untereinander gemifht oft idhmie= ren, audd foldhe Salbe gebrauchen, beren in bem vorigen Eapitel von Dem $23 e b e t a g$ Der 3ähne if́t geoad)t uno bejhrieben morden. Dep̈gleichen folf es aud mit ber Berpflegung gebalten werben.

\section{Daz 35fte Capitel.}

\section{Bon Dem Ģurfiß̧ Doer Der গRundfäule Der Pferde.}

Diez ift eine Sranklbeit mit Geftigen Ěntzünoungen bes ganzen Mundez und 3abnfleifds=:Sejd)müren und

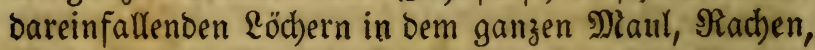
ङdhluno uno. (Surgel, mit (5ntzünoung, Benagungen

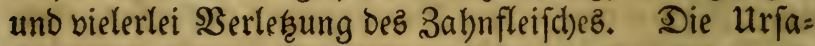
den fino bişge Dämpfe, welche aub Der Leber uno groper Şife ber gallenartigen Feuchtigkeit überfich an biefen Sort fteigen; fo wie audy menn die \$gferbe zu viel neuce Sceu frésen

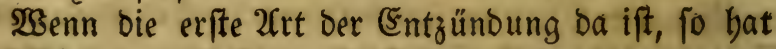

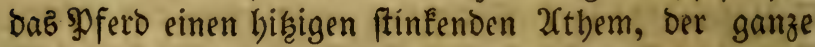
MRuno ift feuerrotb uno läpt einen bişigen હchaum bon (iid) fallen.

Die andere 2 rt wirb aus den hisigen (Se fohnüren felbft erfannt, formmt gemeiniglid) jungen \$oferben an. 


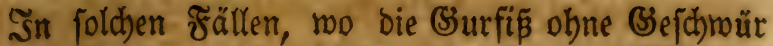
fino, pflegt man bie Sceilung auf folgende 2 Seife ơ berwerfftelligen :

Man ftellt Das \$fero in Den Nothffall, bindet ps auf und verwabret es mohl, hernach bindet man ihm bie

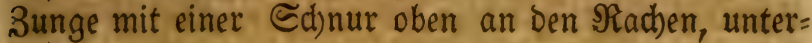
fucht ben Sdhaden, uno majchet hernach Die 3unge, ben Radben und Das ganze Maul mohl mit nadbfolgender Rixtur aus :

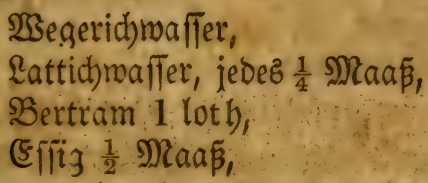

mifche bies untereinander, menn es eine balbe Ctunde,

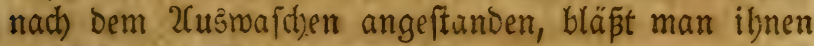
nachfolgendes Sुulver barauf :

\section{Dürte Selbaumblätter, \\ (Sranatäpfelfoclfen,}

mifache es untereinanoer uno gebraud)e es.

Nad) einer balben Stunde wäidbet man Den (d)a= Den wieber mit borbejd)riebener MRixtur aus ; foldes thut man täglid) Morgens uno 2(bents, uno giept ihm etlichemal folgende \$ुourgation ein :

2loes (Epatic. 1 loth), Ecammonium 2 St. 2(garic 1 loth, SRbapontic 3 loth,

(S)ummi (s)uttă 1 souintlein, Beinftein 3 loth,

ftope alles untereinanber, laßje ez über. Nacht in $1 \frac{1}{2}$

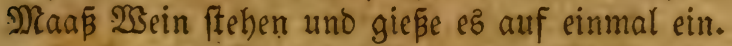

Rach Dem (singuß foll mant bas Maul mit obiget Mixtur wieder abwaichen und Das \$ुfert eine balke Stunde mobl zugebectit reiten. 
230 aber (S)eftwüre vorbanden find, mus man ibm ben Nuno reinigen uno, auch biefe \$urgation gebrau= chen, (jeooch) follte alles im abnebmenoen Nond, bod) nicht wenn ber Mond im 3eichen bes Wibders oder Stiers ift gefchehen.) SRach gefchehener Spurgation 1, 2 ober 3 Iage, foll man ibm bie 2roern am Salz la = fen, wie auch ben Staffel ftechen uno mobl bluten laf = fen; bie (sejchroüre, nacboem fie exöffnet, mit nachfol= genoem wobl auswaichen:

$$
\begin{aligned}
& \text { Sumach, Mintrben, } \\
& \text { Selbaumlaub, } \\
& \text { Ssranatäpfelrinden, jedez } 2 \text { Scändeboll, }
\end{aligned}
$$

fiede es nobl miteinander in flieffendem $\mathfrak{2 s a f f e r}$ und ftreue bernach folgendes \$ulber barauf : ·
Salläpfel,
Selbaumlaub,
Sandel 3 loth,

(Sranatäpfelichelfen,

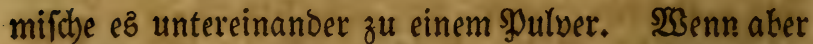
bie (Sefdroulte um fich freflen, fo brauche nad)folgende Sacten:

\section{$\mathfrak{B}$.}

Şepar 21ntimonium 1 Suintlein,

Saffran 2 Scrupel,

Wsein $\frac{1}{4}$ Maaß̄.

mifche es untereinander und fchütte. ę bem \$ुferb auf einmal ein uno fhmiere e's mit nachfolgenoer Salbe:

Rofenpulver, 2 loth,

23egrichjaft,

Sconig, jeoes 6 loth,

mifhe es untereinander zu einer Salbe. 
(E) in andereb.

Sulver গ্রidts, (Salläpfel, jebes 3 loth,

Rojen 2 loth,

Sebörrte @dhlebn 3 loth,

alles untereinander zu einer Salbe gemad)t. Man fann ifm auch öfters bas 3abnfleifd) mit frifcher Salbei reiben.

Die Serpflegung ift wie im vorigen Sapitel von Der 3unge angegeben wurbe.

\section{Das 36 ffe Capitel.}

গ̉on Entzünoungen Der פandeln uno Apoffemer.

Diefe beiben Drüpen, die Mandeln genannt, liegen oben auf Dem Sdluno, auf jeber Seite bes Seinz, baz fid) mit Der 3unge vereiniget. Sie find von einer lu= dern oder fd)wämmigten Subftanz, werden beşbalb von Den Feuchtigkeiten und Den Ealten feuchten Flüpen, wel de von bem Scaupt bajelbit binab fallen, oftmalz ber = mapen eingenommen und überfüllet, baß fie fich Davon aufbläben uns gejdyellen uno bie spferbe nid)t folin= gen Éönnen.

Die 3eichen biejer Stanfleit find biefe :

1. Die Spferde balten Den Sopf ftetz über (th) und in bie Söbe.

2. ふ̊önnen weber elfen nod) trinken, nod) etwas ein= fd)lucken.

3. (Seben basjenige, was fie trinfen, ourch bie $\mathfrak{R a}=$ felöcher ruipoer von fid).

4. Laß̄en viel Shaum aus bem Muno fallen. 
5. Röcheln faft uno boblen fdurerfällig Xtthem.

6. Die 3unge ift bice und idjwarz, mit einem wei= Een Sd) leim umgeben, uno falls fie nod bazu aus Dem Maul beraus hänget, fo ift es befto gefäbrlicher, Denn es ift Dies ein Beichen, Dá̧ bie Strajen jehr eng gewor= ben, benn je böber und bidfer bie Mandeln werden, je megr miro ber Şals verftopft, und Eönnen die \$pferbe enolich weber burch bie \&uftröbre, nod) burch bie seaje= löcher wobl uno genugfam atbmen, müfien aljo, wenn man ignen nicht Shülfe leiftet, erfíticken, mienobl man ifnen audd) fdhwerlid) belfen Eann.

Die \$pferos, welded bamit bebaftet norben, fino meb= rentbeils junge SDferbe, wenn fie eine Beitlang auf bem Feloe lebig gegangen uno bann yon neutem in bie Ställle geführt werben, und gefchiebet folches gemeiniglich an Dem Ënde des Scerbftez.

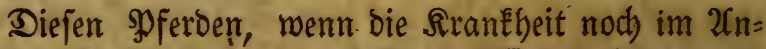
fang ift, forl man eine Soalsaber öffnen, alsoann mit Dem Ropf in einem शothftall in Die Scöbe binden uno ihnen nachfolgenoes, um bas Scaupt zu purgiren, in bie Rajelöct)er fpriţ̧en :

Majoranwafier, 6 loth,

Salpeter 2 loth,

ŞBein, ein halbes SBertel.

(E) ane ande $\mathfrak{R} i x$ tur. Salpeter 2 loth,

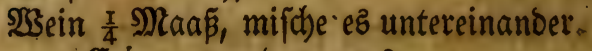

Ein andereb.

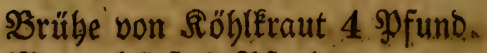

Mangolt faft 2 Sfunt,

Saumöl $\frac{1}{4}$ \$f funo, 
mijh) es untereinander uno fprife es bem $\$$ pferd in bie Naje.

Sfft aber bie 2(poftem nod) neu uno gering zu ber: theilen (Dergleidgen fie Dod) in Diejen Ibieren felten zu fein pflegen, tenn man wirb ez felten gewabr, ez fei benn Die 2fpoftem bereits fo groß geworden und bem SPferd befdumerlich) fo reibe fie mohl und oft mit war= ment Sel, oder lege einen Sd)wamm in (Effig mit Smei= nenifhmalz nermifict, warm barüber, Damit fie vertbeilt merben, oder lege nad)folgende jeitigmadjende SDflafter Darüber.

Maulberblätter 3 Sূändeboll ,

Eamillenöl 3 loth,

$2 \mathfrak{t}$. Sd)meer, fo viel genug zu einem Spfla= fter ift, lape es untereinander marm ftopen.

E in a noereb.

(S)alle von (Seipi, 1,

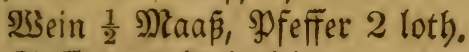

Saffran 1 Suintlein, \$conig $\frac{1}{4}$ )aaß́,

ïiede es untereinander zu cinem פflafter.

SSenn fith aber bie 2(poftem nid)t bertbeilen will, fo (d)miere ben Sort fein warm mit nadfolgender Salbe :

Butter $\frac{1}{4}$ Spfund,

- $\quad$ Ioröl 6 loth, 2iltheanurzel 4 loth,

Sdoneinenfchmalz 6 loth,

lape es warmiuntereinander zergehen.

(E) $\mathfrak{n}$ andereb.

2fit Sdymeer $\frac{1}{2}$ spfund,

SSeftopene Spappelnnutzel 8 loth, mijhe esి untereinanoer uno lege eə roarm über. 


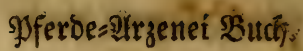

x. atoh (E) $\mathfrak{i}$ andereb. Röblfraut, alt Sd)meer, vermi iche es untereinander wohl warm, ftope ez hernady nod) einmal untereinander uno lege es warm über.

Ein anderes.

Eamilfenöl, Lorbeerol, Dillöl, jëbez fo biel als bas andere, tröpfele es ibnen in bie Shren.

Sobalo fie nun zeitig werben, fo foneibe fie auf, wenn fie von fich felbif nicht aufbrecten mollen, uno balte bie 2 sumben, bis fie genug gereinigt fino, offen, fchmiere bie= feltben etliche Tage nacheinanber mit folgender Salbe:

Effifi, Selhefe, Salz, eines fo viel als bas andere, fiebe es wobl miteinander, menn ez fith gerei: nigt bat, fo ftreue folgendes spulver Darein :

(Seichabtes నupfer 2 lotb,

SSeirauch 1 loth, Esven 2 loth,

mifche es untereinander.

$\mathfrak{B} e n n$ man bas 2(poftem mit Eeinem Schnitt eröfnen will, fo brenme eb, lape ez ber (Siebühr nach) reinigen, nimm eine Feoer ober Baummollenmiegen, beftreidye fie mit egyptifcher Salbe uno ftecke fie bes నagez zmei= mal in bie 28 unden.

(sin anderes.

$\mathfrak{B a n n}$ bie Manbeln auflaufen uno bité werben fo zünde bie Scaar an Demjelben Sort mit einem Ridjt an, bis bie Şaut anfängt gelblicht zu werben, lege alboann alsbalo, um ben Sranot uno bie Sdjmerzen zu ftillem, Eiertlar barüber, uno la liegen, nadbber wenn ou jelbige mieber binweg genom= men baft, fo überlege ben Sort des T̃ags zweimal mit nachfolgenoer Salbe : 


\section{Wferbe:2ragenei Bucti.}

Bitrior, 2fttheamurzel, jebes 6 loth,

20ltes ङ(h)weinefd)malz 12 loth,

mifaje es untereinandar, über einem Soblfeuer zn einer Salbe.

SSenn fie bann zeitig werben, fo öffne fie mit einer Flieten oder brenne uno reinige fie, fotmiere bernad) rings um Den Sdjaben herum roarm Ed)weinenfithmalz

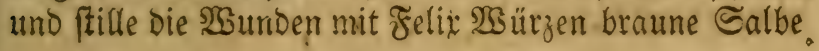

\section{Fi $\mathfrak{n}$ a $\mathfrak{n} D$ er $e^{\prime} \mathfrak{B}$.}

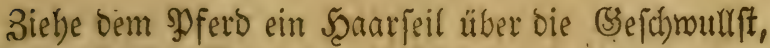

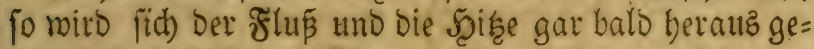
ben, lape Das Scaarjeil barin, bis ber Cdjaden fïl) ganz geféf̧t bat, alsoann beile es mit (Egyptifder Salbe uno endidi) mit linverer Salbe zu.

Sobald Dut aber fpüreft, daß̃ cas sूfero unter an= bauernder (5ur fidlingen, uno Epeipe zu fid) nebmen Eanm, gib ifm aud) folgenoe \$ourgation ein :

Igilben Eucumernifaft 2 loth,

Salap, 2 garic, jebes 1 loth,

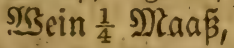

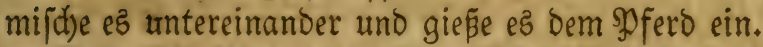

Man foll itm aber anfänglid) ben \&eib wobl offen balten mit nad)folgender (styftier :

Rleienbrübe $1 \frac{1}{2}$ saaß,

Soloquintenmark 2 Suintlein,

Iaufenogüldenfraut 2 Şändeboll,

Seilleraut 1 Şanowoll,

I homazzucter 6 loth,

Sierootter 3.

fiebe es untereinander uno gebrauche es marm.

शBenn aber bie 2fpoftem inmenoig aufbrechete aljo, 
Daß̃ bas (Eiter bem \$fero zum Maul beraub liefe, fo

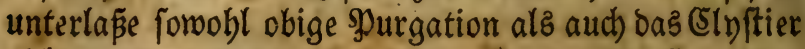
nicht unterwegs, uno falbe ben Sitt ber 2ipoftem täg= lich mit einem Inftrument, weldhes mit Sconig beftrichen ift, oder reibe ben Mluno wohl mit SButter, und fdomie= re auzmendig ben Scalz mit warmem SDel.

Die $\mathfrak{S e r p f l e g u n g ~ i f t ~ m i e ~ i m ~ v o r b e r g e b e n d e n ~ E a p i - ~}$ tel veroronet wurbe.

\section{Daz 37fte Capitel.}

\section{Son ben Fröfchen im Maut.}

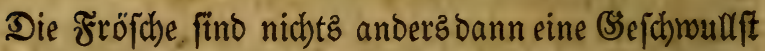
in Dem Maul neben Dem Backen inmendig, bisweilen auch fojmarz ober 2 fichenfarbig anzujeben.

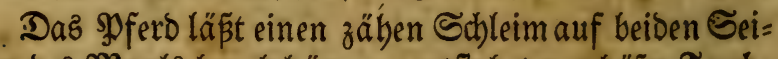
ten bes Mauls berab bängen, entftebet von böjer Feud)= tigkéeit, auth) übermäpigen fteten 2(ufliegenz oer fd)ar= fen walzen Munoftücke, uno Dergleichen Mispbraudb.

Diefe binweg zu bringen ift bas befte Mittel, menn man fie mit einem beisen (Eifen brennet, und nath ber folgende Salbe barauf fchmieret :

$$
\begin{aligned}
& \text { Bwiefeln 4, } \\
& \text { 5ुonig } 8 \text { lotb, } \\
& \text { Ru位 } 2 \text { lotb, } \\
& \text { Salz, }^{1} \text { loth, }
\end{aligned}
$$

fiebe ę mit ein menig $25 a$ fifer uno mache eริ zu einer Salbe, oder fonneibe foldhe Serter auf und ftreue ge-

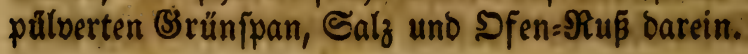


Der zweite Theil

bez

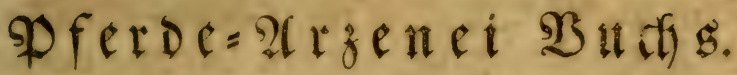

\section{Dab 1 fte Capitel.}

Son ier Seelfudjt doer Etrengel genannt.

Diefe Srankheit entftebet im 2tugemeinen auz zwei= erlei Ur.jachen, innerlicben uno äusertichen; bie inner= lidjen aus ber \&eber, melche fich alsoann burd) bie vier

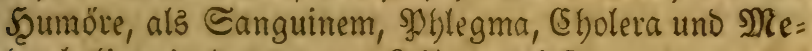
landjoliam in Den ganzen \&eib ausgięst.

Ufeuserliche utrfach)en find, überflüpige Sälte, aud) in Spei uno Tranê, uno anbern äuß̧erlidjen 3ufällen, woourd) bie natürliche $\mathfrak{S a ̈ r m e ~ g e i c h n a ̈ c h t ~ u n o ~ d i e ~ z ̌ a ̈ u l = ~}$ ní in genannten (Sliebern erfolzet, als ftechenoes icharfes Z̈utter, Epreu, faul verfohimmelt Seu, (S)er= ftenäbren, faule ftinfende Streu doer Mift freffen, im

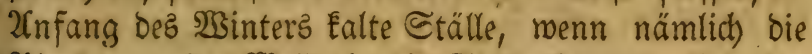

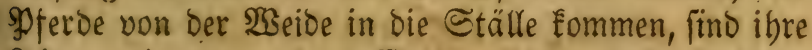
Reiber mit ber grünen 23 eide erfüllet, noourdh bann

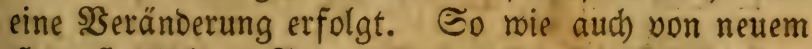
Seu, ftaubidbtem Futter, faulem IrinEmafler und ber: gleichen.

Diefe Srankheiten find zmeierlei 2 rrt, bie feuchte uno bie trocfene Reeljucht genannt, weldbe le çtere gemeinig: lich fidner zu curiren uno faft allemal töotlid iff. 
Son Der erften (Sattung Der Sieelfud)t, Die feud)te Geelfiud)t genannt.

Diefe Srankbeit ift nidbtz anders als eine beftig ftin: Eende Feud)tigkeit, welche aus Den Dämpfen von ber Reber in bas (Sebirn fteiget, unt entweoer burd) bie Rajelöb)er Geraus rinnet, anfangs eine bünne Feudtig= Feit, bizmeilen grünlidbt, Darnach gelblicht uno leçtenz wei $\tilde{\beta}$, uno fo fie überband nimmt und Derfelben nicht in

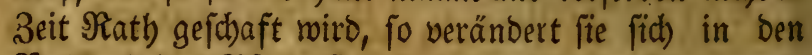
Rof uno baz \$fero ift uno bleibt fooann für immer ungeilbar; ober indem bieje Feudhtigfeit nidbt heraus rinnet, fällt fie von bem Sehirn berunter auf Die Ree: len, Daber fie audc) Seelfud)t genannt wiro, (und nicht wie, theil(s Soioten fie (Selbjutht beisen, weldbes eine an= Dere Srankbeit iff, ) uno von ba auf bie Bruft und \&un= gen, biefelbe erfäulen uno burd) foldben $\mathfrak{W}$ uff einen ichweren 2 them und Shuften erroecten uno verurjachen. 

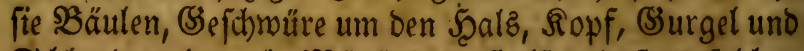

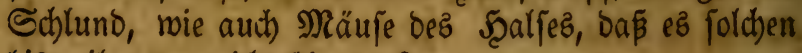
bismeilen gar nicht biegen $\mathfrak{E} a n n$.

Die Beidhen biefer Seelfuct)t fino :

1. Das Miaffeln, Reichen, uno Scuften.

2. Befdymerung bez Sopfez; indent fold)e গুperbe Denfelben traurig unter fich laängen uno nid)t wobl auf= - heben mögen. Siehe frigur शto. 12 .

3. Stblagen fold)e \$ferbe baz ₹utter ab und ner: ben Eraftlos uno matt. 
12

Evite $216^{6}$

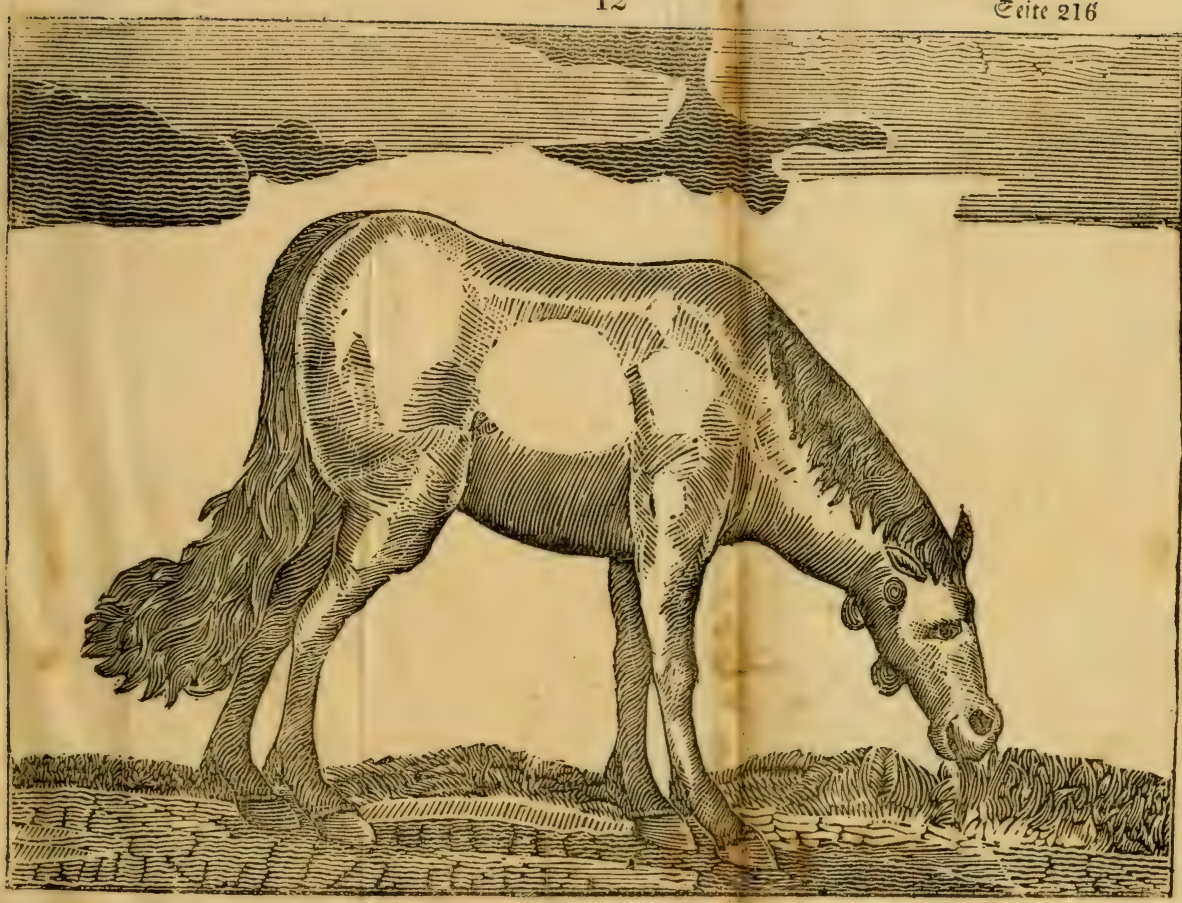


$\sqrt{2}+x^{2}$ 


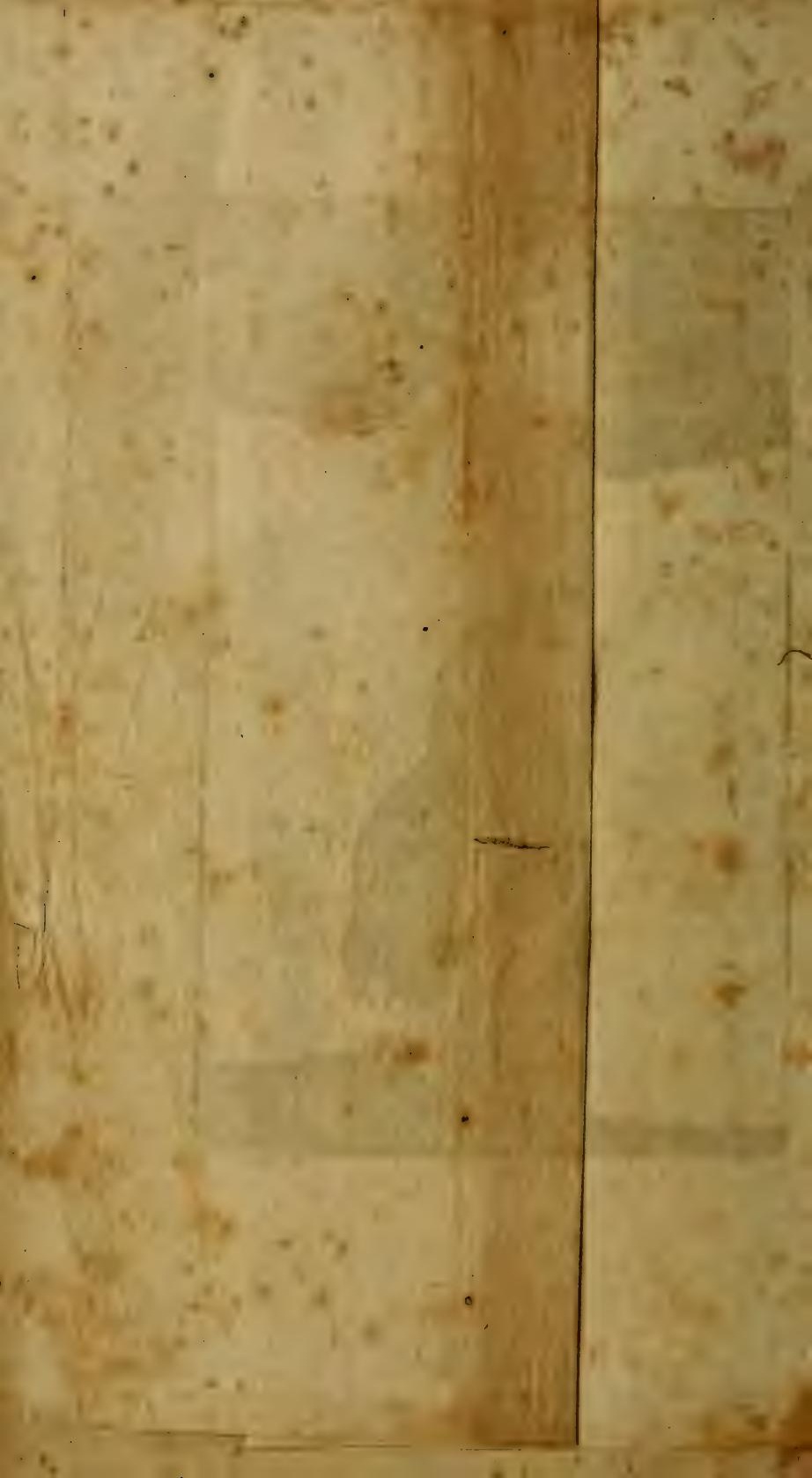




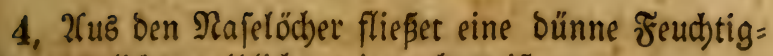
Eeit, grünlid)t, gelblicht, wie aud) weißs.

5. Errdjeinen an Dem Şals, unten am Sopf bei Der Seele, autd) bişweilen an andern Theilen Des Sopfez,

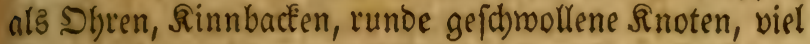

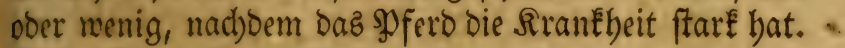
Siebe Figut $\mathfrak{N o}, 12$.

6. Scat Den Mund voller હd)leim, und läp̧t die 3unge bidf zu Dem Maul beraus bängen.

7. Shat Dicfe rothe 2Cugen.

8. Räpt das Irinken mieder zu ben Najelöchern ber: auอ laufen.

9. Befommt-einen gefdumollenen Şals und Sopf.

Der Ifnfang num biefer Sur iff, wenn nemlidy bie juerft berausrinnende Feud)tigfeit nod) nidht ftinfet, fo ift ez cine 2(njeigung, Daßs nod) Eein (Sejchmür auf Der \&unge vorbanoen, fonoern nur überflüffiger. Unratb, ooer bas sूfero fliepest nod) nid)t, fondern röd)elt uno befommt SBeulen an bem Saalz ooer Bacten.

Fürs allererfte foll man biejen \$y ferben ben Reib of: fen balten, wo ber nicht offen ift, nachfolgende (Elyftier gebraudjen :

Slaues ßeilenfraut,

Bingelf́raut, jebę 2 Şändevoll,

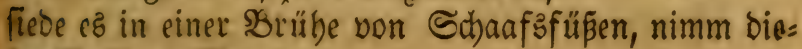
jer SBübe 1 Maa $\tilde{\beta}$,

Extract von (Eapiarinde 2 loth,

Shierä picrä, Beneoict. jebes 1 loth,

3ucter 2 loth, Eierootter 3, Sal 1 loth, mifche es laulid)t untereinanoer uno gebrauche $\mathrm{c} b$. Shierauf gebe ihm des Morgens nachfolgende \$ुur= gation ein : 


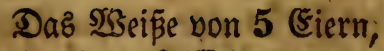

Şonig 5 \&öffelvoll,

2fltes Saumöl,

3. Rerd)enfohwamm, jebes 1 loth,

Salaprourzel Iurbitb, jedes $\frac{1}{4}$ lotb,

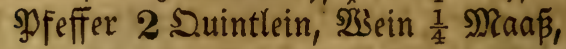

mifche ez untereinander und fohütte es Dem sgfero auf einmal ein, reite es barauf eine Ctunde 20 ormittags und eine Stunde Naddmittags.

Ein andereb.

Ssentian, Sft rlucey,

Säbenbaum, jebes 2 loth,

Sconigmafler ein balbez Mraá,

mifche es untereinander uno fohütte $e s$ dem $\$$ Dfert eit.

(E) $\mathfrak{i}$ andere .

2sild Sucumernnurzel 2 loth,

SSein $\frac{1}{2}$ Maaß, @alpeter 1 loth,

fiebe es untereinanoer uno fchütte es Dem \$ुfero ein, nadboem du bie Brübe vorber nobl abgejeift haft.

e: in anderes গ্BS.

B̧ilde Eucumernfaft 1 loth,

Extract yon ichnarzer Niesmurzel,

Scammonium, jebes 1 Suintlein,

Serchenichmamm,

Salapivurzel jebes 1 loth,

Iurbith $\frac{1}{2}$ Suintlein,

alles untereinanoer gepülbert uno in einem $\frac{1}{2}$ Maaß warmem $2 s e i n$ auf einmal eingegoßen.

(E) in a ก D e r e B.

Sfferlucey 2 loth,

Rerchenichwamm $\frac{1}{2}$ loth, 
$\mathfrak{B}$ einftein 1 lotb, : mifche es untereinander und fhütte es auf einmal ein. (E) in andereb.

Baumől 6 loth, (Seipis=unichlitt 4 loth),

mifd)e es untereinander und fprite es dem spfero in bie Najelöcher.

\section{(4) in andereb.}

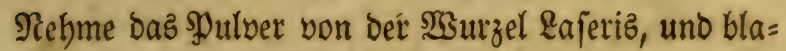
fe ifm bavon in die Rafe.

Mntrben, Enzian, lange Scohlwurzel, Lorbeer,

(Spiduabtes (slfenbein, jedes $\frac{1}{2}$ loth),

ख̧ein $\frac{1}{2}$ Maấ,

fdütte es auf einmal ein uno Salbe ben Sopf mit mar: mem Sel.

Ein andereb $\mathfrak{W}$.

Wुermuth, Scaarftrang,

Iaujenogüloentráut, jeoes 1 Şanovoll,

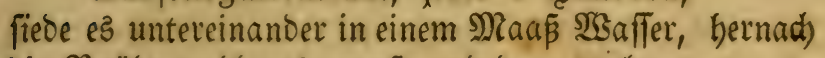
bie Brilbe mobl ausgepreft uno bazu gethan

Rhapontic Rerdsenfdrmamm 1 loth,

Saeinftein 2 loth,

idütte es Dem spferde auf einmal ein.

E $i \mathfrak{n}$ andereb.

WSeirauth 1 Suintlein,

zerreibe foldben in einem $\frac{1}{4} \mathfrak{M a a ß \beta} \mathfrak{B S e i n}$ uno iprif̧e fol= ches bem \$fferd in bie Naje.

\section{(5) in andereb.}

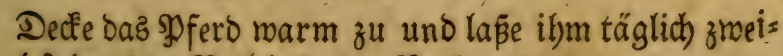
mal folgenden $\Re$ auch in bie $\Re$ a fe geben,

Doften 1 Şandoold, STeiraud), 
220 Ojferbes2trzenei Bud\%.

2ugftein, jebes $\frac{1}{2}$ Suintlein, untereinander gemif fott und auf glühenbe Soblen gelegt.

Ein anderes.

Saffran $\frac{1}{2}$ Quintlein, Bimmetrinden, Mnrrben, jebes $\frac{1}{2}$ Suintlein,

Rorbeer, Eppichjaamen, jeoes $\frac{1}{2}$ loth;

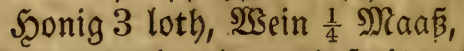

miliche es untereinander uno fprif̧e es in die Nafe,

Ein a noereb.

Sehme bie gefottene Sitube von einem Sdyweinen= Schinken, Epcek, ober fonftigem Echmeinefleifd), wie audb) Schmeinsfüß̄en 1 Maá,

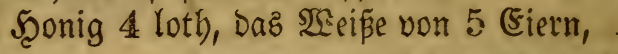

mifche alles untereinander uno fohuttte es bem \$g fero auf einmal ein.

Eะ in and e res.

Srsegtritt 2 Scänowoll,

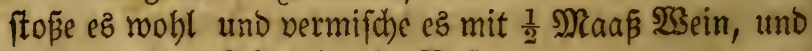

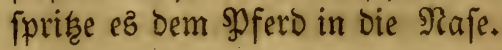

Et a a nereb SI.

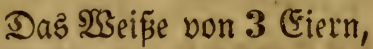

Fif blacten 6 \&öffeluolu,

Sonig 3 Löffelooll, \$P feffer $\frac{1}{2}$ loth,

Baumól 6 loth, sleum (Eyprinum.

Sleum Srinum, jeoez 2 loth,

Salapmurzet, 2 garic, jebes 1 loth,

Iurbith $\frac{1}{2}$ loth),

mifche es untereinander uno fprike es dem Spfero in bie Nafe; foldhes treibet gemaltig aub. 
Ein andereb গ্工ে.

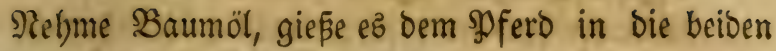
Shren, fere es etlide Iage fort.

(5) in andereb.

Serftopenen fđ)marzen Sümmel 2 loth,

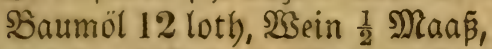

iúutte es Dem SDferd Drei Tage nadeinander ein.

Ein a ndereb

Die gefotiene Sirübe von Bodfabornfaamen, ein

$\frac{1}{2}$ Maa $\tilde{\beta}$, Salap ein $\frac{1}{2}$ lothy,

SR bapontic 1 lotb), 2Cgaric $\frac{1}{2}$ loth,

Sellerbalsmurzel 1 Sountlein,

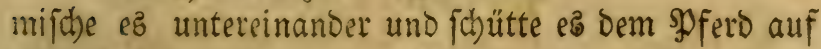
einmal ein.

E in a $\mathfrak{n}$ Dere .

Extract von Säbenbaum,

Extract von $\mathfrak{2}$ ermuth,

Extract von Salap, jebes $\frac{1}{2}$ loth,

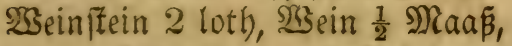

mijh) es untereinander und foütte es Dem SुDferd auf einmal ein.

(5in a ndereb গ্S.

Sermodactil 2 Suintlein,

2rgaric 1 loth, Iutbith,

EBiloe Eucumernnurzel, jebes I Suintlein,

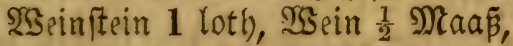

mijide es untereinander und fhutte es auf einmal ein.

\section{Ein anderes গrg.}

SBilde Cucumernmurgel 1 Suintlein,

Suittenjaft $\frac{1}{2}$ Suintlein, 
Rerchenfduwamm 1 loth, Iurbith $\frac{1}{2}$ loth,

Schmertelmurzel 1 loth, $\mathfrak{B S e i n}_{\frac{1}{2}}$ Maá̄,

Simmet $\frac{1}{2}$ Suintlein,

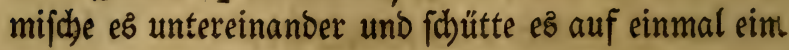

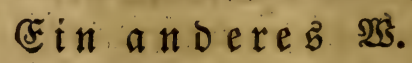

Soldanella 1 Suintlein

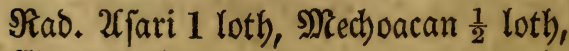

Sinamom,

Extract von Salap jedes 1 Suintlein,

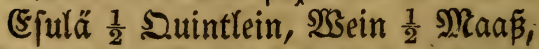

mifche es untereinander und fohütte es auf einmal ein.

Ein a $\mathfrak{n}$ Deres.

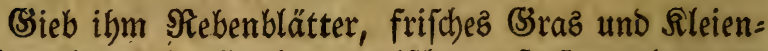
STlümplein mit Shonig vermifotht za freßen uno warm Şerftenwaffer mit Sconig vermiftht zu trinken.

\section{Ein andere $\mathfrak{E}$.}

(Eölnif(t)e నreide 2 loth,

Daz 2 seiṕe von 3 Eierk,

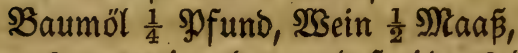

mifche es untereinander und fprifge es bem $\$$ fero auf einmal in bie Naje.

(E) $\mathfrak{n}$ a $\mathfrak{n} \mathcal{D} \mathfrak{E} \in \mathfrak{B}$.

Centauteam, Scaarftrang,

Wermuth, jeoes 2 loth,

Eoche eş in Sconigmaffer uno fprişe ihm foldhes in bie Nape.

\section{Ein $\mathfrak{a} \mathfrak{n D} \in \mathfrak{r} \in \mathfrak{B}_{\text {. }}$}

S3egerid), (Saudb) beil,

Sävenbaum, jebes 1 loth), 


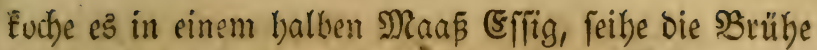

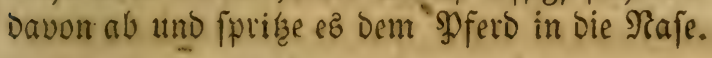

(E) in a noereb.

Stlaje ifm Euphorbium in die Rafe.

(E) in a noeres.

Salbtidgattenfaft 4 loth,

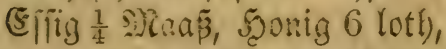

mifd)e e's untereinander uno foh ütte es auf einmal ein.

E i in a n D e e

Die gckod)te Brühe von Reinfaamen,

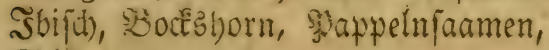

Sd)mertelnurzel,

fdjutte Dem Snfert auf einmal $\frac{1}{2}$ Maaß Dawon ein.

(5) $\mathfrak{i} \mathfrak{\pi} \mathfrak{n} \mathbb{D} \mathfrak{e} \mathfrak{e} \mathfrak{b}$.

Bertram $1 \frac{1}{2}$ Sountlein, \$reffer 1 Suinttein, Şonigwafter $\frac{1}{4}$ I) $(\dot{a} a \tilde{\beta}$,

mif̧de es untercinanoer uno fjütte es alif cinmal ein.

(E) in anderes.

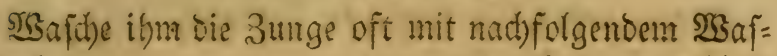
fer ab:

Sumadh, sürte Siojen, jebes 1 loth,

(Seftopene Rimpen 8 loth, פluplaub 3 loth,

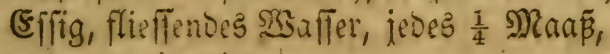
mifate es untercinander.

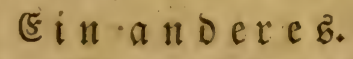

Sergmünje, Raauten, Scolber, jedę 1 Scanbwoll, 2taum 1 loth,

fiebe es in Shonigivaffer, unt fahütte bem \$ferb auf einmal ein $\frac{1}{2}$ Maá ein. 


\section{E $\mathfrak{i} \mathfrak{a} \mathfrak{n} D$ ere}

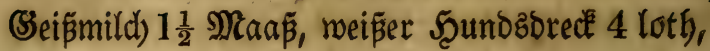
mifche es untereinander uno fichütte es auf einmal ein. E $\mathfrak{i} \mathfrak{a} \mathfrak{n} \mathbf{D} \in \mathfrak{r} \in \mathfrak{B}$.

Blafe bem \$fferd von. nachfolgendem şulver in ben Scals :

Şalläpfel 1 loth,

Wilde Şranatblüth 2 suintlein,

2CHaun, Granatäpfertinden, jebez 1 loth, mifche alles untereinander.

E $\mathfrak{i} \mathfrak{n} \mathfrak{a} \mathfrak{n}$ Dereb.

F̌n̈nfingerfrautwurzel, Stichmurzel,

Rotben Steinbred), Sobermennig, jeoes 2 loth, mache ez zu einem \$ulver uno gib ihm täglich bavon

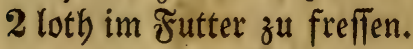

Ein andereb.

Rebme Bockzhornjaamen, bäbe denjelben in $23 e i n$ uno gieb es ihm täglich auf Dem ₹utter zu freffen.

E $\mathfrak{i} \mathfrak{n}$ a n Dere

Nebme geftopenen Sdywefel uno gieb inm benfelben auf bem જrutter zu freffen.

(5) $\mathfrak{i} \mathfrak{a} \mathfrak{n d e r e b}$.

Beitge 5 Eier mit den Schalen 24 Stunden in EF: fig, hernad) ftope fie untereinander uno fochütte fie bem sofero ein.

Ein anderes.

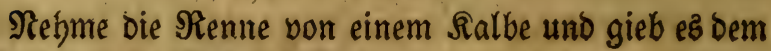
Wferbe etlidbe Tage in $\mathfrak{S B}_{\mathrm{B}}$ ein.

\section{Ein andere} 3ebn Inoblaudbzeben, 1 3wiefel, 


\section{Ein andereb.}

Sngwer 1 loth, 3immetrinden 1 Suintlein,

Rägelein, MRuscatenü, jebes 1 Suintlein,

Earoomötm. Cubeben, jebes $\frac{1}{2}$ S.uintlein,

Epicanaroi 1 loth, (Salgant 1 Suintlein,

Saffran $\frac{1}{2}$ Suintlein, Sümmel 3 loth,

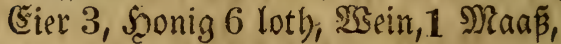

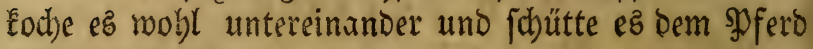
auf einmal ein.

\section{(E) in a d e res.}

Bobnenftrob,

STaberftrob, Doften, jedes 3 Şändevor,

WBeiraud, SMencr hen, jebes 1 Suintlein,

lege es auf glühende Soblen in einem Scafen, und räu= there Das syferb Damit.

\section{E $\mathrm{i}$ in a noereb.}

Siebe Brunnentreflen in Şein, Dörre ihn mieder, lege ihn bernad) in SBranntemein ino verbrenne Denjel= ben Darüber, troứne ifn bernach uno blaje bem \$2fero daz Soutyer in bie গaje.

(E) $\mathfrak{n}$ a noerez গु.

(Gartenfreffenfaamen 3 loth, .

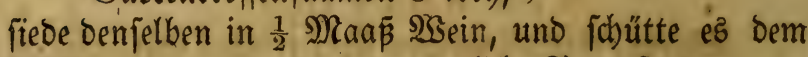
Soferd auf einmal ein, jef̧e es etliche Iage fort.

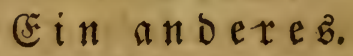

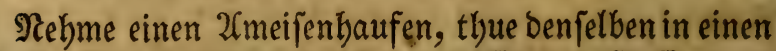
Sack, fiebe Denfelben in einem Refiel mit 2 Saffer und Laß̧e es biz zum britten Theil einfieben, Dämpfe baz sofero bamit, verwabre ihm die 2fugen, Daß̧ ithm ber Dampf nidbt Daran gebe, Denn er ift ibnen fobäolid"). 


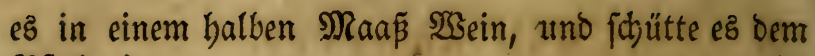
spfero ein.

Ein anderes.

Nebme zerlapenen Spect ober Sdhmeineidhmalz, uno

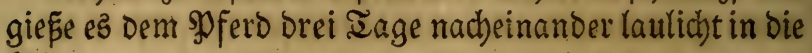
Shlen.

\section{(E) in a ñeres.}

ŞSermuth, Scaarftrang, Taufendgüldontraut, je= Des 2 Şänoevoll,

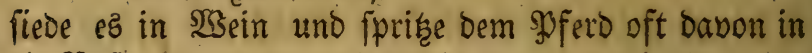
Die Nafe. -

E

- Şepar 2entimonium 2 Suintlein,

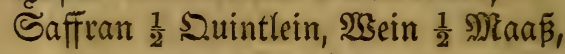

mifche es untereinander, fochutte es auf einmal ein uno feree es etlict) Iage fort.

Ein anderes $\mathfrak{I}$.

Bitrum 2Cntimonium, Saர̄ran, jebez $\frac{1}{2}$ Suintl. $\mathfrak{s e i n} \frac{1}{2}$ Maấ,

läe es 3 Stunden Darauf fteben, uno fohütte es dem Mfero mit einander ein.

Ein a n b e r e $\mathfrak{b}$.

Rellerbatsivutzel, 2alantwurzel,

\$leterfitienwurzel, jeoes 3 loth,

Beernutzel, Felotümmel, jebeż 2 loth),

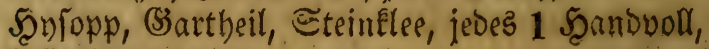

Sifertucen,

Taufenogülbenfraut, jedes 1 Scanowoll,

Myrrben 2 Suintlein, 2lloes 1 loth,

Pukcatenblütbe, 
Earbomỏmlein jeocs 1 suintlein,

(d)önanth 2 suintlein,.

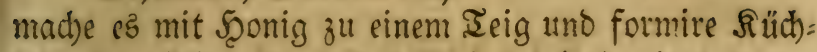
lein obar Belten Daratis, Da seins 1 loth miegt, Davon gibt man 2 auf eimmal in laulid)tem $\mathfrak{W}$ ein zerrieben, fere es etlict)e Iage fort.

\section{E in a nDereb.}

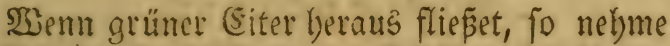
Saumol 4 (oth), SCEein $\frac{1}{4}$ Raā̄,

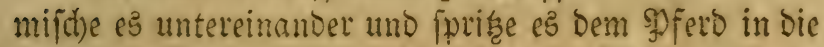
Rafelöd)er.

BBenn bismeilen S3lut von ibm lanfen follte, fo hat es Dod) feine (Sefal)r, Denn es ift blos ein Seitten, Das bas Spfero purgint bat, fold)em foll man bernad) SBaum= Sel, S(t)aaf=unichlitt, eines fo viel als Das andere, un= tereinander vermijat in bie Najelöd)er giepen, weld)ez bie verfelste Şaut bieder reiniget und beilet.

\section{(5) in a no ereb.}

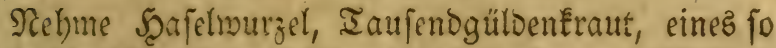
viel als bas andere, Dörte es uno mache es zu Sulver,

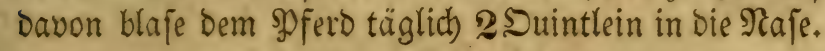

\section{(E) $\mathfrak{n} \cdot \mathfrak{a} \mathfrak{n} \mathbf{D} \in \mathfrak{r} \in \mathfrak{b}$.}

3 Snoblaudj引̧äupter, 4 3wiefeln,

๔ävenbaum 1 Scanovoll,

Saumöl $\frac{1}{4}$ Ş funo, Effig $\frac{1}{2}$ Maañ,

mifbe uno ftope aflesuntereinander, uno fotütte ez bem Sמferd auf eirmal ein.

\section{(5in a $\mathfrak{n}$ bere $\mathfrak{e}$.}

Şühnerfoth 2 Şändeboll,

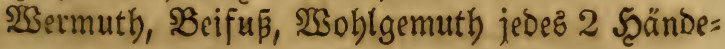


230

P(erbee:2rzenei $\mathfrak{b u d}$.

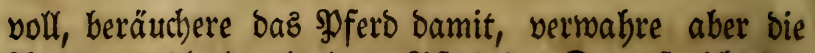

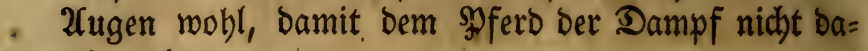
rein gebe.

E $\mathfrak{i} \mathfrak{n} \mathfrak{a} \mathfrak{D} \in \mathfrak{r} \in \mathfrak{b}$.

Bibenellen, Lorbeer, jeoes 2 loth,

2sein $\frac{1}{4}$ Maaß̃,

mifhe es untereinander und johütte es auf einmal ein.

(E) $\mathfrak{i}$ a $\mathfrak{n} D \in \mathfrak{r} \mathfrak{e} \mathfrak{B}$.

(Sieb ihm von nadhfolgendem \$ुulver täglich) 3 loth auf Dem Futter zu freffen :

$\Re$ Ropichnefel 3 loth, 2(lantwurzel 4 loth,

Blaute Rilienwurzel 2 loth,

Shoblmurzel 3 loth, Myrrben 1 loth,

- Bocḱbornfaamen 10 loth,

Säbenbaum 4 loth,

mif the es untereinander zu einem \$ulver.

E $\mathfrak{i} \mathfrak{n} \mathfrak{a} \mathfrak{D} \cdot \mathbf{e r e b}$.

Spect, welcher 24 Stunden in Srunnenwaffer gelegen 2 פfund, ftope inn zu Brei, thue ein spfuno Saumöl bazu, uno fhütte es dem গুfero auf ein= mal ein.

E $\mathfrak{i} \mathfrak{n} \mathfrak{n} \mathfrak{D} \in \mathfrak{e r} \mathfrak{B}$.

Salbliffelblumennurzel,

Ẽrlen Bäpflein, jebes 1 loth,

mifabe ez untereinander und blafe es bem \$pfero auf zweimal ein.

E in andereb $\mathfrak{X}$.

Weipe Niezmurzet $1 \frac{1}{2}$ Suintlein,

Şajelnurzeh, ভäbenbaum, jebez 2 Suintlein,

- Snoblauchshäupter 2 ,

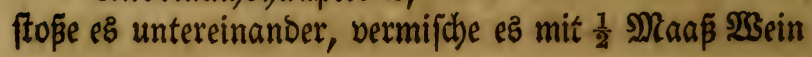


ano fdutte es bem \$fFerd auf einmal cirr, Des anderti ĩnges Darauf nachfolgenden (5ingup :

Scundefomalz $\frac{1}{4}$ Sूfund, Saffran $\frac{1}{2}$ Suintlein, Saumol $\frac{1}{4}$ SW fund, untereinander gemijit)t.

\section{(5) in a noercb.}

Saftran $\frac{1}{2}$ Suintlein, Shein $\frac{1}{4}$ S్leaáp, Sुfeffer 1 loth.

mijibe es untereinander und foütte es Dem Jjero ein. Sin 2llen Reelfuchten follte man dem sy fero täglic: 1 \&öffelvoll von nad)folgenoem \$ু) freffen geben.

Ropichnefel 1 ş fund, Mntrben 8 lorh,

aloes Epatic $\frac{1}{2}$ syfuno,

(3eichabtes Seirjhborn 1 Sुfuno,

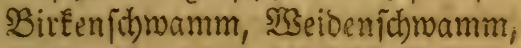

Rerchenjutwamm, jebes $\frac{1}{2}$ sofuno,

(sid)enmifpel 1 Spfuno, sfterlucen,

Sुefítilenzlourzel, jedes $\frac{1}{2}$ गुfund,

¿d)walbenmurzel $\frac{1}{2}$ Sुfund,

Sdinarze Niesmurzel $\frac{1}{4}$ गुfund,

Sleine Sinzennutzer, (sichfabrea,

Spanijh Sdjlangenfunt, jedeb $\frac{1}{4}$ gaprend,

Bootłyornjaamen, Enzian,

Rorbeer, jebes 1 Pfund, Săvenbaum,

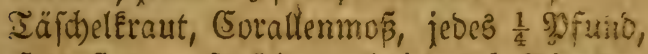

Saarftrang, 5̧afeltwurzel, iebes $\frac{1}{2}$ \$fund,

Xlantwurzel, spfirfing fraut, je১es 1 șfuno,

soermeng, Taupenoblat, Salbei, jebes $\frac{1}{2}$ Sofuno, mifd) eहै untereinander zu einem \$ुulver.

Bon Den Beulen und Rnoten Der Seelfudt. 23.

soulver bon calcinirtem Schmalbenneftern 10 roth, 
Butţer $\frac{1}{2}$ Şfuno, Rilienöl, Şeilöl, jebes 2 loth, Entenja)malz 3 loth,

Sd)leim bon S3otkshornjaamen und Suittenfern fo viel als nöthig iff, mache ein \$flafter aus allen bie: fen vermifd)ten Stücken uno follage es warm über.

(5) in a noeres.

sbijajalbe 6 loth,

(Samillenöl, Seilöl, jedes 1 loth,

Schleim von Bodfahornjaamen 8 loth,

Gibleim von Flöhefrautjaamen 4 loth,

mifhe es untereinander uno fchmiere ben Srt oft bamit.

Ein andere.

Reinjaamen 6 loth́, Bookghornjaamen 2 lotb,

Stbifhfaamen 1 loth, Sappeln,

Samillen, Steinflee, jedes 1 Scanoboll,

laßje es miteinander in einem flieffenden $\mathfrak{W} a f f e r$ fieber,

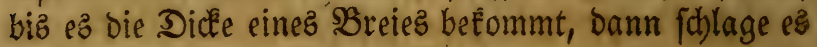
marm über.

Ein anderes.

Rege ifm bas Zerpentiupflafter über.

Ein a noereb.

(Salbanum 1 loth, Shech 7 loth,

Terpentin 5 loth,

macke cin SPflafter Daraus uno lege Davon über.

$$
\text { - Ein andereb. }
$$

Sdineinefdmalz $\frac{\pi}{4}$ SI fund,

Serftenfchleim, fo viel nöthig iff,

Sbifd) Éaut 3 Şändevoll,

SnoblauchsEkraut, oder menn ou feinz befommes 


\section{Mferbe:2(rzenei Bud).}

Eamnft, nebme 1 Inoblaudbhaupt bafür, ftope ę un= tereinander und lege ez über.

\section{(5) in andereb.}

So bie 2(poftem inmendig im Scals räre unto nid)t äuperlid) Eönnte geöfnet weroen, aud) groß̈e (siefabr ivegen bes Erftickens vcrbanden, fo follte man die 2 1 po: ftem no möglid) mit einem Snftrument öfnen, ooer fo man mit bempelben aud) nid)t beifommen fönnte, $c i=$ nen Farrenid)wanz mit Şutter uno fonig woblfchmic= ren, mit Flachs oder leinenem Iud) nobl ummicfeln, uno bas 2 ppoftem fo lang Damit reiben, bis ez fich off = ne und bie Materie beraus fomme; Calbe aud) Dem Spfero bie Seele uno Scals innenoig und ausnendig mit Der Salbe SBoellio ober mit 2rltyäa, $\mathfrak{B}$ cilö umb Gd)leim von Boctęhornjaamen.

\section{E in a noeres.}

Einige merfen bas \$ुfert gat nieder, vermakyen es wohl, fchneiben bic Scaut auf uno öfnen bie 2rpofrem, es ift aber gar gefälurlid) uno miflich mit biefer (5ur.

\section{Ein a noereb.}

Sauterifte die Seule, wenn fie inmendig fino, mit einem beipen (5ifen, oder ziebe ein Şaarfeil barüber, fr wird fich bie Materie beraus begeben.

\section{(5in a n D e res.}

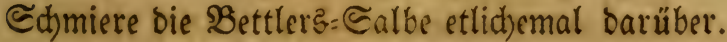

\section{(5) in andereb.}

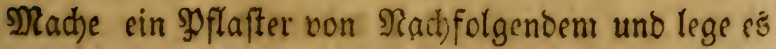
über :

Sdmarze Geife 1 ⿰纟funb,

alte ङdymeere 2 פfund, 
(Eid)enmifpel 4 loth, Scafelmiftel 1 loth)

Dürte Feigen 10, $25 a c h) \frac{1}{4}$ \$ूfuno, mifdye es untereinanter, bei einer linben গ̧ärme.

\section{(F) in a noeres.}

3erftenmebt $\frac{1}{2}$ Bierling,

Berlapenes \$ect), fo viel nöthig ift.

mifche $p$ untereinander uno foblage es tiber.

Ein anieres 23 .

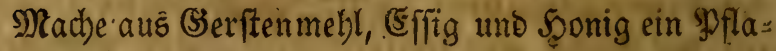
fter uno lege es über.

\section{Ein andereb.}

Feigmartwurzel 2 loth,

Frifac)e Butter fo viel nöthig ift, nache ez zu einem \$flafter.

E i i \& n Deres.

Stidhwurzelfaft 4 loth), Sconig 8 loth,

(Serftenmehl 6 loth, 2 Sein $\frac{1}{4}$ Maaß,

fiede es untereinander zu einem psflafter.

\section{Ei n a noeres.}

Sdbrertelmurzel 16 lotb,

fiede es in Effig und foße es hernach untereinander,

thue fodann bazu

Ierpentin,

- Şarz, Dialtbeä, jeoez 6 lotb,

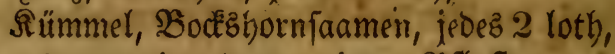

mi(d)e ez untereinander zu einem şflafter.

(E) in anoeres.

Serffenmebl 20 , loth,

Shar in Effig getweitht,

Şadbz, jeoes 1 ⿰冫) funo, \&oröl $\frac{1}{4}$ Sf funo, 


\section{Wperbe:2rrgenei Bud.}

(Summi 2(mmoniac. 2 lotb),

Teufelzbrect 1 loth),

mifia)e es untereinander zu einer Salbe.

E in an Dereb.

2lite Sd)meer 2 şfuno,

Sefto

röfte es untereinander und binoe es warm auf dic ses id)mollenen Bäulen.

Ein andereb.

Srrünipan 2 loth, Sd)wefel 4 loth,

2lite Sd)meer 1 şfuno,

mirde es untereinander zu ciner Salbe uno phtmiere bie Bäuien bamit.

(E) in anderes.

alte Si)meer 1 গुfund,

Sconig 6 loth, 3riefeln 6 ,

frope und mifhe ez untereinander und binde es bem \$f fero roarm über bie Bäulen.

Ein anderez.

Sobecte bie Saalte ab an Dem Srt no bie 2rpoftem oder Räule ift, piče es mit einer Flieten uno reibe pă mohl barauf mit Salz, eine Stunde nad) Dem Reiben idhmiere es mit nad)folgenoer Salbe :

2̧eipe Riešcurzel,

Epanifcte Frliegen, jeoes 2 suintlein,

Dialthäa,

Eoröl, Soputeon, jebes 3 Silintlein, mifche es untereinander, la pe es 24 Stunden catauf, io es noch nicht offen ift, fo lege es nodh einmal barüber.

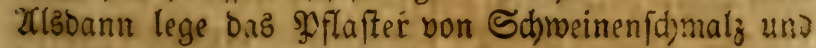
Dem Siraut BärenElau Darüber. 
Sm faall aber oem spfero bie ganze SBruft, wie audj die Seiten geichwollen rären, fo ftecte ifm auf beiden Seiten ber SBruft Ehriftrourzel.

Für bie Seelfucht im 2Ullgemeinen folgt bier noch) ein berrliches Sceilmittel von $\mathfrak{S a l e n t i n}$ Irichter :

Nefme 2 Maaß von Der Srühe, norin ein Ralbs= Sopf (mehr als jonft inzgemein) weict)gefotten murbe, in oiefe SBrübe fonneidet man Elein 5 Roth Süpholz, eben fo viel Rofinen, Sconig, Butter, Setonientourzel, 3 Ioth Nyrrben, 2 loth pulverifirte Fudbs= \&ungen, 2 Roth §ümmel, 1 Roth 2fniz, 3 \&oth \&einfaamen, 6 loth 2llantwourzel, 7 Stüct Feigen, 36 (S)iech) Ëöner uno 8 loth 3ucfer, bie Speciez mache ganz Elein, thue fie in einen Scafen, vermache oenfelben mobl uno laje es 24 Stunden fteben, albdann fchütte 1 Maaß $\mathfrak{s}$ Sein uno 8 Sier baran, rübre alles robl untereinanoer, uno gieb dem

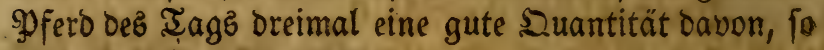
wird es balo befer rerben.

\section{Dả 3te Eapitel.}

\section{Bon ber trodfenen Seer (jucht.}

Diefe Sranlbeit entftebet won ben ins (Ssebirn ge: ftiegenen Dämpfen und mieder herab auf die Bruft \&un1 gen uno \&eber gefallenen barten, zäben uno eiterichten Feudihtigkeiten, welche alfo auf ber Bruft uno Runge baften, das obroobl folche spferde ourd) den fdiberen und emfigen Spuften folchen zu entlebigen fuchen, fie es ood) wegen barter $23 e r f t o p f u n g$ uno 2 bgang ber Siräf: ten nidbt zuwege bringen Eönnen ober vermögen, inbem

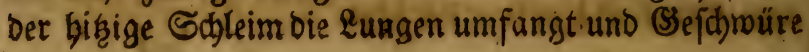




\section{Wferbe:Q(rjenei Bud.}

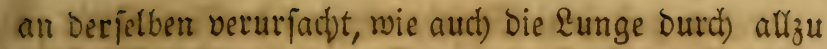
grope Bemühung uno Berwegung wohl gat zerripen viro, weldtes bernad) gar das Eeitenftechen verurjacht.

Iie Beichen Diejer Firanffeit fino nachfolgente:

1. Das Sुfero nimmt plös(ic) $a b$, und fallen ibm die Lenden ein.

2. Sît ihm bie Şaut aufgebähet, Daš wenn man mit cintet flati)en Şano Darauf jiblägt, es einen I bon wie eine syaufe von fich gibt.

3. Raßelt an Der Seele mit einem erbobenen Şu= Ften, unb Eann Doch) Den Gchleim nicht heraus bringen.

4. Sit mart uno mag nid)t wohl auf ben Schenfeln feben.

Dieje Strantbeit iff id)mer zu curiren, indem fie mei= ftentbeils töotlic) iff, und fleisig mill in Sbacht genom= men werden, das fie brecheno werde.

SOr allen Dingen ben ?eib mit Elyffier offen bal= ten, fo es bon nöthen iff.

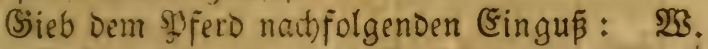
Srül)e vour gejottenem (Sierftenmehl $\frac{1}{4}$ Maas̆. Gdhweinenfdhmalz $\frac{1}{4}$ ş fund,

Sonig 8 loth,

Ed)rofelblumen 1 loth),

תolinen 6 lotb,

ftope und mijh) es untereinander und jüütte es bem Dp fero laulidat ein, feşe es etlid) Iage fort uno beräu: djere Das SPfero mit Den Dämpfen, weldye in borber bejdriebenem Sapitel gemeldet morden.

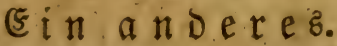

Säbe Dem SDferd Den אopf, Şals und die Bsuft mit warmem $\mathfrak{2}$ ein und gieße ibm folgenden Trant cin: 


\section{Wferbes:2tranei $\mathfrak{B u c h}$.}

Rebare geftopene $\mathfrak{B s e i n b e e r e n , ~ w e l d b e ~ u ̈ b e r ~ s ( a d ) t ~ i n ~}$

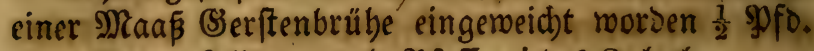
Blaue Riliennurzel, \$ofeffer jeors 2 loth,

Saffran $\frac{1}{2}$ Suintlein,

MRerben, SBeirauch, jedes 1 lotb,

Sdbmefelblumen 2 loth,

5 (sierootter, fammt Dem $\mathfrak{F}$ seiß̄en, aftes mit fammt Der Şerftenbrübe untereinanber,zer= ftopen uno bem \$ofert auf einmal eingegopen.

$\mathfrak{u n o}$ wenn bas spfero nicht freften will, foll man ibm

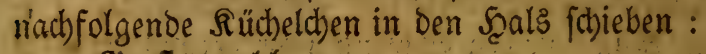

(Serffenmehl,

Weinbeer, jeoez einen $\frac{x}{2}$ SBierling,

Schmeer, Sutter, jeoes $\frac{1}{2}$ sp funo,

madbe Rüblein Daraus in Der Form eines Şühner-(5is, Dofits 3 auf einmal.

WSenn nun ein fhberes erftoctender Shuften erfolgt. fo gieb ibm nachfolgenoen Irank laulid)t ein :

Bobnenmehl $\frac{1}{4}$ ⿰氵 funo,

(Seis:ulunithlitt 6 lotb,

Innoblauch 3 Söpfe,

(Serftenbrübe 1 Maa $\tilde{\beta}_{1}$

mifche es untereinander und ichütte es auf einmal ein.

(E) in anderes.

Butter $\frac{1}{4}$ Mfund (Effig $\frac{1}{4}$ : Maa Baumöl $\frac{1}{4}$ \$ofund, Spfeffer $\frac{1}{2}$ loth,

mifche es untereinander und gieß̃e Staje, to miro es bald anbrechen.

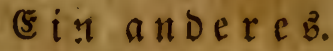

Ratterḱraut 4 lotb),

Brübe von Sodéshorjaamen $\frac{1}{2}$ Maaß, 
3. Das Futter foll fein $2 B e i z e n=$ Stümplein mit Sco= nig vermifcht, gebroct)ne (Serfte, 2 SSidéen, wie aud) junges (5rab, fauberes zartez Sceu, oder gemeichte Berfite.

4. Das Irinken foll fein laulid)t flieffendes $\mathfrak{g} a$ affer, morin in einem Reffel gejotten morben :

Siobe Serfte ein $\frac{1}{2}$ SSierling,

23achbolderbeeren 3 Scändevoll,

Rümmel 3 lotb), 2 Seinftein 6 loth,

2(garic 2 lotb, SBeidenidowamm 3 lotb),

Reinjaamen $\frac{1}{4}$ Mfund, Bodt'bornjaamen,

- WBilde Rürbißsmurzel,

Scollundermurzel, jeoes 1 Şandwoll,

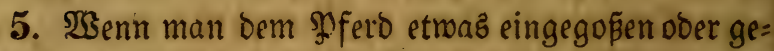

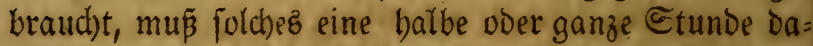
rauf geritten oder geführt merden, camit ber Unrath ourd) Die Senoégung von itbm fomme, jebre Iagez zmei=

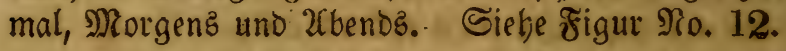

6. Sollen folche \$Pferbe mit Decten marm zugedectit jein.

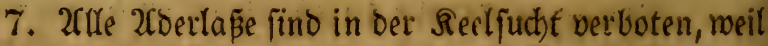
joldhe die Rtanflyeit inmendig in ben Reib ziehen uno Den gemišen Iod verurfachen.

8. Soll man bie sBäulen, wenn fie nicht von felbft aufbrechen wollen, mit einem snffrument offnen ooer cauterifiten, fäubern uno bernach) mie andere $23 u n d e n$ beilen.

9. Riemals falt trinfen lapen, fondern menn man

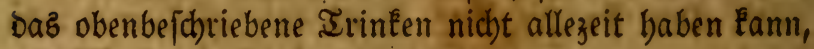
nur Mebl uno Şonig Darunter rübren.

10. Im Frühling uno Sommer ooer Sherbft foll man fie auf bas (Sras laufen laßen, aber auf Eein altę 


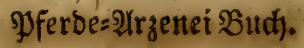

\section{Dả 4te Capitel.}

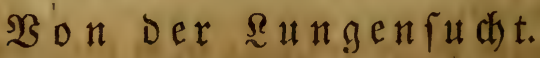

Die Rungenfucht ift eine Strankheit, wenn nemlid) bie Runge mit bicken fobleimichten Feud)tigkeiten ganz an: gefútlet wiro, welche von bem Siopf herás auf bie \&un= ge fallen, uno wenn màn nidht bei Beiten bazu thut, fo

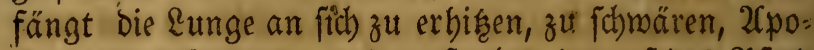
ftem zu befommen, utmo zu faulen, Darauf das spfero umfallen uno aljo fterben muš.

Soldhe SranEbeit überfällt ein \$ofero nicht jäblinge, fonbern fie fammelt fich etlidbe Sabre nad) einander, ehe fie fich herbor thut. 2rreoann menn fie über Şano genommen, fo ift bas Brect)en und utmfallen ein Ding.

Rommt auz bem Blut mit Der EGolera uno \$ghlegma vermifcht, ooer aus ben verfaulten phlegmatifhen Feud)= tiggeiten allein.

- ŞSenn fie aus bem mit ber. (Sholera vermifchten SBlut entfpringet, fo find bie 3eichen ba.

1. Fallen foldye \$ferbe jählings an dem \&eib ein.

2. Rann ein foldhes Spfero ichnerlich athmen, ziebt bie Renoen oft und gewaltig ein.

3. Bläbet bie Sajetöcher beftig auf.

4. Şt an ben Shren, MRaul uno ganzen Siopf febr beip.

5. Sat feurige uno entzündete 2lugen.

6. Şat einen beisen Xthem.

7. Şänget ben Ropf yon negen ber auffiteigenden Dämpfe tief herab.

8. Scat eine gelbe 3unge uno bohe aufgelaufens silutabern.'

9. Sdhronet uno ftrauchelt im Sishen. 


\section{Yferte=:Argenei Budc.}

10. 2Rag ein foldbes Sुferb nicht freffen uno bach vist paufen.

11. Stallt fiid) bizmeilen als fei ę ganz dolerifob.

Sommt es aber aus oer phlegmatifhen freuchtigkeit uno Flÿß̈en ber, "fo

1. Wutfen folde Shferbe eine Beitlang vorber oft uno viet.

2. Geben bišmeilen einen gropenen ๔baum ober @pei= bel von fiid) jum Maul berauz, und

3. B̉enn fie buften, eine wäfferigte Feuchtigkeit zum Naul uno auz den Najelöcbern von fid).

4. Frungen an bisweilen zu röcbeln.

5. Saben einen barten und fdweren $2(t$ bem.

6. Sieben bie $\mathfrak{E} e n d e n$ oft ein.

7. Sittern oftmals mit Dam (sejhröt.

8. Sieben bie Tefticulos über fich in bie Scöhe.

9. Befommen hobe dicfe SSlutabern und gefchmolle= ne Sdbentel.

10. Sperren bie Nafelöcher meit auf uno ftinfen aue Dem Şalz.

11. Sumigen Ealten Sameif.

12. 'Siehet das beraus gelaßjene sBlut recht einit faulen \&unge gleid).

$$
\text { Di e e } u r \text {. }
$$

Sor allen Dingen foll man ben Reib offen balten uno Demfelben mit SInftiren zu Şülfe Eommen.

Wenn bie @ungenfudt) von Entzünoungen berfommt, ift fie an fid) felbit unbeilbar, oieneil bie Naterie num= mebr zu einem 2rpoftem geworden, und folglich fol = (b) idwerlich) ju vertbeilen und an einen andern Srt zu treiben iff, jeood) menn es nod) nid)t gar zu alt tmo 


\section{פิferbe=2Irzenei Buch.}

fehr eingerumzelt ift, foll man ihm auf nadbfolgente 9gseife belfen :

$\mathfrak{L} a \tilde{\beta}$ ibm die $\mathfrak{B}$ ug: uno Sporrabern follagen uno gib itgm nadjfolgendeb Iages folgende \$yourgation ein

Berlaßenen Spect $\frac{1}{4}$ sDfund,

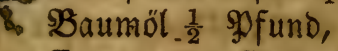

Extract von Eapiarinde 8 loth,

- $\mathfrak{S B S i n}_{\frac{1}{4}}$ Maaß̃,

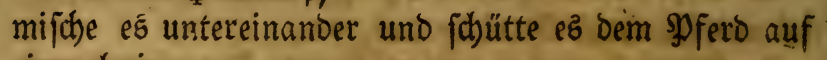
eimmal ein.

Und menn ber Reib nicht offen ift, fo gies ifgm Xbends vor ber Surgation ein Sinftir.

Rad) Der Surgation joll man obie Materie zu einer "3eitigung bringen, und folgendes Iages biejen (Eingü geben :

Schwertelmurzel 1 loth, 12 Feigen,

YYop, Branolattig, jeoes 1 Scanbuoll,

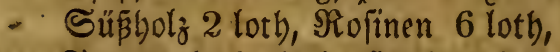

Iraganth ein loth, Sconig 6 loth,

fiede alles wobl mit einander in ein und einer balben

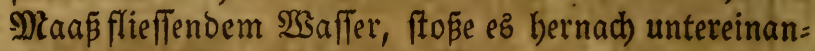

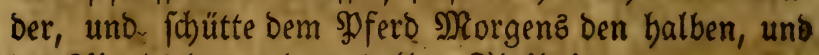
Dez 2Cbenos den andern halben Iheil ein.

ङ in anderer ङinguß.

Viop, Dill, jebes 2 Şänoevoll,

Sdhnertelwurzel 2 loth,

2noorn, $250 h$ lgemuth jedes ein loth,

Süß̈.jolz 4 lotb, SButter $\frac{1}{4}$ SDfund;

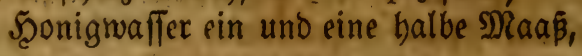

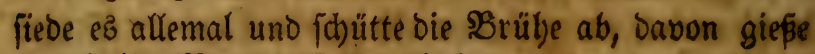
eine halbe Maaß auf.einmal ein. 


\section{jaferbe=2Irzenci Burh.}

Sd)miere แnd reibe Daneben die Bruft tãglich mit nad)folgender Salbe :

(Entenfd)maly 2 loth, Soutter $\frac{1}{4}$ \$fund,

Rautenöl, Schnertelöl, jeoes ein und $\frac{1}{2}$ loth),

mijhe es untereinanoer zu einer Ealbe.

Sdbutte ibm aud 20bendz üter ben andern Iag nad)folgende Mixtur ein, zur Stärfung :

Begn (Eierdottern,

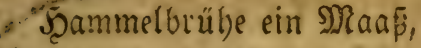

mijit)e es untereinander.

(5iil anderer singuี Deว 2 (6)

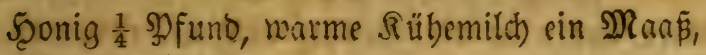
mirde es untereinanier.

Е

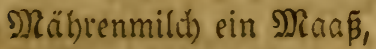

Saffran $\frac{1}{2}$ Suintlein,

Srebbftein 2 Suintlein,

mijche es untereinander uno fitutte es bem \$pferd auf cinmal ein ; miederbole pô einige Mal.

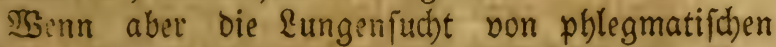
reudtigfeiten berfommt, fo braudbe nachfolgende $\mathfrak{R i t}$ tel :

BrunnenEreffen, ReberEraut,

Rungentraut, jebez 2 \$ृänoeboll,

2(ttichinurzel ein loth),

Saft von פferbeorect 8 loth,

Baumöl, Butter, jeoes $\frac{1}{4}$ Pfuno,

WBein eine balke Maaßs,

mija) es untereinander uno foultte es bem গুperd auf einmal ein. 
Şernadh gieb ibm täglid) von nadb folgenoem \$nulver 2. \&ôffelvoll auf Dem Futter zu freflen :

(sidhenmifpel zebn loth, Saajermifpel 3 lotb, Riebftöcfel 6 lotb, Şiridzungen 4 loth, Seifuß 8 loth, (Ittid)mourzel 4 loth,

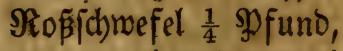
aniche es untereinander zu einem \$ुutvers

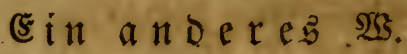

3 Snoblauchşäupter,

Säbenbaum 2 loth, 2flantmurizel 6 loth),

fiebe ę in einer balben Maaß $2 \mathfrak{Z}$ ein, orücté bernad) ben Saft bavon in bie SBrübe, alsbann thue in Diefelbe Brübe

Saffran, Iheriac, jebes ein Suintlein,

Saft von gefottenem Scaber 8 loth,

mifdoe es untereinander uno id)ütte es Dem গুfero auf pinmal ein.

Ein anderes 133 .

Sdhlebblüt, 3 Şändevoll, Scabiofenmurzel 3 loth, .

Meiftermurzel, Scollumbernurzel,

Beilmurzel, Rhapontic, jeoes sin loth,

Salbei, Égrenpreiá, jedez 2 Sä̈ndevoll,

fiede biefes alles mit einanoer in 2 saffer, hernad) prepé pes aus :

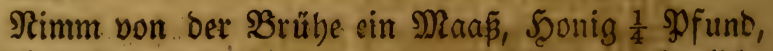
mifdhe ez warm untereinander uno fobutte es lautictst ein.

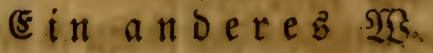
Brunnenkterfenfaft zoölf lotbs 
Saumöl $\frac{1}{2}$ Sूfuno,

giep̃e oem Sמfero zroeimal die 130 be ein, uno gieb if)m täglic) gebactiten Brunnenfrep̃en 3 Scänoevoll neben feinem geroöbnlichen Futter zu freflen.

(E) in anoeres

Saft von frifocm Sुferdedrect jmölf loth,

Baumöl 6 loth, Snoblauchsjaft 4 loth,

Butter $\frac{1}{4}$ șfuno, madie e's rorm untereinniroer uno fdütte ę Dem SPferd laulicht cin.

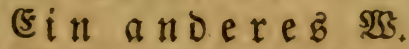

Das Sraut Sakzenfibranz 3 Seändeboll,

Eifentraut 2 Seändevoll,

Rofenturzel 1 Scanoboll,

פgaffer :

Suden-: Sirfiben 2 loth, fiede es alles mohl mit

- Nebme von ber abgefeibten $\mathfrak{B}$ rühe ein $\mathfrak{N a a \beta}$,

Sonig 8 loth, mifdje es untereinanoer uno giepe oem $\mathfrak{S}$ fero auf einmal ein.

(5) in a it o eres.

Salbei zroölf loth,

(5alcinirten Srötenpulver 4 loth,

Enzian 8 loth, @it)warzmurzel,

Rungentraut, Rorbeeren, jedes 6 loth,

Wad)holderbeeren 2 loth,

mija)e es untereinander zu einem Sुlutrer.

(5in anderes Ir.

Balfam Sulpl)uris $\frac{1}{2}$ loth),

Sconigraffer, oder gefotten 2lnismaller sine balbe

Maaß̧,

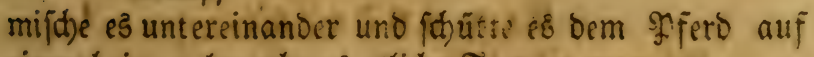
einmal cin, gebraudye eह etliu, Tigi. 
Waadjyoldermuft 6 loth,

Sponig zebn loth,

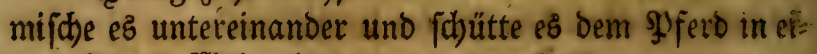
nem Suart 23 sein ein.

Ein anderes.

Sgfeffer 2 loth, Birbelnü 4 lotb,

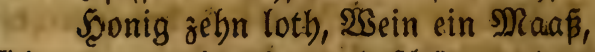

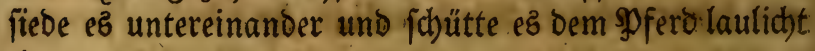
ein.

(Einanderez $\mathfrak{X}$.

aloes Epatica ein loth,

Turbith etn Suintlein,

2fgaric, $\mathfrak{Z}$ niz, Fenchel, jebez ein lotb).

Salap ein Suintlein,

Sconigmafier, eine balbe Maaß,

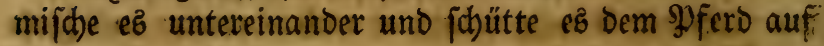
einmal ein.

Ein anoerez.

Rorbeeren znölf lotb,

Senfiaamen 6 lotb,

Fenchell, 2antrourzel,

snnger, fedes 3 loth,

mirche ez untereinander uno gieb dem झूfero des Tage 3 \&offelooll bavon auf bem ₹utter, ober mie bu ez ibm beibringen kannft.

Siebe 3 Şändeboll Şanf in einem Maá : Rild,

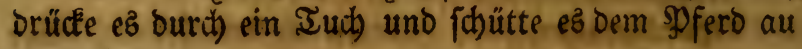
einmal ein.

E i n andereb.

Sdgmeer zebn loth, 


\section{Pferde=2Irzenei Bu(t).}

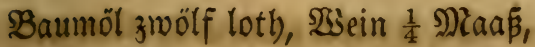
mijde es untereinander uno faütte es Dem $\$$ ferd lau= lid)t ein.

\section{Ein andereb NG.}

Untimonium Diaphoreticum sin Suintlein,

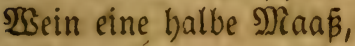

niijhe ę untercinander uno foütte ę bem Sूferb auf einmal cin; reite ocer fübre ez Drtauf,

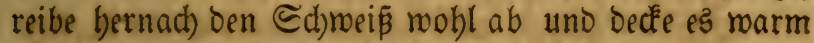
ju, oder nebme Scepar 2Sntimonium 2 Suintlein.

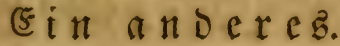

Zlantwurgel 4 loth, fiede es in siner Maấ $\mathfrak{B}$ ein, Darunter mifdoe

Saffian pin suintlein,

Baumöl 6 lotb,

Situnnenftelfeniaft 8 lotb,

Sdbnefelblumen 1 loth,

mifde es untereinander uno fidutte es bem sofero aut einmal ein.

(5) in a noereb SIG.

Srsilde Salbei,

WSegrwart, SBermuth, jedes 3 loth),

Säffele $\mathfrak{B}$ ipfel,

(Erlene $\mathfrak{B B i p f e l , ~ j e d e s ~ j e d ) z e h n ~ l o t h , ~}$

(sid)ene Dolden jedzehn loth,

(Ebermurzel 4 loth, Sirichnurzel 4 loth,

Salbennurzel, sfterlucen bie runde,

Xlantmutgel, jeoes $\frac{1}{4}$ SDfund,

(Enzian 4 loth), Saarftrang 3 loth.

Birnbaumenmifpel,

Ђäjetmiftel, jedes $\frac{1}{2}$ ⿰氵 fund, 


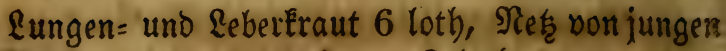
Foblen, Darein fie Eonimen, 2 loth,

Sävenbaum 3 lutb, Ropifinwefer, Rorbeer, (Elfenbein, jedes $\frac{1}{4}$ SDfund, (Ealcinirte ฐgel 12 lotb,

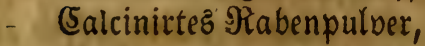
Bodf3hornfaamen, jeoes 6 loth, Eeinjaamen $\frac{1}{2}$ \$ু) fund, Ryrrben 4 loth, alles zujaunmen gepülvert; Dofiz 1 lotǵ Davon täglid) im Futter.

Ein anderez.

Saffran $\frac{1}{2}$ Quintlein, Simmetrinoen, Mntrhen, Iormentill, jebes 1 loth, Scrnig 6 loth, MBein $\frac{1}{2}$ Maaß,

fiebe es untereinander und fchütte es dem \$lferd auf ein= mal ein.

(E) an a erez.

Saffran $\frac{1}{2}$ Suintlein, Simmetrinoen,

Ryrrhen, jebes 1 loth,

SSallwurzel 2 loth, Eameelftroh,

Eseisen $\mathfrak{W}$ feffer, jebez 1 loth,

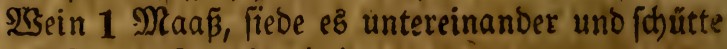
es bem \$ुfero auf zmeimal ein.

(5in anderes.

Dab Şirn von einem Spanferkel,

kodbe es in einer balben Maáp Mein, thue barzu : 
Baumöl 12 loth), id)ütte es bem Pुfero auf zmei= mal cin.

\section{(5in andereb.}

Rorbeer 1 loth), Ierpentin 2 lotb,

Sconig 3 loth), 2 Sein $\frac{1}{2}$ Maa

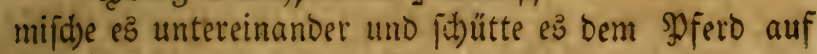
einmal ein.

(5) in a noereb.

6 friçbe 2idäpfel,

Simmetrinden 1 lotb,

M(n) r.tben ein balbes loth),

$\mathfrak{W}$ ein eine balbe $\mathfrak{M a a \tilde { \beta }}$

fiebe es untereinander uno gebe es ben spfero auf ein: mal eill. (5benjo gib Dem Sुferb allezeit Tormentill= $\mathfrak{S}_{3}$ urzel gepülwert unter bem Futter.

\section{Die Berpflegung.}

1. Der Stall foll mittelmäßig warm uno troden fein, jammt einet guten Streu.

2. Das Futter gebrochen, als (3ierfte, SBseizenfleien, Biden, Sidern.

3. Suz Irinfen foll laulidht fein, worin \&iebftöckel,

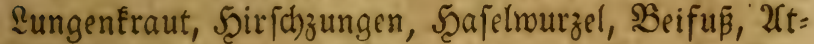
tid), fammt ein wenig Sconig gefotten find, ober fiede Den blofen Brunnenfteffen, uno las es davon laulibt trinken.

4. $\mathfrak{W}_{\mathrm{er}}$ feine Sुferde vor Der \&ungenjudht berwahren will, bet gebe ifnen oft 2rntimonium Eruoum ooer Sce=

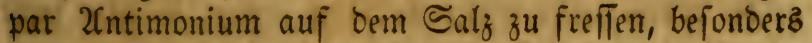
in bem Gommer bei hişiger 3eit, oa e's allem \$iebe gut und ein Şräfervativ gegen bą হiekefterben ift. 


\section{Das 5te Eapitel.}

\section{Bon verfehrten uno zerrifienen sungen.}

Diefe Srankbeit ift auch focher zu curiren uno gemei= niglich töotlich, entffebet aus zmeierlei Urjachen, entroe:

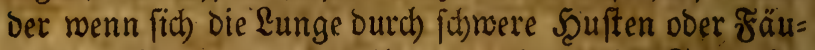
lung anfängt zu zertbeilen uno eine meißße farbe be= Eommt; bie andere Urifache iff von auswendiger Heber= nöthigung, als Springen, Fallen uno bergleichen ge= maltfamen Dingen, wie auch von Dem jäblings.zu viel

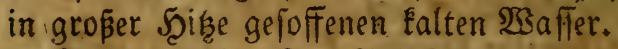

Die inmendige Sranfbeit fommt bon Der im vorber= gehenden (5apitel vermeldeten \&ungenfucht, wenn foldhe allzujehr überband genommen und ourch deten fäul= ung bie \&unge oamit angeftectit uno aljo ourch allzu ftarken Scutten ichabbaft genorden.

Die 3eicben von inmendiger Fäulung fino:

1. Dab Eranfe פDfero fauft uno frist vielmebr als vorber.

2. Der Şulten plagt es obre Unterlaś.

3. SBirft zumeilen zäben, Dicken, gelben uno fableim= igten Unflath aus.

4. Der Ramm, 3ungen und die ganze Sruft wiro mager.

5. Das Maul ift igm allezeit voll biden (siterz.

6. Sinket auf Den vorbern Schenkeln.

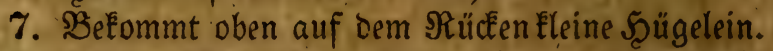

8. Sann nicht recht aufrecht fteben, fondern fucht allentbalben, mo es fich möge anlebnen.

\section{C ur.}

Sor allen Dingen foll man ben \&eiv offen balten : 


\section{Pferbe=2(rzenci Bud.}

Rebme ben Caft von Borzelfraut 6 loth,

Rofenöl 4 loth,

Iragant in einem balben Raaß̧ Şein folvirt 1 loth), mifd)e es untereinanier und (d)ütte eह Dem Sुfere auf einmal ein.

E in a noeres.

Sum. Ummoniac 4 lotb),

Sd)wefelblumen,

Mintrben, jedes 2 loth,

mijhe es mit Edhmeinenjdmalz zu einem Ieig und formite \$ुillen baraus, in ter (Siröße einer melfd)en গuß und gebe Dem Spferd täglid) 2 bavon ein, fetce es etlidse Tage fort.

\section{Ein anoereb.}

\&ege 6 Eier in Efitin, fo lang, bis ber Effitg bie Ei= eridhaalen ganz berab gebifen bat, lohiebe it,meins nach Dem andern in Den Siachen uno id)ütte ifm alsbald da= rauf $\frac{1}{4}$ Sfund Saumöl binein.

\section{Ein andereb.}

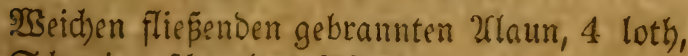
Sdymeinenfdymalz 1 Sुfuno,

Galz 2 Suintlein,

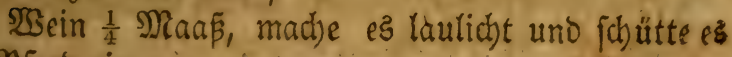
Dem spferd ein.

\section{(5in andereb.}

Sereinigte \$ুimpernüfle 1 ⿰ুग funo, Rofinen 2 Sुfund,

Eaud)e 6 Scündevoll, fiede es mobl in 2 Saffer und fop̈e es untereinander, mijche bernad)

Nonrrben 6 loth Darunter, 
Sconig ein balbes Sু fund und gibs bem \$Dferb auf oreimal eir.

\author{
Ein anderes.
}

Bobnenmehl $\frac{1}{4}$ \$p fund,

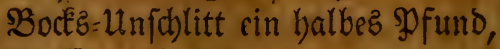

SPfeffer 1 loth,

Şein 1 Maaß̧, fiede es untereinander uno giepe ez dem SDferd auf einmal laulicht ein.

$$
\text { (5 in a n dereb. }
$$

alte ๔a)meer ein balbę ş fund,

Römijhen Spick 6 loth,

Snoblauch 2 Scäupter, Şonig 8 loth,

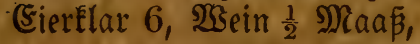

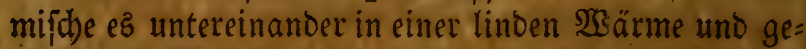
be ee Dem Spfero laulict)t ein.

Son äuperlid)en Ut.jad)en, fo folgen foldbe Beidben :

1. Solet Das Spferd langfam 2them. "

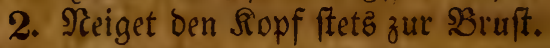

3. Seufzet ez, wenn es 20tbem fdöpfen muß.

4. WSiemohl es ben Souften fobeuet wegen bes @dumer= zes fann es ooch Denfelben nicht halten, fondern ftellet fich), als ob es fpisigige Beinlein in bem Şalz bätte.

5. $23 i r f t$ es blutigen, leibfarben uno fdäumigten unflath aus.

\title{
(c) $\mathrm{r}$.
}

Diefen spferden folle man cine gelinde xoerlaps an Dem Scalz geben, und nachfolgenden (Eingnes cingießen :

Nebme ben Saft pon gefottenem auggepreptem Scaber $\frac{1}{4}$ Maaß̄, (Seifenmild) $\frac{1}{4}$ Maaß̄,

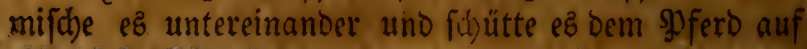
t, einmal lautidyt pin. 
Traganth 2 loth, Wallrad 1 loth,

Şirichunid)litt, Bodésunfdhlitt, jeoes 8 loth,

शiattermurzel,

Enzzian, Erogallen, jebes 1 lotb,

mifhe es untereinander, theile es in zwei abeile und fichütte ez dem \$fferd auf zweimal ein.

\section{Ein anderes.}

(Seftopenen Spect $\frac{1}{2}$ ⿰ু丨 fund,

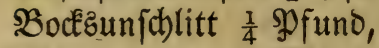

Memichenbarn $\frac{1}{2}$ Maa $\tilde{\beta}$,

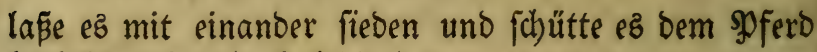
laulicht auf einmal ein.

$$
\text { Ei } \mathfrak{n} \mathfrak{a} \mathfrak{d} \boldsymbol{e r e g} \text {. }
$$

Birnbaumenmifpel 1 pfuno,

Şafelmifpel $\frac{1}{4}$ Shfund,

Iáf heléraut 1 sfuno.

Reiftermurzel $\frac{1}{2}$ ⿰冫 fund,

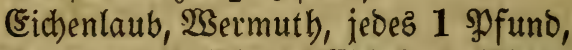

Eentaurea $\frac{1}{4}$ \$fund, Esicheln 1 \$̧ funo,

Ingmer 8 loth,

(Salgant 2 loth, Süpholz $\frac{1}{2}$ \$fund,

mifche es untereinander uno gib bem झुfero täglid brei loth bavon im Futter zu freffen.

2flfe Iränke, bie man ihnen je veroronen und einge= ben will, müsen ja nicht falt, fondern Milchwarm ober laulicht fein.

\section{Die $\mathfrak{B e r p f l e g u n g , ~}$}

Soll fein wie in bem vorhergebenden Capitil von ber Rungenfucht ift gemeldet worben. 
Derjenige Şuften aber; weld)er von 2Cpoftemen Des

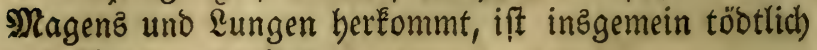
uno faner zu curiren.

\section{Cur Des trodenen Souftenb.}

Bor allen Dingen Den \&eib offen halten :

Nebme Nacedonifdhen Seterlen 4 loth,

Möbrenfame, Nimrrben, Spicanardi,

Doften, Iraganth, jebes 1 loth,

Schwertelnurzel 2 lotb,

Speffer 1 loth,

Extract von Eapiarinde 2 loth,

(S)ummi 2cmoniac 1 lotb),

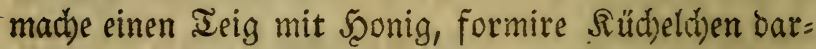
aus wie bie welichen গüs, bavon zerreibe täglich $\mathbf{3}$ in

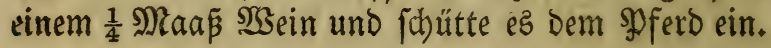

E in andereb.

Röblfraut, Sמappeln,

Seilenfraut, jedes 4 loth,

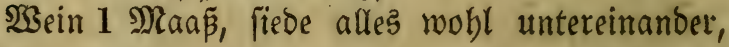
orücke bie SBrübe aus uno giese dem SPferd. laulicht auf einmal ein.

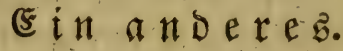

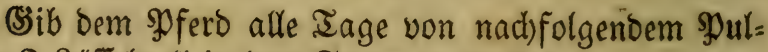
ver 3 Roffelooll in bem Futter zu freflen :

SYsiloe (5ucumernnourzel 10 loth,

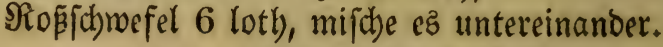

(5) $\mathfrak{i}$ a $\mathfrak{n} \mathfrak{D} \in \mathfrak{r} \in \mathfrak{b}$.

Caft von wilber Sucumernivurzel 6 loth,

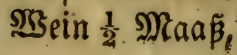




\section{פperbe:2(rzenei Bud).}

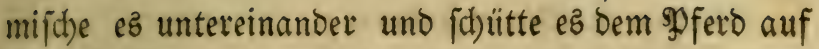
einmal ein.

E $\mathfrak{i n a n d e r e b . ~}$

Rinjen $\frac{1}{4}$ SPfund,

Boufshornfaamen, \&einfaamen, jebes 8 loth,

Rrabificher (S)

Eerdenfit)mamm, jedes 1 loth,

ftope alles untereinander, mifche es mit $1 \frac{1}{2}$ Maaß $\mathfrak{\text { SBein }}$ uno fdutte es auf zmeimal ein.

(5) $\mathfrak{i} \mathfrak{n} \mathfrak{D} \in \mathfrak{r} \in \mathfrak{b}$.

(Serfíte, ssidcken,

Sobnemmehl, jedes 6 loth,

Boufzhornjaamen 4 loth,

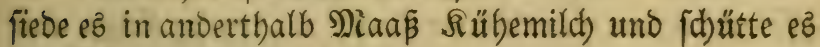
Dem If ferd auf einmal ein.

\section{(5) $\mathfrak{n} \mathfrak{a} \mathfrak{n} \mathbf{D} \in \mathfrak{R} \mathfrak{b}$.}

Boctshornjaamen, Süpholz, jebes 4 loth,

10 Frigen, Bobnenmebl 8 loth,

Butter, Sduneinenjidmalz, jeoes $\frac{1}{4}$ Sp funo,

fiebe es mobl in fliesendem $\mathfrak{B a f f e r}$ fto Der und ichütte es Dem SDFerD auf zmeinal MNorgenz uno 2rbends ein.

\section{(E)}

SBeilfaamen 1 loth,

Sümmel 2 loth, SPfeffer 1 loth,

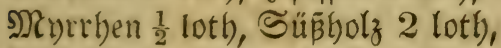

Iraganth 1 loth), ftope es untereinander uno gie=

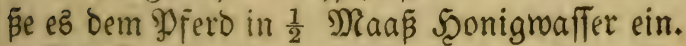

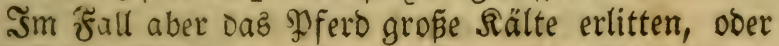

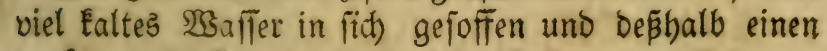
trodenen Souften befommen batte, fo 
Rehne Saft von 2Cndorn,

Süpholzpulver, jeoes 2 loth,

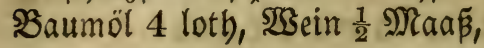

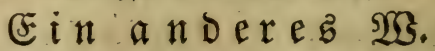

Rebme Ririchbäumentarz 2 loth, zerlape benjel=

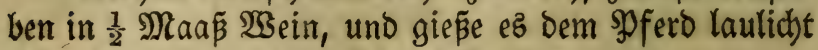
ein, oder 1 Suintlein Schwefelbalfam.

E⿺ $\mathfrak{i} \mathfrak{a} \mathfrak{n} D \in \mathbb{r} \mathfrak{e}$ b.

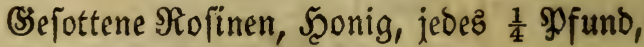

3ehacten Majoran 3 loth,

Woblgemuth 2 loth, Butter $\frac{1}{2}$ פूfund,

3 Inoblaucb3bäupter,

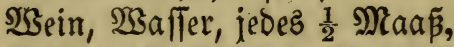

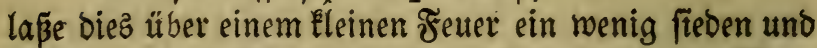
ihütte es bem \$̧ gens uno 2Cbenos.

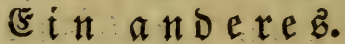

\section{- Saffran 1 Suintlein,}

Myrrben 1 lotb, Ingmer 2 loth,

Simmetrinden 1 loth,

Sconig 10 loth, $\mathfrak{B}$ ein $\frac{1}{2} \mathfrak{M a a \tilde { \beta }}$

mifche es untereinander uno fdüttte es dem \$ुferb lau= lidjt ein.

Ei $\mathfrak{i n}$ a

Enzian, runbe Shohfwurzel, jebes 2 loth,

Eorbeeren 4 lotb), $\mathfrak{B}$ ein $\frac{1}{2}$ Maaß̃,

mifabe ez untereinander und gieß̧e es laulidbt auf ein= mal ein.

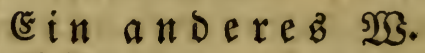

Fenchel, 2 nniz,

Eppichjaamen, jebes 1 lotb, 
Mntrben, Epica Softi Tragant. jebes 2 loth, Sconigmafter 1 Naaß̄,

lape cక über Siad)t untereinanoer weid)en und fdütte e\& Dem \$2) fero sndorgens frübe auf eimmal ein.

Sinde inu täglid) nad)folgende 2 rzeneien auf bas DeunDftüle in cinem Säctdjen ober in einem löd)erid)= ten Scolbié, wie es f(bon befdrieben worben.

Bertram 1 lotb),

Sïpbolz, Etaphifagria, jebes 2 loth),

Sergmünt 1 loth,

Storax 1 suintlein,

mifche es untereinander.

Et $\mathfrak{n}$ a $\mathfrak{n}$ dereb.

Sothen Storax 6 loth,

Irogloontifide Merrben 1 lotb,

Slaue Slgenmutzel,

Serpentin 8 loth,

Des Srauts @imploniä 2 loth,

alles untereinber zerffopen, Init Sconig vermijat uno

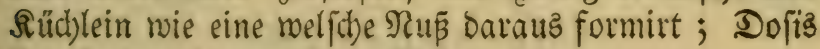
3 auf einmal in roarmen Wein.

Brunnentrefen unter Dą Futter gegeben, erfrifd)t Runge und Reber.

Die $\mathfrak{B e r p f l e g u n g . ~}$

1. Der Gtall foll trodéen, rein uno fauber, mittel= mäpiger $\mathfrak{S}$ ärme uno von allen $\mathscr{S} 3 i n b e n$ befreit fein.

2. Das Futtel foll fein $\mathfrak{B}$ eizenfleien mit Sonig vermijat, gebrodbener Salber, mit rothen Richern uno Süp̧olz vermildt.

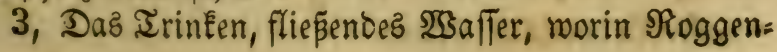


mebl mit Shonig vermijht ift. In dem fließsenden Bsaffer aber foll vorber $\mathfrak{Y}$ fop gejotten fein.

Dan Eann ifnen.auch laulidbt (Serftenwaffer zu trin= Een geben.

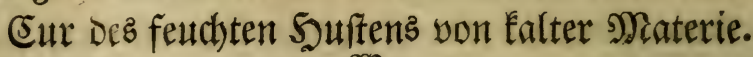
$\mathfrak{B S}$.

Nebme Traganth 1 loth, folvire benfelben in einem Maap fliependem thue bernach bazu

Şonig 8 loth, VYoppulver 2 loth,

3immet 2 suintlein, Sngmer 1 loth,

Süpholz 2 loth,

mijche ez untereinanoer und foutte es bem sूferb auf einmal ein.

Ein anderez.

M(yrrber 2 loth,

Saffran 1 suintlein,

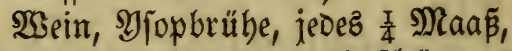

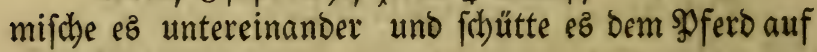
einmal ein.

(5in andereb.

(Šerffe 2 Sfund,

$\sin$

ganzen \&aud) mit fammt feinen $\mathfrak{W u r z e l n , ~ e i n ~}$

balbes Sुfund, (sppid), 8 loth,

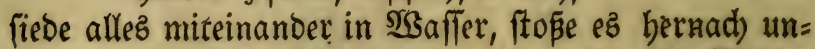
tereinanoer, und preß̧e eอ aนะ zu einer Dünnen SBrübe, thue bazu

Baumỏl $\frac{1}{4}$ SDFuno, $\mathfrak{B}$ ein $\frac{1}{2}$ Mlaaß̧, mifche es untereinander uno foütte ez bem $\$$ pferb ein.

(5) $\mathfrak{t}$ andereb.

(Serftenmebl $\frac{1}{4}$ gPfuno, 


\section{IJferbe=?lrzenei Bud,}

263

Syfefrer 2 lotb, Sonigwaffer 1 Nanaß,

(Seftopiene Rofinen $\frac{1}{4}$ SD) fund,

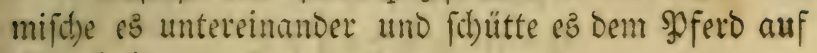
pinmal ein.

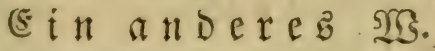

Storax Salamita, 1 lotb,

Iraganth) 2 lotb,

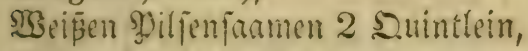

Sïmmel 1 loth, Sgonig fo viel genug ift

mad)e eszut einer Ratwerge; Dofis 2 loth auf eirmal

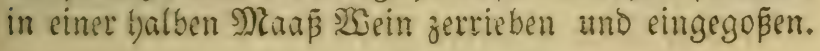

\section{(5) in and ere .}

Murrben ein balb loth,

Storax Salamita,

Sdbuefelbluithe, jedes 1 lot'́),

(S)rffenifleim eime balbe maan,

Bzein $\frac{1}{4}$ 2) Dem \$ै। ferd auf pimmal ein und dämpfe es mit nad) fol: genoem Dampf :

Doften, Rojen, jebes 1 šandwon,

Sanbel 1 loth, .

Samillen 1 Sandooll,

fiede e's woht in MBaffer in cinem jugematiten (S)ephir uno lape bavon Dem Dferd ten Sampf in vie गafege= ben, continuirz etlichemal.

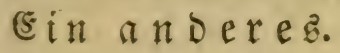

Eprife ifm toarmen SButter mit Dem ad)ten $\mathfrak{I}$ beil

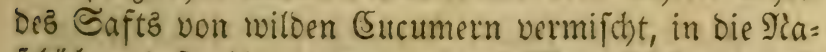
felöd)er, befte ibn berum auf Das Mundftück uno lap̃e Daz gुferd auf Dem in iem vorbergebenden Iheil von 


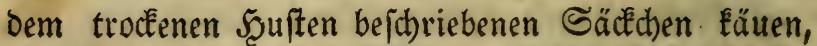
oder binde igm frifhes Sǘpholz auf Das Mtundftüref.

\section{E $\mathfrak{i} \mathfrak{n} \mathfrak{a} \mathfrak{n} D \in \mathfrak{x} \mathfrak{e}$ b.}

פeterfilienwutrzel 4 lotb),

Bibenell 1 lotb,

Minrthen, Spicanardi, jebes 2 loth,

Saffran 1 Suintlein,

(5almus, (S)ummi 2tmmoniac, jebes 1 loth),

pulberifitre alles, mache es mit 5conig zu einem ãeig,

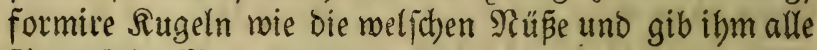
Tage 3 in $\mathfrak{B} e$ ein zerrieben ein.

\section{(5) $i$ and $\mathfrak{n}$ e $\mathfrak{E}$.}

Iraganth 1 lotb,

SAyrrben, Spicanardi, jedes ein halb lotb,

spfeffer 1 loth, Rümmel 1 loth,

Scharlach fraut 2 loth,

fïede alles in ciner Maa Dferb auf einmal ein.

Ein a noeraz $2 \mathbb{3}$.

Shepar 2Sntimonium 1 Suintlein,

Saffran ein baib Suintlein,

Wsein eine halbe Maaß̃,

mifd)e es untereinanoer uno fdütte es bem গুa fero auf einmal ein ; continuirz etlichemal uno lás das \$ferd warm barauf reiten, wobl bernach abmifhen uno bann zudectien.

Ein a n Derez.

Şarn eines jungen Inabenz ein balbes Maaß̄, Ëcbweinenfichmal 1 Wfund, fiebe es mit einer $\mathbf{S u a r t} \mathfrak{W}$ ein, thue barzu 
פgferoc: $\mathfrak{A}$ rzenei $\mathfrak{B}$ uă.

Saumỏ $\frac{1}{4}$ SPfuno,

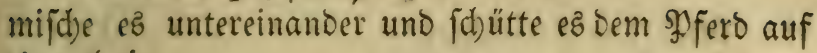
einmal ein.

Die Berpflegung foll fein mie vorbin bei Dem tro= dfenen Scuften vermeloet worden.

(5ur Des alten 5ुuftens.

SihlangenÉautworzel,

SBilde Sucumernmurzel, jeses 10 loth,

mifche es untereinander, gib Davon täglid) Dem झूfero 2 lott) im Futter zu freflen uno lape ibm nadffolgenden Dampf in bie Raje gehen :

Sfterlucer) 2 loth, M(y)rben,

(Salbanum, jeoes 1 loth,

madhe mit $\mathfrak{B}$ utter $\Re$ üdheldhen baraus, bavon etliche auf

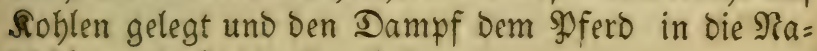
felöcher uno Scalz gehen lǟen.

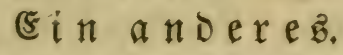

Seftopenen Spect ein balbez \$funt,

Merurben, Storax, jebes 1 lotb,

Bibergeil 2 Suintlein,

(Eppich, MTop, jedes 2 Scändeboll,

mache es mit Magjaamenbrühe z̧u einem $\mathfrak{I}$ eig, mache

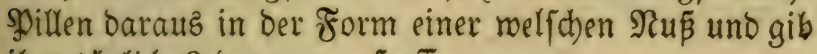
ibm tăglich 6 babon zu freften.

$$
\text { E } \mathfrak{i} \mathfrak{n} \text { - a n b e reb. }
$$

Baumöl 6 loth, 3 robe Eier,

Bobnenmehl,

Bock3hornfaamen, jectes 2 Röffelyol,

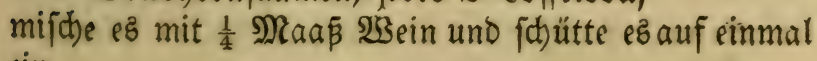
cin. 


\section{Ein a ndereb.}

Saft von Röbleraut,

Rauch)[aft, jedez $\frac{1}{4}$ Maaß́,

Baumöl ein balbes Spfund,

mijhe es untereinanoer und fou ütte es bem Infero auf einmal ein.

(5)

Roprwicken 1 Sp funo,

Majoran $\mathbf{5}$ loth;

Woblgemuth 6 loth,

ungefalzen ๔aneinenjamalz 4 sूfund,

9 Inoblautbẻbäupter,

vermifche alles miteinanber zu einem Ratwerge, bie

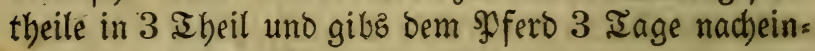
ander in rarmem $\mathfrak{B e i n}$ ein.

\section{E in andereb.}

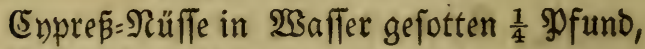

9 Inoblauch błäupter,

Tag = unv Nachtfraut $\frac{1}{4}$ Sुfund,

Echmeinenfchmalz 2 Sp fund,

mache es untereinander zu einem Latwerge, theile ef in

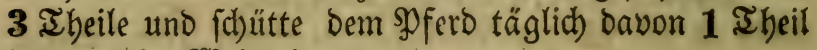
in warmem $\mathfrak{K}_{\text {ein ein. }}$

\section{(E) $\mathfrak{i} \mathfrak{a} \mathfrak{n} \mathfrak{D} \in \mathfrak{e} \in \mathfrak{b}^{\text {. }}$}

Serftenmehl $\frac{1}{4}$ SPfund,

rühre eళ mit warmem $\mathfrak{B a}$ affer laulid)t an und foutte es bem spfeto auf einmal ein.

E $\mathfrak{i} \mathfrak{n}$ a $\mathfrak{n}$ Dereb $\mathfrak{E}$.

\&auchjaft $\frac{1}{4}$ spfuno, S3aumöl ein balbes spfund,

Ed)mefelbluitbe 1 lotb, 


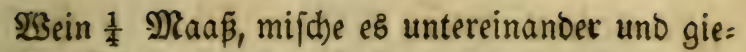
be es bem $\mathfrak{p}$ ferd auf einmal ein.
(E) in andere: $\mathfrak{B}$.

Y) fop, Wallwurzel,

Rauten, jedes 1 Şandooll,

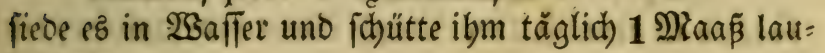
lid)t ein.

\section{Ein andere.}

Saft von 2 noorn 1 Sfund,

Saft von Şallnurzel 6 lotb,

20 Feigen, Sconig $\frac{1}{2}$ Pfuno,

fiebe 6 miteinander in einem roohldermad)en glafirten Shafen, alsoann mijche oazu in einem Mörjer :

Sppoponax 2 loth, Sfterlucey 4 loth,

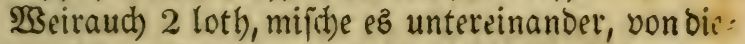
fem dem SPferb täglid) 1 Loth in einer Suart marme: $\mathfrak{R}_{\text {Bein }}$ eingegeben.

Ein a noereb.

Sod'zhornfaamen, 21 Stunden in Wein= 5ffig gelegt und unter Dem Futter gegeben.

\section{(5in a nDereb.}

Wachbolderbeerer,

Şuflattig, jedę 3 Şändeboll.

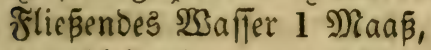

fiede es robl in einem vermad)ten Iopf und foh ütte es Dem Sुferd laulid)t auf einmal ein.

Die Serpflegung ift wie von Dem trockenen Şuften beforteben morden.

Sur Des neuen \$uftenz.

Rautennurzel 3 Scänoevoll, 


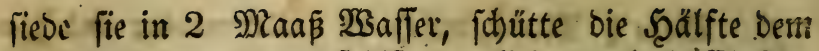
\$2fero ein, bie andere Scälfte applicir burd) ein (Slyftir. (5in andereb.

Şillde Rürbistourzel 2 loth,

Salpeter 2 suintlein,

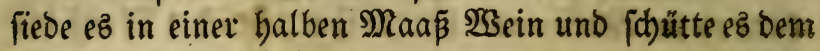
spfero auf einmal ein.

Ein andereb.

Reerzmiebeln 2 loth, $\mathfrak{R} a$ jeris 1 loth,

WBein eine balbe Maā̄,

Baumöl 1 spfuno,

mifube es untereinander uno fchütte esి bem sूfero auf einmal ein.

E in $\mathfrak{a n d e r e b . ~}$

Sinfenmebl 6 loth,

3 (5ier, laulicht $\mathfrak{B a f f e r} \frac{1}{2}$ Maaßa,

mifche es untereinander uno joütte ez bem $\mathfrak{P f e r}$ einmal ein.

Ein andereb গู.

Waach holderöl 1 loth,

Rō̄bufroffer $\frac{1}{2}$ Naa

mifhe es untereinander und ichütte es bem şofero auf einmal ein.

Die Serpflegung ift in ben Şuften=(5uren fhon an= gegeben.

\section{(5) $u \mathfrak{r}$ b}

meicher aus übermäsiger (sthikung uno allzubef= tiger Urbeit bei grofer Sithe entftanden ift.

Die 4 kühlende Saamen jedes 2 suintlein, Iraganth. Süpholz, jedes 1 loth, 
Safran ein balbes Suintlein,

mijche bies untereinander, thue ę in ein bünnes @äct: (b)en, binde fold)es auf oas Munoftück, befte es etliche Stunde täglich Darauf um uno gieb ifm alle Morgen nadfolgenden (Finguß :

Sappelnbrübe $\frac{1}{2}$ Maa $\tilde{\beta}$,

Frijche SButter 8 loth,

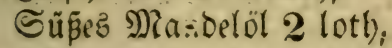

mijhe es untereinander uno fdütte ez auf einmal ein.

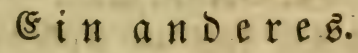

Nenrtben 4 loth,

Ireflenjaamen 8 lotly,

Reinfaamen 13 loth,

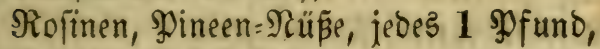

Şonig $1 \frac{1}{2}$ Spfund,

mad)e Rüd)eldjen Daraus in bar (Siröpe einer melfu; rtt

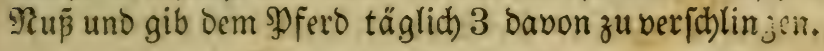

Ein a noereb.

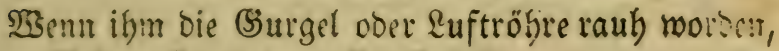

Яehme \&einfaamen 3 loth,

Bock'bornfaamen '2 loth,

Durre Rofen 1 lotb),

Yiop 2 loth,

ïede es in $1 \frac{1}{2}$ Maaß auf pinmal ein.

Ein andere

(Sieb ifm Sefottene (Serfte mit Ragiaamen ver= mifat.

Einanoereb.

Süpholzpulver,

2agfaamen jedes 6 lotb, 
Rleien = Slümplein mit Sconig vermifd)t und ge= fottene SSerfte, anftatt Des Futters zu frefien.

$$
\mathfrak{s} \mathfrak{u} \mathfrak{n} \mathfrak{e} \mathfrak{n}=\mathbb{S}_{\mathrm{tä}} \mathfrak{f} \mathfrak{u} \mathfrak{u g} \text {. }
$$

Nachbem nun bie phlegmatifche Materien alfo ver = zebret find, fo gib bem Shferd um bie \&unge wieber zu

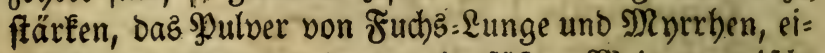
nes fo viel als das andere, mit füpen $\mathfrak{B}_{\text {ein }}$ bermifd)t zu trinfen.

\section{Die Serpflegung.}

1. Der Stall foll fübl uno trodfen uno von allen 2Binden befreit fein.

2. Unter Dem Futter follen erf̈̈blende Sachen fein, als Süpholz, geipttene (Serfte, geidhnitten Stroh, Sెei= lentraut, $\mathfrak{B}$ eibenblätter, Fendolgras.

3. Der Trane foll laulich SGaffer fein, in meld)ens Y) worden, uno etraas (Sserftenmebl binein gerülyret.

\section{Das 7te Eapitel.}

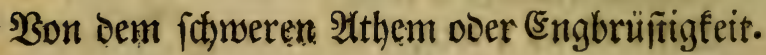

Diefe Srankheit ift oreierlei.

1. Sat baz spfero einen Eurzen uno fhweren 2 them uno leidyt oder röd)elt nidjt Dabei.

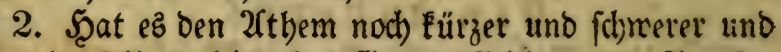
Eann Denfelben nicht obne Ssetös, Seidben ober Irenfen von fich lapen.

3. Rann bas spferd ben Xthem burchaus nicht $\mathfrak{b} a=$

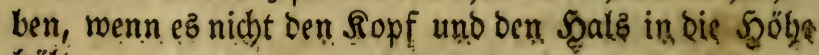
bălts 
Die Urfachen biejer Srantbeiten fino z'weierlei, äuf= jerlidje uno innerlicbe. Die äuperlichen fommen von ftautichen, fdimmlid)en oder fonft veroorbenen Spei= ien, als veroorbenem Sceu, Scaber, Sceterling, Stroh, uno bergleiden, ober wern man fie, wenn fie fehr $\mathrm{el}=$ bigt fino, alsbalo trinfen läpt, oder in bas $\mathfrak{S}_{\mathfrak{B}}$ fffer reitet.

Die innerlichen urjacben find Engigeteit ber Buft

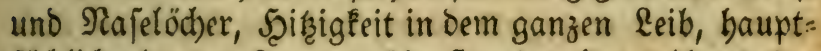
fäblich) aber Der $\mathfrak{R} u n g e n, 2$ poftem bes Sueerblattz oder 3wergbäutd)enz, weldbes die Bruft ber Iänge nad) un= teridbeibet, oder Deßen, mit meldbem bie Rippe inwendig überzogen ift.

Bismeilen verurfad)t ber in bem Nagen oder in bem grofen Darm, Solon genannt, verjammelte $\mathfrak{S}$ ind $\mathrm{ez}$ auch; (5benfo bie (3ejdroullft voer 2 ufbläbung ber $\Omega_{c}=$ ber Doer Des Milzę, ourch nelde daz Sucerblatt ge= Drücft wird. Soer roenn oie \&uftgurgel ourd) ein 2 (po=

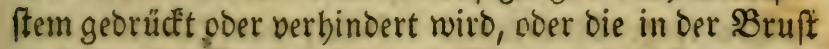
verfammelte feud)tigḱeit uno (siter; die dicke und za $\tilde{a}=$ be Feuchtigfeiten, weldbe entmeier curd) einen Flü bon bem Scaupt berab fallen, ooer jonft aus cinem benad)= barten (Slied berformmen, coer entmeder in oer $\mathfrak{R}_{\text {unge }}$ felbft erroadjen, oie Etrapen bes 2t thems verftopfen und bie nach Der \&änge getidtete. Edbeibewand uno baz Queerblatt fammt Den zur Śruft gebörigen Näuffen einnebmen, überzieben, beteden uno an ibren Beme= gungen bertincern. Sarauf bunn, nactioem nemlid) biejer Srt uno Gtrapen, oură) melche tie \&uft natürli= d)ermeife aus und einmandert, berffefft und umidloßen werben, biefe uno andere bergleidjen forwere und ge= fübrliche 3ufälle mebr, nothnorndig èrfolgen müßer. 
2Cber eben fo menig bie Materie an ibnen, felbft rüet = fict)tlich) ber Sualität uno Suantität, einerlei if uno audc nid)t immer benjelben Sort einnelgmen, fo zeigt fid) biefe Srantefeit aud) oft unter ganz verfdbiedenen 2(us= picien.

Denn biejenige, welthe ben obern uno inmendigen Theil ber Lungen einnimmt uno bas \$ueerblatt uno Ruftgurgel fammt ben Mäuffen, weld)e bie Bruft er=

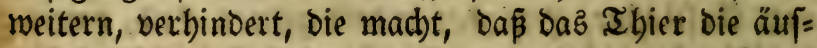

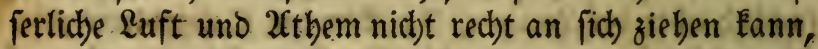
Denn baz Sueerblatt uno die \&unge, wie bereits benterft rourbe, bon Den Feúchtigfeiten tuberfüllet und eingenommen, Eönnen fith niddt recht uno genug jân zufammen thun, noch bie äußerlidbe \&uft gebörig burd) bie (Surgel binein zieben, nod) jonften auch bie Mäuffe, weld)e bie Bruft erweitern belfen, ihe $2(\mathrm{mt}$ red)t ur.o wobt ver= rid)teri.

$\mathfrak{B} e n n$ aber ber ausmendige und unterfte Theil ber \&ungen eingenommen uno erfüllet, uno baneben auch bie Mäuffe, bie fonften bie Bruft einzuzieben pflegen, mit angefouten find ; fo erfolget, Daß̧ Das \$pfero ben Xthem nid)t nobl aus uno von fid) lapin Eann. Denn Die $\mathfrak{R}$ unge Eann fith), indem die ermärmte $\mathfrak{R}$ uft hinaus begehrt, nicht genug fam auf uno voneinander thun, noch auch bie Mäuffe bie Sruft nach Notbourft einzieben.

Sm Fall fie aber bie Materie beiter Seiten ber Run= gen einnimmt, bas Sueerblatt an allen (Enoen verftopft und bie Ruftgurgel fammt ten Mäuffen, meldbe Die Natur bie Bruft aufzuthun uno einzujielyen ver= oronet bat, verhindert, fo fann bas arme I Ifier beina: lye weber ein nod) aus athmen.

und biefe fino viele uno mandherlei fheinbare $u$ unter= 
fdjiebe bes fidweren und furzen 2(tbemz, aus roldjen man nidft allein Den Sot der Rranfbeit, fondern auds wie biefelbe ibrer Sualität uno Siröpe nad) bejuaffen fei, abnehmen fann, merden überdiez aud) baraub deut= (id) offenbar, wenn daz \$perd feine $\mathfrak{B}$ seid)en oder $\mathbb{R} e n=$ Den über und wieder feine fonft geroöbnliche Ratur uno

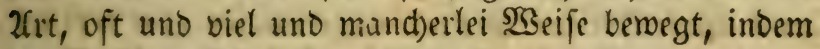
eह aljo fdyerlid) aus und ein atbmet.

Denn etlid)e foldber $\$$ ferde berogen die \&enden oder $23 e i d)$ fehr (d)nefl und gefd)wind auf einander und mit groper (Servalt : entmeder meil bie zu bem 2rthem uno (Seiftern veroronete Inftrumente febr erbifet fino, oder weil bie Rungen etro (Sefdrmüre befommen, ober ein hiçiger 2(poftem, bergleiden in ber \&ungenfud)t zu ge= fibehen pflegt, entitanoen, ooer fonften etwas berglei= d)en erwadjfen, Daraus die unnatürliche Scife in Den (Sliedern Der (Seifter bat Eönnen vermehrt reroen.

Denn mäbreno die Natur ourd) fold)e (sinigkeit ber= bindert wirb, und gleidrmohl Der (Erfüblung hod) von= nöthen bat, wiederholt fie cas 2(tbmen oefto eber uno

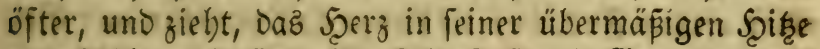
ju erküblen, die äuperlidbe falte $\_$uft mit (Semalt in ben Reib binein, meltbes bann ganz unzmeioeutig zu verfte= len gibt, baß̧ bie Sothnendigkeit zu athmen in einem

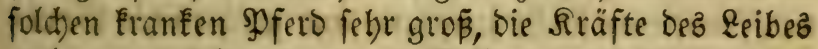
noct) vermöglict) uno gut, Die Inftrumente derjelben aber nicht gemäß uno folglich oie Rranḱteit, befonders bas Reichen, erft von Eurzer Dauer fri; Denn jedes (Se= fd) nür entzündet anfangz den Sort, mo esentffebet, bie Sräfte mögen fich noch-eine 3eitlang erhalten, fpäter aber, beim Ueberhanonebmen des (Sefdnuürs, fangen fie an zu fđminden, moraus fith) alsoann erflären läp̄t, 


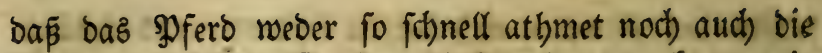
Renoen mit jolcher (Sefdiminoigkeit bemegen Éann, mie ez anfangs ber Fall war.

(Etlid)e aber bewegen bie \&enden barum fo oft und gefinvino, weil fic nemlich eine gleid)fam auzgebörtrte

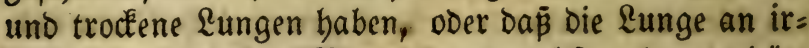
gend einem Sort ber Rippen angerwachjen ober verbär= tet, ober nit 2fpoftemen bebaftet fino, oder vicl (Eiter fid) in ber Saruft verfammelt hat : Soer menn ibnen Des 2fthems Durdbgänge uno ভtraßsen zu eng fino, Denn wo bies ber Fall ift, ba mus bie Ratur bas 2fthmen be= fto öfter wieberbolen, und aljo notbmendigermeife audh bie $\mathfrak{e} e n d e n$ mehr uno öfters benegen, Damit fie mit fol= d)em basjenige, fo fie an Der Giefdnwindigfeit uno Stär = ke nicht vermag, erftatte.

Ettliche berwegen bie $\mathfrak{\Omega}_{e n d e n}$ fein allgemad) uno lang: jam, meil bie nöthigen Sräfte nid)t mehr in İbätigkeit geję̧t merben fönnen, um bie Berwegungen fo gef́bmino und regelmäß̈g herborzubringen alz ę nötbig wäre. Ez liegen bismeilen audh andere $\mathfrak{u} r$ jachen zu (srunde, ez ift oft Der Fall, Daß bie \&unge faft verzehrt, mit (Se) fohmüren, Ealten beralteten 2 (poftemen belaben ober aud) Das ミueerblatt mit einer $\mathfrak{M a p e}$ biffer uno zäher $\mathfrak{M a}=$ terien umgeben ift, welche ez berbindern und fchwäd)en uno fomit eine foldbe langfame uno gefdrwädbte $R$ erve= gung verur jachen fönnen.

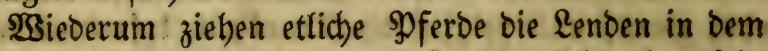
(Einathmen fehr viel und gemaltig an, etliche aber fein allgemad, bergegen aber in bem Xusatymen alle beibe gewaltig heraub, meldjes bann von ber fibwachen und unvermöglichen গatur berÉommt, meldhe bie J̃nftru= menten, fo oen 2(them auf: und annebmen, nid)t alfo 
geid)wind, und gleid) fam in sinem 2 ugenblick sinzieben uno berwegen fann; uno bann auch meil bie Stücfe ber (Sliebergeifter, fammt Den zu Dem 2tthmen veroroneten Näuffen uno fonberlid) Denjenigen, fo bie Bruft einzie= ben, mit angefod)ten fino. (sine andere uriadse ift, weil nid)t allein bas Sucerblatt, fonoern aud) bie ou bet Bruft gebörigen Mäufe in fold)en Sूferten zu Dem Xithmen belfen müpen, uno bann auch weil bie \&unge faft ausigetrodfnet ober fonften mit vielem unrath über. fürlet, bas Sucerblatt aber an feinem Sbertbeil mit bi= deen uno zähen Feud)tigfeiten überzogen uno umgeben ift; melches alles allein Daber entipringet, weil zroar

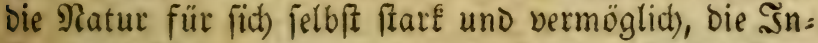
frumente aber zu bem 2(tbem burd)auz nid)t folglam, fondern widerfpenftig fino.

Denn in fold,em 3uftand fann fich bas sueprblatt, indem bas I Sier sinathmet, nid)t genugfam sin: uno jufammen ziehen, es fei benn, daß̧ it)m die andere शäuffe zu Şülfe fommen, bamit es feinem 2(mt genug

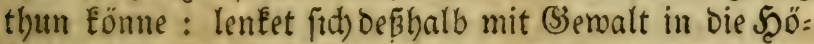
be, und bineinnärtz gegen feinem 2 (nfang, als zu ben Spifen ber unterften balben oder furzen Rippe, an welche es angebeftet ift, uno ziebt baburch aud) ben un: tern Theil ber Sruft, uno alfo aud) ben ganzen $2 a u(b)$ mit fich ein uno zufammen und Daßjelbige alfo, oaj es bas 2 nnjeben befommt, als thäten fich die gemeldete Spi= Een, Der balben und Eurzen Rippe in foldher unnatürli= d)en Berwegung ganz uno gar beraus; uno machen al= fo eine grōe Şöbe (weld)ez aud) bizmeilen ein 2 (nzei= gen ber Rungenjucht ift) und folche Scöbe thut fich ge= möbnlid) mebr überfid), bismeilen aber ziebt fie fich binabnärts, je nacboem fich oas sueerblatt mit ben an= 
Dern Mäuffen mehr ein= uno zufammen zieht, uno ben

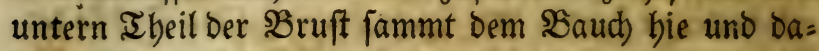
bin bewegt.

Ettliche miederbolen das Einathmen ehe fie nieber aubatbmen, zmeimal gefdomino aufeinanoer uno zieben Dabei bie $\mathfrak{L}$ enden auch zmei verjajiedenemale ein, bei Dem 2luzatbmen aber zieben fie diefelbe gerwaltig in bie 5̧ö= be, welches bann von etlichen ein Doppelter ober zwei= facher Eeufzer genannt miro, und biefe fino oie rechten

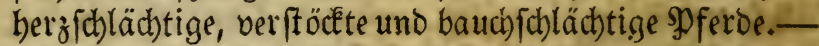
Und diefez allez fommt auch nebft obenbefchriebenen Ur radben aus bem, wenn eine zähe Materie oben an bie Rungenröhre, ba bie gröpte 2efte ibren 26nfang nebmen,

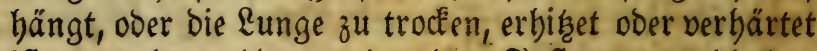
ift, bas sueerblatt uno anbere snftrumente, bie bas 2tthmen beförbern belfen follten, beleidiget fino.

Ettlid) wieberbolen oas 2luzatbmen zweimal, fprei= ten bie \&enden zmeimal aus, bläben fich in folchen ge=

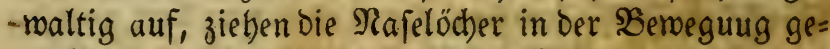
waltig, uno gleidjam mit großer Mühe auf und zu.

(Etliche fehen faft Melandbolifo auz, pfeifen burch

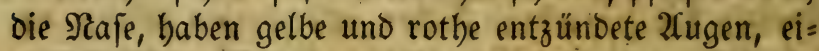
nen ftinfenden brennendbeifen und gefobminden 2 them, röd)eln uno Eeidjen wenn man fie etwaz fothell anttei= ben will, fteben im \&auf wobl gar ftill uno fallen nieber.

פSaz die Sheilung biejer Rrankleit betrifft, fo ift diefelbe, menn fie noch neu ift, zrat möglid, jeboch ftets mit großer (Seffabr verÉnüpft ; ift fte aber fd)on veraltet oder ift fie innerlid) uno bie \&unge angewad)s fen, fo iff dieje Srantheit nicht mebr zu heilen.

$\mathfrak{u}_{\text {no }}$ da biefe Srankbeit mebrentheils ihren ltefprung aus den Ealten und zäben Freud)tigkeiten, weldje fich in 
Det Runge und Den zu bem 20them gebörigen S̈nftru= menten verfammelt bat, alfo wollen wir bieje (Sur all= bier, fo fern die Rranebeit nod) neu ift uno nicht gar ou felyr veraltet, vornebmen uno bejdreiben.

Boctehornjaamen,

2llantmurzel, Bittwer, jedes 1 loth,

Sdivefel 1 loth, ftope allez ourd)einander, gebe

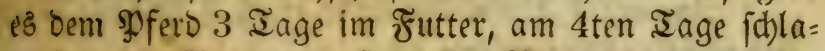
ge ifm die Sportaber, fange bas Blut und gebe es ifm unter bem Futter zu freflen.

\section{(5) in a ndereb $\mathfrak{W}$.}

2lant 3 loth, Enzian 6 loth,

:3ilde Eutumernmurzel 3 loth),

Rerdenfdyamm 6 loth,

SSeidenid)wamm 10 loth,

Sfterlucen 6 loth,

Salap 3 lotb), Scammonium $1 \frac{1}{2}$ loth,

milche es untereinander zu einem Shulver und gebe Dem spfero täglid) 1 Roth Davon im Futter zu freflen, ober

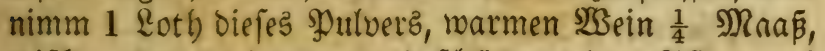
mifdbe es untereinander und fdütte es Dem SDfero auf einmal ein.

(5) in a ndereb.

Raßje ibm eine Ruftläpe geben, nemlid) beibe Sporr= abern ocer beibe \&ungabern, jeood) nicht zu viel, bamit es nut $\mathfrak{\imath}$ uft befomme uno man feben möge, wie das Slut auşebe.

(E) in andereb গুG.

Iaujenogüldentraut,

2 Silde Cucumernmurzel, jedes 3 loth, ïede es in Scammelfleifibbrübe, thue orei Fierbotter 


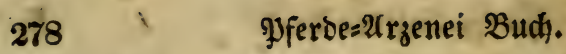

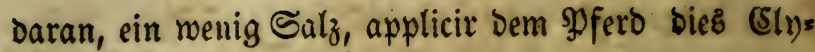

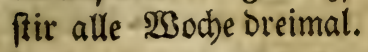

(E i $\mathfrak{a}$ ก

Soldanella $\frac{1}{2}$ loth,

Shermodacttnl 1 Suintlein,

Iurbith 2 Suintlein, cammonium $\frac{1}{2}$ lotb,

sngwer 1 Suintlein, fiede ez in $\frac{1}{4}$ Miaaß $\mathfrak{B}_{\text {Bein }}$ uno fhu ütte ez auf einmal ein.

Ein anderes Elyftir গ্র3.

Eerdbenfdywamm $\frac{1}{2}$ loth),

Z3eibenfdhwamm 2 loth,

2SGeliden Suendel 1 Scanovoll,

Engeliü 1 loth), Euphorbium 1 Sountlein,

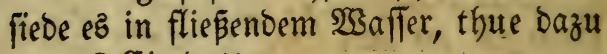

3 Eierbotter,

Salz 1 loth, applicirz.

sin anderes હfyftir.

Soloquintenmare 1 loth,

Rauten, Eamillen

Thymian, jeder 2 Scänoevoll.

2Bsilbe (Sucumernwurzel 1 loth),

fiebe es in flic

2 Eierootter,

Salz 1 loth, applicirs.

Ei a nderez

(3ib bem $\mathfrak{N f e r b} 15$ Tage nadjeinander alle Morgen in einem Rleienfutter von nachfolgendem \$ulver ein \&öffelooll zu freffen,

Lerchenichwamm 3 loth, खseidenidyamm 8 loth, 
Ratwerg wirb, bavon foütte bem Sुferd alle Iage $\frac{\pi}{4}$ Ş fund in warmem $\mathfrak{B}$ ein ein.

\section{E $\mathfrak{i} \mathfrak{n} \mathfrak{n}$ Dereb.}

Nelfen 1 Suintlein,

Nuscatenu泛 2 Suintlein,

Sngwer 1 loth,

(S)algant 2 Suintlein,

Fenchel 2 loth, 3 Esierootter,

Saffran $\frac{1}{2}$ Suintlein,

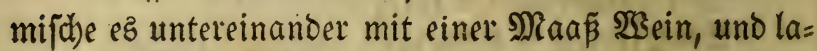
Be einen $\mathfrak{B S a l l}$ auffieden, bernadb dem $\$$ f fero eingegeben.

\section{Ei $\mathfrak{n} \mathfrak{n} \mathbf{D} \in \mathfrak{r} \mathfrak{e} \mathfrak{G}$.}

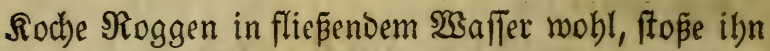
alsbann uno brücke ben Saft mit fammt ber gefottenen Brübe bavon.

Son biejer SBrübe nimm 1 Maáp, füpes Mandelöl,

3 loth,

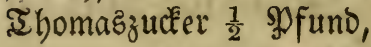

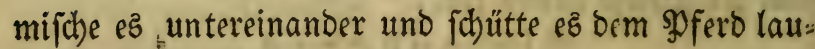
lid)t auf einmal ein.

Ein andereb.

Süpholzpulver 3 loth,

Sngwer 1 loth,

Simmetrinden 2 suintlein,

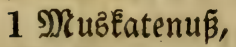

Menid)enbarn $\frac{1}{4}$ Maaß̄,

Wein $\frac{1}{2}$ Maaß̧,

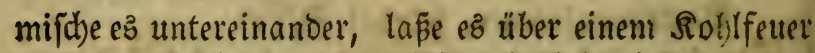
erbiten und faütte es bem Sुferb laulicht ein. 


\section{Ein andereb.}

Sđütte Dem $\Re$ ferb 15 Iage nacheinander Frnübe

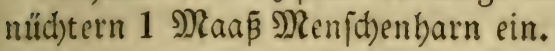

\section{(5) $\mathfrak{n}$ a noerez $\mathfrak{K}$.}

Rebme Neucedanum,

Eariophyllata, fammt bem Sraut,

פyfeffer, Ingmer, jebes 1 loth,

Blane Rilienmurzel,

Rbapontic, jebes 2 loth,

Scabiojen, Rerchenfidranm, jebes 1 loth,

mifche es untereinander uno fiede es moht in 2 saffer, nebme ber abgefottenen Brübe 1 Maaß̃,

Sconig $\frac{1}{4}$ Şfuno, mifothe es untereinander und idütte es auf einmal ein.

$$
\text { E } \mathfrak{i} \mathfrak{a} \mathfrak{n} \mathcal{D} \mathfrak{e} \mathfrak{e} \text {. }
$$

Bodéshornjaamen 2 loth),

Sdwarzen Rümmel I loth,

(Eid)eln 1 Mfund, Wsein 2 Maá,

Garbomömlein, Selelén, jeoes 1 Suintlein,

Muscatemur ; Salgunt, jeoce 2 Suintlein,

Süpülolz 3 loth),

fiebe es untereinander, theile es in 2 Theile und giepe pe Dem

\section{Ein anderes $\mathfrak{T B}$.}

WBilden (Sucumernfaft 1 loth,

Extract von Salapnurzel 2 Suintlein,

2(garic 1 loth), $\mathfrak{B S e i n} 1$ Maa $\tilde{\text {, }}$

mifd)e ez untcreinander und fdütte es auf einmal ein.

(5in anderes.

ferdenifhromm, 
Seellglänzeno Galz, jebez 1 loth,

Scammonium 2 Suintlein, Syonig 8 loth,

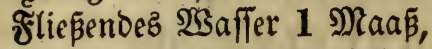

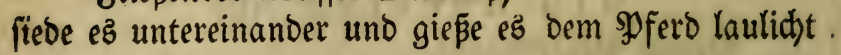
auf einmal ein.

$$
\text { (E) a n neres. }
$$

Rerchenfdymamm 8 loth,

Runbe Sfterlucey 6 loth,

Schiffped 1 פfuno,

\section{Spect, Sconig, Ierpentin, jebes $\frac{1}{2}$ Mfuno, Majoran 6 loth,}

mirche allez untereinanoer, pülnere zuvor biejenigen Sadben, bie zu pülvern find, beftreue die Scand mit Eserf́tenmebl uno formire \$ilfen baraus, theile fie in 3 Theile uno gibs dem $\$$ pfero auf breimal ein.

Ei $\mathfrak{n}$ andereb 2 .

Scthofefelblütlye 1 loth, Ierpentin 3 loth,

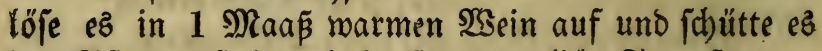

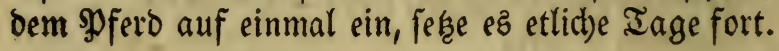

E $\mathfrak{i} \mathfrak{n} \mathfrak{a} \mathfrak{n}$ e e $\mathfrak{e} \mathfrak{e}$.

Unjer Frauenbaar, Sdbmertelmurzel,

2(noorn, jedez 1 Şanovoll;

Süpholz, Bodķhornjaamen, jebes 2 lotb,

פeffer 1 loth, , sonig 6 loth,

Earbomömlein 2 Suintlein,

Refielfaamen 1 loth,

Bittere Mandeln 6 loth,

Scbmalzblumen 2 Suintlein, .

Coloquinten 3 suintlein, 
Tamariskenjchelfen, Iorbeer, jeoes 6 loth,

Eeinjaamen,

Runde Scohlnurzel, jedez 4 loth,

Baumöl $2 \frac{1}{2}$ Sfund,

Sriz Macebonia, ober in Ermangelung biejez,

Blaue Sibwertelnurzel 4 loth,

SSilde Sucumernmurzel 2 loth,

mijche uno ftope untereinander, was zu ftopen ift, laßje ez über einem Feuer ein wenig roarm werben, alzbann Dem SpFerd laulid)t auf einmal eingegeben und bas \$ferd angebeftet uno ibm bie $\mathbb{e} e n d e n$ Des Tagz zmei= mal mit Rammichmalz fdomieren.

WSenn man biefe (5ur einem 2 fero braucht, mus man

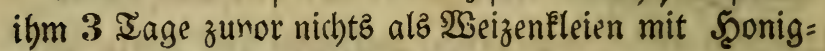
waffer befprengt zu freffen geben.

(5z miro in 2 ober 3 Tagen nichtz freffen, bernach wenn es anfängt zu brechen, foll man ibm ben Muno uno bie 3unge mit ber Mixtur von (sifig, Snoblaud)

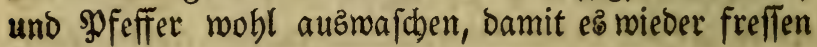
Eönne.

\section{Ein $\mathfrak{a} \mathfrak{n}$ ) $\mathfrak{x} \mathfrak{e}$.}

\section{Spede 3 Pf fund,}

Frifchen $\mathfrak{B}$ utter 2 sfund,

(S) fottenen Bodḱshornfaamen 1 Sf fund,

Scierä picrä 4 loth, Rojenbonig 6 lotb,

Şutzel von willoen Eucumern,

Scammonium, jedes 1 lotb),

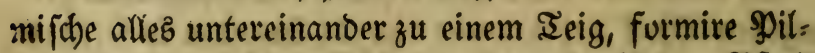

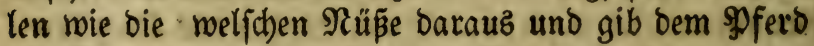
alle Tage 9 bavon ein, fekge ben (Sebraud) bavon eine 3eitlang fort. 


\section{(E) $\mathfrak{i} \mathfrak{a} \mathfrak{n} \mathfrak{D} \mathfrak{e} \in \mathfrak{B}$ গ⿺乚.}

Enzian 2 loth, Simmetrinden $\frac{1}{2}$ loth,

2rgaric, Sialgant, Șierä picrä,

Bruftucerenjaft, jedes 1 loth),

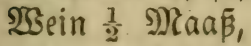

mifche es untereinanoer uno giepe bem Mferb auf ein= mal ein, miederbole es etlicbemal.

\section{(E) in a n Dex e}

\&einöl, Nupöl, jebes 6 loth,

Frifiche Butter,

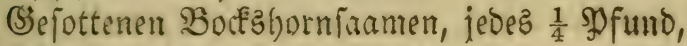
ftope alfes untereinanber, vermifd)e es mit $\frac{1}{2} \mathfrak{Q R a} \tilde{\beta}$ warmem $\mathfrak{S}_{\text {Sein }}$ uno foütte ez auf einmal sin.

E in andereb.

Rojentonig $\frac{1}{4}$ gofuno,

Eerdeniftwamm 2 loth,

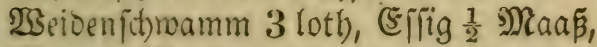

গু马ein $\frac{1}{4} \mathfrak{M a a} \tilde{\beta}$, mifiche es untereinander uno gie= pee es bem spfero auf eimmal ein.

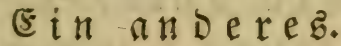

Răud)ere das গুFero oft mit Bibergeil.

$$
\text { E } i \mathfrak{n} \text { a n D e } \mathfrak{C} \mathfrak{B} \text {. }
$$

- Rauge von guter reiner 2 (j) $\frac{1}{4}$ Dfund,

Baumöl $\frac{1}{2}$ Sf funo, miiche es untereinander, und

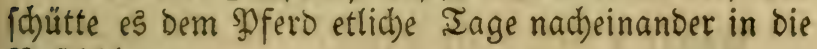
Najelöcher.

Ein a ก Deres গT.

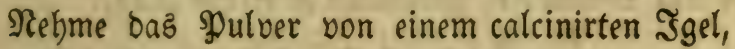
2 loth,

(Enzian, Sävenbaum, jebes 1 loth, 
Sconigwaffer $\frac{1}{4}$ Maaß̃,

mifche es untereinander uno faüutte ę bem झুferb auf einmal ein, ferge es etliche $\mathfrak{T}$ age fort.

\section{É in andereb.}

Umeifen fammt ben (siern $\frac{1}{4}$ \$N fund, Enzian 3 lotb, W̧ermuth $\frac{1}{2}$ Scanovoll.

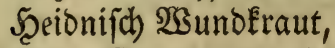

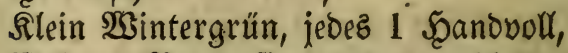

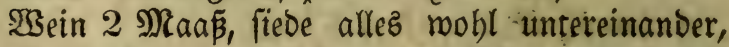
feibe Die $\mathfrak{B r u ̈ b e} a b$ und foultte Dem \$y ferd auf einmal $\frac{1}{4} \mathfrak{M a a}$ bayon ein, mieberbole ez etlichemal.

\section{Ei $\mathfrak{n} \mathfrak{a} \mathfrak{n} \mathfrak{e} \mathfrak{e} \mathfrak{e} \mathfrak{b}$.}

Şäfrele ŞSipfeln,

Ërlene $\mathfrak{B i p f e l n , ~ j e o c e s ~} 2$ Scänoevoll,

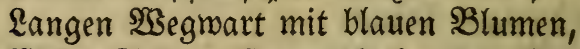

WBitbe Salbei, 2 Bermuth, jebez 1 SSanowoln, mifche ez untereinander uno gibs bem spfero in dem Futter zu frefien.

\section{(E) $\mathfrak{i}$ a noereb.}

\$ulver von geoörttem \&einfaamen 1 \$f fund,

Enzian 8 loth, Boctzhornfaamen 4 loth, mijche es untereinander uno gibs bem \$ुfero im fruttar zu freffer.

Ein andere⿻コ一.

Enzian 1 loth, Salz 2 lotb,

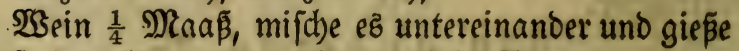
eร̉ auf einmal ein, gebrauche é etliche Iage.

E in a no ere

Rebme daz spulyer bon einem Re 
TSeidenfidramm $\frac{1}{2}$ SPfuno,

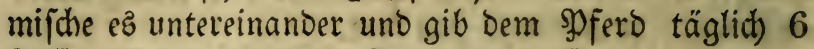
Löffelvoll bavon in Dem Futter zu freffen.

\section{Ein andereb.}

Etabmurzel Blumen uno Saamen,

SSegerich, Sapilluz $\mathfrak{B e n e r i \xi , ~}$

Meifternurzel, (Sartenterefien,

Riebftöckelmurzel;

(3) ropezes Sdhlangenfraut, jeoes cine Scanoboll,

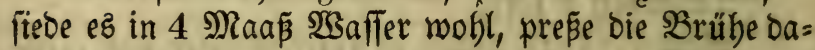
von und füüte bem Sुferd auf einmal ein Maaß von biefer Brübe ein, feçe Den (Sebrauch Dabon cine 3eit= lang fort.

sina $\mathfrak{n}$ Dereb.

SBingeléraut,

Sু appelnmurzel, jebes 2 Şändevoll,

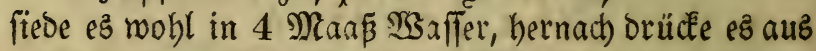

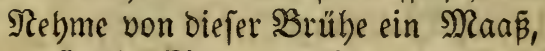

Sonig, Thomazzucter, jedes $\frac{1}{4}$ Pfuno,

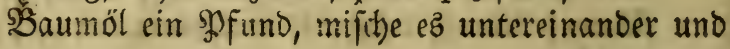
iduttte eร auf einmal ein.

\section{Die SEerpflegung.}

1. Der Stall foll mittelmäsig marm, trocken uno von allen $\mathfrak{B S i n d e n}$ befreit fein.

2. Morgenz uno 2 benoz, ebe man fie füttert, foll man folde Spferbe ein menig berwegen, jeood) nidht zu viel.

3. Die Speife foll fein, Spreu oder Sceu mit Sal= peter gefprengt ober mit SBlättern von wilden Eucum= ern vermifdht, gefottene oder robe gebrochene (S)erfte, mit Erv:n, ŞSiłen, wilbe Eucumernjaamen, \&einfaa= 
men, Şanffaamen, Bock̇hornfaamen uno rothen Si: d)ern vermifd)t (Man mus nid)t afles mit cinancer ver= mifiten, menn man es nid)t baken fann, fondern nur etlid)e 2(rzeneien bavon) Erven allein in Sconigmaffer eingeneid)t.

(5)benfo ift folgende Mifdung felur zwectmäpig:

Eerchenfidwamm, willo (sucumernwurgel,

Enzian, jeoes 2 loth,

2llantwuizel, f̧oblmurzel, jedes 3 loth,

Ealcinirtę şgelpulver,

Siabenpulver, jedes 6 loth,

Weidenjchroamm 2 loth,

mifhe es untereinander und gebe bem $\$$ ferd Davon 2 Iöffelvoll täglich in Dem Futter.

4. Der Irant foll fein fliȩ́endes oder Regenmaffer worin gefotten morden ift: Sconig, Ealpeter, (Serften=

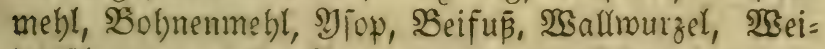
benichmamm, wilde Eucumernmurzel, (ffehet mieber zu belieben, was einer unter biejen 2frzeneien befommen Eann, da man eben nid)t allez miteinander fieden mus.)

\section{Das 8te Sayitel.}

Bon ien Seberfranfleiten uno exfflid bon Dem 5) dangel, weldyer aub Entzünoung Der Seber entifehet uno Siefhwitre verimfad)t.

Die Nängel Der \&eber fino oreierlei, alz erffenz ङnt: zünoung Der Reber uno (Sefdrroüre, zmeitens, Erfältung Der Reber und orittens, SBerftopfung Der Reber, welche alle Sd)madbeiten Der \&eber zu nennen fino, allein wenn man idblechthin von fdrwadber \&eber redet, verfteht man 


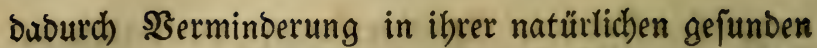
Dperation uno Iemperament, dẩ fie fälter oder bişi= ger ift, als fie fein follte, uno alfo ein allzuhisgiges, bi=

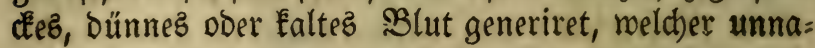
türliche $\mathfrak{B} e r b a ̈ l t n i \tilde{B}$ aber nicht lange befteben Eann, obs ne baß nicht bald hernad) böfe Scumore follten gebäuft werben uno ärgere Edhwadtbeiten ber \&eber uno bes ganzen \&eibes verurfachen.

\section{Die Merfmale Der Seber=-Mängel find nachfol= gende:}

1. Das Maul ift trocken uno oürr.

2. Die 3unge ift rötblicht uno fchwarz,

3. Der झुferch und Etall ftinkend und Eaffran gelb.

4. ভauft biel und fript wenig.

5. Wrendet den Sopf oft gegen bie redtete Ceite, ba Der Sd)merz ift.

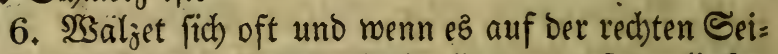
te liegt, foerböbet fich bie linke, liegt es auf Der linken Seite, fo ziehet es die redjte einmärtz, bem Schmerzen meicheno.

7. Saget und beipet fich oft und viel mit ben Säh= nen.

8. WSirb audh mohl häber ben ganzen \&eib främpfig.

9. Rann (d)werlich) uno übel zürchen.

\section{(5) $\mathfrak{u}$.}

Sor allen Dingen foll man ben \&eib offen balten, und wo es vonnöthen, mit einem Sinftir belfen.

Sommt nun bie Srankbeit aub Şike, fo gieb ihm folgenden Eingu自 :

Sümmel 3 loth,

Salpeter ein loth, 
gferde=2(rzenei $\mathfrak{B u d}$.

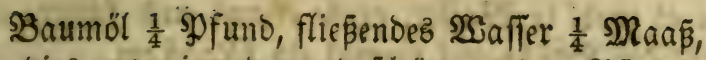

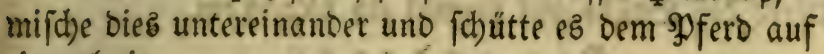
einmal ein.

\section{sin andereb.}

Nebme einen (Sranatapfel, thue die Rinden bayon, Sümmel ein lotb), Gaffran ein Suintlein,

(Serftenbrïbe $\frac{1}{2}$ Maaß̄, mifat)e es untereinander uno foütte ez auf einmal ein.

Man foll ifm aud beibe Sugabern fpringen, wber bod) nidht viel Slut beraus gehen lapen.

s in andereb.

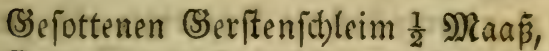

Endivienfaft, Rattich faft, jebes 8 loth,

Gauerampferjaft 4 loth,

miface es untereinanber uno faütte es bem spfero auf einmal ein.

E in andereb.

(Serftenmalfer $\frac{1}{2}$ Maaß̃,

Ronjenöl $\frac{1}{2}$ sofund, mijd)e ez untereinander und gieße es dem झुfero auf einmal ein.

\section{Ein andereb.}

Scrftenbrübe sin und ein halbez 2 Raáf, fiede brei Scändevoll (Eppid) Darein, fechzebn oürte Feigen, preß̄e e's hernach aus, thue bazu Süpholz gepülvert 2 loth, milice es untereinander und futüte ez bem SPfero auf eirmal ein.

\section{E in andereb.}

Serften 2 Sä́noevoll,

(5ncivien, Rattich, Saurampfer,

Reberfraut, Eeeblumen, jedes eine Şanoboll, 


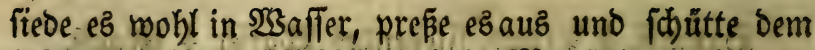
פofero der Brübe auf einmal ein Maā ein.

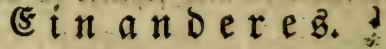

Whenn eine $\mathfrak{B e r f t o p f u n g ~ D a b e i ~ f i c h ~ e i n f t e l l t ~ : ~}$

Epheumurzel 2 lotb,

Zendjel, Eppichmurzel, Eapilluz \$̇eneriê,

Lattich, Saurampfer, Enoivien,

Reberkraut, jeoes, eine Scandooll ober ein loth,

fiebe alles miteinander in 3 oder 4 Maás fließ̄endem Şaffer, prepe es aus und joütte bem \$ofero bon ber

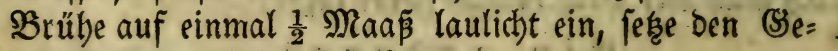
brauch bavon einige 3eit fort.

Wsenn man aber merke baß̄ die Sdymerzen abnebmen,

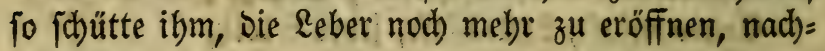
folgender ein :

Sdbwertelwurzel gepülvert 2 loth,

ŞSein $\frac{1}{2} \mathfrak{R a a} \tilde{\beta}$, mifche es untereinander uno gie= Be ez auf einmal ein.

E $\mathfrak{i} \mathfrak{n} \mathfrak{a}$ Dereb.

YYop, Reberfraut,

Eppich, jebę 2 Şänoeboll,

Rojen eine Shandeboll, fiede es in (Serftentwafier prepere es aus uno fitütte bavon auf einmal bem spfero $\frac{1}{2}$ Maá ein.

Die $\mathcal{E}_{\text {ber }}$ zu füblen wäjd)t man bes Iagez breimal bie red)te Seite über Den Rippen mit halb $23 a f f e r$ uno balb Effig morin 2 segerid), Saurampfer, Nacht= idhatten gefotten roorden ; ober aud) mit Scausmurzel, mit Effig und 2 Sein vermifchet.

Ein andereb.

Rojenöl 6 loth, Samillenöl 2 loth, 
Biläl ein lotb),

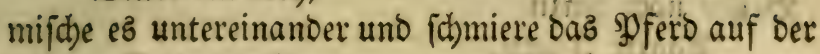
red)ten Seite Damit.

(e) in anoeres.

Steinflee 3 Şándevoll, Sandel 2 loth,

Eamillen 2 Şändevoll,

Rojen eine Şandvoll,

Sleien 8 Şändeboll,

fiebe es wohl uno fichlage ez in einem Sact warm über.

Ei in a noereb.

Rbapontic 2 lotb,

Sejotten Enoivienmaj|er $\frac{1}{2}$ Maa

mifde es untereinanber uno foütte $e \xi$ auf einmal ein.

(E) in a noerez $\mathfrak{S B}$.

Extract von Capiarinde, Manna, jebes $\frac{1}{4}$ Mfuno

Endivientuaffer $\frac{1}{2}$ Maa

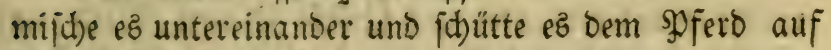
sinmal cir.

Fin arioeres uno ftärferes.

Diaphönicum 2 loth,

Sconig ein פfuno, Ealpeter $\frac{1}{2}$ SPfuno,

ख̧ein 2 खaaß̄,

mifhe oiez untereinander, theile es in zmei I Iheile und inhütte es bem \$pjerb auf zrweimal ein, wieberbole ę ei= nigemal,

\section{Ein andereb.}

Stabnurzelfaamen 2 lvth,

Eppidjaamen 6 lotb,

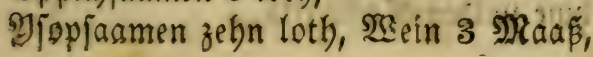


fiebe es robl untereinaniber, thue zu ber abgefeibters Borübe nodb binzu

2 garic 3 loth,

Rbapontic 2 lotb, uno giepe es bem \$ुfero auf zweimal ein.

(5in andereg भु.

Die Sulfe von gefottenem roben Şirfdjorn $\frac{1}{2}$ MA.

Extract von Eapiarinde,

Manna, jebez 3 loth, 2 garic ein loth,

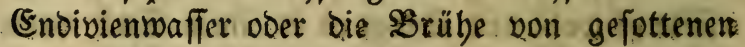
Endibien $\frac{3}{4}$ ) Raā̄.

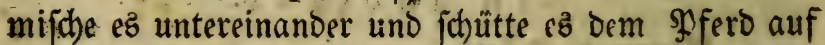

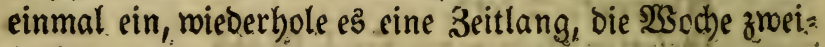
mak.

\section{(5) $\mathfrak{n}$ andereb $\mathfrak{i}$.}

Brunnentrepenjaft,

Baumöl, jedes $\frac{1}{4}$ SP funo,

Sulke bon gefottenem Sirfat)lyorn $\frac{1}{4}$ Maaß̄,

mifhe es untereinander und fibüte fe bem $\$$ ferd auf einmal ein, ober gieb îm eine Seitlang, täglich) 3 Scän= beboll Sirunnenfreffen unter bem Futter zu freffen, wie aurb) \&eberkraut, weldbes in ben $\mathfrak{B r u n n e n}$ wäd) ff.

\section{fin anderes.}

(Erorauth, Soermenig, Eamillen; Wermuth, :Segerid, jedes pine Şanovoll, Spicanarbi 2 loth,

Ebernurzel, 2friz, je be ein loth.

fiede es untereinander mit $\mathfrak{B a}$ affer uno gib dem \$sfert täglich von biefer Brübe $\frac{1}{2}$ Maaß laulicht ein.

(5in andere

Rebme milloen Rosmaring 


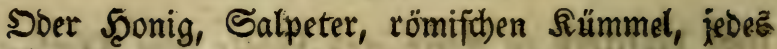
gleichviel in Baumöi wohl gefotten uno eingegoßen.

\section{Ein andereb.}

(Sejottene Brübe von $\mathfrak{B e r m u t h} \frac{1}{2}$ Maaß̃.

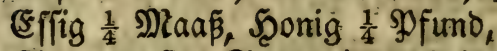

Saurampfer, Syrup, jedez 8 loth,

mifche es untereinander uno fehütte es bem গুferb auf einmal ein.

\section{Ei in a noeres.}

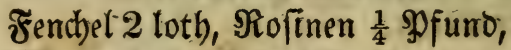

ŞGermuth 2 Sändeboul,

Waffer ein Maá, fiede es rohl untereinander, preßé es aus uno jhütte es bem SPfero laulicht auf ein= mal ein.

(E) ค ก

Begwartbrübe,

Earoobeneobictenbrübe, jebez $\frac{1}{2}$ Maaß̄,

şolfsleber 2 loth, mifche es untereinander uno fohütte es bem \$fero auf einmal ein.

$$
\text { Ei n a noereb. }
$$

2niz, Fenchel, jebes ein loth,

SGadbholdermurzel 3 loth,

Eppichrourzel, soermenig,

WSermuth, Sameel ftroh, jedes eine Scanoboll,

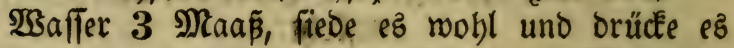
aus, jhüutte von ber 3 Brübe bem sinmal ein.

\section{(E) $\mathfrak{n}$ a $\mathfrak{n}$ bere $\mathfrak{B}$.}

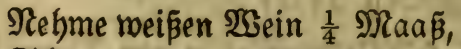

Sdbertelmutzel, Stabnurzel, jedes ein loth, mi= 
id)e es untereinander uno jüutte es bem $\$$ ford auf ein= mal ein.

uno meil bismilen bei ber నälte aud) SEerftopfung ba iff, foll man nebmen

Die Ratwerge Diacatholicon $\frac{1}{4}$ \$f fund,

Wein 1 Raa $\tilde{\beta}$, mifche es untereinander und gies= Be es bem

$$
\text { (Fin a ndereb: }
$$

Rerdenfduramm 2 lotb,

SBeidenichmamm 3 loth),

Rbapontic 2 loth, $\mathfrak{B e i n} 3$ Maaß̄,

fiede es untereinander, betnach theile es in 2 sheile

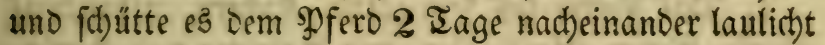
ein.

Man forl bem spferb aud) in rarmen @ädkden, fo warm ez oajelbe erleiden fann, nachfolgenoes überlegen auf bie rechte Seite.

Dill, Stödażkraut, Samillen, Sameelftroh,

2 sermuth, Saap̧bolder, jedes 1 Scanovoll,

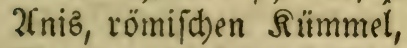

Roggenmebl, jedes $\frac{1}{4}$ Sfund, mohl in Şaffer ge: fotten, untereinander und rarm übergelegt, uno wenn ę Ealt gemorden, oft roieder gemärmt und übergefala gen.

\section{(5in anderez.}

Bodfabornfaamen $\frac{1}{4}$ Sf funo,

(S) pottene Brübe von SBrunnenfreflen 2 Naaß̧, fiebe es nod)mals und ftope es untereinander, thue ber: nach Dazu 23 eiraud) 2 loth uno fdurtte es bem $\mathfrak{\text { ffero }}$ auf ztweimal ein. 


\section{Noch ein anderes.}

(5ine פgferbe- \&eber geoörrt, gepülvert, uno lautid)t in $\mathfrak{B}$ ein eingeben.

Die $\mathfrak{B e r p f l e g u n g ~ b e i ~ b i e j e r ~ F r a n t h e i t , ~ n o c n n ~ f i e ~}$ von Sälte herfommt, ift biefe:

1. Der Stall folf mittelmäffig warm uno trocken, von allen $\mathfrak{S i n d e n}$ befriet fein, uno fid) mebr zor $\mathfrak{S}_{\mathfrak{S} a ̈ r}=$ me als zur אålte lenfen.

2. Soll Daz \$gferó mohl zugedect, und mit einer guten Streu verieben fein.

3. Soll man es aljo anbinden, dás es (iid) nidbt auf bie red)te Seite legen könne.

4. Daz Futter foil fein rothe Ridhern, gebrodjeme Berfte, Erven, Sras, Sceu, mit Salpeter uno Sconig: waffer befprenget, Rleienflümd)en mit Sconig ooer (serfte uno Bockghornfaamen vermifht.

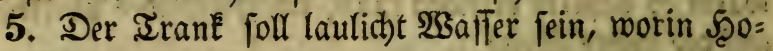

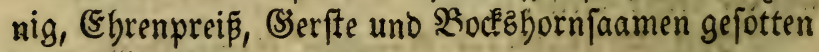
worben.

\section{Das 10te Capitet.}

\section{Son verftopfter seber.}

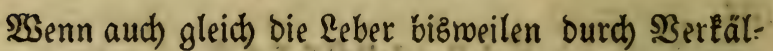
tung verftopft wirb, fo gejdieht biez ood meit häufiger ourd) bie Shitge und eine dolerif the Mlaterie; ez foll

- Daber blos über die aü lekgtern urjachen entffanoene Reberberftopfung hier abgehandelt werben.

Demnach entfteht bie ßerftopfung ber Reber auş pi= ner doolerifden Materie, menn biefelbe Materie weldse 
8. SBerben bizmeilen an bem ganzen \&eib trämpfig.

9. Stoken uno ftampfen mit Den Scüfen an ben Babren uno Srippen.

10. Scaben finftere uno neblichte 2 cugen, uno ber gebet innen oft baz (seficht.

11. Sieben ben Scals mit (serwalt an fich, uno kels= ren fich im geben oft und viel herum.

12. Scaben finftere und neblichte 2 cugen, bas fie ib= re gäärter bie vor ibnen fteben, neober jeben nod er = Eennen.

\section{Sie cur.}

Sor allen Dingen foll man ben \&eib offen balten, Den Mift mit Der Scano von ifnen nebmen, zuerft ein (Slyftir, hernach zum oftern mely (slyftir gebratichen, uno folgenden Eingǘ geben :

Rrübe von BingelEraut,

Mangolt, Sappeln, jeoes $\frac{1}{2}$ Maấ,

Baumól $\frac{1}{4}$ Pfuno, Salpeter 3 lotb,

mifche alles untereinander uno joütte es auf einmal ein.

Lape ifm am folgenden Tage die 2 Scale= und $\mathfrak{B}$ ug = abern fchlagen, jeooch nur ein $\mathbb{u}$ ftläß uno gar roenig Blut beraus laufen la jen.

Wenn foldes geideben, zu reinigen und bie $\mathfrak{S e r}$ : ftopfungen fo viel möglich zu eröffnen, lape etlidje Dlorgen nocheinanber nüchtern ein Serffenwaffer, in weldem $\mathfrak{R e r m u t h}$, Feigbohnen uno SDermennig ges fotten worben, ourch ein Scorn zum Şals binein foult: ten.

\section{Ein anderes $\mathfrak{Z}$.} Seterfilienmurzel 3 loth,

(sppid), blaue Rilienmurzel, Spargesmourzel, jedez 2 loth, 


\section{Ij)eroe=2(rzenei $\mathfrak{B} u d)$.}

Scholfrautwuigel 1 lotb,

\$Bermuth,

Soermenig, Salbei, jebes 1 Scanovoll,

Eappernmurzelfdelfen 1 lotb,

Iamariakenfolelfen,

Mittlete (sfthenrinden, jebes 2 lotb,

Rbapontic,

Senesblätter, Ingmer, jebes 1 loth,

Muecatenblütbe $\frac{1}{2}$ loth,

fieve alles in genugfamem fliepenten $23 a f f e r$, von bie: fer Srübe foütte dem SDfero täglich 1 Maá̃ laulicht ein, gebraudse ez etliche Iage.

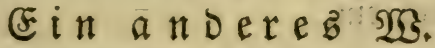

Scepar 2ntimonium 1 souintlein,

Saffran $\frac{1}{2}$ Suintlein,

Erorauchna fler $\frac{1}{2}$ Maá̧,

mijhe es untereinander, gebrauche es etlide Iage.

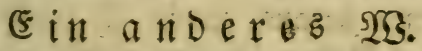

Bitrum 21ntimonium $\frac{1}{2}$ Suintlein,

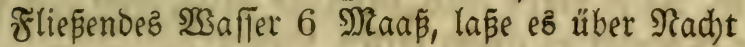
Darüber fteben und la fen, fo viel als es will, gebrauche es etliche Iage, nad)= Dem ou fiehft, daßj ez heftig operiten will.

Ein andereb.

Serftenbrübe, stübe morin Freigbohnen gejotten rorden, jedes $\frac{1}{2}$ Maaßi,

Soermenig, গ্STermuth,

Endivien, jedez 1 Scandooll, gefotten $\frac{1}{2}$ Maá̃, mijde es untereinander und fdütte es bem Sूfero auf einmal ein; gebrauche es etlidbe Iage. 
(E) in a noreb.

Se pottene Rrübe von Betonic $\frac{1}{2}$ Maaß̄,

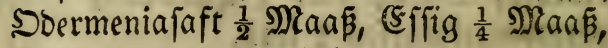

Soermenigfaamen 2 lotb,

mifche alles untereinander und fdütte es bem spfero auf cinmal ein.

\section{E in anderes.}

SSildę Röhlléraut 4 Scändevoll,

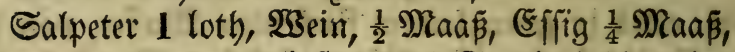
mifche ę untereinander, laß̧e es 24 Stunden über ein= ander weichen, alzbann prepe ez auz uno fchütte eร bem Sofero auf einmal ein.

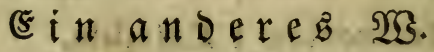

Şlübe einen Stabl uno balte ein Stüc Schnefel baran, fo fdhmilzt Der Stabl, ftefle borber eine Sduüf= fel mit $\mathfrak{B a}$ afer barunter, aus bem $\mathscr{W}$ affer fammle bie getropfte Sörner heraus, mache fie trocken und ftope fie, glühe folithes Sulver in einem irbenen Scafen nobl auz, bis es braun mird, bann iftz fertig, reibe ober fto= ßè ez mieder zu einem zarten şulber,

গimm von diefem Sulver 1 loth,

2aronmurzel $\frac{1}{2}$ loth, $\mathfrak{B}$ ein $\frac{1}{2}$ Maán,

mifjche es untereinander, laßje e\& 12 Stunden ftehen, bernach gieß̄e es Dem spferd auf eimmal ein uno benege baffelbe eine balbe oder ganze Stunde darauf.

\section{E $\mathfrak{i} \mathfrak{n} \mathfrak{a} \mathfrak{D} \in \mathfrak{r} \mathfrak{e} \mathfrak{S}$ গु.}

Rhapontic 2 loth,

Nermutbbrübe 1 Maaßâ,

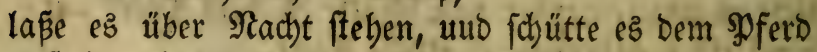
auf einmal ein. 
Rerchenfchwamm 1 loth, mifde cs untereinander uno fichutte es dem Sूferd auf einmal ein.

\section{(E) in andereb গ্G.}

Sdhwarze Niesnurzel 1 Suintlein,

Scammonium 2 Suintlein,

Maftix $\frac{1}{2}$ Suintlein, Bimmet 1 Suintlein,

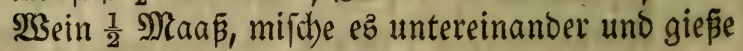
eह Dem Sुferd auf einmal ein.

WSenn nun das Sferd genugiam purgirt ift, foll man ifym etlichemal $\mathfrak{S}$ pin mit $\mathfrak{B}$ affer vernifict in mel= d)em vorber Taujenogúldoentraut eingenveid): worden, in die Najelödber fprüken.

2utzmendig lege ifm über bie red)te Seite in einem Sack nadhfolgende Gadien über :

Endivirn, SSegwarten, Milžraut, Scopfen, 2Sermuth, Flachs=Seiden ober Dotter, Steinflee, Sameelftroh, jedes 1 Şandooll.

(5) pflegen audi) die \$plerbe bismeilen Iebendige (ङgeln zu befommen, weldhe in ber $\mathfrak{L} e$ ber madhfen, wie id) an vielen

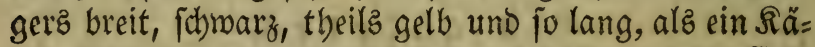
fer, bismeilen länger, entfebet aus böfen auf bie (Erbe gefallenen Feudhtigkeiten, moourd) $\mathfrak{Q}$ uft, $\mathfrak{W}$ alfer und

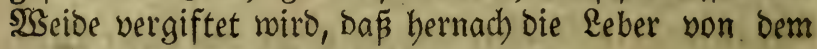
zu fich gezogenen Saft foldhe erzeugt.

Diefem Ulebel ift nidht mebr zu belfen, allein zu \$rä: fervirung will ich bier anfübren, mas ich für gut be= funden habe, uno biejes ift einzig uno allein bas 2enti= monium, weldbes man ben \$pferden unter bem Salz zu ledten gibt. 


\section{gुferbe:?Irzenei Buth.}

\section{Die Berpflegung.}

1. Der Stall foll mittelmä̈ig warm, rein, trodfen und vou allen $\mathfrak{B S i n d e n}$ befreit fein.

2. Soll il)m eine gute Streu untergemad)t merden.

3. Soll man es alpo anvinden, Damit ps fid) nid)t auf Die tedt)te Seite legen fönne.

4. Sor bem füttern foll man es etwas, aber nitt) zu viel, bewegen uno reiben.

5. Daz Futter foll jein gebrochener Saber, Spelz, Dinfel, gefottene (şerite, darunter @übijolzpulber ver= mifit, seut mit Salpater befprengt, rothe Sitdern, Ert= ven, ssicten, was man unter biejen in Der Sabrz̧eit betommen Eann.

6. Der Srint foll laulid)t feil, worin Fend)elrour= zel, (Eppidh, Sid)ernmebl, wie aud) SEeinftein und (5) $)=$ renpreiz und ein menig Salz gefotten ift.

\section{Das 11 te Capiter.}

\section{Bon ber Galle mo cinigen savon berfom= menoen Sranflyeten.}

Die ?ferbe baben feine B̧lafen, in Denen fidt bie (Safle fammelt, mie andere Iflere, jeoout) in Den $500 \mathrm{~h}$ = len Der Srber auf oer redten Eeite, linter ober unter Dem Stamm Der gre B̈n SBlutrobren, unfern von beren Znfang einen (5anal, weliber aus bet Reker fommt, uno bie gallenartige Zeuthigéeiten empfängt, uno etma 2

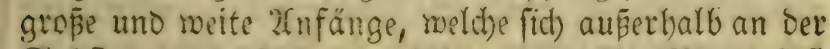
Gubftanz Der Reber vereinbaren uno bie Rinne faft flein madben, bismeilen aber nur eine bat. 


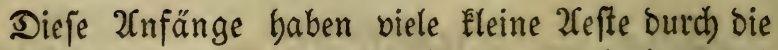
Subftanz der Leber hin uno mieber ausgebreitet, uno in ibrer Mitte faft Eleine Lödher, Damit fie alles bas, fo ber gallenartigen Freuchtigkeiten gleid) uno ähnlich ift, auz ber ganzen Menge bes (Seblütz fönnen in fich ver: fammlen uno in Den Dagu veroroneten Sanal Keiten.Denn bie \&eber felbft fondert biejelben ourd) ibre eigene Sraft bun Dem guten (Seblüt $a b$.

Diefe Rinne mun fübret die in fith empfangene (salle bis in Den zrölffinger langen Darm, etwas fern von bem unterften Magenmuno, in etlichen Spferben vier, in etlidjen aber 8 Finger neit weiter binab, indem fol= d)e SRinne fo lang ift als Der gemeloete Darm felbfit fondern runo, bobl und meit wie eine Blutaber, einer

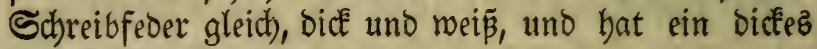
uno ftarkes Scäutchen.

(Ez bedient fich bie Natur, indem fie bie (Salle aljo ourch Den Samal in Das (S) bärme leitet, eben biejer \&ift, wie aud in ben Scarngãngen, benn fie fübret bie (S)all nicht alsbalo in bie ganze inwendige Scöble bes Darms binein, fondern erftlic) allein burd) feine, bes \arms, erfte und äuperfte Scaut, ba bann zmifchen biefer uno ber andern inmendigen Scaut, ein befonderer झुlas uno Raum zmeier Finger weit ift, uno mús bie (S)alle etwas mebrers binab weichen, bis fie ben Durchgang ber 2ten uno invenbigen Scaut antrifft, fo bald fie mun auch outch Denjelben Eommen, uno in bie inwendige $\mathfrak{S e i t e}$ bes Darmz gelanget, fallen die beibe Scäute wieber zus fammen, uno fällt bie inmenoige vor ber äuperften $\mathbb{o}$ od)= uno Durdhgang, gleidh mie hingegen bie äuperfte vor bes inwenoigen ihrer, bamit rie (salle nicht etwa zu= rüct uno wiederum in ihren Sanal gelange, zu relchem 
Ende denn das inwendige Scäutt)en des Damm feite

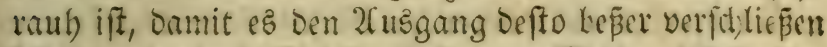
Eönne, indem Die Epeife auక Dem 9langen bis in Den Darm gelanget.

Diefer Canal oocr Rinne ift Defílailb fiei, obne Bla= fe uno überbaupt veridoieben eingerid)tet, als bei andern Ifbieren, weil es für die Sperde weit nüblid)er uno zibectemäpiger if, oa diefelben eine febr bideutende

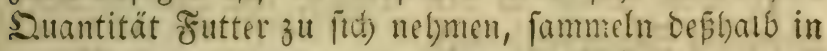

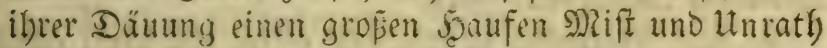
melder wohl etmas bebarf, fo ibu zu feittem 26usgang anteize uno treibe, folbes aber vermag bie S3alle am beften. (5z ift daber erforberlich, daß fitets cime gebö= rige Nenge Davon vorbanden fici und ununterbrod)en zu bem mefrerwähnten Darm hinabfteige, mo aber, fafls eine Slape vorlanden wäre, in Der fie fich aufbal= ten Eömnte, nicht erfolgen würde.

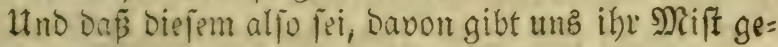
mugfam Seugnis, Denn berfelte ift, fo oft fie ity von (iid) lafen gelb, und Demnad) an Der Farbe Der (S)alle febr gleid).

Entftelsen baber in ber (s)alle aut) veridbiedene Siant= beiten, als allyugroß̧e 2fnbäufung oer (S)alle, ichäblicher Ueberfluñ, 2Custroifnen Derfelben, weld)er ftets nad)= theilige Etörungen berutfachen wiro; Denn wenn bie (3alle zurüf getrieben uno in Den Magen gefoütet wirb, gebieret fie grofie Unoäuung, indem fie wegen th= rer Size uno Sdärfe bie Epeife uno Futter, fo an= fangen foll zu bäuen, ausmirft und zum aufichütten berwegt, welt)es geidhiebt 2infangs mäflerid)t uno ourch= gillet, fomohl ourch ben Scals herausgenorfen, als im

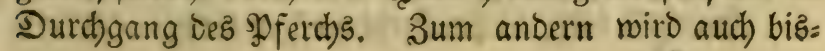


weilen bie (Salle in ben Därmen burd) ben $2 B i n d$ auf = gebalten, ober aus andern zufälligen @achen verftopft,

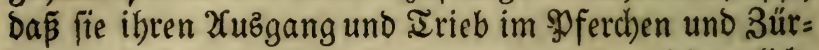
den nicht baben Eann, und eireget hiermit unleibentlicke gefäbrliche und töbtliche ミamerzen.

Die Beidben Der fliebenden ober überflüffigen stalle fino:

1. Daz $\mathfrak{S}$ eipe in ben $\mathfrak{A}$ ugen, wie auch bie $\mathfrak{x}$ der unter ber Sunge wiro gelb.

2. Die Najelöcher fteben weit offen, uno läuft eine gelbe Feuchtigkeit Daraus.

3. Der $\mathfrak{P}$ ferch ift bünn und etwas finnarglicht.

4. Der Etarl ift.gelblid)t.

5. S̃m Stand reibt es fich, ffellt jich mill, als ob es Eollern wollte, fallägt mit ben Finßen von fich, in bem Liegen ftrectt ez alle SBiere von fich, wälzet fich uno ift Eaum im Stande aufzuftehen.

6. (Sebet ihm grope Şize auz Dem Maul.

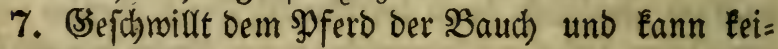
nen $\mathfrak{B S i n d}$ la $\tilde{\beta} e n$.

\section{Die ( $\mathfrak{u} \mathfrak{r}$.}

SBor allen Dingen foll man ibm ben $\mathfrak{L} e \mathrm{~b}$ offen bal ten und nachfolgendes slyftir geben.

\section{B3.}

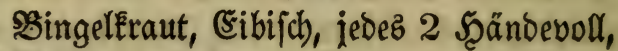

SBeilfraut 1 Sanoboll,

Ugaric 1 lotb, diejes alles fitede $\mathfrak{W}$ ohl in einer

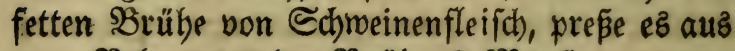

Nefyme von ber Brühe 2 Maẫ,

spulpa colocynt. $\frac{1}{2}$ loth,

Sonig 3 loth, Schweineidomalz 6 lotb) 
310

Pferbe=2(rzenei butd.

Shafelmutzel 1 loth,

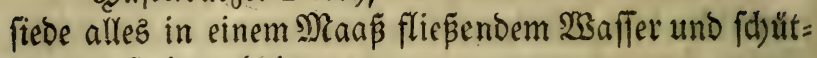
te es auf einmal ein.

E $\mathfrak{i} \mathfrak{n}$ a

Spoponax 1 loth,

Sfeffer $\frac{1}{2}$ loth, $\mathfrak{B}$ ein $\frac{1}{2}$ Maañ

untereinander gemifatt und laulid)t eingegofen.

Ein andereb.

Fendyelfaamen 8 loth, Eteinflee eine Scantowoll, Shonig $\frac{1}{4}$ Wfund, fiebe es untereinander in einer

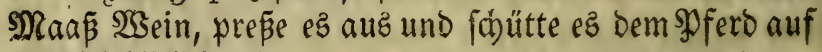
einmal laulidet ein.

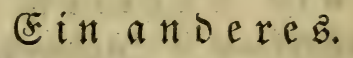

Baummeiben, Espheu, jebes 1 Scanbuoll,

Ddh fenzungenwurzel 3 loth,

fiede es miteinander in rothem Sssein und fichütte bem Shero auf einmal 1 Maá bavon laulicht ein.

E in anderes.

Minurben 3 loth, \$feffer 1 loth, Wein $\frac{1}{2}$ Maá,

untereinander gemifht und auf einmal eingegopent.

(E) i a n o e r es.

Rinden von (Branatäpfeln 2 loth,

2Silde Sliven 3 loth, ftope ez untereinander, ver:

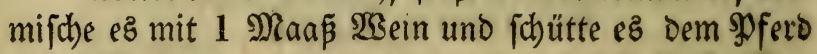
auf einmal ein.

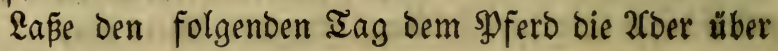
Det Naje.

\section{Ein andereb.}

Meifterwurzel 3 lotb, 
2. Das Futter foll fein grün (Stras, bod) nidht zu viel.

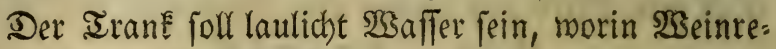
benblätter gefotten worden.

4. Eine gute Streu.

5. Soldbes oft an Dem ganzen \&eib reiben.

Die Beidyen Der Dürren (salle aber find nady= folgende:

1. Der Bauch läuft auf, megen SEerbaltung bes STinde?.

2. Scat an bem ganzen \&eib gropse Şike.

3. S̃ft berfopft im 2 eib, fomobl im Syferchen alz Stallen.

4. Sann wegen gropen Sdjmerzen nicht robl liegen ooer ruben.

5. Scat ein hifigige Maul und hisige Najelöcher.

6. Şat bunfle 2ugen und Eann nicht recht feben.

7. Sittert an Dem ganzen \&eib.

\section{Die cur.}

Sor allen Dingen Den $2 e i b$ offen gebalten, wozu man Die SInftir, Die in biefem (5apitel fdon befdrieben mor= oen, gibrauchen foll, nachber gib ibme folgende \$ु) gation ein :

Extract bon fowmarzer Niesmurzel $\frac{1}{2}$ lotb, Simmet, Naftix, jedes $\frac{1}{2}$ suintlein, Bein $\frac{1}{2}$ Maā̃ untereinander gemifht und auf einmal eingegopen.

Eine andere Surgation. Scammonium 1 loth, Sconig 6 loth, Die Brübe von $\mathfrak{B e r m u t h}$ uno Iaujenogülden= 
Eraut 1 Maẫ,

untereinander gemijht und laulicht eingegopen.

(F) $i \mathfrak{n} \mathfrak{a} \mathfrak{D} \in \mathbb{R} \in \mathfrak{b}$.

Silübe von getod)ten Shappeln uno (sibifd)= Staut

1 Maas, fichütt e⿱乛龰 auf einmal ein.

\section{(5) in a nderes.}

Sd)warze Niestourzel,

Seftopenen Reinjaamen, jebes 4 @crupel,

$\mathfrak{Z}$ ein $\frac{1}{2}$ Maá̃

untereinander gemifot uno auf cimmal eingegopen.

(E) in andereb.

S3eirauth, s) (ntrben, jedes $\frac{1}{2}$ loth,

Sirübe von झappeln $\frac{1}{2}$ Saấ,

untereinander gemifat und auf einmal eingegopen.

Man foll ilym aud) Die Sealsaber offfnen, und wenn viel fduarz Bllut da iff, folches robl laufen lasen.

Dic B̉erpflegung.

1. Der Stall fola mittelmäpig rarm fein.

2. Dus ซ̋tter foll grünes (S)ras oder in Srmange= lung Depelben Das Sceu, mit Mein ober Waffer uno ceffig befprengt fein.

3. Der Irant foll fein ausgeprefite $\mathfrak{B r u ̈ b}$ von ge= mablener (Serfte, morunter Salpeter bermifdst morden ift.

4. Coll man bas Pुferb an bem ganzen Reib oft reiben.

5. Fine gute Streu untermachen. 


\section{Daş 12te Capitel.}

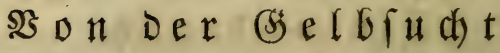

Die Selbjucht ift eine foldbe Srantheit, in neldber fich bie Cholera oder (5afle Durch Den ganzen Leib aus= breitet, Deber Dann bas \$fferd in Den 2(ugen und in ben 21Dern unter ber Sunge augenjueinlich gelb wird, bat ifren Uriprung von Der übermäpigen Şize Der \&eber, oder menn ber (Salle ifr canal, moourch fie ifren Lauf bat, berftopft wiro; bizmeilen auch auz Mitleiben bez Milzez, Da alsbann fich-oie famarze (Sialle mit ber an= Dern bermifcht, Denn wenn foldhe zwei Mängel, nemlich eine übermäpige Şiţe uno die Serftopfung des Sanals Der (3alle zujammen Eommen. Utnter folchen $\mathfrak{U}$ mitän= ben vermehrt fich zwar bie (Salle immer mehr, fann aber megen Der Serftopfung Des (Sanals nid)t binwig noch jut oen Därmen fommen und fonften, wie natür = lich, mit Dem Mift auslaufen. Sie febrt bep̧balb auf foldber ifrer Strapen wieber zurück, uno breitet fid mit Dem. (S) blüt, weil fie nicht anderft kann, in bem ganzen $\mathfrak{e}$ eib auperbalb ourch, alle (S)lieber aus.

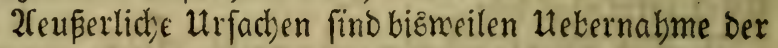

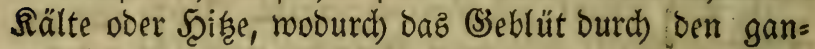
zen $\mathfrak{e}$ eib entzünoet uno biliöz gemadht miro, ober von Schlangenbizen oder anderer giftigen I Ihiere Stechen, meld)es man unter bem SBiebe gebect bei jt, welches

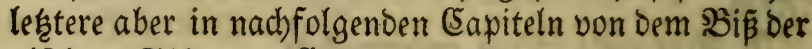
giftigen Ibiere zu finden fein wirb.

Die 3eidhen wenn bie Sislbfucht aus einer erhitsten Seber entffehet, find folgente:

1. Das spferd befommt ballfbeinende, gelb und 
grünlidhte 2fugen, von weld)en zumeilen eine Triefung beraus fommt, fo bart mirb.

2. (sin beíses Maul.

3. Weite Rajelödber.

4. Die 2roern unter ber 3unge fino gelb.

5. Die Shten und \&enden von Dem Shroeis nap̃.

6. Die Saut miro ftarreno, und bie Durdbitterte Feudtigfeit fudbet ibren 2(usgang ourd) bie Sdmeip̈lö: dier.

7. Reibet fich) oft an ben $\mathfrak{T S a ̈ n d e n . ~}$

8. Sferd) uno Stafl fino febr gelb uno Dabei Dünn. So aber Die (Selbfucht burd) eine $\mathfrak{B e r m i f d} u n g$ Der (Salle und von Dem Milz entffebet, fo bat es

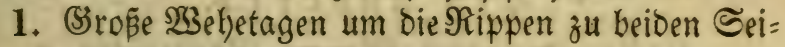
ten, fo in Der andern (S)elbjudt)t nicht iff.

2. Sif unluftig zum Futter uno widerfehet inm ber füpe Trant.

3. Der $\mathfrak{P} f e r d$ ift etwaz grün und fdwwarglicht, wie auch ber Stall.

4. Şat einen foneren 2athem.

Bei Der verftopften Salle aber genoaht man fol= gende 3eidben :

1. Das $\mathfrak{P}$ ferd fällt nid)t von bem $\Omega e i b$, uno bat aud) Eeinen fonderliden Durft.

2. Das $\mathfrak{Z}$ eipe in ben 2 ugen miro ganz gelb.

3. Der Sarn gelb uno bick.

4. Der Şferch hart, und Der Şarn berftopft.

Uno meil bie (salle zu ben Därmen nidbt Eommen Eann, nod) bie austreibende Sraft zu ibrem 20mt anrei= Gen, bleibt ber Mift in ben Därmen liegen und trocket jelänger je mebr aus. 


\section{Cur aller biefer æränger.}

Bor allen Dingen folf man ben Reib offen balten, und bie in bem 11ten Eapitel von ber Balle gefegte elnftir gebrautben; uno unter ber 3unge, wie audh auf Dem redhten vordern Schenkel eine 2roer fohlagen, fo= Dann folgende Mifajung eingiešen. $\mathfrak{Z}$.

2floes epatica, 2Rgaric, Sibapontic, jeoes 1 loth,

Scammonium 1 S.uintlein,

mifiche und ftope es untereinander, folgendes mit einer Maä warmen Srühe, worin 1 Scanbvoll SBoretîh, Siden und Spicanardi gefotten worben, auf einmal eingegoper.

(E) i a ก

Capiarinoe 2 loth, Manna, Rbabarbara, Ribapontic, jebez 1 loth,

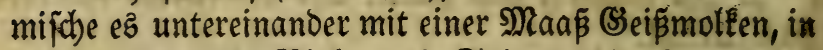
welcher Booretich, SBiolen uno Spicanaroi gefotten wor= Den, uno jchütte es auf einmal laulid)t ein.

(5 $\mathfrak{i} \mathfrak{n}$ andere $\mathfrak{E} \mathfrak{W}$.

2floez, 2fgaric, jebes 1 loth),

Scammonium 1 Suintlein,

Brübe von Soermenig uno Endivien 1 Maaß̃, untereinander gemijht und auf einmal eingegopen.

E in andereb.

2lloes epatica 2 loth,

Srübe vos Scafelmurzel,

2(niz, (Eppid), פsermuth, jebes 1 Maaß̄, untereinanoer gemifcht und auf einmal eingegeben.

(E) $\mathfrak{i} \mathfrak{n}$ and $\mathrm{er} \in \boldsymbol{B}$.

2lloes 1 loth, 2 Raric $\frac{1}{2}$ loth, 
Wein aber $\mathfrak{W a f f e r}$ worin ßịbern gefotten fino, $\frac{1}{2}$ Maa $\tilde{\beta}$,

untereinander gemifcht uno auf pinmal eingegeben.

\section{fin andereb.}

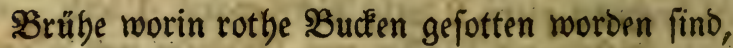

1 Maá̃,

SSeiffen Scunosbred 3 loth, Saffran $\frac{1}{2}$ Suintl. untereinander gemifht und auf einmal eingegeben.

\section{(E) in $n$ Deres.}

Suendel 2 Sändeboll, Fendbel 2 lotb,

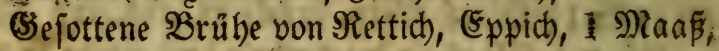
untereinander gemijat und auf einmal eingegetent.

(5: in a n Dereb $:$ B.

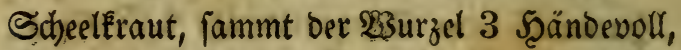
S3ermuth 2 Saảnóvoll,

शäubornblätter 1 Seanbvoll,

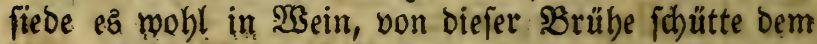
\$fero 1 Mlaaß́ mit $\frac{1}{2}$ Suintlein Saffran vernijpht auf einmul ein.

\section{sin anderes.}

Enzian 3 totb, Taujenogüloenfiraut,

2noorn, jedes 2 Scändevoll,

fiede es mobl in $\mathfrak{W a f f e r}$, von biefer Şrübe fictüte iłm auf einmal 1 Naẩ ein.

cin anteres.

Ferberrötbe, Taujenogüldentraut 2 Scänoevoll, Rothe Bucten, 23 ermuth, jede? 1 Sanowoll, Sobannesblumen 1 Saanovoll,

fiebe es wohl in flieflendem 28 affer uno fichutte von bie: fer Brübe ein $\mathfrak{D a} a \bar{\beta}$ oem 
Im Das (Selbe in ben 2ugen zu vertreiben und das Saupt zu purgiren, fprükęe ihm ben Saft von millden Eucumern oder Mangolt in bie Nafe, oder blafe ifm

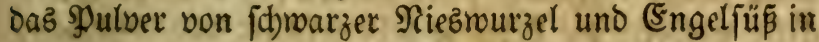

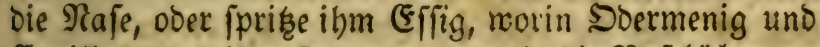
Eapillus veneriz gefotten worden, in bie Riajelöcher.Soer beiberlei Săfte von Coriander uno Saurampfer

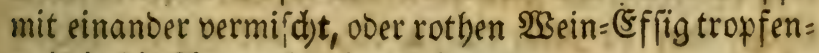
weis in bie 2fugen binein triefen.

Die Berpflegung.

1. Der Stall jơ mittelmäpig narm uno ounkel fein

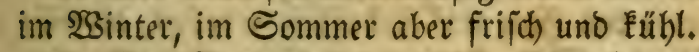

2. Das Futter foll fein Rileienflümplein mit હǘp= bolzpulver, Sconig und Salpeter vermifht, Serfite mit Boç3hornfaamen und rothen Richern, Endivien, $\mathfrak{L}$ at:

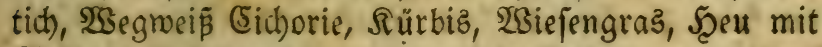
Salpeter befprengt.

3. Der Trank laulidt) $\mathfrak{W}$ alfer frin, morin gejotten werben Engelfǖ, Betonic, Bodł̧bornjaamen, Salpe= ter, $\mathfrak{W e r m u t b}$, 2(noorn uno (5almuz. STn Fall man aber biefe 2 2 rzeneien nitbt alle zu erlangen meis, jo fann man obne SBebenten aud einige bavon weglaften; ood)

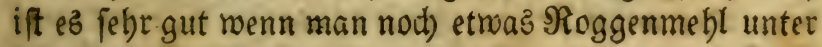
ben Trank mijot.

4. Sine gute Strett.

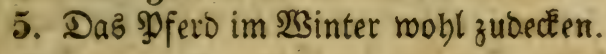

Das 13te Eapitel.

BON Der গ্G afferiudt.

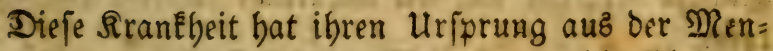
ge uno dem Ueberflü Ealter Materien, weldhe fid) in Die 
(s)lieber himein brängen, uno biefelbe hod auftreiben,

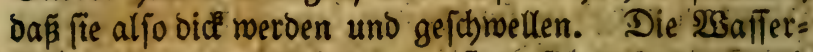
fucht fangt eigentlich bann erft an fich red)t zu entwi= deln, nacboem bie \&eber fo fehr erfältet uno gefdrwädht worben, ba位 fie nid)t im Stande ift, ben im Magen vorbereiteten weisen Saft in silut zu berwandeln, fon=

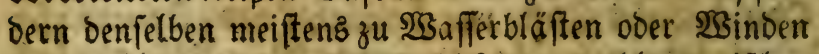
maddt, ooer zu einer Ealten, bičen uno phlegmatifchen

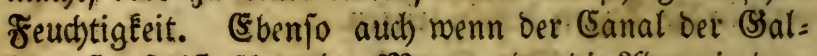
le verftopft ift, fdrwacher Mragen ober bie 2rbern in Dem (Sefrö́s nicht recht bijponirt find, fondern verftopft und

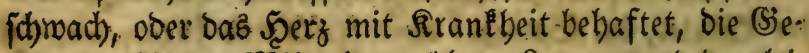
Därme, Nieren, $\mathfrak{R i l}$, Squerblatt, \&ungen und berglei= d)en innerliche Sörpertbeile nicht recht in ibrem natür= liden Stano uno $\mathfrak{B e j e n}$ find, Daber Dann bie Rraft Der Reber bie ben aus bem Magen empfangenen Saft

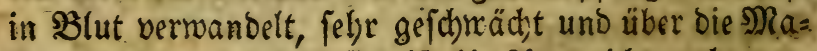

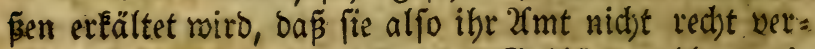
ridsten Eann fonbern anftatt des SBeblütz, phlegmati= idhe bö́fe F̌euchtigkeiten erzeugen muś.

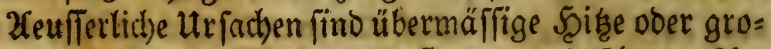
Be unleibentliche Sälte, all zu ftrenge uno fognere $2 \mathrm{r} r=$ beit, ober wenn fie einz Beitlang grobe, bicke und ber= ftrpfende, zu febr erkältende uno Feunthtigéeit gebäh)= renbe Speiffen gefreffen baben, oder in allzu groper Şiķe, von faulem, trübem uno faltem 2 Saffer faufen, benn zu berfelben Beit fino bie Säänge uno Straßen in

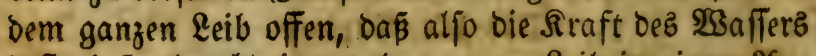
defto beser burdboringen, ben zanzen \&eib in einem 2fu:

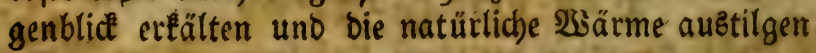
Eann.

Ěz gibt alfo brei verfohiebene Ssattungen ber 2 gaf 
14

Ecite:320

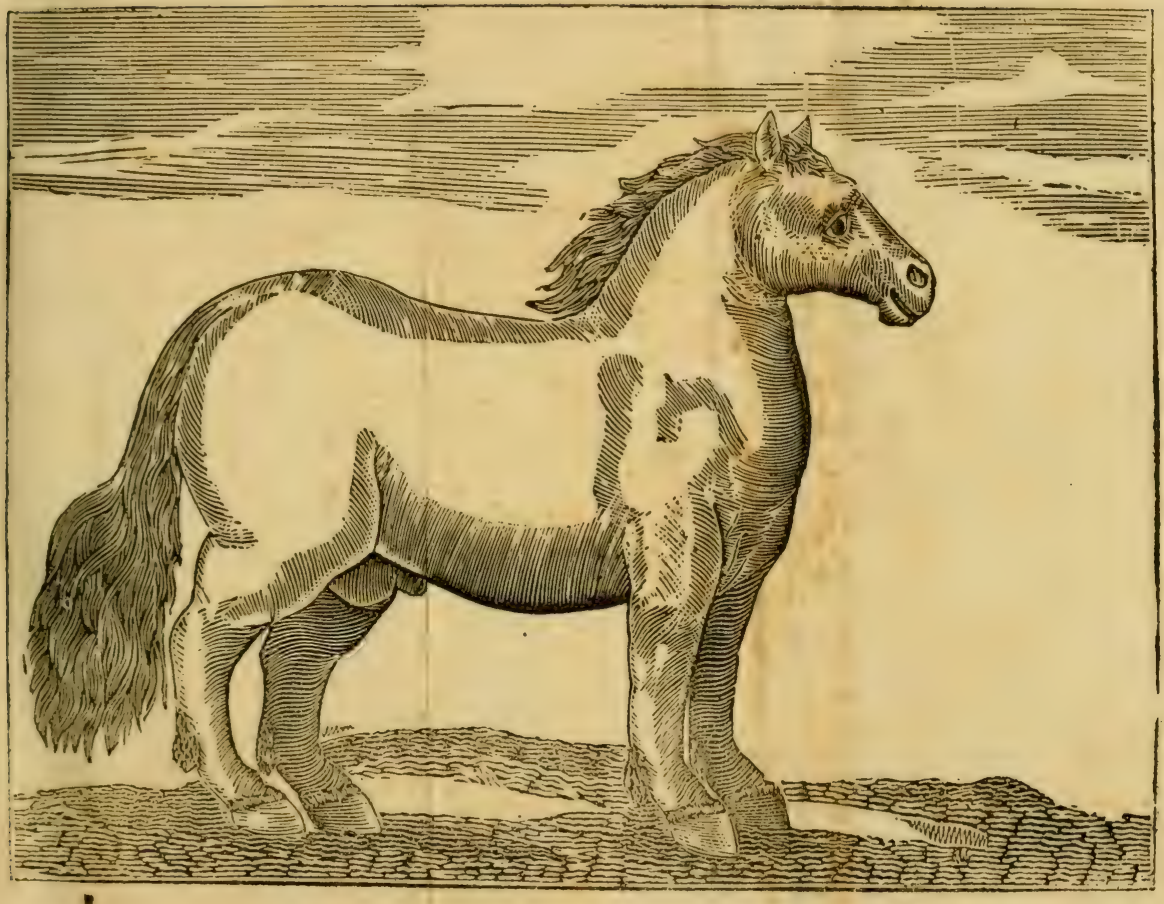




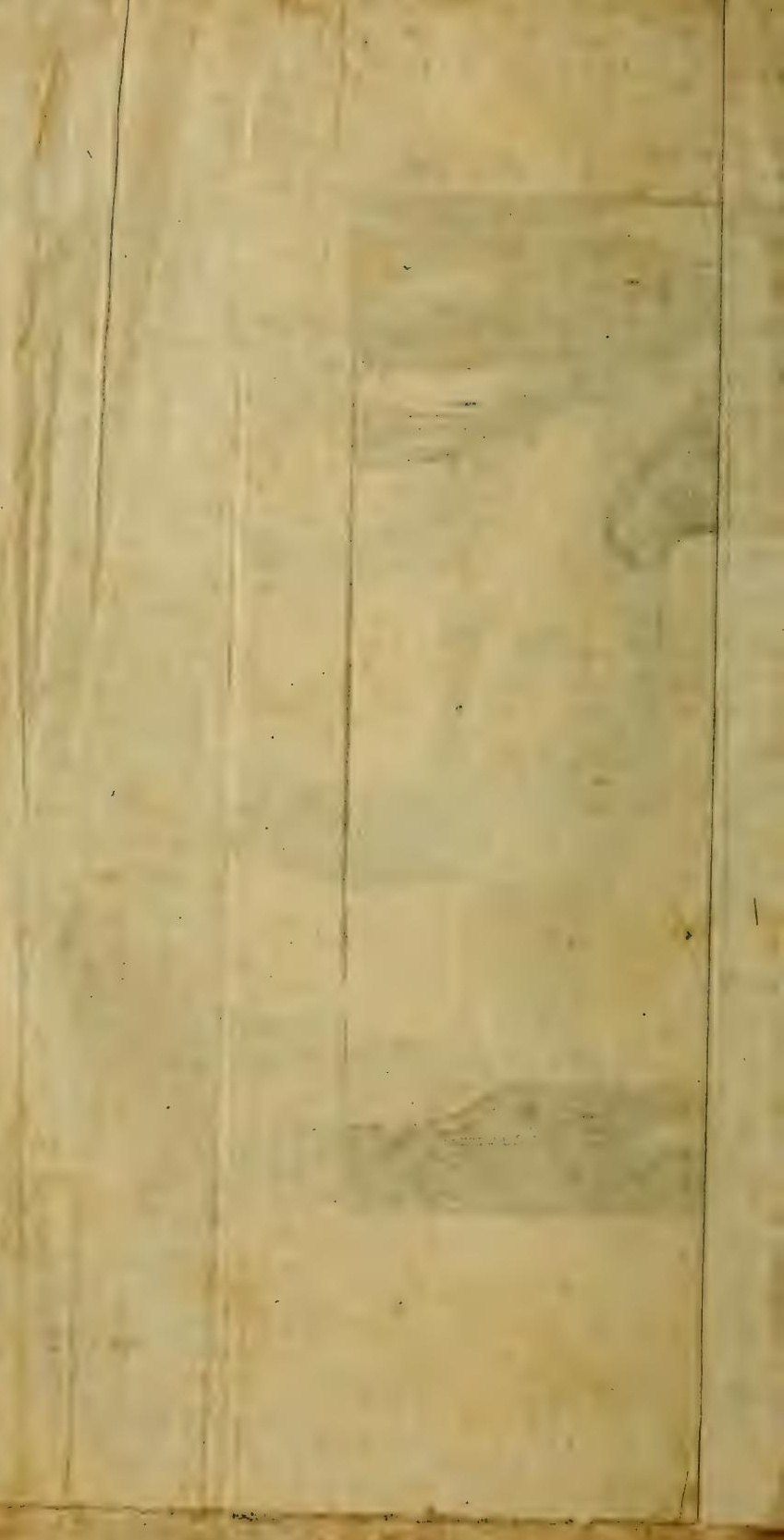


ferfucht ; bie erfte beift 2 najarca ober $\mathfrak{R}$ eucophlegmatia, alb eine, bie fid) mit einer roid)en (Sejdymullft über ben ganzen \&eib aubbreitet. Die andere miro 2ficites ge= nannt, fefet fich mit einer fehr bicken (S)ejchnullft in ben Baud) und die SBeine, Daß̃ foldbe bavon aufichnellen. Die oritte 2frt heipt İympanites, feşet fich zroar auch mit bicfer (Siefdroullft in ben Baud), aber fold)e (S)e idtwuluft ift mebrentbeils von lauter $\mathfrak{S}$ ino und Släften.

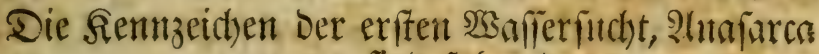
genannt, find folgende:

1. Das Sुferd ift über Dem ganzen Reib mie auch am Ropf, felyr geidhwollen.

2. $\mathfrak{B}$ enn man zu 2 nfang mit sinem Finger barauf

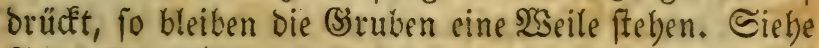
Figur গNo. 14.

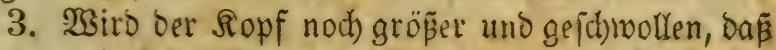
man aud) Eeine Blutadern mekr baran feben ober $\mathrm{pr}=$ Eennen Eann.

4. Die andern Serter Drs ganzen Reikes find trocken und bart.

5. Sm Rirgen fteuren fie fich nicht auf ben 2 atth, fondern ftrecten uno legen fich auf eine Seite, uno laf: fen, indem fie fith reiben, die Scaare fehr aubfallen.

(s) $u r$.

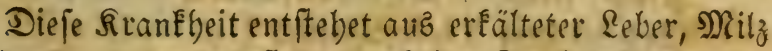
uno allen barausent ftebrnoen Ealten Fruchtigfeiten, von weldben fie fich in Dem ganzen \&eib auştheilet.

Bor allen Dingen foll man bem Ifferd sen Reib of = fen balten, fowobl im spferchen als im. Stallen.

\section{Sin SInftir 23.}

(Eppid), \$pterfilienfraut, jedes 3 şändevoll, 
Wilben Steinflee 1 Şanovoll,

Iniz, Fenchel, jeoes I loth,

(erd)enfdhwamm $\frac{1}{2}$ loth,

fiebe allez wobl in einer Şammelz= Doer Schmeinenbrü= be, nebme von ber abgefeibten $\mathfrak{B r u ̈ b e} \mathbf{1}_{\frac{1}{2}} \mathfrak{M a a \tilde { \beta }}$,

Salz 1 şanowoll, 3 Eierbotter,

\$oulp. Eolocynt, 1 Quintlein,

gebrauche ez auf einmal laulicht.

Dę andern Iagez foütte ibm nachfolgenden Irant ein :

233.

Siebengezeit 1 Sanowod, Salap 1 loth,

\&erd)enfdhwamm 1 loth, Scollunbermurzel 3 loth,

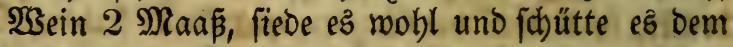
Saferb etliche Tage nacheinander $\frac{1}{2}$ Maá bavon auf ein= mal ein.

$$
\text { (E) } \mathfrak{n} \text { andere } \mathfrak{n} \text {. }
$$

Xttidburzel, blaue Sdymertelmurzel, .. Meifterwurzel, Ferberröthe, jedes I loth,

Soermenig, Salbei, Şamandertein,

פSermuth, Solbanella, jebes 1 Scanoworr;

Rinden non Tamarizcen,

3on Eappernnourzel, jedes 1 loth,

Efulä, Fenchel, Speterfitienfaamen, jebes $\frac{1}{2}$ loth,

Senesblätter 2 loth, Salap,

Eerchenichnamm, jeoes I loth,

Turbith 2 Suintlein, S̃ngmer $\frac{1}{2}$ loth,

Muscatenblütbe 1 suintlein,

fiebe alles miteinander wohl in 6 Maaß flieffendem

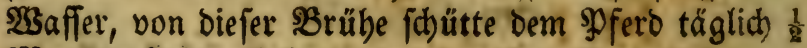
Raap auf einmal laulid)t ein. 


\section{(E) i a $\mathfrak{n}$ Dereb}

SBlaue Schnertelnurzel, Speterfiliennurzel 3 loth,

Erulä 2 Suintlein, soermenig,

Sunigunosktaut, jedes 1 Şanovoll,

Senezblätter, $\Re$ bapontic, jebez 2 lotb,

2rgaric 1 loth), Iurbith 2 Suintlein,

Saffran 1 Suintlein, Rägelein, Simmet,

Ruscatenblüthe, jebes $\frac{1}{2}$ Suintlein,

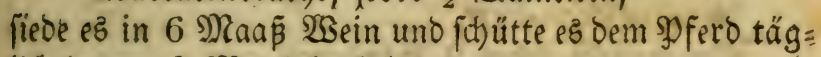
(ic) bavon $\frac{1}{2}$ Maaß (nulid)t ein.

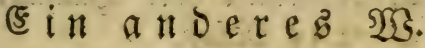

(Summi-guttä 2 suintlein, 2fgaric 1 loth, Iurbith 1 suintlein, Solbanella 2 Suintlein,

Salap 1 loth), wilber (Sucumernjaft $\frac{1}{2}$ lotb), Shermodacftyli 2 Suintlein,

Rad. Iteos noftrat. 1 loth,

(5. fula 1 Suintlein, Scollunoerblüthe,

Ebuli, jebes 2 Seändevoll, fiede biefe @tücłe alle mit einanoer in $1 \frac{1}{2}$ Maaß̃ $23 e i n$ oder flieflendem $\mathfrak{W a} a=$ jer, uno prese es bernad) ourch ein İud), Davon idüutte auf einmal $\frac{3}{4}$ Maaß pin, gebrauche es etlid)emal.

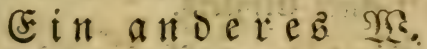

Salcinirtez Spieṕglaz mit Salpeter fräparirt uno unabgefüft, I suintlein, Bermutbwaffer $\frac{1}{2}$ Maa $\tilde{\beta}$,

mijhe es untereinander uno fdütte es dem Sfferd auf einmal ein, fef̧e es etliche Tage fort ; ooer brauche 2 Duintlein Srocus metallorum ftatt bešrn.

\section{Ein andereb গIG.}

Sierä picrä 2 loth, Iaubenfotb 3 loth, श्रtauerrauteu 2 loth, 
Scammelôbrübe 3 Maá̄, fièe es nohl unterein= ander uno nebme von ber Srübe $1 \frac{1}{2}$ Maaß,

Salz 1 Scanoboll, Sconig $\frac{1}{4}$ spfund, mifche es untereinanber uno gebraudbe es laulicht.

\section{(Ein anderes SIyftir.}

Fenchelwurzel,

Espichnurzel, jedes̄ 1 Şanovoll,

Y)op, Bergmünze,

Epicanarbi, jebes 2 Sceảubeboll,

fiede es wohl in ভdbweinen oder Şammelabrübe, von Diefer $\mathfrak{B}$ rübe nimn $1 \frac{1}{2}$ Maā́,

Ş⿻eré picrä 1 loth,

Salz 1 Şanonoll,

mif̧d)e ez untereinanoer uno gebrauche es laulidbt.

\section{(5 i a a n bereb.}

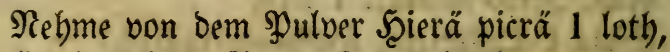
Sonig 8 loth, Iaubentoth 6 loth,

Salz 1 Scanoboll, Seistoth 3 loth,

Mifpeifaamen 1 loth, Effitig, fo viel genug iff, mifche es untereinander, mache 3apfen barauz uno ge= braucbe es ftatt eines sinffirz.

Sin anderes SIyftir 25 .

Bingelfraut,

2(ttid)wurzel uno Blätter 2 Şändevoll,

(Eibifd 1 Scanowoll, fiebe es mobl in fliefiendem 2̧affer, nimm von ber Brübe 1 Maaß̄,

thue baz̧u Şierä picrä 1 loth,

Şonig 4 loth, Rautenöl 2 loth,

Ealz 1 Scanoboll, 5 Esierbotter,

mifate es untereinanber uno gebraudbe es warm. 


\section{Pferbe:2(rzenei Bud).}

\section{Den Şarn zu beföroern.}

Eppidh, Fend)el, SSegroart,

Spargenmurzel, אleenurzel, jedes 1 Scanovoll, geoört uno zu spulver geftollen, bavon täglich 3 \&of $=$

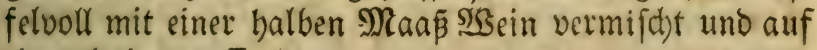
einmal eingegoflen.

Fin anderes Den Saarn zu beförbern.

Bergmünze, Najoran,

TSilde Däumenten, jebes 1 Scanovoll,

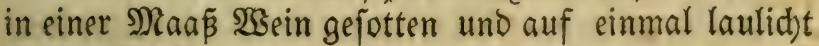
eingegorlen.

Man madbt auch ein SPflafter Doer einen 4 midjlag von (Seiskoth uno Menfdenbarn, oder geftopene Sune= dfentäujer, oder von Steinflee, was alles gewaltig trock= net uno wäjdbet es auch mit warmer \&auge mit Salz vermifd)t.

2⿰亻弋 baß man Den Schnitt vornehme uno die Scaut eröffne, boch mus man fich bamit rool)l vorjeben, Das man nicht viel $\mathfrak{S a f f e r}$ auf einmal beraus lape, meil fonft bas Shfero ohnfehlbar des Todes ift.

Die sefrnung zu verrichten gefdhieht auf folgenbe IJeife :

Rege das গpferb auf Den Siücen und vermahre eह wobl mit Binden, alzbann fafle bie Scaut zwei Finger

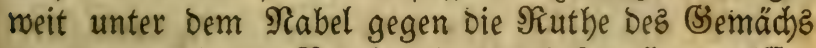
zu mitten auf Dem Saud mit Der linên Scano, offine foldhe bis auf Die inmendige vefte und ftarke Scaut bes unterbaudbes, hernach offne bicjelbe aud bis auf bas Ssedärm hincin, aber fo behut fam es fein Eann, fohiebe

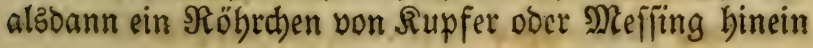


in bie 23 unde uno belfe bem $\mathfrak{B a f f e r ~ a l l m a ̈ b l i d h ~ b e r a u z , ~}$ boch täglidh nid)t melgr alz ein $\$$ fund, baz continuir,

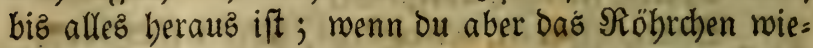

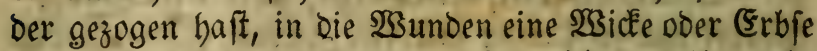
binein fobiebft, Damit fie vor ber Beit nid)t zubeile, nad)= Dem aber alles 2 waffer heraus ift, fo beile es zu wie an= bere $\mathfrak{E u n d e n .}$

Wenn foldjes geicheben, foll man die Reber mit ftop= fenden (Sermürzen wieder ftärken, alz Calmuz, gelken

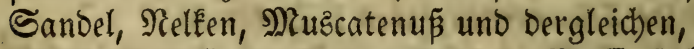

Die Berpflegung wäbreno diefer $\mathfrak{B} a$ fferfucht, $2(n a=$ farca genannt ift :

1. Der Stafl foll mittelmäipig warm, trocken-uno von allen $23 s i n d e n$ befreit fein.

2. Eine gute Streue.

3. Das ซ̌utter foll fein rotbe Ridern, (Serfte, F̌ei= genbohnen in $\mathfrak{B a f f e r}$ eingerweicht, oder $\mathfrak{B}$ eizentleien, gebrothener Sgaber, morunter nachfolgenoem Shulber täglich 3 Löffelvoll follen gemifacht jein :

Blätter von wilder Eucumernmurzel,

Rettidinutzel jeoes 10 loth,

Eoloquinten 2 lotb,

Eerchenfidwamm,

खseibenifhwamm, jebes 4 loth,

alles zufammen gemijêt, gepülvert uno in bem Futter zu freffen geben.

Statt bez Şeus gebe man ihm: WSeibenblätter,

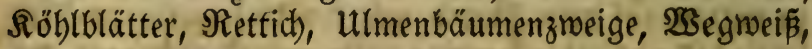
Sceu mit Salpeter beftreuet.

4. Der Irank foll fein, gejottenes Serftenwaffer

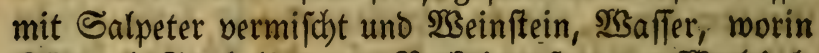
Sümmel, Fendyelfaamen, Boctßhornfaamen, $\mathfrak{B a c h}$ hol= 
Derbeeten, Shollunderrinben, Solbanella, Meiftermur= zel Iamarisênjd)elfen gejotten und ein wenig Roggen= melyl gerührt worden, von biefen folle man bem sूferd laulicht aber wenig zu trinfen geben, nur damit es leben Eönne.

(Fben fo Eann man ifm auth unter bem Trinfen $\mathfrak{L} a u=$ ge von Rebenafd)e, 2Sach bolderafde ober Bobnenftroh= aiche giepen ; Das wenige Irinfen ift hier Das vornehm= fte Mittel und trägt zur Sceilung Der Frankbeit außer= orbentlid) viel bei :

5. Das \$ुterd foll man alle Tage an ber Sonne ober bergigten Sorten, jebod) mit Decken wobl zugebect't berwegen laffen, hernad) Den Schmeis mohl mit mar: men Täthern fein gegen bie Saare und buvon abrei= ben uno wifchen, uno fchmicrt fie alsoann mit foldhen Delen, weld)e bie Rraft baben zu erwärmen.

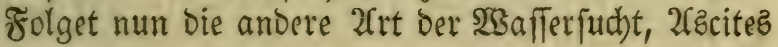
genaunt.

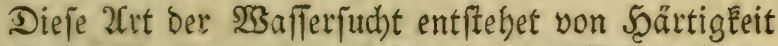
Der Reber, Serffopfungen, Scärtigkeit dez Milzes, fo mie aud) wenn bie (Sallrinnen fammt ben SBlutabern bes Sröfes verftopft fino, woourch Der Magen erfaltet uno bie $\mathfrak{L}_{e}$ ber gejd)mächt niro

\section{Die Seichen Diefer Wafferfucht find:}

1. Sfit ber Utnterbautch anfangs febr bick uno bart, fo mie auch bie Scinterfohenfeln fammt ben Seburtsgai= len uno ganzem (Befdröt hod) aufgelaufen.

2. Die übrigen Sörpertheilen fino bagegen ganz mager uno ausgetroofnet.

3, Innmendig in bem $\Omega_{e i b}$ fühlt baz $\mathfrak{W}$ fero wenn ez fich) reget oder ichüttelt, ein (Setös oder (Setümpel, alb 


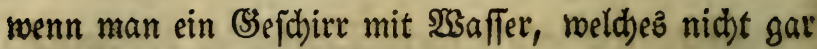
voll ift, rüttelt ober ichuttelt.

4. Rann bas spfero nicht robl athmen, benn bas S2Saffer, mit welchem ber $\mathfrak{L}_{\text {eib }}$ erfülllet iff, brüctet bas Sueerblatt aljo, baß es fich nicht robl bemegen faun.

5. Rann nicht vor fich geben, ftrect menn es fitill ftebet, Die vordern Schenkel gegen bas Maul ges waltig heraus, Deşgleiden audh bie hinterften Sdbenkel, gegen bem Sdyneif hinaus, mag weber effen nod) trin= Een, weil ifm ber Magen zu febr erEaltet uno gejhwäd)t iff.

6. (Sibt einen barten und wenig Nift bon fich und bazu geidhiebt es äuperfit mühfam, wie gleid)falls auch wenig Şarnz, zittert mif Den Füß̈en uno befommt zu= lef̧t ein Freber, weldhes das ohnfeblbare Beichen bes Todez ift.

7. S3irft fich oft vor gropem Sdymerzen auf bie (5r: be, feufoet und ftrampfet auch mit ben Füípen.

(5) $\mathrm{ur}$.

Sor allen Dingen foll man bem Spferd ben Leib of = fen balten, fowobl in bem soferchen als Stallen, mit obenbeidriebenen EInftiren.

Man foll ifm marme Säckden mit 2ajche über ben

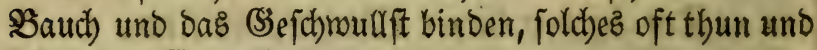
folgenden singur geben :

Siolenteraut, Erorauch,

Sapillus veneris, jedes 2 Sändevoll,

fiede es wohl in $\mathfrak{B a f f e r}$ nehme von ber abgejeiften Brübe 1 Raa

Scierä picrä 2 loth, 2rgaric 1 loth,

untereinanber gemifot uno warm auf einmal eingegeben 


\section{Ein andereb $\mathfrak{B}$.}

Salcinirtez Spieşglaz 1 suintlein,

Saftran $\frac{1}{2}$ Suintlein,

warmen $\mathfrak{S e i n} 1$ Maẫ,

mifche es untereinander und foütte es bem \$fferb aufeinmal ein, oder 2 suintlein Srocus metallorum.

(5i $\mathfrak{n}$ a $\mathfrak{n}$ ie $\mathfrak{r} \mathfrak{e}$.

Inoblauth) 6 loth), (Siolonurzel 3 loth,

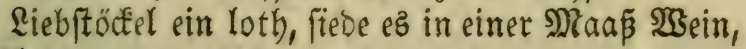
uno foutte es dem Spfero auf einmal ein.

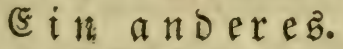

Inoblauch 4 loth, Yy op 3 Şänoevoll,

Bodḱzhornjaamen 4 loth,

Brunnentreflenfaft $\frac{1}{2}$ Maá̄,

$\mathfrak{W e i n}$ eine $\mathfrak{M a a \tilde { \beta }}$, fiede es wohl untereinander und f) ütte von ber Brübe $\frac{1}{2}$ Maaß laulid)t auf einmal ein.

\section{E in Ely fit $i$.}

Endivien, Bingeleraut,

Scariola, SBernuth, Samillenblumen,

Mangold, jeoes sine Scandvoll,

fiede es mohl in einer fetten SBrühe, nelyme diejer $\mathfrak{B r u ̈ =}$ be 2 Maás,

Eapaiarinde, Scierä picrä, jedes ein loth,

Soulpa colocunt ein Suintlein,

Galz eine Scanovoll, mifde es untereinander uno applicirs bem Sुfero auf einmal.

Ein anderes slyftir.

Saft bon wilber Sucumernwulzel $\frac{1}{4}$ Maaß́,

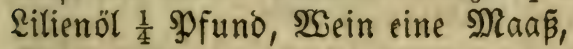

Salpeter 2 loth, milde ez untereinander und ge= brauche ę laulicht. 
ङin Eingu

Selyme ŞBermuth, SDermenig, YYjop, fiebe es in

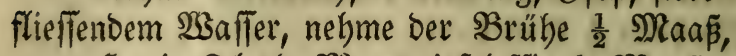

Sconig 8 loth, Meerzmiefeleffitg $\frac{1}{4}$ Maaß̄, mifche es untereinander uno fobutte es auf einmal ein.

E $\mathfrak{i} \mathfrak{n} \mathfrak{a} \mathfrak{D}$ eres.

Daz Sultwer von einem calcinirten sgel, 2 loth, Sconig 6 lotb, $\mathfrak{W}_{\mathfrak{S e i n}} \frac{1}{2}$ Maa $\tilde{\beta}$

mifche allez untereinander und fibütte es dem spfero auf cinmal ein, gebrauche es etliche Iage,

\section{(5) in anderes.}

Saft von Sinmertelwurzel, 2ittich)ourzel jebes $\frac{1}{4}$ \$ofuno, 2Tgaric $\frac{1}{2}$ loth), 2 Sein $\frac{1}{2}$ Maa

mifche es untereinander und fchütte es bem \$ुfero auf eimmal ein.

Ein ano eres.

Shollundernurzel oder Rinden,

2ittichnurzel, jebes 2 loth,

fiebe fie wobl in flieffendem $\mathfrak{x a f f e r}$ und fohütte bem \$fero täglich bawon $\frac{1}{2}$ Maa la laulicht cin.

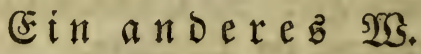

Die Brübe worin 2 loth Soldanella gejotten

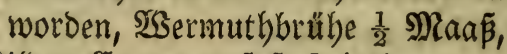
sgilben Sucumernfaft 8 lotb, mifche es untereinander uno ichütte es auf einmal ein. Soldanella Salap, 2fgaric, ŞBilden Eucumernaft, jebes 1 loth,

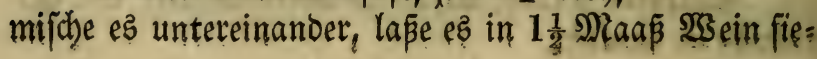




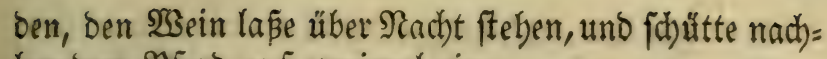
ber bem Sुfero alf zreimal ein.

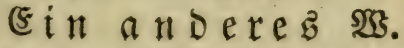

Bilden Eucumernjaft 2 suintlein,

Slaue Sd)wertelnurzel 2 loth,

Extract efulä 1 Suintlein,

2 garic $\frac{1}{2}$ loth,

Rhapontic 1 loth, Iutbith 1 Suintlein,

- Salap $\frac{1}{2}$ loth,

mifche ez untereinander in $\frac{3}{4}$ Raá̃ $\mathfrak{B}$ ein uno jchütte es auf cinmal ein.

Ein $\mathfrak{a} \mathfrak{n} \mathfrak{D} \in \mathfrak{E} \mathfrak{E}$.

Taubenfoth 6 loth,

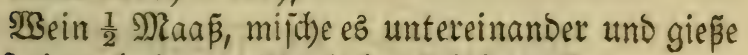
es auf einmal ein; mieberbole es einigemal.

E i $\mathfrak{a} \mathfrak{n} \mathrm{D} \in \mathfrak{r} \in \mathfrak{b}$.

Rebme Thannenól 2

Ierpentinöl 1 loth,

Wegmartwafler oder Brühe $\frac{1}{2}$ Maaß̃, mifd) bies untereinander uno fidutte es bem Sूferb auf einmal ein.

(5in $\mathfrak{a} \mathfrak{n} \mathfrak{D} \in \mathfrak{e} \in \mathfrak{E}$.

Slätter von Meet köbl 8 loth,

ङ\{fig $\frac{1}{4}$ Maá̃, Salz 2 loth,

Sonig 6 loth,

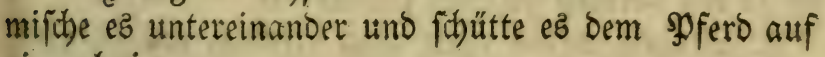
einmal ein.

\section{Ein andereb.}

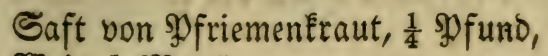

SSein $\frac{1}{2}$ Maaß̄,

mijche alles untereinander uno joütte es auf einmal ein. 
Soer gib ibm bie Meng wilde Cucumern zu freffien.

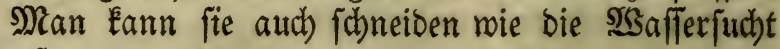
2Cnajarcam.

Ein andereb.

Riebftöckelmurzel 6 loth,

Seernurzel 2 loth, Spoponax 1 loth,

W̧ein $\frac{1}{2}$ Maa

ftope und mifche es untereinander und fchütte es, auf rinmal ein.

Die Serpflegung ift wie in ber exften 2frt ber $23 a$ a = ferfutbt $2 \mathfrak{n}$ ajarca angegeben murbe.

Son Der $\mathfrak{E a f f e r f u t h t ~ T y m p a n i t e z ~ o d e r ~ b i e ~ t r o c k e n e ~}$ ober NGinowafferjuct genannt.

\section{Deren 3eichen fint folgende:}

1. Soldhen झूferben ift ber $\mathfrak{u} n$ terbauch, wegen ber Bläfte und $23 i n d e$, bie fidy in Demfelben verjammelt,

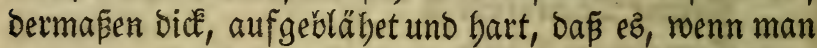
mit einer Şand Darauf Elopfet, einen Scall oder IJ bon wie eine Irommel von fith gibt.

2. Soldhe \$ुferde haben eine auggefpannte Scaut, ftarrichte Şälfe, uno halten felbige bermaßen aüge=

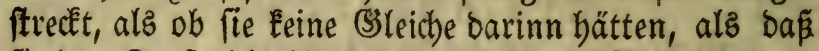
fie ben Ropf nicht binabroärts nad) bem rutter entge= genbuitfen, nod) aud in Dem Sehen bie bintere Schen= Eel zu ben vörbern bringen können.

3. Mögen weber effen nodh trinken, uno jalafen wenig ober gar nicht.

4. Seben ben Mitf und Şarn mit großer SBefchrãr: mís von fich).

Dieje Srantheit entftehet von oer verftopften \&eber, Miliz, mie audy von ber Saallrinnen. 


\section{Sur Derielben.}

Şor allen Dingen foll man ben \&eib offen balter, uno alle bieje vorerwähnte 2frzeneimittel in vorker bes

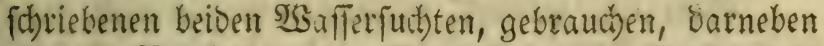
aber bie Refolution ober SBertbeilung Der SBince mobl beobad)ten und befördern.

\section{Folget eine Sinftir.}

Frenchel, (Sartenkreffen, jebes 1 loth,

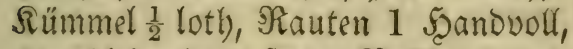
fiede es wobl in einer fetten Brübe, Dovon

Nefyme der SBrühe $\mathbf{1} \frac{1}{2}$ Maa $\tilde{\beta}_{1}$

Şierã picrä 3 loth̆,

Rautenöl, 4 loth, Salz 1 Scanduol, untereimander gemijotet uno laulicht gebraucht.

(sin anderes SElyftir SIG.

Mauerrauten 4 Şändevolu,

Neffelfaament, Rümmel, Lorbeer, jebes 2 loth,

Mangold 3 şänoevoll, fiede es mohl in einer fet= ten $\mathfrak{B u ̈ h b e , ~}$

Rehme biejer Srühe 1 Maá̃

Baumöl $\frac{1}{4}$ Dfuno, Salz 1 Scanovoll, untereinanoer gemifat uno laulidbt gebrauddt.

\section{E in $\mathfrak{a} \mathfrak{n} \mathfrak{D} \in \mathfrak{x} \in \mathfrak{E}$.}

Madje Bapfen von Sconig, uno applicirs dem \$J fero.

E i $\mathfrak{a}$ a D e re

Soer Mixtur von Reffeliaamen, Rorbeer, Gellglän=

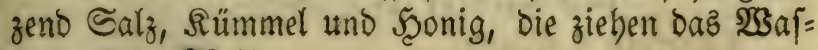
fer aus benateib.

(E) in a nde $\mathfrak{e} \mathfrak{e}$. Wilden Eucumernjaft 2 loth, 
Soloquinten $\frac{1}{2}$ loth,

Eine balbe ßinosgalle,

Sonig fo viel als nötbig zu einer Naffe iff,

Salz 2 Şänoevoll, mijche ez untereinanoer, lape über einem Roblfeuer fieben, biz ez fo bick wirb, baß man 3apfen baraus formilen fann, biefe gebraudbe s:dor= gens uno 2 benos.

\section{Ěin Eingus.}

Reffelfaamen 1 luth),

Extract bon Eapiarinde 3 loth,

Scierä picrä 2 loth, SDulpa (Solocunt. $\frac{1}{2}$ lothy,

Fend)ei ein loth,

Diftillirt $\mathfrak{B a}$ after von (Eppich,

SteinElee ein Maẩ

mijhe es untereinander und foütte es auf einmal ein.

Ueber den Bauch foll man narme 2fiche legen, wel= d)e mit \&einöl und milden Sucumernjaft befprengt nor: ben, uno foldtes oft thun.

sin anderer Utmidblag.

$\mathfrak{l}$ jche, Rleien, jed:s 6 Scăndevoll,

Şirjen 4 Şänoeboll,

Sümmel eine Scanovoll,

SSeinrauten 2 Scänoeboll,

Uniz 2 loth,

mifche es untereinander, mache estrarm uno fablage des Iages oft über.

\section{Ein anderer Umichlag.}

Sübefoth 4 Sg funo,

SBeizkoth $\frac{1}{2}$ গু fund,

Taubenmift ein פound,

Bohnenmebl $\frac{1}{2}$ Maaß̃, 


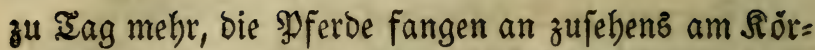
per abzunebmen uno werben enolich fo mager, basj. fie vor Mattigkeit Dabinfallen und fterben.

Diejer Srankyeit Rennzeichen fiebet man vor $\mathfrak{X} u$ gen, mus in allen Dingen auth curirt merben wie in

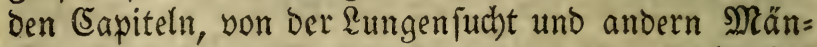
geln ber \&unge und des Scuftens genugfam bejchrieben worben. Naan bält es baber für überflüsig, fich bier weitläuftiger über biefen SSegenftano auszuorücken uno vermeipt ben geneigten aufgebarbte 2 nmeifungen zur gebörigen Bebanolung.

\section{Das 15te Eapitel.}

\section{Bon Dem Mnilz und feinen Frantheiten.}

- Das Milz ift von einer bünnen, lückeridaten uno fobrommichten Subftanz, liegt an ber linken Seite, zroifchen Dem Magen uno Den Rippen, reiniget von

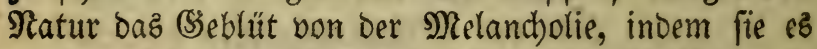
von Der Leber an fich ziebet; Eann fich oeşyalb um ei= ner geringen Uriache millen auzbebnen, auf alle Seiten ausbreiten, bick macken uno erbeben, uno mit dem Sce: fen bes (Seblüts aud) alles andere, fo ifr etroa auffitopt, an uno aufnehmen; Daher ez Dann Eommt, Daß̧ es of = terz ourth einen wiberwärtigen 3ufall von ben bidéen Dämpfen oder ber natürlidben Melandbolie, oder fonft einer bünnen flüfitgen Freuchtigkeit Dermaß̄en eingenom =

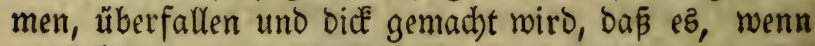
nemlich bie gemeloete Materien in ibm zufammen rin = nen uno gefteben, baburch ganz uno gar verbärtet, als: 
bann fann ę firt) zu gebührender Beit, wie esै fonft zu gefdbeben pfleget, nicht mebr felbft reinigen, fondern ift allenthalben verftopft.

Diefe Mängel uno (Sebrechen aber fommen gewöhns (id) baher, nenn bie SDferbe eime lange Beit nid)ts als grüne Früd)te, frifd)es (S)raz, oder fonịt fruchte, falte uno bicke Speifen in fich freflen, an feuchten ooer füm= pfigten Sorten meiden doer fteben müflen, doer viel (siz= Ealt $\mathfrak{B}$ affer faufen, ja fie entfteben aud bismeilen $D a=$ Ger, wenn baz Milz Der natürlichen bünnen und flief= fenoen molandbolifden Feud)tigkeit in fich bat, weil ent= weder Das (Seblüt berjelben voll, ober Die 』eber für fich felbft einer Srankfeit unterworfen ift, ober weil bas unvermögliche und fdurwache Milz biefelbe zu rechter uno gebübrlicher Beit nicht von fich treiben fann, ober fonft mangelbaft und verftopft ift.

Die Rennzeichen Diefer 2 ufbläbung uno SEerbärtung Des Milzes betrefiend, find diejelbe in allen Syferden nid)t allezeit einerlei, fondern je nachoem bie Sranebeit in biefem grops, in jenem aber gering ift, fehr ungleid, Daber Dann.

1. (Etlidbe baben einen gropen und bicken Bauch, welcher auf Der linken Seite faft raub ift, attymen ba= bei oft uno gefdomino.

2. Siehen etliche die SRippen auf Der linfen Seite mefyr überfich als auf ber rechten, feufzen oft und viel, uno werben alle Tage magerer; uno können fich übel auf Die linfe Seite llegen.

3. Etlichen ift der ganze Saatd) grof́ uno bick und To hart, jeboch auf Der linken Seite etmas mebr alz auf

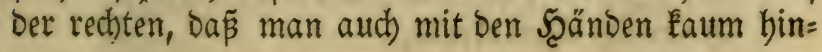


einwärţ brüdéen Eann, athmen oft und viel, geben lang: famer als fonft ifre semohnheit ift.

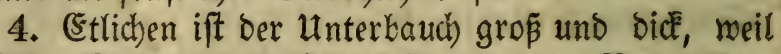

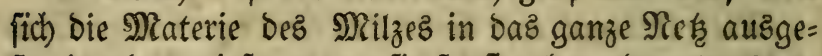
ipreitet Gat, niefen mann fie fonft gehen ober etrwas ar= beiten, wenden yor gropem Edumerzen, Den fie in Der 2ribeit empfinden, Den Siopf balo sorthin bald Dabin.

Diefe Srantheit Eommt die \$oferbe meiftentheils in Dem Frübling an, wenn fie fich mit bem frifchen (Siraz gar zu febr überfülten, ift anfänglid leicht zu curiren, wenn es aber einmal recht eingewurzelt bat, fojwerlich ober gar nid)t mebr zu vertreiben.

\section{Die (5) $\mathfrak{u}$.}

Bor allen Dingen foll man ihm ben Reib offen bals ten, formobl im \$ुferchen als Stallen, und bie (Syftix brautchen, welche in ben Leber=-Suren bejchrieben nor= Den.

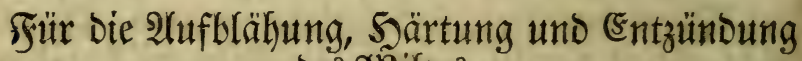
Dees গ⿹ilzes:

Sedmiere ihm bie linfe Eeiten um bie Siegeno mo baz Milz liegt, mit nachfolgender Salbe täglich) zmei= mal.

Shirfachare 6 loth,

Entenid)malz,

SSühnerichmal z, jeoes 2 loth,

Sdbreinenichmalz 1 sfuno,

Süß̌ez Mandelöl 2 loth,

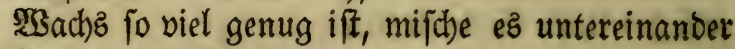

und idhmiere daz \$ferb warm bamit.

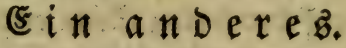

Sceionifd) $\mathfrak{S}$ Sundfraut, 


\section{Pferbes2(rzenei buth.}

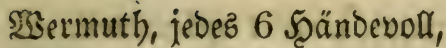

Spicanardi 3 Şändeboll,

Beinrauten 4 Scändeboll,

Dill 3 5ृändevoll, Enzian 6 loth,

Saperntourgel 4 loth,

Siterlucen 6 loth,

Iorbeer 10 loth, Sïmmel 4 loth,

fiede es nohl untereinander und preß̧e den Gaft wohl Davon, biefen Saft fhutte in 2 Sूfund Baumöl, la se ę fieden, biz die wälferid)te Feuthtigkeiten alle verzeh= ret find, alsoann fomiere daz Sמfero damit.

(E) $\mathfrak{n}$ a $\mathfrak{n}$ e $\mathfrak{i} \mathfrak{E}$.

(Fibifd) jaft;

SBilden Cucumernfaft, jebes $\frac{1}{2}$ Maáâ,

Eamillenöl $\frac{1}{4}$ Ş funo, Loröl $\frac{1}{2}$ SP funo,

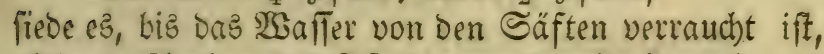
alsoann fdmiere bas Sp fero warm bamit, bernach gib ibm folgenden (singus :

Sarelwurzel 3 loth,

B̧ein $\frac{1}{2}$ Maa $\tilde{\text {, }}$

fiede eŝ wobl, orücke es aus und fđütte es Dem 20 fero auf eimmal ein, gebrauche es etliche Iage.

\section{E i $\mathfrak{a}$ a d e reb.}

Iamarizkenichelfen 3 loth,

Sapernwurzel 2 loth,

Reinfarrentraut 1 loth,

Rorbeer 2 loth, fiede es mohl in 1 Maáp $\mathfrak{M}_{3}$ ein, Drüle die Brühe bavon und foütte es auf einmal ein.

\section{(E) in andereb গIS.}

Sajelmurzel, Reinfarrenmurzel, jebes 2 loth,

Betonien 3 Scänoevoll, 
Unoorn, SBermuth, jebes 2 Scändeboll,

2 garic 1 loth,

fiede eE in $\mathfrak{B e i n}$, uno preß̄e den Saft bavon.

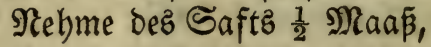

Sierä picrä 1 lotb,

mifche es untereinanoer uno joütte es bem spfero auf einmal laulicht ein.

Etin andereb

SSilden Sucumernjaft 1 loth,

Sierä picrä 2 loth,

Die gefottene Brübe von Taujenogüloentraut uno Sapernourzel brei Siertel Maá̄,

mifhe es untereinander uno fchütte es bem sूfero auf einmal Vaulicht ein.

E $\mathfrak{i} \mathfrak{a} \mathfrak{n} \mathfrak{D} \in \mathfrak{r} \mathfrak{e}$.

Reffelfaamen 2 lotb,

Milzkraut, Iamarißken, jeoes 1 loth,

Frerberrötbe 1 Şandoulf,

(5almut 2 loth,

SBeibenrinden,

Scollunderrinden, jebes 1 Scanovoll,

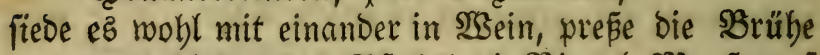

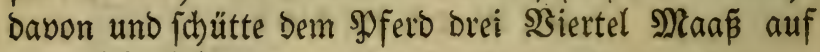
einmal laulicht ein.

Einanderez.

Tamarisken 1 lothy,

Mryrobalani, Engelfüp, jebes 2 loth,

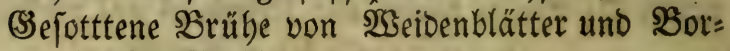
retich 1 Maa

fiebe es wobl untereinander und fdütte bie SBrübe bas bon auf einmal ein. 
2 PFerde:2(rgenei $\mathfrak{B u d}$.

\section{E $\mathfrak{i n} \mathfrak{a} \mathfrak{n} \mathfrak{e} \mathfrak{e} \mathfrak{E} \mathfrak{T}$.}

Extract von fownarzer Niestwutzel, $\frac{1}{2}$ loth), Simmet, Maftix, jeoes $1 \frac{1}{2}$ Suintlein, Die Brübe non gefottenen blauen Merzenveilen, $\frac{1}{2}$ Maán, untereinander gemifht und auf einmal eingegonen.

\section{Ein a noereb.}

Sümmel 8 loth, Şonig $\frac{1}{4}$ Maa $\tilde{\beta}_{1}$ İeufelabrect 1 suintlein,

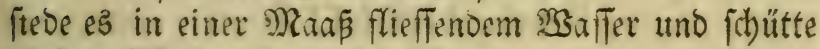
ez bem \$ूfero auf einmal ein.

(5) in and ere

Wermuth, Setonien,

פूeterlein, jedes 2 loth),

(S)amanderlein 1 lotb),

SBibergeil 1 Suintlein,

3ucter 4 loth,

alles gepülvert, fiebe ez ein menig in Sconigwafler eir

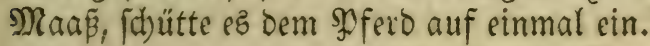

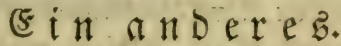

Die Brühe von Sappernmurzel,

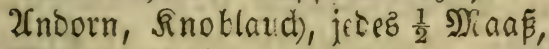

Salpeter 2 loth,

untereinander gemijcht und auf einmal eingrgoôen.

Eine Salbe, Den preghhaften Drt Damit zu fichinieren.

Shirichen $\mathfrak{u n}$ nfwlitt,

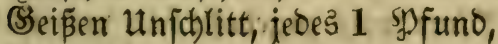

Fseiraudh gepülvert 1 loth, 
SBibergeil, Spoponax, jedes 2 loth,

Ierpentin $\frac{1}{4}$ \$f funo \&oröl 1 SD fund,

Evprinöl $\frac{1}{2}$ S Fund,

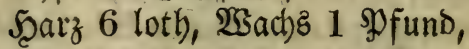

mache ez allez über einem Soblfeuer zu einer ๔albe.

Ein anderes $\mathfrak{n}$.

Sefome bas geichmelzte Stablpulver, fo in Dem $5 a=$ pitel von Den \&eber = Srankheiten befdrieben worben uns wenoe es genau fo an, wie barüber 2rnmeifung ertbeilt murbe.

Ein anderez.

Sittruar 1 lotb, Sconig 4 loth,

Wein 1 Maaß̄, laß̄e es robl miteinanoer fïeden, und fichutte es bem Spferd auf einmal ein.

\section{Die $\mathfrak{B e r p f l e g u n g . ~}$}

1. Sin narmer, trockener und beiterer Etall.

2. Soll man bas \$ffero alle Morgen vor ber Füt=

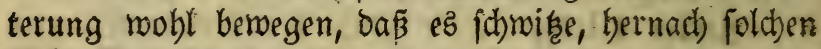
Sdbweiß mobl abreiben uno trocknen.

3. Die Speipen folten nicht fo gar überflüfifg fein,

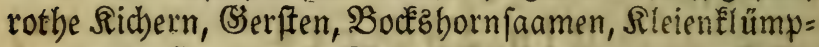
den, mit Sconig uno Salz, Sleien, worunter geftope $=$ ner Lerdyen = uno SBeibenidhwamm, (Eappernwurzel, Ep: = pid), Feigbohnen, Rettichblätter uno SöblEraut ge= mifhot worden.

4. Der Trant foll fein $\mathfrak{W}$ Saffer morin gefotten wor= ben, Fendbel, Soctżbornjaamen, Eppid)muzzel, Fendbet: nurzel, Feeberrötbe, Sdbmalbennurzel, SBraunmurzel, Salpeter, $\mathfrak{B}$ einftein u. F. m.

5. Soll bas spfero robl zugebectit fein und pine gus te Streu baben. 
Sinnerliche Utrfadben find eine einfache und foblechte Unred)tmäp̈igkeit ofne Materie, fie feie gleich bisigig ooer Ealt, Denn foldhe vertbeilt bie Siräften bez ganzen \&ei= bes gar zu fehr uno madht bas Thier farwach uno matt. (Ebenio aud) Die (charfe uno biffige Freuchtigkeiten bie ba fonberlic) einer böfen 2 rt und giftigen Slatur und Den lebbaften Iräften diejez Thiers mit ibrer ganzen Subftanz zumider find. SBizmeilen bie andere Feud)= tigkeit, fo Dem Şerzen mehr nicht, bann mit ibrer Men= ge überläftig find, und Daffelbe rings ber umgeben.Manchmal bie verbrannte (Salle, bie fich) ourd) bie ${ }^{2} u f t=$ abern aubbreitet ; bie $\mathfrak{B}$ ürme, die zum oberften $\mathfrak{M a}=$ genmuno binauf f́teigen; die auffteigende -melancholi= fiche Dämpfe, weder von bem verderkten (Seblüt ober gallenartigen oder anderwärtig aus Dem Magen fom= met, uno zu bem Seerzen gelangen, wovon aud) bas Serzgefperr feinen Uriprung bat ; bie grope und befti = ge Srankbeiten Derjenigen Etücfe uno (Silieber, meldhe nabe bei bem Serzen liegen, ober bempelben fonft zu= gethan ober ourd) genannte Mitleidenjchaft mit ihm vernandt find, nämlich Das (S̈ebirn, Das Scerzbäużd)en

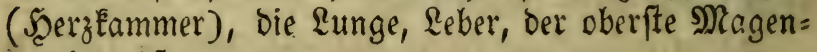
muno, u. F. w.

Die Rennzeichen biefes Scerzmehes find mandherlei, benn biejenigen spferbe welche bamit behaftet find, bie zieben

1. Den $\mathfrak{B a u c h}$ und $\mathfrak{B}$ eidbe eir.

2. Raßen den Ropf bängen.

3. Schlagen Die 2fugen zur Erbe uno baben biefel= ben gewöbnlid) mit Thränen angefüllt.

4. Sdlugen ben Ropf mider ben Boden.

5. Seipen fid felbft in bie $\mathfrak{W}$ eidhen. 
6. Sind am Sijdröt und den Sieburtzgailen ge= fdomollen.

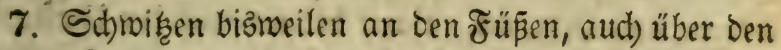
ganzen \&eib.

8. Fallen ronn man fie geben läpet, auf bie vor: bern Sniee, meil fie fich in Dem ganzen \&eib, fonderlich

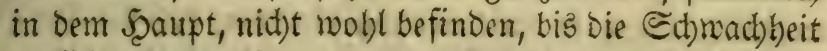
enolic) melsr zunimmt uno gröper wiro.

9. Sittern mit auggebel)nten Serven, bis fie enolid) gar babin fallen, uno wenn fie balo fierben wollen, fo laffen fie die Rute Des (Şemäd) berab bängen, zieben die (3ailen ein uno lapen ben Şarn Iropfenmeiz von fid) fallen.

Das Serzzittern wiro aus diefem erEannt, wenn ez daz Spfert um Das Serz berum, wis auch in Den Schul=

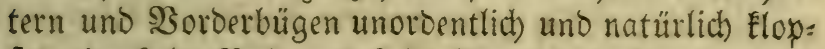
fet, cine Ealte Safe uno kalte Shren bat, luber oen gan= zen \&eib mager wiro, Die Scaut gleichfam an ben 9Rip= pen anflebend und einen ftarrid)ten siluken bat.

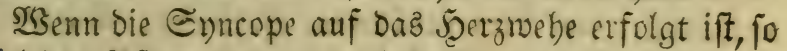

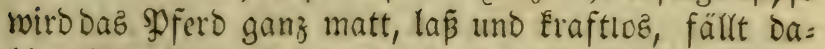
hin als wenn es allerdings geftorben, ift in feinem Sopf

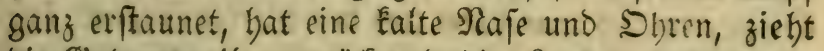
Die (Seburţgailen zurü uno bie \&enden beftig ein, macht einen boben fnorrid)ten Rücten, bat cinen rotben Satrn uno läpt benfelben Iropfenweis von fid), biz die Irantbeit faft zu (Enbe lauft, Da ez Dann aud) Die $\Re u=$ ten feines (Semäch), wie aud) bie Bunge heraus bängen läpt, und Eann biefelbe Eaum mieder zurück hinein zie= ben, meil ę nämlich aller feiner Etärfe uno Sräfte be: raubet, uno bem Iod faif nabe ift.

Die Sebung aller diejer Srantheiten ift jebenfalls 
ăuperft fdwierig uno erforbert eine böhft umfichtige Sebandlung, Denn fie greifen gerabe die $\mathfrak{B u r z e l}$ des

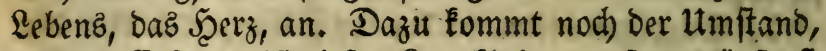

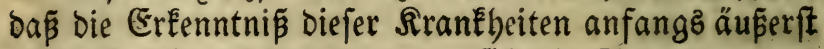
idmierig ift, uno fpäter, menn fich bie Symptome un= verkennbar mabrnebmen laßen, fo ift ote Srankbeit ge=

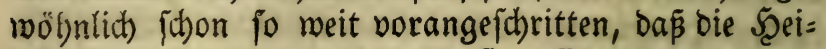
lung Derjelben febr zmeifelbaft ift. (5z erfordert einen geichickten uno erfabrnen 2 rzzt, menn man auf Erfolg redinen will.

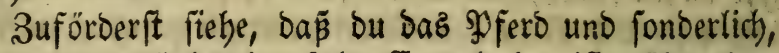
menn bie Uriache eine Ealte Complexion ift, über ben ganzen Saud uno Bruft fein warm zubeckeft, es in einem mittelmäßigen uno jaubern Stall einjperreft und Denjelben mit foldben Socben beftreuft, weldbe einen gu= ten (Şerud) bon fich geben und die Rraft zu ftäifen ba= ben, als in ben bigigen $\mathfrak{t}$ rjachen Minrtenzmeige, bie

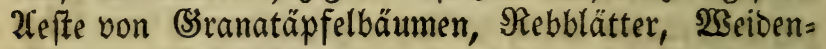
blätter uno bergleicben, in ben Falten aber bie 3meige uno blätter von \&orbeerbäumen, Najoran, Schnertel uno was bergleichen Sachen mebr fins.

Wenn Die Arankbeit von einer bikigen Ur a adbe ber = fommt, welches man bann aus bes Spfirdes Sugend, fei= nem ganzen $\mathfrak{Q} e b e n$, feiner eigenen. Siropmütbigkeit, an = geborner నübnheit ober Frechbeit, (Seftalt Des \&eibez, Farbe, ber Saare uno oer jemeiligen Sabrzzeit mob! abnebmen Eann, fo lape bes \$pferdes Speife fein, Din=

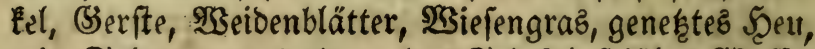

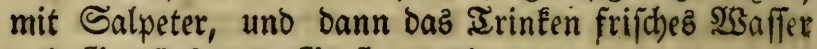
und Sietränfe von Serftenmebl.

Bei Den Ealten Materien und Utracben aber, als

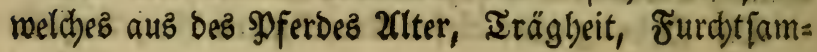


Eeit, melandjolijider Ratur, gelben ober tootbleichen Şarn, Nattigkeit des @eibes uno (3)elegenbeit gegen= wärtiger 3eit (fintemal fold)e mehrentbeils im ßSinter uno Serbft fid) ereignen) Eönnen offentabrt uno etten = net merben, gibt man ibnen rothe ßichern, Soctshorn= faamen, Sleienflümp.t)en mit Şonig, bas Irinfen von Roggenmehl.

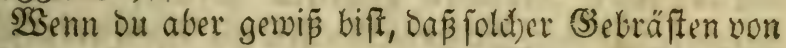
Shife entftanden, fo gib ifm alle Nlorgen Serzftär = fung mit Iränken ein, welche fullelen, jeood) mit etwas erwärmten (Sewürzen vermifot), Damit es befto beffer ourd) uno binein oringen, aljo bie feuchtigkeiten vorbe= reiten uno die Materie verzehren fönne, zu meld)em En= be Dann bienet, Boretich, blaue Sivlen, Sd) Fenjungen, Sandel, Melifien. (5ben fo aud) bie Soutver von Sd): fenzungen, geid)abtes (slfenbein, in gleid)em (Semid)t mit Rojenwaller eingeben, das Eorallempulver, Elfen= bein mit Meliflenwaffer, ooer Brübe von Souretfd) ver= mifchet. Dann foldhes alles wirft zugleid) wioer bisi= ge uno falte Sdywadh beiter, wie gleidh falls bie Eatmer= ge hierä magnä mit $\mathfrak{W}$ ein bermijht gervaltig bilft.

Rauboem alfo bie allgemeine \$urgation vorbergan= gen und bie Srantheit im 2Cbnebmen ift, fo lape ibm

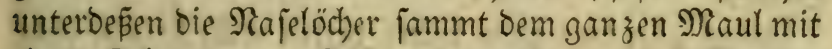
einem ミd)ramm in Effifg allein, ober mit Effig uno Rofenmafler vermifht oft uno viel reiben uno wajchen, um das SPfero Damit zu ftärken und mieder zu feinen verlohrnen ふääften zu hplfen, aud) Die ohnmächtigen Sdbreipe zu verbüten, Den ganzen \&eib, Den Scaaren entgegen, mit unzeitigem sel uno Sojenöl, wobl reiben. Sm Fall aber bie Urjache eine blutartige Materie fein follte, bie fich) an gemißen Rörpertbeilen ober (S)lie: 


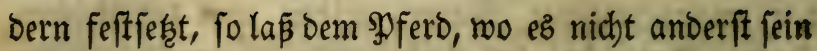
Leben uno 2Clter zuläpt, alzbald eine 2loer öffnen.

Sfft es aber hingegen eine falte $\mathfrak{U} r$ radje, fo balte bich an Mittel weldbe wärmen, uno gib bem \$pero etlidbe Tage viel \$̧ulver von Majoranjaamen mit $\mathfrak{W}$ ein ver: mijht, ober \$dhjenzungenjaft, Majoranjaft, ober bie von benfelben Rräutern gefottene Brühe, Darunter,

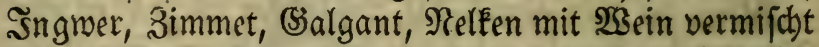
fein. WSoblthätig mirkeno ift audd) Lorbeer, Dfferlu= cev, Munrthen, welfchen Suendel und bergleichen mit Wein vermifchet; ferner 7 loth Meerzwiefel = Effitg, oder 2 loth von ber Meixtur Iryphera Saracenica ge= nannt, in $2 s e i n$ vermi cht. Die Najelöcher, 3unge uno Den ganzen Muno laß̄e ihm mit Dem allerbeften $2 \mathfrak{s e i n}$ osor bet Mixtur von Effíg uno $\mathfrak{B}$ ein, bez Tags oft und biel wajchen, und mit $\mathfrak{B e i n}$ und Sel oft und viel Den yorbern \&eib reiben, ober mit nadffolgender Salbe ithmieren :
WBacbs $\frac{1}{2}$ פf funb,
(3eirautch 2 loth,
Baumöl, jo viel zu einer Salbe genug ift,

mifothe ez untereinander über einem ßoblfeuer, zu einer Salbe.

Wsenn aber biez allez nichtz helfen mill, fo lapee ibm unter Dem Siniee bes vöroern @dhenfelz, auf bem bin= tern $\mathfrak{F} u \tilde{p}$ und auf Dem Sctwanz eine 2 foer öffnen und mit Den gemöbntichen $2 \mathfrak{a z}$ eneien fortfabren.

WSenn aber bie Magenmürmer bie Ur raden find, kann man bie Mittel gebrauthen, weldhe in bem Eapitel, ber im Raufe biefez $\mathfrak{B u c h}$ biefem (Segenftand auz: fofließ̧lich gewiomet werben miro, angegeben, werben follen. 
3ferbe:2(rgenei Bud).

Sommt Diefe Srantheit von Der Sheft, fo fehe man wegen ber Bebandlung in Den (Sapiteln nach, weldbe über bie speft abbandeln.

\section{Dab 17te Eapitel.}

\section{SBD Dem Saerzjittern.}

Das Serzzittern, wenn es feinen Hriprung in Dem Seerzer. bat, ift unbeilbar, uno bringt bas I bier jäb= lings und gefdrmind um, wo es fid) aber verzieht und Das SDfero 2enfangs nicht gleich aljobalo töotet, Eann man ibm mit einer 2 coerla $\beta$ begegnen.

WSenn es aber aus einem andern (S)lied, weld)es mit bem Scerzen (Semeinidaft bat, berfommt, fo fann man eछ (miemobl eहै fadmer uno gefäbrlid) genug bergebet) mit foldhen Nitteln vertreiben, weldbe die Sälte uno Bläfte vertreiben, mie gleichfallz auth mit benen, wel= d)e errärmen, bie (S)eifter fubtil machen, uno bie Durch)= gãnge und \&uftlöd)er eröfnen; indem bas Serzzittern faft allezeit aus einer luftartigen uno bläftigen Sub= fanz, uno bann ben unlebid)ten melancholifden uno blä= ftigen (Seiftern, als aus feinen beiben fonderbaren uno eigenen Utrachen entipringet, weld)e bie Srte, in Denen fie verfd)lopen liegen, mit einer gropen (Sieroalt uno Ungeftumme fo lang uno oft erbeben uno aufbläben, biz fie zu ifrem $\mathfrak{2}$ usgang Fommen und herauzoringen.

Die $\mathfrak{G i r k f a m k e i t ~ D e r ~ n a d ) f o l g e n d e n ~} 2$ rzeneien hat fich in Derartigen Iranḱbeitsfällen ficon vielfältig be: roảhtrt:

\$chenzungenjaft, 
Majoranfaft, jebes 4 loth,

(Seftopene Meten 1 Suintlein,

Dez beften Weinz $\frac{1}{2}$ Maaß,

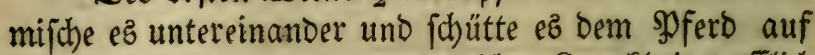
einmal ein, benn es bienet zu folcher Srankheit trefflich wohl, befonderz wenn fie auz einer Rälte berfommen.

E $\mathfrak{i} \mathfrak{n}$ a $\mathfrak{n}$ Dereb.

Spicanarbifaft 3 loth,

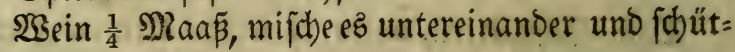
te es auf einmal ein.

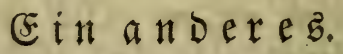

Eorallen, präparitt 1 loth,

Elfenbein, präparint 2 lotk,

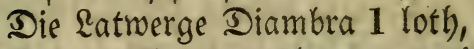

$\mathfrak{S}$ sein $\frac{1}{2} \mathfrak{M a a} \tilde{\beta}$, mifde e? untereinander uno fchüt= te ez auf einmal ein.

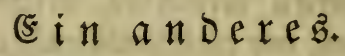

Borretidh, SDdjenzungen,

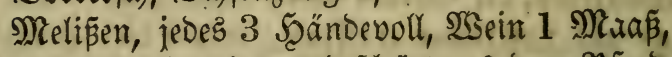

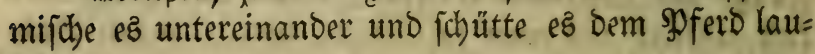
licbt ein.

\section{(E) $\mathfrak{i} \mathfrak{a} \mathfrak{n}$ Dereb.}

פूfeffer 1 Suintlein,

Wein $\frac{1}{2}$ Maá,

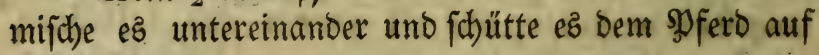
cinmal ein.

(E) in a n Derez.

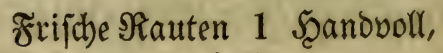

Spoponax 1 loth,

WSein $\frac{1}{2} \mathfrak{M a} a \tilde{\beta}$, 
gib ifm, bie Feudtigkeiten zu vertheilen, Syrup von Saurampfer und $\mathcal{Y}$ fopen, 5 Sage nacheinander ein, und

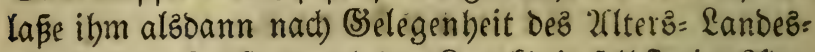

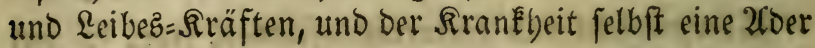
öfrnen.

2Senn aber bie Synmadht auf eine 2rbmattung ober

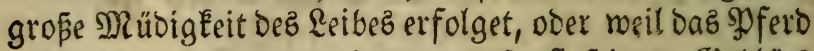
viefleicht zu beftig purgiret, ooer fonft feines (Sieblütz uno Unmas beraubt moroen, fo mus man fleiffig Sors ge tragen, wie man ihm wieber zu feinen Rräften bel= fen möge, uno ibm Margens uno 2Cbends Scübnerbrü= be mit (5ierdotter eingiesen, und bie Mixtur von $\mathfrak{W}$ ein uno Sßaffer.

Sommt ez aber von Rälte her, fo ftelle baz Spferb an einen raimen uno faubern Srt, unterbalte es $b a=$ felbft mit marmen und erwärmenden Epeifen, uno $23 e i n$ mit Spfeffer vermifht.

Sommt es von SSärmern ber, fo brauche man bie Mittel, welche im Eapitel bon Den $\mathfrak{S}$ ürmern befhries ben werben.

Sn fharfen uno beiffigen Feudbtigkeiten, fo gib ibm Brod mit (Sranatwein vermifd)t ein.

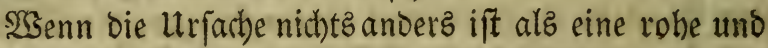
unverbaute Materie, fo gib ifm fold)e Speifen, bie bi= siger Satur fino, aud) bünn uno fubtil mad)en.

2lipo auch menn Des Pferdes Feudtigkeit falt uno bick find, fo gib ibm foldbe Speifen, melche fubtil uno Dünn madben, als rotbe Sichern ober Derfelben SBrübe mit Senf bermifht. Nochmals um bas Şerz zu ftär: fen, vermifche ifm bas Irinken mit geftoflenem spfef= fer uno ŞSein, wie auch Spifanaroi ; Denn ę ftärfet baz Scerz, (bie Materie feie gleirb bifkig ocer Ealt) mit 
feinem lieblithen (sierud) febr fein, bamit es nodymals basjenige, fo ibn zumicer und fichälid) ift, Defto beper von fid) aus und abtreiben Eönne.

\section{Daร 19te Capitel.}

\section{Bont tem Sgerzgefper.}

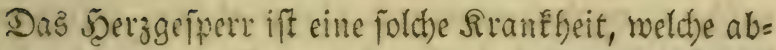
folut nid)t vom Serzen berrübrt, fondern ourth bas (5) ied, weld)es cine Shitleidenfd)aft uno Şarmonie mit bem Serzen bat, verurjadyet wird, weld)ez einig uno al= lein Der Magen iff. Nemlid) wenn bie 933 ürmer im

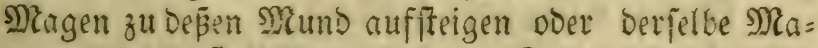
genmuno conft verlef̧t wito ober Edymerzen hat, Des megen sicht alfein baz Seerz, fondern audb die ganze

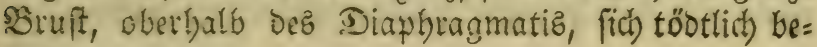
finden.

Die 3etuen bes Serzgefperts find:

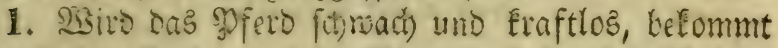
eingefallene \&enden uno die Silppen erbeben fid) fidtbar.

2. Gd)lebäutbet es beljende und beftig.

3. Edtägt es die 2ugen nieder uno ftellet fid) faft träumig mit Drenften:

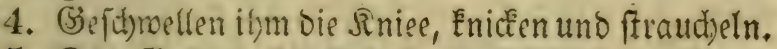

5. Das (Seid)röt läuft alif uno fängt an zu fobroi= f̧en, ob es gleidy rubet.

\section{Die cur.}

Bor allen Dingen foll man ben $\mathfrak{R} e i b$ offen balten, uno folgenden Fingü geben :

speffer, Itymian, 
Meerzmiefel, jebes 1 loth,

Rorbeer 2 lotb, Baumöl $\frac{1}{4}$ Spfund,

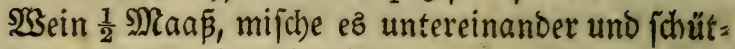
te es bem SDferd auf zweimal ein.

fi $\mathfrak{i}$ a $\mathfrak{n}$ bereb.

Ieufelsbrect 1 Suintlein,

Salpeter 1 loth, Sconig 4 loth,

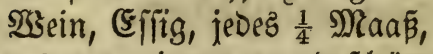

mijche es untereinander und furtte es bem \$pferd auf zroimal ein.

(E) $\mathfrak{i} \mathfrak{n} \mathfrak{a} \mathfrak{D} \in \mathfrak{r} \in \mathfrak{b}$.

Senf, Teufelsoreck, jedes 1 Suintlein, Şonig $\frac{1}{4}$ गुfuno,

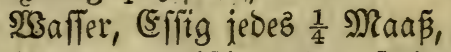

untereinander gemifht und auf einmal eingegeben.

Die SBerpflegung ift mie in Den vorbergelsenden $\mathfrak{C a}_{4}$ piteln von ben Seerzeranébeiten befdrieben morden.

\section{Daz 20fte Capitel.}

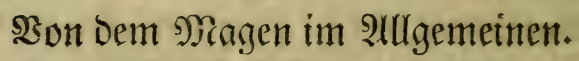

Der Magen ift nebft Dem Scerzen uno Scirn eines ber vornebmiten (S)lieder in einem jeden Shier, auch vielen Sranklyeiten unterworfen, als nemlich :

1. Sdymerzen oder Seleidigung dez s) Ragenmundes uno beflelben SBläițen.

2. Böper Serbauung.

3. Utnerjättlicbem Fraßa, fonften ber $\mathfrak{2 B o l f} z=$ ober Sundobunger genannt.

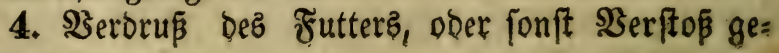
nannt. 
5. Som Futter ïberfreffen, fonft şler genannt.

6. Wुemn ein Wy ferb etwas unted)tes, pe fei maz es

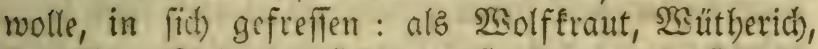
Sualfter, Epinnen, Soütnermift, Doer ba die Şülnner

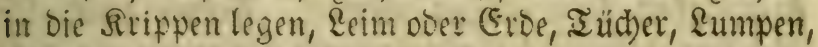
eben fo auti) fitäolid) Irinfwaffer.

7. Magenvürmer.

8. Eeibivelye.

Dies alles frno Siranfleciten, bie alle aus bem $\mathfrak{M a}=$ gen entftehen, und Depivegen hiernäd)ft in ibren (Sapi= teln im Singelnen befdrieten werden.

\section{Dab. 21 fte . Eapitet.}

Son Den @d)merzen, Denen Der Magenmumo un= terworfen iff.

Diefer Sid)merz Des Magenmundes fommt entweber aus ciner sinfad)en Unred)tmäß̈igkeit obne Materien, ober aus einer unred)tmäpigfeit mit uno neben einer Mnterie, ober auf bie Bertrenmung desjenigen, fo von Natur aneinander bängen foll, elfolget.

Die urfachen fino zmeierlei, äufferlid)e uno innerli= d)e: 2(eufferliche urfachen find, fo bie sgferbe etroa Ealtes ober (Eiswafier gefoffen, grope Sälte gelitten, ei=

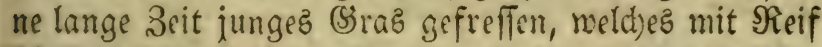
überzogen, oder oben gefroren gewefen, was gemeinig= lid) im sperbft oder Frübling zu gejcheben pfleget, ooer fonft bläftige und giftige Epeifen in fid gefreflen oder gefoffen.

Die innertidjen Urfadjen fino, forarfe uno burdyas: gende Materien, nebft den Feudbtigkeiten, fo nid)t allein 
id)arf, beipend und ourchnagend, fonbern auch einer bo:= fen 2 ret uno giftig find uno fith in Dem obern Nagen= muno verjammelt baben; wienobles aud fonft ourch andere als bie phlegmatifake, melandiolifche und Ealte Feuchtigkeit kann erreget merden. Ferner burch bie 23ürmer, befonderz die jogenannte Säfermürmer, roel= d)e in ben Magenmund hinauf fteigen, welchez ber al= lerempfindlichfite Sot ift, Denfelben benagen unb beisen,

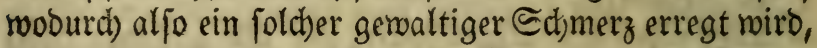
baß

uno wenn man nach bem Iobe bergleichen Sמferde öfner läß̈t, fo wirb man um ben oberften Magenmuno

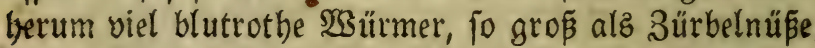
finden, weld)e Dez Magens erftes Scäutchen Durd)naget baben.

Ite Fennzeichen Diefer Franfleiten, bie von Den fuarfen Feuchtigfeiten oder SrGürmer herfommen, fino:

1. SPflegt bas SPferd traurig zu fein, bängt ben sopf uno foblägt baz (sfien ab.

2. WBirb ifm zuweilen bas Maul geiperrt, weldbes bas allergemiffefte 3eid)en iff, baß̧ oie Säfermürmer ben Nagenmund uno ben ganzen Magen Durchbiken

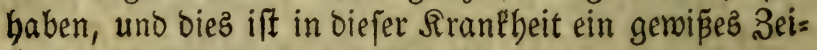
den bes bald erfolgenden Todez.

3. Serlieret eż alle feine Stärke und kann fobroes: (id) mebr geben.

4. Şit bismeilen ber Mift mit Fett vermijat, be= Eommt ein hifgigez Fieber über ben ganzen \&eib, ausge= nommen an ben Schenfeln, weldbe falt und trodén blei: ben, einen Ealten und töbtlichen Sibneí, meldber fich 


\section{Die ce tr.}

Bor allen Dingen foll man ber \&eib offen halten, mit Der Şand ben Mift heraus aus dem Maftoarm zieben, uno folgendes slyftir braudjen. IF.

Sappeln, Bingelfraut,

Blauez Seilchenf́rautt, (Eibijh, jebes 2 Scänder. fitebe alles wohl in Sdyweinebrübe, ober Scammelbrathe Nebme von diefer $\mathfrak{B}$ rübe $1 \frac{1}{2}$ Raaß̄, 2(garic $\frac{1}{2}$ loth, 5̧ierä picrä 2 loth), Eapiarinoe 1 loth, Rautenöl, Samillenöl, jebes 3 loth), Soloquintenmaré 2 Suintlein, Shonig 8 loth, 7 Eierdotter, Salz 1 ober $1 \frac{1}{2}$ Spanbooll,

mifche es untereinander uno gebrauche es roarm auf einmal, man Eann biejez Elyftir einigemal wieberholen.

(sine halbe Stunde nad) Dem (Elyffir foll man nad)= folgenoen (Eingus geben:

Die Brübe von gelben Mryrobalanen und

Iamarinoen, $\frac{1}{2}$ Maa

Extract von (Sapiarinoe 1 loth, Manna 2 loth, untereinander gemifcht und auf einmal eingegeben.

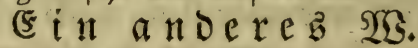
Separ 2fntimonium 3 s.uintlein, Saffran 1 Suintlein, Sorallen, Diptam, jebes $\frac{1}{2}$ loth,

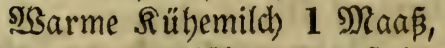
untereinander gemifcht und auf einmal eingrgeber. Ein anoeres $\mathfrak{B}$. Berglastę Spiesglas 1 Suintlein, 


\section{Pierbes?(rgenti But).}

Gaffran $\frac{1}{2}$ Suintlein, SSein $\frac{1}{2}$ Mlaaß̧, lape ç über Nad)t fteben und f(t)ütte bie SErübe bavon auf einmal ein.

\section{(F) in anderez}

SRbapontic 1 loth), Wein 1 Maã̃,

Gcammonium 1 suintlein,

untereinander gemifdt und auf eimmal eingegeben.

Ein andere b.

Sierä picrä 2 lotb), Iamarinden,

Irupherä Saracenica, jeoes 1 loth,

Wein Drei Biertel Maaß̃.

untereinander gemifit und auf eimmal eingegeben.

Ein andereb গIG.

Scammonium 1 Suintlein,

Narrben, Rorbcer, jebes 1 loth,

2Garic $\frac{1}{2}$ loth), MRitbrioat 1 suintlcin,

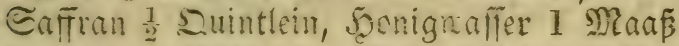
untereinmort gemijtt uno auf einmal eingegoêen.

(E) a n Dereb.

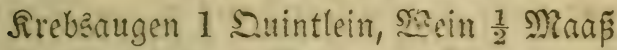

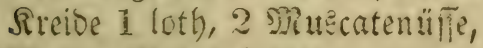

Rotben Bolus $\frac{1}{2}$ loth,

untercinanter gemifht und auf einmal eingegeben.

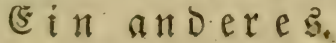

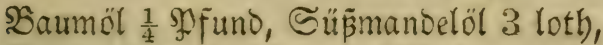

Diptam 1 loth), $\mathfrak{B e i n} \frac{1}{2}$ Maá̃

untereinander gemijht uno auf eimmal eingegeben.

(5) $\boldsymbol{i} \mathfrak{a} \mathfrak{n d e r e b . ~}$

Meergmiefelefifig 4 loth, \&orbeer 2 loth,

S3eiraud $\frac{1}{2}$ loth, Sfterlucen 2 loth, 
Mintrben $\frac{1}{2}$ loth, Sarbenfraut 1 lotb,

WSein $\frac{3}{4}$ Maaß́, mi te es alf einmal ein, Dies madt das Soferd alfobald hatnen.

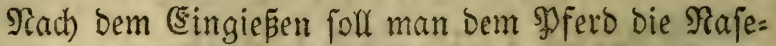

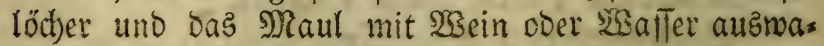
idjen, worin 2lloe oder Mleliffen gefotten worden.

\section{(E) in E r f f $\mathrm{i}$.}

Iaufendgüldbenfraut 1 5anowoll, WBitse Eucumernwurzel 1 loth, Mangolt, Mappeln, jeoes 1 Şanoboll,

fiebe ez woht in $23 a f f e r$, worin Spect oder fonft fettes Fleifh gefotten morden.

Nes,me von diefer Srühe $1 \frac{1}{2}$ Raẫ,

Saumó $\frac{1}{2}$ Sfuns, Eal 1 Scandvoll,

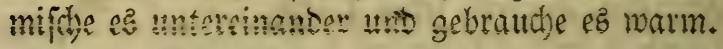

Einen Bapfen in ben Maftorm zu fohieben.

Şonig 4 loth, \$Beilchenöl 1 loth,

$\mathcal{E a l}_{3} 3$ loth, milibe es untereinander 3 u einem Bapfen uno frecte ez bem şfero tief in Den Maftoarm binein.

S2Benn aber bie Giebredten von den SBläften lyerfoms men, in getraudhe ratbfolgendes (Elyfirir, nact)oem Du

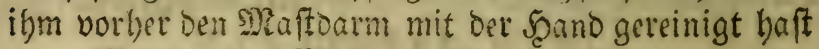
WSeinrauten, 230 blgemutb), sergmünze, Etabwurzel, jebes 1 Scanovoll, 2(nis 6 loth, fiede bies wohl in einer fetten $B$ rd: be, Gernad) nebme biejer Sarübe $1 \frac{1}{2}$ Maaß̃,

Şierä picrä 2 lotb, \&oröl 6 loth,

Salz 1 Scandoofl, mirche es untereinander uno gebraudse es laulicht. 
গูferbe=21rzenti Buth.

(sib ibm eine halbe Stumbe barauf na.hfolgenden Eingur :

STelme Sfterlucer) 3 loth,

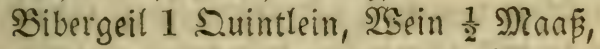
untereinanoer gemifcht und auf cinmal singegeben.

\section{Die Berpflegung.}

1. Ein mittelmäifịg narmer @tall, ber trodken uno von allen $\mathfrak{S}$ sinden befreit fei.

2. Das Futter foll fein Sleientlümpchen mit .5onig vermifdet, gebrod)ene (sierfte, worunter Sorallen, zar= teళ Sceu und Spreu mit Sconiqmaller angefeuditet.

3. Der Iranf foll laulicht Waffer fein, worin Sfter=

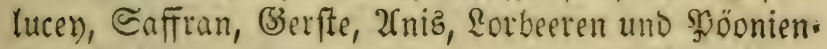
rourzel gefotten worben.

\section{Daz 22fte (Sapitel.}

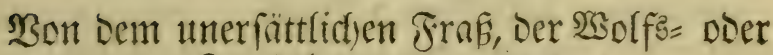 SunDblunger genatmt.}

Dieje Sranfheit quält und fămäd)t bie Pferbe ge: maltig, bringt fie audh ofters fo meit, oaj fite ganz uno gar von fith fommen und in eine Sobnmadit fallen, und menn Derfelbe lange näbret, gar um das \&eben; hat feinen Uriprung vom Reifen in groper Sälte, Da man bie spferde bernach in falte Gtälle fellit, Daneien gro= Ben Scunger leiden läßt, gar bäufig aud) zu ungebübr= licher Seit füttert, rooourd) Der N)?agenmuno mit einer gropen Unred)tmäpigfeit bebaftet wiro, inmendig leer und erfältet, ober fonft unvermöglich uno blöo ift, fommt aud) oft von einer melandbolifchen ๔äure bes 
Nagenz, Doer von ben $\mathfrak{3 s u ̈ r m e r n ~ i n ~ D e m ~ M a g e n . ~}$ Die 3eichen find biefe.

1. Biegen fich bie \$ferbe vor gropeen Scunger, mel: cher fie gleid) fam verzebrt, oft und vielmal zurücf.

2. Bittern und fobroanken, uno gehen äuperfit unfi= der.

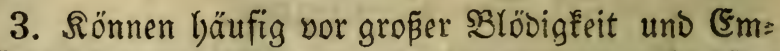
pfindlidkéeit bes Magenmunds ben Şunger nicht län= ger ausffehen, nehmen fehr ab uno fallen nieber auf Die Eroe.

4. Freffendie Streu und ben Mift unter ibnenauf. Die c) $u r$.

STor allen Dingen fino bie in bem vorigen Eapitel bef(hriebene (Styftite zu gebraud)en.

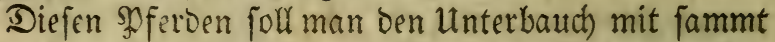

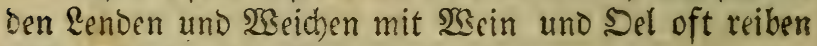

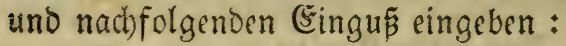

Serieben Brod.1 Mfund,

Simmet $\frac{1}{2}$ loth, $\mathfrak{B}$ Bein 1 Maa $\tilde{\beta}_{\text {, }}$ untereinanier gemifcht und auf einmal eingegebert.

\section{(E) in andereb.}

Serieben SBrod $1 \frac{1}{2}$ SPfuno,

Nelken, 3immet, jebes 1 suintlein,

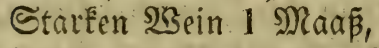

untereinander gemifcht und auf einmal eingegeben.

E in and e re .

(S)uté̃ Meh) 1 आुfund, 12 (Fierbotter,

Wein $\frac{1}{2}$ Maá, Relfen,

sofeffer, jebes 1 Suintlein,

Fleifotbrübe $1 \frac{1}{2}$ Maaß̃,

untereinanoer gemifact uno auf einmal eingegeben: 


\section{(E) in anderez.}

פুimpernüßlein 1 ⿰冫 funo,

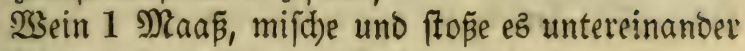
uno fochutte es bem $\mathfrak{g}$ fert auf einmal ein.

\section{E $\mathfrak{i} \mathfrak{n} \mathfrak{a} \mathfrak{D} \in \mathfrak{r} \in \mathbb{s}$.}

(Sepülverte (ङrbe $\frac{1}{2}$ Pfund, WBein $\frac{1}{2}$ Maaß̃, untereinander gemifht und auf einmal eingegeber.

(5in a n D e re .

Rebme neugebacken Brod oder Semmel, bie Brofa men bavon, tauche es in guten $\mathfrak{S}_{\mathrm{sein}}$ und ftope fie ihm in Den Şalb.

\section{(E) in a no e re .}

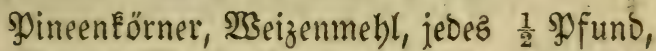

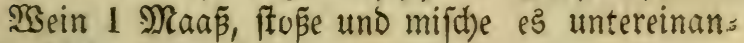
Der und johütte ez auf einmal ein.

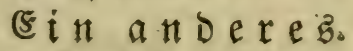

(Froe $\frac{1}{2}$ शु fund, Effig $\frac{1}{2}$ Maa untereinanber gemifd)t uno auf einmal eingegeben.

(E) $\mathfrak{i} a \mathfrak{n}$ bereb $2 \mathbb{B}$.

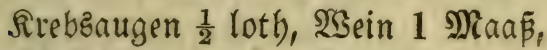

Şirłđhorn, fpag. präparirt 2 loth,

2lgtffein 1 loth, Maftix 1 Suintlein,

Rothen Bolus, Blutftein, jeocs 1 loth, untereinander gemifdot uno auf einmal eingegeben.

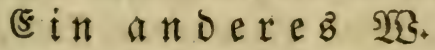

Sorallen, Sirebsaugen,

Simmet, jeoes $\frac{1}{2}$ lotb),

Ealcinirtes Spiesglaz 1 souintlein,

ख̧ein $\frac{1}{2} \mathfrak{M a} a \tilde{\beta}$,

untereinanber gemifht uno auf einmal eingegeben. 
Sommt aber ber Scunger von ben $\mathfrak{W}$ ürmer, fo febe man im Sapitel von ben $\mathfrak{2} 3$ ürmern, fo mirb man ichon Sheilmittel, finden, die gemí̄ helfen merben.

\section{Die $\Re_{\text {Serpflegung. }}$}

1. Der Stafl foll marm uno trodéen, fo wie aud mit einer guten Streu, fein.

2. Daß Futter foll gebrochen fein, morunter SBlut= ftein uno Boluts gemifht iff, uno foll ibm bes నages oft Futter geben, aber nur wenig auf einmal, bamit fie es befto bejer verdauen Eönnen und ibre Siräften nicbt etmaz überwältigt merden.

3. Der Trane laulicht, morin robes Shirfdhorn ge= fotten morden, uno foll man ziemlich niel fdoönes s્debl barunter rübren.

\section{Das 23fte Capitel.}

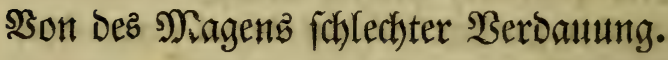

Dieje Srantheit ift nichtz anberz alz eine Sdmäd)= ung uno Scinnahme natürlicher Rräften bez Nagens wesmegen bann berjelbe bas eingenommene Futter uno

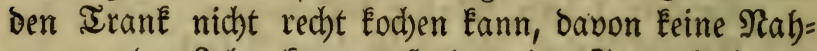
rung zu ber Leber Eommt, fondern baz Futter in lauter Mift und ber Trant in Şarn niro.

Die Utrjachen find erftlid zu viel Futter uno Irin= ken oder Uleberhanonebmen der vier Feuthtigkeiten, wo=

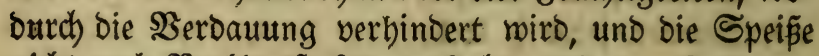
nicht nad) Nothourft fann gefocht weroen. Sum an= bern entffebet biefe Sirankfeit auch, baß bie zerftörte Scumore fich in bie Scaut bes Nagenz, welche zmiefach 


\section{Pferbe: $\{$ rgettei $\mathfrak{B u d h}$.}

ift, als in einen Sdbmamm einzieben uno feine §räf= ten fdrmächen, befonders no viel Nelancholie bazu Eommt.

Die Beichen biefer Srantheit find :

1. Freffen foldbe Spferde viel, und leiden bod babei immer Scunger.

2. Nelymen fie fehr an Dem $\mathfrak{c}$ eib ab, werben fathal und bängen ben Sopf.

3. Die Speipe in Dem Magen verEehrt fich in lau= ter S)dift, uno gebet fold)er gar hart von ibnen.

4. (S) bet bismeilen Daz Futter ganz wieder von $i$ ) $=$ nen.

5. Şollen oft und viel trinken.

\section{D) ie çur.}

S3or allen Dingen foll man ben Reib offen balten, bie in Dem 21. (Sapitel beidhriebene (5lyftir gebrauchen uno nachfolgende shulwer zu freffen geben.

$$
\text { } \mathfrak{3} \text {. }
$$

Separ 2entimonium 2 Suintlein möd)entlich orei= mal in Dem Futter zu freflen geben.

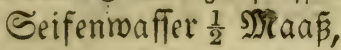

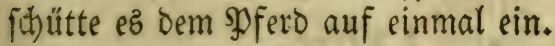

(Ein andereb.

BodfEhornjaamen $\frac{1}{2}$ Shfund,

Neiffermurzel 3 loth,

Sdymefel, Senft, jedez 4 loth,

Şanffaamen $\frac{1}{4}$ Sp fund,

ftope uno mijche alles zujammen uno gib bem झुfero täg= lich eine Şanoboll bavon zu frellen.

Ein andereb.

Shulver von Reerrettig 1 פfund, 
366 Ifferbes:2ngeviet Bud).

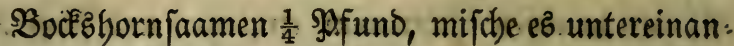
ber und gib dem SDfero täglich 3 lotb bavon zu freffen.

\section{(Ein anoeres.}

Sirnbäumenmiftel 1 pfund,

(Eid)eln, Eichenlaub, jedes 2 ⿰夕㐄fund,

Wermuth, $\frac{1}{2}$ So fund,

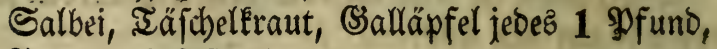

Sngmer, $\frac{1}{4}$ SP fund,

Reifterwurzel, Seiridonurzel,

Sentaurea, Enzian, jedes $\frac{1}{2}$ spfund,

Engelfü $\frac{1}{4}$ פf fund, ftope uno mifche alles zu ei=

nem \$ulver uno gib ibm täglich 3 Löffelvoll in oem Futter zu freflen.

Salbe und reibe das \$pferd mit nachfolgenoer Salbe am ganzen \&eibe, biz ę erroärme uno jhmiłze, uno Dies thue alfezeit über ben oritten Iag, becke es nach ber Salbung mobl zu uno reite ez barauf.

Waachs, Terpentin, Şarz,

Sirfhenmare, jedes 1 spfuno,

Eoról $\frac{1}{2}$ SDfuno, alte Sdymeer 2 SDfuno,

sopuleon 1 spfuno,

Slaue Slgen=spulver $\frac{1}{2}$ spfund,

Majoran 1 spfuno, mifche es untereinander auf einer gelinden (S)luth zu einer Salbe, bernach gib ibm biejen Eingü :

Stabnurzel, Se länger je lieber,

Samanderlein,

:Suturaamen, jébes 8 loth,

Enzian, Mnrrben,

Sppoponax; jebes 4 loth,

Rauten, 3ucter, jeoes. 2 loth. 
alles gepülvert uno untereinander gemijđht, und täglid) von biefem Sulver 2 \&öffelvoll in einer Maás gefotte= ner uno ausgeprefter (Setffe und $\mathscr{B}$ ictenjaft eingegopen uno etlidemal miederbolt.

\section{(E) $\mathfrak{i} \mathfrak{a} \mathfrak{n} D \in \mathfrak{e} e$ s.}

Ealcinirte Eierfchaalen 4 lotb,

SDfeffer 1 lotb), Salz 2 loth,

Effig ein balbes Maaś,

mif̧be es untereinander, lä̧e es ein wenig fieben, uno

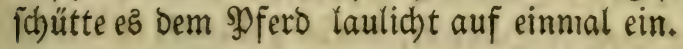

\section{(e) $\mathfrak{n}$ anderes}

Shollumbermurzel oder Rinden 2 loth,

Meiftermurzel, 5ृirfit)wurzel,

2llantwourzel, jebes 1 loth,

(Salgant ein balbes loth,

SRlapontic 1 loth, Nelken 1 suintlein,

fitede es in einer $\mathfrak{M a a \tilde { \beta }} \mathfrak{W}$ Sein und ichütte es auf einmal laulid)t ein.

Ein a no

Lorbeeten 1 loth,

Dofeffer, Ingmer, jebez 1 Suintlein,

ftope uno mipct)e es untereinander uno gebe êิ bem \$fero in einer balben Maá 2 Bein ein.

Ei n a noeres.

Enzian, Iorberr, jebes 6 loth,

Senftmebl 3 loth, Ealmus,

Senedifden $\mathfrak{B u r m f a a m e n , ~ i e b e s ~} 2$ loth,

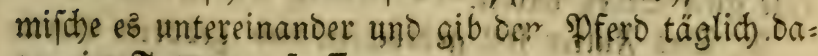
von im Futter zu frefles. 


\section{(E) $\mathfrak{i} \mathfrak{a} \mathfrak{n} \mathfrak{D} \mathfrak{e} \in \mathfrak{b}$.}

Eberwurzet 1 loth,

Senft, Ingmer, jeoes ein balbes loth,

Sুaffer, Nelken, jebes 1 Sauintlein,

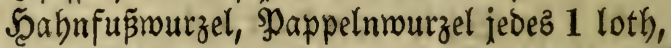

ftope und mif́che es untereinander, fiebe es in 1 Maa 2Bein und fohütte es ibm auf einmal ein.

(E) in anderes.

Nebme eine Saanowoll gepülperte (Eid)eln,

Snoblauch 3 Şäupter, Şein $\frac{1}{2}$ Maaß̄,

antereinander gemifobt und warm auf einmal eingegeben

E $\mathfrak{i} \mathfrak{n} \mathfrak{a} \mathfrak{D} \in \mathbb{R} \in \mathfrak{B}$.

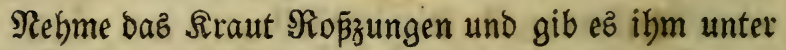
Dem ซ̌utter zu freffen.

(E) $\mathfrak{n}$ andereb.

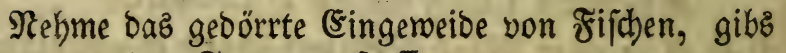
ibm unter bem ₹utter zu freffen.

\section{E $i \mathfrak{a n d e r e s .}$}

(sib ifm Lorbeeren, Enzian, Bittwar und Salz zu frefien, Daz erwärmt ihm ben Magen uno beförbert Die $\mathfrak{B e l}$ bauung.

SDer Seifenwaffer in ben Scals geichüttet, Dies Durt)fäbrt bie (Sedärme purgirt uno mad)t baz sofero mieoer gut.

\section{Die Berpflegung.}

1. Der Stall foll warm und trodén fein, wie aud eine gute Streu baben.

2. Dab Futter foll gebrodjene uno geoörtte Geerfte fein, und barunter gemifht Ingmer, Sgfeffer, Ealmue, 


\section{शferbe=:2rrenei Sudd.}

ein Einftir geben, hernad) Dem \$yfero Den Staffel fte= dhen, auch bie $B$ rand $=2$ doer auf ber 3unge offinen uno wobl bluten laffen, Darauf daz Mlaul mit Salz und 230 blgemuth mobl reiben, 2 Stunde barnach folgenden Eingū̃ geben.

Eppichjaamen 1 lotb,

Eeinfaamen 4 lotb, Fend)el 3 loth,

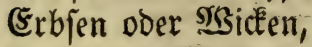

Riebftöókel, Meiftermurzel, jedez 2 loth,

Seildbenwurzel 1 loth, Sävenbaum 2 loth,

fiede bies alles in 2 Maá 2 sein ober flieffendem $23 a$ f = fer, hernach nebme von Der abgejeibten Brübe ben bal= ben $\mathfrak{T}$ heil, thue bazu

Sdbweinenfdhmalz $\frac{1}{2}$ Pfund,

Sconig $\frac{1}{4}$ Pfund,

untereinander gemifht und auf einmal eingegeben, fefere Den (Sebrauch 3 Iage fort uno gib bem soferb unter= Deffen nichts zu freffen.

Reibe ihm bie 3ähne uno 3unge mohl mit Eifeneraut wie auch) ber $\mathfrak{2 S u r z e l ~ b a v o n , ~ o b e r ~ m i t ~} 2 \mathfrak{S e i b e n b l a ̈ t t e r n . ~}$

(E) in a no e res.

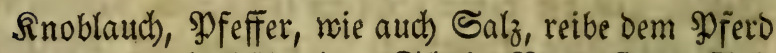
Die 3äbne Damit, bäbe einen Schnitt Brod, ftreue ভalz uno Sconig Darauf, und gibs bem \$ferd zu freffen.

\section{Ein anderes.}

- פpeffer, sngmer, jebez $\frac{1}{2}$ lotb,

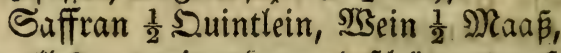

mifhe alles untereinander uno idhütte es auf einmal ein.

$$
\text { Ein anoerez. }
$$

Ingmer, Rorbeeren, jeoez 2 loth,

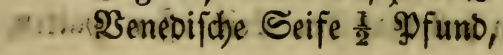




\section{ßJferbe:2(rjentei Budh.}

Gieben Eiermeiñ,

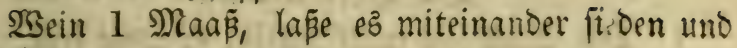
idütte es auf einmal ein.

\section{(E) a nderes.}

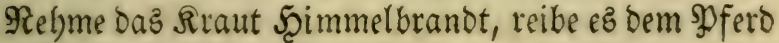
vor bie :ajelöber.

Ein a ndereb.

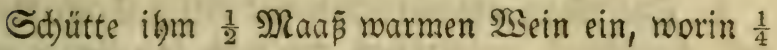
Sু)fund Seife geidabt morden.

E in andereb.

Binden Dem झुferd Farrenwurzel und Sävenbaum auf Das (Ş) bi barauf fteben.

\section{Einandereb.}

Siede Solderblätter in Wein uno fdultte bies bem Pfero auf einmal ein.

E in a $\mathfrak{n}$ Dereb.

Sprife dem Spferd dez Iages oft die Brübe bon suitten ober Bieren gefotten, oder Effig mit Sconig vermifht in bas. Maul.

E in andereb.

Inoblauch 3 Scäupter,

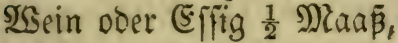

mifche bies untereinander und fchütte es bem $\$$ ferd auf einmal ein.

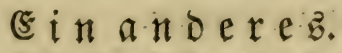

Sdyarzen Soriander 4 loth,

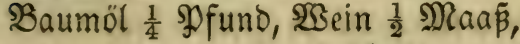
mijche es untereinander uno fdütte es Dem Spfero auf einmal ein. 


\section{Dferbe:2(rzenei Buth.}

\section{Die $\mathfrak{B e r p f l e g u n g . ~}$}

1. Der Stall foll mittelmä́fíg Märme fein.

2. Rein Futter foll man ihm geben, bod) zumeilen ein Élein wenig Sileienḱlümplein, Darunter ein menig Rerchenichwamm gemengt, mit Scanigmafier angemif fot.

3. Der Irank foll aud gar menig fein uno mit Sco: nigwaffer - vermificht.

4. Daz Maul oft mit Salz uno Effitg, İeufelsored uno Innoblaud') auswajchen, wie audb bie 3unge uno Sähne bamit gerieben werben.

\section{Das 25fte Capitel.}

WSenn fich ein Wferb am Futter überfreffen, mel= ches die \$lee genannt nirb.

Dies entftebet, menn man einem \$pferb bas in ber Scife geritten morden, bald Darauf Berfte (oürre ober

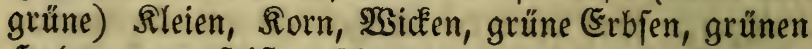
Şaber, guten faiften Rlee uno anderes gutes Setraibe zu freflen gibt, uno joldbes balo baraut trinfen läpt, woburch Der 2 fuggang bez Magenz zugefchloffen uno Der Magen aufgebläbet miro, weşbalb ber Reber Eeine Rabrung zufommen fann uno bie Nerben gefdumäd)t

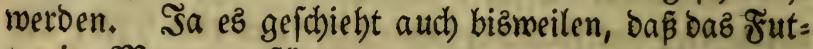
ter im Magen anfängt zu quellen, bas ber Magen ba= von zerberftet uno zeripringet.

Die 3eidyen find folgende :

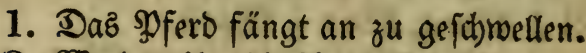

2. \$ुGerben ibm bie 2fugen Dunfer.

3. Die Senn= uno Spannabern begnen fich anz. 
4. Fallen enolid) babin, feufzen und feben immer in die Seite, mo fie bie @idmerzen empfinoen.

5. Rann bizmeilen weder geben nod) fteben, aud)

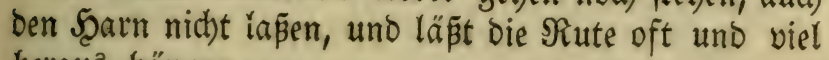
beraus bängen.

6. WBenn es niederfällt fo wirft es fich von einet Seite zu ber andern und fann fonerlid) mebr auffe= ben, befommt aud $\mathfrak{S}$ Sinde und Bläben im $\mathfrak{B a u d b}$.

\section{Die cur.}

Fürs allererfite foll man bem spferb an ben Schien = beinen zur 2loer laßjen, Den \&eib offen balten und ein SInftir geben.

Sুlappeln, (Fibifd), Bingelkraut, jedez 2 Scändev. Mauerrauten 1 Seanovolr, Serchenfobmamm 1 loth, fiede es wohl in Sirübe von 'Gdweinenfleifd.

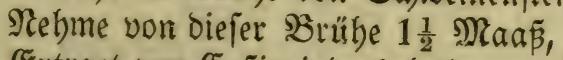

Extract von (sapiarinde 1 loth),

Şierä picrä 2 loth,

Sुulpe Colocint 2 suintlein,

Sconig 6 loth,

9 Fier, Salz eine gute Sandobll, untereinanoer gemijedt und lautid)t auf einmal gebraucht

sin anderes slyftir.

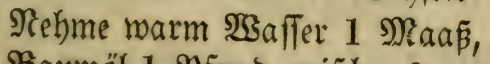
Baumöl 1 গুD funo, mifche eE untereinander.

Sin anderes Slyffir.

Rleienbrübe 1 Maá̃̈,

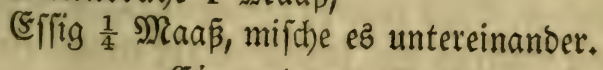

sin anderes slyfitir.

Sappeln, SingelEraut, :Beinrauten, 
Reilchenteraut, Nangolt, jebez 1 Şanovoll,

2Garic 1 loth,

Bockzhornjaamen, 6 loth,

Inis 3 loth, (s)erfte $\frac{1}{2}$ sूfund,

fiede allez in $\mathfrak{S a f f e r}$ nebme von ber abgefeibten

Rrübe $1 \frac{1}{2}$ Maaß̄, Sconig $\frac{1}{4}$ Sfund,

Rautenöl 4 loth, Baumöl $\frac{1}{4}$ Sfuno,

SBilden Sucumernjaft 2 loth,

Salz 1 Sanouoll,

mijobe es untereinander uno gebrauthe es laulicht.

Ein Einguf.

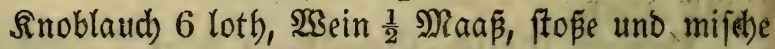
es untereinander und fohutte $\mathfrak{s}$ ferd bem es auf einmal ein.

sin anderer singus.

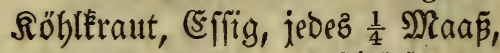

mif che ez untereinanoer uno fdu ütte es auf einmal ein.

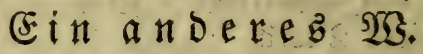

2garic 1 loth, Rhapontic 2 loth,

Eoloquint 1 Suintlein,

2lloes 2 loth,

(S)ummi guttä 1 Suintlein,

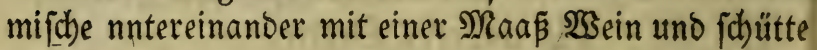
auf einmal ein.

Ei a anderes

Sitrum 2untimonium 1 Suintlein,

Şein $\frac{1}{2}$ Maaß̧, laß̧e es über Nacht fteben; ber: nach bes andern Iags thue zu biejem abgejeibten Şein 1 Suintlein Saffran und foütte es auf einmal ein.

Man muß aber, ebe man bieje \$surgation brauchet, Den \&eib mobl clyftirt haben. 


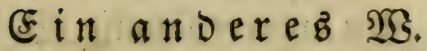

2rntimonium Diaphoret andertbalb Suintlein,

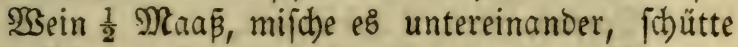
es bem SPferd auf einmal ein uno reite oder fübre es barauf, bamit es einen Sd)neis befomme, weld)en man aber fauber abreiben mus,

\section{E in anderes.}

SPFefTer, die innere Scaut von Scühreraugen, je:

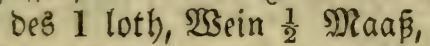

WSeirauch $\frac{1}{2}$ loth, Sconig 4 loth, mifde es untereinander uno fdütte es auf einmal ein.

E in andereb.

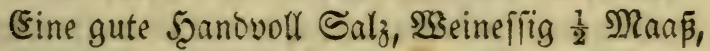
untereinander gemifht und auf einmal eingegoken.

\section{(sin Sinftit.}

Saärenflauen, \$appeln, blaues

Beildbenfraut, jesces 2 Şändevolr,

fiebe es in flieflendem $\mathfrak{B a f f e r , ~}$

sebme von ber abgefeiften SBrühe 1 Maaß̃,

Şietã pictã 1 loth),

Rotben 3utfer 3 loth,

mifjae es untereinander zu einem SInftir.

Ein (S)yftir : 25 ,

Iaubenmift 6 loti), Mangolt,

Shappeln, jedes 1 Şandooll;

fiede es in flieffendem NBaffer,

Nebme von Der $\mathfrak{B}$ rübe 1 maas,

Baumöl,

Sdbreinenfdhmaly, jeoes $\frac{1}{4}$ פfuno, mifîi) es untereinander zu einem (sinftit. 


\section{(sin anderes Sfryftir s2:}

Eamillen, Dill, St. Sobanneß̨́traut,

Beifuñ, jebez 2 Şändevoll,

Ániz, Fend)el, Bodf̧̧ornfaamen,

Siümmel, jeoes 2 loth,

Rnoblauchb:Bäben geíchält, 1 Scanowoll,

frebe es mobl in flieffendem $23 a f i e r$,

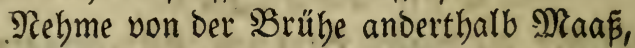

Rautenöl, Eamillenöl, jeocz 3 loth,

Qeinöl $\frac{1}{4}$ श्) fund,

Sconig 6 loth, Salz 1 Şanbwoll, mirche es ull= tereinanoer und gebrautche es laulicht,

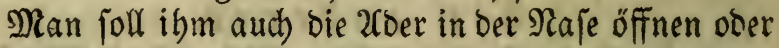
eine Bugaber fpringen laß̄en, Damit ę $2 u f t$ befomme.

\section{Ein Eingus.}

Rauteniaft 3 loth,

Wein $\frac{1}{2}$ Maá̃, Theriac 2 Suintlein,

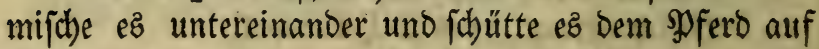
einmal ein.

Ein andereb.

2lloez Epatica, 1 lotb, ITheriac 1 Suintlein,

WSein $\frac{1}{2} \mathfrak{M a a \tilde { \beta }}$

untereinander gemifht und auf einmal eingegopen.

Ein anderes.

2lloes Epatica, 2 loth,

Eorbeeten 4 loth, (Salgant 1 loth,

ftope und milche alles untereinander uno ichütte ben

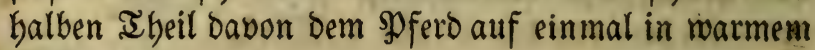
ख̃ein ein.

\section{Meifterwurzel,}

(E) $\mathfrak{n}$ a nof 
Rettig mit Dem Sraut, jebez 2 Sfund,

Spicanardi, S3algant,. Sngwer, jedes 6 loth,

2loes 8 loth, wiloen (Sucumernjaft 3 loth,

2nis 6 lotb, 1 Rindsgalle,

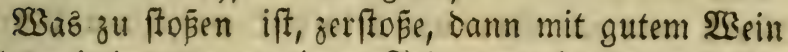
alles miteiranoer zu einem Ieig gemadbt, bernad) fol= (b)en Ieig in einem Bactofen geoört uno wieber zu Sulver geftopen, von biefem \$lulver Dem Sুofero täglid) 2 Roth in $\frac{1}{4}$ Maẩ জsein eingegeben.

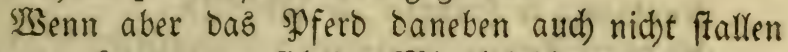
Eönnte, Eann man fich Der Mittel beoienen, reldse in den Sapiteln vom Stallen befdrieben worden.

(5in andereb.

Rorbeeren, Sümmel,

Soterfilienjaamen, פPfeffer,

Unis, Fend)el, eimes fo viel als bas andere, ftopees zu einem \$ुulver, von tiefem \$ुulver gib dem \$pferd täglict) cinen guten \&öffelooll in $\frac{1}{4}$ शaaß warmem Mein, uno 3 lotb Baumöl ein.

\section{(E) in $\mathfrak{1}$ Dereb.}

Spoponar 2 loth,

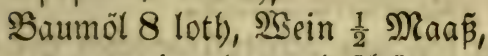

mifid)e es untereinander und fdütte eś bem şferd lau= lid)t ein.

(E) in anderez.

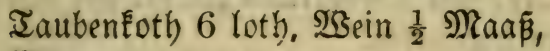

:SBermuth aft 8 loth,

Mauerrautenfaft 3 loth,

untereinander gemijht und auf einmal eingegeben.

Ei in a noeres.

Sorbeeren, (Eppichjaamen, 
Seterfilienjaamen, 2(nis, jedes 1 loth,

Iaujenogülloentraut,

Sdbaafgarbentraut, jedes 1 Scandooll,

mifche uno ftope es untereinander und fdutte es mit $\frac{3}{4}$

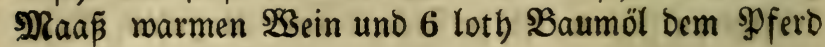
auf einmal ein.

Ein 3apfen, Den man anifatt eines હfyftirs gebrauchen fann.

Snoblauch 5 Şäupter, 5 3miefeln, 10 Dürre Feigen, Salpeter 1 Suintlein, Taubentoth $\frac{1}{2}$ lotb, Sconig $\frac{1}{4}$ Sfund, Salz 2 Scándeboll,

Euphurbium 1 Suintlein, (bies muß bran gethan werden, wenn man ben Sapfen formiren mill) lä̌e ę über einem linden Roblfeuer untereinander mi= foben, und madbe cinen Bapfen barauz.

\section{Die $\mathfrak{B e r p f l e g u n g . ~}$}

1. Der Stall foll mittelmäffig marm uno trocken fein.

2. Man foll bas spferd oft bewegen laßjen, warm zubecten uno eine gute Streu machen.

3. Das Futter foll fein Sleienflümpchen mit Şo= nig vermifht, Sceu, Epelz mit Erven vermifdt, Ep: pid), Bockabornjaamen.

4. Der Trant foll fein narmes $\mathfrak{W}$ affer mit $\mathfrak{N B e i z e n =}$ mehl uno Sconig gefotten.

5. Den Baudb mit rarmem Sel und $\mathfrak{B B}_{\text {ein }}$ oft uno lang reiben.

6. Barme Säckben bon Sleien und Şirfen auf die Seite, roo fie immer hinfehen, in bie $2 B e i d$ en, aud un: ten an ben Saudd binden, 


\section{Ein Elyftir.}

Rauertauten, Sappeln,

(Eibija), Bingelfraut, jedez 1 Scanoboli,

Eerdbenjhroamm 1 loth, fiede es robl in ciner Şammelz= oder Sduncinzbrübe ;

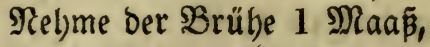

Sonig 6 loth, Roloquinten 1 Suintlein,

Şierä picrä 1 loth, ভalz 1 Şanoboll, untereinanoer gemifact uno laulicht gebraud)t.

Ein Einguf.

Eppicj)aamen 3 loth, Rauten 2 loth,

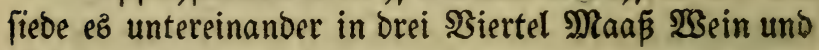
¡uutte es auf cinmal ein.

\section{Yom $\mathfrak{W u}$ üterich.}

Scat bas SPfero ben $\mathfrak{B S u t e r i c h ~ g e f i e f f e n , ~ f o ~ w i r o ~ i b m ~}$ ber Ropf farwer uno taumelt, etliche pflegen auth zu wüten, benen gib nachfolgenden Eingur :

Engian 3 loth, Effíg $\frac{1}{2}$ Maa $\tilde{\beta}_{1}$ untereinander gemijcht und auf einmal eingegeben.

Man Eann ibm auch vorber ein (Elyftir beibringen.

\section{Bon Dualffern oder $\mathfrak{P l e e n}$.}

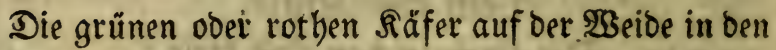
Särten ooer neuem Sçu, find ben Spferden febr fchäblich.

Die Beichen, Daß ein Pfero oergleichen §äfer in fich gefreffen, fino biefe.

1. Der Reib ift ibnen aufgelaufen.

2. Spferchen klein und oft.

3. Soblen langiam uno idrerlid) Xtbem.

4. ふ̊önne lein Futter freflen. 


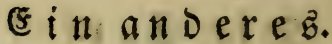

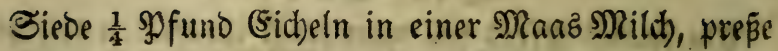
fie bernach auz uno fdütte ez bem \$pferd ein.

$$
\text { E in andereb. }
$$

2ffodilnurzel uno Saamen 2 loth,

Sarbobeneoictenfraut;

Şsermuth, rothe Bücten, jedes 1 lotb), fiede allez untereinander in Milds uno fohütte cs cin.

\section{Ein andereb.}

Siblangennurzelpulver 3 loth, Rauten 1 loth, Baumöl $\frac{1}{4}$ Pfund, Wein $\frac{1}{2}$ Maab, untereinander gemijht und eingegeben.

Man foll es robl zubeden uno reiten, oẫ es fanwizge, ben $S_{d}$ meis fauber abwifhen uno ben Rern ftedhen.

Ei $\mathfrak{n}$ anderes $\mathfrak{n}$.

Scorzoneta 2 loth, 23 ein $\frac{1}{2}$ Maá̃,

(Sitronenfd)aalen 1 loth,

Bermuth faft 8 loth,

Snoblaucbsfaft 4 loth,

Sarbobeneoictenpulver,

Ieufels 2Cbbin, jedes 1 loth,

untereinander gemifitht und eingegeben. I

\section{E $i \mathfrak{n} \mathfrak{a} \mathfrak{n} \in \mathfrak{r} \in \mathfrak{B}$ I্G.}

Salcinirtes Stordbenpulver,

(Sontrajervä, Gcorzonera, jeoes $\frac{1}{2}$ lotb).

Mitbrioat 1 Suintlein,

(5roraudbaffer $\frac{1}{2}$ Raas,

untereinander gemijuht und cingegeben, lape es roob! reiten; סaß̄ ę fabroike. 
פgferbe:2rzenci Bud).

\{̧on Dem Unflath Der şühner, wenn fie in bie Srippen legent.

Die 3 eid en fit $n$ :

1. Der $\mathfrak{e}$ eib wiro Durdfällig.

2. Sebt viel bünner fidleimigter $\mathfrak{U n f l a t h}$ mit $\delta$ em soth binweg.

\section{Di e çur.}

भ̧eiß̄en Şühnermift $\frac{1}{2}$ loth,

(Serftenmehl $\frac{1}{4}$ Maab,

Sd)weinenidhmal 3 loth,

Starfen rothen ober meisen $\mathfrak{S}_{\text {sein }} \frac{1}{4}$ Maas, untereinander gemifht und eingegeben.

Man Eann ibm aud) ein (Styftir beibringen.

Bon Dem Şühnerfoth, wie audh Federn.

Die Beidfen fino:

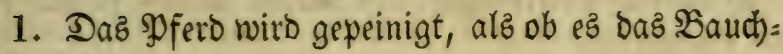
wehe bätte.

2. $\mathfrak{B a ̈ l z e t ~ f i c t ) . ~}$

Sefommt einen idharfen Scuften.

\section{Die (E)}

(Eppichjaamen 2 loth,

Sconig $\frac{1}{4}$ Maas, $\mathfrak{B s e i n} \frac{1}{2} \mathfrak{M a a}$,

mifde es untereinander und jüütte es bem $\mathfrak{3}$ fero auf einmal ein, reite es mohl barauf, báp $\mathrm{e}$ s berwegt und zum গুferd)en gebracht werbe.

Man $\mathfrak{k} a n n$ ibm auch vorber ein SIyftir beibringen.

Ein a no $\operatorname{eres.}$

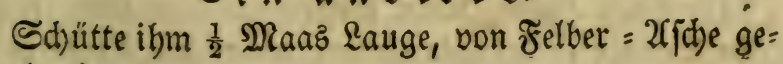
macht ein. 


\section{(5) a noereb.}

Qorbeeren 3 loth, Enzian 3 loth,

(5)fig $\frac{1}{2}$ Naaz, Baumöl 8 loth, untereinander gemifdst und eingegeben.

Bon Seim, Febern doer fonft unreine Sacthen.

Die Beichen fint :

eศึen.

1. Das Şfero wiro mager, unflätig uno will nid)t

Säbenbaum, Bsegnartenfraut,

Beifú, jedes 1 Scanovoll,

fope es untereinander, vermijche es mit piner halben

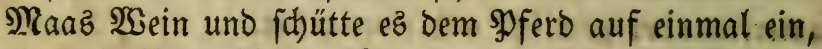
oder gib ifm foldses im Futter zu frefien uno befprenge ibm bas Seu mit Salzwafler.

(5) in anderez.

Benedifd Seifenwaffer ein balbes Maaz, fdhütte ez auf einmal ein.

\section{Ein a n D e re}

Rothe Buchen, \$impenel, jedes 1 Shanovoll, fiede es

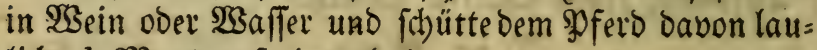
licht $\frac{1}{2}$ Maas auf einmal ein.

\section{(F) in andereb.}

Meifternurzel, Säbenbaum, jebes 1 loth,

SBegroart 2 loth,

Scafelmurzel 1 loth, fiede es in einer Maas $\mathfrak{2}$ ein uno fichüte es bem $\$$ fero auf einmal laulicht ein.

E in andereb.

Laß̧e einen Şakn Rorn freffen, alzoann über eine balbe Stunde fo töbte Denfelben, nebme ben Sropf mit Dem Sorn, bringe foldbes dem Spferb in ben Scalz, baß 
eళ denfelben verfd)linge uno fdütte ifm $\frac{1}{4} \mathfrak{M a a \tilde { \beta }}$ ख̧ein mit $\frac{1}{4}$ Sfund Saumól vermifcht barauf ein.

\section{S3on SBifdutïd)ern ober Sabern.}

Rebme 9 Eier, lege Diefelben in einen Scafen, foüt= te, fdarfen (sffig barüber uno lape es fteben bis die Sd)aalen berabfallen; bernad binde Das \$fero mit Dem Maul in bie Scöbe uno wirf ilym bie (Eier eines nac) Dem andern in Den Saals; gib ifm unter Dem Fut= ter robe (Serfte, Bohnenftrol) oder Şaber mit $\mathfrak{S}$ sein begȫen.

\section{Die ßerpflegung.}

1. Der Stafl foll fauber, rein trocken und marm fein.

2. Das Futter foll gebrodben fein, worunter Sä=

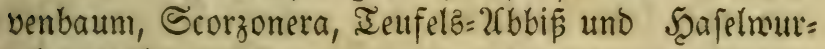
zel gemifht morden.

3. Der Irank foll fein laulicht $\mathfrak{S a} a f e r$, morin, Sca: felwurzel, Scorzonera uno Dract)entourzel, wie aud) Sollunderrinden und Rauten gefotten rorden.

\section{Das 27ffe Sapitel.}

\section{Bon vergiftetem Doer ungefunoem Srinfwaffer.}

(ङE ercignet fich gar băufig, baß fich Pferbe burd) den Senus von faulem, trübem uno anderneitig unge= fundem $\mathfrak{S a}$ afler fich mannigfache Rrantheiten zuzieben. Denn berartiges $\mathfrak{B}$ a fer ift nid)t nur für fid) felbft Der

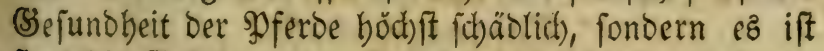
ftetz die (şefabr mit verEnupft, Das fid) Ungeziefer in bemfelben aufbalte, neld)es die (Sefundheit ber shferbe 
fither untergraben, ja bızmeilen gar einen plög̨lidjen Too berbei fülbren fönne. Uunter diefem ungeziefer fino bie SBlutigel am erften gefäbrlic); biefelben bän=

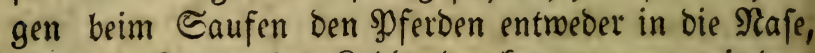
unter bie Sunge oder Reble Doer fommen gar mit bem Waffer in Den Magen.

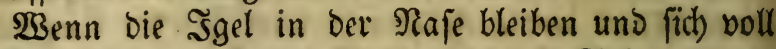
Sluts gefogen haben, fojfprif̧e Sel mit Salz vermen= get binein, fo fallen fie herab uno Eommen alfo heraub, wenn fie aber weit unten fikgen, Eann man fie mit ei= nem Snftrument berauz zieben uno abzmidéen. Sino fie aber bereits im Sd)luno, fo werben fie burd) bas

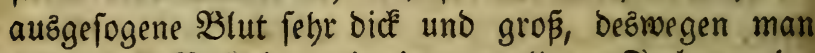

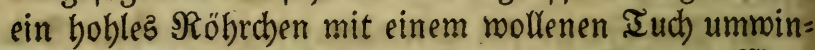
Den und foldse abftopen foll, uno eft Del und 93 sein untereinander vermifd)t eingiepen. SDoer gib ibm fol= genden Eingur :

Shoblmurzel 6 loth, Effig eine halbe Maaß̧, Baumöl $\frac{1}{4}$ शुfund,

untereinander gemifatt und eingegeben.

Sino fie aber gar in Den Magen getommen, fo Eann man fich Derjenigen Sadjen bebienen, welche in bem 28ften Sapitel von Den ßäferwürmern gemeldet wor= Den, bie bauptfächlich aber bes Spieß̄glas uno verfüstez Suecefitiber.

Das 28 ffe Capitel.

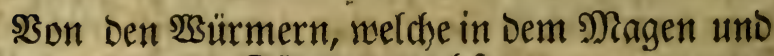
Därmen machien.

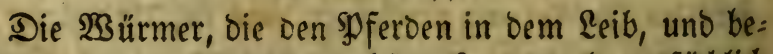
fonbers in ben Därmen wadjfen, fommen bauptfächlid) 
yon innerlichen Utrachen, alı aแ๖ Unrath, Fãule, Der unberbauten bicfen uno phlegmatifd)en Materien her uno verurjachen nicht allein, Daß ein PPferb nicht zuneb= men farn, fonbern fie töbten bas Spfero wohl gar uno braudjen nicht lange 3eit bazu. Denn wenn fie ben Magen oder (3̧edärme Durd)freffen baben, fo fällt ein spferb plöslith babin uno ftirbt.

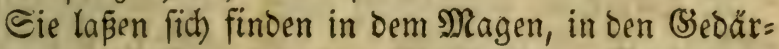
men, im Sack uno in Dem Maftoarm, entîtehen, wie gedad)t aus faulem Futter, ungejunder uno Fetter $\mathfrak{B}$ ei= be uno fonft fidleimigter fauler Materie, weldhe fith in obengefesten innerlichen (3)liedern befinden.

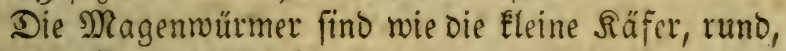
an ber Farbe rötblicht ober braum, mit fpigigen bor = nid)ten Mäulern, weld)e fid) in bie Scaut Des Magens

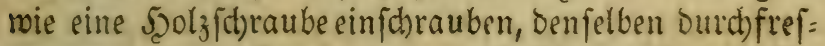
fen, wonad) Das Spferd obne alle Scülfe Des Iodes ift.

Die andere $\mathfrak{S}$ sürmer mach fen und balten fich auf im Eack, weldber auf \&ateinifd inteffinum cöcum genannt wiro, find Den Regenwürmern an Der (S)eftalt gleid, jeood) breit uno wad) fen febr gros, madhen Nefter in biefen (3edärmen, uno mit ber Seit Durdhnagen fie aud)

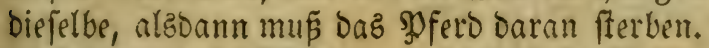

Die oritte 2at $\mathfrak{B}$ uีtmer find in Dem Nlaftoarm uno wachjen aus faulem Soth.

Die Seitben Der Säferwürmer fino:

1. S̈egen Dem Sintern zu, am 2uEgang bez Naft: barms bänget eine Freuchtigkeit gleich einer gejottenen Bobne, roldhe niditz anders ift, als ein (Eiter aus ben Biffen Der $\mathfrak{S}$ ürmer, Denn wenn Eeine Nabuung vorban= Den, fo greifen fie ben Magen und das (Seoärm an.

2. $\mathfrak{B a ̈ l z}_{\text {en }}$ fich Die SPferde und merfen fich gemeinig: 
lich auf ben $\Re$ üufgrab, weil fie bie Sdbmerzen am mei=

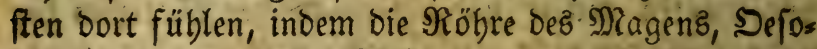

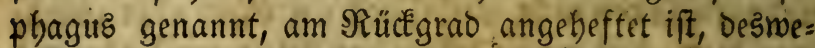

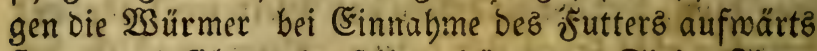
fleigen uno fid an benfelben bängen. Sielbe Figur Ro. 15.

3. Scaben fie gewöhnlich Dabei bas Maulgefperr, alsbann ift es bohe 3eit basinan helfe, fonft ift das \$oferd in 24 Stunden Dez Todes, und ift zu merken,

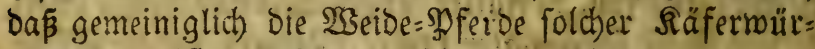
mer am meiften befommen.

Dep̧regen wulfen wir bieje Säfernủrmer vor Das erfte an bie Scano nebmen und berfelben (Sur bejobreiben

$$
\text { Di i e } \mathfrak{c} \mathrm{r} \text {. }
$$

Sor allen Dingen foll man bem \$ferd Snoblaud

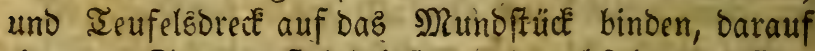
ein paar Stunden ftehen lapeen, und nadbfolgendes (ङ) ftir.

\section{Ein SIyffir 23.}

Milct) $1 \frac{1}{2}$ Maas, 11 (Eierbotter, I bomazzucter $\frac{1}{4}$ D) funo, mifche es untereinander zu einem sinffir.

$\mathfrak{U}_{\text {no }}$ gib itgm alsbald einen (singuß non verfü Quecefitter ober von gejottenem Suecéfilbermurfer ba= ranf ein.

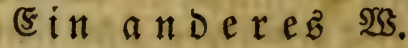

2lloes Epatic. Corallen, jeocs ein balbes \&oth, Saffran ein balbez Suintlein, Serd)enifjwamm, Iurbith, jebes ein balbez loth, 


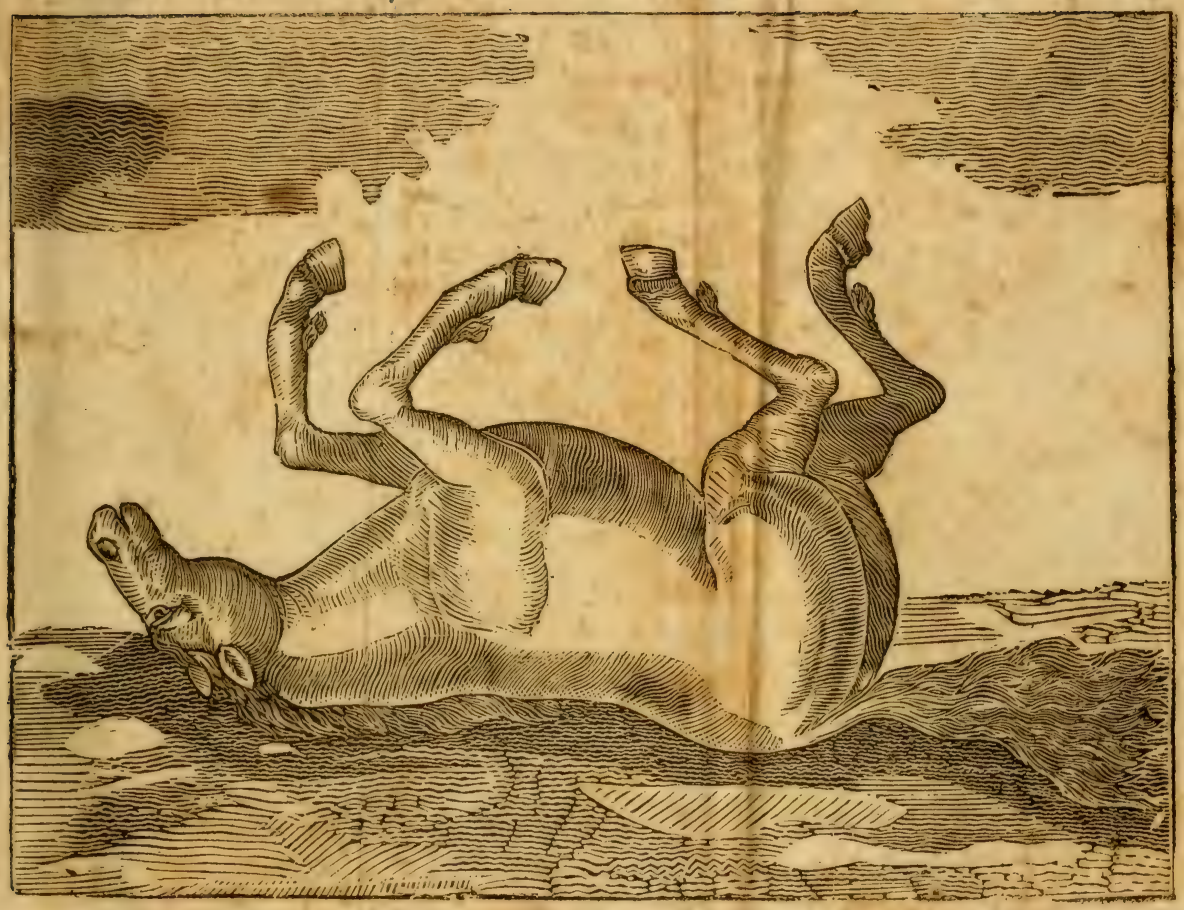




\section{PJerbe=2lrzenei Budy.}

mifdbe es untereinander und fdütte es in einer balben Maas $\mathfrak{s e i n}$ ober Mild ein.

\section{E in andere $\mathfrak{B}$.}

Rauerrauten, Bingelfraut,

(sibifch, Sמappel, jebez 1 Sandvoll,

2garic ein halbes loth, frede es wohl in Garrei= nefleijhbrühe, bernach netyme der abgefeigten

Srübe ein und ein balbes Maas,

Soloquinten ein halbes loth, Şierä picrä,

Extruct yon Sapiarinde, SRbapontic, jedes 1 loth,

Şonig 8 lot'h, Saly 1 Şanovoll,

mijhe es untereinanoer uno gebrauche ez laulid)t.

\$ुSenn Das (5luftit feine Speration verrid)tet, fo gib il)m nad)folgenden (singแผ์.

\section{গู马.}

Siede ein balbes Roth) Suedepilber in 2 Maaz Bitunnenwafler, menn es bis auf ein Maaz eingefotten

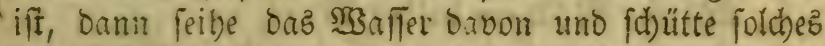
Dem Sf) fero auf einmal ein, lape ez molyl zudecten uno pine halbe Stunde barauf teiten.

Das Suectfilber fann man wieder zu fernerm $\mathbb{S S}_{e}=$ brauch aufietien, foldhen (singus foll man etliche Mor= gen nadbeinanber braudben und 2(benos ein Sluftir ge= bra udben, ift ein allgemeines (S)genmittel für alle $\mathfrak{S}$ ür= mer.

Ein a $n$ Dereb NIB.

Rothe Steinbrech,

(Sauchbeil, jedes 1 Scanovoll,

Täidhelfraut 2 Scänoevoll,

Reffelfaamen 1 loth,

श(eerrettich 2 Şänoeboll, 
Farrentwurzel 1 Şanovoll,

fiede allez in einer Maas balb $\mathfrak{S e i n}$ uno balb Effitg

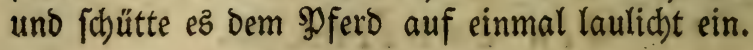

E $\mathfrak{i} \mathfrak{n} \mathfrak{a} D \in \mathfrak{r} \in \mathfrak{E}$.

Rebme warm Slut von einer (Sans, Spanjau, Sd)aaf oder $\mathfrak{L} a \mathrm{~mm}$, am allerbeften von einem \$sferb uno ichütte igm baśelbe auf einmal ein.

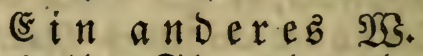

rhapontic, blaue Sdjwertelmurzel,

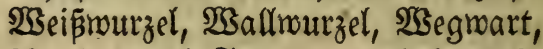

2Cttid)mourzel, Farrenmourzel, jebes 3 loth,

Rräbenäuglein, Scammoniun, jeoes 2 loth,

(S)ummi guttä 1 loth, mifche ez untereinander uno

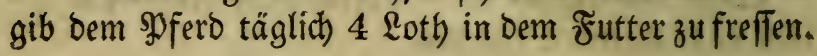

e i $\mathfrak{n}$ anderez

Berjüp̃tez Suedéfilber 1 Suintlein,

Saffran ein halbez S.uintlein,

Warme Mild ein balbes Maab,

untereinander gemifott und auf einmal eingegeben.

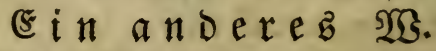

Suedeffitber 1 suintlein,

(Geftopenen 3ucfer 6 loth,

Reibe ben Bucker mit etlichen Iropfen $\mathfrak{B} a$ affer auf

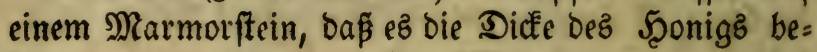
Eommt, bann reibe bas suedffilber barunter mit $\mathrm{Su}=$ idhüttung etlidjer Iropfen Mandelöl, weldbez bas Sueckfilber zertbeilen bilft, daßs ez nicht zujammen

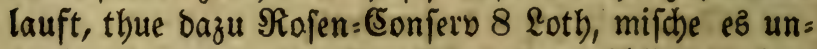
tereinander und gibz bem sofero zu verifblingen, her:

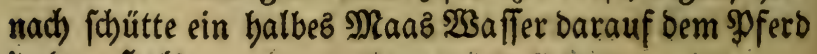
in ben Şalb. 
gुFerbe:2tranei Bud.

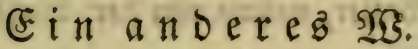

Eictientyolzöl 1 Suintlein, Shajelbolzot ein balbez loth,

Teufelsbred 1 Suintlkin,

Efilig ein balbes Maaz,

untereinanoer gemifdt und auf einmal eingegeben.

$$
\text { (E) i a noereb }
$$

Nebme bas \$nilluer von geid)melztem ভtahl, syfeffer, jeoes ein balbes loth,

Menid)entyarn ein balbe's Maas, untersinander gemifd)t und auf einmal eingegeber.

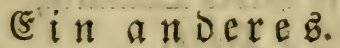

Xttid, Natterfraut, $\Re$ Reinfarren,

Steimpfeffer, Shafellaub, oder bie Sipfel von dek Scapelftanden,

Stabrourzel, Rauten, jedes 1 Scandoofl, miiche und pülvere es untereinander, gebe bem $\mathfrak{N e r o} 3$ Loth dabon auf einmal in einer balben Maá gefotte= ner 2(ttid)brübe.

(F) in anoferez.

Nad)t (j)attenwurzet 1 Scandooll,

Das Rraut bon bem Şanfítengel 3 Scanovoll,

Reinfarren 1 Scanoboll, kodbe ez in einer Maa

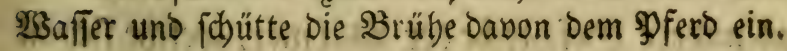

\section{E) $\mathfrak{n} \mathfrak{a}$ nderez.}

Sefỏalten Sinoblauch 3 Şäupter,

פfirfifjiaub oder 23 urzel 3 loth,

Rauten I Scanoboll,

Soloquinten 2 lotb, 
fiebe eళ in $\mathfrak{S a f f e r , ~ n e h m e ~ v o n ~ b e r ~ S B r u ̈ b e ~ e i n ~ b a l b e s ~}$ Maāi,

Baumöl $\frac{1}{4}$ Pfund,

untereinander gemifdt und auf einmal eingegeben.

Ein anderes $\mathfrak{Z}$.

Saffran 1 Suintlein,

Sitrum 2Sntimonium ein halbes Suintleik,

Warme Rübemild 1 Maaß̄,

untereinander gemifat und auf einmal eingegeben.

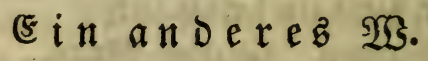

Scepar Untimonium 1 Suintlein,

ङaffran ein balbez suintlein,

Süpe Milch 1 Maấ,

untereinander gemijht uno auf einmal eingegeben.

Ein andereb.

Wermuth 2 Şändevoll,

Sartenf́refienjaamen, $\mathfrak{B}$ urm jaamen,

Corianderfaamen, Rettichfaamen,

Senffiaamen,

Nyrrben, jebes ein halbes luth,

Rod'zhornfaamen 3 lotb,

Baumöl ein balbes Spfuno,

Sü̈en $\mathfrak{B s e i n}$ ein halbez Maaß̧,

untereinander gemijcht und auf einmal eingegeben.

Das anbere (Gefd)lecht ber Whïmer, meldbe fid in

Dem Darm, Der Sał genannt, aufhalten, wirb aus folgenden 3eichen erfannt:

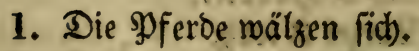

2. Beifen fich in bie Seiten und Rippen.

3. Spctren dab Maul auf uno gäbnen. 
4. baben Sdaum auf ber 3unge.

5. Sidlagen fith mit Den bintern Früßen an ben Baudd.

3ur Bertreibung biejer SMGürmern Eann man fid) al= ler Mittel, welite in Dem borigen I beil bejd)rieben wor: Den, bebienen, abjonderlich dez Suectiflbers und des

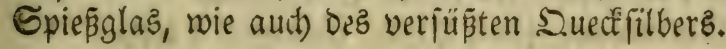

\section{(F) in andereb.}

Stabiwutzel 8 loth,

W3arme Rübemild) ein hal'bes Maaß, untereinander gemifdt uno auf einmal eingegeben.

Ein andereb

Braumwurzel, WSegmart,

Rauten, jebes 1 Scandvoll,

Meerrettid) 2 SSändevoll, Fartenmurzel 1 loth,

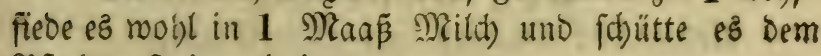
פूfero auf cinmal ein.

\section{(5) in a Meres.}

(Seichabtes Scirich horn 2 loth,

Ŝrebaaugen ein baibes (otb),

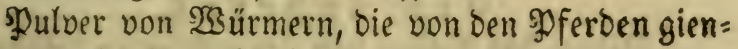
gen 1 Suintlein,

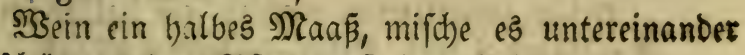
uno fibuttte es bem গু) fero auf einmal ein.

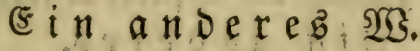

Nebme \$firiüdlaub 3 Şändeboll, fiebe es in einer Muáp Mildh, thue bazu Ieuf ţoref ein balbez loth, ithütte es dem waro auf einmal ein. 


\section{Ein andereb.}

Rebme Menfchentotb, fo viel ou willft,

Effitg ein baloes Raaß̃,

untereinander gemijht und auf einmal eingegeben.

\section{Ein anoereb.}

Nebme geidabtes robes Şirfhborn, SSurmEraut, jedes 2 loth, Sorallen 1 lotb,

Wermuth), robe Feigbohnen, jebes 2 loth,

(3artenfreflenfaamen 1 loth,

Farrennurgel, Sauerrampfer, jedes 2 lotb,

Rettichjaamen, 1 loth,

Sorianderfanmen 2 loth,

Spoponax 1 lotb, ftope allez zufammenuno gib bem \$f fero täglich 3 loth in $\frac{1}{4}$ \$fund $\mathfrak{B a u m o ̈ l}$ mit ei= nem renig füpen $: W_{B}$ ein ein.

(5) $i$ andereb.

=.. Nefme ben Saamen von SBorzeleraut,

SBumfaamen, jeoes 1 loth,

(Seid)abtes robes Seirichborn 2 loth

1 Maaß̃ narme నübemild), untereinander gemifd)t uno auf einmal eingegeben.

(5in andereb.

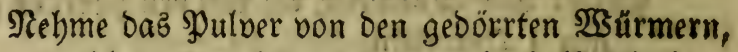
meldhe auzgetrieben worben, ein halbez lotb, Snoblauch 3 loth, (sifig ein balbes Maas, untereinander gemifitt und auf einmal eingegeben.

E in an bereb.

Rebme gefchälten Rnoblauch, 3 Scăupter,

sूfeffer sin balbes lotb,

Biannteroein, Efirg, jeope $\frac{1}{4}$ Maaß, untereinander gemifht und auf einmal eingegeben. 


\section{פferbe:Irgenei Bud).}

\section{Ein andereb.}

Nehme weipen Scundzored 2 loth,

İufeledreck, Soloquinten, jebez 1 suintlein,

शachtid)attennurzel ein balbes loth,

Menichenbarn ein balbes Maaß̃,

untereinander gemifht und auf eimmal eingegeben.

E in a n Dereb.

Rehme Rreide, Nenichentoth, jedes 2 loth,

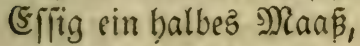

untereinander gemifdt uno auf einmal eingegeben.

Ein andereb.

Nefme Säbenbaum, Sfterlucer),

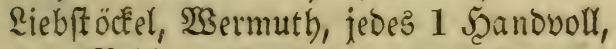
fiebe es in Mrild, wreß̧e es aus uno fit)ütte es ein.

Ei $\mathfrak{n} \mathfrak{a} \mathfrak{D} \in \mathfrak{r} e \mathfrak{B}$.

Rebme 2 ¿urmjaamen 1 loth,

Sorallenmos ein balbez loth,

(Sejuabtes robes Şiridt)born 2 loth,

Wsilden Saffran 1 suintlein,

Senezblätter 2 loth,

\&erchenidrmamm 1 loth,

Diptam ein balbes loth, mirche es untereinander uno ichütte Dem Sfero täglid) Daven 2 loth in einer bal=

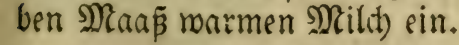

\section{Ein anderes SIG.}

Nebme das \$ulver von geoörten Regenwürmern, Sauerrampfer, Sorallen, jedes 1 loth, untereinander gemifht und in einer balben Maaß Mild) singegeben. 


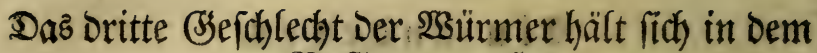
Maftoarm auf.

Die Beichen fino folgende:

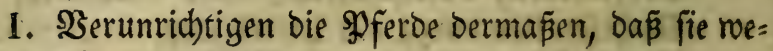
ber das Futter annehmen noch verbauen können.

2. $\mathfrak{B}$ erfen ben Sdjwanz obne 2 uffbören bin und lyer und reiben ben Sintern an ber $2 S_{3}$ and.

Man Eann alle Mittel, meldese in bem erften und an-

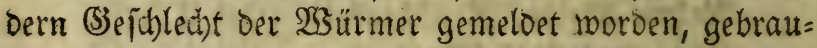
d)en, abjonderlitb das Suecfitlber, Spieşglaz uno daz (Ely)fiti.

Ein andereb.

Nebme Gundelreben 2 loth,

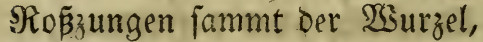

Riebftöctel, Ireide, jedes 1 loth,

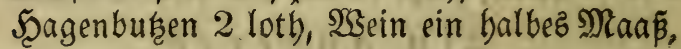
untereinander gemifcht und auf einmal eingegeben.

Ein anoeres.

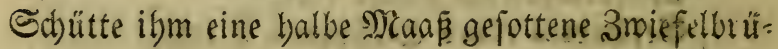
he ein.

\section{Ein a n Dereb.}

Siede Şanfiaamen in Mitch, prep̧e ihn aus und

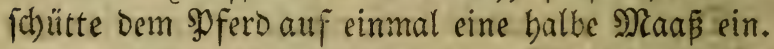

(5) $\mathfrak{n}$ a

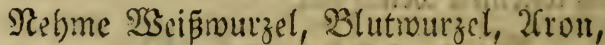

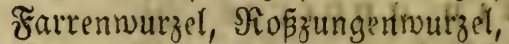

Deterbmurzel, Braumnurzel, jeope 3 loth,

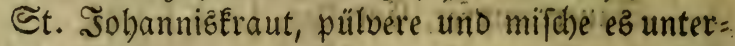
einander uno foütte bem \$fFiro bavon auf einmal 3 Loth in $2 \mathfrak{S e i n}$ ein. 


\section{Ein anoerez.}

Nebme SSoblgemuth 2 Şändeboll,

Flöbejaamen 1 Şanovoll,

Salz 1 Şandoull,

Wein ein balbez Maaßa,

untereinander gemifdst uno auf einmal eingegeber.

(E) in a $\mathfrak{n}$ Dere .

Rothe Rofen 1 J̧anovoll,

Sorianderfáamen 2 loth,

(3)artenEreffenfaamen 1 loth,

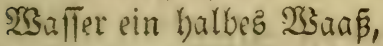

untereinander gemijht uno auf einmal eingegeben.

(s) in and $\mathfrak{e} \mathfrak{e} \mathfrak{E}$.

Sd)ufteridowarze 10 lotb,

WSermuth geftopen uno gepülvert 2 ioth,

Ieufelabrect 1 S.uintlein,

(Sefeiltes Sairid) yom, ein balbes loth,

- Snoblauch 3 Şäupter,

(Effig ein balbes @iaán,

ftope uno mifche alles untereinander und fouttte ez Dem Dferb auf einmal ein, es ift gut zu allerlei W3ürmern.

(5) $\mathrm{t}$ tl andere .

(Seoörte rothe 2(meifen 1 loth,

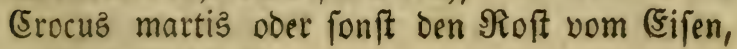
ein halues loth,

(S)epülverte (Eierichalen,

(3audb) beil, jebes I loth,

mijche es untereinander uno id)ütte $e \xi$ in einer balben Maaß Eifig ein, bies ift auch zu allen $2 s u ̈ r m e r n g$ gut.

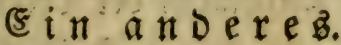

2locs (Epatic 1 loth, 


\section{8}

\section{f פferbe:22rzenei Budd).}

Mtaftix, Biebergeil, jebes 1 suintlein, Rorbeeten 1 lotb, SBein $\frac{1}{2}$ Maaß̃,

(5) ummi 2Immoniac 2 Suintlein, untereinander gemifott und auf einmal eingegeben.

\section{E i n a n D e reb.}

Bittwenfaamen geftopen und in warmem $\mathfrak{B}$ ein eingeichüttet; biejes MRittel, fo einfach ez auch ift, hat (iid) jeoerzeit benäbrt, oas ez im Etande ift alle 293 ür = mer, von welcher (S)attung fie auth) fein mögen, zu töo = ten. E5z verdient baber bejonderz anempfoblen zu meroen.

Die Berpflegung.

1. Der Stafl foll mittelmápig warm uno trodfen uno mit einer guten Streue verfeben fein.

2. Daz Futter foll rein und entweder Dinfel ober Spely fein.

3. Das Irinfen laulid)t motin Dinfel, suect filber ober Nadbtfdattenmurzel, Tormentillwurze uno Sdd)= fenzungenfraut gefotten woroen.

4. BBei allem (3ephlect)t der $\mathfrak{B}$ ürmer foll man bie Elyftir oft gebraudien.

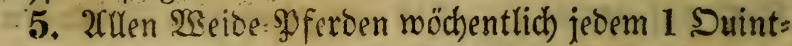

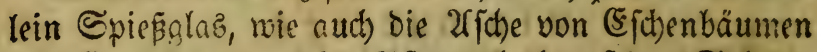
uno Scafelftanden auf 1 ⿰ুل) fero 1 loth auf bem Salz zu lecten geben, Den andern bez Monatz cinmal.

Das 29fte Eapitel.

Bon Den Grimmen im seib uno befonders yon Der Darmgicht Der Pferde.

Das (Srimmen ber spferbe ift eine fdomere, beftige und töotliche Srankbeit, weldhes ein \$ofero, wofern nid)t 
geitlid Ratl) geidafft wird, leid)tlich und gefdwind zu (Sirunbe ridstet, und wiro in jweierlei 2 rten unter: fohieden, nemlid) in bie Darmgid)t uno bie Solif.Der Inbalt Dez folgenden (5apitels miro fid) auf Die abbandlung Der erften (Sattung, Der Darmgicht, be= (d)ränten.

Die Darmgiht entifebet von Den Schmerzen Des Eingemeioes, Sleon genannt, fommt von fiblechter $\mathfrak{S E l}_{\mathrm{el}}=$ Dautng bes Futterz, von vielen Eingüßen, wenn die= felbe ibre Speration nidbt haben können, ferner roenn sin Syfero ben Unflath, Den bie Scübner in bie Sirippe gelegt in ben \&eib befommt, uno aljo oer Darm Sleon von verbärtetem Mift verftopft ift und entzünoet wiro,

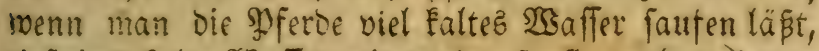
tief ins falte $\mathfrak{S}$ affer reitet, oder fonft nach getbaner

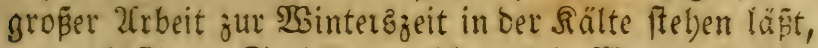
bon bläftigen Gpeifen, meld)e viel $23 i n d$ madjen, bon (Sefchmülften des Rröfes uno (Singemeides, Durd) welde daz (Sebärm zufammen georüdt wirb uno ter Mift in Demielben verbärtet ; von $\mathfrak{S}$ ürmern, welthe iii) in Dem (Sedärm berwickeln, oder fonft etwas bel= gleidjen, moourd) Daz (Sedärme beftig ein uno zujammen gezogen, verfenft und verichloken merden Eann; (sken= fo bun bicken zähen Feuchtigkeiten, Entzünoung uno Xpolfemen Der Därme, oder menn bie Gallrinne ver: ftopft ift, Daß̧ fie zu Den Därmen nitat gelangen Eann, nod) Diefelbe zu 2(ustreibung Dez Mifts reizen; oder wenn ein snferd im beftigen Iravalliren oen Stall uno DFferd) übergangen bat.

Die Seidjen find biefe :

1. Rann das̉ \$pfero ben Mift nid)t von fid geben, fontrin ftoft ifn auz gropem Schmerzen ourd) ben $\Re a=$ 
d)en uno Naje beraub, rooburch es auch meder raften nocb ruben fann.

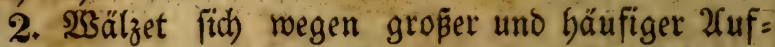
blähung, fo ez in bem \&eib und um ben Nabel berum empfindet, mit folchem Ungeftümm herum, Dá̧ ez aud) bismeilen bavon zeripringt uno ftirbt. Siabe Figut श्. 15.

3. Sdhnaufet uno äd)zet mit groper Mühe.

4. Wirft fith nieder auf bie Erde und ftebet rieder auf.

5. F̌ängt bismbeilen an zu zittern und wiro über ben ganzen Leib Ealt.

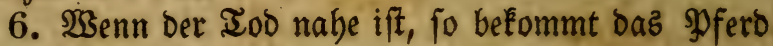
einen Ealten Sthweip.

7. Sann nidht ftallen.

8. Befommt einen Eurzen 2 them, uno miro faft kei= cheno.

9. Raufen bie Singemeide in einander mit Seulen uno Antren, Daß̃ fie fichtbare Seulen uno Sinollen in Der Seite erbeben, nno oer Sauch lauft auf mie eine

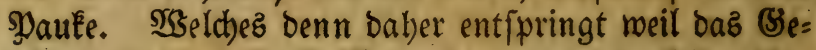
Därme unten verftopft ift uno derowegen benfelben Un= rath Durch ben 2ffter nicht läen Eann, baber bann bie Natur einen anbern $\mathfrak{B}$ eg zu fuchen, Den Soth überfich, und burch den Mund und Naje auछzuftopen genöthigt miro.

(Sur Der Darmgid)t von verhaltenem Soth.

SBor allen Dingen foll man es mit einer Rokenen warm zubed'en und zu ifm greifen, mit Baumöl ober Sdynei= nenichmalz gefdumierten Şänoen, uno no eฮి möglid, etwas ven bem barten Mift heraus nebmen, bernach folgendes (sinftir gebrauchen. 


\section{Ein andereb গIG.}

Eibijch, Spappeln, Bingeleraut,

Eamillen, jebez 2 Scändevoll,

BockEhornjaamen,

Reinfaamen, jeoes 6 loth,

Sorbeeren, ふäumel, jedes 2 loth,

fiede es alles mit einander in $25 a f f e r$,

Rehme von Der Brühe $1 \frac{1}{2}$ Maá̃,

Soloquinten 1 suintlein,

Der Ratwerge SBenedictä laxativä,

Samillenöl, Diflöl, jeoes 6 loth,

Sdyeinenidhmalz 1 Sf fund,

Salz eine gute Scanoboll,

mijche alles untereinander und gebrauche es laulicht.

(3ib iflm nadsfolgenden Trant.

Rebme Eibifdhnurzel,

Bingelfraut, Sappeln, jebez 2 Scändevoll,

Senesblätter 3 loth,

agaric, Rhapontic, jedes 2 loth,

Iamarinden, SEeinftein, jedes 3 loth,

\&einfaamen, $\mathfrak{B b e i n f t e i n , ~}$

Sümmel, jedes 2 loth,

(S)efchälte (Sserfiten 12 loth,

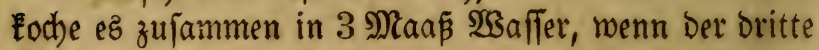
Iheil ausgefotten ift, bann prepe es aus und thue zu ber abgejeiften Brübe :

Snrups von wildem Saffranjaamer 6 loth, mifdue es untereinander zu einem Iranf, bavon alle 2

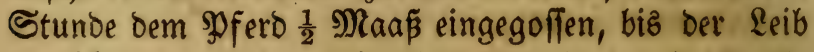
erweicht mirb.

Man Eann ibm aud eine 2(Der in ber 2 Beidbe off nen im Fall ein roftemen vorhanden pein mödte. 


\section{Pferbe=2(rgenei şud\%}

\section{'Sin Elyftir.}

B3eintanten, Bingelfraut,

פaueitauten, Mangold,

șappeln, IaujenogülloenEraut,

(sibijd), jedes 1 Şanovoll,

fiede es wobl in einer fetten SBrübe,

Rebme von Der Brübe $1 \frac{1}{2}$ Maa $\tilde{\beta}$,

Eoloquinten, SBibergeil,

Spoponax ミcammonium, jedes 1 suitleim,

Sierä picrä $\frac{1}{2}$ lotb), Sconig 12 loth,

Salz 1 Scanowoll,

untereinander gemifdst und auf einmal getraud.

Ein anderes Elnfitir.

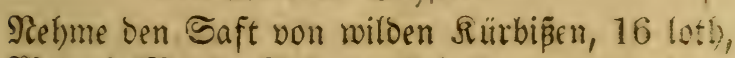

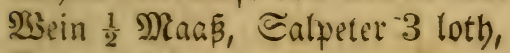

Saumöl 16 lotb,

untereinander gemijht und laulidat gebraudit.

sin anderes Styftir.

Iaben = oder Scühnermift, 8 loth,

Salpeter 1 loth,

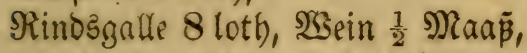

unteleinanoer gemifact uud laulidist gebraucht.

So bald ber \&eib́ geoffnet ift, foll man bem Syjets Die 2roer an Dem Sitwanz eine 3merd)bant von Dem: Raftoarm öffnen.

\section{(Ein Eingus.}

Bodf3bornjaamen 3 lotb,

Rorbeeren 2 loth, Saumöl 8 (cth),

Soundsichmalz 3 lrth,

sofeffer 1 loth, 


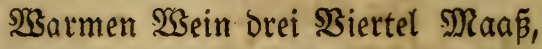
untereinander gemifat und auf einmal eingegeben.

\section{Ein Eingup.}

Beilchentraut, Sappeln,

Bingelfraut, Éndivien, jedes 1 Şandondr,

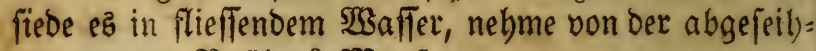
ten $\mathfrak{B r}$ ühe $\frac{3}{4}$ Maáp,

Soloquinten 1 Suintlein,

Extract von Eapiarinde,

Silipes s) Mandelöl, jeder 2 loth,

untereinanber gemifht uno auf einmal eingegeben.

\section{Ein Elyftir.}

2) Kangold, IaujenogülbenÉraut,

(S)nttentrepen, $\mathfrak{B e i n t a u t e n , ~ B i n g e l f r a u t , ~}$

Blaute Şeilktaut, (sibijch,

Sुappeln, jedes 1 Scandoolu,

fiede eร̃ in einer Sdyreinebrübe,

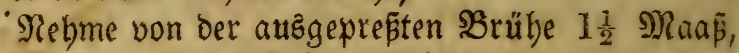

Camillenöl, Roröl, jedes 3 loth,

B̉aumól $\frac{1}{4}$ Şfuno, Sconig 10 loth,

Soloquinten 2 loth,

5 Sierbotter, Salz 1 Scanoboll,

unterimander gemifdt und warm gebraucht.

\section{Ein andereB $\mathfrak{B B}$.}

Saffran $\frac{1}{2}$ Suintlein, Mitbrioat 1 lotb,

Iberiac 3 suintlein,

Siblangenpulver 1 suintlein,

SSrauntemein 10 lotb,

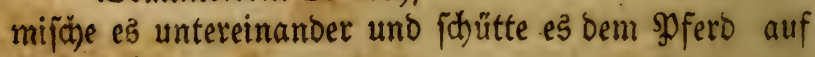
einmal ein. 


\section{Pferbes?rzenei $\mathfrak{B u d})$.}

\section{Der Singus.}

Wach) bolderöl $\frac{1}{2}$ loth,

Die Brühe von Mäusöbrlein und 2lngelica, ein balbes Maá̃,

interpinander gemifht und auf einmal eingegeben.

Ein a n Dereb.

SBeinrautenjaamen,

Siefentümimel, jeoes $1 \frac{1}{4}$ loth,

Rorbeeren 2 lotb̆, SBein $\frac{1}{2}$ Miaá,

mitite 2 untereinancer und foblitte es bem Spferd auf titmal laulid, ein.

Ein anderes.

Iniz, §ümmel, SBeinrauten, jedez 1 loth,

Mangolofaft $\frac{1}{4}$ Maá, Salz, Rautenöl,

Şierä picrä, jeoes 2 loth, $\mathfrak{B e i n} \frac{1}{2}$ Maa

matreinanier gemifht und auf einmal eingegeten.

(5 in andere.

Nehme reipen Spfeffer,

Billenjaamen, jebez $\frac{1}{2}$ lotb,

Bertran, Spicanardi, jedés I Suintlein,

Soblmurzel 1 loth,

Saftran 1 suintlein,

Sonig 2 loth, $\mathfrak{W}$ sin $\frac{1}{2}$ Maá,

atreinanber gemifht uno auf einmal eingegeben.

Eine. Salbe.

Dialtbeä 1 şfuno, Roröl 4 loth,

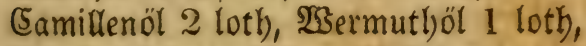

Reinöl 12 loth, Rautenöl 2 loth,

Bocţ̧yornfaamenöl 8 loth,

sitithe es untereinander zu einer Salbe und reibe bem Dferd ben Bauth roobl bamit. 


\section{sin singup.}

Baumöl $\frac{1}{2}$ Sf funo, Sconig 8 loch,

sूfeffer, \$peterfitienjaamen, jedes 1 loth,

Brübé von gejottenem Enzian uno Seufendel= nurzel $\frac{1}{2}$ Maā̄,

untereinander gemijht und auf einmal eingegeben.

E in a ñ e $\mathfrak{e}$.

Mangolosbrübe $\frac{1}{2}$ Maaß̃,

Baumöl 6 loth, Salpeter 1 loth,

untereinander gemifdt uno auf einmal eingegeben.

(E) in and ex e .

Weidenlaub und Rinden 2 Şändevoll,

Dill, Camillen,

Bingelfraut, Mangolo, jebes 1 Scandboll,

fiede e? in Scammelsbrübe,

Nebme der Brübe 1 Maaß̃.

Baumöl $\frac{1}{4}$ Pfuno, Salz 1 Scanovoll,

untereinander gemijat und auf einmal eingegeber.

Ein andereb.

Sdbweinefleijdbrübe $\frac{1}{4}$ PPfund,

Baum ö 8 loth, SPfeffer 1 loth,

Sngmer ein balbes loth,

Muscatenblüthe 1 sutntlein,

untereinanoer gemijat uno auf einmal eingegeben.

sin anderes für die Darmgidht $\mathfrak{S}$.

Rebme lebendig suedfitlber 3,4 bis 5 ⿰מ funo, ma=

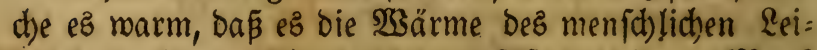
bes bat, alzbann ichütte rs Dem SPferd mit $\frac{1}{2}$ Rauß twarmem $\mathfrak{B a f f e r}$ auf cinmal ein, lape baz $P$ fero wot)! barauf berumfübren. 


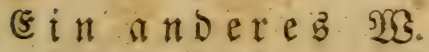

allantwurzel, Meifferwurzel,

Ungeliea, Nettid), Matterḱraut,

Iaufengüldoenf́raut,

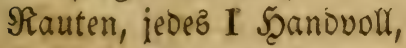

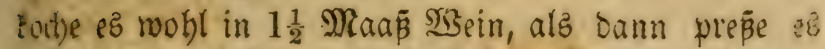

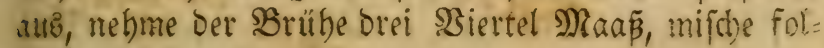
gendez Shulver barunter :

2lloes 1 Suintlein, Eeberfraut $\frac{1}{2}$ loth,

Sorallen 1 Suintlein,

(Salgaut $\frac{1}{2}$ Suintlein, 3 Mubcatenüpe,

Saffram $\frac{1}{2}$ Suintlein, Salpeter 1 lotb, untereinander gemifdt und auf einmal eingegeben.

E $i \mathfrak{n}$ a noereb.

Röhlfraut 6 Şändevoll, $\mathfrak{R} a$ aud 1 Şandooll, Innoblauch 3 Şäupter,

Brübe von einem Scammetsfópf ober Şammets. Tieifch 2 Maás, fiebe es wohl mit einander, bernact)

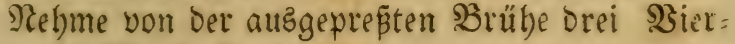
tel Maá, Iurbith,

Scammonium, jedes 1 Suintlein, whtereinander gemifht und auf eirmal eingegeben.

(E) in a no eres.

Sd)warzen \$feffer,

Deterfitlienjaamen, Sämmel, jeoes $\frac{1}{2}$ loth),

Senft, \&iebfitöckel,

Mryrrhen, Salpeter, jeoes 1 lotb),

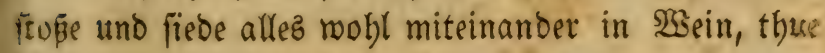
baz̆

Şonig 8 loth, fỏütte eŝ auf einmal eim. 


\section{E in a $\mathfrak{n}$ Dereb.}

Rebme bie Srübe von Refleln, Nangold, Spap= peln und Bingeléraut $\frac{1}{4}$ Maá̃

Butter $\frac{1}{2}$ şfuno, Baumöl 6 loth,

mijace alles untereinander uno joütte es auf einmal ein.

(F) $\mathfrak{n} \mathfrak{a} \mathfrak{n}$ ber $\mathbb{e}$.

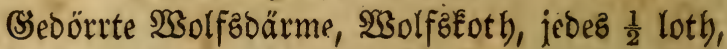

Sräparirtes Scirfah)horn 1 loth,

Saftran 1 Suintlein, 3udker 1 suintlein,

Bsein ein balbes Maẫ,

untereinander gemifdt und auf einmal eingegeben.

E $\mathfrak{i} \mathfrak{n} \mathfrak{n} \mathbf{D e r e b}$.

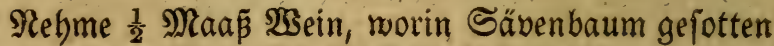
worben, thue bazu 1 loth 2 SolfzEoth, mifche es unter = einander und joütte es auf einmal ein.

\section{Die Berpflegung.}

1. Dev Stall foll rein, trodłen uno mittelmäpig warm fein, von allen $\mathfrak{B S i n d e n}$ befreiet und eine gute Gtreue baben.

2. Das \$p fero foll robl zugededt fein, uno nach bem singu的 herumgefübrt werden.

3. Das Futter foll fein, gefottene (Serften, Scaber, Dinfel mit Salpeter geftreuet, rein Sceu.

4. Der Irank foll laulicht fein, gefottenes $2 \xi a f f e r$ von Sappeln, Rauten, BingelEraut, barinnen Sel uno (Serftenmebl gerührt worden.

\section{Daz 30fte Eapitel. Y o n D $\mathfrak{R}$ S lit.}

Diefe Sranḱbeit miro Daber die Solik genasunt, meil fie in bem lef̧ten Darm von oben berab zu zäblen, $5_{0}=$ 


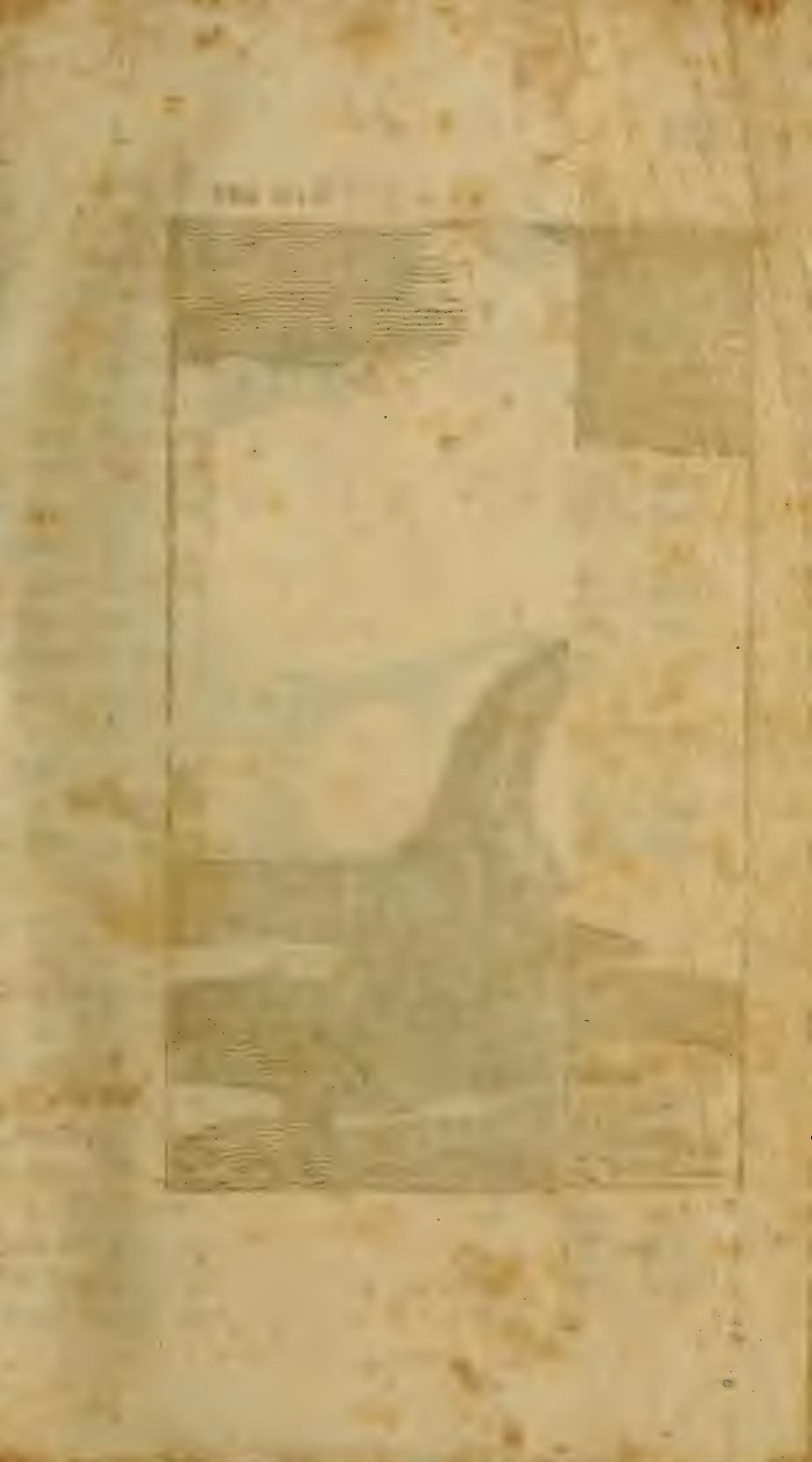




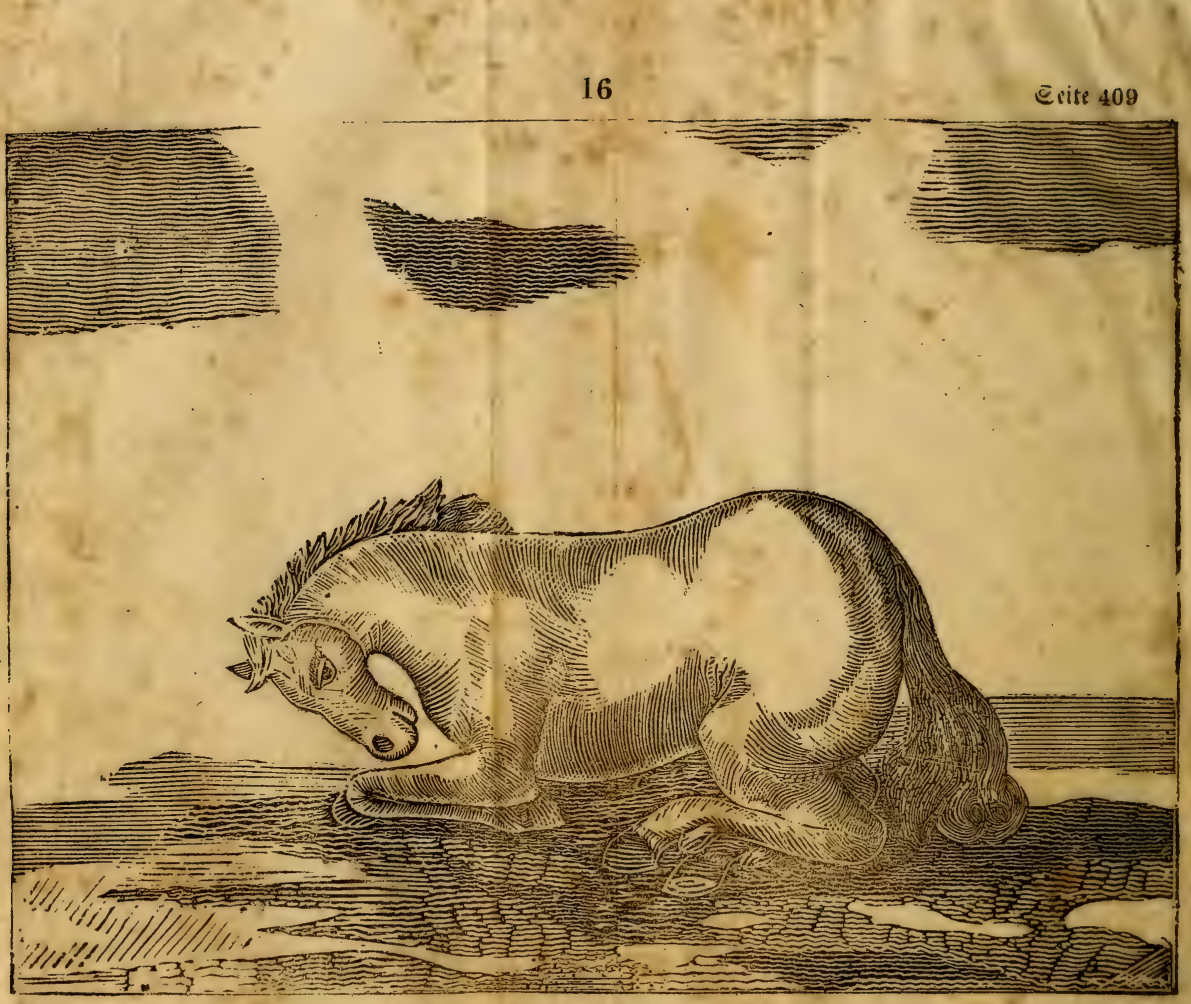




\section{Dif (ङ) $\mathrm{r}$.}

23 or allen Dingen greife mit ber Şand z̆u itgm, räume ben- Mift binmeg uno gebrauche folgendez (Els: ftir. SBS.

Samillen, Eteinflee, Şáppeln, Bingelf́raut,

Mauerrauten (sibija),

Mangolt, jedez 1 Şanovoll,

SBockEhornjaamen 6 loth,

Dillaamen 2 loth,

\&einfaamen $\frac{1}{4}$ Sofund,

Rerchenichnamm 1 Şanowoll,

fiebe es in flieffendem $\mathfrak{B}$ affer,

Nebme ber abgefeibten SBübe $1 \frac{1}{2}$ Maaß̂,

Soloqninten 1 Suintlein, 5 Eierootter,

Samillenöl 2 loth, Salz 1 Scanoboll,

Reinöl $\frac{1}{2}$ Spfund, Яautenöl 2 lotb,

Extract von (Eajiarinde 1 lotb,

untereinander gemifcht und rarm gebraudbt.

Nan fann aud) alfe (sinftire gebrauchen, weld)e in vorbergebenden Eapitel befdrie ben worben find; ben: in biefen beiden SranÉbeiten man bie (SInftir eber als die (singüpe gebraudjen mús, Damit die Därme von bes. Soth, $\mathfrak{B}$ inden uno Släften und andern Unreinigkeitr gereinigt merben, alzbann bie Csingüpe braucben. Nat ten Clyftiren läß́t man Daz syferd allezcit an einem un: ebenen Sort auf uno abfteigen, Damit die SBläfte non ibm Eommen.

(sin andere? (SInffir গুG.

(ङibijd), Mauerrauten, (Samillen, Steinflee, Igseinrauten, jedes 5 Şändeboll,

Sileiên 4 Scänoevoll, Bockshornfaamen 5 lotl), 
Eppidjfaamen, Şeterfilienfaamen, Dillfaamen,

jebes 1 loth, fiebe es in flieffendem 2 Saffer,

Nimm von Der $\mathfrak{B}$ rühe $1 \frac{1}{2} \mathfrak{M a a \tilde { B }}$

Rautenöl, 2Seipez \&einōl, jedes 1 loth,

Nuâ̄öl, Saumöl, jebes 4 loth, Reinöl 12 loth,

Salz 1 Scanovolu, untereinanter gemifd)t und warm gebraucht.

E i $\mathfrak{n}$ a nDereg $\mathfrak{T}$.

\$eilfraut, Wseintauten, (Eppid), jeoeb 3 Scändev.

2(men, 2Cniz, Süummel, jeoes 1 loth,

fiede es mit Scammelsbrühe und nimm bavon 2 Maâ,

Bibergeil, Suplorbium, jebes 1 Suintlein,

Butter 1 Şfuno. Calz 1 scanovod,

untereinander gemijatt und warm gebraucht.

(5in anderes SInftir ș.

Weintauten, Eேnzian, Bergmünze, B̧ermutb,

Däumenten, YYjopp, suenoel, Iaujenogülden=

fraut, jebes 1 scanbwoll,

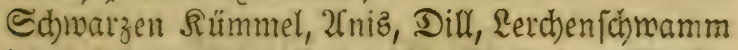

jeoes 1 loth, fiede afles mohl in flicfiendem $23 a f f e r$ uno nimm bavon 2 Maa

Eamillen: Sel, Rauten=SDel, jedez 4 lotb,

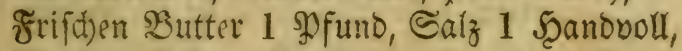

(Electuar Snoum 2 loth,

untereinander gemifht und warm gebraudst.

Ěin Eૈinguß গুG.

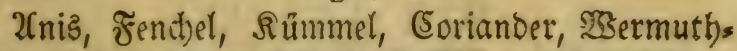
faamen, jebes 1 loth, fiebe es in Mein, uno fujütte es

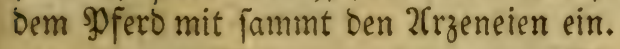

(E)

Branntewein fo rectificirt worben, rectificirten Spis 
ritum nitri, jedes 2 Ioth, warmes $\mathfrak{2 S a f f e r ~} \frac{1}{4}$ Maaß́, mi= fde ez untereinander und fohutte es bem spfero ein, laß̧e das \$fferd wobl barauf reiten oder fübren bis es idbrict, alobann reibe uno wifhe ifm ben Sdyneís rein $a b$.

Ueber die Sieren und SBeichen foll man nachfolgen= be warme Säḉd)en legen uno binden.

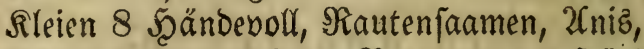

ふümmel, jedez 2 Loth, Sergmünze 3 Scändevoll, mijeche es untereinander.

Man foll bem SুJerd auch mit nadfolgenden Gal= ben ben Batth fdmieren uno wohl hinein reiben. Uno nach Det Salbung einen Ueberfdhlag mit warmen Scaber auf den Baudb binden.

Dialthea 1 SPfuno.

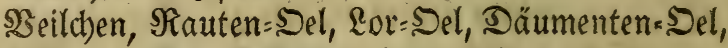
Eamillen=\$Del, Dill=:Sel, jedes 3 loth,

Lein=:Del, Bodébornjaamen=SDel jebes 8 loth, mijhe es untereinander zu einer Salbe.

Folgen die Eingüfe.

Meifterwurzel 2 Roth, Suendel, (Eppid), jebes 2 Şänoeboll, Engelfü 1 Şanovoll, 10 Feigen, SBibèr = geil 1 suintlein, fiede alles wobl in flickendem $\mathfrak{Z}_{\mathfrak{B} a \text { a }}=$

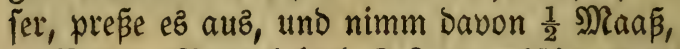

Bitter Mandel:SDel 3 Ioth, mifhe es untereinan= ber und jdütte es auf einmal ein.

(E) in andereb.

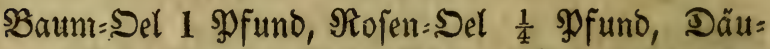
menten=Sel, Camillen:Sel, Sümmel=:Sel, gereinigten Weinftein jebes 2 \&oth, untereinander gemijcht und auf ninmal eingezeben. 
(5) $\mathfrak{n}$ a $n$ Dereb $\mathfrak{T}$.

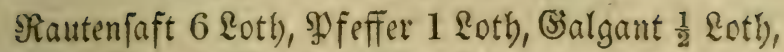
warmen $\mathfrak{W}$ ein $\frac{1}{2}$ Daañ, miju)e alles untereinander uno fid) ütte es auf cinmal ein.

Ein andereb.

Enzian, Säufend)el, jedes 2 soth, fiebe es in SBein nimm bavon $\frac{1}{2}$ Maa SDiterfitienfaamen 1 Roth, SDfeffer $\frac{1}{2}$ Loth, mijche es untereinander uno fdütte ez bem Sुferd ein.

Ein anderes.

Sioblêtrutfaft, Eppich faft, Baum= Sel jedes 8 Roth, warmen $\mathfrak{B}$ ein $\frac{1}{2}$ N) Zaa $\tilde{\beta}$, mifde es untereinander uno fid) ütte es auf einmal ein.

(5) $i \mathfrak{a}$ a d e reb.

Ratwerge von Rorberen 8 Ioth, SDeffer $\frac{1}{2}$ Maá

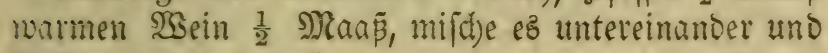
(d) ütte es auf einmal ein.

E in a noereb.

Theriak, Sffeffer, jedez ein Suintlein, warmen Wein $\frac{1}{2}$ D) Der und fututte es bem Spferd ein.

Ein anderez.

S(haafmilch $\frac{1}{2}$ Maaß̧, Saffran $\frac{1}{2}$ suintlein, mifde es untereinanoer und foütte ę bem Spfero auf eirmal laulicbt ein.

(5)

(Sebranntes $\mathfrak{B a f l e r}$ bon groper Reflelnurzel ein balbes Naaß̃, auf einmal eingegeben.

\section{(5) in a $\mathfrak{n}$ e $\mathfrak{r} \in \mathfrak{b}$.}

Baum=Del $\frac{1}{4}$ Df uno, Wein $\frac{1}{2}$ Maá̉, SPfeffer ein 
balbez Suintlein, Saffran $\frac{1}{2}$ Suintlein, mache ez narm uno gebe es auf einmal ein.

\section{(sin andereb.}

Raute faamen, Dillaamen, jebes ein Roth, Rorbee=

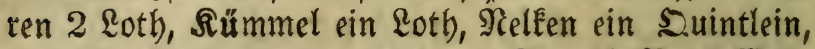

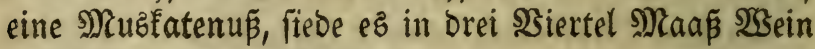
uno ichütte es bem Sf ferd ein.

Ein andereb.

Rbapontic ein \&oth, 21noorn pine Scanovoll, Stab= wurzel, Rauten, Soleb, Saujenogüldentraut jebes ei= ne Scanovoll, freoe alles in Mein uno nebme bavon $\frac{1}{2}$

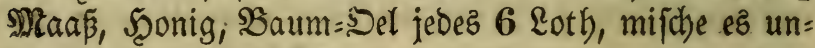
tereinanoer und fdütte es ein.

\section{E $\mathrm{i} \mathfrak{i}$ ङ $\mathfrak{y}$ fit $\mathfrak{i} r$.}

Brübe von Mangolt ein uno ein balbes Naaß̧, wil= be Cucumernjaft 4 \&oth, Saum=SDel $\frac{1}{2}$ Spfuno, Sals eine \$anovoll, untereinander gemifdit und laulich ge= braucht.

\section{Ein andereb.}

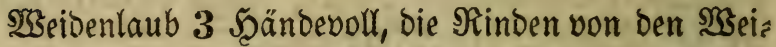
ben 2 Scänbevoll, Şarzel vom Şappelbaum eine Scand= voll, fiebe es wohl in şasein, und nimm bavon ein Mlaás, Saffran $\frac{1}{2}$ Suintlein, 2loes (spatica $\frac{1}{2}$ Ioth, Theriac ein halbes suintlein, mijh) eह untereinander uno fdütte es auf einmal ein.

Ein andereb.

Nebme ein 23 ürmd)en bas in ben Rartendifteln ge= funden worden, weld)e bie $\mathfrak{B}_{e}$ ber brauchen, in einem (Ei eingegeben, $\mathfrak{2 s i a f}$ fich aber ber Mift uno Unrath 
nicht aubfübren laßjen, fo nimm Sucumern, Soloquin= termark̂, Sindşgalle, ŞGeinrauten uno Sconig, madbe tänglid)te 3äpfdien baraus und fohiebe fie nacboem fie vorber mit Sel gefchmiert tief in ben 2ffter himein, ober mad)e folgenden Sapfen, Der anftatt eines (Sty)ftirs gebraudbt reerben Eann.

3ehn 3wiefeln, oürre Freigen, Salpeter, jedes 8 Ioth

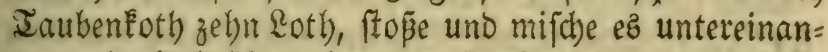
Der mit Selbäfen, formire 3apfen baraus uno fuche 3 ooer 4 in ben Sintern binein zu bringen.

\section{sin singup.}

Miftel, Taujenogüldentraut, jebes ein Rotb, milben und zabmen Rautenfaamen 2 Ioth, mifbe ez unter=

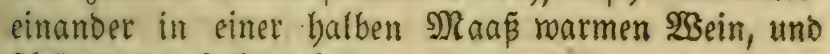
fchütte es auf cinmal ein.

\section{Sin anderes SInftir.}

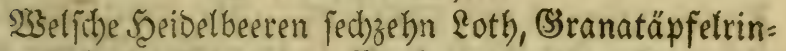
Den 8 Roth, firbe es in $\mathfrak{S a f f e r}$ uno nebme bavon sin

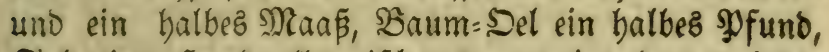
Salz eine Scanoboll, mifche es untereinanoer zu einem Slyftir uno gebrauche es laulicht.

Die $\mathfrak{s e r p f l e g u n g ~ f o l l ~ f e i n ~ w i e ~ i m ~ v o r b e r g e b e n d e n ~}$ Sapitel über bie Darmgicht ift befchrieben worben.

\section{Das 31 fte Capitel.}

\section{Son Dem Durdbrud) Der Pferde.}

Der Durdbruch zeigt fich auf brei verfdhicbene Xrten. Die erfte 2frt niro Rienteria ober Söliaca \$affio ge: nannt, meil die spferde nälyrend der saurr berfelbes 
baß eingenommene Frutter bald mieder burd) ben 2 (fter von fich gibt, wobei es jebod) wenig ভd)merzen empfin=

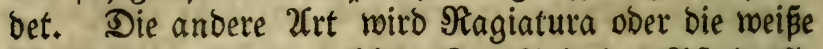
Nufer genannt, in weldcher Sirankbeit bas \$perb alle veroauten Speifen bünn und wäfferidst von fich gibt.

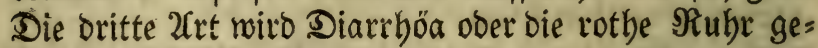
nannt, weldhe gropere Sdbmerzen madht, uno ift ber Mift ein bünner Sdbleim mit SBlut bermichchet, aud bat man

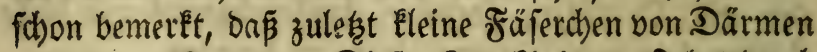
mit herauskamen. Dieje Rrankbeit entftebet burdh

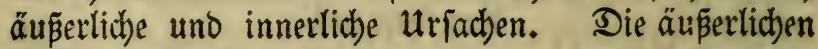
fino bie verberbten Speifen, bie entweder in allzu gro= Ber sRenge genoffen worben, ober fonften fátimmlidbt,

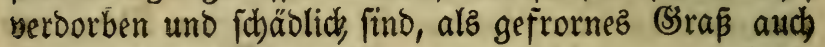
5̧ühnertotb, Mäuzbrect uno bergleichen, moburch bie Däunng gefdomädht miro uno nochmals allerlei zähe Feuchtigkeiten in ibm erwachjen. Die innerliche $\mathfrak{u} r=$ facher aber fino bie Satharr, fo in groper Menge aus bem Scaupt in ben Magen fallen, Denn badurch wiro berjelbe nicht allein erkältet, jondern auch joblüpfericht uno meid) gemacht, Daß̄ es bernach mit (Sejchmüren behaftet wiro, fo ben \$ferden aus dem Scintern heraus

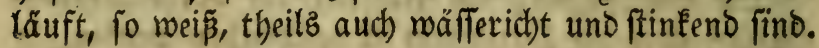
son biejem Capitel nun wollen wir bon ber erften 2art bez Durchbruchz reden, welcher entffehet auz Man= get ber gegährten Säure in Dem Magen, badurd) ber Magen feine gebörige Bearbeitung uno rechte natür = liche Serbaiung nicht verrichten Eann, uno aljo erÉal= tet verffhleimet, und ber \$nyloruz relariret miro, baß er entweber gat offen ffeben bleibet, ober nicht recht mehr wie ez fein follte, zugef́hlopen mirb. 2Cuz mangel ber Săute Eónnin bie Speifen nid)t verzehrt werben, uno 
Der Durchlauf bält alsbann fo lang aln, biz ber $\mathbb{M a}$ = gen feine Cäurung wieder erlanget. Sommt aus Er $=$ Eältung aud faltem phlegmatifchen Schleim, weldber in Den Magen fällt uno Die Falten Des Magenz glatt uno fohlüpferid)t machet, von verberbten Epeifen, gefrobr: nem (S)ras, Şlühner Unflath, menn die Selthnet in bie Srippen legen, SMäubEtoth; ferner wenn ein \$ferd viel Gerften zefreffen uno alsbalo viel Ealtę Saaffer in fid) fauft, in Ealte Etälle geftellet wiro, ingleidhen won (5atharten, weltive von Dem Scaupt in Den Magen berabfallen; ebenfo wenn bie Sbolera, gefalzene Sghleg. ma ober fonften eine fdarfe, wüthende Feudhtigfeit dem Magen in großer Mienge uno Ueberflup zuläuft uno überichüttet.

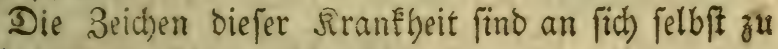
erfennen uno fidon befitrieben.

\section{Die E $\mathfrak{u}$.}

Dien Fluß foll man anfangs nicht gleid ftillen, fon= bern bemịellen aufz menigftenz 3 Iage feinen (sang lapen, benn wo man folchen frtacke ftillet, fann bas

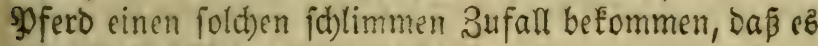

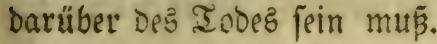

\section{Folget tas હinftit.}

(3erftenficleim drei Siertel Maá, rother Sucter ein

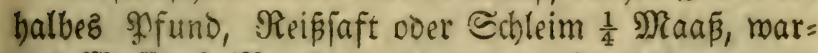

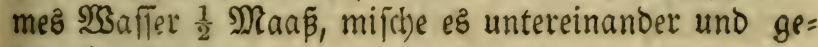
braudbe ç.

\section{Ein anderez હinffir.}

Nimm BBrühe von einem gefottenen Scammelstopf

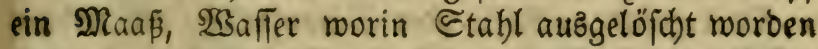
- ein und ein balbes Maa $\tilde{\beta}_{1}$ \$appeln, Bingelfraut, $\mathfrak{E}_{a}$ 


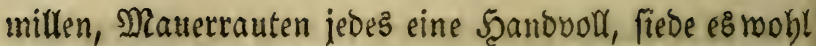

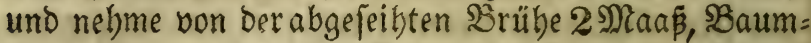
SDel $\frac{1}{4}$ SP fund, Samillen=SDel, gelbes Rilien:Sel, jedes 2 Iotb, Salz eine Scandooll, mifthe es untereinander zu einem SInftir.

N2. B. Man fann auch alle SInftire gebrauchen, welche in Den Sapiteln von ber Solik und Darmgicht fino gemeldet roorden. SDer bie Clyftire melche die Sraft baben, bie Site zu reinigen uno zu ftärken :als ba fino die von (Serftenbrübe uno rotben. Sucter,

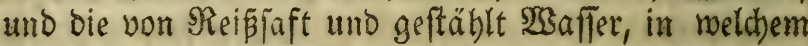
ein Ropf von einem Scammel ift gejotten worben.

\section{folgen die Eingüfe.}

Regenwaffer ein balbes Maá̧, Scafenblut, Bocks= blut gebört jedes cin balbes Ioth, mifche es unterein= ander uno foütte es laulicht ein.

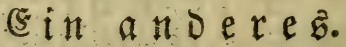

Siebörten und gepüloerifirten (S)artenfreffenfaamen 2. Loth, Sseismild brei soiertel Maaßs, in weldher nor = ber glühender Stabl oder glüheno Sifelftein etlichemal if abgelöfht worben, milche ez untereinander uno gie= हुe eह bem spfero ein.

(5in andereb.

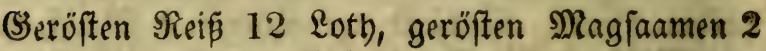
Eoth, Mild in welcher glübender Stabl abgelöicht wor= oen brei Siertel Maấ, gegeben.

\section{Ein a noereb.}

Soer gefottene Rübe ober Sdbaafmild, von meldber bie $\mathfrak{B u t t e r}$ abgefondert. 
Mferbe=2largenei Buth.

(E) in a n D e re $\mathfrak{k}$.

Sebme Sleien, gebe fie Dem şferb orei Iage nact)= einander zu freflen, uno nid)tz anderz.

\section{Daz 32fte çapitel.}

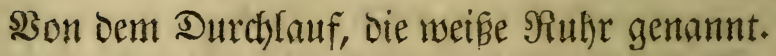

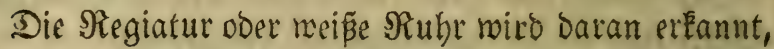
weil fie in Dem Frue bie Epeifen nicht unverdauet uno ganz von fidch läst, fondern einen oünnen wäfferrid)ten uno fd)leimigten, bismeilen gelblid)ten aud) ftinfenden Soth ausfübrt, Eommt aut den im vorbergebenden Capitel gemeloeten Urfachen, zum I beil auch von all=

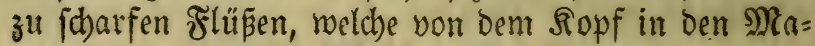

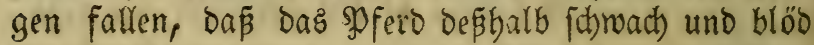
wirlo.

\section{Si e cur.}

3u biefem foll man bie in ben vorlyergebenden znei Sapiteln befdriebene SInftire brauchen, und folgende Eingüpe geben, jeooch vor bem oritten ז̃ag ben Durd): rauf nid)t fitllen.

Relume das Shulver von einem gebörten Secht 3 loth,

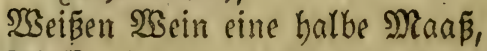

Syfeffer $\frac{1}{2}$ loth, mifhe es untereinander uno gebe

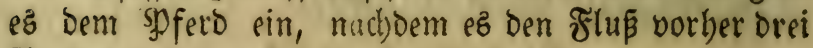
Iage gebabt bat.

Ei in a nDereb $\mathfrak{B}$. Sitrum 2Nntimonium 1 Suintlein,

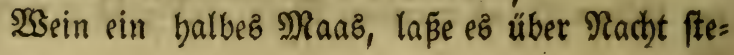




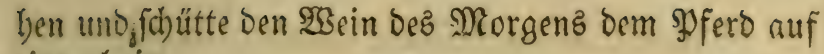
pinmal ein.

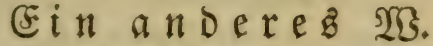

Rbabarbara $\frac{1}{2}$ loth, Shapontic $1 \frac{1}{2}$ loth,

(G)

(5id)orienwafler $\frac{3}{4}$ Maa

Raritende Sojen= Sncup 6 lotb,

untereinanoer gemifatht und auf einmal eingegeben.

233.

\$gä̉parirten Blutftein 2 loth,

(3) bramtes Elfenbein 4 loth,

Dradjenblut 2 lotb, Mafíti 1 lotb),

Terrafigillata ङilefiaca 2 lotb,

SRotben SBolus 4 loth, mifit) es untereinander 34 einem Shulver und gib Davon Dem Syfferd 3 loth in $\frac{1}{2}$ Maã̃ $\mathfrak{S}$ Gein ein.

É in a กDereb.

Debme Saft von gemöhnlichem geflederten f̈löbe= fraut,

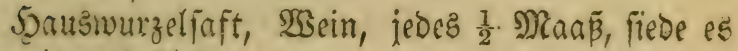
ein wenig uno fdutte es ein.

(5) in a th

(Seftopene uno gedörtte Mefpeln $\frac{1}{4}$ פ̧fund,

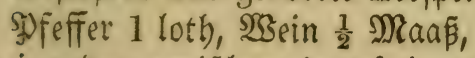
untercinander gemifdt und auf einmal eingegeben.

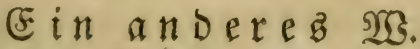

Im rall es eine allgemein giftige Eeuche wăre, io

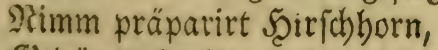

(Seoörtrte Suittenpulver jedes 2 loth,

İheriac 1 suintlein, 
Diptam, Ierra figillata, rothen

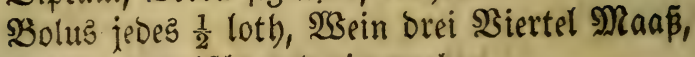
untereinander gemijat und eingegeben.

(E) $\mathfrak{n}$ andere $\mathfrak{E}$.

Nenrtben 1 loth, 9 Eierdotter,

Simmetrinden $\frac{1}{2}$ loth,

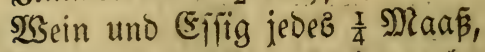

untereinander gemijot und eingegeben.

(5) in andereb.

(5aftanienmebl 12 loth, NSein $\frac{1}{2}$ Naaß̄, untereinander gemijht und cingegeben.

\section{Ein a noereb.}

Fünffingerḱrautmulzel 2 loth,

SEegerichjaamen 1 loth,

Die mittelften $\Re$ Rinden von Eichenbols 3 loth,

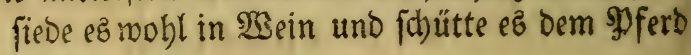
auf einmal ein.

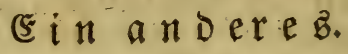

\$3ermuthfaft, 2 segerichjaft jebes 8 lotb,

Wein $\frac{1}{2}$ Maaß,

untereinander gemifht und auf einmal eingegeben.

sin andereb.

Eaubanum 1 suintlein,

Maftix pin balbes loth,

Salmus, 2inis jebes 1 loth, mifd)e es untereinan= ber und fdütte ten Myrrben uno Summadhafter ein.

$$
\text { (3: in a n Deres গ্ডে. }
$$

Sebranntes Seiridborn! 
Die Beidfen find:

(Exftlid) ein Sdbleim wie reverenter Rok anzujeben, bernach eine Freftigkeit mit B̧lut bermijat. Drittens laßjen-fich) unter ben gallichten uno vielfärbigten (ङx= crementen Fäjerchen uno Scäutchen, feben, bie von Där: men abgeichabet werben, uno mit (sefchmüren bebaf: tet fino. Enotich gar Stüdtichen vom zerfreffenen uno corrumpirten Sebärme.

Sonnerliche Urfachen ftno fcharfe Şauptflüfie, weldse vom Ropf in ben Magen fallen, uno mit ibrer Sthäl= fe nod) mebr bergleichen Freuchtigkeiten von andern Srten, fomobl aus ber verbrannten (5bolera, als auch) auz bem gefalzenen \$ुblegma, berbeizieben, over auz Berftopfung ber \&eber, 3erreifung uno Durdnagung einer Slutaber und andern, fo in ben zmei vorbergeb: enden Sapiteln jabn bejchrieben.

\section{Die E $t$ r.}

Diejem Uebel begegnet man mit Elnftiren, mie in Den vorbergehenden zwei Capiteln gemeldet worben.Dann aud) in biefer ber Flup vor bem britten Iag nid)t zu ftillen ift, und gibt ibnen folgenden (singur,

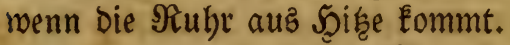

$$
\text { WB. }
$$

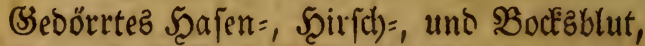
Tormentill, (Srocuz Martiz $\frac{1}{2}$ loth),

Saft von $\mathfrak{B s}_{\text {egerich, }}$

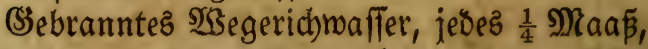
mifche es untereinanoer uno fchütte es bem SDferd auf einmal ein.

Sin Slyftir zu ben fchnärenden Därmen. Nebme Sdheinenfleifh = oder Scammelafopfbru= be 1 Maán, 
Rotben Solue 1 loth,

(Summi 2rabischen 2 loth,

Dradbenblut $\frac{1}{2}$ loth), Rofenöl 6 loth,

(S)isunfd)litt, von Den Nieren, $\frac{1}{2}$ Sुfund,

Salz 1 Sanovoll, mifche es untereinander zu ei= nem Slyffic uno laulicht gebraudst.

Ein anveres Slyftir für sie fdwärende Därme.

Siothe Rit)ernbrübe 1 Maaß̄,

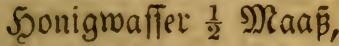

(Sscizunfd)litt 1 SPfuno,

Salz 1 Şandooll, 5 (5ierdotter, mifde eह unter= rinanber uno gebraudbe es laulid)t.

sin anderes Sinftir.

Sinjenturübe, Srübe von Summach und (Sranat: äpfeln, jebes 1 Maẫ,

Rotben Bolus 2 loth,

Drachenblut 1 loth, 12 Eierdotter,

Salz 1 Şanovoll, Saumöl $\frac{1}{2}$ spfuno, untereinander gemijat uno laulicht gebraucht.]

Ein (singū̂.

Dürren (Seisetoth 3 lotb, Effig $\frac{1}{2}$ Maaß̄, untereinander gemifitt uno auf einmal eingegopen.

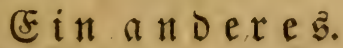

Rebme Die $\mathfrak{B r u ̈ h}$ bon bell mittelften eichenen $\Re$ Rin = Den uno (Eid)eln $\frac{1}{2}$ Maaß̄, laulicht eingegōenen.

(5in anderes

(Salläpfel, Eummach, jedes 2 loth,

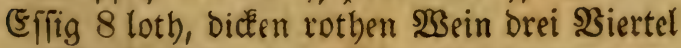

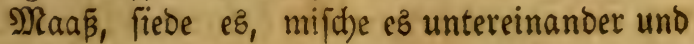
idütte pछ auf einmal ein. 


\section{(E) $\mathfrak{i} \mathfrak{a} \mathfrak{n} D$ ereb}

Sauerrampfer, rothez

(3)arbenfraut jedę 2 Şãndevoll,

23egerich) 2 Şändevoll,

Endivien 1 Sanovoll,

Soriander 1 loth,

WSilbe Sranatäpfelblüthe 1 lotb,

S(halen von Siranatäpfeln 2 loth,

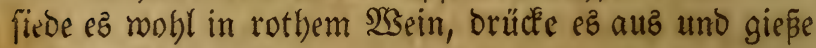
ç dem \$ferd auf einmal ein.

Sin anderes wenn fie auz Sinlte fommt.

Brübe von Caftanien = und Bohnenmebl $\frac{1}{2}$ Maaß untereinander gemifdt und auf einmal eingegeben.

E in anderes.

2Beirautbrinden 2 loth,

Dradbentlut $\frac{1}{2}$ lotb), 2 Sein $\frac{1}{2}$ Mlaaß̧,

untereinander gemifict und auf einmal eingegeben.

Ein andereb.

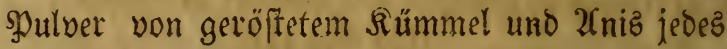
2 loth,

Die Brübe von Summad), 5̧eibelberren uno (ङi= cheln,

untereinander gemifot und auf einmal eingegeben.

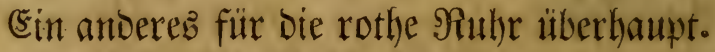

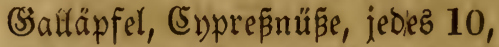

Sdbalen von Giranatäpfeln 3 loth,

fiede es roobl in rothem 2 Sein oder. Effitg und fchütte Dem $\mathfrak{g} f e r \delta$ ein balbez Maá̃ ein.

Ein andereB,

Saffran 1 suintlein. 
Dferbe:2(rgenei Bud).

Miyrrben 2 loth,

Blütbe vom (Sartbeil 4 lotb),

Mुeterfiliemfuamen 1 loth,

SBeinrauten, rotbes (Sarbenfraut 4 lotb),

פy [op, Sertram, Tormentill jedes 2 loth,

(Siebranntes Scirfahorn 3 lotí),

Simmetrinden 1 loth,

Ierra Sigillata, rotben Boluz,

(Erocus MRartis, jeoes 2 loth, mijche es unterein= ander zu einem \$ultwer uno gib bem Syfero auf einmal 4 loth) ein, mit ciner balben Maá̄ (Serftenbrüte oder rotben $\mathfrak{E}$ ein.

Ein anoerez.

Diptam 1 loth,

Sunnigunoištraut, 2(ttiit), $\mathfrak{E}$ etnrauten,

Cävenbaum, fleine Fartenmurzel, jedes 1 Şano: voll fieve alles moht in 2 sein uno nibme bavon orei Biertel Maa $\tilde{\beta}_{1}$

Baumöl 6 lotb), $\mathfrak{B a c h}$ folderbol 2 loth),

7 (sier Murthen ein balbes loth, untereinander gemifot, und auf einmal eingegeben.

(5. in a noeres.

5 3miebeln, Mnrrben 1 lotb),

Saumöl ein balbee \$funo, untereinanber gemifht uno auf einmal eingegeben.

E in a $\mathfrak{A}$ Dereb.

Frifche Süubemildh, in welcher etlid)e heiße Steine abgelöid)t worben find.

(E) in a noere

Frifabe Mild 1 Maaß̧, glübe eimen Etabl oder Siefelfzein, löjthe ihn brei ober 
viermal barin aus und fdütte es bem Sूfero auf ein= mal ein, mit einem suintlein Srocus Martiz.

\section{E in andereb}

Sontrajervä, Mryrobalan.

Sitrin jedees ein balbez lotb,

Iormentill, (5rocus Nartis jedes 1 loth,

Rotben Solus 1 loth,

Ihyeriac 1 Suintlein, theile es in zmei Igeile und

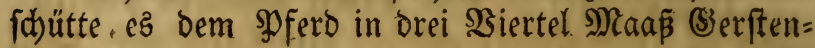
brübe ein.

E i n a

spfeffer von Fröfhidraalen, Scorzonera,

Iormentill, rotbes (Sarbenfraut, jeoes 2 loth),

Eontrajervä, Scoroium, jeoes 1 lotb,

Saffran 2 Suintlein, mifche ez untereinader und gib dem Syferd täglich Davon 3 loth in rothem $\mathfrak{B}$ ein oder Sierftenmaffer ein.

\section{Die Berpflegung.}

1. Der Stall foll mittelmäpaig warm, trodłen uno bon allen SWinden befreit fein, und eine gute Streue baben uno das syferd narm zugedect werben.

2. Daz ₹utter foll fein Rleien mit Sconigmaffer an= gefeudtet, Errlenlaub auf Dem Futter oürr zerrieben, (Sranatäpfelfchalen, bürre ScechtBpulber, bie SBlätter von Brombeerftanden, gebranntes Scirichborn, Epelz, Saber, geróftete Berfte mit Ssffig befprenget, oder

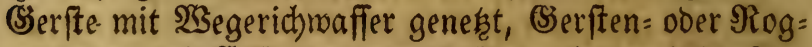
genpreue mit Effig genest und Sumach vermifd,t, Linfenmebl, Sleien mit Scirfenmebl bermifat jeboch foll Das Futter nicht in zu groper. Menge gegeben werden:

3. Ser Irank foll fein $\Re$ Regen= oder flieffendes $\mathfrak{R} a$ f: 
Samilten= Del 2 loth,

Şonig 6 loth, 9 Fierdotter,

Galz eine balbe \$̧anovoll, mijd)e es untereinan= Det und gebrauche es laulid)t.

İm Falll diejes (5lyfitir, nadboem man es mebrete Rale angeroendet, dic gewünichte. Wirtung nicht ber = vorbringen follte, fo gebraucbe man birjenigen (5Inftire Die in ben Drei vorbergebenden Sapiteln bejdrieben rourden fino; leftere find ftärker und werden boffent: lich ben gewünjidten 3roect erreidjen.

\section{Sernach gebe folgenien (singur.}

Şefferḱörner $\frac{1}{4}$ loth,

Speterfitien 1 Şanovoll,

- 2céermilnze 1 Saríboll,

(Samanderlein 1 Scandvoll,

నümmal; 3 lotb,

Eppich faamen 2 loth, mijhe es untereinader uno

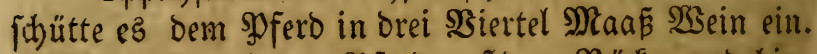

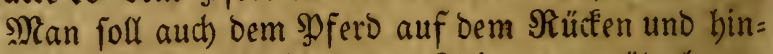
ter Dab (Sejhröt Sädẻhen von ßleien warm überlegen. K3enn aber bie eiterichte Materie mit Blut erfchei= net, fo braube vorbergebende linbe (Elyftir, Dämpfe

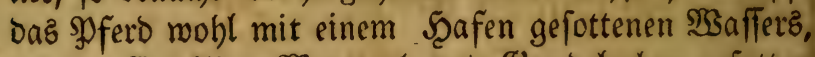
morin Samillen, SBermuth uno Sundelreben gefotten worden, das SPfero mup aber zugedectet fenn; bernach trockene es fleiffig ab, uno fomiere Den Sort binter bem (Sejuröt robl mit Baum= Del uno Lor = Sel untercin = ander gemircht; man nimmt aud) Sonig, vermifcht Denjelben mit Єalz, madjt länglid)te Etulzäpchen'ba. raus und fdiebt ifm foldhe ein.

Sm Uebrigen ift bie Serpflegung wie in bem vor= 
SSalläpfel, jebes 3 loth

Sebranntes Şirichborn 2 loth,

Dürre rotbe Rofen 1 Scanowoll, mifdbe eș, unter= cinander zu einem Spulver uno ftreue bavon auf ben ausgegangenen Darm.

(s in a noeres.

Dürre Sceidelbeeren 4 lotb,

Rojenfaamen 1 lotb,

(Gebranntes Shirfchborn 2 loth,

SBermuth 1 lotb,

(Salläpf fel 2 lotb, mijche ę untereinander zu ei= nem \$oulver uno ftreue ez Darauf.

हैं in a noereb.

2(nis, rendyel, jebes 2 loth,

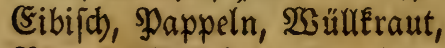

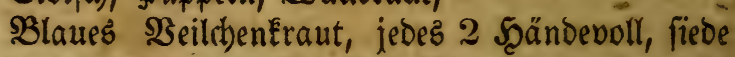
es wobl, laze ben britten I beil einfieden, bernach tauche einen Sdroamm in baß̃elbe und lege inn oft warm $D a=$ rüber, bis er wieber bineingehet; wenn er nun mieder ermeicht ift, Eann man ibm, wie obenbefdrieben, mit Den Fingern fittfam binein belfen, uno in folgenden 2Cbfieb einen Sdbramm taudben, aud ebenmäpig oft warm überlegen, wie zuvor :

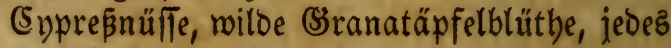
1 loth,

Sumach) 3 loth, (Eichenlaub 3 şändevoll,

Siranatäpfétrinoen,

Sceibelbeeren, jebes 2 loth,

Şalläpfel 1 loth,

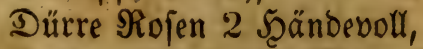

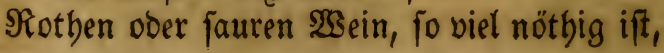


mijal uno fiebe ses wobl untereinander.

Sit aber ber Darm nid.t Dick, nod) bod) aufgelau= fell, fo wajiche ilyn erftlic) mit einem warmen zujammen= ziebenden 2 sein, ftreue bernad) frlgendes Spulver ba= rauf uno bilf itym alsbann mit ber Şand fein gemäd)= (id) binein.

Bleimeiñ, (Salläpfel jedez 4 loth),

2claun 1 loth, mifd)e es untereinander zu einem Spulver.

So aber ber Maftbarm fdwärt, foll man ifm ミca= biofenfraut in 2 Saffer gefotten aufbinben.

\section{(5in Einguf.}

Fünffingerfraut 2 Şändeboll,

2 Snoblauchbảupter,

Baumöl $\frac{1}{4}$ SDfuno,

untereinander gemifitht uno auf einmal eingegeben.

\section{Die Berpflegung.}

Man gibt dem bamit bebafteten \$ुferd foldhe Epei= fen zu freflen, bie erweichen und ben fdhlüpfrid) madjen, Damit e马 fid) in Dem 3urthen nicht fehr nöthigen uno hart brücéen braud)e. (Enolic) laf= jet Den Scintern mit einem Sd)wamm etlidje Iage nad)= einander zuftopfen.

\section{Das 36fte Sapitel.}

\section{Son $\mathfrak{B e r f t o p f u n g e n ~ D e r ~} \mathfrak{P}$ ferbe.}

Die $\mathfrak{B e r f f o p f u n g ~ r u ̈ b r e t ~ b e r ~ v o n ~ e i n e r ~ h i f i g e n ~} \mathfrak{S}_{e}=$

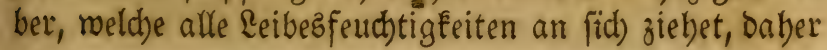


bie Därme ibrer natürlichen Feuchtigêeiten beraubet werben, ba bann nothwendig erfolget, bas bie Excre= mente auch trockenen uno verbärtet weroen müffen, ferner wenn ein \$f fero im Reiten übernöthigt woroen und jei=

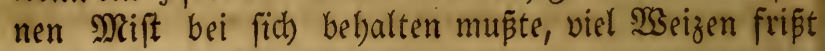

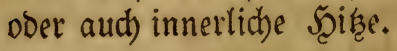

\section{Die (s) $r$.}

In foldhen Făllen foll man ermeirhende Sachen, als (sinffire gebraudben, beren genug im vorhergebenden vierten (Eapitel befchrieben find; nadboem oie Elyffire ibre Speration getban baben, alsoann foll man bie sourgation gebrauchen, biejelbe warm balten uno foldhe Epeifen zu fieffen geben, weldye erroeid)en, als gejotte= ne Berffen Mangolteblätter; (ङibijchblätter, u. T. m.

Inz Irinken foll man cin wenig Serftenmebl uno Agaric rübren.

\section{Das 37 fte Capitel.}

Bon Der Purgation Der Pferoe, uno erfflich von Der Gsrabftellung oier Fütterung.

Die Sronung, marum man bie \$gferde in das (Siras zu laufen ober zu ftellen, vor biejem zu halten im Şe: brauch gebabt, ift nummebr bei ben Meiften in eine

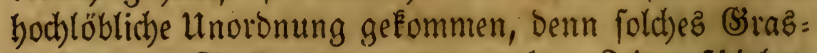
laufen ober હtellen, wenn es zu rechter Beit gef́chiehet, ift febr nügelic) uno gut, merm man aber daz (Segen: theil thut, auf das alferichäblidsfte auf bie soferbe mintt.

(Es ift aber folche (Srabfütterung zweierlei: Die er= fte ift bie gemeine (Srasfütterung, inbem bie jungen 
bung gewisier 2 cutboren, füttern fie bie Brrüne Gerfte, menn fie eine uno eine balbe Spanne boch iff, uno vor 2fufgang ber Sonne mit fammt bem feud)ten Tau $a b=$ geichnitten worben, in ciner nieoern నrippe, boch an= fangs menig, bred)en bas bürte Futter täglid) àb, neb= men mit der (S̈erfte bagegen zu, bis fieiţm enolid) nid)ts anderz alz bie blope Serfte geben, tränten es zroar zur oroentlichen 3eit, oesenen fie doch je länger befto weniger begehren, reiber. ibnen Daneben täglich tas Maut, bie

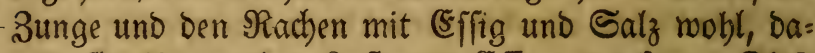
mit fie ignen eine $\mathfrak{e n f t}$ zum Esfen ermectent. Diefe Şerftenfütterung wäbset einen ganzen Monat, in wel: ther man fie nidt)t ftriegelt, fäubert, butget, biefweniger ibnen ausmiftset und alfo tief im Sotb fteben läpt, Da= won fie beftig im \&eib, als aud) burch ben Utrin purgirt werben bazu brect)en fie ignen bie (Sijen ab, ebe man fie in bie Frütterung ftellet. SIn ber vierten 2 sod)e folla= gen fie ibnen eine Scalzader, Eporraber, und nod) wobl eine andere bazu, uno lap̃en viel SBlut, hernach miro noch 10 Tage mit Dem (Serftenfüttern fortgefabren, alzoann entzieken fie ihnen allmäblig das grüne Fut= ter, geben ihnen täglić) mehr uno mehr eingeweidhte (Serfte biz fie wieber zo $u$ Dem rech)ten Futter fommen.

Die Staliäner, laut Den Berichten follen nebft Dem

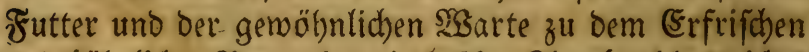
uno jäbrlid)er şurgation einér 2(tt Rlee (welches nid)te anders als ber vorgemeloete Meoilche Slee, uno nun= megr auth in Spanien und ber SRiedertanden zu fimben iff) fith bedienen, bavon bie \$pferbe gar fanft purgiren, bei \&eib bleiben und Dabei igre 2frbeit unaebindert ver= ridsten. Diefer Rlee, wem er einmal gefäet wiro, Dauert 3 Sabre Darauf aut, und fann man Denfelben bes Sabrz etlidbemal abidnneiden. 
Etlide purgiten ibre \$f ferbe eine 3eitlang mit grü= nen Bobnen, fammt Den Stengelı uno Sraut, oder mit Rettich uno Rübéraut.

(3leid)mie nun alle oben ermäbnten (3iraspurgirun= gen gut fino, weun fie in ifrem gemiß̄en Naaß̧ gebal= ten weroen, fo fabalith fino fie Dagegen, wenn man bie: felbe unmäs̄ig gebraud)en läp̄t. Eรz foll bier in weni= gen 230 orten von ben (Sirazorbunngen gerebet merben.

(5rfflid) fragt man nicht Darnad); zu weld)er Beit man ¿క berwerfftellige, obs im Eommer voer im frrübling oder Seerbft gefdebe; in 2fnjebung aber baj man gleidjwohl aud) will gejeben fein, fo wie aud) Daş es Der (Sebrauch lange 3eit fo gerwefen, ba man zumcilen Den Stallfnedten folgen mur, Die gleich mie das Sra= Eel fagen, id) bin fidon fo und fo lang in biefem Mar= ftall, mein Bater uno (Sropervater ift auch folang barin gewejen, es ift allezeit fo gebalten worben, Damit ift e马 nun verantwortet. Sernach fichlagen foldhe Soioten Die Sräuterbüd)er, aber fonft ein von einem alten SSSeib

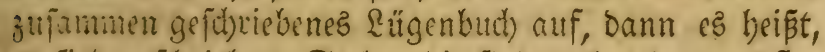
es fino gejuriebene Earben bie find probat, Denn es fte= bet Darunter gefitrieben probatum eft, bie georuditen Silicher fino nitht fo gut, fondern gar zu gemein. 2⿰l⿱z. Dann nimmt man Das (Sias erft, roenns fdier zeitig werden mill, S̃m Šuni, furz che man es mähen will, Denn es hat vorber Eeine vollfommene Sraft, wie fie fprechen, Davon fübret man eine große Nenge in ben Stall, bamit man fiti) nid)t alle Iage Damit braudst zu (d) leppen, gibt ibnen fold)es vollauf inz $\Re$ Reff $\mathfrak{S}_{\text {seizen, }}$ Sleien uno Serfte genug Dabei, backt ibnen allerlei Rräuter barunter, (Sott gebe bã̄ fie feien purgirender Qoer ffopfender 2frt, Denn, fprechen fie es müpen afler= 
lei Rräuter fein, indem bie \$ferbe im Frelo und auf ber

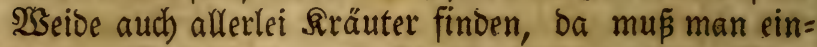
tragen SBalomeifter, Scafelmurzel, Ěbrenprei Delreben, Şühnerbarm, Deumenten, "Iaurenogüldon= Eraut, Sthaafgarbenḱraut, Tormentill, Sibenelu, Di= fteln, 2Cnoorn, Salbei, Rungen = und Reberfraut, YYjop, (Eichenlaub, Buchenlaub, SDolev, Sollunberlaub, S.uen= Del, Sifterlucen, Baldrian, Doften, Soermenig, Brun= nenfrę̧en uno was bergleichen heilfame Sräuter mebr find ; ja menn man alle Fräuter im ganzen Sräuter= buch) haben Eốnnte, fo hacteten fie es auch Darunter, benn

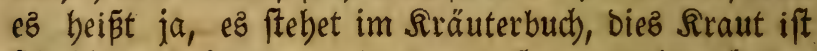
für bies uno jenes gut, Darum mús man es braucben.

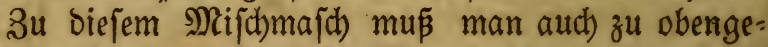

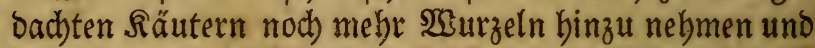

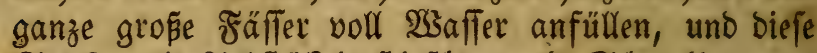

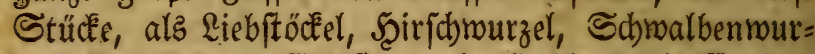

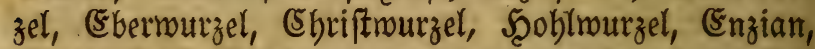
Meiftermurzel, Sdhwarzmurzel, Darin liegen lapen, ba= mit baz $23 a f f e r$ bie Rraft red)t berauz ziebe, uno bie spferbe bavon tränken, ba gehet nun bie (Sur elft recht

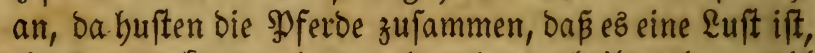
eines verteckt $b a$, baz andere bort, theils gehen mobl bie Scufe meg, einez cholert, bas andere befommt bie Darmgirht, einez befommt ben lauter Stall, bas anbe= re Eann gat nicht Stallen.

Uteberbies müßen fie wöd)entlich zmei oder breimal

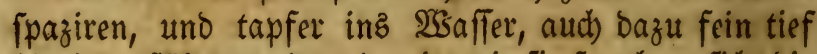
binein geführt meroen, Damit, wie fie fprechen, fich bie Spferbe fein abtühlen, weldhes ibnen gar gefund fei.

(Etlidbe reiten fie wohl gar auf ber Reitfdule, ober in 
bereinander, und baben ganz entgegengefefte $23 i r f u n=$ gen uno kein einförmiges Sujammenmirken unter fich.

5. 233 enn foldbe Srăuter uno $\mathfrak{2} 3$ urzeln alfo lang in bem $\mathfrak{B a f f e r}$ liegen, gäbren und faulen fie, was (S)uteל Eönnen Dann hernach bie spferde bavon trinken?

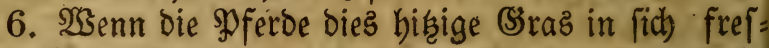
fen, ŞSeizenkleien, eingefeuchtete Serfte, fo vielerlei Iräuter, fo ein ftattlictes erfaultes, Siäuternaffer, fo müpen fie ja gut (Sejchirt machen, ez gebe gleich oben oder unten auz, oder werbe gar auf Dem Sarren $b a=$ von gefübret.

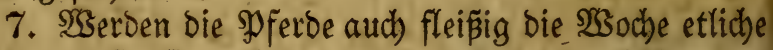
mal ins $\mathfrak{K}$ affer uno bazu fein tief bineingeführt, $b a=$ mit fie fith fein abFülelen, ja ich meine, menn fie bie Eolic ober bie Darmgicht berlangen, feie Eein bes̄er Mittel bazu, als bies $\mathfrak{S}$ Safferfübren, bejonders menn fie auch vorber ourchs Reiten tapfer erbigt worben fino.

8. Eäst man ifnen bann fleifig bie 2Coern barauf, baß̧ das böje (3eblüt fein aus bem \&eibe fomme, Damit

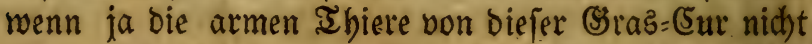
gar aufgerieben morden, man ifnen ibren edlen Saft vollenos aus bem \&eib ziebe, es mag auch bie 3eit fo hisigig, uno im Sonmer fein wie es molle, fo liegt nid)tz baran.

$\mathfrak{S}_{3 a s}$ num biefes für eine (sur fei, will ich jebem Serftänoigen zu feiner eigenen Beurtbeilung beim= ftellen.

Sch will indeßen auch etliche, meiner (Stragoronun= gen bieber feşen : $: 23$.

So bald daz (stras eine gute Spanne bod) und nicht höber (iünger tanns auch wohl papiren) geworden, 
es mag aud) gleid) im 2(pril ober im 2infang $\mathfrak{R}$ (ai, fein, foll man ben झुferben, nadboem fie 8 Tage zuvor Das Spieşglä (für jebes \$ুferd $1 \frac{1}{2}$ suintlein) orei: mal genofen, folthes Siras vorlegen. Siebe řigur

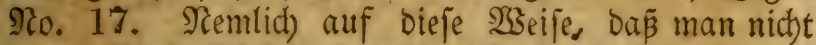
mebr (Siras Morgens abjhneiben follte, als man bes Iages über verfüttern fönne, bie erffen brei $\mathfrak{I} a g e$ ib= nen renig aber bod) nad) uno nad) mehr geben, uno fie alle völlig 14 Iage barin ftehen lašen; ibr gewöhn= lidhes Futter follte fein eingemeid)te (Serffe, Doch Deffen nidjt überflüfilig, aud) nidst fo viel als fonft ibr ge= wöbnlides ₹rutter in fith bält, Doch) Daneben (siraz ge=

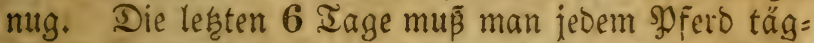
lid) 1 Şanbuoll frifde Scafelwurzel, fammt ben sBlät= tern frühe, ehe man ibnen etwas zu freffen gibt, zu freffen geben laß̄en, Daneben mü

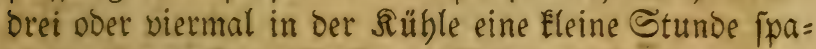

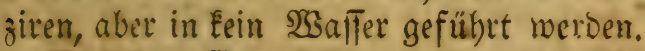

SRad) Dem (Şras foll man ihnen die Mäuler buţen, Den Staffel fted)en, Das Maul und bie 3unge wacter mit Efifig und Snoblaud, ভalz und פूfeffer abreiben, ibnen nod) etlid)e Iage (Serfte, aber nur ein Elein we= nig angefend)tet reichen lapen, damit fie Dez harten Futters wieber gewohnt werden.

So ball hernach ber Mono in Dem 2cbnehmen, uno

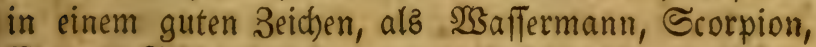
2Saage, Fifch, 3willinge, ober Firebs wäre, zwei Tage nacheinanoer, jedem 3 Suintlein Spiezgla $1 \frac{1}{2}$ Suintlein Srocus metallorum, uno fie aljo mie zu= vor fteben lapen.

Das Irinfen unter wäbrender Şrasftellung foll nicht falt, fondern einen balben Iag im Єtall vorber 
Yyferbe:2trgenei Budh.

fohon geftanden fein und allemal ben \$oferben etwas fchönes Mebl mit ein menig 2rgaric Darunter gerübrt reerben.

\section{Sine andere (Strasftellung $\mathfrak{2}$.}

So balo ber Nieberländifche Rlee eine Spanne bod) wirt, foll man benfelben ihnen vorlegen auf folgende SBeife. (Erfitlich den erften Iag ein wenig mit etwas gehacterter Scajeltrourzel uno Sleien, Den andern Iag ein mehreres mit fammt diefem $\mathfrak{B}$ ei= Futter, Des 3, 4, uno 5. Tages alfo vermehrt, bis fie völlig barin ftehen, bes 6ten Iages thue man die Scafelmutzel binneg, fammt Den Sleien, und nehme eingeweichte (Serfte, uno lape fie alfo ftehen, bis 15 Tage vorüber fino, alzbann breche man ihnen täglich wieber $a \mathfrak{b}$, ba $\tilde{\beta}$ alfo innerbalb 5 Tagen der völlige $2(b b r u d)$ wieber ba iff, fo fommen in allem 20 Tage beraus.

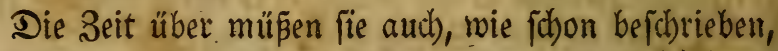
fpaziren gefübrt uno getränfet werben, mit nachfolgen= Dem Irane :

Rbapontic 6 loth,

Xgaric 2 loth,

Weidenichnamm 4 lotb,

Taujenogüldenfiaut 6 Scändevoll,

fiebe es in zmei (5imer $\mathfrak{B a f f e r}$ und tränke bie \$ferbe Des $\mathfrak{Z} a$ agez einmal Davon, Des 2 Cbenos kann man fie bon

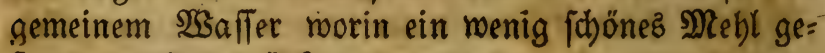
fotten worden tränkeen.

Darauf wenn ez in bem Calender gut, und bie Şike nod) nid)t vorhanden wäre, jebem eine Scalsaber und Sporraber auf ungleidjer Seite öffnen lapen, innen bie Räuler reinigen, uno an bas trodene grutter ftellen. 


\section{(5in a ndereb $\mathfrak{N}$.}

(Sib ifnen (3rüne gefd)nittene (S)erfte, auf bie $\mathfrak{M a}=$ nier, wie im vorbergebenden von bem Sieberländifden Slee befdrieben morden, anftatt Deb Futters aber gar nid)ts, als gehadte Scafelmutrzel, Bibenell, Sraunellen, (5)undelteben, Egrenpreip, wilben Salbei, jedes pine Scantovoll, bes Tages zroeimal für 1 Spfero fo viel ver= mijot)t mit şseizenfleien, läe es 12 Iage aljo fteben, bernach thue das Sräuterfutter hinweg, entziebe ifnen allgemach bie grüne SSerfte uno gib ibnen eingemeichte Dafür, bis 18 Iage vorüber find, alsbann bie झpferbe völlig im Ditrten Futter wieder ftehen follen.

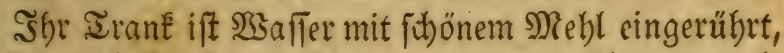
follen auch fpaziren gefübrt werden, wie fonon vermel= bet rorben. Man muß ifnen aber bie Näuler, wie id)on oft erwähnt, reinigen, ehe man fie an bas bürre Futter ftellt.

\section{(5) in a noereb গুG.}

SBet viel grüne SBobnen hat, Der. Eann ifnen fold)e geben, nemlid die erften Iage gar wenig, uno alfo bis es red)t Darein fommt, Dic Sobnen aber müffen etwas welf fein. Sobald es anbebt grün zuzürben, fo gib ifm Norgens ein wenig (serfte bazu, biefe (5ur foll man über 9 Iag nidht gebrauchen, alsbann wieber $a b=$ bred)en, Das Das Sूferd in 13 Iagen mieber in vollliger. trodkenen Futter fiebe.

Der Irant foll roarm fein und mit Sleien vermifd)t.

Den 15ten నag barnaúf foll man jedem spfero eine Scalz: oder Sportader auf ungleidjer Seite follagen. Ran mur fie auch täglich fpaziren fübren, nie fobon oft ermälynt morben. 


\section{Iferbe=2(rgenei buth).}

\section{sin a no e res.}

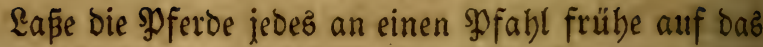
(S) ras binden, uno fobalo bie Scif̧c fommt, in Den Stall führen, bez 2rbendz mieder cin paar Stunden bin= auz, anftatt bes Futterz aber eingemeid)te (Serfte mit 1 Sanowoll Scajeltrurzel jebesmals geben, lap̃e es alfo 3 פ̇ochen lang gehen, alsoann ziehe es vom Giras, gib ifm mieder bürres Futter, uno im abnefmenten Mono barauf 3 Iage nadbeinanber jebesmal $\frac{1}{2}$ loth, 2Antimo= nium, ober $1 \frac{1}{2}$ Suintlein Scepar 2intimonium ein.Sieke Figut No. 19.

Ěin anderes, menn ein $\mathfrak{T}$ fero ganz mager, Dür

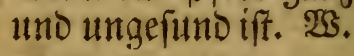

(3ib dem \$fero 3 Iage nact)einander im abnehmen= Den Mono biefés ein :

Şepar 2fntimonium, 1 Satintlein,

Saffran $\frac{1}{2}$ Suintlein,

Corallen 2 suintlein,

mifche ez untereinander, auf einmal in $\frac{1}{2}$ Maa $\bar{\beta}$ mal= men Mildy eingegeben.

Darnach ftelle Das \$gferb in einen Etano, brid) ifm die (Eifen ab, madhe ihm in 18 Tagen feine Streu un= ter, frtriegele uno buşe es auch nicht, uno tractire ez auf nachfolgenie Manier :

(Sib ifm nichts als gebactte Difteln zu eflen, ie jün= get bie Diffeln find, Defto beß̈er fie fino, mif́t)e barun,

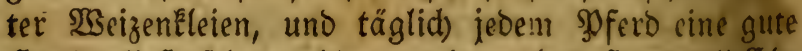

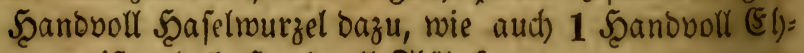
renpreís uno 1 Scanowoll Flöbefraut.

Der Irañ foll fein mattez flieffendes 2 Saffer, bas

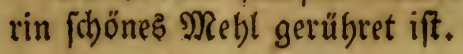




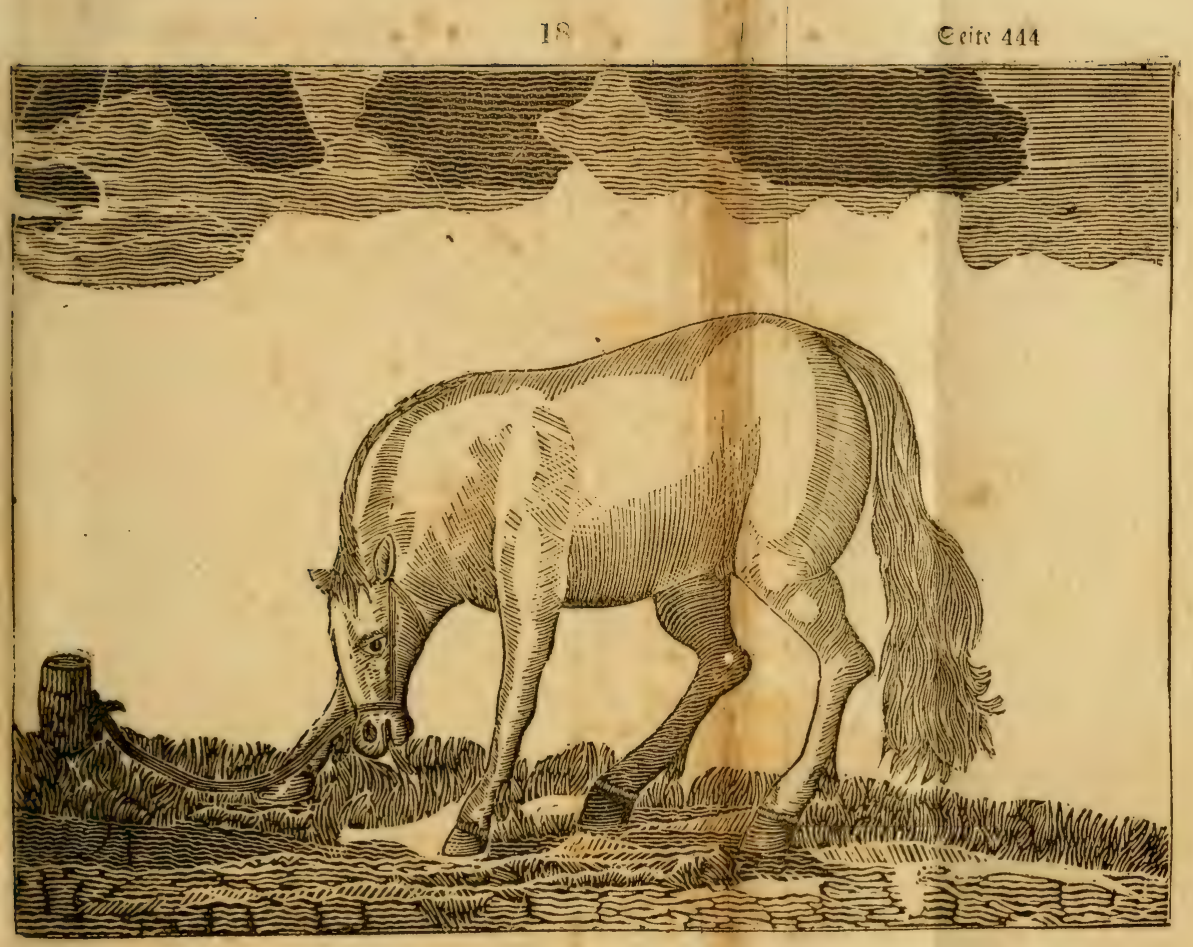




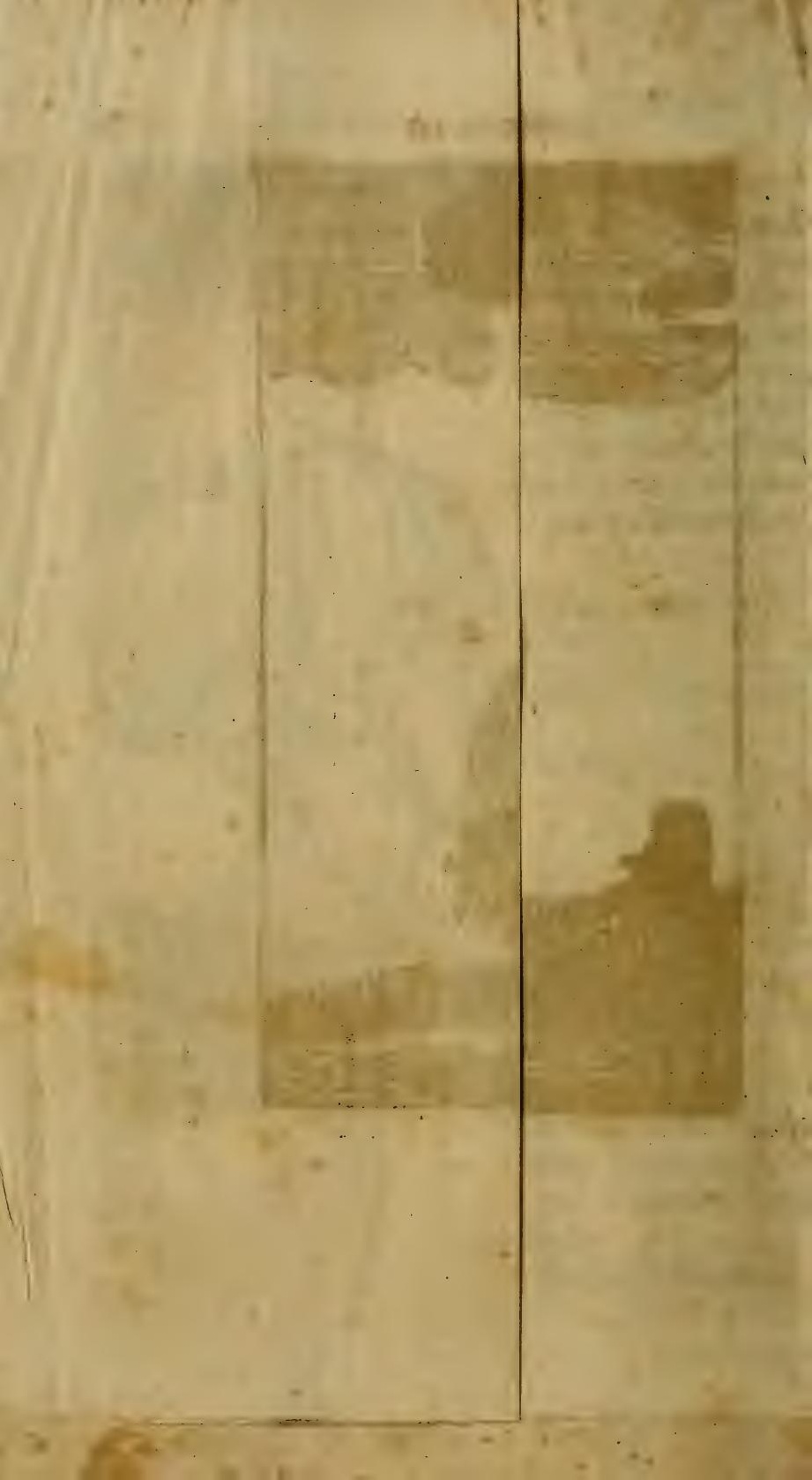


গad) verflopenen 18 Iagen foll man fie allmäblid) non Difteln entzieben, die ŞSurzeln uno Sräuter gar auslapen, uno ihnen etraz dürres geben, dafi fie aljo Den 22. Tag völlig in Dürren Futter ftehen. Sobals Die Spferbe ins trodene Futter fommen, mus man fie wieber fäubern, buţen uno befd)lagen, aud) täglich 2 Dal fpaziren fübren, 5 Iage bernad) wieder jedem Sp fero 3 Tage nad)einander 1 Suintlein 2fntimonium geben, und Dann wieder arbeiten laßen.

Nachoem Die SPferde wieder ins Dürre Futter geftellt jino, Eann man ibnen mebrere Iage jeben Tag eine 5̧anowoll grünes Bauchenlaub geben, melches die Scaare wieber id)ön uno glatt mad)t.

Dabei ift zu merken, Daś man wohl $\mathcal{Z}$ dotung auf die S) ferbe geben forl, inie fie purgiren, dann es hat nicht eines cine Natut wie bas andere uno wenn fich ein Pfero gar zu febr purgiren follte, fann man Demjelben die anftatt

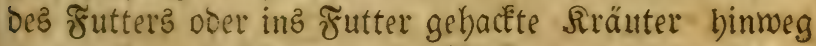

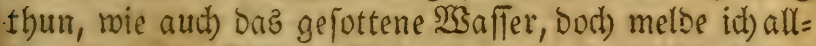
bier von liberflüfigem Shurgiren, on fie befwegen ins (3ras sefteft werden, dap fie fich fein tapfer purgiren follen.

\section{Daz 38 fte Capitel.}

S3on andern \$urgationen Der NTferbe inzggemein.

Sorwohl bei jeber Srantheit ifre orbentliche Spurga= tion gefert iff, fo roerden Doch nodh etlidbe allhier ab= fonoerlid) verzeid)net, Die man nac) (Selegenbeit gebrau= d)en Eant.

6 (Eier, lege fie in $\frac{1}{2}$ Maap. Effig über Sacht, fhütte Diefes Dem Sुferd MRorgenz frübe ein. 


\section{Pferbe=2(rzenei SBat).}

\section{Ein andereb.}

SSanfförner geftopenen, 3 Şänbevol,

Edowefel 2 loth,

mifche es untereinander und gib es dem গুoferd alle $\mathfrak{T} a=$ ge zu freffen, fete es etliche Tage fort.

E $\mathrm{i} \mathfrak{n}$ a $\mathfrak{n}$ Deres.

Mangolt 5 Şändecboll,

fiede benfelben wohl in 2 Maa sa Milch,

ftope ez untereinander und foütte es' dem \$ofero auf einmal ein, lape ez 4 Stunden barauf fteben, bernad nimm brei Scändevodr Scafellaub, zerftope es roobl in 1

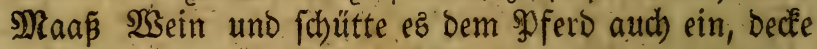
es warm zu uno lape es ein menig barauf reiten, fpren= ge ibm eine Zeitlang bas Sceu mit Calzmaffer.

\section{E $\mathfrak{i} \mathfrak{n} \mathfrak{a} \mathfrak{n} \mathbb{e} \mathfrak{e} \in \mathfrak{B}$ II.}

Säbenbaum 2 loth,

Mangolt 3 Scänoeboll,

Eiebitöokel faamen 3 loth,

Şanffaamen 5 Şänỏevoul,

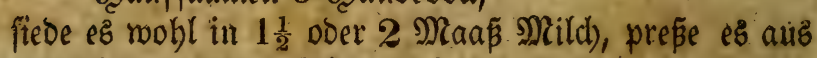
uno fchitte es bem Sofero auf einmal ein.

E $i$ and $\operatorname{ereb}$.

Man foll ihnen oft bon bem Erlengolz Salz, mie audd) vom Scollunderbolz Ealz zu frefien geben. Sol= dhes Salz wiro auf folgende $23 e i f e$ gemadtst:

Nimm Scollunder = uno Erlenlyolz, fo im Eaft ift, ein Stüct 2 Ëluen lang, bobre den Sern heraus uno füllle bas god) feft mit Salz aus, fablage oben uno un= ten ein Bled) vor, alsoann verbrenne bas Scolz mitein= ander, fo mirft bu ein graures Salz finden, hebe es auf зи Deinem (Sebrautd). 
Pferbe 2 (rzenei $\mathfrak{B}$ uक

Ein anderes.

Baaumöl $\frac{1}{2}$ Pfuno, Effig $\frac{1}{2}$ Maa $\tilde{\beta}_{1}$

Salz 1 Scandooll,

untereinanoer gemijcht und auf einmal eingegeben.

Ein a n Deres.

Ragelfraut 5 jäảnoevoll;

Sunges Seafellaub, ober die Sisipfel babon, smei

Scănoeboll,

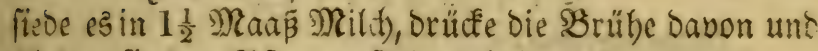
finutte fie Dem $\$$ fero auf einmal ein.

Ein anderes IB.

Spect oder Sdbweinenichmalz, Das nidht gefalgen worben 2 syfund,

(Serftenmehl $\frac{1}{2}$ Mfund, 2(garic 1 loth),

Salap $\frac{1}{2}$ loth, $\mathfrak{E}$ ein 1 Maa $\tilde{\beta}_{\text {, }}$

untereinanber gemifdt und auf einmal eingegeben.

Ein andereb.

Mild) $\frac{1}{2}$ Maa $\tilde{\beta}_{1}$

Unverjornes junges SBier $1 \frac{1}{2}$ Maaß̃,

untereinander gemifht und auf einmal singegeben.

(E) in anderes.

Igaric, 2lloes Epatica, jebez 1 loth,

Extract von (Eapiarinde, (Enzian, jebes 2 lork),

Salap $\frac{1}{2}$ loth, Sconig $\frac{\pi}{2}$ \$f fund,

Iurbitb), Soldanella, jebes 1 Suintlein,

Fliefiendes $\mathfrak{B a} a$ fer 2 Maā,

untereinander gemifd)t und auf einmal eingegeben.

(E) an a neres.

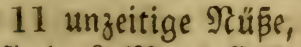

fiebe fie in $\frac{3}{4}$ Maá Effitis, thuz bazu 


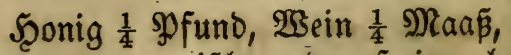
untereinander gemifcht und auf einmal eingegeben.

Ein andereb.

Saft von milden నiürbizmurzeln 3 loth, Salap 1 loth, Shonig $\frac{1}{4}$ \$ुfund, Zliependę $\mathfrak{2 s a f f e r ~} \frac{1}{2} \mathfrak{M a a} \tilde{\beta}$, untereinander gemifdbt und auf einmal eingegeben.

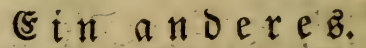

Raulbeetwutzel 2 loth,

Sdjwefel, Salpeter, jeoes 1 loth,

Mfeffer $\frac{1}{2}$ lotb, $\mathfrak{W}$ ein $\frac{1}{2}$ Maa $\tilde{\beta}_{\text {, }}$

Bibergeil 1 Suintlein, \&ffig $\frac{1}{4} \mathfrak{M a a} \tilde{\beta}_{\text {, }}$

mifche e's untereinanber uno fahütte es bem spfero auf einmal ein.

\section{E $\mathfrak{i} \mathfrak{n} \mathfrak{a} \mathfrak{n} \mathfrak{D} \in \mathfrak{r} \mathfrak{e}$.}

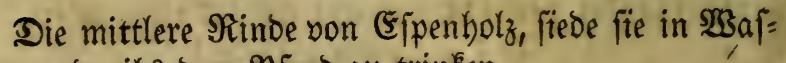
fer, und gibs bem \$ferd zu trinken.

\section{Ein anderez.}

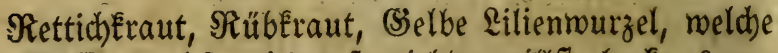

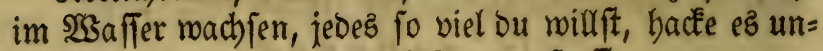
tereinander uno gibs dem $\$$ ferd zu freffen.

\section{Ei i a n Dereb.}

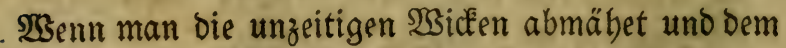
פSferb zu freffen gibt, follen fie auch wobl purgiren.

Ein anderes: $\mathfrak{i}$.

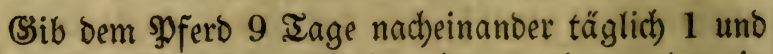
ein balbes Suintlein 2Cntimonium crubum, ober ein SZuintlein Scepar 2Intimonium zu freffen, es purgirt Das \$ूferd unfithtbar. 


\section{(5: in a nof $\mathfrak{x} \mathfrak{e} \mathfrak{g}$ IB.}

Seepar 2fntimonium 3 Suintlein,

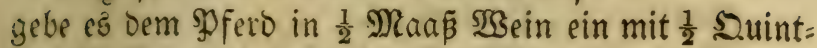
lein $\Im_{a}$ frran, és purgirt unfithtbar,

(5) in a n Derec.

Şajellaub 3 Scänievoli, Snoblauch $\frac{1}{4}$ PPłund,

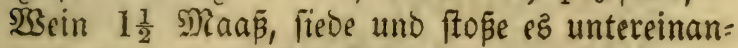
iar und fichutte es Dem Shferd ein.

\section{(E) $\mathfrak{i n}, \mathfrak{a} \mathfrak{n} \in \mathfrak{r} \in \mathfrak{b}$.}

Snoblaud $\frac{1}{4}$ SPfund, Mangolt 4 Şändeboll, Şafellaub 2 Şändevoll,

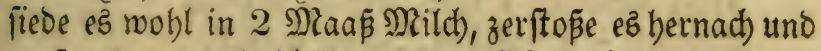

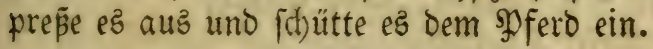

(sin anteres গIB. Spedt= Sur.

(Sib Dem Nfert, wenn ber Mono abnimmt, brei $\mathfrak{I} a=$ ge nid)ts als $\mathfrak{2}$ seizenfleien zu freflen : hernach

Ungefalzenen Epect, oder foldten Spect, ber orei Tage im 93 affer gelegen uno bas Salz heraus gezogen morden, 3 SDfund, ftope inn zu einem Brei, thue bazu

Saumol $1 \frac{1}{2}$ Dfund, Rorbeeren,

Jamarizénichelfen, jeoes 6 loth,

Runde Şoblmurzel, Reinfaamen, jedes 4 loth,

untereinander gemifcht und auf einmal eingegeben, uno

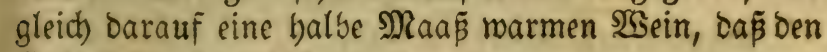
Şals folgender abjumengt.

Reite es alle Iage etwab, oamit es eine Berwegung babe, uno nenn es anfängt zu operiren, foll man bem

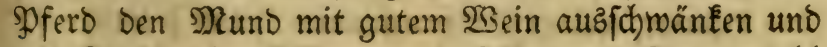
mit Snoblaud = (5ffig uno bie 3ähne und 3unge wohl

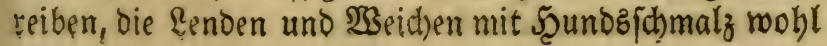


famieten und bem Sfferd täglich von nachfolgendem \$ulver 2 \&öffelvoll auf bem Futter zu freffen geben. Allantwurzel, Scohlmurzel,

SBlaue Sdivertelnurzel, jedes 3 loth, Meifternurzel 4 lotb, Rorbeeren 8 loth, Sellglänzende Dinrrben,

Boctzhornjaamen,

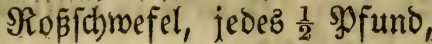
allez zujammen grob gepultbert.

(5) in andereb :

Scammonitum $\frac{1}{2}$ loth, Beinftein 2 lotb, aloes bepatica 1 loth, 2(garic $\frac{1}{2}$ loth, Iurbith 1 Suintlein, Salap $\frac{1}{2}$ lotb, Senesbtätter 1 toth,

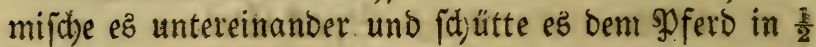

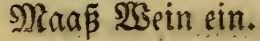

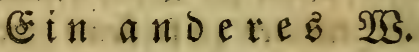

Sollunderrinden 2 Sändevoll, 24ttidbrourzel, Fsilde Sürbiznurzel, jeoez 2 lotb,

sunge Schöß̄linge vom feollunder 1 Scanovoll,

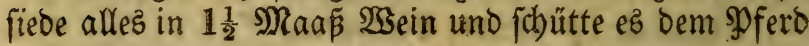
auf einmal ein.

3wei herrliche Fräuter=\$urgationen, befonberz fiir einen Sengit.

- Bom beften Manna 4 lot?), Engelfüp̈rurzel, Sonnenblumenblätter, sijegrwarten, jedes 1 loth, Iamarinoen 2 lotb, Scorzoneranurzel und Blätter, milder Safranjaamen, jebez $\frac{1}{2}$ loth, caroffelwurzel $\frac{1}{2}$ loth), Earoobeneoictentraut 2 loth, 


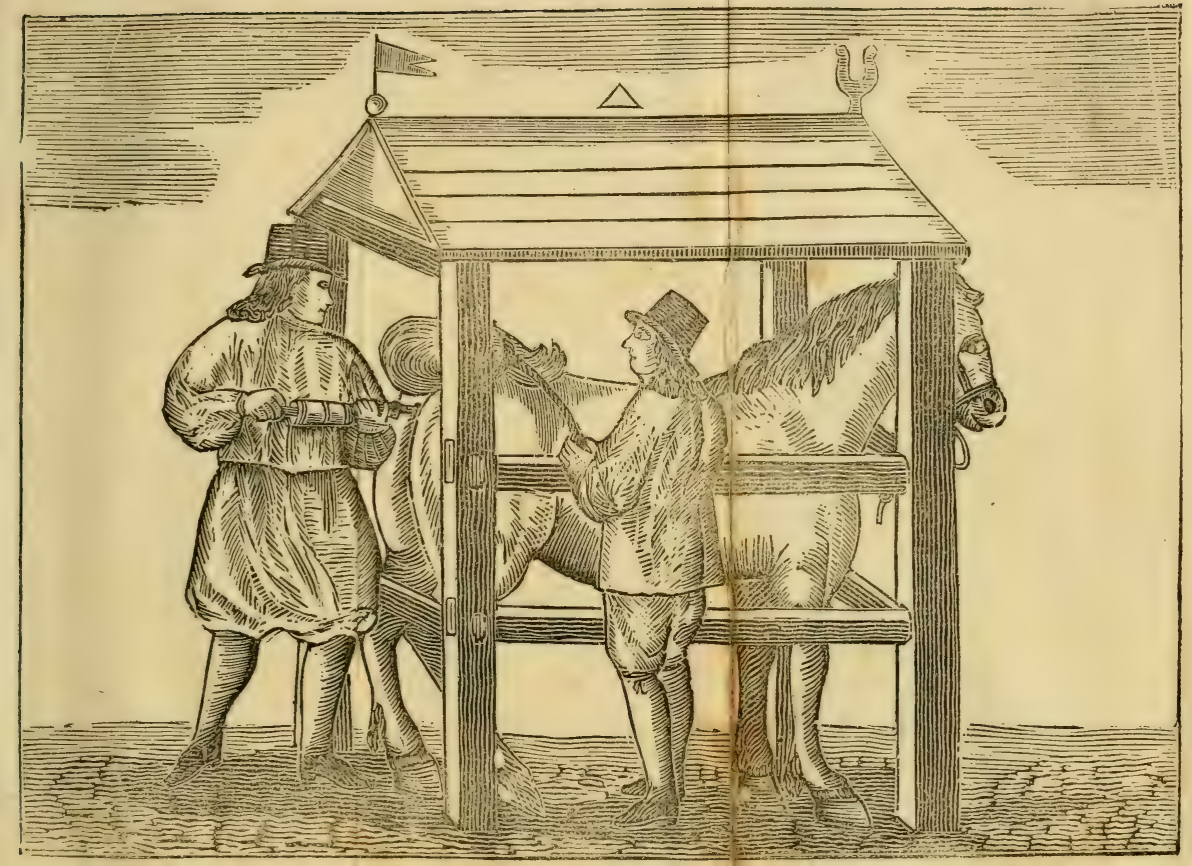




\section{(Salgant $1 \frac{1}{2}$ Suintlein,}

\section{Subentecflein 1 loth,}

Xntimonium, nad) Des şferbes 2lter, 1, 2 ober 3 Suintlein,

Dieje Siräuter zelfad)neide man flein, gebe ez dem Şengft Des Morgenz, laß̄e ilyn allezeit oarauf 6 Stunden fa= ften uno jefe pe fo lang fort, bis man meint, ez babe genug getban.

Die Dofiz ift auf einmal 2 loth.

Eine andere frräter $=$ Purgation, für eine Ctute befonderz.

Iamarinben 2 lotb, weipen Diptam 1 luth,

Rlyabnibara, Riebftöfelfaamen, jebes 1 Suintr.

2llantmurzel mit Dem Mlaut 1 loth,

Röffelfiaut 1 Scanbooll;

2fntimonium 1 ober 2 suintlein, je nach bes

Spferbes 2uter.

Diefes zerichneide man Elein uno gebe ber Stute nad) einem gelinden Futter bes $\mathfrak{R}$ orgenz 2 loth), laß̧e fie 6 Stunden barauf faften, uno fefe es fo lange fort, bis

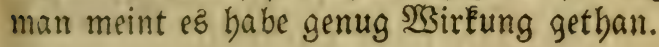

\section{Dab 39fte Capitel.}

Bon SInftiren uno Stulzäpfdyen inşgemein.

Sbroob! in allen ffezifizirten Srankbeiten ifre (Sly)= ftire veroronet find, (fiebe baz Reichen $\triangle$ ) follen bod) jum Ueberflus inggemein allbier nod) etlid)e gefegt ner= ben.

Rẳ̧pappeln, Särentlauen, Steintlee, 
Esibijh, Samillen, Sdhmeerkraut, jebes $1 \frac{1}{2}$ Scantov. Şseizenlleien 2 Şändebol, Eeinjaamen $\frac{1}{2}$ loth, Senesblätter 2 loth, Sajmarze Niesmurzel 1 loth,

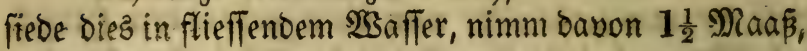
thue bagt:

Diaphönicon 2 loth, Salz 1 Scanouoll, mijche bies untereinander und gebrauche ef warm.

ein $\mathfrak{n} \mathfrak{n}$ exe .

(Eibifd, singelfraut, Rothen Beifup, Şlaues Şeilfraut, Sুappeln, jedes 2 Scändevoll, Eerchenjobromm 1 loth,

fiebe-ez in einer fetten Srühe, uno nebme bavon cit uno ein Galbes Maaß̃,

Extract von (5apiarinde 3 loth, Şonig $\frac{1}{4}$ SPfund, 7 Eierootter,

S̆alz 2 Şänoevoll,

mijoce es untereinander uno gebrauche es laulicht.

\section{Ein a ndereb- $\mathfrak{Z}$.}

Manerrauten, Eamillen, (5ibijch, Bingelmurzel, Sappeln, jedes andertbalb Scanovoll, Steinflee 1 Sanowoll, Boct3bornjaamen, Eximfaamen, jebes 8 loth, 2 2 niz, Fenchel, Rerchenichramm, Rbapontic, jeoes 1 loth, ftebe es in einer fetten Schmeimenbrübe, nebme davon anderthalb Maấ,

Eamillenöl, meipes হiđlienöl, jebes 2 loth, (5oloquintenmare 1 suintlein, 7 Esierbotter, Sconig 8 loth, Salz 1 Scanovoll, mifde es untereinander uno gebrauche es laulid)t. 


\section{(5) in a nDereb $2 B$.}

Robe Sierfte 6 Şändevoll,

Sleien, $\mathfrak{B u ̈ l f f r a u t , ~ ( E i b i f c h , ~}$

গappeln, jedes 2 Şändeboll,

Mauerrauten 1 Scandooll,

fiebe alles in fliepenoem $\mathfrak{B}$ affer, nebme bavon andert= balb Naaß̧,

Sdbreinenfdmalz $\frac{1}{2}$ spfund, Sconig 4 loth,

Baumöl 6 loth), 5 (sierdotter,

Soloquinten 1 s.uintlein,

Salz. 1 Sanovoll,

untereinander gemifdst und laulidht gebraud)t.

Ettlidye Etulzapfen, wenn ein \$ffero nidbt zürchen fann.

(5)reife fu Dem Sुferd und leere ifm Den Maftoarm, alśbann nimm ein Stück Spat pine Spanne lang uno 3mei ober 3 Fingerdi beftreue ifn mit dem Shulver von sopermenig und 2(ttic), und ftecfe es Dem Sמferd in Dem Maftoarm wohl hinein.

(5in andereb.

গimm Speck, in oer Sröpe, mie-allererft kefdrieben, beftreue denfelben mit gepüloertem Soriander, uno ge= braudje es wie vorbin.

Ein andereb.

Nimm Speck, mie ichon gemeldet, beftreue denfelben mit gepüloertem 2fgtfein uno gebrauche es wie oben be= merkt.

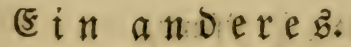

$\mathfrak{B}_{e}$ fdhmiere eine lange (Sanz=Feder mit Sonig, be= ftreue fie mit ein renig sofeffer Darauf uno fiecte es in Den Şintern. 
Pferbes:2(rzenei Budy.

(5in andereb. tern.

Stope dem spfero etliche Stücte Seife in ben Scin=

(5in anderes.

Rimm Dinten=3eug mit (5ierbottern angemad)t uno applicirs bem Dffero binten ein.

Daz 40 fte Eapitel.

Sagere Pferbe wieder zurecht zu bringen.

Diejenigen Spferbe, weldbe von üblei Bebanolung, Şunger ooer fonft vom $\mathfrak{L} e \mathrm{~b}$ fommen, mús man vorber examiniren, wie fie im $\mathfrak{L}_{e} i b$ befdaffen, ob fie alt ober jung find ; Denn nicht ein jedes spfero ift mebr zu cu= riren, wenn ein 3uftand überband genommen und ein = gewourzelt hat.

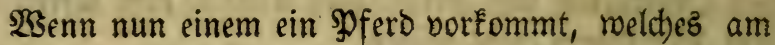
Reib angenachjen wäre, bas foll man jogleich purgiren. 23.

Scammosium 2 suintlein,

Aloes bepatic, Rerdbenid,wamm, jedes I loth,

Wein $\frac{1}{2}$ Maaßa, mifche es untereinander und ichüt= te eध Dem shferd auf einmal ein, continuirs über ben 4ten Iag zweimal im abnebmenden Nono, reibe uno

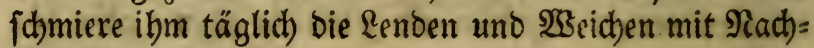
folgendem :

Sundsjichmalz $\frac{1}{2}$ Spfuno,

Sd)weinenidbmalz 1 spfund,

ख̉eí̄ę Rilienöl 8 loth,

\&oröl, Dialthäa, jedes $\frac{1}{2}$ Sp funo,

mifhe es untereinander zu einer Salbe. 
\$3̧enn nun bas Sुferd zmeimal aljo purgirt morben, fo lap̉e es in einem Sothffall mobl verwabren, uno rei=

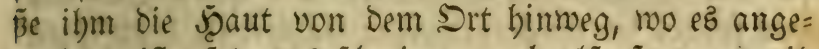
wad) fen iff, fese das (d)mieren nod) alfo fort uno gib if) unterbesen im Futter nachfolgendes \$ुulver zut freilen. $\mathfrak{3}$.

Enzian, Scoblnourzel, jedes 6 loth), Şajelrwurzel 4 lotb, Näusöbrdien, F̌löbetraut, jedes 4 5̧änbevoll, (Seipflee 8 loth, Scäfeline Bäpflein 6 loth, Bodf'bornjaamen 12 loth, Rorbecren 8 loth, Merrber 3 loth), (Sejuluabtes (slfenbein 4 lotb), arloes bepatic 1 lotb), Sd)wefel $\frac{1}{4}$ Spfund, mifche ez untereinander zu einem gröblichten Sुoulver, bie Dofis ift täglich 2 Röffelvoll im Futter zu freffen gegeben.

(sin anoeres, wenn ein Wfero nidst angenad)jen ift, Dem braucbe Folgentes.

(3ib ifm 2fntimonium $\frac{1}{2}$ loth 3 Iage nacheinander im abnefmenten Mlond; bernach lape ez auf bie IBseide am Pfald laufen, wie fdon im (Eapitel bon ber (Srasftellung gemeldet worben; oder brauche die Di= itel=(sur, meld)e auth in felfigem Sapitel befdrieben worden; Dodh foll man ihnen in räbrender (Sraşftel= lung oder Diffel=(5ur wöd)entlid) 1 loth 2(ntimonium: zu frellen geben.

(5in andereb.

Rorbeeren $1 \frac{1}{2}$ Ş fund,

Dürre $\mathfrak{B a}$ achbolderbeeren 1 SDfund,

Snzian uno Senftmebl, jeoes $\frac{1}{2}$ SIfund, 
mijche es untereinander uno gib ibm täglich 2 \&offel= voll mit 2 Röffelvoll Scollunoer = uno šrlen Salz wie fdon foldhes im vorbergebenden Sapitel ift befdrieben worden.

\section{E ina d d e reb.}

Birnbäumen Mifpel 1 ⿰冫 fund,

Saajel Miipel $\frac{1}{2}$ Pfuno,

כ̋urre $\mathfrak{B a c h b o l d e r b e c r e n ~} 1$ SDfuno,

Sãvenbaum $\frac{1}{2}$ Sp fund,

Erlen Salz 1 pfuno.

mijche es untereinander uno gib bem $\$$ pfero täglich 4 Roffelvoll im Futter.

(E) $\mathfrak{i}$ andereb.

Soctahorn jaamen $\frac{1}{4}$ şfund,

12 gefdälte 3miefeln,

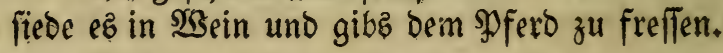

\section{(E) inderez.}

SSegmarten 12 loth, Sciridtrurzel,

Stbmalbenmurzel, jedes 8 loth,

Betonien $\frac{1}{2}$ Sfuno, 2(nis 6 loth,

Riebfítỏel jaamen 3 lotb,

(3roperer Neffel faamen 8 loth,

Sittwer, (Salgant, jeoes 2 loth,

Lorbeeren 1 Spfuno,

mijace es untereinander zu einem spulver und gib bem Spfero täglich 3 Röffelvoll im Futter zu freffen.

\section{Ei $\mathfrak{n}$ a noeres.}

Scajelnurzel 12 loth, Enzian $\frac{1}{2}$ \$fund,

- 2lantwurzel $\frac{1}{4}$ \$f funb,

Meiftermurzel 12 loth, Säpenbaum, 
Sinau, Sobrmenig, jebes 8 loth,

Flöbefraut, Birnbaummifpel, jeores $\frac{1}{2}$ ⿰冫funt,

5ajelmifpel, Bodţ̧ornjaamen, Edjwefel,

Eorbeeren, jedez $\frac{1}{4}$ Şfuno,

untereinander gemifht uno Dem গgfero täglid) 4 \&öf = felvoll auf bem ₹utter zu freffen gegeben.

E in a

Sodbe eine Scenne wobl, thue bazu

Sngiver 1 loth, şfeffer 1 Suintlein,

Saffran $\frac{1}{2}$ Suintlein, Rägelein $\frac{1}{2}$ loth,

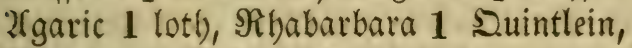

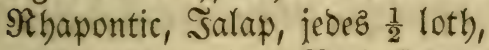

ftope allez wohl zu einem Brei, fef ese ez 2 Mtonate fort, alle 14 Tage einmal, gib ifm unterbesen ein wenig Serfte unter Dem Futter zu freffen.

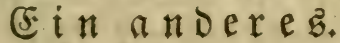

Rauten 2 Scändewoll, Mnrrhen 1 loth,

Rorbeeten $\frac{1}{4}$ \$funo, §ümmel 3 loth),

Baumol 1 গু) funo, $\mathfrak{W}$ ein 1 Maa $\tilde{\beta}_{1}$

theile es in 3 I Theile und fountte es Dem pfero anf 3 Mal ein.

E

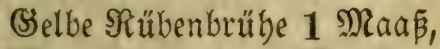

Mangolt3brühe $\frac{1}{2}$ Maa $\tilde{\beta}$,

Rauten, Rop̈münze, SteinElee, Iraganth,

(Eppid), $\mathfrak{N}(\mathrm{sermuth}$, jedes 2 loth),

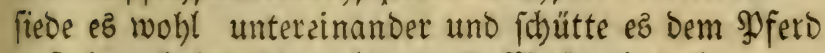
auf einmal ein, gebraud)e ez alle $\mathfrak{W}$ odhe einmal.

\section{Ein a n Deres.}

Die geoörtten (Sipfel von $\mathfrak{W a c h b o l d e r f f a n d e n ~} 1$ গुfunt, 
Senftmell $\frac{1}{4}$ Pfund, Salz $\frac{1}{4}$ Maá̃,

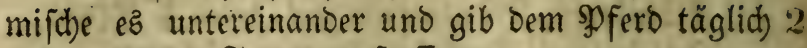
Scändeboll im Futter zu freflen.

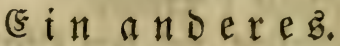

Siede গefleln in $\mathfrak{S a f l e r ~ u n d ~ t r a ̈ n f e ~ d a s ~ S P f e r b ~ t a ̈ g = ~}$ (id) eine Seitlang Damit.

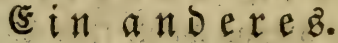

Bobnenmebl,

Erbjenmebl, gleich viel,

fitede es mit Şaffer uno Dörte es mieder, von biefem gib bernach Dem spfero in feinem geroöhnlichen Futter allemal eine Şanovoll.

(5) $\mathrm{in}$ andereb 2

Die Gipfel an ben Tannen und Fid)ten im Netz, Dörre biefelben, nimm bavon 2 sfuno,

Enzian, Ebermurzel jedes 4 loth, mifche ez untereinander zu einem Spulver, von biefem

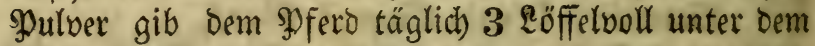
Futter mit ein menig $\mathfrak{B}$ eizenteleien uno Salz.

(E) in a n e reb.

(3ib Dem झुferd etliche Tage Mild)molken zu trinfen, fo purgirt es fich bavon und nimmt nad) und nad) zu.

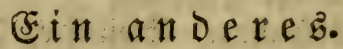

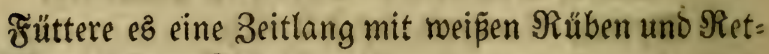
tich fammt bem fraut bavon.

Ein andereb.

Fütere baz sूferb eine 3eitlang mit halb gefottenem uno balb ungefottenem Roggen uno gib ibm fonft nichts zu freflen. 


\section{Pferbe=2(rgenei $\mathfrak{B u d}$.}

Ein $a \mathfrak{n}$ Dereb.

Rothe $\mathfrak{B u c f e n , ~ R e i n f a r r e n , ~}$

Seionifd) Wunderaut,

Brunnenfreften, jebes 3 Şändeboll,

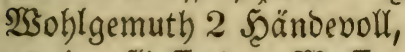

fiebe es in flieffendem $\mathfrak{W a f f e r}$ und tränle bas \$fFerd Dayon.

Ein andereb.

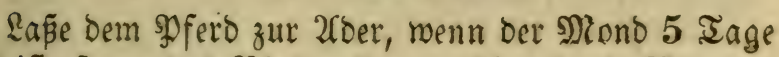

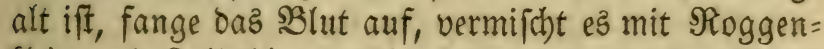
Eleien uno Ralbzblut, wohl gebört und gibs dem Sुferd ơ freffer.

(5) in andereb.

Das Sägmehl bon Tannen = ober fidhtenholz, fiede

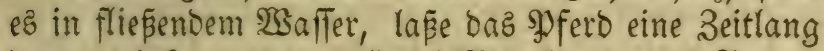
Davon trinfen uno thue Saạel Mijpel unter Daz Futter.

\section{(5) $i \mathfrak{n}$ and $\mathbb{E} \mathfrak{X} \mathfrak{E}$.}

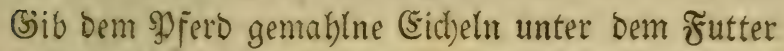
Doer fiede gefdnittene und unauggedrof chene Sabergar= ben im $\mathfrak{2}$ Gafler, tränEe das Sferd Davon uno gib ifm das (Giefonittene zu frellen.

$$
\text { E } i \mathfrak{a n d e r e s . ~}
$$

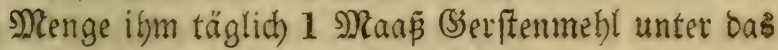
Futter.

(F) in andereb

Enzian $\frac{1}{4}$ Sूfund, Ealmub $\frac{1}{2}$ SDfund,

3ittwer, 3 loth,

(3rauen Sdjwefel 2 Sp fund,

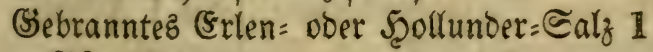

şofuno, 


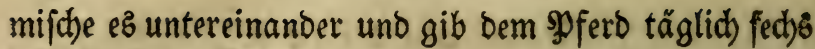
\&öffelooll ins ₹utter.

\section{Ein a noeres.}

(Sib ibm bie blofe 2lantwurzel 1 Nonat auf Dem Futter zu freffen.

$$
\text { E i n a n o ere b. }
$$

Scajelnurzel $\frac{1}{2}$ Sfund, 1 2meifenbaufen,

Eorberen, Bodłzhornjaamen, .

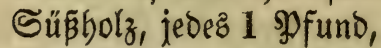

Senezblätter 3 Scändevoll,

Rerchenfotwamm 1 lorh,

23eidenfchroamm $\frac{1}{4}$ PFuno,

\&ungenÉraut, \&eberEraut, Ełrenprei mī mer Sal= bei, Sceionifch Şundkraut, jedes 6 Scändeboll, fiede es in einem Seffel mit fliependem $\mathfrak{B a f f e r}$ uno la eE 1 Mcnat folchen Trank trinken, (man Fann bie $\mathfrak{2} \mathfrak{r}$ : zeneien zum zmeitenmal fieden, uno oarnad) frif(t)e neb)= men) uno gib ibm nach, folgendez \$ुulver zu freflen, wenn ber Tlank über ift.

\section{Ei $\mathfrak{n} \mathfrak{a} \mathfrak{D} \in \mathfrak{r} e \mathfrak{b}$.}

Säbenbaum 2 loth, \&orbeeren 3 loth,

Sdhnefel $\frac{1}{2}$ loth,

SunigunoisEraut, fammat ber Sצurzel 2 loth, mifche und pülbere es untereinander, thue bazu 3 Eier,

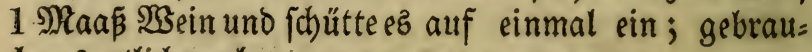
dbe es etlichemal.

\section{(5) $\mathfrak{n}$ a}

Dürre $\mathfrak{W}$ adb bolderbeeren 3 Sp fund, Enzian, Bodæzbornfaamen, jedes 1 Pfuno, Bobnenmebl 2 sfund, Stabrutzel, 
(Sitauen Sd)mefel jedes $\frac{1}{2}$ SJ fund,

mifde es untereinander, und gibz dem भूfero im fut= ter mit ein menig gebranntem Erlen= ober Scollunder= Salz täglid) 4 ober 6 Ioffelvol.

\section{E in andereb.}

ऽdütte Dem

(5 i $\mathfrak{n} \mathfrak{n}$ De $\mathfrak{r} \mathfrak{e}$.

(Sib dem Spferd täglid) 3 Şändevoll gefottenes Şei= Denforn unter bem Futter.

\section{Ein andere}

(5i) ifm gemallene Flatbjbollen, aus benen Der Reinfarmen beraus ift, zu freflen.

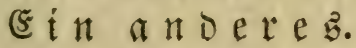

Roggen, Şerfte, Şaber, Wraizen, jedes 1 Maaß,

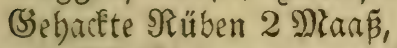

fiede es in ${ }_{23}$ affer, uno von biefem allem gib ify alle= mal 2 5änorooll im futter mit ein menig Salz auf einmal zul freflen.

\section{Ein andereb.}

?Rimm ungeoroidbene Şaber= uno Roggen=(S3arben lape fie flein foneiden, mit $\mathfrak{S a l}_{3}=\mathfrak{W}$ alfer angemadyt, und bem spferd gu freffen gegeben.

(f) $\mathfrak{i} \mathfrak{a} \mathfrak{n} \mathbf{D} \in \mathfrak{r} \in \mathfrak{b}$.

(sut (s)efoo, 2 Ibeil,

(3)brobene (Serfte 1 Theil,

untereinander gemifht und bem spfero zu freffen gege= ben.

Ein a noeres

(3)eörrte $\mathfrak{2 3 a d b o l b e r b e e r e n ~ z e r f t o p e n , ~ S e n f ~ u n o . ~}$ 
Salz untereinander vermifcht und bem \$pfero unter bas Futter gefidultet.

\section{Die Serpflegung.}

1. Der Stall foll mittelmáfî̉ warm und trocten fein.

2. Das Futter ift zum offtern in ben Recepten be= fdrieben morben, wie aud) ber Irante.

3. Șm Sommer foll bas Spfero mittelmäpig warm, im $\mathfrak{B i n t e r}$ aber wohl warm gebalten werden.

Das 41fte (Sapitel.

Bon Den Nieren=Sranfheiten Der Pferde, und erfttich vom Sand. Srief und Stein Derfelben.

Dieje entfitehen aus Den fcharfen uno fibleimigten Feuthtigkeiten uno mancherlei (sebrechen, als Sano, Stein, Ěnzünoungen, Schwären, fo wie audh von ftar= Eer Bemegung, Fallen, Schlagen, Iaumeln uno 1 teber= nöthigung mit bem Gsräbenjpringen uno bergleichen, ba bann leichtlid) bas (seäber zerriffen wirb.

Die Beidben fino meiftentheils an oem Sarn zu felien.

1. Sommt ber Sdymexz bon zufliipenden uno beif= fenden Feurchtigkeiten, wie auch vom Stein, jo ift ber Scarn trüb uno itwas röthlicht.

2. Rommt er von Shfíwären, ober ba etwas zerrif= fen ift, wie auch vom Stein, fo iff ber Scarn blutig, ei= terid)t uno etras jodwärzer.

3. Rönnen foldhe Spferde mit bem Scintertbeil be ¿eibes nid)t nachgeben, fondern bauthen oft barnieder. 
4. Sönnen ben ltrin nicht leichtlich laffen.

5. Sino Eraftlos, uno lebnen fid) im geben an bic Waand.

6. Die Bande, welthe das (siefdäft befeftigen, lau= fell auf uno werden länger.

7. Rönnen baz Maul nicht weit auftbun.

Sur Der Gdymerzen, weldye von Den fdarfen Feuchtigfeiten, Edynterzen, Sand, Siries uno Stein herfommen.

Diefen spferden foll man vor allen Dingen Clyftir gebraud)en.

¿einfaamen, Bingelfraut, syappeln, (5ibifh,

Nauetrauten, jeoes 1 Seanonoll,

(3)erfte 2 Şändeboll,

fiebe alles in fliesendem $\mathfrak{B g a f l e r , ~ n e b m e ~ v o n ~ b e t ~}$

Brübe 1 Maañ, Galz 1 Şanovoll,

Loröl, Samillenöl, jedes 4 loth,

$\mathfrak{B a u m = S D e l} \frac{\mathrm{I}}{4}$ SDfuno,

mifde es untereinander zu einem (styftir und gebrauthe ę laulicht.

Ein andereb.

(Fppid), Bibenell, Dillen, jeoes 2 loth,

Mrurtben 1 Suintlein, rotben $\mathfrak{B}$ sin $\frac{1}{2}$ Maas, untereinander gemifdt uno auf einmal eingegeben.

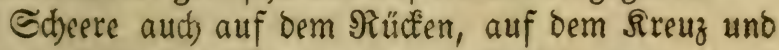

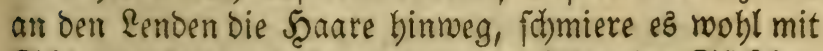
Sdblangenfett uno lege ibm oft folgende Säcéden marm über.

Srombeerftanden,

Eicbenlaub, eines fo viel als das andere,

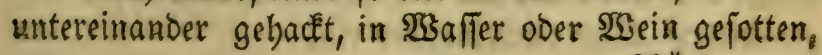
$39 *$ 
in Sädechen gefüllt und oft marm übergelegt, Dapelbe barneben mit einer Decke nobl zugebunben.

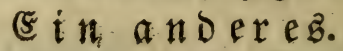

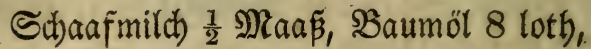
Sciridenmare 4 lotb,

warm untereinander gemijht uno eingegeben.

E $\mathfrak{i}$ a $\mathfrak{n}$ Dereb.

Gundelreben, Mauerrauten, Sinngrün,

Steinflee, rotben Mangolt,

Şach holberbeeren, jedes 2 Şändeboll,

fiede eb zujammen in $\mathfrak{S e i n , ~ n e b m e ~ b a v o n ~} \frac{1}{2}$ Naaß

Srebsaugen 1 suintlein,

untereinander gemifdht und auf einmal eingegeben. -

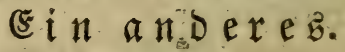

SBeinreben, Sfirfichlaub,

2ttich, jedes 3 Scändeboll,

Steinbred), Mauerrauten, Schaafgarben,

Rorbeeren, jedes $\frac{1}{4}$ If fund,

miface es untereinander, fiede es rookl uno fautte bent SDFerd täglich $\frac{1}{2}$ Maa $\tilde{\beta}$ ein.

E $i \mathfrak{n}$ a $\mathfrak{n}$ Dereb.

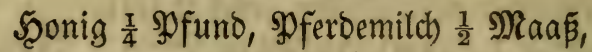
untereinander gemijcht und laulicht eingeaeben.

Ein and ereb.

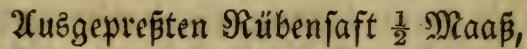

Speterleinşaft 4 loth, Rettichjaft $\frac{1}{2}$ Maá̃,

Srunnenkrepenjaft 8 loth,

\$ firfichlaubwaffer 1 Maaß̄,

mijche alles untereinander und fhütte es bem spferb auf goveimal 2 Iage nadbeinander ein. 
SWenn grope Scike vorbanden, fo Eann man nad)= folgenden singuß getien :

N. SB. Süpjbolz 4 loth, Scabiofen,

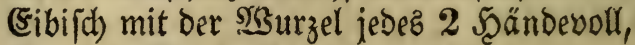

(Sichchälte SSerfte 3 Scänoevoll,

fiede es wohl untereinander, nimm von ber abgefeibten

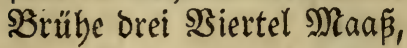

Irrebsaugen $\frac{1}{2}$ loth,

untereinanoer gemilicht uno auf einmal eingegeben.

Ein andereb $\mathfrak{B}$.

(Sarbentraut, $\mathfrak{2}$ egtritt jedes 2 Scändevoll,

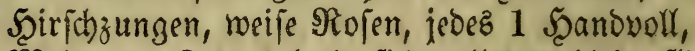
Melonen = Siern 1 loth, fiede alles mobl in flief:

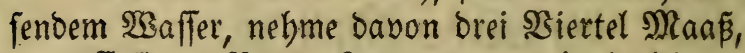

(5ffig $\frac{1}{4}$ Maaß́, Rrebsaugen 2 Suintlein,

Spiumtinftur $\frac{1}{2}$ Scrupel, untereinander gemifdt und auf einmal eingegeben.

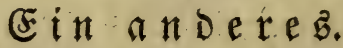

Eibifchmurzel 8 loth, Srope Rlettenwurzel, Bingelfraut, $\Re$ öbrleinḱraut, Scaubedbl, jedez 4 Scändevoll, Süßjolz 8 loth, SPfirfichern, Melonentern, jedes 3 loth, sffifg 1 Maá, Ierpentin 2 pfuno, Branntenein 6 Maá̃, Saffran 2 Suintlein, 3immet 2 lotb,

nerbaue ez im Salneo 14 Iage, hernach diftillirs lino berüber, von biefem diftillirten $\mathfrak{B} B a f f e r$ nimm 6 loth,

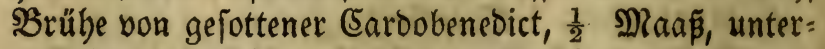
einander gemifdot und foütte es auf einmal ein, ge= brauche ez bis zur Sefferung. 


\section{Pferbe=2(rzenei buth.}

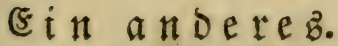

Rotbe Bifer= (sibjen, faubere (serfte 10 loth,

(Eibiji) faamen, Spappelfaamen,

Sittullenjaamen, jebes 1 loth,

Melonenfaamen, Rürbizaamen,

Sucumernfaamen, jebes 2 suintlein,

Süpholz 3 loth, 11 Feigen,

Butuffeerdisen 1 loth,

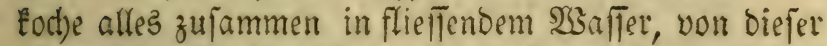
abgefeibten Brïge foutte Dem SDFero auf einmal brei Biertel Nana ein, gebraud)e diş etlid)e Tage.

\section{(5) i $\mathfrak{A} \mathfrak{n}$ De $\mathfrak{i e b}$.}

Salpeter 2 loth, Sirebzaugen 1 Suintlein, Bibenellaamen 2 suintlein,

$\mathfrak{B} e i \tilde{\beta} e n$ 2ugftein 1 suintlein,

Solue 2 Suintlein,

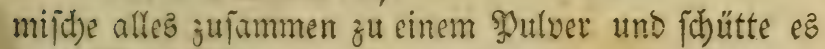
in $\frac{1}{2}$ Maą $\mathfrak{g e i n}$ ein.

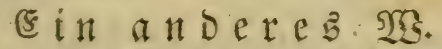

Sirebsinugen 2 saintlein, 2llantwurzel,

Sappernutzel jeoes 1 loth,

Syeteritlienfaamen 3 Suintlein,

Singroer 2 Suintlein,

Nuscatenblüthe $\frac{1}{2}$ Suintlein,

pülvere und mifiche es untereinander uno foütte ę dem

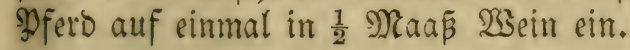

(5) in andereb.

Bockbblut 2 suintlein, SSilde Sd)meinezähne 1 lotb, Meerrettig, Speterfitienmurzel, . Rettich, jedes anderthalb loth, 
Sreb́ăaugen 2 suintlein,

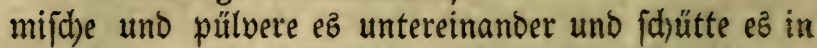
einer balben Maaß̄

Ei in anderes 23 .

Subenftein, Eryftall, jedes 4 loth,

\&uxftein, Sdnnammftein,

acolerftein, jebes 2 loth,

Riefelftein, rotben, gelben uno meip̈en,

SBeinftein jedes 8 lotb, Salpeter 1 spfund,

calcinire es miteinander in einem Şäffnetsofen.

Nimm von biejem Sulver andertbalb loth,

Sarpfenftein $\frac{1}{2}$ Suintlein, Terpentin 6 lotb),

Sirebzaugen 2 Suintlein,

Warmen $\mathfrak{W e i n} \frac{1}{2}$ Maaßä,

untereinander gemijht und auf einmal eingegeben.

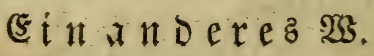

(Salcinirte Meiffen,

Calcinirte $\mathfrak{B} a \mathrm{ch}$ ftelzen,

Salcinitte Sud?ude, jebes I loth,

Calcinirte Merjbaafen 6 loth),

Sräparitte Efelzmürmer, Bod̋blut,

Merzhaajenblut, jedes 2 loth,

$\mathfrak{Z}_{3}$ adb boloerjalz;

(5id)enbaumfalz, jeoez 2 suintlein,

SGermutbjalz, Seafelfanden falz,

Sdjöllerautialz, Şseinfteinjalz, jeoez 3 lotf,

Salpeter 6 loth,

pülvere es uno mijche es untereinander uno gib bem şofero täglich 1 loth von biefem soulver in einer balben

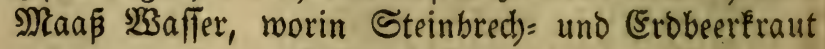
gefotten roorben, auf einmal ein. 
E in a noerez

Terpentin= $\$$ el $1 \frac{1}{2}$ loth, 2 getftein 1 loth,

Iniz=:Del $\frac{1}{4}$. Suintlein,

Sirebsaugen 1 Suintlein,

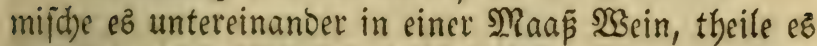

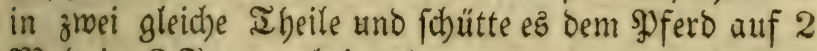
mal pin, 2 Iage nadpeinander.

\section{ธี i n no eres 25 .}

Balfamum futphuruz İerebinth, İerbentinöl,

TSach holderkeeren: Del, jebes $1 \frac{1}{2}$ loth,

Stebzangen 1 S.uintlein, $\mathfrak{B s e i n} \frac{1}{2}$ Maá̃, untereinander gemifcht und auf einmal eingegeben.

\section{(E) i a n D e re b.}

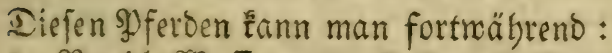

1. Rettict)=2Saffer-2. Salz-3. Neterlingfaft4. Mauerrauten-5. Sinngrün-6. Rothen Man= golt-7. Sorunnenfrepen-8. Sundelreben in 2 sein gejotten, geben.

\section{Die Berpflegung.}

1. Ein trodêner mittelmäpig warmer ๔tall.

2. Dab Futter foll gebrodbene Serfte ober Shafer fein, fo mie auch Seeu mit Salpeter befprengt, allerlei fteinbred)ende Rräuter uno 2 Şurzeln.

3. Der Iranf foul laulid)t fein, in weldhem Etein= bred), Schaafzgarben, SGachbolderbolz, (Ef foenbolz uno Xlantwurgel gefotten roorben, worunter $\mathfrak{B}$ Seinftein und Salpeter follte vermifaht meroen.

4. Dab গুferb joll ftill gehalten merben. 


\section{Das 42fte Capitel.}

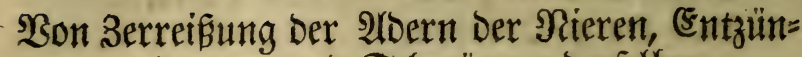 Dungen und Cofwärung Derfelben.}

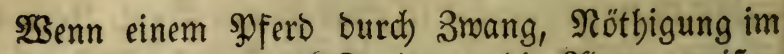
Bieken, Iragen, ober, Springen, bie 2Coern zerripen rorben, fo ift biefes aus ber \$siellyeit Dez blutigen Scarnz zu erkennen, Dem foll man alfo vor allen Din= gen ben \&eib mit borbejdriebenen Sinftiren offen bal= ten uno reinigen, bie 2roern beim (Sejdröt, boch nicht viel Blut laffen, zu Dem SBlut foll man Edbmeer neh: men und die \&enoen und auf Dem $\Re$ ücten nobl binein reiben, aud) folgenoen Irant oft eingeben :

Weizenmebl $1 \frac{1}{2}$ Sanovoll,

(siranatäpfelichalen 1 loth,

Sdineinenfd)malz $\frac{1}{4}$ Sfund,

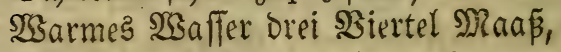

untereinander gemifcht und eingegeben.

Man foll inm auth bie vorbeforiebene Elyftire ge= brautben, befonders in zufälliger Scise, und warme Säckd)en von Bobnen, Serfte, Reinfaamen uno Boctz= bornjaamenmebl oft überfhlagen.

Ein andereb.

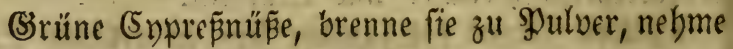
bon biefem Shulver $1 \frac{1}{2}$ loth,

Salpeter 3 loth, Baumöl 6 loth,

פBein $\frac{1}{2}$ Maás, mifche es untereinander uno gebe eక dem SDferb auf einmal ein, gebraude ez etliche $\mathfrak{Z} a g e$.

\section{(E) $\mathfrak{i} \mathfrak{a} \mathfrak{n} D \in \mathfrak{r} \in \boldsymbol{B}$.}

ఇebme ausgemachten Scirfen, thue benfelben in einen Ieffel, fdütte (Efitg Daran, bamit ir feudst merbe, uno 
mathe Denfelben heis; thue alsbann Dialtheä und $\$_{0}=$ puleor: bazu, famiere daz פDferb wohl um bie \&enden

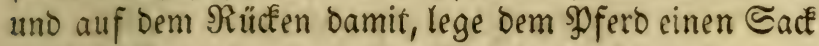

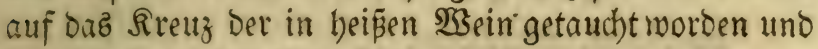
mieberbole foldhes Uleberichlagen oft.

\section{Ei in a n ere}

TSaths, lebendigen Gdinefel, jedes 3 loth,

Spoponax 1 loth, Effig fo viel nötbig ift, untereinander gemifdt und bie Renden bamit gefochiert.

(E) i I andere .

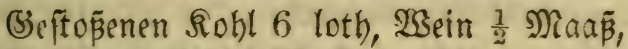

(Ein wenig Ealtez Safler, mifde ez untereinan= Der uno lege es auf Den jamerzbaften srt.

E in a n o ereb.

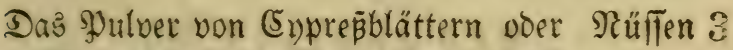
Siertel Spfund, (Serftenmebl 1 Dfuno,

23 ein=sfifig fo viel als nöthig ift, madje einen Brei baraus uno lege e's auf ben fdaobaf= ten Sort.

\section{(E) in a nexeb.}

5atz 4 loth, fiede es bis es zergehet, thue baju

(Serftenmel)l, Bodfunichlitt, biz ç bicf mirb, algbann fid)lage es roarm über.

(5in anderes, menn die Nieren fownüren.

(Serftenbrübe $\frac{1}{2} \mathfrak{M a a \tilde { \beta }}$

Das $\mathfrak{W}$ cí̄e bon 9 (5iern, untereinander gemijat und eingegeben.

\section{Ein a noereb.}

Soche (Sierftenmeb! in @ibaafmild), 


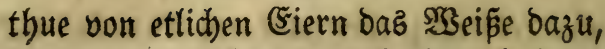
untereinander gemifdt und auf einmal eingegebent.

Ein a $\mathfrak{d}$ de $\mathfrak{r}$ e \& $\mathfrak{B}$.

SodłEblut, Şirfhblut, Şajenblut, jebes '2 Suintlein, ふrebsaugen 1 suintlein, Senedifchen Terpentin $1 \frac{1}{2}$ loth);

W3ein $\frac{1}{2}$ Maaß̧, mache eకs marm untereinander und jhütte es bem \$ुfero auf einmal ein.

Soer ben Sopf uno Sdbwanz von einer Siblange gefdnitten, Denielben weggethan, Das Nittlere zu flei= nen Stücken zerbackt, uno es in einer \$Dfanne braten lapen, bejer aber ift ę an einem Spiés gebraten, bis alles Feuchte Davon trieft, mit bem übrigen Fett bie Lenden und daz Sreuz gefdymielt.

E i n a n Deres $\mathfrak{B S}$.

Rbabarbara 2 Suintlein, Rbapontic 1 lotb,

Die Brübe von gefottenem $\mathfrak{B}$ egerid) $\frac{1}{2}$ Naá̃, untereinander gemifdt und auf einmal eingegeben.

$$
\text { Ein anderes }
$$

Benedifchen Ierpentin $1 \frac{1}{2}$ loth,

Srebsaugen 1 Suintlein,

Diftillirtes :Saffer von Ebrenpreiß,

Sorzelfraut, $\mathfrak{S}$ egtritt, Sanickel, Seeblumen,

Rofen, jedes 6 loth,

untereinander gemijht und auf einmal eingegeben.

$$
\text { 5 in a n D e e s. }
$$

Rbapontic 2 loth, $\mathfrak{B}$ ein $\frac{1}{4}$ Maaß́,

Rlbabarbara 2 suintlein,

\$rãpuritten Blutftein 1 lotl),

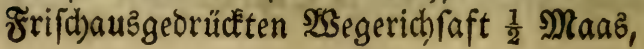


unteleinander gemifdt und auf einmal eingegeben.

\section{(5in a noerezs ș.}

S(baafmild) Drei Biertel Maā́, Irodiffi be Sarrabe 1 Suintlein,

Rotben Bolus 2 Suintlein, untereinander gemif(ht und auf cinmal eingegeben.

E in a noerez $\mathfrak{B}$. Tormentill, $\mathfrak{2 B a l l m u r z e l , ~ j e d e s ~} 2$ loth,

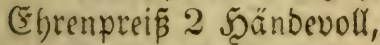

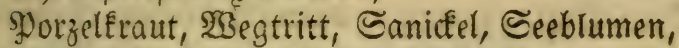
Rotbe Rofenblätter, jeoes 1 Scanovoll,

liebe es in rotben $S_{3}$ ein :

Nimm Det gefottenen Brühe $\frac{1}{4}$ Maá̃,

Shräparirten Slutfein, Negelein $\frac{1}{2}$ Suintlein,

Soluz 2frmen. jeocs 1 Suintlein,

Ierra Sigillata 2 Suintlein, unteteinander gemifht und auf einmal eingegeben.

Ein a nderez 2 S.

(Gid)enlaubmaffer $\frac{1}{2}$ Maấ,

Solzelfrautwalfer,

2Begeridymaffer jeoes 6 loth,

Raubani opiati 12 Sran, untereinander gemifdt und auf einmal eingegeben.

Ein andereb.

Salbe von Dialtbeä, Spopuleon jedes $\frac{1}{4}$ spfund,

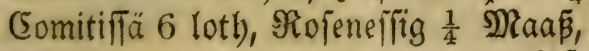

mifd)e es untereinanoet und falbe bas şfero an ben Renoen uno auf Dem Siüden mobl bamit.

Die 25 arte ift wie in Dem vorbergebenden Sapitel bijhrieben worben, auffer Daß̄ man Terpentin in ben Irane rübren foll, weldber Trant aber gefotten fein iollte von folgenoen 2 rzeneien als: 
Pferses:2trzenei Budy.

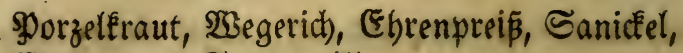
Waallwurzel, Tormentill, Seetlumen, jebes gleid) viel.

\section{Dab 43|te Capitel.}

Bon Dem Saarn und Der Blaie, ihren Srant= beiten und von Der Sarnwinde."

Dieje Blaje ift breien unterifbiedlichen Iranbeiten unterworfen, als ber Scarnwinde, Eauterftallen und Blutftallen, Desmegen wir in biefem Eapitel bon ber Scarnwinde allein reden wollen, melche wieber in brei unterichieblid)e Urten getbeilt wird, als in Stranguri= am, Dyjuriam und $\Im$ idouriam.

Stranguria wirb genannt, wenn bas şferb Den Scarn Iropfenweiz mit einem Irieb und 2inteizung aud) gropen Sdymerzen von fich gibt, und beżwegen bie Scarnminde genannt wiro. Siebe figur No. 19.

Dyfuria, wenn bas \$fero fibwerlich uno mit Soth ftallet, miro von etlichen oer Ealte Said) genannt.

Sid huria miro genannt, wenn ber Scarn gar verbal= ten uno daz \$ুfero gar nid)t faallen mag. Siełe Fi= gur $\mathfrak{R}$. 20, biez ift bie gefährlidffe, uno bie nennt man ben গothffall.

Die Stranguria oder Şarnwinde, (Da bas \$fer ben Scarn nur Tropfenmeis lap̄en Eann, ) wie bie Fi= gur 19 zeigt, bat inren uriprung entweber von ver= gallter Sdjärfe, ober auz einem Manget Der Rieren

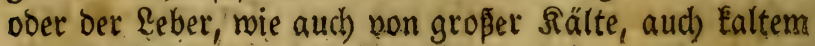
Saufen. 
Eeite 474

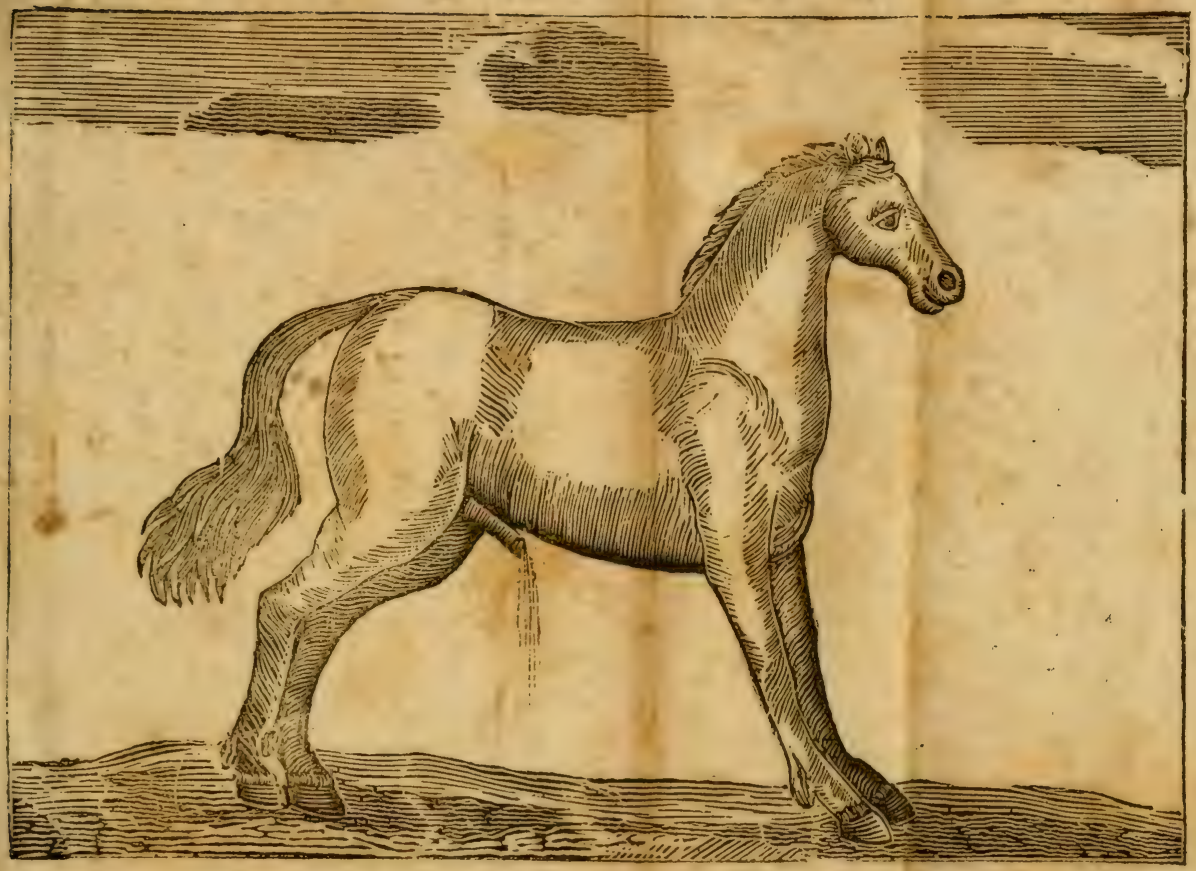




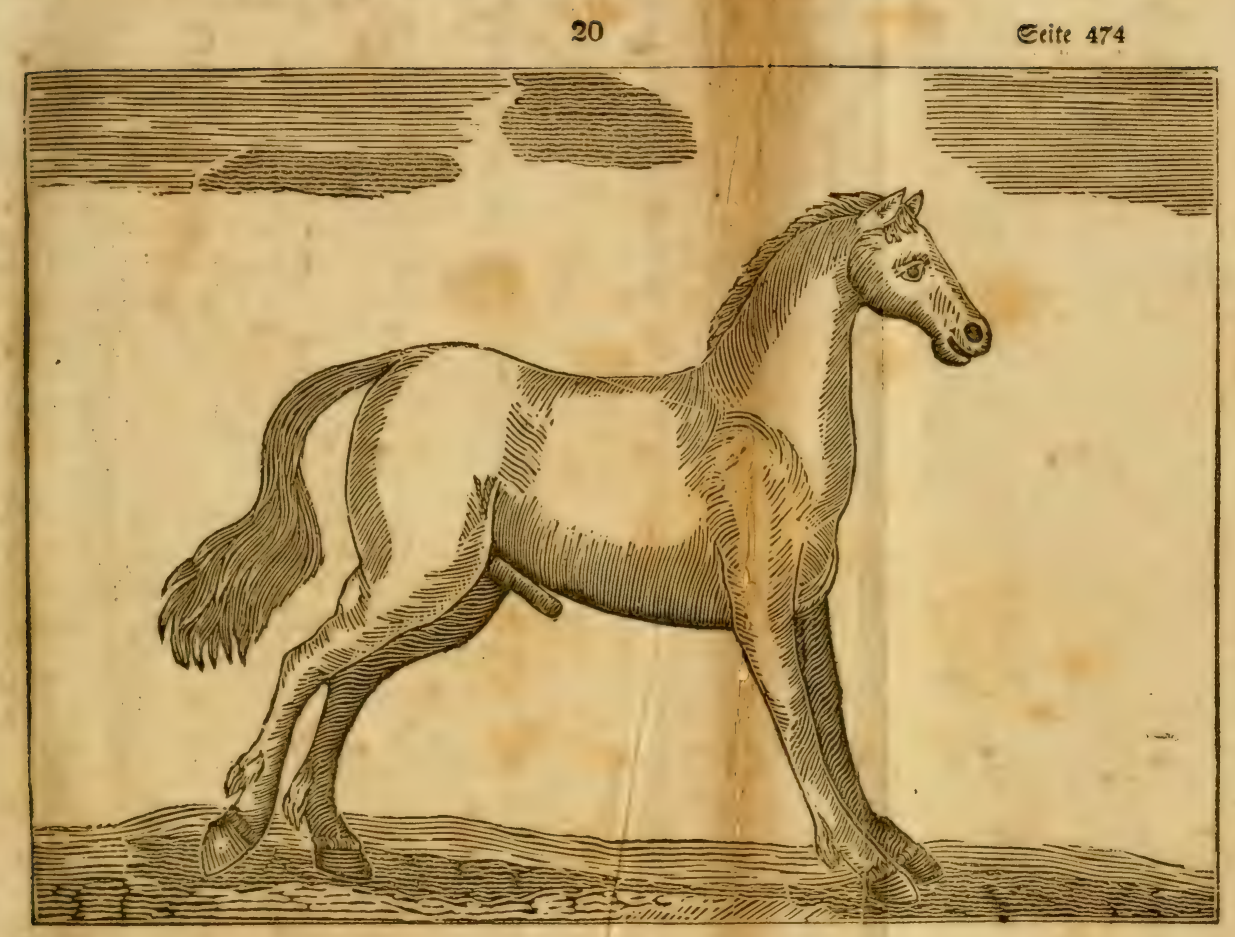




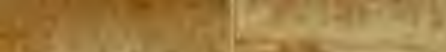

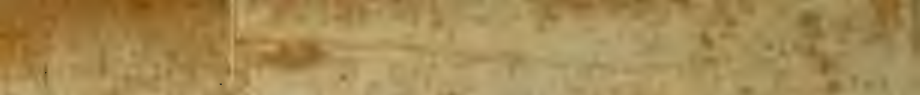

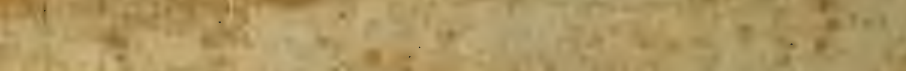

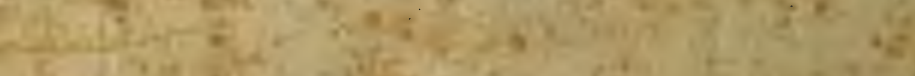

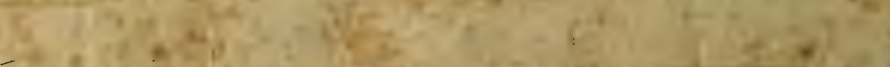

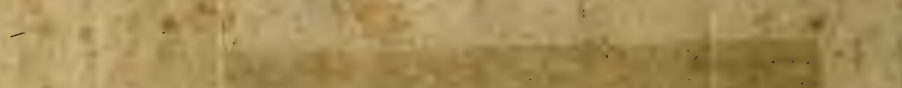

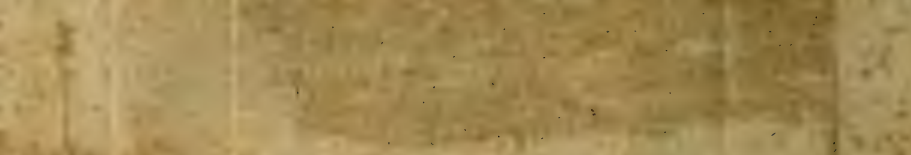
64.

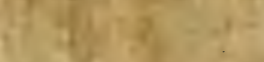

$+4 y^{2}=5$

40

85

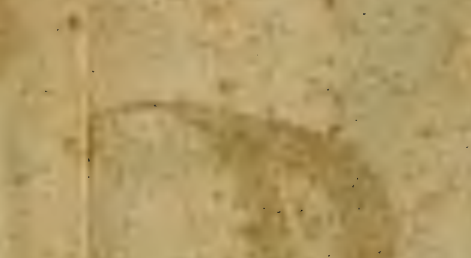

$x^{2}+x^{2}+2$

$x^{2}$

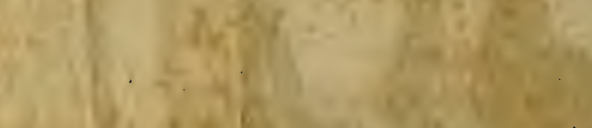
anditis

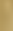

(4) $x_{10}, y_{1}$

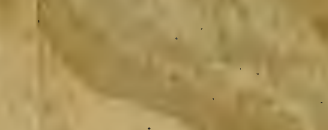
$\therefore$ :

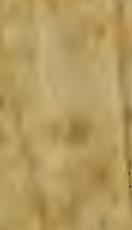

Wis:

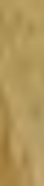<smiles>[SiH3]</smiles>
3)

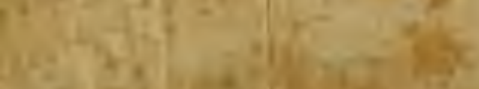
Sysing

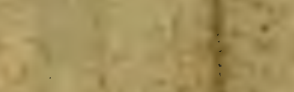
$+$ ; 8 (1) 


\section{Mferdes Argenei Bint).}

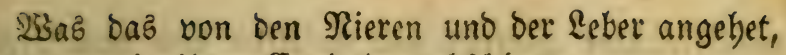
lant man in ifjen (Sapiteln nad)jhlagen.

Sun mollen wir von Diefer bandeln, relche ron ber Sd)ärfe Der (Sallen berEommt, Das Eann man an Dem gelblichten Şarn an ber Farbe nobl erkennen.

\section{Die ç 4 r.}

Nan foll dem Pfero den leib offen balten und ein linbes SInftir braucben :

Salpeter 2 Suintlein,

Teufeladed 1 suintlein,

zerftope uno fiebe es miteinander in $\frac{1}{2}$ Raaß $\mathfrak{\text { Sein uno }}$ it)ütte es dem झुfero pin.

Ein andercs.

Saldrian 1 lotb, Fend)elfaumen,

(Eppid) Famen, jpoes 2 suintlein,

Wein orei Şiertel Maấ,

Fiede es untereinander und ichütte es dem SPferd lau= lidjt ein, gebraudbe es einige Beit.

E in a n s ereb.

Sd) meinefoth 8 loth, Mein $\frac{1}{2}$ Raa

unteleinander gemifat und auf einmal eingegeben.

\section{(5in a nderes.}

Salmus $1 \frac{1}{2}$ Suintlein, Wein $\frac{1}{2}$ Raaß,

Möbrenjaamen $\frac{1}{2}$ loth,

untereinander gemifht und auf einmal eingegeben.

\section{(E) in a no ereb̀.}

Salbe das (3ejhröt mit Schaaf = Unichlitt, barnad nel)me eine Maẩ $\mathfrak{B a f f e r , ~}$

Sdjaaf unfichlitt $\frac{1}{2}$ \$ू fund, 
untereinander gemifht und gejotten uno bem spfero eingegeben.

\section{Fin andereb̉.}

Rümmel, Meergmiefeleffitg, jedez 2 loth,

\&auct 1 gute Scanoboll, $\mathfrak{B}$ ein $\frac{1}{2}$ Maa

untereinander gemifat und auf einmal eingegeben.

\section{(5) in a nereb.}

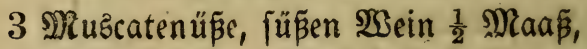
untereinander gemijht und auf einmal cingegeben. .

Ei in a n D e reb.

Sprüke mit einem Šnftrument ober einer Sprike,

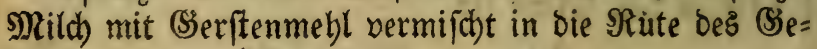
mäđbs.

(E) i a n

Salcinirte Esieridaalen 2 suintlein,

Srebsaugen 1 Suintlein, $\mathfrak{B}$ ein $\frac{1}{4}$ Maá̃, untereinanber gemifat und auf einmal eingegeben.

(Fin $\mathfrak{a} \mathfrak{n} \mathfrak{D} \in \mathfrak{e} \mathfrak{e} \mathfrak{B}$ IG.

Färberrötbercuzzel $1 \frac{1}{2}$ loth, M̉ein $\frac{1}{4}$ Maá̃, mijhe es untereinanoer uno foütte es auf einmal ein.

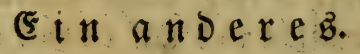

SRimm frígige Rlettennurzel 1 loth, pülvere es und gibs ifm unter bem Futter zu freffen, man fann aud) 2 loth in $\mathfrak{B}$ ein fieden, uno auf einnal eingiepen.

\section{Ein andereb.}

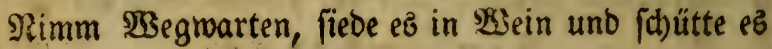
Dem sffero cin.

\section{Ein anderez.}

Sühemilt), löiche einen glühenden Stabl etlichemal barin aus und foütte eहै bem sofero ein. 


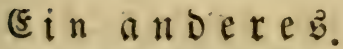

Sduutte bem \$ferd die Brübe ein, morin ein Sarp= fen gejotten morben.

Ein anderę $\mathfrak{Y G}$.

Salcinirte (5ierid)aalen 2 suintlein,

1 Inoblaudjbaupt, Strbsaugen,

Bad)nünźaamen jedes 1 s.uintlein,

Weip̄en $\mathfrak{B S e i n} \frac{1}{2}$ Maa $\tilde{\beta}$,

untereinander gemifdt uno auf einmal eingegeben.

Ei $\mathfrak{n}$ a

Siebengezeit, Blãtter uno Saamen $1 \frac{1}{2}$ loth,

Sd)aafgarbenfraut 1 loth, 3 Rarpferftein,

Rretsangen 1 Suintlein, foche es in $\frac{1}{2}$ Maa 23ein und foütte es auf cinmal cin.

Ein a nderez $\mathfrak{S}$.

9) Xäuรbornfaamen uno Blätter 1 loth,

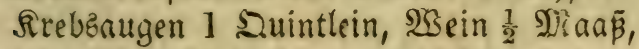

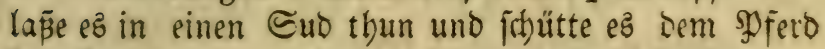
laulid)t ein.

\section{(F) a}

Sorbeeren 1 lotb), Sngwer 2 suintlein,

Rrebsaugen 1 Suintlein, $\mathfrak{S}$ ein $\frac{1}{2} \mathfrak{M a a \tilde { \beta }}$ untereinander gemifd)t und auf einmal eingegopen.

(E) $\mathfrak{n}$ a $\mathfrak{n}$ Dereb.

Şulver von einem Rop̧buf 2 Suintlein,

$\mathfrak{3 e i n} \frac{1}{4} \mathfrak{M a a \beta}$, untereinanber gemifdt und auf einmal eingegeben.

\section{(E) in anderes.}

Säbe daz Spferd mit beipem Sunder, welchen ou

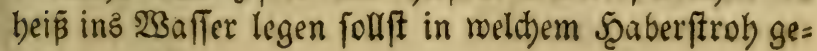
fotten morden. 
E in anderez $\mathfrak{W}$.

Baldrianmurzel, Schaafgarben, $23 a d$ holderaja), Sobnenftrobajhe, jeces 4 loth, attichiourzel, Scafelnutzel, Soldanella, Iurbith, sngmer, jeoes 2 loth, Beilmurzel, Sdbralbenmurzel, Siebengezeit jebes 3 loth, Srebsaugen 1 loth, 20 Rarpfenftein, mif che es untereinander zu einem $\$$ pulver und gib bavon Dem \$f ferd auf einmal 3 loth in einer $\frac{1}{2}$ Maa 2 Bein und \$yolen=2Saffer ein.

\section{(E) in $\mathfrak{n}$ Dere $\mathfrak{Z}$.}

§itebsuagen 1 Suintlein, 3 Rarpferftein, \$räparirte (5 felzmürmer $\frac{1}{2}$ Suintlein, 2fotftein 1 Suintlein, $\mathfrak{B}$ ein $\frac{1}{2}$ Maá̃, soterfitienjaamen 2 souintlein, untereinander gemifht und auf einmal eingegeben. Ein anderes

Baeisen Weinftein 1 loth, Iartarum $\mathfrak{B i t r i o l a t u m , ~}$ Irebżaugen jebez 1 Suintlein,

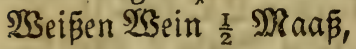
untereinander gemifott und auf eimmal eingegeben.

(E in anderez Iartarum $\mathfrak{B i t r i o l a t u m , ~}$ Tartari nitrati, Eremor Iartari, \$Deter fitienfaamen,

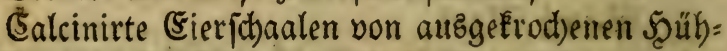
nern, Sirebsaugen jedes 2 suintlein, pülvere und mifche $e \mathfrak{s}$ untereinander, theile $\mathfrak{c} s$ in zmei

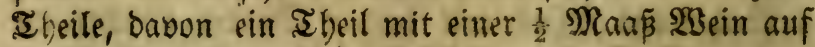
einmal eingegopen. 
Die Beidjen find diefe:

1. Der Stall oder Şarn ift reip̄, Dünn uno bič, nachoem ber inwendigen Falten Feuchtigkeiten viel vor: banden.

2. Rommt von groß̧er 2 rtbeit in groß̄er Rälte, Eal: ten Ställen, uno von Satur erkältenden Speifen.

\section{Die (5 ur.}

Man eann bem Syferd aud ein linbes Elyftir brau= d)en vor allen Dingen ben \&eib offen balten uno fol= genoen Eingur geben :

2usgepresten Rauch) faft,

Bein jedes $\frac{1}{2}$ Maa $\bar{\beta}$, Baumöl $\frac{1}{4}$ Şfuno. untereinanoer gemijht uno auf einmal eingegeben.

\section{Ein andereb}

Theriac, Spiritum falis marina,

Rrebsaugen jebes $\frac{1}{2}$ Suintlein, $\mathscr{B}$ ein $\frac{1}{4}$ Maañ, untereinanoer gemifht und auf einmal eingegeben.

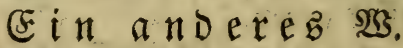

spappelnjaft, Eibijhjaft, jebez von den frifdben

- Jräutern gepreśt 3 loth,

11 Subenfirichen, Rrebsaugen 1 Suintlein,

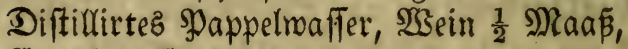

Sibifhnalfer jedez 6 loth,

untereinander gemijht und auf cinmal eingegopien.

E i n a norez.

(Eppichfaamen, Deterfilienfaamen jedes 2 suintl.

Seildhenrourzel 1 loty, N3ein $\frac{1}{2}$ Maa untereinander gemifat und eingegeben.

Ein a noereb $\mathfrak{r b}_{3}$.

Rrebbaugen, Spagyr. präparirt Şirich horn, jeoes 2 suintlein, 
mijobe es untereinanoer, iprige es bem \$pferd in Das Röbrchen Del Rutbe mit einer Eprike uno käbe bas (Sejd)röt wohl mit warmem $\mathfrak{B a f f e r , ~ w o r i n ~ @ a ̈ b e n b a u m ~}$ gefotten morder.

\section{(F) $\mathfrak{i n}$ a}

(Sejdjabten Rophtuf 1 Suintlein,

Irebzaugen $\frac{1}{2}$ Suintlein,

Deteriflienfaamen $\frac{1}{2}$ loth,

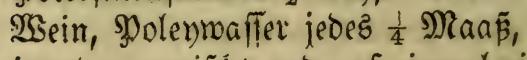

untereinander gemijat uno auf einmal eingegeben.

E in a $n$ Deteb.

Nehme Den Soth unter Den vorbern Eifen bes \$ুFer: Des, fohutte ibm Denjelben in $\mathfrak{B}_{\text {ein }}$ ein.

(5i $\mathfrak{n} \mathfrak{a} \mathfrak{n} \mathfrak{d} \in \mathfrak{r} \mathfrak{e} \mathfrak{b}$.

Fübre das \$fferd an einen Stt, wo andere Thiere geftallet baben oder in einen Schaafifall.

E in anderes.

- Blaje ifnen burd ein Röhrd)en etliche Räufe in bie

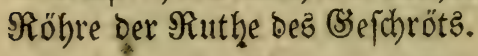

(E) in andereb.

Stalléraut 2 Şändeboll,

Flieffendis $\mathfrak{W a f f e r ~} 1$ Maá̃,

fiede es wohl untereinander und nehme der $\mathfrak{B r u ̈ b} \frac{1}{2}$

Maā̄; 3 Rarpferftein,

Rrebsaugen 1 suintlein,

untereinander gemifcht und auf einmal eingegeben.

\section{Ein andereb.}

3 Şeringsblafen ( Seel) Şeringzmild) 1 ,

Salzmalfer $\frac{1}{4}$ Maás

untereinander gemifht und auf einmal eingegeben. 


\section{Pferbe:2(rzemei Bud).}

\section{(E) $\mathfrak{i} \mathfrak{a} \mathfrak{n}$ er}

Rorbeeten 2 loth, Srebsaugen 1 Suintlein,

Saffran $\frac{1}{2}$ Suintlein,

Effig, $\mathfrak{B}$ ein, jedes $\frac{1}{4}$ Maaß,

fiebe es untereinander und fchütte es bem SুJerb ein.

E in $5 \mathfrak{i n f t}$ fr.

Melifien 2 5̄ändevoll, Şappeln, (sibija),

Bingelfraut, Nautrauten,

Samillen jebes 1 Scanovou,

Retchenfchwamm $\frac{1}{2}$ loth, Eoche es in flieffenden

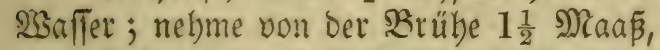

Soloquinten 1 suintlein, 7 Gierdotter,

Baumöl $\frac{1}{4}$ SDfuno, Rilienöl,

Camillenöl jedes 2 loth), Salz 1 Sanowoll,

Sd)meinenfd)mal $\frac{1}{2}$ ş) funo,

untereinander gemifht und laulid)t gebraud)t.

Ein amberer Einguß 23.

Sfterlucev, Sd)aafgarbenfraut, 2fgrimonia, Sdinertelmuizel jeoes I Scanovoll,

Eorberren 1 loth, fiede fie in flieffendem $\mathfrak{S B}_{3}$ ffer,

Nebme Der Srübe $\frac{1}{2}$ Maá̃,

Srebsaugen 1 Suintlein, 3 Sarpfenftein,

Sুräparirte (5ịlsnörmer $\frac{1}{2}$ suintlein,

1 Şaajenfprüng,

untereinander gemifdt und auf einmal eingegeben.

\section{E $i \mathfrak{n} \mathfrak{a} \mathfrak{d}$ ere $\mathfrak{E}$.}

Rangen Spfeffer 1 loth, Rorbeeren 2 loth,

Sreide 1 loth, 1 Muscatenú,

2Barmen $\mathfrak{W}$ ein oder Bier orei şiertel Maaß́, untereinanoer gemifht uno auf einmal eingegeben, $a_{a}=$ 
pe es lebig in einem Sdbaafítall laufen, ober ftelle es auf einen Mrift.

(E) $\mathfrak{i} \mathfrak{a} \mathfrak{n}$ beres.

(5idbenajche 2 Suintlein, Effig $\frac{1}{4}$ Maá̄,

Saffran $\frac{1}{2}$ Suintlein,

untereinander gemijdt und auf einmal eingegoéen.

E $\mathfrak{i} \mathfrak{n} \mathfrak{a} \mathfrak{d}$ ere $\mathfrak{B}$ :

Steinbrech), ๔chaafzgartentraut, (sundelteben, Earbobenebicten, Erobeerfraut,

Schollfraut, jebes 1 Scanoboll,

fiede eE in fließ̧endem $\mathfrak{B a}$ afler;

গebme ber Brübe $\frac{1}{2}$ Maaá,

Saffran $\frac{1}{2}$ Suintlein, 2 Şajeniprüng,

Rrebzaugen 1 Suintlein, \&orbeeren;

Seneoifhen Ierpentin jeoes 1 loth,

Bein $\frac{1}{4}$ Maaß̃,

untereinander gemifdt und auf einmal pingegeben.

Ei in andereb.

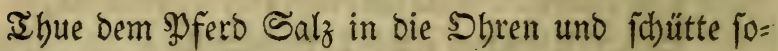
gleid) frifches flieffendes $\mathfrak{B a f f e r}$ binein.

Ei $\mathfrak{n} \mathfrak{a} \mathfrak{D} \in \mathfrak{r} e \mathfrak{b}$.

Dämpfe das şfero mit (sffíg auf einen beipen Bie= gelfein gegopen.

Ein andereb NB.

Farrentourzel 3 loth), Lorbeeren 1 loth,

Şundelreben 2 Şändevoll,

fiebe es wobl in 2 sein ;

Nebme diefer Brübe $\frac{1}{2}$ Naaß̂,

ふrebsaugen 1 suintlein, 2 Şajenjprüng,

3 Rarpfenftein sूeterfilienjaamen 2 Suintlein,

untereinander gemijcht und auf einmal eingegeben. 


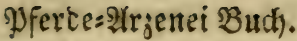

Ein andereb.

Rorberen 2 (oth, Şeiraud), Menrrben, Teufelsorect, Rrebzaugen, jedez 1 Suintlein, Sheterfitientraut uno $\mathfrak{W}$ urzel 2 Şăndeboll,

Fenchelfaamen 1 loth,

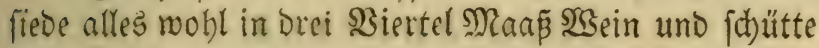
ez auf einmal ein.

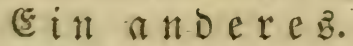

Sinde Dem Sy) fero Nattetrourzel auf Daz Munoftü uno fübre es auf eimen MRift oder in einen @uaafítall.

(5in an o ereb.

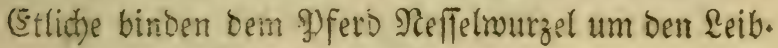

E in a $\mathfrak{n}$ De reb.

Burfopene Smiefeln coer Snoblauch $\frac{1}{4}$ SIfund, Geife 3 lotb), Sdameet $\frac{1}{4}$ Sुfuno,

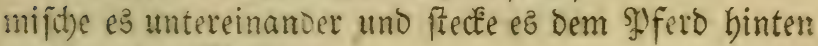
wobl in ben snlaftoarm.

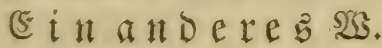

Refleliaamen,

Seterfilienfaamen, jeoes 2 suintlein,

rorbecter sin loth, ein 5ृaajenjprüng,

Rangen SDFffer, Srebsaugen, jeoes ein Suintlein

Sngwer, 2 Suintlein,

Sdarafgarbenfraut=\$olver, sin loth,

3. Sarpfenftein, fiede allez wohl in Drei SBiertel

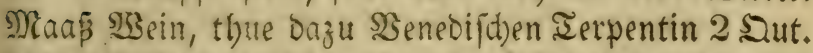
untereinunder gemifit)t uno allf einmal eingegeben.

(5) in a n bereb.

SBivenell, Iormentill jedes ein loth,

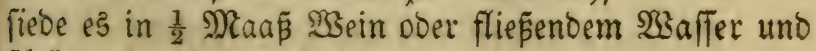
[d]ütte es auf sinmal ein. 
(sin anderez.

Rehme ein $5 i$, offne ez, thue barein Srebsautgen ein S.uintlein, Saffran $\frac{1}{2}$ Suintlein, einen Stengel langen Dfeffer gepülvert uno gebe ez dem Sמfero in ben Scals zu berjolingen.

\section{Ein a nde $\mathfrak{T}$ e}

Schneibe Dem Spferd vornen ein wenig von ben

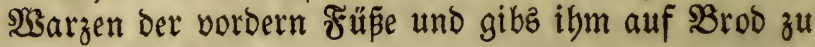
freflen.

E in a noereb.

Serftope eine Sanbooll Şauswurzel, vermifche ez

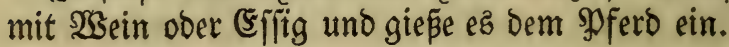

Ein andereb.

Sdbäle eime 3miefel, beftreue fie nohl mit Salz und ftope fie bem Pferd in Den Naftoarm.

Ei $\mathfrak{a} \mathfrak{n d e \mathfrak { e }}$.

Rebme 2 geleinurgel binde es bem spferb auf bic sunge.

Ein andereb.

פehme bas Spulver von einem Dattelfern in $\mathfrak{2 3 e i n}$ eingegeben.

(E) $\mathfrak{i} \mathfrak{a} \mathfrak{n} \mathfrak{D} \in \mathfrak{r} \mathfrak{e}$.

Sheterfitienmurzel und Sraut,

Şundelreben, jedez 2 Şänoevoll,

Rorbeeren, 2 seinftein, jedes ein loth,

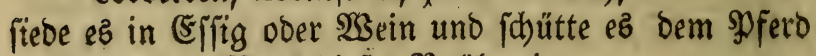
auf einmal $\frac{1}{2}$ Maaß biejer $\mathfrak{B r}$ rube ein.

E $\mathfrak{i} \mathfrak{n} \mathfrak{n} \mathfrak{d} \mathfrak{e} \mathfrak{e} \mathfrak{b}$.

Die obern (s)ipfel von ben Sceiterneffeln, 
Sals, ein wenig, fope es untereinander uno fto= ह̈e eక bem Spjerd in ben Schlauch.

E in a n D e reb.

Ref)me das inmere Şäutben von einer gebratenen

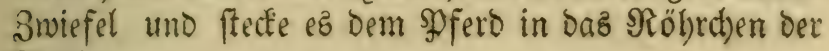
Rutbe.

\section{(5) in a ก Dereb 2 .}

Siöbelfraut, Siebengezeit, Speterfilien,

Sombed)el, Sdaafizarbenfraut,

Steinureab), Nannetreu, jeoes 2 Şändevoll,

IIZad) bolderbeeren eine Sandyok,

Epheubeeren, Fend)el, jebez ein loth,

Rlettenjaumen ein Suintlein,

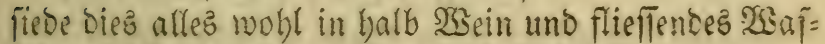

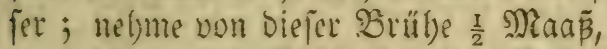

Syräparitte (5) felmütmer $\frac{1}{2}$ suintlein, untereinander gemifd tut singegeben.

(5: in a t Dereb.

Ctecte Dem SPfero (Sundelreben in oie Najelöd)er uno

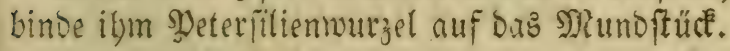

Ein a noereb.

গrebme Sngmer uno Preffer, eines fo viel alz bas andere, in ben (d)laud) geftedt.

(5) in a noereb.

(5ib Dem Sुferd unn Den mittlern zarten Rinden eines Bivt'enbaums auf SBroo zu frellen.

(5) $\mathrm{in}$ a $\mathfrak{n}$ Dereb.

Nebme Dintenzeug, fonft 2utrament genannt, ftreue ein Stüc Speck, welches 2 Finger lang if, Damit uno ftope bem \$fFero in Den Mlaftoarm. 
E $\mathfrak{i} \mathfrak{n} \mathfrak{a} \mathfrak{D} \in \mathfrak{r} \in \mathfrak{b}$.

20 ober 30 sुfirfich) Eerne,

Lurbeeren ein lotb, Saffran $\frac{1}{2}$ Suimilein,

ftope es untereinander, fiede es in einer balben Naẩ Mtilch uno ichütte eblaulicht ein.

E i n anderez $\mathfrak{s}$.

(s)artentereß̄en 2 Şändeboll, -

ఇeunzebn Subentirichen,

3 Srope gefchälte 3miefeln,

fope alles untereinander uno nimm barzu

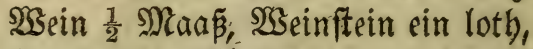
untereinander gemifitht uno eingegeben.

(E) $\mathfrak{i} \mathfrak{a} \mathfrak{n} \mathfrak{D} \in \mathfrak{r} \in \mathfrak{B}$.

Stope bem \$ferd wilbe Melifien in ben Maftoarm.

E $\mathfrak{i} \mathfrak{a} \mathfrak{n} \mathfrak{d} \mathfrak{e} \mathfrak{e} \mathfrak{b}$.

Stope dem SDfero Seife in ben Scintern, aber nebme ein wenig Seife, lafe fie in warmen 2 saffer vergehen uno fhütte eE ifm ein.

Ein andereb.

Stecke ifm Ribenellentraut in bie Rafe.

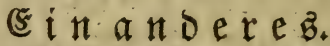

simm eine oünne $\mathfrak{B a c h b E e r z e , ~ b e f e u c h t e ~ f i e ~ m i t ~} \mathfrak{B}$ aum=

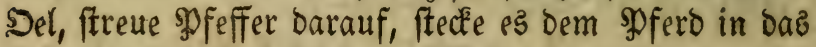
Röhrchen, ziebe es über eine $\mathfrak{G}$ eile nieber heraus und rape ben shfeffer barin.

(5i a a n

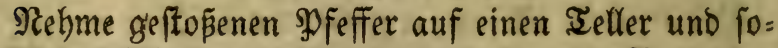

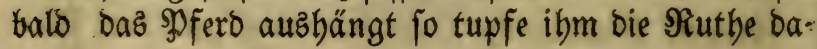
rauf.

E i n a no eres $\mathfrak{Z}$. (S) topene Regenmürmer 2 suintlein, 
Srebsaugen 1 suintlein,

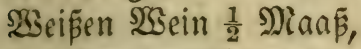
untereinanoer gemifat uno auf einmal singegeben.

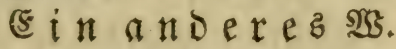

Seunzebn Sudentirfden,

Srrbsaugen ein Suintlein,

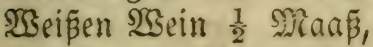

untereinanoer gemifdt uno auf einmal eingegeben.

E in anderez $\mathfrak{X}$.

Spiritum Salis marini, जrebsaugen,

jeopez 1 Suintlein,

Weip̄en $\mathfrak{B}$ ein $\frac{1}{2}$ Naañ,

Senedifit)en Terpentin $\frac{1}{2}$ loth,

untereinander gemifd)t unb auf einmal eingegeber.

Nean muß oie SDferde um die SBlafen berum am un=

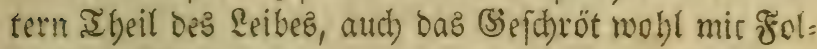
genoem jomieren :

Şbilo fopthenöl 2 loth,

Regentulmeról 3 loth, Dillöl,

St. Sobannizblumenól, jedes 2 loth,

Sarab) bolderöl 1 loth), mijhe es untereinander,

Nan Eann ifm autb mit Dem Snffrument mit $\square$ bezeid)net, Durd) Die Rölyre ber Rutbe binein greifen uno von Der Blaje binweg räunen.

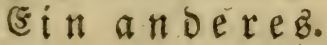

2fllaun 3 loth,

Speck fo viel genug zu einem Sapfen ift, ftreue ben achaun barauf uno ftede es in ben Naftoarm.

\section{E $\mathrm{i}$ in: $\mathfrak{a}$ noeres.}

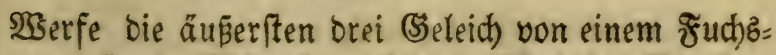

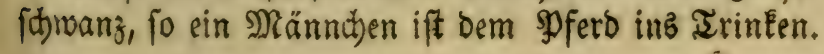


Yyferbe=:Irzenei Buth.

Ein andereb.

Nimm blate (Silgenmurzel 2 Ioth, fhneide es Elein, fiede ez in $\mathfrak{B i e r}$ oder $\mathfrak{B a f f e r}$ und fchütte es cin.

(E) in anderes.

Nimm Sitriol und Salz uno ftope ez bem গুpero in Den Maftoarm, oder Epect mit Niesmurzel beftreut.

(s in a no e $\mathfrak{e} \mathfrak{e}$.

Stope Snoblaud), mifche Sofeffer barunter und fto= pe es Dem Sुfero in Den Sdlaud).

(E) i a ก Derebi.

Siede Snoblaud) in Shein uno fduttte es bem \$pferd miteinander eir, und reike Dem Sुferd die Bähne und 3unge mobl mit Snoblaud), sofeffer und Ealz unter: einander gemifdet.

\section{(5) in andereb.}

SGenn das (Sefit)röt fich überfich in ben $\Omega_{e} i b$ binauf= ziebzt, diefes foll man mieber berabzieben, uno mit ei= nem Riemen bon einer roben Scirfhbaut wohl binden,

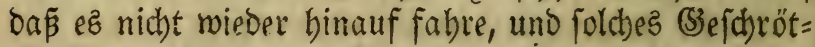
fichaft mit marmem SDel fidmieren uns bitnften, wie in bicfem Sapitel fchon befdrieben morden.

(5) in andereb.

(S) oörtes Bienen= \$pluer 1 loth,

¿iebftöckelfaamen $\frac{1}{2}$ loth

Sceubedelrwaffer,

Retticbroaffer, jedę $\frac{1}{4}$ Maaßá,

untereinander gemifdit uno auf einmal eingegeben.

(E) in andereb গ⿴囗.

Spiritum urinä $\frac{1}{2}$ lotb), Rettichmafler 6 loth, 


\section{פy ferbe:2(rzenei Bud).}

SBad) bolderwaffer 12 loth, untereinanoer gemifht und auf einmal eingegeben.

\section{(5in andereb $\mathfrak{H}$.}

Sal uriä 1 loth, $\mathfrak{K}$ ein $\frac{1}{4}$ Maaß́,

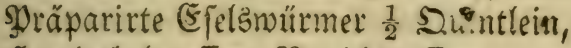
Saubed)elmafler, Rettidiwaller, Steinbred)maller, jedes 6 loth, untereinander gemifht und auf einmal eingegeben. (E in a ndereb গIS.

Spiritum Iartari andertbalb loth, Rettichmafler, Scauhecbelmafler, Sörbelerautwa fier, jedes 6 loth, untereinander gemifdt und auf einmal eingegeben.

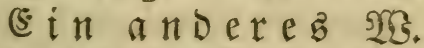

Ejelsmürmer 1 Suintlein, 2 Muscatenüßё,

F̌lores Saliz 2 mmoniaci 2 suintlein,

Bencoifden Ierpentin 1 loth,

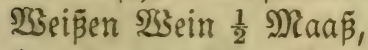
untereinanoer gemifdt und auf einmal eingegeben.

(5) $\mathfrak{n} \mathfrak{a} \mathfrak{d} \in \mathfrak{r e b}$ IS.

Ş) räparirte Ef felênürmer $\frac{1}{2}$ Suintlein, Rörbelfaft, Beterfilien faft jedez 8 loth, Slettenfaamen 1 Suintlein,

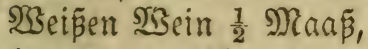
untereinander gemifdt und auf einmal eingegeben.

(F) in anderez $\mathfrak{I G}$.

Salcinirte Fröld fichaalen 1 loth,

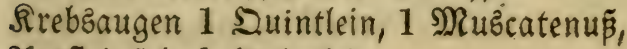
Xgtíteinfalz $\frac{1}{2}$ Suintlein, Galpeter, Benedichen Ierpentin jeoez 2 suintlein, 


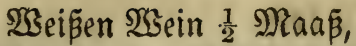
untereinanoer gemifht uno auf einmal eingegeben.

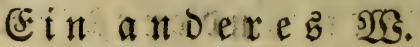

Sal Tartari 2 Suintlein,

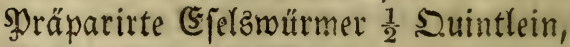

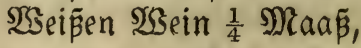
untereinander gemifd)t und auf einmal eingegeben.

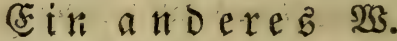

şadb) bloerfalz, $\mathfrak{B}$ ermuth falz,

Srebzaugen, jedes I Suintein,

Ugtfteinfalz $\frac{1}{2}$ Suintlein, Salpeter 1 loth,

Ealcinirte Eierfibaalen 1 lotb, 9̧ein $\frac{1}{2}$ Maas, untereinander gemifdt und auf einmab eingegeben.

$\mathfrak{B}$ enn alle obengeferte Mittel nid)t berwirten mollen uno bas Spferd in etlichen Tagen nid)t ftallen Eann, wo = rüber endlid) die SBíaje zeripringen und das פoferd tre=

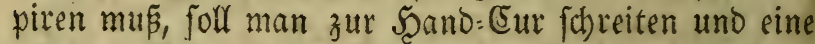

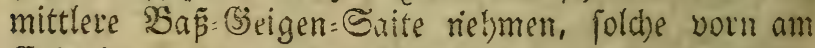
Ende in ein bremneno Ridft balten, bamit fie etrwas zu= fammen laufe und ein Elein Snöpfchen befomme, biefe Saite beftreicht man mit Ecorpionol und ftecft es in Daz $\Re$ öbriben Der Rutbe uno ziehet es nach uno nad) wieder beraus, fo wiro allerlei Shleim uno umratb mit berauş tommen; menn nun foldhes etlichemal roieder = bolt miro, fo miro daz \$y ferd anfangen Iropfenweis und bernach mit räicher (S)emalt zu frallen, wie folchez umftänolicber in SBalentin Iridbters \$ुfero = 2(natomie zu jeben iff.

\section{Die Berpflegutmg.}

Die Serpflegung foll fein wie in ben vorbergeben: Den zwei Sapiteln zur SSentige beforieben morden. 


\section{Pferbes:2(rzenei 5 bud).}

\section{Ein $\mathfrak{A} \mathfrak{n} \in \mathbb{r} e \mathfrak{B}$.}

(sib ibm gepülvertez Erlenlaub unter bem Futter zu freflen.

Ein andereb গIG.

Rorberen 1 loth, Sümmel 2 loth,

Sholev 1 Sandoull,

W̧armen $\mathfrak{3 e i n} \frac{1}{2}$ Maá̃

fiede eहै untereinander und id)ütte es sem Sूfero sin.

E in andere .

Simm das Sraut Şüfnerbarm, prepe den Saft beraus uno fdütte es ibm mit 2 ein ein; ober foche bas Sraut in $\mathfrak{B e i n}$ und foütte ibm bie SBrube bavon ein

(5) in a ndereb.

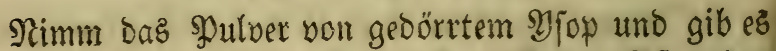
inm im Futter zu freffen, reibe auch bem Spferd Dem Nabel mit marmem un idhlitt etlichemal.

(5) in $\mathfrak{A} \mathfrak{n}$ Deres $\mathfrak{B B}$.

sisach holoerbeeren, Slettenmutzel,

Sappeln jedes 1 Scanovoll,

Snoblauch 2 Scäupter,

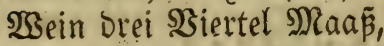

fiebe es miteinander, prepe die Şrühe bavon uno fdüt= te fie dem Spferd ein.

\section{(sin andereb.}

Bobnenmebl,

(Saftanienmebl, jebes 3 loth,

(sier in sifig vorber gejotten 12,

$\mathfrak{s e i n} \frac{1}{2}$ Maaß;,

untereinander gemifat und auf einmal eingegeben. 


\section{Mferbs $=2($ rzenei $\mathfrak{B u d})$.}

\section{Ein a noeres.}

(sid)enlaub 3 loth, Selbaumlaub 2 lotb,

Sipen 1 lotb, Şühnerdarmjaft 8 loth,

mija)e es untereinanoer in $\frac{1}{2}$ Maaß $\mathfrak{R}$ ein uno fdütte so auf eimmal ein.

\section{(5) in a n}

Binde ifm Saumminden oder (5pheu um ben gan=

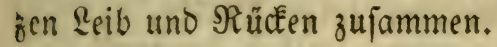

\section{Fi $\mathfrak{n}$ andereb.}

Şühnerbarmjaft 8 loth, $\mathfrak{B}_{\text {ein }} \frac{1}{2}$ Maaß

Spiritum Sitrioii $\frac{1}{2}$ Suintlein, untereinander gemifat und auf einmal eingegeben.

(5) in andereb.

Den Nabel mit rarmem Ialg oder Unidhlitt gerie= ben.

Die Berpflegung.

1. Trodener, mittelmä̈ig marmer Stall.

2. Sim Futter foll man inm gepülverte Eidteln zu frelien geben, wie auch Mlop uno Selbaumlaub.

3. Der Irank foll fein laulicht $\mathfrak{B a f f e r}$, worin ge= mablne Sommergerfte, einmenig Salz uno etwas ভpi= ritus vitrioli gemifht ift.

\section{Das 47fte Capitel.}

\section{Bon Dem Blutifallen ocer Sarnen.}

Diefe Sranfleit entffebet entweder yon einem $\mathbb{B}_{\digamma}=$ (G)nür, fcharfen Flüpen, ober einen rauben Stein, wel= c)er im Blajenbals bismeilen vorfommt; ober ez 
Fommt aud von ber Nieren Şerleşung, wie auch fdbon in Felbigen Sapitel bavon gemeldet morden.

Das Seidben iff fdueinbar, entweber blutiger Şarn, ober geronnen Blut in bem Scarn.

$$
\text { Di e } 5 \text { u } r \text {. }
$$

Die Cur ift bismeilen febr miß̧lich, Doch Eann man nachfolgende gebrauchen :

Şeionifdes $\mathfrak{B}$ und fraut, rothe Bucken,

Soermenig, $\mathfrak{B e g m a r t e n , ~ j e b e s ~} 1$ Scanovoll, gepülvert und auf

$$
\text { Ei in andereb. }
$$

\$ulver bon einer Sdblangenhaut 1 Suintlein,

Sienediktennurzel 1 loth,

Die Blaje von einem Sarben (ein Fija))

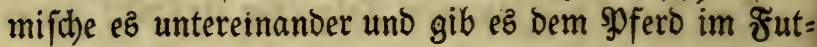
ter zu freflen.

(5) $\mathfrak{n}$ a $\mathfrak{n}$ Deres $\mathscr{W}$.

Scepar 21ntimonium 2 Suintlein,

Saffran $\frac{1}{2}$ Suintlein, $\mathfrak{B e i n} \frac{1}{2} \mathfrak{R a a} \tilde{\beta}_{1}$

untereinander gemijd)t uno auf einmal eingegeben, ge= brauche bies einige Iage.

$$
\text { Ein anderes. }
$$

গু马oblgemuth 3 Şänoevoll,

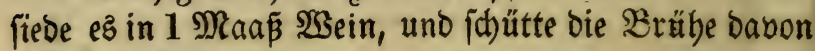
auf einmal ein.

\section{E $\mathfrak{i} \mathfrak{a} \mathfrak{n} \mathfrak{D} \in \mathfrak{e} \mathfrak{b}$.}

Sobnenmebl,

Eaftanienmebl, jeoes 3 loth,

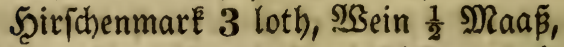

Eocbe es roohl miteinander uno fchütte ez ein. 


\section{Pferbe:2(rzenti $\mathfrak{B u d}$.}

Ein andereb.

Xgrimoniam 2 Scänoevoll, 2anoornnurzel,

SGegwarten jedes 1 Şandooll,

fiebe es zufammen in $\mathfrak{B e i n}$, uno nebme von ber $\mathfrak{B r u ̈ b e}$ ein $\frac{1}{2}$ Maan, thue Dazu

(Sepülberte Şajeniprüng,

Rarpfenftein jedes 3 ,

untereinander gemifht und auf einmal eingegeben.

(c) in andereb.

Snoblaud)śflautiaft, (sibijchaft,

Tasegerid) jaft, 22 noornjaft jebes 4 lotb,

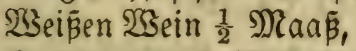

Sirebsaugen 1 Suintlein,

untereinanoer gemifdt und auf cinmal cingegeben.

(sin anderes

Shlage ifm beide Sporradern, fo mie aud beide Sdrantudern.

(E) in a n Dereb.

Rorbeeren, fpiçigen Rleenurzel jedes 1 loth,

Ingwer $\frac{1}{2}$ loth, Şein $\frac{1}{2}$ Maaß́, untereinander gemifot und auf einmal eingegeben.

E i $\mathfrak{a} \mathfrak{n}$ bereb.

Drachenblut 2 Suintlein,

Sümmel 1 loth, $\mathscr{W}$ egeridhfaft, (5ibijd) faft,

Eijenfrautraffer,

(5ibifdhroafler, jeoes 6 loth,

untereinander gemifat und auf einmal eingegeben.

(5) i $\mathfrak{a}$ noeres $\mathbb{Z}$.

Şafenblut, Şirid)blut, Bookzblut,

Rrabiaugen, jebes 1 Suintlein, 
Rotben Boluz, präparirtę Shirfhborn, jebes $\frac{1}{2}$ loth,

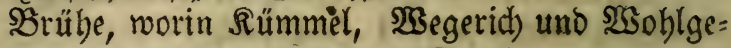
muth gefotten worben, $\frac{1}{2}$ Maa $\tilde{\beta}_{\text {, }}$

untereinander gemifobt und laulid)t eingegeben.

E i n a

Irodbifci atkééngi 1 loth,

\&auban. opiat. 8 Sran,

Weí̄en $\mathfrak{B e i n} \frac{1}{2} \mathfrak{M a a \beta}$,

untereinander gemifats und auf einmal eingegeben.

(E) in anderez 2 .

Relonenfern, Sucumernkern, Sürbiskern,

Eitruflenkern, jedez $\frac{1}{2}$ lotb,

\$orzelfrautjaamen,

WBeißen Magfaamen, jebez 2 Suintlein

affez gepülvert, untereinander gemifatt uno bazu ge= than: bie Brühe worin Subenkirfoben, (Eibifd) uno WSegerid) gefotten worden $1 \frac{1}{2}$ Maá, untereinander ge= mifobt uno auf zrweimal eingegeben.

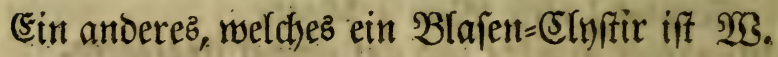

9 Magfaamenfäupter, 13 Subentirichen, Rad)t [chattenblätter,

Rä3pappetn, jedę 2 Şänbevod,

fiebe ez rohl untereinander ;

Regme von Der abgefeihten Brübe 14 loth,

Seeblumenöl, Magiaamenöl, jeoes $1 \frac{1}{2}$ loth,

Murmeltbierishmal

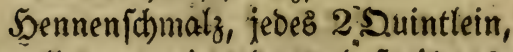

mifche allez untereinander uno iprişe es mit einer Spris: ke in bie $\mathfrak{B l a j e}$. 


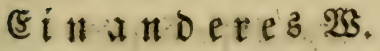

Sfterlucey, Sinngrün, Saničel,

Sobannizfraut und Saamen, jedę 2 Şãndevoll,

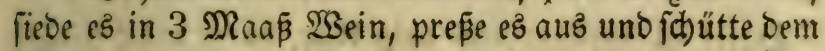
Sy fero auf einmal $\frac{1}{2}$ Maā mit 2 suintlein rotben $\mathfrak{B}_{0}=$ lus bermifcht ein.

(5in anderez.

Beinrautenfaft,

Saft bon meiper Rilienwurzel, jeops 2 loth,

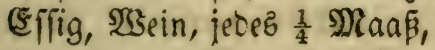
untereinander gemijat uno auf einmal eingegeben.

Ein a noete s.

Dedfe bas Sুpfero marm ju uno gib ibm nad, folgen= ben Irant :

Saumöl, Ierpentinöl, jedez 1 Suintlein,

Sabafmild), Eaffran, jedes 1 loth,

matm gemadt und Dem sp fero eingegeben, fdmiere ez

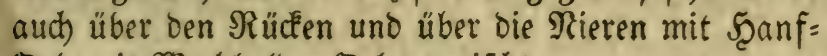
Del, mit 2 Badholder= Del vermifht.

\section{Sie Berpflegung.}

1. Dir Stall foll trodfen, mittelmäpig roarm fein, uno bas Spferd eine gute Streu haben.

2. Das Futter foll fein gebrodbener Scaber uno (Serfte, worunter Rorbeeren, fpifige Sleetourzel uno sngroer bermifht iff.

3. Der Irant foll laulid)t fein, in reld)em reife Rilienmurzel, Eifenfraut uno $\mathfrak{B S o b l g e m u t h ~ g e f o t t e n ~}$ worben. 


\section{Daz 48fte Capitel.}

\section{Bon dem Slajenftein.}

Diefer ift meiftentbeils unbeilbar, ba er nicht alleir am Sonitt gefäbrlich ift, fondern er iff aud fo bart als ein Riefelftein immer fein Eann, gemeiniglid) rund, mäd)ft je länger je größer.

St) will bod) bier ein (šebeimnis mittbeilen, mit weldsem midh ein guter Freund befannt gemacht bat.

Spiritum urinä zum böd)ften rectificirt, ein balbes suintlein, baß̃ er ein Steindben, fo man inn barüber.

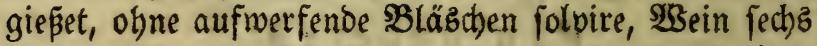
lotl), mijd)e es untereinander und fprifge es mit einer Sprize in bie Blaje.

Mit ber Şand:(Sur, welche am Ende des 45. (sapi= telz befurieben, kann man auch baz \$p fero bor biefen (siebredben lange beroabien, indem ber sBlafeftein ourch.

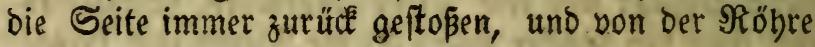
Dez $\mathcal{C}$ ubgangs fann wiggewiejen wetoen.

Die. Serpflegung ift nach ben 2Angaben zu befor= gen, bie in bem vorbergebenden Sapitel gemacht murben.

\section{Dą 49fte Capitel.}

\section{Bon Fiebern ber $\$$ Pferde.}

Das Fieber Eommt von mandberlei urjachen, uno ift mantberlei 2 rt ; innerlidbe Urjachen fino überflüpige uno verberbte Feudtigkeiten, Durch beren auffeigente Dämpfe bie (Sseifter bes Scerzens wie auch die bes (S)e: hirns, eingenommen merben. 2(eufferlid)e find böfe

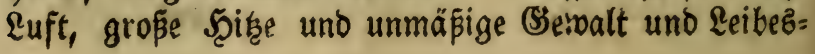


Uebungen, von meld)en bie äuperlid)en (şlieber, meld)e (id) in folchen (Gejdäften am meiften bewegen, erbifet uno entzünoet moroen, bernach aud bie innerliche, uno auf Diefe 2 seife vermehrt biz es aud jum Serzen fommt. Ebenjo wiro ifnen, menn fie beftig gearbei= tet haben uno mübe fino, Der Schneis nicht abgemifd)t fondern nod) barüber tief in sin Ealtes $\mathfrak{W}$ a fler geritten, moourch, bie \&uftlöd)er verftopft werben, uno bernad) Die Dämpfe in Dem \&eib liegen bleiben müpen, alzoann eine Eorruption oder Fäulung entffebet, roourch baz. Serz auch inficirt wird, uno die Seite in allem über: band nimmt, Dep̃roegen baz \$ferd enolid) zu (Srund ge= hen muß.

Ueberdies fönnen fie aud) bizmeilen bie Speife nicht verbauen, nenn fie nemlid) Des frifhen (Sirafes zu virl oder fonit boje berberbte Sachen in fich freflen, ober faules und ftinkendez $\mathfrak{x a f l e r ~ f a u f e n , ~ o d e r ~ a b e r ~ f t e h e n ~}$ etwa auf ber Streu zu lang müßig, benn foldbes alles gibt erfitlich zu einer Fäule und folglids auth zu ben. Frebern urfacte.

Die Seichen fino biefe :

1. Das Sुferd hat in allen SSliedern Scike.

2. Raufen ifm bie 2roern fehr auf.

3. Sebet oem spferd ein hifiger ftintender 2 them aus bem Maul.

4. Befommt ez zuweilen über den ganzen \&eib eine Rälte uno fängt an zuzittern.

5. SPaufen ifm die 2ugen dind liegen meit beraus, uno werden ounkel; neben ben 2(ugen!befincet fich bis: meilen auch eine zäbe uno flüßige Feuchtigkeit.

6. Der ganze Reib mirb fdner uno fdlaffüdtig baneben ifm aud das (Sefdröt etroas gefdroollen uno 
berab bängt, fdrwanft mit Dem Reib und Eann nicht red)t geben, uno menn es barnieder fällt, Eann ez Eaum wieder auffiteben. Daber legen fie fict niemals nieber, fonbern bleiben allezeit fteben, baben immer gropen Durfít, Eönnen weder ruben nod fdlafen, idheinen faft obne Sinn und oumm zu fein, ftehen ftarrid)t an einem Srt und baben piztalte Şbren.

7. In bem hikigen Fieber, bas Feuer genannt, läßt es dic Scaare forobl an ber Möhne, als bem Sdyneif

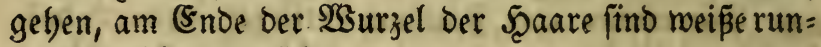
de Snöpfchen zu feben.

8. Sd)lägt das frutter $a b$ und rill nidbt freffen.

9. SBiro träg, Eraftlos uno la sá, nanket balo auf biefe, ballo auf jene Scite.

\section{Die 5 ur,}

Sor allen Dingen foll man ibm ben \&eib offen bal: ten uno SInftire braudben, aud bie Şalbabern, Sport: abern uno bie Xoern am Sdblaf lapen, mie aud) bie Shrwanzabern.

Und in Der Sur mebr auf bie Materie uno $\mathfrak{u} r \mathfrak{a} a=$ d)e als auf bas fieber felbit feben.

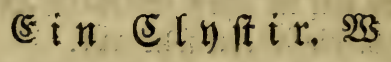

Taufenogüldentraut 2 Şänocboll, Bingelfraut, Eibifh, Mauerrauten, sappeln, jedes 1 Şandooll, Ugaric 1 loth, Bertram 2 Suintlein,

fiede es robl in fließ̈endem $25 a$ fifer,

Rebme Der $\mathfrak{B}$ rübe andertbalb Maaß̄, Sdbeinenidbmalz anderbalb \$ुfund, Saumöl, Sconig jedes $\frac{1}{4}$ Sמfuno, 
Roloquintenmark 2 Suintlein,

Salz 1 5̧anoboll, 9 (5ierbotter, untereinander gemifht uno laulicht gebraudht.

Man Fann fich in biejer Rrankbeit aller Derjenigen Shyftire wie auch oer meiften 2 rzeneien, welche in ben Reber= Irantbeiten befdrieben ncroen bedienen.

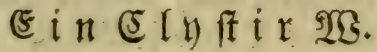

Stöd)asfraut, Beildbentraut, (Fibifd),

Bingelfraut, Taujenogüloenfraut,

Suendel, jedes 2 Şändevoll,

Senezblätter 1 lotb,

fiede es wobl in fliependem $23 a$ fler;

Nebme der Srühe $1_{2}^{\frac{1}{2}}$ Nanaß̄, Sonig 6 loth,

Sdjmeinenid)malz 1 ş funo,

Baumöl 8 loth, Seilden ôl 4 loth,

Extract von (5apiarinde 2 loth),

Soloquintenmark 1 Suintlein,

7 Fierbotter, Salz 1 Şanovoll, untereinander gemifdst und laulicht gebraud)t.

E in a n Dereb গצG.

Stecte dem Spfero die Shriftrourzel vornen an bie Bruft, uno gib ibm folgenden (singué ein :

Saujenogüldenfraut 2 Scändevoll,

Rbapontic 1 loth, Rbabara, 2rgaric,

Salap, jedes 2 suintlein,

fiebe es robl in flieflendem 2 salfer ;

Rebme Diejer auzgeprep̃ten $\mathfrak{B}$ rübe $\frac{3}{4}$ Maấ,

Saffran $\frac{1}{2}$ Suintlein,

SBeinftein 1 loth,

mild)e es untereinander und idütte ez bem Sूferd auf einmal sin, continuirs über ben 4ten Iag; Șm Faû. 
aber bie Cyriftmurzel ftark gezogen, fann man bem Syfero nur $\frac{1}{4}$ Maaß biejes Irankz eingeben. Dieje obenbejdriebene Elyftir, shriftwurzel und (singus find bauptfäd)lich in ben bisigen Fiebern zu gebrauden.

\section{E in a noereb.}

Mangolt, Rappesłraut, jedes 3 Şändeboll,

fiede es uno nehme der $B$ rübe $\frac{1}{2}$ Maá̃,

Bimmet, Nellen, jedes 1 suintlein,

Fendbel 1 loth, Rojenbonig 6 loth,

2rgaric 2 suintlein,

untereinander gemifat und eingegeben.

(E) in a $\mathfrak{n}$ ber $\mathfrak{e}$.

Taujenogüloenfraut 1 Şanovoll,

Suendel, Engeliüs, Neiftermurzel,

Enzian, jebes 1 loth, $\mathfrak{B e i n} \frac{1}{2} \mathfrak{M} R a a \tilde{\beta}$,

untereinander gemifott uno auf einmal eingegeber.

Ein anderez.

Enzian, Meiftermurzel, sifterlucey,

Engelfüp̃, jedez 1 loth,

Mnrrben 2 Suintlein,

Lorbeeren 1 loth, $22_{3 e i n} \frac{1}{2}$ Maaß̧, untereinander gemijht und auf einmal eingegeten.

Sin anderes, weldbes färter lariret.

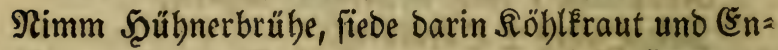
gelfüß, preße die Brübe davon, thue 6 loth Sconig, 1 loth (Extract von Eapiarinde barin uno fautte bavon

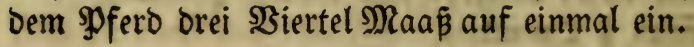

(5in SIyftir $\mathfrak{2}$.

WSeinrauten, Nangolt, Stö(baß̨Fraut,

Eamillen, blaues Şeild)enfrnut,

spappeln, jedes 1 Şanoboll, 


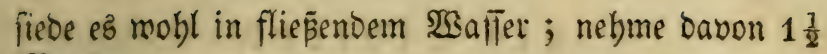
Maā́,

Şierä picrä 2 loth, Ealz 1 Scanovoll,

Extract von Eapiarinde 1 lotb,

Reinöl 1 Sp funo, 5 sierootter,

(5amillenöl 4 loth),

untereinanoer gemifd)t uno laulicht gebraudht.

(sin anberes saxativ.

Stöchaskraut, Soretich,

Unfer Frauenbaar, jeoes $1 \frac{1}{2}$ Şanovoll,

(sngeliüs, 2 2 niz, jeoez 1 loth,

fiede es wobl in flieffendem $\mathfrak{B a f f e r}$;

Nebme von oer $\$ 3$ rübe $\frac{3}{4}$ Miaa

Extract von Capiarinde 2 loth,

Diacatbolicon 1 lotb,

untereinander gemijcht uno auf einmal eingegeben.

E i i a n D ereb.

Iberiac, Schwalbentraut, jedez 1 suintlein,

Diitren Menidyentoth 2 loth,

Wein $\frac{1}{2}$ Maá̃,

untereinander gemifdt und auf einmal eingegeben.

(5 $\mathfrak{i}$ a $\mathfrak{n} D \in \mathfrak{r} \in \mathfrak{B}$.

Eppichlaamen 6 loth, (Serfte 3 Şändeboll

Şeinrauten 2 Scändeboll,

Rorbeeren, Enzian,

Sfterlucen, jedes 1 loth,

fiede es rohl in flieffendem $\mathfrak{S a f f e r}$

Rebme ber Srühye orei Biertel Maaß̃,

Extract von (5apiarinde 2 loth,

21garic 2 Suintlein,

Scammonium 1 Suintlein, untereinander gemifdet und auf einmal eingegeben. 
Ei $\mathfrak{n} \mathfrak{a} \mathfrak{n} \mathfrak{D} \in \mathfrak{x} \mathfrak{e} \mathfrak{b}$.

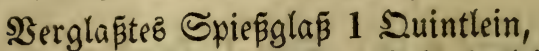

Şein $\frac{1}{2}$. Maa $\tilde{\beta}$, Saffran $\frac{1}{2}$ Suintlein,

mifche es untereinander, laße es über $\Re(a d) t$ ftehen, als= Dann feilje bie Brübe bavon und fóntte fie ein.

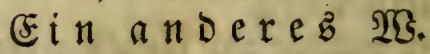

Ealcinittes હpiȩ̄glas 1 Suintlein,

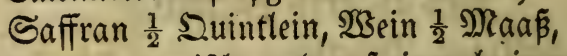

untereinander gemifdt und auf einmal eingegeben, reite ez nobl barauf.

E in a $\operatorname{nd}$ dereg $\mathfrak{B S}$.

Separ 2fntimonium $1 \frac{1}{2}$ Suintlein,

Saffran $\frac{1}{2}$ Suintlein, $\mathfrak{B e i n}^{\frac{1}{2}}$ Maá,

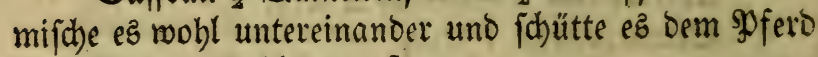
ein ; reite es mobl barauf

(E) in noeres

2lloes hepatica, צseinftein, jedes 1 loth,

Scammonium, Salap,

(Š

2Egaric, Fendhel, 2(niz, jebez $\frac{1}{2}$ Loth,

ŞGein $\frac{1}{2}$ Maaß̃,

warm untereinander gemifd)t uno eingegeben.

\section{E i $\mathfrak{n}$ and $\mathfrak{C r} \mathfrak{e} \mathfrak{B}$.}

Sentaurum, Senesblätter, jebeb 1 loth, Srope Alettenmurzel 3 loth, Earoobenebict, Taufenogüldenfraut, jedes 1 Scanoboll, fiebe allez in flieffendem $\mathfrak{B a f f e r}$;

Nebme der Brühye orei \$Biertel Maaß Salap, 2 garic, jebes 2 Suintlein, Saffran $\frac{1}{2}$ Suintlein, 


\section{פpferbe:2rzenei Buth.}

(S)ummi (Suttä 1 Suintlein, Tartari vitriolati $1 \frac{1}{2}$ Quintlein, untereinander gemifdt uno auf einmal eingegeben.

Das (Sebifis oder Irenfe mú man ifnen mefren= theils Den ganzen Iag im Maul lap̃en, Daneben bis=

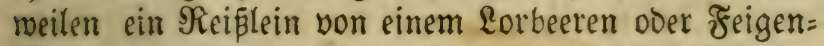
Baum zu zerfäuen geben, ober etmas \&erd)enjchmamm uno Sertrammurzel zerftopen, in cin reines $\mathfrak{I} u d$ ) bin= Den, Dapelbe ifnen inwendig an taz (Sebie anbinden und Fie daran Eäuen lap̉en; Denn ę ziebt die Feuchtigkeiten gemaltig berab.

Die Berpflegung.

1. Der Gtall foll mittelmäfifg kühl, bunkel und trodfen fein.

2. Das IJferd foll mit warmen Decten wobl zuge= becft fein.

3. Das Futter foll fein gebrocheme (3ierfte und Şa=

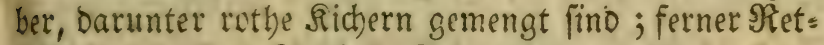
tid) Elaut, grüner Fend)el, Eergmünze. MNan Eann auch) unter das Futter mengen täglich 4 föffelvoll

Softerlucen,

Iaufenigüldentraut 3 Scāndevor,

(Enzian, Meifternutzel, jedes 3 loth),

Rorbeeren 4 loth,

Nerrben 2 loth,

¿erchenjohmamm $\frac{1}{2}$ loth;

mifd)e es untereinander zu einem Spulver.

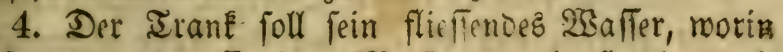
gefotten morben Enzian, Meiftermurzel, Şohlmurzel, Iaujenogüldenfraut, Salpeter, Serfte uno Bergmünze. 


\section{Das 50fte Eapitel.}

\section{SBon Der Rebe, Die fonft audh Borfdlagen}

\section{genannt niro.}

Die Rebe ift eine fdnelle Srantbeit, uno beftebet in

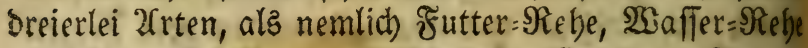

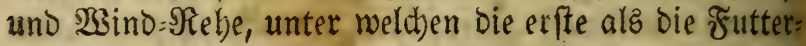
Rebe die ärgfte uno gefäbrlichfte ift, oavon mir aud) guerft reden rollen, Eommt baber, wenn ein Spfero ent: weber aufz Futterfrelfen unaufhörlich gejagt uno ge= rennt woroen; ooer fo ez hifig geritten oder gefübrt vorden uno man ifm alzbalo viel Futter vorfchüttet, rooburch Der Magen und bie \&eber erftecket rorben, nem=

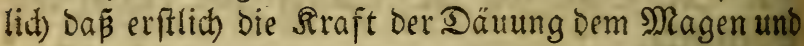
bon Darauz der 3ugang der abgedäueten Epeife, fo man fonften Shylum nennet, dex \&eber benommen, und anftatt Derfelben robe, grobe unoäuliche Nabrung atto bem SMagen Durd) bie \&eber Şungerz halber angezogen wiro, weldbe die \&eber erftecien, uno daz näbrende (se= blüt Durd) bie 2oern nid)t Eann aubgefübrt werben, alboann fallen die Feudtigkeiten berab bem spferd in bie Sid)enfel, die Sräfte des humioi radicaliz allen (S)lie: bern benommen, fo daß bie \$Nferde anfangen Eraftlos żu netben, zittern, uno jäbling barnieber fallen.

\section{Die Seidhen find folgende:}

1 Uteberläuft ę den ganzen Rücfigrad.

2. 2llsbann fällt ę in bie Ghenfel, melthe anfan=

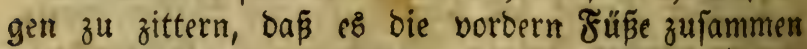
ih)renft, Daber eह nicht allein aus Mattigkeit berjelben auf beibe Seiten fowwantt, fonbern auch fich geftaltet, ale ob es hinter fid) fallen wollte. 


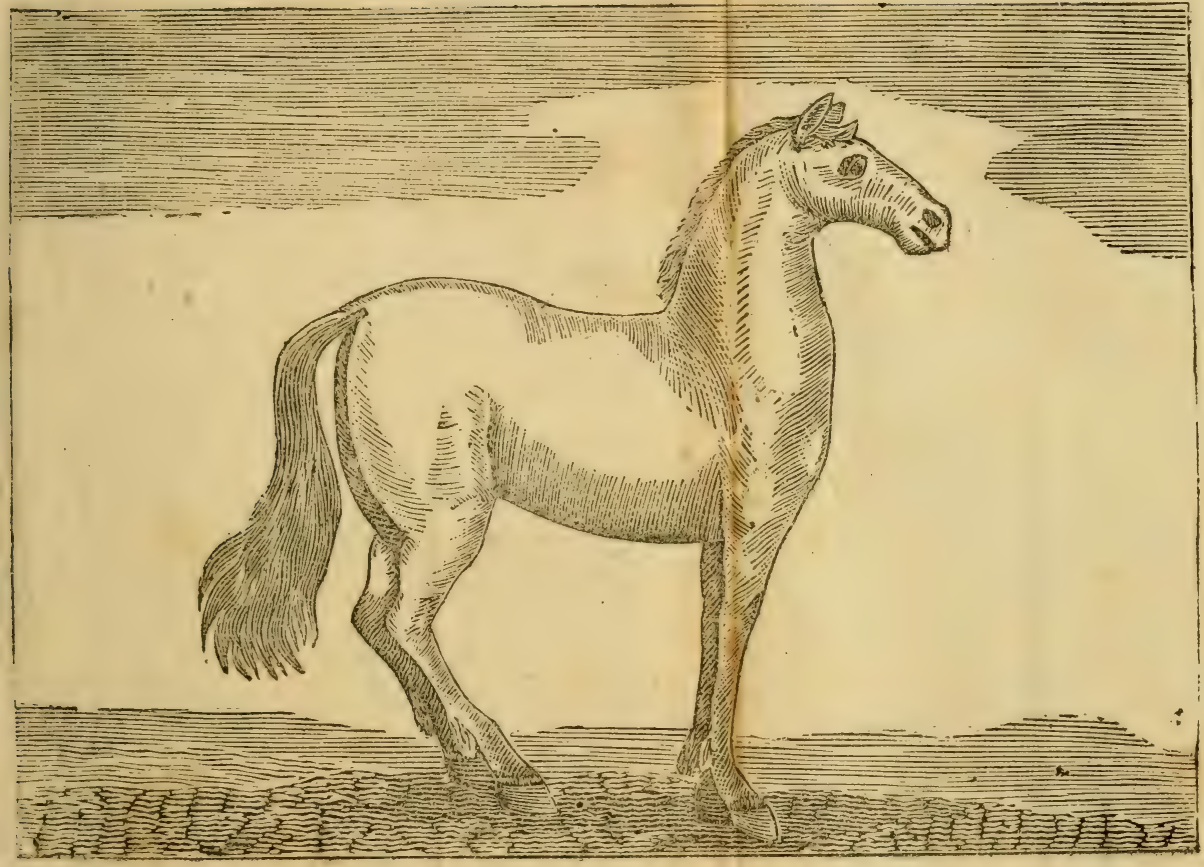





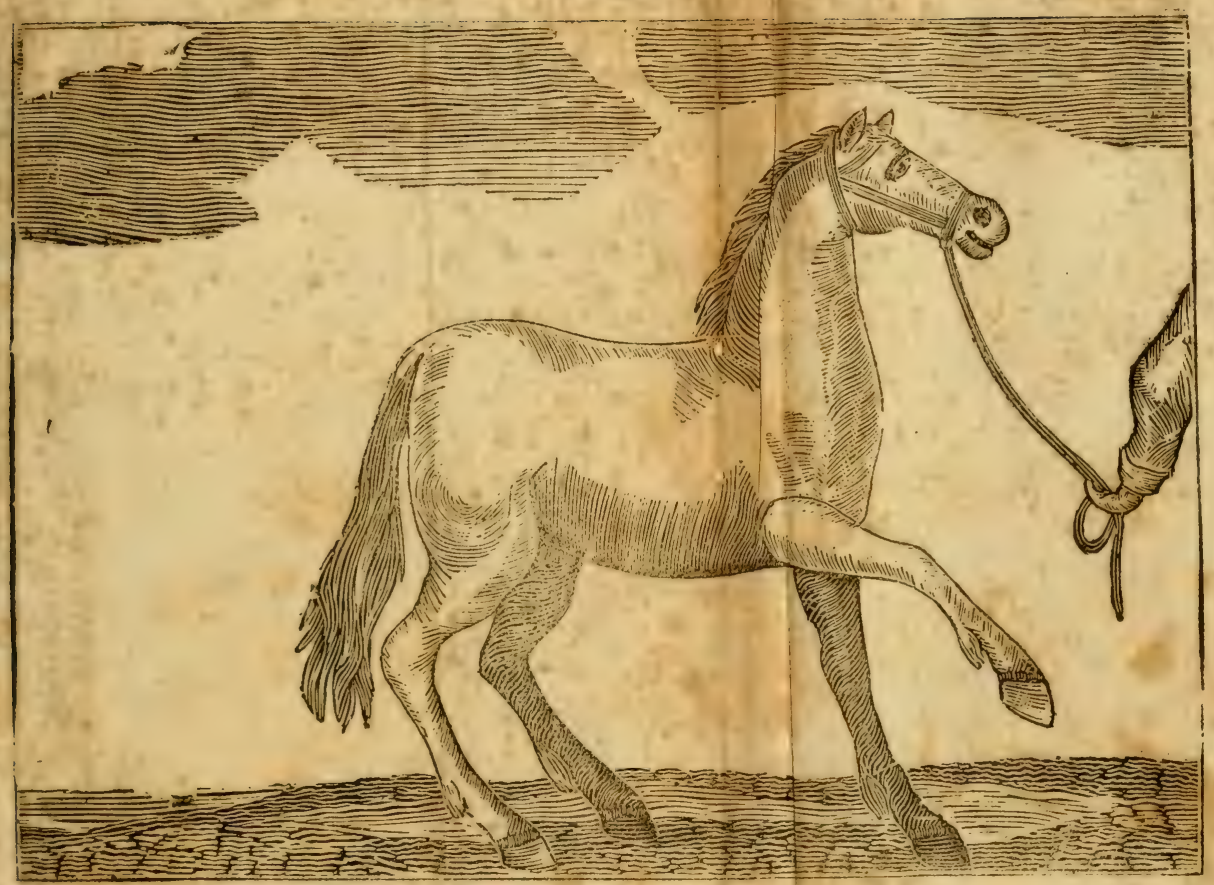




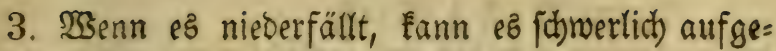
bracht reerden.

4. Sthwiset bisweilen an Den $\Re$ Rippen und an ben গ̧Seidjen.

5. Räß̄et ben Scarn mit 3wang von fid).

6. Fabren ibm zumeilen in Dem Maul frinfende Bläschen auf.

7. ŞGerben bie Fǚpe je länger je fieifer uno ftred fie alle von fith, und bie Saufe befommen Singe.

8. Shat es einen fehr beisen und finfenden 2 them.

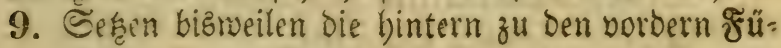
pen. Siebe Figur No. 21.

10. SBläbet fid oft.

11. ŢSemn es geführet miro, Eann ę feine Edgen= Eel nid)t biegen. Eieke Figur No. 22.

\section{Die (5) $\mathfrak{r}$.}

Bor allen Dingen foll man bem \$ुferd die (Eijen

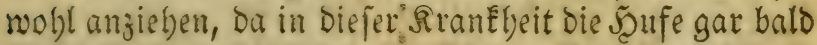
himbeg fallen und alzbann fich ber (Styptir, welthe in Den Eapiteln von ben $\Omega_{e}$ berfranfheiten, und in bem $\mathcal{S}_{a}=$ pitel vom 23 erffoß bes Futterz, ober in Dem Eapitel bo!n "verfid)lagenen Scarn find befáricben morben, ge= brauden, audd fobalo Dem syfert \&uft maden, als ba

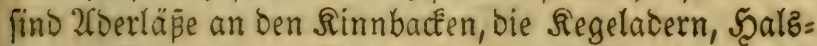
adern, Sporradern, Sdyrentabern und Bugadern, wel= dhe alle ober fo viel jemand unter biefen yonnöthen ju feir, erad)tet, alzbann

Rimm von bem ß̧lut $\frac{1}{2}$ Raa untereinander gemifatt und eingegeber.

\section{(E) $\mathfrak{i}$ an of $\mathfrak{e} \mathfrak{e}$.}

Senedifate Seife 6 loth, 
510

\section{Pferbe:2Argenei Budh.}

\{3atme Mild $\frac{1}{2}$ Maaß̃,

untereinanoer gemifht und laulidht eingegeben.

Ein anoer $\mathbf{e}$.

Tormentill 1 loth, Saffran 1 Suintlein,

Springmurzel 2 Suintlein,

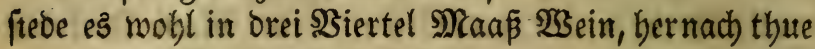

Dazu Menid)enfoth 8 loth,

untereinander gemijht nno eingegeben.

Ein andereb.

Spagivi. präparirtez Sॄirfdh horn,

Iberiac, jeoes 2 suintlein,

Saffran 1 Suintlein, Rein $\frac{1}{2}$ Maaß;,

uktercinander gemijcht uno auf einmal eingegeben.

Ein andereb.

SRimm ein langes Stüct Sped poer Seife; ftecte es bem SDFero in ben Scintern uno treibe es noly um.

E in anderes.

Reite oder führe es in ein fliep̃endes $\mathfrak{S}_{\text {Saller gegen }}$ ben Strom, laße ez bis an ben Bauth etliche Stunden alfo ftehen, und fȩ̂ eริ einige Iage fort.

Ein andereb.

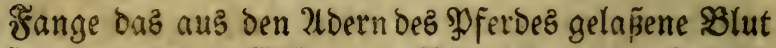
auf, nimm bazu (sifitg uno Baumöl uno macke bem Syferb einen 2 nftrrich Davon.

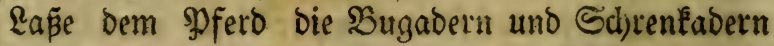
(b)lagen, bermad) gib ify folgenden 2 nftrid) bavon:

(sin anberer 2 (nftrict)

Siemeinen B̊oluz 6 शुfuno, 30 Esier,

Sauerteig 3 פुfuno, NBeinbefe 1 Maá̃

20yrrben 1 loth, Dradbenblut 2 lotb, 
Sdbönes $\mathfrak{N e h l} 1 \frac{1}{2}$ Bierling,

Ietpentin $1 \frac{1}{2}$ ⿰冫 funo, Sconig $\frac{1}{4}$ SPfuno,

Langen Syfeffer 2 loth,

Rnoblaucbsjaft $\frac{1}{4}$ Maá̃

Branntewein $1 \frac{1}{2}$ Maaß̃,

Ejfig jo viel genug ift, daß̃ es wie ein bicter B̂rei merde ;

biez mifut)e alles untereinanoer und ftreiche das spferd an alfen Sieter, am Bauch) und am ganzen Reib bamit an, außer Dem Şatz, Sopf uno Rücten.

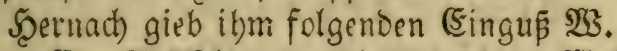

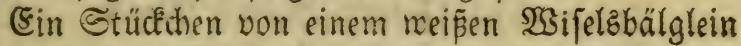
(andere $\mathfrak{B i f e l}$ thun ez aud)) fo groß als ein 10 Senteftüc,

Sembo, Darauf Daz MRenftruum Sirginiz vel $\mathfrak{R u}=$ liers, fo grop alz ein Thaler ift,

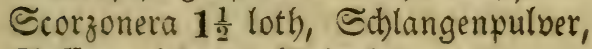

Safran, jebes 1 Suintlein,

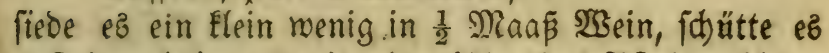
auf einmal ein uno reite oder fübre das şfero roobl ba= rauf.

\section{Einandereb.}

21 Feigen, Sמfeffer 1 Suintlein,

Bobnenmebl 4 loth, Saffran $\frac{1}{2}$ Suintlein,

Baumöl $\frac{1}{4}$ SDfuno, $\mathfrak{W e i n} \frac{1}{2}$ Maaß̧,

untereinanoer gemifot uno eingegeben,

\section{Ein andereb.}

Nache ein Sflafter von Sleien und Fid)tenbarz uno fullage es ibm rarm um bie Beine.

\section{E in andereb.}

Siebe Scaberftroh wobl in fliependem $\mathfrak{H}_{3}$ ffer und 


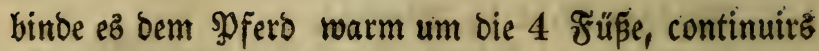
oft.

Ein 2 nffrids.

Boluz 3 Pfuno,

Nachtichattentrautiaft $\frac{1}{4}$ Maañ

Effitg fo niel genug if zu einer bitfe wie ein Brei, Salz 3 Şänopuoll,

milche ezs untereinander, reibe bem \$ferb die Beine da= mit uno fhlage es ithm mit Säuf́th ein.

Ein a no eres $\mathbb{3}$.

Salapwurzel $1 \frac{1}{2}$ loth, $2 \mathfrak{s e i n} \frac{1}{2}$ Maa

Scammonium 1 Suintlein,

Ertract von Soldanella, Saffran, jebee $\frac{1}{2}$ Sut.

Rerchenridumamm 2 Suintlein,

mifche es untereinander und foütte ez bem \$ofero auf einmal ein, fo wird eb fich purgiren.

Ein anderes.

Sahlage ihm ein mit beiper 2 fiche und Esfitig unter: einandêr gemengt, ober brate ein (Si in Baumöl uno fallage ifm bamit ein.

(E) in anberez.

Menicheneoth 6 loth, Saffran, Sibergeil,

Sirebsaugen, jeoes 1 Suintlein,

Lerchenfdymamm,

WBeinfteinjalz, jeoes 2 Suintlein,

Bein orei Siertel Maáá,

untereinander gemifcht uno auf einmal eingegebeu.

E $\mathfrak{i} \mathfrak{a} \mathfrak{n} b$ ereb.

grofdlaidhwafler,

Erorautbraffer, jedes $\frac{1}{4}$ Maaß̄,

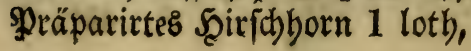


Şermutbjalz,

Garbobenedictenfalz, jedes 2 Suintlein,

Sdlangenpulver 1 Suintlein,

Saffran $\frac{1}{2}$ Suintlein,

mifde es untereinander und fdütte es bem Spfero auf eimmal ein; reite oder fül)re eŝ wohl barauf.

(5) $\mathrm{i}$ andereb.

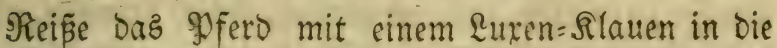
Nafelöber, Dlsen, wie aud) am (Saumen, uno offne ifm auch Die 2loern unter Der Sunge Damit.

Ein andereb.

Reibe ifm auch bie Beine mit ๔alzwafler.

(5) in a ndereb.

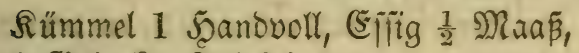

6 (S) badte 3roiefeln,

fiebe es robl mit einander, alsbann thue bazu.

İjeriac ober Mithribat 1 Suintlein,

Menichentoth 8 loth,

untereinanber gemifht und auf einmal cingegeben.

(5i $\mathfrak{i}$ andereb.

Reibe ifm bie Beine wohl mit Snoblaud)=(sfitg uno Branntewein.

\section{(F)}

Salz 1 Sandoull, Rupöl 6 loth,

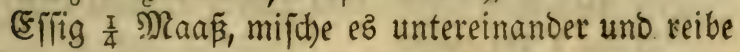
die Beine robt damit.

(5) in a $\mathfrak{n}$ Dereb.

(5riflich) laffe bem Spferd auf allen Bieren oie vier F゙effelabern őfinen, hernach gib ibm folgenden Eingus :

Sngwer, Rorbeeten, jedes 3 loth,

İeriac 1 loth, das $23 e i p e$ von 20 Eiern, 
$\frac{1}{2}$ Dुfund gute Saracenifiche Seife,

Wein 1 Maā́,

biefe Stücfealle roarm gemadht, aber nicht fieben la jen, uno bem झूferd auf einmal eingegojen, Decke es mit ei=

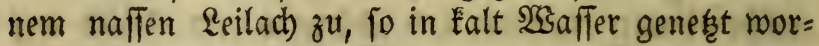
Den, uno lape es in 24 Stunden weder effen noch trin= Een; nach Den 24 Stunden gib ibm erfflich lau'icht $23 a f f e r$ zu trinfen, reite ez gemach, biz es fdhroiket, alz= bann wern es wieber erénblet iff, jo gib ifm fein ge= wöbnlid)es Futter.

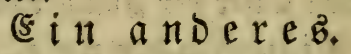

Sd)lage ifm alle 4 Siertelabern,

Nimm Rorbeeren 4 loth, Wcin 1 Maaß́,

Sngroer 2 loth, Saffran 1 Suintlein,

fiede afles mobl miteinanoer uno fidutte es bem \$Dfero

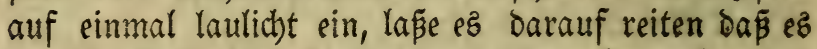
wohl jomike, reibe es trocken ab, bernach mache ifm nachfolgenoen 2 (nftrich :

Rimm Das şlut von ben 2 doern gelapen

Branntemein $\frac{1}{4}$ Maá̃, 16 Eier,

Bucbenajübe 2 șändeboll,

Roggenmebl fo viel genug zu einem bicken $B$ rei ift, Efifig $\frac{1}{2}$ Maa $\tilde{\beta}$,

Sconig Terpentin, jedes $\frac{1}{4}$ Ş fund, mijtbe ez untereinander zu einem 2 nftrich.

Den 3ten Tag nebme eine gute Scanoboll Salz, Zajde 1 Sanoboll,

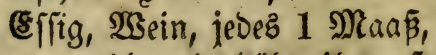

fiebe es wohl uno bäbe ifnn, fo warm ou es an oer

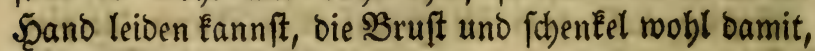
sebrauche es etlichemal,

Ein anderes.

Shlage bem Spferb bie Sporrabern und 2 Biertel: 
abern, nimm bas Blut, 2 Scänbeboll Salz und fautte es bem Safero auf eimmal ein ; wenn e? zu bide iff, fo Eann man ein menig $\mathfrak{S}_{3}$ ein batan giefen.

\section{Ein andere}

Froficlaichmafier 6 loth,

Saffian 1 Suintlcin,

23arme Mild) $\frac{1}{2}$ MRaaß,

untereinander gemifitt unt auf einmal eingegeben.

E $\mathfrak{i} \mathfrak{a} \mathfrak{n}$ be $\mathfrak{x} \mathfrak{e} \& \mathfrak{B}$.

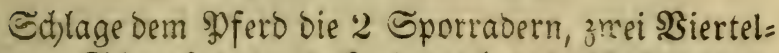
abern, Schrenfadern, becke hernat) Das şfero mit ei=

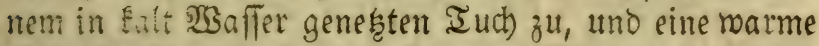
Soghe barüber, mache ibm eine gute Streu und gib ihm nad)folgenden (Eingu位:

Bibergeil, Theriac jeoes 2 Suintlein,

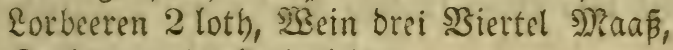

Arebşaugen 2 Suintlein,

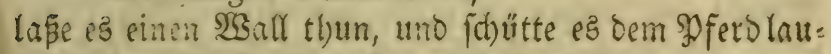
lid)t cin unb lape es macter barauf teiten.

\section{Ein andereb.}

sbuchenaiche fo viel bu willfi, 6 Eier, Şonig $\frac{1}{4}$ ⿰氵

Das Blut, won bem Pferd, nadjoem vorher bie Skugabern uno Edjeantabern aufallen \$ieten gelapen worben,

mifche $e z$ untereinander zu einem 2 (nffriet).

\section{(E) in ander $\mathfrak{e}$.}

Lape ibm alle 4 Bierteladern, Rimm Menjchenfoth 16 Isth, 9 geftopene Snoblaudbzäupter. 
516

פfferbe:2Irzentei Budh.

Şein orei Niertel Maaß̧,

untereinanoer gemifd)t uno auf einmal eingegeben.

Reite ooer fübre es robl barauf bernach ibm fol= genden $\mathfrak{2} \mathfrak{n}$ (frich gemadht :

SSeinbefe, \&eim, mifde es untereinander und freiche es bem গুPfero an alle Siere.

\section{(E) in andereb.}

Sthlage ifm die $\mathfrak{B}$ uabern auf beiden Seiten,

গimm bas Sferbeblut, thue Dazu

Rotben Bolus :2 Sofund, Mebl ein 2Chtel,

Terpentin 1 Sp funo, 20 Eier,

SSeirauch 8 loth, Maftix 4 loth,

mifche es untereinander mit id)arfem (sffig, freidye dab SPferd am ganzen \&eib, auffer am Scals und Sopf ba= mit an.

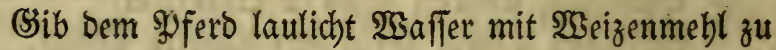
trinken, lapee es in 4 Tagen nicht nieberlegen uno alle Stunde des Tages umfühien, Den vierten Iag fübre

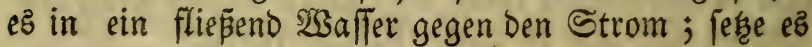
etlidbe Iage fort.

SBenn aber ber Schaben alt räre, fo fdneide ibn bis aufs $\mathfrak{c}$ ben aus; গimm ein Eitereifen, fhneide ibm am Schuß binein, biz Blut von 2loern beraus gebet, nimm ein $\mathfrak{B}$ ergnege mit Effitg uno (5ierklar lege inm die (sifen mieber auf, fhlage ihm mit alter Sit)meer ein uno fomiere ben Scuf mit guter Scornjalbe aus= menoig.

\section{(Einanderes $\mathfrak{B}$.}

Shlage bem Sמferd beide Scalz= und Sporrabern, ben andern $\mathfrak{I} a g$ beide $\mathfrak{B}$ ugabern; ben vierten $\mathfrak{I}$ ng bernach gib ifm nachfolgenden Irane : 
Den Gxft von Gcordium 6 loth, oder bie gejot=

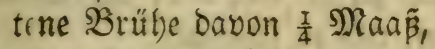

Snoblauchşaft 4 loth,

3miefelfaft $\frac{1}{4}$ Maa

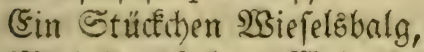

Nithridat $\frac{1}{2}$ loth, SBein $\frac{1}{4} \mathfrak{R}$ Raaf,

Stblangenpulver 1 Suintleir,

untereinander gemifit und auf einmal eingegeben.

(5i in andereb.

Schlage die 2 Felleladern, die 2 Gahranfadern, bie 2 Eporradern, Die zwei Saugabern, la pe fie ziemlid. laufen, funge bas sllut auf, fo viel bonnötben zu ei= nem (5infas ; bernad) nimm gefdualten Snoblaud), eine

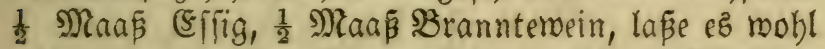
miteinander in einer SDFanne fieden, reibe Dem $D$ ferd bie füfie mobl Damit uno verbinde es gut mit Strob bis an ben Saud) berauf ; bas thue jweimal bez Tages bis an ben oritten Iag, bernach nimm gute $\mathfrak{B}$ utter und $\mathfrak{W}$ ein, bähe alle 4 Füfle bes Iagez zreimal, Mor = genz uno 2rkendz, Dies fere etliche Tage fort.

(sin \$räfervatio Mittel für die Rebe.

\section{Frofichlaich 1 Maấ,}

Senedifche Seife flein geidabt 1 Şfund,

Eorbeeren gepullwert 4 loth),

fiede bas Froichlaich in einer $\$$ fanne, alabann wenn es anfängt zu fieden, fo thue nad) uno nad) bie \&orbeeren uno bie Ecife barein, rübre es mit einem Sod)löffel mobl um, uno lapee es cine gute reil fieden, algoann orüce es burch ein $\mathfrak{3} u d$, uno verwabre es robl in ei= nem SFlas oder verglafurten irbenen (Seichirt. SBenn bir nun ein झुferd vorEommt, roldhes zu Rebe ift, fo nimm von biefem 3 loth, bermifde es in warmem $\mathfrak{X}$ ein 


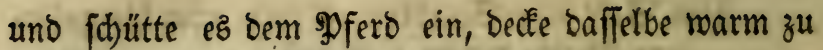

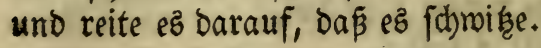

\section{(E) in a nderes.}

Siede 200 Frö(d) in einern Seffel wobl, merfe ber = nach 2 sfuno Elein gefchabte Renebifd)e Єeife binein, lä̧e es wieder mit einander fteben, orücte es Durch ein Iud) uno bebalte ez zum (Sebrauth),

Nimm Davon 3 loth, Snoblaud) 3 loth,

Ieufelabrect 2 Suintlein,

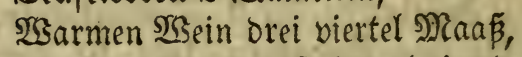

f(b) ütte es bem Sूferd auf eimal ein, Decte es wobl zu

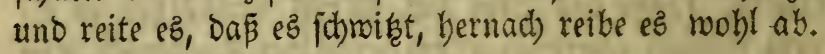

(sin andereb.

Salze Frofdlaid) mobl in einem verglafurten 50 a $=$ fen, wenn bu Dann was brauchen willft, fo nimm ba=

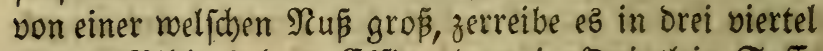
Maaß Mild), 8 loth) (sifig, thue ein suintlein Saff=

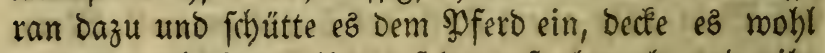
zu baß̄ ez fonwike, leibe es fobann fauber ab, uno reibe

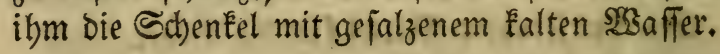

Sin anderes, menn ein \$ferb auf frifder Stelle Refie genorden.

Steche ihm mit einer Schufterabl butd) bie Nafe=

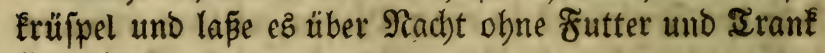
fteben.

\section{E in andereb.}

Nimm 9 Eamillenblumen, gib es dem $\$$ fero ein, ma=

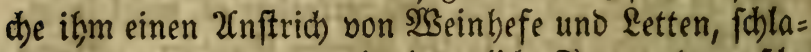
ge ifm bamit ein; continuirs etliche $\mathfrak{I}$ age und rafdhe ibm die Beine nobl mit Seiferwaffer ab. 
$\mathfrak{u}_{n}$ idblitt, $S_{a} l_{z}$, fo viel zu einem (sinjwlag ge: nug ift.

Ein anoerez.

Mildh 1 Maá̃, Salz 1 loth,

Beneoifdhe Seife 2 loth,

Saffran $\frac{1}{2}$ Suintlein,

untereinander gemifht. uno auf einmal eingegeben.

Bon Der $23 a f i e r=$ uno 2 sinorehe.

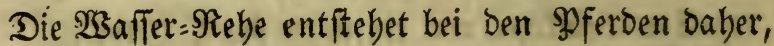
wenn fie in groper Şike ober nach groper 2 rrbeit ge=

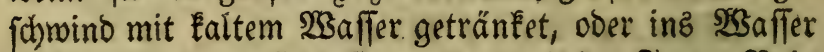
geritten werben, ift fonft in allem mit ber \&utter=-Rehe

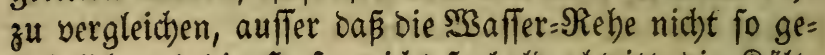
fäbrlid uno bie Şufe nicht fo bald abtritt, Die Sälte

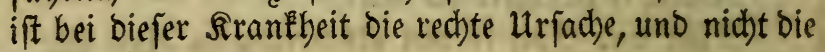
Şerftopfung.

Die Beichen fino folgende:

1. Die Ra elöbjer triefen ihnen.

2. Scaben Ealte Shren und andere Beichen, bie jobon

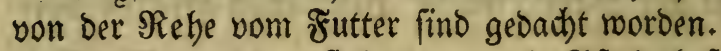

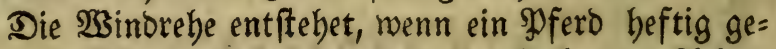
gen ben $\mathfrak{S}_{3 i n}$ gejagt worben, woourdh ifm ber 2 them in ber \&unge verffectet worben, auch ber MRagen und bas (Singerveibe mit $\mathfrak{B i n d e n ~ e r f u ̈ l u t , ~ w o r b e n , ~ w o b u r d ) ~ n i c h t ~}$ allein bie Serbauung verbindert, fondern auds ber na= türliche Durd)gang verftopft.

Die Beidjen find folgende:

1. Setommt ez einen furzen fdjweren 2 them, und ftellt fith, alš wenn ę herzichlächtig wäre.

2. Laufen ibm bie 2 (ugen auf uno geben Bäbren yon fith. 
Die anoern 3eid)en find aud fdjon von ber Futter= Rebe gemeloet norden.

Dieje beibe Reben rocroen curirt auf alle $\mathfrak{B} e i f e$, wie die Futter: Rebe curirt wiro.

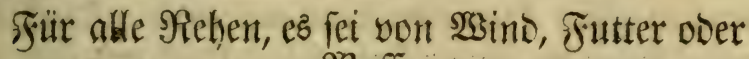
खुßafler.

Simm Iberiac auf einen @dnitt Broo, ober wie ou ce ifsm einbringen fannft, bermad) lape ibm bie Bier= telader auf beiben Sdbenfeln, die Sporrabern und bie Baud)adern auf einmal follagen, uno fohlage ifm am erften 2 bend mit beißer 2 fitbe und (5ffig in die Scufe, und fiede Şirfenbrei in einer Brübe, und binde eह ifm aljo warm über bie Beine, von unten an, bis an ien Bautc); Den andern 2fbend lapee ein (5i bart braten, Salj in einer \$ूfanne braun brennen uno fablage ifm ein; Den britten 2 beno mache $\mathfrak{B a ̈ u m o ̈ l}$ aufe närmfte, fadlage ein Ei brein, bas es woh! gebraten werbe und

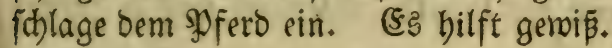

\section{Die ミerpflegung.}

1. Det Stall foll mittelmälfig marm uno trocfen fein.

2. Das Futter foll renig fein, uno Eein Scaber ober (Serfte, fondern (S)raz, Scell mit Salniter gefprengt, Rattich, Nangolt, Rleien Slümpdon.

3. Der Irane foll aud) wenig uno laulidt fein, wo= runter Serftenmebl, Sleien, Scolluniermurzel ober Rinden und 2attich gefotten worden, mit Gaffran ver= mijht.

4. Daz \$Dfers foll narm zugededt und oft geritten ober gefübrt werben.

5. Soll das Pुfero angebeftet werben, Damit es fid) nidht legen fönne. 


\section{Bon Der Peftilenz Der Pferbe.}

Die speftilenz entftebet aus dem Einflup des (S)eftirns uno aus einer faulenden corrumpirenden Sualität, welche bizmeilen in ber $\mathfrak{R}$ uft fich aufhält und bals bie Sörper ber Thiere, wenn fie ein menig Fermentation Gaben, ourd) bie Schmeiplöher und Den 2(them anfte= deet; ebenjo auch von böjen, ftinkenden uno giftigen in fid) gefoffenem $\mathfrak{W a f f e r}$ giftiger $\mathfrak{S B}_{\text {eide }}$ und Futter, mie auc) böfem uno giftigem (S)eftank, ftinkenoen Siebeln, namentlich in bisigen Sommerzzeiten mo bizmeilen bie ungünftigen 2fipekten nod) Dazu fommen uno bie fdonel= lere 2 uzbreitung Dez Srankbeitsftoff's begünftigen.

Diefe Srantbeit ift febr anfteckeno, Defroegen wo

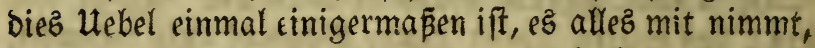
man thut baber am beften, oas nan gleid) im 2(nfang bie gefunden von ben franken abjondere und in andere Ställe fübren laß̧e.

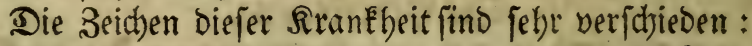

1. Stöpt eš ein $\$$ ferd zumoilen an wie ein Fieber mit einem jäblingen Froft, uno ift inmenoig boch Scige vorbanden, weldbe man aus bem hisigen und ftinken= ben $\mathfrak{X}$ them abnebmen Eann.

2. Scänget ben Ropf und wiro faläferig, wie bie shblegmatici zu thun pflegen.

3. Senn das (Sehirn ergriffen wirb, fo werden fie wie bie Ebolerici ungeftümm, uno feben mit ven 2 fu= gen fidrectlid aub.

4. Stößet ę folden Spferben oft auf, zieben bie Seiten beftig ein und baken cinen unerfättlicben Durft.

5. Saben ețliche ein bigigez Maul, eine trocfenc 
uno fdhwarze 3unge und fino über ben ganzen Reib beis.

6. Fabren foldsen פoferben auth Beulen auf, bejon= Derz aber binter ben Shren, an ser Rafe, am Rinn= bacten, am Scalz, an oer Bruft, an Der $\mathfrak{E s e i d h e , ~ u n t e n ~}$ am Baud), am Sefódröt. Siebe Figur No. 23.

7. SSinken foldhe şferde jeghe bäufig.

8. WBeroen innen bismeilen die 3äbne loz.

9. äß̈t einen foldhen Mift, Şarn und andern $\mathfrak{U} n=$ rath von fich, Der über bie Maßse ftinfet.

\section{(2) i e है $\mathfrak{r}$.}

Bor allen Dingen foll man bem Mfero ben Reib of: fen balten und (Sinftire gebraut)en, wie aud) Die 2roer= lap̃e bor die Şand nebmen.

Brüle von einem gefottenen Şal) 1 Maas̃,

9 (sierbotter, Salz 1 Scanbwoll,

Rojenöl, Baumöl, jedes 6 loth,

mi che es untereinanber und gebrauthe ez laulidht gmei. mal bez Tagez.

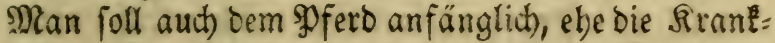
beit überbano nimmt, sine ooer zmei 2roern öfinen, ent= tweder am Saals, Die Sporradern, 3iugabern oder auf bem Sdjlaf oder unter ber 3unge $2 c$.

\section{(5in Eingus.}

Iheriac 2 Suintlein, Saffran $\frac{1}{2}$ Suintlein,

Sauerrampferwafier $\frac{1}{2} \mathfrak{R a a}$, untereinander gemijatt und auf einmal eingegeben.

Ein anderes.

Shäparirten Smarago 1 Suintlein,

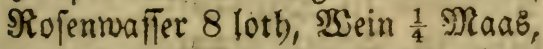
untereinander gemifht und auf einmal eingegeben. 


\section{(Fin a n D e $\in$ e B.}

Citronenfaamen $1 \frac{1}{2}$ loth, 2Bein $\frac{1}{4}$ Maaz,

Iormentill 2 loth, Sorallen 1 loth,

Rotbe $\Re$ ojenblätter 2 lotb,

Rojenmaffer 8 loth,

(Eijenkrautjaft 10 loth,

untercinander gemifht und auf einmal eingegeben.

Ein anderes.

Dürren Menfobentoth 3 loth,

Rothen Bolus 1 lotb, $\mathfrak{u s e i n}_{\frac{1}{2}}$ Raas,

untereinander gemifht uno auf eimmal eingegeben.

(E) in a noes.

Iormentill, (sijenkraut,

Betonica, jebes 1 Scanoboll,

fiebe ez in 1 Maas $\mathfrak{X s e i n}$, thue $\frac{1}{2}$ Saintlein Saffran an bie Brühe, und ichütte ez auf einmal ein.

SSifteugeln, wowon bem Siranfen \$ferb 3 auf ein mal einzugeben im 2 sein ober Effitg, wie man will, zur Yräfervation aber wö̈hentlich einem Pferd eine ober anderthalbe $2 \mathbb{3}$.

Zingelica, Liebftöofel, șeftitenzmurzel; Zllantwurzel, Tormentill, Natternurzel, Enzian, Ebernurzel, Meifterwurzel, Sirifid)murzel, Farrenwurzel, Rbapontic, jebes $1 \frac{1}{2}$ Pfuno, Sthwarze Niezmutzel, vorther eine Nad)t in Effitg gebeint,

Bryonia, Modelgeer, Ecorzonera,

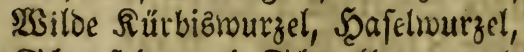
Sabrefelnurzel, Sd)walbenworzel, Dradbenworzel, Sraunmourzel, Nieznourzel, 
Pferbe=2lrzenei Bud).

Ieufelzabbiñnurzel, jeoes 1 sp funo, Sin- oder 3weiblatt, জiebengezeit, Şuflattid, jeoes $1 \frac{1}{2}$ Pf funo,

Soldanella, Scorbium, Diptam, Bitenell, Balorian, jedez 1 s) funo, Siräbenäuglein, Ssummi guttä, ミcammonium, 2 garic, jeoes $\frac{1}{2}$ SPfuno, Iubith $\frac{1}{4}$ SDfuno,

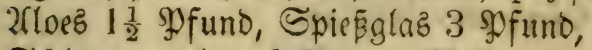
Sd)langenpulver $\frac{1}{2}$ Sfuno, Minrtben 12 loth, Sirjhborn 1 SP funo, Sieidenjhwamm, Birkenithnamm, jeoes 1 Şfund, Ecorpionöl, Eichentolzöl, Waabbolderbolzöl, jedes $3 \frac{1}{2}$ Pfuno, Mithridat 1 Pfund, $\mathfrak{B}$ ad bolder=?atmerge, Soluncer: Ratnerge,

2Attict-Latwerge, jeces fo viel gemug iff, aus allen biefen Gtücken einen İpig ou madhen uns Iugeln baraus zu formiren, fo gró̧ als sin eleines Sübnerei.

E in a n Derezs. SIG.

Sorrigirte fonnarze গicŝnurzel, \$peftilenznurzel, Angelica, jeoes 1 Pfuno, Iormentila, Schnalbennurzel, Safelmurzel, Sticknurzel, jedes $\frac{1}{2}$ Ş funo,

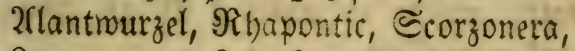
\&ungen: uno \&ebertraut, daz an Den (Fid)eln

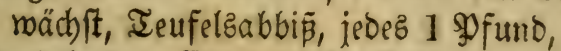

Sundelreben, Ebrenprei⿱乛龰, Diptam, Bibenell, milbe Salbei, Şuflattig, jebes $\frac{1}{2}$ SDFuno, Sdblangenpulver, Siräbenaugen, Eerd)enichwamm Scammonie, Summi guttä, 
Aloee, jedes $\frac{\pi}{4}$ Pfuno,

2Beibenidnamm 1 Pfuno,

Spieşglas 2 Pfuno,

mi iche bies untereinander zu einem Spulver, babon Dem Bieb alle Iage 3 lotb zu freffen geben; menn man roill, fann man mit Şonig uno Ecorpionöl Süugeln baraus formiren, wie bie vorgemeloete Sift = Sugeln fino bem sperb aljo eingeben.

$$
\text { Ein anderez. }
$$

Soloquinten 1 Suintlein, Rein $\frac{1}{4}$ Maaßá,

untereinanoer gemifabt und auf einmal eingegeben.

E in a n bereż.

Saft von miloer Sürbismurzel 3 loth, Salpeter 1 loth, $: \mathfrak{Z s i n}^{\frac{1}{2}}$ Maa untereinander gemijot uno auf einmal eingegeben.

Ein anderez.

Säbenbaum 1 ⿰冫 fund, SSamanderlein, Iaufenogüldenfraut, jedes 6 (oth), Sd)malbenmurzel, Scohlmurzel, Scirfhwourzel, \&orbeeren, jebez 8 (otb), 9):urrben 3 loth,

ftope und pülvete es untereinander, nimm von biefent

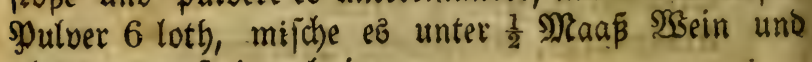
id) ütte e's auf einmal ein.

\section{E in andereb.}

Der $\mathfrak{B}$ urzet Sמanacis, Mannstreumurzel, Frenchelfaamen, jeoes 6 loth), 2lleos 4 loth, mific) es untereinanber, von biefem spulver 3 loth bem

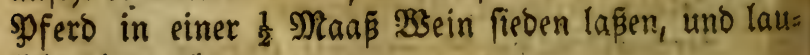
licht eingegeben. 


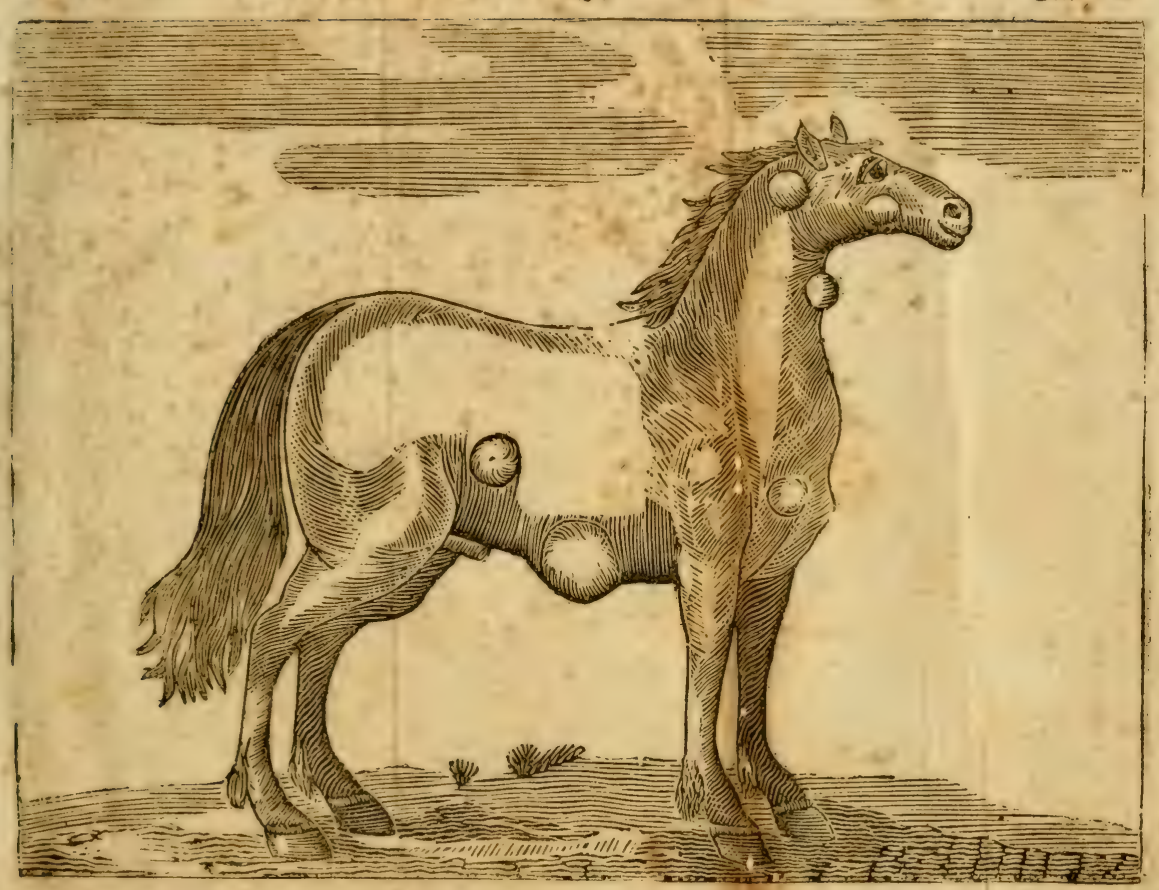




\section{Perbe:?(rjentei Butd).}

\section{Ein andereb.}

Spieß̧e Sröten lebendig Durd) Den Sopf, und büre fie in ber $\Omega$ uft, lege eine fold)e Sröte über oie Beulen; wenn fid) bie אröte vollgezogen, fo wirft man fie hin = meg und legt sine andere liber.

E in a noereb.

Rttichnurzel, Reflelnutzel, jebes 2 saintlein,

Durd)gejeifte Fifhlacten eine (Fierifibale voll, mifd)e es untereinander und fprike es sem Shfero in bie Najelöd)er.

Sin anderes $\mathfrak{B}$.

Salcinirte Stotben in einem 5̧afen, er fei jung ooet alt, nimm biefre 1 loth), (5nzian,

Siebengezeit, Säuenbaum, jedes ? loth,

Spräparites Şirid)born 1 loth,

Mgein $\frac{1}{4}$ Maas,

untereinander gemijdt und auf einmal eingegeben.

\section{(5in anderez}

Whenn feine Beulen vor! banden fino, foll man ilfnen Die CShriftrourzel vornen an bie SBrüfte oder zmifchen die Beine ftecfen; no aber Benlen vorbanden, foll man fich Des Shriftnurzelftecfen gänjlich entbalten, uno folgenden Iranḱ eingiepenen.

Berglastes Spiep̧glas 1 Suintlein,

2Bsein $\frac{1}{2}$ Maa $\tilde{\beta}$,

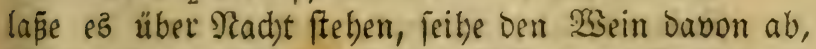
ihütte es dem $\$$ fero nuf einmal ein uno lape es roobl

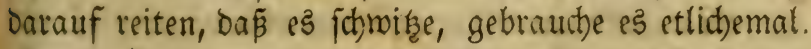

Ein anderes.

Sipfel von Dannzapfen,

Rerchenbäumen, Fidjtenbäumen, 
(sibifd)murzel, jedes fo viel ou milft, untereinander geftoßen und gejotten, bernadbas $23 a$ a = fer eingejotten uno spflafterweiz auf bie Bseulen wobl warm gelegt.

E $\mathfrak{i} \mathfrak{n} \mathfrak{a} \mathfrak{n}$ deres

Shepar 2Untimonium 2 Suintlein,

Ecorzonera 2 loth,

Sd)langempulver 1 suintlein,

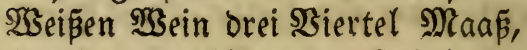

untereinander gemifd)t und auf einmal eingegeben.

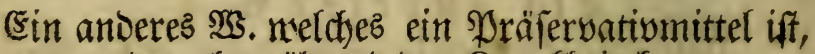
unt auch währeno ber Franfleit Eann gebrautht nerben.

Shafelmurzel, RnoblaudbzFraut, ভtictmurzel,

Ẽnzian, jeoes 6 Şändevoll,

Sheftilenzmurzel, Meifternurzel,

Sirifd)wurzel, (Ebernurzel, Iormentill,

Stdmalbenmurzel, 2Ingelica, jebces 16 lotb,

Sdbwarze Niesmurzel 6 loth,

Scorzonera 1 p̧ fund,

Modelgeerwurzel, $\mathfrak{2}$ Sintergrün,

WBeinrauten, (Sropées Sdböllfkraut,

Säpenbaum, Şausmurzel, (Sundelreben,

Areuzmurzel, Siebengezeit, jebes 6 Scändevoll,

Wgilde Salbei, Taujenogültoenfraut, Diptam,

(Samanderlein, Bibenell, jebes 16 loth,

Gcorbium $\frac{1}{2}$ spfuno,

Şadbholderiprößlinge, Ringetblumen,

Lorbeeren, jeoes 6 Scändeboll,

\$̧räparirtes Şirīh horn 16.

Ealcinirtes Storchenpulver 6 loth,

Ealcinittes Taxenpulver, $\frac{1}{2}$ פfuno, 
Snoblaudhjaft 3 loth, Effig 10 lotb,

Branntrwein 1 loth, mifche es untereinander uno id)ütte es Dem झlferd auf einmal ein, ober nimm die troctene 2 rzeneien uno gete fie ibm auf Dem Futter zu freffen oder im Salz zu lecten.

\section{Ein an o e e b.}

Reifterwurzel, Die $\mathfrak{B}$ urzel Panaciz,

Die 23 ulzel von \$rallenoifteln,

Fenchelfaamen jebes 1 loth, Saaizenmebl,

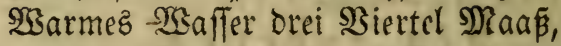

untereinander gemifd)t und aufecenmal eingegeben.

E i in anoereb.

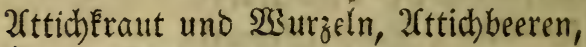

Sibenellekraut uno $\mathfrak{B}$ urzel,

Sisadjolderbeeren,

Lorbeeren, eines to viel als bas andere,

allez geoörrt uno gepülvert, Davon alle Iage dem \$ुfero 2 \&offelvoll im Futter zu freffen geben.

\section{Ein andereb.}

Schiep̧pulver 2 loth, Effïg $\frac{1}{4}$ Maaß̄, untereinander gemijht und auf einmal eingegeben. Sin anberes, wenk die giftigen $B$ eulen lommen $\mathfrak{B}$.

Siebe über bie Beulen, fie feien wo fie mollen, oder wie viel beren find, ein Saatjeil von SPferdebaaren und gib ifm nadfolgenoen Trane :

$\mathfrak{B s e i n}$ Der eine Nacht über verglaztem Spieşglas

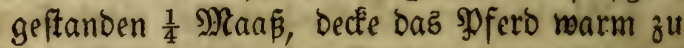

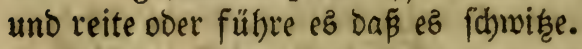

(5 in a noeres $\mathfrak{Z}$.

Separ 21ntimonium 2 Suintlein,

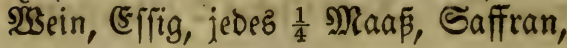




\section{פferbe=2(rzenei Buth.}

(E) $\mathfrak{n} \mathfrak{a} \mathfrak{n}$ oereb $\mathfrak{B}$.

Schwefelbaljam, İheriac, Saffran,

Echlangenpulver jebez I Suintlein,

Spagyr. präparirtez Şirf(d)born 2 S.uintlein,

$\mathfrak{B}$ ein $\frac{1}{2}$ Maaß̧,

untereinander gemifdt und auf einmal pingegeben.

(Fir a nDereb $\mathfrak{B B}$.

2ungelica, Enzian, jeoes 6 loth,

Sittwer 1 loth, Fünffingerkraut,

Bibenell, Sitronenicbalen jeoes 4 loth,

Dürre : Sachboloerbeeren 6 loth,

Sdinefel $\frac{1}{2}$ Mfund,

mifche es untereinander uno gib dem \$ूfero bayon täg= (id) 3 loth im Futter zu freffen.

Ein andereb গুS.

(Sib Den Sुferden über bendritten Iag jedem ein $\frac{1}{2}$ Suintlein Spiep̧glas im Salz zu leden, befonderz in Der gröpten Schise des Sommers.

(5in andereb

SBachbolderfolzöl 1 suintlein,

Schwetelbalfam $\frac{1}{2}$ Suintlein, Wein $\frac{1}{2}$ Naaß̃, untereinander gemijcht uno auf einmal eingegeben.

Ein guter nüblicloer Dampf.

Nimm Schaalen von Suitten, von (Sranat=24epfeln, Eittonen, Murrben, Sampfer, gelben Santel, Rojen, Siolen, Maftix, Muscatenü $\tilde{\beta}$ uno Simmetrinoen, ei= neEి fo viel als bas andere vermifds, lege etwas bavon auf glübende నoblen, uno halte es bem soferd unter bas Saupt, Damit ihm ber Dampf burch Die Rafelöcher hinein oringe, weldbes ihm bie श्रattigfeit benimmt. 


\section{Der}

Dritte Theil DeBs

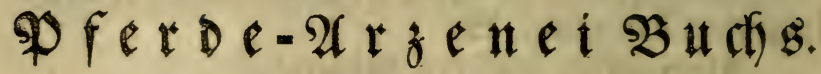 bon}

verichiebenen äuserfichen nach Dem 2 Hrphabet be= farriebenen (Sebrechen Der \$ferde, nebit genau= er 2 ngabe, nie biefelben zu keilen findo.

3um Boraus ift bei allen Eapiteln biefez yanzen Budty wohl zu merfen, bá der Stall jeberzeí fauber, trocten,

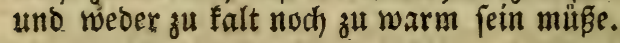

Das 1fte Eapitel.

গ̧on allerlei Salben, Delen und Barfamen zu den äukertichen Schäben ber Pferde zu gebrauchen.

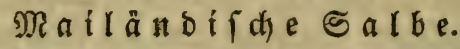

2ltes Sdbmeer, Maibutter jebes 2 \$fund, 2litheafalbe 1 sofund, B̧rininpan 3 loth, Spanifche Müufen, anoerthalb loth, S3itriol 2 loth, 2llaun 3 loth, Salpeter 2 Suintlein, Loröl 1 Dfuno, Sconig $\frac{1}{2}$ Şaa

ftope zu einem soulver waz zu ftopen iff, uno mad)e es über einem linden Roblfeuer mit ftetem §iühren zu ei= ner Salbe, lậ̉e ez nidbt überlaufern. 
Pferbe:2(rzenei $\mathfrak{B u d}$.

Eime Ealbe für Entzunoungen uno jede 2rtt van Brant.

Branntewein $\frac{1}{4} \mathfrak{M a a \tilde { \beta }}$

Senebifden Ierpentin 2 lotb,

jetflopfe es robl untereinander und thue bazu

3 Eierbotter,

Sobannisktrut $=$ Del 2 loth),

lege alzbann von biefer জalbe auf bie Entzünoungen, und baruuf cin boppeltes leinene? Iuch, neld)es in Siranntewein genefert worben ift.

(E) ine Branofalbe. TS.

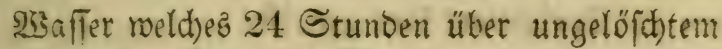

Siald) geftanden 1 Maás,

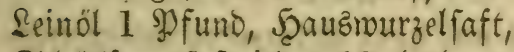

Sdjofferautjaft jedes 12 loth,

Sampfer $=$ Del 6 loth,

mifid) und rübre es miteinander zu einer Salbe.

Die Bettier s: Salbe.

Ietufclz=2(bbiß 10 loth, Rotbe Brenneffel,

(5) uten Seinrid) jodes 6 loch,

(Fitune Satbbolderbeeren 10 loth,

2ulberbroft 6 loth, Enzian,

Iitbuckzfraut jebes 8 loth),

Sirid)zungentraut,

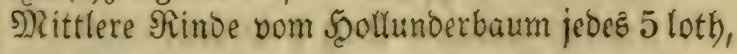
ftope uno mifiche alles untereinander und nimm frifhe

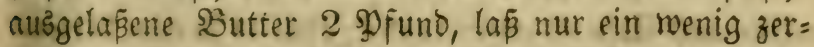

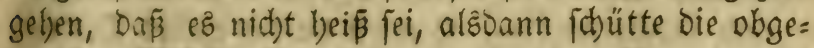
nanniten Gtücle alle miteinander hinein, rübre es molkl untereinander uno laße es über einer (Slut robl fieden bis die bimein gethane 2 rzeneien anfangen zu raujhen, alsoann thue ez vom Feuer hinmeg uno prepe ce auz, 
xübre es alsoann mit einem Şajel Steçen herum, bis es Eait wird, fo ifts fertig.

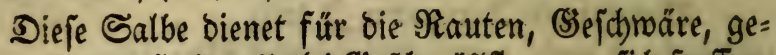

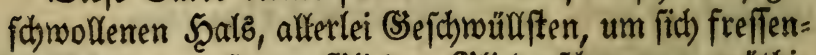
be Sđäben, erfrorne (S)lieber, BSlieberichmerzen, wütbi= ge Şunosbi werben; wenn fie anfängt ju wirken, fo madjt fie

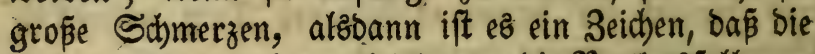
Eur anyejolagen hat, mirb darum bie Bettlerşalbe ge= nannt, weil fie faft zu allen Bettlers=. SranEbeiten, wie man im Spridbroort aagt gut ift.

(E) $\mathfrak{i}$ andere

(S)etöbtetez uno ganz glänzendez fublimirtes Suedefitber,

Spiésglas jebez 1 Theil,

mifdse uno ftope es untereinander uno biftillire es brei= mal in ber Retorte über fein Capur mortuum berüber, alsoann nimm bas Kerüber gegangene Del und recti= fizire ez mit Sranntemein, bann iftz fertig, bas Sel

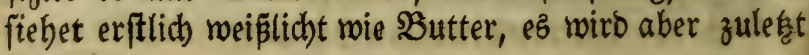
rotb.

\section{(E) in anderes.}

Spiȩ́glą 1 Pfund,

Dürres gemeines Salz $\frac{1}{2}$ ⿰力 fund,

Rlein geftopene Siegelfteine 1 sofund,

mifcbe uno ftope ez untercinaber, thue ez in eine Retor= te uno treibs berüber, fo wirft ou ein gelbes Del be Eommen, von biefem sel ziebe fein \$blegma binmeg fo bleibt ein \$olver, welches bu auf einen MRarmor im

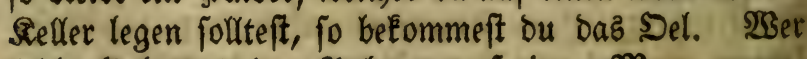
poldbe Sele aus ben \$ulvern auf einem Darmor mas 


\section{gुferbe=21rzenei Buch).}

then with, mus es in ben folgenoen 3 Monaten thun, alé Suni, Suli, 21uguft, fonft befommt er kaum ben balben sheil Sel.

$$
\text { E }
$$

Spiepglas 1 ⿰冫 fund,

Salmiac $\frac{1}{4}$ Spfund,

miliche eह untereinander uno fublimire es tuber lindem Feuer, hernad) nimm Daz Sublimirte, und mifdes nod) pinmal 10 loth frifd) Spieşglaz barunter uno jublimire es noch einmal, bann folvire biefen Sublimat auf ei= nem Marmor im Reller zu einem Del.

Eine fúblende uno beilende Ealbe zu allen @isáben bie nod) frifit) find. $\mathfrak{x}$.

Dilaltbeä $3 \frac{1}{2}$ Pfund, Loröl $\frac{1}{2}$ Pfuno,

Sopuleon $1 \frac{1}{2}$ Pfund,

Siridunfdlitt oder Şirfd)mark 1 Sf fund,

Regenwürmeröl 6 loth,

Sobannižtrautöl, İerpentinöl,

Siebengezeitöl, Rofenöl,

2Bseipes Rilienöl jedes 4 loth,

Mausöbrleinöl 6 loth,

mijhe es untereinander zu einer Salbe.

E i ne $\subseteq$ a $\{$ b e, die reiniget und fühlet.

Slauenichmalz $1 \frac{1}{4}$ Pfund, Butter $1 \frac{1}{2}$ Dfuno,

Bärenichmalz $\frac{1}{4}$ sp funo,

Soirichenmark 1 sूfund,

Şiridenunfdlitt $1 \frac{1}{2}$ SP funo,

Reinöl, Roröl jedes $\frac{1}{2}$ Ş funo,

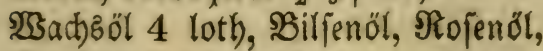

Samillenöl jeoes 6 loth,

mijhe ę untereinander über einem linden Fruer. 


\section{Pferbs:22rzenei buth.}

\section{Eine 3 ug falbe.}

S3eiraud) 2 loth, Sampfer,

- Sirünipan jedes 4 loth,

Das \$ुulver von (Eppich Eraut 1 Sp fund,

Sd)meinenfd)malz $\frac{1}{2}$ Sfund,

Scirichenunfchlitt 1 \$fund,

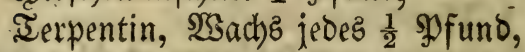

mifhe es untereinander uber einem linden Roblenfeuer.

Eine bure Salbe.

2laun, Salmiac jedes 1 loth,

Utngelöichten Salch 6 loth,

15 Eierweis, Iraftmehl zehn loth,

Branntwein 12 loth, Sconig 6 loth,

mijhe es untereinander zu einer Salbe.

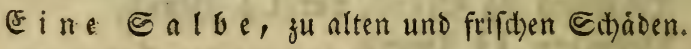

Populeon, Ierpentin jedes 2 lotb,

Campfer, Sirunfpan jebes 2 suintlein,

Spifenmegerichlaft 4 loth,

mifhe es untereinander über einem Soblenfeuer.

E i ne rotbe $\subseteq a \mathfrak{l} \in$, die reiniget und beilet.

Nothen Boluz 3 loth, NEeiraud), (Srünipan,

Minrthen, 2laun jebes 1 lotb,

Şitriol 2 loth, Sconig $\frac{1}{4}$ Maaß̄,

mifche e己 untereinander über einer (S)lut.

Dies ift gut, wenn einem \$ferd Der Rern fdhwindet: uno man die Sohlen ausmirft.

Eine Enlbe fúr tie Etrupfen uno $\mathfrak{B}$ unden an ben Fúker.

Srünipan, 2llaun, S3itriol jedes 3 loth),

Salpeter 2 suintlein,

Şonig $\frac{1}{4}$ Maán,

lape es miteinander über einer (Slut fieden. 
Stimeer oder Sthmeinefdymal;,

Baumól jeoes 2 pfund,

Dialthea 1 SPfuno, SBeitaud,

Raftix jeoes 6 loth,

lape alles wobl miteinander fieden, bernach thue es ber= auz in einen berglajurten Şafen, thue Dazu

Sd)aaf=unfwlitt 1 Sुfund,

Neues $\mathfrak{W a d b} \frac{1}{2}$ \$p fund,

vermad)e Den Safen wohl uno fege denfelben in einen

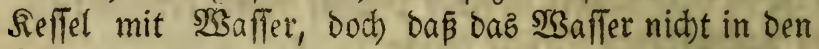
Dectel bes Scafens fomme, fiede es mieber eine Stunde,

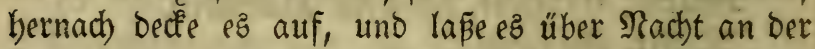
Ruft ftehen. Des Morgenz, fo ez zu dick wäle, fann man geläutertes Baumól baran gieß̃en uno umrübren, To iftz fertig.

Diefe_Salbe ift gut, wenn ein Soferb gebrennt mard, für offene Schäben uno abjonderlich bie, welche vom

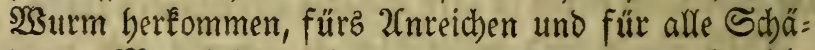
ben. Man foll es über einmal oder zweimal nid)t brauchen, fo ift es fichon genug.

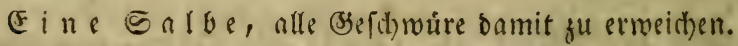

Das Rraut von Sockghornfaamen Elein gebact uno zerftosen, Baumöl,

SEein jeoce 3 গुfund,

macerirs untereinander, 15 Iage bernach prepe ez durd)

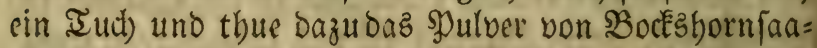
men uno $\mathfrak{B a c b 5}$, fo viel genug ift zu einer Salbe, mi= foce es untereinander.

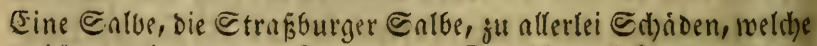
ii) von sinem guten greuno nus Etrafgurg befo mmen.

Der Stein ben man aus dez Sdymios Sfen nimmt, 
(Sebrannten alaun jedes 1 loth,

(3) rünpan 4 loth), (5fifig 12 loth,

Eaput mortuum Sitrioli 2 lotb,

Sconig 8 loth, Eudte erfflid) Den Şonig, (5fitg uno (Silünjpan wobl untercinanoer, bernad) bie anoern $2 \mathrm{l} r=$ zeneien Darein gerüfrt, uno nadker zu einer Salbe fie= ben lap̃en. Dies ift bie fo meit beriit)mte @trapbur= ger Salbe, und meldees Rezept um fein (Selo zu be= fommen iff.

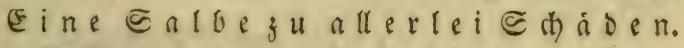

Maftix 2 loth, Sdjiffped) 6 loth,

Sdhaaf: Unidhlitt 1 spfuno,

Ulaun 4 lotb, alte Sdbmeet 1 spfund,

Batimöl, $\mathfrak{B a d}$ ) j jedes 2 loth),

mifde es untereinander liber einer (S)lut.

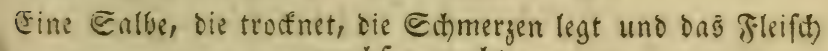
wadb fen madt.

Scimm Sconig, sffig,

(3irünpan jebes 1 \$p fund,

fiede es mobl mit einander zu einer Salbe.

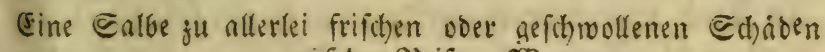
auf ber פieife. $\mathfrak{X}$.

Dialthea 1 Sf fund, 6 loth,

IBach holderbeetenöl,

Terpentinöl, St. Sohannisöl,

Rojenöl, jedes 3 loth,

mifde alles untereinander.

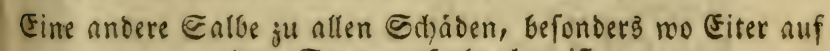
Dem હnum nufgebrocben iff.

Bitriol 2 loth, 2(laun 4 loth,

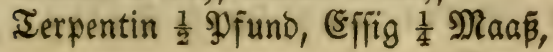




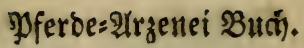

Şonig $\frac{1}{2}$ Maá,

mijche es untereinander zu einer Salbe.

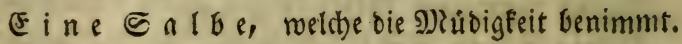

Silberglätt 2 loth, gebrannt Supfer 1 loth,

Sconig, $\mathfrak{W}$ ach je jedes 2 loth,

Effig 3 loth, lape die obengemeloete Gtücte mit einander fieden biz es eine braune Farke befommt, $10=$ bann idütte ben (sffig auch cazu und lape es ein renig fieden zu einer Salbe.

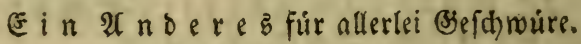

Sd)aaf=unfhlitt 1 Sूfund,

Silberglätt 6 loth,

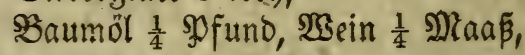

fiede es mohl untereinander.

$$
\text { Das } \mathfrak{F} \text { rof } \mathfrak{d}=\text { D e bl. }
$$

Nimm Fröfit)e, thue fie in ein (Slas und vermad)e eह rookl, grabe es in SPferdemift, und lape es 14 Iage oder länger barin fteben, fo merben fie fich folviren zu einem Sel; bernach nimm eś herauts uno giepe es outch ein $\mathfrak{I} u d$, foldes burdhgefeinte thue in ein (Sllaz und ftel= le ez an bie Sonne, fo wiro baz Sel fich nods keffer läu= tern.

Eine andere beilfaloe.

Weirauch, Naftix, jebes 4 loth,

ふümmel 6 loth,

Wein Der um die Scálfte eingefotten ift $\frac{1}{2}$ Maaß̧,

Rojenöl, 3wiefelfaft,

Eier $=$ Sel 4 loth,

fiebe ę untereinander zu einer Salbe.

Eine $\Re$ úbl=un Şleimeiß̄, Silberglätt, 


\section{Pferbe:Arzenei Buth.}

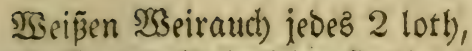

Saffran 1 I luintlein, 5̧onig 16 lotb),

mija)e es untereinander über einer (S)lut zu einer Salbe

E ine heit f a I be.

Laße Tannemped) auf 2 affer fliepen, wieber ge= Dört und gepülbert, von biefem Mutuer nimm

1 Pfuno,

Tabactzfrautpulver $\frac{1}{2}$ spfuno,

Sutter 2 SPfuno, Şonig 1 Pfuno,

Sranntemein $\frac{1}{2}$ Mna 5 , 3ucfer 6 loth,

Pfeffer, Ingmer jedes 3 loth),

nifde es untereinander zu piner Salbe.

Eine andere Sacilfalbe:

Samillenöl, Terpentinöl jedes 4 loth,

Regenmürmeröl 6 loth,

Dialthea 1 spfuno, Shopuleon $\frac{1}{2}$ sofuno,

Sirfd)en=unfidblitt,

Bodéltnj(t)litt jedes 1 shfuno,

mifd)e $e b$ untereinanber über einem Soblfeuer zн einet Salbe.

Eine (3) áderfalbe.

Machbolderöl, Baumöl,

Sirfchen= un falitt jedes 8 loth,

Ror=Sel 12 loth, Spict=Sel 4 loth,

Sdyrarz Sibnecten:SDel, Nenedifhe Seife,

Bodés= Ilnfditt, jedes 6 loth,

Scundsfd)mal ${ }_{3}$, Rammichmalz,

Reinbergefdmeer,

Branntemein jedes 10 loth,

2rthea 7 loth, Serpentin 12 loth,

mifd)e es untereinander uno fđ)micte das (s)eäber bamit. 
Eine Sthwind a tbe.

Iaxidnmalz 8 loth, Lor $=$ Sel 18 loth, Sdymeinefdmalz 16 loth,

Waad)bolder= Del vier lotb,

Spict: Sol 1 loth,

lä̧e ez untereinander über einem linben Feuer zerge= ben, uno mijdbe nadb)er folgende Stüde barunter :

Sävenbaum 8 lotb,

Nefiel jaamen,

Feberweis, jedes vier loth,

rübre ę robl untereinander zu einer Salbe,

(Eitre grüne englift)e Snlbe für allerlei Duetfhungen, Ssliebere

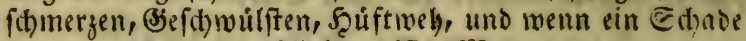
gefdinitten ift. $\mathfrak{B}$.

Nimm junge \&orbeerenblätter,

Rotbe Ealbei jedes 1 spuno,

ftope alles in einem Nörjer wohl untereinander; nimm oazu

Scammelö: Un nfditt,

ftoßje uno mif̧be auch unter bie Sräuter, uno vermifache es wohl mit 2 Maaß $\mathfrak{B}$ aumol, thue es hernad) in eine irtoene Sdüffel und laje ez 8 Tage fteben, fiede eక bernach vier Stunde lang bei gelindem Feuer und rül)= re ę allezeit um, feçe ifm nod) 8 loth Spicköl zu uno lapee ez nod) vier Stunden fieben. W3enn man einen Iropfen von biefer Salbe auf cinen Teller fallen läpt uno Derfelbe grün ift, fo thue fie nom Feuer berunter, und bebe fie auf zum (sebrauch.

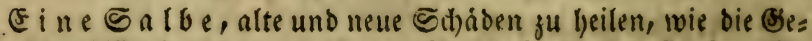
fdtwuilfte eiterid)t zu machen $u$. f(t)noljafte Orte ju ftárfen. $\mathfrak{W}$.

Baumöl $\frac{1}{2}$ Pfund, sBleimeiß̄,

(S)ologlätt, (Solophonium jebes vier lotb), 


\section{Reurę গুGad) 16 loth, \\ M(yrrben vier loth,}

Foibe erftlid) bas Baumol $\frac{1}{2}$ Stunde aflein, thue her= nad) baz Bleimeí̄ binein uno laß̄e ez eine Stunde $D a=$ rim fod)en, bernad) fodbe Das (5) ologlätt aud) eine $\frac{1}{2}$ Stunde, die (Solopbonium eine $\frac{1}{4}$ Stunde, bernad) thue

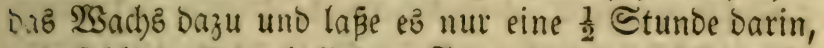
uno jold)ez alles mit linoem Feuer, bamit biefelbe nicht mel)t fiede, hernad) bebe es nom feuer und rübre bie

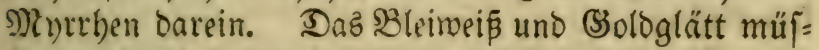
fen roobl und fubtil gerübrt werden.

E ine

Beiß̄e 5ุarz 6 loth),

Süße Maibutter 12 loth,

Saft von Sinauf́raut 2 lcth,

Eanicfel, SKintergrün jedes 1 loth),

(Seifkart, SBaum = Del, jedes 6 lotb,

die Säfte von Den Siräutern Eod)e mit einanber biz alle Feud)tigfeit verzebrt ift, thue nad)her daz Scarz binein uno menn ez zergangen ift, aud bie Maibutter, feibe e's enolid) ourd) ein Tuch) uno rübre es bis es falt nito.

(Fine $\mathfrak{B}$ undfalbe, befonders̆ ju (s)

WBintergrün, গatterzungen, Sanickel,

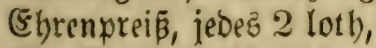

ङt. Sobannizkrautblumen,

Iaufenogüldenfrautblumen, jeoes $1 \frac{1}{2}$ loth),

allez flein jerbackt uno zerftopen, thue es in ein gropes (3)las, weldbes oben eng iff, fdütte barüber

Baumöl vier loth,

Schroeineid)malz 6 loth),

Friidue Butter 8 lotb), 
vermache daz (Slas wohl und laß̄e es 8 Tage im beiper Sano oder beisen 2 Saffer ftehen, bis das Schmaly uno oas Sel allez untereinander zerfichmolzen, thue es ber= nach beraus in eine kupferne Pfanne uno lape es fieden biz alle Feuchtigkeiten verzebrt find, prepe es alzoann ourch ein Iudh, uno wirf bie Fäces hinmeg, thue in bas Uebrige wäbreno es noch bei iff, $^{2}$ Loth בerpentin, uno wenns ein wenig erkaltet ift, fo rübre nachfolgen: oe $\mathfrak{X r z}_{\mathrm{z}}$ eneien barunter, bie vorker aufz reinfte zerftopen fein müв̈en.
Maftix, $\mathfrak{B e i r a u d}$,
Mutrben jedes $\frac{1}{2}$ suintlein,
aloéz bepatica 2 loth,
(3)rünjpan $1 \frac{1}{2}$ Suintlein,

rübre ez robl untereinander uno lapee ez erfalten, uno im Fall biefelbe zu bünn wäre, fo mifche nod) vier loth K3ache barunter.

Eine anoere: $\mathfrak{B}$ unofalbe.

Şonig 2 Spfund,

Frifches Srunnenmaffer $1 \frac{1}{2}$ Sfuno,

fiede ez wohl über bem feuer, verfdäume $p z$, bernach thue nachfolgende zerbackte uno zerftopene Fräuter $D a=$ runter und lape es 8 Tage wohl bermad)t an einem marmen Sort fiteben :

SSallmurzelfraut 1 lotb,

Seionifh Munofraut, Ed)langenEraut,

Sinau, Saničel, jebes 2 loth,

Breiten $23 e$ gerich 8 loth,

nach folcher 3eit fiede eళ bis der Sconig ein menig oicter miro, als er fonft ift, bernach prese ę aus und thue bazu

Maftix, Weiraud, 
5) Rrrben, jedes $\frac{1}{2}$ suintlein,

rübre ez robl um uno lape es crfalten, fo ift die Sal= be fertig.

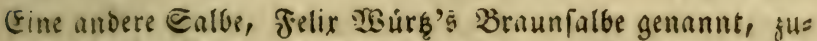
gleid) für $\mathfrak{B}$ undorn, fúrä Bliedwaffer, den Brand und allen um fiid) freffencen fid)arfen Flúfen, und beilet ftarf. 2 .

Nimm 2 Sुfund guten Sitriol, thue ifn in einen it= denen Iopf, umlege denfelben mit Joblen, und anfangs ganj langlam, Daßj ber Sitriol fomelje uno bie Feud)= tigkeit verfiebe, bann gib um uno um fark Feuer, baß er wobl glühe und roth werde, zerichlage alsdann ben Iopf, zerftope Den Sitriol und fiebe ifn mit eirier bal= ben Maas biffiltirtem $\mathfrak{B}$ eineifig in einem andern neu= en verglafurten Iopf, biz ein $\mathfrak{Z}$ beil yom (5ifig verfie=

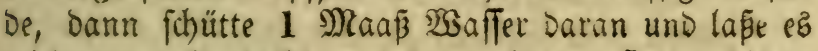
roiederum halb einfiteden, lape ez alsbann fteben biz ez

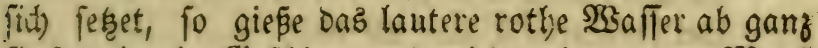
fittfam in ein Sefdirr, und wirder eine andere Maa

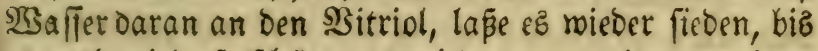
es toth rirb, fo fdütte eह wieberum zu dem vorigen

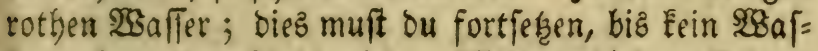
fer mefr roth gefärbt wirb. 2(lzbann fdütte allez zu= fammengefammelte rotbe $\mathfrak{B}$ alfer in ein (Sefothirr und laje ez in einer (5apelle abraudjen, bis ber rothe $\mathfrak{B i}=$ triol auf bem Booen liegen bleibt. Denfelben glübi mie= Det ftarf auz in einem irrbenen Tiegel, fochutte Denfel= ben alfo glühend in ein (Sefichirr mit Regentwaffer, taßs

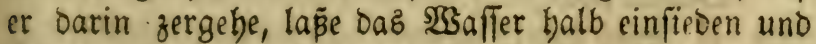
(id) hernach fegen, idulte das rothe abermals herunter,

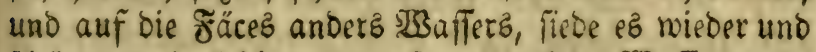
fd) ütte es ab, fold,es feke fort, bis kein $23 a$ fler mebr

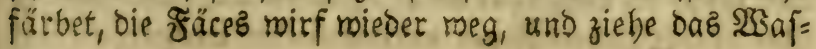




\section{Spferbes:2rzenei \$oud\%.}

Fer abermals ourch 24uछbämpfung Davon, glübe den $2 B i=$ triol noch einmal, uno ziebe ibn wieder aus rie zuvor, alfo baßj er breimal aużgezogen uno drcimal trocten ge= worben, und wenn er zum orittenmal trocken ift, Dann ift er zu ber Salbe tauglidh. Ferner

Sraunnurzelfraut,

Wegtritt, Ed)ölfraut,

(5) brempreis jeoes 1 Saanobol,

hade alles flein, thue es in ein (Slas, uno foütte fo viel

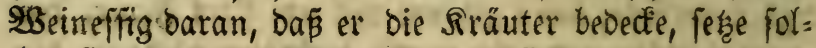
dees Sslas mit den Rräutern uno Effitg an einen war= men Sort und balte es 8 Iage in linder $\mathfrak{B a ̈ r m e , ~ b r r = ~}$ nach prése es aus :

Des \{uzgepresten 6 loth, thue hinzu von Dem borber alfo präparirten $\mathfrak{B i t r i o l , ~}$

\$oblegmatiz Sitrioli, jeoes vier loth,

Berfchaumten Sconig 12 loth,

(S) eläuterten Girünjpan, orittbalb loth,

Eodbe allez zujammen bis ez did wiro wie pine Calbe, jo ift se fertig.

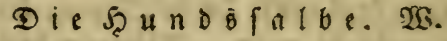

Bein 6 Maá̧,

Rothe Sappeln, fammt bet $\mathfrak{W u r z}$,l, Säspappeln, farrentraut, Sdoölleraut,

Sfterlucen, soermenig, Beifup,

Scajellaub, Iormentill,

Șdhroarzmurzel, jedes 2 Scändeboll,

fiede es roobl untereinander, und rährend dem fieden merfe vier ober fünf junge \$unde binein uno lape ç nod ftärter fieden, ftoßße bernad) alles untereinancer uno preße es aus, thue nachfolgendes dazu uno lape es uีber einem linben Feuer untereinander mengen, 
5ृunosf(t)mal $3 \frac{1}{4}$ SPfuno,

Iaxidumalz,

Särenidhmal; jedez $\frac{1}{2}$ D) funo,

Sd)nedfend 8 loth, Rorol vier loth),

Regen xürmet: Del 6 loth,

WBad)loloer = Del, Terpentin = Del jeoes vier lotb),

Spick: Sol, Spetroleum jedes 2 loth,

Sonig $\frac{1}{2}$ spfuno,

Sirfiden:Lnfichlitt $1 \frac{1}{2}$ Pf fund,

2itte Sd)meer 1 gुfund,

Scundzzungentourzel gepilloert 6 loth),

Balfamól 1 loth,

mijob alles mit einander über einem fruet zujammen.

Dicje Salbe ift für Sुferde, weldbe fteif auf Den Sit)enfeln, Selynen uno 2CDern fino, wenn man fie et: lichemal bamit fadmieret.

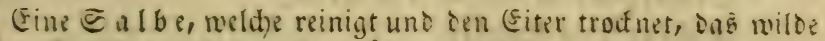
Treifit) verzebrt, und ju befen un!peilbaren, faulen und bolen Ed)áben bienet. $\mathfrak{W}$.

allaun, Salmiac jedes 1 lot'́),

Scorbien= oder Radjenfnoblauch faft 8 loth,

Inoblaudb) Erautjaft,

Rautenjaft jeoes 6 loth,

fod)e alles untereinander bis ber 2rataun uno ber Sal: miac zergangen, Dann nimm

Sonig, fo mit Dem 2rbfaib vom Gcorbio unb

23ermuth verfacumt roorden 32 (oth),

Diftillirten (s) rünipan 8 lotb),

Deerzmiefel: 5 ffig 12 lotb),

fodbe foldes in einer fupfernen SPfanne anfänglich jiemlid) fark, bis bie grüne Farbe fid) in braun ver= mandelt, bann lod)e es mit linoem reuer, bis es bick uns 
fteifer wiro, als fonft bie gewöbnliche Sonfiftenz ber Salbe erfordert; thue alsoann ferner bazu

2laun, Salmiac jedes 1 loth,

Snoblaudjb̈rautjaft,

Ladbenenoblauchjaft,

Rautenjaft jedes 8 loth,

Eodbe es mieder in Dem Feuir zur gebübrlichen Didé, thue es alsbann vom feuer uno wann es nicht mebr baif iff, fo rübre Dar unter

İberiac, Mithribat jedes 1 loth,

Sampfer welcher im Branntemein ober in einer Slität jerlapen worben 2 loth,

rübre alleg mobl untereinander, bis es erfaltet, bann ift $e^{\text {G }}$ fertig.

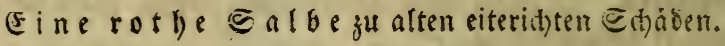

Srünjpan, Römifden Sitriol,

(3ebranntes Supfer,

Supferidhaum jedes 2 loth,

Sonig 8 loth,

mijhe es untereinander uno la rotbbraune Farbe befommt.

Eine Siúblfabe, ju den Entzunoungen, Siräbe, fit)arfen flect)= ten und bigigen $\subseteq d$ diben. $\mathfrak{x}$.

Sleimeiß̄ 24 loth,

fiede eg mit mit biffillittem Effig gefdhmino, und offern berum rübren, bis falt aller sfifig verjotten, rübre ber= nach, wenns ein wenig erfaltet ift barunter

Das $\mathfrak{2 B e i \beta e}$ bon 6 (5iern nohl untereinanber ge= fidlagen,

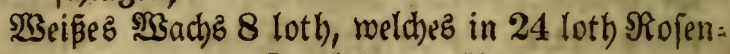
öl zergangen ift, alzoann rübre 
Gampfer $\frac{1}{2}$ loth in fo viel Rofenöl als nötbig ift, Darunter, uno lẩe ę vollende erfaltert.

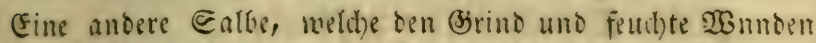
beilet, wellhe wegen ber Feu(t)te nicht beilen mollen.

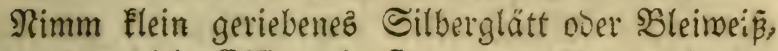
fiede es roobl in (sfifig mit ffetem umrïbren biz Der (5ifig wie Sel wiro, Dann rübre fo viel Siofenol ca= runter mit ftetiger: Untereinanderjollagung, fo viel ge= nug zu einer Salbe iff, uno fich zu einer weipen હal= be fdlagen läpt; rübre alsbann barunter

SBeirauch, Maftix,

(Salmei, jedes 2 loth), uno entid)

Sampfer 1 loth), in SRofenoll polvirt,

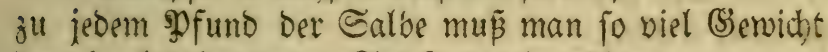
ber vier leģtbenamten Stücfe batein rübren.

E ine Dirrfalbe.

Iemperir Sraftmebl und Sranntenein, Daßj es net: be wie ein Ieig, uno lege es über.

\section{Die $\mathbb{R}$ áfer falbe.}

Nimm die Sdynarze Säfer im Mai, die in ber (El: de ober auf ber Eroe gefunden werden, melche man aud) Sdbmalzkäfer nennt; man mús fie aber mit kei= ner blofen Scano anrübren, fonft lap̄en fie den beften Saft fallen, nimm beren 200 an ber 3abl, zerreibe fie wobl in 2 spfund Sdhweinenfumalz, thue es in ein (Slas uno feke ese in die Sonne, laß̄e es den ganzen

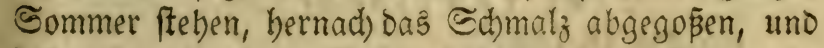
bas andere ourd) ein Iud) gefeift, wicoer znfammen in ein (S)laz gefchüttet uno aufgeboben. Shenn man her: nach braudien will, eann man Davon unter altes Schmeer mifhen, uno pine Salke Dareus madjen, ooer unter Unjolitt. 


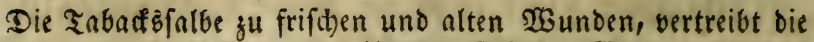

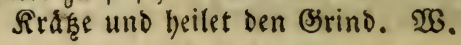

Frijche Tabackgblätter '2 SPfund,

Frifhes Schmeinenichmalz 1 pfund,

backe bieje slätter Elein uno zerftope fie mit bem Sdymalz untereinanoer, fdütte barauf noch 1 sু funo

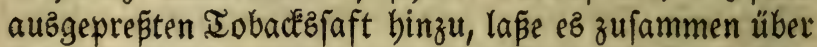
Nacht maceriren; Des andern Norgenz foche fie lino zufammen, biz alle $\mathfrak{B} a$ flferichtfeit berjotten, bann pleße es aus, lape alsoann Fidutenbarz uno frifdes $\mathfrak{W B a d}_{3}$, jedes vier loth mit einander zergeben, zwinge es ourd) ein Iuch, uno thue fie zu Dem Sorigen, rübre Darun= ter vier loth gepüloerte runde Splerlucey und mache es zu einer Salbe.

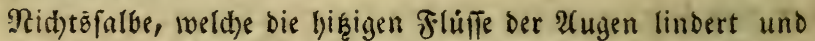
ftillet, und igre Biotbe und Entzünoung vertreibt. 2 S.

\$gräparirt Tutia 2 loth,

Rothe präparirte Corallen,

Serlemutter, jebes 1 loth,

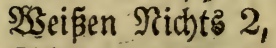

Sd)meinenfthmalz bas ofine Salz in 2 Bein ge: majden worben 1 פfund,

Gieriebenen ๔ampfer 1 Suintlein,

folvire den Eampfer in Dem Sdymalz, jebod) nidbt febt roarm, bamit er nicht nerrieche, uno rühre obenbenann= te pulberifitte Stücfe hinein, bas ez eine Salbe meroe.

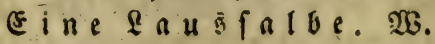

Ior $=$ Del 18 loth),

Sd)weinefdomal $1 \frac{1}{2}$ gg fund,

Senedifabe Geife $\frac{1}{2}$ gpfund,

Läus̆faamen 4 loth,

SBseißße Riezmurzel 2 loth, 
Pferse=:Irjenei Bud).

Salz 1 loth, Sd)wefel,

Salpeter, jebes 2 loth,

Suecfifitber 1 lotb, Srinnjpan 2 lotb),

Bitriol 3 loth,

Effitg, oarin vorher Suecfitlber gejotten worten,

fo viel genug ift,

fiebe alles zujammen wohl untereinander, zulefert aker wonn es vom Feuer fommt, fo rühre alfererft ten Sd) wefel und bas getöbtete Surectfilber hinein.

Eine 3 u 3 falbe.

Weidenaid)e 2 loth, Sampfer 1 æfund,

2ftte Edymeet ein $\mathfrak{B}$ ierling,

Wirichen=Unfolitt 1 Shfund,

Das Sraut von Ephen 1 sूfuno,

pülvete und mi ja)e es untereinander, lape es zu einer Salbe fiecen, es lindert und ziebet fehe mohl.

$$
\text { Eine Dirrfalbe. }
$$

Unaelöiduten Ralk,

Eiertlar, Branntemein, menge ez wobl untereinander zú einer Ealbe uno $i d$ ) $(a=$ ge es über.

Eine andere Dorrfalbe.

Gebrannte \a jepiä,

Bleimeí̄ jebes 2 loth,

Binober 2 Suintlein, 2aflaun 1 loth,

ftope alles zu şulner, nimm bann

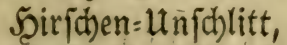

Bock' $=$ Un

mifche es untereinander in einer fupfernen 9 fanne über linoem Freuer.

EFine a noere Dirrfalbe.

Silbers oder (S)ologlätt 4 lotb), 
4 Eierelar, Esfitig,

Shonig, jebes ein $2(d) t e l$ Maá̃

(S) ünppan 1 loth,

milche alles untereinander über einem linden freut.

$$
\text { Eine andere Dorrfalbe. }
$$

Simm Sraftmebl ur. Branntemein, temperirz un= tereinander, ba über.

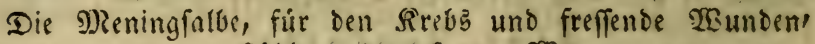
fúllet und trof́net. $\mathfrak{X}$.

Mening 6 loth, Bleimeís 3 loth,

Silberglätt 4 loth),

Mräparitt Iutia 3 Suintlein,

fiede es mit biftiflirtem Esfitg zu einem Brei, bann thue Dazu $\Re$ ofen= Sel $1 \frac{1}{2}$ Spfuno,

Foche fie miteinander, la pe aud barunter zergehen

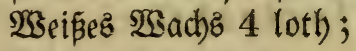

(Enolich rübre barunter

Eampfer welder in Miofen=Sel folvirt ift.

Eine Enlbe für verrentte Bslicder und Befeichen.

STraujenmünźaft 2 gfuno,

Terpentin $\frac{1}{2}$ ⿰氵 funo, etorax 2 lotb,

SDellium, Bsalbanum jedes 2 loth,

\$ped), Sconig, jeoes $\frac{1}{2}$ \$f fund,

mifche e\& untereinander über einem linben Feuer zu ei= ner Salbe.

E nglif山er $\mathfrak{B}$ unbbalfam.

Wsilbe SBranatenblüthe 1 loth,

(SPbörrte (Sranatäpfeltrinden 2 Suintlein,

Storax Ealamita $1 \frac{1}{2}$ Suintlein,

2 Eypreß̄nüß̄e, 


\section{(E) $\mathfrak{n}$ and}

Roggenbroofrummen 4 loth,

2(jd)e 2 loth, Snoblaud) $1 \frac{1}{2}$ loth,

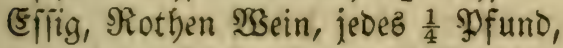

fieve es in einem Şafen zu einem $R$ Rei uno ftreiche baz Pfert auf allen ssieren bamit an, hernach gib ifm fol= genden Einguß̃.

Ein andereb.

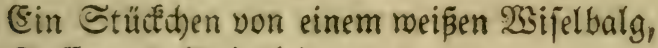

Saffran 1 Suintlein,

Milich ooer (sifig 1 Maaß́,

fiebe es wohl, fdutte es bem झुferd auf einmal ein uno (d) lage iflu mit nachfolgendem ein :

Nimm 6 hartgefochte (5ier,

2fidje und $\widetilde{S}_{\text {alz }}$ io viel als nöthig zu allen vier

Füflen ift.

(5ib ifm Şafelwurzel unter Dem Futter zu freften, und Saffran ins Irinken, majd)e bem Sुferb bie Shen: fel wohl mit 2 Baller, worin Sceublumen gefotten mor = Den.

Ein anderes.

Reibe ifm die Sici r nohl mit Inoblaud), (5fitg uno Biannterwein untereinander gemengt.

(5) in andereb.

Smiefelfaft $\frac{1}{4}$ Maañ, Saffran 1 Suintlein,

Rein orei Siertel Maaß̄,

untereinander gemifat und auf einmal eingegeben.

$$
\text { E in a noeres. }
$$

Botax, 2uaun, jedes 1 loth, 
Unjoblitt, $\varsigma_{a l}$, fo viel zu einem Einjoblag ge: nug iff.

(5) in and

IRilch 1 Maaß̃, Salz 1 loth,

Szenebifde Seife 2 lotb,

Saffran $\frac{1}{2}$ Suintlein,

untereinander gemijht uno auf einmal eingegeben.

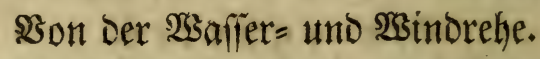

Die $: 23 a f f e r=\Re e b e$ entffebet bei ben spferden baber, menn fie in groper Scife ober nach großer 2Trbeit ge=

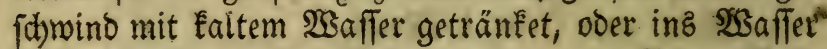
geritten merden, ift fonft in allem mit ber Futter= Rebe

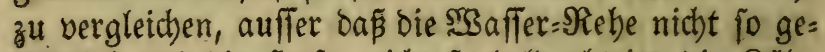
fäbrlich uno die Scufe nidht fo bald abtritt, Die Sälte ift bei biefer Srantheit bie red)te Utrfache, und nicht bie Serftopfung.

Die Beichen find folgende :

1. Die Slafelödber triefen ifnen.

2. Şaben Ealte Shren und andere Beichen, diefdon von Der Rebe vom Futter fino gebacht worben.

Die Bsinorebe entiftehet, wenn ein Pferb beftig ge= gen ben Şino geiagt worden, woourd ihm ber 2 (them in ber sunge verffect morden, aud) Der $\mathfrak{D}$ Ragen und Dä (singeneide mit $\mathfrak{B i n}$ ben erfüllt, worben, woourch nid)t allein bie Şerbauung verhinbert, fondern auch) ber na= türlid)e Durchgang verftopft.

Die Beicten find folgende:

1. Befommt ez cinen Eurzen fitroeren 2 them, uno ftellt fitch, als menn ę Gerzichläd)tig mäte.

2. Laufen ifm bie 2ugen auf uno geben Bähren non fidb. 
Die andern 3eidjen find aud) fdon bon oer Futter= Rebe gemeldet worben.

Dieje beibe Reben merben curirt auf alte $\mathfrak{B}$ eije, nie Die Futter: Rebe curirt woird.

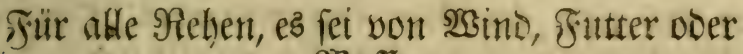
Sुaffer.

Mimm İberiac auf einen Edjnitt Srod, ober mie bu

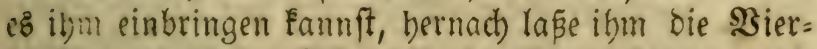
telaber auf beiben Schenfeln, bie Sporrabern uno bie Bauchabern auf einmal ichlagen, und ficlage ibm am erften 2Cbend mit beiper 2 fobe und Effig in bie Scufe, uno fiede Scirfenbrei in einer Brable, und binde es ibm aljo marm über bie Beine, von unten an, bis an ben Bauth) ; Den andern 2 (bend la je ein (Ei bart braten, Saly in einer Syfanne braun brennen uno follage ifm cin ; Dent britten 2 (bendo mad)e $\mathfrak{B a ̈ u m o ̈ l}$ aufs märmfte, fd)lage ein (Ei brein, daß̄ es robl gebraten werde und

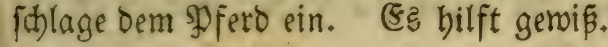

\section{Die Berpflegung.}

1. Der Stall foll mittelmäffig marm uno trockem fein:

2. Das Futter foll wenig fein, und kein Saber ober (Serfte, fondern (Sraz, Seu mit Salniter gefprengt, Iattich, Mangolt, Rleien אlümpchen.

3. Der Trant foll aud) renig uno laulid)t fein, roo= runter (S)erfitenmebl, Sleien, Scollundermurzel oder Rinden und 2(ttic) gejotten roorben, mit Gaffran ber= mijatst.

4. Das Spferd foll warm zugededt und oft geritten ober gefübrt reerden.

5. Soll baz Pferb angebeftet merben, Damit es fid) nicht legen Éönne. 
Bon Der Peftilenz Der \$ferbe.

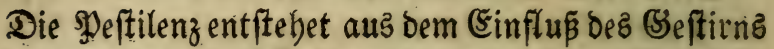
นทঠ aนอ einer faulenden corrumpirenden Sualität, welche bismeilen in ber suft fich aufbält und bals oie Sörper ber İbiere, wenn fie ein menig frermentation Gaben, butch bie Schweiplöd)er und ben 2(them anfte= det; ebenjo auth bon böjen, ftinkenden und giftigen in fid) gefoffenem $\mathfrak{W a f f e r}$ giftiger $\mathfrak{S}$ eide und Futter, wie auch böfem und giftigem (Sieftanf, ftinkenden Nebeln, namentlich in hígigen Sommerszeiten wo bismeilen bie ungünftigen 2 fipetten nod) Dazu fommen und bie fdhel= lere 2uzbreitung Dez ふrantheitsftoff's begünftigen.

Dieje Srantheit ift febr anfteckeno, Despoegen wo dies Utebel einmal einigermap̃en ift, ez allez mit nimmt, man thut baher am beften, oas man gleich im 2rnfang bie gefunden von ben tranten abjondere und in andere Stålle fübren lapere.

Die 3eichen biejer Srantheit fino febr verfchieden :

1. Stößt es ein \$ूferd zuneilen an wie ein Fieber mit einem jählingen Froft, uno ift inmenoig ooch Scice vorbanden, weldhes man aus bem bif̧igen und ftinfen= ben 2 them abnebmen kann.

2. Şänget Den Rokf uno miro falläferig, wie bie soblegmatici zu than pflegen.

3. Wsenn das Behirn ergriffen mirb, fo merben fie wie bie Eholerici ungeftümm, uno fehen mit ten 2 fu= gen farrecélich auz.

4. Stöpet es foldhen Spferden oft auf, zieben bie Seiten beftig ein und baben cinen unerfättlichen Durft. 5. Şaben ețid)e ein hisiges 2 taul, eine trodéen: 
Teufelsabbī̄murzel, jeoes 1 Spfuno,

Sin: oder 3meiblatt, Siebengezeit, Souflattid), jeoes $1 \frac{1}{2}$ Sf funo,

Soldanella, Scorbium, Diptam, Bibenell,

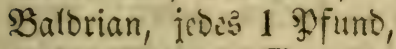

Srảbenäuglein, (Siummi guttä, Ecammonium,

2Garic, jedes $\frac{1}{2}$ Pfuno, Iurbith $\frac{1}{4}$ SDfuno,

Iloes $1 \frac{1}{2}$ Dfuno, Epiep̧alas 3 sूfuno,

Sd)langenpulver $\frac{1}{2}$ Sf funo, Mnrtben 12 loth,

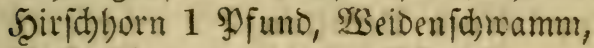

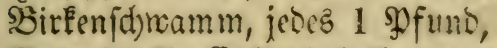

Scorpionöl, Eichenbolzol,

23ad)boloe:bolzöl, jeDes $3 \frac{1}{2}$ SPfund,

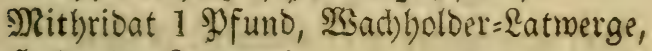

Sollumber= Ratwelige,

2ttid): $\mathbb{R}$ atwerge, jeoes fo viel genug iff,

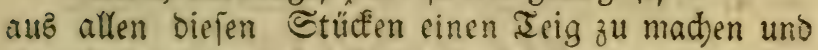
§ugeln barauz zu formiren, fo grop als sin Fleines Şülnerei.

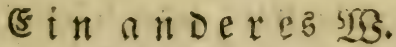

Sorrigirte fowwarge Nicsmurzel, פeftilenzwourzel,

2Cngelica, jebez 1 Sुfuno, Iormentill,

Sdymalbennutzel, Sajelmurgel,

Sticknurgel, jedes $\frac{1}{2}$ sूfuno,

2lantrourzel, Rbapontic, Scorzonera,

\&ungen: uno \&eberfrant, das an Den (Fid)eln

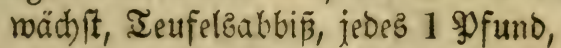

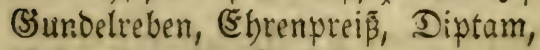

Sibenell, milloe Salbei,

5̧uflattig, jeoes $\frac{1}{2}$ SDfund,

Sdlangenpulver, Jirübenaugen,

- Serd)enfdnoamm @cammonie, Summi guttä, 
2loez, jedes $\frac{\mathrm{I}}{4}$ SPfuno,

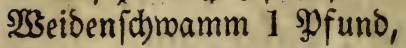

Spiérglaz 2 spfuno,

mif the bies untereinanoer zu einem Spulber, bavon bem Bieh alle Iage 3 loth zu freflen geben; menn man will, fann man mit Sconig uno Ecorpionöl Sugeln Daraus formiren, wie bie vorgemeloete Sift = నugeln fino bem sfero alfo eingeben.

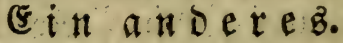

Soloquinten 1 Suintlein,

23 ein $\frac{1}{4}$ Maa $\tilde{\beta}_{\text {, }}$

untereinander gemifht und auf einmal eingegeben.

\section{E i n a no.eres.}

Saft von milber Rürbismurzel 3 loth,

Salpeter 1 loth, $\mathfrak{W}$ sein $\frac{1}{2}$ Maaß̃.,

untereinanoer gemijht uno auf einmal eingegeben.

\section{Ein andereb.}

Sävenbaum 1 sfund, Ssamanderlein, Saujenogüloenfraut, jebes 6 loth,

Sdmalbenmurzel, Scohlmurzel,

Shiridhourzel, Lorbeeten, jeoes 8 loth,

श्र? urrben 3 loth,

ftope und pülpere es untereinander, nimm von diefem Sulver 6 loth, mijache es unter $\frac{1}{2}$ Maaß̄ idütte es auf einmal ein.

\section{Ein a ndereb.}

Der $\mathfrak{B}$ urzel Panacis, Mannstreumurzel, Fenchelfaamen, jeoes 6 loth, 2lleos 4 loth),

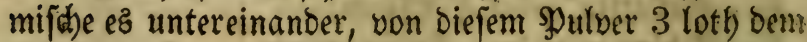
Mferd in einer $\frac{1}{2}$ Maaß $\mathfrak{B}$ ein fieden lapen, und laus: lid)t eingegeben. 
uno fd)warze 3unge uno fino über ben ganzen Reib beip.

6. Fabren foldben şferben aud Beulen auf, befon=

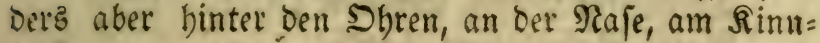
bacfen, am Scalz, an Der Sruft, an ber $930 i d)$, unten

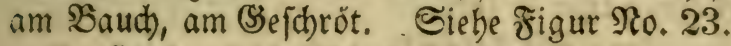

7. Sinfen folde şferde febr bäufig.

8. Werben ifnen bismeilen die 3äbne loz.

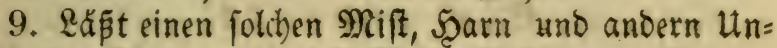
rath von fich, ber über bie Maje ftinfet.

\section{Die ¿ $u r$.}

S3or allen Dingen foll man bem shfert sen Leib of:

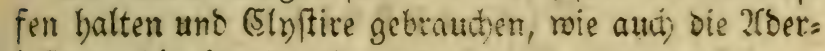
lape bor die Sgand nebmen.

Srühe von einem gefottenen 5̧abn 1 Maab,

9 Eierdotter, Salz 1 Sanoboll,

Rojenöl, Baumöl, jebes 6 loth,

mifde es untereinander uno gebrauche es laulidgt zroei. mal Des Iagez.

) Zan foll auch bem Spferd anfänglid), ebe bie Stane" beit überband nimmt, sine ober zroei addern offfnen, ent= weder am Salz, Die Sporradern, S3ugadern odet auf Dem Sd)laf oder unter ber 3unge 2c.

(sin sing $u \hat{\beta}$.

Theriac 2 Suintlein, Saffran $\frac{1}{2}$ Suintlein, Sauerrampferma untereinander gemifht uno auf einmal eingegebent.

Ein anderes.

Sräparirten Smarago 1 suintleir,

Rofenwafler 8 loth, 2Sein $\frac{1}{4}$ Maaz, untereinander gemijht und auf einmal eingegeben. 


\section{Pferbes2 2 rzentei $\mathfrak{B u d}$.}

(E) $\mathfrak{n} \mathfrak{a} \mathfrak{n} D \in \mathfrak{r} \in \boldsymbol{z}$.

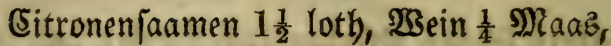

Iormentill 2 loth), (Soraffen 1 loth,

Rotbe $\Re$ ofenblätter 2 lotb,

Rojenwaffer 8 loth.

(sijenkrautjaft 10 loth,

untereinander gemifht und auf einmal eingegeben.

$$
\text { E } \mathrm{i} \text { a anoerez. }
$$

Dürren Menichenétoth 3 loth,

Rotben Boluz 1 lotb, 2Bein $\frac{1}{2}$ Maas,

untereinander gemifest und auf einmal eingegeben.

Ein andereb.

Iormentill, (sijenEraut,

Betonica, jebes 1 Scanoboll,

fiebe es in 1 Maas $\mathfrak{B s e i n}$ thue $\frac{1}{2}$ Suintlein Saffran an bie Brühe, und jountte ez auf einmal ein.

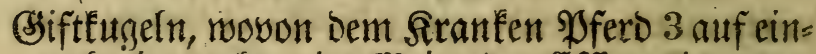
mal einzugeben im Bein ober Effín, nie man will, zur \$räjervation aber mödhentlich cinem!

\$ferd eine ooer anderthalbe 23 .

2ungelica, Riebftöckel, Meftilenznurzel,

Ulantwurzel, Iormentill, Natternurzel,

Eีnzian, (Ebermurzel, sæe ifternurzel,

SSirict)wourzel, Farrentourzel,

Rbapontic, jebez $1 \frac{1}{2}$ Pfund,

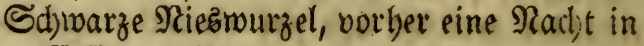

Effitg gebeikt,

Bryonia, Modelgeer, Scorzonera,

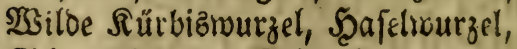

Sabivefelnurzel, Sthwalbennurzel,

Dradbennurzel, Braunwurzel, Niegnurzel, 
(5ibifdnurzel, jedes fo biel bu wilft, unteveinander geftoß̄en und gefotten, bernach bas 2 sajs fer eingefotten uno \$gflafterweiz auf bie Beulen moht warm gelegt.

(E) in a n beres:

Shepar 2intimonium 2 Suintlein,

Ecorzonera 2 loth,

Sdiblangenpulver 1 suintlein,

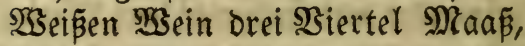

untereirander gemifd)t und auf einmal eingegeben.

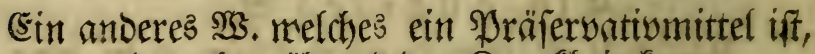
uno auch während oer Frantheit fann gebrautht werben.

Shajelmurzel, Rnoblaudjskraut, Etidémurzel, Enzzian, jeoes 6 șändevoll, Meftilenzworzel, Meiftermurzel, Şirfhburzel, Ebernutrzel, Iormentill, Sidnoalbenmurzel, 2 ngelica, jedez 16 loth, Sthmarze Piesmurzel 6 loth, Scorzonera 1 ⿰氵 fund, Modelgeernurzel, 2 sintergrün, Wseinrauten, (Sroß̄ez Schöllkraut, Säbenbaum, 5̧ausmurzel, Sundelreben, Rreuzrmurzel, Ëiebengezeit, jebes 6 Scänoevoll, פgsiloe Salbei, Iaujenogüldenfraut, Diptam, (S)amanderlein, Bibenell, jebes 16 loth, Scordium $\frac{1}{2}$ spfuno, Wadbbolderiprößlinge, Ringelblumen, Lorbeeren, jedes 6 Şändewoll,

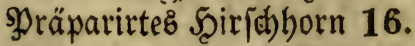
Ealcinirtes Storchenpulver 6 loth, Salcinirtes Taxenpulver, $\frac{1}{2}$ פfund, 
Sd)langempulver 12 loth, Sdbuefel, SGeidenfitwamm jebes 1 sूfund,

Reritjenjoroumm 10 loth,

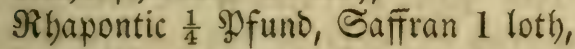

ftope uno raifd)e allez untersinander, bavon nimm fed)s Rotb), fiede ez roobl in einer guten Naaj̃ be es Dem $\mathfrak{P} f e r d$ auf einmal cin. 3ur Präfervation aber foll man alle Norgen Dem S) ferb 2 Suintlein bie= fes \$ुulvers im Futter zu Freffen geben, ift aud aflem andern 2 sieb zu gebraudben.

\section{(5) in a ndereb.}

Siridynurzel, Ebermurzel, 2flantwurzel,

Sd)malbenmurzel, 2fngelica,

Meifternurzel, Sdmefelmurzel,

Syeftilenzmurzel, Ein= oder 3meiblatt,

Riebftöcel jedes 1 Sूfund,

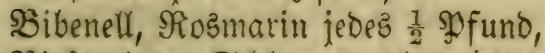

Sirfenrinde, Schlangenpulver jedes $\frac{1}{4}$. SP funt,

Safran 2 suintlein, Iberiac,

Scorpionol, Mithribat jedes $\frac{1}{4}$ Sूfund,

Sconig ober Scothunder Ratwerge, fo viel man zu einem İeig bedarf, mache Sugeln wie bie welichennüpe Daraub, Davon orei bem \$ूfero auf einmal eingegeben.

(5in andereb.

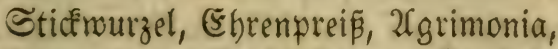
\&ungenfraut, Nachtichatten, (S)undelreben, Eichenlaub, Eifentraut, $\mathfrak{Z} 3 a d$ bolderbeeren,

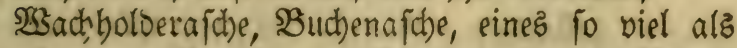
daz andere, mifd)e es untereinander, Davon gib bem

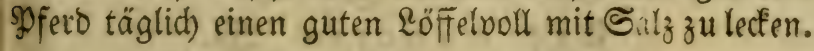

sin anberes Dräjerwatiomittel.

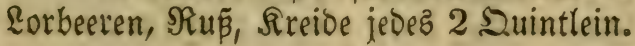


Inoblauchjaft 3 lotb, (sfifig 10 loth,

Branntewein I loth, mifche es untereinander und ichütte es bem Shferb auf einmal eir, ober nimm bie troctene $2(\mathfrak{r z e n e i e n}$ un' geke fie ibm auf Dem Futter z̆u

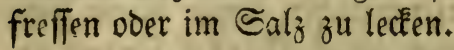

\section{Ein anderes.}

Meiftertourzel, Die SSurzel \$anaciz,

Die $\mathfrak{Z}$ urzel von 2 Sallendifteln,

Fenchelfaamen jebes 1 loth, SRaizenmebl,

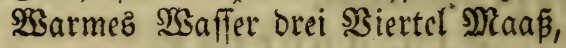

untereinander gemifdst uno auffeinmal eingegeben.

(E) in an beres.

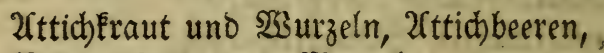

SBibenellekraut uno $\mathfrak{B}$ urzel,

23adbyoloerbeeren,

Eorbeeren, eines fo viel als baz andere,

alfez gebörrt uno gepülvert, Davon afle Tage Dem \$fero 2 \&öffelvoll im Futter zu frefien geben.

Ein andere .

Schießppulver 2 loth, (Esfig $\frac{1}{4} \mathfrak{R a a}$, untereinander gemifdht und auf einmal eingegeben. Sin anderes, wenk bie giftigen Beulen lommen 25 .

Siebe über bie $\mathfrak{B}$ eutlen, fie feien roo fie mollen, oder wie viel beren find, ein Scaarfeil von $\$$ ferbehaaren und gib ibm nachfolgenden Irane :

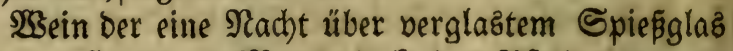

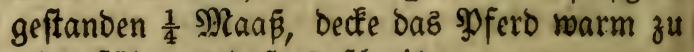
uno reite oder führe ez

E in anderes $\mathfrak{B}$.

Shepar 2fntimonium 2 Sountlein, खsein, Effitg, jebez $\frac{1}{4}$ Maaß̄, Saffran, 


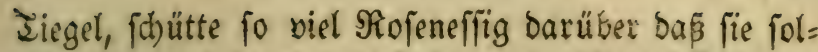
virt werber, lafe es wohl fodben uno rübre es ftetig um ıno wenn eह anfängt Dicflid)t zu werden, alsoann rübre Seneoifh) Bleimei $\frac{1}{2}$ Sfuno,

Imerifanifden Boluz 8 loth, binein, fooann mus man mit Dem SRübren fortfahren, bis die Mafīa zun Stein geworden, alscann iblägt man ben Tiegel ent: zwei unto bebt ben Stein zum (Siebraudy auf.

23 enn man es brauthen will, fo thuse 1 loth bon Dem Stein in fliependem= oder Regenraffer uno lapee es barin folviren, bernad) filtrirs uno mafthe bie $\mathfrak{B S u n =}$ Den bamit aü, neţe aud) leinene \&appen Datin uno le= ge ę über bie $\mathfrak{g}$ unben.

\section{Die 25 a fien $\{$ a 16 e.}

Schmeer von einem wilden Scauptifjmein,

Bärenfitmalz jedeś 6 loth,

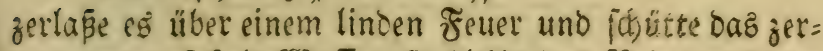
gangene auf Ealt $\mathfrak{Z} a$ fier, fo bleibt bas Reitte auf bem

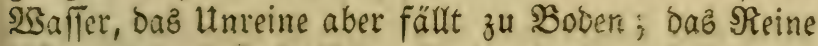
laßje wieder auf Roblen jergeben, aber richt zu beiñ, wenn es laulid)t gemorben fo nimm

Rothen Sandel,

Blutftein jeoes '2 loth,

(5)ereinigte uno gepulverte Regenmürmer, 4 loth; Slein gefeilte geoörtte Sdhwarzmurzer I loth, Moop von einem juftificirten Ropf ry suintlein, (von einem erfchopenen ober getöoteter spferbe= idäbel ift auch gut.)

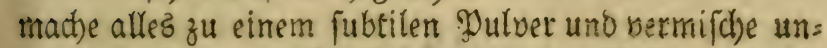
ter Die zerlap̧ene feifte Gtücke, biz eine Galbe mirb, bie mus man in einer blect)ernen $\mathfrak{B u ̈ d}$ ) fe robl verwabren und an cinem laulidten Srt aufheben. 
Bebraud biefer Salben.

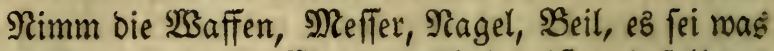
es wolle, womit bie $\mathfrak{3}$ unde gefdheben ift uno falbe ez

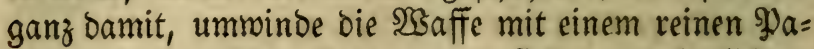
pier uno verwabre fite an einem ftillen und laulichten auch faubern Srt, bie B̧unden foll man nur mit Scarn ausెnajchen uno ein leinen Tuch Darüber binden. $3 u$ ben Eleinen $\mathfrak{2}$ unden verbindet uno falbt man bas (S)e= mebr nur einmal, zu ben gropen $2 \mathfrak{Z}$ unden aber zroei= mal.

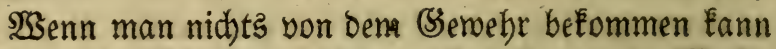
womit Der Sdjaben geichehen ift, foll man ein Neffer von Eichenbolz machen, dapelbe in bie 23 unde ftopen

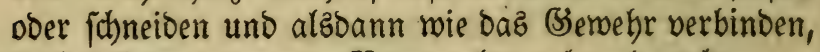
foldbes Eann man zum Dernageln auth gebraudjen.

\section{Das 4te Capitel.}

Bon Den 2 lpoftemen Den $\mathfrak{B a r z e n ~ a ̈ f n l i c h ~ a m ~ b i n = ~}$ terfen Drt Der Fübe bei Den Ferfen.

Diefe find offene 2rpoftemen, aus welthen ein über= flüffitg unnatürlich böfes Fleifob beraus bängt, fommt von Flüffen bie in bie Sdbenel gefallen, je älter fie fino, befto übler fite zu curiten fino.

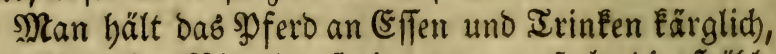
läßst ibm eine Biutaber fpringen, unterjucht bie Scöble bes Flußjes mit einem Snftrument biz auf bas \&eben= bige hinein, nimmt bas böfe Fleifh alles beraus, ba man ben Boden feben Eann. Wenn aber ber Sda $a=$ ben gering und flein iff, fo laßje es oreimal bez Tags mit idarfem Effitg, in welchem 3ranatäpfelrinden, 


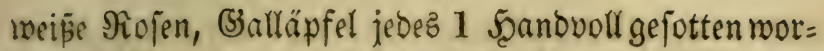
Den, waichen, und nact) folgendes Soulver barauf ftreuen. (S)alläpfel, (Siranatäpfelrinden,

Fiä)tenbolzrinden, 2llaun,

Ungelöftoten Salf jebes 6 loth,

untereinanoer zu einem şulver gemifd)t.

Diez spulver reiniget, trocknet uno verzehrt baz bö= fe Fleijh. Saenn bies zu leis wäre, fo brauche nach)= folgende Salbe, bie mehr Sraft hat :

(S) rünipan, Ssebranntez (5iz,

Iupferfdyaum jedes vier loth,

Jonig 8 loth), (5ffitg $\frac{1}{4}$ Maấ,

lǟe es über cinem Sohlenfeuer fo lange einfieden bis es roth wird, uno Die Sonfiftenz einer Salbe hat.

Eine nnoere salbe.

Teufelsorect, Galpeter,

Sitriol jedez vier loth,

Efifig jo viel genug ift,

temperits zu einer Salbe.

Ei in andereb.

Iröpfle beizes Del hinein, waidhe fie bernach mit id)arfen (5ifig robl aus, ftreue gepülverten \$itriol binein uno binde $\mathfrak{B g e r g}$ barauf.

\section{Ein andereb ST.}

Sdmiere Baljamum Sulphuris Therebintbinarum binein, oder Felix SSürzen Braunfälblein.

\section{Das 5te Sapitel.}

Bon Den 2lpoftomen Der Beburtigailen.

Die innerliche Urfachen fino SBläfte, Flüffe ber bişi= gen ooer Ealten Feuchtigkeiten, fo ourd) 2(ufblähung bez 
(Şejchrötz, uno bann aud), menn man auf bez $\$$ Pferdes (5ang 2f(d)tung giebt, leidhtlich erkennt werden, ob ez ifm nemlid) an bemielben viel oder menig mangele.

2euperlict)e urjachen fino, vom Schlagen, Stopenen, Seipen, Stecten uno Fallen.

Die Seicben find, menn die Siefdrouluft ober 2 uf = bläbung des (Sefchröts von Dem Ueberflué hisiger Feuthtigkeit Eommt, fo ift ber Srt nicht allein anzu= greifen faft beip, fondern bas \$fero empfindet aud) großen Sd)merzen, und ift bie Shike ber S3eburtagailen viel größer uno ichärfer, als bei ber ealten Materie, bie Sefhnullit aber bei ber kalten Materie ift febr bart uno bick.

\section{Di e ç $\mathfrak{i}$.}

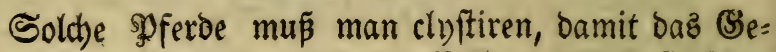
bärm gereinigt wirb, uno da die Naterie hisig ift, lann man bem \$fero eine 2Coer offnen lapen, aud hernach) folgende Salben, Bäber, Spflafter, 2c. brauchen.

Unfänglid) Eann man auch folche Salben brauchen, uno ben gefdrollenen Srt bamit fdmieren :

Sofen $=$ Del 6 loth, SEeildben=s Del vier loth,

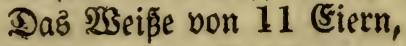

Rofenmaffer 10 loth,

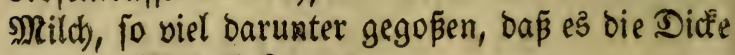
einer Salbe befommt,

gitb ifm auch शrageltraut uno 2 surzel zu freflen.

Ein anderes.

Gaft von Ssegerid) 10 loth, Rofen = \$el vier loth, 7 (sierflar, mifbe es untereinander zu einer Salbe. (5) $\mathfrak{i} \mathfrak{a} \mathfrak{n}$ bere

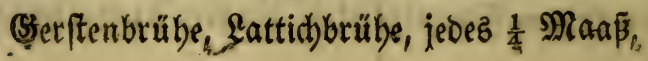




\section{(E) in andereb.}

Bierftenmebl, Baumöl,

mifche es untereinander zu einem SPflafter.

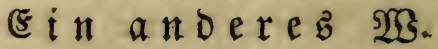

SRolus vier SPfund, Eierklar 19,

Brannteroein 1 Maẫ,

Ierpentin $\frac{1}{4}$ Ş fund,

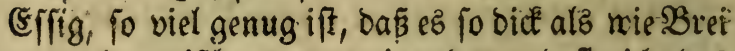
werbe, mifche es untereinander und ftreiche bas Beforót bamit an.

\section{(5in a noereb.}

Csefottene Sappeln, Sbifdnurzel,

Roggenmebl, Leinjaamen,

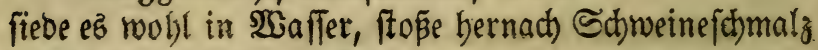
daran, uno fiblage es über,

\section{E in andereb.}

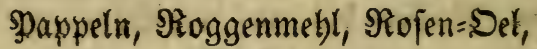

Eeinjaamen, Sock'zbornjaamen,

alles mit $2 B$ sein gefotten zu einem SPflafter.

\section{E in anderes.}

Sodtzhornfaamen, Dill, Roggenmehl,

Shappeln, Mauerfiaut, (5amillen: Sel,

fiede allez nit $\mathfrak{B}$ ein zu einem $\mathfrak{P}$ flafter.

\section{E in a ndere .}

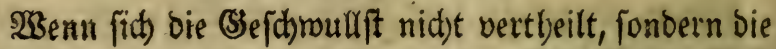
Mlaterie zeitig wiro, fo foll man ien Sort öfnen, fleif= fig reinigen, und wie andere 2⿰pofiemen zubeilen, Dazu

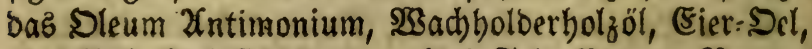

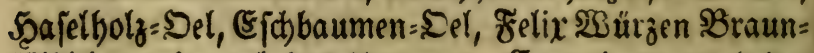
fălblein, wie audb bas unguent. Egyptiacum uno ber 
Sd)refel= \$3aljam gut ift, man mag von biejen brauden raz man für eins will.

Wenn aber bie (Seburtzgailen aud Materie mit ba=

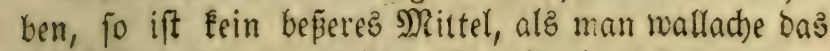
Spfero, und idoneide ez ibm alle beide berauts.

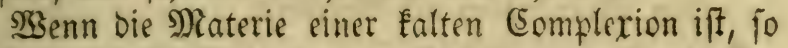
pflegt man ben Sdbmerzen zu filllen uno Dann bie (Se= ichwurlft auf folgende 2 Jeife zu refolviten :

Sd) wertel-5pl 4 loth, Rojen= Del 2 lotb,

Samillen=5De! 3 lotb),

mifhe es untereinander und fomiere ben Srt bamit.

(5) in a $\pi$ Dereb.

Soctzborn, \&einfaamen,

Bobnenmebl, jeces glerdoviel,

Söblblätter vier gute Şändevoll,

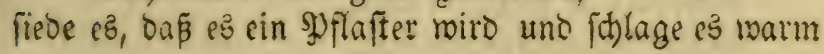
liber.

Ein a noe $\mathfrak{i} \in \mathfrak{b}$.

Sejottene Bohnen, Butter, untereinander gemijat und übergejăllagen.

\section{Ein a n}

Saffran 1 Suintlein, Eorbeeren, Bodf'bborn, jedę $\frac{1}{4}$ Spfund,

afted)meer 2 Sffund, ftop̧e es untereinander uno madje ein sy flafter Daraub.

Sft aber die (Seichnullf hart und beraltet, fo fomiert man fie anfänglid) mit ber Galbe von 2(lthea uno SPo= puleon, bäbet fie bernad) mit gejalzenem Baffer, no= rin Feigen und Samillen gefotten rorden, uno legt alboann zum britten nachfolgendes Syflafter baruber:

গimm Iaubenfotb vier Şändeboll, 
Roggenmehl 6 Scändevoll, Eiffig, fo viel genug zu einem bicken soflafter ift.

\section{Ein a noereb.}

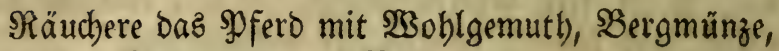
Samillen, $2 \mathfrak{S}$ einrauten und Bertram.

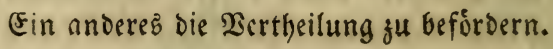

(Serftenmebl 1 \$f funo, 2fniz,

Enprep̄nüpe, jedes 2 lotb,

(Eicheln $\frac{1}{4}$ \$D funo, Maftix 1 loth,

Baumöl $\frac{1}{2}$ sूfuno,

Efifig, fo viel als nöthig ift bap̃ es bie Dicke ei: nez soflafters befommt.

\section{- Ein andereb.}

Rinden von Franzojentolz,

Wsildee Granatäpfelrinden,

Suttoer von Rofenblättern,

Roకmorin, Eyprep̃nüp̄e,

Reufdlammiaamen,

Sarcocolla, jeoes 2 lotb),

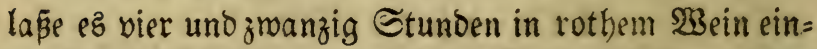
weichen, nachber bis zum balben Theil einficben, einen Sd)mamm barin neşen und benferbin narm über bie (Sefdomulfift legen, aud joldhes oft mieberbolen.

$$
\text { - Ein andereb. }
$$

Siebe ein Scaarfeil burd) Das (Sefd)röt, fo miro bie Materie balo heraus laufen, folches foll man zubeilen, mie oben gemeldet.

Sm Fall aber bie Sseburtägailen mit feiner 2lpoftem behaftet find, fondern verfaboren, foll man nachfol: gende Salben brauchen, und bamit fobmieren: 


\section{Pferde=2(rzettei $\mathfrak{B}$ ud).}

Eilberiłaum, Bleimei $\tilde{\beta}$, Sobolt,

Sd)leenoornidjalen,

Sranatäpfelfdualen, jeoę 2 suintlein,

2loes, Sireiraud),

2llaun, jedes 1 suintlein,

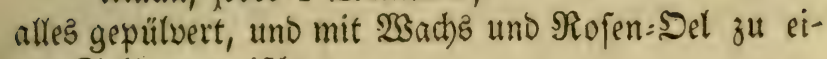
ner Salbe vermifcht.

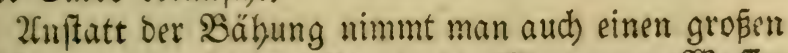
Sdjwamm, taud)t benfelben in bie Mixtur von $\mathfrak{2}$ affer uno (5fifg, odet in Die von 2 Segrichfaft und $\Re$ ofen= $2 B$ affer,

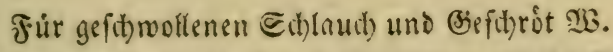

Säbe benfelben oft mit gejottenem und beifem $5 \mathfrak{a}=$ berfitroh.

\section{Ein a noer}

Răuçere eริ oft mit

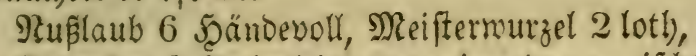

(ampfer, $\frac{1}{2}$ Suintlein, untereinander gemifd)t.

\section{(5in a nderes}

(Siepe Biegenmilth) auf einen glübenden Biegelftein uno bäbe das Pfferd Damit.

(5in andereb.

Seftreiche es mit Şausmurgelfaft.

E $i \mathfrak{n}$ andereb $\mathfrak{I}$.

Saustourzelfaft, Rautenjaft, jebes 3 loth,

2̧eizenfleien 4 Şändevoll,

Baumöl, fo viel genug iff, madbe einen 2 nftrich barauz.

\section{E in a n Dereb.}

Rauten 2tttich Eraut, jedes 2 Scändeboll, 
576 Pferbe=:2rzenei $\mathfrak{B u d})$.

Seafer 3 Sändevoll,

fiede es untereinander und lege ez rarm über.

\section{(5) in andereb.}

Siede robes (Sarn in $\mathfrak{B a}$ alfer und bähe das \$pfers alle Iage bamit, fo warm es dapelbe erleiden fann.

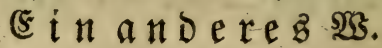

\&einfaamen, \&injen, jedes gleid) viel,

ftope eह untereinander, rófte es in einer \$fanne, uno binde ez oem \$ffero fo warm über, alz ez bapelbe er= leiben Eann.

\section{(5) in a nd}

Scaużnurzel, meip̧e Șlgenmurzel,

Rauten, jebes gleid) viel,

Saumöl $\frac{1}{4}$ SP funo,

Effitg fo viel genug ift,

mijche es untereinander uno lege es warm über.

\section{(E) $\mathfrak{i} \mathfrak{a} \mathfrak{n} \mathbf{e r e b}$.}

S3achbolderbeeren, Sdhwarzmuizel,

2fmeifen, fo viel als nöthig fino,

fiede ez untereinander und bähe das (s)efabröt bamit.

Șm Fall aber bie Seburtzgeilen mit Eeiner 21poftem bebaftet, fondern gar gefdoworen find, fo nebme Sil= berichaum, gerwafchen Sleimeis, אiobolt, 2feaica uno (Sranatãpfelfd)alen, jedes 2 Suintlein, 2(loe, SBseiraud) und flieffenden 2llaun, afles gepülvert jebes 1 Suint=

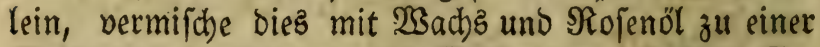
Salbe und romiere bie mit (S)idhroären bebaftete (S)= faróte bamit. 
Ropbeine, jedes 3 SPfund,

Siridbbeine 2 Pfund, Seiriden=Utnjd)litt,

Baum=:Del, jebez 3 গুfund,

madje bas Schmalz warm, Daş man es ausిgiepenen fann, bernach madbe bie Beine (nad)oem fie vorber in Stü= çe zerichlagen morden) glübeno, uno giepe obigez Sd)maly, untereinanoer gemifht gefdomino über bie Beine in einen verglajurten Scafen, becte ifn mit ber Stürze gefdowino zu, Daßj Die Seine die Flamme fan: gen, uno lake fie erfalten, wenn fie falt genoroen fino, fo thue fie in eine Retorte uno treibe fie mit farfem Feuet herüber; jo befommtz ein ftarfriechendes Sel. Mit foldem Sel fdhmiere bie verzucfte ober verfürzte 2Coern, es iff Eein beperes Mittel auf ber $\mathfrak{B}_{\text {elt }}$ als bie=

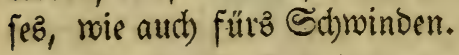

E

$\mathfrak{b e n n}$ bas (seäber gejdhrollen ift, fo fiede geriebe: nes Roggenbrod in Effig zu einem SBrei, rübre Booluछ barunter, und binoe ez bem \$pfero, forwarm alz ez daf= felbe erleiden Eann, auf Den Echaden.

E i n a n D reb.

Şunosichmalz $\frac{1}{2}$ शfund,

Rein=SDel, Sconig, jedes 8 loth),

laße es untereinander über einer (s)lut zergeben uno fdumiere bas Spfero bamit.

E in andereb.

Frifaen SButter,

Sdbneinenjd)malz, jeoes $\frac{1}{2}$ Dfund,

Fuchsfdhmalz,

Dialtbäa, jeoes 8 lotb;

Spopuleon, Baumöl, jedez 4 loth,

mifche es untereinander auf einer (S)lut. 
Shmiere das spferd bamit, iff abjonberlich für jun= ge Foblen, weldbe Bockzbeinigt merben wollen gut.

Ein andereb, menn ein 'Nfarb bie $\mathfrak{Q}$ bern verrúat.

Siede 3 Scändevoll Salz mit $\mathfrak{S B}_{\text {ein }}$ in einer $\mathfrak{P f a n =}$ ne, uno binde es Dem $\mathfrak{M f e r d}$ in einem rollenen Rappen auf, fo roarm es bajelbe erleiden Eann.

Ein andereż, wenn ons ß̧eáder gefínwollen.

Siede Şrunnentreffen uno હdimeer in Effig uno Wein uno jhlage es warm um ben ₹̌us.

Ein anderez.

Nimm Staubmebl mit $\mathfrak{B a f f e r , ~ e i n e n ~} B$ rei bavon gefod)t, und marm auf ben Gdoaben gebunden, $3 \mathfrak{T} a=$ ge liegen la lfen, bernad) menn mans abnimmt, und ber Schaben nod gefdrollen ift, fo fdmiere ben sort mit nathfolgender Ealbe.

Dialthäa 6 loth, Loröl 1 loth,

Şopulcon 3 loth,

mijche es untereinander;

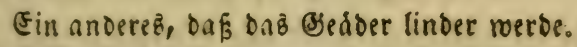

Sappeln, Söhl, jebes 3 Scändevoll,

Sdjmeer $\frac{1}{4}$ SDfuno,

fiede es wohl untereinander, uno majhe bem spfero bie

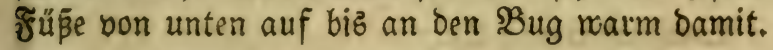

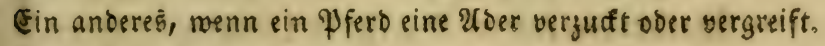

Ror:\$el 10 loth,

Baum=Del 1 Nfund,

⿰习习Tetroleum 4 lotb,

Dach fenichmals 1 sुfund,

Rabenfchmalz 2 loth, frifores Butter,

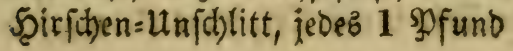




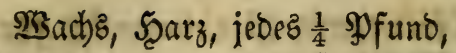
mifche es untereinanter auf einer (S)lut und fdomiere bas Spferb warm bamit.

Ein andécé.

Sounosfid)malz,

Déabjenfichmalz, jeoez $\frac{1}{2}$ sofund,

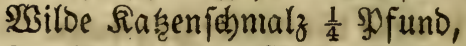

Lor $=$ Del 8 loth, şachboloerbeeren= Del,

Ijachbolderbolz=:Del, jedę 6 loth,

Reinbergerichmeer,

Ungeroäflerte SButter, jedę 1 Sু funo,

Dialtbäa,

Saft bom Säbenbaum,

Saft von Reffelwurzet, jebes 6 loth),

Inoblaudbsfaft 8 loth,

Salz 1 Sanoboll, ftede es roobl untereinander auf einer (Slut, bernach menn es ein wenig abgetüblet ift, fo rübre 4 lotb Spetroleum barunter.

Ein andereg, menn ein Pferd auf eine 2coer geffofien múrde.

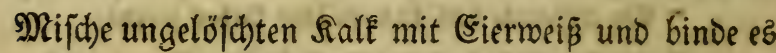

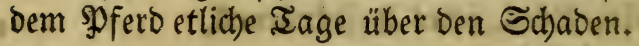

Eine sèdberfalbe, bie gelino mad)t, baš verwundete (seàder beilet un@ ftárft $\mathfrak{W}$.

SGachbolderbolz=5 $5 \mathrm{el}$,

ISsachboloerbeeren = Sel, jebez 10 loth,

Sdhwarzes Schuecken=: Del 8 loth,

Lor $=$ Sol 6 loth,

Das obenbefdriebene Sel von Suunos $=$, Pferde $=$,

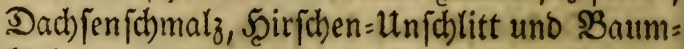

Del gemad)t 4 loth,

Selpentin:Del, Spick:=\$el, jebez 6 loth, 
Sd)weinefdumaly 2 Sूfund,

Siridben= ltnfallitt,

Senedifibe Seife, jeoes 1 pfund,

mifd)e ps alles auf einer (3ilut zu einer Calbe.

(5in anderez.

Sd)reinejhmalz, Das zerlasen iff,

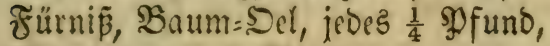

Brannteroein 1 Maá̃,

mijd)e es untereinanocr, uno lape es über einer (S)lut ein menig erwärmen, alsbann fomiete bas \$ूferd bamit.

Ein a noereb.

Saft von 2lngelicanurgel uno Siraut 1 Sh funo, Sonig, Dialtbản, Terpentin=:Del,

Lor = Sel, jedes $\frac{1}{4}$ Şfuno,

miche es untereinander zu ciner Salbe über einer (s)lut uno fit)miete Das \$fero Damit.

\section{Das 7 te Sapitel.}

Bon Dem 2lberlafen Der $\mathfrak{D}$ ferde.

So nüflich Det 2 coerlaßj einem (iib) felbiges in gewiffen firantheiten gefdiebet uno mäf= ifg oamit umgegangen wiro, fo ichäolid) ift e's bei an= Dern Sranfheiten, Die Derfelben nidht beoürfen, bejon= Ders in ber Jeblfud)t, Denn wenn man in biefer Jranf: beit bem SMfero eine 2coer offnet, fold)es unfehlbar Den gewiffen Iod, oder zuni allerwenigften sine lang= wabrende Sranelbeit verurfachet.

(5z ift aber leiber beutigez Iages der Mipbrauch)

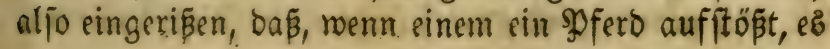


fei ifm audj was es wolle, fo mus man ihm 2coevlasen, obngeadstet; man kenne bie Srankfheit oder nicht, ba bann manches fdoönes bochtheures \$ofero, Durd) einen einzigen 2toerlas verwabrlofet, uno bem Corvo aufge= opfert wirb.

Deswegen folle man beobadten, weldhen \$yferben bie żoerläße tauglich oder nicht tauglid) fino.

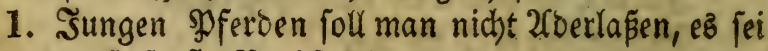
bann ber äuß̈erfte Rotbfall ba.

2. Den ganz alten şferden aud nicht.

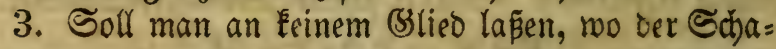
De ober fidmerzhafte Sort fich befindet, viel meniger bann wenn ber Mono in felbigem 3eichen fich befinoet, weldyem 3eidyen oas (s)lieo zugeeignet ift.

4. Soll man Eeinem গুferde zur 2roer lapen, in ben säcbften 3 Iagen bernach, wo man Spiépglaz yebraucht bat.

5. Bin idh mein Rebtag fparjam mit Dem 2roerlapenen umgegangen, fonderlid) in innerlichen Srankbeiten, an=

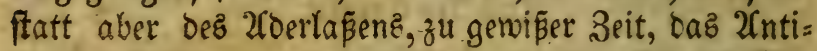
monium cruoum, Separ 20ntimonium, (Erocub )Res tallorum;) SBitrum 2(ntimonium gebraucht, melcher $\mathfrak{S}_{a}=$ d)en 1 . Suintlein mebr $B$ lut reiniget, als 12 zoderläße vermögen, weldbes 2Antimonium (Sebraud) fobon 2(nno 1672 in meinem Stuterei=Sud) mut mit menigen be meloet babe. Dods velneife ids bie 2roerläpe nicht ganz, wenn fie auf ben Nothfall an blutreichen ober bi:

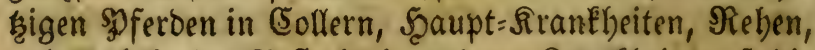
und auch in ber פeftzeit, in andern Sranlbeiten, fo bie 2rberläpe bochnötbig erfordern, gebraud)t werben. SBie benn aud gar viel syferbe ibnen von fidd felbft laf.

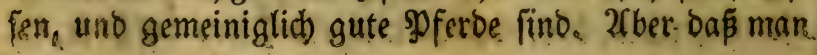




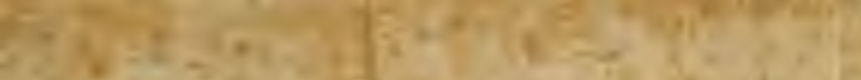

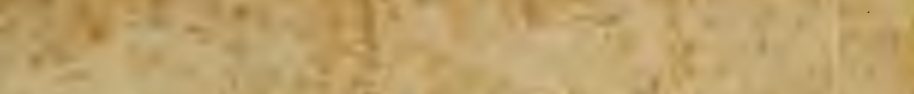

)

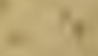

$x^{2}$

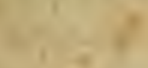

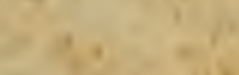

1
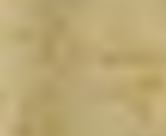

(1)

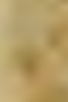

$+2$

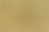

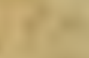

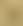

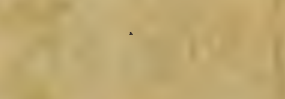

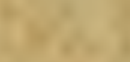

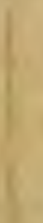

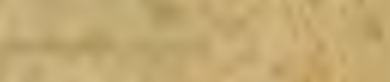

\section{aAt $=4$.}

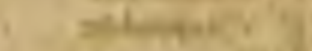

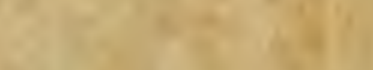

$1+10 x+10$

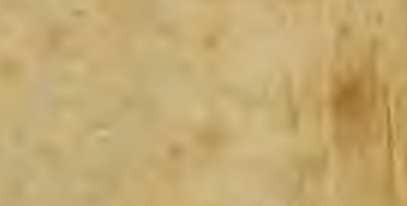

1

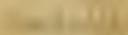

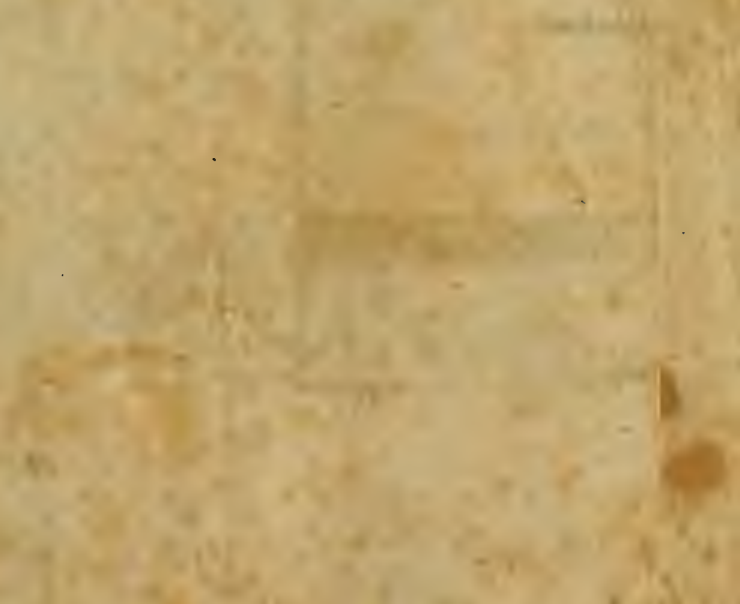

3.

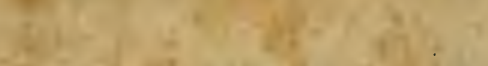

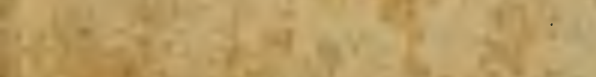

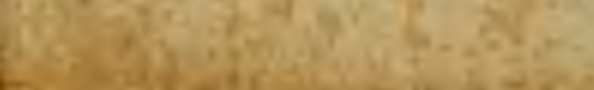

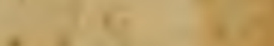




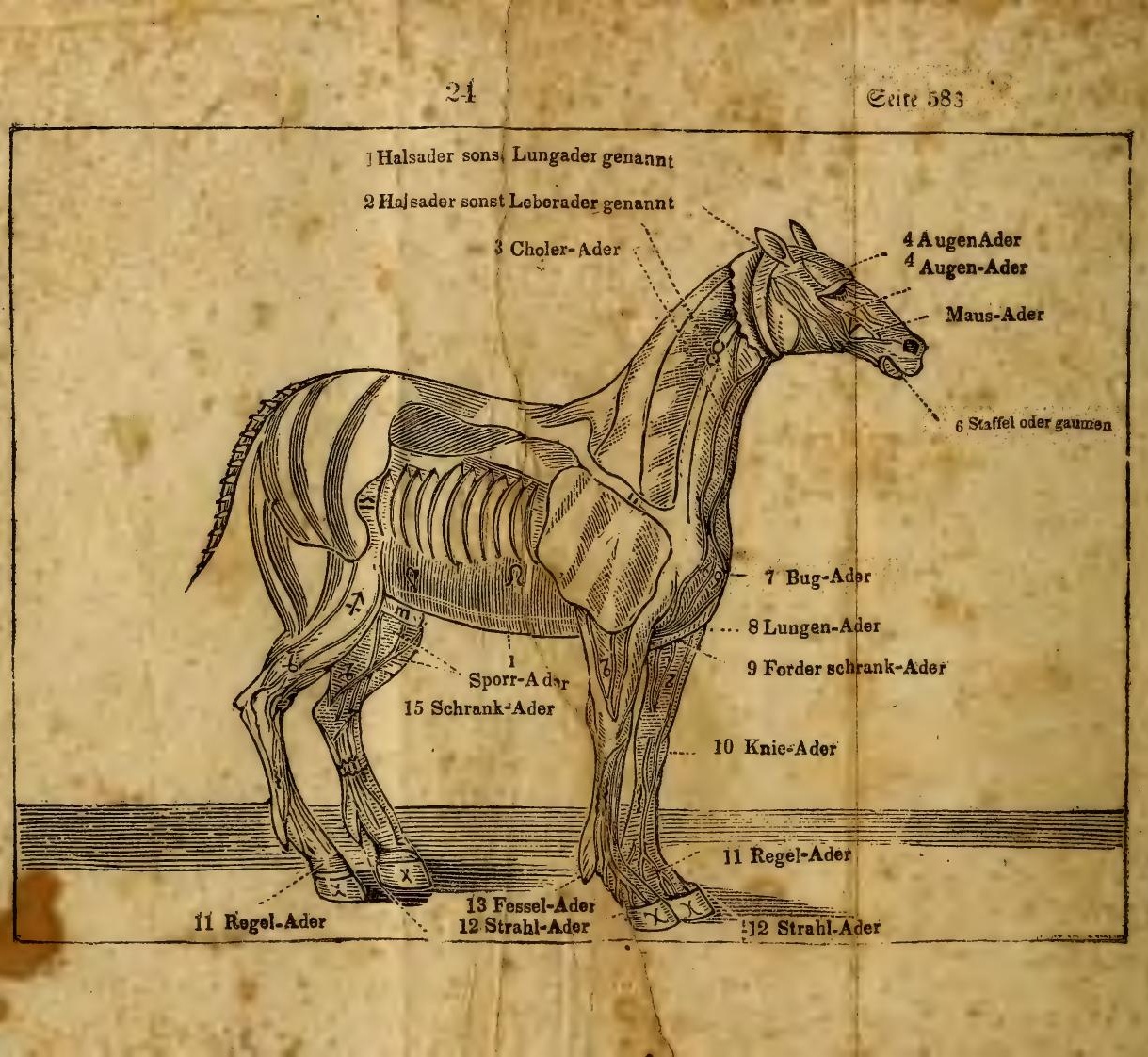


Die Spferde Daran gemöbnen jollte, oder jo vid sRlut beraus lapen, als wenn man gar meken und $\mathfrak{g}$ ürfte mad)en wollte, bas iff zum alletichäblichften.

Man foll auch bei Dem 2loerlapen alle bimmlijoner: 3eid)en, Die Nenozbrïd)e uno 2Derlä̈zeichen im Ea= lender wobl beobad)ten, wie id bann zu bem Ende bie

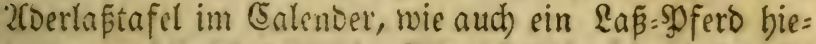
ber verzeidnet babe, fiehe Figur 24, fammt Den zroolf bimmlifchen 3eict)en an jeoem (Sllied, ba jedes 3eichen fein Regiment bat, abgeriflen, als nemlich:

Der Wribuet

Der Stier

Der 3willing

Der Sirebs

Der Rörve

Die Sungfras

Die :raage

Der ๔corpion

Der Sれüh

Der Steinbode

Der 2 Saflermann

Die Fifuthe
Sat inne den Sopf.

Sals und sieble.

Die Sithultern.

Bruft, $\mathfrak{L}_{\text {eber }}$ und $\Omega_{\text {unge. }}$

Den Nagen uno frinen (singang uno Das Scerz.

Den $B$ auch und Eingerceide.

Die Renden, das untertbeil des

Bautbs und ben Nabel,

Das (Sefd)röt.

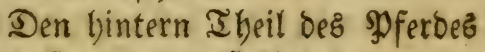
fammt ben Scüften.

Die Inie,

Sdbental uno Sdjienbeins.

Den unterften Theil Der Füpe uno die Şüfe.

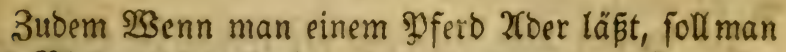
dą Blut mohl beobachten, ein wenig vom erftem uno leşten SBlut, jeood) jedes abjonberlic), in ein (slas lau= fen laßen, uno baraus die Sranlbeit beurtbeilen uno bie (5ur hernad) anfangen. 


\section{A bertaf $=$ Tafel.}

3u beobadten ift in einem jeben Monat bes ganzen Sabrz, Daß wenn ber Nono Sormittags neu wiro, fo

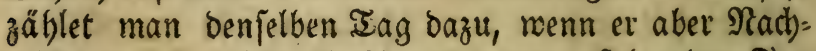
mittag̨ neu wiro, fo fängt man ben folgemben $\mathfrak{x} a g$ an z̧u zäblen.

Den $6,11,12,15,17,18,21,22,23,24,25$, 26 uno 28 gut.

Den $1,2,3,4,5,7,8,9,10,13,14,16,19$, $20,27,29$ und 30 böz.

Folgenoe Iage find auch unglücflich, Mariä SBer= künoigung, Simon Sีubä, 2Noreaz.

Folget ferner, meliten $\mathfrak{P}$ ferben und an welit)em Ort bie $2(d e r s$ láfe fidádlich) fei.

1. Nahe bei bem Seidtröt.

2. $\mathfrak{U n}_{n}$ ben Fïßen, wo daş Şorn anfängt, melden Srt man fonft ben Saum oder \$ुreiß nennt.

3. Mtüben Spferden foll man nicht fogleich, fondern utber oder nach bem oritten Tag lapen.

4. Den 93 alkachen foll man gar nicht, ober ba es ja bie Noth erfordert, meniger $\mathfrak{B l u t}$ laß̧en, alz einem gan= zen gferd.

Nach ber 20erla $\beta$ gibt man bem Spfero eingequellte (5)erfte bez $\mathfrak{T a g}$.

Sm Scerbft läß̧ man auf ber linfen, im Sommer auf ber redten Seite, jeboch ben Rothfall ausgenom= men. 
פgferde:2Urgenei Buci).

Das 8te Sapitel.

\section{S3on Der Aftergeburt wenn fie niclyt von bem \$fero mill.}

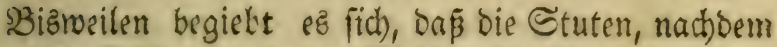
fie das Füllen auf bie 2 Gelt gebrad)t, alsoann ber Sada)geburt nid)t fönnen los werben ; und foldhes ent reber von wegen der llnvermöglichefeit ofr auétreiben: ben Siraft, oder bes melandjolijd)en (3iblïts cine grope 2) Zenge in Der (S) bär= D) Zutter liegen und fiken bleiben, Den muß̃ man mit nad)folgenden Mitceln zu Silfe Fom = men : als

Fend)el 6 loth,

Solte benfelben in Salfer;

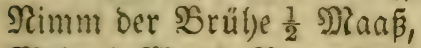

$\mathfrak{Z}$ ein $\frac{1}{4} \mathfrak{B} a$ a

untereinanber genifht uno auf eimmal eingegeben.

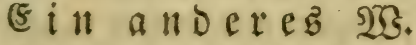

Beräudi)ere bie Gtute mit (5 jelahuf, Sirichlauen, Sübemift ooer Iaubenmift, weldes ou am bequemften baben fannft, und fdütte ifm $\frac{1}{2}$ Suintlein? Saffran, Mferbehoben 2 loth, in einem viertel $\mathfrak{S B}_{\text {ein ein. }}$

\section{(5) $\mathfrak{n}$ a nofreb গুG.}

Scalte ber Etute die Najelöchet ou und mache fie viel niep̄en.

\section{(E) in andereb গצ.}

Saft von 2 2 noorn,

Saft bon Sifmertel, jebes 1 loth,

Saft von \&aud 3 loth,

$\mathfrak{3}$ armen $\mathfrak{Z}$ sein $\frac{1}{4}$ Maá̧,

untereinander gemifht und auf einmal eingegeben. 


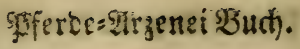

\section{Das 9 te Capitel.}

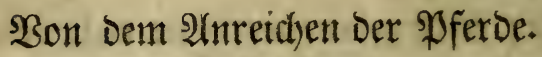

Dies gefchiehet, menn ein Şfero mit ben hintern Şu= fen in bie voriere sBeine an Daz CSeäber oder Fefleln reichet, waz meift bei jungen unvermöglichen SPferben der Fall iff.

Sft febr gefäbrlich, no man es lang anfteben läpt.

Diefe sgferde biegen die Regel auzwärtz, daz (Seä= Der fängt an zu fdowellen, uno bernach zu fdhinoen.

Soldhe Spferde foll man an ben Füpen robl mit nar: mem $\mathfrak{Y}$ Gein bäben, und bernach folgenden Ueberidblağ barum fhlagen :

Srofamen bom Roggenbrod 1 ßु fund,

3 Snoblaucbb̉bäupter,

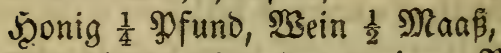

fiebe es wobl untereinander zu einem SBrei, uno foblage

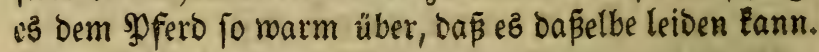

\section{Ein anoeres.}

(S) ftopene Farrentourgel,

Shonig, jebes 6 loth),

Sitter $\frac{1}{2}$ Sfund,

mifche es untereinander auf einem Soblenfeuer uno ficlage eร raim über.

\section{Ein a nereb.}

Bierbefe oder $\mathfrak{W G}_{\text {einbefe }}^{\frac{1}{2}}$ Maaß̧,

Efitig $\frac{1}{4}$ Maa $\tilde{\beta}_{\text {, }}$

Salz 3 Şändeboll.

mifche es untereinander bet einem Soblenfeuer uno fdhlage es über. 


\section{YjFerbes:2rzenei $\mathfrak{3 u d}$.}

\section{(5) $\mathfrak{n} a \mathfrak{n}$ bere}

23ad) holderbeeren 3 Scändevol,

Roggentleien 6 .5̃ändeboll,

Einen Spajenbalg,

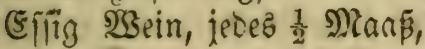

mijä) es untereinander, fiede ç uno follage es über, fo

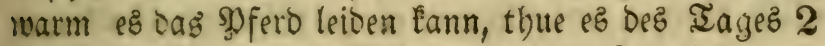
Nal uno fatmiere bas (Beäoer wohl mit Reinöl.

\section{(E) in andereb.}

Bäbe ben Fup robl mit $\mathfrak{B}$ ein und binde ifm bas शach folgende batüber :

BienenwerE 1 Spfund,

SBeitaud), Maftix, jeoes 1 loth,

Roggenfleien 4 Seändevoll,

গু马ein 1 Maá̃,

fiede ę wobl, fitreidbe es auf ein $\mathfrak{I} u d$ und fdylage es marm über.

(5in a ndereb.

Binde Dam Sुpero mit cinem id)malen Etrick ober Rebichnur von unterbalb beg Sinies an biz auf Den Segel binab; Darnad) fdneide mit einem Nefler Ereuzmeife ourh bie $23 a r z e n$, melhe zu unterft am Fü ein menig obert)alb ber Feffel ftebet, lape es wob! blu= ten, uno thue alsbann ben Strict hinmeg, reibeeg bar = nath wobl am ganzen Gdyentel mit Meinbefe uno Men= id)entarn eines fo viel als bas andere uno fohlags ifm

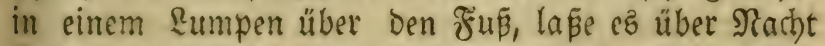
fteben, bernad) Des andern Morgens reite es ing flic=

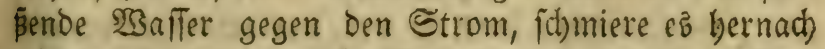

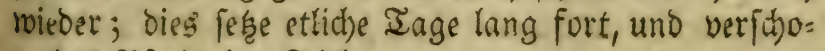
ne das Pferd eine 3eitlang. 
588:

9ferbe:20 r

\section{(Fin a noereb}

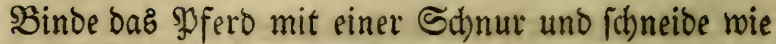
vorgemeldet, mad)e einen Ieig von ungelöfdhtem Sale uno EierElar, ftreidhe benfelben auf ein blaues mollenes

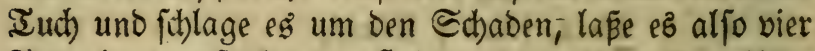
Iage lang aufgebunden fteben; bann thue ben $u m=$ foblag binweg, uno fabmiere es mit folgender Calbe.

Dradyenfdhmalz,

afchenfchmalz, jeoes 6 loth,

Shafelmurzelfaft 8 loth,

Baumoll $\frac{1}{2}$ : Pfuno,

'mifhe "eg untereinander über einer (S)lut und fdhmiere Dab \$fFero warm bamit.

(E) $\mathfrak{i}$ a n

Binde bas \$Jfert wie vorgemeldet, bis an den Sie= gel, fo wirb ein SBläschen auffahcen, Dap̈elbe öffne mit einem Inftrument, fo wiro $\mathfrak{B a f f e r}$ und SBlut beraus rinnen, binde bie nachfolgende Salbe barüber, und la= Be es 3 Iage uno Mäd)te liegen :

Shonig 3 \&öffeluorl.

Salz 1 Scanovoll,

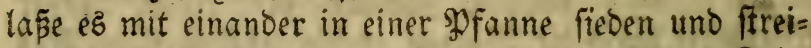

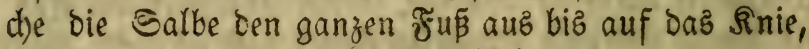
verbinde es alsbann mohl mit Tüchern.

Ein anderes.

Binde uno fatneibe eb rie obengemeldet, uno lege Nachfolgendes barüber :

Semmel fauerteig $\frac{1}{4}$ Maa $\tilde{\beta}$,

Ungelöfhten Rale, fo viel, baß alles mit einan= Der bermif(t)t ein bünner Teig gibt, ftreide ę auf ein Iuch uno lapee ez brei Iage barauf liegen. 
Ein andereb.

Sinte und fdneibe wie fuvor, alsbann binbe Rach= folgendeg roarm Darüber:

(Sieläuterten Şonig $\frac{1}{4}$ Pfund,

Frifd,e SButter 1 Sुfund,

(S)eftopenen \&eim, fo viel baß̃ es einen Brei gibt, fiede es untereinander, man muß aber den \&eim zuleget binein thun.

\section{(5) itt andereb.}

Reive Den frup mit warmem $\mathfrak{W B}_{\text {ein }}$ wobl, bernad) binde ibm গad)folgendes über Den ganzen Fũ :

(Seffopenen Sinoblaud) 3 lotb,

Sonig $\frac{1}{4}$ Sp fund,

Brofamen vom Roggenbrod 1 Şfund,

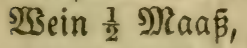

fiede es untereinanoel zu einem $\mathfrak{B r e i}$ und follage ps über, wie fobon vermeloet.

\section{Ein a noereb.}

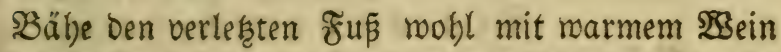
und lape ifn mieber trocken werben, alsbann gebrauche nachfolgenden $\mathfrak{H}$ michlag :

Ulte Reinberger Sdmeer $\frac{1}{4}$ Sfund,

Spanifdi Fliegen 1 lotb,

ftope es zufammen in einem शörjel zu einer Salbe, ftreiche es auf ein blaues Tuth ober auf ein Scanfwerk, lege es über den ๔ababen uno laje es alfo 18 Stun= ben Darauf liegen; es mirb zroar bem Snfero febr webe tl)un, ba ez beftig ziebet, es fchabet aber nichtz; alz= bann nimm Reinöl uno Dialthea, jeoes 2 loth, reibe bie Sdienfel robl bamit alle నag zroeimal. 


\section{Ein andereb $\mathfrak{W}$.}

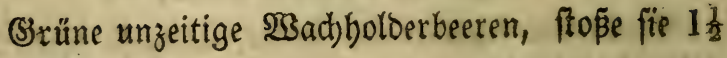
Sy fund,

Schaaf=un $\mathfrak{n}$ fhlitt $\frac{1}{2}$ I fund,

Terpentin, SBaumöl, jebes $\frac{1}{4}$ ⿰ুلfuno,

Regennürmer= Sel,

Sdbwarzes ভdhnecten=: Del,

Waabholoerbolz= Del, jeoes 3 loth,

- Inngeläuterte $\mathfrak{B u t t e r} 1 \mathfrak{P}$ fund,

sungfraumadis 6 loth,

mifde e’ untereinander üter cinem Roblenfeuer z̆u ei= ner Salbe und fajmiere das spfero damit,

Ein anderez.

Siedz geftopenen gebrannten \&eim uno altes ङdjmeet untereinanoer, uno jhlage ez über.

\section{Ein a noereb.}

Sranr.temein, Effig,

Eierweis, jedes fo viel nöthig ift,

mirche ez untereinander und reibe bas sford damit.

(E) i a $\mathfrak{n}$ Dereb.

(Seftopenen \&einjaamen,

Semmelmehl, jeoes $\frac{1}{2}$ DPfund,

Wermuth 2 șändevoll,

હd)warzmurzel 1 Şanowoll,

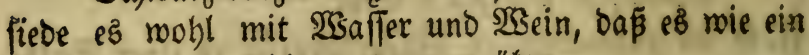
Brei wirb, uno fachlage es warm über.

\section{Ein anderez.}

\section{(Effig 1 Maak,}

Sileien, Şeublumen, jebes 3 Scănoevoll,

Baumöl $\frac{1}{4}$ DPfund, mact) es warm untereinander uno fhlage es bem פfero fo warm über, als es baffelbe leiben lann. 


\section{E in andereb.}

Siebe Epheu in 2 affer und (5fitg und binde es marm Darüber.

\section{E in andereb.}

Bacfe (5ier in Sd)malz und fiblage ez dem Sמfero über, fo warm als es baffelbe erleiben Eann.

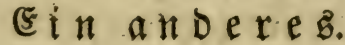

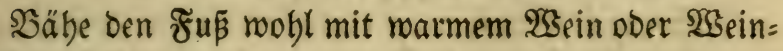
befe, algoann nehme

2lte Sdmeer, frifhen SButter; jedes $\frac{1}{2}$ SP fund,

Roggen Brofamen 1 sfuno,

mijche es untereinander über einer (S)tut und fallage es mit einem blauen IIud warm über.

$$
\text { (5) in a noerebs. }
$$

Scunosichmalz $\frac{1}{2}$ श्रuno, Eoröl $\frac{1}{4}$ SPfuno, trifche SButter 1 SD funo;

lape bies untereinanoer jergeben und fhmiere daffeltie warm bamit, barnach ziehe ober tauche alzbald ein blau= es wollenes Tuch burch beisen $\mathfrak{S e i n}$ uno fohlage baffe! be um oen fobabhaften Sort.

\section{(E) in a ndereb.}

Seffne dem Syferd die Sdranfacern; fiede einen Scajenbalg in gutem (sfiig, uno jollage ez warm ühei Den Sdjaden.

\section{(5in a no}

Siede einen Scapenbalg in (Seismild); uno fd)lage ben warmen Scafenbalg, nachoem ou vorker ben @d)aben wobl mit marmer (Seizmild) gerieben haft, um Denfel= ben; bes andern Norgens binoe ibn auf, fo findeft ou an bem Feffel ein Sảckchen ober Bläzchen, daz öffne 
mit einer filieten ober anderm Snftrument, fo lauft gelbes $\mathfrak{Z}$ saffer oder verftodtes $\mathfrak{B}$ lut herauz, bernad) freidbe folgendez Sglafter auf ben Scafenbalg und lege ez rarm über.

E i nanderes:

Brannterwein $\frac{1}{4}$ Naấ,

(S)emeinen Soluz $\frac{1}{4}$ SPfund,

Şonig $\frac{1}{4}$ Maaß̃.

כึaz $\mathfrak{B e i \beta e ~ v o n ~} 6$ Eiern,

Schönes M্লehl 2 Şändevolu,

(Seftopenen \&einjaamen 8 loth,

mifche alles untereinander in einer \$ुfanne über einem Feuer; wenn es zu dick merden mill, fo mus man mebr (Eiermeiß und $\mathfrak{B}$ ranntemein baran fchütten.

\section{E in anderez.}

Schmiere ben Srt mit Dialthea eine ganze Stunde, bernach ziebe ein blaues Tuch ourch beipes $\mathfrak{N}_{3}$ achs uno binde ez über ben Sdbaden, hefte bas spferb auf, Daß eE fich nicht legen fann, und binde ihm ben gefunden Fuß an einen Şurt oder Stegreif, bamit ez auf Dem (d)adhaften Sort ftehen mußs, laße es 12 Stunde aljo fiteben, thue das 3 Iage nacheinander.

\section{Ein andereb.}

Binde Dem $\mathfrak{P f e r d}$ Den gejunden $F u \tilde{\beta}$ an einen (Surt, umminde den kranken F̌ß ganz feft mit einem Şir=

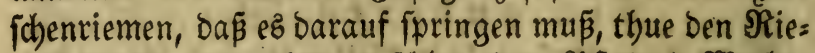
men nieder meg, alsbann ichlage Dem sofero ein $\mathfrak{W a}$ achs= tuch um ben Funs, auf welcbem 3niebeln in beipem Waach geröftet, fammt bem warmem $\mathfrak{W a d}$ ) geichüttet fein, lafle es 3 Iage alfo fteben, am britten Iage muß man es wieder aufz গeue verbinden. 
Ein a n bereb.

গimm Sdureinefoth und geftopene 3roiebeln, binde ę bem शुferd um den fdäblidien Srt.

\section{(5in a noere b.}

Bobnenajde, alte Edtmeer,

Salz, pines to viel als das andere,

ftope ç untereinanoer in einem Nörfer, uno binde es Dem Spferd um ben Sdjaden.

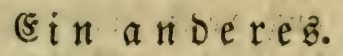

5ुonig 3 \&öffelooll, 4 (Eierootter,

šin Slas $\mathfrak{r s e i n ,}$

Salz 1 Iöffelvolr,

mad)e ç rvarm miteinanoer, rübre barunter

SGeiraud),

Soçahorniaamen, jedez 1 loth,

falbe ben Sdyaden Damit.

(5) in andereb.

Ftlitbe Säupter geichälte 3miebeln,

Submeinefoth, alte Sdymeer, (5ffig,

fiede es miteinander in einer \$fanne, ftreid)e es ber= nad) auf ein blauez mollenez Tud), und follage es bem shferd rarm über, feçe es etlicbe Iage fort.

(5in andereb.

2 Gilden Salbei, breiten $\mathfrak{Z} 3$ egerid,

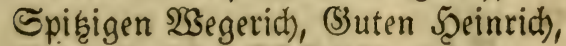

(3io

Stordbenichnabel,

Dannzapfen, Salz, jebes 1 Scanovoll,

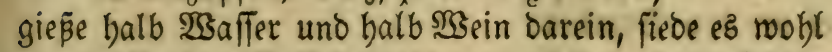
uno majd)e tas (Seäber robl marm bamit, hernach bin= 
de bie narmen Rräuter auch Darüber; wiederbole bieg einige Iage.

Sonig, alte Sdmmeer, \&einöt,

S3achs, jeoes gleich viel ;

mijhe ez untereinander über einer (s)lut uno fdomiere oab Spfero warm bamit.

Ein a noexer.

Schneide dem SPferd die Marzen über Den Felleln auf, lape ibm auch bie Feflelabern fhlagen, hernad) nehme $\mathfrak{B}$ eizenmehl, Effig uno Butter, röfte biefes alles

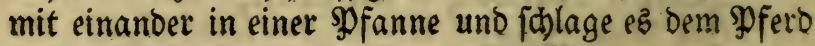
warm mit einem Şajenbalg um ben $8 u$.

inanderes.

Baumöl, গRuß̄ol, jedes 8 loth,

5 Esierflar, Salz 1 Sanonoll,

mifcthe ez untereinander und binde eร über ben Shaden.

(a) a noereb.

Die Brofamen vom Roggenbrod,

sfitig, jeoes fo viel als nöthig iff,

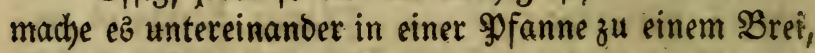
thue bazu

Bolus 4 loth,

SBallourzel $1 \frac{1}{2}$ loth,

mifhe e's untereinander über einem freuter und follage eह roarm über:

Ein anderes.

Şonig, ซ̛urnißß, jedes 8 loth,

mifche $e z$ untereinanoer über einem freuer uno fidlage eह um ben Sababen.

Ein anderez.

Sinde ibm 3 Riemen an bie bintere Snie uno laß̧e 


\section{Pferdes:2(rjenei Buth.}

Folde an bas Şinterzeug feft anmadben, fo Eann ez nicht weiter vorgreifen, als ez bie Riemen zulaffen, uno mur (iid) joldses nad) und nach abgewöbnen,

\section{Daz 10te Eapitel.}

\section{\$on S. Antoni Feuer doer Rotlauf.}

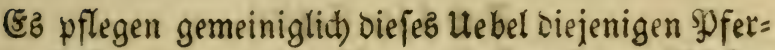
De zu befommen, weldse idnere $\mathfrak{L} a$ ft auf dem Siücten tragen müpen, denn ez jobieflen ibnen grop̈e Bిeulen an Den Sibenkeln auf, meldhe bart wie Eteine fino, uno ftecten voller (Fiter, babon Daneben viel Eleine sBläșchen oder Blätterchen um fïh) fteben.

Soluten PFerden foll man Diejelbe offnen, Den Saft von einem fauren (S) ranatap feliginein ftreichen und oben Darauf (Serftenmebl mit Granatiaft thun; bernach wenn biefes ein, oder brei Iage gebraudht roorben, foll man es berunter thun, und Nachfolgendez darauf bin= Den :

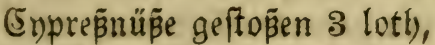

(Serftenmebl 8 loth),

(5)îtg, fo viel genug ift, Dã es fo dict roie ein Srei rirb,

mifd)e es untereinander uno binde es auf.

( $i \mathfrak{n} \mathfrak{n}$ Deres $\mathfrak{W}$.

Sib ifm Separ 21ntimonium, 1 Suintlein unter bem Futter, die şoche zroeimal zu freffen.

\section{Ein a n D $\mathrm{res}$ :}

Nebme Shodunderlatwerge und id)lage es über hel: 
nad) öfne bie Beulen uno beile fie mit bem unguento Égyptiaco, oder F̌elix $2 B$ ürzen \$Braunjälblein. zu.

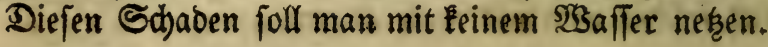

Ein anderez.

Mappelfraut, $\mathfrak{B u r z e l}$ und Caamen mit Beriftenmehl untereinander geftopenen unb barauf gelegt.

Das 11 te Capitel.

Ş on Dem $\mathfrak{A} \mathfrak{u} \mathfrak{b} \mathfrak{e g} \in \mathbb{l} \mathfrak{n}$.

Das seiden ift biejes :

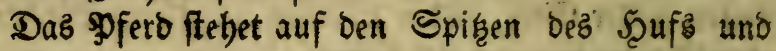
bie Feffel fino frumm. Denen foll man ben Regel al= fobalo über einen Brügel ziehen uno mieder einrichten. Siede alsbann Sdjolleraut und 2 ttid) in 2 Sein uno binde ez ihm oft über, alzbann binoe ben gejunden Fus oben mit einem Riemen oder Striff an ben Sat=

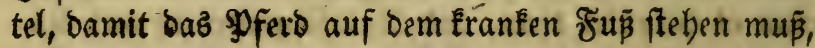
laffe ę 6 Stunde barauf ftehen, alzbann löfe es mie=

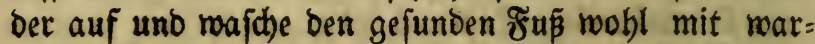
mem Effig, bamit er nidbt aud) gefdowelle uno frum:m merbe, uno wenn nadh Entbindung beb gefunden Fuf=

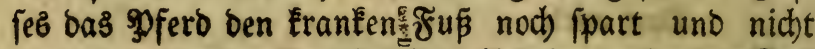
Darauf treten roolte, fo binde ibm ben gefunden $\mathcal{F} u \tilde{\beta}$ wieder und laffe eb ein paar Stunden auf Dem Eranken

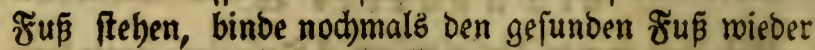
auf und wajd)e benfelben mit warmem Effig mie zubor.

Ein anderez.

Beftopenen Reinjaamen $\frac{1}{2}$ gofund, soonig 4 Eöffelvoll, 


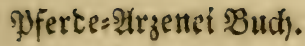

Effíg, fo viel man bebarf Daß̂ ein SBrei Daraus werbe,

la le es miteinander fieden uno lege es dem \$fero warm über Den Sduaben.

(E) in a ndereb.

Baaumöl 1 Sूfuno,

Loröl 8 lotl), Butter 1 ⿰氵 funo,

fiede es outchrinander und fhmiere daz $\$$ pferd damit.

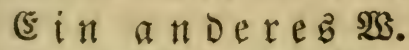

Reinfaamen geftopen, zroei brittheil sofuno,

Sallnurgel 6 loth, Qeinöl $\frac{1}{2}$ Sfuno,

Sdmeet 1 SDfuno, 5̧onig $\frac{1}{4}$ Şfuno,

fiede alles wohl miteinander in einer sofanne und fichla= ge es auf einem blauen Iuch bem Sूfero roarm über.

(5i $\mathfrak{n}$ a $\|$ De $\mathfrak{r} \in \mathfrak{E}$.

Dialtbea $\frac{1}{2}$ Dfund, Metternurzel,

Slaue Rilientwurzel,

Sfiülletaut, jedę 1 Şanovoll,

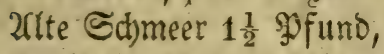

fiede es mit einander und binbe es rarm über.

(E) in andereb.

Sceublumen 3 Şänbeboll,

Baumöl $\frac{1}{4}$ SD funo, $\mathfrak{B s e i n} 1$ Maaßá,

fiede es rohl mit einander und jhlage es rarm über.

Ein andere b.

Salbe bem SুJerd Den Segel 3 Tage nadbeinander mit ber $\mathfrak{M a i l a ̈ n b e r f a l b e , ~ f o ~ w i r b s ~ e i n e n ~ S d h l e i m ~ b e r a u s ~}$ jiehen, laffe das sुferd alfo 6 Iagelang fteben, alsoann fđmiere es mit frif đer $\mathfrak{B}$ utter täglich etlichemal, bis

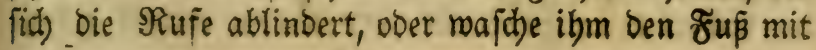


23ein, in welchem Şeionifch 2 Bunofraut, Samillen und Ifgrimonia gefotten worben; alsbann falbe ihn mit Soundeffdmalz uno binoe ibm balb Sconig uno halb

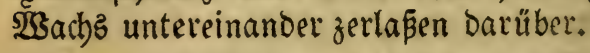

Ein anderes.

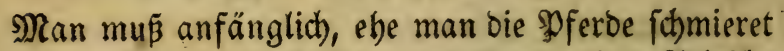
Den guten Fú ibnen binden, uno fie mit einer speitiche forttreiben, Damit fie etlidbe Eprünge thun, uno alfo oen Regel mieoer eintreten; bernad) Eann obenbefdriebe= ner $\mathfrak{u m i d b l a g}$ uno Salbe gebraudst merben. Siefe Frigur $\Re$ o. 25 uno 26.

E

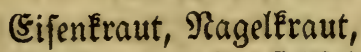
Şausmourzel, Riebftöckel,

Šolderblätter, $\mathfrak{S a c h b o l d o e r b e e r e n , ~}$

Şopfenblumen, jeoes 2 Ş̦ändeboll, zerbarte affez wohl und ftope ce in einem Mörier, laffe es in 2 Sein brei Stunden lang wohl fieden, ftope her: nac) reieber untereinander uno fdlage eb bem \$ffero warm über ben $\widetilde{J} u \tilde{\beta}$, rerbinde es wohl mit einem mol= lenen $\mathfrak{I} u d$; thue es etlid)e Iage nadjeinander.

\section{Das 12te હapitel.}

\section{Bon $\mathfrak{B}$ e inbred) $\mathfrak{n}$.}

Das Beinbrechen ber \$ferbe ift meiftentbeils un= beilbar und was unter bem Snie ift, fehr gefäbrlid) zu curiren, bejonbers wenu ein \$fFero fchon bas 2atter von fünf Sabren zurücé gelegt hat, uno wenn eอ̉ audb wie= ber beil miro, taugt es nur zum Sieben, uno ift gänż= 


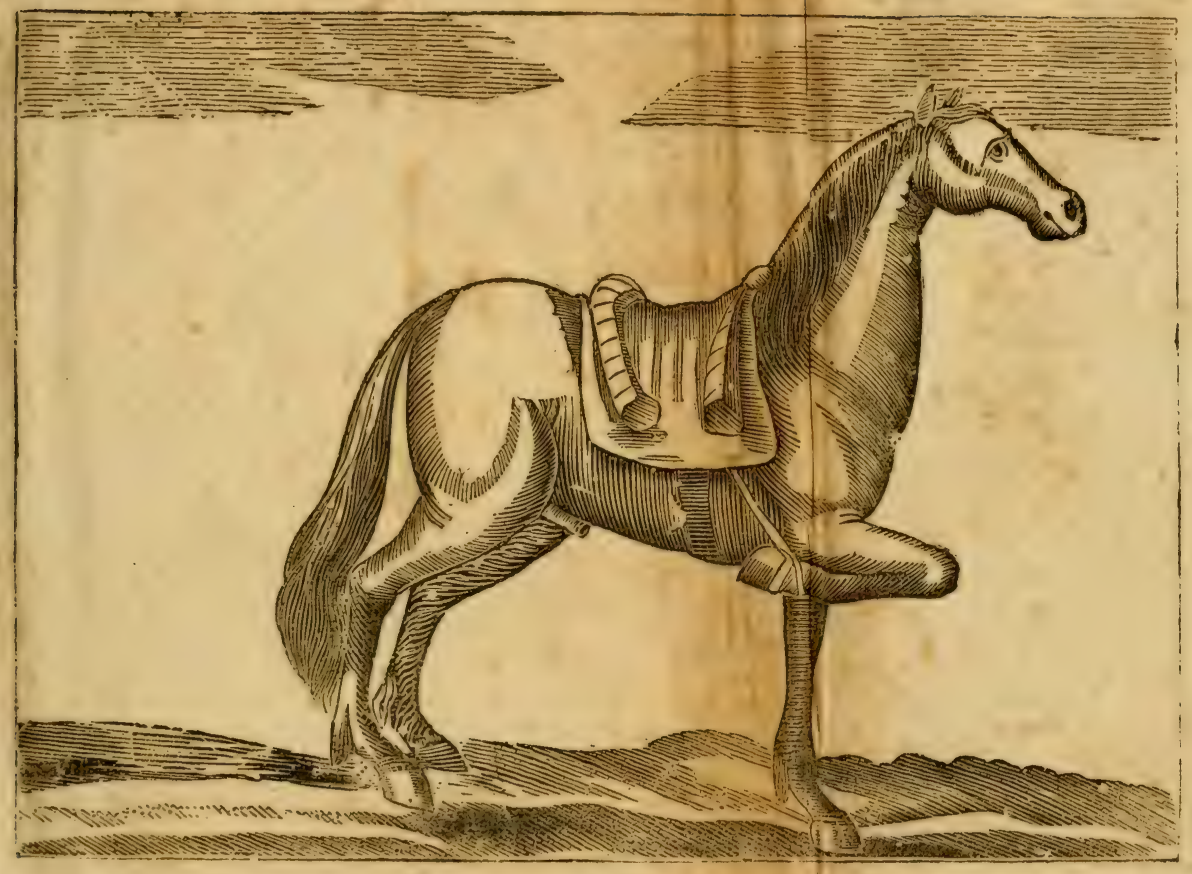




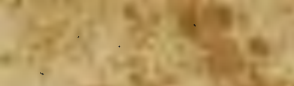

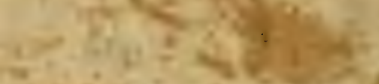

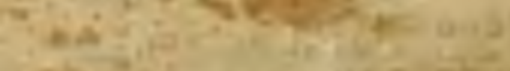

$\sin , \quad<\frac{1}{2}$

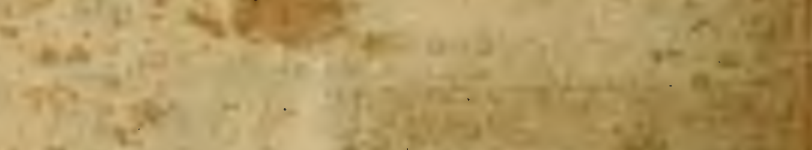

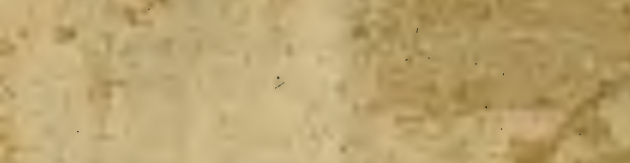

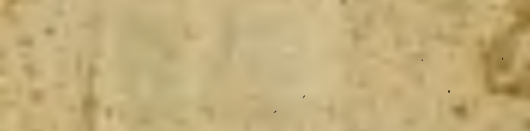

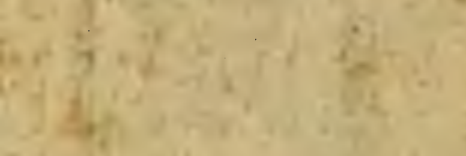
) $+2+2$

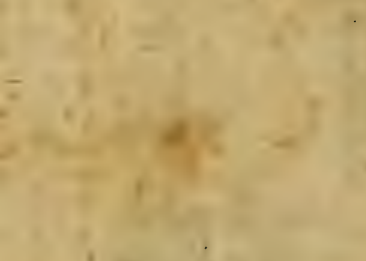

.

1.9

$-1$

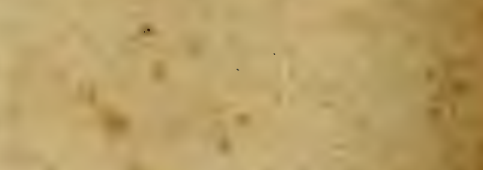

$+7$
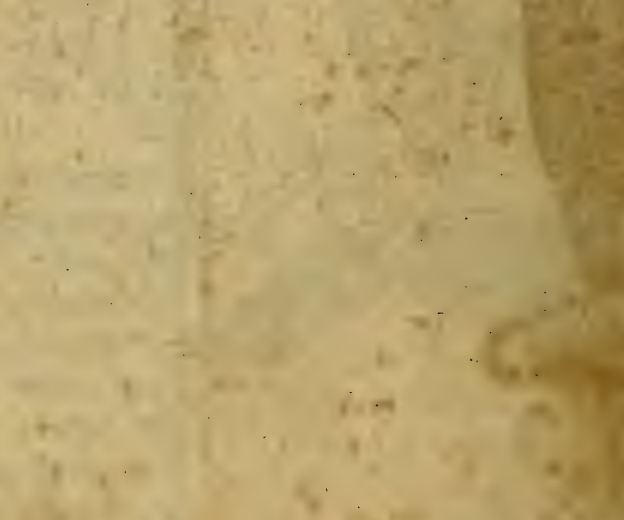

$$
\text { i. }
$$

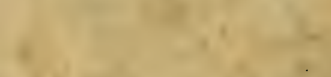
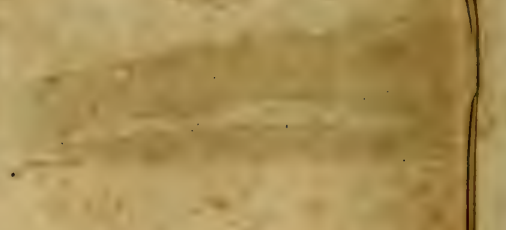


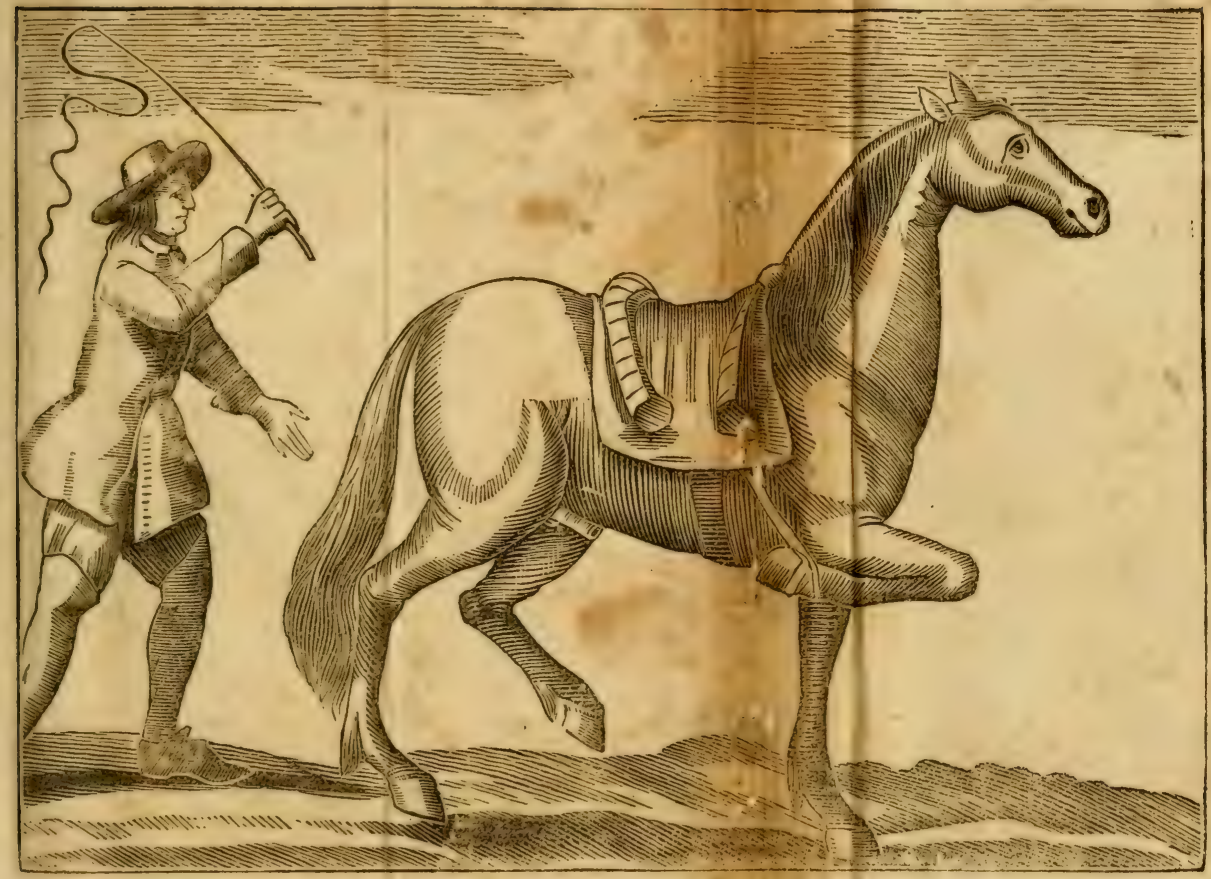




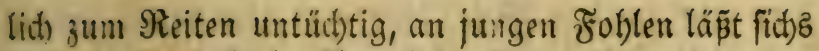
nod) wobl, obgleid) (d)werlich thun, aber mit alten \$oferben iftz vergebens.

Sdrwarzmurgel 4 Sändevoll,

Rindentörmer 3 Sărndevoll,

2lte $6 d$ meer '2-spfund,

mijde und ftopie es untereinander, und fallage es über

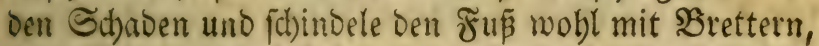
Die dazu mit allem Flei gemad)t find; lafle oas Sुfla= ftet 7 Tage batauf liegen, Den fiebenten Iag thue bas alte Dflafter berunter uno lege ein neuez barauf, uno jo oft du es verbindeft, nelyme Barfammurzel, Sappeln, (Erobeerentraut, Iannenpect), feudite es mit Sel uno Butter, orücte Den Saft Durd) ein Tud) uno falbe bas \$ferd bamit auf Dem SBauch.

Ei in a no exe

SBaflrourgel, fo viel als nöthig ift,

fiede fie in SBein uno ftoß̄e Daz (S)anze zu einem SBrei, bernad) thue bazu

RindsmarE, Sd)meer:

utnidblitt, jeoes gleid) viel,

mijd)e es untereinanoer uno fd)lage es rarm über ben zü, laffe es 6 ober 9 Iage barauf fteben, hernad) fie:

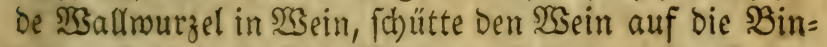
Den, und binde auf bie Sinden gefottene uno geftopene \$Ballwurzel täglich nobl marm.

(E) in a n Deres sig.

Umerifanifchen 3 olus 12 loth,

Nüblftaub 8 loth),

(Sepülverte Şaflrourzel 12 loth,

Eamillentnöpfe 3 loth,

3epüloerten Blutfein 4 loth, 
fiebe alles mohl in 23 : in, follage es über ben Shaden, lafle es 9 Iage liegen, fohindle ben Frobien nobl uno

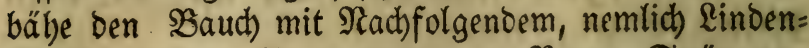
Blüthe, und bie Rinoe bavon vom Baum, Späne von

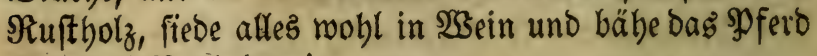
über den $\mathfrak{B a n d}$ bamit.

Dem Spfero thue in bas Trinen gefottene 3 rübe von Balorian uno $\mathfrak{B}$ allmurzel, Bibenell, amerifanif́chen Boluz, ben rotben und weißen täglich unter baz Futter.

\section{(3) $i \mathfrak{n}$ andere .}

Rebme Storchenichnabelfraut mit Spanferkelfichmalz vermifht uno übergeichlagen.

Ein andereb, menn cinem Pfero ein bein nbgebrod)en oder gefd)lngen ift.

Bäbe das spferd wohl mit ber warmen Srübe, wo: rin $\mathfrak{B i b e n e l l}$ gefotten worben, und ftreiche ibm bernady Frolgendes warm über:

Iungfraumachs,

Iannenbarz, jebes 1 Pfund,

Laffe es in einer spfanne zergeben, nebime Mallwurzel 1 Pfuno,

Stope alles in einem Nörier wohl zufammen uno id)lage es Dem \$pfero warm über, laß̄e es 6 Iage liegen uno lege alsoann wieber ein frifches Spflafter über, uno

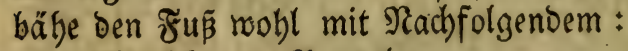

Attid)Eraut, Şappeln,

TSEermuth, $\mathfrak{B}$ üllEraut,

Gamillen, Nachtichatten,

SBalliwurzel, Sropie Rlettennurzel,

Beifú̃, einz fo viel alz baz andere,

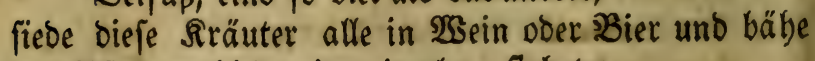
bag spfero roobl bamit, wie oben [tehet.] 
602

9)ferbe=21rzenei $\mathfrak{B u}$.

Das 13te Eapitel.

Bon Den Bisen Der giftigen Thiere, Schlangenbif Doer Stich.

Die Beichen find biefe :

1. Der ganze $\mathfrak{L}$ eib zittert.

2. Die 2rugen baufen ibm und find mit $\mathfrak{B l u t}$ über= laufen.

3. Fallen ifm die Scaare aus bem Sdyopf ode: saläbne.

4. Um ben Schaden und am ganzen $\mathfrak{e}$ eib fabren unflätige Blätterchen auf.

5. Läß̣t Das (S’efdröt aub̂hängen.

গebme sofeffer $\frac{1}{2}$ loth,

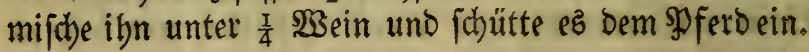

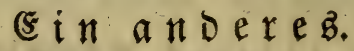

(Sieftopene Rorbeeren 2 loth,

Rein $\frac{1}{2}$ Maas,

untereinanoer gemifdt und auf einmal eingegeben.

E i $\mathfrak{n} \mathfrak{n} \mathfrak{D}$ e $\mathfrak{e} \mathfrak{B}$.

2noorn, willoe Salbei,

Sdhjenzungenmurzel, jedes 1 loth,

Şein $\frac{1}{2}$ Maaß́,

untereinander gemifht und auf einmal eingegeben.

\section{E in andereb.}

SSeinrauten, Iyymian,

Seifuß́, jeder 1 Scanoboll,

ङiebe eв in NSein ;

Rebme von ber Srübe $\frac{1}{2}$ Maaß,

Rofenöl 1 loth,

untereinander gemifht und auf einmal eingegeben. 


\section{פpferbe=2(rzenei Buc).}

(5) $\pi$ a noereg $\mathscr{R B}$.

Sd)langenpulver 1 loth,

Sd)langenid)malz 2 loth,

Beneoijhen Ietpentin 1 loth),

$23 a d j$ jo viel zu einer Salbe genug ift,

mirde es untereinander.

(5in anderes $\mathfrak{B}$.

Dörve Fröfd)laid) im Martio, unb madte es zu झुul= ver, bavon ftreue in bie $\mathfrak{B}$ unden.

sin anderes.

Tannenzapfenfern oder Şafelnuffern 1 Şanob.

(Ein Snoblaucbshaupt,

(5in wenig Ifyeriac,

mifdue es mit $\mathfrak{W}_{3}$ ein ober $\mathfrak{B i e r}$ und fdütte Davon ein uno lege e? ibm aud) uber ben Sdaden.

\section{Ei $\mathfrak{n} \mathfrak{a} \mathfrak{n} \mathbb{D} \mathfrak{r} \in \mathfrak{b}$.}

Eauterifire ben Sdyaden, bernad)

(Siejottene Şanfförner, Soblblätter,

2lte Sútmeer, einz fo viel als bas andere,

ftope uno mijhe ç untereinander, uno lege es über ben Sd)aden, gib ilfm aud) Mild zu trinken, in weld)es Scanfförner gefotten und ausgeprefit morden 1 Maaßs.

\section{(5) $\boldsymbol{i} \mathfrak{a}$ ndereb.}

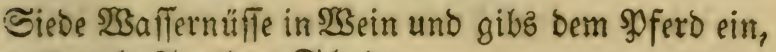
lege es aud) über Den Sdjaben.

E $\mathrm{i} \mathfrak{n}$ a n Dereb.

Streiche es mit einem meipen $\mathfrak{X}_{\text {siefelthalg. }}$

Ei $\mathfrak{n}$ a $\mathfrak{n D e r} \in \mathfrak{E}$.

3erftope ein Sdbwalbenneft zu şulber, vermifd)e eร mit $\mathbb{W}$ ein und foblage pəి über. 
E $\mathfrak{i} \mathfrak{n}$ a $\mathfrak{n}$ De $\mathfrak{x} \in \mathfrak{B}$.

Saft von Siebengezeit 3 loth, Wुein $\frac{1}{2}$ Maaß̧,

untercinander gemifht und auf einmal eingegeben.

Rege inm auch bie $\mathfrak{B l a ̈ t t e r}$ von Siebengezeit mit Salz untereinander geftoffen über ben ऽd)aben; wenn man aber baz frifdhe Sraut nid)t baben fann, Eann man 3 loth Des büren গulvers babon einnehmen.

\section{E in andereb.}

Pferbemild), $\mathfrak{B}$ ein $\frac{1}{2}$ Naa命 untereinander gemijht und auf cinmal eingegopen.

Ein anderes

Scorzonera 3 loth,

(Sepullverte Citronenjobaalen 2 lotb,

Sd)langenpulver,

Rrebsaugen, jeoes 1 Suintlein,:

Saffran $\frac{1}{2}$ Suintlein,

SBein orei Siertel Maá̃,

untereinander gemiicht und eingegeben, und beftreiche ben Sdhaben mit Eier=SDel, ober Sdhrefelbalfam, ober fdnarzem Sdunedien= \$లl.

E in andereb.

Sdröpfe ben Sdbaben mohl, und ziebe viel slu auह, bernad) lege Silettenblätter mit Salz zerfifoffen ba= rüber.

Ein a noeres

Spagyr. Mräparirtes Şirjhborn 2 loth, Salcinirtes Srebsipulber 1 loth,

Stordenpulver 1 suintlein, Scorzonera 2 loth, 
Pferbe:?trzenei Bud).

Saffran $\frac{1}{2}$ s.uintlein,

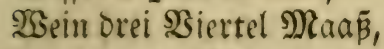

untereinander gemija)t und eingegeben.

Ein anderes.

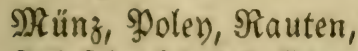

3rwiefeln, jeoez 1 Scanowoll,

Salz 2 loth,

untereinander gemifot und auf Den Edjaben gelegt.

E in a nt $\mathrm{D}$ ereb.

Binoe NReerrettid) uno Scollunderblätter durcheinan= Der geftollen utber den Sdhaden.

E i I ก ก De re

Siebe rohes Şanfgarn in Esffig uno fitlage eร über Den Sdjaben.

\section{(5) a n noeres $\mathfrak{Z}$.}

Den Saft von 2rgrimonia, Rautem[aft, Braunellen faft,

Snoblauchsjaft, jeoes 4 lotb,

Mild), worin Sanfeörner gejotten und geprep̈t worden 1 Maá,

Scorzonera 1 loth,

Sirebzaugen 1 Suintlein,

untereinander gemif́cht und auf einmal eingegeben.

$$
\text { (E } i \mathfrak{n} \mathfrak{a} \mathfrak{n} \text { ber } \mathbb{E} z \mathfrak{Z B} \text {. }
$$

Sitronenfaft 8 lotb), Sitronenfern,

Gitronenid)aalenpulver, jebez 1 loth,

İerra figill. 2 Suintlein,

Đräparittę Şirfd)horn,

Scorzonera, jebes 1 loth,

W3ein brei $\mathfrak{B i e r t e l} \mathfrak{M a a} \tilde{\beta}_{1}$

untereinander gemifht und auf einmal eingegeber. 


\section{E in anoerez 95 .}

Theriac ober Mitbribat 2 Suintlein,

$\Re$ Rutenfaft 6 loth,

Braumellenjaft 4 lotb;

Saffran $\frac{1}{2}$ Suintlein,

Ecorzonera 1 loth, 2 sein $\frac{1}{2}$ Maá.

untereinander gemifdt uno auf einmal eingegeben.

(Ein anderes $\mathfrak{B}$.

Eitronenfobalenpulber 1 loth,

Eerra figil, 2 loth,

Saffran $\frac{1}{2}$ Suintlein,

Schmefelbaliam 1 Suintlein,

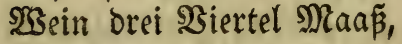
untereinander gemifht und auf einmal eingegeben.

(E) in anderes

Enzian 1 loth,

\$ูräparirte Rrebsaugen 1 Suintlein,

Ealcinirte Rrebspulver 2 Suintlein,

Sitronenichaalenpulver 1 loth,

Schlangenpulver 1 Suintlein,

Saffran $\frac{1}{2}$ Suintlein,

$2 B_{\text {ein }} \frac{1}{2} \mathfrak{M a a}$, untereinander gemifht und auf eirmal eingegeben, uno jhmiere ben Sdbaben mit Scor= pionől.

\section{Bom Spinnenfted)en.}

Lege baz $\mathfrak{R} a u b$ von @d)aafsmülbe gequeticht barü= ber, ober 3wiebeln, Salz, Rauten, $\mathfrak{B}$ segerich, Sieben=

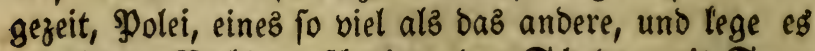
barüber. Nadboem fdomiere ben Sdbaden mit Scor= pionöl, ober Spinnenöl. 


\section{Pferbes:2(rgenei Dutr). \\ E in a n D e reb.}

Stolle Şanf und binde denfelben Darauf.

Sintten= Fle fermáแ

Der Sibaden lauft auf uno wiro eine barte (Se= (d)wulft, bas Dfero feufzet uno Eann nicht effen.

\section{D) i e c u $\mathrm{r}$.}

Ierpentin, Raldh), (5ierroeiñ, mijde es untereinander und binde es über.

\section{E in a noereb.}

Die Eroe aus einer $\mathfrak{B S a g e n l e i f t ~ g e n o m m e n , ~ m i t ~}$ Nenichen barn angeftridben und Daruber gelegt.

\section{E $i n a n d e r e z$.}

Shide das forabhafte (stied mit einer Fliete mohl, lege carüber Robl in Effig gefotten oder geftopen ober Inoblauch mit Eilitg zerftoflen uno bermengt.

\section{Ein a noereb.}

Sd)miere Den Srt mit Irottenöl.

\section{(5) in andere b.}

Das Şulver, weld)es in Den Shlaffunzen Der MRo= fenftöce gefunden wiro, uno nadjoem ber gebiffene Sort mobl ift gepickt morden, barauf fitreuest.

\section{(5i $\mathfrak{a} \mathfrak{n} \mathbf{D} \mathfrak{e} \mathfrak{e} \mathfrak{B}$.}

Rege Butter mit einem Sierootter Darüber.

(F) in a ndereb.

¿ege zerftopenen Snoblauch barüber.

\section{Ei $\mathfrak{n} \mathfrak{a} \mathfrak{n} \in \mathfrak{r} \mathfrak{e} \mathfrak{b}$.}

Sdbmiere ben Srt mit (Fieröl, reldbes im abneb)= menden Mono gemadt worden ift. 
Ein a it bereos.

Sdhwarzen నümmel 2 loth,

Wein $\frac{1}{2}$ Maaß̃,

untereinander gemifcht uno auf einmal eingegeben.

E in a n $b$ ere b.

Sege ifm geftollenen Sinoblaud, నümmel uno Sals. untereinander gemifdht über ben Sdhaben.

E $i$ n a n beres.

(G)eftoffenen Sümmel, Pedh,

Sdbreinenfidmalz,

mache ein SPlafter Daraus, brenne aber vorber bent Scbaben.

Wenn aber die (Sejchroulft nach bem Siennen nod) Göber auflauft, to fomiere ben Schaben mit altem Schmalz uno lege geröftete und geftopene (Serfte ba: rauf.

$$
\text { Scorpion= S tid. }
$$

Das lauft auf und geichwillt, erftarren bie Beine uno werben Erumm, binfen, fönnen nicht freffen, lauft ifnen grüner (Eiter zu Den Nafelödbern beraus, uno cönnen fonerlid ben 2 them an fich zieben.

\section{Die હur.}

Diejes foll man mit Scorpionöl fammieren, wenn man zulammengejektes Scorpionöl befommen Eann, fo ift ez defto beper.

Ei in a noeres.

Sdhmiere das fdhabhafte (Slied mit Sdhmeine- Siothp

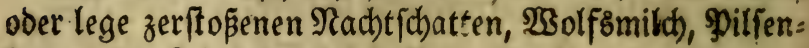
Eraut oder \&einjaamen barüber.

Ein andere 8 .

Die 2 jche vom gebrannten $\Re$ obr 5 lotb, 


\section{Pferbe:2(rzenci Buá).}

(5irope Slettenmurzel 3 lotb),

2̧ein $\frac{1}{2}$ Maấ,

untereinander gemifht und auf einmal eingegeben.

(5) in a n bere s.

Die $\mathscr{B}$ Burzel von Feigbohnen 2 Suintlein,



untereinander gemijht uno auf einmal eingegeben.

(F in a n bere s.

Irreide, SDel, Efifig, Ieufelïbred,

Schroalbennefter,

untereinander zu einem Brei gemacht und aufgelegt.

$2 B$ i efel bece n.

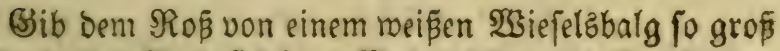
wie ein 10 Sentsftü in $\mathfrak{B}_{\text {Sein }}$ ein, uno beftreicbe ben Sdjaben mit einem neiffen $\mathfrak{W}$ Siejelzbalg.

ङ in an

Iberiac, SBein, untereinander gemifht und auf einmal eingegeben.

E $i$ a $a$ i $b$ e $p$ b.

Scorpionöl mit alter Schmeer vermifict und ba: rauf gelegt.

Fin a noeres.

Sd)langennurzel,

B3adjbolderöl, alte Schmeer,

mifd)e es untereinander und lege es auf ben Schaben.

Wa u the no

2Ran foll beflelben Scunoz eigene Scaare darauf les gen.

(e) in a noere

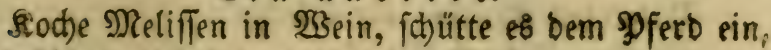
uno id)lage Das Siraut über Den $\mathfrak{B}$ i 
(5) i a I Deres,

(Sauthbeil, Wegerichtraut,

(snzian, jedes 1 loth),

Das :Saffer von Enzian,

bon (Sauth) beil,

von $\mathfrak{B s e g e r i c h , ~ j e o e s ~} 10$ loth,

untereinander gemifcht und auf einmal eingegeben.

E in an bereb.

SRöfte Scundszungen in Sdhmalz, uno lege ę auf Den $\mathfrak{B i \beta}$.

Ein anderez.

Werfe das Soferd etlichemal ins 2 Saffer.

Ein anderes $\mathfrak{x}$.

Salcinirte Srebspulber, (bie Srebfe müffen aber cal= cinirt werden, wenn die Sonne im Seicken beg Srebs ober \&öwen nach 2A ufgang beg Scundefterns im roach)= fenoen Miono,)

Enzian, Elfenbein, jeoes 1 loth,

Rosmarin 2 Suintlein,

Diftelmaffer oder bie gefottene Brübe $\frac{1}{2}$ Naaj, untereinanoer gemifcht uno auf einmal eingegeben.

Ein a nores $\mathbb{R}$.

Salcinirtez Srebspulper,

Terra figill jedes 1 loth,

(S) fottene Srebsbrübe orei Siertel Maá̃, untereinander gemijht und auf einmal eingegeben. (E) $\mathfrak{n}$ a $\mathfrak{n}$ beres $\mathfrak{M}$.

Diffelblumen, 1 loth,

Sצilde Raplieben 3 loth,

Salcinirte Srebspulver 1 loth,

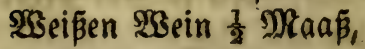

untereinander gemifdt und auf einmal eingegeben. 
Ein anber:b.

Siebe robes (Sarn in flieflendem $\mathscr{2}$ anfer und binde eg roarm über.

(5) $i$ a $a$ th $b$ e s.

Sungeg Birkenlaub, $\mathfrak{B e r m u t h}$ in fojarfer Lauge ge= potten, bie (Sejchmulfif täglich bamit gerwajchen, und

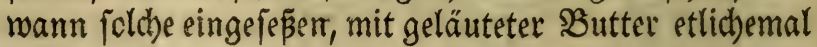
gefdimiert.

Ein anderes, menn die (sefichnulft vom Burt fommt.

SBenn bie Gefonnulf zeitig ift, mus man foldbe mit einem S̃nftrument öffnen, beg Felix $\mathfrak{B}$ üt:ęen Braun= fälblein gebraudben und hernach um bie (Sefdnulft ber= utm mit Dialthea und populeon nohl famieren.

\section{Dag 15tc Capiter.}

\section{Bon beiffenoen Bhtutbeulen.}

Die seichen fino biefe :

1. Die sperde reiben fich ftet?.

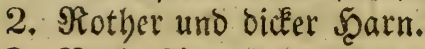

3. Rotbe 2 ugen.

4. Ueber Dem Reib find blaue Beulen.

5. Die 2loern unter Dem Reib laufen auf.

6. (Sienen foldty פुferde oft.

2Benn man nid)t bei Beiten zu Şilfe eilt, fo befommt daz \$ुferb den Stharbock Doer WGurm Davon.

\section{Die ce $u r$.}

Eape ben Sort, befonders am Scalb, wo fid am mei= ften bie Boulen fehen laffen, mit breiten flieten wohl

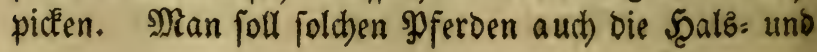


Eporraber laffen, bernad) folgenden (singuß geben :

Ritbrioat 1 suintlein,

3miebelfaft 2 loth, Effig $\frac{1}{4}$ Mnaß̧,

untereinander gemifdt und auf einmal eingegeben.

(E) i a n o e res $5 \mathfrak{B}$.

Scepar 2fntimonium 1 suintlein,

Saffran $\frac{1}{2}$ Suintlein,

Kein $\frac{1}{2}$ Maas untereinander gemifdet und auf eimmal eingegeben, mieberbole eg einige Mal.

(3ib if)m 9 Iage nacbeinander täglich 1 Suintleir Spieß̧glaz im žutter zu freffen; wenn man ibnendaz Epieß̈glag gegeben hat, barf man ifnen barauf nid)t zur 2roer laßjen.

(5) i a n bereb $\mathfrak{M}$.

Salap 1 loth, 20loes 2 suintlein,

Scammonium 1 suintlein,

2lgaric 1 loth,

(S)ummi guttä 1 suintlein, Beinfteinrabm 1 loth, 2(nis,

rend) jed, jeos 1 suintlein,

Saffran $\frac{1}{2}$ Suintlein,

ख̧ein 1 Maá̃.

untereinander gemijht und auf einmal eingegeben.

Dab 16te Sapitel.

\section{$\mathfrak{B}$ D $\mathfrak{D}$ Den $\mathfrak{B}\lfloor$ t $\mathrm{r} u$ fen.}

Die Blutrufen wachjen an ben Pferben gerne auf Dem Rücken unter Dem ङattel, Das Fommt Daher, menn

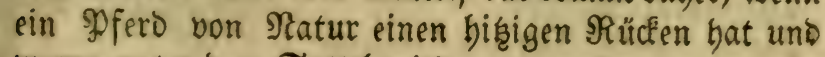
roarm unter Dem Sattel wird. 


\section{Die. C) $\mathfrak{u}$ r.}

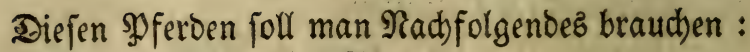
Seaberneß̄eln, 2ulte Edymeer, mijhe und ftope es untereinander und binde es barauf.

Ein a nderes $\mathfrak{B}$.

Ungelöidten Ralk,

Seife, jeors gleidhuiel,

lege es auf bie Seutlen oder Şurzel, in orei ober vier Stunden lebiget eg biejelben auf, mo nid)t, fo laffe eg nod) länger liegen, alsoann menns beraut ift, fo falbe Den Srt mit Rofenfalbe, Dialtbea und SDopuleon ; ift $a b c r$ faul Fleifid) Doer (siter barin, fo kann man

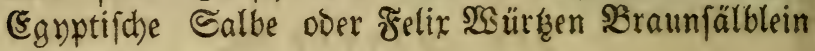
gebrauchen.

(5) in a noered.

$\mathfrak{u n g e l o ̈ | c h t e n ~ \Re a l k e , ~}$

Sconig, fo viel als nơthig ift,

calcinire es untereinanoer, pülvere uno ftrette fold)es spulver Darauf.

(E) $\mathfrak{t}$ andereb.

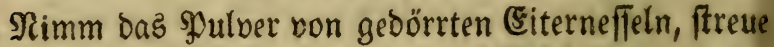
ez auf eine Spectichwarte, bie viel Schnitte in einan= ber bat, uno lege ee über Sacht auf bie SBlutrufen, albbann fo fie abgelöfet bat, jo ziehe ez mit einem 3ängden berah, ftreue bernad) bas Sylver von ben gropen Eiternefffln hinein.

(e) in anderez.

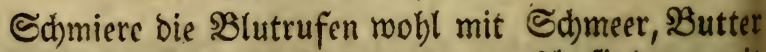
ober Dialthea, bis fie lind merden, roafdefie bann mit gefottenem Flöhefraut= oder 2 Igrimoniamaffer wobl aนรి uno ftreue (S) ünpan binein. 


\section{Dfferbe:Irzentei Buth.}

Ei a a beres In.

Strue Dab Eaput mortum Bitrioli barein, ober calcinitte Edhnectenbäuzd)en, calcinirte Sirid)bcine, odit buz gुhtuer van Soblmutrzel.

\section{Daz 17te Capitet. \\ IJom $\mathfrak{B}$ lutitellen.}

9)?an foll frifouen Sुferdefoth barauf legen, ober les ge cin Buffit)den SEolle bie in Sel getnucht morben auf Die 2loet.

Fit a

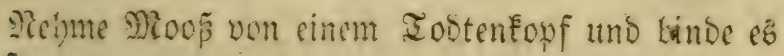
mif.

(5)

Die ?(jd)e won serbramnten Fröfd)en,

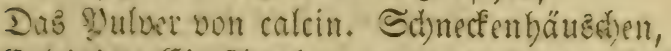

Salcinite Eieridualen, woraus junge Şülfnet gefdlüpft fino.

Ealcirirtes Shirid)hort;

Iifidelerantpulver, jebes:3 loth,

żunfingerfrautpulver 4 loth;

Nelelrourzel 6 loth

mific) es untercinanter zu einem \$ुolver, meld)es man cimitreuen ocer über!egen Eamn.

\section{(5) i}

Bince ifm Eäutoth auf ben blutenden Sot, mb bänge ifin cas (sicidgrót in Efitig,

(5in a noereb.

Iäpheleraut, 
Calcinirten Reffelfaamen, jeoes 3 loth, mifche es untereinander und binbe ę auf bie sssunde, bänge ibm auch Seffelnurzel und $\mathfrak{I} a ̈ j$ chelfraut an ben Şals.

(E) in a noerez.

Sebme die Sinöpfe, welche an Den Rinden wachjen, gepullvert uno aufgelegt

$$
\text { - Ein andereb. }
$$

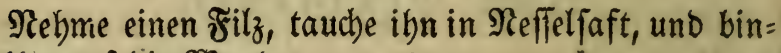
be ibn auf bie 2 Sunde.

(5in a noerez.

Siede Sormentill in $\mathfrak{S a f f e r}$ und gibs bem Pfferd zu trinken.

Ei $\mathfrak{n} \mathfrak{a} \mathfrak{n}$ ber $\mathfrak{e}$ в.

WSeirauch) gepülbert, mit Eiertlar vermifdt und mit Şanfwerk übergefdlagen.

(5in an $\mathfrak{a}$ ere

Calcinire bie meiffen Şaajenbaar, meldbe ben Şaa= jen binten zwifden ben seinen wadj jen, wie aud am Schnänzlein; ebenjo Rebebaare, uno binde es auf bie $\mathfrak{B s u n d e n .}$

Ein a n bere

$\mathfrak{L a p e}$ weipen $\mathfrak{B}$ itriol in einem eifernen $\mathfrak{R} b$ ffel zerge= ben, tauche $\mathfrak{S}$ erE binein und lege es über Den Sdbaben.

(E) in a no reb.

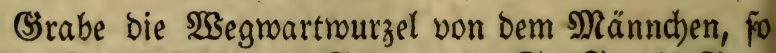
rotbe Stängel bat, am Freitag vor St. Sacobz నag, zwijchen 11 uno $12 \mathfrak{u b r}$ zu Mittag unbeidhryen, ba= von gib bem spfero 3 Stücke zu effen, movon eines fo lang ift, als bas mittlere (s)eleid) am fleinen Finger. 
Pferde:2(rzenei Bud.

(5in a nbereg.

Sd)lage ibm die Sporrabern 3 Iage nadbeinander. (5) $i$ it a n $b$ e reb.

Sinde gebrannten 2flaun barauf.

(5) $i$ it a แ bere в.

Gtreute das şulver von ben Ratten, welde in Dem Sorn wachifen auf die $\mathfrak{F u n d e . ~}$

Ein a noereb.

2loes bepatica 1 loth,

Beiraud) 2 lotb,

midhe es untereinanoer zu einem Sुulver uno ftreue $b a=$ von in bie $\mathfrak{2 B u n d e n .}$

(5) i t a n bereb.

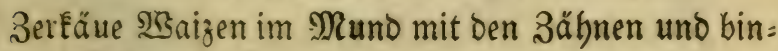
be benfelben barauf.

\section{Das 18te (Sapitel.}

Bom 'Slut, meldhes in sie Glieber geronnen ift.

Siede Reinöl in Effitig und fdhmiere ę über.

$$
\text { (E) } \mathrm{in} \text { andere } \text {. }
$$

Die 2 fache vom Scaberftrob, von Sageocrn, jedes 3 loth,

2llte ๔d)meer 1 şfund,

mifa)e es über einem Soblfeuer untereinander und bin= De.ę warm über.

\section{E in andere}

Siebe Sdhmarzmurzelfraut in Ejiftg uno jollage es über. 


\section{Pferbe:2(rzenei $\mathfrak{B} u$ ă.}

\section{Ein anderes.}

Roggeneleien " Şändevoul,

Sorbeeren 2 loth, Sfeffer $\frac{1}{2}$ loth,

Branntewein, fo viel als nöthig ift zu einem Sirei, mifit)e es über einem tinden Soblenfeuer unter = einander uno fallage es ïber.

Eith a $\mathfrak{n}$ Dereb.

Streiche die Mailänder Salbe barüber.

\section{Ein a noereb.}

(sijentraut, Nagelf́raut,

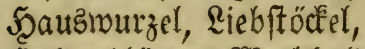
Scolderblätter, SGachboloerbeeren, Wadbbolderipisen, Scopfen, pines fo viel als bas andere,

fiede es roohl in Srein, ftope es bernach, uno fiebe e己 roieder, bann folage ez dem SPfero warm über.

\section{Das 19te Eapitef.}

\section{Ron Der Sreuzyerzudtung.}

Diefe Syferbe geben vom Stall aus auf ben bintern 3äben uno halten daŝ Jireuz ganz fteif. Siebe Fi= gur $\mathfrak{N o . 2 7 .}$

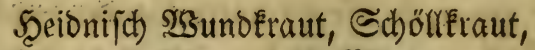

Suendel, Egrenpreis, Şintergrün,

Samillen, jedes 1 Scanboull,

fiede ez in Salzmaffer uno fidlage ez über, fo marm es

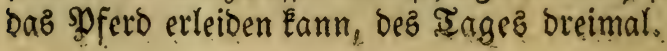




\section{S3on bem faulen ober willoen Fleifh.}

Das Faule Fleifh wädff gemöhnlid) Den Shferben in ben $\mathfrak{K}$ unden ober offnen Echäben, beflen $\mathfrak{l}$ rjache ift, menn bie 2 Sumbe ooer ber Echaden zu lang offen ge= fanden, doet wenn man nitht bazu gehörige 2rizenei= mittel brauchet, welche bie SSunden reiniger.

Das wilde fleifch aber mus̃ man erkennen, wenn

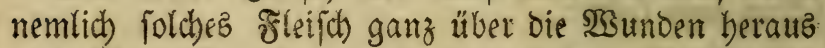
gemad) fen ift uno dem anoern gejunden Flcifch nicht gleid) fithet, oie geringfte Berührung befferben ift für Das \$ffero äuflerfit empfindlich.

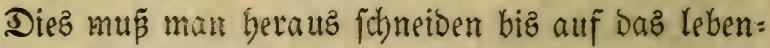
Dige, wofern ez bie 2toern Saarwad)s nid)t verbindern; Dann forl man ähen mit Machfolgendem : (Erftlich) foll man ben Sababen ein wenig cauterifiren, (jebod) obne Sdaden ber 2roern und bes Scaarmadyfez) alsbann bes.

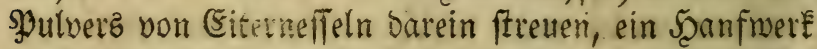
butch Eieroottern gejogen barauf binden uno brei $\mathfrak{I} a=$ ge aljo liegen laffert, alsbann foll man Rad)folgendes şutver barauf ftretuen :

Ungelöichten Salk 6 Scänoevoll,

Sdivwarze MNRufcheln 4 Şändeboll,

$\therefore$ Salz 2 Şäntoevoll, Scirichborn 2 Scändevolf,

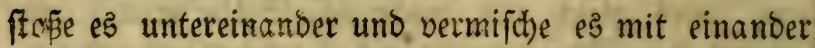

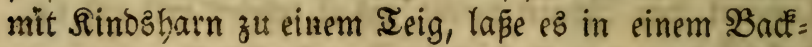
ofen ganz Gart backen, bernad) ftope und mache ez zu einem \$ulver.

Woann bas gute grteith anfangt zu roadjen, for 
man Den Sd)aben mit Schneinenfdumaly fdymieren, ooer Scanfwerk Durd) Mild)raum jieben uno barauf legen.

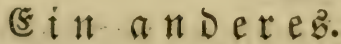

Sebme ungelöithten Salk 2 I beil,

alte Seife 1 I bril,

vermijo) es mit (5ierflat zueinem Iasig uno jhlage ez über.

\section{Ein: $\mathfrak{A}$ Dereb.}

Simm (3rünjtan uno ungelöidten Raif, eines fo

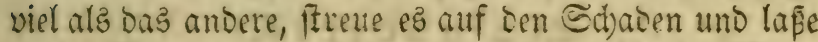

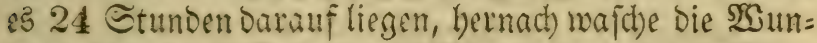

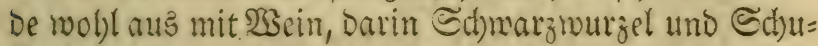

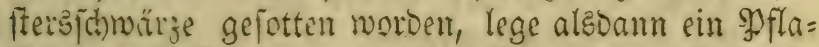
fter von Neflelfanmen uno Der $\mathfrak{B S}_{3}$ arzel gemad)t barü= ber, uno fo oft man cin frifobes Sfflafter liberlegt, foll

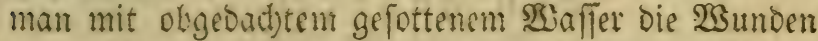
ausmafden.

\section{Eี in a \#Deteb.}

Salcinite in eincm Şafen nadifolgente Sadje und freue es in bie $\mathfrak{W}$ unde :

Siorn, Scaber, ScübnetEoth,

alte Sdubfohlen, pines fo viel als bas andere.

(5) in a noeres.

Strette ourte Niesmurzel binein.

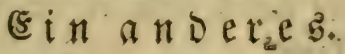

Rauten,

Deumenten, jeoeక 3 Şändevorr,

alaun 3 lotb,

fiebe es wohl in flieflentem $23 a$ fifer uno wajd)e ben - Sdjaden bamit aus. 
Ein a n

Rotbe Sucten, (Suten Seeinrid),

SReffeln, Sappeln,

Sceionific) \$̧unofraut, jeoes gleich viel,

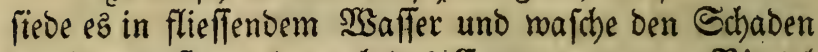
Damit aus, ftreue bernach Das (Eaput mortuum Sitriol binein.

(5) $\mathfrak{i} \mathfrak{a} \mathfrak{n} \mathfrak{D}$ e re $\mathfrak{B}: \mathfrak{S}$.

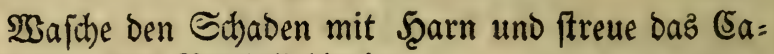
put mortuum Bitrioli binein.

Ei $\mathfrak{n}: \mathfrak{a} \mathfrak{d} \in \mathfrak{r} \in \mathfrak{b}$.

Sitriol 2 loth, (Sallar,

Alaun, jeoes 1 loth, roeipen Şarz,

Baumöl, jedes 1 spfund,

fiede bieje Stücke alle miteinander ju einer Calbe.

E i $\mathfrak{n}$ a

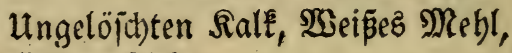
Sübnertoth,

Serberlohrinden, jedes $\frac{1}{2}$ Nofund, Sonig 1 Pfuno, ein menig Effig, formire einen Ieig Daraub, badfe eE ganz hart in einem Bactofen, püloere ę uno fitreue es in bie $\mathfrak{B}$ unde.

Ein anderet.

গabme jublimirtes suedfitlber, freue eg Darein, ha: be aber mobl acht babei, Denn es ift (sift, fo einem leidtlich jobaden Eann.

\section{Ein andereb.}

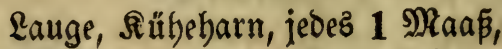

Salz 1 Şanoboll, 2laun 8 lotb,

fiebe alles wohl, mit biejem wajhe ben Schaben gut นร. 


\section{(E) $i \mathfrak{n} \mathfrak{n} \mathfrak{D} \in \mathfrak{r} \in \mathfrak{b}$.}

(S)rünipan, 2llaun, Bitriol, jebes 2 loth, Salmiac 3 lotb),

Gublimirtes suedfitlber,

Maftix; jedes 1 lotb,

2rab. Giummi 2 loth, şein 3 Mla

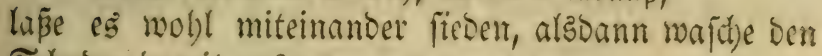
Sdjaben bamit aus.

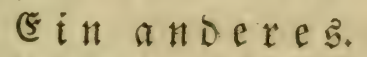

Gäubere den Subaben mit Saft von Sूolberblättern, Scholletraut uno fpişigen Saegerid).

\section{E $i \mathfrak{n} \mathfrak{n}$ De $\mathfrak{r} e \mathfrak{b}$.}

Siebme Flöljefraut, bas Männchen mit den rotben Blumen, prep̧e den Saft betaus uno ftreidje Denfelben in bie 2 sunien, oder ftreue Das solulver von biejem Siraut binein.

\section{E $\mathfrak{i n a n d e r e b . ~}$}

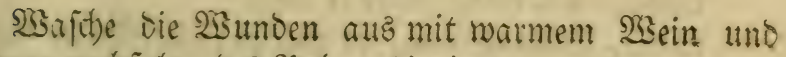
fireue nad)folgenoes Sुulver binein :

2) Raftix $\frac{1}{2}$ loth, 2(loes bepat. 1 loth,

\$oblimurzel 2 loth, Şeiraud),

(Sebranntea 2llaun,

(Siünipan, jeoes 1 loth,

ftope und mifde es untereinander.

(5in a ndereb.

Mache einen $\mathfrak{T} e i g$ mit Şonig und Salk, calcinire benjelben in einem Scafen, uno ftreue bas Bulver binein.

(sin andereb.

Silberglätt 4 Iöffelborl, Eifig $\frac{1}{4}$ Maa Rofenöl 2 loth, 
miface es untereinander, fiede es und reinige ben Sdja= ben bamit.

(5in andereb.

Das Sulver von groper Silettenturzel,

গacht fd)atten, jebes 3 loth,

mijake es untereinanoer uno ftreue es in ben Sdyaden.

Ein a noereb.

Scafelmurzel, Farrennurzel,

Şeil aller ŞSelt, Sanictel, jebes 2 loth,

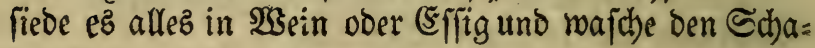
Den bamit aus.

Dab 21 fte Eapitel.

Fleifh wadhien zu machen.

Sorbeeren 2 loth, Scife 3 loth,

Eauge, Brannterwein, fo biel zu einer Salbe nö=

thig ift, zerflopfe eg wohl burcheinander uno fommiere ben Schaben bamit.

E i $\mathfrak{a}$ a

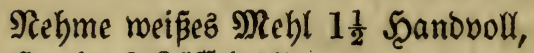

Sconig 6 \&öffelvoll,

Das $\mathfrak{W}$ sipe von 9 Eiern,

Effig, fo viel als nöthig zu ziner Salbe ift. mijche uno zerflopfe es mohl untereinander.

(5)

Siebe Sdnwarzmurzel in 2 Bein uno waide ben Sdha= ben-bamit, hernach lege bas Sraut bon ber Sdhwarz= wurzel barauf. 


\section{Ein andere}

Baumoll 4 loth, Sconig 3 loth,

פूed), Ierpentin, jedez 2 loth,

Maftix, SBeiraud), jedes $\frac{1}{2}$ loth,

mijt)e es untereinander über einem Soldenfeuer, uno nadbem es langfam Ealt genoorden ift, ftreidse es über Die $\mathfrak{2 B u n d e . ~}$

(5) in a n Dereb $\mathfrak{B}$.

Şeiraud), Drachenblus, Naftix,

Nurrben, jedes 1 lotb,

fope uno mifche es untereinander, uno wenn bu bies

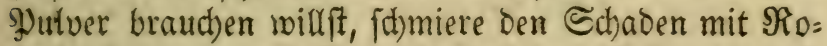
fenbonig vorber und ftreue bernad) bas Shulver barauf.

(E) $\mathfrak{i}$ andereb গুS.

Salafbe ben Sdyaben oft mit gefottenem S3ermuth)=

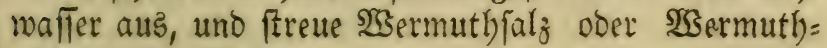

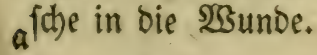

\section{Das 22fte Capitel.}

\section{Bon Den Feigwarzen.}

Die ₹reigmarzen find barte und fonwülichte Rufe voller Sdbruden, an (Seftalt Den ungefchmackten Fei= gen gleid, entfeben linten am untern $\Xi d$ enfel nach Der Rănge unter Dem Scaarmachz oder Der großen গRer= ven, fo fich an Dem Schenfel binten binab ftrectet, uno in bie Feflel eingepflanzet, ober audb, bismeilen an ben Geiten Dez (Seleichs, befonders zmijhen Den langen und Dicken Scaaren unten am $\mathfrak{z} u \tilde{\beta}$, die man bie §öthe zu nennen pflegt. 
Die Feigmarzen entfteben baber wenn bie Spferde oft uno viel mit ben F̌̈ßßen aneinander ftoßen, auf Eothi= gen falten uno naffen Reifen nidht an ben Füpen ge= reinigt merben, ober wenn man fie mit naffen Füken unabgerieben in Den Etällen fteben läpet, oder auz ei= ner gefalzenen Feudtigkeit ; diefelben erfobeinen weit bäufiger im 2 sinter als zu andern Sabrez̧eiten.

Die Feignarzen feben an oer Farbe afdengrau, lang, yart uno dick mie die Schwüblen, baben bismeilen eine rotbblaue (sefurbulfit um fit), oben auf ber Spice quer viele länglid)te Gchrunden und unter benjelben pt= liche Eleine nad) Der Iänge, am felben Sit ift alle F̌eud)= tigéeit verichmunoen, unten aber nächft an Der Şaut find fie aufgeidsunden.

Sie bängen aufferbalb Der Şaut, uno reiden nicht

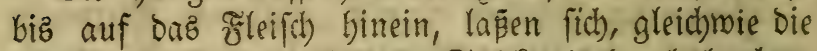
Sdłmüblen mit ben Scänden Gtüctweis berab brechen, uno bleibe bod) Der gröste I beil an Der Scaut, und ge= ben vor groper Brunf, Trocfenbeit uno @djärfe Det Feuchtigkeit, fo bie Saut mit (3)emalt aufgeft)runoen, Blut von fich.

Diefes Utebel ift jdiwer zu curiren.

Sindeflen menn fie nidft gar zu alt, fann man fid) nod) etwas unterfteblen, wiemshl eine lange Beit uno groper Fleis orazu geböret, Daß̧ man nemlich cine rechte

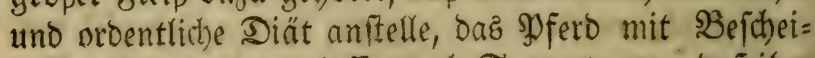
Denkeit fich bewegen lafle, autd) Sorge tragen, baş ifm

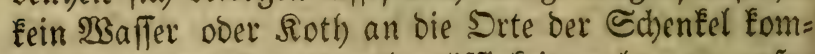
me uno Der hisigen Unrert)tmaffigfeit zu begegnen fu= djen.

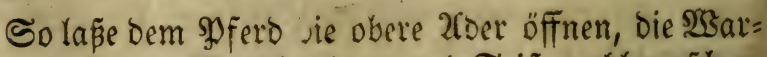
zen mit Lange, Menfd)enbain und Eeife mohl wajdyen, 
die Saare fauber binmeg fheeren und fomiere es mit Rach) folgendem :

(5uphorbium=Sel 1 Suintlein,

Sitriol-Spl 2 suintlein,

sranntewein, Geifewaffer, jedes 3 loth,

mijhe es untercinander und reibe es roobl bamit.

Ein andereb.

Şiringslack sin Theil,

Sd)weinefdmalz oder Scammelsunfd)litt 2 న beil mifche es untereinanter zu einer Salbe.

(5) in a noereb.

Rebme Sperment, vermifhe $e \mathfrak{s}$ mit Sffig zu einer Salbe.

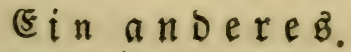

Mache aus Tauben= ober (Seismift mit SF[fig einen Ieig und fallage ę über.

\section{(E) in anderes.}

Refme (Srünipan 4 loth, Sconig 2 loth),

Effig fo viel genug ift,

vermifde eg zu einer Salbe.

\section{(5in anderes গIB.}

Brauche die Ëgnptifhe Salbe oder Felix 233 ürzen

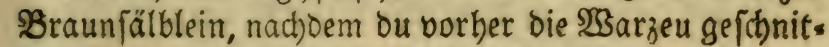
ten ooer cauterifirt baft. (ङs müfen aber nacboem ber Brand mit ভdomeer mieder gelöfdt morden, oie Sal= ben gebraudht meroen.

\section{(E) $\mathfrak{n} \mathfrak{a} \mathfrak{n} \mathfrak{D} \in \mathfrak{r} \in \mathfrak{B}$.}

Spaniiche Fliegen $\frac{1}{2}$ Suintlein,

Euphorbium $\frac{1}{2}$ Scrupel,

Sutter fo viel genug zu einem spflafter iff, mifdoe 
ez̉ untereinander uno lege es über, fo wiro ez şlajen ziehen, lā̄e ez zmei Iage Darauf liegen, bernad) lege nadbfolgendes $\mathfrak{p f l a f t e r}$ barauf :

20 Snoblaudbhäupter in ber 22 che balb gebraten, Schweinefdimalz 1 gofund,

\section{פुfeffer 1 loth,}

fope ez untereinanber zu einem פoflafter uno lege über, lāe es auth) zmei Tage barauf liegen, alebann wegnebmen, Den Schaben mit Menichenbarn wobl aubz= roajden, abtrocknen uno nachfolgenoe Salben braucten.

Euphorbium 1 Suintlein, Maftix 2 Suintlein, SSitriol 2 loth,

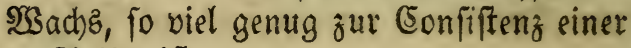
Salbe ift.

mif he es über einem linden Soblenfeuter untereinander.

ŞSenn fie beil find, bann fohmiere ben Sort oft mit Der Mixtur vom Edbeibewaffer und 23 egerichjaft, ber= nad) bie Scaut oft mit Şirich= ooer Scammels: Un nichlitt.

\section{E $\mathfrak{i}$ a $\mathfrak{n}$ ber $\mathfrak{e}$.}

Brenne ez und lege 2flte Sdhmeer barauf, lap̧e es vier Iage barauf liegen und alb einen Stano beilen.

Ein andereb.

Siede RitteripornEkraut und $\mathfrak{B}$ urzel in Effitg ober פsein uno follage es bem $\$$ Pfero warm über.

E in a n o e e $\mathfrak{B}_{\text {. }}$

Maftix 1 Suintlein, $\mathfrak{B S a c h}_{3}$,

Soermenig, Nachtichatten,

WSegerid), jebes 1 Scanovoll,

fitede es in $23 e i n$ uno fichlage es miteinander warm über.

(E) in andere

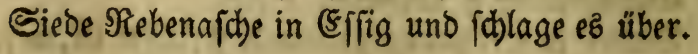


granzojen befommen. Da pflegt man biejelbe (S)e=

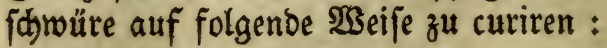

\section{Die (E) $\mathfrak{r}$.}

Fübre ben Sengft an einen Srt, no Stuten fino,

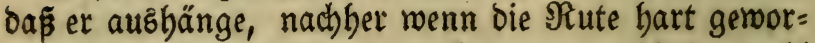
ben, fo wajke biefelbe mit nachfolgendem 2Kbfub wohl แนอ่:

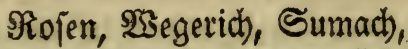

Delbaumlaub, jebes 2 Scănoeboll,

laße ez miteinander fieden uno majhe ben Sdaden ba= mit, bernach ftreue von nachfolgendem SPulver barauf :

Uloes 1 loth, Nichts,

Sucker, jedes 2 loth,

mijhe es untereinander zu einem zarten \$ुUlver.

Ein anderez Ctreupulver $2 \mathfrak{B}$.

Calcinirteg Sirichborn,

Calcinirte Scirichbeine, jedes gleich viel, untereinander gemifht uno barauf geftreuet.

\section{(a) $\mathfrak{i}$ a $\mathfrak{n} \mathfrak{D} \in \mathfrak{r} \in \mathfrak{b}$ TS.}

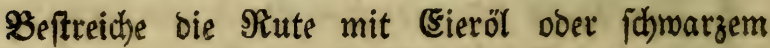

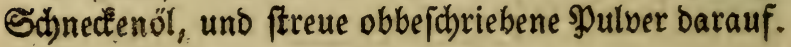

E $i \mathfrak{n} \mathfrak{a} \mathfrak{n} \dot{D} \in \mathfrak{r} \in \mathfrak{B}$.

Sebme Sdywertelwurzel, gepülbert uno hinein geffreuet.

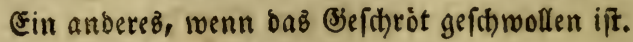

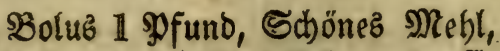

Zerpentin, jedes $\frac{1}{2}$ ⿰马丨 fund, 10 Eierwe

Branntetwein $\frac{1}{2}$ Maaß̃,

(5)ifig, fo viel genug ift zu einem Unftrich uno ftreidje bab sofero bamit an. 
neage einen Sdbramm baretn, bäbe bas (Sejhäft nobl bamit uno fdymiere eg mit nadffolgender Salbe.

Bleimeí̄, Baumöl, Bodéz:Lnichlitt,

Eierweiṕ, jebez fo viel vonnötben, mache barauz eine Salbe.

\section{Ein andere}

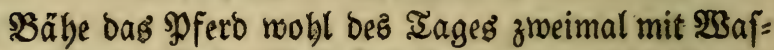
fer morunter Efffig, Salz uno Sreibe vermifcht ift, und

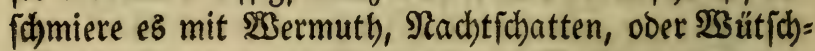
erlingsfaft, ober mit $\mathfrak{B l e i w e i \tilde { \beta }}$ mit $\mathfrak{B a f f e r}$ vermengt.

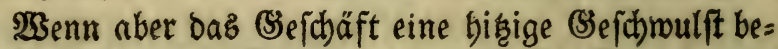
Eáme, foll man baffelbe mit warmem Maffer norunter Solbefe gemengt ift, mohl bäben uno mit ausgegoße= nem Rnabenbarn auf glühenden Riejelfteinen nobl bä= ben, ober mache ibm einen 2 nfftrich mit Bolub, Efifig, Drachenblut, Eierklar, fdönem Mtebl und Ieerpentin.

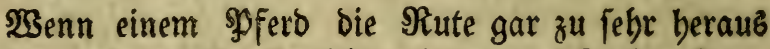
bångt, uno bapelbe fie nicht wieber zurücţzieben Eann,

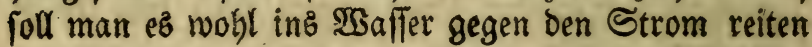
boer führen lafen, oder mit Salzwaffer oft begiefen.

Ein anberes, wenn ez nid)t gefithmollen ift.

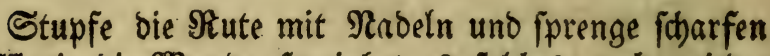
Efitig in bie Wunde, jo ziehet es polches auch mieber zastúdé, ober reibe ibm Brenneffel darauf.

Ein anderes.

STreibe 10 loth, Bleimei 6 loth,

Esfig, fo viel als nöthig iff,

mache eine Salbe baraus jobmiere bas \$pFero bamit un ftelle ez um ben Mittag biz über ben Baud) in flieffen. Des $23 a$ affer gegen ben Strom. 
Dferobsilligenei Budh.

633

\section{Ein a n o e $\mathfrak{e} \mathfrak{B}$.}

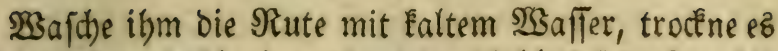
wieder $a b$ uno fadmiere es mieder, fold)es feçe fort bis bie (Sefdrwalft vergangen iff.

\section{(5 in a ndereb.}

WBenn aber ber Rangel aus Şike ber Nieten vom Springen getommen ift, fo ftellt man zwar bas Spferd auch ins Ealte $\mathfrak{B S a f f e r , ~ u n o ~ w a ̈ f d h t ~ i f m ~ D a n e b e n ~ d a s ~}$ (S)lied oft mit nachfolgenoen $\mathfrak{B S a}_{\text {Tern }}$ oder Säften.

SBegeridh, SSappelnfraut,

Nachtichatten, Nabelfraut,

Rörbelz̨raut, Blutfraut,

Şrusivurzel, milde Siranatenblütbe,

Şalläpfel,

fiede es in 2 Theil flieffendem $\mathfrak{B}$ affer und 1 Theil Effig

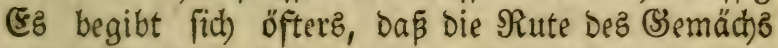
ben Seengften bart, ftarrid)t uno dicf miro und aljo fte: ben bleibt, biz man ifnen mieber $\Re$ ath fd)aft; und bies Uebel Eommt entweder aus allzu bifiger natürlicher $\mathfrak{B}_{e}=$ gierde zum Springen oder 2uffteigen, ober aus gar

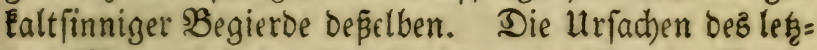
ten Nangels find, allzu feudte uno bide zebe Feud)= tigkeiten, weldbe bie bläftige (Seifter, fo die \&uftadern fammt Den boblen Rerven ber Rute ganz und gar er= füllen, in fich verfajt baben, und Dann Die unbermög=

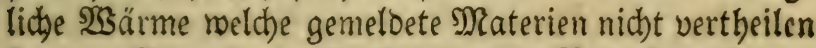
Eann. Die aber aus allzu bişiger SBrunft entifteben, Eommt Daber, menn man bie Foblen allju jung fprin= gen läpt, woourch) fie fid) bann burd) bie (sinbiloungen Der $\mathfrak{Z}_{\text {B }}$ lluft bes Springenz erinnern; oder wenn fonft bas spfero einer blutreichen bif̧igen feuchten Satur uns voller Samen ift. 


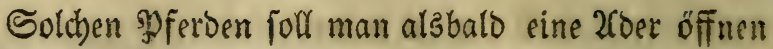
und bas (S)efdröt mobl mit Nachfolgendem bäben :

Reuldi)baum, (Eamillen,

Steinflee, $\mathfrak{Z}$ einrauten, Sholey,

fiebe alles robl in 2 sein, bábe es oft bamit uno binde eह auch über.

Man Eann Daz (Sefdröt audb mit nadyfolgender Salbe fdumieren :

Rofen-Sel 3 loth, Eamillen=sel 2 loth,

Saugimurzeljaft 10 lotb,

Gilberglätt,

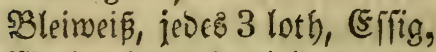

TSachs, jeoes fo viel vonnöthen,

mifbi alleg untereinander zu einer Salbe.

Das syfero for man an einen Eüblen, trockenen und ftillen sit fifllen.

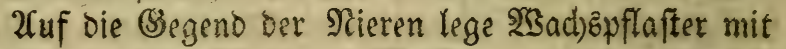

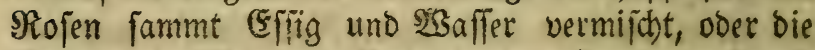
Srübe uns Säfte von Sact)tichatten, Scausిwurzel, mit Spium, Sandel mit Effifg bermifd)t.

Wenn einem $\$$ ferd der Same wiber feinen 2 Biflen entgeyt.

Diez fommt von groper SBegierde zu fteigen uno zu fpringen, ooer allzu viel Samens, ober mann bie Sn= frumente des Samens. (sefäpezes berlest find.

Man gibt ben Syferden nichts alz füblende Sadjen zu freflen, als : Eattich, Endivien, Eucumern, Schaft= beu, Serfte, entweder allein, ober mit Seanffaamen, Sautenfaamen, Neffelfaamen vermifht, Seirfenflump: lein, Serftenftrobe.

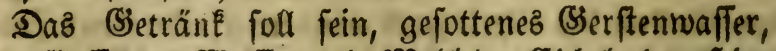

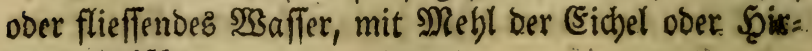
fen vermijabt. 
Ein anoeres Trineroffer.

Scausworzel, milde Difteln,

Eattiđblätter, Magโaamenblätter,

Rofenblätter, (Siranatäpfelrinoen,

(Salläpfel, Raucenjaamen,

Deumenten, Salcinirtes Scirfhborn,

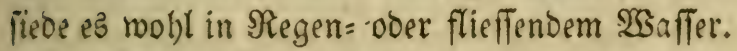

Ein andereş, wenn einem Scengit die Siute nid)t fethet, und er feime 厄tute befpringen fann.

Reipe die 3meige von nad)folgendem Scolz mit ber Sano binmeg, binde fie zujammen mit Rinoenbaft mie cinen Bejen, Eebre die Schoṕ überfich, uno die Strüm= pfe unterfich, und lape den Sengft bon oben barien barnen.

Die Şolg find Diefe.

Birfenbaum, Scolder, Spfriemenbolz,

Ein andereș, wenn fiil) Der Seengif am હd)wang bei ber Siute verunreiniget bat.

Saflafras 1 loth, Saffaparilla 3 loth,

Engelfüß 2 loth, פুoterfitienjaamen,

Terra figillata,

Setonien, jeoes 1 loth.

fieve es mohl in SBier uno fhütte ifm etlichemal biefen Irank auf einmal ein.

\section{Ein anoereğ গ্马.}

Scepar 2intimonium $1 \frac{1}{2}$ Squintlein,

gib ilym röchentlich bie Dofiz zmeimal zu freffen im Salz oder joniten.

Utno fdmiere Den Edbaben mit (5ier:SDel, ober mit Dem Sleum 2intimonium. 


\section{Das 24fte Capitel.}

\section{Son allerband siefdrütren.}

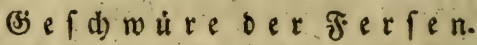

Diefe Eommen bismoilen nach Setrenfung her Füpe, wenn biefelben nicht techt fins gebeilet woroen, oder bon innerlidben (Sefchwüren Der Füßpe, und reiken al bann oben auf, wo bie Scüfe zu wachfen pflegen. Diefelbe fommen aud vom Sernageln ber spferde, ober menn bie פुferbe in etwas Scharfes getreten, ober fonft einen s)langel an einem Fup beẼmmen baben, woourd) bie Srone gefpalten und nachmals nidtet recht gebeilet miro.

Diefe (Siejdnoüre fino bös zu beilen.

23ajche ben Schaden bes Iages etlidjemal aus mit Menfichenbarn uno Salz ober mit Echollerautfaft un= tereinander gemifcht, ober ftreue baz şulber von SDfter= lucen binein.

\section{(E) in a noereb.}

- Siede die Sapperwurzeln in 5 ffig uno $\mathfrak{B e i n}$ und wafke ben Schaden oft bamit aus.

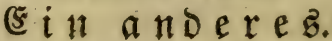

Rebme gepülverte Sappernnourzel und Erbjenmebl, mache mit Sconig ein Sু flafter barauz uno lege ę über.

\section{(s $i \mathfrak{n}$ a $n$ bere $\mathfrak{B}$}

aloes bepatica 1 loth,

Römifhen Sitriol 1 Suintlein,

mifche es untereinander und ftreue es oem 9 fero in ben

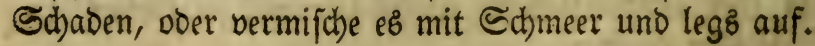

(5) $\mathrm{i}$ a $\mathfrak{n}$ bereb.

Sehme bas \$ुulber von Cdhnertel und Sppoponax mit Şonig vermifdst. 


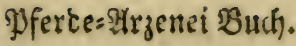

\section{Ein andereb $\mathfrak{X}$.}

Rebme Frelix : tifdoe Ealbe.

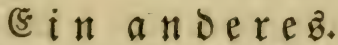

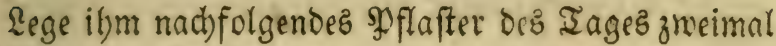
über:

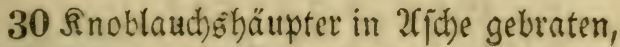

(Ge)topenen Sy. feffer 4 lotb,

Sd)weinefomalz 1 sुfund,

bermifd)e ę zu einem Sुflafter.

\section{(E) in andereb.}

(s)rümpan, 2flaun, jedes 2 lotb),

Ietpentin 6 loth,

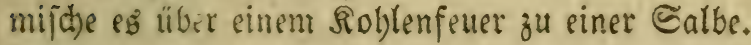

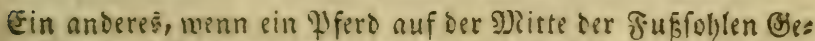

fithoure befoment, oder unten an ben fúfen wund roird.

Solde mü man öfinen uno bem (S)efhnür $\mathfrak{s}$ uft madben, wobl austwirken uno jdyneiben, mit einem Sdwamm in Effitg geweid)t wobl auswajden, hernach gepülverten Sojwefel barauf ftreuen, einen હdhwamm in (5) fitg tauchen uno mieder au?brücken, über ben @dyree fel legen und oben mit Sibindeln berbinden und ver= machen, Damit es nicht heraus falle; man mú fold)es bes Tazes zneimal thun.

\section{E in a n Dereb গIG.}

W3ajhe den Shaden wobl mit gefottenem $\mathfrak{B a f f e r}$ von ₹löbefraut aus, und menns trocfen gemorden ift, mit Ierpentin: Sel gemifit)ten Echrefeltualfam ober Baad)holderbolz = Sel, meldes im abnebmenoen Mono getoonnen rourde, binein. 


\section{(E) in andereb $\mathfrak{W}$.}

Eier $=$ Del 2 loth, Birkenbolz=:Del,

(s;d)bäumenbolz=:Del,

WSoch holderbolz: Sel, jedez 1 loth,

mifdbe es untereinander und beftreidbe den Gchaben ba= mit.

\section{(E) in andereb.}

Streue daz Spulver von (SSoldowizel und Sceionifd) 2̧undéraut binein.

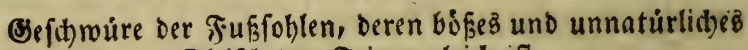
Fleif̣t) Den Feigen gleid) iff.

Sdneide bie Soblen und ben Scuf um den Sdjaben berum fo tief und weit auz oder vóllig hinmeg, bajizri= fiben Dem feigenförmigen Fleifc) unboer Fupfoblen ein

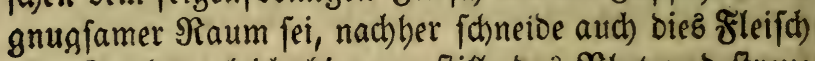
ben Soblen gleich hinneg, ftille bas slut und ftreue folde Spulber barüber, neldbe Das übrige negäken uno ber Fäule webren; folget das \$ulver:

Solonurzel 2 lotb,

Rotben Sitriol 1 lotb,

mifdoe es untereinander uno frreue

Soer brauche bie Egyptifche Salbe oder Felix 23 ür: Een Sraunfalbe, Saput mortuum Sitrioli, fo nidt abgefüpt ift.

Andere (sefdhwire an unterf(b)edithen Drten.

Brenne das (sefchmüre freuzmeife und binde gebäht Roggenbrod Darauf.

\section{Ein a noeres.}

Eibifdrourzel,

Fladhşaamen, jeoes gleid) viel,

roffte es in altem Sdbmeer oder Sdyroeinejdymaly uno binde eg auf. 


\section{Pferbe:2(rgenei $\mathfrak{B u d}$.}

639

\section{E in andereb.}

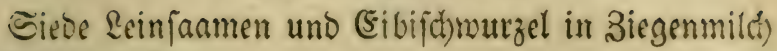
uno lege es über.

sin andereb.

Siede 2 frodill in $\mathfrak{W e i n b}$ efe uno lege es auf.

Ein andereb.

Sidye Silettentourgl und Siaut in Shmeet und le: ge ę auf.

(e) in andereb.

Salz, Saaumöl oder Reinol,

Senig, jeses fo viel als nöthig ift, fiede e's unteteinander und lege es über.

(F) $i \mathfrak{n}$ a $n$ D e reb.

Brate Bmicfeln uno lege fie marm Darauf.

(5) in andexes.

Bittel $\frac{1}{4}$ Pfund Dialthea 8 loth),

Terpentinãl "2 lotb);

mijche êे untereinander zu pinet Salbe und fumiere Das (Sefdröt marm Damit.

Ein andereb.

5autwurzel, Raumol, Efitg,

mifude es untereinanoer uno ftreide es roarm über.

Ein andereb.

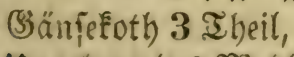

Ungeteuteltes M(e)l 1 Ibeil,

mifche uno fiede pes mit (sinig mohl untercimandel uno lege es marm über.

(5) in a n D e re .

Streue blaue Sdhmettelnutzel bariuber, fo brecthen bie (sientanuzre bald auf. 


\section{Pferbes:2rgenei $\mathfrak{B u}$}

\section{Ein andereb.}

2umerifanijchèn $\mathfrak{B o l u s}$,

3miebeljaft, jedes 4 loth,

attichmeer $\frac{1}{4}$ SP fund

fiede es wohl untereinander und follage es bem \$ू) ferd über, wenn ez zeitig ift fo öffne ez mit einem S̊nftru= ment.

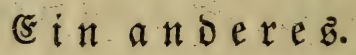

Eauterifire das Sूferd abmärts, bamit ber (5iter aus= laufen Eönne; thue Den erften Iag beipen Schnefel barein, bernach Eiertlar, uno allemal binde warm ge= bäbetes Sirod Darauf, mechsle alle Tage um ben an= Dern bamit um, biz ou fiebeft, Daß̧ ez fich zum SDeilen fdicke, hernach folmiere es mit nadjfolgender Salbe:

Rindsmark, Sirichen=Lunichlitt,

Rinosfchmalz, \&or=SDel,

Şunosfchmalz, ât thchmeer, jebez gleidyviel, mifhe ez untereinander zut einer Salbe.

c

\section{Das 25fte Capitel.}

\section{Son Den Siefdrutlften insgemein.}

(s) ef d) wolfenes ş a $u$ pt.

Siede Nachtichattenfraut und 2 grimonia in $\mathscr{S B}_{\mathrm{B}}$ in, bäbe bas Saupt bamit, foutte auch Şein auf glühen= de Riejelfteine und dämpfe das \$pfero.

Ein andereb.

Qiekiföôtel 2 Theil,

Brenneffel 1 I beil,

fiebe eริ zujammen in $\mathfrak{W}$ ein uno bähe bas Scaupt bamit. 


\section{Mferbe=2lrzenei Budh.}

(Befd)wúllfte jwifchen Scaut uno Fleifd) an einigen Sorten am

$$
\text { ganjen \&eib. }
$$

Durch biefe foll man, wofern ez an Eeinem Srt, wo Spannadern, Sennen oder Nerven find, ein Scaarfeil ziehen, oder Die Ehriftrourgel ftecten.

\section{(5 i n a n e reb.}

Sege Darüber Şauznourzel,

Siad)tijuatten, jebez 2 Sänocuoll,

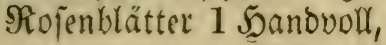

mifut)e es mit marmer Schmeer uno lege ç über.

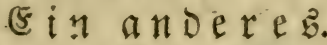

:

Scabermebl, jeoes 3 Şändeboll,

9 Eierbotter, $\sigma_{d}$ weinejd)malz $1 \frac{1}{2}$ Sfiund, mifhe es untereinanoer und fallage ez über.

E in a nderea:

Frif(t) jerla lenes @ibreinefámalz 3 Sुfund,

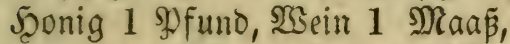

lape afles untereinander über einer (Şlut zergeben uno fd)lage ę über.

\section{(5) in a n Dereb.}

Ungelöjhten Ralk, Salz,

Fid)tenfoblen, ftope es untereinander und binde

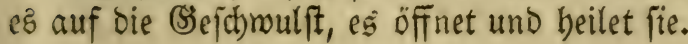

$$
\text { (E) in an oere } \text {. }
$$

2(merifanifd)en Boluz, 5 (Eiermeiz,

Baum= Del, Efifig,

rübre allez zu einer Salbe, mache es trarm und id)lage ç über,

Wenn ein Pferb cinen gefit)wollenen Şals hat.

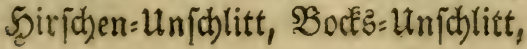


2attifimeer, jebes $\frac{1}{2}$ spfund,

Sodf'bornfaumen 8 loth,

\&einfaamen $\frac{1}{2}$ Sfund,

Sconig, fo viel vonnöthen,

mijace es über einem Feuer untereinander uno binde es warm über die (sefchnoulft.

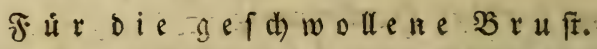

Madbe einen Teig mit Nad)tichattenErautfaft unt \&eim uno fichlage es über.

Ein anderéb.

SBod $z=$ un idlitt,

2lte Shbinberger Schmeer, jedes 1 SD funo,

Sävenbaum 10 loth, Salz 2 Şändevoll,

mifche es untereinander über einer (S)lut und fomiere es rarm an.

Einandereb.

Stecte ihm die Shriftrourzel vornen an bie SBruft.

(5in andereb.

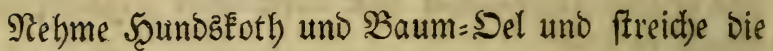
(S)eichroulft Damit.

(E) in andereb.

Cauterifirs uno laßje es rinnen, beile es bernach wie man einen Brand beilet.

Fúr dis (Befinmulft unter bem ङattel.

Sfenleim, Salz 1 Scanoboll,

sifig, fo viel vonnöthen,

laße ez auf einer (S)lut mobl fieden, mache einen Bret bavon uno ftreiche bas \$ffero bamit an über bie (Se: fhroulft, fo bald es hart miro, fo fdblage ein frifdes auf.

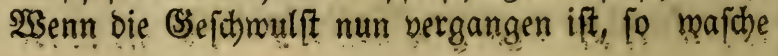




\section{Pferbes?(rzenei Buá,}

fie mit warmer \&auge mieder ab, wenn es fich aber zu cinem (Sefthmür wollte zieben, 10 mad)e mit Sconig uno Staubmebl ein Spflafter uno lege es liber, fo ziebet $e$ z fith) zujammen.

\section{(5in anderes.}

Siede Samillenblumen uno Rojenfuchen mit Effig,

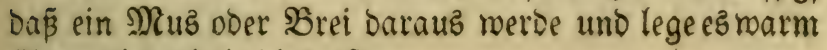
über, rieberbole riez oft.

\section{Ein anderes.}

Branntemein, Efîig Eievklar,

(Gebrannten Leim aus tem Bactofen,

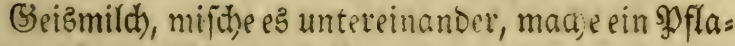
feer Daraus uno inlage es tiber.

\section{(5)}

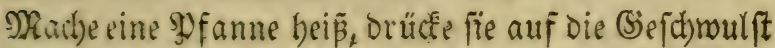
fo ftark bu fannft, mafche bernad) mit faltem Salzmaí fer bie (Sefdwwulft, lege den Sattel wieder barauf und gürte ibn feft zu, laße es fteben bis es trodfen wiro, als= bann thue ben હattel berab und waiche es abermals.

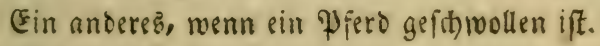

Sühefoth), Salz,

Rojenblätter, marbe eimen $\mathfrak{B}$ rei daraus uno jd)la= ge es über, wenn man fpifigen 2 segeridjaft Dazu nimmt, fo iffe befto berier.

\section{(E) i n a Deres.sig.}

Rebme einen Schnitt von idwarzem \$rob, fohneide

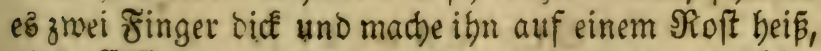

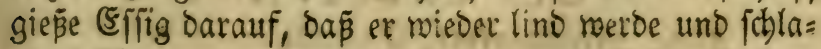
ge eş über. 


\section{Ei $\mathfrak{n} \mathfrak{a} \mathfrak{n}$ bereb $\mathfrak{X}$.}

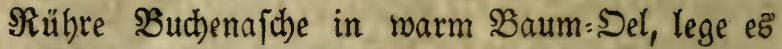

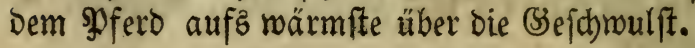

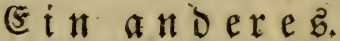

Siede Steimpfeffer in 2 sein und binde es bem \$gfero über शad)t auf bie (Sejdimulft.

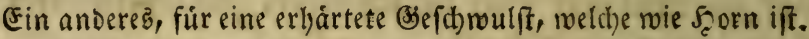

Bähe fie ein paar Iage, alle Iage biermal mit $\mathfrak{3 e}=$ fottenem (Eppid)= Doer Niieswurzelwarfer, bernach) lege folgendes splafter barüber :

\section{Utttichblätter,}

Scolderblätter, jebes gleich viel,

röfte fie in Sithmeinejchmalz uno lege es warn über.

SDer mache ein \$flafter vom Rraut şülnnerdarm,

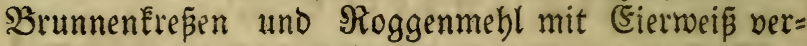

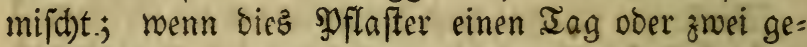
braudit morben, bann brenne ez, lege cin einfach leine= nez Tuch barauf uno lape beipen Specte barauf tropfen, Daßs ber Spect burch bas Iuth binein bringe ; Gernad) lege mieder ein leinenes Tuch Darn̈ber, uno laß̧e bas

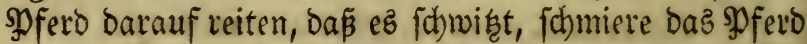
oft mit warmem zerlasenen Spect, biz daz Şorn fid) fetält, alzbann ziebe es beraus, lege barnad) ein \$ुfla= fter von rotben હdynecken barüber, fo lang biš es beis len will, alsbann lege Şanfwert barein, und beile es

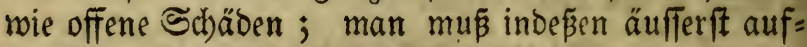

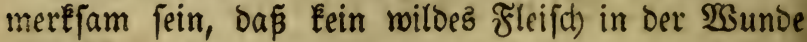
aufwachfe.

Ein anderes. Xfiche, Menichentoth, Baumöl, temperirz untereinander und id)lage es marm äber. 


\section{Ei}

(s)ummi (5lemi 2 lotb),

Iannenped) $1 \frac{1}{2}$ गु) fund, SBeiraud),

Drachenblut, jebes 1 loth,

(5ampier in Rojenul zermeben $\frac{1}{2}$ loth),

Salz, Tetpentin, jeoces $\frac{1}{2}$ \$ू funo,

mifide es untereinander ju einem Soflafter, fdepere bie Sarate binweg uno lege pe über.

\section{E in a nDereb.}

Rege ifm einen frifchen $\mathfrak{B}$ a fen barüber ein paar $\mathfrak{T} a=$

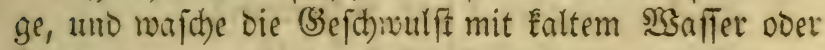
Rauge.

\section{(5) in anderes.}

Rege ilm bie Srofamen von Edyarzbroo mit (si= fig vermifdt barüber.

(5) i $n$ anderez.

2Rę̧e Dergament in frifó)em Brunnentwaller uno le= geez über.

(5) in in o erez.

Bolus, (Siermeiz, Baaumöl, Eilig, zerlā̄en 2eltichmeer,

mache es untereinande: zu einer Salbe, fidmiere biefel= be loarm auf ein Iud) uno binde es bem Sुfero itber, lege feimen Sattel barauf und lafpe ę teiten bis ez $\mathrm{er}=$ marmt, Daz treibt die (s)efdrwulft in die (Enge und zeiti= get fie, bie foll man offnen uno beilen wie alle alte ऽchäben, und 2ldhtung auf bas faule Fleifh) geben.

\section{Ei inanderes.}

Rehme rothez Flöhetraut, lege es über ben @ibaben uno la lie es ermärmen oder über Racht barauf liegen, 
Gernad) vergrabe es in ben Mift, und wajd) bie 23 un= be tăglidh mit warmem $23 e i n$ aub, worin Neffel jaamen gejotten worben.

Ein anderez.

Scolderblätter, ipişigen $\mathfrak{B S e g e r i d}_{\text {, }}$

eines fo riel als bas andere, ftope es unterein: ander, lege es über uno binde ein leinenes I Iuch barauf.

E i n a n berez.

פBilbe Sdbeinefdmeer, andertbalb \$gfund,

Seiridhen=unichlitt $\frac{1}{4}$ Sofund,

Eierootterpulver 1 lotb, 9 (siermei龵,

şulver von Sholderbeeren 2 loth,

mijhbe ez zu einer Salbe und fohlage es über.

Ein anbereb, wenn ein Pfero ein gefthmollenes sernie ourd) eis nen @idlag ober Fall, oder von einem Fluş befáme.

Flöhefraut, wilben $\mathfrak{2}$ ttich),

fiebe es in $\mathfrak{B}$ affer, bäbe ben Sibenfel bamit uno fidla= ge ez warm über bas §nie.

Ein a noereb.

Sd)miere bas \$pferb wobl mit Sieröt.

Für bie gefthmollene Shenfel.

Mache einen $\mathfrak{T}$ eig von Rübetoth uno (s.fitg uno fhlage ez bem gfero über.

Ein anoerez.

(Srünipan, Sdbwefel, jebes 3 loth,

Rein-Del 1 şfuno,

untereinander gemijht und bas gpfero damit gefd)miert.

\section{Ein a n ore}

Rauten, WSüllfEraut, Şaußnurzel,

WSolfąraut, Soltoerblätter, 
fope alles gufammen, firde es in zerlapener Butter uno EIitg uno fid)lage es über.

(E) $\mathfrak{i}$ a $n d \mathfrak{i} \in \mathbb{E}$.

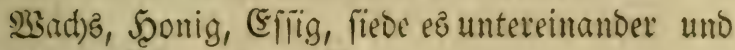
binbe es Dem Pfero warm über.

(5) in a n Derez.

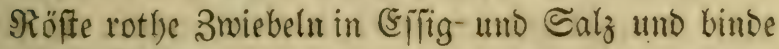
eहै rarm über.

(5) in anderez.

Eauorteig 2 Sुfund,

¿einöl $\frac{1}{2}$ \$funo, Sconig,

siitg, ङalz, jeoes 8 lotb),

mad)e ein Pfflufter Daraus uno fdlage es Dem Syferd über ben Sd)aden.

Ein a no ere

Siebe Iannzapfen in einem Seffel uno bäbe das Pfets oft Damit.

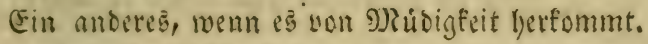

Soluz oder Sfenleim,

$\Re$ un, einez fo viel als das andere,

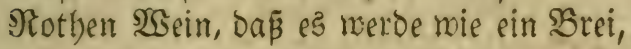
mijid)e es untereinander, lape es fieoen und ftreid)e eร Dem झुfero warm um bie Seine thue es etlidemal.

$\mathfrak{B a f d j e}$ ifm hernach bie Beine mit ftarłer \&auge ab, uno wenn fie wieder troden find, fo reibe es nobl mit jerlap̃ener SButter uno Saumöl untereinander.

(5iefpe ifm rarme Sameer in bie Säfe uno binbe Spferbemift Darauf, bas ziebet Die Mribigkeit beraus uno vertreibt die S'efhnulft.

\section{(5-in a $\mathfrak{n}$ Dere $\mathfrak{x}$.}

Mangoltạblätter, Şausmurzẹel, 
Şanffaamen, jebes gleid) viel, ftope es untereinander in Efffig, fiede es und binde es bernach rarm über; ober fiede saubentoth in 5 fifg und binde es über.

(E) $\mathfrak{n}$ a $\mathfrak{n}$ - e $\mathfrak{e} \mathfrak{e}$.

Rein: Sol 3 ⿰מfuno, fpanifbe fliegen 1 loth,

fiebe es nohl untereinander, bernach zerreibe es und fdymiete bas spferd an bem Shenfel mohl, fo miro ber Schenfel, menn er etlidbemal bamit geidhmieret morben, offen merden und gelbez $\mathfrak{W a}$ affer beraus laufen, bernad) Rebme Reinberger Schmeer.

Rein=:Del, Waachs, Sconig, jeoes $\frac{1}{2}$ Sfuno, mijche es untereinanber über einem ふohlenfeuter uno fd)miers bamit, wenns Ealt geworben ift, foldhes ftart î́m mädotig bas (seäber.

\section{Ein andereb.}

Nebme weipe Tannentinden jammt ben jungen (S)e.

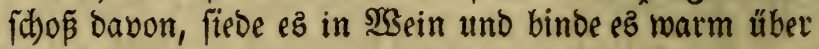
bie Seine.

\section{Cin anderes.}

Frifabe Butter, Baum=: Doll,

Sobnenmebl, 2altidhmeer,

mijhe es untereinander zu einer Salbe und falbe bie Beine oamit.

Ein andereş, vom langen Etehen ober Fieiten.

Shöllkraut, Runigundiskraut,

NBermuth, Meifternurzel,

Ilettenmurzel, 2llantwurzel, jebes gleid) viel,

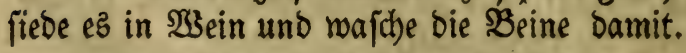

Ein anbereż, von großer 2 crbeit.

Sier ober Iropfwein, Butter, 


\section{Pferbe=2(rzenei $\mathfrak{b u d}$.}

\section{Das 26fte Capitel.}

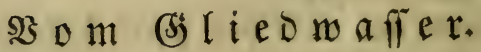

Diefer 3ufall ift gar gefäbrlich, wenn bei einet

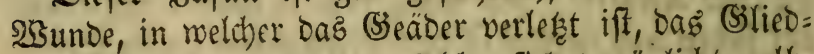
waffer anfängt zu fliesen, fold)es ftebet grünlicht, gelb: lid)t, aud weī̄ ; Denn es folget fehr gerne, baß̄ Das (3)lied Darauf anfängt zu fobminden, ober gar labm zu merben, da bat es bann wobl vomöthen, Daj man ba= iauf 2uffebens babe, foldses zu fellen, Dod) foll man

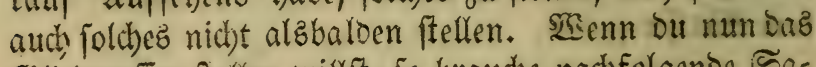
Ssliebraffer fieflen willft, fo braude nad)folgende $S_{a}=$ (b)en :

(Salcinirte souzälone 3 loth,

Schieppulver $1 \frac{1}{2}$ loth,

SBleimeis 1 loth,

Sierflar, to viel genug zu einer Salbe iff, mifbe es untereinanber uno lege ein soflafter Darauf uno jolage daz (Sanze über die $\mathfrak{W}$ unde.

\section{( in andereb.}

Siede ScanfmerE und Neffeln miteinander in $\mathfrak{B a f =}$ fer uno fohlage es über.

\section{Ein andereb.}

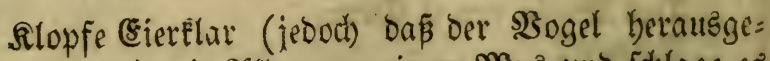
nommen fei) mit 2(llaun zu einem $\mathfrak{N u s}$ und fchlage über.

\section{E in andereb.}

Stope (sibifachnurzel flein, thue Reinfaamen balun= ter, fiede es mit $\mathscr{2}$ affer nohl und idblage es miteinan= ber über. 


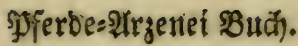

\section{E in a n D e reb.}

Rege pulverifirte Deilchentourzel uno Rettich barauf.

(E) $\mathfrak{n}$ a $\mathfrak{n} \mathfrak{D} \in \mathfrak{r} \in \mathfrak{b}$.

Rege Den Moof von einem Todtentopf barauf.

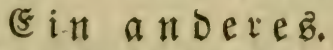

Rege calcinirte Scirfdbeine Darüber.

Ei $\mathfrak{n}$ a n Dereb.

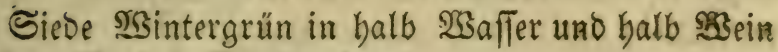
uno wajd)e den @djaden damit.

Ein a noereb.

Siede 2 Sintergrün in balb 2 Saffer und balb 2 Bein

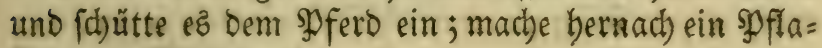
fter von $2 \mathfrak{B i n t e r g r u ̈ n . ~}$

\section{(5) in a nderez.}

Stope Srebsaugen und Eierklar untereinander uno lege

Ein andere in.

(Sepulloertes $\mathfrak{S}$ sad) yolderbolz, Sdwefel, 2allaun, Slettennurzel, jeors gleidoviel, binein geftreut.

E $i \mathfrak{n} \mathfrak{a} \mathfrak{D} \in \mathfrak{r} \in \mathfrak{b}$.

(5) oörte und gepülverte Şagenbutten binein ge: freuet.

\section{Ein andereb.}

Stope eimen lebenoigen Srebs und $\frac{1}{2}$ Suintleit Roggenförner Darauf.

\section{Ein a $\mathfrak{n} \mathfrak{D} \in \mathfrak{r} \mathfrak{e}$.}

Säufoth, von denen die (S) Bilfenjaamen, \&einjaamen, 
fiebe biefe Stücke wobl zujammen mit Siaffer, mifhe Sel barunter uno lege ez über.

(5in andereb.

Galcinirtes Şirjhborn ober calcinirte Scundsbeine barüber gelegt.

Ein anderez.

Sauerteig, Bierbefe, Saffran,

mifche es untereinander uno lege es Soflaftermeiz über, verbinde eg bis an ben britten Tag.

E i $\mathfrak{a}$ n $b$ e re

Roggenmebl, Rakentotb,

2Bseipen Şundztoth,

madbe es mit Efffig zu einem Pflafter uno lege ez über.

(5) $i \mathfrak{n}$ a $\mathfrak{n}$ ber?:

3erftope Soldermark mit Baum= Del, lege es über, ober ftreue Seitlofentwurzel batein.

(5) $i$ a $a$ nore

(Salläpfel, Dürres (sichenmoṓ,

Lorkeeren, jeocs gleich viel,

ftope ez zu Spulver uno lege ez über den. Schaden.

Ein a noerez.

Ealcinirte Eierjchaalen, moraus die Şüfner ge= fdhlüpft find 3 loth,

Ulaun 1 lothy,

mij d)e ez untereinander zu einem Sুulver uud nachoem ou ben Schaben mit $\mathfrak{S B}_{\text {ein }}$ ausigemajd)en baft, fo fäe es Darauf uno lege Scanfwerg über.

Ein a noeres

Weirauth, פ्Atyrtben,

פ्रlaftix, jebez gleich viel, 


\section{Pferbe=2(rzenei Bud).}

ftope ps untereinander und fäe es in die $\mathfrak{W}$ unde, lege

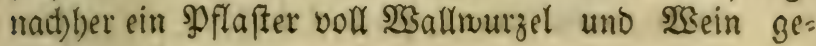
mad)t barüber.

(5) in a n bere. $\mathfrak{B}$.

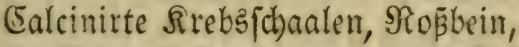

Sirfibbeine, Scundabeine jedes 2 loth,

2laun 1 loth, Serftenmebl 6 loth,

Eierwein, wovon Der 230 gel genommen fo viel genug iff,

mache es zu sinem Sूulver und ffreid)e eह über.

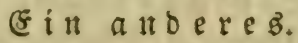

Die aetbe Rinde vom Sollunder,

Şaużnurzel, Süheḱoth,

âtichmeer,

mifthe es untereinander und lege es über ben Schaden.

(E) it a nt be res.

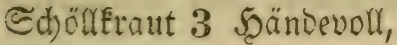

2flaum, 2 loth, Eifitg, fo viel genug ift,

temperirs untereinanoer of einen $\mathfrak{g}$ flafter.

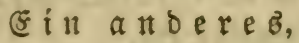

Simm die rberften (sipfel von Brombeerfauben, fiebe fie robl in Mild), ftope fie bernady, fd)lage alfo marm auf einem Safenbalg über Den Schaben.

(5) in an bere $\mathfrak{M}$.

Streid)e $\mathfrak{S}$ cinbefe auf ein wollenes Iud) und binde es über.

\section{(5) ก ก ก เ}

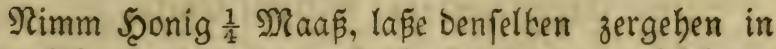
einet Spfanne über einem Soblenfeuer, thue nachfolgen= De Stücle eins ums andere Darein, rübre es nohl um, fo miro eine Salbe Darauz, man mus aber ben Sconig nicht fiebert lapen. 
Reirauch Naftix, Sirünipan, Gebrannten 2Alaun, jedes 1 loth,

E $\mathfrak{i} \mathfrak{n} \mathfrak{a} \mathfrak{n} \mathfrak{b} \mathfrak{x} \in \mathfrak{B}$ :

Nimm F̌elix Würęen Braunịalbe.

E $f$ a noeres $\mathfrak{T}$.

- Calcinirte Mufdeln, Die im $\mathfrak{2}$ affer liegen,

Shbeinsbeine, Wirichbeine,

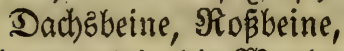

gepülvert uno in bie 2 Sunde geffreuet.

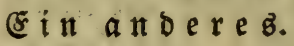

Stope Eiterneffelwurzel, fiebe fie in Effig und lege es über Den Schaden.

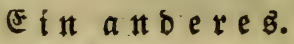

Nimm calcinirte $\mathfrak{S}$ üllÊrautwurzel, gepülbert uno in Den Schaben geftreuet, uno wenn das (s)liebmaffer ge= fanden, fo ftreue bas \$ulver von Eyrenpreís in bie :Sunde.

Ein a n bereb.

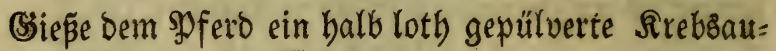
gen in Eyrenpreiß̄mafler ein.

(ein anderes.

Röpte Spect in \$Butter uno lege es auf die 203 unbe. (E) in a nderes $\mathfrak{B}$.

Brenne einen alten Filz zu Şulver, f́treue ę binein uno gib ifm Diffelmurzel zu freffen.

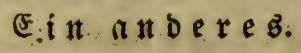

Streue Eaput mortuum Sitrioli binein.

$$
\text { E } \mathfrak{i} \mathfrak{n} \text { anderez. }
$$

Stope Brumnentreßpen, nebme bernach Roggenmebl uno. Effig, fiebe es in einer Spanne uno lege eb marm. über. 


\section{Pferbe:itrgenet Bttci.}

Tobtenbeine gepullvert und eingeitreut ift auch feht gut.

\section{(E) in andereb 2 .}

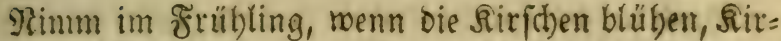
f(t)enfmöpfe, wenn fie im 2(ufbrect)en find, 10 ober 12 5̋änoevoll,

Xlaun $\frac{1}{4}$ Pfuno, Salz $\frac{1}{2}$ Maá,

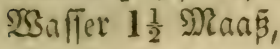

thue es zufammen in einen neuen verglafurten Safen, verflebe Denfelben wobl, Daßj Der Dampf nicht herau gebe, uno laßje denfelben ofngefäbr zum halben Theil einjieden, alsoann peibe die Srühe oavon, uno bebe es in einem (S)las auf und bebalte es zum (Sebrauch; menn ou bavon brauchen roillft, fo fprife er in bie F̧unde und ftede cinen פleipel von Scanfwer mit 2Baller genest barauf in bie 23 unden.

\section{Dag 27ftc Eapitel.}

\section{જ̉on Den (S)allen inşgemein.}

Die S3allen Der Pfferdefind Dreierlei, aber Eeine (Stal= len in Der Reber, fondern es find bie erften 2 2rtert garte und meidge SEculen, mie bie Fifd)blafen, in (S3ro"=

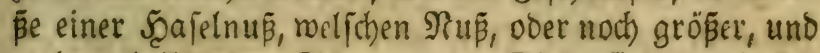
mebrentheils obne Sdymerzen. Diefe fino zreierlei, die bläftige, in weld)en nid)ts als W3ino uno Blaft iff, uno die Flö̈gallen, meldt)e vollet böfen Feuchtigkeit ftecten.

Die windige (şallen entfteben aus şläften ober

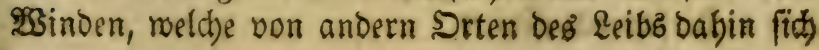


fenter, bie Flop̈gallen aber fino erblich vo t Befdaalern und Stuten, fooann entiteben fie auch von Flüllen, Sd)lägen, naßjen Ställen, uno nicht Sauberbaltung ber Sdjenfel, harter uno jonerer $\mathfrak{2}$ rbeit, aud vom aflzu

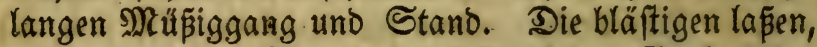
wenn man einen Finger einorüct; Eeine (Srube oder Mablzeichen zurüd, hingegen bie Flo logallen laffen fid) obne allen Fiderftand binein. Siebe Figur No. 28.

Die britte 24rt ber Ballen nennt man Steingallen, Rrappenmäler oder Iobtenblüthe, find in Den Scufen zu finden, von weldhen lektern audh zulekt gehandelt werben foll.

\section{D) $\mathfrak{i}$ e c $\mathfrak{u}$.}

Folgt nun bie Cur bex erften, fo vom 2 sind und şläften gefüllt find, aus meldhen boci) zuleg̨t aud) Flopgallen werden. Diefe foll man mohl mit einer Brübe von Salpeter, Eiftg, Salz uno \&auge unter= einander gejotten, oft und roarm bähen, ober einen

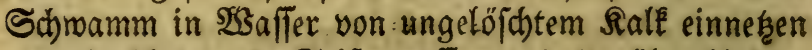
ober in jhnarzes Seifenwaffer uno barüber binden, ober famieret fie mit Sel von Euphorbium, ober mit \$) feffer $=$ SDel, nachoem bie Saare vorber binmeg geicho= ren fino.

Ein a noered.

Rege ein Sfflafter von Rorbeeren uno $\mathfrak{B a c h s}$ unter=

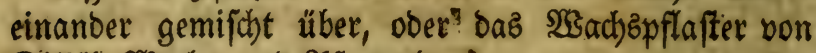
Dillöl, $\mathfrak{X}$ ach

\section{Ein anderes গ্জ.}

Ssummi Slemi 2 loth,

Drachenblut 1 loth,

Sirjonen=Lnjwlitt 


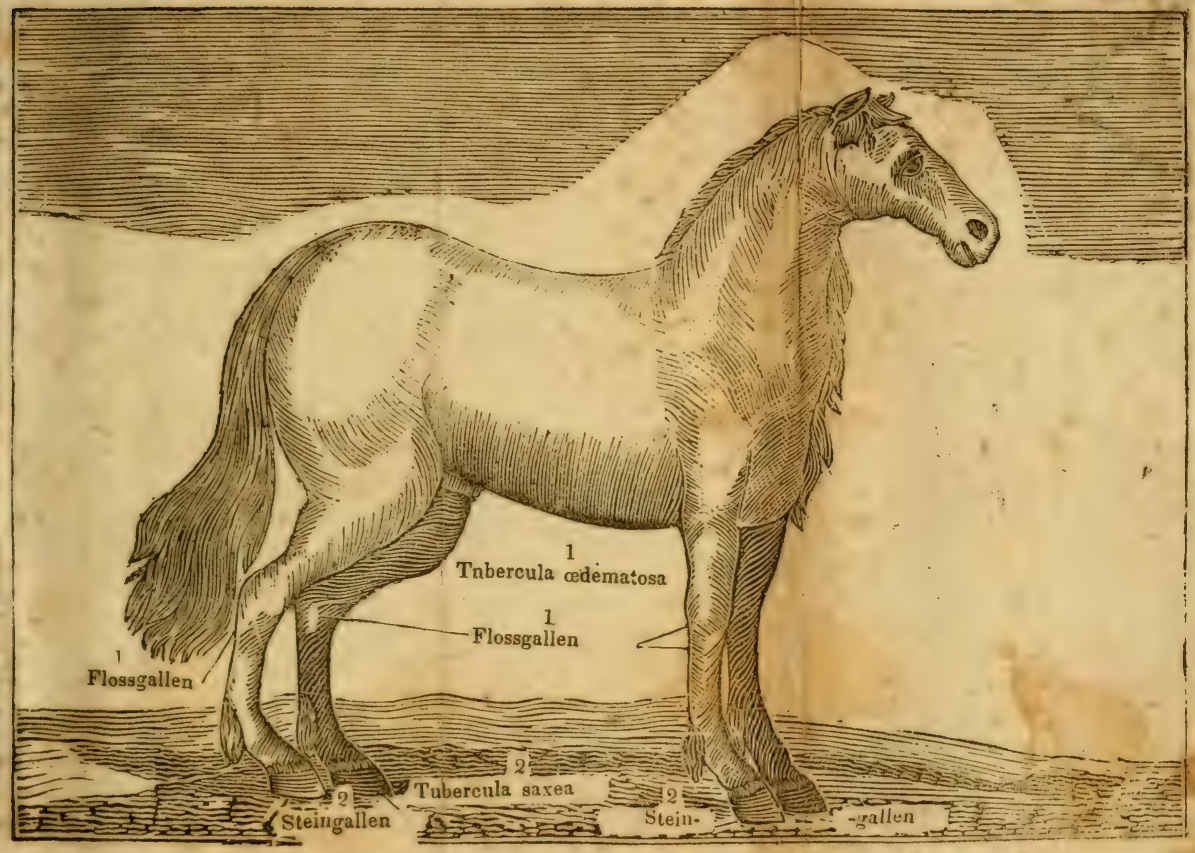





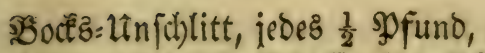

Scurz 1 Pfund, Ediffped $\frac{1}{4}$ Sfund,

İplpentin $\frac{1}{2}$ Sूfund,

mijd)e alles zu einem \$flafter uno lege es über.

SSenn man bies gebraucht, und bie (S)allen noch nid)t: folvitt baben, foll man fie in allem, wie bie Flopgal= len, Deten Cur jegt folgt, curiren.

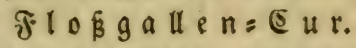

Sur Serwirkung Der Sur foll man Die Slutader, mel= d)e auf Derfelben Eeiten binab fteigt, cauterifiren, uno mie eimen SBrand mit Brandjalben beilen, Gernach cau= terifite bie (Siallen aud), und beile e's als einen Brano.

\section{(5 in anderés $\mathfrak{X}$.}

ख3enn ez cauterifirt ift und ber Brano gelöfdt, fo

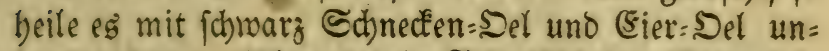

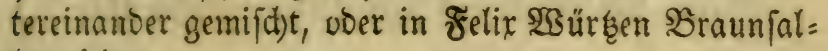
be roieder zu.

(E)

(Sebranntes Rupfer 1 ⿰马 fund,

Senft, Salz, jebez 1 Şandooll,

Effig, fo viel alz nöthig iff,

bermijhe ez mobl untereinanoer zu einer Salbe uno fhmiere die Ballen bamit, mieberbole bieg eine Beitlang fo wiro es fid) öffnen, und beile cs nadb ber wie andere Sdäben.

(E) in a no ere.z.

2uripigment 1 loth,

Edowefel 2 loth, Iorberen 1 spfuno,

lape es miteinander zu einer Salbe fieden.

Ein an bereb.

Sdeere ben Drt Ginneg, und pide Denfelben volu. 
fleiner \&ödlein, reibe es mohl mit Salz, bes nachfol= genden Tags lege nachfolgendes \$ुflafter barüber :

Spanijhe Fliegen 1 loth),

Lor. Sel $1 \frac{1}{2}$ loth,

(Suphorhium $=$ Del $\frac{1}{2}$ loth),

mijhe es untereinander und lege ę Sुflaftermeis über, laßje 3 Iag liegen, hernach nimms berab und fomiere den Sort Des నagez mit Butter, biz heraus fällut, und reibg mit Salzraffer, ober bäbe ben Srt, uno legz auth) Darüber mit Steinflee, SBergmünze, \&oröl uno (3)ranatäpfelrinden, (5ibijch und $\mathfrak{S}$ sein gefotten.

Ein a n beres.

Brenne ben Drt uno lege daz soflafter von (sypref= fen barauf.

Ein andered.

Brenne Das Sुferd und lege $2(t) j d$ meer barüber.

(5) in $\mathfrak{a}$ ก

Deffne bie (Sallen, uno lege nachfolgenoes soflafter Darüber :

Ungelöfchten Salk, Bierbefe,

Branntemein,

mijhe es untereinander zu einem spflafte.

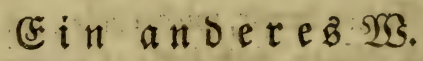

Seffne die Sallen uno lege die Straß̄burger Salbe Darüber, oder bie (syyptifole Salbe.

\section{(E) in andereb $\mathfrak{n}$.}

Brenne die Blutabern über ber (Sallen, bernach) menns gebeilt ift, fo zieke mit einer gropen sabel ein 5aarieil bon 3 Ro fo rinnt fie aus; beile es bernad) mit Felix 233 ürşen 


\section{Pferbe:2(rzenei Bud).}

Şraumfalbe ober Sannecten = und Eieröl untereinander gemiftht, wieder zut.

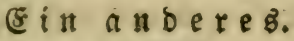

Brannterwein, Eierflar,

Ungelöfichten Ralf,

mijhe es untereinander uno jollags über.

(5) in a n bereb.

Snoblauch, Salz, sffitg,

mifit)e es untereimanoer, fheere bie Saare hinmeg uno

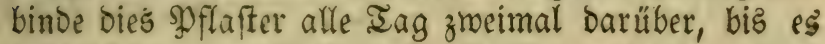
auf(urid)t; man folls aud) alle Iag reiten, bamit es feine Berwegung babe.

(Fin a tt bereb.

Şrenne die (Salllen Durd) uno lege Roggenbrod oa= rüber jo twarm als es aus bem Bacfofen fommt, wenn e? 3 IIng barauf gelegen, fo nimms berab, madbe eine Salbe von alter Situreer, Saumöl und Tannenpech uno legs über.

E

Seffne die Săulen, alsoann lege nadyfolgendes Pflafter Darüber :

(S)elben 2 gtitein, (sfitg, mache einen ITeig Daraus.

(5in and ereb.

Dürre Feigen, Sconig,

Srunnentrellenjaamen, (sfitg, mache ein Mas daraus uno idlags über.

Steinga llen.

Die britte 21rt dex Ssallen ift die Steingalle, roovon bie झुferde gar fehr binfen, befonderg auf hartem $\mathfrak{B O}=$ Den. 
Die Utrachen find Flüpe, bie fich von oben berab in

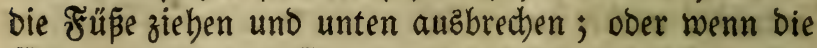
(sifen zu bart aufliegen und daz \$pfero orüden, Doer von groperer 2rrbeit und Mübigkeit ; fie erbeng auch vom Beichälen und ben Stuten.

Die Steingallen jeben unten am Scuf mie rotbe Fle= déen an einem alten $\mathcal{R}_{a ̈ b}$ gemeiniglid nicht neit von bem Srt ber Sohlen, uno wenn man fie nidjt gebübr= lid) ausmirkt, feken fie Materie und brechen alsoann gar oben aus, Daß̧ ein febr böfer Sdjaben uno Fiftel Daraus wirb. Siebe Figur श. 28.

\section{Deren (s $\mathrm{r}$ ift wie folgt:}

Dieje foll man im abnebmenden Mond im Siebs wohl auswirken, und fo tief nach bem (3) rund wirken, als bes \&ebenz balber möglich ift, hernach Mgaftixförner uno 3udeer beiß̄ binein tropfen laffen.

(F) in a n Dereb $\mathfrak{B}$.

SSirke Dem Pferd mohl auz, wenn ber Mrono im Arebs ift, und brenne Drachenblut binein, oder eine le: benoige Spinne, uno auf bie Spinne Sucker= Eandi, ober giep̃e baz Sleum 2 ntimonium etliche Iropfen bin= ein.

Ein a noeres.

Rimm Lorbeerenmebl uno Eiermeiñ, lege es auf ben Sduaben.

(Fin andereb $\mathfrak{B g}$.

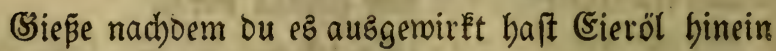
uno binde Scanfwert Darüber.

E $\mathfrak{i n a n d e r e b . ~}$

\section{alaun, Sitriol,}




\section{פferbes:2rgenet Bud).}

Sdnoefel, Sirünipan,

Narcafit. jeses 1 loth,

Baumöl, Esierêlar,

alles untereinander obne Feuer gemengt uno barauf geidhlagen, jeben Iag einmal.

(5in andereb.

attichmeer, \$feffer,

Inoblaud),

mijhe es untereinander uno lege es auf Den ๔chaben.

23enn Die materie heraus ift, fo nimm das Spulver vom gebrannten \$antoffelbolz, S3alläpfel und \$sitriol und freue ez bincin.

Ein andereb.

Nimm die fhmarze Materie, welde Dem Shferd im Siflaud) ftedfet, laş es mohl Dünn ausmürfen uno brenne es Darauf, laß̄ den Şuf Dabei oben robl fdomie= ren.

Ein a n Dereb.

Schneide Die Garlen aus im abnebmenden Mond und thue 3 oder 4 Iropfen Stheiderwaffer hinein, hernach tröpfle cine gute Scornjalbe barauf.

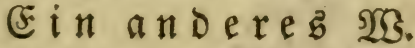

Sdaneibe bie Sallen aus im abnebmenden श्रloni uno thue Felix $\mathfrak{B}$ ür fiche Salbe oder die Strapburger Salbe barauf.

\section{Daz 28fte Capitel.}

Son Den (Semächien, alz (sllbogen, saift, Siölb= lein und Srotte am Şalz.

Die Erlbogen Eommen Den \$Dferden an zroeierlei Sr= ten, etlichen an ben vordern Beinen binten nabe no das 
- Sein am $\mathfrak{B u g}$ anfängt, etlichen binten an bie bintern Sdhenfel binter ober ober bem (S)eleich. Siebe Figur No. 29.

Soldbe nenn fie nod) jung find, find fie einer (se: fdwoulft äbnlid), Denn fie entffeben von ben phlegmati= fohen Feudhtigkeiten Des (S)blütz, weldbe zu keinem (5i= ter ober Seitigung fommen, und werben auch bon ben Befchälern uno Stuten geerbt, laêen fich mit ben Şän= Den auch bin und wieder fichieben.

\section{Die हैur.}

Soldse foll man erftlich berfuct,en mit ermeichenden uno refolvirenden 2rzeneien, als mie Bähungen, Sal= ben uno şflaftern.

Sur Bályung foll man nelymen :

Ealmiac 1 loth, Meerfalz 3 loth,

(Semeines Salz 8 loth,

Salpeter 3 loth,

Römifden Sitriol 1 loth,

2laun 3 loth),

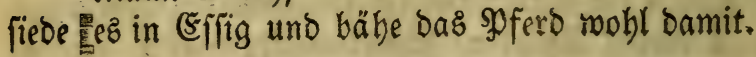

\section{Ein andereb.}

Sdhiffped) $\frac{1}{2}$ गु Fund,

Fichtenbarz 1 Sुfund,

(s)eiskoth 6 loth,

2mmoniacum, (salbanum, jeoes 1 loth,

Sdbneinefdymalz fo viel als nötbig ift,

mifche ę zu einem SDflafteriuno legś über.

\section{Ein andereb.}

Salbanum, 2(rmmoniacum, jedes 1 loth,

Sdiffpec) 4 lotb,

gid)tenharz, Ierpentin, 。 


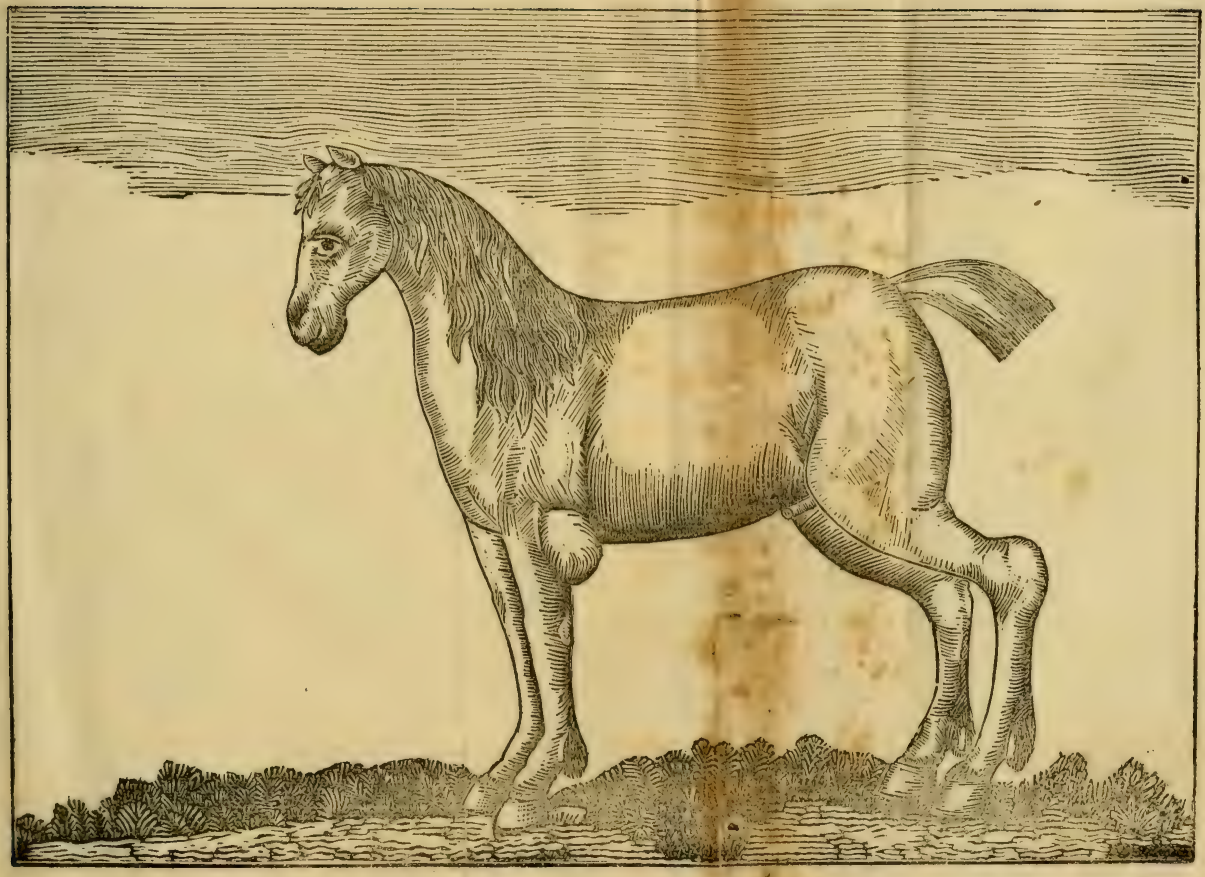




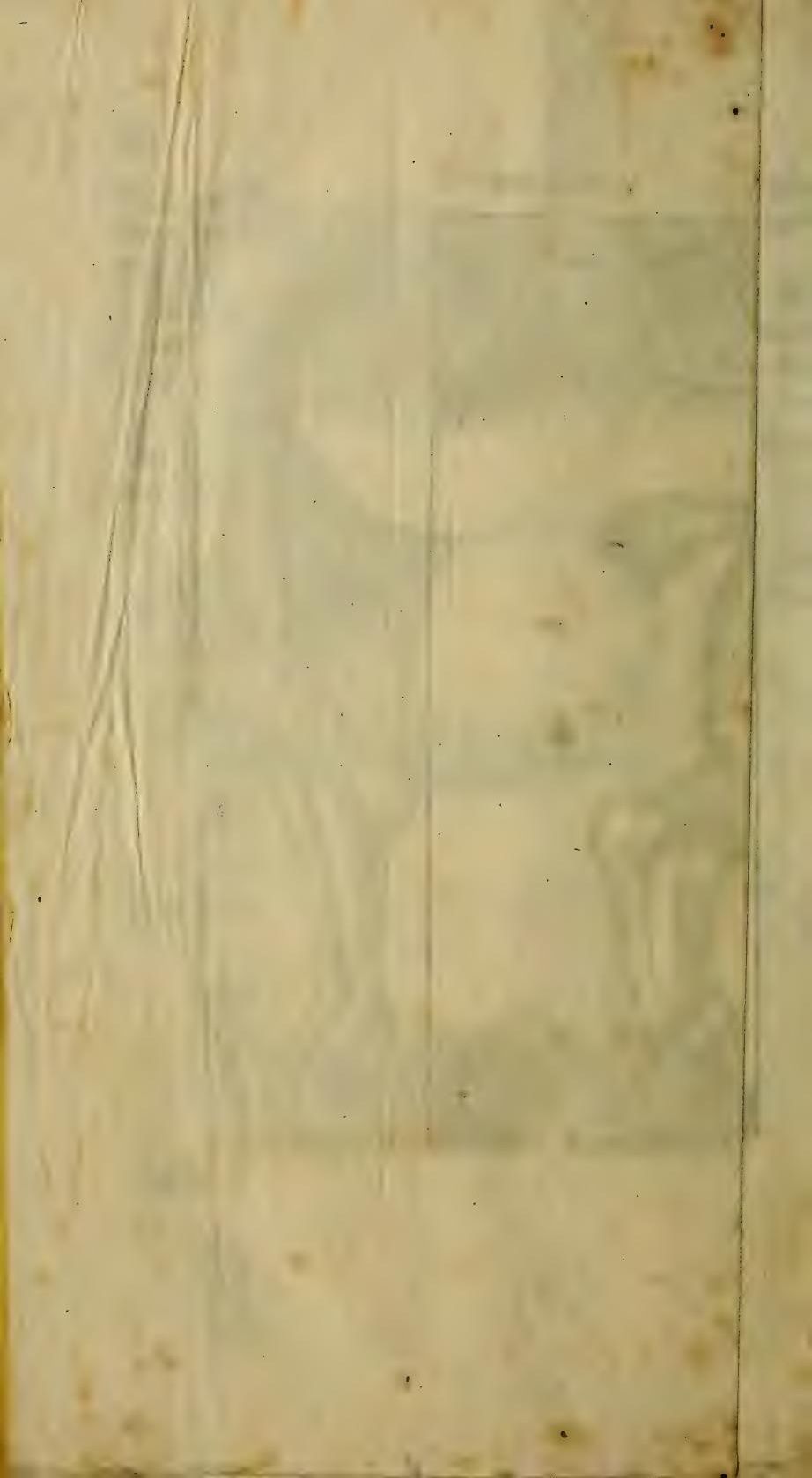




\section{Pferbe=:2rzenei Budh.}

(S) riectifiches Shed), Boellium, jedes 2 loth),

Bitriol, 2 Beirauch),

Subenbarz, jeoes 3 loth,

lape bie (Summi in Efïig jergeben, nochmals bei einem Fener in Der Form eines Sुflafters vermift ten.

Szenn aber ber Sdaden gar alt, bict uno bart mor= Len, jo ift er mit biefen Mitteln nicht jult vertreiben, fonbern er ift barnad) ein unberreglid)es (Senäd), nel= d)es mit ber $\mathfrak{B a}^{2}$ )rbeit ein (5abogen genannt witD, uni nid)t als mit bem Sobnitt oder Eauterifinung Eann ge: beilt werten; man mus aber fich mit cent Schneiden und Sauterifiten mobl vorfehen, Damit man nidyt bie

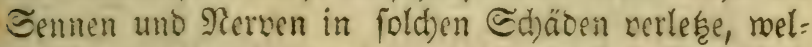

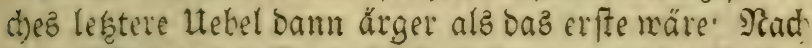
tem Sonitt oder Cauterifiten foll man folde Salbe: uno Spflafter braucten, weldhe den SBrand löfchen un bas faule Fleifd) vergebren.

(5) in a noereb.

Sauterifire ben Sort wohl und fdmiere nad)folgente Salbe Darüber:

Dialtbea 1 spfuno,

Sopuleon, Sammfett,

Şumberfet, jedes $\frac{1}{4}$ sofund;

mifche es untereinander.

\section{(5) in andereb.}

Sauterifire den (Eabogen, treuffele bernadi) Denfelben mit einem İ̈hlein an einem Stecken gebunden, mit

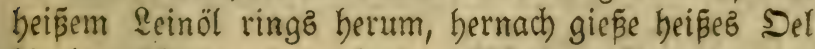
binein; fomiere bernad) Den Schaden oft mit einer: Salbe von gebranntem 2flaun, Eietflar uno SBaumö! gemacht. 
Ein andere

Pidfe Den Schaben mit einer Fliete uno lege nach)= folgende Salbe barauf :

Snoblauch, 2atten Speck,

Scunosifomalz,

untereinander geftopen uno vermifat.

\section{Ein and ere $\mathfrak{E}$.}

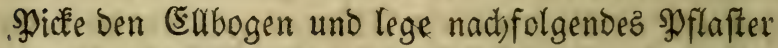
warm über den Schaden, lapee es 3 Stunden lang lie= gen, ober to lang bis ber Salk bavon ftäubt, nenn man an bem Spflafter Eraket :

Senedifche Seife,

Brannteroin,

mifdbe es untereinander über einer (S)lut; bernach) rüb= re barunter

Ungelọ̈d)ten Salf,

Sakenloth ein wenig,

macke ein Spflafter Daraus.

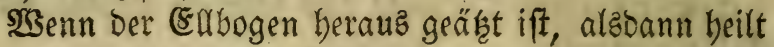
mans roie alle andere Schäben.

\section{Ein a noeres.}

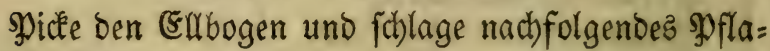
fter Darüber :

Ungelöichten Sale 2 Scändevoll,

Sdbwefel 1 Sfuno,

pulverifits uno bermipcte es mit Esiermeis zu einem Sfllafter, über 3 ober 4 Iage thue es betab und wafde es mit Eierklar uno $\varsigma_{a l z}$.

\section{Ei $\mathfrak{a} \mathfrak{n}$ Dereb.}

Sמiďe ben Êrbogen mit einer Fliete uno orücfe bas 


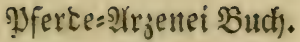

SBlut mit cinem Safelsftab wohl aus, ftreue geplultvertes Sras binein, madbe bernad) ein Pflafter vom Senft= mebl, ungelöfdten falf, Senedifhem (Slas uno (Eier= flat une binde rs tiber ten Ethaden, lape es 3 oder 4 Iage fteben uno thue alsorm ten Şand hinmeg, Das

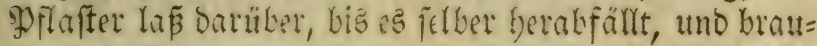
dhe das Soferd unterde

\section{(5) in a}

Siebe Senftmety in :Lisein zu cincm oünnen Sbrei, fitle ibn liber Diad an cin marmes Sort, fo wiro pr Difflid)t, reibe bemadt) bon (Erlbogen 8 Iage lang täg= lid) z!weimal camit uno fullogg ibm aud über, fo fallen

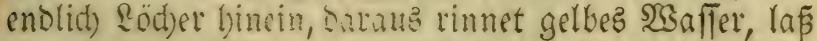

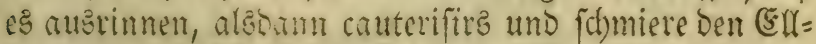
bogen mit Sdmeet nder mit einer Srandjalbe, bis er

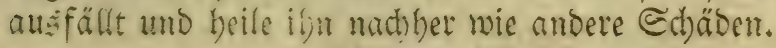

Ein andereb.

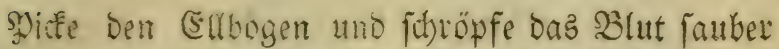
beraus, alsoann reike Eteingiaspulver uno Salz bin= ein; bernach mijale (Eicrflat uno ungelöphten Salk untereinanter, legs mit Şanfmerg über unt balte ein gliit)ent Eifen baran, biš ez troden wird.

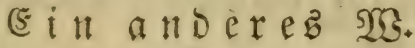

Biebe ein Saarfeil cadurth, babe aber baneben $2(d)=$

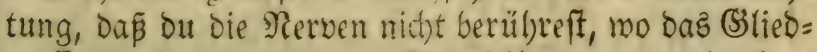
maller gebet, menn Das Scaarfeil genug operirt bat, Dam thue es beraus uno beile oen Gdaben mie ande= re ๔äben.

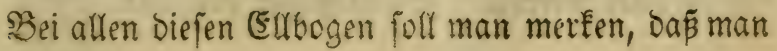


vorker bie Scaut abjcheeren folle, ehe man bie (cur $b a=$ mit anfängt.

Ein andereb.

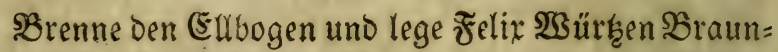
oder bie rothe ভalbe barüber, welthe unter Den ভalben zu finden iff.

Eี $\mathfrak{i} \mathfrak{n} \mathfrak{n} \mathfrak{D} \in \mathfrak{C} \mathfrak{e} \mathfrak{b}$.

झुicée Den Sdyaben uno reibe Salz binim, hernact) ftreiche bem \$ofero nachfolgenoe Salbe brei Iage nadh= einander über ben Schaden.

Euphorbium,

Spanifthe Flliegen, jebes 1 loth,

$\mathfrak{L o r}=$ Sel 4 lotb),

Diefe Salbe wirb in 24 Stunden Blafenaufąiehen, bie laß̧ von fich felbft auzrinten, fohmierz bernad) täg=

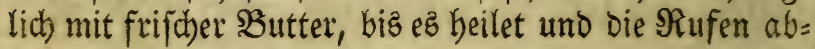
fallen.

Bon Dem $\&$ a ift.

Diejer Eommt Den Sुferden vornen über ben Şufen oder ben Feffeln, über ben ßnicen, oder unter ben アrite= en an ben Schienbeinen. Derjelbe ift Durd) bie näm= licte Bebanolung zu curiren, mic ber Estrbogen, mito fonft auch, wenn ex Elein ift, Das Sölblein genannt.Siebe Figur 30.

$$
\text { Rrotte a m Şa } 18 .
$$

Diez Hebel fommt ifm oben am Şalz, unter, aud) bismeilen etwas linter ben Shren. Sit ein febr böfes (Sejd)mür, mill cauterifint fein, uno wie alle alte $S_{d} a ̃=$ ben gebeilet rerben. Siehe Figur No. 30. 


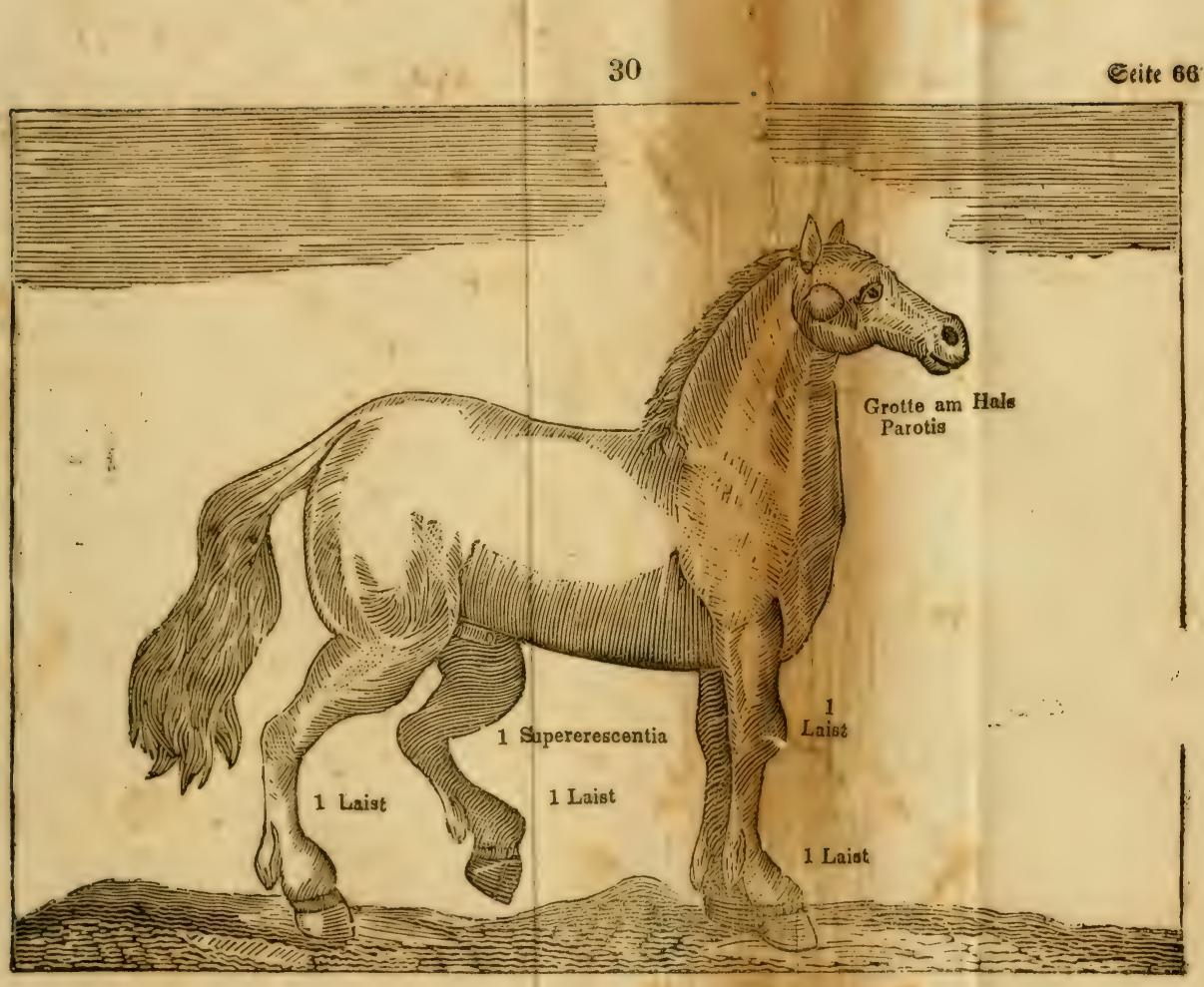





\section{Pferbes?(rgenei Buth).}

\section{Das 29fte Eapitel.}

\section{Son bent Geleich = uno GSlieberwehe.}

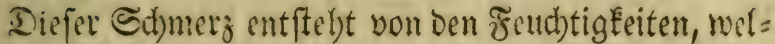
d) in ben (Sisleichen uno (Sislenfen zufammen fließren,

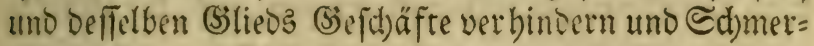
jen madben. Diefe Sranfleit fennt man unter ver: fdiedenen Benenmungen, theils wird fie genannt von Der 2frt Feud)tigkeit, To es verurjad)t, theils von ber 2rt Der (Seleid)e, Die es angreift, unter meld)er lef̧terer 2rit das eine bas Saliftwelee, das andere bas \$obagra genannt wiro. Die erffe 2lit behält ben siamen des (Sieleid)webes, Das (Sieleid)webe fommt von übermäffit:

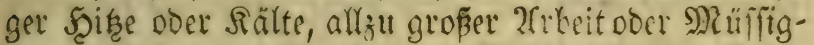
gang uno langen Stano, woourd) die Berbautnge=

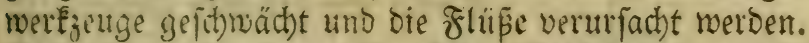
SBišneilen fommt es auch von den SBefduallern von all= zu vielem Springen oopr Eteigen, auch von Edhlagen, Gtopen uno Dergleidben.

Die Siennzeiden, wonad) man fich jut rid)ten bat, find, wenn fie an Eeinem gerwiß̄en Sort bleiben, fonbern fid) bald in biefem bald in jenem sort bes Reibes, als in Den (3) leichen Des Scalfes oder Rlüten, balo in Den vor= Dern Sügen, bald in ben bintern; balo in ben Schert= feln, balo in Den Sinien Deg \&eibs; und manchmal gleid) Darauf in Den \&̈üen, bald in Den Gintern, Lald in ben vördern, bald a f Der rechten oder linken ๔eite, balo in ber frone bes Fupes oder Dem Sork fid erzeu = gen, machen cine ssefumulft an bem Srt, wo fie find, mo.je melyr fie von bigigen Feudtigkeiten berfommen, Defto gröper: Samerzen fie werurfachen. 
Sie baben auch) ibre inner = uno äufferliche $\mathfrak{U}$ rjachen: oie innerliche find die Unrectstmäpigkeit mit uno nebfit einem Flus, welche Den \$fferden gemeiniglid) von kal= ten phlegmatifosen Feuchtigkeiten erregt miro, die in bie (Spleiche und andere Epanäberichte Srte berab fal= len, diefelbe ausbebnen und erbeben, und bie sfferde binfeno machen.

Die äuperliche urfachen aber find bie unrechtmäpit= ge Silge, welche refolvirt und vertbeilet, die vielfältige aälte, melche im segentheil bick macht, uno zujammen bält, Denn bie Şise ift unter allen Sualitäten die

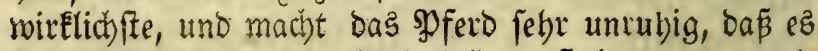
nidht fitul ftehen fann, mirb dabei ungeftaltet, mager und traurig, betommt sine barte Scaut, bat raube frupfige Scaare, uno Dergleichen.

Solden şfersen foll man Sourgationen gebrauchen, welche bie Flüpe ansfübren, alz

Soloquintenmarê 1 Suintlein,

Salap 1 Suintlein,

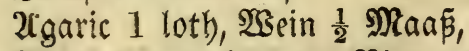

Extract bon jobnarzer Niesmurzel,

Anis, jeoes 1 suintlein,

Mafitix, Simmet, jeoes $\frac{1}{2}$ Suintlein,

untereinanoer gemifht und auf einmal eingegeben.

E in andereb $\mathfrak{X}$.

2lloes bepat. 1 Ioth, Soldanella,

Ifgaric, jeoes $\frac{1}{2}$ loth,

(S)ummi guttä 1 Duintlein,

Znis, Fenchel, jedes 1 suintlein,

Saseinftein 1 loth,

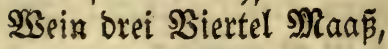

untereinander gemifht unb auf einnal eingegeben. 


\section{Eี $\mathfrak{A}$ andere}

Shepar 2Cntimonium $1 \frac{1}{2}$ Suintlein,

Saffran $\frac{1}{2}$ S.uintlein,

Wein $\frac{1}{2}$ Maā̄,

untereinander gemifdt und auf einmal cingegeben.

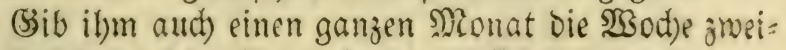
mal 1 suintlein Epieß̧glas zu freften.

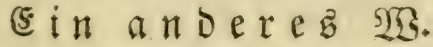

Shiera picta,

Extract von Capiarinoe, jebes $\frac{T}{2}$ loth,

Igaric $1 \frac{1}{2}$ loth,

SEammonie 2 suintlein,

Extract von ichnarzer Piesmurzel 1 Suintlein

Maftix $\frac{1}{2}$ Suintlein,

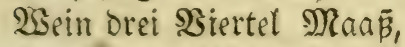

untereinander gemifd)t uno auf cinmal eingegeber.

(E) in andereb.

Bingelfrautbrübe 1 Maá̃

Sdyarze Niesmurzet $1 \frac{1}{2}$ Suintlein,

Senezblätter 1 lotb),

Eerd)enichwamm $\frac{1}{2}$ loth, untereinander gemifdot und eingegreber.

(E) $\mathfrak{n}$ anderes $\mathfrak{3}$.

WBilben Cucumernjaft 2 Suintlein,

Igaric 1 loth,

Soldanella 2 Suintlein,

Iloes, Scammonie 1 suintlein,

Saffran $\frac{1}{2}$ Suintlein,

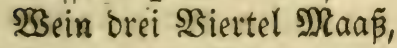

untereinamoer gemifht und auf einmal eingegeben. 


\section{(E) in anderes.}

Stecfe dem \$ुfero Die Chriftmurzet.

E in andere $\mathfrak{B}$.

Eege nad)folgendes \$flafter über :

Maftix, : $\mathfrak{B}$ eirauth, jebez 1 loth,

Saipen Sandel 3 loth,

Dürtę Rofenpulver 2 loth,

Bemeinen Bolus 1 \$funt,

Gerftenmebl $1 \frac{1}{2}$ Pfund,

Dradbenblut 2 Suintlein,

Effitg, fo viel als nöthig ift zu cinem \$ुflafter, mijche eहै untereinander uno ftreid) über.

E $\mathfrak{i} \mathfrak{n} \mathfrak{n} D \in \mathbb{R} \mathfrak{e}$.

Garlläpfer 6 loth,

Maftix 1 loth,

2rabijcter (B) ummi 4 loth),

Dradbenblut,

Sambaraca, jebes 1 loth,

Rithernmebl,

Ěrvennebl, jedes 2 gofund,

Brähe von Sänenbaum uno Mnrtenblättern, fo viel genug ju einem 2(nftrich ift.

(5in a noeres.

Den Sobleim von (Eibijh),

Zeinjaamen, Flöhefraut,

Bockzhorn

madhs mit Sdymeinenichnalz zu einer Salbe.

$$
\text { (E) } \mathfrak{i} \mathfrak{a} \mathfrak{n} \text { Deres. }
$$

SBäge Den Sort oft mit Ephen tho gefotenem soir fus. 
E inandereb 23 .

Serftenmehl 3 Sुfuno,

Sieftopene Sdymedten bis es ein Ieig gibt, binde eร झूflaftermeis über.

\section{E in a ndereb.}

Sraudse bie Fröfh fartbe uno reibe Den Sort moblba= mit; ooer brauche die Siberfalbe, die im Sapitel von allerbano @alben zu finden ift.

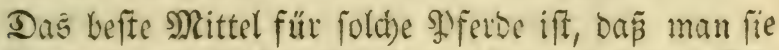
vertauft, Da ein foldes Slferb, weld)es auf peinen fü=

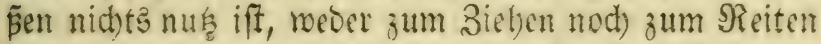
taugt, und wenns gleid) Dev foönfte Bejuallet oder Stute wäre, find fie bod) Deproegen böd)lich zu fuenten.

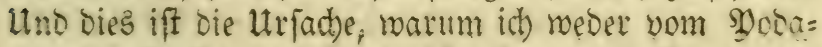
gra ober fonft etmas bavon fidreiken mag. Dennmenn gleid) Die Flïpe ober das \$fodagra einmal curiut wer: Den, fo fommen fie ood) wieber uno bleiben nidht aus.

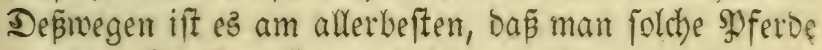
aus bem Etall muftere uno binmeg thue.

\section{Das 30fte Eapitel.}

SBon Den Şufen uno ifren פängeln.

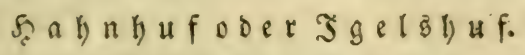

Dies ift ein foldes (Sebred)en, weld)es in oer Sirone Dev Şufe mie ein fpişiger (Sirino fid) bervor thut, uno Die Scaare über fid) fteben madht, Eommt bei ben \$Pfer= Den gemeiniglidh Daber, wenn man fie nicht fauber bält, noch an ben Schenteln und Füpen fleiffig abtrodénet; 
ober roenn bie Syferde fonft mit bigigen und verbrann= ten Feudtigkeiten bebaftet fino, fo in biefe Site berab fallen, uno burth bie \$ুoren uno 25 urzeln ber Scaare berauz bringen, oder auf Dem Eis geritten oder verna= gelt morben. Daber fie bann biefelbe erfflid) überfich ragen, uno nod)mals gar ausfallen machen, wenn man ibnen nicht bei Seiten mebret.

Shye Sennzeichen find die Schuppen und Eleine Srino, meldhe fich Dafelbit befinden.

Diefe Sirantheit hat zweierlei 2 rten, als bie trocene und bie feutbte; bie trocfene hat breite, bünne uno afdenfarbige Sibuppen, unter weld)en Die Scaut ganz gefund iff, und wenn man bie Situppen berab macht, wachfen gleid) andere uadh, und biefe find leicht zu cu= riren : Dis andere 2frt aber bat feuchte Rufen, unter

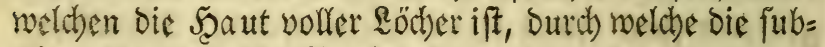
tile gelbe uno zäbe Feudjtigkeiten beraus bringen, ver= Derben mit ber Seit, wenn man ifnen mit ber Şülfe nid)t borkommt, bie ganze Feftel uno machen bie Scaa= re aนิืfallen.

Die trodene mäidt man mit Seife uno $\mathfrak{R}_{\text {autige, }}$ went fie nod) in ibrem 2(nfang fino, ober mit $\mathfrak{R} a u g e$ worin Erven, Feigbohnen, Bockshornjaamen uno Ëi= bijch gefotten moroen; bernad roenn fie abgetrodenct fino, fohmieret man fie mit Schnertelöl, in meichem Esi= bifch faamen gejotten worden, oder mit Dialtbeajalbe. Wenn fie aber alt geworden fo foteeret man dic Saare binweg uno wäfdt es wobl mit $\mathbb{R} a u g e$, morin nadfol= genoes gejotten worten, als (sibijh, SJappeln, Bocks= bornfaamen, Mangolt uno Stcinflé ; bernact reibt man ben Srt mit wollenen Tuldern, biz fid bie Sdbul pen ablöen, und die Scaut fait heip weroen will, alzs 
(Srünipan, jedes 4 loth,

Ungelörchten Rale 6 loth,

Sd)meinefdimalz, be gibt.

Effig, fo viel bierzu nöthig ift, bấ ps eine @al=

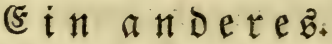

Erorauch,

Borretich, Scabiofen,

(Srinomurzel, jeoes gleid) viel,

prese den Saft davon :

Nimm von Dem Saft $1 \frac{1}{2}$ Maañ,

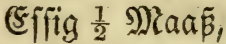

fiebe bie Säfte bis fie ein wenig vertaucht haben, als= bann tühe binein,

(sirünipan 2 lotb,

rabsts rohl um; endlich thue bineit

Sped) 1 Suintlein,

SGach, fo viel zu einer Salbe nöthig fein wirb.

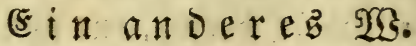

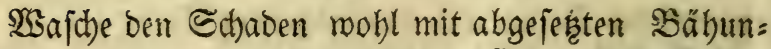
gen, und falbe ben Sdjaden mit ber Egyptifonen Salbe.

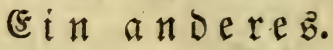

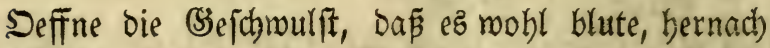
tröpfle dem SPfero beißes $\mathfrak{B a c h s}$ binein, thue fold)es 2 Iage nacheinander, alsbann öffne es noch einmal, und tröpfle wieder heipes $\mathfrak{S a c h}$ s binein, continuirs 6 Iage nadbeinander; nimm barnad) Şanfmerg, beftreute es mif Salz und binde es barauf.

\section{(5i $\mathfrak{n}$ a noereb.}

Siebe einen (Sranatapfel fammt ber Schaale, ftope ifn, hernach vermifde mit 


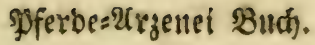

Rzeirauch, Naftix, jebes $\frac{1}{2}$ loth,

Sffeffer 1 suintlein,

mijde alles untereinanber mit Branntewein unb lege es barauf.

\section{(5)}

Süridners: Beize, Sauerteig,

mifd)e es untereinander und laßje es üler Ract fteben, barnach thue bazu

2attichmeer, Sconig, \&einöl,

mifche es untereinander zu einer Salbe.

Siede darnach 5̧arz, thue eb auf ein ITuch, und fo balo bu das Spfero gefchmiert haft, fo fdulag ithm das heipe Scarz Darüber, thue es Des andern Iage roieder berunter, und fomirs mit voriger Salbe roieber, uno rajd)e es aus mit gejottenem ßübeharn, foldhez Sal= ben und 23 ajden feçe fort bis ç beil miro, aber bis

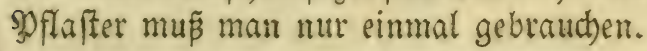

5 in andereb.

Madbe eine Salbe aus Bagenfohier, Spanngrün uno Effig, und falbe es bamit.

Ein andere $e^{-}$.

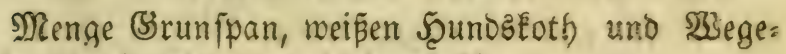
ridh untereinander, unt binde es über.

(5. i a $\mathfrak{n}$ De reb.

(Siebranntes Supferwaffer 1 loth),

Ulaun 2 loth, Sonig,

Ierpentin, jedes $\frac{1}{4}$ Sूfund, -

Silberglätt 3 loth,

mifde ef untereinander und Galbe bas झुfero bamit.

(F) $\mathrm{r}$ i

Dies Uebel entffebet baber, renn man im Sommex 
fark reitet; ebenfo vom Bernageln, oder wenn bie Eijen zu bart aufliegen.

Denen, die von ben hişigen Reip̈en entffeljen, foll

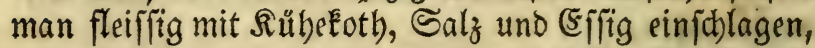
uno ehe man ausereitet, bie Şüfe roobl mit Swiebelfaft fomieren.

SBenn fie aber aus andern Utrachen berfommen, foll man ifnen bie (sifen abbrechen und oen Schaben fuchen, bernach, wie man ibn befindet curiren.

(s in a ndereb.

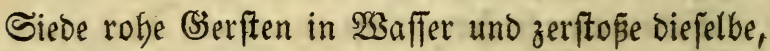
mijobe bernad) Darunter

Säuťoth, Salz,

Scabernefteln, (sffig,

brid) Daz (Eijen ab uno binde es Dem Sुferd auf ben Şuf uno unten an bie Soblen.

(E) andereb.

Rimm die mittlere Rinden vom Scolder, ftope fie mit alter Sibmeet, und jhlag dem Sुfero bamit ein.

Ein anderes.

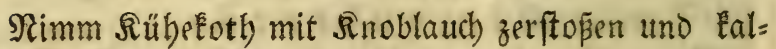

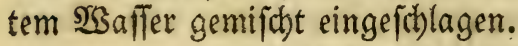

E $\mathfrak{i}$ andere: $\mathfrak{B}$.

Siede robe Serfte und Snoblauch mobl mit $\mathfrak{Z}$ affer, zerftope es miteinanoer, milche Sconig uno Sümmel ba= runter uno binds um ben Scuf, fhütte ifm die inwen= bige Soblen fingergobick mit warmer aber keiner heípen Sdhmeer oder Schmeinefdmalz.

\section{Ein andereb.}

Şann man ausreift, foll man bem \$ुfero bie Şufe von ben ausgeroach fenen 3wiebelröhren fommieren. 
$S_{\mathfrak{z}} u f z \mathfrak{w}$ a $\mathrm{ng}$.

Det Scufgrwang ift ein Mangel uno Eommt baher, wenn bie Scufe binten gar jumal zufammen wadjen, Der Siern weid)t uno viel übrigez Shorn binten uno vor: nen ift.

Dempelben bilf aljo: Gifneibe daz 5orn vormen

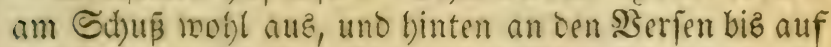
Das Relven, auf beioen Seiten Des Straalez, jebod) ob= ne Sertibrung Des Sacins im Şuf; bernad) menn Daz Sd)ereifen aufgeidtagen ift, meld es binten am Stol= len eine $\approx$ d)raube baben foll, bamit mans auf=uno zu= (a)rauben fönne fo follag ifm mit nadjolgenoem Esin= id)lag ein :

¿einfaamen,

Rorn, 3wisbeln;

Ultid)meer jeoes gleidjuiel,

fiebe es und ftope ez untereinander; Diefen Einfdhlag continuir 3 over 4 Iage, vermifde allezeit etroas vom alten (5infd)lag unter ben neuen; am britten Iag frü= he idbraube das Sdherteifen um einen Etrobbalm breit weiter; am vierten Iag aber, wenn ou findeft, bajper

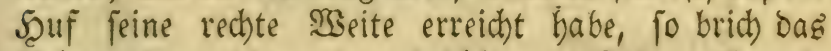
Edeereifen wieber ab, und ichlag ein Eifen auf, wel= ches robl bick fei, innen und auffen, fdy lag ifm bernady mit nadfolgenoem (sinfi)lag ein :

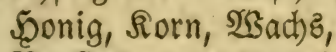

Sorfto $\tilde{\beta}$, eines fo viel als bas andere,

fiede es miteinander, und fhlag Dem Snferd bamit ein; mieberbole dies einige 3rit.

\section{E in an Dere .}

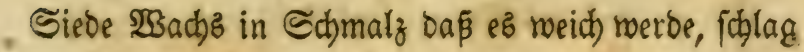


bamit ein, und lap̧e Den Einjhlag 2 Tage barin, mie= berbole ez.

\section{Ein a n Dereb.}

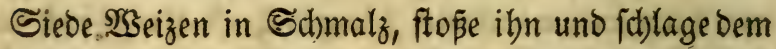
Soferb bamit ein, binde inm auch biefes mit einem nol= lenen Iuch um bie 5̦üfe; oder fiede $\mathfrak{S i c k e n ~ i n ~} \mathfrak{B u t}=$ ter, bas fie meich werden, ftope fie und binos auf ben Scuf, uno idhlag auch bamit ein; ober ftope \&einfar= men und aftefdmeer untereinander, fdhlag bem SDfero bamit ein, uno binds um ben Şuf.

\section{E $\mathfrak{i} \mathfrak{n} \mathfrak{A} D \in \mathfrak{D} \in \mathfrak{B}$.}

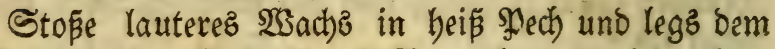
sूfero um den Scuf, über 3 Tage thue es wieber her = $a b$, nimm Sleien uno Salz zugleich, vermi idoe es mit farkem Effig uno reibe bie Füpe oft Damit.

\section{Ein anderes.}

Sappeln, Saumöl,

Sonig, 2f(t)d meer,

mijhe ez untereinander und fablag Dem Sुferd bamit ein.

E. in a nd ereb.

(Setechte meipe Rüben, altifhmeet, Sdjaafkoth,

mifche es untereinander uno fallag bem भुferd bamit ein.

Cin a $\mathfrak{i}$ Dereb. Sorn, Reinfaamen, jedes 3 Scändevolf, Utnfdhlitt, 2Attid)meer, jebes I SPfund, untereinander gemifat und fallag bem $\$$ pero bamit ein. $\mathfrak{B}$ ernagelt.

Die Beichen bes Eernagelns fint diefe: 


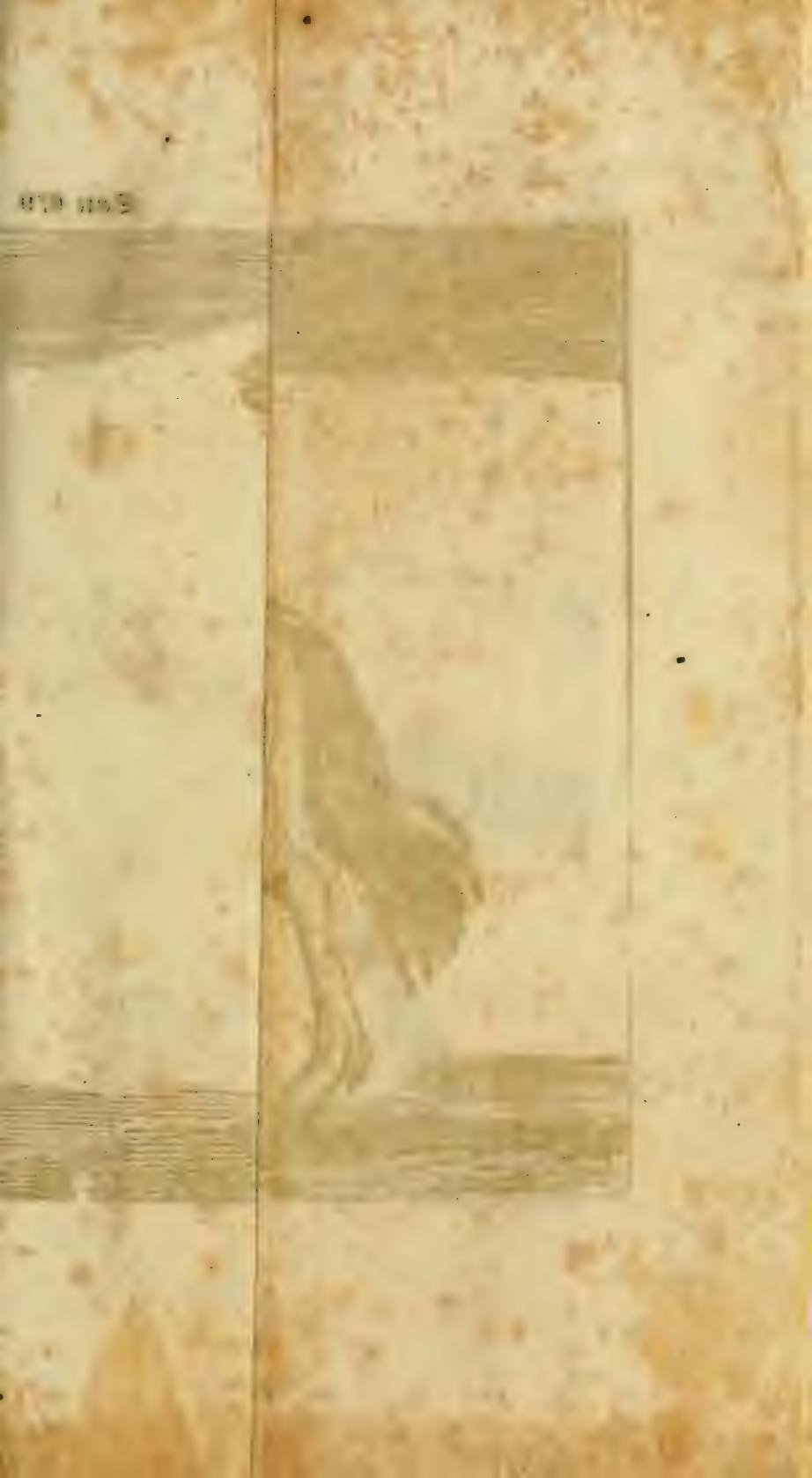




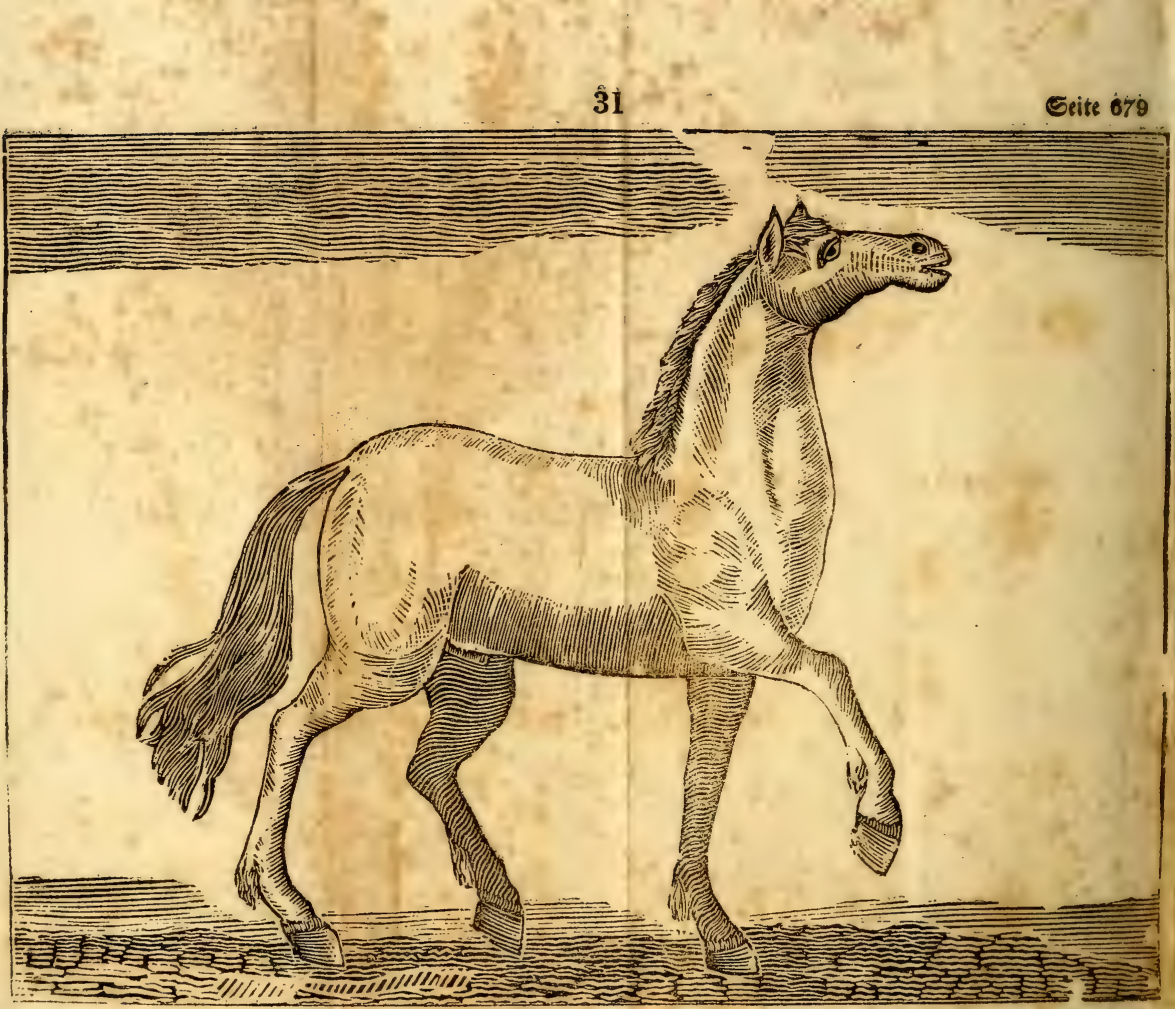





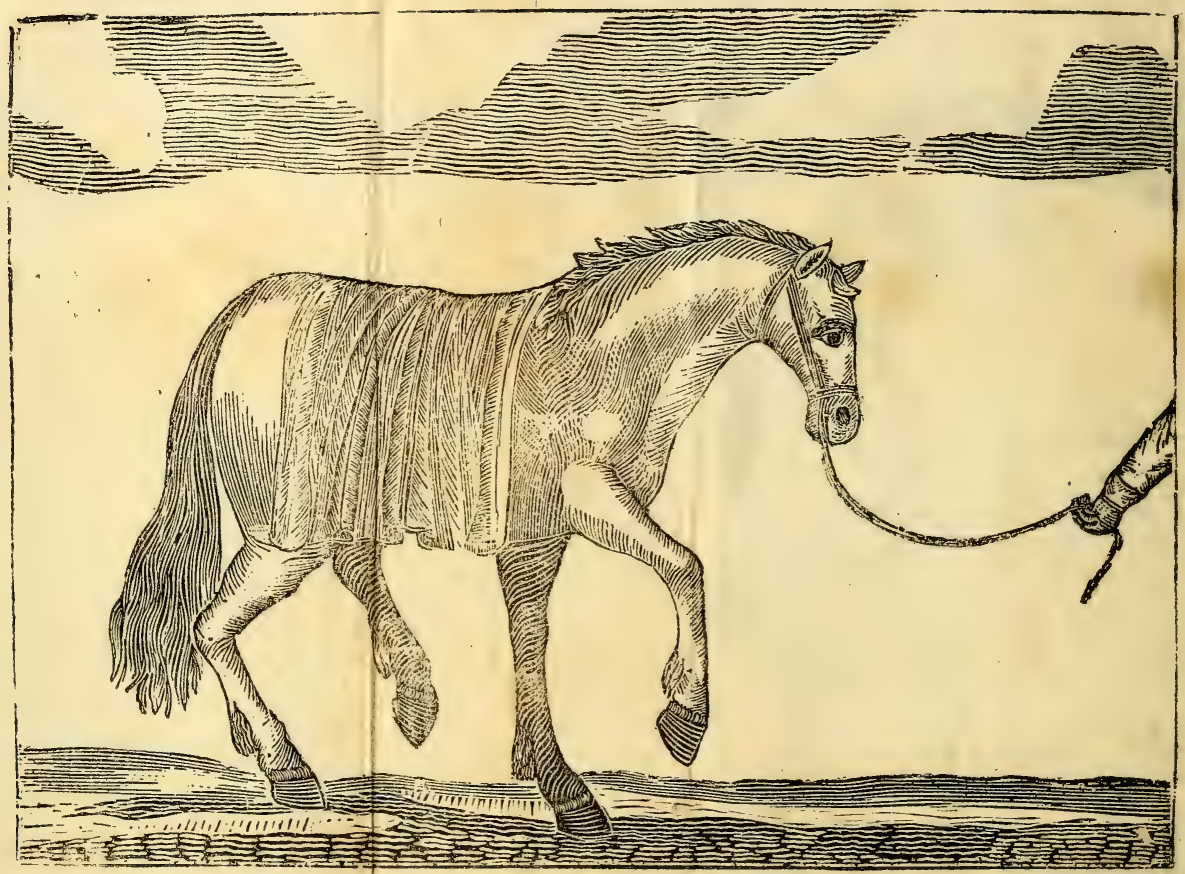


1. Şinft bag SPfert an felben Fup. Siebe Figur গ⿻. 31 uno 32.

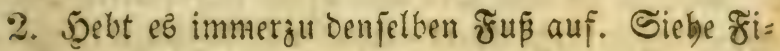

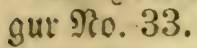

3. $\mathfrak{B}$ enn man auf bie গägel flopft, fo zudet es aft bemrelbigen Sagel, wo es vernagelt ift.

4. RSenn man bas (5ijen abgebrochen, uno mit einet 3ange an bie $\mathfrak{B a ̈ n}$ be hart greift, fo zudet eb aud) am felten Sort, wo es vernagelt worden.

\section{Die (5)}

Răume ifm zu, bisิ ou bas Esiter finbeft, alzbanm giefe ibm auf einem beipen (5ifen, Branntemein in baz Roib), lege Salz Darauf, uno giepepe ein wenig Srannte= wein auf Das Saly, lege Şanfmeig balauf, uno befte

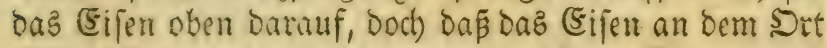
an weld)em es vernazelt worben, nicht aufliege; obet majche Den ansgeräumten Edbaben mit warmem 953 ein, uno ftreiche ober giepe ben (Englifit)en 23 undbalfam birein.

\section{Eitt anderebi.}

Stope gefottene Scirfen wohl mit Scirchen=unichlitt, brich) bas (Eifen ab, räume zu bem SDrt, wo eह verna= gelt morden und fiblage ifm über.

Ein a n Derez.

Siede Eeinfaamen in beiper Sd)meer, rübre es un= teleinander und folage Dem \$ुferd bamit ein.

\section{Ein a noereb $\mathfrak{Z}$.}

(5ießße den (Englijd)en $\mathfrak{S u n b b a l j a m ~ i n ~ b a s ~ \& o d ) ~ u n d ~}$ wermachs robl mit Sanfwerg, roiederbole es bis ez. beilet, 
680

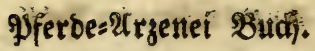

\section{(5) in andereb.}

Rrume zu oem Srt und ftreue gepülverteg Nagel= Eraut hinein, lege $\mathfrak{B s e r}$ barauf und befchlage es nieder.

\section{(a) $\mathfrak{i} \mathfrak{a} \mathfrak{n} \mathfrak{D} \in \mathfrak{r} \in \mathfrak{b}$. $\mathfrak{B}$.}

Siebe ben Nagel aub, ziehe denfelben mit ber Spize in einen Schmeerlaib uno gieb bem Sffero Mãubőbr: leinEraut zu freffen, fo bricht ibm Eein Eiter aus.

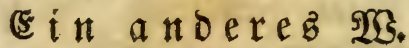

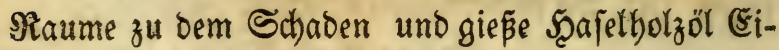
eról ober $\mathfrak{S}$ achbolderholzöl binein.

\section{Ein a n Dereb.}

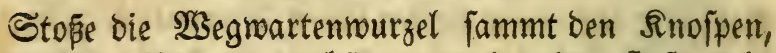
woraus die slumen wachfen untereinanoer, fope es in ben Sthaben uno gib inm Sagelfraut fammt ber $\mathfrak{W}$ ir= zel, wie audh $\$ 2$ segmartenmurzel zu freflen.

(E) in andereb.

ख̉enn man ben Stumpf von bem Nagel nidht ge= binmen Eanm uno er noch barinnen ftect, fo lege $\mathfrak{R a}=$ gelfraut und Sdbölkraut untereinander zerftopen barauf

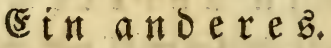

(S) brannten 2lllaun, gebrannten SBitriol, jebes gleid)= viel, zerlaß̧ Sconig, rübre bas Soulver hinein, thue ez warm in bas \&od uno vermache bas \&od) mit Scanf= werg.

$$
\text { Ei in a noerebs }
$$

Raume ben Sdhaden, thue Felix Ş̋̈rten Sraun= falbe ooer bie Egyptijhe Salbe binein.

\section{(5in andereb $\mathfrak{i s .}$}

Raume ben Schaben uno giepe ifm nachfolgende Galbe roarm hinein: 


\section{Sirfiden=Unfablitt 2 \$ुfund,}

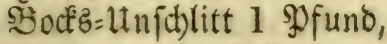

2ftedomeer $1 \frac{1}{2}$ gfuno,

Ierpentin 1 loth,

mijhe es untereinander tiber einer (S)

\section{Ein a no eres 23 .}

Raume zu Dem Sdjaden und lape auf einem wal: men Eifen die Straß̄burger Salbe bineintropfen, lege Scanfwerg barauf und fd)lage Das (Eifen wieder auf,

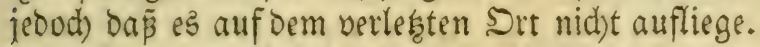

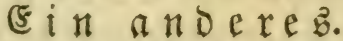

Raume zu Dem Sdjaden, gieß̄e Sd)reinģgallen lin:

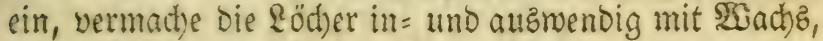

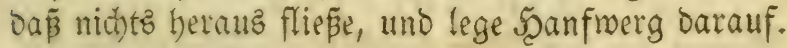

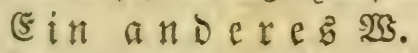

Faume fut Dem Sort, mo der Sdaden ift, uno fiebe 52opfen und 2(ttid)meer untereinander, uno fhlag bem פुfero bamit warm ein.

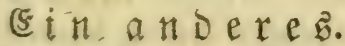

Biebe Den Stagel aus, ftecke inn in 2lltichmeer und

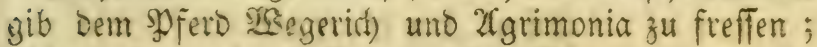
follage ifm audí) mit Del und alter Sd)meer ein und $Y_{e}=$ ge Shanfwerg Darauf.

Ein anderez $\mathfrak{I}$.

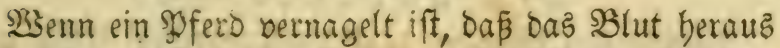
gebet, fo tröpfle beípez Sol oder beísen Ierpentin in oie xsinde.

(5) in anderes.

3erftope das Rraut Mauerpfeffer mit Salz uno thue e? in bas Roch. 


\section{Ein andereb.}

Siebe Sairfarnbaar in 201 thmeer und lego auf ben Schaden.

\section{(s) in andereb.}

Raume zu Dem Rod), ftreue 3uderer= Sandi binein und vermache ez mit Şanfwerg.

\section{(Einandereb.}

3iebe ben Nagel beraus, mache einen Nagel von $\mathfrak{R} e g=$ rartenmuzal uno ffecte benfelben in bas $20 d$.

sin andereb.

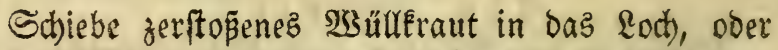
Shulber babon mit Sconig vermifdt.

\section{(a) anderez.}

Raume zu Dem Lodb, treufele St. Sobannibol mit Ierpentin oder Fichtenbarz beis binein uno lege Şanf: merg barauf.

E i $\mathfrak{a}$ n Deres srb.

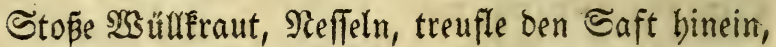
oder ftede Die Sräuter hinein, menn die $\mathfrak{B}$ unoe nod) neu iff.

\section{Ein a ndereb.}

Raume zu Dem (siter und ftecke cinen Maiffel von (siertlar, Salz uno SBseiraudi binein.

\section{Ein anderez}

WSaf̧che den Shaden täglich mit warmem (sffitg uno Salz aus, und freue das

Sulver von Rojen,

Minrrben, (Salläpfel,

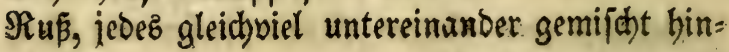
sin. 


\section{Ei $\mathfrak{n} \mathfrak{a} \mathfrak{n} \in \mathfrak{r} \in \mathfrak{b}$ TE.}

Saume zu Dem ミdaden und faubere ifn, alzbann thue himein nad)folgende Salbe,

\section{\$ुech), Şonig, $\Re u \beta_{1}$}

miide es untereinander zu einer Salbe.

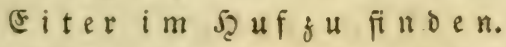

2Beun man die (siter nid)t finden fann, fo brecte

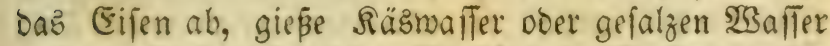
auf Den Suf, auf welther Etelle Das SBaffer meid)t, Dajelbft ift Das citer, fold)es foll man mit bem Snftru= ment cocr fonften offtuen, bamit bas Ěiter heraug fum= me, gieß̃e beip̃es Unjhlitt barauf, bectz mobl mit $\mathfrak{W}$ etE zu uno fítlag Daz Eifen wieber auf.

\section{(5 $\mathrm{i} \pi \mathfrak{a} \mathfrak{n} \mathrm{D} e \mathrm{r}$ e \& $\mathfrak{W}$.}

¿ape die Coblen ober den Şuf wohl aufichneiden, Damit bas (Siter beraus Eomme, giepe \$pech) uno Iung= fraunadis untereinander gemifd)t marm in Das Loch; ober treufle Bocfs=Utnjulitt hinein, bis bas Rod) yoll mirb, lege Sirithifar barauf, fomiere auth ben Souf überall mit Sockz: Un nichlitt.

\section{Ein anderes $\mathfrak{s}$.}

Raume zu Dem (Eiter und treufle bon nad)folgendem Spflafter bimein :

(5)ummi Elemi 2 loth,

Tannenpech,

Şarz, jedes 4 loth,

Drachenblut 1 loth,

Etorax Salamita 1 Suintlein,

mifdue es untereinander auf einem Roblenfeuer und wenn alles folvirt ift, fo hebs vom Feuer, la 
nig crtählen, uno rübre ein loth Campfer binein, wel= chez zuwor in Rojenól zerrieben worden.

\section{(E) i anoeres.}

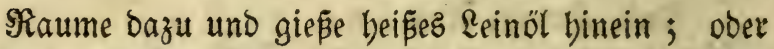
brauche ben (Englifchen গsunobaliam.

(E) $\mathfrak{i} \mathfrak{a} \mathfrak{n} \mathcal{D} \in \mathfrak{r} \in \mathfrak{s}$.

Raume bazu uno nimm $\Re$ oggenbrofamen, Salz uno Errbjenbrühe, mifche ę untereinander zu einem Teig uno binos über.

E in a noerez: 2 .

Siede $\mathfrak{B r u n n e n f r e p e n ~ i n ~ a l t e r ~ S c h m e e r ~ u n o ~ f d j l a g ~}$ Dem \$ुfero Damit ein ; Doer fiede Şirfen und Reimfaa= men in Sdymeinefdymalz, fto

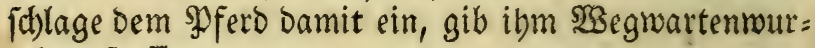
zel zu frefien.

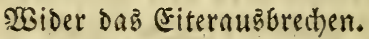

İm Fall aber baz (siter oken bei ber STrone aużge: brodjen märe, fo mache unten, no ber Schaden iff, wobl \&uft, unterfuche es mit einem Sonftrument uno les ge oben über die Rrone nachfolgendes Sुflafter :

Dinkelmebl, Eierweiß

Sdjöllfrautjaft,

Nagelfraut,

mache ein \$flafter baraub.

Ein anderes.

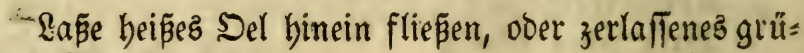
nes Siegelwadhs.

\section{שin anderes.}

Bähe es mit gefottenem 2 (ttid), und treufle aud) $2(t=$ tidjaft binein. 
aużorücken, nochmals etlidhe Tage nichts als gefottenen Inoblauch mit ein menig Sffeffer angeftopen barauf binden und endich mit Der (Egyptifden Salbe vollende auzheilen. Wrenn baz lödhen tuber ber Sirone ganz

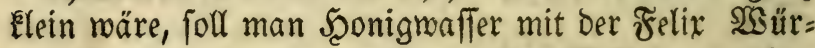
sen Braunfalbe oder Der Egyptifden Salbe vermijuen uno mit einer Eprife barein fprifen, ober aud) bie Mixtur von $\mathfrak{B s e i n}$, Sonig uno (strbjenmebl.

Alaunwaffer,

Ein andereb.

Fif chlacken,

(S) falzene Fleifdlacten,

Tseī̄en $\mathfrak{B}$ ein,

mijche es untereinander uno binde es barauf mit Şanf: merg.

Soblen auszuzieben.

Wenn aber Der Nagel zu tief hinein gegangen uno

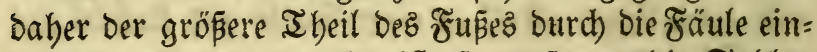
genommen und verberbet ift, fo mus man bie Soblen auf folgende $2 \mathfrak{s e i j e}$ auszieben.

Shneide die Soblen bez Fupes unter Dem Scuf um ben Sreis berum mit einem (sijen auf allen Seiten rings herum hinneg, fape hernach bie Spitze Der Soh= len mit einer 3ange uno ziehs gleidjam mit aller Macht rüdfwärtz berab; menn aber bie Soblen bart

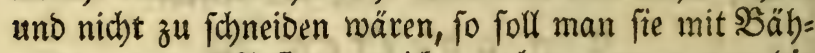
ungen uno soflaftern weid) macher; menn nun bie Soblen berab uno bes (Seblütz eine gute Menge ber: aus uno bem (siter abgebolfen ift folege, ben Sd)mer= zen fammt ben Feud)tigkeiten zu ftillen, 2 serg ober Fäjern in EierElar uno Branntewein geneşt über, ober wenn es beftig blutet, nur frifden Roṕzoth uno 


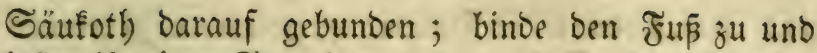
laßje alfo einen Tag ober zwei unafgebunden Darüber liegen; alsoann binde ben Schaben wieder auf, lap Die Sefdnwüle uno Soble mit Sconig, פ̧ein uno Salz warm wafit)en, biffe SBüfd)en mit $2 \mathfrak{S e r g}$ in (Eierflar,

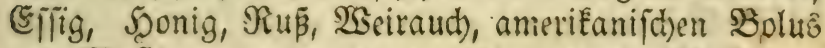
und Maftix untercinander gemifht getaud)t, überlegen, uno fubtil (sijen=Bled) Darauf mit einem paar: Nägel beften, Damit bie Soble nid)t zu bod) betaus wadje ober zu dick werde, hinten aber mū foldes Bled)eifen 2 Ringe baben, in weldbe man etlid)e fubtile uno breit

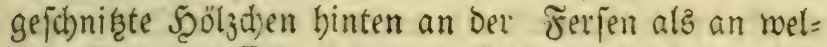
bem Srte baz (Eifen bart und fteif angebunbeu und 3 Tage alfo unverändert gela te hinein f(t)ieben fönne. Nad) fold)er Beit nimm al=

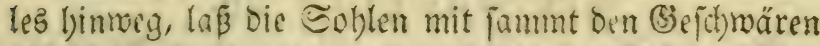
täglidu joweimal mit warmem (5ffig uno Galz wajoben, uno mathfolgenoes \$ulver Daranf ffretten :

2fmerifanifden Bolus,

SGeinftcin, Salläpfel,

Salz, 2llaun,

$\Re u \overline{3}$, jedes gleich viel,

untereinanocr gemifidt uno gepulvert.

Sernad) cin Büfthen $\mathfrak{B}$ Bero in (silig, in melchem Rojen, Eamirlen und Rinden von SGeibenholz gejotten roorben, oben Darüber legen und bas (Fifen, mie oben= gemeloct, sum anoernmal barauf thun.

MSenn mun die neue Soble etruas ftark und feft ge= worden ift, fo thue biefe formale Eifen bintweg uno fohlag ein anders uno gröpers auf, 'auf melchem bas פुfero getniffer fteben uno bie శeefe fid) ausbreiten fön= 
ne. Utm alzoann bie Seilung zu vollenden, gebrauche man die rotbe Salbe.

\section{Ein a}

Sobalo die Reinigung gejheben ift, jo brauche Nach= folgences :

\section{$2(t+i d)$ meer,}

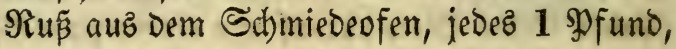

mijche es untereinanoer über einer (S)lut, laß̧ es fieden,

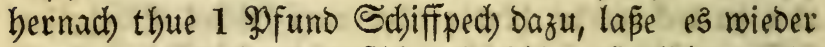

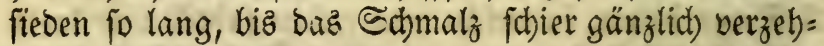
ret iff, orüczs bernad) aljo marm ourd) ein Iudh, thue noch 4 loth (Srünfpan bazu, lapee es noch ein menig fie= Den, Dann bebaltz zum (Sebrauch.

\section{E in a noeroz 2 S.}

Man foll ben 2(bend zuvor, ehe man dem Dfero bie. Soblen auzzieben will, ben Şuf woll nalles Scanfmerg legen, und mit breiten Solzen vermachen, Damit Das Scanfwerg nicht beraus fallen Eönme. 2llsoann wenn man bez andern Iagez die Soblen ausgezogen, foll

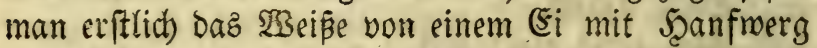
barauf binden uno 3 Tage barauf liegen lapen, hernad) berunter thun und Das Scanfwerg in frijchem Brunnen: waffer mit \$itriol uno (Eierweis vermifcht tauchen, uno wieber barauf legen, wenns ben Sern nicht ichlie= pen will, fo ftreid)e nachfolgende Salbe barauf :

(S)ünipan 2 loth,

Iupferwafler 3 loth,

Terpentin 2 loth,

Srünes Siegelmadbs $\frac{1}{4}$ sp funo,

fiebe es orei oder viermal, bis es eine rotbe Salbe miro, 


\section{PFerbe:2traenei Bud.}

und frreue aud gebranntes Supfermaffer und bas \$ul: ber von Sajelzapfen batauf.

\section{E. i n a n D e e.}

Sd)neide rings herum ben Şuf hinneg, nimm bann eine Dünne Slinge, hebe Die Єoblen am Fuß auf, biz ou fie mit Der 3ange gewinnen fannft, ziebe es berab, wafhe Den Srt mit warmem (Effig, taudbe bernach Sounfwerg in Effig, ortüb ein wenig auz, nef̧e ez in Eierflar und Galz und binds über.

\section{(5in andereb.}

Weip̌es Mehl,

$\Re$ Rै von einem $S_{f e n ;}$

mait) mit (5fitig gu einem İeig uno fichlagz über.

\section{E in anderez.}

Ctreue Daz Sुulver bon Rorbeeren barauf, bernad) mathe eine NRijoung mit Roggenbrofamen und (5ier=

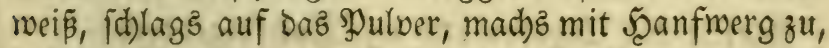
bas̄ es nid)t heraus falle, thue es alle నage zmeimal und balte Das Şorn mit guter Sornjalbe feucht.

\section{Ein in therez.}

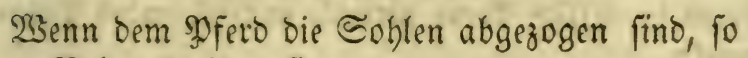
ఇehme meipen Şar,

şech, jedes 8 loth,

פखad) 4 loth,

SBeirauch 1 loth,

Sdimefel 2 loth,

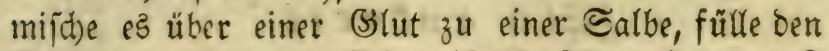
Fup bamit, fithlag ein @d)eereifen auf, uno lap̄e eg 3 Iage bamit ftehen, am britten Tag nebme ben Ein: fhlag binmeg uno freuse geftopienen Schrofel barauf, 
nimm ein breit beip (Sijen und zünde ben ऽdwefel an,

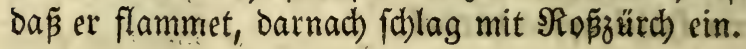

\section{Einanderez.}

Streue alle 24 Stunden geobrrten Spifenmegerich barauf, continuirs bis bie Soble wäd)ft, alsoann lape warm Sconig hinein laufen.

Für Das Straljlgefdimüre.

Dies. Eommt von überflüpiger Feuchtigéeit, von naf= fen Ställen uno $\mathfrak{W}_{e} i_{b e}$ auch unjaubere $\mathfrak{S a r t e}$ ber Fǚe ber Spferbe.

Diejen SDferden foll man ein paar mal purgirende

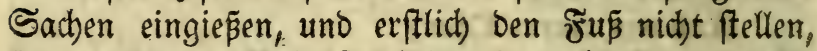
fonbern eine weile laufen lapen, hernach bünn austoür.

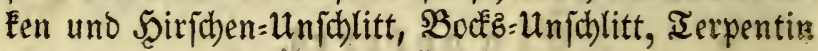
untereinander gemificht, aufiftreichen.

\section{(5in andereb গT.}

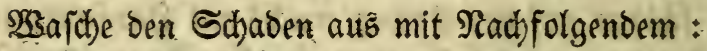

(Siranatäpfelfchaalen,

Summach, (salläpfel,

MAnrrthenblätter, jeoes gleidyuiel.

fiede es in (5iffig, freue bernad) nadb folgendes sylulnet barauf :

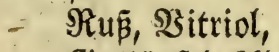

(S)aulläpfel, 2rlaun,

W3üllfraut, jedes gleich viel,

untereinander gemifd)t und zu einem SDulver gemad)t.

\section{Ein anderez.}

\section{Siupferwafter, 2llaun,}

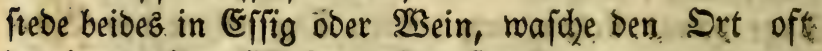
Damit uno lege Scanfwerg brauf, 


\section{פgFerbe=2(rzenei Buth.}

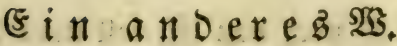

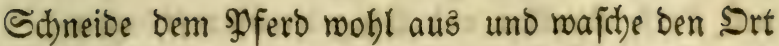
mit $\mathfrak{S}_{\mathrm{S} a f f e r}$ morin 2laun, Siranatäpfelrinden uno (Salläpfel gefotten morden, ftreue bernach bas (Saput mortuum Sitrioli barauf.

\section{Ein andereb.}

Nebme 2altfameer uno rweipen Scundzfoth, mache es warm uno lege ez darüber, hernach Scanfmerg barüber und oben barauf Rop̧zürch.

\section{Ein a noereb.}

Befaneide den Strabl wobl, jedod) daź or nicht blute, bähe ifm dinfelben mit warmem Misin, rorin Weirauch gefotten fei; algotann binde ihm dez Tags Rachfolgendez zmeimal warm auf :

\section{Nebme Sarz,}

Waacb), jeoes $\frac{1}{2}$ \$f fund,

(3rünfpan 6 loth,

Unid)litt $\frac{1}{2}$ SPfund,

BSeiraudb,

jerlape uno mijhe es unteleinander über dem Freuer.

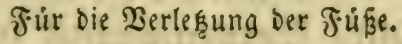

ß3enn ein \$fero in etwaz Spitigez, alz Scolz, Dorn, fpiţige Sägel, oder prisige Steine, Beiner uno der = gleichen, getreten, melche ifm in Die Soblen bincin ge= hen und das \&ebendige beidäoigen, Daran empfindet ez gleid) zum 2infang groflen @dbmerzen uno bălt, menn es ftille ftebet, den $\widetilde{F} u \tilde{\beta}$ von der Erde. Siehe Figur शRo. 32.

Denen foll man zum Schaben albbalo räumen, bas Epifige, nofern es barin ftecken geblieben, heraug $58 *$ 
nebmen, wenn es nod) neu ift, foll man bie Nifoung von Salk, Eierelar uno (sfifig barüber fichlagen.

Ein anderes.

(3)iepe den Englifchen 533 undbalfam hinein, gebraudje eह einige 3eit fort.

Ein andereb, се jei neu doer alt.

Sornblumennurzet,

(Sarten Rreffen,

Schlüffelblumentourzel,

Scajenidymalz, 2fltichmeer,

¿ebenoige Rrebje,

ftope afles untereinander uno binos über ben Sdaden, Iap̃ Iag uno Radjt bartuber, bann wajche e's aus mit marmem $\mathfrak{B}$ sein, worin Neffeliaamin gefotten worden, uno menn noch etmaz barin wäre, fo hat ez biefes über= fich gezogen, weldhes man mit einem Bängchen beraus zieben joll; fdhlag ibm hernady mit zerffoftener Reffel= wurzel, Sdomefel, 2fltid)meer, Sonig, Iorbeeren, Supf= ermaffer uno Salz untereinander gemijd)t barauf uno verbinds mobl mit Şanfwerg.

E i $\mathfrak{i} \mathfrak{n} \mathbf{D} \in \mathfrak{e}$.

(Sib Dem Pfero $\mathfrak{Z}$ segmartentourzel zu freflen, uno ftope die Sinöpfe von $2 \mathfrak{B}_{\text {egrarten }}$ lumen fammt ber SGurgel untereinander geftopen inz $\mathfrak{l}$ od).

Ein andereż, menn ber Etumpfe noch barin ift $\mathfrak{2}$.

Sablage ibm nachfolgendę \$flafter über bie 2 sunde: srebablumentraut,

Einen Şajenbalg,

Saacte e? Elein untereinander, thue bazu

Scajenfett,

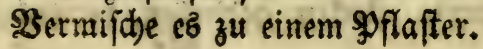




\section{(5: $\mathrm{t}$ anderez.}

Mildrabm, Roggenmebl,

mad)e ein Noflafter Daraus uno finde es barauf, fo bei alz ę Daz झुferd erleiden Eann.

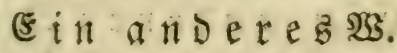

Reinige den Irtitt, zerlaß̧e Şonig und Benedijche Geife untereinanoer, rübre gebrannten 2laun uno ge= biannten $\$$ Sitriol binein, thue es aljo rarm in bas \&od) und verbinde es mit Scanfmerg.

(5 in a noe reb $\mathfrak{B}$.

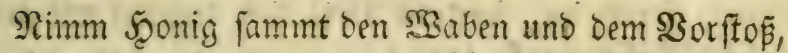
madjs miteinander warm und ichlag Dem sूfero bamit sin.

E in: a nDexeb.

şenn der Etumpfe nod) Darin märe, fo

Rebme Şanfiramen,

Icinfaamen, jedes 1 I beil,

altichmeet 2 Ibril,

frope es unteleinander und bindz auf die $\mathfrak{W} u n b e$ la läe ę 3 Iage barüber folyen, alzoann binds auf, fo fin= Deft ou ben Stumpf in Dem Spflafter.

\section{(F) in andereb.}

Reinige ifm ben Iritt, wajd)e benfelben mit mar= mem NGein aub, menns troden ift, fo giepibm ben (5ng =

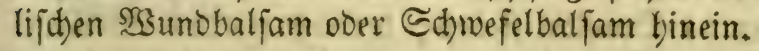

\section{(5in a noereb.}

SुBenn ein SPFero in einen Dorn getreten bat, fo zer= fope einen (siderentopf alfo frifch uno legs über, fo zie= bet er Den Spreifel beraus.

2lle (5uren, reldbe zu Den vernagelten spferben ge= braucht werben, Eonnen allhier auch angetwendet merben. 
Wenn ein Pferd fidt felbft, oder von andern getreten wird.

Wenn ber Tritt nicht offen ift, fo foneibe benjelben auf, oder öfne ifn fonft mit einem Sinftrument, treufe= le beipes $\mathfrak{B a d b}$ und $\mathfrak{u}$ idhlitt untereinander binein.

Ein anderes $\mathfrak{B}$.

Nimm gebrannten Sfenleim zeritopen, vermifhe ben= felben mit Sconig uno (sffig uno follagg über Den Scha= ben.

\section{(5) i a noeres $2 \mathfrak{s}$.}

Şenn ber Iritt noch neu ift, fo rúbre benjelben mit Eeimer Şand an, fondern trete ifm oreimal mit dem rechten Fũ barauf.

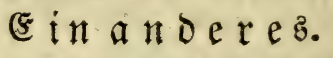

Treufele ifm nadjfolgendes binein :

Xnrrben 2 loth,

Sonig $\frac{1}{4}$ Sf funo, - Spect $\frac{1}{2}$ SPfund,

Saumöl, Bodfz: Un íchlitt,

Sirfdeen= un fichlitt,

Echnefel, jeoes $\frac{1}{4}$ SPfuno,

mifhe er untereinanoer.

\section{E $i \mathfrak{n}$ a $D$ e}

Mache einen Ieig von ungelöldtem Salf und Eier:

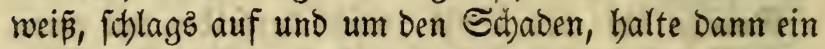
glübeno Eijen baran, bis es bürr wirb, la $\beta$ unaufge= bunden 24 Stunden fiteben; bernach mache einen Teig mit Şonig, Esierweiṕ uno ungelöfdtem Ralk, binos ba=

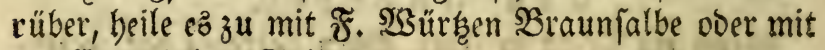
Der Esyptijoen Salbe.

Ein anderez.

গRebme Cierweís, 


\section{Pfferbe:2(rzenei Bud).}

Sebrannten 2flaun, untereinander gemifd)t und barauf gelegt

Ein a n Deres.

altid)meer Sd)wefel,

untereinander gemijd)t und aufgebunden.

(5) $\mathfrak{i}$ it $\mathfrak{n} \mathfrak{D} \in \mathfrak{r} \mathfrak{e} \mathfrak{b}$.

Taud)e ein leinenes Tud in beipes Saumöl und (c) lage beî́ über.

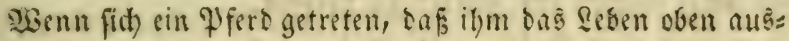
gelyen roill.

¿ege ibm gebrannten uno noth beipen Scunoskotb, barüber, fo fliebt ber Sern binter fid), alzbann foll man benfelben mit einem beipen (sijen nod) einmal, aber renig brennen, uno şonig uno Roggenmebl ba= rüber legen.

\section{(5) in andereb.}

Nelye Şundztoth,

Ealcinirten Menichentotb,

mifde es untereinander uno thue $e^{\circ}$ in bie $\mathfrak{B} u n d e$.

ein anoeres.

Strete gepül(bertez Şirfhborn mit 3ucfer gemijht bincir.

$$
\text { Ein andereb. }
$$

\section{Ruß Eiertlar,}

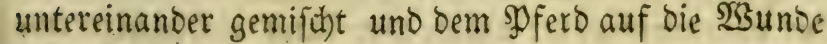
gebunoen.

$$
\text { Ein andereb. }
$$

Stope Shlüllelblumentraut und $\mathfrak{B}$ urzel, lege über bie 25 unde und gib ifm auch foldyes unter bem Futter zu frefter. 


\section{(E) in a noerez.}

Sieểe warmes Baumöl hinein, uno lege bie Mifahung von $\Re u \tilde{s}$, ungelöfdhtem Ralk uno Eierflar barauf mit Şanfwerg.

\section{Einandereb.}

2Segmarten,

Nagelfraut,

mifche ez untereinander, fteck's in bie $\mathfrak{2}$ sunden uno gib ibm auch foldbes im Futter zu freffen.

\section{(5in anderez.}

ITröpfele grünez Siegelwachz poer Schaaf=Unnfdlitt binein.

Fur oie Şornfluft.

Diefes entffebet von allzu trockenen uno $\$ 3$ ermabr: lofung Der Şüfe; auch von fteinid)ten SSegen uno über groper forctrung ber spferoe, befonders berienigen, welche von Natur hisigen Iemperaments, von groß̧er

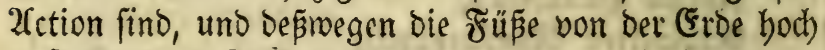
aufbeben und fare niederfdlagen.

Ez ift ein fehr übler Schaben zu beilen, befonder's im

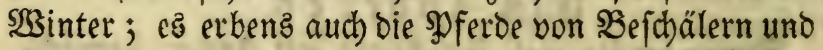
Stuten.

(Etlidben gebet die Spaltung ben ganzen Scuf burch)= aus bis in bie Srone uno Reben; andern aber nur über Die Saälfte, ber erfte ift einer langen uno befchnerlidben Sur unterworfen, ber andere aber kann viel leichter cu= rirt nerden.

\section{Die cur.}

Reinige die Scornfluft auf Das allerfleiffigfte mit cinem (sifen, fobabe mit einem Sdjabet bas 2flte wobl oben binneg und lege $\mathfrak{R a d}$ folgendez barauf : 


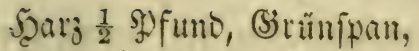 5ूonig jeoez 8 loth, Ierpentin $\frac{1}{4}$ Po fund,}

mifde alles über einer (Silut untereinander und fifreid)e Davon auf bie Scornfluft, verbinds alle Norgen uns iblag bem Sुfero mit Eibifdrwurgel und ミd)meet sin.

\section{E}

SGenn aber ber Sornfluft nidht in bas Rebendige ober gar bis in Die firone gegangen ift, fo reinige und $\mathrm{cr}=$ weitere biefelben aud), rojdye fie alle Iage zweima! mit ?achfolgendem aus :
(3)
(Sialläpfel 3 loth,
Rofenblätter 2 lotb),

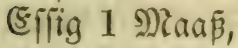

mifdse uno fiede es rookl unteteinander.

Sernad) ftreue nad) folgendes gुulvet binein uno ver: binbe den Fũ mit Scanfwerg.

(5)alläpfel, Gumach,

Siranatäpfeltinoen,

ISiflleraut, jebez gleid) viel.

untereinander gemifdt uno gepülvert.

Nach) 5 ober 6 Iagen wajue bas Seorn alle Iage jweimal mit nachfolgenoem 2rbfuo:

(Fibijd), Bockzhornfaamen,

Steinflee, jedes 1 Şandvoll,

Röblfrautiaamen,

Reinfaamen, jeoes 2 loth,

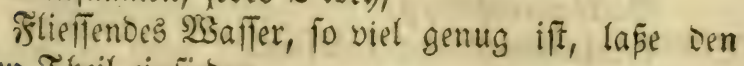
oritten I Geil einfieden.

Sd)lage Dem SDferd aud) täglich gefottene (Eibird)= 
routzel mit 2attichmeer zerftopen ein, Damit ber Scuf feucht bleibe und radsfe.

2̧enn aber Die Scornfluft biz ins \&eben und an die Srone binauf reicht, fo mus fie mit einem glübenden (sifen fubtil gebrannt, uno mit obiger angeniefener Brandfalbe gefdmiert meroen, auffer Dem wirb ez lan= ge 3eit brauchen, bis fie felbft anjefst und fid zui Scis lung anjohickt.

Fine andere bályung deb̉ Scufs.

gisilde (Sucumernwurzel $\frac{1}{2}$ Scandvoll,

Samillenblumen 1 5̧anoboll,

Saffian 1 Scrupel,

Şein 1 Maaß̄,

fiebe es wohl untereinander, nefe einen $\approx$ chwamm $D a=$ rin und bäbe das Şorn bes Iages oft bamit, oder fdymiere bas Scorn bes నagez einmal mit nachfolgender Salbe:

(5)ummi (S)albanum,

Ifmmoniacum, jedes 1 loth,

Fistenterz,

Eolophonia, jeoes 6 lrth,

Slibanum 2 suintlein,

Naftix 1 Suintlein,

Scammels=Unichlitt $1 \frac{1}{2}$ \$f fund,

mifche e's untereinanoer über einer (S)lut zu einer Salbe.

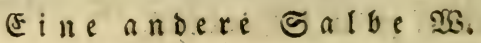

Den Schleim von Flöhefrautjaamen,

Bockzhornfaamen,

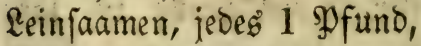

(5) ummi 2Cmmoniacum.

Salbanum, jeoes 1 loth, 


\section{PFerde:2Trzenei 3 แh.}

Rinos:, Sälber $=$ ober Seirịit)enmark, Bärenj(d)malz ober Dad) (enjid)malz,

$$
\text { jedes } 1 \text { פfund, }
$$

mijche alles untereinanoer uno lod)

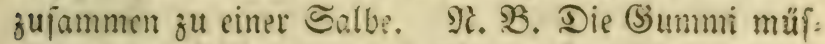
fen voi Der (simmijhung in Sifig aufgelö̈t werden.

Jृat man mit biejem mun cine 3eitlang fortgefab: ren, bie E Stgrunde fith ganz hinab gefentet uno gebeilt, fo foll man rs befd)lagen uno bab (sifen barmad) rid).

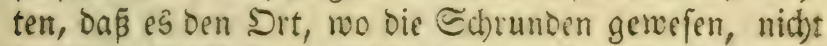
berübre oder ftoß̉e, uno fámiete Daneben die Şüfe mit guter Şornfalbe.

Z3ennaber Die Scornfluft auf daš Rebendige binein: gegangen ift, to reinige bie Epalte auci) uno ftreuse \$ulver von 2 sulferaut bincin, ober fithmiere an bepen Etelle $\mathfrak{Z}$ üllftautfaft uno Bleimeis untereinanoer ge: mifid) binein; ober treufele die Stübe von gefalzenem 8leifch oder Fifd)lacten bincin, welches trefflid) reini= get, ooer alt Baumol mit Ealz marm gemacht, obpr alte heipe uno gefalzene Schmerr, ober mifd)e Sd)lan= genid)maly, ङalz uno altes Sel untereinander üler pi: nem Fruet uno beftreici)e Die. Sornfluft Des నagps ztweimal bamit.

Benn aber bie Sornfpalte fehr alt iff, fo muß man nod) fleifitger aušräumen, bis das şlut auslauft, unb fit) Der Boden ber Scornfluft feben läst, aletrann äge bag "übermäfilige Fleifch hinweg, töote es, beile bie

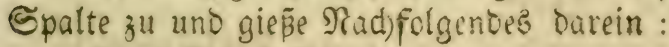

2fltes Sol $\frac{1}{4}$ ş fund,

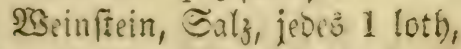

mifhe eక über einem sifflenfeuer untercinander und gebrauche es. 


\section{(E) a n n}

Wajabe die $\mathfrak{B}$ unde woll mit fibarfem Elfig, in mel= chem Salz gefotten worden ift, und fireue vom ge: brannten (5iz binein, ooer Sुulver von zu 2riche ge= brannter GSolonurzel; Die vorermäbnten 2rizeneien baben bie (sigenidaft beg 3ujammenzielyens uno trod": nenz.

(1) in anoereb IS.

SRrenne Die Sorntluft und feile es Dann geforwind berab, räume wohl auf das \&eben, bernad) lege bie Egyptifhe Salbe ober Felix Würhen SBraunfalbe da: rauf.

\section{(5: in a $\mathfrak{n}$ Dereb $\mathfrak{X}$.}

SBrenne bie Scorntluft und räume fie aub wie ge= bräuchlich uno renne $\mathfrak{S a r b z ,}$, forol, Ierpentin unter. einander bei einem Feuer gemifut warm in Diefelle.

\section{(5) in a noerez.}

Raume es bis auf Dab \&oben, cauterifits ein wenig, mifche Sconig, Blcimeis uno $\mathfrak{R e}$ eirauch, jeope gleichviel untereinanoer uno binde mit Sanfinerg über oie $2 B u n=$ De, continuirs 3 Tage, jeben Iag frifd) übergebunden, alsbann lege fo lang bie $\mathfrak{B}$ unde bauert sin Etüd

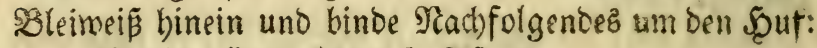
Waadb, Şarz, jeoes $\frac{1}{2}$ Sुfuno,

Sirfichen=Unfidhlitt,

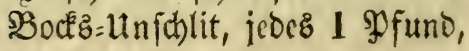

Reinol $\frac{1}{4}$ Pfuno,

mijhe es untereinanoer über einem Soblenfeuer zu ei= ner Salbe.

$$
\text { Ein a no ere. }
$$

Räume bem $\mathfrak{P}$ ferb biz auf bas $\mathbb{Q}_{\mathrm{eb}}$ en, madye einen 
fein \&ebtag mebr zuredt fommt, als es im 2 nfang ge= wejen, wenn man gleid) aud alle Mittel anmendet; es $^{2}$ Eommt von Der Rebe, Bernagelung, Upoftemen und andern Feud)tigkeiten ber Fülle; aud) wenn man bie Steingallen nicht fleiffitg aubwirft, von einem Iritt in bie Srone burchs \&eben, wenn bas \&eben unten zu fehr zorüce getrieben wiro, beswegen oben ausgebet und afl= zu lang gewährten Mauken.

SBenn fich nnn ber Şuf an einem Srt bon bem Fun abgethan bat und unter bempelben ein neues hervor: wächft, fo nebme ben alten Şut nabe an Dem Srt, no ber neue wädhit, binroeg, bamit er mit feiner Scärte ben zarten jungen Şuf nicht bejchäbige, und famiere ben seuen mit einer Salbe, welche ftärket uno wadjen macht :

Şanmelz=U1nichlitt 1 POFund,

Waachs 6 loth,

Baumöl 4 loth,

mifhe uno fiede es untereinanoer, uno beim Sieben rübre Darunter:

Weiraud), Maftix, jedes 1 loth,

Eine anoere salbe.

Shammels= Uunfhlitt,

Śdbmeinejhmalz, jeoes 1 Pfund,

Reinöl, Saumöl, jeoes 6 loth,

Sconig 4 loth,

Sisachs 2 loth,

mifde ez über einem Rohlenfeuer zufammen, bernad) hebs vom Feuer und rühre nachfolgende Solver hinein:

Drachenblut,

SBeiraud, Maftix, jebes 1 lotb,

milche ez untereinanoer. 
ift, fo braucbe, um benjelben zu ftärfen und Gart zu madhen, nachfolgenoes :

(Salläpfel 6 loth,

Salz 1 Scanovoll,

Sleien 3 Şandooll,

fiebe folches in idharfem (sfifg, ftreiche es um ein leine.

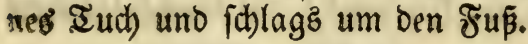

Eine andere salbe.

Butter 2 গfund, Roról 6 loth,

Sonig 8 loth, Drachenblut,

Fiseirauth, jeoes 1 loth,

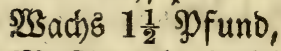

Naftix 2 suintlein,

milche eg über einem Feuer untereinander zu sinet Salbe.

\section{Eit and $\mathfrak{a} \mathfrak{e} \mathfrak{e}$.}

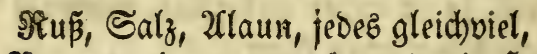

mit Branntwein angemacht uno mit Seanfwerg über= gellegt.

Sad) habe beren Spferde etliche gefeben, und auch pi= teb unter Scänden gebabt, fo beibe vorbere Scüfe bin: weg gegangen, welches zmar leicht curirt morben, aber fein $\mathfrak{L}$ btag feine Stärke mebr auf ben Şüfen gehabt gat.

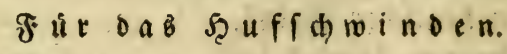

Diefen Spferden muß man mit guten Scornjalben, uno intoendig mit guten Einfchlägen geholfen werben, ba= mit baz Scorn mieder wach fen fönne.

2̧adbloldergipfel 6 Scändeboll,

Waad) holderöl 5 loth,

Zlten Spect $1 \frac{1}{2}$ spfuno

Sunosidnalz. 


\section{Dad) fenfdhmalz, $\frac{1}{2}$ SPfund, Sirid)enmart 1 gुofund, \\ Iannenzapfen 6 lotb),}

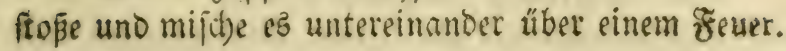

\section{Ein andere}

Regenwürmer,

Baumol, jedes 3 Sुfund,

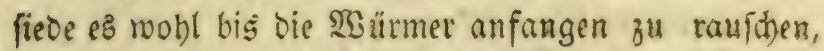
bann ifte genug, brücfe eह bernad) aนอ :

গebme von Diefem Sil,

Wadb, jeoes 1 Pुfund,

Butter 2 Sुfund,

Rlauenfett $\frac{1}{2}$ ⿰豸口f fund,

Dis Sthmalz von gefottenen Rübetörnern, wel: dees oben auf Dem 2 bafler f(t)rimmt $\frac{1}{4}$ Sp fund, mifit)e es unterpinander zu ciner Salbe uno fotmiere bas $\mathfrak{p}$ ferd oft Damit.

Eine andere Salbe.

E.t)mert 1 sुofuno, Sonig 10 loth,

Sarz, Edjaaf:unidylitt,

Dialthea, jeoez $\frac{1}{2}$ șfund,

$\mathfrak{B}$ adjs $\frac{1}{4}$ Ş funo,

mifhe alles luber einer (3lut zu einer Calbe.

E. in a noereb.

Eeife 1 sुfuno, Iannenpedh,

Wagenidbmier,

:23ad)s, jebez 4 loth,

Sibaaf: ltnidblitt $\frac{1}{2}$ Pf fund,

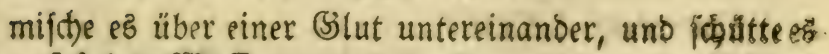
auf Paltes $2 \mathfrak{B}$ âfer. 


\section{Ei}

zrttitgmeer 2 \$fund, Şonig 4 פूfuno,

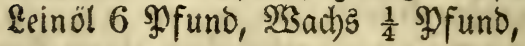

mijat)e eร untereinander über einer (S)lut gejotten, bis e⿻尸 bie Didêe ciner Salbe befommt.

$$
\text { Şornfalbe. }
$$

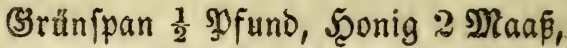

Supferwafifer 1 Mfund,

Schnefel $\frac{1}{2}$ Pfund, $\mathfrak{B a c h}$,

Schieppulver, jeoes 1 ⿰氵工 funo

milche es untereinander, alsbann fetge es nach $\$$ Bermi= fotung über ein Joblenfeuer und fiebe eg zu einer Salbe.

Eine andere Saornfalbe.

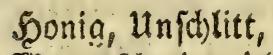

23agenjatmier, jeoes gleidybiel,

madhe zu einer Salbe.

\section{(5) in andereb $\mathfrak{Y G}$.}

Souflattigaft, 3iwiebel jaft, jedez $\frac{1}{2}$ DRaá,

Eindenbolderrindenfaft $\frac{1}{4}$ Maás,

Sd)aaf Unidblitt,

Bocés: Un nichlitt,

Shirfiden:Utnifblitt, jeoes $1 \frac{1}{2}$ Sofuno,

22Sach3, (3rünipan, jedes $\frac{1}{2}$ Pfund,

mifhe $\epsilon \dot{B}$ untereinander über einer (S) lut, uno lape fo lang rübren, biz daz $\mathfrak{S} a$ affer von Den Săften nerbampft. ift, Dann hebs vom reuer, jo iffe fertig.

E

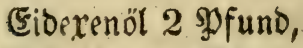

Suvenleim $\frac{1}{2}$ Mfund,

Tannenpech 18 loth, 2attichmeer 2 gofuno, 


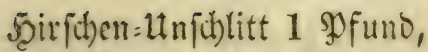
über einem Feuter ofu einet Ealbe gemifdt.

\section{(E) $\mathfrak{i} \mathfrak{a} \mathfrak{n} \mathfrak{e} \mathfrak{e} \mathfrak{E} \mathfrak{B}$.}

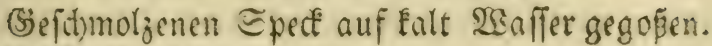

Bodf's= Un nit)litt,

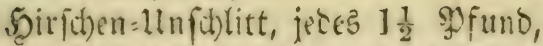

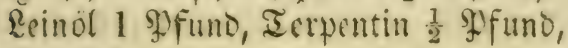

शुad) 1 ⿰ু fund,

mifd)e es untereinanoer über einer (3) lut.

Silutunfett $1 \frac{1}{2}$ Shfund, Reinot 1 Sुfund,

Bumol $\frac{1}{2}$ sfund, 3uter 1 ffund,

Ierpentin, $\mathfrak{W}_{\mathrm{a} a d)}$, jeces $\frac{1}{2}$ D fund,

Seife andertbalt $\mathfrak{g}$ fund,

SDirfden=Unfoblitt 1 Ffund,

Rinos:Unjhlitt 2 Sf fund,

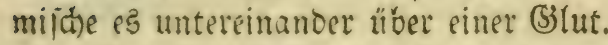

E in a noerez.

Sibaaf: 1 tnfdhlitt 2 Sf funo,

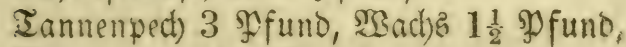

W3agenfdmier 1 WJund,

miiche es untereinander liber einer (Sil tt.

E in anderes $\mathfrak{B}$.

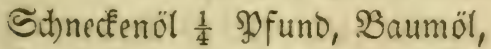

Eoröl, jebez I \$funb,

Spect ¿2 \$f funo, 2attidmeer,

Shirichen:unichlitt, jeoes 3 Pfund,

Socks=Unjedlitt 2 sofund,

WBad)s, fo viel bierzu nöthig ift.

mifhe es untereinanoer über ciner (S) lut.

$\mathfrak{B} \circ$ Il $)$ f.

Diez miro cigentlid) ber $\mathfrak{B}$ ollyuf genannt, wenn bem 
Y) ferd der Sern je länger je größer wächft, bas aud) gar keine Şöble mehr zu feben ift.

Rommt Den \$ferben yon naffen Ställen, moraftigen פgseiden, überflüfirger F̌eudtigkeit der Sobenkel, üblem Bejhlag, gar zu fliffitiger (sinjitlagung mit §übemift;

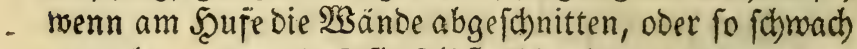
gemadht woroen, das fie felbfit abbredben; auch wiro es von Befbäletn uno Stuten ererbt.

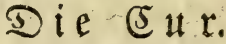

Treibe daz \&eben mit beisem פ̧ed) zurück, aber man mus Dabei tie Srone feud)t balten, Damit es nicht oben

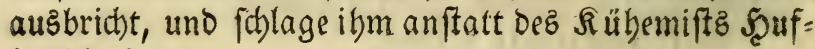
lattid) ein.

\section{Ein a noreg.}

$\mathfrak{R}_{\mathfrak{B}}$ daz syfero im abnebmenden Mond bejhlagen.

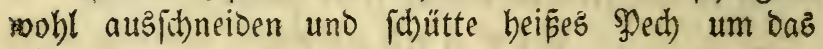
Shorn herum, oder fhlage ibm mit nachfolgendem Ein= follag ein :

Ungelöfuten Salk 2 Scänoevolr,

SBitriol 3 loth,

SSirfiben=Unjichlitt $\frac{1}{4}$ פfuno,

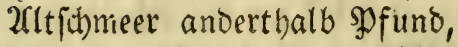

mifache $e \mathfrak{G}$ untereinander uno fchlägs über mit Şanf= swerg, uno fohmiere ben Scuf mit ungefalzenem Epect,

Ein a noereb.

Sallage ibm ein mit Menfchenbarn ober Rüheharn mit feimen angemacht.

(5) in anderez.

Mifdhe Scheiberwafler und $\mathfrak{B a d h b o l d e r o ̈ l}$ untereinan= ber, ftreichs ez in Den Scuf, laß̄e ibm daz Scorn mit 


\section{Wfertes:Vraenei Butt\%}

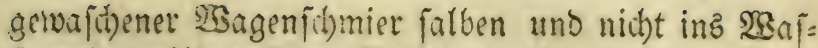
fer reiten, biz es feime 2 sirfung getban bat.

b. $\mathfrak{a} \mathrm{t} t \mathfrak{b} \mathrm{u}$.

Der Şlattluf uno ber \$̇ollyuf fino gerne beifam: men, ift aud) einerlei (Sur.

Fommt, renn tie Wand von ben Soioten gar zu viel wegge(d)nittrn, aurt) won bem Eifen abgeftochen uno georidt miro, fonterlid) wenn man folden Pfer: Den nod̉) bohle (sifen daju mad)en läspet, fo Eann bie

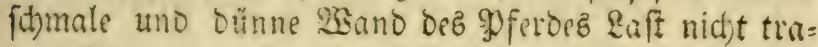
gen, fondern muz cerfelben meiden uno abbredten, bez= halb follen Die 2 sände, worauf das Eifen liegt, allezeit

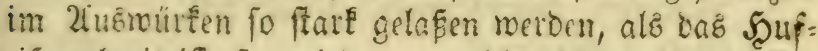
eifen breit ift, fo miro man nicht leicht blatthüfige গू) ferbe befommen.

Diefer Mangel mū mie bar 20 abuf curit merden,

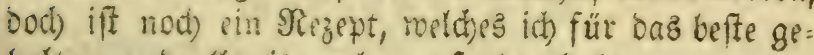
balten, und allezeit probat gefunden bake.

Sduffe Das गjpero, fo balo oufannft, aus bem Stall, benn Diejer sangel if unbeilbar, inoem nie ein blatt= bufig ober vollhufig SOfero itber alle angemanote MRit= tel, cinen redten uno formirten Scuf, wie eb fein folle, betommen bat.

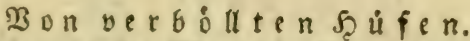

Die Beid)en biefes Mangelb find, menn bie Spferde die Fülfe von fich ftrecten uno fo leiṕs geben, als ob fie auf Rabeln träten.

fommt entmeter yon gor zu bartem ober reichem Scuf, reenn memlich cas \$ffero lang barfúp oaralif ge= ritten roorcen, uno wo man biefem Uebel nid)t kei Beit Rath fithafft, mup̃ man foldhen SDferden enolich gar bie Soblen abzieben. 
Diefen foll man bie Şüfe mit Epect fleiffig fdmic= ren und innen mit zerftopenem Sped, Wadjbolderbe: ren und anoblaud) einjdblagen.

Ein anderev.

Rorftõ 1 Sf funo,

Wachs ein balbes \$ofund,

2altichmeer 1 Sfund,

Salz 1 Şanovoll,

mifhe es untercinander und follage bem sofero damit ein.

Ein andereb.

Geftopene Şanftörner 3 Şändevoll,

Salz I Scanduoll,

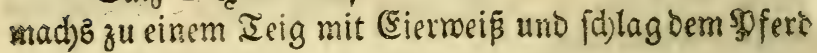
bamit ein.

\section{Ein a noereb.}

Rebme Sranntemein, fibutte ifn in bie Shüfe uno lege Scanfroerg Darauf.

(sin $\mathfrak{A} \mathfrak{n}$ Dereb.

(stliche foütten auch beike $2(j$ d)e barauf, meld)es aber nidbt allemal zu ratben ift.

Ein andereb.

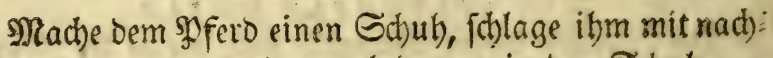
folgeniem ein uno thue audb Davon in ben $S_{(b)}$ :

Ein a ndere $\mathfrak{B}$.

Bodैz= un id)litt,

Sonig, jeoeg $\frac{1}{4}$ Sfund,

uitfimeer 1 sfuno,

2Bachs ober SBorfto $\frac{1}{4}$ Pfund,

Roggenmeb) 2 Scändevoll,

sfiig, fo viel genug ift, 
röfte es miteinanber in einer SDfanne, gebraudbe es marm uno lape es 3 Iage aljo ruben.

\section{(E) i $\mathfrak{a} \mathfrak{n}$ De $\mathrm{reb}$.}

Raßje Daz Esifen bobl richten uno leife aufbeften, uno gib ibm nachfolgenden (sinfollag :

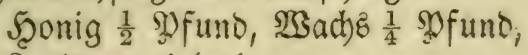

Rorbeeten 4 loth,

fiede es untereinander uno fd)lage marm ein.

(5) i I a no ere

Sdhlage dem sffert mit marmen (5iern in Sd)malz ein.

\section{(5) in andereb.}

Schütte beip̄en Şonig in Den Scuf, lege Şanfwerg Darüber uno fd)lag Ropzzird) Darauf.

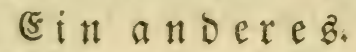

Birfene 2fic) 3 Şändevoll,

Rū 2 Scänoevoll,

Salz 1 Seanovoll,

Effig, fo viel als nöthig ift zu einem Teig,

9 (sielflar, mijhe es untereinanoer uno fdhlage Dem spferd Damit cin.

(F) in a $\mathfrak{n}$ exe .

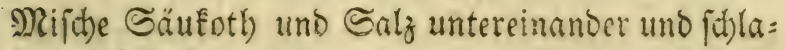
ge dem pferd Damit ein.

\section{(5in andereb.}

Gdjlage bem Syfert mit Saly uno Eierklar ein.

(Ein a noereb.

Serffope Snoblaud) und Spect und fichlag Dem Spferd bamit ein. 


\section{(5) in a nderez.}

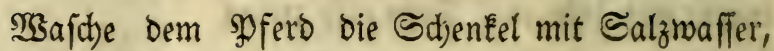
bernach röfte Saly in Butter, daß̧ es wie ein Suchen werde, uno fidlag bem Spferd bamit marm ein; reenng Ealt iff, fo nehme ein frifhes, binde bas Spfero an, baß se (iic) nicht legen Eann, uno gib ibm 2 Sallet zu trin= Een, worin $\mathfrak{B S e r m u t h}$ und Beifü gejotten worden.

(E) in a D e e b.

Shmiere eine Epectid)marte mit 5onig, lege fie auf ben Fup und ichlage das (sifen roieber auf.

(E) in a $\mathfrak{n} \mathfrak{D} \in \mathfrak{r} e \mathfrak{b}$.

Shlage ifm Rojen mit fammt tem \$ूonig, wie aus bem Bienenftocé genommen, untereinander zerftopen ein.

\section{Ein andereb.}

Röfte einen mit $\mathfrak{W a f f e r}$ gefochten Sirfenbrei in $\mathfrak{B}_{\text {ut }}$ ter ober Sabmalz, und binos warm über.

Ein andereb.

Serftope SSadholderberen und Sranntemein un= tereinander und fhlag bem $\mathfrak{P}$ ferd bamit ein.

Ein andereb.

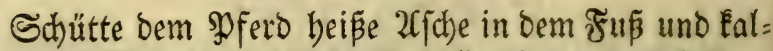
ten Effitg darauf, vermachs mit Şanfroerg uno lape pe über গad)t Darauf ftehen.

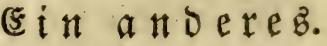

Şitriol und $\Re$ op̧zürch untereinanoer gemifd)et, uno Dem Şferb bamit eingefdlagen.

$$
\text { Ş infen be pfer be. }
$$

Diefe Eann man felbft erkennen, an weldyem Sheil 
folvirz miteinanber in Effitg uno madbs nadbyer mit alter S(d)meer zu einer Salbe.

Man foll ibnen aud) mit Rad)folgendem einid)la= gen :

Gefottenen Snoblauch 1 Şanowoll, B̧efottene Eibijaburzel 2 Scăndevolf;

Schmeinefdhmalz, fo viel zu einem (sinjolag ges nug ift, mifche es untereinander.

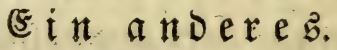

Den Sdhleim pon Dillfaamen,

Bodkgornjaamen, Eeinjaamen,

(Eibifdjaamen, jebes $\frac{1}{4}$ Pf fund,

Dillöl, \&einöl,

3miefeliaft, jebes $\frac{1}{2}$ loth,

Wrachs, fo viel genug iff,

madbz über einem Roblfeuer zu einer Salbe.

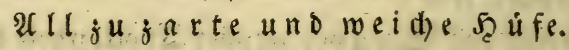

Dies Eommt von allfu überflüffigen falten Feuch= tigkeiten, oder wenn bie \$pferbe lang an leimid)ten, fumpfigten uno feuchten Srten geftanoen. Sismeilen ift es auch ein (Erbmangel.

\section{Die Cur.}

3u biefen (S)ebrechen mus man trodenende uno hart: machende $2 r_{z}$ eneien gebrauchen.

Summad), (Sranatäpfelrinden,

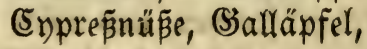

Murrtenblätter, jeoes 1 Şanovoll,

Euphorbium $\frac{1}{2}$ loth,

fiebe alles miteinander mohl in Effig ober faurem gSein und wajhe bie Shüfe oft bamit; fdmier? fie aud) mit nachfolgenoer Salbe: 


\section{Pferbe:2(rzenti Budy.}

Rothen Sitriol $\frac{1}{2}$ Sf funo,

Silberid)aum, $\frac{1}{4}$ פf fund,

2furipigment 4 loth, \&oröl 1 Pfuno,

3wiebeliaft 1 Maấ,

Euphorbiumöl 1 Suintlein,

Wadhs jo viel zu einer Salbe nöthig iff,

mijde es untereinander über einem Sioblenfeuer ou ei= ner Salbe.

Daz 31fte Eapitel.

Bon Der Sautfrenge Der Pferes.

Solde Eönmen nid)t zunehmen, man mup etliche $\mathfrak{T} a=$ ge mobl mit G(t)reinefbmals fomieren, bernah mit einer 3ange bie Şaut am Reib wegreißen, aber an ben Renden wobl 2(d)tung geben, Das man nichte im \&eib jerreine, barum man an felbigem Sort fold)e 2robeit mit bei blopen Scand vertidten mußs. Nad) geidhebenern

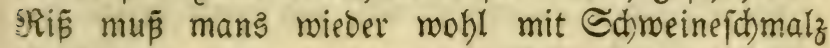
fchmieren, uno contimuiren eine 3eitlang, unterbepenen aber Dem Spferd von Der Şafelronrzel zu trinken geben, und ofters bergan reiten.

\section{Das 32fte Capitel.}

\section{$\mathfrak{B}$ D m Sa a r rad fent.}

Foche Shappeln, SRuben, mit fammt Dem STraut, Glettentourzel, jeoes gleich viel, fiede es in flieflendem $\mathfrak{B}$ affer uno roajhe ben Sit bamit. 
716 Pferbe 2 (rzeneisร)

(5in andereb.

\&einöl, Şonig, jeoes $\frac{1}{4}$ spfund,

গiegenmürmeröl 3 loth,

miface es untereinander zu einer Salbe.

sin a noeres

Iannenzapfen 6 \$ändevoll,

Rattid 2 seänoevoll,

fiede es miteinander in flieffendem $\mathscr{W}$ affer.

Ein a noerez.

(S)eftopenen Speck,

Borftop, jedes 1 Sy fuud,

Loröl 3 loth, mijche es untereinander über einem Feuer zu einer Salbe.

E in andereb $2 \mathfrak{B S}$.

Reibe bas \$ferd oft mit 3miebelfaft obar Saajelholz= ol, und ftreue Soblen von Saajelbolz barauf.

(E) it a n Dereb $\mathfrak{B S}$.

Streiche es oft an mit (Sieröl, uno ftreue betnad) ge= pülberte MA ücken barauf.

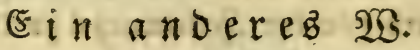

Streide es oft an mit Sonigöl, uno ftreue gepül= verte calcinirte Schubjoblen barauf.

Eina n Dereb $\mathfrak{B}$.

Beffreiche es oft mit Frett, welches oben im Reffel - forvimmt, wenn man $\mathfrak{S}$ ürfte fiebet,

Man hat aud) gewize (Sebeimmittel, soferden aus: nebmeno lange Möbnen und Sdymeif bon $12,14,16$

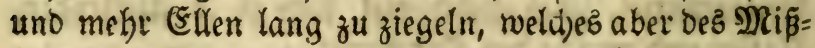
brauchs millen nicht gern gemein gemadht werben. - 
und in allem procediren, wie in Dem Sapitel von ber (Eur bes \$Jollibufs ift gebadit morden.

$\mathfrak{B}_{\text {enn }}$ fid) Der Rern geöffnet vornen an Der Zäbe Des Scufs, bem foll man nachfolgende Mifchung barauf ftreiden uno een Fus mit Scanfwerg wobl vermadben :

Sublimirtes Suecefillber 1 loth,

(Sirünipan 2 loth,

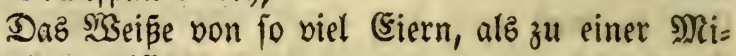
folung genug ift.

Das Rernichwinden anbelangend, iff foldber in Dent Sapitel von ben Sdbminden zu finden.

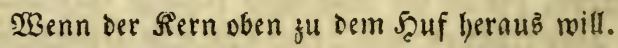

Rofenbrolamen,

Salz, jedes fo viel vonnötben,

Schlag Dein Spferd Damit ein.

WE n n o e r Rernjuviel wáth.

2fiche, Sitriol, jedes 1 Seanowoll,

Alaun 2 loth,

SBeinftein 1 loth,

fiede alles miteinander in Effig und fablag bent sofero Dannit ein.

Ein andereb.

Sdütte heippe Del hinein.

Ein andereb.

Mifhe Supferwaffer und Effig untereinander uno fchlags über. 
uno augfübren, fonbern auch biejenigen ๔achen, fo im Capitel von bem 2 Surm zu finden fein, gebrauchen. Man foll ihn aud) tãglich Scanffaamen int Futter zu freffen geben, uno ben Gchaben mit Eeiner Feuchtigkeit beneken.

\section{(5 in andereb.}

Bauntöl $1 \frac{1}{2}$ Maás,

Srünen Taback, Sicotiana genannt $\frac{1}{2}$ SD funo, mif che es zufammen in ein rundes (3̧las, uno vergrabs $4 \mathfrak{3}$ ochen in $\$$ ferdemift, bernach nimm es beraus uno prese es Durch, to wirft ou ein grünes Sel haben; wenn mar: brauchen will, fo foll man ben Sdjaben mit Scarn auswajchen, leine Iüber in baz Sel taud,en uno Dez זagez zmeimal barauf legen.

\section{(E) in a no ereb.}

Sauterifire rings um ben Schaben uno ftreiche täg= lid) Denfelben mit nachfolgenoer Mifchung :

Rojenöl 4 loth, Fudbsid)malz,

(Seipichmalz, jeces 1 spound,

(Sepüloerten 2rijenif 1 loth,

mijche es untereinander, continuirs 4 Tage, wajche bernach ben Schaden mit fdarfer Lauge uno lebendi= gem 2llaun wobl aus uno idmiere ibm bernad) folgen= de Salbe binein :

Maftix 4 loth, Beirauch,

Salmiac, jebes 2: loth,

Minrrben 1 loth,

(Salbanum, Dradsenblut,

(S) rünipan, jedes 2 loth,

Sonig ein balbes spfuno,

mifche es untereinander. 


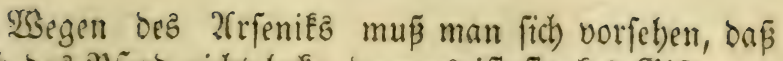
(iit) Das sुfferd nicht lecte, tenn es ift farfes (sift.

\section{Ein a noereb.}

Brem oen $\subseteq$ daden rings um, wajhe den sbrano uno Edaben mit (sfing uno ftreue nad)folgenoes \$ुJul: ber binein :

Solowurzelfait 14 lotb,

¿ebenoigen Rale 6 lotb,

thue es verinifdt in einen rohlvermachten Şafen uno Düre es, bermad) menns falt geworden, fo pülvere e马.

$$
\text { Ein a n b e } \mathfrak{r e z} \text {. }
$$

Eebenviger Salt 1 SD funo, Gpanifide fliegen 6 loth,

(3)olowurzeljaft, fo viel, bas bie 2 andern Mate= rien 3 u pinem Ieig bamit Eönnen gebracht merbert,

thue es in einen roblvermad)ten Safen, mad) bernad) ou eirem Sु)ulver uno ftretre es in Den Gchaden.

\section{(5) in a nderez.}

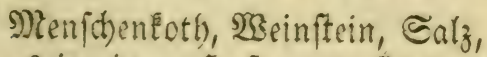

bürre es in einem Şafen uno ftreue es in den ๔d)aben.

(5) $\boldsymbol{i n} \mathfrak{a} \mathfrak{n}$ e $\mathfrak{e} \mathfrak{e b}$.

(Geftofinen Snoblaud) $\frac{1}{4}$ Sf fund,

Bertram 2 loth, SDfeffer 1 loth,

2fitfidmeer 1 Spfuno,

mithe po untereinanoer of einet Salbe und ftreid)e pe über die 2 Sumbe.

E in a noeres.

2rrenie 1 loth, Bitriol 4 loth,

(Stünfpan 2 loth, Flöhefraut 2 loth, 


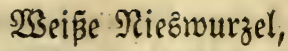

Schnarze Niesnurzel, jeops 1 loth,

mifoce es untereinander zu einem Sुulver und ftreue es auf ten Schaden.

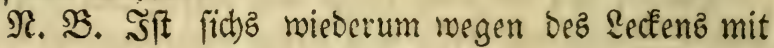
Dem $\mathfrak{X} r$ fenil in adjt zu nebmen.

(5) in a n Derez $\mathfrak{S S}$.

Streidye es oft mit Dem Sdyrefelbalfam ober mit Dem Sleum 2intimonium.

Dag 37fte Sapitel.

Bon Den seäufen der Pferde.

WBenn ein Syferd Räufe bat, bas fieket man an bem Reiben und Sraken am Sopf, Şals, befonders an ber Mähne.

Diefem Ungeziefer foll man alfo abbelfen :

Stope die gar jungen Iannenzapfen, fo noch in oev Blüte find, und vermifche mit $\mathfrak{W} a f f e r$, oder fiede bie. felben gar im $\mathfrak{S a}$ fler uno majke ben Sit bamit.

Ein andereb.

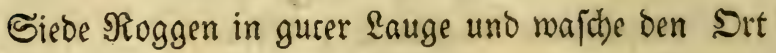
bamit.

E in a nderes.

Rebme Errlenlaub mit Den Beeren und ftop̧e fie mit einander, thue fie in Ealtez $\mathfrak{B a f f e r , ~ u n o ~ l a p e ~ f i e ~ u ̈ b e r ~}$ Nacht barin liegen, bernach wajd) Das Pferb Damit

Ein andereb.

Rebme zerftopene Rorbeeren, $\mathfrak{3 e r m u t h}$, zerriebene 


\section{פpferbe: 2 rzenei $\mathfrak{B u d}$.}

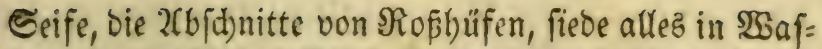
fer uno wafthe bas SPfero Damit, bernad) fdomiere mit alter Sdmeer uno getöotetem Suecfillber untereinan= Der vermijact.

(5) $i$ a $n$ Dereb.

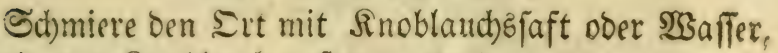
morin Der Snoblaud) gefotter worden.

(5) $\mathfrak{n}$ andereb.

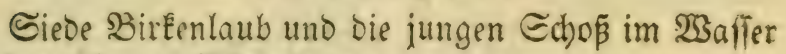
uno wafd)e Das भूferd Damit.

(sin anderez.

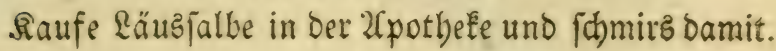

(5in anderes গ্রু

WBafde Dag SPferd etlichenal mohl mit Rauge roorin Snoblatid) uno Beitlofennurzel, mie audh 2(lantmurzel gejotten worden, oder mit Rauge oder $\mathfrak{M a f f e r}_{\text {worin }}$ lebendiges saedefilber gefotten worden.

Ein andereb $\mathfrak{B}$.

Sidwefel 1 Pfund, Bitriol,

Salpeter $\frac{1}{2}$ Dfund, Grünโpan $\frac{1}{4}$ \$ुfund,

Schięppulver 1 sूfund,

2ttijhmeer, to viel zu einer Galbe nöthig ift. mifd)e ę untereinander über einem Soblenfeuer un (d)miere das Spferd damit.

\section{Daz 38fte Eapitel.

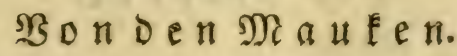

Diefe fommen unter ben langen Şaaren zrwifder Den Feffeln berbor, uno fino Sd)runden Der Saut, mels 
dhe nach ber Sueer fich aufipalten, ein gelbez $25 a f f e r$

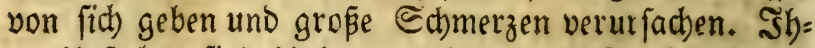

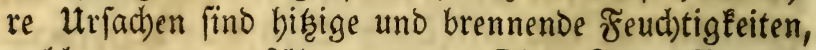
welche unten augefübrt werden. Siehe Figur No. 34.

Enpbeuaft $\frac{1}{4}$ Maa

Sonig 12 lotb. Maftix 2 lotb,

Euphorbiumöl $\frac{1}{2}$ \&oth,

mijche eg untereinander zu piner Salbe und fomiere เe bamit.

(5in andereb.

arte Butter 4 loth, Rojenöl 6 loth,

Uuripigment 3 loth,

(soldichaum 2 loth,

$\mathfrak{B a d b}$, fo viel genug zu siner Salbe iff, mifche ce untereinander.

(5) $\mathfrak{i}$ anderezs.

Seife, গুech, Scarz,

Nenfouentoth, jeoes gleidjuiel,

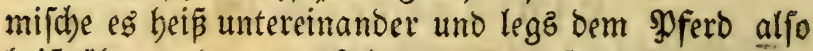
beiß über, uno menng Ealt geworden, fo nebme ez ber= ab uno falbe ben Srt mit Sconig uno Saaumöl unter: einander gemifdt.

(5in andereb.

Röfte den Soth oder bie Eroe, fo cin Maulmurf aufgemorfen, und zum nächften bei ben soch ift, in Baumöl, ftreichs auf ein blaues $\mathfrak{x}$ uch und legs über.

(a) $\mathfrak{i}$ andereb.

Maftix, 20llaun,

(Sirünpan, Wsitaud), Ierpentin, jedes 1 loth, 


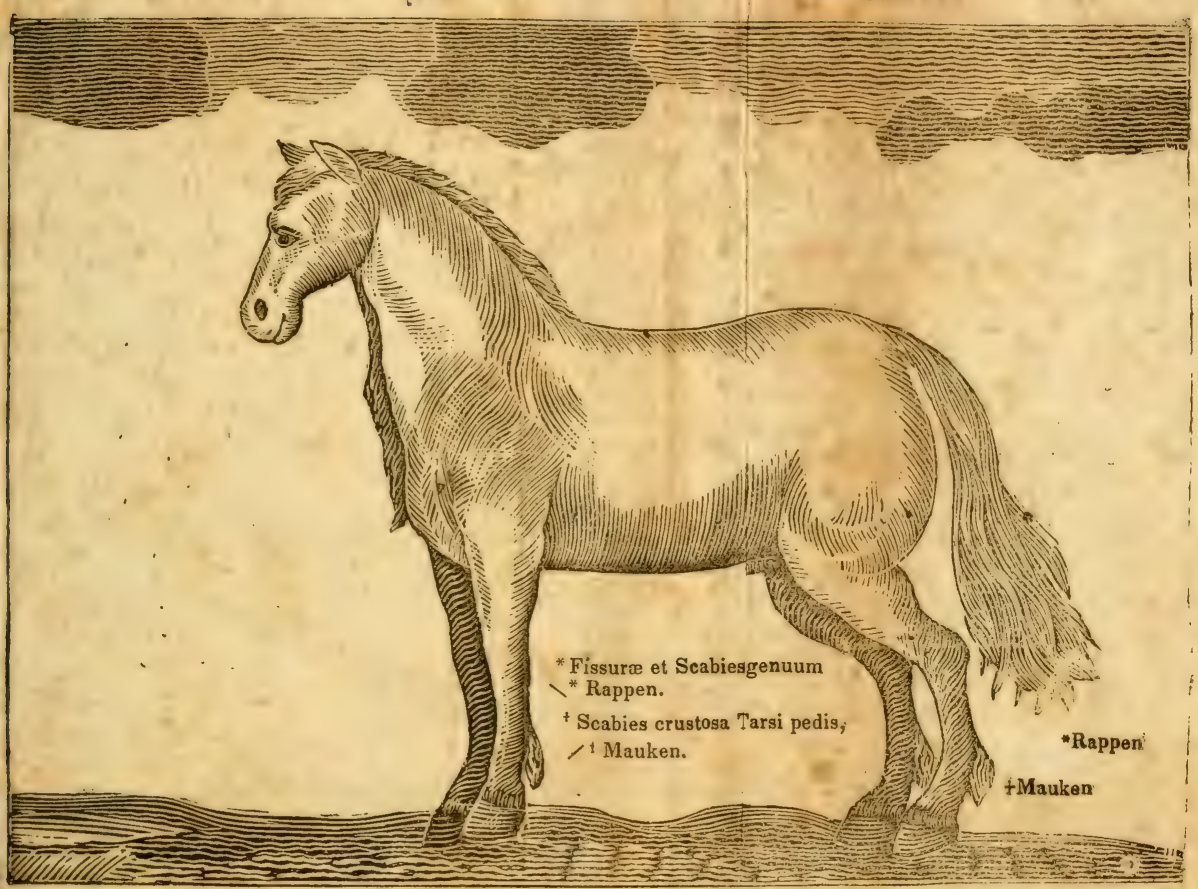




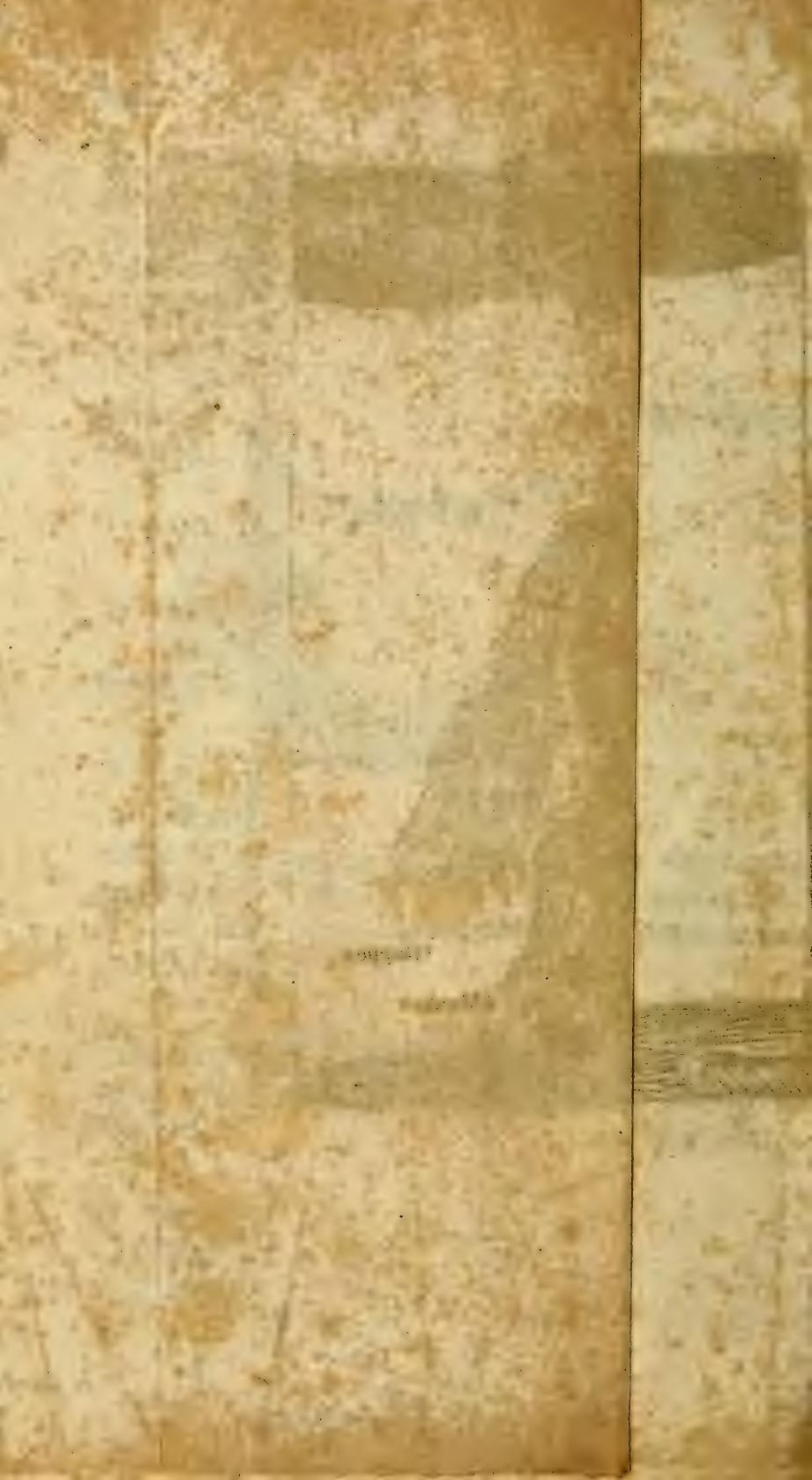




\section{פferbe:20rzenei Bud.}

Şonig ein halbes Naaß̧,

mifd)e es untereinander über einem linden Soblenfeu= pr zu einer Salbe.

Ein andereb.

Ref)me Sconig uno geftopenen finoblauch und reibe die Maufen Damit.

\section{(5) in a ndereb.}

(Eauterifite die Maufen uno picfe fie bernach mit einer Fliete, mijde die beißen Brofamen vom Roggen= broo mit ๔alzuno legs darauf, fiteue bernact) (Srün: fpan hinein oder das Spulver von RindenEoblen.

\section{E $i \mathfrak{n}$ andereb}

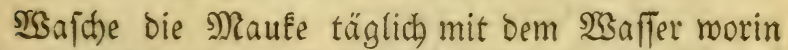
Sranatäpfelrincen, Salläpfel, Eumach) und Bitriol gefotten worden, uno ftreue bernad) oas Spulver von calcinirtem Şitfd)bein Darauf, oder bas (5aput mor= tuum $\mathfrak{2}$ itrioli.

E in a n Derez $2 \mathfrak{F}$.

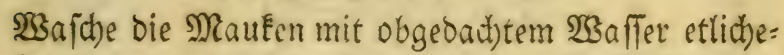
mai aus, uno wenns trodfen geworben, fo fitreiche ifm mit einer Feder Schmefelbaliam binein.

গ. $\mathfrak{B}$. Soldhen Sffrtben foll man täglid) vom Spieß̈glas zu freffen geben, fo reinigt es invendig ben Flü binweg.

\section{(5i $\mathfrak{i} \cdot \mathfrak{n} \mathfrak{i} \in \mathfrak{r} e \mathfrak{b}$.}

Röfte 3wiebeln in @dymeer, binde es beip über, uno lape ez 3 Iage darauf liegen.

\section{Ei $\mathfrak{n}$ andereb.}

Eierflar mit Maftixpulver zerrieben und die Maus. Een wohl bamit gefalbet. 


\section{E in $\mathfrak{a n d e r e b . ~}$}

Röfe einen Maulwurf in Sdymeer uno binbe ibn barüber.

E in anderes.

Sinoblauch geftoren $\frac{1}{4}$ gofund,

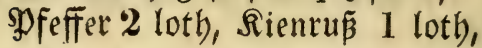

mifche ez untersinander uno follags über den Schaden, man mus aber vorber den Schaden mit warmem (5)

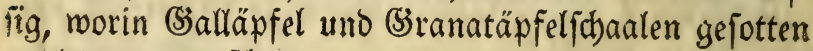
morden, auswajchen.

\section{E}

Epheufuft 1 Suart, Sconig. 12 loth,

Frifche $\mathfrak{B}$ utter 6 loth,

Mtaftix=: \$ulver 3 loth,

vermifche eg mit bem Sel von Euphorbium zu einer Salbe, und gebrauch.

Daż 39fte Eapitel.

Bon Den YAilben in Den Şarer.

SReinblumen, 3 Şänoboll, 2Clantmurzel,

Salbei, jebes 1 Şanovoll,

Eorbeeren 1 loth,

fiebe es untereinander in jharfer $2 a u g e$ und wafthe bas Pfero oft Damit.

\section{(E) $\mathfrak{i}$ and}

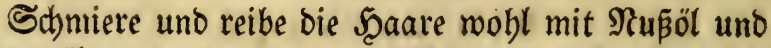
Baumöl untereinander gemifht, und lapee ihm bie roer auf ber ßiebe follagen. 


\section{7}

อิ० =

fur

ige

nit

no

- $0=$

b)t

if

$\varepsilon=$

i=

$=$

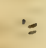

i:

$=$ 
.35

Ẽeite 727

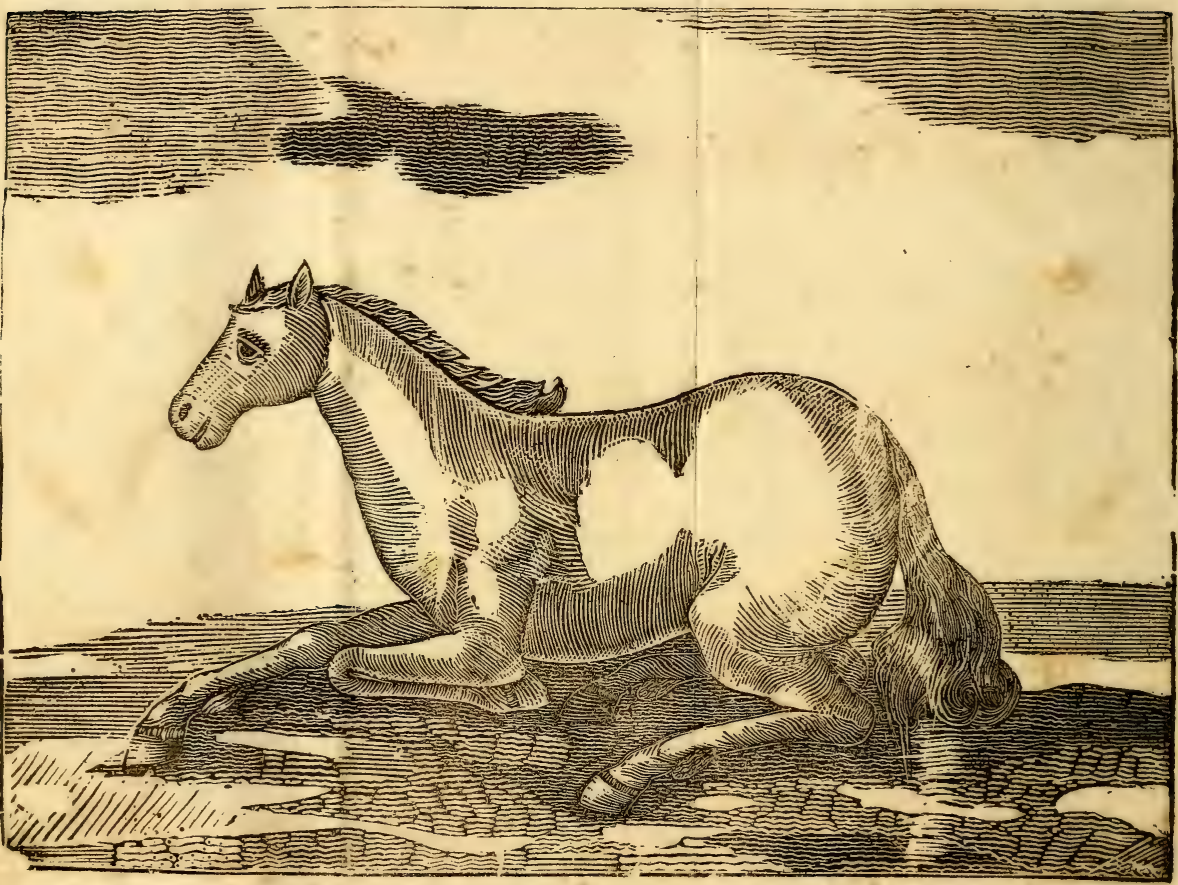


Ein a n Dereb.

Rap̧e es oft in ein flieffendes $\mathfrak{W a f f e r}$ gegen ben Strom fübren, und eine 3eitlang barin gegen ben Strom fteben.

(5) in andexe

Man foll auch foldben müben Pferden Sofnenmebl im Futter zu freflen geben, uno 2 Seizentleien unter bas Trinfen rübren.

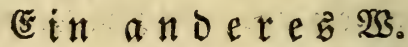

Müben Sfferden foll man keine 2 doer öffnen, Denn folches ift ifnen höchit fchädich, fondern ifnen einen guten 2 nftrich machen von Boluz, Effig, SBrannterwein uno Snoblaudh, Sauerteig, 2c. wie in bem Sapitel bon

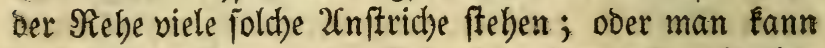
auch folchen SDferben bie Sdbenfel oft mit Snoblauche = brübe reiben, uno ihnen babei mit $\varsigma_{a l}$, Inoblaud und alter 5 d)meer untereinander geftopen einfdlagen.

\section{(Ein anderes গIG.}

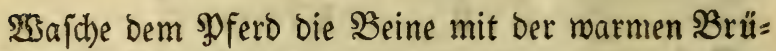
be, worin Scaberftroh gefottten worden, und binde ibm auch foltbes um bie Beine wohl warm, gib ihm auch

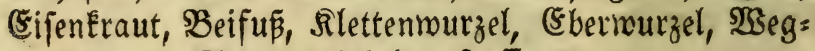
roarten uno Sonnenmirbel zu freffen.

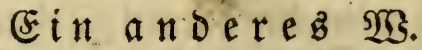

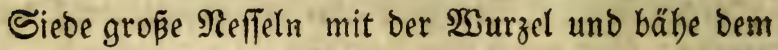
Dfero bie Sdbentel oft bamit.

$$
\text { (E) } \mathrm{in} \text { a } \mathfrak{n} \text { ereb }
$$

233afthe bie Sdenfel oft mit Spülmaffer bernad)

Refme Scanfö 8 loth,

\&ein=:Del 12 loth, 


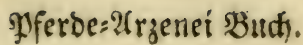

ভaly 2 Şändevoll,

mifd)e es untereinander uno reibe dem झुfero die Beine wohl Damit, renn es vorber vom $\mathfrak{B S a j d}$ en Iroden worben, und fdlage ifm sin mit nadjfolgendem (sin: id)lag :

Seftopene rotbe 3roiebeln 2 Şändevoll,

Butter $\frac{1}{2}$ SDfuno, Sconig $\frac{1}{4}$ Ş funo,

SEat) 3 lotb), sfirig fo viel als nöthig iff. mija) es untereinanoer ju einem (sinju)lag:

(Fin Đulver für múte 7 ferde, tíglid) auf ter gicife ein oder jwei Seffelvoll einzugeben.

Meifterwurzel,

Ebermuizel, jeoes 3 loth,

2Cngetica, Bibenefl,

Florentinijhe szeilchenwurzel,

Jarelmiftel, (sid)enmiftel,

Sirnbaummiftel, jedes 2 loth,

Silid)elauen 3 loth,

(5alcinites Soirid)horn 6 loth,

3ittwal, (Salgant, jeoes 1 loth,

Bodfshornfaamen $\frac{1}{4}$ Pfuno,

mijche es untereinanoer.

(5i $\pi$ a $\|$ b e reb $\mathfrak{R}$.

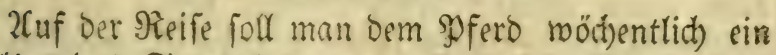
balbes loth Spiep̃glas, oder 1 Suintlein Erocum $2(n=$ timonium mit $\widetilde{S}_{\text {al; }}$ vermifht, zu fieffen geben, uno lape ifm fleinig einjollagen mit Eilig und Sübefoth, ober mit alter @ibmeer, Snoblaud) und Sal $_{3}$ unterein= ander gemif(ht, ooit) aud) nicht gar zu oft, lape es aud) niemals ins న̦afferteiten, fondern bie früpe fein tro= den mit Strob) ooer einem wollenen Iud) abreiben.WSenn man aber von ber Seife zurüc'́geḱebrt ift, uno 
ez in beißer Săbrzzzeit fein follte, fo laßje ez täglich ins Baffer reiten und eine balbe Gtunde Darin gegen ben Strom fteben.

\section{Das 41 fte Sapitel.}

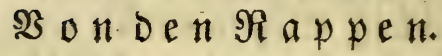

Die Rappen find raube Sdrunden Der Scaut, ha= ben harte, ajchenfarbige Rippen, reißen Die Scaut $10=$ mobl binten alz vornen in Dem (Semerbe ber Snie auf, und fino fchwerlich auszurotten; uno nicht aflein bez= megen weil bie Echentel ftets berwegt werden, fondern auch bon regen ber trockenen Feudtigkeiten, weldhe burd) bie Bewegung der Sibenfel bajelbft hinein rin= ren, Die (3)lenke austrodénen, uno aljo ber graujen Falten und fowwüligten Sd)runden je länger befto mebr verurfachen.

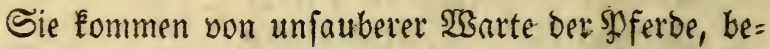

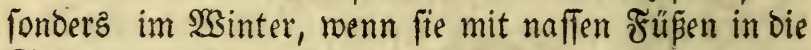
Ställe gebracht, uno nicht fleipig abgerieben und ge= trodknet werden, denn bas Ealte Seblüt uno bie FlüFe fallen ibnen baburch in bie Schenkel und machen eine (̧)efchmulft, bauptiächlich in bie bintern Schenfel; ma: den bie Füpe bernach rinnend, und daz Scaar an ben Schentel ftebet überfich mie Säuborften. Siebe Fi= gur No. 34.

\section{Die (5) $\mathrm{r}$.}

Sd)eere die Şaare ab von bem Srt, no ber Sdabe.

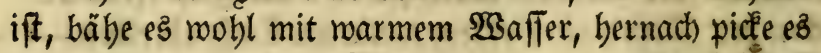
ein. nenig mit einer Flliete, aber man mus dabei bas 
(Seãber in adjt nelmen, und felbiges nid)t bamit be= rübren, bernad) fidlage నad)folgendes Darüber :

Rebendigen Ralé, Roggenmell,

Salz, গiū, jeces gleid)viel,

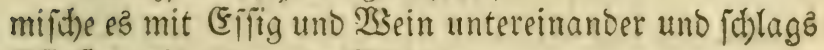
splaftermeis uber ben Gitaden.

(5) $\mathfrak{i}$ andereb.

Mercurium fublimatum,

Sräcipitatum, jedes gleid)viel, vermifd)e eร mit Baumöl zu einer Єalbe uno leģ über, habe aber ad)t, Das fich bas spferd nicht lecke.

(sin andèrez.

Sermifue ungelöfiten Rulk mit (5ierklar uno legs über.

\section{fin andereb.}

Serlaffenes Sommer,

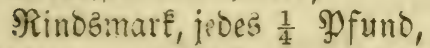

Rübre menns no.t) warm ift, barunter

(Seftopenen Sdyrefel,

(S) rünpan, jeoes 2 loth,

binde davon Dem Mferd über.

(5in andereb $\mathfrak{B}_{\text {. }}$

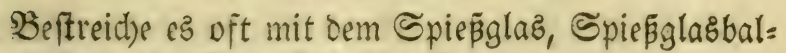
fam, ober mit Sdbuefelbaljam.

Ein andereb Tr.

Reibe die Rappen mohl, hernach iddmiere mit nad)s folgender Galbe:

Geftopenen Echmefel 3 loth,

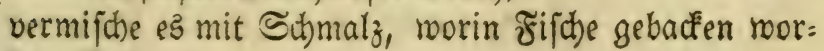
ben fino. 


\section{Ein anderes TY.}

Reibe fie wobl mit $\mathfrak{G a f f e r , ~ w o r i n ~ I a n n e n z a p f e n ~}$ und (Sipfel von $23 a c b$ boldorftanden gefotten morden.

(E) i $\mathfrak{n}$ a $\mathfrak{n}$ b e res $\mathfrak{B}$.

Schmiere bas \$f fert mit nad.jolgender Salbe :

Iannenzapfen,

SGachbolderbolzöl, jeoes 3 loth,

Saajelbolzöl 2 loth, Eieröl,

Sdbmarzeg Sdinedfenöl,

Schmefelbaliam jebes 1 loth,

Schweineidhmalz $1 \frac{1}{2}$ Sofuno,

Seirfachen=Utnjoblitt $\frac{1}{4}$ sofund,

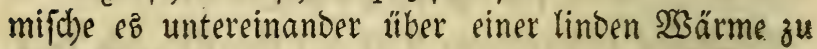
einer Salbe.

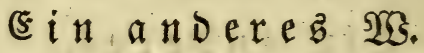

Den Englifchen $\mathfrak{B u n d b a l f a m} 1$ loth,

Tannenzapfen 6 loth,

Ierpentinöl 4 loth, (sieröl 2 loth,

mifche es untereinander uno beftreiche bie SRappen damit.

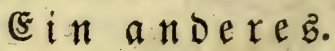

Sinde oft heiß gebackenez Brod Darüber.

E $\mathfrak{i} \mathfrak{a} \mathfrak{n} \mathfrak{D} \in \mathfrak{r} \in \mathfrak{B}$.

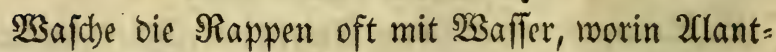
wurzel uno Riestrurzel, oder Rleien uno Sappeln ge= fotten worben, hernach wenns trocken geworden ift, fo fdhmiere es mit Radbfolgendem :

Senftmebl, vermifc)e e’s mit \&einöl und Şonig zu siner Salbe. (5) $\boldsymbol{i}$ a $\mathfrak{a}$ bere 8 .

(Seftopene Birfenrinden 3 Şănbeboll, 
Salz andertbalb Şanowoll, fiebe es in Effitg uno reibe bag sofero täglid) zneimal bamit.

Ei in a no ere b.

Nifche $\mathfrak{B i t r i o l}$ und Firnis untereinander uno fdomie= re bie Rappen Damit.

(5) ก a n bere

Sdmiere baร গু)ferd mit Mailänder= Salbe.

(5i $\mathfrak{a}$ a berez.

3erreibe altan Säs mit pen oft bamit.

(5in an bere g.

Sübnertoth, Iaubenfoth,

Sdubloblen, jedes $\frac{1}{2}$ SDfund,

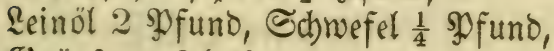

(Sirünpan 6 loth,

attichmeer, fo viel als nöthig ift zu einer Salbe, mijche es untereinander zu einer ভalbe.

(5) in a $n$ ber $\geq \mathfrak{b}$.

Schiespulver 1 ⿰מॅนno,

(Srünipan $\frac{1}{4}$ Spfund,

ungelöjten Salk 1 Dfuno,

Edhneimeichmalz, fo viel als nöthig zu einer Sal= be iff,

vermifhe es über einer (s)lut untereinander.

(E) i a no ere $\mathfrak{B}$.

WSafde bie Rappen oft mit Dem SGaffer, meldes 24 Stunden über ungelöfhtem Ralf geftanden ift.

(F) in a n beres.

Mache ein SPflafter von Shech und Siegelfteinen und binos über, la $\tilde{\beta}$ es 3 Iage fteben, bernad) thue es ber ab uno beftreiche mit Şajengallen. 


\section{(E) in: a n b red,}

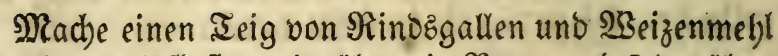
und leg ez Şflaftermeiz über die Rappen, la biz das Pflafter ganz bart ift uno nichts mebr operirt, bernach nebme es herab nno fdhmiere es mit nadffol= gender Salbe :

\$ुech $\frac{1}{2}$ P Fund, Waachs $\frac{1}{4}$ Ş fund,

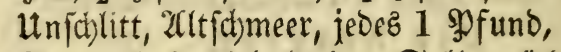

Baumol, to viel zut einer Calbe nöthig iff, vermifche es miteinander über Dem Feuer zu einer Salbe.

(5) in a noereb.

Rege bas Shflufter Martiatum barüber.

(E)

Ierperitin, Sleimeín, jedes 6 loth,

Rofenöl 8 loth, Raache 2 loth,

Baumöl, fo viel nötbig ift zu einer Salbe. mifache es untereinander.

(5in andereb.

Schlage oft Menfdhenfoth barüber, wafche es mit unin.

(5) in anoere 8.

Naftix 2 suintlein,

2atifein 1 lotb,

Sibrefel 1 Suintlein,

Baumöl $\frac{1}{2}$ loth,

Edbreineformaly, fo viel als nöthig ift

Eifig, fo viel genug zu einer Ealbe ift,

Wann fie heil find, wie auch unter mäbrender (Sur foll manz nid)t fobalo ins 2 Saffer reiten, und die Sden fel oft mit Salzwaffer abreiben. 


\section{Das 42fte Sapitel.}

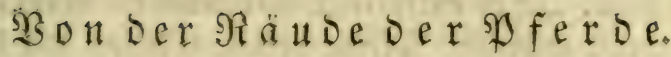

Die Siäube oder Rrärge an Den Thieten ift ein wohlbekanntes unflätiges (Sebrechen, Denn fie madjet Die Scaut ganz for uptidht, raub, bolfer rufen uno Srut= ften, ober es fino fleine (Sefdinulte, weldbe Die Scaut ourd)nagen unb beipen ; biejelbe ift eine erblid)e Sranf=

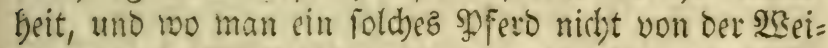

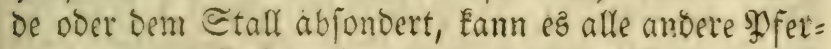
be bamit anftecten, ja menn man ein \$ूfero nur mit einem Striegel, Sisijt)tudt, Decke, Sattel oder Baum anrübret, reld)e zu einem foldhen unreinen SDfero find gebraud)t worbert, erbet folches diefe Siranelyeit augen= blicelid);

(5) ift aber bie Räube jmeierlei, als nemlid) bie tro= dene, neld)e gar Eeinen (Fiter uno Feuchtigkeit von fich fübret uno Den oberften uno äufferften Theil ber Şaut eiinnimmt, uno wird von etlichen bas id)led)te uno ein= fad)e Bittern odet (Beflecht genannt. Die anoere Räu: be ift bick und feudt, frift tief in bie Scaut binein unb mito Der rechte (S)rino get)eipen, entfpringet von vielen uno mand)erlei Feud)tigfeiten, welche ifre Patut etli= cher saffen verlaflen, und fich untereinander vermifdet Gaben, beren jectrman aus des (S) rindes Rufen, Daratts flieflendem Eiter, und Deffen Farbe erfentren fann; Dem es entfintinget entweder aus Dem verberbten und berblennten 2 lut allein, ober aus einem foldten, fo wie= Derum entroeder mit verbennten gallenartigen Feud)= tigfeiten, obpe mit ber nicht natürlic)en meland,olifonen, ober mit Dem gefalzenen oder berbrennten Syblegma 
vermifchet ift, ba bismeilen bie Freuchtigkeit bie Sber=

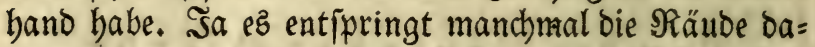
ber, wenn man bie Noferde beftig arbeiten uno babei Scunger leiben läst, oder fie nidjt fleififg puçet uno rei= niget, fondern allerbano Staub uno Unratb auf ibnen liegen läpt.

Die Beichen find offenbar, zu bem reiben fie fid) $D a=$ neben an bie $\mathfrak{W a ̈ n d e , ~ M a u e r n , ~ B a ̈ u m e , ~ u n d ~ t o ~ f i e ~}$ binfommen, fie Erafen fich aud) mit Den Säbnen und

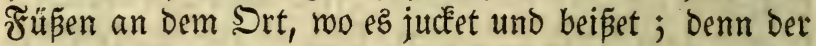
(s)rind nimmt Den gand 2 eib ein, befonders aber bie Schenel, Seleidhe, Mathne uno Schmanz.

\section{Di e c ur.}

Dem spferd foll man den \&eib offen balten und (E) fitie gebrauchen, hernad) folgenden (singue geben : WS.

Serglap̧tez Spiep̈glaz 1 Suintlein, Saffran $\frac{1}{2}$ Suintlein,

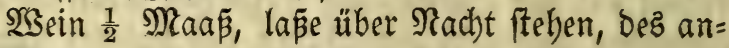
Dern Norgen feibe es ab uno giepe ez ein.

(5 $\mathfrak{i} \mathfrak{n} \mathfrak{a} \mathfrak{D} \in \mathfrak{r} \mathfrak{e} \mathfrak{b}:$

Separ 2Antimonium $1 \frac{1}{2}$ Suintlein,

Safran $\frac{1}{2}$ Suintlein,

Schmarze Nieznurzel 1 Suintlein,

Salap, \&ercheninamm,

Uloes, jedes 2 Suintlein,

W̧ein, $\frac{1}{2}$ Maaß̄,

untereinander gemifcht und auf einmal eingegeben.

E in anderes $\mathfrak{x}$.

Rerchenfchnamm 2 suintlein, 2loes 1 Suintlein, $\mathfrak{B e i n} \frac{1}{2}$ Maa 


\section{Pferbes:21rzenei Budt.}

\section{Seneşblätter 1 lath,}

2̧ildoe Cucumerufaft 2 suintlein,

Extract von fithorzer Niesmurzel, untereinander gemifdtt uno auf einmal eingegeben.

\section{E in andereb.}

Man foll Den Syertoen bie Saalsadern, bie auf ber Bruft, in Den Steichen, binten oberm Sd)enkel, Feffel, Soug, Regel und Bäbeadern fidlagen, weldye man be=

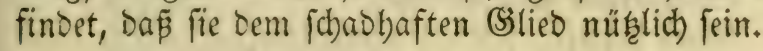

\section{(E) $\mathfrak{i} \mathfrak{a} \mathfrak{n} D \mathfrak{e r} \in \mathfrak{B}$.}

Scabiojen, F̌ünfingerfraut,

(5rinowurzel,

Edjmeinsbrod, jebes 1 Şandooll,

(Eroraud)maffer $\frac{1}{2} \mathfrak{M a a \hat { \beta }}$

Wegmartenbrül)e $\frac{1}{2}$ Maa $\tilde{\beta}$,

untereinander gemifdt und auf eirmal eingegeben.

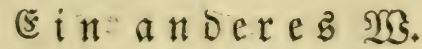

2lloes bepatica. Rerchenidnomm, jedes $\frac{1}{2}$ loth,

Salap 1 loth, $\mathfrak{W e i n} \frac{1}{2} \mathfrak{R a a} \tilde{\beta}$,

(Summi guttä 1 suintlein,

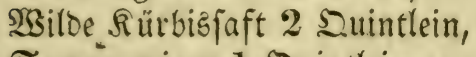

Scammonium 1 Suintlein, untereinander gemifdtt uno auf einmal eingegeben.

E in a noeres 23 .

Shollundertinden, Enoivien,

(Eroraud), Ecabiojen, ŜSegmeis,

Fünffingerfraut, jebes 2 Şänoevoll,

2llantwurzel 3 loty,

Brinomurzel 2 Scändevoll,

(Eberwurzel 3 loth, 


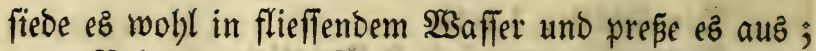

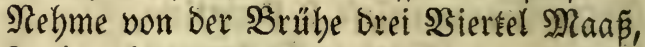
Qerdbenfonamm 2 suintlein, unteleinanoer gemifht und auf einmal eingegeben.

$$
\text { Ein andereb }
$$

Extract von fdwarzer Niesmurzel 1 Suintt.

Salap 1 Suintlein,

Solbanella, Scammonie,

2lloes bepatic. jebes 1 suintlein,

2Garic 2 Suintlein, @affran $\frac{1}{2}$ suintlein, untereinander gemifdt und auf einmal eingegeben.

E $\mathfrak{i} \mathfrak{n} \mathfrak{a} \mathfrak{D} \in \mathfrak{x} \in \mathfrak{b}$.

\$ুappeln, Esrinonurzel,

Schroalbennurzel, jedes 1 Scanovoll,

fiede es wohl in flieffendem $\mathfrak{W}$ affer uno wajd)e es täg= (ich) Damit.

\section{Ein andereb.}

(S)rinonuzzel 3 Șändevoll,

Alnntwurzel 2 Scändeboll, çalmuz,

Schnertelnurzel, jeops 1 Scanovoll,

Stichnurzel $\frac{1}{2}$ Sp fund,

গiep̄nurzel, Ebermurzel, jeoes $\frac{1}{4}$ SPfund,

sappeln, 3 loth,

Scabiofen, (Erorauth),

Sd)ölleraut, jedes 3 Şänoevoll,

SeifenEraut,

Bergmünze, jedes 2 Şändevoll,

Taubentoth 1 Sूfuno,

SSanze robe (serfte $\frac{1}{4}$ Sfund,

fiede es untereinander in flieffendem $\mathfrak{W}$ affer uno mas fche bas \$fero mohl bamit. 


\section{פferbe=:2rzenei Buch.}

\section{(5 in and e res.}

Sdeere die Şaare am Srt, mo die Raude ift, mit einem Sitheermefler glatt hinmeg, bis baj es blutet, und braudje nad)folgendes:

Wafibe Das Syfero wobl mit Rauge, worin 2flant= wourzel und Éberwurzol gefotten morden, wenns trccken ift fo fomiere es mit nad)folgender Galbe :

Rebenoigen Sithefel 1 Pfuno,

Serpentin $\frac{1}{4}$ Pfund,

Eîtg, fo viel genug iff zur Dicke piner ऽalbe. mijche es untereinander.

Ein andereb গू.

Sdbefelbaliam 1 suintrin,

Ierpentin 3 loth,

(Eroraututwa untereinander gemijht und auf einmal eingegeben.

(5) in a $n$ Deres $\mathfrak{B Z}$.

Sdrrefelbaljam oder das gemeine Sdumefelöl, uno id)miere Den Sit Damit.

(E) in andereb.

2) (urobalani 3 loth, Efifig $1 \frac{1}{2}$ Maá̃,

Salpeter 2 loth,

fiede es untereinander und majhe das Spferd damit.

(5in anderes.

Sd)micre das spfert mit \$echöl.

Ei

Fidutenlyolzöl, Tannenbolzỏl,

$\mathfrak{B}$ adbbolderbolz= Sel,

(5ieröl, weldes im abnefmenten 92Rono gemadt 
worden, jedes 2 loth, untereinander gemijcht und fichmiere es bamit.

$$
\text { E in a n ere } \mathfrak{b}^{2} \text {. }
$$

๔diespulver 1 Sfuno, 2ut jad)meer 6 Sुfuno, Salpeter, Sirunipan, jedes $\frac{1}{4}$ Dfuno, alantwourzel 16 loth, Sdimefel $\frac{1}{2}$ loth,

mijhe eb über einem linoen Soblenfeuer, uno fdmiere e's mohl bamit.

Ein andereb.

Alaun, (s)rünpan, Sdbrefel, jebes 3 loth,

Sdmeer 1 Sूfund, mifche ez über einem linoer Soblenfeuer untereinander.

(E) in a n $\mathfrak{d} \mathfrak{e} \mathfrak{e} \mathfrak{b}$.

alantwurzel 6 loth, Sdymefel $\frac{1}{2}$ sूfuno,

Menfichenbarn to viel genug iff, mache eine Salke barauz.

E in a n b e r e

Eberwurzel 12 loth, Bitriolol 6 loth,

Sitronen= SDel 1 lotb,

Sdyroimidymals, fünf viertel \$f fund,

mijhe eहै untereinanber zu piner Salbe.

(s in and e res.

Rebenoigen Schnefel $\frac{1}{2}$ sofuno,

Serpentin 4 loth, (Euphorbium 1 lotb,

Salz 1 Sanovoll, 12 Esiermeís,

Frificher 3 utter 1 Sf funo,

Sdimeer $\frac{1}{4}$ Pfund,

mijhe es untercinanoer zu einer ऽalbe.

Ein a no eres.

Sdjmefel, Baljam, Salz, 
Terpentin, jebes 1 ⿰冫 funo, mijche es untereinander zu einer Ealbe.

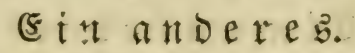

Frifche ober gefottene 2llantwurzel 1 Sffuno,

(Getöbetes Suecffitter 1 loth),

SBitriol 3 loth, @d) wefel 8 loth,

2f(tid)meer 3 . şfuno,

miface es untereinander zu einer Salbe.

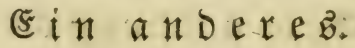

Sirberglätt, Merruben, 2floez,

(3etöotetes Sueck fillbet, jebes 1 loth,

Lorbeeren 8 loth,

mifube es untereinander zu einer Salbe.

E $\mathfrak{i} \mathfrak{n} \mathfrak{a}$ noereb.

Weinftein, Grünipan, Satz,

Salpeter, lebendigen Sdibefel, jedes 4 loth),

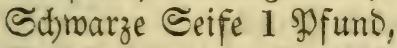

Suñ: Del 1 loth, Ecabiofenjaft,

(Eroraucbjaft,

Brinomurzel, jedes 16 loth,

milobe ez untereinander zu einer હalbe.

Ein a noereb.

Taubenfoth 8 loth, (Bologlätt 1 pfund,

SSetöbetes Suecéfillber 2 loth,

Lebendigen Sdyrefel,

Weinftein, jeoes 12 loth, SDperment,

Schölf rautmurzelpulver, jeoes 4 loth),

$\Re u p=$ \el, fo viel als nöthig iff,

mifjue es untereinander ơ einer Salbe.

$$
\text { Ein andereb } \mathfrak{B} \text {. }
$$

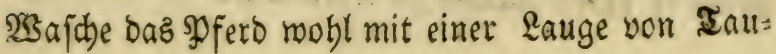


benkotb, in weld)er $\mathfrak{L a u g e}$ bernad) Salpeter, 2(lant= murzel uno Seinftein gejotten worben.

Ein andereb.

WBadbyolderbeeren $\frac{1}{2}$ פf fund,

5oühner= ober Taubenfoth, Niestwurzel,

Rebendigen Edhmefel, jedes 6 loth,

Sd)weineidmalz 2 ⿰氵 fund,

mifhe es untereinander-zu einer Salbe.

Ein andere .

Scollündifhe Seife 2 \$fund,

Lor=\$Nl 1 Mfund, Salpeter 6 loth,

(Setöbetes suectifilber 2 loth),

(Srünipan, MSeinftein, jebes 4 loth,

Sdbreinefdimalz 1 Pfund,

mijche es untereinander zu einer Salbe.

Ein a $\mathfrak{n}$ bereb.

4. Seife, Speck, jebes 2 \$fund,

- 2llantwurzel $\frac{1}{2}$ \$f fund,

mijabe $\mathfrak{e \mathfrak { s }}$ untereinander $z \mathfrak{u}$ einer Salke.

\&in a noeres 23 .

Ebermurzel, Zftantwurzel,

Rieswurzel, Iorbeeren, jedes 6 loth,

(Srünfpan, Salpeter, jebes 4 loth,

Qor: Del, fo viel genug ift,

mifhe es untereinander zu ciner Salbe.

E $\mathfrak{i} \mathfrak{a} \mathfrak{n} b \operatorname{ereb}$.

Terpentin, 2ifhe, Schaafunfdlitt,

Supferwafier, $\mathfrak{S}_{3}$ ad)z,

2litjd)meer, jeoes gleidy viel,

mifd)e ez untereinander zu einer Salbe. 


\section{Wertes:}

\section{E}

Strupfwurzel 3 loth, (Stünfpan 1 lotb,

Eebendigen Sdinefel 3 lotb,

2(ttîd)meer 1 sofund,

Men(d)enbarn, fo viel als nöthig ifft,

mifde es untereinander zu einer Calbe.

(E) in anderez.

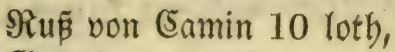

(Srünipan 6 (oth),

Sperment $2 \cdot$ toth

Rebenoigen Rale 1 loth,

Sonig, fo viel genug ift,

mifche es ủber einem Felier zu einer Salbe.

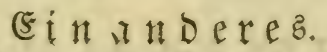

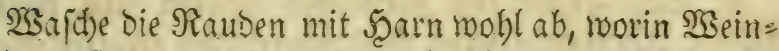
ftein gefotten morden, bernad) (d)miere nadhfolgente. Salbe Darauf :

reigbohnenmebl 1 ⿰冫 funo,

\$ech) 2 (oth, Bautmöl 6 (oth),

Effitg, fo viel genug ift,

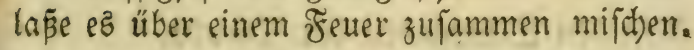

E $\mathfrak{i} \mathfrak{a} \mathfrak{n} D$ er $e \mathfrak{B}$.

Şahnenfur 3 loth, ভalz 3 Scändeboly,

Saum=:Del, Eein: Sel, jeoes $\frac{1}{2}$ Sofund,

miljo ez untereinander zu einer Salbe.

(E) in andereb.

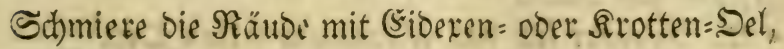
Doer Frof $h=$ :

(E) in anderez.

Sieșmurzel 6 loth, SDelbefe, 
Brübe, worin Feigbohnen gejotten worben fino jebes $\frac{1}{2}$ Maá⿱㇒㠯二亅,

mifhe es untereinander und fchmiere daz \$ूferb bamit.

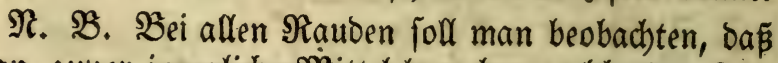
man zuvor innerlidhe Mittel braud)en, weldhe Den \&eib uno baz (Seblüt reinigen, und bie Rauben herauztrei= ben, ebe man fie fdomieret, uno wenn fie mieber beil geworben, mus man baz \$Jferb nobl mit Lauge abma= fithen.

\section{Die $\mathfrak{s e r p f l e g u n g . ~}$}

1. Der Stall foll im Sommer trocken uno mittelmä: pig kühl, im SBinter aber warm fein.

2. Snz Futter foll man wöd)entlid 1 loth Spießs= glaz geben.

3. Der Irank foll flieffendes 2 saffer fein, wurin 2 garic, 2Clantwurzel und Scollunderrinden gefotten wor: Den fint.

\section{Das 43fte Capitel.}

\section{Bon Den Sdywinden Der $\mathfrak{P f e r b e . ~}$}

Diez fommt den \$ferden vom Fallen, Stốen, \$ex: bügen, Sdblagen $\mathfrak{B e r r e n k u n g ~ u n d ~ a n d e r n ~ S c h a ̈ b e n . ~}$

Die Beichen fino:

1. Das B̧lied, an ben ez fchroindet, ift allezeit käl= ter, als bas andere.

2. Şerliert fid) Daz frleifh am felben Sort.

3. Şat ez Eeine Rrăfte mehr am felben Ellied, wie zuvor. Siebe Figur $\Re 0.36$.

4. Sุinft ez auch zule eqet baram, 


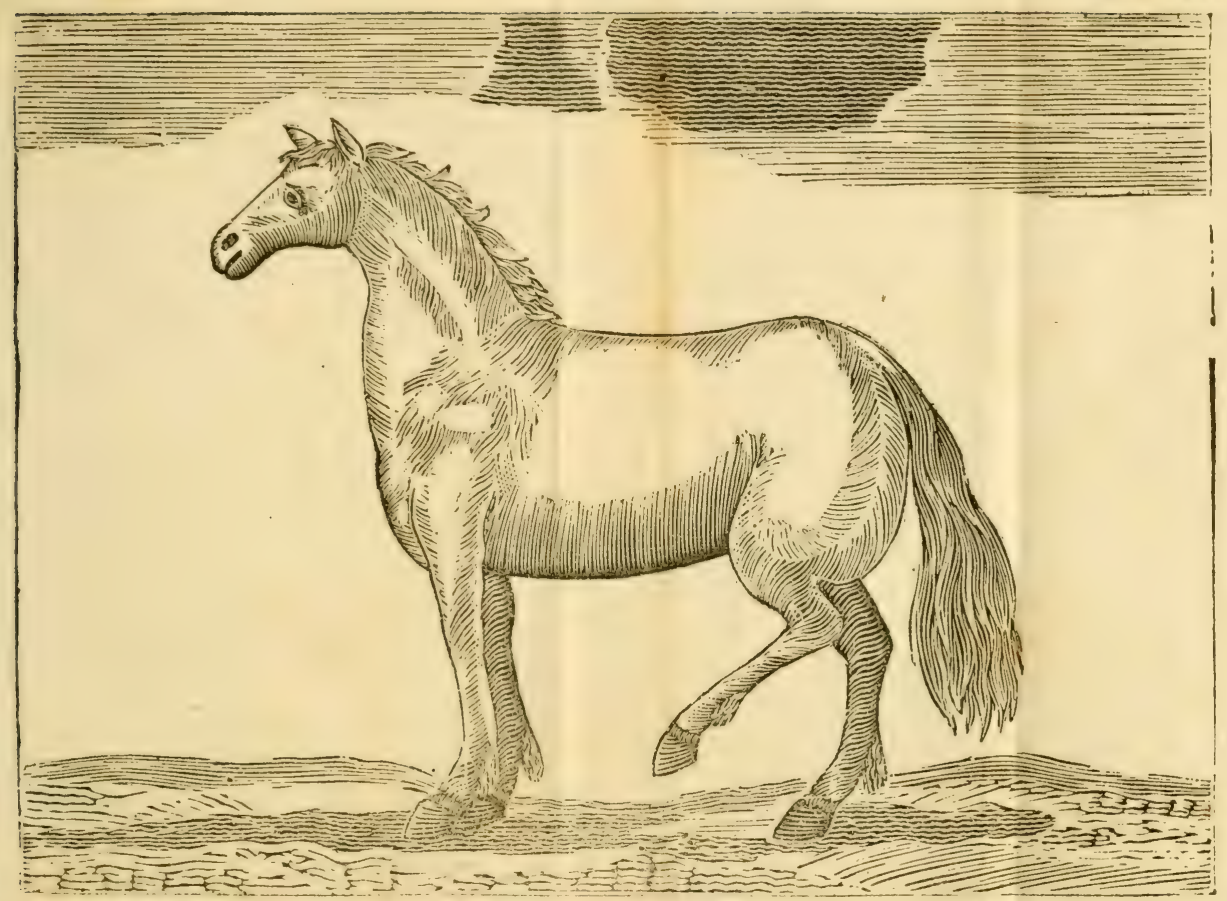




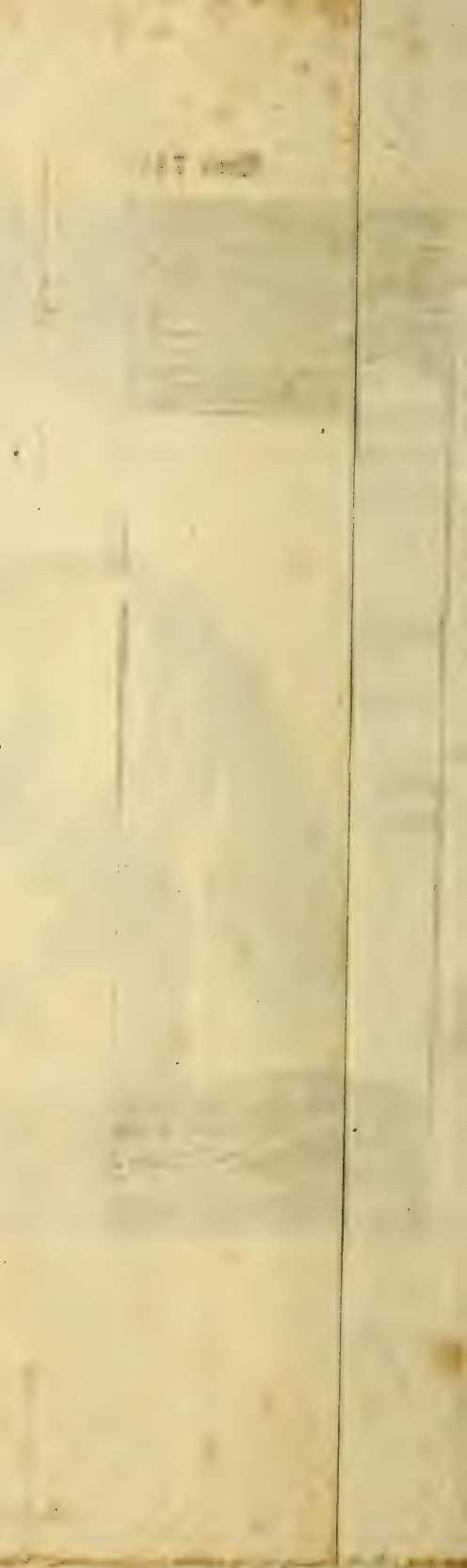




\section{Mferbe=21rzenei Bud\%.}

গ. $\mathfrak{B}$. Sei allen Sdwinden, wo man brauden mill, mus man bie Scaare vorber von ber Sout abjofeeren.

(Fine $S$ d) winbialbe.

Bärenidamalz 12 loth,

Dad) (enid)malz 6 lotb),

2 bilbe Rafenidumalz 3 loth,

weipen Senf 1 loth), Euphorbium,

Rangen SPfefter, jeoes $1 \frac{1}{2}$ loth,

milche alles untereinander obne Feuer, fdyiere ce mobl Damit uno balt ein rarm Eijen bagegen. Dieje Enl= be mus man zmeimal braudjen.

SBenn aber das (Seäber zu bart morben wäre, fo fie=

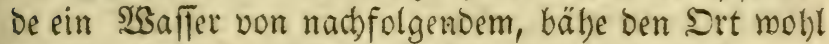
bamit uno bince auch bie Sräuter warm barauf, man mús es aber oft thun :

Samillen, rotbe Sucken, jebes 2 Şändevoll, Saaberftrob 1 Sanonodl,

șein, fo viel genug ift.

(5) in a $\mathfrak{n}$ bereb.

Şaustwurzel, Steinflee,

Şirichzungen,

Sanfêorner, jedes 1 Scanoboll,

Seife $\frac{1}{2}$ Sुfund, bermifche es mit Bier und fobla: ge eg über Den Sit, mo es fichnindet.

$$
\text { (5 i n a n Deres } 2 \mathfrak{B} \text {. }
$$

Regenmürmer $=$ Del, SSach holderberen $=$ Sel,

23ad)holderbolz=:Del, jebes 4 lotb,

Safeltholz=:Del 3 loth,

Lor: Sel 6 loth, Euphorbium 1 loth,

Benedifche Seife 1 Spfuno,

¿angen Spfeffer, oritthalb loth, 
Bibergeil 2 Suintlein,

Branntemein $\frac{1}{4}$ Maá̃,

mifche es untereinunder zu einer Salbe.

(5) i it a noeres.

Brannterwein $\frac{1}{2}$ Maaß̄, Bibergeil,

Rangen Mfeffer, jebes 2 loth,

mifche es untereinander und reibe bie jammindende Srte wobl bamit.

(5) in anderes.

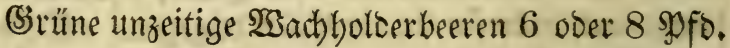
fitope fie uno vermifd)e es mit guter Şefe, brenne ein פasaffer bavon, bis alles beifammen ift, thue zu 10 Maá von biefem Maffer

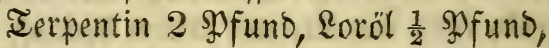

Eorbecrenblätter,

Salz, jedes 20 loth,

mifibe es untereinander uno reibe die GSlieber mobl bas mit.

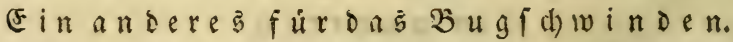

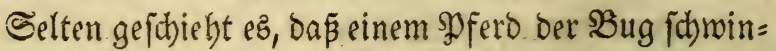
bet, und ifm ber Rern nicht auch fdhwinoet; besmegen wenn man zu bem $\mathfrak{B u g}$ fhwinden waz braudt), fo mus man für baz Sernidhwinden audj etroas brauden.

(E) ine 5 d w w ind a f be 2 .

2utichmeer 2 Sfuno, Sundsfamalz,

Dachjenichmalz, jeoes $\frac{1}{2}$ Sp funo,

2Bachbolder=Sel, Ror= Sel, jedes 4 loth,

Eichenbolz= Del, Rein= Del, jedes 2 luth,

Dialthea, langen SPfeffer, jedes 4 loth,

Euphorbium 2 loth,

Snoblauchaft 8 loth, 
Spanifde Fliegen 1 lotb,

mifde es untereinander zu einer Salbe, fdomiere es et= lid)emal bamit.

(E) in andereb

Brauche die S3ettlersfalbe etlichemal, ift im Eapitel von allerlei Salben zu finden, wie aud) bie Räferjalbe.

\section{Ein andereb.}

Bibergeil, Samillen: \el,

Beiß̄es Rilien=Sel,

Rotbes Rofen:Sel,

SBachbolder: Sel, jedez 3 loth,

Suphorbium Del 1 loth,

mifd)e es untereinander zu einer Salbe.

(5) in andereb.

Wreidenajche 6 loth,

Rangen Shfeffer 3 loth),

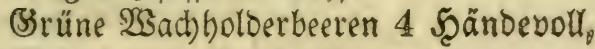

Salz 1 gute Scanovoll,

Branntemein $\frac{1}{2}$ Maaß́,

mifothe es untereinander.

\section{(5) in andereb গুG.}

Dajentoürmer = Sol 1 loth,

Lor $=$ Del 2 loth), Dialthea 3 lcth,

miliche es untereinanoer zu ciner Salbe.

Sanneide ein Roch zwildhen Şaut und Fleijd, blaje bie Şaut auf mit einem Federkeil oder Blabbalg, uno ftecte etliche Neflelnurzeln binein, fo mirbs in etlicher

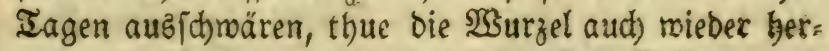
aub, und fdymiere es mit oben bemerfter Salbe. 


\section{Ein andereb:}

(Sirünen oder frifden Sävenbaum, Saberneffeln,

(S) rüne $\mathfrak{B a c h b o l o e r b e e t e n , ~}$

Die জpifen von $2 \mathfrak{G a d}$ bolderftanden,

Beiderlei నeffelmurzel, jebes 3 5̋ändevoll,

frope alles mobl untereinanoer, uno thue bagu,

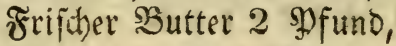

Rlauenidmalz 1 Sp funo,

Sdyeinefomaly 2 sp fund,

mijobe es untereinander über einem Feuer uno prepe ez aus, fo wird eine Salbe baraus.

Ein anoeres.

Sdhmiere es wohl mit der Scundsialbe.

\section{(E) $\mathfrak{i} \mathfrak{a} \mathfrak{n} \mathfrak{d} \in \mathbb{R} \in \mathfrak{b} \mathfrak{W}$.}

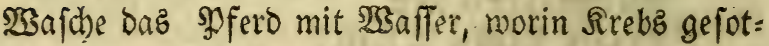
ten worden, und falbe es mit Radfolgendem:

Säuenbaum 2 Sändeboll,

Rangen Sुfeffer geftopen 2 loth,

Eliphorbium 1 loth,

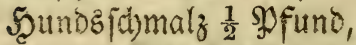

2(ttid)meer $1 \frac{1}{2}$ sp fund,

Sundsfalbe $\frac{1}{2}$ Dfund,

Sajelmiftel 6 loth,

mifche alles über einer (S)lut untereinanter.

\section{(5) in a deres}

Fange eine Srotte, reise ifgr lebendig ein folches, Bein $a b$, an welchem bas Spferd fchmindet, la s bie Jrot= we wieder laufen, und bänge dẩelbe abgeriffene firot: tenbein Dem \$ুferb an Den fobabhaften Sort. 


\section{Pferbe=:2(rzenei $\mathfrak{B u d})$.}

\section{(5) in andere $\mathfrak{B}$.}

Sole das Hineam, das ift daz Mooz von einem Tootenfopf, (mand)e lapien es von alten SুJ ferdeföpfen

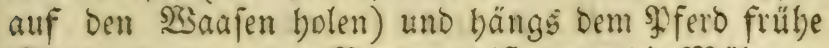
Morgens, mem ber Mono neu ift unter die Näbne.

\section{E $\mathrm{i} \mathfrak{n} \mathfrak{n} \mathbf{D} \mathfrak{e} \mathfrak{e} \mathfrak{G}$.}

3roifuen bora Tovilunii foll man Dem Sfferd 3 Iropfen SBlut oder melkr, liegt nid)tz an ber $3 a b l$, aud Scaar von bem formincenten Gilieb grnommen, auf eir

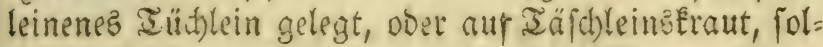
d)es zufammen gewidelt, uno in ben MRift, wer in ein feuchtes sort vergraben; es mus aber forthes oreimal gefcheben.

\section{Ein anderes IT.}

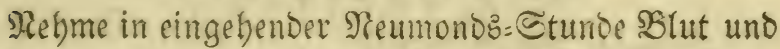
Saare von bem fichwindenden Sort, wicke! fordhes in ein leinenes Räppd)en, gelye Damit zu einem Srlenbaum, bobre ein sodb binein gegen Eomenaufgang mit einem neuen nodh ungebrauchten Neber, thue bas Şaar uno Blut binein, uno folage einen bagedormen 3apfen Dafür.

刃. $\mathfrak{B}$. Jü alles Schwinten zu curiren, foll man im wadjenden Mond anfangen.

Sernid) winden.

Die Beichen find:

1. W̉enn fith Der Sern oben an ben פEerjen zufam: men ziebet;

2. Sid) nach und nach verlieret.

Sommt yon üblem B̉efollagen, menn die $23 a ̈ n b e$ bis an bie Scrien binweg gefdrnitten fino; Darnadb von allzu bürren Şüfen; Drittens ift das Rernidninden gemeiniglid) beim $\mathfrak{B}$ ugid)minden. 


\section{Die ç $\mathfrak{u}$.}

Rehme frifthen Säufoth mit Salz uno Snoblauch untereinander gemijatt und eingejchlagen.

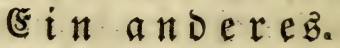

Fladbaballen, 2altid d)meer, untereinander gemifcht und bamit eingefallagen.

\section{E $\mathfrak{i} \mathfrak{n} \mathfrak{a} \mathfrak{d} \in \mathfrak{x} \in \mathfrak{b}$.}

Wsirke ibm bünn aus uno ichlag ifm mit Menichen= kotb ein.

\section{(E) $\mathfrak{n}$ andereb.}

alt fdomeer, 3miebeln,

Snoblauch),

untereinander gemifcht und bamit eingefdlagen.

Ein a $\mathfrak{n}$ o e e b.

Schmeer, Speck, $\mathfrak{2}$ adb3,

Baumöl, Sconig,

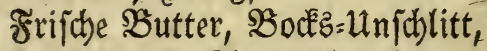

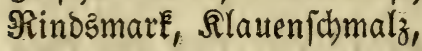

Searz, Sech, jebez gleid, viel,

mifche es untereinander, wirk den F̌n aus biz auf das

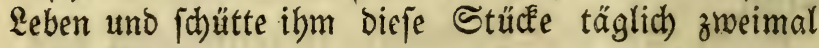
warm binein.

$$
\text { (E) } \mathfrak{n} \mathfrak{n} \mathfrak{N} \in \mathfrak{e} \mathfrak{e} \text {. }
$$

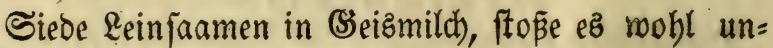
tereinander und fihlage bem pfero bamit ein.

\section{Ein anderez.}

WBitke ihm wohl aus uno fhlage ihm mit nachfol= gendem ein :

Schaafąłoth), 4 Şändeooll, Snoblaud) 2 Şänoevorl, 


\section{Pferdes?(rzenei Bưf.}

Riltid)meer 1 Sofuno, 9 Eierneif́,

lap̈e ę 3 Iage barin und fd)lag ifym wieder frifd) ein.

\section{(a) in a}

Shneide bem SPferd nohl aut, und fohlag ifm mit geftopenen rotben Ectucefen ein, continuirs über 8 Iage, fo mitke ifm wicder aus, fithlage ifm wieder mit

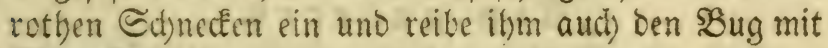
Sdjneden.

\section{(5) i a n}

Sablage bem sूfero mit Scirjenbrei, Sappeln, 2rit= id)meer miteinander in S్Sein gefotten raarm ein, uno wieoerbole es.

\section{(5) in anderez II.}

Snoblaut), stunnenfrễen,

Solberblätter, jedes 3 Sănoeboll,

2ittfumeer, fo viel genug zu einem Teig iff.

Salz 1 Sanowoll,

mijde ez untereinander und foflage bamit ein.

\section{sin anderez.}

ajde, 2utichmeer, $\varsigma_{\text {alz, }}$

machs untereinander beis, uno itblag bem spfero bes Iages zreimal bamit ein.

\section{Ein a nDereb.}

Säbenbaum, 2rtidymeer,

untereinander geftopen und bem spfero bamit einge= id)lagen.

\section{Ei in a noeres. 23 ,}

WSirke ben Şuf nobl aus uno idjlage ifm mit ge: ftokenen Siebjen ein. 
752 gpferbes:2irgenet But).

Ein andereb.

Speterling 1 ober 2 Scändevoll,

Salz 1 Scanowoll,

2lltid)meer poer Spect 1 pfund,

fope und mifche allez untereinander und fajlag dem Syferd bamit ein.

Ein a no eres.

Reipe die Soblen aus und ftreidhe Rachfolgendes Ginein :

Umerikanifchen SBolug, : $\mathfrak{B}$ eirauch.

Mevrrben, (S) rünipan,

Rlaun, jedes 1 loth,

Sitriol 2 lotb, Şonig $\frac{1}{4}$ Maa

mijche es untereinander über einem Soblenfeuer zu ei= ner Salbe.

Ein anderes.

Şerr von Scod)berg recommendirt Nad)folgendeg :

Rebme Scühnerkoth uno Sdbaafbohnen, Ebermur:zel uno Snoblauch mit 2attidhmeer, alles ourdheinanoer gegoffen uno eingeichlagen, uno jagt, es fei gar be=

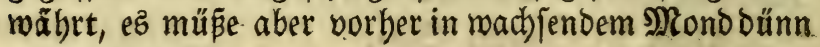
aubgervirkt fein.

\section{D)ą 44 fte Capitel.

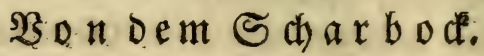

S马ben am SBSiederuft läuft ę auf, uno läpt fich fe= ben, als menns ber Sattel georücḱt bãtte, allba foll mans offnen, fo wiro ein gelbes $\mathfrak{B a f f e r ~ h e r a u b l a u f e n ; ~}$ *u? bem Sdjaben geben \&ödher binunter in ben Scals, 
unter bie 3ähne, in (Seftalt fdowarzer 2(eberchen, in bieje foll man Eaput mortuum Bitrioli freuen, oder auf Die $2 \mathfrak{B}$ unde Sleum 2Cntimonium, oder Edbefel= balfam, ober (sichenbolz= Del ftreid)en, und in allem in = nerlic) als äup̃erlic) wie Den $\mathfrak{B}$ urm beilen.

\section{Das 45fite Capitel.}

\section{Эon Den Sennen ober Nerven und ifren Sie= bredten.}

Die 3eid)en, wenn cin $\$$ ferd die Sennen ober $\mathfrak{A e r}=$ ven übertreten, oder verzuckt, ober baran geftopen, ge= id)lagen, ooer zerquetid)et worben, find augenficheinlid).

1. Sjinft es jehr an felbigem Fuß̃.

2. Sann ez den Fũ gar nicht fortfęen.

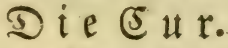

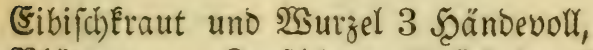
Blätter vom Seutchbaum 2 Şändevoll, Majoran 1 Şanovoll,

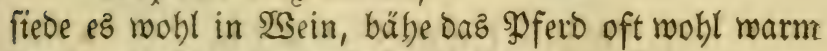
bamit uno fallage die Rräuter über den Gdjaben.

E in a noeres.

Sgappeln 2 Scänoeboll,

ŞBeizenteleien 3 Scändevoll,

Shopfen 1 Sanovoll,

Sceublumen vier Scänoevoll,

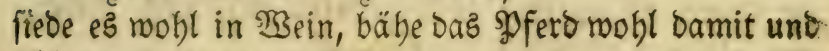
ihlage es oft rarm über.

(5) in a noeres:

3iegel $=$ D fl 3 loth, Regenwürmer $=$ Del, 
Seife, jedes: 6 loth,

Terpentin $=$ Del,

fdumarzes Sduneden=Sel, jedez vier loth,

Siop̧beinöl, Scirid)beinöl, jebes 3 loth,

mifithe alles untereinander und reibe ben Srt nobl ba= mit.

(5in a n Dexeb $\mathfrak{K}$,

Rege ein gutes Rervenpflafter um ben Srt.

E in a $\mathfrak{n}$ Dereb $\mathfrak{B}$.

Şunosfid)malz, Dad) fenjumalz, jeoes $\frac{1}{2}$ şfund,

Rillo Sakenfd)malz vier loth,

:Saad) bolderöl 2 lotb,

Eein= Del vier loth, Spetroleum 1 loth),

mijhe es untereinanoer und fdymiere daz sूferd warm bamit.

গR. 2B. Man foll foldbe Mferbe vor bem Enoe ber Cur in Eein $\mathfrak{W a f f e r}$ aeben lapen.

\section{Daz 46fte Eapitel.}

\section{SD n D e E E a th.}

Der Spath ift pine Fleine barte und bicke (sepdonulft,

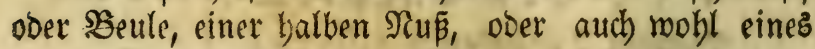
balben (siez grofi, uno dies fommt gemeiniglich an bem bintern rechten Echenéel innerbalb dez Sniez, felten aber an alle Beibe, wirb ein barter Beule, bavon binkt ein פpferd, bis es eine meile geritten wirb uno erroăr = met, alşann läst baz Şinfen nad).

Sommt von falten Feudtigkeiten, welche binabfal= len uno verbärten; ooer aud) von vieler uno groper 
37

Ecite 755

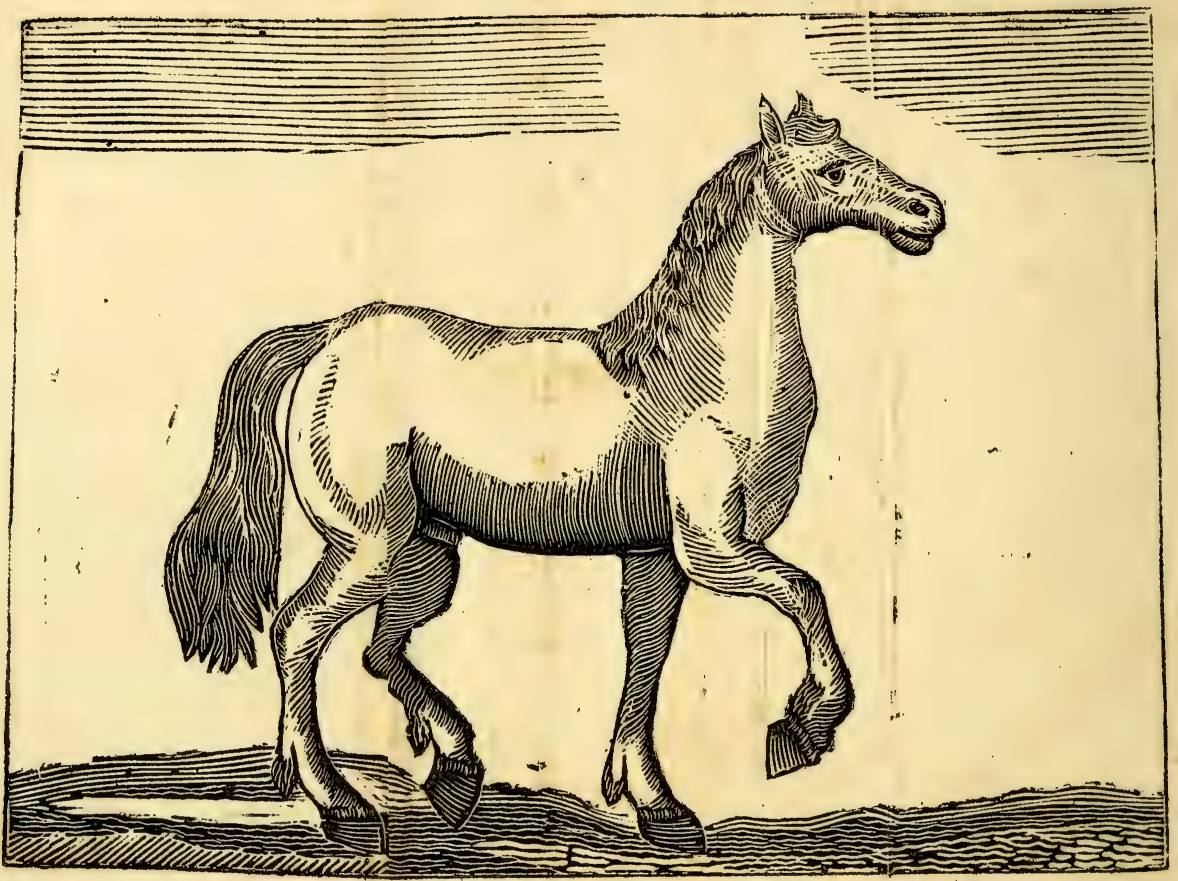


Ei n n

Senftmebl $\frac{1}{4}$ Dfund,

Reffelfaamen vier loth,

Softerlucen 3 loth,

Schwefel 6 loth,

(3) ummi SBbellium,

"2(mmoniacum, jebes $1 \frac{1}{2}$ loth,

WSache $\frac{1}{4}$ \$ुfund, Scarz,

Dech, jedee $\frac{1}{2}$ sf fund,

altes Saumöl, jebes fo viel als nöthig iff,

mifche es untereinander über einem Feuer zu sinem Pflafter.

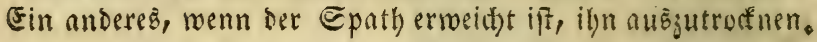

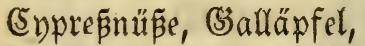

(3)ranatäpfel, jedes 2 Ioth,

Maftix $\frac{1}{2}$ loth,

Tragant 2 loth,

Dradenblut 1 loth,

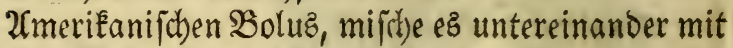

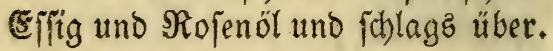

E $i$ it a noeres.

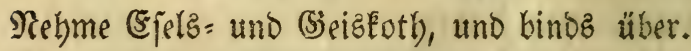

Ein anderez.

Sd) jenteoth, Sammichmalz,

Schweineichmalz, jectes vier loth,

vermifdue es mit Esffig uno fallags über den Sort.

(E) in a th $b$ eres.

Eauterifire ben Spath uno lege bie Mifatung von einem Esberbotter uno Rofenöl über, uno fchmiere ę biz zu gänzlidher Şeilung oft mit warmem Sdbweinen. idomaly. 
(5in a n o e re b.

ş3enn fid) Der Gpath angefegt, fo (d)eere ifm Das Saar binweg und cauterifite daz Spfert, und faniere es hernad) mit शad) folgentocm :

\section{Şonig $\frac{1}{2}$ SP funo, Sitriol 3 loth),}

Ilaun 2 loth, (stünjpan 1 loth, fiede ce miteinan= ber mit Eîig zu cimet Ealbe.

$$
\text { (F) } i \text { a } n \text { beres. }
$$

Thue bie Sout mit cinem פMeffer vom Epath bin= mig, und ftreue Das Pulver won Geeblumen binein, bin= be cin Seeblatt Daruber 3 Tage und fdmicrs bernach mit einer warmen Galbe.

Fin anderes W.

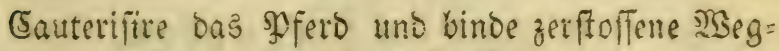
martennurzel tarauf, reite es alle Irage, uno wenn ber Sithaden ausflest, fo beile ihn mit oer Ëguptiphen Salbe, oder mit F̌elix $\mathfrak{X}$ ür

(E) $\mathrm{t}$ a a bere

Sdmeide ifm den Gpath Ereugroife auf, uno binde geftopene Siemian, Smicfel, ober Sdmeinefoth orei Tagen nad)eimander barauf.

Fin andere .

Rebme calcinirtes Sirottenpulber und binds barauf.

(F) in a nó exe z.

Ungelördeten Sildh,

Seife, jeosz gleich viel, berflopfs robl mit (Siermeis, und binos über, uno lege alle Iage ein frifhes Sुflafter Darüber.

(5in an oereb.

Rache ein \$ुFlafter von geftopenem \$ुfeffer, Cenfs mebl uno Bmiefelfaft, thue auf Das soflafter 3 (Enbfen 
groß Mercurium fublimatum, baß recht auf bie Mitten bes Srtz fomme, uno lege das spflafter über, bas thue fo lang, bis die Şaut abgebet und (5iter madbet; man mus täglich ein frifbes Spflafter auflegen, hernach lege

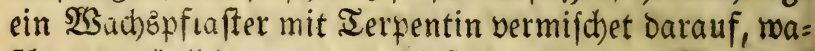
fhe ę täglid aus, uno wirf gepülverten $\mathfrak{S}_{\text {einftein }}$ binein.

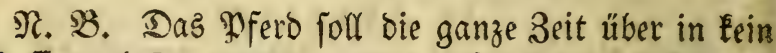
$\mathfrak{B a f f e r}$ gelā̄en werden, und Der Stall trodéen fein.

\section{Daz 47ffe Eapitel.}

\section{Son Den Gtrupfen.}

Die Strupfen, meld)e mie Säuborften am Şaar überfich fteben, Eommen aus Ealten böfen Ftüsen, uno fino mit Der siappen uno Mauken faft cinerlei Rrant=

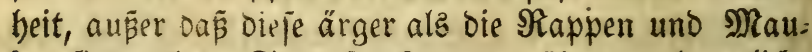
Een fino. etlibe Strupfen fommen überzmerch, etliche nach) Der \&änge. Siebe Figur No. 38.

\section{Die 5 ur.}

2rgaric 1 loth, 2loes,

Scxmmonium, jeoes $\frac{1}{2}$ loth,

SBeinftein 2 lotk,

Salap $\frac{1}{2}$ loth, 2unis 1 loth,

mifche alles untereinander in brei SBiertel Maaß wat: mem Ssein, uno fidutte es oem soferd auf einmal ein, hernach fismiere es mit Nachfolgendem :

Igtffein, Ierpentin,

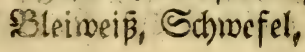




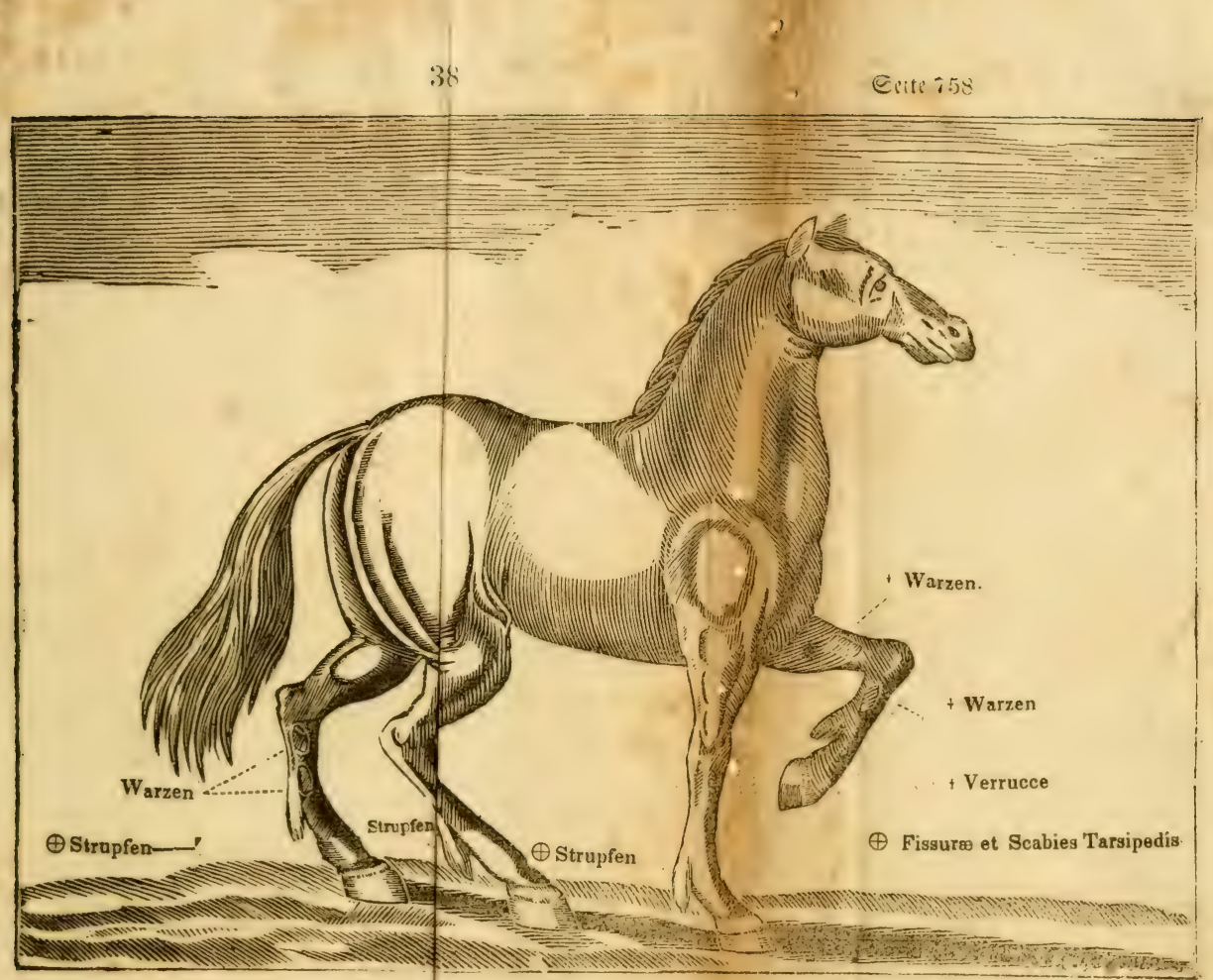




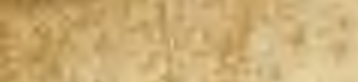

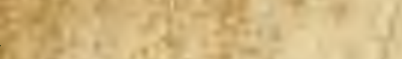

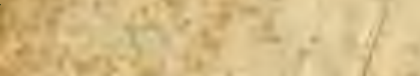

$\cot ^{2}+x^{2} x^{2} y^{2}-2=$

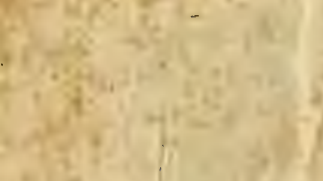

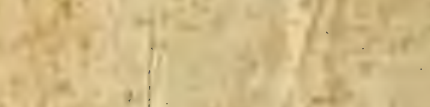

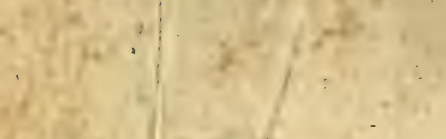
.

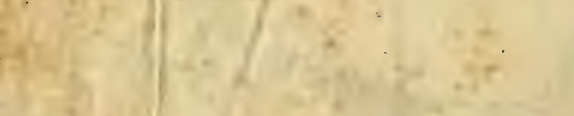

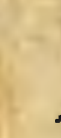

1)

(1)

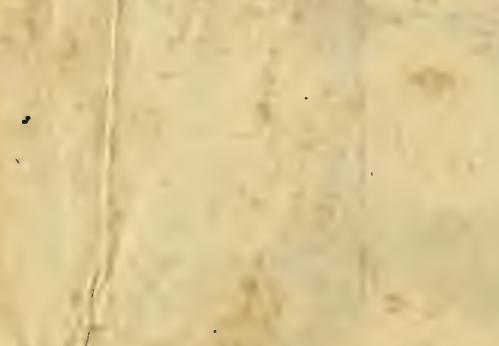

4

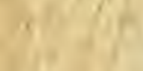

1

$1+2$

(2)

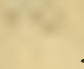

$\therefore$

$\left(x+2 x^{2} x^{2}\right.$
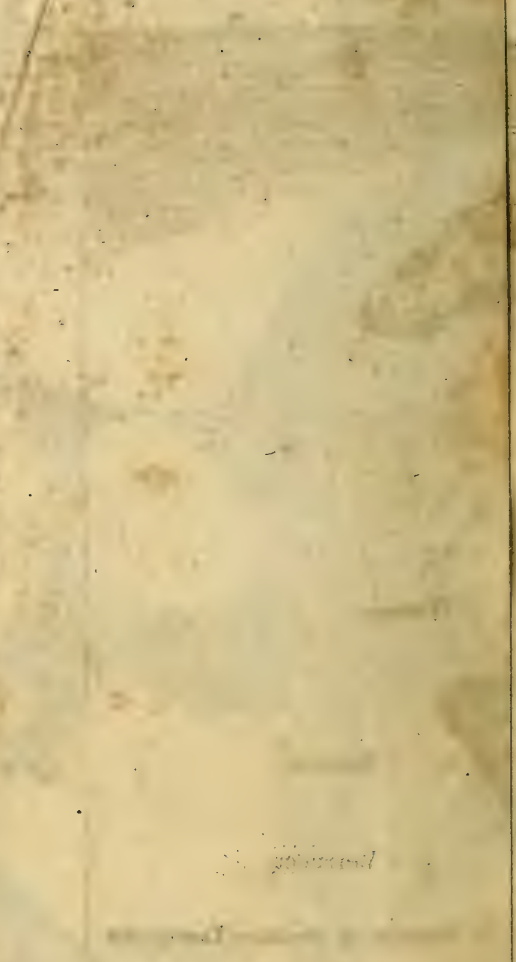

B.
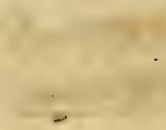

$-6 \times 1=0.0$

$-x_{-1}$

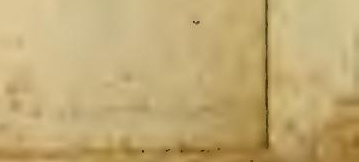


Specf, eines fo viel als bas andere,

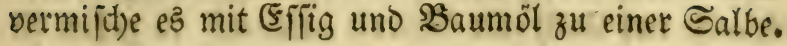

(E) in an beres $\mathbb{B}$.

Sumicre bie Strupfen mit bem Baljam oder bem

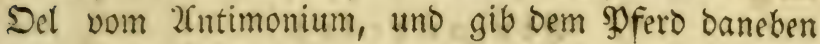
Das Seppar Xntimonium zu freflen.

E i n a nderez $5 \mathbb{B}$.

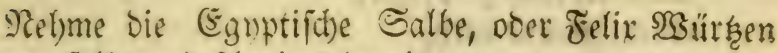
Sraunfalbe uno fomiers bamit.

(E)

Man catutifitit fie auch, und procebirt bamit mie mit bem Spath.

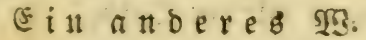

2i3ajd)e lie oft mit $\Re$ übeharn, worin (5id)enrinoen, Gialläpfel tmo Granatapfelrinden gefotten worden, uno ftreue das Eaput mortum Bitrioli binein.

(5) i n a noeres.

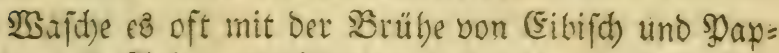
peln, aud Eulz untereinanoer geneingt.

S2. 33. 3u Diejen Etrupfen tönen alle Mebicamen: ten, io gu Den gुappen und Maufen gerwaud)t werben, auch) genommen werben; man folf aud) bas spferb wäb= reno der Eur in Eein $\mathfrak{2}$ affer gelyen laffen.

bi it a noered.

Sicbe Den Inild)raum und 2 aads roobl untercinan= ber, utu binde es auf bie Etrupfen, micbethole es etli= d)e rage.

(5) in a noereb.

Binde warmen 2Renjidenteth barüker.

Fi.tl a nberes $\mathbb{T S}$.

Taudje ein wollenes Iud) in beipe? 
ez aljo warm über, lape ę 3 Tage barauf liegen, bers nact) reipe bas Tuch mit (Sewalt berunter, fo geben fie mit heraus, foldhes beile mit ber (sgyptifhen Sal= be, ober Felix $\mathfrak{s}$ ürhen Sraunfalbe.

\section{Ein a noeres.}

SBagenfdhmier 2 Sfuno,

Schufterpech $\frac{1}{2}$ spfund,

(Srünipan 3 loth,

- Sdbuefel 8 lotb,

mifche es untereinanoer über einem Soblenfeuer, als= bann mifche $\Re u \tilde{s}$ barein, bis es eine Salbe miro, wa= fiche bie Saut nobl mit jobarfer \&auge, hernach jalbe die Strupfen marm mit ber Salbe.

(5in andereb.

Stelle Das Spferd täglid eine Stunde in Miftlad)en, hernach roajde es mit Lauge at, welche kalt gegoilen worden; wennz trocken worden, fo madbe einen SBrei von flieffendem $\mathfrak{Z}$ saffer uno ungelöfdtem Salf, uno binde darüber, über 3 Iage procedire wie am erften.

(sin anderes.

Sdjieppulver,

Sdinefel, jebes 1 ⿰氵

Ssrünipan $\frac{1}{2}$ SP funo,

Specḱ, fo auf ein Ealtes $\mathfrak{B a f f e r}$ gegopen worben vier syfuno,

laß̧e Den Speck über einer (3)lut niebar zergehen, und rüfre obige 2rtifel wohl untereinander gepülvert $D a=$ runter zu einer Salbe, uno fdimiere das \$fferd bamit.

Ein an berez.

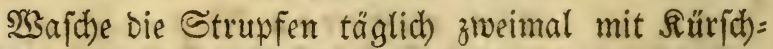
neräbaís ober Gchufterfanwärze. 


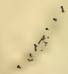

$\vdots$ 


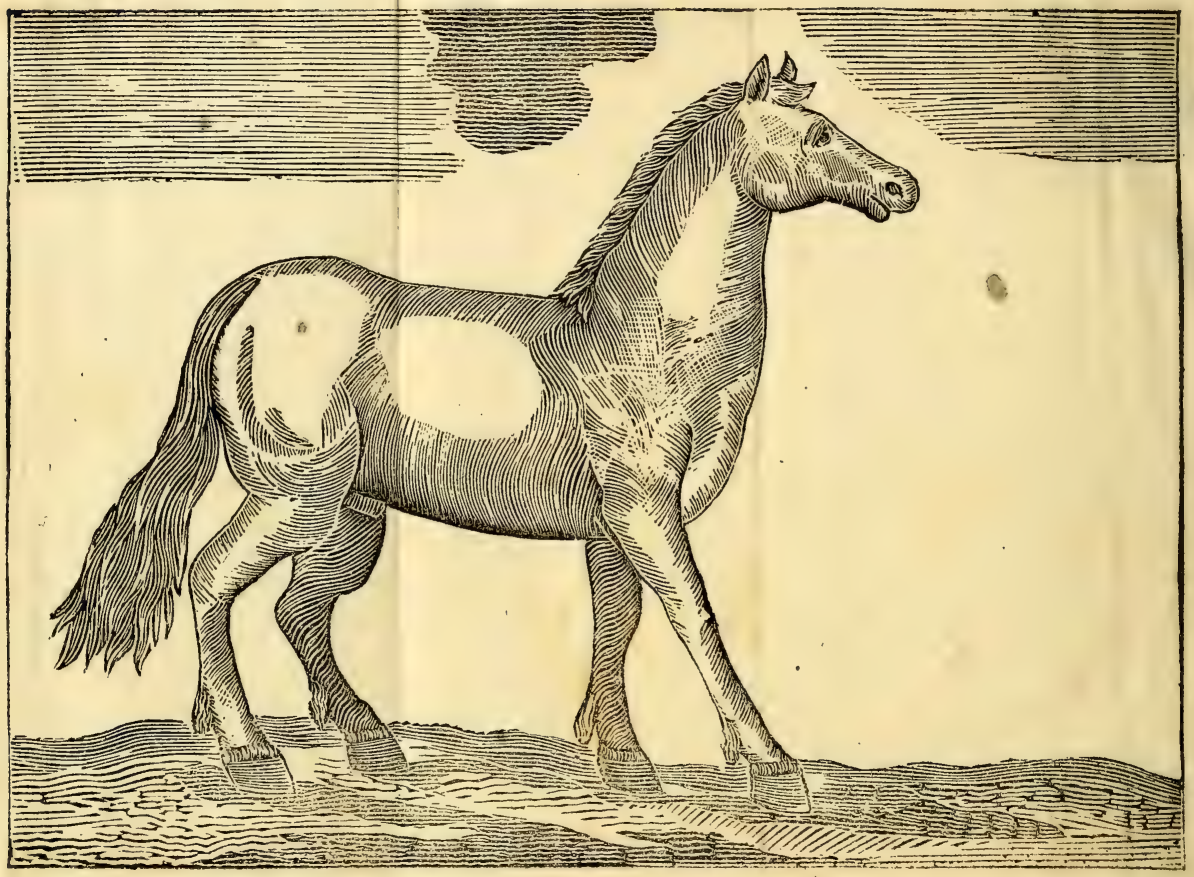


762

\section{Wferbe:-2rrenei Bud.}

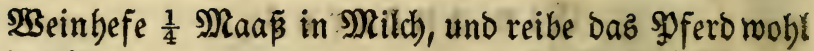
Damit.

(E) in noeres.

Beftónenen Säbenbaum 1 Şanoboll

Schmeer 1 Wfund,

fiede es untereinander zu einer Salbe uno fdhmiere bas \$fero robl oamit.

E in a n Dereb.

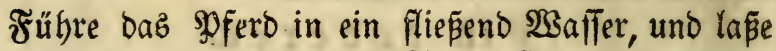
es 1 Stunde lang gegen den Strom fteben, thute e? et= lidbe Iage nadbeinander

\section{(E) $\mathfrak{i} \mathfrak{n} \mathfrak{a} \mathfrak{n} \in \mathfrak{R} \mathfrak{e}$.}

Salbe es mit der SBiberjäbe.

$$
\text { (E) inatiores } \mathfrak{B} \text {. }
$$

Schlage bem \$fero die 2 Bugadern, und fange bas silut auf, herwach

Nehme Roggenmehl,

2ijche, jebes 2 Seändeboll,

11 Eier, Branntewein,

Effig, Shonig, jedez $\frac{1}{4}$ Maa

mifche folches mit fammt dem Bfut untereinander uno

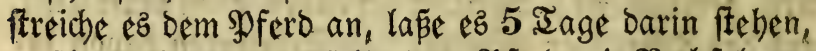
wajthe es berab, und falbe bas \$fero mit Rachfolgen= bem :

Sammichmalz, saärenichmalz,

Dachjenjfdmalz, jeoes 6 loth,

Fuchsfchmal, Camillenöl,

Terpentinöl, jedes 8 loth,

Siegenmứrmeról bier loth,

milobe affes untereinander zu einer Salbe. 


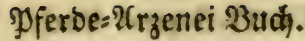

\section{Einandereb.}

Sundzid)malz $\frac{1}{2}$ ⿰马 funo,

WBilde RaGenjd)malz,

Sjanf = Sol, jeoces 6 lotb),

Şiridnumat 3 loth,

Sanidelel, 3 Scänoevoll,

Sd)meineidmalz I SDfuno,

mifde es untereinanoer zu cincr Salbe,

(F) a

Daš grüne Fröíftöl,

Şunosichmalz,

Dadbienid)malz, Slautenfett,

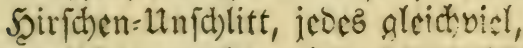

falbe bas \$fero mobl bamit, micoerbole es etlict, emal.

E inanderes

Sirfatbeinöl, Sundzbcinöl,

Ropbeinöl, jeoes 2 loth,

Ierpentinöl, Sanföl, jeses vier loth,

Sadd bolderöl 3 loth,

Ror = Sel $\frac{1}{4}$ SD fund, Rein= Sell $\frac{1}{2}$ SDfund,

Shiridhen=Unichlitt,

Şodfs:Unfolitt, jedes $1 \frac{1}{2}$ Sfund,

Rinos: Unfchlitt,

Dialthea, jebes 1 SPfund,

Rlauenfett $\frac{1}{2}$ Sf fund,

WaAcb $\frac{1}{4}$ פf funo,

Saft von zerfopenen Srebjen,

Saft von frifchell Solocrblättern, jockes $\frac{1}{2}$ Şfo.

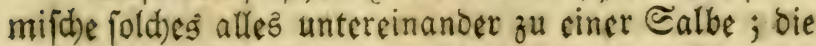

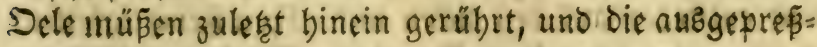
ten Säfte zün erften gefotten meroen. 


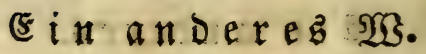

Sdjmiere ben Sort mohl mit Der Bettlersfalbe.

E $\mathfrak{i} \mathfrak{n} \mathfrak{n}$ ber $\mathfrak{e} \mathfrak{b}$.

Einen Elein gebacêten roben Scajenbalg,

15 lebendig zerftozene Rreble,

Bseizenfleien, etliche Şänoevoll,

fiebe alfez miteinander in ङfffig zu einem Sirei, ftreiche

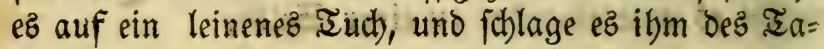
gez zmeimal über, wieberbole ez etlidjemal.

Ein anderez.

(Sauterifite ben $\mathfrak{B u g}$ und fohmiere hernach eine gute Brandjalbe darauf.

\section{Das 49ftc Capitel.}

$\mathfrak{B}$ on $\mathfrak{B}$ er $\mathfrak{x} \mathfrak{e n} \mathfrak{u} \mathfrak{n} \mathfrak{g} \in \mathfrak{n}$.

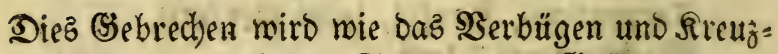
verrüứcung, wie auch) Daz Sennen ober (Şeäber verzu= dén curirt, bespogen idblage man in ibren (Eapiteln nad).

\section{Dab 50fte Capitel.}

\section{Bon Den Ueberbeinen.}

Die Ueberbeine fino barte fichnülid)te Seich)mülfte ano Beulen, welche fich nid)t laßen zurück brüclen, nod) einige Sdbmerzen verurfadjen, einer Şafelnü gleid, uab entfteben aub den bicken uno zähen žeuchtigkeiten, weldte von Den obern Sorten bez \&eibes in bie untern 

Ifbeile, als bie Sdbenfel, fid) binab gezogen, liegen ge= blieben, uno alfo verbärtet morden. Diefelbe fommen aud) vom Stopen, ভdblagen, uno werben aud von $\mathfrak{B}_{e}=$ id)älern uno @ituten ererbet.

Diefelbe liegen bart auf Den $B$ seinen auf uno lap̃en (id) nicht abjondern; fie liegen den Shferden gemeinig =. (id) am untern İbeil bes Fup̃es, neben Dem Snie, neben Den Füpen, inwendig, aušwendig und vornen auf Den Edbienbeinen, felten oberbalb Den Snie; jeocd fommen fie auth) unter bie Simnbacten, und frecten fid bizmeilen längft binab gegen Den Srt, no die Sinneet= te zul liegen pflegt. (53befommen fie aber junge Foh: len und \$ुferve viel leid)ter als bie alten. Siebe Fix gur शro. 40.

\section{Die હur.}

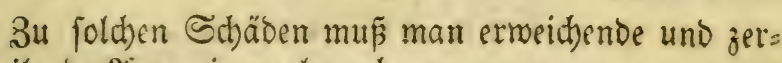
theilende 2 irzeneien gebrauchen.

Lape bie Saare binmeg fdjeeren, uno nebme

Ror=:Del, Dialthea,

(S)eftopene 3wietuln,

Marciaton, jedes $\frac{1}{2}$ SPfund,

Unguentum $\mathfrak{2}$ grippa 1 \$funo,

mijche es untereinander und lege es roarm auf Dert Sort, bis er aufbridht, und zur Seitigung Eommen, alb= Dann beile inn wie andere $\mathfrak{B}$ unden.

(Fin andereb :

Eibijdrourzel,

İ̧ülferaut, meife Rilien,

fiebe ez miteinander uno ftope ez, bernact) vermifdse eह mit Sibmeinenfdbmalz zu einem spflafter uno lege ce alle Iage zneimal narm über. 


\section{Ein $\mathfrak{i} \mathfrak{n} \mathfrak{D}$ ere}

Seftopenen నümmel,

Butter, jedes 1 פfund,

Ierpentin 8 loth,

vermifhe ez miteinanoer uno la je ez fieden uno fhlags roarm über; fo bald nun bie Seuten bes Ueberbeing

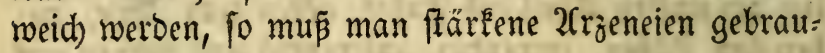
dien :

Wermuth, (Eppid),

Maurrḱraut, sGärenflauen,

Mengetwurzel, auf Lateinifch Lapatbum genannt, jeves gleid viel,

fiede ez moht in $\mathfrak{B a} a$ fer, hernach ftope bie Slätter nobl mic Sdbweinenfomalz zu einem Spflafter, uno lege ez warm über.

$$
\text { Ein andereb. }
$$

Sarz 2 loth, Maftix 1 loth,

Beirauch 3 lotb,

Bleiwei s vier loth,

Baumől 12 loth,

vermifche es untereinander zu einer Ealbe, uno fobimie= re ben Sort oft Damit.

\section{Ein anderez.}

Feigbohnenmebl,

fitede es im Effig uno fchlagg warm über, tăglid) einmal.

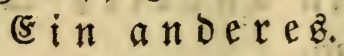

Teufelabreck, vermifhe foldhes mit (sffig und 5 Se= nig, uno legs über.

(E) $\mathrm{il}$ a NDereB

Lape bie Şaare hinweg idheeren, picte dab Uteberbein 


\section{פूferde:2Irzenei Budh.}

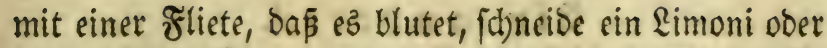
bart gejotten (si entzmei, beftreiche fold)es mit gepül= vertem Euphorbium, und binde ₹s über.

\section{(5)}

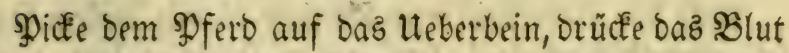
wohl beraus, hernad) jchmiere ez mit nachfolgender Salbe, oder lege diejelbe gar über :

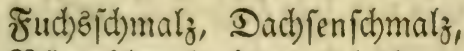

Särenfd)malz, jeoes 6 loth,

Euphorbiumöl 2 lotb,

T3adbboloerholzöl,

Sarelbolzöl, jeoes 3 loth,

Schwarzes Sduneckenöl 2 loth,

mijuse es untereinanoer.

(5) i

Euphorbium 2 loth,

Eantharioes 1 loth,

Butter, fo viel genug zu einer Galbe ift.

mijtbe es untereinander uno lege es 3 Iage nacheinanDer üher, nach 3 Iagen fdmiere ifn mit Dadjenfd)malz, Roröl und Dialtbea untereinander gemifat.

\section{(5in a nderes.}

SKenn aber bas Heberbein in einem (Seleid) raãre, fo mus man fold)es vorfid)tig beraus löfen, uno ben Sit mit andern Sceifalben uno Sु) flaftern mieder beilen.

\section{E $i \mathfrak{n} \mathfrak{a} \mathfrak{D} \in \mathfrak{r} \in \mathfrak{B} \mathfrak{W}$.}

Sauterifire das Ueberbein etlichemal überzmerchs, und beile es Darnach mit Den Mitteln, noelche in Dem Eapi= tel von ben (Serwät)fen ber Sfferbe zu finden find. 


\section{Pferbes:Arzenei Bud.}

\section{Ein andereb.}

Sicke bas Uteberbein uno lege bie Mifchung vom Scarz und Sdbrefel Darủber, ooer die Säferfalbe.

Ein anderez:

Sidfé bas $\mathfrak{U}$ eberbein uno ichmiere es mit hei fel= ooer Efchenbolzöl, fecte es eine Beitlang fort.

E $\mathfrak{i} \mathfrak{n} \mathfrak{a}$ Dere $\mathfrak{B}:$

Sidée bas $\mathfrak{H}$ eberbein uno lege folgendes barüber :

(5)ummi (s)albanum,

"2 2mmoniacum, jebes 3 loth,

löfe es in Effitg auf, thue hernad) Dazu

Sarz, פech, jeoez 6 loth,

Baumól $\frac{1}{2}$ Mfuno,

Ierpentinố 6 lotb,

mifhe es untereinander über einem Feuer.

\section{Eี $\mathfrak{i} \mathfrak{n} \mathfrak{n} \mathfrak{b} \in \mathfrak{r} \in \mathfrak{B} \mathfrak{B S}$.}

Salbanum,

2fmmoniacum, jebes vier loth,

löpe es in Effitig auf, uno thue nadyfolgendes bazu,

Ierpentin 1 spfund,

Langen $\mathfrak{P f e f f e r} 3$ loth,

Spopanax, Boellium, jeoez vier loth,

Eoröl, Baumöl, $\mathfrak{S}$ actbz,

Ded), jebes 1 Pfund,

mifhe alles untereinander über einem Feuer und fanmie= re bazsofero wohl bamit, ober lege es ifm warm über.

E i $\mathfrak{n} \mathfrak{n} \boldsymbol{D} \in \mathfrak{r} \mathfrak{e}$.

2uripigment,

Ungelöfdoten నalE,

Grünipan, jedes 2 lotf),

fiebe ea miteinander in Effig, fallage es dem झfert 


\section{Mferde:2(rzenei Buá.}

10ohl marm über, wieberbole ę tăglich jec)smal, als= bann reibe eŝ mit einem glatten $\mathfrak{I} u d$ abroarts, fo mird ę lebig, alzbann fanr: manz beraus löjen.

\section{(F) in andereb.}

Dicke ben Srt und binde शad)folgendes über :

Şafentäz, foarfen ઉenf,

untereinander gemifdt und baruber gebunden.

\section{E in andereb.}

SGenn bie Gadbe fid aber fo verhalten follte, Daßa aud ein Sd)merz bazu Eäme, uno bas spferd zu binfen an= fienge, fo offme bie Scaut, und ftreiche शad)folgendes Darauf :

Sfeffer, Ungelöichten Sale, jeoes gleiduviel,

Eilig, fo viel genug zu einer Salbe ift, mijhe es untereinander.

\section{Eี in a no exe}

SDache einen Ieig von Senftmebl uno Sdbjengarlen, uno fd)lage es Darauf, uno laß̄e ç 5 Iage uno ?äd) barüber, alsoann binde wieber ein frifhes barüber uno laje es wieder zwei Tage Darüber, alsoann wenn es weid) iff, fo cauterijirs Ereitzweife uno fdomiere es mit Nachfolgendem :

Sirid)en=L!nichlitt, Bocfunichlitt, jebes $\frac{1}{4}$ SP fo.

פ) Reifterwu;iel 2 loth),

Dadjenfidmalz $\frac{1}{4}$ Sूfund,

mijuthe es untereinanoer zu einer Ealbe.

(5in andereb 2 .

Sauterifire den Sut and brile ifn mit dem Epiep̧glaz.

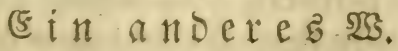

¿edige die Salut auf cem Uebertein von einander, uno gebraudie Die Räferfalte. 


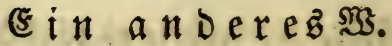

Lebige bie Scaut auf bem Ueberbein, und nebme Sal 2Cmmoniacum 2 Suintlein, פofeffer 1 loth,

10 Snoblaucbzäben,

ftope alles untereinander und thue es unter bie şaut auf Das $\mathfrak{H e b e r b e i n , ~ u n o ~ n a ̈ b e ~ b i e ~ S c a u t ~ D a r u ̈ b e r ~ m i e b e r ~}$ zu, lape es 5 Tage uno Näd)te aljo ftehen, hernad) binde es mieder auf; ferner vermifdhe Dachjenfdhmalz und Baumöl untereinanocr mit ein wenig ungelöfchtem

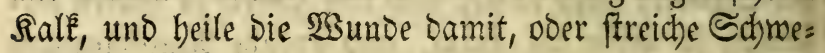
felbalfam binein.

\section{Eีin andere $\mathfrak{E}:$}

Rebme einen gropen runden Crryftalffein, binde ibn feft auf bas lteberbein, und wenn ber Sollmono vorï= ber ift, fo lape daz Mferd alle Nactst in ben Monofchein fübren und gegen Den Mlond mit Dem Ernftall orei Stunde lang fteben, Damit ber Mono feine Etrablen recht auf ben Stein merfen Eönne, fereze ę fort bis ber Mono wieder neu miro, alle Radht, bieg thue zmeimal wenn ber Mono abnetgmen will.

\section{Das 51 fte Sapitel.}

\section{SO D De n II a r}

Die Şsarzen find nidht allemal jo leidht fu vertreiben, wie fid) einige vorftellen, benn mand)e find fo tief ein= gemourzelt, Das man fie audh nicht beraus fdnneiben Eann. Siebe Figur $\mathfrak{N o}^{3} 38$. 


\section{Pierbe:2Trzenei Buth.}

\section{Di i e c ur.}

Utmminde die $\mathfrak{3}$ arzen mohl mit einem Rophaar,

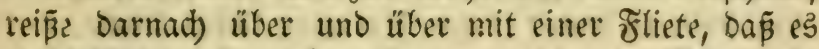
mohl blutet; hernad) reibe ę wohl mit (Sänjerid), nebme bernad) Denfelben (Sänjerid) uno grabe ifn un= ter eimen Mift. 2 2. $\mathfrak{B}$. Diefes mú gefdeben im $a b=$ nebmenoen Mono, wenn et im Srebs ift.

Ei $\mathfrak{A} \mathfrak{n} \mathfrak{D} \in \mathfrak{r e b}$.

Sauterifite Die Sarzen und lege Ringelblumen mit Sd)meinenjhmalz angeftopen barüber.

\section{Ei a noere}

Sdneide Tarzen heraus uno binde Shiepspulver mit Spect vermifd)t Darüber.

(5) in a'n Dereb.

Tröpfele beip̄en Spect auf die $\mathfrak{B a r z e n , ~ f r r e u e ~ a l s = ~}$ Dann $\mathfrak{B}$ einftein und 2Curipigment untereinander ge= mijd)et barauf.

\section{E in a ndereb গู马.}

Nebme (Efulafrautiaft, in Deutid) 230 olfsmild) ge= nannt, (Sänjerid) jaft, jeoss fo viel als nöthig iff, ver=

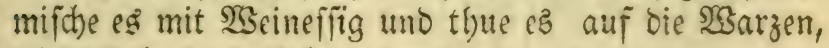
riederbole dies etlichemal.

\section{(sin anderes}

Sajaje die Warzen oft mit bem SSaffer, in meldyem die Sdmiebe das (sifen ablöfthen, ober mit Maffer wo= rin man ben Sactofenwifa abgetöftht bat, mieberbole es eine 3eitlang.

\section{Eี in a noereb̉.}

Sicke bie Warzen und fdmiere Seitlofenmurzelfaft baruber ober 2 grimoniajaft. 
R. 2. 2Ulle Curen Der $\mathfrak{B a r z e n ~ m u ̈ f f e n ~ i m ~ a b n e b = ~}$ menden Nono gefdeben, und das shfero fo angebun= ben werden, Damit es Den Sort nid)t lecken Eönne.

\section{Das 52fte capitel.}

\section{$\mathfrak{B} \mathfrak{D} \mathfrak{N} \mathfrak{B} \mathfrak{x} \mathfrak{w} \mathfrak{n} \mathfrak{D} \mathfrak{n} \mathfrak{g} \in \mathfrak{n}$.}

WGenn ein Pfero mit einem Pfeil Doer Siugel gefthofen murde.

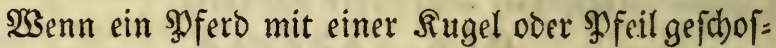
fen worben, uno bie Rugel Darin ftecken geblieben ift, fo foll man biejelbe, no möglich, beraus zieben, entwe= ber mit einem \{ugelzieber, ober our(h) einen Schnitt, Dem Spfero täglich 3 loth Schieppulver in warmem Bein, worin $\mathfrak{B e t o n i e n}$ gefotten worben, eingiepen, unt foldhes 5 Tage fort jeten, auch unter bem Futter Schießs= pulver zu freffen geben, uno lap̃e täglid) Salpeter un= ter bas Irinkmaffer thun, Damit es ben Brano inner= (iic) verwebre und lege nadifolgendes Spflafter barüber:

5 Lebendig zerftopene ふrebje,

Saarenichmal; vier loth,

Sa penbaare 1 loth),

Sornblumentourzel,

Stictrourzel, jebes 2 loth,

Diftelnurzel, Betonien,

Bobnenblätter, jedez 1 loth,

Ierpentin, $\mathfrak{R a d})$,

2lttichmeer, jedes 3 loth,

Magnetifeinpulver 1 loth,

Sonig $\frac{1}{4}$ Pfuno,

mifde biefe 2 rtikel uber einem linoen geuet zu einem 


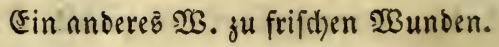

Sanidel, Ein= ober Bmeiblatt,

Seionifd $\mathfrak{2}$ und Eraut,

(3)arbenf́raut, jedes 6 Scändeboll,

fiebe es zujammen in flieffendem 2 Baffer, ftope es zu einev Ratwerge, und orücke pz burd) ein Iuth, nebme

Des auzgeprepten 1 Maá̃,

Siebengezeitpulver 6 loth,

Bod₹z= Lunjhlitt $1 \frac{1}{2}$ SDfuno,

Reinbergeridameer 1 Sf fund,

Baumöl $\frac{1}{2}$ DNfuno,

$3 a$ adb, fo viel genug zu einer Salbe ift,

laßje es mitcinander über einem linden Soblenfeuer ver: mijhen, ift gut alle ŞSunden zu beilen.

\section{Ein andereb.}

Serlapene Butter 10 loth,

idhütte biejelbe auf Sauerkrautbrübe, bernad) nebme

Diejer Butter 4 loth,

Sanföl 8 loth,

Sal 2 mmoniacum 2 loth,

Eampfer 1 lotly,

6 (siermein,

ftope alles untereinander in einem Möffer zu einer Salbe. Den Gampfer mup man vorber in Rofenöl zerteiben.

\section{Ein andereb.}

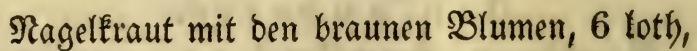

(Sepullverte Magneten 1 loth,

Saeipe Rilienturzel 3 loth,

Sdyweineidhmalz 1 spuno,

mirche ez untereinanoer uno lege es über. 
(E) in andereb.

6 (3) ftopene Sirebje,

Sconig 12 loth, 9 (Eierbotter,

Mebl, fo viel zu einem Syflafter genug ift, lege es über.

(5) $i \mathfrak{n}$ a $n$ De $\mathfrak{r} \mathfrak{e}$.

Nimm gebranntes Rrebspulver mit Sconigidmalz vermifat uno übergelegt.

(5) in anoereb.

Baumöl 1 P̧funo,

¿ebendige Regentürmet $\frac{1}{4}$ SDfuno,

2Geinftein 2 loth,

mijhe es untercinander uno laß̧e es über einem Fetter fieden, bis der SSeinftein zergangen ift, alsbann feike es Durt) ein Iuth uno vermij(t) es mit Shirichen = $\mathfrak{u n}_{\mathfrak{n}}=$ idhlitt zu einer Salbe.

\section{(F) $\mathfrak{i} \mathfrak{a} \mathfrak{n} \mathfrak{D} \in \mathfrak{r} \in \mathfrak{B}$ IIG.}

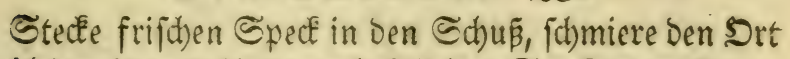
wobl bamit uno binbe aud) frifden Sped barauf.

Ein anderez.

Nache ein Pfflafter von geftopenen Scanfërnern uno Sajenidimalz.

(sin anderes.

9 Rebendig geftopene Rrebie,

Sorianderfaft, Şausnurzeljaft,

Aunigundigktautiaft,

temperirs mit (Seißsmild untereinander uno lege es über, eg löfcht Den SBrano gerwaltig.

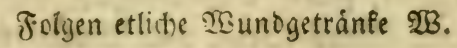

Das నraut (Seipbart, 
Sanickel, jebez gleich viel,

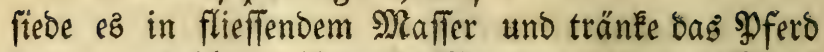
bavon, und faututte ifym alle Morgen in einer $\frac{1}{2}$ Mraa gejottener $\mathfrak{B r u ̈ h}$ bo von $\mathfrak{B}$ etonien 1 loth Des dürren \$gul= vers vom Beipbart ein.

(E⿱ $\mathfrak{i} \mathfrak{a} \mathfrak{n} \mathfrak{D} \in \mathfrak{r} \in \mathfrak{B}$.

Şuflattid, Bibenell,

Wiltben Mangolt,

STeionifdes 2 şundraut,

Socrmenig, Scabiojen,

St. Sohannizkraut,

Sanickel, Fenchel,

Wallhwurzel, jeoes gleidjuieí,

in fliefiendem 2 saffer gefotten uno bas spero bavon getränket.

E $\mathfrak{i} \mathfrak{a} \mathfrak{n}$ bereb.

2utichmeer, Schaaf:unichlitt,

saaumöl, jeoes 6 loth,

Şeipęe Şarz 2 loth,

Sopuleon 6 loth,

Şajelnurzel, Scuflattich),

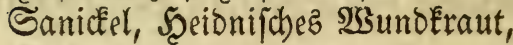

Bibenell, jebes 1 Scanowoll,

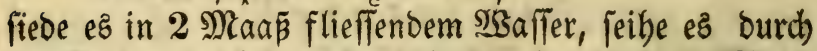
ein Iuth und fhütte bem Pferd auf einmal ein Maá bavon ein.

(E) in anderes.

Sinau, Sanickel,

Wintergrün, jeoez 1 Scanonoll,

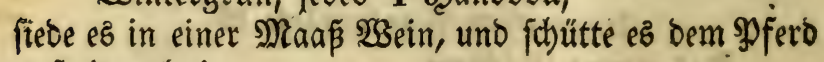
auf einmal ein. 


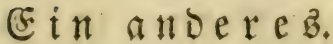

Şraumellen, $\mathfrak{x i n t e r g r u ̈ n , ~ j e b e s ~} 2$ Scändevoly.

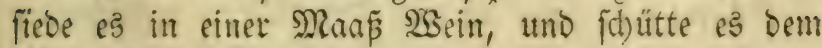
Pferd täglida cin.

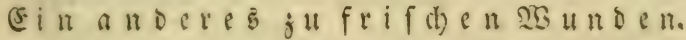

Iangen 23 segerid), Näusöbrlein,

Seionifides Busunofraut, Ginau,

Situllelblumen, Sanicfel, Braunellen,

Erobecrenfrat, jedes 1 Seandooll,

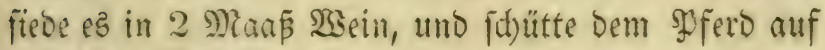
einmal 1 Maá̃ Davon ein.

Man Eann auth fold)e Rräuter in einem Seffel mit

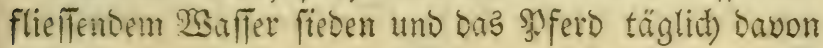
tränten.

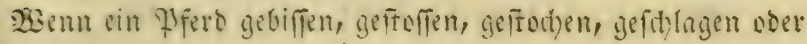
gehauen wurde.

23rathe ben Sitaden wohl aus mit SBein, morin ?effelfamen ift gefotten worden, bernach fiblage Sad)= folgenbes watm luber:

Brunnenfreflen, 2Bermuth,

Sunigumofraut, Flöbptraut,

Şintergrün, Sachtid)atten,

Scattermurzel, (5̌brenpreiś,

Reinjaamen, jedes 1 Scanovoll,

fiede alles in balb (seifinila) uno balb $\mathfrak{x a f f e r}$ uno fotlage es über Die $\mathfrak{B}$ unde.

\section{sin anderes.}

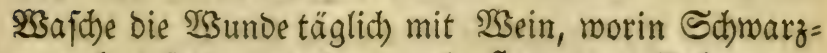
rurzel gefotten morben, uno ftreue bas spulver von arormentill uno (5iternefleln hinein. 
Ein anderes, menn ein Pferd mit einer Eanjen voer Epief ges ftorlen worben, und felyr gefdyollen wáre.

Scheere daz Saar an bem Srt binmeg und fdhmiere Den Schaden mit zerlapenem Specte uno Baaumöl mobl warm, bernadh lege nadbfolgendes \$Plafter barauf :

Bibenell, RBermuth,

2(ttid) blätter

Şuflattich, jeoes gleichvier,

attichmeer, fo viel zu einem Spflafter genug ift,

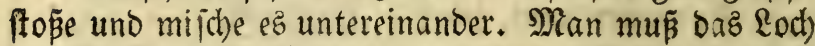
bes Stichs wohl offen halten, bamit es \&uft habe, uno die Materie beraus flieffen möge, und menn bie (Sese= fd)mulft alt wäre, foll man ein Şaarjeil barüber zie= Gen, Damit ễ Defto mehr Materie gebe, bernad) Den Schaden wie alle andere Schäben beilen.

(Ein anderes, wenn ein Pferd geftod)en murbe.

Rege das \$fflafter SDpodelooch Darüber.

Ein anderes, ju friften 2 sunden.

Rebme Flöbefrnutiaft uno tröpfele benfelben in oie গ̇unde.

Ein andereš, zu friften $\mathfrak{T}$ unden $\mathfrak{W}$.

Sanidel, Mäusöhrlein,

Seionifdues $\mathfrak{B s u n d E \text { raut, }}$

Ein = oder Bmeiblat,

(Sarbenfraut, Natternurzel,

Siebengezeit, Flöbefraut, jedes 2 Şändeboll,

fiebe alles mobl in flieffendem $\mathfrak{B a f f e r}$ (5ffig oder $\mathfrak{W}$ ein, wajdbe ben Schaoen täglid) einmal bamit aus uns freue das \$ulver von Siebengezeit hinein.

\section{Ein a nDereb.}

(3ib Dem spfero täglid) (5brenpreiß im Futter zu 


\section{Iferbe=:2rzenei Bิud).}

freflen, majue bie 2 sunde mohl aus mit SEaffer, wo= rin folgende Stücke gefotten worden :

\section{Syerficaria, Sanickel, Seionifhes 23 unotraut, \\ Sibenell, Sinau, Rö̈buf, Sajelwurzel, Seifus, jedes 1 Santovoll.}

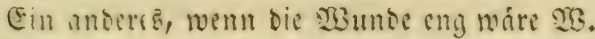

Sn biefelbe mad)e Meiffel von Neffelwurget, ftecte

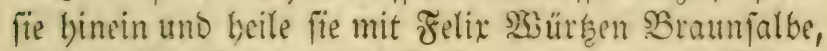
oder mit ber Egyptijuen Ealbe, oder mit oem Epießs= glasbalfam, ober mit Dem (snglifa)en $\mathfrak{B}$ umbbalfam.

\section{$\mathfrak{Z}$.}

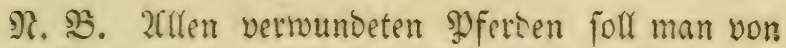
nad)folgendem \$ु)ulwer 1 loth täglid) zu freflen geben :

Suflatticb, Neäusöbrlein,

SBibertell, Sanidél, jeors 6 (nth),

Betonien, Sallwumel, jedes 4 loth,

Teufelabrect '2 lotb),

Rother uno weip̄er 2 merifanifd)er $\mathfrak{B}$ oluß 10 loth, mifde es untereinander zu einem Syulver.

(Fin Pffnfter รั Den 23 unden.

Şonig, Schönes Mehl, B̧aumöl,

2fmeriEanifder Bolus,

mifche es untereinander zu einem Sुflafter.

(Eime Salbe zu offenen $\mathfrak{T}$ unden.

Näusöbrlein, Riebftöçelfraut,

RunigunoEruat,

Şolderbroft, jebez gleidjuiel, 
ftope es untereinander, und mache es mit 2 Butter zu ei= ner Salbe.

Ein andereb̆, wenn bie $2 B$ unde alt ift.

Braucbe bie Bettlerşalbe.

Ein andereż, ร̆u neuen und alten $\mathfrak{Z}$ unden $\mathfrak{B}$.

Sdymiere fie oft mit Sdhnecken= ober Eieröl,

2 Benn die Rerven vermundet find.

Diefe $\mathfrak{B u n d e n , ~ w e n n ~ f i e ~ e n g ~ f i n o , ~ m u s ̃ ~ m a n ~ w e i t e ̣ r ~}$ macken, bamit das Esiter beraus laufen könne, uno um die Sd)merzen zu filllen tröpfle das Scolder = und Sdymertelöl hinein, uno lege das Sুflafter von sinjen= mebl in jüpem $\mathfrak{E}$ ein gejotten über.

Einanderez $\mathfrak{x}$.

গT. $\mathfrak{B}$. zu allen Sdbäben, fie mögen geidyofien, ge= ftochen, gebauen fein, oder roie fie rollen, foll man ben Syferden täglich 1 loth von nachfolgendem Spulver im Futter zu fieffen geben :

Seufelabrect 3 loth,

Rother 2 merikanifcher Solus,

2Beiper do. jedes 6 loth,

Rorbeeren 3 loth,

SGallmurzel,

Bibenell, jeoes 4 loth,

Schnarze präparirte Siesmourzel $1 \frac{1}{2}$ loth,

mifube es untereinander zu einem Spulver.

Ein a ndereb.

Sdbmiere ben Sdbaben mit Regenmürmeröl, ober bet Mixtur von Eierbottern mit Terpentin und Rofenöl vermifajt. 


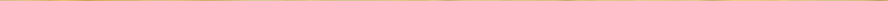




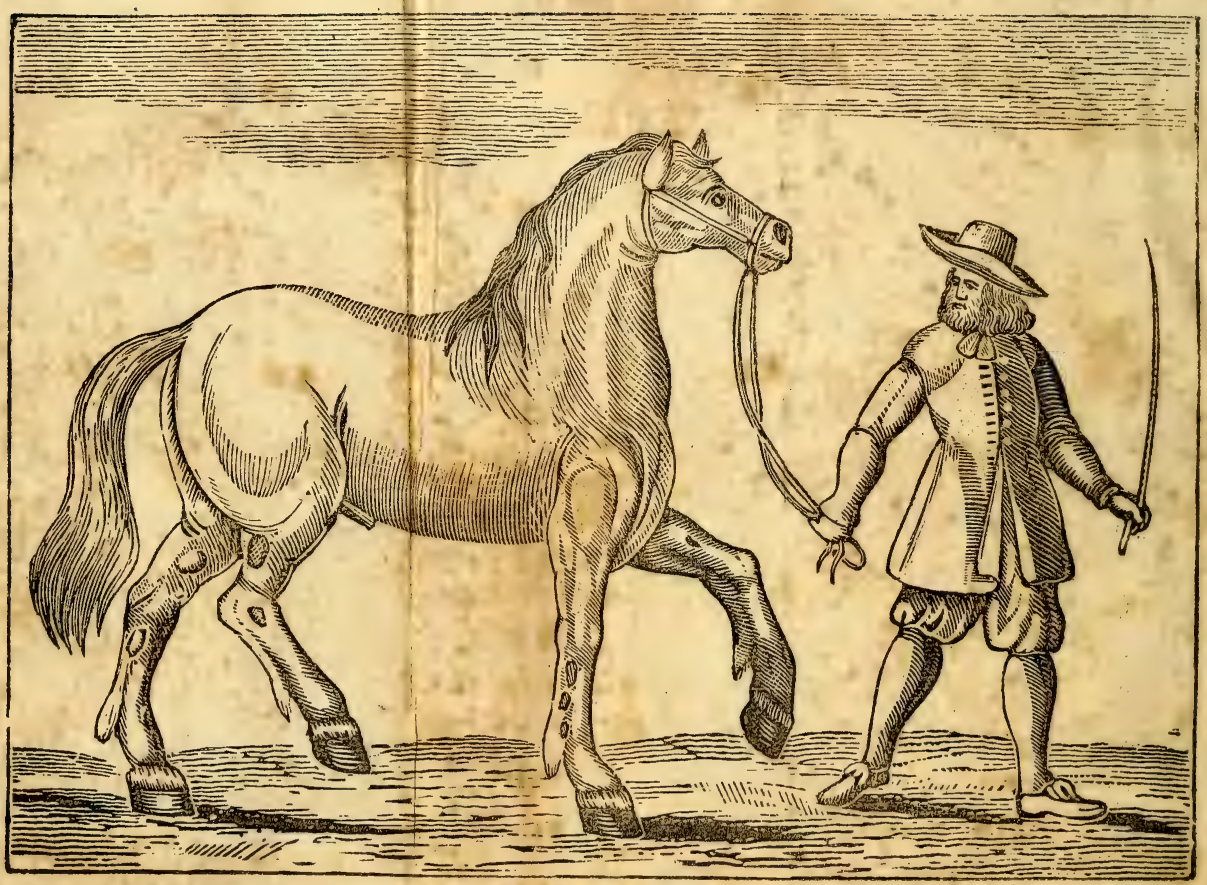


2Bsunden zu beften, oder jufammen zu beilen.

खुenn die 2 munde frifh) ift, fo lege geftopene (5id)= blätter barauf, ober ftreue das Pulver von Salläpfeln, Sumadh uno Granatäpfelidaalen binein.

\section{Das 53 fte Eapitel.}

\section{भु D $n$ De $m$ NG $\mathfrak{r} \mathfrak{m}$.}

Dieje Srinkbcit, welde man Den S3urm nennet, bat ibren Namen nicht baber, als roenn es ein $\mathfrak{W u r m}$ wä= re, wie Dann ber gemeine $\mathfrak{W a h n}$ nodh heutigeక Iages unter vielen Soioten ift, meldhe aud) to gar diefelben

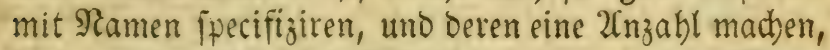

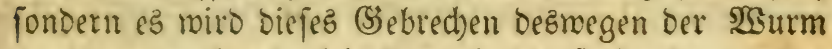
genannt, weil es gleid) fam wie die jెolgwütmer ober Maulnürfe balo ba, balo bort unter Der Eroe hinfrie= d)en, und einen Şaufen Erbe Da, bald Den andern Dort aufroerfen, aud) bald Da, balo oort am Eribe Beule auf: wirft, uno ba bod) fdon eimer in einem Sort zubeilet, balo bingegen an einem andern Sort ein anderer Beule aufgemorfen mirb.

(53 ift nid)tz anderes als ein faules unteines (Seblüt, uno miro in Diejem allein unterfocheden, baß̧ er in ei= nem SJfero andere Sualitäten, als in bem andern hat. Ult zum Exempel, in einem SPferd fommt ex aus viel verberbter Sholera, in bem andern aus Dem SDblegmas te falio, in dem oritten ex Melandjolia nimiacum Sुblegmate falfo commixta; uno baber entfteben fo vie= lerlei 2rrt berjelben, uno erfobeinen aud) an mandberlei

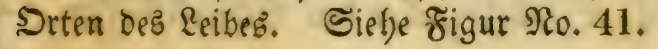


Sif an fid) felbften eine anftectende, langmierige uno

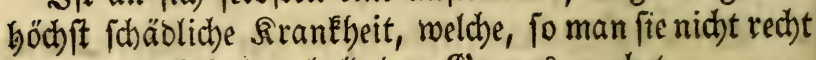
curirt, Den spferoen balo ben (Saraus machet.

\section{D i e c $\mathfrak{u} r$.}

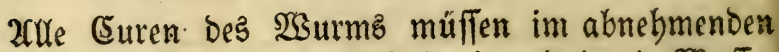
Mond gejdeben, und das Spferb niemals in ein 2 Raffer gelapen, audi) 2(d)tung gegeben werben, bamit fid) bie Mferbe nidjt an ben Edjäben lecten, wie aud) foldhe spferbe alsbalo von ben andern zu entfernen fino. Und

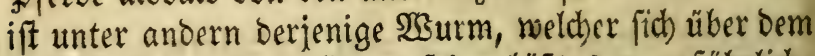
Serzen uno an Dem Scaupt feben läpt, Der gefährlich= fte; nad) diefem, ber an ben Cdenteln, Der aber Den ganzen $\mathfrak{L}_{e i b}$ augvagirt, am allerleichteften zu beilen,

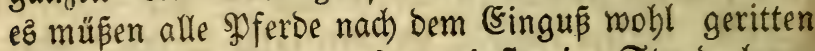
oder geführt merden, aufs menigfte eine Ctunde lang.

$\mathfrak{2}$.

Separ 2Rtimonium $1 \frac{1}{2}$ Suintlein,

ふ̊räbenäuglein 1 Suintlein,

Teufelsored $1 \frac{1}{2}$ Suintlein,

- (S)ummi guttä 1 suintlein, 2lloes, Teufelzabbir, jeoes 2 suintlein, Saffran $\frac{1}{2}$ Suintlein,

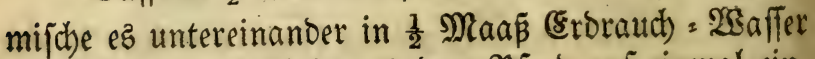

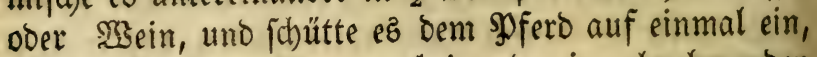
wieberbole ez 5 Tage nacheinander im abnehmenden Mono, gib Dem Sুfero täglid) 2 Suintlein 2rntimoni= um im Futter zu freffen, uno bas gefottene SSaffer von T⿱eufelzabbißs zu trinken; nofern bie Beulen fid nicht berzebren, cauterifite fie auf, uno ftreidse bie

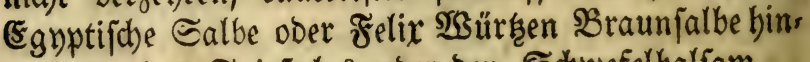
ein, ober das Spieşglaz, oder ben Sdhwefelbaljam. 


\section{Ein andereb . Tb.}

\section{Mercurium oulcem 1 Suintlein;}

Separ Antimonium 2 Suintlein;

vermifche e\& mit $\frac{1}{2}$ Maaß $\mathfrak{B}$ ein, uno fdütte \$) fert auf einmal ein, fege e? 5 Iage fort, und ftreiche in bie Schäben Netcurium jublimatum allein ober mit Dem Slev 2fntimonium, oder SBalfamo 2rntimonium.

\section{E in anderes $\mathfrak{B}$.}

Lape bem SDferb die 2 Sugabern, 2 Sporrabern uno 2 Satrenfabern, uno gib ifm täglid) von nad)folgen= Dem Syulver zu fieflen 3 loth:

Irräbenäuglein 3 loth,

Tormentiul 6 lotb,

গ3allmurgel, Teufelzabbin, jebę 12 loth,

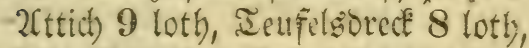

2merifanijder $\mathfrak{B}$ otus 8 loth,

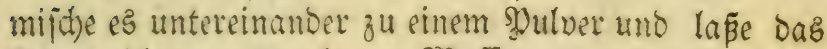

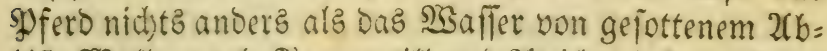

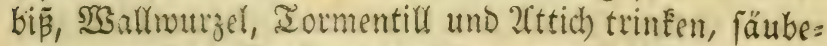

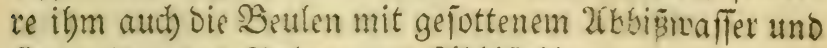
fireue ifm bas sुutwer vom 2lbbin binein.

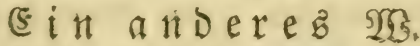

Siräbenăltglein 2 s.uintlein,

Sermodact. 3 Suintlein,

Rerchenfduamm,

Iurbith, jeces 2 suintlein,

(5) summi guttä, 2floes,

Scammonium, jebes 3 Suintlein, Salrp I loth, Maftix 1 Duintlein,

Extract von Ejulä 1 Suintlein,

Extract von Şrleb. nigri 2 Suintlein, 
Extract von Rhapontic 1 loth,

Extract von Elaterii 2 Suintlein,

Teufelzabbís 2 loth,

Simmet 2 Suintlein,

miphe es Elein untereinanber, fiede es in zmei Maaß flieffendem $23 a$ ffer, theile es in zroei gleidbe I Ibeile uno fd)ütte ez dem soferd 2 Iage nadheinander im abnet)= menden Mond ein, miederbole ez etlichemal, uno frteiche ben Sdjaden ausmendig mit Spiē̄glaz, ooer mit Bal= jamo julphuris, oder (Ejchentyolz= oder Scajeltholzöl.

(sin anderez $\mathfrak{x}$.

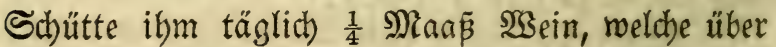
Rad)t über bem $\mathfrak{S i t r i o} 2 \mathfrak{2}$ ntimonium geftannden, ein, uno feege ez 5 Iage fort ; Jernach gib ifm täglid) im Fatter 2 Suintlein Seepar 2(ntimonium uno 1. loth

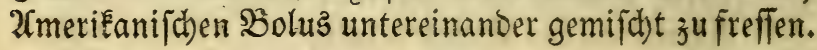

\section{(E) $\mathfrak{i} \mathfrak{a} \mathfrak{n} \mathfrak{D} \cdot \mathfrak{e} \mathfrak{e} \mathfrak{B}$ IS.}

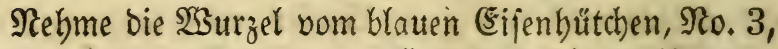

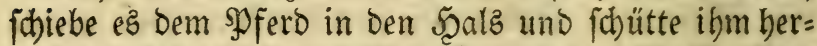

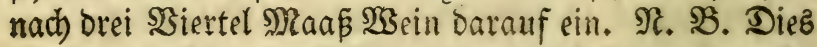
ift gar ein ftrenges (ssift, befwegen fict) hierin vorzufe= ben, bamit keinem niftsts in Das Maul bavon fomme;

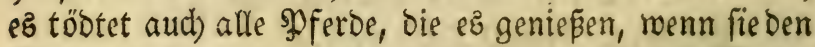

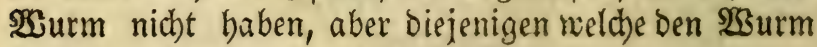
baben, curirt es uno confervirt fie.

\section{(5) $\mathfrak{n}$ a noereb}

Uloes 1 loth,

Rbabarb. 2 Suintlein,

Rbapontic 2 loth,

Lerdbanjhroamm 1 lotb,

Iurbitb, (3ummi guttä, 


\section{Pferbe=2frgenei Suth).}

Scammonium,

SBifoen Sucumernfaft jeoes 2 suintlein,

2ttid) faft 4 lotb,

Sholderlatwerge 3 loth,

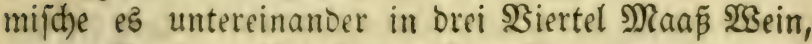
motin Iaujenogüloenfraut ift gefotten worben, uno id)ütte es auf einmal sin, wieberbole es etliche Iage, man muś ihm aber 2 Iage vorher bie 2 Sporrabern, 25 albadern uno 2 Ed)ranfabern gelapen baben.

$$
\text { Ei } i \text { a ndereb. }
$$

Rege über Die SBeulen, nadjoem ou Dem \$ुferd vorber innerlid) etwas eingegeben baft und ftreid)e nadbfolgen= Des himein :

Sublimirtes Suedffitber 4 loth,

Euphorbium 2 Suintlein,

Eoröl 8 loth,

mifche es untereinanoer.

Ein a noeres.

Brenne die Beulen uno ftreid)e Spiep̧glaz ooer

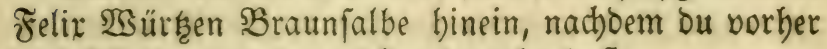
Dem gfero etwas innerlich gebraucht baft.

E in a n o e r e $\mathfrak{B}_{\mathfrak{B}}$.

Sd)warze Niestwurzel 1 Suintlein,

2(ttichwourzel 1 loth,

Teufelzabbís 2 loth,

Eerdenifhivamm 1 loth,

Teufelzorect,

Scammonie,

2lloes, jeopes 2 suintlein,

(3)ummi guttä 1 Duintlein,

mi jache alfes untereinander uno id)ütte es in brei $\mathfrak{B i e r t e l}$ 


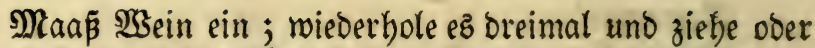

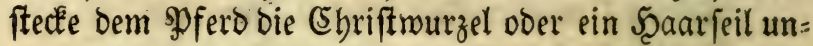
ter ober über bie Seulen des Srsurms, abjonderlich fo er vorn an ber Sruft ift ; fein Senoöhnliches dabei im

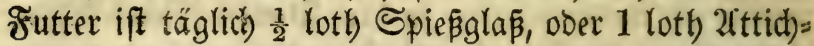
murzel uno I loth Seufelzabbiás untereinander gemifat.

$\mathfrak{Z}$ enn die Beule auछgefallen mū man fie mit Spieşglazöl, Schmefelbaliam ober ber Egyptifchen Salbe beilen.

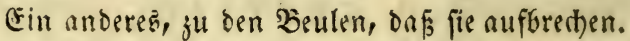

Euphorbium 2 lotb,

Rorôl 4 loth,

mijche eह untereinander uno lega über die \$Beulen. Eapiz 2rifenicaliz.

Antimonium,

Schwefel,

arifenic, jedes 4 loth,

ftope ez Elein zu eniem Shulver, fese es in einem (5) as ein warmen Sano und lape es fo lang f́teben, bis ez zufammen fliest uno mie ein roth braun (Slaz werde, alsbann zerbrich baz (5)la un uno nimm: berauz, biez ziebet alle (s)ifte aub.

(5) inandereb.

Sinoblaudb,

SBeipwourzel,

Diftelnurzel,

SBgermuth, jedez 3 loth,

fiebe ez in 1 Maa einmal ein.

Sdhlangenpulver,

Teufelzabbin, jedes 2 loth, 


\section{Pferdes2(rzenti But).}

Theriac 1 loth,

SGein orei SBiertel Maá,

mija)e eह untereinander uno id) ütte es bem sूfero auf finmal ein, continuirs etlid)emal uno reite daz SDfero wobl barauf; den Sdyaden beftreiche mit Spiefglasol coer Sdowefelbalfam.

$$
\text { * Cin andereb. }
$$

Renidenfuth 2 Pfuno,

Ieufelşorect :2 Suintlein,

Sãvenbaum, 2flaum,

Salpeter, jedes 2 loth,

mifde es untereinonoer uno ftreid, alif ben @dyaben, nad)oem ou ifm vorber imnerlid) etma? gekruutht haft.

Ein andereb.

3wicfelfaft,

Rieblöofeliaft,

(5berwurzeliaft,

alantmuzzelfaft, jeoes 4 loth,

Rinds̄galle ooer allerlei (sallen von Fifden uno

Ifbieren 1 Maaß̄, mifde es untereinander uno jd)miere den $\approx$ dhaden bamit.

Fin anderes.

(S)ummi 2Tmmoniacum,

$$
\begin{aligned}
& \text { " Gagapeni, } \\
& \text { "Salbani, jeoes } 3 \text { lotl), }
\end{aligned}
$$

folvire es in fid)arfem (fifig, jeibe es ourd) uno lodbe biz zur red)ten Diffung, alkdann thue razu

Baacbs,

Zerpentin, jedes orittbalb loth,

Rapioiz arjenicalis 3 loth,

agefteinöl 2 loth, 
Ierram Nitrioli 1 lotb,

bas $\mathfrak{W a c h}$ erfftich zerlapen, bernach bie (Summata bin = ein vermifdt, den Lapidem arfenicalem batauf, alsbann bie Tertam Sitrioli (weld) von aller Sdärfe mus auछgefüpet fein) bann das 2fgtfteinöl, rübre ez nobl untereinanoer uno malaxirs mit Ecorpionól.

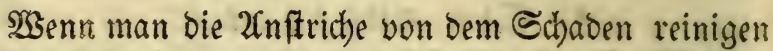

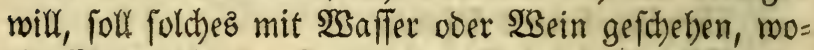

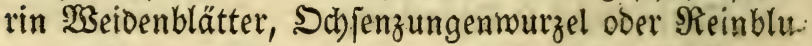
men gefotten worden.

(sin anderez.

Senesblätter 1 loth,

Scammonium '2 Suintlein,

Iurbith,

aloes, jedes 1 loth,

๔chmarze Sciesmurzel 2 Suintlein,

Rbabarbara 3 suintlein,

2uiz, Fenchel,

Sitigner;

Museatenuี̃, jeoes 1 suintlein, verjüptę Suedfilber 2 suintlein,

Wsein, orei Miertel Maā̄,

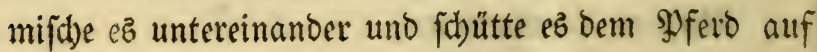
einmal sin.

Ein Pflafter liber ben હ(t)adent.

Sublimirtez Suedefilber 8 lotb,

3ucker,

Brofamen von Roggenbrod, jedes 6 luth,

Sonig 12 loth,

mifche ez untereinander fu einem \$flafter uno lege es auf ben Shaben. 
Şafel holzö $1 \frac{1}{2}$ loth,

Ẽd)warzez ভdinectenol 1 lotb, mijaje ez untereinanoer uno frreue gepültverte $\Re$ oṕbei=

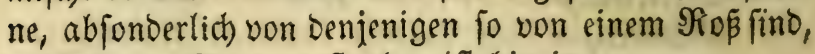
weldeb am 23 urm geftorben iff binein.

Man foll ibm aud

sichentolzöl,

Shajeltolzol jebes 2 loth,

Baach holderbolzöl 1 loth,

2(bbbi的 2 lotb, mit

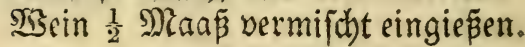

(E) $\mathfrak{n} \mathfrak{a} \mathfrak{n} D \in \mathbb{R} \in \mathfrak{b}_{\text {. }}$

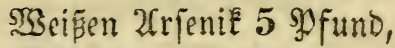

Salpeter 2 פpuno

fublimirs in einem Solben poer in einer Retorte im Sand, fo fteigt cin wenig 23 affer barüber, uno fubli= mirt fid) ein menig 2 rrjenif, lape es 24 Stunden im Feuer ffeben, nimm hernach die Maffe uno reibe frifden Salpeter binein, precedir wiedar wie zuvor, je offter bu Das thuft, je fixer ber 2frfenil wiro; zum letgten alfez mit ŞSeinfteinöl angefeudbtet uno 48 Stunden ftehen

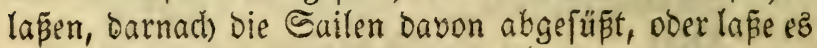
im Retler zu einem Del fliepen und bebalte es dann zum

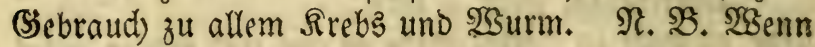

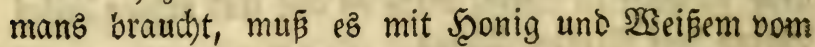
(si rermifht und \$flaftermeip übergelegt werden.

\section{Ein anderez.}

Braunmurzel,

Ebermurzel, 5̧apelwutzel,

Bertram,

B̧eí̈e Rieşwurzel, 


\section{Pferdes:(rzenei Bud).}

Enzian,

Fenchel, jebes 1 loth,

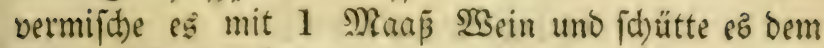
Spferd auf cinmal eim.

E $\mathrm{inandereb.}$

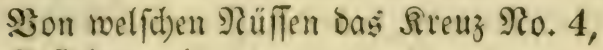

Diftelmutzel,

abbié, jedes 1 loth,

vermifd)e es mit einer balben Maás 963 ein uno fdütte bem SDfero auf eimmal ein, continuirs etlichemal.

\section{(E) in noeres.}

BBumErautwurzel,

Niesmurzel,

Snoblaud),

Scorbium,

Detfoliata,

2cbbis, Sävenbaum, jedes 1 loth),

vermifhe es mit orei \$iertel Maã $\mathfrak{B}$ ein uno foütte se auf einmal ein.

\section{sin anderes.}

Stecte über bie Beulen anftatt Der Shriftrourgel die :Surzel von ben Donnernägelein, weld)es rotbe Blüm= d)en find und auf ben Şaiden oder $23 i e$ en mad) fen.

Ein andereb

Salap 2 loth,

aloes 1 loth,

Scammonie,

Summi guttä, jedez 2 Suintlein,

Seriüptes Suecéfilber 1 Suintlein,

İberiac 1 lotb,

șకein 1 Maaß̄, 
mijhe alles untereinander und jhütte es auf sinmal cin, wieberbole es breimal.

(E) $\mathfrak{i} \mathfrak{a} \mathfrak{n} D \in \mathfrak{r} \in \mathcal{B}$.

(S)ieb dem Sמfero 3 Iage nacbeinander 100 Iropfen von Sciridhborn Spiritus in warmem Bier ein, alzbann nebme das Brenneifen, hebe die Şaut ein renig über fid), uno brenne die Beulen fo viel ifrer find; bernad) nebme fo viel Stückdben Sdbrofel, ftecke fie in bie $\mathbb{Q}_{00}=$ doer und zünte ben Sdbrefel an; jobald er brennt, fo löfd)e ifon gleid) wieber auz, fo töbtet eg̊ ben 23 urm, hernad) fhmiere die gebrannten Beulen gleid) mit $\mathfrak{L} i=$ lienöl, Dẫ ez mieder beilet, daz ift ein Univerjal Şeil= mittel.

1. Trockener Stall.

\section{Die Serpflegung.}

2. Rleien anftatt bes frutters und etwas von gepull= vertem Schlangenbaly barunter.

3. Ehe man bem $\mathfrak{D}$ ferd $\mathfrak{B a}$ affer zu trinken reicht, foll man folgende Species barin abfieden :

S3adboloeripäne, Saffafrab, Shina,

Saffaparilla, Fendbel, 2(ttic) uno abbifinurzel. 
Soldbes ift ifm am bequemften alfo zu nebmen : fo= bald bie Stute gefoblet, uno man ben Sopf an ber (Ses= burt bemerft, bas man in bes Foblens Maul binein greifen Eann, foll man gleid) Das Nefs auf ber rechten Seite mit einem Finger eröffnen, und das (Serwäd)s auf ber 3tunge, in (sile uno mit Bebhänoigkeit (ehe ę von bem Foblen verfd)ludet wird) abnebmen. Diefez bält man für genisis, und die täglidje (strabrung lebrt eE auch, baß es den Foblen zu gutem 2rtbem und ftar= Een Sräften gereicht, Daß́p ez auch Dauerhaft uno ver: möglich werde, menn es bavon entledigt wird, und fol des nidht verifhlingt.

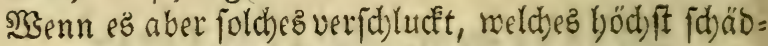
lid) ift, Dafür nachfolgendes Mlittel :

Saffran 1 Suintlein, W3ermuthenoppe 7 Stük,

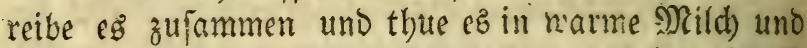
foütte es ibnen sin, fo treilet ez ilnen bapelbe alskalo aus bem Reib.

\section{Daś-2te Eapitel.}

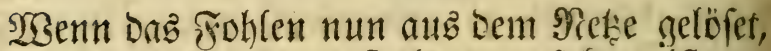
wie mit Sopf und Sals zu verfatyren ift :

Sebe mit Der linken Scand ben Ropf auf bie Scöbe, bamit eక Den Scals wobl überfic) ausftrecten mus, alz= Dann tauche einen wollenen Lappen in zerlapenen Sped und falbe ifm Den Sals auf beiben Geiten mobl, als: bann reibe foldjen mit ber red)ten Sand auf uno $a b_{\text {, }}$ fum lesten brücke ifm Den Sopf wohl berbei an ben Salz, fo miro fich baz (Senict oben biegen, und Sopf und Şals fid) zu einer fdönen Sुoftur berbei geben, 
Denn ber Şals ift anfänglid) wie Waachs, uno läp̈t fid) Dehnen wie man will; Seood) muß̧ man behut jam mit umgeben, fonft fann man ihm aud) Sd)aben thum.

\section{Das 3te Capitel.}

SBie man Dem Fohlen alsbalo audi) Die Fubbeine reinigen foll, oamit es gute uno beftänoige

şilfe befommen möge.

Sierzu nebme einen Span von Dürrem Efibenbolz, madbe baratus sin S̃nftrument wie ein Mefler, jeood) Dajes an ber Ed)neioe nidht jo gar fd)arf uno Dünn fei, mit fold)em Inftrument fdabe Dem Foblen Die F̆" = Be inmendig runo umber, uno formire ifm die Goble uno Den Sttahl auf Das befte, gleichfalls aud) ausmen= big unter bem ミaum ober Srrone, fdabe ifm Dabei bas Şăutlein unter itch fein rein $a b$, fibone jebod) beg Saums, weld)er gat jubtil, bamit bie Gohle nidht ver:

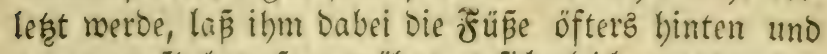
vornen aufheben, fo gewöhnt es fid) gleid) etwas an ben Subenfel zu liben, uno foldje bod) aufaubeben.

\section{Das 4te Saptel.}

Mie ถ⿱一𫝀) Fohlen won feiner Matter gereiniget, geliebet, uno an siefelbe gewöhnt merben mag.

Nebme J్రonig 2 Pfuno, brenne benjelben in einem Tiegel bis er anbrennt uno riecheno wiro, alsoann fitope ibu zu shulver, nebme $D a=$ runter 4 sूfund $\Xi_{\text {aly }}$, mijche fold)es roobl untereinan= Der, ftreue es Dem froblen auf ben \&eib, oa es bie Mut=

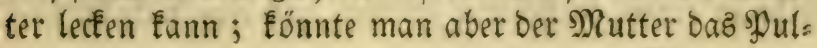


ver zu lecten beibringen, ebe das Froblen damit beftrichen würde, fo räre es befto beffer ; Denn je eher bas Fob= len gereiniget wiro, je nüblid)er ez ibm iff.

\section{Das 5te Eapitel.}

ISie man einem frohlen den Gchopf, গ)ähne und Edwmanz fert, ftart uno wohl gee roädyitg madyen Eann.

Sobalo das Foblen von der Mutter fommt, foll man ifm die Scaare mit einer Gdbeere ober Gdbeermef = fer von (Sruno abnebmen, jeood) mus fold)es im Suneh= men gejdhehen, und alzbann mit nadhfolgender Salbe rdomieren :

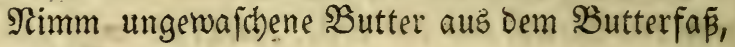
2 Sfuno,

Alantwurzel 1 Sp funo;

Die 2flantwurzel muß aber geoört uno mit ciner Feilen aufs Sleinfte gefeilet fein, laß̃e alsbann bie Butter in einem glafitten Tiegel zergeben, reibe bie alantwurzel himein, lǟe eg nid)t zu hei pä werben ober verbrennen; wenn man es nun für genug adjet, fo bebe es vom Feuter, thue es in ein (Sefä́, worin es je länger je bejer wirb, uno fo oft man es bedarf, fchmiert man bie Srte bamit.

\section{Das 6te Sapitel.}

গGenn einem Fohlen ber Gdymanz. Mälyne uno Schopf fidsbidht ober fdyobaft

\section{nürbe.}

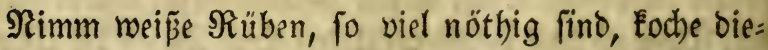
felbe in einem $\mathfrak{R} e f f e l$ mit $\mathfrak{B a f f e r}$, Daß̄ eine biffe $\mathfrak{B}$ rübe 


\section{જferbe=2(rgenei $\mathfrak{H}$.}

Daraus metbe, feike es alsbann burd) einen Durd)= fblag; mit fold)er SBrübe fämme uno waid)e die Fob)= len täglid).

\section{Das 7te Eapitel.}

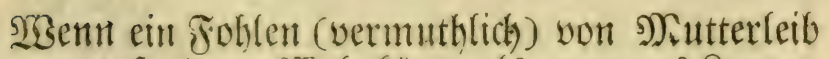

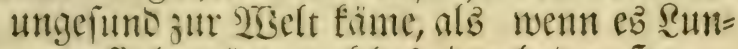
genfied) witre, weldes Durd) Den 5au= ften zu erfentren, nute Demfelben zu

$$
\text { belfen tif. }
$$

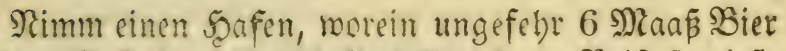
geben, ftecfe Denjelben halb voll grünen SBeifǘ, giefe Darauf fo viel SBier, biz Der Scafen voll miro, becfe fol= d)en wohl zu, lǟe ihn 2 Finger breit einfieden, feibe ez bernad) Dutit) sin Iuth, nimm Dann einct guten $\mathfrak{S}_{\mathfrak{B}} \mathrm{el}=$

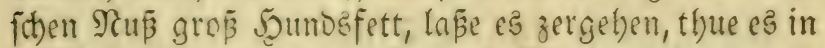
ein Sännlein, voll Dę gefottenen Siets, gieß̄e ç Dem ซ̌oblen laulidt pin, lape ps 3 Stunden gemad) berum

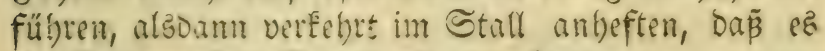
24 Stunden fein Futter erlangen Eann.

Sobalo es Dem Fohlen eingegopen ift,

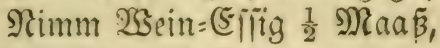
Snoblauch 2 Scäupter,

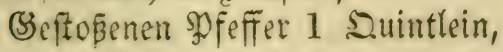

foldbes mijide mohl untereinanoer uno reibe bie \&efzen

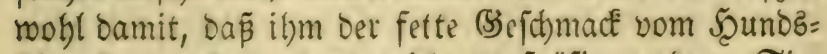
fidmalz vergebe, uno es mieber gefräĭg merde. Sie=

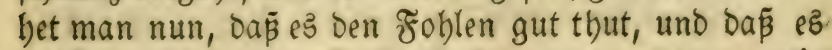
Seflerung bavon befindet, fo fann man es zum zmei: ten uno orittenmal, ooer jo oft es nöthig iff, gebrauchen.. 
Das 8te Eapitel.

IIBnn einem Frohlen Die finwere Noth ober Fraif anftöset, neldyes oftmals zu ge= idjeben pfleget.

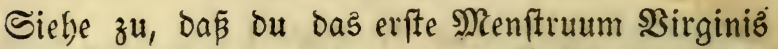
befommft, weiche es mit fammt dem IItch in eine bal=

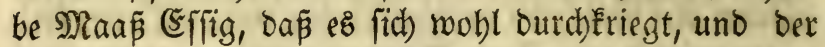
(sfifig fich) Davon färbet, brücte ez alsbann fein rein auz, und fdütte ez Dem Fohlen laulicht ein, laffe ez Darauf eine balbe Stunde umfübren, folches ift oft probirt worden.

\section{Das 9te Sapitel.}

SKenn einem Fohlen bie Sselbjudyt anftößst, wie ihm zu belfen.

Nimm ganzen Saffran 5 loth,

thue Denfelben in ein reines weiffes I üblein, binde cE feft zu, merfe eह in Den Sübel, moraus die פutter trinkt, fich ütte frifhes $B$ runnenmaffer bazu und lafle es wobl barin weidben.

Beiter nimm reines $\mathfrak{3}$ achs 5 loth,

2 Utngarifche Sucaten,

thue dieje beide Stücke miteinander ins $\mathfrak{B}$ affer. SBSenn man bie Stute tränken will, foll man bag @ädł́dben mit Dem Saffran gar rein auzorücken uno mieber inz $\mathfrak{W} a$ f = fer merfen, und die Stute bavonitrinfen laffen, märe baz Foblen alt genug"aus bem Schaff zu trinen, foll man bie obengenannte Stücke in laulichte Biegen = oder Sü= bemild thun, uno bas Foblen bavon trinen laffen, poer inm foldbes einjuhütten. 


\section{Pferde:?trzenei Bud\%.}

\section{(5) in a noereb}

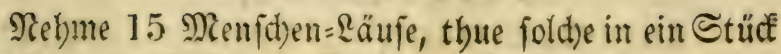
SBrob, uno gitb fie Dem Foblen zu freflen.

\section{Dą 10te Capitel.}

Co ein Fohlen bie Sehlfuctst befäme, wie ihm zum (Sang zu helfen, wenn fie hart ffect.

STund: $\{$ d)

Baum. Sel 1 loth,

Sonig $\frac{1}{2}$ loth,

$\widetilde{C a l}_{3}$, Suintlein,

W3ein=-(sifitg 1 Suart,

SRaute für einen \$feming,

joldjes alles teibe und temperite untereinander, laffe es ein wenig laulitht werben, und fdütte es bem Fohlen burd) bie Shajelöd)et ein ; ftelle es baneben in einen warmen Etall, und lafle ez täglich von 2 seizenfleien lautlidst tränfen, uno nid)t viel in bie taube $\mathfrak{Q}$ uft fom: men.

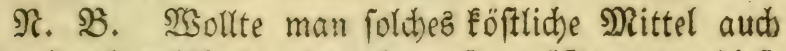
für ein altes $\$$ Pfero gebraud)en, fo müste man biefe 2rezeneimittel alle boppelt nehmen.

BSollte bie Iruje nidyt in Bang fommen :

Nimm Soriander mit Dem Sraut $\frac{1}{4}$ SIfund,

Selben Senft mit bem Rraut $\frac{1}{4}$ gifund, mad)e Davon einen Raudh aub Rohlen uno laffe ifn bem Froblen allgemad in Den Şals uno Fafe gehen.

Rach Demielben nehme geriebenen getben Senft 2 ¿ộffelvoll,

Das $2 B$ eiße von 4 Esiern, 
(3) branntes ভalz 2 \&öffelvoll, Butfer: Eandi 2 loth,

temperire bies alles untereinanoer und foütte es dem Foblen in ben Şals, bavon wito ę gleidy gangbar.

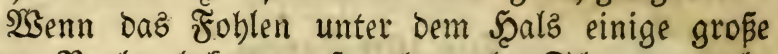
Garte Beulen befommt, fo nebme alte Edhmeer, madhe es warm, fdomiere bie Beule wohl bamit, bis fie meid) wiro und aufbricht; wollte fie aber nicht aufbrechen, fo laffe man fie mit einer Fliete ober $\mathfrak{E} a$ jort aufbauen, alsoann nebme Baum=\$el und fEfig, jeoes 3 loth, ma= be es ein wenig laulicht und joütte es ibm in bie $\mathfrak{N a}=$ felöcher.

Wenn man bie 2 ntimonium = (Sur gebraudb), fo ift blos zu bemerken : Dä́ wenn ein roblen öfters pur= girt wird, ez ber אeblfudbt hernad) nidht biel untermor= fen fein wirb.

\section{Das 11 te Sanitel.}

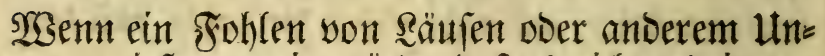
geziefer unrein nürbe, Dẩ eร nicht gebei= hen fann.

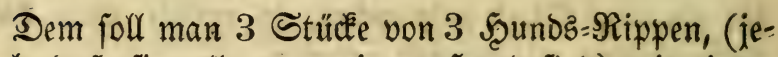
ood) Dás fie alle von einem Şund fino) mit einem Bänochen an ben Scals bängen; ba aber cą Ungezies fer überbano genommen, Daß̄ Das Foblen ganz fihä= bidft merben mollte, fo foll man bie folgende Rautfalbe gebrautchen.

Rebme bas $\mathfrak{B s e i p e}$ von 2 Esiern,

Suecéfillber $\frac{1}{2}$ loth,

töote das Suecfilitber in bem Ei, uno rühre ez barun= ter, alsoann nimm ein Soblband von einem rothen 


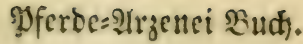

Tud) uno beftreide cs mit Diejer Calbe, binde ç bem Foblen Ealt um Den Şats, fo bleibt Ecin Ungejiefer bei ifm.

Tad)gebents mad)e eine fid)arfe \&auge, thue Darein Beneoijhe Seife uno wajhe tas Foblen fein tein Da= mit ab uno balte es bernad) aud) jauber.

\section{Daz 12te Eapitel.}

STEenn ein Fohlen die Sarmgicht hätte.

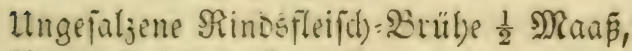

Baum= Sel 3 Röfrelvoll,

Rilien= Sol 1 Roffelvoll,

Sals 1 loth),

Niesmurzel 2 suintlein,

milde bies alles unteremanter und gebraude es wie ein (5luffir.

Dazu mbme auth Sibernellenmaffer 1 Suart, (S)epultwerte Sorberten 2 loth,

miift)e es Durd)inanoer und fd)ütte es Dem Fohlen lau= lidbt ein.

Daz 13te Capitel.

গুGenn Das Frohten Dabei verftopft ift.

Nimm Senezblätter 3 suintlein,

Enzian 2 loth,

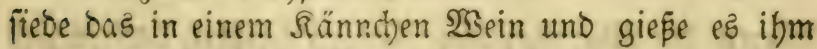
eir, es purgirt febr gelind und reiniget.

\section{(5) in andereb.}

Soer tauche Benedifhe Seife in Baum=: Del und laf: fe binten im 2 fter ftecken. 
802

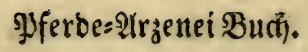

Das 14te Capitel.

SEenn ein Fohlen Den Durd)lauf lyat.

SRimm Eicheln 4 Scändevoll,

oürre uno ftope fie Hlein, mifche es ibm nebft piner Sandoboll reinen Sleien unter Daz Futter.

\section{Daz 15te Eapitel.}

\section{SSenn ein Fohlen nidyt Stallen fann.}

Nebme Srebzaugen, ftope fie flein, fhütte fie in ein balb Maaß rotben $\mathfrak{W e i n}$ madye den $\mathfrak{S e i n}$ etwas warm, faütte es bem Foblen ein, und laßje eg ein we= nig herum fübren, oder

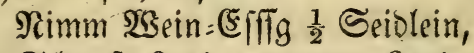

Sdbaafz-Rorberen, gute Rorberen, 6 Stüd, beide gepultuert, mifd)e ez Durdjeinander, fdutte es ifm laulid)t ein, fo miros Stallen.

Soer, wenn gar nichts belfen will, fo gebrauche bie Scand $=$ (Sur, berobalben nimm eine Saite von einer $\mathfrak{B i} i=$ ol bi (3amba, balte bas eine Enbe bavon in einen

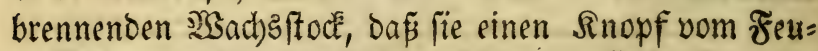
ex befommt, alśbann nebme foldhe, uno ftecke fie unge= fähr eine balbe Ellle ins Robr hinein, und ziebe es et= lickemal gemach beraus, fo mus es unfeblbar Stallen.

\section{Das 16te (Sapitet.}

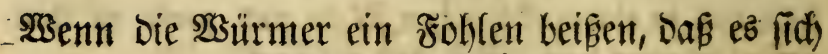
Davon umwälzet.

๔attenbaum 1 \$fund,

Salz 1 SDfuno, 
Bodf3hornfaamen $\frac{1}{4}$ Sूfuno,

Ropfidwefel aranen $\frac{1}{4}$ \$ू) funo,

Dieje Stüffe pulverifite Elein uno gib ifm alle Iage ei= nen Eleinen Röffelooll auf sem Futter, bag contimuire 3 ober 6 Iage.

SGofern foldes aber Das Foblen megen des fharfen (Serud) S balber nid)t freflen wellte, fo foll man ibm Diefs Sु)ulvet mit Biegenmild) vermifden, uno laulid)t einidulüten.

Man Eamn ç ibm jührlid) 4 Mal als cin \$ुrejerva= tiv cingeben, fo lä̈t cô feinen Şum auffommen.

\section{Das 17 te Capitel.}

Wenn Die Spulwirmer ein Fohlen im Magen beifen, oaß eร mit Den Füßen fdarret, und fidh won einer Geite zur anbern mirft.

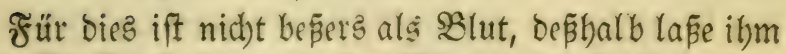
Den Ctaffel ftecten, unD Das sklut in Den Şals laufen, alsbann binde ihm $\frac{1}{2}$ loth I Pufrledred ing (S) ebir, und lap̧e es binlaufen mo es will, tränfe és aud) mit $\mathfrak{B a} a \tilde{f}=$ fer, worin Ieufelsorect gerreid)t iff.

Ferner, gib ibm Eegelbaum gebadft in Ellig ein, oa= von fterben bie 23 ürmer uno geben Scaufenweiz fort.

\section{Daz 18 te Capitel.}

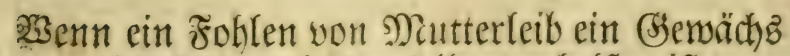
mitbrähte, wie temielben ju helfen ift.

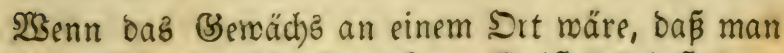
ses ohne sdyaden foneiden fann, fo ift bas befte und 
nächfte Mittel, baß̃ foldhes je eber je beffer gefchebe, fo balb es gefdnitten, foll man baz Meffer mit ber $\mathfrak{W} a f=$ fenjalbe, nie obenbefdrieben, verbinden.

Darnach bem Frohlen 3 Stüd von $\mathfrak{B}$ egmartentwur= zel in $\mathfrak{B}$ roo oder Salz zu freffen geben, und bann zur Sorkommung bes (S) Slieonaffers nadbfolgende Mittel gebrauthen.

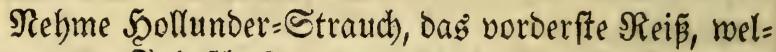
dhes man J̃africhus nennet, fhabe bie oberfite graue Rinde bavon ab, nebme alzbann bie grünen Schaalen welche unter ber grauen liegen, eine gute (s)eippel voll,

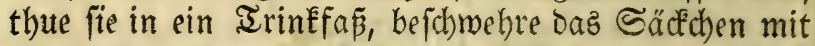
einem Siegelffein, fduttte frifhes $\mathfrak{B a f f e r}$ barauf, laffe bas Foblen fort unb fort bavon trinken, biz ę ein (5n= de hat.

Sft ez aber nicht an einem Sort no man esfüneiden - Fann, fo nimmt man ein Elein fcharf Esijen, und bren= net es meg uno braudst eine Branofalbe zur Şeilung.

\section{Daš 19te Eapitel.}

\section{Fiir Die lteberbeine Der Fohlen}

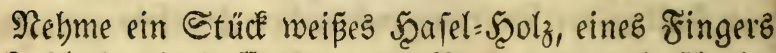
bick, fduabe bie äufferfte graue Rinbe bavon ab, fohmie= re bemielben bie Ueberbeine mit nüd)term Speichel, ma= che bas Scolz ein wenig warm uno reibe alsoann bas Uleberbein gar ftark mit bem Scolz von Dem (Selenfe, daß̄ és ganz warm wird. Man fann e's aud) alterna= tim einen $\mathfrak{S a g}$ mit Speidjel, ben andern mit Regen=

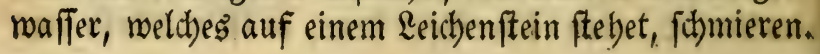


Eine andere gute Eathe fïr bie Heberbeine.

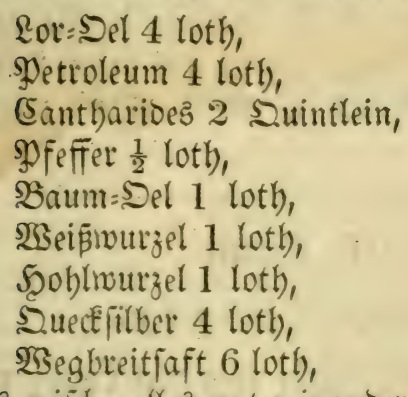

Diejes mijue alfes untercinanoer, mathe eine Ealbe bas raus uno fdmiere das Ueberbein etlid)emal wobl samit, jo bitict pz daffelbe ganz hinmeg.

\section{- Daz 20fte Eapitel.}

Boran man erfennen fann, menn ein Foblen Den Spith oder Ellbogen befommen will.

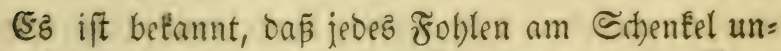
tex Dem Snie inwendig eine $\mathfrak{B g a r z e}$ zu haben pflegt, Dasjenige nun, welches folche $23 a r z e n$ nicht bätte, bas

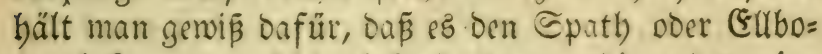
gen befommen möchte, bejonders wenn bie anoern in= mendig unter bem sinie auflaufen, und bicker alz bie andern werden. Diefem nun vorzubeugen, foll man ifm die ङpathader entzmei fohneiden, oder, wie fonft gebräud)lich ift, zeitlid) bremnen.

(3leichfalls, wenn bas Foblen vom Etall ausgehet,

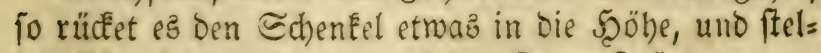
let fid) gleid), als menn es der Srampf zöge; menn man nun foldbes bemerft, io bat man geminle Nadbrid)t baß ifm ber Spath oder fonft ein (seroäd) auf bie 
Sdbenél fallen wiro; wenn fid) nun bas (SSetwäds jeben läpt, ez jei Spath, Laift, oder die Sdbale, fo ne= Get man es mit Regenmaffer, meldbes auf einem \&eiden= ftein fteben bleibt, fo bat es Eeine Sraft mebr zu wachjen.

\section{Das 21fte Sapitel.

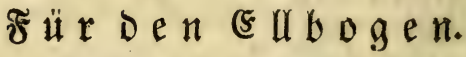

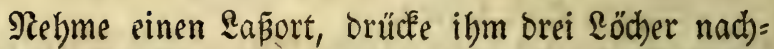
einanoer bie \&änge berab an Den Srt, ba Der Ellbogen iff, alzbann

Rebme Sockzunichlitt $\frac{1}{4}$ Pfund,

(s)rünipan 1 lotb),

mache ez in einer \$ुfanne auf dem fouer mobl hei $\beta_{1}$ rübre es burcheinander, nimm als ein Scolz, mache vorn ein runbez Inöpfdien oran, fo grop als eine melfche

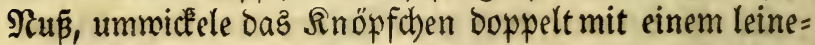

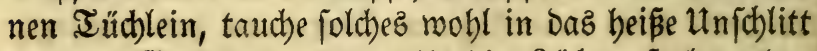
- uno den (Srünipan, uno reibe bie \&öcher, fo lang Der Elubogen ift, wohl bamit, biz die Scaare faft abgehen; Ueber Den andern Tag thue es nod einmal, fo geben bie Saare ab. 2urboann

Nebme ungelöfhten Saif 2 Röffelool,

Daz 2 Seipe von zwei Eiern,

mifche es burdheinanoer, börre es in einem SIfen, ma: d)a ez zu einem \$ulver, ferner

গebme (säñef̧malz,

Baumöl, jeoes 1 Röffllooll,

thue es zufammen, fdutte bie beibeu şulver aud) bazu, mache eine Salbe Daraub, lape fie ein menig warm wer= 


\section{Pferbe:2rrzenei Budh.}

Den, ftreid)e fie auf ein Iud), und binbe es alfo raarm auf ben Sd)aben, 'o borret ber (5nbogen ein, binde es unter 8 Iage nid)t auf, alsoann wirb es wieber gut.

\section{Das 22fte Capitel.}

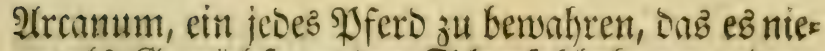
mals Gienvidhie an Den Sdjenfel befommt ober aušmidhit, weoer Gdyienen, Siallen, Heber= bein, Eparren doer Flopgallen u. F. no.

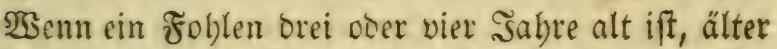
aber foll es nid)t fein, foll auth nidjt fidon ein (Se= wäd)s baben, fondern gefunbe (slieder baben ; bie be= fte 3eit baju ift im Serbft, wenn es $3 \frac{1}{2}$ Sabr alt ift.

Nebme SBam= Del 1 Pf fund,

(S)lasgarlen 1 Siering,

Dradbenblut 5 lotb,

Bibergail fuft Dür 1 Biering,

ftope bie (3lasgallen gar flein, uno mijhe bann biefe

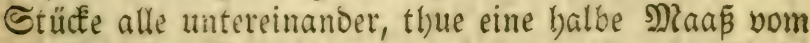

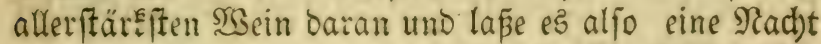
baran fteben, nimm Dann jharfen ftarfen Wein=sfifg und jo viel ttrin, la fle es alles ourd)einander fieden und id)aume es robl ab,

Mit Diefer Ealte idmmiere Dem Foblen die Füpe al= le viere, bis an ben $\mathfrak{L}_{\mathrm{cib}}$ und brauche die Salbe fo marm man fie an ber Şano erleiden Eann, bies thue 8 Tage natheinander, jeben Tag breimal, als Morgens, Mittagz uno 2 benob, uno la fle es unterdefifen in Eein

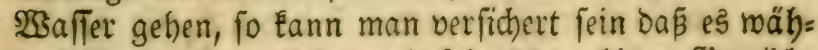
reno feiner ganzen \&ebengzeit Éeines der obigen (Senäd)= 
pe befommt. (5s ift oft probirt und febr gut befun= Den worden.

\section{Das 23 fte Capitel.}

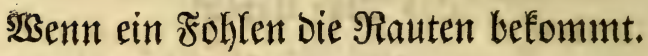

Nimm gute reine Scolzajche, ferner vie afche von Saberftroh, gebrannt, ana, fchitte $\mathfrak{W}$ affer barauf, ma= d)e baraus eine fdarfe Lauge, alsoann thue eine Scand= voll Slettenmurzel in bie Eauge uno wajche bas Fob= len an einem marmen Srt rein uno wohl bamit, und wenn es trocken geworben, fo id)miere es mit nachfol= gender Rautenjalbe : alz

alte Sdbmeer $1 \frac{1}{2}$ loth,

fdomelze uno giep̌e es auf frifdes Brunnenwaffer in ei= nen Becken; wenn ps nun wieder gerinnet, fo feibe bas $\mathfrak{2 a} a f f e r$ Davon $a b$, fhabe auch unten vom Schaum bas Salz ganz uno gar ab, ferner nebme

suedéfilber 1 loth,

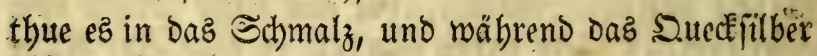
atfo getöotet wiro, nebme

(Sebrannten Rellerbalz 1 Iöffelvoll,

(S) rauten Ropjchnefel 1 sp funo,

Gelben Sdyefel 2 Sreuker,

(S)eftopene \&orbeeren 2 Ireuker,

Slaun 1 Sireuter,

foldhes alles gepülvert, thue es in bas Sdbmeer uno Queḉfillber, temperire $e g$ mohl untereinander baj̃ es zu einer Salbe miro, fomiere den Sdjaden damit bis ps abfällt. 


\section{Das 24fte Eapitel.}

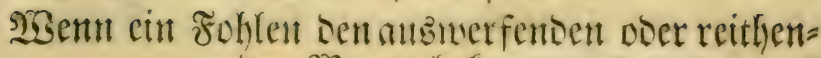
Den Sisurm befonmt.

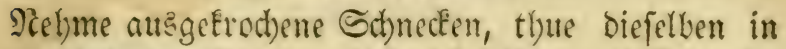
einen glafurten Iopf, verklebe Denfelben mit Ieig, fe= Ge ibn auf glübende Robien, lafle es eine balbe Stun= De barauf fieben, fehre alsoann ben Ionf um ur.b laffe ifn roieder eine $\frac{1}{2}$ Gtumbe firden; wenn bie Sioblen nun verglimmt, und ber Iopf erfirltet, algbann ftolfe

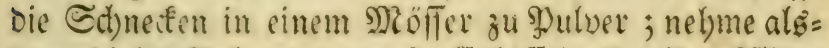

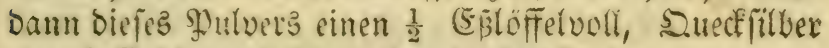
eine $\frac{1}{2}$ (Erbje grofi, thue es unter das જुulver, vermenge es wobl untereinander, zuvor aber und ehe man bem Foblen diefes cingiefsen mill, fo lape ifm beibe Scaleza= Dern uno beide Sportabern follagen, aber nidbt viel

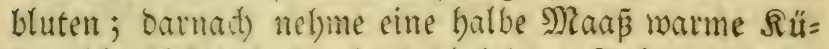
bemild), fdütte oas obenbeid)riebene Shulver hinein, temperire es untereinander and ichütte es bem Foblen ein, uno laffe cespene Stunde Darauf umfülyten, im=

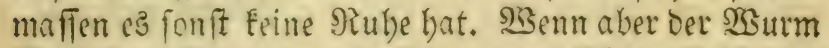
Beulen aufgemorifon, fo fireue ungelöfden Salk bia: ein, fo mito Der sisurm getöotet uno fället aus.

\section{Das 25fte Eapitel.}

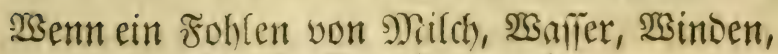
ober ionft verfangen bat.

Rebme einen Biegelftein, madbe ifn glübeno beiß,

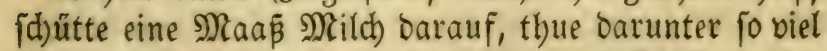
SRoggenmehl als man mit fünf fingern faften fann uno laffe e's baffelbe roarm trinken, aud) foll man ben Stu= 
ten allezeit baz Irinken mit einem beiß̄en Biegelffein ablöjden und gleidffalls eine gute Scanowoll Roggen= mebl binein rübren.

\section{Doer:}

Rebme Bibergeil uno Gaffran, jedes $\frac{1}{2}$ loth, (s)eftopene Rorbeeren 15 Stück,

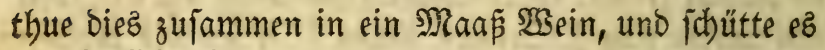
ifm laulicht ein.

\section{Das 26 fte Capitel.}

\section{SSenn ein Fohlen Darigel an ben 2lugen hat.}

Es ift zmar nicht zum Beften wenn ein Froblen im 2rnfang bie 2 ugen (siebred)en an fich merken läpt, bie =

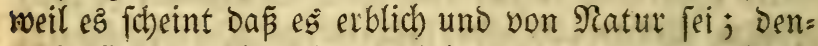
nach ift für foldbe febr bienlich, uno nomit man fie ei= ne gute Beit erbalten Eann; nemlich wenn ber Mono neu ift, ben britten Iag hernach ben Staffel geftodben,

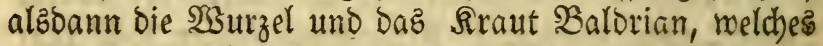
auf ben St. Sobanniz Iag vor Sonnenaufgang ge= graben, auf ber Seite no bas SDferb den Mangel hat, an ben Siblaf gebunden, nemlich an bie Sealfter, aud in bie Mähne uno Schopfbaare, alsbann foldse $\mathfrak{B S u r =}$ zel in bas Irintmaffer gelegt uno bavon faufen laffen, babei alle Morgen ben Siopf uno um bie 2ugen herum mit frifhem Brumenmaffer geroajchen, diefes nimmt bie Flüße binmeg, uno bält Den Sopf mager. F̌er= ner, wenn fie unter ben 2 ugen fette, bicke Mäuje baben, mús man ibnen foldhe foneiden laffen, welches aud gut ift, und viele Fläße mit hinneg gehen. 


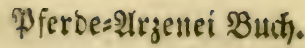

\section{Das 27fte Capitet.}

TBenn thm sie 2 hugen liberidofien wären unb man vermuthet bas es Mohnfichtig wer= Den witroe.

Itngenefit (appaunfámalo 1 Siering,

Rein gclefene Brumnenfreffen 1 Şanovold, zerbacte eq alfs fleinfte, thue fie in ein Moorffer uno

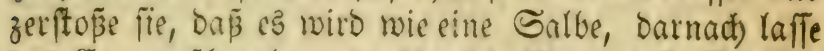

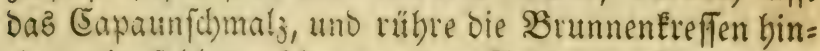
ein, mit foldem f(t)miere Dem Foblen Die 2fuggruben uno reibe es mit einem Finger woht hinein.

Man foll ifm aud) alle Morgen Das 2fuge mit ben Fingern outud) cin reines Sit)mänmlein eröfrnen, $b a=$ mit bas bitgige $13 a f f e r$ beraus (aufen fann, aud) nücb)= tern Speid)el binein idtmieten.

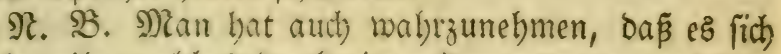
nid)t reibe, weld)es burd) einen 2tuggatter zu verbüten iff.

\section{Das 28fte Capitel.}

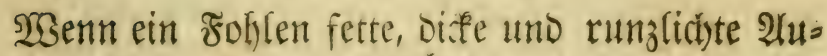
gen hat.

Für biefes ift nichts befiers, als das ifym der Scauge und Das Feifte nus ben 2 fugen ge fonnitten merben mag, auch nad) bemjilben ibm bie Maäu aufgenorfen rers. ben, biefes nimmt aut) bie zlüße binmeg.

Das 29fte Capitel:.

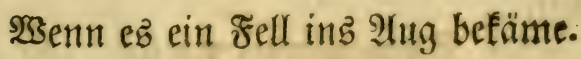

Ein frifdes (Ei bart gerotten, ben Saft aub bem 
2reipen gebrückt, und mit einem Feberchen in baś 2 (u= ge geftriden.

\section{Das 30 fte Capitel.}

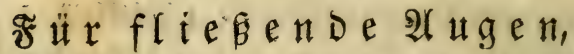

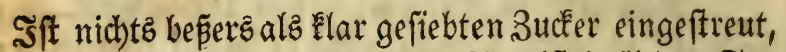
ober menn bas nicht helfen mill, Biegelfteinöl bes $\mathfrak{I} a=$ ges einmal eingef́tricten.

\section{Daz 31 fte Capitel.}

2ronn ein Fohlen in Das Uuge geftopen doer ge= (d) lagen nutroe.

গimm Den Saft von Schellfraut, ftreiche ifn bes Tages Dreimal mit einer Feder in Das 2ruge, nebme bernach ein Salvet, lege ez 4 oder 6 fach zujammen, tautche es in warmen $\mathfrak{W}$ ein, orücte es wobl auz, baj ber warme Dunft barin bleibt und leiblich ift, follage ez bem Foblen über uno lape es liegen fo lange ez warm iff; wenn eg Ealt ift, wieberbole es noch einmal, und fere es etliche Iage fort, es bilft, menn auch bas \$äutchen verlest uno mit lauter $B$ lut unterlaufen märe.

\section{Das 32fte Capitel.}

જs?enn Das Foblen von einem giftigen Thier gefto= djen noird.

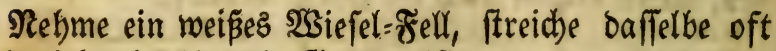
uno vielmals über bie (Se)fchnulft, no ez aufgelaufen ift, eछे hilft.

\section{Ein andereb.}

\section{Renichenbain,}


Das 35fte Eapitel.

Wenn ein Fohlen am Bauch gefthwollen ift, uno man glaubt Durs es von einer Sd)lange gebif= fent oder geftochen worden warre.

Nebme (Siras und sffig,

fieos es in einem Scafen, binde es Dem Foblen alle $\mathfrak{I} a=$ ge zneimal alfo warm über bie (Sefchwulft.

\section{Das 36fte Capitel.}

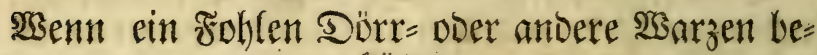
frime.

Sierzu ift bas befte und bequemfte Nittel, Dap man biefelbe rein aus ber Scaut faneidet und mit einem bei= jen (sifen bie 2loern tujchet, barnach nebme ein roenig gefalzener Butter, lege Denfelben auf ben Srt mo bie TSarzen geftanden, freijche fie mit einem marmen (E) fen fein binein, ez wächft Eeine $\mathfrak{B} a r z e$ mebr.

Das 37fte Sapitel:

$\mathfrak{F} \mathfrak{u} \mathfrak{r}$ bie $5 \mathfrak{d} \mathfrak{n} \mathfrak{e r}=3$ is

Diefe findet man am (S)aumen unter ber sunge; Schneibe fie mit einer foharfen Scheere hinmeg, bat e? (Eiter befommen, fo freiche guten \$enebifchen İberiac mit Salz vermifht barauf.

Das 38fte Capitel.

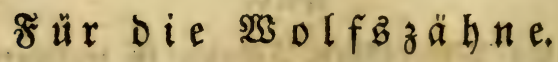

sisenn man foldbe findet, fo gibt man 2 daftung, mean 
biejelbe betwad)fen, lojet man bas 3ahnfleifd) inmen= big und ausmenoig fein von bem 3alnn, follägt ben 3alyn ausmuartb ab, Damit man ifn mit ben Fingern faffen Eann, ziebt ibn beraus uno ftreut ibm Salz in Die Sirube.

\section{Das 39 fte Eapitel.}

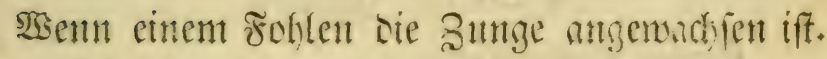

Rimm eine Eleine @edjere, löfe bie 3unge von Dem untern (Saumen, fo weit man es nötbig zu fein glaubt, ab, fidmeide fodann bie angemadjene Scaut, fo weit fie unten abgelö̈t iff, von ber 3unge, Damit rs nid)t gleid) wieder anbeilen fann.

Dá̧ es ater aud) roieber beilct, fo

Nebme Sconig,

Iberiac uno Ealz, jeoes ein wenig, vermifid) es untereinanoer uno id)micre es bamit.

Daz 40fte Capitel.

SSenn cin Fohlen nit sen Srantp geplagt ift.

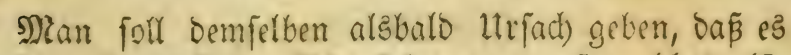
auf Den Erampfigen Sd)enfel treten mus, welches aljo gefdieht:

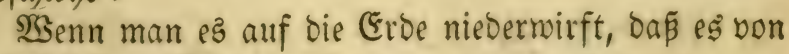
fich felbit aufftehen muß̃.

Benn ein Fohlen in Der Sugend von bem Srampf geplagt miro, fo ift zu befürd)ten, das es fdumerlid) ge: junbe bintere @abenfel befommt, biejem nun vorzu. 
Eommen, muß man ifym bei 3eit bie Sdjrankaber ent= zmei fdineiden, und bie Cennenaber mit Baljamöl be= fireichen, es vergeht.

\section{Daz 41 fte (Sapitel.}

Wenn ein Sahrgang ift, Daß Dą Sterben unter Den

(3)rabe 2abbismurzel, gibs Den Foblen unterm Futter zu freffen.

\section{Daz 42fte Sapitel.}

F̈น̆ Das Gdywinten Der Fohlen.

Nimm eine lebendige Maus, und eine Nabel und Faben, fitch Der Maus bie Nabel Durch beibe Rugen, Daß̃ ber Faben burch Den ganzen Siopf gezogen mirb, barnad) binde ifn um bas (slied wo és fd) windet, wiro es alsbalo nachlaffen, und nach) und nach wieber völlig werben, wie zuvor.

\section{Das 43 ffe Capitel.}

Wenn ein Fohlen bie Manfen befommt.

Nimm Reinől,

Reuez $\mathfrak{s a c h s , ~}$

Sebrannten 2flaun, jedes 4 loth,

Niesmurzel 2 loth,

biefe Stücle mifobe alle untereinander uno madbe fie zu 
Fohlen geboren worben ift, börre und pulverifire ę uno gebe bem Foblen in Mild) fo viel babon, als man mit einem breiten runden Mefler erbeben Eann; diez Sylulver ninmt daz Şäutchen, welches ben Fohlen im Magen zu rachjen pflegt, uno wovon bieje Jrantheit Fommit; man foll ez aber nur ben Foblen thun, welche unter 6 Monat und nicht brüber find.

(E) ift aud eine bewäbrti Sunft, soenn ein Foblen fonft frank ift und man nicht weis was ifm gebricht, fo mag man eE brauchen.

\section{Ei $\mathfrak{n}$ anderez.}

Für diefes (sebrechen ift eine gebörte Fuchslunge aud) gut, foldbe pulverifitt uno bem jungen Foblen ein= gegeben.

\section{Das 46fte Sapitel.}

Gine Wurgation für Fohlen.

Sib ifm erftlich 3 Iage Felberen=sిlätter, weil fie nod) zart und nidht erftarket, weldbe fie gerne freffen, 3 Iage hernach wilde Salvien, bie find trefflich gejuto, bernach 3 Iage willo $\mathfrak{2}$ egnarten und andere gefunde Sräuter. Ueber 10 Iage foll die (5ur nid)t räbren, benn fie purgirt beftig, Doch allezeit ifr gemöhnlides Futter; wenn bas geicheben, gib ifm bas ${ }^{2} a u b$ von ben Buchen etlicke Iage, Das puigirt nicht, machet ba= bei fobone glatte \$caare.

(Ez ift aud) gut wern man ben jungen \$ferben 2 Mal bie $\mathfrak{W}_{\text {oche }}$ Salz gibt, worunter nachfolgendez \$ulver gemijh)t ift, als Énrenprei $\beta$, \&ungenkraut, Eifen= 
fraut, milbe und zahme Salvia, $\mathfrak{K}_{3}$ adhholoerbeeren, bie

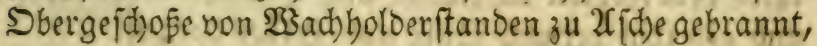
(Eid)enlaub, 2Cgrimronium, Seionifh) SBundefraut, Şil= lenfraut, Rad)tid)atten, Etaffelmurgel, gute Budbena= id)e, Segelbaum, Eorbeeren, fdroarzen Sdomefel. Dic: fe Stücfe alle in cinem Sadfofen geoörtt, Elein pulve= rifit uno in glcid)em geroidht unter bas Sals gemijd)t.

\section{Das 47fite Sapitel.}

গ̧ent ein Fohlen anfängt boofleinigt zut merten, muf man bei 3eiten vorfommen.

Dafür ift folgende ๔albe trefflich gut :

Frifde Sutter $\frac{1}{2}$ Sf funo,

Ropifid)malz $\frac{1}{2}$ Sf funo,

Frijd)ez ๔(bmeincid)malz $\frac{1}{2}$ Pjuno,

Fudbs(d)malz 8 (otl),

althea 8 loth,

sopuleon vier loth,

Baumöl 3 loth,

Dieje Stüce lap̈e in ciner Syfanue mohl zergeben uno bas (Seäoer alle Iage cinmal bamit fomieren, fo met= ben fie wieder grab.

\section{Das 48 fte Eapitel.}

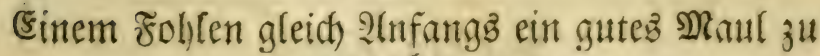
madien.

Thue in brei Röffelooll Eifrg, zwei Röfrelvow Sconig, uno menn ou Dem Foblen wilft Dab (šcbié angewöb= nen, wenn es allbereit aufgezaumet ift, to binde ein

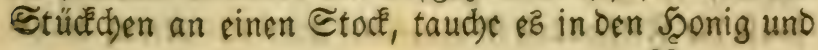


reibe Dem foblen bie 3unge uno (saumen wohl bainit, uno gib ibm hernact) Ealz uno şaber bara uf.

\section{Das 49 fte capitet.}

\section{$\mathfrak{B} \cup \mathfrak{M}$ A e r $\mathfrak{l}$ a f fen.}

Sungen Yferben foll man nur im äuperften Notb= fall 2roerlaffen, menn es aber fein mǘ, foll manignen erftlich im Frübling und Dann im Sctober laffen.

Man foll ibnen auch 14 Tage auf einander vor und nach ber Räffe einen Röfialboll von folgendem Syulyer im Futter geben :

Säbenbaum,

Enzian,

Uno $\mathfrak{B}$ ockghornjaamen,

biefe Stücke in gleichem Semoidht untereinander gemen= get.

\section{Das 50 fte Eapitel.}

\section{Die 9 bern zu folagen, follen biefe fein.}

Im Frühling bie Scalzaber, tuno im Seerbft bie Sporrabern, benn es iff' bejer allezeit eine als beite zugleid) zu laffen.

\section{Das 51 fte Capitel.}

\section{Daf ein Foblen feinen Rangel befommt.}

खsenn eine Stute foblet, es fei ein Shengft ober Stute, to ftich Das Fohlen mit bem Iuchselauen, wo fonft bie flopgallen ftehen, uno über bas Rreuz an at: 
len vier Fin benżzeit feine Nängel.

\section{Daz 52fte Eapitel.}

Bom Stulfun Der Folylen.

Sas Etolpern coer Etraudbeln ort jungen Sfferten

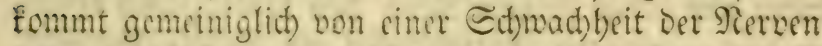
ber, und Die fam man nidite ander's als ourd) penetran= te uno Durdjoringente Eriritus verbefern. Somft aber find aud SDferoe, weld)e von Natur febr fdwad) fino, zumal auf Den vorbern Beinen; Diefes ift $(5, b=$ mangel uno ift nidit leid)t gu verbeflern, Dennes ift Das Fobien im Natter=?eibe serumrubigt norben, Durd) ei= nen barten Exrung, doer gäben ftarfen 2rnzug ber Nutter, Das ç fiti im Mutterleibe vermendet, uno an= Dets barin zu liegen fommt, woourd) Die Aerven, wel= d) vom S.uts Durd) Den Silicken zu ben Edjenfeln tei= d)en, Dermajen verorebt, fo tap fie alfzu lang merden, uno fid) nid)t meht anzieben; wenn baz Sूfero ben FuE erkebt uno den Şuf auf oen Booen feret, es mider fei=

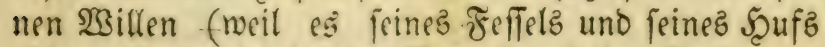
nidht mehr mädytig) über $\mathfrak{S} u$ urzeln, Scolz, Steine und Dergleichen ftolpert, uno menn ein bifiger Reiter foldhe Spferde hart anfpornt, ftolpern fie aus Furdht uno un= geichicklicheeit noch mehr, biz fie gar Danieber ftürzen. Für diefes Uebel ift nid)ts beêer, als mit rectifizirtem Branntemein allein, ooer benjelben über Spickblumen gefulittet, uno folden sgferden öfterz bie Feffel und Sdbentel gemajden, aud) etruas bavon in bie Spalten grwifden bie Ferjen eingeidhüttet uno joldes einfriechen la fen. 


\section{Sperbe=2(rzenti Bưk.}

\section{Das 53fte Capitel.}

\section{Vom Safter Deb Soppenb Der Fohlen.}

Saz Soppen ift ein crbliches Rafter, gleichnie bei ben Foblen bie tiefe 2 uggruben, neldhes oft auf bas 3te und vierte (şlied fich erftrecft uño ausbreitet, und wenn nun junge Fohlen fobon von Natur cines etmas weitern angeerbten Schlunoded éel alz andele, bie nicht von oergleichen 2irt find, baben, fo incliniren fie befto mefr zum Soppen, nozu nod) bie Sdjulden fommen, wenn man fie im 2fuffeflen an allzu bobe Babren

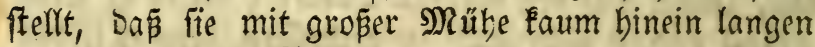
tönnen, um ibv శ̧utter zu genieß̄en, fo bebnen fie bez Schlunds Esingänge je länger je mehr aus, Daß̄ pร̧ her= nach einen red)ten Sectel voller Falten gibt, worein fich. bernach Der Scaker uno Seccerling verfoblägt, uno das

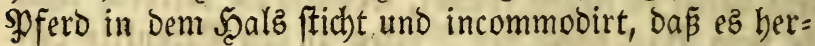

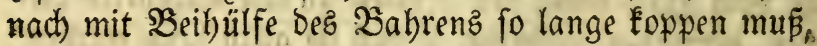
bis ez die verichlagene Speife beraus göcket. Diefez Iafter if: fidroer zu curiren.

\section{Daz 54 f́te Capitel.}

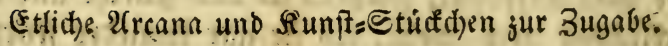

Ein Yfero hinfens zu madjen, Daß̧ if)m nidhtỏ fidjabet.

Stebme brei oder vier Sुferdebaare zujammen, binde fie bem Syfero ganz féft um bie Srone, la pé ez aber nicbs gat zu lange alfo gebunden, fonif iffẹ nicht gut 


\section{פferbes2razenei Bud).}

\section{Das. 55 fte Capitel.}

\section{Dan ein Wfero nidyt frelie, fo lang man will.}

Rebme Seife und reibe dem গfero bie 3äbne da= mit, es wirt feinen Biffen freflen; wenn ibr es aber

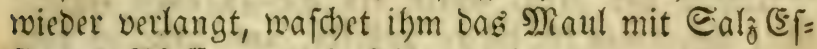
fig und Syfeffer aus, fo frip̂t es wieder.

\section{Das 56 fite Capitel.}

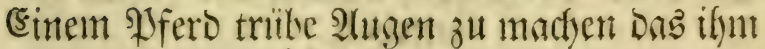

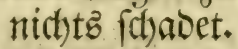

Rebme \&infen ing Maul, jerfäue foldse uno baudhe Dem \$yfero in bie 2 (ugen, fo miro ilfm gleid) ein Fell Darauf, menn man ilym aber frifdes Brunnenwaffer binein fprif̧et fo werden fie wieder ganz bell.

\section{Das 57fte Eapitel.}

Einem einen Toîn ju madjen.

Refyme einen $\mathfrak{R a g e l}$ aus einem Iootenbahre, ftecte Denfelten an dez \$rperdes Stund, fo fann ez niemano baraus bringen, bis man ben Nagel mieter heraus ziebet.

\section{Ein andereb.}

Beftónene (Eidhornflauen, eine Mefierpipize dem

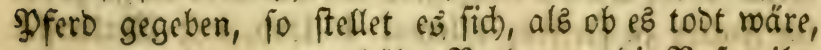
menn man ibm aber gebäbet Brod unter Die Naje reibt, fo ftebet es roieber frifd) uno gefuno auf. 
Daš 58fte Eapitel.

\section{Einem jungen Pfers Muth uns Courige ou madben.}

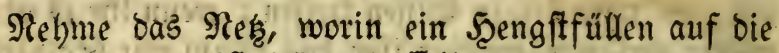
2 selt gefommen ift, büre baffelbe, uno gebe pe dem: Pfard ein.

\section{Das 591te Capitel.}

ein altez Pfero ganz muthig uno furioz zu madjen.

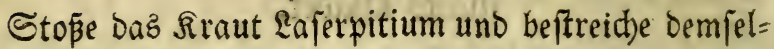
ben die Nafelöcher bamit.

\section{Daz 60 fte Capitel.}

Gine Stärfung, wenn man ein $\mathfrak{P f e r d}$ zum $\mathfrak{B}$ ett= laufen gebrauchen will.

Epheu 1 lotf),

Son (sidtenbaum 1 loth),

Sirnbaummiftel 1 loth,

(5)algant 1 lotb,

Meifternutzel 1 loth,

Ebermurzel 1 loth,

Silium convallium 2 lotb,

Speterleinnurzel 1 loth,

Diefe Stüde julverifire, uno untercinanoer gemifact uno wenn inan vennen will, gibt man es brei Tage zuvor im Futter zu freffen, allemal 1 loth, mit Nalvafier

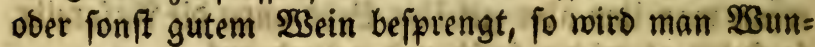
Der feben. 


\section{פyferdes2(rzenei $\mathfrak{B}$ แd).}

\section{Ein a n Dere b.}

2lantwurgel bem SIferd unter Dem Futter gegeben, färlet fie munberbarlich), weld,es and) Die Tüken febr gebrauchen und bod) baltell. (Sleid)faltz, einen פgolfzzalyn ins Munoftüref gebunden, bavon find fie aud) ungemein bauerbaft.

Das: 61 fte Eapitel.

গูBenn cit Şengft junt tïglidyen gebraud) all zu viel Sietlheit bat.

(Sib iflm zumeilen ein paar Mefieripige Dlei:ajd)e unter bem Futter, eङ nimmt ifm Die übermäfïge (Seit= beit. (Sampfer ift aut) gut.

\section{Daz 62 fte Sapitel.}

SGenn cin Soengit fid nad) Den Etuten abwitther und abtobet.

Dem j(t)miert man Murgens (Sarbjeetöl in Die నa= felöt)er, fo bat er ben ganzen Iag feinen (Serud) bon ben Stuten.

\section{Das 63 fte Capitet.}

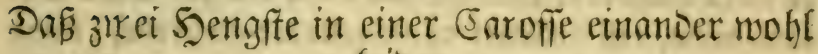
leiver.

Denen gibt man einem bes andern Schaum vom Maul, oder Urin im $\mathfrak{W} a$ flet zu trinfen, uno einem Deś andern Staub unter Dem Futter; befprenge innen aud) beiben bie Nafelöcher mit Branntervein, fo riedst einet wie ber andere, wenn fie pinander bejdnoppern, 
und werben einander befto eber leiden, und Dienfte mit= einander thun, benn mutbige Sengfte rollen 2robeit baben.

\section{Das 64fte Capitel.}

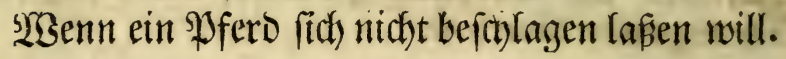

Nebme einen Feoerkeil, fülle inn mit souedffilber, vermadbe ben Riel mit $\mathfrak{S a d b}$, binde einen Faben $b a=$ rum, uno bänge foldben bem Sy ferd in bie Syren, fiebe aber wobl zu, bẩ nid)tz heraus Eomme, fonft bringts

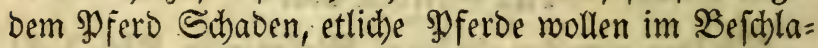
gen nicht angebunden fein, fondern balten lieber frei ; andere hingegen fteben lieber, wenn man einen leichten Serl barauf figen läßt, melches alles zu probiren ift, ebe man fie im Notbftall befchlagen läst.

\section{Das 65fte Eapitel.}

Sุa a $\mathfrak{r}=\mathscr{R}$ ún fit e.

SIie man Pferbe = Mähne unb Sdyneif roth fär $=$ ben foll.

Nimm andertbalb Spfund Präfitien, thue fie in ei=

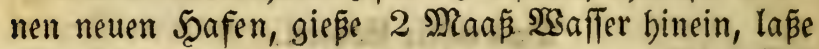
es wohl einfieden, thue hernad) bazu cin gut Theil $\mathfrak{S}_{a}=$ larmoniac, la $\bar{\beta}$ nod)mal untereinander einfieden, wenn es gerecht ift, fo majd)e bas spfero zuvor mit icharfer Lauge, tauche alsoann bas Scaar, fo marm ou es erlei= ben Eanft binein, widéele bie Şaare in leinene Iüd)er ein, uno wenn $e$ s trocten iff, uno man es noch rötber baben will, fo rajde es noch einmal, benn je offer man et mieberbolet, je rötber bie Scaare merben. 


\section{Wierbe:?Irjenei Budh.}

\section{Das 66 fte Sapitel.}

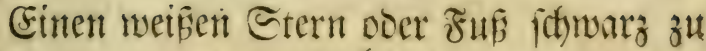 madjen.}

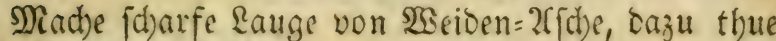
ungelöf)ten Rale, Silberglätt, Englifd) Bleimeip̃ ana, Elein geftosen, wobl zu einer Galbe gerüblet, auf bie Szaut geftridjen, uno fobald es trodéen worden, mit 2̧affer abgerwajhen.

Ferner nimm eimen Maulmurf, fiebe ifn in gejalzener Sutter, befiumiere es bamit, es wadjen jobrarze Şaare.

\section{Das 67ffe Sapitel.}

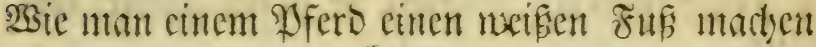
foum.

Simm zmei Ibeil rotbe Sdnecten und ein Theil S(b) weinenichmals, ftope diefe Etücfe wobl burcheinan= Der, nimm barnad) weipen gebrannten 2llaun, ftope ifn Elein zu Shulver, fdeere Dem Sמferd Die Scaare, fo weit man ez baben will, wafit): ifm den sit mit Scarn uno ftreiche alsoann bie erfte Naterie auf ein Reber uno

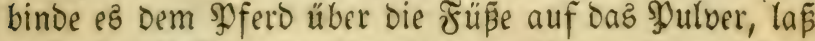
es 1 ober 2 Tage Darüber liegen, alzoann tbue es ber: unter, bie Scaare bie nun nadber radjjen werden reí. uno bleiben beftänoig 10.

Das 68fte Capitel.

Einem Pferd einen Stern anf Die Stirn zu madjen.

Sheere ifm die Scaare ab, reibe ifgm bie Stätte mit: 
pinem reinen Şanfenen Iud) fo lange; bis fie frifd) wirb, fek bann eimen Bentufen barauf, zerpicke die Scaut barnach mit einer Flieten wobl, wajd)e bas SBlut fauber $a b$, nimm cin wenig marmen Sconig, ftreide Denjelben binein, rajche es ben andern Iag mit Utrin $a b$, uno menn es trodéen geworden, fdymiele es wie zu= vor, biefes thue alle Iage, bis die Scaare mieber ge= machjen fino, fo miro es fchön weís uno bleibt auch fo.

\section{Das 69fte Sapitel.}

Sin Fohlen ober alteb \$ferd gefpiegelt ober geap= felt zu machen.

(3ib ifym Sonnenmirbel = 2 Surzel, flein zerfannitten im Futter zu freffen, ez bauert biz ez fid) wieder ver= băiẹt.

\section{(5) $\mathfrak{N}$ (5.}




\section{Ettidbe}

nothuensige Sufrumentet,

weldye fur

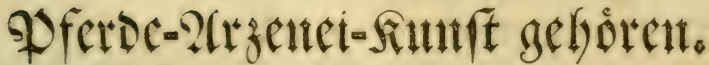

Dabei if aber zu bemerten, das bie Inftrumenten nict) in ber (siröße allbier zu jeben fino, wie fie billig bätten fein follen, fondern die meiften, um Der (snge Des SBlatts wegen, fu Elein gemad)tworden find, Dod) gleid)wohl aud) fo, bas̄ man menigftenz die form Daran abnefimen fann.

2. Ěit Sorn zum Eingief̃en.

3. Der Scidulag= 5ammer.

(5. Die Bange.

D. Das Wirk Eifen.

(5. Dies Sัnftrument Dienet Den unjaubern Şals z̆ reinigen, und wo $\mathfrak{z}_{\text {ürmer }}$ barimen fino, fie beraus zu zieben.

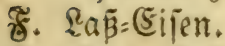

(3. Dies Inftrument niro gebraucht, bie seuten uno Serife zu brennen.

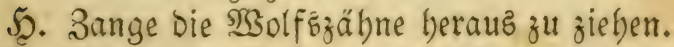

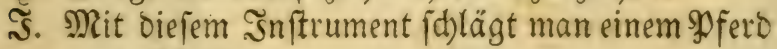
die Säbne $a b$.

§. Dies Snftrument braucht man, menn man einem SpFerd die 3unge abidneiden mill. 
R. Dię Inftrument wiro gebraucht zum Näus= uno Specf=2roern zu foneioen.

פ. Dies Snftrument wiro gebraudbt, renn man einem \$fferd die Sofren abidneidet.

$\mathfrak{R}$. Eine Sprife, in bie ๔däben einzufprifen.

5. (sin Sdnneiomefler.

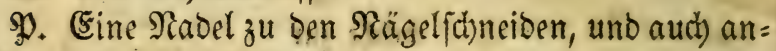
derez zu beften.

S. Sine Sdbcere.

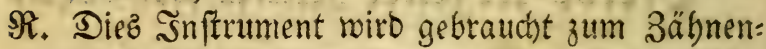
abichlagen, wie auch jum Şufeifen aufzuichla= gen.

5. Maul (Satter.

I. Dies Snftrument wirb gebraucht, wenn einem Sfferd die Şüfe abgrgangen fino, oder binweg getreten, fo wiro foldhes mit ber @dyraube an

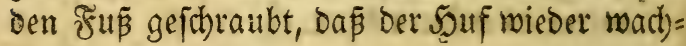
fen fann.

23. Dies S̈nftrument miro gebraud)t, menn ein SPferd, aus einem Nangel nicht auf ben Fup tretten will, fo fohlägt man $e \&$ auf ben guten

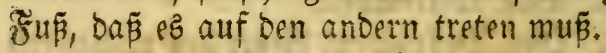




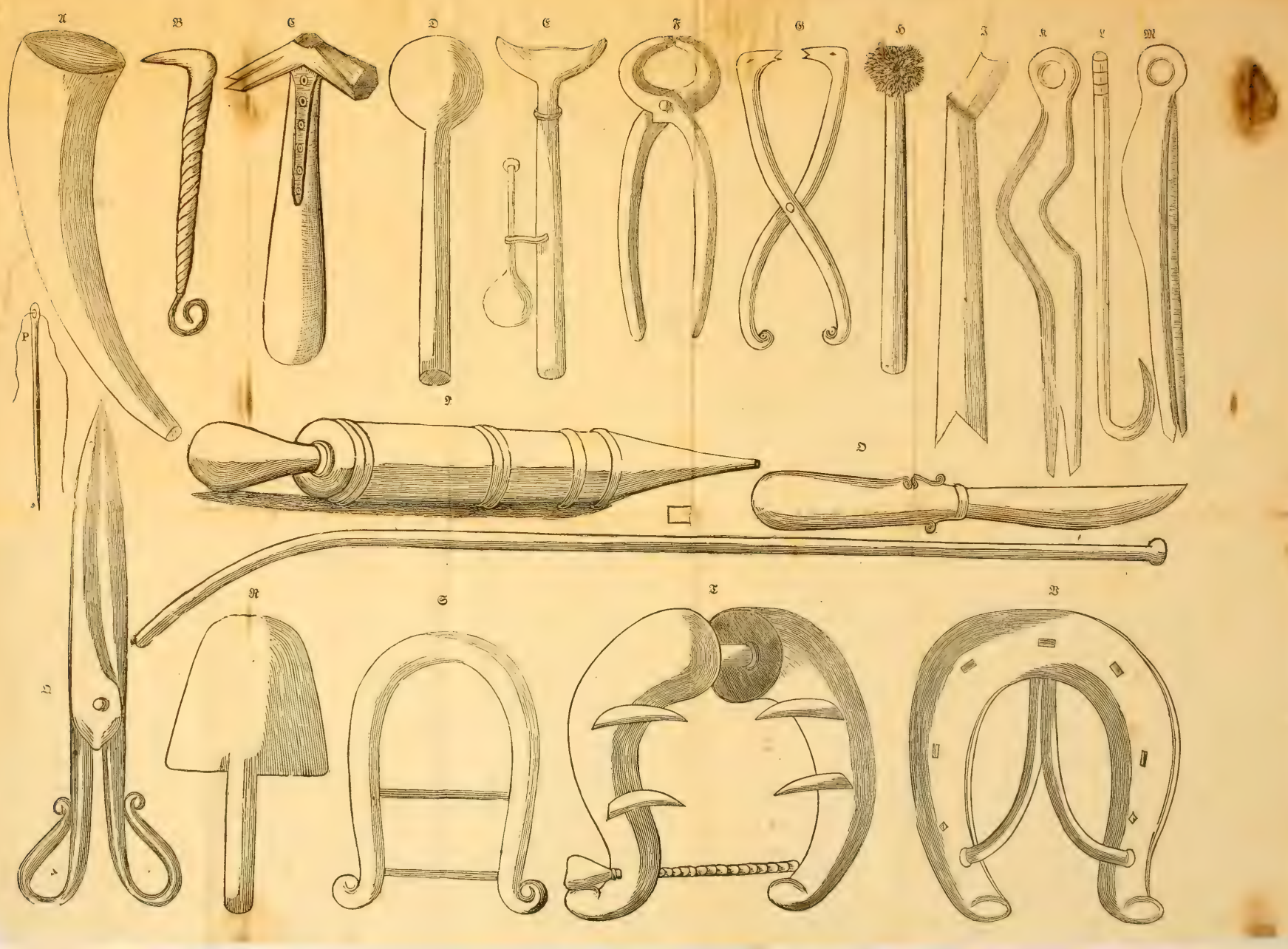



Bon ber binfallenden Sudtt $=\quad=\quad=83$

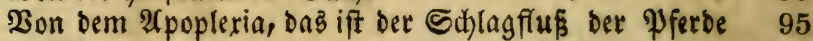

Bon ber Sd)lafiucht

Bon bem Sirampf

Bon bem Feifel

Bon ben 2ugen

Bon Flecten und Fellen in ben 2(ugen, aud) trúben

\section{Augen}

Bon bem Ragel ber $\mathfrak{A}$ ugen

$=$

$=\quad=96$

Zon ben likgigen, füwárenden und triefenden 2 (ugen,

wie aud Blattern in benfelfen ober andere Sdáden

$\begin{array}{llll}=\quad & = & =103 \\ = & = & = & =120\end{array}$

$=126$

Bon ben Slyen=Siranfleiten, und erftlid) yon ber Taub: beit

Bon ben Dhren=Sthmergen, welde von einem B̈efdruár

berrúbrt

Zon Dem $\Re$ ajengefhwúr

Bon bem úbermáfigen Fleifich ober Befdumulit in ber

Rafe, Polnpue genamnt =

B̉on Dem úbermáffigen $\mathfrak{R} a$ fenbluten

Son ben Flüsen, melthe von Dem Eseljirn Gerabfallen

Bon ben falten şlúsen,

Bon ben Flúfen, welthe aus der Scisce entftanden fino

Bon dem Siog ober Eitnuder

Bon bem hellen und flaren Rafentropfen :

Bon ben Sungenfranfheiten, uno erftid) von berfelben

- Siefolution oder Paralufis genannt

Bon Den Bálynen uno beren Eebrechen

Bon bem 2(poftem bei ben Şundşál)nen (Şaden) die

bot,n gentannt, wie aud) von runglichter Fenut ưber

Den Zả̆hnen,

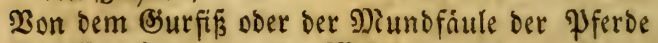

Bon Entgundungen ber פ) (nindeln und 2(poftemen Bon ben Frof́chen im Maul
$=$

$=205$

$=206$

$=209$

- 214 


\section{Dar gueite Theil.}

Bon oer fiecliud)t voer Etrengel genannt $=\quad=215$

Den der erifen Gattung ber fieclifut)t, die feud)te Sieel=

fuct) genannt $=\quad=\quad=\quad=216$ Don ber trodenen fieerfudt $=\quad=\quad=236$

Bon oer Eungenfudt $=$ s $=242$

Bon verfethrten uno jerrifenen Eungen . . 25\%

Bon bem Suften . • . 257

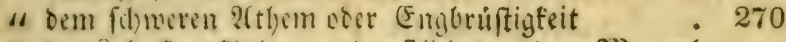

"Den Seberfranfleciten uno erfitlid) von Dem 9) angel

meliber aus Entjuntung ber feber entfifelt uno

Befdimule verurfad)t. : $\quad . \quad 289$

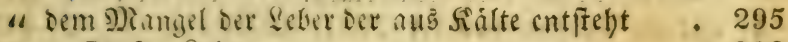

“ verftopfter Qever . . 298

"Der Gialle uno cinigen bavon lerfommenden sirane:

beiten . . . . 305

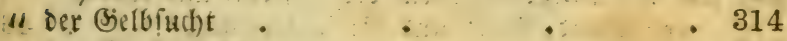

" oer 20 nfferfud)t $\quad . \quad . \quad . \quad 319$

4. Der Edwindfud)t $\quad . \quad \ldots . . \quad 335$

" Dem פ)iif uno feinen firanflyeiten . . 356

" Dem Sererzen . . . . . . . . 343

\#. Dem Jeergittern . 349

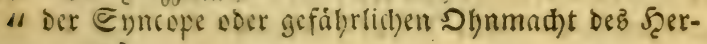

jenz

" oem Sergerfperr

" Dem श)Rngen im 20llgememen : 354

" Den S(t)merjen, Demen oer פlagenmuno unterworfen if . . 355

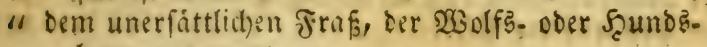
bunger genannt . . 361

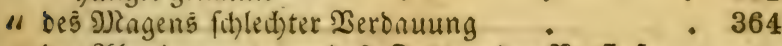

"Der 2Aoneigung gegen ons Futter, oer Borftof gea nannt

369

2Eenn fid) ein Pferb am Futter ủberfreffen, meldes bie

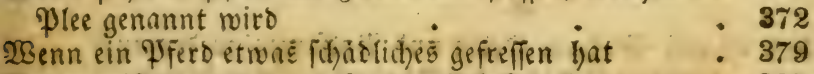

Bon vergiftetem ooer ungefundem Trinfraffer : 385

"Den $\mathfrak{T}$ úrmern, reldhe in bem Jlagen uno Dármen toadjen

386 
4 bem Brimmen im seib uno befonders von ber

Darmgidt)t ber 叉ferde. • . 398

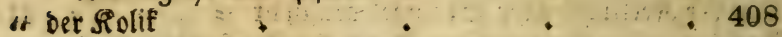

" bem Durdtbrud) ber Pferde @ 415

" bem Durdblauf Die weifse 9iulje genannt 420

"Dem Durdjlauf Die rotke Piulgr ober Diarthón ge-

nannt .423

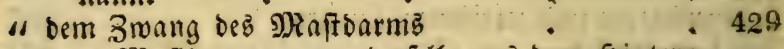

« bem \$inftorm, wenn berfelbe auร bem Şintern

weid)et odev gefd)wúret . . . 431

“ Berftopfungen ber $\mathfrak{P f e r d e}$. . 433

" Der Purgation Der Pferde, uno erftlich von ber

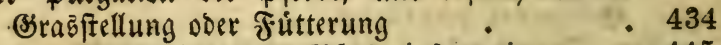

" andern \$urgationen ber Pferte inğgemein • 445

"Elıftiren uno Stulzápfoben inb̆gemein 451

J) (agere Pferbe wieber zuredtt zu bringen . 454

Bon Den Rieren=Siranfheiten Der Pferoe, uno erfflich'

von ๔and, Erief und Etein berfelben 462

" 3erreifung Der exdern Der Rieren, Entjünoungen

uno Ednwárung berfelben $\quad .470$

4 Dem Şarn und Der Blafe, ifjen Siranflyeiten und

von ber Sharnminde. • . • 474

" ber Drfuria, dna ift yon ber falten Eaid) . 479

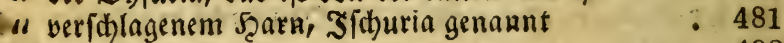

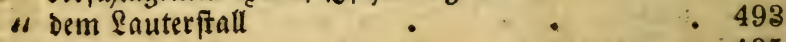

" bem Blutitallen ober Şarnen $\quad \therefore \quad 495$

+ Hem Blafenftein $\quad . \quad 500$

¿ Jiebern der Pferde $\quad 500$

fi ber Mebe, bie fonft aud) Deríd)lag genannt wirb. 508

“ ber Peftileng ber $\mathfrak{P}$ feroe : . 522

Der Drtte Theil.

Bon allertei Galben, Deten unb Balfamen ;u ben ảụs ferlithen Edáben ber pferbe ju gebrauden . 534 " allexbano Pfifafern 4. ben alten Edjâben und Brúdjen unter bem Sattẹl 562 
"ben 2(poffemen, ben $\mathfrak{W a r g e n ~ a ́ h n l i d ) ~ a m ~ b i n t e r : ~}$ fent Dort ber Fuffe bei ben Ferfen . 568

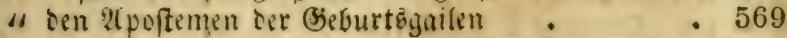

"Den acoern, meldt)e verrenft, gefdrwolten und ju furg geworden fino . . . 577

"Dem 20erlaten Der Pferde . . 581

"bir 2(fterigeburt, menn fie nid)t von bem Pfero will 585

“ Dem 2(nreiden ber Đferde - . . . . 586

"હ. Antoni feuer oder Piotllauf • . 595

" Dem 2lus̆fegeln — • • • • 596

"Beinbred)en . 598

"Den bifen der giftigen ₹liere, @d)langenbif ober

Etid) . . 602

" Den Saud)gefdwulften : • • . 611

"beifenden Slutbeulen . . . . . 612

" ben Blutrufen. . . . . .

" Dem B̉lutiteller $\quad$ • $\quad 615$

" Dem Blut welltes in bie Bstieder gerounen ift 617

“ Der Rreuguerjuctung . • • 618

$"$ " Dem finten coer mitsen fleifit) • • 620

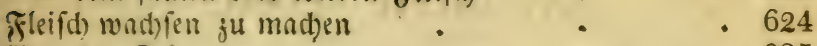

Zon ben Teigwargen $\quad . \quad$. 625

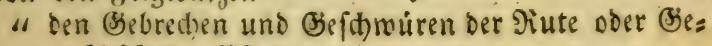
f(táft ber 'yferde . . . 629

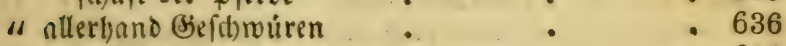

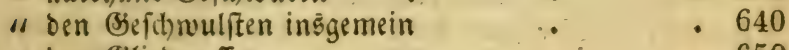

" bem Ssliedraffer $\quad$. . . . 650

"Den Baflen ing̈gemein ... 655

"s ben Ssewáb)fen, als Ellbogen, \&nift, Siblblein unb

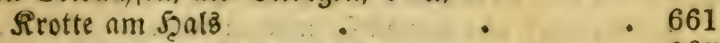

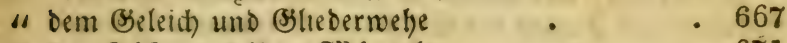

“ Den Şúfen uno ihren 9) lángeln . . 671

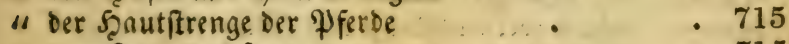

" bem Scarmadifen

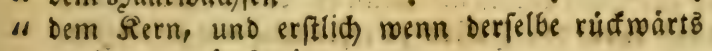
ober vormártz tritt . . . . 717

“ Den Rammgefímúren $\vdots \quad .719$

“ ber Sirotte am Şalह . . . . . . 719

“ bem Rrebs ... • . . . 719 


\begin{tabular}{|c|c|c|}
\hline ben fảnfen ber Pferde & - & - 722 \\
\hline ben g) Dauten & $n$ & - 723 \\
\hline ben múben Yferben & $\%$ & $\because 727$ \\
\hline Den Piappen - & . & . 730 \\
\hline Der Piáude ber Pferbe &. & . 735 \\
\hline ben Edhminden ler Pferbe & . & 744 \\
\hline 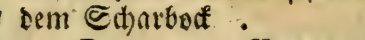 & - $\quad$. & . 752 \\
\hline Den @ennen oder Rerven & und ifren sebreityen & . 753 \\
\hline bem Spath . & . $\quad$. & . 754 \\
\hline Den Etrupfen. & . & . 758 \\
\hline Dem Berbugen. & . & 761 \\
\hline Serrenfungen . & . & . 764 \\
\hline Den lleberbeinen. & . & 764 \\
\hline Den $\mathfrak{1 B a r g e n}$ & . & 770 \\
\hline ßerwunoungen . & - & 772 \\
\hline Dem 20 urm . & . & 781 \\
\hline
\end{tabular}

Bon der Follenjudt .

793

Wenn ein Fohlen nuร Dem શeke gelofet, wie mit bem Siopf und Shals ;u verfahren ift

Wie man bem Foblen alşbald aud bie Fuffeine reini= gen foll, bamit eร̃ gute \$̧úfe befommen mogge

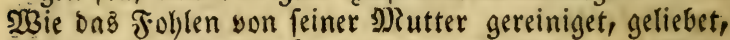
und an biefelbe gewóhnt werben mag.

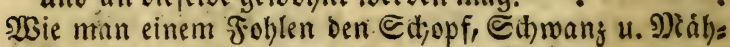
ne feft, ftarf und gewád)ifg madten fann

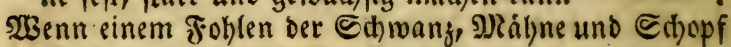
fhábigt ober fihabljaft wúrbe

Wenn ein Foblen (vermutblid) von \$)tutterleib unge:

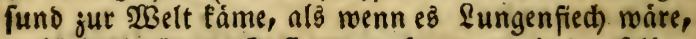
weld)ez burd) ben Şuften gu erfennen, wie bemfelben zu belfen ift.

Wsenn einem Fohlen bie fawere शoth ober Fraif anftos

Eet, roeld)ez oft ju gefdeben pfiegt.

787

794

795

795

796

796

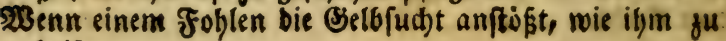


Eo ein Foblen die fiellfutht befáme, wie ifm jum Bang ju belfen wenn fie bart fiesft

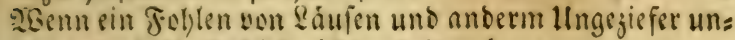

rein wúrbe, onf es nid)t geteilyen fann 2BEenn ein Foblen Die Darmgid)t bátte

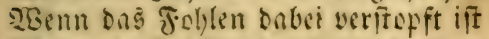

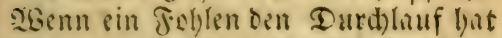
DEenn ein Tollen nidt)t Etallen fonn

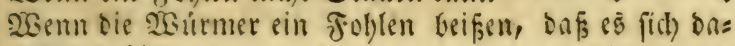
son wálget

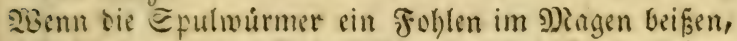

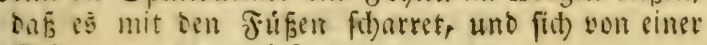
Eeite jur andern wirft

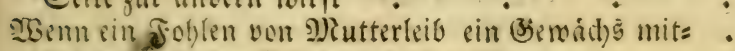

bríct)te, wie bemfelben jul belfen ift

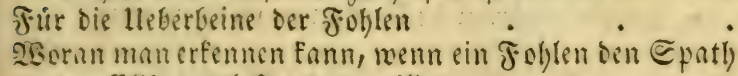

voer Ellbegen befommen will

Tór ben Ellbogen

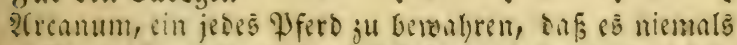

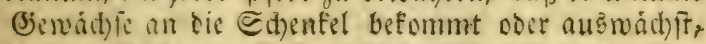
weier Ëbiemen, Gsallen, Lleberbein, Eparren ober

Flofgallen u. f. wo. $\quad . \quad . \quad . \quad . \quad .807$

26 enn sin Foblen bie Sinuten befommt . . 808

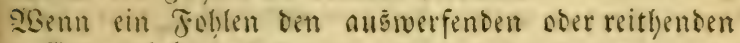

23 urm vefonint

Weenn ein foljlen won 9)

fonft werfangen lyat $=:=\quad=\quad=809$

Şenn ein Foblen 9)

2Genn if)m tie 2(ugen úberfd)offen wóren uno man vers

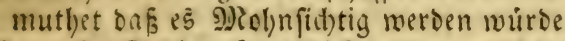

$=811$

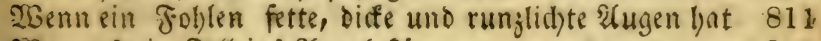

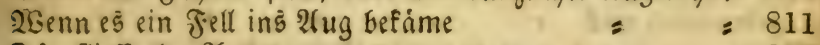
Tár flieffende 2lugen $=\Rightarrow \quad=812$ खGenn eill Follen ins 2 (uge geftofen ober gefd)lagen wurbe $=$ = $=212$

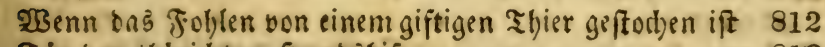

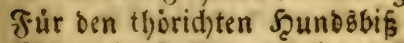
$=813$ EEenn sin Feblen von eimem Wiefel gefoden wird = 813 
Wenn ein Foblen am baud gefdrodlen ift, und man glaubt daf es yon siner Edblange gebiffen oder gefto= then morden wäre

$=814$

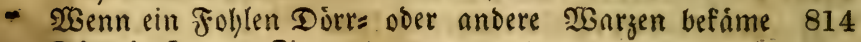
T) Für bie Wolfaz̧álne $=\quad=\quad=814$

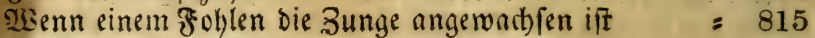
2Senn ein Foblen mit Dem Sirampf geplagt ift $=815$ Woenn ein Jahrgang iff, onf bas Eterben unter ben

Pferben regieret $==816$ Fưr Dnş @dwinden ber Foblen $=\quad=\quad=816$ TEenn ein Fohlen bie \$laufen befommt $\quad=\quad=816$ IGenn ein Foblen frupflufig roird $=\quad=\quad=817$ Fúr baz Reithen Der Fohlen $\quad=\quad=\quad=817$ Eine Purgation fúr Foblen $=\quad=\quad=318$ XBenn ein Foljlen anfángt bocfbeinigt ju werden, mußs man bei Beiten yorfommen $\quad=\quad=\quad=819$

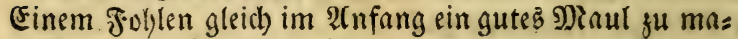
d)en $=\quad=\quad=\quad=$ Bom 2loerlaffen $=\quad=\quad=\quad=820$ Die 20ern ju fithlagen follen biefe fein $=\quad=820$

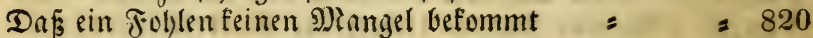
Bom Etolpern seer Fohlen $=\quad=\quad=821$ Bom Enffer Des Sioppens der Fohlen $=\quad=\quad=822$ Ein Pferb linfend ju maden daf́ ibm nichtş fenndet $=322$ Daf ein Pferb nidht freffe, fo lang man will $=\quad=823$

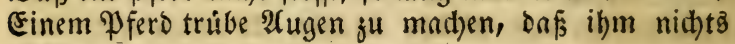
fit)abet - = = = = $=823$ Einem einen Poffen ju maden $=:=823$

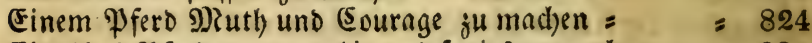
Ein altes \fero ganj muthig uno furiob ju machen = 824 Eine @tárfung, menn man sin Pfero jum Wettlaufen gebrauden mill $===824$ Wenn ein Şengfít zum tágliden (Bebraud) all ju viel Beillbeit bat $=$ 825 Wenn ein Scengft fid) nad) ben. Stuten abwuthet und ab tobet

Daf jwei Scengfte in einer Earroffe einander woll teiben Wenn ein Pferb fiid nid)t befdlagen laken will

825 825 826 
2Gie man Pfortemálye und Sd)weif ratl) fárben fann $8: 26$ Einen meifen Stern ooer Fuf fatwarg ju maden - 827

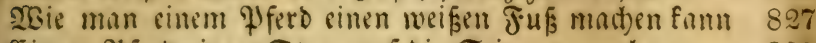
Einem Pferd einen Stern nuf Die Stirn ju mad)en - 827 Ein Foblen oor altes Pforo gefpiege!t ooer genffelt ju mathen

\section{Tabcife.}

Folgendes ift cine Tabelle Der Maape uno (Semidte, rolde nad) Den 2(merifanifden bered)net worden if:
1 Souintlein entbält 1 Dradbma,
1 Sfund
1 Ioth
1 Maณ́
1 Suart
1 \&oth
" 32 \&oth,
" 4 Suintlein,
11. 2 Suart,
" 2 Peint,
" $\frac{1}{2} \mathfrak{U n}_{\mathfrak{j}} \mathrm{e}_{\text {e }}$ 


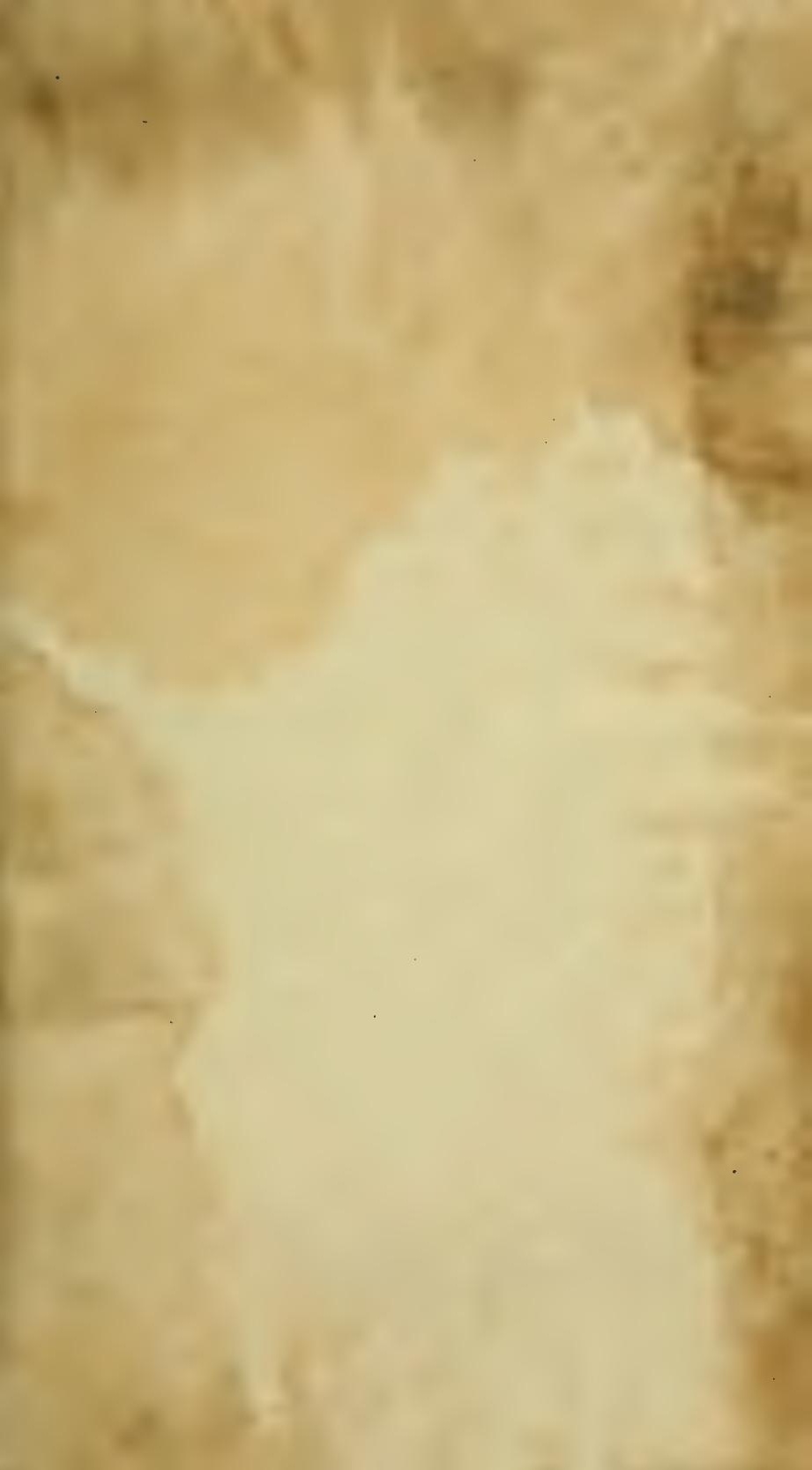




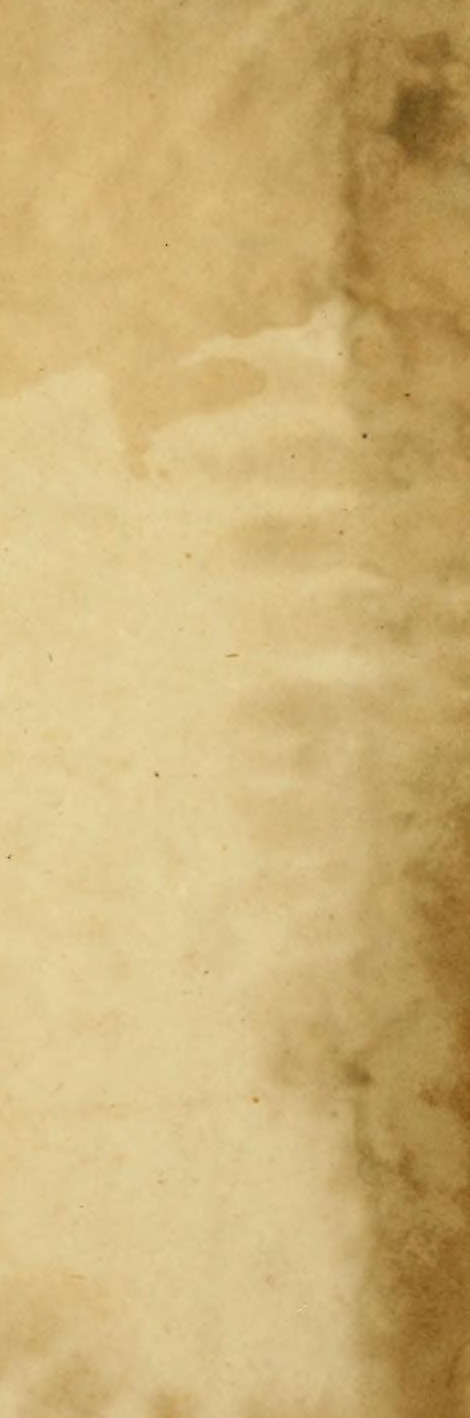
6.8. 



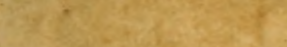

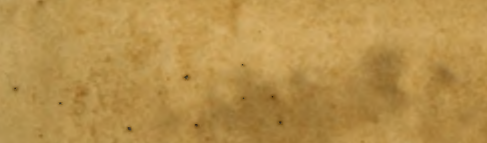

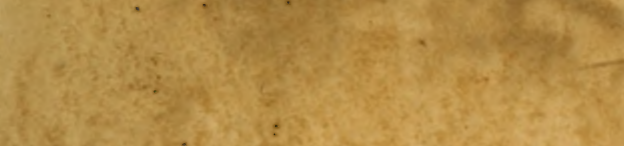

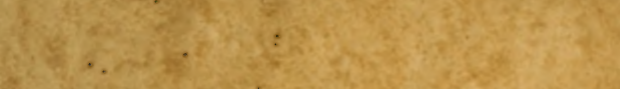

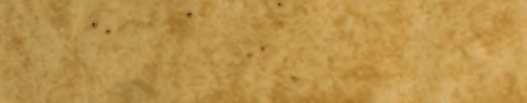

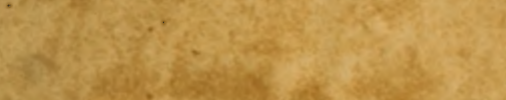

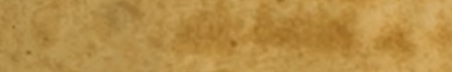
I.

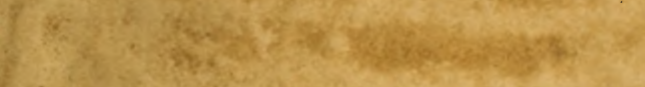

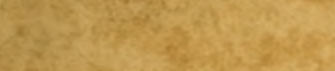
6.

(6)

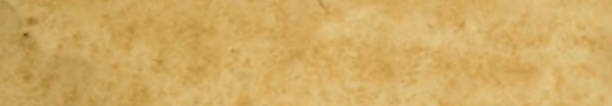

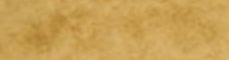

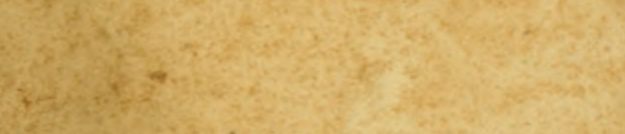

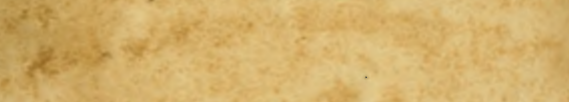

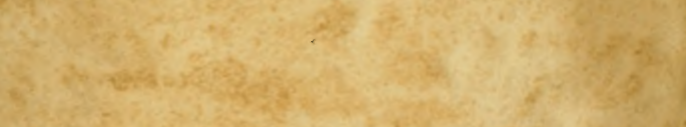

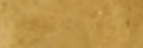

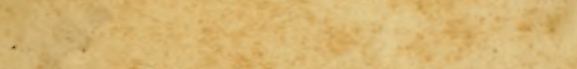

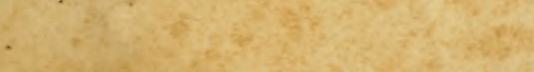
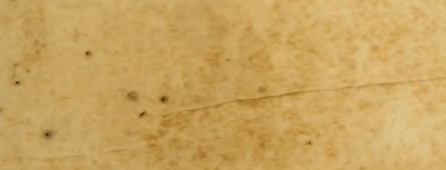

intis

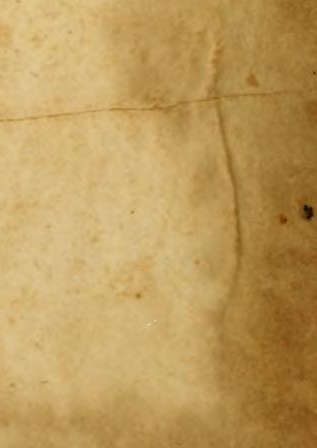


